\title{
A LIST OF NORTH AMERICAN LEPIDOPTERA AND KEY TO THE LITERATURE OF THIS ORDER OF INSECTS.
}

\author{
B Y \\ Harrison G. Dyar, Ph. D., \\ Custodian of Lepidoptera, United States National Museum,
}

ASSISTED BY

C. H. Fernald, Ph. D., the late Rev. George D. Hulst, and August Busck.

Order LEPIDOPTERA.

\section{Superfamily PAPILIONOIDEA.}

Family PARNASSIIDAE.

(C. =Skinner, Syn. Cat. No. Am. Rhop., 1898, pp. 72-73.)

PARNASSIUS Latreille.

Latreille, Somm. Buff., xiv, 110, 1805; Scudder, Proc. Am. Ac. Arts \& Sci., x, 241, 1875 .

1. clodius Ménétries, Cat. Lép. Pét., i, 73, 1855; Mts. Pac. Skinner, C. no. 438. States.

syn. baldur Edwards, clarius Boisduval.

a. ménétriesii Hy. Edwards, Proc. Cal. Acad. Sci., vii, $164,1878$.

b. altaurus Dyar (Spots yellow instead of red).

2. smintheus Doubleday \& Hewitson, Gen. Diurn.

Lep., pl. 4, 1847; Skinner, C. no. 439.

syn. sayii EDwards.

Wyo.

Mts. Pac.

States,

Rocky Mts.

a. behrii Edwards, Trans. Am. Ent. Soc., iii, 10, 1870.

b. hermodur Hr. Edwards, Pap., i, 4, 1884.

c. nanus Neumoegen, Ent. Amer., vi, 61, 1890.

d. sedakovii Ménétries, Cat. Lép. Pét., i, 71, 1855.

4630 - No. $52-02-1$ 
*3. nomion Fischer, Ent. Russ., ii, 242, 1823; SKIn- Alaska. NER, C. no. 440.

4. ex ersmanni Ménétries, Cat. Lép. Pét., i, 73, 1855; SkInNer, C. no. 441.

Alaska, Siberia. syn. wosnesenski MÉnétries.

a. thor Hy. Edwards, Pap., i, 4, 1881; SkInner, C. no. 441.

\section{Family PAPILIONIDAE.}

\section{(C.=Skinner, Syn. Cat. No. Am. Rhop., 1898, pp. 73-78.)}

\section{IPHIDICLES Hübner.}

HüBner, Verz. bek. Schmett., 82, 1816; Scudder, Proc. Am. Acad. Arts \& Sei., x, 197,1875 .

5. ajax Linneus, Syst. Nat., 1, 750, 1758; SkInNER, C. no. 442.

Atl. States.

syn. walshii Edwards, abbotii Edwards.

a. telamonides Felder, Reise Novara, Lep., i, 60 , 1865; SkInNer, C. no. 442.

b. marcellus Boisduval \& Le Conte, Lép. Am. Sept., pl. 2, 1833.

*6. sinon Fabricius, Syst. Ent., 452, 1775; SKInNER, C. no. 443 .

Fla., Antilles.

\section{PAPILIO Linnæus.}

Linneus, Syst. Nat., i, 76, 1758; Scudder, Proc. Am. Ac. Arts \& Sci., x, 238, 1875.

7. pilumnus Boisdural, Spec. Gén., i, 340, 1836; SkINNER, C. no. 461.

Ariz., Mex.

8. daunus Boisduval, Spec. Gén., i, 342, 1836; SKInNER, C. no. 460.

Rocky

Mts.

9. eurymedon Boisduval, Ann. Soc. Ent. Fr., (2), x, 280, 1852; SKInNer, C. no. 458.

a. albanus Felder, Reise Novara, Lep., i, 93, 1865.

10. rutulus Boisduval, Ann. Soc. Ent. Fr., (2), x, 279, 1852; SkInNer, C. no. 459.

a. arizonensis Edwards, Pap., iii, 4, 1883.

b. ammoni Behrens, Can. Ent., xix, 199, 1887.

Pac.

States,

Col.

Pac.

States,

Rocky

Mts.

11. glaucus Linnæus, Mus. Ulr., 190, 1764; SkINNER, C. no. 457.

Atl.

States,

a. turnus Linnaus, Mant. Plant., v, 36, 1771.

Can., Alaska.

syn. alcidamus Cramer, antilochus LinnaUs, fletcheri Kemp, Ent. News, xi, 481, 1900.

b. australis MaYnard, Man. Butt., app., 215, 1891. 
12. palamedes Drury, Ill. Exot. Ent., i, 19, 1773; SKinner, C. no. 456. syn. calchas FABricius.

13. troilus Linnæus, Mus. Ulr., 187, 1764; SKInner, C. no. 455 .

syn. ilioneus Smith \& Aввот.

a. texanus Ehrman, Can. Ent., xxxii, 348, 1900.

b. radiatus STREcker, Lep. Rhop. Het., suppl., 3 , 17,1900 .

14. thoas Linnæus, Mant. Plant., 536, 1777; SkinNER, C. no. 462.

Atl. States, N.-W. Terr.

syn. cresphontes Cramer, oxilus HüBNER.

*15. cresphontinus Martyn, Psyche, iii, f. 8, 1797; Fla., Antilles, Skinner, C. no. 463.

So. Am.

syn. aristodemus EsPER, temenes GODART, daphnis Gray.

16. machaon Linneus, Faun. Suec., 267, 1761; KIRBy, Cat. Diurn. Lep., 565, 1871.

a. aliaska Scudder, Proc. Bost. Soc. Nat. Hist., xii, 45, 1869; SkInner, C. no. 447.

Atl. States, Ariz., Mex.

17. bairdii Edwards, Proc. Ent. Soc. Phil., ii, 200, 1869; SKINNER, C. no. 448.

syn. utahensis STRECKER.

a. oregonia Edwards, Butt. N. A., ii, pl. 7, 1880.

b. brucei Edwards, Can. Ent., xxvii, 11, 1895.

c. hollandii Enwards, Can. Ent., xxv, 253, 1893.

18. zolicaon Boisduval, Ann. Soc. Ent. Fr., (2), x, 281, 1852; Skinner, C. no. 449.

syn. zelicayn Lucas, californica Ménétries.

19. americus Kollar, Denksch. Akad. Wiss. Wien., Math., i, 354, 1850; SkInNer, C. no. 450.

syn. sadalus Lucas.

20. indra Reakirt, Proc. Ent. Soc. Phil., vi, 125, 1866; SkInNer, C. no. 452.

Eur., Alaska, No. Pac. States.

Pac. States, Rocky Mts.

Pac. States, Rocky Mts.

Ariz., Mex.

Cal., Rocky Mts.

N.-E.

Coast.

21. brevicauda SAUnders, Packard's Guide, 245, 1869; SkInner, C. no. 453.

syn. anticostiensis STRECKER. 
22. polyxenes Fabricius, Syst. Ent., 444, 1775; SKINU. S. NER, C. no. 454.

syn. asterius Cramer.

a. calverleyii Grote, Proc. Ent. Soc. Phil., ii, 441,1864 .

b. amplicata Ménétries, Cat. Lép. Pét., ii, 99, 1857.

c. alunata Skinner \& Aaron, Can. Ent., xxi, 127, 1889.

d. semialba Ehrman, Can. Ent., xxxii, 348, 1900.

e. curvifascia Skinner, Ent. News, xiii, 183,1902.

\section{LAERTIAS Hïbner.}

Hübner, Verz. bek. Schmett., 84, 1816; Scudder, Proc. Am. Acad. Arts \& Sci, x, 201,1875 .

23. philenor Linn eus, Mant. Plant., 535, 1771; SKIN- U. S. NER, C. no. 444.

syn. astinous Drury.

a. obsoleta Ehrman, Can. Ent., xxxii, 348, 1900.

b. wasmuthi WeEks, Jn. N. Y. Ent. Soc., ix, 82, 1901.

\section{ITHOBALUS Hübner.}

Hübner, Verz. bek. Schmett., 88, 1816; Scudder, Proc. Am. Acad. Arts \& Sci., x, $198,1875$.

24. acauda Oberthur, Études d'Ent., iv, 98, 1880; New Mex., SkINNER, C. no. 445 . Mex.

syn. nezahualcoyotl Strecker, corbis Godman

\& Salvin, orsua Godman \& Salvin.

25. polydamas Linnæus, Mus. Ulr., 192, 1769; SKInNER, C. no. 446.

Fla., Antilles.

\section{Family PIERID A.}

$$
\text { (C.=Skinner, Syn. Cat. No. Am. Rhop., 1898, pp. 60-72.) }
$$

\section{ARCHONIAS Hïbner.}

Hü Bner, Zutr. exot. Schmett., f. 461, 1825; Kirby, Cat. Diurn. Lep., 429, 1872.

*26. lyceas Godman \& Salvin, Biol. Cent. Am., Lep. Rhop., ii, 123, 1889; Barnes, Ent. News, x, 331, Ariz., 1900 .

\section{LEPTALIS Dalman.}

Damman, Anal. Ent., 40, 1823; Scudder, Proc. Am. Acad. Arts \& Sci., x, 204, 1875.

27. melite Linneus, Syst. Nat., 775, 1767; Skinner, Mex.. New C. no. 376 . 
NEOPHASIA Behr.

Behr, Trans. Am. Ent. Soc., ii, 303, 1869; Scudder, Proc. Am. Acad. Arts \& Sci., x, 226,1875 .

28. menapia Felder, Wien. ent. Mon., iii, 271, 1859; Skinner, C. no. 377.

Pac. States, Col.

syn. tau SCudder, ninonia Boisduval, suffusa STRETCH.

29. terlooii Behr, Trans. Am. Ent. Soc., ii, 304, 1869. Ariz., Mex.

syn. epyaxa Strecker, Lep. Rhop. Het., suppl.,

38, 1900; Skinner, Ent. News, xi, 533, 1900.

a. princetonia Poling, Can. Ent., xxxii, 358, 1900.

\section{TACHYRIS Wallengren.}

Wallengren, Trans. Ent. Soc. Lond., (3), iv, 361, 1867; Scudner, Proc. Am. Acad. Arts \& Sci., x, 274, 1875.

30. margarita Hübner, Zutr. exot. Schmett., ii, pl. 120, 1830; Godman \& Salvin, Biol. Cent. Am., Lep. Rhop., ii, 155, 1887.

Fla.,

Tex.,

syn. molpodia HüBNER, ilaire GodART, mysi

Godart, poeyi Butler.

a. neumoegenii Skinner, Ent. News, v, 110, 1894;

C. no. 379 .

31. amaryllis Fabricius, Ent. Syst., (3), i, 189, 1797;

SKINNER, C. no. 378.

Tex.,

Mex.

syn. josephina Godart, Godman \& Salvin, Biol. Cent. Am., Lep. Rhop., ii, 135, 1887.

PONTIA Fabricius.

Fabricius, Ill. Mag., vi, 283, 1807; Scudder, Proc. Am. Acad. Arts \& Sci., x, 255, 1875.

32. monuste Linnæus, Mus. Ulr., 237, 1764; SKINNER, C. no. 380.

So. States, So. Am.

syn. cleones Boisduval \& Le Conte.

a. phileta Fabricius, Syst. Ent., 471, 1775.

33. beckeri Edwards, Butt. No. Am., i, 30, 1871; SKINNER, C. no. 381.

34. sisymbri Boisduval, An. Soc. Ent. Fr., (2), x, 284, 1854; Skinner, C. no. 382.

35. nelsoni Edwards, Butt. No. Am., ii, pl. 1, Pieris, 1883; Skinner, C. no. 383.

36. occidentalis Reakirt, Proc. Ent. Soc. Phil., vi, 133, 1866; Skinner, C. no. 384; Cockerell, Ent. News, xii, 18, 1901.

Pac. States, Col.

Col., Pac. States.

Alaska.

Rocky Mts. to Pac.

a. calyce Edwards, Trans. Am. Ent. Soc., iii, 189, 1870. 
37. protodice Boisduval \& Le Conte, Lép. Am. Sep., U.S. 45, 1833; SKInNer, C. no. 385.

$a$. vernalis Edwards, Proc. Ent. Soc. Phil., ii, $501,1864$.

38. napi Linnæus, Faun. Suec., 271, 1766; SкInNER, C. no. 386.

a. bryoniæ Ochsenhemer, Eur. Schmett., i, 151, 1808.

7. hulda Edwards, Trans. Am. Ent. Soc., ii, 370, 1869.

c. venosa Scudder, Proc. Bost. Soc. Nat. Hist., viii, 182, 1861.

syn. flava EDwards.

d. oleracea Harris, N. E. Farm., viii, 402, 1829.

e. borealis Grote, Bull. Buff. Soc., i, 185, 1873.

$f$. frigida Scudder, Proc. Bost. Soc. Nat. Hist., viii, $181,1861$.

g. virginiensis Edwards, Trans. Am. Ent. Soc., iii, 13,1870 .

h. acadica Edwards, Pap., i, 87, 1881.

i. pallida Scudder, Proc. Bost. Soc. Nat. Hist., viii, 183, 1861.

syn. nasturtii BoIsduval.

k. castoria Reakint, Proc. Acad. Nat. Sci. Phil., $31,1866$.

syn. resedx Boisduval.

7. cruciferarum Boisduval, Spec. Gén., i, 519, 1839. syn. casta Kirby, restiva Harris.

*39. ochsenheimeri Staudinger, Stett. ent. Zeit., 199, 1886; SKInNer, C. no. 387.

40. rapæ Linnдus, Syst. Nat., 468, 1758; SKInner. C. no. 388 .

syn. marginalis Scudder, yreka REAKIRT.

a. novangliae ScudDer, Can. ent., iv, 79, 1872.

b. immaculata Skinner \& Aaron, Can. Ent., xxi, $128,1889$.

c. manni MAYER, Stett. ent. Zeit., 151, 1851.

NATHALIS Boisduval.

Borsduval, Spec. Gén., i, 587, 1836; Scudder, Proc. Am. Acad. Arts \& Sci., x, 224, 1875.

41. iole Borsduval, Spec. Gén., i, 589, 1836; SkInNER, C. no. 389.

No. U. S., Cal., Eur.
Asia, Alaska.

Eur., U. S.

$$
\text { syn. irene Fitch, felicia Poey, luteolus Reakirt. }
$$

So. U. S., Mex. 
SYNCHLOE Hübner.

Hü Bner, Verz. bek. Schmett., 94, 1816; Scudder, Proc. Am. Acad. Arts \& Sci., x, 273, 1875; Euchloe HüBner, Verz. bek. Schmett., 94, 1816; Midea HerrichSchatfFer, Corr.-Blatt zool.-min. Ver. Reg., xxi, 105, 1867.

42. creusa Doubleday \& Hewitson, Gen. Diurn. Lep., pl. 7, 1847; Skinner, C. no. 391.

So. Cal.

43. olympia Edwards, Trans. Am. Ent. Soc., iii, 266, Ariz. 1871; SKINNER, C. no. 392.

a. rosa Edwards, Pap., ii, 45, 1882.

44. ausonides Boisduval, Ann. Soc. Ent. Fr., (2), x, 286, 1852; SKINNER, C. no. 393.

a. hyantis Edwards, Trans. Am. Ent. Soc., iii, $205,1871$.

b. coloradensis Hy. Edwards, Pap., i, 50, 1881.

45. lotta Beutenmüller, Bull. Am. Mus. Nat. Hist., $\mathrm{x}, 243,1898$.

Rocky

Mts.

46. lanceolata Boisduval, Ann. Soc. Ent. Fr., (2), x, 284, 1852; SKInner, C. no. 390.

Pac. States, syn. edwardsii BEHR.

47. cethura Felder, Reise Novara, Lep., ii, 182, 1865; Skinner, C. no. 394.

Pac.

States,

Col.

Rocky Mts.

syn. cooperi BeHR, angelina BoIsduvaL.

a. morrisoni Edwards, Pap., i, 143, 1881.

48. genutia Fabricius, Syst. Ent., iii, 193, 1793; So. Atl. SKInNer, C. no. 397.

Pac.

States.

syn. midea HüBNER.

49. sara Boisduval, Ann. Soc. Ent. Fr., (2), x, 385, Pac. States, 1852; SKInNer, C. no. 395.

Rocky Mts.

syn. thoosa Scudder, flora Wright.

a. reakirtii Edwards, Trans. Am. Ent. Soc., ii, $369,1869$.

syn. stella EDwARDs.

b. julia Edwards, Trans. Am. Ent. Soc., iv, 61, 1872.

*50. pima Edwards, Can. Ent., xx, 158, 1888; SkIN-

Ariz. NER, C. no. 396.

CALLIDRYAS Boisduval \& Le Conte.

Boisduval \& Le Conte, Lép. Am. Sept., 73, 1829; Scudder, Proc. Am. Acad. Arts \& Sci., x, 131, 1875 .

51. philea Linnæus, Syst. Nat., 764, 1776; SKInner, C. no. 401. So. Miss. syn. aricye Cramer, melanippe Cramer. Val., So. Am. 
52. eubule Linnæus, Syst. Nat., 743, 1766; SkIn- So. States, NER, C. no. 398.

syn. sennae Linnaeus, marcellina Cramer, drya FABRICIUs, yamana REAKIRT.

\section{APHRISSA Butler.}

Butler, Lep. Exot., 155, 1873; Scudder, Proc. Am. Acad. Arts \& Sci., x, 116, 1875.

53. statira Cramer, Pap. Exot., iii, pl. 120, f. C., 1779; SKINNER, C. no. 399.

Fla., syn. neleis BoIsduval, boisduvalii Felder, jada Butler, floridensis Neumoegen, fabia Fabricius, evadne Godart, alcmeone Cramer.

\section{PHCBIS Hübner.}

HüBner, Verz. bek. Schmett., 98, 1816; Godman \& Salvin, Biol. Cent. Am., Lep. Rhop., ii, 142, 1887; Scudder, Proc. Am. Acad. Arts \& Sci., x, 249, 1875.

54. argante Fabricius, Syst. Ent., 470, 1775; SKINNER, C. no. 403.

Fla., Tex., So. Am.

syn. cipris Cramer, hersitia Cramer, minuscula Butler, pallideflava Goeze, xanthia SEPP, larra FABricius, volcania Perry, cnidia Godart.

55. agarithe Boisduval, Spec. Gén., i, 625, 1836; SKInNer, C. no. 402.

So. Miss. Val., So. Am.

syn. maxima NEUMOEGEN.

\section{GONEPTERYX Leach.}

Leach, Edinb. Enc., ix, 128, 1825; Krrby, Cat. Diurn. Lep., 487, 1872.

56. clorinde Godart, Enc. Méth., ix, suppl., 813, 1823; Kirby, C'at. Diurn. Lep., 487, 1872; Barnes, Tex., Ent. News, x, 131, 1900.

syn. swainsonia SwAInson, mærula HüBnER, godarti PERTy.

\section{KRICOGONIA Reakirt.}

Reakirt, Proc. Ent. Soc. Phil., ii, 355, 1863; Scudder, Proc. Am. Acad. Arts \& Sci., x, 201, 1875.

57. lyside Godart, Enc. Méth., ix, 98, 1819; SкINNER, C. no. 404. Tex., Mex.

syn. terissa Lucas.

a. lanice Lintner, Pap., iv, 138, 1884; SKInner, C. no. 406 .

58. fantasia Butler, Trans. Ent. Soc. Lond., 170, 1871; SKInNer, C. no. 405.

Tex.,

Mex.

59. unicolor Godman \& Salvin, Biol. Cent. Am., Lep. Rhop., ii, 151, 1889; SKInNER, C. no. 407. 


\section{ZERENE Hübner.}

Hüвner, Verz. bek. Schmett., 97, 1816; Scudder, Proc. Am. Acad. Arts \& Sci., x, $291,1875$.

60. eurydice Boisduval, Ann. Soc. Ent. Fr., iii, 32, 1855; SkInNer, C. no. 408.

Ariz., Cal., Oreg.

syn. wosnesenski MÉnétries, lorquini BoIsdu-

VAL, helena REAKIRT.

a. amorphæ Hy. Edwands, Proc. Cal. Acad. Sci.,

vii, 169, 1876; SKInNer, C. no. 408.

b. bernardino EDwards, Butt., iii, pl. 1, 1887.

61. cæsonia Stoll, Suppl. Cramer, Pap. Exot., pỉ. 41, fig. 2, 1790; SKInNer, C. no. 409.

So. U. S.,

So. Am.

syn. caroliniana Petrok.

a. rosa McNeile, Can. Ent., xxi, 45, 1889.

\section{EURYMUS Swainson.}

Swannson, Horsf. Cat. Lep. E. I. Mus., 129, 1829; Scudder, Proc. Am. Acad. Arts \& Sci., $\mathrm{x}, 175,1875$.

62. meadii Edwards, Trans. Am. Ent. Soc., iii, 267, 1871; SKInNer, C. no. 410.

a. elis Strecker, Proc. Acad. Nat. Sci. Phil., 24,

Rocky

Mts. 1885; SkInNer, C. no. 411.

63. hecla Lefèbre, Ann. Soc. Ent. Fr., v, 383, 1836; SKINNER, C. no. 412.

a. glacialis McLachlan, Jn. Linn. Soc. Lond., xiv, 108, 1878.

b. hela Strecker, Bull. Brook. Ent. Soc., iii, 33, 1880.

c. pallida Skinner \& Mengel, Proc. Acad. Nat. Sci. Phil., 156, 1892.

*64. boothii Curtis, Ross Nar. Second Voy. N.-W. Pass., app., 62, 1835; SKInner, C. no. 413.

Arctic

Aretic

Am.,

Eur.

a. chione Curtis, Ross Nar. Second Voy., app., 62,1835 .

65. eurytheme Boisduval, Ann. Soc. Ent. Fr., 286, 1852; SKINNER, C. no. 414.

syn. amphidusa BoIsdu vaL, californiana MÉnÉTRIES, keewaydin EDw ARDs, intermedia CoCKERELL, autumnalis COCKERELL.

a. ariadne Edwards, Trans. Am. Ent. Soc., iii, 12, 1870.

b. eriphyle Edwards, Trans. Am. Ent. Soc., v, $202,1876$.

syn. hagenii EDwards.

c. fumosa Strecker, Lep. Rhop. Het., suppi., 3, 19,1900 . 
66. philodice Godart, Enc. Méth., ix, 100, 1819; SKINNER, C. no. 414.

syn. palrno Cramer, europome StePhens, pallidice SCUdDER, virida STRECKER, miscidice Scudder, nigrina Strecker, Lep. Rhop. Het., suppl., 3, 19, 1900, albinic SKINNER, melanic Skinner, Syn. Cat. N. A. Rhop., 68, 1898.

a. anthyale Hübner, Zutr. exot. Schmett., f. 307, 1823.

b. nigridice SCUDDER, Butt., ii, 1114, 1889.

c. luteitincta Wolcott, Can. Ent., xxv, 104, 1893.

67. hartfordii Hy. Edwards, Pac. Coast Lep., No. 24, 9, 1877; SKInNer, C. no. 416.

syn. barbara Hy. Edwards.

68. occidentalis Scudder, Proc. Bost. Soc. Nat. Hist., ix, 109, 1862; SkINNer, C. no. 417.

syn. chrysomelas Hy. Edwards.

69. christina Edwards, Proc. Ent. Soc. Phil., ii, 79, 1863: Skinner, C. no. 418.

States.

syn. astræa EDwards.

a. pallida Lyman, Can. Ent, xix, 6, 1884.

70. alexandra Edwards, Proc. Ent. Soc. Phil., ii, 14, 1863; Skinner, C. no. 419.

syn. alba Strecker, pallida Cockerell.

a. edwardsii BeHr in Edwards, Butt. N. A., i, 55,1870 .

b. emilia Edwards, Trans. Am. Ent. Soc., iii, 12, 1870.

71. interior Scudder, Proc. Bost. Soc. Nat. Hist., ix, 108, 1862; Skinner, C. no. 420.

syn. laurentina SCUDDER.

72. scudderi Reakirt, Proc. Ent. Soc. Phil., iv, 217, 1865; SKinner, C. no. 421.

a. flavotincta Cockereld, Psyche, ix, 186, 1901.

73. pelidne Boisduval, Icones, pl. 8, 1832; Skinner, C. no. 422 .

syn. labradoriensis SCUdDER.

a. skinneri Barnes, Can. Ent., xxix, 39, 1897.

b. gigantea Strecker, Lep. Rhop. Het., suppl., 19. 1900 .

74. palæno Linneus, Syst. Nat., 764, 1767; SKinNER, C. no. 423.

syn. europomene EsPER, philonomene HüBNER, lapponica StaUdinger, chippewa Edwards, helena EDwards.

a. werdandi Herrich-Schaeffer, Schm. Eur., f, $403,1848$.

Cal., B. C., Utah.

Rocky Mts., Brit. Am.

Col., No. Pac. States.

No. Atl.

States.

No. Rocky Mts., No. Pac. States. Rocky Mts.

Eur., Alaska, Labrador. 
75. nastes Boisduval, Icones, pl. 8, 1832; SKinner, C. no. 424 .

Aretic Am., Eur.

a. rossii Guenée, Ann. Soc. Ent. Fr., 199, 1864.

b. streckeri Grumm-Grshimaïlo, Hor. Ent. Soc. Ross., xxix, 290, 1895.

*76. moina Strecker, Bull. Brook. Ent. Soc., iii, 34, 1880; Skinner, C. no. 425.

Hudson Bay.

77. behrii Edwards, Proc. Ent. Soc. Phil., vi, 201, Mts. Cal. 1866: Skinner, C. no. 426.

\section{PYRISITA Butler.}

Butler, Cist. Ent., i, 35, 1870; Scudder, Proc. Am. Acad. Arts \& Sci., x, 261, 1875.

79. gundlachia Poer, Hist. Nat. Cuba, i, 246, 1851 SKINNER, C. no. 427.

Tex., Ariz., Mex.

80. proterpia Fabricius, Syst. Ent., 478, 1775; SKINNER, C. no. 428.

Tex., Ariz., Mex.

81. mexicana Borsduval, Spec. Gén., i, 653, 1836; Miss. Val., SKInNER, C. no. 430.

Mex.

syn. damaris Felder, depuiseti Boisduval.

*82. boisduvaliana Felder, Reise Novara, ii, 200, 1865. Ariz., Mex. syn. damaris SKInNer (not Felder), C. no. 431; ingrata FELDER, gratiosa REAKIRT.

\section{EUREMA Hübner.}

Hübner, Verz. bek. Schmett., 96, 1816; Scudder, Proc. Am. Acad. Arts \& Sci., x, 173,1875

83. nicippe Cramer, Pap. Exot., iii, 210, 1782; Skin NER, C. no. 429.

a. flava Strecker, Cat. Lep., 84, 1878.

*84. westwoodi Boisduval, Spec. Gén., i, 666, 1836; SKINNER, C. no. 432.

So. Atl. States, Ariz., Cal.

Tex., Mex.

syn. dina Hübner, calceolaria Butler \& Druce.

85. euterpe MÉnétries, Bull. Mose., 299, 1832; Godman \& Salvin, Biol. Cen. Am., Lep. Rhop., ii, $102,1889$.

syn. lisa Boisduval, clappii Maynard.

a. alba Strecker, Cat. Lep., 85, 1878; Skinner, C. no. 433 .

*86. linda Edwards, Pap., iv, 53, 1884; Skinner, C. no. 434 .

87. delia Cramer, Pap. Exot., pl. 273, f. A, 1782; Skinner, C. no. 435.

So. Atl. States, Mex.

Mex.

Gulf

States. syn. demodita. Hǘner, daric Godart. 
88. jucunda Boisduval \& Le Conte, Lép Am. Sept., Gulf States, 52, 1833; Skinner, C. no. 436.

Mex. syn. ebriola Poey, albina Poey.

89. gnatheme Boisduval, Spec. Gén., i, 680, 1836; Krrby, Cat. Diurn. Lep., 445, 1872. Fla., a. blakei Maynard, Man. Butt., app., 216, 1891.

\section{Family NYMPHALIDAE.}

(C.=Skinner, Syn. Cat. No. Am. Rhop., 1898, pp. 3-33.)

\section{COLAENIS Hübner.}

Hübner, Verz. bek. Schmett., 32, 1816; Scudder, Proc. Am. Acad. Arts \& Sci., x, $146,1875$.

90. julia Fabricius, Syst. Ent., 509, 1775; Skinner, Tex., Fla., C. no. 7 .

a. delila Fabricius, Syst. Ent., 510, 1775; SKInNER, C. no. 8.

syn. cillene C'RAMER.

AGRAULIS Boisduval \& LeConte.

Boisduval \& Le Conte, Lép. Am. Sept., 142, 1833; Scudder, Proc. Am. Acad. Arts \& Sci., x, 105, 1875.

91. vanillæ Linnæus. Syst. Nat., 482, 1758; Skin- So.Atl.States, NER, C. no. 9.

syn. passiflorae Fabricius.

\section{EUPTOIETA Doubleday.}

Doubleday, Gen. Diurn. Lep., 168, 1848; Scudder, Proc. Am. Acad. Arts \& Sci., x, 172,1875 .

92. claudia Cramer, Pap. Exot., i, pl. 69, f. E, 1779;

Skinner, C. no. 10.

Atl. States,

syn. columbina Godart, daunus Herbst.

93. hegesia Cramer, Pap. Exot., iii, pl. 209, f. E, Cal., Tex., 1782; Skinner, C. no. 11.

syn. hortensis Blanchard.

\section{SEMNOPSYCHE Scudder.}

Scudder, Bull. Buff. Soc., ii, 258, 1875; Butt. E. U. S., iii, 1798, 1889.

94. diana Cramer, Pap. Exot., pl. 98, f. D, 1779; So. Atl. SkInner, C. no. 12. 
SPEYERIA Scudder.

Scudder, Syst. Rev., 23, 1872; Proc. Am. Acad. Arts \& Sci., x, 269, 1875.

95. idalia Drury, Ill. Exot. Ent., i, pl. 13, 1775;

SKInNer, C. no. 13.

Atl.

syn. astarte Fischer, ashtaroth Fischer.

\section{ARGYNNIS Fabricius.}

Fabricius, Ill. Mag., vi, 263, 1807; Scudder, Proc. Am dead. Arts \& Sci., x, 118, 1875 .

96. nokomis Edwards, Proc. Acad. Nat. Sci. Phil., 221, 1862; SKINNER, C. no. 14.

Ariz. ,

Utah.

97. nitocris Edwards, Trans. Am. Ent. Soc., v, 15, 1874; SKInNer, C. no. 15.

Ariz.,

Nev.

a. cærulescens Holland, Ent. News, xi, 332, 1900.

b. nigrocærulea Cockerell, Ent. News, xi, 622, 1900.

98. leto BeHr, Proc. Cal. Acad. Sci., ii, 173, 1862; SKInNer, C no. 16.

Pac. States,

syn. charlottii Barnes, Skinner, C. no. 18

99. cybele Fabricius, Syst. Ent., 516, 1775; Skinner, C. no. 17 .

Col.

syn. daphnis Cramer, baal STRECKER.

a. carpenterii Edwards, Trans. Am. Ent. Soc., v, $204,1876$.

100. aphrodite Fabricius, Mant. Ins., ii, 62, 1767; SKInNer, C. no. 19.

Atl. States,

syn. daphnis Martrn, cypris EDwARDs, nausiRocky Mts cal EDwARDs.

a. alcestis Edwards, Trans. Am. Ent. Soc., v, 289, 1876.

101. lais Edwards, Can. Ent., xv, 209, 1883; SKINNER, C. no. 21.

102. atlantis Edwards, Proc. Nat. Acad. Sci. Phil., 54, 1862; SkInner, C. no. 22.

Atl.

States.

103. hippolyta Edwards, Can. Ent., xi, 81, 1879; SKIN-

Brit. Am. NER, C no. 28.

a. oweni Edwards, Can. Ent., xxiv, 105, 1892; SkInner, C. no. 23.

*104. cornelia EDwards, Can. Ent., xxiv, 106, 1892; Skinner, C. no. 24.

105. electa EDwards, Field \& Forest, iii, 143, 1878;

Skinner, C. no. 25.

Col.

Atl.

States.

Oreg., Cal.

Rocky

Mts. 
106. columbia Hr. Edwards, Pacific Coast Lep., no. Brit. Col. 26, 1877; Skinner, C. no. 26.

107. hesperis Edwards, Proc. Ent. Soc. Phil., ii, 502, 1864; Skinner, C. no. 27.

Rocky Mts.

108. bremnerii Edwards, Trans. Am. Ent. Soc., iv, 63, 1872; Skinner, C. no. 29.

Pac. States.

109. zerene Boisduval, Ann. Soc. Ent. Fr., (2), x, 303 , 1852; SkInNer, C. no. 30.

Cal., Nev

syn. hydaspe Boisduval.

110. monticola Behr, Proc. Cal. Acad. Sci., ii, 175, 1862; Skinner, C. no. 31.

Pac.

a. purpurascens Hy. Edwards, Proc. Cal. Acad. Sci., vii, 170, 1876.

111. rhodope Edwards, Trans. Am. Ent. Soc., v, 13, 1874; Skinner, C. no. 32.

112. behrensii Edwards, Trans. Am. Ent. Soc., ii, 370 , 1869; Skinner, C. no. 33.

113. halcyone Edwards, Butt., i, 83, 1869; Skinner, C. no. 34 .

114. platina Skinner, Can. Ent., xxix, 154, 1897; C. no. 36 .

115. coronis Behr, Proc. Cal. Acad. Sci., ii, 173, 1862; Skinner, C. no. 37.

syn. juba BoIsduval.

116. callippe Borsduval, Ann. Soc. Ent. Fr., (2), x, 302, 1852; SKInNer, C. no. 39.

117. snyderi Skinner, Can. Ent., xxix, 154, 1897; C. no. 38 .

118. nevadensis Edwards, Trans. Am. Ent. Soc., iii, 14, 1870; Skinner, C. no. 40.

States.

Brit. Am.

Cal.

Rocky

Mts.

Rocky

Mts.

Cal.

Brit. Am.

Cal.

Utah,

Idaho.

Rocky

Mts.

a. meadii EDwards, Trans. Am. Ent. Soc., v, 69, 1872.

119. edwardsii Reakirt, Proc. Ent. Soc. Phil., vi, 137, 1866; Skinner, C. no. 41.

Rocky

Mts.

syn. aglaia EDWARDs.

*120. chitone Edwards, Can. Ent., xi, 72, 1879; SkinNER, C. no. 35.

Rocky Mts.

121. liliana Hr. Edwards, Proc. Cal. Acad. Sci., vii, Cal., 170, 1876; Skinner, C. no. 42.

Utah.

a. baroni Edwards, Trans. Am. Ent. Soc., ix, 3, 1881. 
122. rupestris Behr, Proc. Cal. Acad. Sci., ii, 175 1862; Skinner, C. no. 43.

Cal.,

Utah.

syn. irene EDwards.

a. irene Boisduval, Ann. Soc. Ent. Belg., xii, 59,1869 .

*123. laura Edwards, Can. Ent., xi, 49, 1879; SKInNER, C. no. 49.

Cal.,

Nev.

Cal.

124. semiramis Edwards, Can. Ent., xviii, 61, 1886; SkInNer, C. no. 46.

*125. inornata Edwards, Trans. Am. Ent. Soc., iv, 64, 1872; Skinner, C. no. 47.

Cal.,

Nev.

Cal.

*126. atossa Edwards, Butt. N. A., iii, pl. 8, Arg., 1890; Skinner, C. no. 48.

127. adiaste Behr, Proc. Cal. Acad. Sci., ii, 175, 1862; SKINover, C. no. 49.

syn. adiante BoIsDuval.

128. eurynome Edwards, Trans. Am. Ent. Soc., iv, Rocky Mts., 66, 1872; Skinner, C. no. 55.

Cal.

syn. macaria Edwards; SKInNer, C. no. 45;

SNyder, Occ. Mem. Chic. Ent. Soc., i, 11. 1900.

a. erinna Edwards, Can. Ent., xv, 33, 1883.

b. bischoffi Edwards, Trans. Am. Ent. Soc., iii, 189, 1870; Skinner, C. no. 53.

c. artonis Edwards, Trans. Am. Ent. Soc., ix, 2, 1881; Skinner, C. no. 50.

d. clio Edwards, Trans. Am. Ent. Soc., v, 106. 1874; Skinner, C. no. 51.

syn. opis Edwards; Skinner, C. no. 52.

e. arge Strecker, Cat. Lep., 114, 1878; SkInNer, C. no. 54 .

f. cunninghami Owen, Ent. News, iv, 246, 1893.

129. montivaga Benr, Proc. Cal. Acad. Sci., ii, 174, 1862; Skinner, C. no. 56.

Cal.,

Nev.

130. egleis Borsduval, Ann. Soc. Ent. Belg., xii, 59, Cal., 1869; SkINner, C. no. 57.

Nev。

syn. mormonia BoIsduval, nenoquis REAKIRT

\section{BRENTHIS Hübner.}

Hübner, Verz. bek. Schmett., 30, 1816; Scudder, Proc. Am. Acad. Arts \& Sci., x, 128,1875 .

131. myrina Cramer, Pap. Exot., ii, pl. 189, f. B, 1779; No.

Skinner, C. no. 58. 
132. pales Denis \& Schiffermüller, Syst. Verz. Eur., Alaska. Wien.,177,1776; Staudinger \& Rebel, Cat. Lep. Eur., i, no. 210, 1901.

a. alaskensis Holland, Ent. News, xi, 383, 1900.

*133. youngi Holland, Ent. News, xi, 283, 1900.

Alaska.

134. triclaris HüBNER, Samml. ex. Schmett., ii, 1824; SKInNer, C. no. 59.

Aretic Am., Col.

syn. ossianus Boisduvat.

135. helena Edwards, Trans. Am. Ent. Soc., iii, 268, 1871; SKINNER, C. no. 60.

Rocky Mts.

36. montinus Scudder, Proc. Ess. Ins., iii, 166, 1862; SKINNER, C. no. 61.

137. chariclea Schneider, Neu. Mag., v, 588, 1794; Skinner, C. no. 62.

a. arctica Zetterstedt, Ins. Lap., 899, 1828.

N. H.

b. obscurata McLachlan, Jn. Linn. Soc., xiv, i10, 1878.

syn. butleri: EDwards.

c. boisduvalii Duponchel, Lep. Fr., suppl., 1, pl. 20, f. 4, 1832; Skinner, C. no. 64.

138. freija Thunberg, Diss. Ent. Suec., ii, 34, 1791; SKINNER, C. no. 65.

Arctic Am., Eur.

Eur., Col.

syn. freya Herrich-Schaeffer, lapponica EsPER.

a. tarquinius Curtis, Ross Nar. Second Voy. N.-W . Pass., app., 68, 1835.

139. polaris Boisduval, Ind. Méth., 15, 1829; SKINNER, C. no. 67.

Aretic Am.

140. frigga Thunberg, Diss. Ent. Suec., ii, 33, 1791; Skinner, C. no. 68.

Aretic Am.

a. saga Kaden, Stett. ent. Zeit., 350, 1864.

b. improba Butler, Ent. Mo. Mag., xiii, 206 1877; Skinner, C. no. 66.

141. bellona Fabricius, Syst. Ent., 517, 1775; SkinNER, C. no. 69.

syn. myrina MARTYN.

142. epithore Borsduval, Ann. Soc. Ent. Belg., xii, 58, 1869; SKinner, C. no. 70.

a. kreimhild Strecker, Rept. Surv. Dept. Mo., RUFFner, app., 1854, 1879.

*143. alberta Edwards, Can. Ent., xxii, 113, 1890; SKINNER, C. no. 71.

*144. astarte Doubleday \& Hewitson, Gen. Diurn. Lep., pl. 53, f. 5, 1848; Skinner, C. no. 72.

Atl. States.

Pac. States. syn. victoria EDWards. 
APATURA Fabricius.

FAbricius, Ill. Mag., vi, 280, 1807; Scudder, Proc. Am. Acad. Arts \& Sci., x, 115, 1875.

145. misippus Linnæus, Mus. Ulr., 264, 1764; SkIn- Fla., Africa, NER, C. no. 160.

India, etc.

syn. discippus Fabricius.

EUPHYDRYAS Seudder.

Scudder, Syst. Rev., 27, 1872; Proc. Am. Acad. Arts \& Sci., x, 172, 1875.

146. phaeton Drury, Ill. Exot. Ent., i, pl. 21, 1767; SKINNER, C. no. 73.

Atl.

syn. phrtana HüBNER, phxtoneta GODART, States. phadon HERRICH - SCHAEFFER, superba STRECKER, phrthusa HuLst, streckeri ElLsworth, Ent. News, xiii, 104, 1902.

\section{LEMONIAS Hübner.}

Hübner, Tent., 1, 1806; Scudder, Proc. Am. Acad. Arts \& Sci., x, 203, 1875.

147. cooperi Behr, Proc. Cal. Acad. Sci., iii, 90, 1863; SKInNer, C. no. 74.

Pac.

syn. perdiccas EDwards.

148. chalcedon Doubleday \& Hewitson, Gen. Diurn. Lep., i, 180, 1847; Skinner, C. no. 75.

States.

a. dwinellei Hy. Edwards, Pap., i, 51, 1881.

b. fusimacula Barnes, Can. Ent., xxxii, 42, 1900.

c. mariana Barnes, Can. Ent., xxxii, 42, 1900.

149. macglashani Rivers, Proc. Cal. Acad. Sci., (2), i, 103, 1889; SKInner, C. no. 76.

150. colon Edwards, Pap., i, 45, 1881; Skinner, C no. 77 .

Pac.

States.

151. anicia Doubleday \& Hewitson, Gen. Diurn. Lep., i, 179, 1848; Skinner, C. no. 78.

a. beani Skinner, Can. Ent., xxix, 155, 1897.

b. brucei Edwards, Can. Ent., xx, 81, 1888.

151. 1. maria Skrnner, Can. Ent., xxxi, 12, 1899.

Cal.

152. nubigena Benr, Proc. Cal. Acad. Sci., iii, 91, 1863; SKInNer, C. no. 79.

a. wheeleri Hy. Edwards, Pap., i, 52, 1881.

Wash.,

Oreg.

syn. capella BARnes.

153. gillettei BARnes, Can. Ent., xxix, 40, 1897; SKINNER, C. no. 80.

Rocky

Mts.,

Pac. States.

Utah.

Rocky

Mts.,

Cal.

$4630-$ No. $52-02-2$ 
154. quino Bemr, Proc. Cal. Acad. Sci., iii, 90, 1863;

Cal. SKInner, C. no. 81.

*155. augusta Edwards, Can. Ent., xxii, 21, 1890; SKINCal. NER, C. no. 82.

156. baroni Hy. Edwards, Pap., i, 52, 1881; SkInner, C. no. 83.

157. rubicunda Hy. Edwards, Pap., i, 52, 1881; SKInNER, C. no. 84.

158. taylori Edwards, Can. Ent., xx, 82, 1888; SKInNER, C. no. 85.

Cal.

Cal.

Brit. Col.

159. editha Boisduval, Ann. Soc. Ent. Fr., (2), x, 304, 1852; SkInNer, C. no. 86.

Cal.

syn. anicia ScUDDER.

*160. helvia Scudder, Proc. Bost. Soc. Nat. Hist., xii, 405, 1869; Skinner, C. no. 87; Holland, Ent. News, xi, 384, 1900.

161. sterope Edwarus, Trans. Am. Ent. Soc., iii, 190, 1870; SKInNer, C. no. 88.

*162. acastus Edwards, Trans. Am. Ent. Soc., v, 16, 1874; Skinner, C. no. 89.

Alaska.

Oreg.

Rocky

Mts.

163. neumoegeni Skinner, Ent. News, vi, 113, 1895; C. no. 90 .

Utah.

164. palla Boisduval, Ann. Soc. Ent. Fr., (2), x, 305, 1852; Skinner, C. no. 91.

Rocky Mts., Pac. States.

*165. whitneyii Berr, Proc. Cal. Acad. Sci., iii, 88, 1863; SKInNer, C. no. 92.

Cal., Nev

syn. pola BoIsduval.

166. hoffmanni Behr, Proc. Cal. Acad. Sci., iii, 89, 1863; SKInNer, C. no. 93.

a. helcita Boisduval, Ann. Soc. Ent. Belg., xii, $55,1869$.

Pac.

States,

Rocky

Mts.

167. gabbii Benr, Proc. Cal. Acad. Sci., iii, 89, 1863; SKInNer, C. no. 94.

Cal., Utah,

Ariz.

syn. sonoræ BoIsduval.

*168. approximata STREcker, Lep. Rhop. Het., suppl. $3,23,1900$.

\section{CINCLIDIA Hübner.}

Hübner, Verz. bek. Schmett., 29, 1816; Scudder, Proc. Am. Acad. Arts \& Sci., x, 142,1875 .

169. harrisii Scudder, Proc. Ess. Ins., iii, 167, 1862; SKINNER, C. no. 95. 
170. ulrica Edwards, Can. Ent., ix, 189, 1877; SKINNer, C. no. 96 (as elada Hewitson).

syn. imitata STRECKER.

171. dymas Edwards, Can. Ent., ix, 190, 1877; SKINNER, C. no. 97.

syn. lamunda STRECKER.

172. perse Edwards, Pap., ii, 136, 1882; Skinner, C. no. 98.

173. chara Edwards, Can. Ent., xv, 209, 1883; SkInNER, C. no. 98.

*174. albiplaga AAron, Pap., iv, 175, 1884; SkInner, C. no. 100 .

Tex.

Tex.

Ariz.

Ariz.

Tex.

THESSALIA Scudder.

Scudder, Bull. Buff. Soc., ii, 265, 1875.

175. leanira Borsduval, Ann. Soc. Ent. Belg., xii, 27, 1869; Skinner, C. no. 101.

a. obsoleta Hy. Edwards, Proc. Cal. Acad. Sci., vii, $171,1876$.

176. wrightii Edwards, Can. Ent., xviii, 64, 1886; SKInNer, C. no. 102.

177. alma Strecker, Lep. Rhop. Het., 135, 1877; Skinner, C. no. 103.

Pac. States, Rocky Mts.

Cal.

178. theona Ménétries, Cat. Mus. Pét., i, 86, 1855. syn. fulvia Edwards, Can. Ent., xi, 117, 1879; Skinner, C. no. 104.

178. 1: cyneas Godman \& SALvin, Biol. Cent. Am., Lep. Rhop., i, 191, 1882.

Mex., Ariz.

179. thekla Edwards, Trans. Am. Ent. Soc., iii, 191, 1870; Skinner, C. no. 105.

Cal. to

Tex.

Tex.,

Ariz. SkINNer, C. no. 106.

Tex.

181. definita Aaron, Pap., iv, 176, 1884; Skinner, C. no. 107 .

\section{SCHENIS Hübner.}

Hübner, Verz. bek. Schmett., 28, 1816; Scudder, Proc. Am. Acad. Arts \& Sci., x, $266,1875$.

182. minuta Edwards, Proc. Acad. Nat. Sci. Phil., 161, 1861; Skinner, C. no. 108.

Rocky

Mts.

183. arachne Edwards, Trans. Am. Ent. Soc., ii, 372, 1869; SKinner, C. no. 109.

Rocky

Mts.

184. nympha Edwards, Pap., iv, 53, 1884; Skinner,

Ariz. C. no. 110. 


\section{CHARIDRYAS Scudder.}

Scudder, Syst. Rev., 26, 1872; Proc. Am. Acad. Arts \& Sci., x, 139, 1875.

185. nycteis Doubleday \& Hewitson, Gen. Diurn.

Iep., 181, 1847; Skinner, C. no. 111.

Atl.

syn. enome SCUDDER, harrisï EDwards.

a. drusius Edwards, Pap., iv, 57, 1884.

186. ismeria Boisduval \& Le Conte, Lép. Am. Sept., 168, 1833; SKINNER, C. no. 112.

Rocky Mts. syn. carlota REAKIRT.

\section{PHYCIODES Hübner.}

Hübner, Verz. bek. Schmett., 29, 1816; Scunder, Proc. Am. Acad. Arts \& Sci., x, $249,1875$.

187. vesta Edwards, Trans. Am. Ent. Soc., ii, 371, 1869; SkInNer, C. no. 113.

Tex.,

Mex.

a. boucardi Godman \& Salvin, Biol. Cent. Am.,

Lep. Rhop., i, 194, 1882.

188. phaon Edwards, Proc. Ent. Soc. Phil., ii, 505, 1864; SkInNer, C. no. 114.

Gulf States.

189. tharos Drury, Ill. Exot. Ent., i, 43, 1770; SKINNER, C. no. 115.

Atl.

States.

syn. gorgone HüBNER, morphea GODART, euclea

Bergstresser, marcia EDwARDs, packardii

SAUNDERS.

a. morpheus Fabricius, Syst. Ent., 550, 1775.

syn. cocyta Cramer, pharos Harris.

190. batesii Reakirt, Proc. Ent. Soc. Phil., v, 226, 1865; SkInNer, C. no. 116.

191. pratensis Beнr, Proc. Cal. Acad. Sci., iii, 86, 1863; Skinner, C. no. 117.

syn. campestris BeHr, pulchella Borsduvar.

a. orseis Edwards, Trans. Am. Ent. Soc., iii, 206, 1871; Skinner, C. no. 118.

192. camillus Edwards, Trans. Am. Ent. Soc., iii, 268, 1871; SkInner, C. no. 119.

Rocky

Mts。

a. emissa Edwards, Trans. Am. Ent. Soc., iii, 269, 1871.

b. pallida Edwards, Proc. Ent. Soc. Phil., ii, 505, 1864.

c. mata Reakint, Proc. Ent. Soc. Phil., vi, 142, 1866.

193. mylitta Edwards, Proc. Acad. Nat. Sci. Phil., 160, 1861; SKInNer, C. no. 120. 
194. barnesi Skinner, Can. Ent., xxix, 155, 1897; Col. C. no. 121 .

195. montana Behr, Proc. Cal. Acad. Sci., iii, 85, 1863; Cal., Nev. SkInNer, C. no. 122.

syn. orsa BoIsduval, pratensis SCUDder.

196. picta Edwards, Proc. Ent. Soc. Phil., iv, 201, Rocky Mts., 1865 ; Skinner, C. no. 123.

Tex.

syn. canace Edwards.

MICROTIA Bates.

Bates, Ent. Mo. Mag., i, 83, 1864.

196. 1. elva Bates, Ent. Mo. Mag., i, 83, 1864.

Mex., Ariz.

ANTHANASSA Seudder.

Scudder, Bull. Buff. Soc., ii, 268, 1875.

197. frisia Poer, Cent. Lep. Cuba, 9, 1832; Skinner, C. no. 124 .

Fla., Antilles.

syn. gyges Hewitson.

198. təxana Edwards, Proc. Ent. Soc. Phil., ii, 81, 1863; Skinner, C. no. 125.

Tex., Neb., Mex.

syn. cincta Edwards, smerdis Hewitson.

*199. tulcis Bates, Ent. Mo. Mag., i, 82, 1864; SKINNER, C. no. 126.

Ariz., Tex., Mex.

syn. punctata Edwards, archesilea Felder.

\section{CHLOSYNE Butler.}

Butler, Cist. Ent., i, 38, 1870; Scudder, Proc. Am. Acad. Arts \& Sci., x, 141, 1875.

200. janais Drury, Ill. Exot. Ent., iii, pl. 17, f. 5, 1782; Skinner, C. no. 127.

201. lacinia Geyer, Hübner, Zutr. exot. Schmett., f. 899, 1837; Skinner, C. no. 128.

syn. tellias Bates, quehtala REAKIRT, ardema REAKIRT, paupera FELDER, mediatrix FELDER, misera FELder, pretoria BOISDUVAL, crocale Edwards, adjutrix Scudder.

a. adelina Staudinger, Verh. zool.-bot. Ges. Wien, 102, 1875.

b. saundersii Doubleday \& Hewitson, Gen. Diurn. Lep., i, 186, 1850.

*202. erodyle Bates, Ent. Mo. Mag., i, 84, 1864; SkinNER, C. no. 129.
Tex., Nev.,

Mex.

Tex., Ariz., Mex。 
MESTRA Hübner.

Hübner, Samml. exot. Schmett., ii, 1826; Scudder, Proc. Am. Acad. Arts \& Sci., x, 217,1875 .

203. amymone Ménétries, Cat. Mus. Pét., 123, 1857;

SKINNER, C. no. 130.

Tex.,

Mex.

*204. floridana Strecker, Lep. Rhop. Het., suppl. 3, Fla. $24,1900$.

\section{POLYGONIA Hübner.}

Hübner, Verz. bek. Schmett., 36, 1816; Scudder, Proc. Am. Acad. Arts \& sici., x, 253,1875 .

205. interrogationis FABRICIUs, Ent. Syst., sup., 424, 1798; SKINNER, C. no. 131.

Atl. States.

syn. fabricii EDwards.

a. umbrosa Lintner, Trans. Am. Ent. Soc., ii, 313, 1869.

206. comma Harris, Ins. Inj. Veg., 221, 1842; SKINNER, C. no. 132.

Atl.

syn. harrisii EDwards.

a. dryas Edwards, Trans. Am. Ent. Soc., iii, 17, 1870 .

207. satyrus Edwards, Trans. Am. Ent. Soc., ii, 374, 1869; SKInNer, C. no. 133.

States.

a. marsyas Edwards, Trans. Am. Ent. Soc., iii, $16,1870$.

*208. hylas Edwards, Trans. Am. Ent. Soc., iv, 68, 1872; Skinner, C. no. 134.

209. faunus Edwards, Proc. Acad. Nat. Sci. Phil., 222, 1862; SKInNer, C. no. 136.

Rocky

Mts.,

Pac.

States.

Col.

No.

U.S.

syn. rusticus Edwards; SKInNer, C. no. 135.

210. silvius Edwards, Trans. Am. Ent. Soc., v, 108, 1874; SkInNer, C. no. 137.

211. zephyrus Edwards, Trans. Am. Ent. Soc., iii, 16, 1870; Skinner, C. no. 138.

Rocky Mts., syn. thiodamus SCUDDER.

212. gracilis Grote \& Robinson, Ann. N. Y. Lyc. Nat. Hist., viii, 432, 1867; Skinner, C. no. 139. Pac. States. syn. c-argenteum ScudDER.

*213. oreas Edwards, Trans. Am. Ent. Soc., ii, 373, 1869.

No.

U.S.

a. silenus Edwards, Trans. Am. Ent. Soc., iii, 15,

Pac.

States. 1870; SKInNer, C. no. 140 
214. progne Cramer, Pap. Exot., i, pl. 15, f. E, 1775; Skinner, C. no. 141.

Atl. States, Pac. N. $-W$.

syn. argenteum KirBy, grogne Fabricius.

a. 1-argenteum Scudder, Bull. Buff. Soc., ii, 253, 1875 .

\section{EUGONIA Hübner.}

Hübner, Verz. bek. Schmett., 36, 1816; Scudder, Proc. Am. Acad. Arts \& Sci., x, 170,1875 .

215. j-album Boisduval \& Le Conte, Lép. Am. Sept., 185, 1833; Skinner, C. no. 142.

Atl. States.

syn. auriomarginata COCKERELL.

216. californica Boisduval, Ann. Soc. Ent. Fr., (2), x, Pac. States, 306, 1852; Skinner, C. no. 144.

Col.

\section{EUVANESSA Seudder.}

Scudder, Butt. E. U. S. \& Can., i, 387, 1889.

217. antiopa Linneus, Syst. Nat., 476, 1758; SKInNER, C. no. 143.

U. S., Eur.

syn. pompadour Pollich, morio Linneus, $a b$ scura COCKERELL, hippolyta LyMAN, grandis

Ehrman, Can. Ent., xxxii, 348, 1900.

a. hygiæa Heydenreich, Verz. eur. Schmett.,

7,1851 .

syn. lintnerii Fттсн.

\section{AGLAIS Dalman.}

Dalman, Vetensk. Akad. Handl., xxxvii, 56, 64, 1816; Scudder, Proc. Am. Acad. Arts \& Sci., x, 105, 1875.

218. milberti Godart, Encl. Méth., ix, 307, 1819; SKIN-

U. S. NER, C. no. 145 .

syn. furcillata $\mathrm{SAY}$.

a. subpallida Cockereld, Ent., 185, 1889.

\section{VANESSA Fabricius.}

Fabricius, Ill. Mag., vi, 281, 1807; Scudder, Proc. Am. Acad. Arts \& Sci., x, 287, 1875.

219. atalanta Linnæus, Syst. Nat., 478, 1758; SKINNER, C. no. 146.

U. S.,

Eur.

syn. admiralis Retzius.

220. huntera FABricius, Syst. Ent., 499, 1775; SkINNER, C. no. 147.

U. S., Mex.

syn. belladonna Petrver, virginiensis Drury, iole Cramer, hunteri HübNer.

a. fulvia Dodge, Can. Ent., xxxii, 92, 1900. 
221. cardui Linneus, Syst. Nat., 475, 1758; Skin- U. S., Eur. NER, C. no. 148. Asia, etc.

syn. carduelis Seba, minor Cockerell, elymi RAMBUR, ate STRECKER.

222. carye HübNer, Samml. ex. Schmett., i. 1806; SKInNer, C. no. 149.

Pac. States. syn. charie Blanchard, muelleri Letcher.

\section{JUNONIA Hübner.}

Hübner, Verz. bek. Schmett., 34, 1816; Scudder, Proc. Am. Acad. Arts \& Sci., x, 200,1875 .

223. cœnia Hübner, Samml. exot. Schmett., ii, 1825; Skinner, C. no. 150.

syn. genoveva Cramer, orythia Sмith \& Aввот, larinia GodART.

So. Atl. States.

\section{ANARTIA Hübner.}

Hübner, Verz. bek. Schmett., 33, 1816; Scudder, Proc. Am. Acad. Arts \& Sci., x, $111,1875$.

224. jatrophæ Linnæus, Mus. Lud. Ulr., 289, 1764; Fla., SkINNER, C. no. 152. So. Am.

VICTORINA Blanchard.

Blanchard, Hist. Ins., iii, 447, 1840; Scudder, Proc. Am. Acad. Arts \& Sei., x, 288, 1875.

225. steneles Linneus, Syst. Nat., 465, 1758; SkIn- Fla., NER, C. no. 151. So. Am.

syn. lavinia FABRICIUS.

HYPANARTIA Hübner.

Hüвner, Samml. exot. Schmett., ii, 1825; Scudder, Proc. Am. Acad. Arts \& Sci., $\mathrm{x}, 193,1875$.

226. lethe Fabricius, Ent. Syst., iii, 80, 1793; SkINNER, C. no. 153.

Tex., syn. demonica HüBNER.

\section{EUNICA Hübner}

Hüвner, Verz. bek. Schmett., 61, 1816; Scudder, Proc. Am. Acad. Arts \& Sci., x, 171, 1875 .

227. monima Cramer, Pap. Exot., iv, pl. 387, f. F, Tex., Fla., 1782; SKInNer, C. no. 154. So. Am. syn. myrta Godart, modesta Bates.

228. tatila Herrich - SchaffFer, Samml. ausser. Schmett., f. 69, 1855; SKInNER, C. no. 155. syn. cærmea Godman \& SaLvin. 
DI $A$ THRIA Billberg.

Billberg, Enum. Ins., 78, 1820; Scudder, Proc. Am. Acad. Arts \& Sci., x, 269, 1875.

229. clymena Cramer, Pap. Exot., i, pl. 24, f. E, 1775; Mex. Kinby, Cat. Diurn. Lep., 207, 1871.

AMPHICHLORA Felder.

Felder, Neu. Lep., 19, 1861; Scudder, Proc. Am. Acad. Arts \& Sci., x, 109, 1875.

230. fornax HübNer, Samml. exot. Schmett., ii, 1824; Tex., Kirby, Cat. Diurn. Lep., 207, $1871 . \quad$ Mex.

231. feronia Linnæus, Mus. Ulr., 283, 1764; Kirby, 'Tex., Cat. Diurn. Lep., 215, $1871 . \quad$ Mex.

TIMETES Boisduval.

Boisduval, Cuvier, Règ. An., ii, pl. 139, 1836; Scudder, Proc. Am. Acad. Arts \& Sci., x, 284, 1875.

232. coresia Godart, Enc. Méth., ix, 359, 1823; SKINNER, C. no. 156.

Tex.

Mex.

syn. zerynthia HüBner, sylla PERTy.

233. chiron Fabricius, Syst. Ent., 452, 1775; SKIN-

NER, C. no. 159.

Tex.,

Mex.

syn. marius Cramer, chironias HüBNER.

ATHENA Hübner.

Hübner, Verz. bek. Schmett., 36, 1816; Scudder, Proc. Am. Acad. Arts \& Sci., x, 123,1875 .

234. peleus Sulzer, Abg. Gesch. Ins., pl. 13, f. 4,

1776; SKInNer, C. no. 157.

Fla.,

Mex.

syn. petreus Cramer, tethys Fabricius.

235. eleucha HüBner, Samml. exot. Schmett., ii, 1824;

Skinner, C. no. 158.

Tex., Fla.,

syn. pellenis Godart.

Antilles.

\section{BASILARCHIA Scudder.}

Scudder, Syst. Rev., 8, 1872; Proc. Am. Acad. Arts \& Sci., x, 126, 1875.

236. astyanax FABricius, Syst. Ent., 447, 1775; SKINNER, C. no. 161.

Atl. States,

Ariz.

syn. ephestion Stoll, ursula Godart.

a. arizonensis Edwards, Pap., ii, 22, 1882.

b. cerulea Ehrman, Can. Ent., xxxii, 348, 1900.

237. arthemis Drury, Ill. Exot. Ent., ii, pl. 10, f. 3 , 1773; SkInNer, C. no. 162.

syn. lamina Fabricius.

a. proserpina Edwards, Proc. Ent. Soc. Phil., v,

148, 1865 . 
238. weidemeyerii Edwards, Proc. Acad. Nat. Sci. Rocky Phil., 162, 1861; SkInNer, C. no. 163.

a. sinefascia Edwards, Pap., ii, 22, 1882.

239. archippus Cramer, Pap. Exot., i, pl. 16, f. A, U. S. 1779; SKInNer, C. no. 164.

syn. disippe GODART.

a. pseudodorippus Strecker, Cat. Lep., 143, 1878.

240. floridensis STRECKER, Cat. Lep., 143, 1878; SKINNER, C. no. 165.

So.

States.

syn. eros Edwards.

241. obsoleta Edwards, Pap., ii, 22, 1882; SkInner, C. no. 166 .

Utah, Ariz.

syn. hulstii EDwards.

242. lorquinii Boisduval, Ann. Soc. Ent. Fr., (2), x, 301, 1852; SKInNer, C. no. 167.

Pac. States. a. eavesi Hy. Edwards, Proc. Cal. Acad. Sci., vii, 172,1878 .

\section{LIMENITIS Fabricius.}

Fabricius, Ill. Mag., vi, 281, 1807; Scudder, Proc. Am. Acad. Arts \& Sci., x, 206, 1875.

243. bredowii HüBner, Zutr. exot. Schmett., f. 825 , 1837; SkInNer, C. no. 168.

Pac. States. syn. eulatia Doubleday \& Hewitson.

a. californica Butler, Proc. Zool. Soc. Lond., 485,1865 .

\section{CHLORIPPE Boisduval.}

Borsduval, in Doubleday List. Brit. Muś., 108, 1844; Scudder, Proc. Am. Acad. Arts \& Sci., $\mathrm{x}, 140,1875$.

244. celtis Boisduval \& Le Conte, Lép. Am. Sept., 210, 1833; SKINNER, C. no. 169.

So. Atl.

States.

245. antonia EDwards, Field \& Forest, iii, 103, 1877; SKINNER, C. no. 170.

Rocky

Mts.

a. montis Edwards, Pap., ii, 7, 1882.

246. leilia Edwards, Trans. Am. Ent. Soc., v, 103, 1874; SKInner, C. no. 171.

247. alicia Edwards, Butt. U. S., 135, 1868; SKINNER, C. no. 172.

248. clyton Boisduval \& Le Conte, Lép. Am. Sept., 208, 1833; SKInNer, C. no. 173.

syn. ocellata EDwards.

a. proserpina Scudder, Proc. Bost. Soc. Nat. Hist., xi, 401, 1868. 
249. flora Edwards, Butt., ii, 1876; Skinner, C. no.174. Fla., Tex. *250. cocles Lintner, Pap., iv, 141, 1884; Skinner, C. Tex. no. 175 .

\section{SMYRNA Hïbner.}

Hübner, Samml. exot. Schmett., ii, 1826; Scudder, Proc. Am. Acad. Arts \& Sci., x, $269,1875$.

251. karwinskii HüBner, Samml. exot. Schmett., ii, 1826; Kirby, Cat. Diurn. Lep., 266, 1871.

Mex.,

Tex.

\section{CEA Hübner.}

Hübner, Verz. bek. Schmett., 48, 1816; Scudder, Proc. Am. Acad. Arts \& Sci., x, 144,1875 .

*252. acheronta Fabricius, Syst. Ent., 501, 1775; Mex.

Kirby, Cat. Diurn. Lep., 264, 1871.

syn. eodamus Cramer, pherecydes Cramer.

\section{HISTORIS Hübner.}

Hübner, Verz. bek. Schmett., 35, 1816; Scudder, Proc. Am. Acad. Arts \& Sci., x, $192,1875$.

253. odius Fabricius, Syst. Ent., 457, 1775; KIrby, Cat. Diurn. Lep., 263, 1871.

Fla.,

syn. orion Fabricius, danae Cramer.

So. Am.

\section{AN EA Hiibner.}

Hübner, Verz. bek. Schmett., 48, 1816; Scudder, Proc. Am. Acad. Arts \& Sci., x, $111,1875$.

254. andria Scudder, Bull. Buff. Soc., ii, 248, 1875; SKInNER, C. no. 176.

Miss.

Val.

syn. ops DruCE.

255. portia Fabricius, Syst. Ent., 507, 1775; Skinner, C. no. 177 .

Fla., Antilles.

*256. morrisonii Edwards, Pap., iii, 8, 1883; Skinner, Ariz. C. no. 178 .

Family AGAPETID E.

(C.=Skinner, Syn. Cat. No. Am. Rhop., 31-41, 1898.)

CERCYONIS Speyer.

Speyer, Bull. Buff. Soc., ii, 241, 1875; Scudder, Butt. E. U. S., i, 156, 1889.

257. pegala Fabricius, Syst. Ent., 494, 1775; SKInNER, C. no. 210. 
258. alope Fabricius, Ent. Syst., iii, 1, 229, 1793;

SKINNER, C. no. 211.

Atl.

a. texana Edwards, Can. Ent., xii, 23, 1880.

States. syn. incana Edwards.

b. boopis Benr, Proc. Cal. Acad. Sci., iii, 164, 1864.

c. nephele Krrby, Faun. Bor. Am., iv, 297, 1837 syn. olympus Edwards, ariana Borsduval.

d. baroni Edwards, Can. Ent., xii, 91, 1880.

e. maritima Edwards, Can. Ent., xii, 23, 1880.

259. wheeleri Edwards, Trans. Am. Ent. Soc., iv, 343, 1873; SkINNer, C. no. 212.

Cal., Ariz.,

Utah.

syn. hoffmani STRECKER.

260. gabbii Edwards, Trans. Am. Ent. Soc., iii, 192, 1870; SKinner, C. no. 213.

Oreg.,

Utah.

261. meadii Edwards, Trans. Am. Ent. Soc., iv, 70, Rocky Mts. 1872; Skinner, C. no. 214.

262. paulus Edwards, Can. Ent., xi, 50, 1879; SkinNER, C. no. 215 .

263. sylvestris Edwards, Proc. Acad. Nat. Sci. Phil., 162, 1861; SKInNer, C. no. 216.

syn. phocus EDwards.

a. charon Edwards, Trans. Am. Ent. Soc., iv, 69, 1870; SKinner, C. no. 216.

*264. œtus Boisduval, Ann. Soc. Ent. Belg., xii, 63, 1869; Skinner, C. no. 217.

*265. sthenele Boisduval, Ann. Soc. Ent. Fr., (2), x, 308, 1852, Skinner, C. no. 218.

Cal., Nev.

Pac.

States,

Rocky Mts.

Cal.

Cal.

GYROCHEILUS Butler.

Butler, Ann. Mag. Nat. Hist., (3), xx, 267, 1867; Scudder, Proc. Am. Acad. Arts \& Sci., $x, 182,1875$.

266. tritonia Edwards, Trans. Am. Ent. Soc., v, 18, 1874; SKInNer, C. no. 207.

Ariz., Mex.

\section{EREBIA Dalman.}

Dalman, Vetensk. Acad. Handl., xxxvii, 58, 79, 1816; Scudder, Proc. Am. Acad. Arts \& Sci., x, 165, 1875.

267. fasciata Butler, Cat. Satyr. Brit. Mus., 92, 1868; Aretic Am. SKINNER, C. no. 198.

268. discoidalis Kirby, Faun. Bor. Am., iv, 298, 1837; Aretic Am. Skinner, C. no. 199.

269. rossii Curtis, Ross Second Voy. N. W. Pass., Aretic Am. app., 67, 1835; Skinner, C. no. 200. 
270. disa Thunberg, Diss. Ent. Ins. Suec., ii, 37, 1791; Aretic Am. Kinby, Cat. Diurn. Lep., 67, 1871.

a. mancinus Doubleday \& Hewitson, Gen.

Diurn. Lep., 380, pl. 64, f. 2, 1851; SKInner, C. no. 201.

271. vidleri Elwes, Trans. Ent. Soc. Lond., 195, 1898; SKINNER, C. no. 202.

Brit. Col., Wash.

272. tyndarus Esper, Schmett. Eur., i, 2, pl. 67, f. 1, 1781; Krrby, Cat. Diurn. Lep., 63, 1871.

Col., N. M., Eur.

a. callias Edwards, Trans. Am. Ent. Soc., iii, 274, 1871; Skinner, C. no. 203.

273. epipsodea Butler, Cat. Satyr. Brit. Mus., 80, 1868; Skinner, C. no. 204.

Rocky Mts., Alaska.

syn. rhoda EDwards.

a. brucei Elwes, Trans. Ent. Soc. Lond., 326, 1889.

syn. sineocellata SKInNER.

274. sofia Strecker, Bull. Brook. Ent. Soc., iii, 35, 1880; Skinner, C. no. 205.

Rocky Mts.,

Alaska.

syn. ethela EDwards.

a. alaskensis Holland, Ent. News, xi, 387, 1900.

275. magdalena Strecker, Bull. Brook. Ent. Soc., iii, 25, 1880; Skinner, C. no. 206.

276. youngi Holland, Ent. News, xi, 388, 1900.

\section{NEOMINOIS Scudder.}

Scudder, Bull. Buff. Soc., ii, 241, 1875.

277. ridingsii Edwards, Proc. Ent. Soc. Phil., iv, 201, 1865; Skinner, C. no. 208. syn. stretchii EDwards.

278. dionysius Scudder, Bull. U. S. Geol. Surv., Hayden, iv, 254, 1878; Skinner, C. no. 209.

Rocky

Mts.

Utah, Ariz., Col.

syn. ashtaroth STRECKER.

\section{COENONYMPHA Hübner.}

Hübner, Verz. bek. Schmett., 65, 1816; Scudder, Proc. Am. Acad.-Arts \& Sci., x, 145, 1875; Skinner, Trans. Am. Ent. Soc., xxvi, 299, 1900.

279. californica Doubleday \& Hewitson, Gen. Diurn. Lep., ii, 398, 1852; Skinner, C. no. 189.

Pac.

syn. galactinus Borsduval, ceres Butler,

States.

eryngii Hr. EDWARDS.

a. pulla Hr. Edwards, Pap., i, 51, 1881. 
280. elko Edwards, Can. Ent., xiii, 57, 1880; SkInNER, C. no. 190.

Pac. States.

syn. ampelos Edwards; SKInNer, C. no. 193.

281. ochracea Edwards, Proc. Acad. Nat. Sci. Phil., Rocky Mts., 163, 1861; SkinNer, C. no. 192. So. Cal.

syn. brenda Edwards; Skinner, C. no. 195.

282. kodiak Edwards, Trans. Am. Ent. Soc., ii, 375, 1869; Skinner, C. no. 194.

a. yukonensis Holland, Ent. News, xi, 386, 1900.

283. pamphilius Linneus, Syst. Nat., 472, 1758; SKInNER, C. no. 196.

Cal., Asia.

syn. pamphiloides Reakirt, gardetta De Loche, nephela Hufnagel, menalcas Poda.

*284. typhon Rottenburg, Naturf., vi, 15, 1775; Kirby, Cat. Diurn. Lep., 99, 1871.

Alaska.

a. laidon Borkhausen, Eur. Schmett., i, 91, 29,

1788; Skinner, C. no. 191.

syn. inornata EDwards.

285. haydenii Edwards, Rept. Hayden Expl. Surv. Mont., 467, 1872; Skinner, C. no. 197.

Rocky Mts.

\section{ENODIA Huibner.}

Hübner, Verz. bek. Schmett., 61, 1816; Scudder, Proc. Am. Acad. Arts \& Sci., x, 163,1875 .

286. portlandia FABricius, Spec. Ins., ii, 82, 1781;

SKINNER, C. no. 179.

Atl.

States.

syn. andromacha HüBNER.

*287. creola Skinner, Ent. News, viii, 236, 1897; C. no. 180 .

So. States.

\section{SATYRODES Seudder.}

Scudder, Bull. Buff. Soc., ii, 242, 1875; Butt. E. U. S., i, 187, 1889.

288. canthus Linneus, Syst. Nat., 768, 1767; SKIN-

Atl. NER, C. no. 181.

syn. boisduvalii Harris.

\section{ENEIS Hübner.}

Hübner, Verz. bek. Schmett., 58, 1816; Scudder, Proc. Am. Acad. Arts \& Sci., x, 231,1875 .

289. macounii Edwards, Can. Ent., xvii, 71, 1885;

Can.

SKINNER, C. no. 219.

290. nevadensis Felder, Reise Nov., iii, 89, 1867; SKInNer, C. no. 220.

Pac.

syn. gigas Butler, californica Boisduval, iduna EDwards. 
291. chryxus Doubleday \& Hewitson, Gen. Diurn. Lep., ii, 383, 1851; Skinner, C. no. 221.

Can.

a. calais Scudder, Proc. Ent. Soc. Phil., v, 7, 1865.

b. ivallda Mead, Can. Ent., x, 196, 1878; SKInNER, C. no. 223.

Nev., Cal.

Aretic Am. NER, C. no. 230.

syn. balder Boisduval.

a. alaskensis Holland, Ent. News, xi, 389, 1900.

293. uhleri Reakirt, Proc. Ent. Soc. Phil., vi, 143, 1866; Skinner, C. no. 226.

Rocky Mts.

a. varuna Edwards, Can. Ent., xiv, 2, 1882; Skinner, C. no. 225.

294. tarpeia Pallas, Reise, i, 18, 1771; Skinner, C. no. 227.

syn. celimene Cramer.

a. alberta Elwes, Trans. Ent. Soc. Lond., 467, 1893; Skinner, C. no. 224.

295. norna Thunberg, Diss. Ent. Ins. Suec., ii, 36, 1791; Skinner, C. no. 222.

Arctic

Am.,

a. dauria Strecker, Can. Ent., xxvi, 225, 1894; SKINNer, C. no. 228.

b. katahdin Newcomb, Ent. News, xii, 206, 1901.

Can.,

Eur.

c. hilda Quensel, Act. Holm., 272, 1791.

d. celæno HüBner, Eur. Schmett., i, f. 152, 1794.

e. bore HüBner, Eur. Schmett., i, f. 756, 1825. syn. fulla Eversmann.

$f$. taygete Hübner, Samml. exot. Schmett., iii, 1824; Skinner, C. no. 229.

syn. bootes Boisduval.

g. semidea $\mathrm{S}_{A Y}, \mathrm{Am}$. Ent., iii, pl. 50, 1828; SKINNER, C. no. 231.

syn. ano Boisduval, assimilis Butler, nigra EDWARDS.

h. peartiæ Edwards, Butt., iii, pl. 14, Chion., 1897; Skinner, C. no. 233.

$i$ subhyalina Curtis, Ross Second Voy. N.-W. Pass., app., 68, 1835; Skinner, C. no. 234.

syn. crambis Freyer, also Möschler, deno SCUdDER.

k. brucei Edwards, Can. Ent., xxiii, 33, 1891; Skinner, C. no. 235.

l. beanii Elwes, Proc. Ent. Soc. Lond., 476, 1893; Skinner, C. no. 236. 


\section{NEONYMPHA Huibner.}

Hübner, Verz. bek. Schmett., 65, 1816; Scudder, Proc. Am. Acad. Arts \& Sci., x, $225,1875$.

296. gemma HüBner, Zutr. exot. Schmett., i, f. 4, 1818; Skinner, C. no. 182.

So.

syn. cornelius GodarT.

297. henshawii Edwards, Trans. Am. Ent. Soc., v, 205, 1876; SKINNER, C. no. 183.

States.

298. phocion Fabricius, Sp. Ins., ii, 138, 1781; SKINNER, C. no. 184.

Rocky

Mts.

syn. areolatus SмITH \& AвBot, helcita HüBner.

So.

\section{CISSIA Doubleday.}

Doubleday, List Brit. Mus., app., 33, 1848; Scudder, Proc. Am. Acad. Arts \& Sci., $\mathrm{x}, 143,1875$.

299. eurytus Fabricius, Syst. Ent., 487, 1775; SKINNER, C. no. 185.

Atl. States.

syn. cymela CRAMER, eurytris FABRICIUS.

300. mitchelli French, Can. Ent., xxi, 25, 1889; SKInNER, C. no. 186.

Atl. States.

301. sosybius Fabricius, Ent. Syst., iii, 1, 219, 1793;

SkInNer, C. no. 187.

Atl.

States.

syn. camerta CraMER.

302. rubricata Edwands, Trans. Am. Ent. Soc., iii, Tex., Ariz., 212, 1872; SKINNer, C. no. 188.

Mex.

\section{EPINEPHELE Hübner.}

HüBner, Verz. bek. Schmett., 59, 1816; Scunder, Proc. Am. Acad. Arts \& Sci., x, 164,1875 .

303. xicaque Reakirt, Proc. Acad. Nat. Sci. Phil., Mex., 336, 1866; KIrBy, Cat. Diurn. Lep., 78, 1872;

Ariz.

Barnes, Ent. News, x, 330, 1900.

\section{Family HELICONID A.}

\section{APOSTRAPHIA Hübner.}

HüBner, Verz. bek. Schmett., 13, 1816; Scudder, Proc. Am. Acad. Arts \& Sci., x, 116,1875 .

304. charithonia Linneus, Syst. Nat., ii, 757, 1767; Skinner, C. no. 6.

Fla., Antilles. 


\section{Family ITHOMIID E.}

DIRCENNA Doubleday.

Doubleday, Gen. Diurn. Lep., pl. 17, 1847; Scudder, Proc. Am. Acarl. Arts \& Sci., $\mathrm{x}, 157,1875$.

305. klugii Hübner, Zutr. exot. Schmett., f. 801, 1837:

SKINNER, C. no. 5.

Mex.

Tex.

\section{MECHANITIS Fabricius.}

Fabricius, Ill. Mag., vi, 284, 1807; Scudder, Proc. Am. Acad. Arts \& Sci., x, 212, 1875 .

*306. californica Reakirt, Proc. Ent. Soc. Phil., v, 223,

1865; SKINNER, C. no. 4.

So.

Cal.

\section{DYNOTHEA Reakirt.}

ReAkirt, Proc. Ent. Soc. Phil., 222, 1866; Scudder, Proc. Am. Acad. Arts \& Sci., x, $160,1875$.

307. lycaste Fabricius, Ent. Syst., iii, 1, 161, 1793;

Cal., SKInNER, C. no. 3.

Mex.

a. negreta Reakirt, Proc. Ent. Soc. Phil., v, 223, 1865 .

Family LYMNADIDA.

$$
\text { (C.=Skinner, Syn. Cat. No. Am. Rhop., pp. 1-2, 1898.) }
$$

ANOSIA Hübner.

Hübser, Verz. bek. Schmett., 16, 1816; Scudder, Proc. Am. Acad. Arts \& Sci., x 113,1875 .

308. plexippus Linneus, Syst. Nat., 471, 1758; SKInU. S. NER, C. no. 1.

syn. archippus Fabricius, erippus Cramer, megalippe HüBNER, menippe HüBNER, fumosus Hulst, pulchra Strecker, Lep. Rhop. Het., suppl. 3, 21, 1900.

309. berenice Cramer, Pap. Exot., iii, pl. 205, f. E, 1782; SKInNER, C. no. 2.

$$
\text { So. }
$$
States, a. strigosa Bates, Ent. Mo. Mag., i, 32, 1864.

\section{LYCOREA Doubleday.}

Doubleday, Gen. Dium. Lep., 105, 1847; Kirby, Cat. Diurn. Lep., $18,1872$.

310. cleobæa Godart, Enc. Méth., ix, 222, 1819; KIRBY, Cat. Diurn. Lep., 18, 1872.

a. atergatis Doubleday \& Hewitson, Gen. Diurn.

Lep., pl. 16, f. 1, 1847 .

b. pales Felder, Wien. ent. Mon., vi, 75, 1862.

$4630-$ No. $52-02-3$
Fla., So. Am. 
Family LIBYTHEID A. (C. =Skinner, Syn. Cat. No. Am. Rhop., p. 42, 1898.)

HYPATUS Hübner.

Hübner, Cat. Frank., 85, 1825; Scudper, Proc. Am. Acad. Arts \& Sci., x, 194, 1875.

311. bachmani Kirtland, Am. Journ. Sci., ii, 13, 336 , 1852; SKINNER, C. no. 237.

312. carinenta Cramer, Pap. Exot., ii, pl. 108, f. E, 1779; SKLnNer, C. no. 238.

Atl. States.

Tex. a. larvata Strecker, Lep. Rhop. Het., 130, 1878.

Family RIODINID E.

(C.=Skinner, Syn. Cat. No. Am. Rhop., pp. 42-43, 1898.)

CHRYSOBIA Boisduval.

Borsduva t, Ann. Soc. Ent. Belg., xii, 52, 1869; Scudder, Bull. Buff. Soc., iii, 102, 1876.

313. mormo Felder, Wien. ent. Mon., iii, 271, 1859; SKINNER, C. no. 239.

S. - W. U.S.

syn. dumeti BeHr, mormonia BoIsduvaL.

314. duryi Edwards, Pap., ii, 47, 1882; Skinner, C. no. 240 .

New

Mex.

315. cythera Evwards, Trans. Am. Ent. Soc., iv, 345, 1873; SKINNER, C. no. 241.

Ariz., Mex.

316. virgulti Benr, Proc. Cal. Acad. Sci., iii, 178, 1865; SkInNer, C. no. 242.

So.

Cal.

syn. sonorensis FELDER.

POLYSTIGMA Godman \& Salvin.

Godman \& Salvin, Biol. Cent. Am., Lep. Het., i, 469, 1886.

317. nais Edwards, Trans. Am. Ent. Soc., v, 291, 1876;

SKInNer, C. no. 243.

Rocky

Mts.

318. palmerii Edwards, Trans. Am. Ent. Soc., iii, 195, 1870; SKINNER, C. no. 244.

Rocky

Mts.

\section{EMESIS Fabricius.}

Fabricius, Ill. Mag., vi, 287, 1807; Scudder, Proc. Am. Acad. Arts \& Sci., x, 162, 1875.

319. zela Butler, Ann. Mag. Nat. Hist., iv, 364, 1870;

SKINNER, C. no. 245.

Ariz.,

syn. ares EDwARDs.

Mex.

a. cleis Edwards, Pap., ii, 137, 1882. 
CALEPHELIS Grote \& Robinson.

Grote \& Robinson, Trans. Am. Ent. Soc., ii, 310, 1869; Scudder, Proc. Am. Acad. Arts \& Sci., 129, 1875.

320. cænius Linnæus, Syst. Nat., 1, 2, 796, 1767;

SkInNer, C. no. 246.

So.

States.

syn. cerea HÜBNER, virginiensis BOISDUVAL, pumila Boisduval \& Le Conte, cerens DOUBLEDAY.

321. borealis Grote \& Robinson, Ann. N. Y. Lyc. Nat. Hist., viii, 351, 1866; Skinner, C. no. 247.

322. australis EDwards, Field \& Forest, iii, 87, 1877;

SKInNer, C. no. 248.

syn. guadeloupe STRECKER.

*323. nemesis Edwards, Trans. Am. Ent. Soc., iii, 212, 1871; Skinner, C. no. 249.

Atl.

States.

Tex.,

Ariz.

So.

Cal.

\section{CARIA Hübner.}

Hübner, Zutr. exot. Schmett., 14, 1823; Godman \& Salvin, Biol. Cent. Am., Lep. Rhop., i, 447, 1886.

324. melicerta Schaus, Ent. Amer., vi, 18, 1890.

Tex., Mex.

\section{Family LYCANID E.}

\section{(C. =Skinner, Syn. Cat. No. Am. Rhop., pp. 43-60, 1898.)}

\section{EUM EUS Hübner.}

Hübner, Verz. bek. Schmett., 67, 1816; Scudder, Proc. Am. Acad. Arts \& Sci., x, 170,1875 .

325. atala Poer, Cent. Lep. Cuba, ii, 1832; Skinner, C. no. 250 .

Fla.,

syn. toxea Gray.

226. minyas HüBner, Samml. exot. Schmett., i, 1806;

SKInNer, C. no. 251.

Cuba.

syn. godartii Boisduval, toxana BoIsduval.

Tex.,

Mex.

HABRODIAS Scudder.

Scudder, Bull. Buff. Soc., iii, 113, 1876.

327. grunus Boisduval, Ann. Soc. Ent. Fr., (2), x, 289, 1852; Skinner, C. no. 252.

Cal.,

Nev.

\section{HYPAUROTIS Scudder.}

Scudder, Bull. Buff. Soc., iii, 112, 1876.

328. crysalus Edwards, Trans. Am. Ent. Soc., iv, 344, 1873; SkInner, C. no. 253.

Cal., Ariz., Utah.

a. citima Hy. Edwards, Pap., i, 53, 1881. 


\section{A TLIDES Hibner.}

Hübner, Verz. bek. Schmett., 80, 1816; Scudder, Proc. Am. Acad. Arts \& Sci., x, 124,1875 .

329. halesus Cramer, Pap. Exot., ii, pl. 98, f. B, 1779;

SKINNER, C. no. 254.

Gulf States

syn. dolichus HüBner, juanita SCudder.

\section{EUPSYCHE Scudder.}

Scudder, Bull. Buff. Soc., iii, 112, 1876.

330. m-album Boisduval \& Le Conte, Lép. Am. Sept., 86, 1833; SKINNER, C. no. 255.

So. Atl. States, Mex.

syn. pysche Boisduval \& Le Conte.

*331. telea Hewitson, Desc. Lyc., iv, no. 10, 1868; SKINNER, C. no. 256.

*332. martialis Herrich -Schafferer, Corresp.-Blatt Regens., xviii, 164, 1864; SkInner, C. no. 257.

*333. hugon Godart, Enc. Méth., ix, 640, 1843: SkInNER, C. no. 258.

syn. hugo Doubleday \& Hewitson.

*334. jada Hewitson, Ill. Diurn. Lep., 87, 1870; SkinNER, C. no. 259.

URANOTES Scudder.

Scudder, Bull. Buff. Soc., iii, 107, 1876.

335. melinus HüBNER, Zutr. exot. Schmett., f. 121, 1818; SKINNER, C. no. 263.

syn. hyperici BoIsduval \& Le Conte, favonius Boisduval \& Le Conte, lemmuli Harris, pan Harris, silenus Doubleday, pudica Hy. EdWARDS.

THECLA Fabricius.

\section{Fla.,}

Mex.

Fla.,

Cuba.

Fla., Antilles.

Ariz., Mex.

U. S.

Fabricius, Ill. Mag., vi, 286, 1807; Scudper, Proc. Am. Acad. Arts \& Sci., x, 279, 1875 .

336. favonius Sмгтн \& Аввот, Lep. Ins. Ga., i, 27, 1797; SKINNER, C. no. 260.

Gulf

States.

337. autolycus Edwards, Trans. Am. Ent. Soc., iii, 271, 1871; SKINNER, C. no. 261.

Tex., Mo., Kans.

338. alcestis Edwards, Trans. Am. Ent. Soc., iii, 271, 1871; Shinner, C. no. 262.

Tex.,

Ariz.

339. acadica Edwards, Proc. Acad. Nat. Sci. Phil., 55, 1862; SKINNER, C. no. 264.

No. States, syn. souhegan WHITNEY.

Nev., Ariz. 
340. californica Evwards, Proc. Acad. Nat. Sci. Phil., 233, 1862; SKInNer, C. no. 265.

Pac. States. syn. borus Boisduval, cygnus Edwafds.

*341. itys Edwards, Pap., ii, 23, 1882; SkInner, C. Ariz. no. 266.

*342. auretorum Boisdural, Ann. Soc. Ent. Fr., (2), x, 288, 1852; SKINNER, C. no. 261.

343. dryope Edwards, Trans. Am. Ent. Soc., iii, 19, 1870; SKInNer, C. no. 268.

Cal., Nev., Utah.

Cal.

*344. sylvinus Boisduval, Ann. Soc. Ent. Fr., (2), x, 287, 1852; SKInNer, C. no. 269.

345. edwardsii Saunders, (an. Ent., i, 99, 1869; SKINNER, C. no. 270.

syn. fabricii KIrBY.

*346. wittfeldii Edwards, Can. Ent., xv, 136, 1883; SkInNer, C. no. 271.

347. calanus Hübner, Samml. exot. Schmett., i, 1824; Skinner, C. no. 272.

syn. falacer Godart, inomata Grote \& RoBINSON.

a. lorata Grote \& Robinson, Trans. Am. Ent. Soc., i, 323, 1868.

*348. ontario Edwards, Trans. Am. Ent. Soc., ii, 209, 1868; SkInNer, C. no. 273.

No. Atl.

States.

349. liparops Boisduval \& Le Conte, Lép. Am. Sept., No. Atl. States. 99, 1833; Skinner, C. no. 274.

Rocky Mts.

syn. strigosa HARRIs.

*350. putnami Hr. Edwards, Proc. Cal. Acad. Sci., vii, 143, 1876; SKInner, C. no. 275.

*351. spadix Hy. Edwards, Pap., i, 53, 1881: SKInner, C. no. 278.

Utah.

*352. tetra Behr, Trans. Am. Ent. Soc., iii, 19, 1870; SKInNer, C. no. 277.

*353. chalcis Benr, Trans. Am. Ent. Soc., ii, 376, 1869; SkInner, C. no. 278.

Atl. States, Rocky Mts.

354. sæpium Borsduval, Ann. Soc. Ent. Fr., (2), x, 288, 1852; SKInNer, C. no. 279.

a. fulvescens Hy. Edwards, Proc. Cal. Acad. Sci.. vii, $172,1876$.

355. nelsonii Boisduval, Ann. Soc. Ent. Belg., xii, 43, 1869; SkInNer, C. no. 280.

So.

Cal.

Cal.

Cal.,

Utah.

Pac.

States.

Col.

a. exoleta Hy. Edwards, Pap., i, 53, 1881.

b. muirii Hy. Edwards, Pap., i, 53, 1881.

Cal.,

Col. 
356. adenostomatis Hy. Edwards, Proc. Cal. Acad. Cal. Sci., vii, 144, 1876; SkInner, C. no. 281.

*357. tacita Hy. Edwards, Pap., i, 54, 1881; Skinner, C. no. 282.

358. spinetorum Borsduval, in Hewitson, Ill. Diurn. Lep., 94, pl. 45, f. 198, 1867; Skinner, C. no. 283. syn. nimus EDWARDs.

359. blenina Hewitson, Desc. Lyc., xii, 29, 1868; Vanc., Ariz., Skinner, C. no. 284. syn. siva Edwards.

*360. castalis Edwards, Trans. Am. Ent. Soc., iii, 208, 1871; Skinner, C. no. 285.

*361. ilavia Beutenmüller, Jn. N. Y. Ent. Soc., vii, $254,1899$.

Cal.

Pac. States.

syn. mirabelle Barnes, Can. Ent., xxxii, 43, 1900 .

\section{MITOURA Seudder.}

Scudder, Syst. Rev., 31, 1872; Proc. Am. Acad. Arts \& Sci., x, 220, 1875.

362. damon Cramer, Pap. Exot., iv, pl. 90, f. C, 1782; SKINNER, C. no. 286.

Atl.

syn. gryneus HüBNER, damastus Godart, smilacis BoIsduval \& LE Conte, auburniana HARRIS.

a. discoidalis SkInNer, Can. Ent., xxix, 156, 1897. *363. simæthis Drury, Ill. Exot. Ent., i, pl. 1, f. 3, 1770; SkInNer, C. no. 287.

syn. sarita SKInNer, lycus HüBner.

364. acis Drury, Ill. Exot. Ent., i, pl. 1, f. 3, 1773; SkInNer, C. no. 288.

syn. mars Fabricius. States.

CALYCOPIS seudder.

Scudder, Bull. Buff. Soc, iii, 108, 1876.

365. cecrops Fabricius, Ent. Syst., iii, 1, 270, 1793; SKINNER, C. no. 289.

So.

syn. paeas HüBNER.

\section{CALLICISTA Grote.}

Grote, Bull. Buff. Soc., iii, 107, 1876.

366. columella Fabricius, Ent. Syst., iii, 1, 282, 1793; SKInNer, C. no. 290.

Atl. States, Mex.

syn. eurytulus Hübner, modesta Maynard, ocellifera Grote, istapa REAKIRT, salona Hewitson. 
*367. clytie Edwards, Field \& Forest, iii, 88, 1877; Skinner, C. no. 291.

Tex., Ariz.

368. leda Edwards, Pap., ii, 23, 1882; Skinner, C. no. 292.

Ariz., Mex.

Ariz.

*369. ines Edwards, Pap., ii, 25, 1882; Skinner, C. no. 293.

\section{CALLIPSYCHE Seudder.}

Scudder, Bull. Buff. Soc., iii, 106, 1876.

370. behrii Edwards, Trans. Am. Ent. Soc., iii, 18, Rocky Mts., 1870; Skinner, C. no. 294.

Pac. States. syn. kali STRECKER.

\section{INCISALIA Minot.}

Minot, Scudder, Syst. Rev., 31, 1872; Scudder, Proc. Am. Acad. Arts \& Sci., x, 196, 1875 .

371. augustus Krrby, Faun. Bor. Am., iv, 298, 1837; SKInner, C. no. 295.

No. Atl.

States.

syn. augustinus WESTWOOD.

372. iroides Boisduval, Ann. Soc. Ent. Fr., (2), x, 289, 1852; SKInNer, C. no. 296.

373. fotis Strecker, Lep. Rhop. Het., 129, 1878; SKInNer, C. no. 297.

374. irus Godart, Enc. Méth., ix, 674, 1823; SkInNER, C. no. 298.

a. arsace Boisduval \& Le Conte, Lép. Am. Sept., $103,1833$.

375. mossi Hy. Edwards, Pap., i, 54, 1881.

Vanc. Is.

376. henrici Grote \& Robinson, Trans. Am. Ent. Soc., i, 774, 1867; SkInner, C. no. 299.

377. eryphon Boisduval, Ann. Soc. Ent. Fr., (2), x, 290, 1852; SkInNer, C. no. 300.

W. Va.

Cal.,

Col.

378. niphon Hübner, Zutr. exot. Schmett., f. 203, 1823; SKInNer, C. no. 301.

Atl. States, Rocky Mts.

\section{CALLOPHRYS Billberg.}

Billberg, Enum. Ins., 80, 1820; Scudner, Proc. Am. Acad. Arts \& Sci., x, 132, 1875.

379. affinis Edwards, Proc. Acad. Nat. Sci. Phil., 223, Utah. 1862; SkInNer, C. no. 302.

380. dumetorum Boisdural, Ann. Soc. Ent. Fr., (2), Rocky x, 291, 1852; Skinner, C. no. 303.

syn. viridis EDWARDs. 
381. apama Edwards, Pap., ii, 137, 1882; SkInner, Ariz. C. no. 304 .

382. sheridanii Edwards, Field \& Forest, iii, 48, 1877; Rocky SkINNER, C. no. 305. Mts.

\section{ERORA Scudder.}

Scudder, Syst. Rev., 32, 1872; Proc. Am. Acad. Arts \& Sci., x, 166, 1875.

383. læta Edwards, Proc. Acad. Nat. Sci. Phil., 55, 1862; SKInNer, C. no. 306.

Mont., syn. clothilde EDWARDs.

\section{STRYMON Hïbner.}

Hübner, Verz. bek. Schmett., 74, 1816; Scudder, Proc. Am. Acad. Arts \& Sci., x, 271,1875 .

384. titus Fabricrus, Ent. Syst., iii, 297, 1793: SkIn-

NER, C. no. 307 .

Atl.

syn. mopsus HüBNER.

\section{FENISECA Grote.}

Grote, Trans. Am. Ent. Soc., ii, 308, 1869; Scudder, Proc. Am. Acad. Arts \& Sci., $\mathrm{x}, 177,1875$.

385. tarquinius FABRICIUs, Ent. Syst., iii, 319, 1793;

SkInner, C. no. 308.

Atl.

syn. cratregi Boisduval \& Le Conte, porsenna States.

SCUDDER.

THARSALEA Scudder.

Scudder, Bull. Buff. Soc., iii, 125, 1876.

386. arota Boisduval, Ann. Soc. Ent. Fr., (2), x, 293,

1852; SKInNer, C. no. 309.

Cal.

387. virginiensis Edwards, Trans. Am. Ent. Soc., iii, 21, 1870; SKinner, C. no. 310.

Cal., Nev.,

Col.

Cal.,

Nev.

\section{GAIDES Scudder.}

Scudder, Bull. Buff. Soc., iii, 126, 1876.

389. xanthoides Boisduval, Ann. Soc. Ent. Fr., (2), x, 292, 1852; SKInNer, C. no. 312.

Cal.

390. dione Scudder, Trans. Chic. Acad. Sci., i, 330, 1869; SKInNer, C. no. 313.

Miss.

Vall.

391. editha Mead, Can. Ent., x, 198, 1878; Skinner, C. no. 314.

392. gorgon Borsduval, Ann. Soc. Ent. Fr., (2), x, 292, 1852; SKInner, C. no. 315. 
CHRYSOPHANUS Hibner.

HüBner, Verz. bek. Schmett., 72, 1816; Scudder, Proc. Am. Acad. Arts \& Sci., x, $141,1875$.

393. thoe Boisdural, Gray Griff. An. King., pl. 56,

f. 4, 1832; SkInNer, C. no. 316.

Atl. States,

Col.

EPIDEMIA Scudder.

Scudder, Bull. Buff. Soc., iii, 127, 1876.

394. mariposa Reakirt, Proc. Ent. Soc. Phil., vi, 149, 1866; Skinner, C. no. 317.

Cal..

syn. nivalis Boisduval.

Rocky Mts.

395. zeroe Boisduval, Ann. Soc. Ent. Belg., xii, 45, 1869: SKINNER, C. no. 318.

syn. ianthe Edwards.

396. helloides Boisduval, Ann. Soc. Ent. Fr., (2), x, Rocky Mts., 291, 1852; SKINNER, C. no. 319.

Cal.

syn. castro REAKIRT.

397. dorcas Kirby, Faun. Bor. Am., iv, 299, 1837; SKINNER, C. no. 321.

Aretic Am.

a. florus Edwards, Can. Ent., xv, 210, 1883; SkINNer, C. no. 320; Dyar, Proc. Wash. Acad. Sci., ii, 489,1900 .

398. epixanthe Boisduval \& Le Conte, Lép. Am. Sept., 127, 1833; Skinner, C. no. 322.

Cal.

Col.

Atl. States.

\section{HEODES Dalman.}

Dalman, Vet. Akad. Handl., xxxvii, 63, 91, 1816; Scudder, Proc. Am. Acad. Arts \& Sci., x, 187, 1875.

399. hypophleas Boisduval, Ann. Soc. Ent. Fr., (2),

x, 291, 1852; SkInNer, C. no. 323.

Atl.

syn. phlzas Boisduval \& Le Conte, americana

D'Urban, fasciata STRECKER, fulliolus Hulst.

a. fieldeni McLachlan, Jn. Linn. Soc., xiv, 111, 1878.

\section{CHALCERIA Scudder.}

Scudder, Bull. Buff. Soc., iii, 125, 1876.

400. cupreus Edwards, Trans. Am. Ent. Soc., iii, 20, 1870: SkINNER, C. no. 324.

States.

401. snowi Edwards, Trans. Kans. Acad. Sci., vii, 69 , 1881; SkINner, C. no. 325.

Cal.,

Oreg.

Rocky

Mts.

*402. rubidus Edwards, Proc. Ent. Soc. Phil., vi, 208, 1866; Skinner, C. no. 326.

Rocky Mts.,

Oreg.

a. sirius Edwards, Trans. Am. Ent. Soc, iii, 270, 1871; Skinner, C. no. 327. 
SATYRIUM Seudder.

Scudder, Bull. Bufĩ. Soc., iii, 106, 1876.

403. fuliginosa Edwards, Proc. Acad. Nat. Sci. Phil., 164, 1861; SKInNer, C. no. 328.

Cal.,

syn. suasa Boisduvat.

Nev., Utah.

\section{CUPIDO Schrank.}

Schrank, Faun. Boica, ii, i, 153, 206, 1801; Scudder, Proc. Am. Acad. Arts \& Sci., x, $149,1875$.

404. heteronea Boisduval, Ann. Soc. Ent. Fr., (2), x, 298, 1852; SKInNer, C. no. 329.

Cal. to Col.

405. clara Hy. Edwards, Pacific Coast Lep., no. 26. 1877: SKInNer, C. no. 330.

So.

Cal.

406. lycea Edwards, Proc. Ent. Soc. Phil., ii, 507, 1864; Skinner, C. no. 331.

Rocky

Mts.

syn. arapahoe REAKIRT.

407. fulla Edwards, Trans. Am. Ent. Soc., iii, 194, 1870; Skinner, C. no. 332.

Pac. States.

syn. fuliginosa STRECKER.

408. icarioides Boisduval, Ann. Soc. Ent. Fr., (2), x, 297, 1852; SKINNer, C. no. 333.

Cal.

syn. pardalis BeHR, drdalus BEHR, erymus BoIsDUVAL, mintha Edwards.

a. maricopa Reakirt, Proc. Acad. Nat. Sci. Phil., $245,1866$.

409. sæpiolus Boisduval, Ann. Soc. Ent. Fr., (2), x, 297, 1852; SKINNER, C. no. 334.

Pac. States, syn. zhaja BeHR, mufescens BOISDUvAL.

*410. amica Edwards, Proc. Ent. Soc. Phil., ii, 80, 1863; Skinner, C. no. 335.

Brit.

Am.

syn. orbitulus SCUDDER.

411. pembina Edwards, Proc. Acad. Nat. Sci. Phil., 224, 1862; SkINNER, C. no. 336.

Brit.

Am.

412. pheres Boisduval, Ann. Soc. Ent. Fr., (2), x, 297 , 1852; Skinner, C. no. 337.

Pac.

a. evius Boisduval, Ann. Soc. Ent. Belg., xii, 49. 1869 .

States,

Rocky

Mts.

Cal.,

Ariz.

*413. phileros Boisduval, Ann. Soc. Ent. Belg., xii, 50, 1869; Skinner, C. no. 338.

syn. helios Edwards.

*414. ardea Edwards, Trans. Am. Ent. Soc., iii, 209. 1871; Skinner, C. no. 339.

Nev. 
*415. kodiak Edwards, Trans. Am. Ent. Soc., iii, 20, Alaska. 1870; SKInNer, C. no. 340.

*416. mela Strecker, Lep. Rhop. Het., suppl. 3, 20, Col., B. C. 1900 .

\section{NOMIADES Hübner.}

Hübner, Verz. bek. Schmett., 67, 1816; Scudder, Proc. Am. Acad. Arts \& Sci., x, $228,1875$.

417. xerces Boisduval, Ann. Soc. Ent. Fr., (2), x, 296,

Cal. 1852; SKInNer, C. no. 341.

418. antiacis Boisduval, Ann. Soc. Ent. Fr., (2), x, 300, 1852; SKInNer, C. no. 342.

Cal., Nev, Ariz.

syn. polyphemus BoisduvaL, orcus Edwards.

a. behrii Enwards, Proc. Acad. Nat. Sci. Phil., $224,1862$.

b. mertila Edwards, Proc. Ent. Soc. Phil., vi, $206,1866$.

419. couperii Grote, Bull. Buff. Soc., i, 185, 1874; SKINNER, C. no. 343.

No.

U. S.

syn. pembina STrecker, afra EDwards.

420. lygdamas Doubleday, Entom., 209, 1842; SKInNER, C. no. 344.

a. oro Scudder, Can. Ent., viii, 23, 1876.

So. Atl. States, Col., Cal., N. Mex.

\section{PHADROTES Scudder.}

Scudder, Bull. Buff. Soc., iii, 115, 1876.

421. sagittigera Felder, Reise Novara, Lep., ii, 281, 1865; SKInNer, C. no. 345 .

Rocky Mts., Cal.

syn. catalina REAKIRT, lorquinii BEHR, rhæa BoIsduval, viaca EDwards, daunia EDWARDS.

*422. speciosa Hr. Edwards, Proc. Cal. Acad. Sci., vii, 173, 1876; SkInner, C. no. 346.

So.

Cal.

\section{PHILOTES Scudder.}

Scudder, Bull. Buff. Soc., iii, 116, 1876.

423. sonorensis Felder, Reise Novara, Lep., ii, 281, 1865; SkInNer, C. no. 347.

So. Cal.,

Mex. 


\section{AGRIADES Hübner.}

Hüв>re, Verz. bek. Schmett., 68, 1816; Scudder, Proc. Am. Acad. Arts \& Sci., x, 105,1875 .

*424. podarce Felder, Reise Novara, Lep., ii, 282, 1865:

SKINNER, C. no. 348.

Cal., Ner. Col.

syn. tehama REAKIRT, cilla BeHr, nestos BoIsDUVAL, orbitulus STRECKER.

425. aquilo Boisduval, Icon., 62, 1833; SKInner, C. no. 349 .

syn. frantilinii Curtis.

426. custica Enwards, Proc. Ent. Soc. Phil., iv, 203, 1865: SKINNER, C. no. 350.

Aretic

Am.

Col.. Brit. Am.

\section{RUSTICUS Hïbner.}

Hübner, Tent., i, 1806; Scudper, Proc. Am. Acad. Arts \& Sci., x, 264, 1875.

*427. enoptes Boisdural, Ann. Soc. Ent. Fr., (2), x, 298. 1852: SKINNER, C. no. 351.

428. glaucon Edwards, Trans. Am. Ent. Soc., iii, 210, 1871: SkInNer, C. no. 352.

429. battoides Benr, Proc. Cal. Acad. Sci., iii, 282. 1867; SKInNER, C. no. 353.

430. shasta Edwards, Proc. Acad. Nat. Sci. Phil., 224, 1862; SKInNer, C. no. 354 .

syn. aelmira FELDER, calchas BEHR, nivium BoIsduval, lupini BeHr, minehaha SCUdDER.

431. melissa Edwards, Trans. Am. Ent. Soc., iv, 346, 1873; SKInNer, C. no. 355.

432. scudderi Edwards, Proc. Acad. Nat. Sci. Phil., 164, 1861; SKInner, C. no. 356.

*433. lotis Lintner, 30th Rept. N. Y. Sta. Mus., 169, 1879: SKINNER, C. no. 357.

434. acmon Doubldeday \& Hewiston, Gen. Diurn. Lep., pl. 76, 1852; SKInNER, C. no. 358.

syn. antixgon BoIsDuvaL.

*435. aster Edwards, Can. Ent., xiv, 194, 1882; SKINNER, C. no. 359.

436. annetta Mead, Pap., ii, 48, 1882; Skinner, C. no. 360 .

437. anna Edwards, Proc. Acad. Nat. Sci. Phil., 163, 1861: SKINNER, C. no. 361.

syn. cajona REAKIRT, argyrotoxus BEHR, philemon Boisduval.
Pac. States.

Col.

Cal., Nev., Col.

Pac. States. Rocky Mts.

Rocky

Mts.

Atl. States.

Cal.

Pac. States. Rocky Mts.

Newfound land.

Utah.

Pac. States, Col. 
*438. neurona Skinner, Ent. News, xiii, 15, 1902.

\section{CYANIRIS Dalman.}

Dalman, Vetensk. Akad. Handl., xxxvii, 63, 94, 1816; Scudper, Proc. Am. Acad. Arts \& Sci., x, 150, 1875.

440. ladon Cramer, Pap. Exot., pl. 270, f. D, 1782; U.S.

Butler, Can. Ent., xxxii, 91, 1900.

syn. pseudargiolus Boisduval \& Le Conte,

Lép. Am. Sept., 118, 1833; SKInner, C. no. 362, arqiolus SмIтH \& Aввот, intermedia

STRECKER, echo EDwards, nigra EDwards.

a. lucia Kirby, Faun. Bor. Am., iv, 299, 1837.

b. marginata Edwards, Pap., iii, 86, 1883.

c. violacea Edwards, Proc. Ent. Soc. Phil., vi, $201,1866$.

d. cinerea Enwards, Pap., iii, 83, 1883.

e. arizonensis Edwards, Butt. E. U. S., ii, pl. 2, Lyc., f. 18, 1884.

f. neglecta Edwards, Proc. Acad. Nat. Sci. Phil., 56,1862 .

g. piasus Bolsduval, Ann. Soc. Ent. Fr., (2), x, $299,1852$.

h. gozora Boisduval, Lép. Guat., 17, 1870.

\section{EVERES Hübner.}

Hüвner, Verz. bek. Schmett., 69, 1816; Scupder, Proc. Am. Acad. Arts \& Sci., x, 176,1875 .

441. amyntula Boisduval, Ann. Soc. Ent. Fr., (2), x, 294, 1852; SKInNer, C. no. 363.

Pac.

a. herrii Grinnell, Can. Ent., xxxiii, 192, 1901.

442. comyntas Godart, Enc. Méth., ix, 660, 1823; SkInNer, C. no. 364.

States.

*443. monica Reakirt, Proc. Acad. Nat. Sci. Phil., 244, 1866; Skinner, C. no. 365.

Atl. Stater, Rocky Mts.

So.

Cal.

\section{HEMIARGUS Huibner.}

Hü bner, Verz. bek. Schmett., 69, 1816; Scudder, Proc. Am. Acad. Arts \& Sci., x, 186,1875 .

444. isola Reakint, Proc. Acad. Nat. Sci. Phil., 332,

Rocky 1866; Skinner, C. no. 366.

Mts. syn. aachæina Butler \& Druce, alce Edwards.

445. gyas Edwards, Trans. Am. Ent. Soc., iii, 210,

Ariz. 1871; SKInNer, C. no. 367. 
*446. cyna Edwards, Trans. Am. Ent. Soc., ix, 3, 1881; Tex.

SKINNER, C. no. 368.

447. hanno StolL, Pap. Exot., suppl., pl. 39, f. 2, 1790;

SKInNer, C. no. 369.

Gulf

syn. antibubastus HüBNER, hamo Lucas, pseuStates.

doptiletus Boisduval \& Le Conte, astenidia Boisduval, filenus Poey.

448. ammon Lucas, Sagra, Hist. Cuba, vi, 612, 1856; Skinner, C. no. 372.

Fla., Cuba.

BREPHIDIUM Scudder.

449. isophthalma Herrich-Schaeffer, Corr.-Blatt. zool.-min. Ver. Reg., xvi, 141, 1862; SkInNer,

Fla., Ga.

C. no. 370 .

syn. pseudofea Morrison.

450. exilis Borsduval, Ann. Soc. Ent. Fr., (2), x, 294, 1852: Skinner, C. no. 371.

S. -W. U. S., Col. syn. fea Edwards.

\section{LEPTOTES Scudder.}

Scudder, Bull. Buff. Soc., iii, 124, 1876.

451. marina Reakirt, Proc. Acad. Nat. Sci. Phil., 87, S. -W. 1868; SKINNER, C. no. 373.

452. theonus Lucas, Sagra, Hist. Cuba, vii, 611, 1856; SKINNER, C. no. 374.

Fla., Cuba. syn. cassius Morrison.

*453. striata Edwards, Field \& Forest, iii, 86, 1877; SKINNER, C. no. 375.

Tex., Wis.

Family MEGATHYMIDA.

(C.=Skinner, Syn. Cat. No. Am. Rhop., p. 99, 1898.)

MEGATHYMUS Seudder.

Scudder, Syst. Rev., 62, 1872; Proc. Am. Acad. Arts \& Sci., x, 213, 1875.

454. yuccæ Boisduval \& Le Conte, Lép. Am. Sept., pl. 70, 1833; Skinner, C. no. 643.

So. States, syn. coloradensis RILEY.

455. cofaqui Strecker, Proc. Acad. Nat. Sci. Phil., 148, 1876 ; SKInNer, C. no. 644.

456. streckeri Skinner, Can. Ent., xxvii, 179, 1895; C. no. 645 .
So. States, Col.

Col., N. Mex.

Col., Tex., Ariz. 
457. neumoegenii Edwards, Pap., ii, 27, 1882; SKInNER, C. no. 645 (bis).

Ariz.

Mex.

457. 1. ursus Poling, Ent. News, xiii, 97, 1902.

Ariz.

Family HESPERIID A.

(C.=Skinner, Syn. Cat. No. Am. Rhop., pp. 79-99, 1898.)

\section{PYRRHOPYGA Hübner.}

Hübner, Verz. bek. Schmett., 103, 1816; Scudder, Proc. Am. Acad. Arts \& Sci., x 261,1875 .

458. araxes Hewitson, Desc. Hesp., ii, 3, 1867; Skin- Ariz., NER, C. no. 642.

Mex.

\section{AMBLYSCIRTES Scudder.}

Scudder, Syst. Rev., 54, 1872; Proc. Am. Acad. Arts \& Sci., x, 109, 1875.

459. vialis Edwards, Proc. Acad. Nat. Sci. Phil., 58,

1862; SKInNer, C. no. 565.

No.

U. S.

*460. nysa Edwards, Can. Ent., ix, 191, 1877; SKinTex.

NER, C. no. 566.

syn. similis STRECKER.

*461. eos Edwards, Trans. Am. Ent. Soc., iii, 276, 1871; Skinner, C. no. 567.

*462. celia Skinner, Ent. News, vi, 113, 1895; C. no. 568 .

463. samoset Scudder, Proc. Ess. Ins., iii, 176, 1862; Skinner, C. no. 569.

syn. hegon SCUDDER, nemoris EDWARDs, alternata Grote \& Robinson.

464. ænus EDwards, Field \& Forest, iii, 118, 1877; SkINNER, C. no. 570.

S. -W.

U. S.

*465. simius Edwards, Trans. Am. Ent. Soc., ix, 6, 1881; SkINNER, C. no. 571.

So. Cal.,

Ariz.

Ariz.

466. cassus Edwards, Pap., iii, 71, 1883; Skinner, C. no. 572 .

467. nanno Edwards, Pap., ii, 142, 1882; Skinner, C.

Ariz. no. 573.

468. textor HÜBNER. Zutr. exot. Schmett., f. 515, 1825 ; SkINNer, C. no. 574 .

So. Atl. States.

syn. oneko Scudder, wakulla Edwards. 


\section{PAMPHILA Fabricius.}

Fabricuus, Ill. Mag., vi, 287, 1807; Scudder, Proc. Am. Acad. Arts \& Sci., x, 236, 1875.

469. palæmon Pallas, Reise, i, 471, 1771; Skinner, No. U. S., C. no. 465 .

Eur.

syn. paniscus Fabricius, brontes Denis \& SChifFermüller, mandan Edwards, mesapano SCUDder, skada Edwards.

*470. floridæ Mabille, Bull. Soc. Ent. Fr., 67, 1876; SKINNER, C. no. 90.

(Unknown.)

\section{POTANTHUS Seudder.}

Scudder, Syst. Rev., 54, 1872; Proc. Am. Acad. Arts \& Sci., x, 256, 1875.

471. dara Kollar, Hügel's Kashmir, iv, 455, 1848; Asia, SKINNER, C. no. 466.

syn. masoides Butler, omaha EDwards, mingo

Edwards, californica Scudder.

\section{ANCYLOXYPHA Felder.}

Felder, Verh. zool.-bot. Ges. Wien, xii, 477, 1862; Scudder, Proc. Acad. Arts \& Sci., $\mathrm{x}, 112,1875$.

472. numitor Fabricius, Ent. Syst., iii, 324, 1793;

SKInNer, C. no. 467.

Atl.

syn. puer HüBNER, marginatus HaRRIs.

*473. longleyi French, Can. Ent., xxix, 80, 1897;

SKINNER, C. no. 468.

*474. arene Edwards, Trans. Am. Ent. Soc., iii, 214. 1871; SKInNer, C. no. 470.

\section{States.}

Ill.

Tex.,

Ariz.

\section{COPAODES Speyer.}

Speyer, Edwards Cat. Lep., 49, 56, 1877.

475. procris Enwards, Trans. Am. Ent. Soc., iii, 215, 1871: SkInNer, C. no. 469.

S. -W. U.S.

syn. minima Edwards, candida Wright.

a. waco Edwards, Trans. Am. Ent. Soc., ii, 122, 1868.

476. wrightii Edwards, Can. Ent., xiv, 152, 1882; SkInNer, C. no. 471.

477. myrtis Edwards, Pap., ii, 26, 1882; SkInner, C. no. 472 .

*478. eunus Edwards, Pap., i, 47, 1881; Skinner, C. no. 473 .
Cal.

Ariz.

Cal. 
OARISMA Scudder.

Scudder, Syst. Rev., 54, 1872; Proc. Am. Acad. Arts \& Sci., x, 231, 1875.

479. garita Reakint, Proc. Ent. Soc. Phil., vi, 150, Col., Dak., 1866; SKInNer, C. no. 474.

Br. Am.

syn. hylax EDwards.

480. powescheik Parker, Am. Ent., ii, 271, 1870; SKINNER, C. no. 475.

Ia., IIl. to Utah.

*481. edwardsii Barnes, Can. Ent., xxix, 42, 1897; Col. SkINNER, C. no. 476.

\section{POANES Seudder.}

Scudder, Syst. Rev., 55, 1872; Proc. Am. Acad. Arts \& Sci., x, 252, 1875.

482. massasoit Scudder, Proc. Ess. Ins., iii, 171, 1862; Atl. States, SKINNER, C. no. 477.

Col.

a. suffusa Laurent, Ent. News, iii, 15, 1892.

\section{ATRYTONE Scudder.}

Scudder, Syst. Rev., 56, 1872; Proc. Am. Acad. Arts \& Sci., x, 124, 1875.

483. zabulon Boisduval \& Le Conte, Lép. Am. Sept.,

pl. 76, f. 6, 1833; Skinner, C. no. 478.

484. hobomok Harris, Ins. Inj. Veg., 313, 1862; SKIN-

NER, C. no. 479.

a. pocahontas Scudder, Proc. Ess. Ins., iii, 171, 1862 .

syn. quadraquina SCUDDER.

485. taxiles Edwards, Trans. Am. Ent. Soc., ix, 5, 1881; SKINNER, C. no. 480.

*486. ruricola Boisduval, Ann. Soc. Ent. Fr., (2), x, 350, 1852; SKINNER, C. no. 481.

\section{ERYNNIS Schrank.}

Schrank, Faun. Boica, ii, 1, 157, 1801; Scudder. Proc. Am. Acad. Arts \& Sci., x, 176, 1875 .

487. comma Linneus, Syst. Nat., 484, 1758; SkInNER, C. no. 482.

syn. virgula Retzius.

a. oregonia Edwards, Can. Ent., xv, 150, 1883.

S. - W.

U.S.

Cal.
No. U. S., Pac. States, Rocky Mts., Eur.

b. columbia Scudder, Syst. Rev., 56, 1872.

c. colorado Scudder, Mem. Bost. Soc. Nat. Hist., 349, 1874.

$4630-$ No. $52-02-4$ 
d. idaho Edwards, Can. Ent., xv, 148, 1883.

e. nevada Scudder, Mem. Bost. Soc. Nat. Hist., ii, 347,1874 .

f. assiniboia Lyman, Can. Ent., xxiv, 57, 1892.

q. laurentina Lyman, Can. Ent., xxv, 58, 1893.

h. manitoboides Fletcher, Rept. Ent. Soc. Ont., 19, 86, 1888.

i. juba Scudder, Syst. Rev., 77, 1872.

k. viridis Edwards, Can. Ent., xv, 147, 1883.

l. manitoba Scudder, Mem. Bost. Soc. Nat. Hist., ii, 351,1874 .

488. sassacus Harris, Ins. Inj. Veg., 315, 1862; SKINNER, C. no. 483.

*489. harpalus Edwards, Trans. Am. Ent. Soc., ix, 3, 1881; SKInner, C. no. 484.

490. pawnee Dodge, Can. Ent., vi, 44, 1884; Skinner, C. no. 485 .

Atl.

States.

Nev.

Neb.,

Mont.

*491. ottoe Edwards, Proc. Ent. Soc. Phil., vi, 207, 1866; SKInNer, C. no. 486.

Neb., Ind. Ter., Ariz.

*492. lasus Edwards, Rap., iv, 54, 1884; SkInner, C. no. 487 .

So.

Ariz.

*493. cabelus Edwards, Trans. Am. Ent. Soc., ix, 4, 1881; Skinner, C. no. 488.

Nev.,

Cal.

494. napa Edwards, Proc. Ent. Soc. Phil., iv, 202,

Coì. 1864; SKInNer, C. no. 489.

syn. dacotah EDwards.

*495. scudderi Skinner, Ent. News, x, 111, 1899.

496. metea Scudder, Proc. Ess. Ins., iii, 177, 1862;

SKInNer, C. no. 490.

syn. ridingsii REAKIRT.

497. rhesus EDwards, Field \& Forest, iii, 116, 1877; SKInNER, C. no. 491.

498. carus Edwards, Can. Ent., xv, 34; 1883; SKInner, C. no. 492 .

Col.

Atl.

States.

Col.,

Ariz.

Tex.,

Ariz.

499. uncas Edwards, Proc. Ent. Soc. Phil., ii, 19, 1863; SKINNER, C. no. 493.

Atl. States.

Ariz.

Tex.

*500. licinus Edwards, Trans. Am. Ent. Soc., iii, 276 , 1871; SKINNER, C. no. 494.

501. attalus EDwards, Trans. Am. Ent. Soc., iii, 276, 1871; SKInNer, C. no. 495.

So. Atl.

States.

syn. seminole Scudder, slossonæ SKInNer.

*502. yuma Edwards, Trans. Am. Ent. Soc., iv, 346,

Ariz. 1873; Skinner, C. no. 496. 
ANTHOMASTER Seudder.

Scudder, Syst. Rev., 57, 1872; Proc. Am. Acad. Arts \& Sci., x, 114, 1875.

503. snowi Edwards, Can. Ent., ix, 27, 1877; SKINNER, C. no. 497.

Rocky

Mts.

504. leonardus Harris, Ins. Inj. Veg., 314, 1862; SKINNER, C. no. 498.

Atl.

States.

*505. meskei Edwards, Can. Ent., ix, 58, 1877; SkINNER, C. no. 499.

Tex.,

Fla.

syn. straton EDWARDS.

506. nemorum Boisduval, Ann. Soc. Ent. Fr., (2), x, 314, 1852; Skinner, C. no. 500.

Cal. syn. yreka EDwARDs.

507. sylvanoides Boisduval, Ann. Soc. Ent. Fr., (2), x, 313, 1852; SkInner, C. no. 501.

Pac. States, Col., Neb.

syn. somora ScUDDER.

508. agricola Boisduval, Ann. Soc. Ent. Fr., (2), x, Cal., Ner. 314, 1852; SKInNer, C. no. 502.

Wash.

Oreg.

*509. milo Edwards, Can. Ent., xv, 34, 1883; Skinner, C. no. 503.

*510. pratincola Boisduval, Ann. Soc. Ent. Fr., (2), x, 315, 1852; SKInNer, C. no. 504.

Cal.,

Wash.

Cal.

*511. verus Edwards, Trans. Am. Ent. Soc., ix, 4, 1881; SKInNer, C. no. 505.

\section{HYLEPHILA Billberg.}

Billberg, Enum. Ins., 81, 1820; Scudder, Proc. Am. Acad. Arts \& Sci., x, 193, 1875.

512. campestris Boisduval, Ann. Soc. Ent. Fr., (2), x, 316. I8 22 ; SKINNER, C. no. 506.

syn. huron EDwaRDs.

*513. stigma Skinner, Can. Ent., xxviii, 188, 1896; C. no. 507 .

\%514. morrisonii Edwards, Field \& Forest, iii, 116, 1878; Skinner, C. no. 508.

515. phylæus Drury, Ill. Exot. Ent., i, pl. 13, f. 4, 1770; SKInNer, C. no. 509.

syn. augias HüBner, bucephalus Stephens.
Atl. States, Ariz., Cal.

Tex., N. Mex.

So. Cal.,

Ariz.

So. U. S., Mex. 


\section{THYMELICUS Hübner.}

Hǘner, Verz. bek. Schmett., 113, 1816; Scudder, Proc. Am. Acad. Arts \& Sci., x, 283,1875 .

516. brettus Boisduval \& Le Conte, Lép. Am. Sept., pl. 75, 1833; Skinner, C. no. 510 .

Atl.

syn. wingina SCUDDER.

a. brettoides Edwards, Pap., iii, 71, 1881; SkINNER, C. no. 510.

*517. chusca Edwards, Trans. Am. Ent. Soc., iv, 346,

Ariz. 1873; SKInNer, C. no. 511.

518. draco Edwards, Trans. Am. Ent. Soc., iii, 274, 1871; SKINNer, C. no. 512.

Col., Brit. Am.

519. otho Sмiтн \& Aввот, Lep. Ins. Ga., i, 31, 1797; SKInNer, C. no. 514 .

Atl.

a. egeremet Scudder, Proc. Ess. Ins., iii, 174, 1862.

syn. atna SCUDDER, ursa Worthington.

States.

520. mystic Scudder, Proc. Ess. Ins., iii, 172, 1862; SKInNer, C. no. 516.

521. siris Edwards, Pap., i, 47, 1881; Skinner, C. no. 517 .

*522. mardon Edwards, Pap., i, 47, 1881; Skinner, C. no. 518 .

523. cernes Boisduval \& Le Conte, Lép. Am. Sept., pl. 56, f. 1, 1833; SKInNer, C. no. 519.

Atl. States.

Wash.

Wash.

Atl. States. syn. ahaton HARris, taumas SCUDDER.

*524. alcina Skinner, Ent. News, iv, 519, 1893; SkInNER, C. no. 520 (=no. 554).

\section{POLITES Scudder.}

Scudder, Syst. Rev., 57, 1872; Proc. Am. Acad. Arts \& Sci., x, 252, 1875.

525. sabuleti Boisduval, Ann. Soc. Ent. Fr., (2), x, 316, 1852; SKInNer, C. no. 513.

Cal., N. Mex.

526. peckius Kirby, Faun. Bor. Am., iv, 300, 1837; SKINNER, C. no. 515.

Atl. syn. wamsutta HaRRIs.

527. baracoa Lucas, Sagra, Hist. Cuba, vi, 650, 1857; SkInNer, C. no. 521.

Fla., Cuba.

syn. amadis HerRich-SCHAEFFER, myus French. 
EUPHYES Scudder.

Scudder, Syst. Rev., 69, 1872; Proc. Am. Acad. Arts \& Sci., x, 172, 1875.

528. verna Edwards, Proc. Acad. Nat. Sci. Phil., 57, 1862; SKInNer, C. no. 523.

Ati.

syn. pottawattomie WoRTHINGTON.

529. vestris Boisduval, Ann. Soc. Ent. Fr., (2), x, 317 , States.

1852 .

syn. kiowah ReAKIRT, osceola Lintner.

a. metacomet Harris, Ins. Inj. Veg., 317, 1862;

SKINNER, C. no. 524.

syn. merea EDWARDs.

530. bellus Edwards, Pap., iv, 57, 1884; Skinner, C. no. 525 .

So.

Ariz.

531. osyka Edwards, Trans. Am. Ent. Soc., i, 228, 1867; SKInNer, C. no. 556.

Gulf States,

Ind.

*532. comus Edwards, Trans. Am. Ent. Soc., v, 206 , 1876; SKINNER, C. no. 557.

Tex., So. Col.

syn. nilus EDWARDs.

533. eufala Edwards, Trans. Am. Ent. Soc., ii, 311 , 1869; SKINNER, C. no. 558.

Fla.,

Tex.

Ariz.

*534. arabus Edwards, Pap., ii, 26, 1882; SkInner, C. no. 559 .

535. fusca Grote \& Robinson, Trans. Am. Ent. Soc., i, 2, 1867; Skinner, C. no. 560.

*536. oslari Skinner, Ent. News, x, 112, 1899.

Atl.

States.

Col.

537. nereus Edwards, Trans. Am. Ent. Soc., v, 205, 1876; SKInNer, C. no. 561.

Ariz.

\section{LEREMA Scudder.}

Scudder, Syst. Rev., 61, 1872; Proc. Am. Acad. Arts \& Sci., x, 205, 1875.

538. accius Sмптн \& Aввот, Lep. Ins. Ga., pl. 23. 1797; SKInner, C. no. 526.

So. Atl.

States.

syn. monoco SCUdDer, nortonii EDwards, punctella Grote \& Robinson.

*539. loammi Whitney, Can. Ent., viii, 76, 1876; SкinNER, C. no. 527.

Fla.,

N. C.

syn. regulus EDwards.

*540. horus Edwards, Trans. Am. Ent. Soc., iii, 277.

1871; SkInNer, C. no. 528.

541. deva Edwards, Trans. Am. Ent. Soc., v, 292, 1876;

Skinner, C. no. 529.
So. Cal.,

Ariz. 
542. lunus Edwards, Pap., iv, 56, 1884; Skinner, C. So. no. 530 .

Ariz.

543. hianna Scudder, Proc. Bost. Soc. Nat. Hist., xi, Atl. 382, 1868; SKInNer, C. no. 562.

States.

\section{OLIGORIA Scudder.}

Scumder, Syst. Rev., 61, 1872; Proc. Am. Acad. Arts \& Sci., x, 232, 1875.

544. maculata Edwards, Proc. Ent. Soc. Phil., iv, 201, 1865; SKINNER, C. no. 531.

So. Atl. States.

*54. drurii Latreille, Enc. Méth., ix, 763, 1823; Mex. SKInner, Ent. News, xii, 171, 1901.

\section{PRENES Seudder.}

Scudper, Syst. Rev., 60, 1872; Proc. Am. Acad. Arts \& Sci., x, 256, 1875.

546. panoquin Scudder, Proc. Ess. Ins., iii, 178, 1862; SKInNer, C. no. 532.

So. Atl. syn. ophis EDwards.

*547. panoquinoides SkInNer, Ent. News, ii, 175, 1891; C. no. 533 . States.

Fla.

548. ocola Edwards, Proc. Ent. Soc. Phil., ii, 20, 1863; SkInNer, C. no. 534 .

So. Atl. States.

549. errans Skinner, Ent. News, iii, 174, 1892; C. no. Cal. 535.

\section{CALPODES Hübner.}

Hübner, Verz. bek. Schmett., 107, 1816; Scudder, Proc. Am. Acad. Arts \& Sci., x, 135,1875 .

*549. 1. coscinia Herrich-Schaeffer, Corr. - Blatt. Regensb., xix, 54, 1865 .

Mex., Tex.

550. ethlius Cramer, Pap. Exot., iv, pl. 392, f. A, 1782; SKInNer, C. no. 536.

So. States.

syn. chemnis Fabricius, olynthus BoIsDuvaL \& LE Conte.

551. pittacus Edwards, Pap., ii, 138, 1882; SkInner, C. no. 537 .

552. python Edwards, Pap., ii, 139, 1882; SKInner, C. no. 538 .

*553. cestus Edwards, Pap., iv, 57, 1884; Skinner, C. no. 539 .

Ariz.

Ariz.

So.

Ariz.

*554. rhena Edwards, Field \& Forest, iii, 115, 1877; Skinner, C. no. 540.
So.

Cal. 


\section{LIMOCHROES Seudder.}

Scudder, Syst. Rev., 59, 1872; Proc. Am. Acad. Arts \& Sci., x, 207, 1875.

555. bimacula Grote \& Robinson, Ann. N. Y. Lye.

Nat. Hist., viii, 433, 1867; SkInner, C. no. 541.

syn. acanootus SCUDDER, illinois DodGE.

556. pontiac Edwards, Proc. Ent. Soc. Phil., ii, 17.

1863; SKINNER, C. no. 542 .

States.

syn. conspicua Edwards, orono SCUDDER.

557. manataaqua Scudder, Proc. Ess. Ins., iii, 175, 1862; SKInNer, C. no. 522.

syn. cernes HARRIS.

*558. yehl Skinner, Ent. News, iv, 212, 1893; C. no. 543 .

Atl.

States.

U.S.

559. dion Edwards, Can. Ent., xi, 238, 1879; Skinner,

C. no. 544 .

So. Atl.

States.

Atl.

States.

560. arpa Boisduval \& Le Conte, Lép. Am. Sept., pl. 63, 1833; Skinner, C. no. 548.

Gulf

States.

Gulf

561. palatka EDwards, Trans. Am. Ent. Soc., i, 287, 1867; SKInNer, C. no. 549.

States.

Fla.,

Tex.

NER, C. no. 554 .

So. Cal.,

Ariz.

\section{PHYCANASSA Scudder.}

Scudder, Syst. Rev., 56, 1872; Proc. Am. Acad. Arts \& Sci., x, 249, 1875.

564. viator Edwards, Proc. Ent. Soc. Phil., iv, 202, 1865; SKInNer, C. no. 563.

Atl.

States.

*565. carolina Skinner, Ent. News, iii, 222, 1892; C. N. C. no. 564 .

566. vitellius Fabricius, Ent. Syst., iii, 1, 327, 1793; Skinner, C. no. 545 .

Atl.

syn. delaware EDwards, logan EDwards, hübneri PLötz.

*567. streckeri Skinner, Ent. News, iv, 212, 1893.

Fla.

568. howardi Skinner, Can. Ent., xxviii, 187, 1896.

Fla.

569. aaroni Skinner, Ent. News, i, 6, 1890; C. no. 551.

So. Atl.

States.

570. melane Edwards, Trans. Am. Ent. Soc., ii, 312, 1869; Skinner, C. no. 552. 
*571. lagus Edwards, Trans. Am. Ent. Soc., ix, 5, 1881; SKINNER, C. no. 546.

572. arogos Boisduval \& Le Conte, Lép. Am. Sept., pl. 76, f. 3,1833 ; SKInNer, C. no. 553.

Gulf States, syn. iowa SCUDDER.

\section{ERYCIDES Hübner.}

Hübner, Verz. bek. Schmett., 110, 1816; Scudder, Proc. Am. Acad. Arts \& Sci., x, 166,1875 .

573. urania Westwood \& Hewitson, Gen. Diurn. Lep., 510, 1852; Skinner, C. no. 638.

Tex.,

Mex.

syn. texana SCUdDER.

*574. lilea Reakirt, Proc. Acad. Nat. Sci. Phil., 339, 1866; Skinner, C. no. 639.

Tex.,

Mex.

syn. albicilla Herrich-SchaEfFer, cmentus

SCUdDer, sanguina SCUdDER, socius BUtler

\& Druce, decolor Mabille.

575. batabano Lefèbre, Sagra, Hist. Cuba, vii, 624, 1867; Skinner, C. no. 640.

Fla.,

Cuba.

syn. mancinus Herrich-SCHAEFfer, okeechobee

WoRTHINGTON.

576. amyntas FabriciUs, Syst. Ent., 533, 1775; SkINNER, C. no. 641; Ent. News, xii, 171, 1901.

Fla., Ariz., Mex.

syn. lividus Hübner, savignyi LatreIlle.

\section{EUDAMUS Swainson.}

Swainson, Ill., ii, 48, 1832; Scudder, Proc. Am. Acad. Arts \& Sci., x, 169, 1875.

577. proteus Linneus, Syst. Nat., 484, 1758; SKInNER, C. no. 633 .

Atl.

States.

578. simplicius StolL, Suppl. Cramer, Pap. Exot., pl. 39, f. 6, 1791; Skinner, C. no. 634.

Tex., Ariz., a. eurycles Latreille, Enc. Méth., ix, 730, 1823;

Skinner, Ent. News, xii, 171, 1901.

579. dorantes Stoll, Suppl. Cramer, Pap. Exot., pl. 172, pl. 39, f. 9, 1790; Godman \& Salvin, Biol. Mex.

Cent. Am., Lep. Rhop., ii, 278, 1893.

Tex.,

Ariz. syn. protillus HerRich-SchaefFer, amisus Hewitson, rauterbergi Skinner, C. no. 635.

580. albofasciatus Hewitson, Desc. Hesp., ii, no. 2, 1867; Skinner, C. no. 636.

581. dorus Edwards, Pap., ii, 140, 1882; Skinner, C. no. 637 .

582. zilpa Butler, Lep. Exot., pl. 40, f. 2, 1872; Skinner, Ent. News, xii, 171, 1901.

583. alcæus Hewitson, Desc. Hesp., 3, 1867; SKinner, Ent. News, xii, 171, 1901.
Tex., Ariz., Mex.

So. Ariz., Mex.

Ariz., So. Am.

Ariz., So. Am. 
EPARGYREUS Hiibner.

Hübner, Verz. bek. Schmett., 105, 1816; Scudper, Proc. Am. Acad. Arts \& Sci., x, 163,1875 .

584. tityrus Fabricius, Syst. Ent., 532, 1775; SkIN- U. S. NER, C. no. 632.

HETEROPIA Mabille.

Mabille, Le Nat., xi, 68, 1889; Godman \& Salvin, Biol. Cent. Am., Lep. Rhop., ii, $296,1893$.

*585. melon Godman \& Salvin, Biol. Cent. Am., Lep. Rhop., ii, 297, 1893.

Ariz.,

Mex.

RHABDOIDES Scudder.

Scudder, Butt. E. U. S., iii, 1854, 1889.

586. cellus Boisduval \& Le Conte, Lép. Am. Sept., pl. 73, 1833; SkINNER, C. no. 629.

syn. festus HüBNER.

*587. hesus Westwood \& Hewitson, Gen. Diurn. Lep., pl. 78, 1852; SKINNER, C. no. 630.

So. Atl.

States,

Ariz., Mex.

Tex.,

Mex.

588. zestos HüBner, Zutr. exot. Schmett., f. 615, 1832; SKInNer, C. no. 631.

Fla., So. Am.

syn. oberon WORTHINGTON.

PROTEIDES Hübner.

HÜBner, Verz. bek. Schmett., 104, 1816.

589. idas Cramer, Pap. Exot., iii, pl. 260, f. A, 1782; Kirby, Cat. Diurn. Lep., 595, 1872; Barnes,

Ariz.,

Ent. News, x, 332, 1900.

Mex.

syn. mercurius Fabricius.

\section{TELEGONUS Hübner.}

Hübner, Verz. bek. Schmett., 104, 1816; Godman \& Salvin, Biol. Cent. Am., Lep. Rhop., ii, 305, 1893.

*590. hahneli Staudinger, Exot. Tagf., 291, 1888; Mex. Godman \& Salvin, Biol. Cent. Am., Lep. Rhop., ii, 306, 1893; SKInner, Ent. News, xii, 171, 1901.

\section{ACHLARUS Scudder.}

Scudder, Syst. Rev., 50, 1872; Proc. Am. Acad. Arts \& Sci., x, 100, 1875.

591. lycidas Sмiтн \& Aввот, Lep. Ins. Ga., pl. 20, 1797; Skinner, C. no. 628. 
THORYBES Seudder.

Scudder, Syst. Rev., 50, 1872; Proc. Am. Acad. Arts \& Sci., x, 282, 1875.

592. epigona Herrich-SchaffFer, Prodr., iii, 59, 1868; SkInNer, C. no. 627.

Tex.,

Ariz.

syn. epigena Butler, orestes Lintner.

*593. coyote Skinner, Car. Ent., xxiv, 164, 1892.

Tex.

594. drusius Edwards, Can. Ent., xv, 211, 1883; SкINNER, C. no. 625 .

So. Ariz.,

Mex.

595. outis Skinner, Ent. News, v, 332, 1894.

Tex.

596. hippalus Edwards, Pap., ii, 27, 1882; Skinner,. C. no. 623 .

Ariz.,

Mex.

597. caicus Herrich-Schaffrer, Prodr., iii, 68, 1868; Skinner, C. no. 622 .

Ariz.,

Mex.

syn. schäfferi Plötz, moschus Edwards.

598. æmilia Skinner, Ent. News, iv, 64, 1893; C. no. 621.

599. bathyllus Sмiтн \& Аввот, Lep. Ins. Ga., pl. 22, 1797; Skinner, C. no. 620.

Oreg.

So. Atl. States.

600. mexicana Herrich-Schaeffer, Prodr., iii, 68, Rocky Mts., 1868; SKInner, C. no. 619.

Cal.

syn. nevada Scudder, ananius Plötz.

601. pylades Scudder, Proc. Bost. Soc. Nat. Hist., xiii, 207, 1870; SKInner, C. no. 618.

Atl.

States.

*602. electra Lintner, Can. Ent., xiii, 63, 1881; SKIn-

Ont. NER, C. no. 617.

\section{ACHYLODES Hübner.}

Hübner, Verz. bek. Schmett., 107, 1816; Scudder, Proc. Am. Acad. Arts \& Sci., x, $100,1875$.

603. thraso Hübner, Samml. exot. Schmett., i, 1806; Tex., SKInNer, C. no. $616 . \quad$ Mex.

syn. tamenund EDwards.

*604. asychis Cramer, Pap. Exot., iv, pl. 334, f. E, Mex. 1782; SKInNER, Ent. News, xii, 171, 1901.

\section{PHOLISORA Scudder.}

Scudder, Syst. Rev., 51, 1872; Proc. Am. Acad. Arts \& Sci., x, 249, 1875.

605. catullus FABricius, Ent. Syst., iii, 348, 1793; U. S. SKInner, C. no. 608.

*606. mexicana Reakirt, Proc. Acad. Nat. Sci. Phil., Rocky Mts., 334, 1866; SKInNer, C. no. 609.

Mex. 
607. pirus Edwards, Field \& Forest, iii, 119, 1878; SKINNER, C. no. 610.

Rocky

Mts.

608. ceos Edwards, Pap., ii, 140, 1882; Skinner, C. no. 611 .

Ariz.,

Mex.

609. hayhurstii Edwards, Trans. Am. Ent. Soc., iii, 22, 1870; Skinner, C. no. 612.

So.

U. S.

610. libya Scudder, Bull. Geol. Surv. Terr., iv, 258, Utah, 1878 ; Skinner, C. no. 613.

Cal.

611. alpheus Edwards, Trans. Am. Ent. Soc., v, 206, S.-W. 1876; SKinner, C. no. 614.

U.S.

*612. lena Edwards, Can. Ent., xiv, 5, 1882; Skinner, Mont. C. no. 615 .

SYSTASEA Butler.

Butler, in Edwards, Can. Ent., ix, 120, 1877; Lintneria Edwards (not Butler).

*613. pulverulenta Felder, Verh. zool.-bot. Ges. Wien, S.-W. 478, 1869; Skinner, C. no. 607.

U.S.

syn. zampa EDwards.

GRAIS Godman \& Salvin.

Godman \& Salvin, Biol. Cent. Am., Lep. Rhop., ii, 381, 1894.

*614. stigmaticus Mabille, Bull. Soc. Ent. Belg., liv, 1883; Godman \& Salvin, Biol. Cent. Am., Lep. Rhop., ii, 381, 1894; Barnes, Ent. News, x, 331,

Ariz.,

Mex. 1900 .

\section{TIMOCHARES Godman \& Salvin.}

Godman \& Salvin, Biol. Cent. Am., Lep. Rhop., ii, 417, 1896.

*615. ruptifasciatus Plötz, Jahrb. Nass. Ver., xxxvii,

Mex. 27, 1884; Godman \& Salvin, Biol. Cent. Am., Lep. Rhop., ii, 418, 1896; SKinner, Ent. News, xii, 171, 1901.

\section{STAPHYLUS Godman \& Salvin.}

Godman \& Salvin, Biol. Cent. Am., Lep. Rhop., ii, 429, 1896.

*616. brennus Godman \& Salvin, Biol. Cent. Am., Lep. Mex. Rhop., ii, 434, 1896.

\section{THANAOS Boisduval.}

Boisduval, Icon., 240, 1832; Scudder, Proc. Am. Acad. Arts \& Sci., x, 279, 1875.

617. brizo Boisduval \& Le Conte, Lép. Am. Sept., pl. 66,1833 ; Skinner, C. no. 586 . 
618. icelus Lintner, 23 Rept. N. Y. Sta. Cab. Nat. Hist., 162, 1872; SKINNER, C. no. 587.

Atl. States, Col., Ariz.

619. somnus Lintner, Pap., i, 73, 1881; Skinnnr, C. no. 588 .

620. lucilius Lintner, 23 Rept. N. Y. Sta. Cab. Nat. Hist., 162, 1872; SKInNer, C. no. 589.

Fla.

Atl.

States.

621. persius Scudder, Proc. Ess. Ins., iii, 170, 1862; SKINNER, C. no. 590.

Atl. States, Rocky Mts.

*622. ausonius Lintner, 23 Rept. N. Y. Sta. Cab. Nat. Hist., 166, 1872; SKINNER, C. no. 591.

Atl.

States.

Col. ,

Ariz. Hist., 175, 1878; SKInNer, C. no. 592.

624. martialis Scudder, Trans. Chic. Acad. Nat. Sci., i, 355, 1869; SKInNER, C. no. 593.

Atl. States, Col.

625. juvenalis Fabricius, Ent. Syst., iii, 339, 1793; SKINNER, C. no. 594.

syn. juvenis HüBNer, costalis Doubleday \& Hewitson, ennius Scudder \& Burgess.

626. petronius Lintner, Pap., i, 70, 1881; Skinner, C. no. 595 .

627. horatius Scudder \& Burgess, Proc. Bost. Soc. Nat. Hist., xiii, 301, 1870; ShInner, C. no. 596. syn. virgilius SCudder \& Burgess.

628. terentius Scudder \& Burgess, Proc. Bost. Soc. Nat. Hist., xiii, 292, 1870; SkInner, C. no. 597. syn. ovidius Scudder \& Burgess.

629. propertius Lintner, Pap., i, 71, 1881; Skinner, C. no. 598.

*630. nævius Lintner, Pap., i, 69, 1881; Skinner, C. no. 599 .

631. pacuvius Lintner, 30 Rept. N. Y. Sta. Mus. Nat. Hist., 172, 1878; SKINNER, C. no. 600.

Atl. States, Rocky Mts.

Fla.

So. Atl.

States.

Atl.

States.

Pac.

States.

Fla.

Rocky

Mts.

632. tatius Edwards, Pap., ii, 179, 1882; Skrnner, C.

Ariz. no. 601 .

633. clitus Edwards, Pap., ii, 180, 1882; Skinner, C. no. 602 .

634. funeralis Scudder \& Burgess, Proc. Bost. Soc. Nat. Hist., xiii, 293, 1870; SKInNer, C. no. 603.

S. -W.

U.S.

635. tristis Boisduval, Ann. Soc. Ent. Fr., (2), x, 311, 1852; SKInNer, C. no. 604. 
*636. tibullus Scudder \& Burgess, Proc. Bost. Soc. Nat. Hist., xiii, 298, 1870; Skinner, C. no. 605.

*637. plautus Scudder \& Burgess, Proc. Bost. Soc. Nat. Hist., xiii, 304, 1870; SKInNer, C. no. 606.

Cal.

Fla.

\section{HELIOPETES Billberg.}

Billberg, Enum. Ins., 81, 1820; Godman \& Salvin, Biol. Cent. Am., Lep. Rhop., ii, $444,1897$.

*638. laviana Hewitson, Desc. Hesp., 48, 1868; GodMan \& Salvin, Biol. Cent. Am., Lep. Rhop., ii, $448,1897$.

syn. pastor Felder, leca Butler.

\section{HESPERIA Fabricius.}

Fabricius, Ent. Syst., iii, 1, 258, 1793; Scudder, Proc. Am. Acad. Arts \& Sci., x, 187, 1875 .

639. ericetorum Boisduval, Ann. Soc. Ent. Fr., (2), x, 313, 1852; SkInner, C. no. 575.

Pac. syn. alba EDwARDs.

*640. macaria Reakirt, Proc. Acad. Nat. Sci. Phil., 334, 1866; SKInNer, C. no. 576.

Mex. syn. oceanus Edwards, locutia Hewitson.

*641. domicella Erichson, Schomb. Reise, iii, 601, 1848; SkInNer, C. no. 577.

States.

a. nearchus Edwards, Pap., ii, 26, 1882.

642. tessellata Scudder, Syst. Rev., 73, 1872; SKINNER, C. no. 578.

syn. communis Grote.

*643. montivagus Reakirt, Proc. Acad. Nat. Sci. Phil., 46, 1866; Skinner, C. no. 579.

Ariz., Mex.

Ariz., Mex.

U.S.

644. centaureæ Rambur, Faun. Ent. And., pl. 8, f. 10, 1839; SKInNer, C. no. 580.

syn. muralis Boisduval, wyandot Edwards.

*645. philetas Edwards, Pap., i, 46, 1881; Skinner, C. no. 581 .

646. cæspitalis Boisduval, Ann. Soc. Ent. Fr., (2), x, 312, 1852; SkInNer, C. no. 582.

Rocky Mts., Fla., Mex.

No. Atl. States, Eur.

Tex.

Pac. States, Rocky Mts.

syn. ricara EDwards, petreius EDwards.

*647. xanthus EDwards, Field \& Forest, iii, 142, 1877; Skinner, C. no. 583.

Col.

*648. scriptura Boisduval, Ann. Soc. Ent. Fr., (2), x, 312, 1852; SKInNer, C. no. 584.

Cal., Ariz., Mont. 
649. nessus Edwards, Can. Ent., ix, 192, 1877; SкINNER, C. no. 585 .

So. Atl. States. syn. notabilis STRECKER.

*650. unna Plötz, Stett. ent. Zeit., xliv, 204, 1883; SKINNER, C. no. 90.

651. polingii Barnes, Can. Ent., xxxii, 44, 1900.

*652. syrichtus Fabricius, Syst. Ent., 534, 1775; Kirby, Cat. Diurn. Lep., 610, 1872; SkInner, Ent. News, xii, 171, 1901.

syn. orcus Craner, oileus Westwood \& HumPHREYs, tartarus HÜBNER.

\section{Superfamily SPHINGOIDEA.}

Ariz.

(Unknown).

Mex.

\section{Family SPHINGIDA.}

HEMARIS Dalman.

Dalman, Vet. Akad. Handl., 207, 1816; Krrby, Cat. Lep. Het., i, 624, 1892.

*653. diffinis Borsduval, Sp. Gén., i, pl. 15, fig. 2, 1836; Sмith, C. 95.

Atl. States. syn. æethra STRECKER.

a. axillaris Grote \& Robinson, Trans. Am. Ent. Soc., i, 23, 1868; Sмiтh, C. 95.

syn. marginalis Grote, grotei Butlen.

b. tenuis Grote, Bull. Buff. Soc., i, pl. 1, fig。6, 1873; Smith, C. 94.

syn. fumosa STREcker, metathetis Butler.

c. thetis Grote \& Robinson, Trans. Am. Ent. Soc., i, 325, 1868; SмIтн, C. 90-94.

syn. mubens Hy. Edwards.

d. cynoglossum Hy. Edwards, Proc. Cal. Acad. Sci., v, 88, 1876; Sмiтн, C. 91.

No. Cal. Pac. N.-W.

e. senta Strecker, Rep. Chief Eng., 1878, pl. 2, fig. 1; Sмith, C. 93.

f. palpalis Grote, Bull. Buff. Soc., ii, 145, 1874; SмIтн, C. 89.

654. brucei French, Can. Ent., xxii, 133, 1890.

Col., Utah.

655. gracilis Grote \& Robinson, Proc. Ent. Soc. Phil., v, 174, 1865; Sмiтh, C. 97.
Atl. States. 
656. thysbe Fabricius, Syst. Ent., 548, 1775; Sмith, C. 98 .

Atl. States, Miss. Vall.

syn. pelasgus Cramer, cimbiciformis Stephens, etolus BoIsduvaL, fuscicaudis WALKER.

a. ruficaudis KirBy, Faun. Bor. Am., iv, 303, 1837;

SмIтH, C. 103.

syn. uniformis Grote \& RobInson, pyramus, Boisdural, floridensis Grote \& Robinson, buffaloensis GROTE.

\section{LEPISESIA Grote.}

Grote, Proc. Ent. Soc. Phil., v, 38, 1865; Smith, C. 109.

*657. flavofasciata Walker, Cat. Brit. Mus., vii, 87, 1856; SмIтH, C. 111.

Arct.

a. ulalume STrecker, Lep. Rhop. Het., 135, pl. Amer. 15, fig. 3, 1878 .

b. rachel Bruce, Ent. News, xii, 19, 1901.

658. phaeton Grote \& Robinson, Proc. Ent. Soc. Phil., v, 178, 1865; Sмiтh, C. 112.

So.

Cal.

syn. errato BoIsDuval.

a. euterpe Hy. Edwards, Ent. Amer., iv, 25, 1888; SмIтH, C. 235.

659. clarkiæ Boisduval, Ann. Soc. Ent. Fr., (2), x, 318 , 1852; Sмптн, C. 112.

syn. victoriæ Grote.

660. gauræ Sмптн \& Aввот, Lep. Ins. Ga., i, 61, pl. 31, 1797; Sмith, C. 114.

So.

States.

a. circæ Hy. Edwards, Pap., ii, 9, 1882; Sмith, C. 114.

661. juanita Strecker, Lep. Rhop. Het., 112, 1878; Sмith, C. 114.

*662. terlooii Hy. Edwards, Proc. Cal. Acad. Sci., vi, 90,1875 .

663. vega DyAR. (Fore wings as terlooii, with an additional dark green band at base; hind wings as juanita; exp. $54 \mathrm{~mm}$.)

Tex.

Mex.,

Ga.

N. Mex.

ÆLLOPOS Hubner.

Hübner, Verz. bek. Schmett., 131, 1822; Kirby, Cat. Lep. Het., i, 634, 1892.

664. tantalus Linnæus, Syst. Nat., i, 493, 1758; SмIтH, C. 119-121.

So. Amer., So. States occ

syn. titan CRAMER, zonata DRURY, tripunctata Goeze, annulosum SwaInson, balteata KIRTLAND.

a. ixion Linneus, Syst. Nat., i, 493, 1758.

syn. fadus Cramer. 
TRIPTOGON Ménétries.

Ménétries, Enum. Corp. An. Mus. Pet., Lep., ii, 94, 1859; Kirby, Cat. Lep. Het., i, 644, 1892.

665. lugubris Linn eus, Mant. Plant., 537, 1771; Sмптн, So. Am., Fla., C. 123 . occ. northw.

syn. fegeus Cramer, camertus Cramer, huctuosus Boisduval.

\section{CALLIOMMA Walker.}

Walker, Cat. Lep. Het. B. M., viii, 101, 1856; Krrby, Cat. Lep. Het., i, 646, 1892. 666. pluto Fabricius, Gen. Ins., 274, 1777; Kirby, Cat. Lep. Het., i, 646, 1892. So. Am., syn. thorates HüBNER, crosus DALMAN. So. Fla.

\section{AMPHION Hübner.}

HüBner, Verz. bek. Schmett., 135, 1822; Sмiтh, C. 125.

667. nessus Cramer, Pap. Exot., ii, pl. 107, f. D, 1777; Sмith, C. 125.

Atl. States, Miss. Vall.

\section{SPHECODINA Blanehard.}

Blanchard, Nat. Hist. Ins., iii, pl. 20, f. 4; Kirby, Cat. Lep. Het., i, 638, 1892. 668. abbotii Swannson, Zool. Ill., i, pl. 60, 1821; Sмiтн, C. 129.

Atl. States, Miss. Vall.

\section{DEIDAMIA Clemens.}

Clemens, Jn. Acad. Nat. Sci. Phil., iv, 137, 1839; Smith, C. 128.

669. inscriptum Harris, Am. Jour. Sci., xxxvi, 306, 1839; SмIтн, C. 129.

Atl. States, Miss. Vall.

\section{DEILEPHILA Ochsenheimer.}

Ochsenhermer, Schmett. Eur., iv, 42, 1816, Smith, C. 130.

670. gallii Rottemburg, Naturf., vii, 107, 1775; Eur., Asia, Kirby, Cat. Lep. Het., i, 665, 1892; Smith, C. $131 . \quad$ U. S. syn. epilobii Harris, intermedia KIRBY, canadensis GUENÉE, chambener $\ddot{i}$ HARRIS.

671. lineata Fabricius, Syst. Ent., 541, 1775; SмiтH, C. 133 . 
THERETRA Hübner.

Hüвner, Verz. bek. Schmett., 135, 1822; Kirby, Cat. Lep. Het., i, 649, 1902.

672. tersa Linnæus, Mant. Plant., ii, 538, 1771; Sмiтh, C. 135 .

673. porcus HüBNER, Samml. exot. Schmett., ii, 1824; Kirby, Cat. Lep. Het., i, 671, 1892.

\section{So.} States. So. Am., So. Fla.

\section{ARGEUS Hübner.}

Hübner, Verz. bek. Schmett., 134, 1822; Sмith, C. 136.

674. labruscæ Linnæus, Syst. Nat., 491, 1758; Sмптн, So. Am., Fla., C. 137. occ. northw.

syn. clotho Fabricius.

\section{PACHYLIA Walker.}

Walker, Cat. Brit. Mus., i, 189, 1856; Sмith, C. 138.

675. ficus Linneus, Syst. Nat., 491, 1758; Sмiтн, C. 138.

So. Am., So. Fla.

syn. crameri Ménétries, lyncea Clemens, venezuelensis Schaufuss.

\section{PHOLUS Hübner.}

Hüвner, Verz. bek. Schmett., 134, 1822; Kirby, Cat. Lep. Het., i, 668-670, 1892.

676. linnei Grote \& Robinson, Proc. Ent. Soc. Phil., So. Am., So. v, 157, 1865; Sмiтh, C. 141.

States.

677. vitis Linnæus, Syst. Nat., 491, 1758; Smith, C. So. Am., So. 143.

States.

syn. jussieuæ HüBNER, fasciatus Sulzer.

678. pandorus HüBner, Samml. exot. Schmett., ii, East. \& Cent. 1824; Sмith, C. 144.

States.

syn. ampelophaga BoIsduval.

679. achemon Drury, Ill. Exot. Ent., ii, 51, 1773; U. S. Sмiтн, C. 145.

syn. crantor CRAMER.

680. typhon KLug, Neu. Schmett., pl. 3, f. 1, 1836;

Kirby, Cat. Lep. Het., i, 668, 1892.

Mex., Ariz.

AMPELOPHAGA Bremer \& Grey.

Bremer \& Grey, Beitr. Sch.-Faun. Chin., 11, 1853; Smith, C. 146.

681. chœrilus Cramer, Pap. Exot., iii, 91, 1779; Sмith,

C. 147.

Atl. States, Miss. Vall.

syn. clorinda Martyn, azaleæ Sмith \& Aввот.

$4630-$ No. $52-02-5$ 
682. myron Cramer, Pap. Exot., iii, 91, 1779; SмIth, C. 148 .

Atl. States, Miss. Vall.

syn. pampinatrix SмптH \& ABвот.

a. cnotus HüBner, Zutr. exot. Schmett., ff. 321-2, 1823; SмITH, C. 148.

683. versicolor Harris, Am. Jour. Sci., xxxvi, 303, 1839; SмIтн, C. 149.

Atl. States, Miss. Vall.

\section{COCYTIUS Huibner.}

HüBNer, Verz. bek. Schmett., 140, 1822; Kirby, Cat. Lep. Het., i, 686, 1892. 684. antæus Drury, Ill. Exot. Ent., ii, 43, 1773; SмIth, C. 153 .

Antilles, Fla.

syn. jatropha Fabricius, annonic SHAw.

\section{PSEUDOSPHINX Burmeister.}

Burmerster, Verh. nat. Ges. Halle, 69, 1856; Kirby, Cat. Lep. Het., i, 684, 1892. 685. tetrio Linnaus, Mant. Plant., 538, 1771; Kirby, Cat. Lep. Het., i, 684, 1892.

So. Am., syn. hasdrubal STOLL, rustica SEPP. - Antilles, Fla.

\section{DILOPHONOTA Burmeister.}

Burmeister, Verh, nat. Ges. Halle, 69, 1856; Sмith, C. 154.

686. ello Linneus, Syst. Nat., 491, 1758; Sмith, C. 156 .

687. lassauxii Boisduval, Bull. Soc. Ent. Fr., (3), vii, 157, 1859; KrnBy, Cat. Lep. Het., i, 697, 1892; Schaus, Ent. News, vi, 144, 1895.

So. Am., Fla., occ. Northw.

syn. cercyon BurMeister.

a. merianæ Grote, Proc. Ent. Soc. Phil., v, 75 ,

1865; Sмгтн, C. 158.

syn. omphalex BoisduvaL.

688. alope Drury, Ill. Exot. Ent., i, pl. 27, f. 1, 1773; Kirby, Cat. Lep. Het., i, 699, 1892; Sмiтн, C. 159; Schaus, Ent. News, vi, 144, 1895.

So. Am., Fla.

syn. fasciata Swannson, flavicans Goeze, edwardsii ButLER.

689. caicus Craner, Pap. Exot., ii, pl. 125, f. F, 1779; Kirby, Cat. Lep. Het., i, 697, 1892.

So. Am., Fla.

So. Am., Fla.

690. œnotrus Stoll, Pap. Exot., iv, pl. 301, f. C, 1780; Smith, C. 160; Schaus, Ent. News, ix, 136. 1898.

syn. melancholica Grote, janiphix Borsduval, cinerosa Grote, piperis Boisduval.

691. crameri Schaus, Ent. News, ix, 136, 1898.

So. Am., Fla. 
692. obscura Fabricius, Syst. Ent., 538, 1775; Sмптн, So. Am.,Fla., C. 157 . occ. northw.

syn. stheno HüBNER, rhabus BoIsduvaL.

a. domingonis Butler, Proc. Zool. Soc. Lond., 258, 1875; Sмith, C. 161.

syn. festa Hy. Edwards.

\section{CAUTETHIA Grote.}

Grote, Ann. Lyc. Nat. Hist. N. Y., viii, 202, 1867; Kırby, Cat. Lep. Het., i, 699, 1892.

693. noctuiformis Walker, Cat. Brit. Mus., viii, 232, Antilles, 1856 ; Krrby, Cat. Lep. Het., i, 699, 1892. So. Fla.

a. grotei Hy. Enwards, Papilio, ii, 1882; Sutw, C. 163 .

DILUDIA Grote \& Robinson.

Grote \& Robinson, Proc. Ent. Soc. Phil., v, 188, 1865.

*694. brontes Drury, Ill. Exot. Ent., ii, pl. 129, f. 4, Antilles, 1773; Kinby, Cat. Lep. Het., i, 681, $1892 . \quad$ So. Fla. syn. collaris W ALKER.

*695. cubensis Grote \& Robinson, Proc. Ent. Soc. Phil., Antilles. v, 189, 1865; Kirby, Cat. Lep. Het., i, 681, 1892. So. Fla.

\section{PHLEGETHONTIUS Hïbner.}

Hüвner, Verz. bek. Schmett., 140, 1822; Krrby, Cat. Lep. Het., i, 687, 1892.

696. quinquemaculata HaworTH, Lep. Brit., 59, 1803; Sмith, C. 165.

No. syn. celeus Hübner.

697. sexta Johanssen, Amon. Acad., vi, 410, 1764; So. Am., SмiтH, C. 167.

U.S. syn. carotina LinN aus.

698. rustica Fabricius, Syst. Ent., 540, 1775; Sмith, C. 168 . syn. chionanthi Sмiтн \& Aвво'т.

699. convolvuli Linn eus, Syst. Nat., 490, 1758; Kirby, Cat. Lep. Het., i, 690, 1892; Merrick, Faun. Hawai., i, 193, 1899.

a. cingulata FABricius, Syst. Ent., 545, 1775; Smith, C. 170; Dyar, Ent. News, vi, 195, 1895. syn. affinis Goeze, pungens Eschscholtz, dmuræi Donavan, decolorata Hy. Edwards.

So. Am.. So. States.

Eur., Asia.

So. Am., So. States, Hawaii. 


\section{SPHINX Linnæus.}

Linneus, Syst. Nat., 489, 1758; Kinby, Cat. Lep. Het., i, 690, 1892.

700. kalmiæ Sнгтн \& Аввот, Lep. Ins., Ga., i, 73, 1797; Atl. States. Sмith, C. 177.

*700. 1. franckii Neumoegen, Ent. News, iv, 133, $1893 . \quad$ Mo.

701. drupiferarum Sмгтн \& Аввот, Lep. Ins. Ga., i, U. S. 71, 1797; Sмптн, C. 177.

a. utahensis Hy. Edwards, Pap., i, 115, 1881.

702. perelegans Hy. Edwards, Proc. Cal. Acad. Sci., v, 109, 1874; Sмith, C. 179.

703. gordius Stoll, Pap. Exot., iị, pl. 247, f. B., 1780; Sмптн, C. 180.

Atl. States, syn. poecila STEPHENS.

704. Iuscitiosa Clemens, Jn. Acad. Nat. Sci. Phil., iv, 172, 1859; SмIтH, C. 181.

Cal.

Miss. Vall

705. vancouverensis Hy. Edwards, Proc. Cal. Acad. Sci., v, 111, 1874; Sumth, C. 183.

syn. vashti STRECKER.

a. albescens Tepper, Bull. Brook. Ent. Soc., iv, 1. 1881; SмIтh, C. 182.

706. chersis HüBner, Samml. exot. Schmett., ii, 1824; Sirth, C. 184.

syn. cinerea Harris, oreodaphne Hy. Edwards. a. libocedrus Hr. Edwards, Pap., iv, 115, 1881.

*707. insolita Lintner, Pap., iv, 145, 1884; Smith, C. 186.

708. pinastri Linneus, Syst. Nat., 492, 1758; Sмiтн, C. 186.

Atl. States.

syn. saniptri STRECKER.

709. sequoiæ Borsduval, Ann. Soc. Ent. Belg., xii, 86, 1868; Smith, C. 188.

*710. dollii Neumoegen, Pap., i, 149, 1881; Smith, C. 189.

711. coloradus Sмrтн, Ent. Amer., iii, 153, 1887; C. 189.

U.S.

Tex.

Europe, U. S. ?

Cal.

Ariz.

Col.

712. elsa Strecker, Lep. Rhop. Het., 126, 1878; Smith, C. 189.

Ariz., Utah.

713. canadensis Boisduval, Sp. Gén. Het., 93, 1875; SмiтH, C. 190. syn. plota Sitrecker. 
*714. eremitoides Strecker, Lep. Rhop. Het., 93, 1874; Suith, C. 191.

S. - W .

States.

715. andromeda Boisduval, Lép. Guat., 74, 1870; S. $-W$. Smith, C. 191; Schaus, Ent. News, vi, 142, 1895. States. syn. separatus Neumoegen.

*715. 1. lugens W ALker, Cat. Brit. Mus., viii, 219, 1856; Schaus, Ent. News, vi, 143, 1895.

716. eremitus HüBNER, Samml. exot. Schmett., ii, 1824; SмITH, C. 193.

syn. sordida Harris.

717. plebeia Fabricius, Gen. Ins., 273, 1777; Sмith, C. 194.

Atl. States.

So. States.

\section{DOLBA Walker.}

W Alker, Cat. Brit. Mus., viii, 229, 1856; Sмıth, C. 195.

719. hylæus Drury, Ill. Exot. Ent., ii, 45, 1773; SMITH, C. 196.

Atl. syn. prini Sммтн \& Аввот.

States.

\section{CHLANOGRAMMA Smith.}

Sмrte, Ent. Amer., iii, 154, 1887; C. 197.

720. jasminearum Boisduval, Icon. Règ. An. Ins., 494, 1844; Sмiтh, C. 199.

Atl. States.

\section{CERATOMIA Harris.}

Harris, Am. Jn. Sei., xxxvi, 286, 1839; Sмith, C. 200.

721. amyntor GEyer, Zutr. exot. Schmett., iii, 1824; Smith, C. 201.

Atl. States, Miss. Vall. syn. quadricornis HARRIs.

722. undulosa W ALKer, Cat. Brit. Mus., viii, 231, 1856; Sмith, C. 203. syn. repentinus Clemens.

723. hageni Grote, Bull. Buff. Soc., ii, 149, 1874; Smith, C. 204.

Tex.

724. catalpæ Boisduval, Sp. Gén. Het., i, 103, 1875; Sмith, C. 205. 


\section{LAPARA Walker}

Walker, Cat. Brit. Mus., viii, 232, 1856; Ellema Clemens; Smith, C. 206.

725. bombycoides Walker, Cat. Brit. Mus., viii, 232,

1856; SMITH, C. 205.

Atl. States,

syn. harrisii Clemens.

a. pinetum Lintner, Ent. Cont., i, 37, 1872;

Sмптн, C. 209.

726. coniferarum Sмптн \& Aввот, Lep. Ins. Ga., i, 83, 1797; SмITH, C. 210.

syn. cana Martyn.

\section{EXEDRIUM Grote.}

Grote, Check List, 11, 1882; Sмiтн, C. 211.

*727. halicarniæ Strecker, Bull. Brook. Ent. Soc., iii, 35. 1880: SмIтH, C. 211.

Fla.

\section{MARUMBA Moore.}

Moore, Lep. Ceylon, ii, 8, 1882; Kirby, Cat. Lep. Het., i, 706, 1892.

728. modesta Harris, Am. Journ. Sci., xxxvi, 292, U. S. 1839; SмITH, C. 216.

syn. princeps WaLKER, populicola BOIsDUvaL, cablei von Reizenstein, occidentalis Hy. EDWARDS.

a. imperator Strecker, Lep. Rhop. Het., 125, 1878; SмIтн, C. 217.

\section{SMERINTHUS Latreille.}

Latreille, Hist. Nat. Ins., iv, 209, 1802; Sмith, C. 218.

729. jamaicensis Drury, Ill. Exot. Ent., ii, 43, 1773; SMITH, C. 219.

Atl. syn. geminatus SAY, tripartitus Grote.

730. cerysii Krrby, Faun. Bor. Amer., iv, 301, 1827; SMITH, C. 223.

a. astarte Strecker, Proc. Acad. Nat. Sci. Phil., 36, 283, 1884: SмITH. C. 223.

b. ophthalmicus Boisduval, Ann. Soc. Ent. Fr., xii, 67,1869 ; Sмiтh, C. 221.

syn. pallidulus Hy. EDwards, vancouverensis No. Atl. States.

Col. BUTLER.

No. Pac. States. 


\section{PAOINIAS Hiibner.}

HüBner, Verz. bek. Schmett., 142, 1822; Krrby, Cat. Lep. Het., 712, 1892; Sмтн, C. 226 .

731. excæcatus Sмптн \& Aввот, Lep. Ins. Ga., i, 49, 1797 ; Sмптн, (. 226.

Atl.

syn. pavonia GEYER.

732. myops Surth \& Aввот, Lep. Ins. Ga., i, 51, 1797: SMITH, C. 227.

syn. rosacearum BOIsDUVAL.

733. astylus Drury, Ill. Exot. Ent., ii, 4., 1773; SMIth, C. 228.

Atl. States, Miss. Vall.

syn. integerrima HARRIs, io BOISDUVAL.

Atl.

States.

\section{CRESSONIA Grote \& Robinson.}

Grote \& Robinson, Proc. Ent. Soc. Phil., v, 161, 1865; Smith, C. 229.

734.juglandis Sмгтн \& Аввот, Lep. Ins. Ga., i, 57, Atl. States, 1797; Smith, C. 230; Kirby, Cat. Lep. Het., i, Miss. Vall. 713,1892 .

syn. robinsonii ButLer, pallens. STRECKER, hyperbola SLOsSON.

\section{ARCTONOTUS Boisduval.}

Boisduval, Ann. Soc. Ent. Fr., (2), x, 319, 1852; Smith, C. 232.

735. lucidus Boisduval, Ann. Soc. Ent. Fr., (2), x, 319 , 1852; Suith, C. 232; Kirby, Cat. Lep. Het., i,

Pac. 714, 1892 .

\section{Superfamily SATURNOIDEA.}

\section{Family SATURNIIDAE.}

(C.=Smith, Proc. U.S. Nat. Mus., 414-437, 1886; Neumoegen \& Dyar, Journ. N. Y. Ent. Soc., ii, 121-132, 1894.)

PHILOSAMIA Grote.

Grote, Proc. Am. Phil. Soc., xiv, 258, 1874; Kırby, Cat. Lep. Het., i, 748, 1892.

736. cynthia Drury, Ill. Exot. Ent., ii, pl. 6, f. 2, Japan to 1773: Smith, C. 146; Neumoegen \& Dyar, C. Java, Atl. 121; Hampson, Moths Ind., i, 16, 1892. coast cities.

syn. aurotus FABricius, insularis Vollenho. VEN, vesta WALKER, camningii WALKER, walkeri Felder, pryeri Butler. 


\section{ROTHSCHILDIA Grote.}

Grote, Verh. Ges. deutsch. Nat. Aerzte, 68, 2 div., 1 Heft, 204, 1897.

737. orizaba Westwood, Proc. Zool. Soc. Lond., 158, 1853; Kinby, Cat. Lep. Het., i, 747, 1892.

Mex., Ariz.

738. jorulla Westwood, Proc. Zool. Soc. Lond., 159, 1853; Neumoegen \& Dyar, C. 122.

Mex., syn. cinctus TEPPER.

SAMIA Hübner.

Hübner, Verz. bek. Schmett., 156, 1822; Neumoegen \& Dyar, C. 123.

739. cecropia Linneus, Syst. Nat., i, 447, 1758; Sмiтh, C. 427 .

Atl. States.

740. gloveri Strecker, Lep. Rhop. Het., i, 1, 1872; Rocky Mts., Sмith, C. 425. Ariz.

a. reducta Neumoegen, Ent. News, ii, 152, 1891; Neumoegen \& Dyar, C. 123.

741. columbia Surth, Proc. Bost. Soc. Nat. Hist., ix, 343,1865 ; C. 424.

N. Atl. States.

742. rubra Behr, Proc. Cal. Acad. Sci., i, 46, 1855; Neumoegen \& Dyar, C. 124.

Pac.

syn. euryalus Boisduval, californica Grote, ceanothi BEHR.

\section{CALLOSAMIA Packard.}

Packard, Proc. Ent. Soc. Phil., iii, 379, 1864; Neumoegen \& Dyar, C. 124.

743. calleta Westwood, Proc. Zool. Soc. Lond., 166, 1853; Neumoegen \& Dyar, C. 124.

Mex., syn. polyommata TEPPER.

744. promethia Drury, Ill. Exot. Ent., ii, pl. 11, f. 1, 1773; Sмith, C. 423.

745. angulifera WALker, Cat. Brit. Mus., v, 1224, 1855; Sмith, C. 424. 
TROP EA Hübner.

HüBner, Verz. bek. Schmett., 152, 1822; Kirby, Cat. Lep. Het., i, 765, 1892.

747. luna Linnæus, Syst. Nat., 496, 1758; Sмiтh, C. 429.

Atl. States, a. dictynna Walker, Cat. Brit. Mus., vi, 1264, Miss. Vali. 1855 .

b. rossi Ross, Cat. Lep. Can., 5, note, 1872; Neumoegen \& Dyar, C. 126.

\section{TELEA Hübner.}

Hübner, Verz. bek. Schmett., 154, 1822; Sмith, C. 429.

748. polyphemus Cramer, Pap. Exot., i, pl. 5, f. A, U.S. 1775; Smith, C. 430; Neumeegen \& Dyar, C. 126. syn. paphia Linneus, fenestra PErry, oculea NEUMOEGEN.

\section{SATURNIA Schrank.}

Schrank, Faun. Boica, ii, (1), 149; Neumoegen \& Dyar, C. 126.

749. mendocino Behrens, Can. Ent., viii, 149, 1876; No. SмIтн, C. 432.

Cal.

\section{AUTOMERIS Hübner.}

Hübner, Verz. bek. Schmett., 154, 1822; Neumoegen \& Dyar, C. 127.

*750. zelleri Grote \& Robinson, Trans. Am. Ent. Soc., ii, 193, 1868; Sмгтн, C. 434.

Mex., ? Tex.?

Ariz., Mex.

751. pamina Neumoegen, Pap., ii, 60, 1882; Smith, C. 435; NeuMOEgen \& DYAR, C. 127.

a. aurosea Neumoegen, Pap., ii, 61, 1882.

syn. boucardi Druce, Biol. Cent. Am., Lep. Het., i, 178, pl. 17, f. 5, 1886.

*752. zephyria Grote, Can. Ent., xiv, 215, 1882; Smith, N. Mex. C. 436 .

753. io Fabricius, Syst. Ent., 560, 1775; Smith, C. 434; Neumoegen \& Dyar, C. 128.

syn. corollaria PERRY, varia W ALKER, fabricii

Boisduval, argus Neumoegen \& Dyar.

a. lilith Strecker, Lep. Rhop. Het., 139, 1878.

THAUMA Hy. Edwards.

Hy. Edwards, Proc. Cal. Acad. Sci., v, 265, 1875; Neumoegen \& Dyar, C. 128.

754. socialis Feisthamel, Mag. Zool., pl. 20, f. 1, Peru, Chile, 1839; Neumoegen \& Dyar, C. 128. Brit. Col. ? syn. angulifera WALKER, ribis Hy. EDWARDs. 
COLORADIA Blake.

Blake, Proc. Ent. Soc. Phil., ii, 279, 1863; Sмiтh, C. 436.

755. pandora Blake, Proc. Ent. Soc. Phil., ii, 279, Rocky 1863; Neumoegen \& Dyar, C. 129.

a. doris Barnes, Can. Ent., xxxii, 46, 1900.

\section{HEMILEUCA Walker.}

Walker, Cat. Brit. Mus., v, 1319, 1855; Neumoegen \& Dyar, C. 129.

756. electra Wright, Pap., iv, 19, 1884; Neumoegen \& DYAR, C. 129.

So.

Cal.

757. maia Drury, Ill. Exot. Ent., ii, pl. 24, f. 3, 1773;

Neunoegen \& Dyar, C. 130.

Atl. States, Col.

syn. proserpina Fabricius.

a. lucina Hy. Edwards, Ent. Am., ii, 14, 1887.

758. nevadensis Stretch, Zyg. Bomb. N. A., 108, 1872; Neumoegen \& Dyar, C. 130.

Rocky Mts. to Pacific.

syn. californica WrIght, artemis PACKARD.

759. juno Packard, Rep. Peab. Acad. Sci., iv, 87, 1872; Neumoegen \& Dyar, C. 130.

Mex.,

Ariz.

syn. yavapai NeuMOEGEN.

*760. grotei Grote \& Robinson, Trans. Am. Ent. Soc., ii, 192, 1868; Neumoegen \& Dyar, C. 131.

Col., Tex. syn. diana PACKARD.

761. neumoegenii Hy. Edwards, Pap., i, 171, 1881; Neumoegen \& Dyar, C. 131.

Ariz., Cal.

762. tricolor Packard, Rep. Peab. Acad., iv, 89, 1872; Neunoegen \& Dyar, C. 131.

763. hualapai Neumoegen, Pap., iii, 138, 1883; NeUMOEGEN \& DYAR, C. 131.

N. Mex.

Ariz., Mex.

a. sororius Hy. Edwards, Pap., i, 100, 1881;

Neumeogen \& Dyar, C. 129, note.

b. oliviae Cockerell, Psyche, viii, 252, 1898.

\section{PSEUDOHAZIS Grote \& Robinson.}

Grote \& Robinson, Ann. Lye. Nat. Hist. N. Y., viii, 377, 1866; Neumoegen \& Dyar, C. 131.

764. eglanterina Borsduval, Ann. Soc. Ent. Fr., (2), x, Rocky Mts. 323, 1852; Neunoegen \& Dyar, C. 132. to Ariz.

syn. arizonensis STRECKER.

a. nuttalli Strecker, Lep. Rhop. Het., 107, 1875. 
765. shastaensis Behrens, No. Am. Ent., i, 62, 1880: Pac. States, Neumoegen \& Dyar, C. 132.

a. denudata Neumoegen, Can. Ent., xxiii, 145, 1891.

766. hera Harris, Rep. Ins. Mass., 286, 1841; NeuMOEGEN \& DYAR, C. 132.

W. Col. syn. picta WALKER.

a. marcata Neunoegen, Can. Ent., xxiii, 146 , 1891: Neunoegen \& Dyar, C. 132.

\section{HYLESIA Hübner.}

HüBNer, Verz. bek. Schmett., 186, 1822.

766. 1. alinda Druce, Biol. Cent. Am., Lep. Het., i, $197,1886$.

Mex. Ariz.

\section{Family CERATOCAMPIDA.}

\section{(C:=Neumoegen \& Dyar, Journ. N. Y. Ent. Soc., ii, 147-152, 1894.}

\section{ANISOTA Hïbner.}

Hübner, Verz. bek. Schmett., 193, 1822; Neumoegen \& Dyar, C. 147.

767. stigma Fabricius, Syst. Ent.. 563, 1775; NeUMOEGEN \& DYAR, C. 147.

768. senatoria Sиттн \& Аввот, Lep. Ins. Ga., pl. 57, 1797; Neumoegen \& Dyar, C. 147.

769. consularis Dyar, Journ. N. Y. Ent. Soc., iv, 166, 1896.

770. virginiensis Drury, Ill. Exot. Ent., ii, pl. 13, f. 2, 1773; Neumoegen \& Dyar, C. 148.

syn. astymome OLIVIER, pellucida HerrichSCHAEFFER.

771. rubicunda FABricius, Syst. Ent., 429, iii, (1), 1793; Neumoegen \& Dyar, C. 148. a. alba Grote, Bull. Buff. Soc., ii, 183, 1874.

syn. pallida Bowles.
Atl. States.

Atl. States.

Fla.

Atl. States.

Atl. States.

\section{ADELOCEPHALA Herrich-Schaeffer.}

Herrich-Schafffer, Auss. Schmett., i, 9, 1855; Kirby, Cat. Lep. Het., i, 741, 1892; Dyar, Proc. Ent. Soc. Wash., iv, 427, 1901.

772. bicolor Harris, Rep. Ins. Mass., 203, 1841; Miss. Neumoegen \& Dyar, C. 148.

syn. distigma W ALSH.

a. suprema Neunoegen, Ent. Amer., i, 94, 1885;

Neumoegen \& Dyar, C. 149.

b. immaculata JEWETT, Pap., ii, 144, 1882. 


\section{SYSSPHINX Hübner.}

Hübner, Verz. bek. Schmett., 143, 1822; Kirby, Cat. Lep. Het., i, 741, 1892; Dyar, Proc. Ent. Soc. Wash., iv, 428, 1901.

773. quadrilineata Grote \& Robinson, Trans. Am. Miss. Ent. Soc., i, 11, 1867; Neumoegen \& Dyar, C. Val. 149 .

774. bisecta Lintner, Can. Ent., xi, 10, 1879; NeUTex. MOEGEN \& DYAR, C. 149.

syn. nebulosa Neumoegen.

775. heiligbrodti Harvey, Can. Ent., ix, 110, 1871; Ariz. Neumoegen \& Dyar, C. 149. a. hubbardi DYAR (dark stone-gray instead of pale gray).

\section{CITHERONIA Hübner.}

Hübner, Verz. bek. Schmett., 153, 1822; Neumoegen \& Dyar, C. 150.

776. regalis Fabricius, Syst. Nat., 1ii, (1), 436, 1793;

Atl. NEUMOEgEN \& DYaR, C. 150. States.

syn. regia Sмiтн \& Aввот.

a. infernalis Strecker, Pap., iv, 73, 1883.

b. saengeri Neumoegen, Ent. News, ii, 151, 1891.

777. sepulchralis Grote \& Robinson, Proc. Ent. Soc. Phil., iv, 222, 1865; Neumoegen \& Dyar, C. 151.

Atl. States.

\section{BASILONA Boisduval.}

Borsduval, Ann. Soc. Ent. Fr., (4), viii, 314, 1868; Neumoegen \& Dyar, C. 151.

778. imperialis Drury, IIl. Exot. Ent., i, pl. 9, f. 1, 1773; Neumoegen \& Dyar, C. 151.

Atl. States.

syn. imperatoria Sмгтн \& Аввот, punctatissima

Neumoegen.

a. didyma DE Beauvors, Ins. Afr. Amér., 52, pl.

20, 1805; Neumoegen \& Dyar, C. 157.

b. nobilis Neumoegen, Ent. News, ii, 150, 1891.

\section{Superfamily BOMBYCOIDEA.}

$$
\text { Family SYNTOMIDA. }
$$

${ }^{\prime}$ C.=Hampson, Cat. Lep. Phal. Brit. Mus., i, 1898.)

\section{COSMOSOMA Hübner.}

Hübner, Samml. exot. Schmett., ii, 1827; Hampson, C. 225.

779. auge Linneus, Syst. Nat., i, (2), 807, 1767; Hampson, C. no. 477.

So. Am.,

syn. omphale HüBner, me 'it'" Möschler. Mex., Fla. 


\section{SYNTOMEIDA Harris.}

Harris, Am. Jn. Sci., xxxvi, 316, 1839; Hampson, C. 305.

780. ipomeæ Harris, Am. Jn. Sci., xxxvi, 316, 1839;

HaMpson, C. no. 679.

So.

syn. ferox WALKER, euterpe HERRICH-SCHAEF-

States.

FER.

781. epilais Walker, Cat. Brit. Mus., i, 227, 1854;

Hampson, C. no. 680.

Fla.,

So. Am.

\section{PSEUDOMYA Hübner.}

Hübner, Verz. bek. Schmett., 124, 1827; Hampson, C. 262.

782. minima Grote, Proc. Ent. Soc. Phil., vi, 298, 1867; Hampson, C. no. 569.

Cuba, Fla.

\section{DIDASYS Grote.}

Grote, Can. Ent., vii, 174, 1875; Hampson, C. 360.

783. belæ Grote, Can. Ent., vii, 145, 1875; Hampson, C. no. 797.

Fla.

\section{HORAMA Hïbner.}

HüBner, Verz. bek. Schmett., 124, 1827; Hampson, C. 417.

784. texana Grote, Proc. Ent. Soc. Phil., vi, 184, 1867; HaMpson, C. no. 928.

Cent. Am., Mex., Tex.

\section{EUCEREON Hübner.}

HüBner, Verz. bek. Schmett., 123, 1827; Hampson, C. 485.

785. confine Herrich-Schaeffer, Ausser. Schmett., f. Cent. Am., 277, 1855; Hampson, C. no. 1117.

Mex., Fla. syn. carolina Hy. Edwards.

\section{LYMIRE Walker.}

Walker, Cat. Brit. Mus., ii, 489, 1854; Hampson, C. 414.

786. edwardsi Grote, Pap., i, 4, 1881; Hampson, C. Fla. no. 923.

\section{SCEPSIS Walker.}

Walker, Cat. Brit. Mus., ii, 285, 1854; Hampson, C. 520.

787. fulvicollis Hübner, Samml. exot. Schmett., i, Atl. States to 1827 ; Hampson, C. no. 1148. Rocky Mts. syn. semidiaphana HARRIS.

a. pallens Hy. Edwards, Ent. Amer., ii, 8, 1886. 
788. packardii Grote, Proc. Ent. Soc. Phil., iv, 318 , 1865 .

syn. matthewi Grote.

789. wrightii Stretch, Ent. Amer., i, 101, 1885; Hampson, C. no. 1149.

a. gravis Hy. Edwards, Ent. Amer., ii, 8, 1886.

No. Pac.

States.

Cal.

\section{LYCOMORPHA Harris.}

Harris, Am. Jn. Sci., xxxvi, 317, 1839; Hampson, C. 522.

790. grotei Packard, Proc. Essex Ins., iv, 47, 1864; Rocky Mts., Hampson, C. no. 1152.

Tex.

$$
\text { syn. palmeri PACKARD. }
$$

a. pulchra Dyar, Jn. N. Y. Ent. Soc., vi, 34, 1898.

*791. fulgens Hy. Enwards, Pap., i, 116, 1881; Hampson, C. no. 1153.

N. Mex.,
Ariz.
U.S.

792. pholus Drury, Ill. Exot. Ent., ii, pl. 28, f. 3, 1773; Hampson, C. no. 1154.

a. miniata Packard, Rep. Peab. Acad., iv, 84, 1872.

*792. 1. desertus Hy. Edwards, Pap., i, 81, 1881; NeuMOEgen \& Dyar, Jn. N. Y. Ent. Soc., ii, 173, 1894. (Type lost.)

\section{CTENUCHA Kirby.}

Kirby, Faun. Bor. Am., iii, 305, 1837; Hampson, C. 523.

793. venosa WALKer, Cat. Brit. Mus., ii, 284, 1854; Hampson, C. no. 1165.

Mex., Tex., Col.

794. cressonana Grote, Proc. Ent. Soc. Phil., ii, 64, 1863; Neumoegen \& Dyar, Jn. N. Y. Ent. Soc., i, $106,1893$.

Ariz.

a. sanguinaria Strecker, Rep. Ch. Eng. Ruffner, 1878, app., 1858; Hampson, C. no. 1166.

b. lutea Grote, Can. Ent., xxxiv, 104, 1902.

795. brunnea Stretch, Zyg. Bomb. N. A., i, 30, 1872; Hampson, C. no. 1168.

796. multifaria Walker, Cat. Brit. Mus., ii, 478, 1854; Rocky Mts.

Hampson, C. no. 1169.

a. luteoscapus Neumoegen \& Dyar, Jn. N. Y. Ent. Soc., i, 106, 1893.

797. rubroscapus Ménétries, Cat. Lép. Pét., ii, 142, 1857; Hampson, C. no. 1170.

Pac. syn. walsinghami Hy. EDwards.

a. ochroscapus Grote \& Robinson, Trans. Am. Ent. Soc., i, 330, 1868.

syn. corvina BoIsduval. 
798. virginica Charpentier, Esper's Exot. Schmett., ii, suppl., pl. 2, f. 3, 1830; Hampson, C. no. 1171.

No. Atl. States. syn. latreillana KirBy.

DAHA NA Grote.

Grote, Can. Ent., vii, 175, 1875; Hampson, C. 531.

799. atripennis Grote, Can. Ent., vii, 175, 1875; НамPson, C. no. 1174.

Fla.

\section{Family LITHOSIIDA.}

(C.=Hampson, Cat. Lep. Phal. Brit. Mus., ii, 1900.)

CRAMBIDIA Packard.

Packard, Proc. Ent. Soc. Phil., iii, 99, 1864; Hampson, C. 126.

800. pallida Packard, Proc. Ent. Soc. Phil., iii, 99, 1864: Hampson, (. no. 244.

No. Atl.

States.

801. uniformis DYar. Jn. N. Y. Ent. Soc., vi. 33. 1898; Va., Hampson, C. no. 246.

Md.

802. cephalica Grote \& Robinson, Trans. Am. Ent. Soc., iii, 176, 1870; Neumoegen \& Dyar, Jn.

Col., N. Y. Ent. Soc., i, 109, 1893.

Ariz.

803. casta Sanborn, Packard's Guide Stud. Ins., 284, 1869; Hampson, C. no. 247.

No. U. S.,

Can.

syn. candida Hy. EDwards.

804. lithosioides Dyar, Jn. N. Y. Ent. Soc., vi, 33, 1898; HaMpson, C. no. 245.

Tex.

\section{PALPIDIA Dyar.}

Dyar, Jn. N. Y. Ent. Soc., vi, 33, 1898; Hampson, C. 513.

805. pallidior Dyar, Jn. N. Y. Ent. Soc., vi, 34, 1898;

Fla. Hampson, C. no. 1103.

\section{LEXIS Wallengren.}

Wallengren, Vet. Akad. Handl., (2), 5, (4), 41, 1865; Hampson, C. 115.

806. bicolor Grote, Proc. Ent. Soc. Phil., iii, 74, 1864; No. States, Hampson, C. no. 224. 
HYPOPREPIA Hübner.

Hübner, Zutr. exot. Schmett., iii, 21, 1825; Hampson, C. 515.

807. miniata KIrBy, Faun. Bor. Am., iv, 305, 1837;

Hampson, C. no. 1108.

States.

syn. vittata HARris.

a. subornata Neumoegen \& Dyar, Can. Ent., xxv,

$124,1893$.

808. fucosa HüBner, Zutr. exot. Schmett., f. 471, 1825; Hampson, C. no. 1109.

syn. tricolor FiтcH.

a. plumbea Hy. Edwards, Ent. Amer., ii, 9, 1886.

809. cadaverosa Strecker, Proc. Dav. Acad. Sci., ii, 270, 1878; Hampson, C. no. 1110.

Rocky

Mts.

Col.

810. inculta Hr. Edwards, Pap., ii, 13, 1882; НАмpson, C. no. 1111.

H EMATOMONIS Hampson.

Hampson, Cat. Lep. Phal. Brit. Mus., ii, 514, 1900.

811. mexicana Druce, Biol. Cent. Am., Lep. Het., i, 131, 1885; Hampson, C. no. 1106.

Mex., Ariz.

\section{COMACLA Walker.}

Walker, Cat. Brit. Mus., vii, 1679, 1856; Hampson, C. 338.

812. simplex Walker, Cat. Brit. Mus., vii, 1679, 1856; Rocky Mts., HAMPSON, C. no. 712.

Tex.

syn. murina WALKER, clame GROTE \& ROBINson, texana French, Can. Ent., xxxi, 9, 1899.

813. fuscipes Grote, Can. Ent., xi, 86, 1883; NeuMOEGEN \& Dyar, Jn. N. Y. Ent. Soc., i, 114, 1893.

Ariz.

\section{NEOPLYNES Hampson.}

Hampson, Cat. Lep. Phal. Brit. Mus., ii, 520, 1900.

814. eudora Dyar, Ent. News, v, 198, 1894; Hampson, Tex. C. no. 1117.

\section{BRUCEIA Neumoegen.}

Neumoegen, Jn. N. Y. Ent. Soc., i, 36, 1893; Hampson, C. 514.

815. pulverina Neumoegen, Jn. N. Y. Ent. Soc., i, 36,

Col. 1893; Hampson, C. no. 1105.

816. hubbardi Dyar, Jn. N. Y. Ent. Soc., vi, 33, 1898. 
CLEMENSIA Packard.

Packard, Proc. Ent. Soc. Phil., iii, 100, 1864; Hampson, C. 398.

817. albata Packard, Proc. Ent. Soc. Phil., iii, 100, 1864; Hampson, C. no. 853.

No. U. S., Cal., Mex.

syn. albida WALKER, cana WALKER, umbrata, Packard, irrorata Hy. Edwards, patella Druce, philodina Druce.

*818. lactea Stretch, Ent. Amer., i, 103, 1883; Намpsov, C. no. 792.

\section{OZONADIA Dyar.}

Dyar, Psyche, viii, 359, 1899; Hampson, C. 365.

819. schwarziorum Dyar, Psyche, viii, 359, 1899; Hampson, C. no. 769.

Cal.

820. unifascia Grote \& Robinson, Trans. Am. Ent. Soc., ii, 175, 1868; Hampson, C. no. 770.

a. tenuifascia Harver, Bull. Buff. Soc., iii, 4, 1875 .

\section{ILLICE Walker.}

Walker, Cat. Brit. Mus., xix, 1019, 1859; Hampson, C. 363.

821. subjecta Walker, Cat. Brit. Mus., ii, 534, 1854; Hampson, C. no. 776.

So. Atl.

States.

syn. packardii Grote.

a. striata Otтolengui, Can. Ent., xxx, 101, 1898;

Hampson, C. no. 777.

822. plumbea Stretch, Ent. Amer., i, 102, 1885;

Tex. Hampson, C. no. 787.

823. faustinula Borsduval, Ann. Soc. Ent. Belg., xii, Cal. 73, 1868; Hampson, C. no. 787.

a. fusca Stretch, Zyg. Bomb. N. A., 49, 1872.

824. nexa Boisduval, Ann. Soc. Ent. Belg., xii, 74, Cal. 1868; Hampson, C. no. 785.

syn. grisea PACKARD, deserta FELder.

\section{Family ARCTIIDÆ.}

(C.=Hampson, Cat. Lep. Phal. Brit. Mus., iii, 1901.)

PTYCHOGLENE Felder.

Felder, Reise Novara, Lep., iv, pl. 106, f. 26, 1874.

*825. coccinea Hy. Edwards, Ent. Amer., ii, 9, 1886. 
826. phrada Druce, Ann. Mag. Nat. Hist., (6), iv, 90, 1889: Hampson, C. ii, no. 507.

Ariz., Mex.

syn. Alammans Dyar, Jn. N. Y. Ent. Soc, vi, $39,1898$.

827. sanguineola Borsduval, Lép. Guat., 95, 1870; Hampson, C. ii, no. 505.

Ariz., Mex.

\section{EIBAPHE Hïbner.}

HüBner, Zutr. exot. Schmett., ii, 9, 1823; Hampson, C. 188.

828. læta Gú́rix, Icon. Ins., pl. 88, f. 6, 1829; НАмpson, C. no. 1567.

Atl.

- syn. treatii Grote, mbropicta PACKARD.

829. intermedia Graef, Ent. Amer., iii, 42, 1887; Haмrson, C. no. 1575 .

States.

a. parvula Neumoegen \& Dyar, Ent. News, iv, 140, 1893.

syn. cocciniceps Schaus, Ann. Mag. Nat. Hist., (7), vii, 269, 1901; Hampson, C. no. 1565.

830. ostenta Hy. Edwards, Pap., i, 12, 1881; НамPson, C. no. 1568.

831. fragilis Strecker, Rep. Eng. Ruffner, v, app., 1859, 1878; Hampson, C. no. 1574.

- syn. costata Stretch, opelloides Graef.

832. opella Grote, Proc. Ent. Soc. Phil., i, 345, 1863; Hampson, C. no. 1576.

syn. obscura STRECKER, mubicosta EHRMAN.

a. nigricans Reakirt, Proc. Ent. Soc. Phil., ii, $371,1864$.

syn. nigrifera WALKER.

b. belmaria Ehrman, Can. Ent., xxvii, 3\$5, 1895.

833. immaculata Reakirt, Proc. Ent. Soc. Phil., ii, 372, 1864; Sмrтн, Can. Ent., xxi, 195, 1889.

Tex., Col.

Ariz.

Tex.

Atl. States.

Atl.

States.

a. trimaculosa Reakint, Proc. Ent. Soc. Phil., ii, $372,1864$.

834. aurantiaca HüBner, Zutr. exot. Schmett., f. 411 , 1825; Hampson, C. no. 1573.

a. rubicundaria HüBNer, Zutr. exot. Schmett.,

Atl. States to Rocky Mts., f. 511,1825 .

syn. rosa French, diminutiva Graef.

b. ferruginosa W ALKer, Cat. Brit. Mus., ii, 535, 1854; Sмith, Can. Ent., xxi, 195, 1889.

c. brevicornis WALker, Cat. Brit. Mus., ii, 536, 1855 .

syn. belfragei STRETCH. 
d. quinaria Grote, Proc. Ent. Soc. Phil., ii, 30, 1863.

syn. choriona REAKIRT, bimaculata SAUNDERs.

\section{DODIA Dyar.}

Dyar, Jn. N. Y. Ent. Soc., ix, 85, 1901.

835. albertæ Dyar, Jn. N. Y. Ent. Soc., ix, 85, 1901.

Alberta.

\section{UTETHEISA Hübner.}

Hübner, Verz. bek. Schmett., 168, 1823; Hampson, C. 480.

836. bella Linnaus, Syst. Nat., 534, 1858; Hampson, C. no. 2091.

Atl.

States.

a. hybrida Butler, Trans. Ent. Soc. Lond., 361, 1877.

syn. intermedia ButLer.

b. terminalis Neumoegen \& Dyar, Jn. N. Y. Ent. Soc., 1, 162, 1893.

c. venusta Dalman, Anal. Ent., 28, 1823.

syn. speciosa WALKER.

837. ornatrix Linnæus, Syst. Nat., 511, 1758; Hamp- Fla., Antilles, son, C. no. 2090.

So. Am.

a. stretchii Butler, Trans. Ent. Soc. Lond., 361, 1877 .

syn. pura ButLer.

\section{HAPLOA Hübner.}

Hüвner, Verz. bek. Schmett., 182, 1822; Sмiтh, Proc. U. S. Nat. Mus., 338, 1887; Lyman, Can. Ent., xix, 181, 1887; Hampson, C. 492.

838. clymene Brown, Ill. Zool., 96, 1776; Hampson,

C. no. 2099.

Atl.

syn. intermptomarginata DE BEAUvOIS, comma

States.

W ALKER.

839. colona HübNer, Eur. Schmett., ii, 135, 1804;

Hampson, C. no. 2100.

Atl.

States.

syn. carolina HARRIs.

a. reversa Stretch, Ent. Amer., i, 104, 1885.

syn. suffusa SмITH.

b. fulvicosta Clemens, Proc. Acad. Nat. Sci. Phil., 536, 1861; Hampson, C. no. 2103.

syn. duplicata Neumoegen \& Dyar.

c. consita Walker, Cat. Brit. Mus., xxxii, 377 ,

1865 .

syn. lactata Suith.

d. triangularis Sмiтн, Ent. News, x, 126, 1899. 
840. lecontei Boisduval, Icon. Reg. An., Ins., 517, 1829; Hampson, C. no. 2101.

Atl.

syn. leucomelas Herrich-Schaeffer.

a. dyari Merrick, Ent. News, xii, 45, 1901.

b. confinis W ALKER, Cat. Brit. Mus., iii, 651, 1855.

c. militaris Harris, Rep. Ins. Mass., 243, 1841.

d. harrisii DyaR (oblique band broken).

e. smithii DYAR (marks broken and confused).

$f$. vestalis Packard, Proc. Ent. Soc. Phil., iii, 108, 1864; Hampson, C. no. 2105.

841. confusa Lyman, Can. Ent., xix, 185, 1887; Hampson, C. no. 2104.

No. Atl.

States.

a. lymani DYAR (marks broken and reduced).

842. contigua Walker, Cat. Brit. Mus., iii, 651, 1855; Hampson, C. no. 494.

a. lumbonigera DYAR (outer band broken or absent).

Atl. States.

EUERYTHRA Harvey.

Harvey, Can. Ent., viii, 5, 1876; Hampson, C. 254.

843. phasma Harvey, Can. Ent., viii, 5, 1876; Нavpson, C. no. 1695 .

844. trimaculata Sмгтн, Ent. Amer., iii, 17, 1887; Hampson, C. no. 1696.

Tex.

Tex.

\section{ECPANTHERIA Hiibner.}

Hübner, Verz. bek. Schmett., 183, 1822; Hampson, C. 365.

845. muzina Oвerthur, Étud. d'Ent., pl. 12, f. 4, 1881; Hampson, C. no. 1928.

Tex., Mex.

syn. albicollis Oberthur, thiemei Oberthur, abscondens Oвerthur, depauperata OBerTHUR, garaoni OBERTHUR, xanthonota OBERTHUR, yukatanensis OBERTHUR, sennettii LinTNER.

846. deflorata Fabricius, Syst. Ent., 582, 1775; HaMrson, C. no. 1918.

syn. scribonia STOLL, chryseis Olviner, occulatissma Suith \& Aввот.

a. confluens Oberthur, Étud. d'Ent., 110, 1884.

b. denudata Slosson, Ent. News, iii, 212, 1888.

TURUPTIANA Walker.

Walker, Char. Lep. Het., 19, 1869; Hampson, C. 425.

847. permaculata Packard, Fourth Rept. Peab. Acad. Sci., 80, 1872; Hampson, C. no. 1995.

So. Atl. States, Mex syn. reducta Grote, cæca Strecker.

Rocky Mts., Ariz. 


\section{LEPTARCTIA Streteh.}

Stretch, Zyg. Bomb. N. A., 118, 1873; Hampson, C. 220.

848. californiæ W ALker, Cat. Brit. Mus., iii, 625, Rocky Mts., 1855; Hampson, C. no. 1634. Pac. States.

syn. lena Borsduval, adnata Borsduval, fulvo-

fasciata Butler, wrightii French.

a. decia Borsduval, Ann. Soc. Ent. Belg., xii, $72,1869$.

syn. boisduvalii ButLer, latifasciata Butler, albifascia French, occidentalis French.

b. dimidiata Stretch, Zyg. Bomb. N. A., 123, 1873.

syn. stretchii Butler.

\section{SEIRARCTIA Packard.}

Packard, Proc. Ent. Soc. Phil., iii, 119, 1864; Hampson, C. 422.

849. echo Sмiтн \& Aввот, Lep. Ins. Ga., ii, 135, 1797; Hampson, C. no. 1989.

syn. niobe STRECKER.

So.

States.

\section{ALEXICLES Grote.}

Grote, Trans. Kans. Acad. Sci., viii, 46, 1882.

*850. aspersa Grote, Trans. Kans. Acad. Sci., viii, 46, 1882; Hampson, C. no. 1853.

N. Mex.

\section{ESTIGMENE Hübner.}

Hübner, Verz. bek. Schmett., 184, 1822; Hampson, C. 338.

851. acræa Drury, Ill. Exot. Ent., i, pl. 3, f. 2, 1770; Hampson, C. no. 1868.

U. S., Mex.

syn. caprotina Drury, menthastrina Martyn, psenderminea PECK, californica PACKARD, packardii Schaupp, klagesii Ehrman.

a. dubia WaLker, Cat. Brit. Mus., iii, 682, 1850 . syn. rickseckeri BEHR, Zoe, iv, 247, 1895; Skinner, Ent. News, vi, 186, 1895.

b. mexicana Hampson, Cat. Lep. Phal. Brit. Mus., iii, 345, 1901.

852. albida Stretch, Zyg. Bomb. N. A., 203, 1873; Hampson, C. no. 1869.

853. prima Slosson, Ent. Amer.,v, 40, 1889; Hampson, C. no. 1869 .

854. congrua W ALker, Cat. Brit. Mus., iii, 669, 1856. syn. antigone Strecker; Hampson, C. no. 1871. a. athena Strecker, Lep. Rhop. Het., suppl. 2, 4, 1899.

\author{
So. \\ Cal. \\ No. Atl. \\ States.
}

Atl. States, Col. 
HYPHANTRIA Harris.

Harris, Rep. Ins. Mass., 255, 1841; Hampson, C. 335.

855. cunea Drury, Ill. Exot. Ent., i, pl. 18, f. 4, 1770; Hampson, C. no. 1852.

syn. budea Hübner, punetatissima SмIth \& Aввот, punctata Fitch, pallida PACKard, suffusa STRECKER, brunnea STRECKer, Lep. Rhop. Het., suppl. 3, 28, 1900.

856. textor Harris, Rep. Ins. Mass., 255, 1841. syn. candida WALKER.

So. Atl. States.

U. S.

\section{ARACHNIS Geyer.}

Geyer, Zutr. exot. Schmett., f. 457, 1873; Hampson, C. 319.

857. picta Packard, Proc. Ent. Soc. Phil., iii, 126 ,

1864; Hampson, C. no. 1942.

So.

a. maia Otrolengui, Ent. News, vii, 125, 1896.

Cal.,

b. citra Neumoegen \& Dyar, Ent. News, iv, 140, Col. 1893.

c. hampsoni Dyar (Hampson, C. 392, subsp. 2).

d. perotensis Schaus, Ent. Amer., v, 190, 1889.

858. zuni Neumoegen, Ent. Amer., vi, 173, 1890; Hampson, C. no. 1944.

Ariz.

ISIA Walker.

Walker, Cat. Brit. Mus., vii, 1698, 1856; Pyrrharctia Packard, Proc. Ent. Soc. Phil., iii, $120,1864$.

859. isabella Sмгтн \& Аввот, Lep. Ins. Ga., ii, 131, U. S. 1797; Hampson, C. no. 1821.

syn. californica PACKARD.

\section{PHRAGMATOBIA Stephens.}

Stephens, Ill. Brit. Ent., Haust., ii, 73, 1830; Hampson, C. 233.

860. fuliginosa Linneus, Syst. Nat., i, 509, 1758; No. States, Hampson, C. no. 1672.

Eur.

syn. rubricosa HaRRIs.

a. borealis Staudinger, Cat. Lep. Eur., 59, 1871.

b. fervida Staudinger, Cat. Lep. Eur., 59, 1871.

c. subnigra Mrluière, Lep., vi, pl. 8, f. 7, 1881.

d. pulverulenta Alpheraky, Rom. Mém. Lép., v, 84, 1889.

861. assimilans Walker, Cat. Brit. Mus., iii, 630, 1855; Hampson, C. no. 1673.

a. franconica Slosson, Ent. News, ii, 41, 1891. 
DIACRISIA Hibner.

HüBner, Verz. bek. Schmett., 196, 1827; Hampson, C. 256; Rhagonis Walker, Trans. Ent. Soc. Lond., (3), i, 270, 1862.

862. virginica Fabricius, Syst. Ent., suppl., 437, 1798; U.S. Hampson, C. no. 1710.

a. fumosa Strecker, Lep. Rhop. Het., suppl. 3, 28,1900 .

863. latipennis Stretch, Zyg. Bomb. N. A., 133, 1872; HaMPson, C. no. 1706.

Atl. States.

864. rubra Neumoegen, Pap., i, 79, 1881; Hampson, C. no. 1797 .

No. Pac. States.

a. walsinghami Butrer, Ann. Mag. Nat. Hist., (5), viii, 311, 1881.

b. danbyi Neumoegen, Ent. News, iv, 141, 1893.

865. vagans Boisduval, Ann. Soc. Ent. Fr., (2), x, 322, 1852; Hampson, C. no. 1796.

Pac. States.

syn. pteridis Hr. EDWARDs, bicolor WALKER,

Trans. Ent. Soc. Lond., (3), i, 270, 1862.

a. rufula Boisduval, Bull. Soc. Ent. Fr., (3), iii, 32,1855 .

syn. punctata PACKARD, proba Hy. EDwards.

\section{M $E$ NAS Hübner.}

Hübner, Verz. bek. Schmett., 167, 1827; Hampson, C. 247.

866. vestalis PaCkard, Proc. Ent. Soc. Phil., iii, 125, 1864; Hampson, C. no. 1680.

Pac.

a. amelaina Dyar, Psyche, vi, 512, 1893.

NEOARCTIA Neumoegen \& Dyar.

Neumoegen \& Dyar, Ent. News, iv, 141, 1893; Hampson, C. 233.

867. brucei Hy. Edwards, Ent. Amer., iii, 183; Hamp-

Col. son, C. no. 1666.

868. beanii Neumoegen, Can. Ent., xxiii, 123, 1891; Hampson, C. no. 1670.

No. Rocky a. fuscosa Neumoegen, Can. Ent., xxiii, 124, 1891.

*869. yarrowi Stretch, Zyg. Bomb. N. A., 221, 1873; Hampson, C. no. 1671. Mts. a. remissa Hy. Edwards, Ent. Amer., iii, 184, 1888. 
HYPHORAIA Hïbner.

Hüвner, Verz. bek. Schmett., 182, 1822; Hampson, C. 232.

870. lapponica Thunberg, Diss. Ent., ii, 40, 1791; Hampson, C. no. 1635.

syn. hyperborea Curtis, alpina Quensel, thulea

DALMAN, avia HüBNER.

871. subnebulosa Dyar, Ent. News, x, 130, 1899; Hampson, C. no. 1635 a.

Aretic

Am.

872. parthenos Harris, Agassiz's Lake Sup., 309, pl. 7, f. 4, 1850; Hampson, C. no. 1639.

syn. borealis Möschler.

\section{PLATYPREPIA Dyar.}

DyAR, Can. Ent., xxix, 215, 1897.

873. virginalis Boisduval, Ann. Soc. Ent. Fr., (2), x, 321, 1852; Surth, Can. Ent., xxi, 215, 1889.

No. Pac. States, Col.

syn. ochracea STRETCH.

a. guttata Boisduval, Ann. Soc. Ent. Fr., (2), x, 321,1852 .

APANTESIS Walker.

Walker, Cat. Brit. Mus., iii, 631, 1855; Hampson, C. 395.

874. virgo Linneus, Syst. Nat., 501, 1758; Hampson, C. no. 1948.

Atl.

a. citrinaria Neumoegen \& Dyar, Ent. News, iv, States. $142,1893$.

875. virguncula Kirby, Faun. Bor. Am., iv, 304, 1837; Hampson, C. no. 1957; Gibson, Can. Ent., xxxiii, No. Atl. States. $325,1901$.

$$
\text { syn. speciosa Möschler. }
$$

a. otiosa Neumoegen \& Dyar, Ent. News, iv, 142, 1893.

876. michabo Grote, Can. Ent., vii, 197, 1875; НАмРson, C. no. 1951.

a. minea Slosson, Ent. News, iii, 257, 1892.

Atl. States.

So. Atl.

States.

Neumoegen \& Dyar, Jn. N. Y. Ent. Soc., ii, 7. 1894.

a. stretchii Grote, Can. Ent., vii, 197, 1875.

878. parthenice Kirby, Faun. Bor. Am., iv, 204, 1837;

Hampson, C. no. 1949.

No. Atl.

States.

syn. saundersii Grote.

a. approximata Stretch, Ent. Amer., i, 104, 1885. 
879. oithona Strecker, Lep. Rhop. Het., 131, 1877.

a. rectilinea French, Can. Ent., xi, 45, 1879; Haypson, C. no. 1950.

880. anna Grote, Proc. Ent. Soc. Phil., ii, 433, 1863; Hampson, C. no. 1955 .

a. persephone Grote, Proc. Ent. Soc. Phil., ii, $433,1863$.

881. ornata Packard, Proc. Ent. Soc. Phil., iii, 114, 1864; Hampson, C. no. 1953.

syn. simplicior Butler, perpicta Dyar.

a. achaia Grote \& Robinson, Trans. Am. Ent. Soc., i, 334, 1867.

syn. edwardsii Stretch.

b. ochracea Stretch, Zyg. Bomb. N. A., 125, 1872. syn. barda Hy. Edwards.

882. arge Drury, Ill. Exot. Ent., i, 35, 1770; Hampson, C. no. 1952.

syn. dione FABricius, incarnatomibra GoEze, colebs Martyn, nerea Boisduval, doris BoisDUVAL.

a. nervosa Neumoegen \& Dyar, Ent. News, iv, $142,1893$.

883. quenselii Paykull, Act. Hafn., ii, 99, 1793; Hampson, C. no. 1956.

syn. strigosa Fabricius, gelida Möschler, liturata Ménétries, complicata WaLKer.

a. turbans Christoph, Iris, v, 349, 1892.

*884. obliterata Stretch, Ent. Amer., i, 105, 1885; Hampson, C. no. 1954.

885. proxima Guérin-Méneville, Icon. Reg. An., ii, 514, 1844; Hampson, C. no. 1958.

syn. docta WaLKer, mexicana Grote \& RobINSON, arizonensis STRETCH, mormonica NEUMOEGEN.

a. autholea Boisduval, Ann. Soc. Ent. Belg., xii, $76,1869$.

*886. cervinoides Strecker, Proc. Acad. Nat. Sci. Phil., xxviii, 151, 1876; Hampson, C. no. 1962.

887. blakei Grote, Proc. Ent. Soc. Phil., iii, 523, 1864.

syn. bolanderi Stretch; Hampson, C. no. 1959.

888. nevadensis Grote \& Robinson, Proc. Ent. Soc. Phil., vi, 1, 1866; Hampson, C. no. 1961.

syn. behrii STRETCH.

a. incorrupta Hy. Edwards, Pap., i, 38, 1881.

syn. shastaensis French.
Atl. States,

Miss.

Vall.

Atl.

States.

Pac.

States.

U.S.

Aretic Am., Eur.

(Unknown.)

So. Cal. to Utah, Mex.

Col.

Rocky Mts., Cal.

Rocky Mts. to Pacific. 
b. superba Stretch, Zyg. Bomb. N. A., 227, 1873;

Hampson, C. no. 1963.

syn. geneura STRECKER.

c. sulphurica Neumoegen, Ent. Amer., i, 93, 1885.

syn. ochracea Neumoegen, elongata Stretch.

889. williamsii Dodge, Can. Ent., iii, 167, 1871.

syn. villiamsi Hampson, C. no. 1964.

Rocky

a. determinata Neumoegen, Pap., i, 28, 1881.

syn. dieckii Neumoegen.

890. phyllira Drury, Ill. Exot. Ent., i, 15, 1770; Hampson, C. no. 1965.

syn. b-ata Goeze, plantaginis Martrn, dodgei

Butiar.

a. excelsa Neumoegen, Pap., iii, 70, 1883.

syn. lugubris Hulst.

b. favorita Neumoegen, Ent. Amer., vi, 173 , 1890; Hampson, C. no. 1960.

891. celia SAunders, Proc. Ent. Soc. Phil., ii, 59, 1863.

syn. franconica Hy. EDwards.

892. figurata Drury, Ill. Exot. Ent., ii, pl. 12, f. 4, So. States. 1770 .

syn. ceramica HüBNer, f-pallida STRECKER.

893. placentia Sмiтh \& Aввот, Lep. Ins. Ga., ii, pl. 65.

1797; Hampson, C. no. 1968.

a. snowi Grote, Can. Ent., vii, 197, 1875.

syn. quadranotata STRECKER.

b. flammea Neumoegen, Pap., i, 9, 1881.

894. nais Drury, Ill. Exot. Ent., i, pl. 7, f. 3, 1770; Hampson, C. no. 1967.

Atl. States.

syn. cuneata Goeze, defloriana Martyn, ochreata, Butler.

895. vittata FABricius, Mant. Ins., ii, 127, 1787; Hampson, C. no. 1966.

a. radians WALker, Cat. Brit. Mus., iii, 632, 1855. syn. colorata WALKER, incompleta ButLER.

b. phalerata Harris, Cat. Ins. Mass., 73, 1837. syn. rhoda ButLer. 
KODIOSOMA Streteh.

Stretch, Zyg. Bomb. N. A., 67, 1872; Hampson, C. 413.

896. fulva Stretch, Zyg. Bomb. N. A., 67, 1872;

Hampson, C. no. 1970.

a. nigra Stretch, Zyg. Bomb. N. A., 68, 1872.

b. eavesii Stretch, Zyg. Bomb. N. A., 69, 1872.

c. tricolor Stretch, Zyg. Bomb. N. A., 68, 1872.

\section{ECTYPIA Clemens.}

Clemens, Proc. Acad. Nat. Sci. Phil., xii, 529, 1860; Hampson, C. 475.

897. bivittata Clemens, Proc. Acad. Nat. Sci. Phil., Tex. xii, 529, 1860; Hampson, C. no. 2076.

syn. nigroflava GraEF.

*898. thona Strecker, Lep. Rhop. Het., suppl., 4, 1899; Hampson, C. no. 2075.

New

Mex.

\section{EUVERNA Neumoegen \& Dyar.}

Neumoegen \& Dyar, Ent. News, iv, 141, 1893; Hampson, C. 457.

899. clio Packard, Proc. Ent. Soc. Phil., iii, 120, 1864; Rocky Mts., Hampson, C. no. 2053. So. Cal.

a. jessica BARnes, Can. Ent., xxxii, 45, 1900.

\section{PARASEMIA Hübner.}

HüBner, Verz. bek. Schmett., 121, 1822; Hampson, C. 458.

900. plantaginis Linnæus, Syst. Nat., i, 501, 1758; Hampson, C. no. 2054.

No. Pac. States, Eur.

syn. alpicola Scopoli, hospita Denis \& SchifFERMÜLLER, matronalis FrEY, caucasica HERRICH-SCHAEFFER, petrosa W ALKER, nictitans Ménétries, cespitalis Grote \& Robinson, chicorii Grote \& Robinson, macromera ButLER, leucomera BuTLER, melanomera BuTLER, selwynii Neumoegen, floceosa Graeser, syfamia Grumm-Grshimaïlo, melas Christoph, flava KILIAN.

a. modesta Packard, Proc. Ent. Soc. Phil., iii, $113,1864$.

b. scudderi Packard, Proc. Ent. Soc. Phil., iii, 113, 1864.

c. geometrica Grote, Proc. Ent. Soc. Phil., iv, 318, 1865 .

d. geddesi Neunoegen, Pap., iii, 137, 1883. 
LERINA Walker.

Walker, Cat. Brit. Mus., ii, 477, 1854.

901. incarnata WaLker, Cat. Brit. Mus., ii, 477, 1854; Druce, Biol. Cent. Am., Lep. Het., ii, 394, pl. 77, f. 14,1897 .

syn. robinsomii Boisduval; Neumoegen \& Dyar, Jn. N. Y. Ent. Soc., i, 107. 1893.

Mex., Ariz.?

\section{PYGOCTNUCHA Grote.}

Grote, Trans. Kans. Acad. Sci., viii, 46, 1883; Protosia Hampson, C. ii, 255, 1900.

902. terminalis WaLker, Cat. Brit. Mus., ii, 478, 1854. Mex., Ariz. syn. harrisii Boisduval, Ann. Soc. Ent. Belg., xii, 72, 1869; pyrrhoura Hulst., votiva Hy. Edwards; Neumoegen \& Dyar, Jn. N. Y. Ent. Soc., i, 107, 1893.

*903. funerea Grote, Trans. Kans. Acad. Sci., viii, 46, 1883.

N. Mex.

ARCTIA Sehrank.

Schrank, Faun. Boica, ii, (2), 151, 1802; Hampson, C. 463.

904. caia Linnæus, Syst. Nat., 500, 1758; Hampson, C. no. 2059.

No. U.S., Eur.

syn. erinacea Retzius, phrosoma Butler, orientalis Moore.

a. americana Harris, Rep. Ins. Mass., 246, 1841.

b. wiskotti Staudinger, Hor. Ent. Soc. Ross., xiv, 333, 1878.

syn. utahensis Hy. EDwards, auripennis But-

LER, transmontana NEUMOEgeN \& DYAR.

c. opulenta Hy. Edwards, Pap., i, 30, 1881.

AMMALO Walker.

Walker, Cat. Brit. Mus., iii, 622, 1855; Hampson, C. 83.

905. tenera HüBner, Zutr. exot. Schmett., i, 7, f. 3, 4, 1818; Hampson, C. no. 1340.

Atl.

syn. collaris Fitch, antica WALKER.

a. sciurus Boisduval, Ann. Soc. Ent. Belg., xii, $79,1869$.

syn. yosemitx Hy. Edwards.

906. insulata W ALker, Cat. Brit. Mus., iii, 734, 1855; Haypson, C. no. 1339.

Fla., Antilles.

syn. cadaverosa Grote, affinis Grote, aurata Butler. 
907. eglenensis Clemens, Proc. Acad. Nat. Sci. Phil., xii, 533, 1860; Hampson, C. no. 1341.

So. Atl.

a. inopinatus Hy. Edwards, Pap., ii, 13, 1882.

states.

\section{EUCHATIAS Lyman.}

Lyman, Can. Ent., xxxiv, 27, 1902; Euchxtes Harris (not Dejean), Rep. Ins. Mass., 257, 1841; Hampson, C. 417.

908. murina Stretch, Ent. Amer., i, 106, 1885; НАмеTex. son, C. no. 1983.

909. bolteri Stretch, Ent. Amer., i, 106, 1885; HaмpTex. son, C. no. 1984.

syn. oscepsiformis GraEF.

910. egle Drury. Ill. Exot. Ent., ii, pl. 20, f. 3, 1773; Hampson, C. no. 1985.

Atl. a. cyclica Hy. Edwards, Pap., iii, 148, 1883.

911. oregonensis STRETCH, Zyg. Bomb. N. A., 187, 1873; Hampson, C. no. 1986.

No. States.

Tex.

912. pudens Hy. Edwards, Pap., ii, 126, 1882; НAмpson, C. no. 1987.

913. perlevis Grote, Can. Ent., xiv, 196, 1882; НАмрson, C. no. 1981.

*914. antica Walker, Cat. Brit. Mus., vii, 1708, 1856; Hampson, C. no. 1979.

syn. zonalis Grote.

914. 1. expressa Hr. Edwards, Pap., iv, 60, 1881; Hampson, C. no. 1982.

Ariz., Mex.

\section{PYGARCTIA Grote}

Grote, Can. Ent., iii, 124, 1871; Hampson, C. 415.

915. abdominalis Grote, Can. Ent., iii, 124, 1871; HAMPSON, C. no. 1975.

916. vivida Grote, Pap., ii, 131, 1882; Hampson, C. no. 1974 .

917. spraguei Grote, Can. Ent., vii, 200, 1875; НAмpson, C. no. 1973.

Fla.

syn. conspicua NEUMOEgEN.

918. elegans Stretch, Zyg. Bomb. N. A., 189, 1873; HaMpson, C. no. 1976.

Cal., Ariz.,

a. roseicapitis Neumoegen \& Dyar, Jn. N. Y. Ent. Soc., i, 166, 1890. 


\section{HALISIDOTA Hübner.}

Hüвner, Verz. bek. Schmett,, 170, 1822; Hampson, C. 145.

919. tessellaris Sмптн \& Аввот, Lep. Ins. Ga., ii, 149, 1797; Hampson, C. no. 1498.

Atl.

syn. antiphola WaLsH.

920. harrisii Walsh, Proc. Ent. Soc. Phil., iii, 430, 1864.

States.

921. cinctipes Grote, Proc. Ent. Soc. Phil., v, 242, 1865: HaMpson, C. no. 1497. syn. davisii Hy. EDwards.

Atl.

States.

Fla., Tex.,

Ariz..

So. Am.

922. maculata Harris, Rep. Ins. Mass., 259, 1841; Hampson, C. no. 1481.

No. Atl.

syn. fulvollava WALKER, guttifera HERrichSCHAEFFER.

a. angulifera W ALker, Lord's Trav. Vanc., ii, $355,1866$.

syn. alni Hy. EDwards.

b. agassizii Packard, Proc. Ent. Soc. Phil., iii, 128,1864 .

syn. californica WALKER, salicis BoIsDUVAL.

923. caryæ Harris, Rep. Ins. Mass., 258, 1841; Haмpson, C. no. 1479.

States.

syn. annulifascia WALKER, porphyria HERRICH-SCHAEFFER.

*924. pura Neumoegen, Pap., ii, 133, 1882; Hampson, C. no. 1508 .

925. longa Grote, Can. Ent., xii, 213, 1880; НАмрson, C. no. 1508.

*926. otho Barnes, Can. Ent., xxxiii, 53, 1901.

No. Pac.

States, Rocky Mts.

Cal.

Atl.

States.

Ariz.

Fla.

Ariz.

HYPOCRISIAS Hampson.

Hampson, Cat. Lep. Phal. Brit. Mus, iii, 216, 1901.

*927. minima Neumoegen, Pap., iii, 138, 1887; Hampson, C. no. 1628.

syn. armillata Hy. EDwARDs.

\section{HEMIHYALEA Hampson.}

Hampson, Cat. Lep. Phal. Brit. Mus., iii, 129, 1901.

925. edwardsii Packard, Proc. Ent. Soc. Phil., iii, 129, 1864; Hampson, C. no. 1437.

Cal.

syn. translucida WaLKER, quercus BOISDUVAL.

929. labecula Grote, Pap., i, 174, 1881; Hampson, C. no. 1438 .

Col. 


\section{EUSCHAUSIA Dyar.}

Dyar, Can. Ent., xxix, 209, 1897.

930. argentata Packard, Proc. Ent. Soc. Phil., iii, 129, 1864; Hampson, C. no. 1476.

a. subalpina French, Can. Ent., xxii, 47, 1890.

b. sobrina STRETCH, Zyg. Bomb. N. A., 87, 1873.

No. Pac.

States.

Col.

Cal.

*931. mixta Neumoegen, Pap., ii, 133, 1882; Hampson, C. no. 1479 , subsp. 2.

Ariz.

932. ingens Hy. Edwards, Pap., i, 39, 1881; Hampson, C. no. 1477.

Rocky

Mts.

syn. scapularis STRETCH.

\section{EMILIA Kirby.}

Kirby, Cat. Lep. Het., i, 218, 1892; Hampson, C. 182.

933. ambigua Strecker, Proc. Dav. Acad. Sci., ii, 272, 1878; Hampson, C. no. 1554.

Rocky

Mts.

syn. bolteri Hy. Edwards, syracosia DrucE.

*934. roseata Walker, App. Lord's Trav. Vanc., 336, 1866; Hampson, C. no. 1555.

Pac.

States.

syn. cinnamomea BoIsDuvaL, sanguivenosa Neumoegen.

a. significans Hy. Edwards, Ent. Amer., iii, 182, 1888.

*935. occidentalis Frexch, Can. Ent., xxii, 46, 1890. Rocky Mts.

EUPSEUDOSOMA Grote.

Grote, Proc. Ent. Soc. Phil., v, 240, 1865; Hampson, C. 27.

936. involutum SEPP, Surin. Vlind., iii, pl. 115, 1852; Hampson, C. no. 1229.

So. Am., Fla.

syn. nived Herrich-Schaeffer.

a. floridum Grote, Can. Ent., xiv, 187, 1882.

syn. immaculata Graef.

\section{CALIDOTA Dyar.}

Dyar, Proc. U. S. Nat. Mus., xxiii, 368, 1900; Hampson, C. 432.

937. strigosa Walker, Cat. Brit. Mus., iii, 736, 1855; Hampson, C. no. 2004.

Fla.,

syn. cubensis Grote, laquecita Hy. Edwards.

938. muricolor Dyar, Jn. N. Y. Ent. Soc., vi, 38, 1898;

HaMpSON, C. no. 2011.

Antilles.

Ariz. 
939. zella DyAR. (Brownish gray, a slightly angular Ariz. yellowish discal dot; hind wing subhyaline, whitish; abdomen crimson above with small dorsal black points; exp. $25 \mathrm{~mm}$.)

\section{BERTHOLDIA Sehaus.}

Schaus, Jn. N. Y. Ent. Soc., iv, 137, 1896; Hampson, C. 78.

940. trigona Grote, No. Am. Ent., i, 46, 1879; Намгson, C. no. 1332.

Col., N. Mex.

PHEGOPTERA Herrich-Schaeffer.

Herrich-Schaeffer, Auss. Schmett., 16, 1850; Hampson, C. 117.

941. astur Cramer, Pap. Exot., ii, pl. 120, f. B, 1779; Ariz., Mex., Hampson, C. no. 1433.

So. Am.

syn. albicans WALKER, maculicollis WALKER, pustulata PACKARD.

\section{Family AGARISTID E.}

\section{(C. = Hampson, Cat. Lep. Phal. Brit. Mus., iii, pp. 515-663, 1901.)}

\section{MISA Karseh.}

Karsch, Ent. Nach., 349, 1895; Hampson, C. 622.

942. sabulosa Boisduval, Rev. Zool., ii, (3), 106, 1874; HaMpson, C. no. 163.

Ariz., syn. noctuiformis Möschler.

\section{ANDROLOMA Grote.}

Grote, Bull. Buff. Soc. Nat. Sci., i, 30, 1873.

943. mac-cullochii Krrby, Faun. Bor. Am., iv, 301, 1837; Hanpson, C. no. 179.

Can.,

a. lorquinii Grote \& Robinson, Trans. Am. Ent. Rocky Mts.

Soc. i, 328, 1868.

944. similis Stretch, Zyg. Bomb. N. A., 14, 1872.

Cal.

syn. edwardsii BOIsDUVAL.

a. conjuncta Hy. Edwards, Pap., iii, 34, 1883.

*945. disparata Hr. Edwards, Pap., iv, 13, 1884; Hampson, C. no. 180.

Tex., Mex.

syn. gracilenta Graef, desperata Kirby.

*946. brannani Stretch, Zyg. Bomb. N. A., 8, 1872;

Cal. HaMpson, C. no. 181. 
ALYPIA Hübner.

Hübner, Verz. bek. Schmett., 351, 1825; Hampson, C. 635.

947. ridingsii Grote, Proc. Ent. Soc. Phil., iii, 521, 1864; Hampson, C. no. 179.

Rocky

Mts,

948. mariposa Grote \& Robinson, Trans. Am. Ent.

Cal. Soc., i, 329, 1868; Hampson, C. no. 185.

a. lunata Stretch, Zyg. Bomb. N. A., 15, 1872.

949. octomaculata FABricius, Syst. Ent., 830, 1775; Hampson, C. no. 182.

Atl. States.

syn. bimaculata GmeLrs, quadriguttalis HüB-

NER, matuta HY. EDWARDS.

a. albomaculata Stoll, Pap. Exot., pl. 345, f. C, 1782 .

950. wittfeldii Hy. Edwards, Pap., iii, 34, 1883.

Fla.

*951. dipsaci Grote \& Robinson, Trans. Am. Ent. Soc., i, 326, 1868; Hampson, C. no. 183.

Tex.,

Mex.

952. langtonii Couper, Can. Nat., (2), ii, 64, 1865; Hampson, C. no. 184.

Can., Cal.

syn. sacramenti Grote \& Robinson, hudsonica Hy. EDwards.

\section{ALYPIODES Grote.}

Grote, Trans. Kans. Acad. Sci., viii, 46, 1883; Hampson, C. 641.

953. bimaculata Herrich-Schaeffer, Ausser.Schmett., f. 26, 1853; Hampson, C. no. 187.

So. Cal., Mex., N.Mex.

syn. trimaculata Boisduval.

a. crescens Walker, Cat. Brit. Mus., vii, 1774

1856.

syn. grotei Boisduval, flavilinguis Grote.

b. dugesii Cockerell, Ent. News, vi, 201, 1895.

PSEUDALYPIA Hy. Edwards.

Hy. Edwards, Proc. Cal. Acad. Sci., v, 101, 1874; Hampson, C. 634.

*954. crotchii Hy. Edwards, Proc. Cal. Acad. Sci., v,

Cal.

101, 1874; Hampson, C. no. 178.

a. atrata Hy. Edwards, Pap., iv, 121, 1884.

955. geronimo BARnes, Can. Ent., xxxii, 44, 1900.

Ariz.

\section{COPIDRYAS Grote.}

Grote, Can. Ent., viii, 99, 1876.

956. gloveri Grote \& Robinson, Trans. Am. Ent. Soc., ii, 185, 1868; Hampson, C. no. 154.

Tex.,

Ariz.

$$
4630-\mathrm{No}, 52-02-7
$$


Family NOCTUID \&.

(C.=Sмrth, Bull. 44, U. S. Nat. Mus., 1893.

Subfamily NOCTUINAE.

PANTHEA Hübner.

Hüвner, Verz. bek. Schmett., 203, 1816; Sмith, C. 31.

957. furcilla Packard, Proc. Ent. Soc. Phil., iii, 374, 1864; Smith, C. 31; Smith \& Dyar, Proc. U. S. Nat. Mus., xxi, 15, 1898.

958. portlandia Grote, Mitth. Roem. Mus. Hild., 14, 1896: Sмith \& Dyar, Proc. U. S. Nat. Mus., xxi, $17,1898$.

959. gigantea French, Can. Ent., xxii, 134, 1890; Smith, C. 31; Smith \& Dyar, Proc. U. S. Nat. Mus., xxi, 16, 1898.

960. acronyctoides Walker, Can. Nat. Geol., vi, 37, 1861; Smith, C. 31; Smith \& Dyar, Proc. U. S. Nat. Mus., xxi, 18, 1898.

syn. leucomelana Morrison, cucomelana SMith, C. 31.

\section{DEMAS Stephens.}

Stephens, Ill. Brit. Ent., Haust., ii, 59, 1829.

961. propinquilinea Grote, Trans. Am. Ent. Soc., iv, 293, 1873; Smith C. 32; Sмith \& Dyar, Proc. U. S. Nat. Mus., xxi, 20, 1898.

962. flavicornis Syrth, Bull. Brook. Ent. Soc., vii, 3, 1884; Sмmth \& Dyar, Proc. U. S. Nat. Mus., xxi, $22,1898$.

963. palata Grote, Can. Ent., xii, 258, 1880; Sмrth, C. 31; Suith \& Dyar, Proc. U. S. Nat. Mus., xxi, 23, 1898.

Atl.

States.

Pac.

States.

Col.

Atl. States.

Atl.

States.

Atl.

States.

Col., Ariz.

CHARADRA Walker.

k Walker, Cat. Brit. Mus., xxxii, 445, 1865.

964. deridens Guenée, Spec. Gén., v, 35, 1852; Suith, C. 32 ; Smith \& Dyar, Proc. U. S. Nat. Mus., xxi, 25, 1898.

Atl. States.

syn. circulifera WALKER, contigua WALKER.

965. dispulsa Morrison, Proc. Bost. Soc. Nat. Hist., xvii, 213, 1874; Smith, C. 33; Sмith \& DYar, Proc. U. S. Nat. Mus., xxi, 27, 1898. 
966 decora Morrison, Proc. Acad. Nat. Sci. Phil., 55, 1875; Smith, C. 33; Smith \& Dyar, Proc. U. S. Mex., Nat. Mus., xxi, 28, 1898.

Ariz. ?

syn. felina Druce, Biol. Cent. Am., Lep. Het., ii, 471,1898 .

*967. illudens Walker, Cat. Brit. Mus., ix, 37, 1856. Mex., Fla.

syn. pythion Druce, Biol. Cent. Am., Lep. Het., i, 259, 1889; ii, 471, 1892.

RAPHIA Hübner.

HüBner, Verz. bek. Schmett., 212, 1816; Certila Walker, Cat. Brit. Mus., xxxii, 448, 1865; Saligena W Alk ER, Cat. Brit. Mus., xxxii, 605, 1865.

968. frater Grote, Proc. Ent. Soc. Phil., ii, 435, 1863;

Atl.

Smith, C. 32.

States.

syn. personata WaLker, flemosa W ALker, Cat.

Brit. Mus., xxxii, 449, 1865.

969. coloradensis Putnam-Cramer, Ent. Am., ii, 142, 1886; Smith, C. 32.

Col.,

Cal.

syn. pallula Hr. EDwards.

970. abrupta Grote, Proc. Ent. Soc. Phil., ii, 336 , 1863; SмIтн, C. 32.

Atl. States, Col.

APATELA Hiibner.

Hübner, Tent., 1810; Acronicta Ochsenheimer, Schm. Eur., iv, 62, 1816; Smith \& Dyar, Proc. U. S. Nat. Mus., xxi, 28, 1898; Trima Hü BNer, Verz. bek. Schmett., 200, 1816; Hyboma HüBner, Verz. bek. Schmett., 200, 1816; Jochara HüBner, Verz. bek. Schmett., 201, 1816; Arctomycis HüBNER, Verz. bek. Schmett., 202, 1816; Pharetra HüBNer, Verz. bek. Schmett., 202, 1816; Megacronycta Grote, Bull. Buff. Soc., i, 79, 1873; Lepitoreuma Grote, Bull. Buff. Soc., i, 80, 1873; Eulonche Grote, Bull. Buff. Soc., i, 81, 1873; Mastiphanes Grote, New Ch. List, 23, 1882; Merolonche Grote, New Ch. List, 23, 1882; Cuspidia Chapman, Ent. Rec., i, 27, 1890; Viminia Chapman, Ent. Rec., i, 26, 1890; Tricholonche Grote, Die Apateliden, 16, 1896; Philorgyia Grote, Die A pateliden, 17, 1896.

971. rubricoma Guenée, Spec. Gén., v, 49, 1852; So. Atl. Smith, C. 42; Smith \& Dyar, Proc. U. S. Nat. States. Mus., xxi, 42, 1898.

972. americana Harris, Rep. Ins. Mass., 317, 1841; SмiтH, C. 40.

Atl.

syn. acericola Guenée, Spec. Gén., v, 48, 1852; States.

Smith, C. 41; obscura Hy. Edwards, Ent. Amer., ii, 169, 1886; Smith \& DYar, Proc. U. S. Nat. Mus., xxi, 44, 1898.

973. hastulifera Sмiтн \& Aввот, Lep. Ins. Ga., ii, 183, 1797; Smith, C. 41; Smith \& Dyar, Proc. U. S. Nat. Mus., xxi, 47, 1898.

974. hesperida Suith, Ent. News, viii, 148, 1897; Sмiтн \& DYar, Proc. U. S. Nat. Mus., xxi, 49, 1898.

Atl.

States.

Pac.

States. 
975. dactylina Grote, Proc. Bost. Soc. Nat. Hist., xvi, 239, 1874; Smith, C. 40; Sмith \& Dyar, Proc. U. S. Nat. Mus., xxi, 51, 1898.

976. felina Grote, Bull. Geol. Surv. Terr., v, 208, 1880; Simth, C. 39; Sinth \& Dyar, Proc. U. S. Nat. Mus., xxi, 53, 1898.

977. frigida Sмiтh, Ent. News, viii, 148, 1897; Sмiтн \& Dyar, Proc. U. S. Nat. Mus., xxi, 54, 1898.

978. pacifica Sмiтh, Ent. News, viii, 148, 1897; Sмiтh \& Dyar, Proc. U. S. Nat. Mus., xxi, 56, 1898.

979. insita Walker, Cat. Brit. Mus., ix, 61, 1856; Sirth, C. 41; Sмith \& Dyar, Proc. U. S. Nat. Mus., xxi, 56, 1898.

980. canadensis Sirth \& Dyar, Proc. U. S. Nat. Mus., xxi, 57, 1898; Surth, Can. Ent., xxxii, 334, 1900.

981. cretata Sмiтh, Ent. News, viii, 148, 1897; Ммптн \& Dyar. Proc. U. S. Nat. Mus., xxi, 58, 1898.

982. leporina Linveus, Syst. Nat., 109, 1766; Sмiтh \& Dyar, Proc. U. S. Nat. Mus., xxi, 59, 1898.

syn. vulpina Grote; Surth, C. 40; sancta Hy. EDWARDS.

983. populi Riley, 2d Rept. Ins. Mo., 119, 1870; Sмith, C. 40; Smith \& Dyar, Proc. U. S. Nat. Mus., xxi, $61,1898$.

984. lepusculina Guenée, Spec. Gén., v, 46, 1852; Smith, C. 39; Sirth \& Dyar, Proc. U. S. Nat. Mus., xxi, 63, 1898.

985. cinderella Sмгтн, Ent. News, viii, 149, 1897; Smith \& Dyar, Proc. U. S. Nat. Mus., xxi, 64, 1898.

986. transversata Sмптн, Ent. News, viii, 149, 1897; Smith \& Dyar, Proc. U. S. Nat. Mus., xxi, 65, 1898.

987. tota Grote, No. Am. Ent., i, 12, 1879; Sмith, C. 39; Smith \& Dyar, Proc. U. S. Nat. Mus., xxi, $66,1898$.

988. innotata Guenée, Spec. Gén., v, 50, 1852; Sirth, C. 38: Smith \& DYar, Proc. U. S. Nat. Mus., xxi, $73,1898$.

$$
\text { syn. graefii Grote. }
$$

989. betulæ Riley, Bull. Brook. Ent. Soc., vii, 2, 1884; Sirth, C. 37; Sмith \& Dyar, Proc. U. S. Nat. Mus., xxxi, 75, 1898.

Atl. States.

Pac. States.

Pac. States.

Pac. States.

Atl. States.

No. Rocky Mts.

Col.

Atl. States, Eur.

Atl. States.

Atl. States.

Rocky Mts.

Col.

Tex.

Atl. States.

Atl. States. 
990. morula Grote, Trans. Am. Ent. Soc., ii, 196, 1868; Sмith, C. 36; Simth \& Dyar, Proc. U. S. Nat. Mus., xxi, 76, 1898. syn. ulmi HaRris.

991. interrupta Guenée, Spec. Gén., v, 46, 1852. syn. occidentalis Grote \& Robinson, Proc. Ent. Soc. Phil., vi, 16, 1866; Sмiтh, C. 35; Sмiтth \& Dyar, Proc. U. S. Nat. Mus., xxi, 79, 1898.

992. lætifica Sмгтн, Ent. News, viii, 150, 1897; Sмгтн \& Dyar, Proc. U. S. Nat. Mus., xxi, 89, 1898.

993. lobeliæ Guenée, Spec. Gén., v, 44, 1852; Sinth C. 36; Sмith \& Dyar, Proc. U. S. Nat. Mus., xxi, $82,1898$.

994. furcifera Guenée, Spec. Gén., v, 44, 1852; Sмiтh, C. 37; Suith \& Dyar, Proc. U. S. Nat. Mus., xxi, 85, 1898.

995. hasta Guenée, Spee. Gén., v, 45, 1852; Surth, C. 36; Sмith \& Dyar, Proc. U. S. Nat. Mus., xxi, 87, 1898.

syn. telum GuenéE.

996. manitoba Surth, Ent. News, viii, 150, 1897; Sмгтн \& Dyar, Proc. U. S. Nat. Mus., xxi, 90, 1898.

997. thoracica Grote, No. Am. Ent., i, 94, 1879: Sмith, C. 37 ; Smith \& Dyar, Proc. U. S. Nat. Mus., xxi, 91, 1898.

998. strigulata Sмгтн, Ent. News, viii, 150, 1897; Sмгтн \& DYar, Proc. U. S. Nat. Mus., xxi, 92, 1898.

999. radcliffei Harver, Bull. Buff. Soc., ii, 270, 1875; Sirth, C. 39; Smith \& Dyar, Proc. U. S. Nat. Mus., xxi, 107, 1898.

1000. quadrata Grote, Bull. Buff. Soc., ii, 154, 1874; Smith, C. 38; Smith \& Dyar, Proc. U. S. Nat. Mus., xxi, 106, 1898.

1001. spinigera Guenée, Spec. Gén., v, 45, 1852; Sirth, C. 39 ; SMith \& Dyar, Proc. U. S. Nat. Mus., xxi, 122, 1898.

syn. harveyana Grote, Proc. Acad. Nat. Sci. Phil., 418, 1875; Smith, C. 39.

1002. clarescens Guenée, Spec. Gén., v, 5t, 1852.

syn. pruni Harris, Ent. Corr., 313, 1869: Smith, C. 44; Smith \& Dyar, Proc. U. S. Nat. Mus., xxi, 123, 1898; Sirth, Can. Ent., xxxii, 335, 1900 .

Atl.

States.

Atl. States.

Atl.

States.

Atl.

States.

Atl.

States.

Atl.

States.

Man.

N. Mex.

Col.

Atl.

States.

So.

States.

Atl.

States.

Atl. States. 
1003. hamamelis Guenée, Spec. Gén., v, 52, 1852; Smith, C. 44; Smith \& Dyar, Proc. U. S. Nat. Mus., xxi, 141, 1898.

syn. subochrea Grote, Bull. Buff. Soc., ii, 153, 1874; SмIтн, C. 42.

1004. superans Guenée, Spec. Gén., v, 53, 1852; Smith, C. 43; Sмrth \& Dyar, Proc. U. S. Nat. Mus., xxi, $119,1898$.

1005. lithospila Grote, Proc. Bost. Soc. Nat. Hist., xvi, 240, 1874; Smith, C. 45; Sмith \& Dyar, Proc. U. S. Nat. Mus., xxi, 89, 1898.

1006. tritona HübNer, Zutr. exot. Schmett., f. 107, 1818; Smith, C. 37; Suith \& Dyar, Proc. U. S. Nat. Mus., xxi, 104, 1898.

1007. connecta Grote, Bull. Buff. Soc., i, 79, 1873; Smith, C. 43; Smith \& Dyar, Proc. U. S. Nat. Mus., xxi, 115, 1898; Dyar, Jn. N. Y. Ent. Soc., vii, 253,1899 .

1008. funeralis Grote, Proc. Ent. Soc. Phil., vi, 17, 1866; Sirth, C. 43; Simth \& Dyar, Proc. U.S. Nat. Mus., xxi, 102, 1898.

1009. fragilis Guenée, Spec. Gén., v, 34. 1852; Suith \& Dyar, Proc. U. S. Nat. Mus., xxi, 94, 1898.

syn. spectans WALKER.

1010. minella Dyar, Jn. N. Y. Ent. Soc., vi, 41, 1898.

1011. paupercula Grote, Proc. Acad. Nat. Sci. Phil., 197. 1874; Syith, C. 38; SMIth \& Dyar, Proc. U. S. Nat. Mus., xxi, 97, 1898.

1012. vinnula Grote, Proc. Ent. Soc. Phil., ii, 436, 1864: SMith, C. 38; SMIth \& Dyar, Proc. U. S. Nat. Mus., xxi, 93, 1898.

1013. revellata Smith, Ent. News, viii, 150, 1897; Sмiтн \& Dyar, Proc. U. S. Nat. Mus., xxi, 112, 1898.

No. Atl. States.

No. Atl.

States.

Col.

Tex.

Atl. States.

Col.

1014. grisea Walker, Cat. Brit. Mus., ix, 56, 1856; Smith, C. 37; Smith \& Dyar, Proc. U. S. Nat. Mus., xxi, 113, 1898.

syn. pudorata Morrison.

1015. mansueta Sмrтн, Ent. News, viii, 151,1897; Sмrтн \& Dyar, Proc. U. S. Nat. Mus., xxi, 10n, 1898.

*1016. falcula Grote, Can. Ent., ix, 86, 1877; Sirth, C. 38; Smith \& Dyar, Proc. U. S. Nat. Mus., xxi, $109,1898$.

1017. parallela Grote, Can. Ent., ix, 53, 1877; Surth, C. 38; Snith \& Dyar, Proc. U. S. Nat. Mus., xxi,

Pac. States.

Miss.

Vall. $110,1898$. 
1018. afflicta Grote, Proc. Ent. Soc. Phil., ii, 438, 1864; SMith, C. 42; Sмith \& Dyar, Proc. U. S. Nat. Mus., xxi, 127, 1898.

1019. persuasa Harver, Bull. Buff. Soc., ii, 271, 1875; Sмith, C. 43; Smith \& Dyar, Proc. U. S. Nat. Mus., xxi, 130, 1898.

1020. liturata Smith, Ent. News, viii, 151, 1897; Sмiтн \& Dyar, Proc. U. S. Nat. Mus., xxi, 129, 1898.

1021. marmorata Sniтн, Ent. News, viii, 151, 1897; Smith \& Dyar, Proc. U. S. Nat. Mus., xxi, 131, 1898.

1022. albarufa Grote, Proc. Bost. Soc. Nat. Hist., xvi, 239, 1874; Smith, C. 38; SмIth \& Dyar, Proc. U. S. Nat. Mus., xxi, 134, 1898.

syn. walkeri AnDREws.

1023. increta Morrison, Proc. Bost. Soc. Nat. Hist., xvii, 131, 1874; SмIтH, C. 44; SmIth \& DYaR, Proc. U. S. Nat. Mus., xxi, 144, 1898.

1024. modica Walker, Cat. Brit. Mus., ix, 56, 1856; Smith, C. 44; SMITH \& Dyar, Proc. U. S. Nat. Mus., xxi, 138, 1898.

syn. exilis Grote.

1025. ovata Grote, Bull. Buff. Soc., i, 80, 1873; Sмith, C. 43; Smith \& Dyar, Proc. U. S. Nat. Mus., xxi, $135,1898$.

1026. brumosa Guenée, Spec. Gén., v, 52, 1852; Sмith, C. 43; Smith \& Dyar, Proc. U. S. Nat. Mus., xxi, 117,1898 .

syn. inclara Smith, Can. Ent., xxxii, 335, 1900.

1027. hæsitata Grote, Bull. Geol. Surv. Terr., vi, 575, 1882; Smith, C. 44; Smith \& Dyar, Proc. U. S. Nat. Mus., xxi, 140, 1898.

1028. retardata WALker, Can. Nat. Geol., vi, 38, 1861; Smith, C. 45; Smith \& Dyar, Proc. U. S. Nat. Mus., xxi, 145, 1898. syn. dissecta Grote \& Robinson.

1029. sperata Grote, Bull. Buff. Soc., i, 81, 1873; Smith, C. 45 ; SMith \& Dyar, Proc. U. S. Nat. Mus., xxi, 154, 1898.

1030. noctivaga Grote, Proc. Ent. Soc. Phil., ii, 437, 1864; Smith, C. 42; Smith \& Dyar, Proc. U. S. Nat. Mus., xxi, 156, 1898.

1031. impressa Walker, Cat. Brit. Mus., ix, 61, 1856; Smith, C. 41; Smith \& Dyar, Proc. U. S. Nat. Mus., xxi, 159, 1898 (larva of distans in error).

Atl.

States.

Tex.

Col.

Mont., Cal.

Atl.

States.

Atl.

States.

Atl.

States.

Atl.

States.

Atl.

States.

Atl.

States.

Atl.

States.

Atl.

States.

Atl.

States.

Atl.

States. 
sýn, fasciata W.ALKer, verrillii Grote \& RoBINSON,

1032. distans Grote, Can. Ent., xi, 38, 1879; Sмгтн \& Atl. DYar, Proc. U. S. Nat. Mus., xxi, 161, 1898 (larva of impressa in error).

1033. barnesii Smith, Ent. News, viii, 153, 1897; Sirth \& Dyar, Proc. U. S. Nat. Mus., xxi, 162, 1898.

1034. perdita Grote, Can. Ent., vi, 154, 1874; Sмith, C. 42 ; Sмith \& Dyar, Proc. U. S. Nat. Mus., xxi, $163,1898$.

1035. edolata Grote, Pap., i, 153, 1881; Sмгтн, C. 45 ; Smith \& Dyar, Proc. U. S. Nat. Mus., xxi, 164, 1898.

1036. extricata Grote, Bull. Geol. Surv. Terr., vi, 575, 1882; Sмith, C. 45; Sмith \& Dyar, Proc. U. S. Nat. Mus., xxi, 165, 1898.

1037. xyliniformis Guenée, Spec. Gén., v, 50, 1852; Sirth, C. 45; Sirth \& Dyar, Proc. U. S. Nat. Mus., xxi, 166, 1898.

syn. longa Guenée, pallidicoma Grote.

1038. emaculata Sмiтh, Ent. News, viii, 152, 1897; Smith \& Dyar, Proc. U. S. Nat. Mus., xxi, 158, 1898.

1039. impleta W ALKer, Cat. Brit. Mus., ix, 57, 1856; Sмith, Can. Ent., xxxii, 334, 1900.

syn. luteicoma Grote \& Robinson. Trans. Am. Ent. Soc., ii, 179, 1870: Suith, C. 42; Smith \& Dyar, Proc. U. S. Nat. Mus., xxi, $152,1898$.

1040. illita Sмптн, Ent. News, viii, 152, 1897: Sмптн \& Dyar, Proc. U. S. Nat. Mus., xxi, 151, 1898.

1041. oblinita Sмгтн \& Aввот, Lep. Ins. Ga., ii, 187. 1797; Sмith, C. 46; Sмith \& Dyar, Proc. U. S. Nat. Mus., xxi, 169, 1898.

syn. salicis HARRIS.

1042. lanceolaria Grote, Proc. Acad. Nat. Sci. Phil., 418, 1875; Sмith, C. 46; Sinth \& Dyar, Proc. U. S. Nat. Mus., xxi, 171, 1898.

*1043. insolita Grote, Bull. Buff. Soc., i, 82, 1873; Smith, C. 46; Smith \& Dyar, Proc. U. S. Nat. Mus., xxi, 173, 1898.

*1044. arioch Strecker, Lep. Rhop. Het., suppl. 1, 5, 1898 .

Col., B. C.

Pac.

States.

Ariz.

Tex.

Atl. States.

Pac. States.

U. S.

Atl. States.

Atl. States.

Atl. States.

La. 
*1045. gasta Strecker, Lep. Rhop. Het., suppl. 1, 5, IIl. 1898.

APHARETRA Grote.

Grote, Proc. Ent. Soc. Wash., iv, 368, 1901.

1046. dentata Grote, Can. Ent., vii, 222, 1875 ; SMrth, C. 37; Smith \& Dyar, Proc. U. S. Nat. Mus., No. Atl. xxi, $173,1898$.

1047. pyralis Sмmтн, Ent. News, vii, 26, 1896; Suптн \& Dyar, Proc. U. S. Nat. Mus., xxi, 174, 1898.

States.

Rocky Mts.

\section{ARSILONCHE Lederer.}

Lederer, Noct. Eur., 70, 1857; Sмith \& Dyar, Proe. U. S. Nat. Mus., xxi, 174, 1898.

1048. colorada Sмiтh, Proc. U. S. Nat. Mus., xxii, 414,

Col. 1900 .

1049. albovenosa Goeze, Ent. Beitr., iii, 3, 251, 1781; Smith, C. 34; Sirth \& Dyar, Proc. U. S. Nat. Mus., xxi, $175,1898$.

Atl. States, Eur.

a. fumosum Morrison, Bull. Buff. Soc., i, 275, 1873.

b. henrici Grote, Bull. Buff. Soc., i, 10, 1873.

c. evanidum Grote, Bull. Buff. Soc., i, 10, 1873.

\section{MEROLONCHE Grote.}

Grote, Ill. Essay, 50, 1882.

1050. lupini Grote, Bull. Buff. Soc., i, 79, 1873; Sмrтн, C. 35; Smith \& Dyar, Proc. U. S. Nat. Mus., Pac. xxi, $179,1898$.

1051. ursina Smith \& Dyar, Proc. U. S. Nat. Mus., xxi, $180,1898$.

*1052. spinea Grote, Bull. Buff. Soc., i, 79, 1873; Smith, C. 35; Smith \& Dyar, Proc. U. S. Nat. Mus., xxi, 179, 1898.

\section{HARRISIMEMNA Grote.}

Grote, Trans. Am. Ent. Soc., iv, 293, 1873.

1053. trisignata W ALker, Cat. Brit. Mus., ix, 29, 1856; Smith, C. 47; Smith \& Dyar, Proc. U. S. Nat. Mus., xxi, 181, 1898. 
MICROCELIA Guenée.

Guenée, Spec. Gén., v, 33, 1852.

1054. dipteroides Guenée, Spec. Gén., v, _34, 1852; SMITH, C. 48.

a. obliterata Grote, Proc. Ent. Soc. Phil., iii, 79, States. 1864.

\section{JASPIDIA Hübner.}

Hübner, Tent., 1806; Euthales Hübner; Bryophila Treitschke.

1055. lepidula Grote, 6th Rept. Peab. Acad. Sci., 23, 1874; SмITH, C. 49.

Atl. States.

*1056. nana HüBner, Zutr. exot. Schmett., f. 53, 1818; Sмiтн, C. 49.

So. States.

No.

Am.

Cal.

1058. viridata Harvey, Can. Ent., viii, 35, 1876; SuIth, C. 49 .

1059. teratophora HERRICH-SCHAEFFER, Exot.Schmett., f. 213,1853 ; Sмith, C. 49.

Atl. States.

\section{DIPHTHERA Hübner.}

Hü Bner, Tent., 1806.

1060. fallax Herrich-Schafffer, Exot. Schmett., f. 211, 1853; Sмiтh, C. 34.

Atl. States.

\section{POLYGRAMMATE Hübner.}

HüBner, Verz. bek. Schmett., 203, 1816.

1061. hebraicum HüBNER, Zutr. exot. Schmett., f. 25 , 1818; Smith, C. 48; Dyar, Proc. U. S. Nat. Mus., xxi, 9, 1898.

syn. hebræa Guenée.

\section{CERMA Hübner.}

Hübner, Verz. bek. Schmett., 207, 1816.

*1062. galva Strecker, Lep. Rhop. Het., suppl. 1, 5, 1898.

1063. cora HüBNer, Zutr. exot. Schmett., f. 59, 1818; SMith, C. 47.

syn. festa Guenée.

Atl. States.

N. Y.

Atl. States.

1064. olivacea Smith, Trans. Am. Ent. Soc., xviii, 103, 1891; C. 48. 
CYATHISA Grote.

Grote, Bull. Geol. Surv. Terr., vi, 576, 1882.

1065. percara Morrison, Proc. Bost. Soc. Nat. Hist., xvii, 213, 1874; Smith, С. 50.

Fla., Tex., Col.

Cal.

*1066. pallida Sмiтh, Jn. N. Y. Ent. Soc., x, 35, 1902.

\section{CHYTONIX Grote.}

Grote, Bull. Buff. Soc., ii, 66, 1874.

1067. palliatricula Guenée, Spec. Gén., v, 26, 1852; SмITH, C. 50.

Atl. States.

syn. iaspis Guenée.

1068. sensilis Grote, Pap., i, 49, 1881; Smith, C. 50.

1069. semifascia Sмrth, Proc. U. S. Nat. Mus., xxii, $415,1900$.

*1070. connecta Smith, Trans. Am. Ent. Soc., xxi, 42, 1894.

\section{COPIBRYOPHILA Smith.}

Smith, Proc. U. S. Nat. Mus., xxii, 416, 1900.

1071. angelica Sмгтн, Proc. U. S. Nat. Mus., xxii, 416, 1900.

\section{ALEPTINA Dyar.}

Dyar, Can. Ent., xxxiv, 105, 1902.

1072. inca Dyar, Can. Ent., xxxiv, 105, 1902.

\section{BAILEYA Grote.}

Grote, Abh. nat. Ver. Brem., xiv, 123, 1893; Leptina Guenée (not Meigen), Spec. Gén., v, 14, 1852.

1073. ophthalmica Guenée, Spec. Gén., v, 15, 1852; Smith, C. 30.

Atl.

States.

1074. australis Grote, Can. Ent., xiii, 152, 1881; Sмith, C. 30 .

Tex.,

Ala.

1075. doubledayi Guenée, Spec. Gén., v, 15, 1852; Smith, C. 30.

Atl.

States.

1076. dormitans Guenée, Spec. Gén., v, 15, 1852; No. Atl.

SмIth, C. 30.

States.

syn. latebricola Grote. 


\section{HADENELLA Grote.}

Grote, Pap., iii, 123, 1883.

1077. pergentilis Grote, Pap., iii, 123, 1883; Sмith, Wash., Col., C. 164 . Wyo.

1078. minuscula Morrison, Proc. Bost. Soc. Nat. Hist. xvii, 147, 1874; Sмith, C. 144.

Atl. States, Col.

syn. subjuncta SмIтH, Can. Ent., xxx, 323, 1898.

1079. lævigata Sмгтн, Can. Ent., xxx, 321, 1898.

Col.

\section{ACOPA Harvey.}

Harvey, Bull. Buff. Soc., ii, 279, 1874.

1080. carina Harver, Bull. Buff. Soc., ii, 279, 1874; SмITH, C. 264.

1081. perpallida Grote, Can. Ent., x, 68, 1878; Sмiтh, C. 264.

*1082. incana Hy. Edwards, Pap., ii, 128, 1882; Smith, C. 264.

*1083. pacifica Hy. Edwards, Pap., iv, 46, 1884; Smith, C. 265.

Tex.

Kans.

Ariz.

Ariz.

\section{CATABENA Walker.}

Walker, Cat. Brit. Mus., xxxii, 631, 1865; Adipsophanes Grote.

1084. lineolata Walker, Cat. Brit. Mus., xxxii, 631 , 1865; Sмiтh, C. 194.

syn. miscellus Grote.

*1085. terminellus Grote, Can. Ent., xv, 132, 1883; Suith, C. 194.

*1086. egestis Smith, Trans. Am. Ent. Soc., xxi, 77, 1894.

\section{CRAMBODES Guenée.}

Guenée, Spec. Gén., vi, 152, 1852.

1087. talidiformis GunnéE, Spec. Gén., vi, 152, 1852; Sмith, C. 194.

Atl. States, Col. syn. conjugens WALKER.

\section{PLATYSENTA Grote.}

Grote, 6th Rept. Peab. Acad. Sci., 28, 1874.

1088. videns Guenée, Spec. Gén., v, 78, 1852; Smith, C. 184.

Atl. States, Col.

syn. indigens WALKER, meskei SPEYER, atriciliata Grote. 
*1089. albipuncta Smith, Jn. N. Y. Ent. Soc., x, 46, 1902. Tex., Col.

1089. 1. angustiorata Grote, Bull. Geol. Surv. Terr., Col. vi, 584, 1882; SмIтн, C. 184.

\section{SENTA Stephens.}

Stephens, Ill. Brit. Ent., Haust., iii, 279, 1829.

1090. defecta Grote, 6th Rept. Peab. Acad. Sci., 29, 1874; Sмith, C. 183.

Atl. States.

Fla.

*1091. enervata Guenée, Spec. Gén., v, 105, 1852; Sмптн, C. 183.

syn. fodiens Guenée.

\section{BALSA Walker.}

Walker, Can. Nat. Geol., v, 250, 1860; Nolophana Grote.

1092. malana FiтcH, Rep. Ins. N. Y., i, 244, 1856:

Sмith, C. 193.

Atl.

syn. obliquifera WALKER.

1093. tristrigella W ALker, Cat. Brit. Mus., xxxv, 1734

1865; Sмiтн, C. 193.

Atl.

syn. zelleri Grote.

1094. labecula Grote, ('an. Ent., xii, 217, 1880; Sмith,

C. 194.

States.

States.

*1095. albopunctella Walker, Cat. Brit. Mus., xxxv, 1735, 1866; Sмiтн, C. 194.

1096. camina Surth, Trans. Am. Ent. Soc., xxi, 60,

Col. 1894.

1097. præacuta Sмiтн, Trans. Am. Ent. Soc., xxi, 61, 1894.

Col.

1098. discistriga Smith, Trans. Am. Ent. Soc., xxi, 61, 1894.

\section{FOTELLA Grote.}

Grote, Can. Ent., xiv, 181, 1882.

*1099. notalis Grote, Can. Ent., xiv, 181, 1882; Smith,

Ariz.

C. 195 . 


\section{ANORTHODES Smith.}

Smith, Trans. Am. Ent. Soc., xviii, 115, 1891.

1100. prima Smith, Trans. Am. Ent. Soc., xviii, 115, 1891; C. 198.

So. Atl.

States.

\section{CARADRINA Ochsenheimer.}

Ochsenheimer, Schmett. Eur., iv, 80, 1816.

1101. meralis Morrison, Can. Ent., vii, 215, 1875; Sмiтн, C. 195.

syn. bilunata Grote.

1102. multifera Walker, Cat. Brit. Mus., x, 293, 1856; SмIтH, C. 196.

syn. fidicularia Morrison

1103. exigua Hübner, Eur. Schm., 362, 1827; STAUDINGer \& Rebel, Cat. Lep. Eur., i, no. 1990, 1901.

syn. fulgens HüBNER, junceti ZeLLer, sebghana Austant, orbicularis WaLker, venosa ButLER, cilium GUENÉE, insulsa W ALKER, erica Butler, cycloides Guenée, caradrinoides W ALKER, insignata COTES \& SWINHOE, flavimaculata Harvey, Can. Ent., viii, 54, 1876; Smith, C. 168; Meyrick, Faun. Haw., i, 153, 1899.

1104. spilomela Walker, Cat. Brit. Mus., xxxii, 648, 1865 .

syn. conviva Harvey; SMIth, C. 196.

1105. extimia Walker, Cat. Brit. Mus., xxxii, 687, 1865; SмIтн, C. 196.

syn. civica Grote.

1106. mantalini Surth, Trans. Am. Ent. Soc., xxi, 77, 1894.

1107. rufostriga Packard, Proc. Bost. Soc. Nat. Hist., xi, 36, 1866; Sмmith, C. 186.

syn. punctivena Smith, Trans. Am. Ent. Soc., xxi, $77,1894$.

*1108. insipida Strecker, Lep. Rhop. Het., suppl. 3, 32,1900 .

1109. miranda Grote, Bull. Buff. Soc., i, 11, 169, 1873; Sмith, C. 195.

*1110. tarda Guenée, Spec. Gén., v, 243, 1852; Smith, C. 195 .

*1111. fragosa Grote, Pap., iii, 76, 1883; Suitı , C. 196.
Atl. States,

N. Mex.

Atl.

States.

Cal., Col., Eur., Hawaii.

Tex.

Pac. States, Col.

Col.

Lab.,

Col.

Wis.

U. S.

W. Va.

Ariz. 
*1112. derosa Morrison, Proc. Bost. Soc. Nat. Hist., xviii, 121, 1875; Sмith, C. 195.

*1113. fervens Walker, Cat. Brit. Mus., x, 266, 1856. syn. subaquila Harver; Smith, C. 196.

1114. leucorena Sмith, Proc. U. S. Nat. Mus., xxii, 477, 1900.

N. J.

Tex.

Cal.,

Ariz.

PERIGEA Guenée.

Guenée, Spec. Gén., v, 225, 1852.

1115. xanthioides Guenée, Spec. Gén., v, 227, 1852; SмITH, C. 152.

a. enixa Grote, Bull. Buff. Soc., ii, 310, 1875.

*1116. iole Grote, Proc. Bost. Soc. Nat. Hist., xviii, 414,1875 ; Sмith, C. 152.

1117. vecors Guenée, Spec. Gén., v, 230, 18.52; Sмith, C. 152 .

syn. remissa W ALKer, luxa Grote.

1118. epopea Cramer, Pap. Exot., iii, pl. 272, f. G, 1782; Sмith, C. 152.

syn. cupentina Cramer, infelix Guenée, palpalis WaLker, confederata Grote.

1119. sutor Guenée, Spec. Gén., v, 231, 1852.

syn. claufacta W ALKER; SMITH, C. 153; fabrefacta Morrison.

*1120. falsa Gpote, Can. Ent., xii, 215, 1880; Sмith, C. 153 .

1121. albolabes Grote, Can. Ent., xii, 216, 1880; SмIth, C. 154 .

*1122. punctifera Walker, Cat. Brit. Mus., x, 263, 1856; Sinth, C. 153.

Atl.

States.

Fla.

Atl. States,

Col.

So. Atl.

States.

Atl. States.

Cal.

Ariz.,

Col.

Antilles,

Fla.

*1123. loculosa Grote, Pap., i, 154, 1881; Sмith, C. 154 . Ariz., N. Mex.

*1124. fasciata Hr. Edwards, Ent. Amer., ii, 169, 1886; Ariz. Sмiтh, C. 154.

1125. alfkenii Grote, Abh. nat. Ver. Bremen, xiv, 81,1895 .

Cal.,

Ariz.

1126. pulverulenta Sмiтh, Trans. Am. Ent. Soc., xviii, 105, 1891; C. 154.

Col.

*1127. continens Hy. Edwarls, Pap., iv, 122, 1884; Ariz. Sмith, C. 154.

1128. veterata Suith Trans. Am. Ent. Soc., xxi, 62, 1894.

Col. 
1129. lucetta Sмптн, Proc. U. S. Nat. Mus., xxii, 474, 1900 .

*1130. cervina Smith, Proc. U. S. Nat. Mus., xxii, 475, 1900 .

1131. texana Sмптн, Proc. U. S. Nat. Mus., xxii, 476 , 1900 .

1132. consors Sмiтh, Proc. U. S. Nat. Mus., xxii, 477 , 1900.

*1133. proxima Morrison, Proc. Bost. Soc. Nat. Hist., xviii, 240, 1875; SмIтн, C. 155.

*1134. mersa Morrison, Proc. Bost. Soc. Nat. Hist., xviii, 120, 1875: SмIтH, C. 155.

*1135. niveirena Harvey, Can. Ent., viii, 53, 1876; SMITH, C. 154.

Col.

Fla.

Tex.

Ariz.

Tex.

Cal.

B. C.

\section{OLIGIA Hübner.}

HüBNer, Verz. bek. Schmett., 404, 1816.

1136. festivoides Guenée, Spec. Gén., v, 220, 1852; Sмiтн, C. 149.

Atl. States.

syn. varia WALKER.

1137. chalcedonia HüBner, Eur. Schmett., Noct., 404, 1815: Sмith, C. 150.

Atl. States. Col., N. Mex.

svn. vincta W ALKER, irresoluta W ALKER, arma Guenée, tracta Grote.

1138. versicolor Grote. Proc. Acad. Nat. Sci. Phil., 204, 1874: Sмгтн, C. 150.

Atl.

States.

Fla.

1139. exesa Guenée, Spec.Gén., v, 222, 1852; Smith, C. 150 .

syn. floridiana W ALKER.

1140. fuscimacula Grote, Bull. Geol. Surv. Terr., vi. 262, 1881; Sмiтh, C. 151.

Fla.,

Tex.

1141. grata HüBNER, Zutr. exot. Schmett., f. 71, 1819; SMITH, C. 151.

syn. rasilis Morrison.

1142. nucicolora Guenée, Spec. Gén., v, 24, 1852; Sмith, C. 151.

syn. unisignata W ALKER, paginata Morrison, clara HaRveY.

1143. trientiplaga WALKER, Cat. Brit. Mus., xv, 1677, 1858; Dyar, Proc. Ent. Soc. Wash., iv, 453, 1901.

Atl. States.

Fla., Tex.

syn. aduncula Felder, Reise Novara, Lep.,pl. 110, f. 4,1872 .

*1144. rubiginosa Walker, Cat. Brit. Mus, xxxii, 674. 1865 .

B. C.

Fla., So. Am. 


\section{HILLIA Grote.}

Grote, Proc. Ent. Soc. Phil., xxxi, 168, 1883.

1145. crassis Herrich-Schaeffer, Schmett. Eur., ii, 361, 1845; SмIth, C. 147.

syn. erdmani Möschler, semisigna WALKER, senescens Grote, vigilans Grote.

1146. algens Grote, Can. Ent., x, 236, 1878; Sмiтh, C. 147 .

No. Atl.

States.

Col., Eur.

Me., N. Y.,

Col.

1147. discinigra Walker, Cat. Brit. Mus., ix, 27,1856;

Can. Sмith, C. 148.

\section{HADENA Schrank.}

Schrank, Faun. Boica, ii, 2, 158, 1802; Luperina Borsduval, Ind. Méth., i, 77, 1829; Xylophasia Stephens, Ill. Brit. Ent., Haust., ii, 174, 1829; A pamea Ochsenhermer, Schm. Eur., iv, 75, 1816; Xylena HüBner, Tent., 1806; Cladocera Rambur (not Hope), Cat. Lep. And., pl. 6, 1858; Helioscota Grote, Abh. nat. Ver. Brem., xiv, 78, 1895; Achatia HüBner, Tent., 1806.

1148. evelina F Rench, Can. Ent., xx, 71, 1888; Smith, C. 141.

1149. bridghami Grote \& Robinson, Proc. Ent. Soc. Phil., vi, 17, 1866; SмrтH, C. 141.

Cal., Col.

Atl.

States.

1150. transfrons Neumoegen, Pap., iii, 139, 1883;

B. C. Smith, C. 141.

1151. violacea Grote, Bull. Geol. Surv. Terr., vi, 261, 1881; Sмптн, C. 141.

Cal.

Col.

1152. leucoscelis Grote, Sixth Rept. Peab. Acad. Sci., 26, 1874; Sмith, C. 142.

Atl. States,

Col. syn. fibulata Morrison.

1153. claudens WALKER, Cat. Brit. Mus., ix, 753, 1857; Sмith, C. 142.

No. Atl. syn. hillii Grote.

1154. paviæ BeHR in Strecker, Lep. Rhop. Het., 94, 1874; Sмith, C. 142.

States.

syn. inconspicua Smith, 142.

1155. binotata Walker, Cat. Brit. Mus., xxxii, 663, 1865; Sмiтн, C. 142.

Pac.

States.

syn. curvata Grote, extersa WALKER.

1156. adnixa Grote, Can. Ent., xii, 243, 1880; Sмпtн, C. 142 .

Nev.

1157. indirecta Grote, Can. Ent., vii, 28, 1875; Smith, Pac. States, C. 143 . 
1158. modica Gunnée, Spec. Gén., v, 207, 1852; Smith, C. 146 .

syn. subcedens W ALKER.

1159. hausta Grote, Can. Ent., xiv, 217, 1882; Sмiтh, C. 146 .

1160. characta Grote, Can. Ent., xii, 243, 1880; Sмiтh, C. 143.

1161. genetrix Grote, Can. Ent., x, 237, 1878; Smith, C. 143 .

1162. patina Harver, Bull. Buff. Soc., iii, 7, 1875; SмIтн, C. 146.

*1163. egens W ALKer, Cat. Brit. Mus., x, 263, 1856; Sмiтн, C. 144.

1164. unicincta Sмiтн, Jn. N. Y. Ent. Soc., x, 41, 1902.

1165. diversicolor Morrison, Proc. Bost. Soc. Nat. Hist., xvii, 132, 1874; Sмrтh, C. 146.

1166. mactata Guenée, Spec. Gén., v, 207, 1852; Sмiтн, C. 145.

1167. turbulenta Hüвner, Zutr. exot. Schmett., f. 67, 1820; Sмith, C. 145.

syn. arcuata WALKER.

1168. divesta Grote, Can. Ent., vi, 215, 1874; Sмiтh, C. 143 .

*1169. tusa Grote, Bull. Geol. Surv. Terr., iv, 177, 1878; Sмith, C. 143.

*1170. tonsa Grote, Can. Ent., xii, 214, 1880; Sмiтh, C. 143 .

1171. chryselectra Grote, Can. Ent., xii, 244, 1880; SMith, C. 147.

syn. benigna Hy. Edwards, Pap., iv, 122, 1884: SMITH, C. 154.

1173. fumosa Grote, Bull. Geol. Surv. Terr., v, 205, 1879; Sмith, C. 143.

*1174. tortilis Grote, Bull. Brook. Ent. Soc., iii, 46, 1880; Smith, C. 146.

1175. marina Grote, Bull. Buff. Soc., ii, 67, 1874; SмITH, C. 145.

1176. didonea Sмiтh, Trans. Am. Ent. Soc., xxi, 58, 1894.

1177. antennata Sмгтн, Proc. U. S. Nat. Mus., xiii, 439, 1890; C. 140.

1178. viridimusca Sмrтн, Can. Ent., xxi, 262, 1899.
Atl. States, Col.

No. Atl. States, N. M.

Nev., Ariz.

Nev.,

Ariz.

Tex.,

D. C.

Can., Col.

Cal.

No. Atl. States.

Atl. States, Col.

Atl.

States.

Pac. States, Col.

Cal.

Nev.

Col.

Col., Wash.

Wash.

Cal.

Col.

Cal.

Ohio. 
*1179. loda Strecker, Lep. Rhop. Het., suppl. 1, 8, Wash. 1898.

*1180. una Strecker, Lep. Rhop. Het., suppl. 3, 32, Wis. 1900.

*1181. thula Strecker, Lep. Rhop. Het., suppl. 1, 7, Wash. 1898.

1182. Iuteocinerea Sмmтн, Proc. U. S. Nat. Mus., xxii, Mont. 468,1900 .

1183. lætabilis Sмrтн, Can. Ent., xxi, 264, 1899.

1184. pausis Sмith, Can. Ent., xxi, 262, 1899.

*1185. moilena Strecker, Lep. Rhop. Het., suppl. 1, 8, 1898.

*1186. lona Strecker, Lep. Rhop. Het., suppl. 1, 8, 1898.

syn. runata SмrTh, Can. Ent., xxxi, 257, 1899.

1187. catalina Sмrтн, Can. Ent., xxi, 261, 1899.

1188. virguncula Sмiтh, Can. Ent., xxi, 259, 1899.

1189. barnesii Sмiтн, Can. Ent., xхi, 258, 1899.

1190. dionea Sмrтh, Can. Ent., xxi, 258, 1899.

*1191. satina Strecker, Lep. Rhop. Het., suppl. 1, 8, 1898.

1192. mustelina Sмгтн, Proc. U. S. Nat. Mus., xxii, 469 , 1900 .

1193. tenera Sмiтh, Proc. Wash. Acad. Sci., ii, 491, 1900.

1194. jocasta Sмптн, Proc. U. S. Nat. Mus., xxii, 470 , 1900.

1195. tela Sмiтн, Proc. U. S. Nat. Mus., xxii, $470,1900$.

1196. tapeta Sмiтh, Proc. U. S. Nat. Mus., xxii, 467 , 1900.

*1197. cluna Strecker, Lep. Rhop. Het., suppl. 1, 7, 1898.

1198. allecto Sмгтн, Can. Ent., xхi, 260, 1899.

1199. versuta Sмiтh, Ent. News, vii, 27, 1896.

*1200. dilara Strecker, Lep. Rhop. Het., suppl. 1, 7, 1898.

N. Mex.

Cal.

Col.

Wash.,

Man.

Ariz.

Col.

So. Dak., Col.

So. Dak.

Anticosti.

Cal.

Alaska.

Dak.,

IIl.

Ariz.

Fla.

IIl.

B. C., Man., Dak.

Aiberta.

Col.

1201. ethnica Sмiтн, Can. Ent., xxi, 263, 1899.

Cal. 
1202. miseloides Guenée, Spec. Gén., vi, 89, 1852; Sмптн, C. 145; Jn. N. Y. Ent. Soc., x, 39, 1902. a. miscellus Sirth, Jn. N. Y. Ent. Soc., x, 40, 1902.

1203. macerata Sмптн, Jn. N. Y. Ent. Soc., x, 40, 1902.

*1204. chlorostigma Harver, Can. Ent., viii, 53, 1876; Sirti, C. 145.

1205. semicana WaLker, Cat. Brit. Mus., xxxii, 675, 1865 ; Sмiтh, C. 144.

syn. vulvivaga Morrison.

a. fractilinea Grote, Can. Ent., vi, 15, 1874; Sмith, C. 144.

b. modiola Grote, Bull. Geol. Surv. Terr., v, 204, 1879 .

1206. misera Grote, Bull. Geol. Surv. Terr., vi, 582, 1882; SмITH, C. 144.

1207. cylindrica Grote, Can. Ent., xii, 214, 1880; Sмiтн, C. 146.

1208. basilinea Fabricius, Mant. Ins., 183, 1787; Staudinger \& Rebel, Cat. Lep. Eur., i, no. 1710, 1901.

a. cerviana Sмiтh, Can. Ent., xxxii, 220, 1900.

*1209. smaragdina Neumoegen, Pap., iii, 140, 1883; SMITH, C. 145.

1210. niveivenosa Grote, Bull. Geol. Surv. Terr., v, 206, 1879; Sмiтh, C. 131.

1211. stipata Morrison, Proc. Acad. Nat. Sci. Phil., 64, 1875; Sмiтн, C. 131.

1212. passer Guenée, Spec. Gén., v, 195, 1852; Suith, C. 131.

syn. incallida W ALKER, loculata Morrison, viral is GROTE.

a. conspicua Morrison, Bull. Buff. Soc., ii, 110, 1874.

1213. trigona Sмiтh, Jn. N. Y. Ent. Soc., x, 39, 1902.

1214. burgessi Morrison, Bull. Buff. Soc., ii, 109, 1874; Sмith, C. 132. syn. discors Grote.

1215. longula Grote, Bull. Geol. Surv. Terr., v, 204, 1879; Sмiтh, C. 132.

1216. contradicta Sмгтн, Ent. News, vii, 28, 1896.

Rocky Mts., Kans., Wash.

Alberta.

Atl.

States.

Nev.

N.-W. Pac. States, Eur.

Ariz.

Mont., Col.

No. Atl. States.

No. Atl.

States, Col., Oreg.

Tenn.

Mass., Ariz., Nebr. 
1217. remissa HüBNER, Eur. Schmett., Noct., 423, 1812; SMith, C. 132.

Atl.

States.

syn. indocitis WALKER.

1218. separans Grote, Bull. U.S. Geol. Surv. Terr., vi, 260, 1880; SмIтH, C. 133.

N. Y..

Wis.

1219. suffusca Morrison, Proc. Acad. Nat. Sci. Phil., 61, 1875; Sмiтh, C. 133.

Atl. States, Col.

1220. vultuosa Grote, Proc. Acad. Nat. Sci. Phil., 420, 1875; Smith, C. 134.

Atl.

States.

1221. apamiformis Guenée, Spec. Gén., v, 137, 1852; Sмiтt, C. 133.

syn. contenta WALKER.

1222. exornata Möschler, Wien. ent. Mon., iv, 364, 1864; Sмith, C. 134.

1223. morna Strecker, Rep.Ch. Eng., Ruffner, v, 1861, 1879; Sмith, C. 134.

syn. hulstii Grote, No. Am. Ent., i, 93, 1880; Sмiтh, C. 134.

1224. finitima Guenée, Spec. Gén., v, 206, 1852; Surth, C. 134 .

1225. lateritia HüBner, Berl. Mag., iii, 306, 1767; Sirth, C. 134.

syn. molochina HüBNer, obliviosa WALKer.

1226. cogitata Sмгтн, Proc. U. S. Nat. Mus., xiii, 421 , 1890; C. 135 .

1227. dubitans W ALKer, Cat. Brit. Mus., ix, 232, 1856; Sмiтн, C. 135.

syn. insignata WALKer, sputatrix Grote.

1228. plutonia Grote, Can. Ent., xv, 9, 1883; Sмптн, C. 135 .

1229. alticola Sмптн, Proc. U. S. Nat. Mus., xxiii, 423 , 1890; C. 136.

1230. ducta Grote, Bull. Geol. Surv. Terr., iv, 176, 1878; Sмith, C. 136.

Atl. States,

Col.

Lab.,

Col.

Col.

No.

U. S.

No. U. S.,

Eur.

No.

U. S.

No. Atl.

States.

Me.,

Wis.

Col.

No.

U. S.

Atl.

States.

SмITH, C. 136.

a. mixta Grote, Bull. Geol. Surv. Terr., vi, 264, 1880 .

1232. devastatrix Brace, Am. Jn. Sci., i, 154, 1819; Sмiтth, C. 136.

U. S.

syn. ordinaria WALKER, contenta WALKER, marshallana Westwood. 
1233. exulis Lefk̀bre, Ann. Soc. Ent. Fr., v, 393, 1836; Sмiтh, C. 137.

Lab., Greenl.

syn. gelata LeFèBre, groenlandica ZetTERSTEDT, marmorata ZETTERSTEDT, diffua Geyer, gelida Guenée, poli Guenée, borea Guenée.

*1234. sommeri Léfèbre, Ann. Soc. Ent. Fr., iii, 391, 1836; Sмith, C. 137.

Lab., Greenl.

1235. arctica Boisduvat, Gen. Ind. Méth., 120, 1840; Sмiтн, C. 137.

syn. amputatrix Fiтсн.

1236. albina Grote, Bull. Buff. Soc., ii, 157, 1874; Sмптн, C. 138.

1237. pluviosa WaLker, Cat. Brit. Mus., xxxiii, 725, 1865 ; SмIтн, C. 138.

syn. castanea Grote, cymosa Grote.

1238. occidens Grote, Bull. U. S. Geol. Surv. Terr., iv, 177, 1878; SмITH, C. 138.

Atl. States, Col.

Cal.

Pac.

States.

Col.,

Cal.

*1239. perpensa Grote, Can. Ent., xiii, 229, 1883; SмITH, C. 138.

Ariz., New Mex.

Cal.

1240. cuculliformis Grote, Check List Noct., 24, 1875; Sмiтh C. 139.

1241. verbascoides Guenée, Spec. Gén., v, 141, 1852; Sмith, C. 139.

1242. nigrior Sмгтн, Proc. U. S. Nat. Mus., xiii, 437, 1890; C. 189.

1243. cariosa Guenée, Spec. Gén., v, 144, 1852; Suith, C. 139 .

syn. idonea Grote.

1244. vulgaris Grote \& Robinson, Proc. Ent. Soc. Phil., vi, 19, 1866; Sмrth, C. 139.

*1245. cristata Grote, Bull. Geol. Surv. Terr., iv, 176, 1878; SмITh, C. 140.

1246. relecina Morrison, Proc. Bost. Soc. Nat. Hist., xvii, 216, 1874; SмIтн, C. 140.

Atl. States.

Me.

No. U. S., Ariz.

Atl. States.

N. Y.

Tex.,

Col.

1247. cinefacta Grote, Pap., i, 77, 1881; Sмгтн, C. 140 .

1248. centralis Sмпth, Proc. U. S. Nat. Mus., xiii, 141 , 1890 ; C. 140.

1249. auranticolor Grote, Bull. Buff. Soc., i, 109, 1873; Sмптн, C. 140.

Pac. States, Col.

Cal.

Oreg., Col., Neb. 
1250. lignicolor Guenée, Spec. Gén., v, 140, 1852; Sirth, C. 140.

Atl. States, Col. Ariz. a. quæsita Grote, Can. Ent., viii, 26, 1876.

1251. genialis Grote, Bull. Buff. Soc., ii, 66, 1874; Sirth, C. 141.

Cal.

1252. inordinata Morrison, Proc. Acad. Nat. Sci. Phil., 63, 1875; Sмптн, C. 141.

Mass., Me., Col.

a. montana Sмrтh, Proc. U. S. Nat. Mus., xiii, 414, 1890 .

*1252. 1. semilunata Grote, Pap., i, 58, 1881; Smith, C. 141.

Wash., Col.

\section{CALOPHASIA Stephens.}

Stephens, Ill. Brit. Ent., Haust., ii, 61, 1829.

1253. strigata Smith, Trans. Am. Ent. Soc., xviii, 107. 1891; C. 156.

\section{EPIDEMAS Smith.}

Smith, Trans. Am. Ent. Soc., xxi, 40, 1894.

1254. cinerea Sнmтн, Trans. Am. Ent. Soc., xxi, 41, 1894.

Col.

\section{MACRONOCTUA Grote.}

Grote, 6th Rept. Peab. Acad. Sci., 27, 1874.

1255. onusta Grote, 6th Rept. Peab. Acad. Sci., 27, 1874; Smith, (. 163.

Atl. States.

\section{FISHEA Grote.}

Grote, Can. Ent., ix, 21, 1877.

*1256. enthea Grote, Can. Ent., ix, 21, 1877; Sмith, C. 167.

\section{PACHYPOLIA Grote.}

Grote, 6th Rept. Peab. Acad. Sci., 27, 1874.

1257. atricornis Grote, 6th Rept. Peab. Acad. Sci., 27, 1874; SMIth, C. 164.

Me.

\section{POLIA Hübner.}

HüBner, Tent., 1806; Ochsenheimer, Schmett. Eur., iv, 73, 1816; Andropolia Grote, Abh. nat. Ver. Brem., xiv, 83, 1895.

*1258. ædon Grote, Can. Ent., xii, 154, 1880; Sirth, Col., Nev., C. 165 . 
1259. theodori Grote, Can. Ent., x, 237, 1878; Sмптн, C. 165 .

Col., Cal., a. epichysis Grote, Can. Ent., xii, 219, 1880.

*1260. olorina Grote, Bull. Buff. Soc., iii, 84, 1876; SмITH, C. 165.

N. M.

261. confragosa Morrison, Proc. Bost. Soc. Nat. Hist., xvii, 138, 1874; Sмrth, C. 166.

Cal., Col.

Can., Wis.

1262. connecta Sмптн, Trans. Am. Ent. Soc., xxi, 72, 1894.

*1263. speciosa Morrison, Proc. Bost. Soc. Nat. Hist., xvii, 137, 1874; Smith, C. 166.

Col.

Mass.

*1264. pallifera Grote, Can. Ent., ix, 88, 1877; Smith, C. 166 .

1265. pulverulenta Sмгтн, Trans. Am. Ent. Soc., xviii, $106,1901$.

1266. contacta W alker, Cat. Brit. Mus., ix, 58, 1856; Sмiтн, C. 166.

syn. aspera Morrison, diffusilis Harvey.

1267. diversilineata Grote, Bull. Geol. Surv. Terr., iii, 119, 1877; Sмith, C. 165.

syn. illepida Grote.

1268. medialis Grote, Ann. Lyc. Nat. Hist. N. Y., xi, 306, 1876; Sмith, C. 167.

III.

Col.

Can., No. N. Y.

Rocky

Mts.

1269. extincta Smith, Proc. U. S. Nat. Mus., xxii, 471, 1900.

1270. acera Sмiтh, Proc. U. S. Nat. Mus, xxii, 472, Wash. 1900 .

*1271. acutissima Grote, Check List Noct., 23, 1875;

- Sмith, C. 167.

1272. resoluta Sмiтh, Trans. Am. Ent. Soc., xxi, 70, 1894.

Can.,

N. Y.

N. H.

Can.

Col.

*1273. contadina Sumth, Trans. Am. Ent. Soc., xxi, 71, 1894.

B. C.

*1274. sansar Strecker, Lep. Rhop. Het., suppl. 1, 8,

Wash. 1898.

1275. ochracea Surth, Proc. U. S. Nat. Mus., xxii, 474, 1900.

Ia.

1276. dispar Sмrтh, Proc. U. S. Nat. Mus., xxii, 473, 1900. 
DRYOBOTA Lederer.

Lederer, Noct. Eur., 100, 1857.

1277. illocata Walker, Cat. Brit. Mus., xi, 758, 1857; Atl. States, SмiтH, C. 164.

syn. stigmata Grote.

\section{HYPPA Duponchel.}

Duponchel, Cat. Méth., iv, 231, 1844.

1278. xylinoides Guenée, Spec. Gén., vi, 106, 1852; Sмith, C. 155.

Atl.

States.

syn. contraria WALKER, ancociscomensis MORRISON.

1279. indistincta Smith, Trans. Am. Ent. Soc., xyi, 63, 1894.

1280. rectilinea Esper, Schmett. Eur., i, 127, 1777; Staudinger \& Reber, Cat. Lep. Eur., i, no. 1828, 1901: Dyar, Proc. Wash. Acad. Sci., ii, 491, 1900.

*1281. brunneicrista Smith, Can. Ent., xxxiv, 31, 1902.

FERALIA Grote.

Grote, Bull. Buff. Soc., ii, 58, 1874.

1282. jocosa Guenée, Spec: Gén., v, 37, 1852; Smith, C. 33; Seifert, Jn. N. Y. Ent. Soc., vi, 182, 1898.

1283. februalis Grote, Bull. Buff. Soc., ii, 60, 1874; SмITH, C. 33.

1284. major Surth, Ent. Amer., vi, 26, 1890; C. 34.

1285. brillians Barnes, Can. Ent., xxxiii, 56, 1901.

\section{MOMOPHANA Grote.}

Grote, Stett. ent. Zeit., xxxvi, 195, 1875.

1286. comstocki Grote, Bull. Buff. Soc., ii, 59, 1874; Sмiтн, C. 34.

Atl.

States.

\section{VALERIA Germar.}

Germar, Mag. Ent., iv, 1821; Stephens, Cat. Brit. Ins., no. 118, 1829.

1287. opina Grote, Bull. Geol. Surv. Terr., iv, 178,

Cal.

1878; SмIтH, C. 156. 
EUPLEXIA Stephens.

Stephens, Ill. Brit. Ent., Haust., iii, 3, 1829.

1288. lucipara Linneus, Syst. Nat., 518, 1758; SмIth, C. 171.

U. S.,

Eur.

TRACHEA Hübner.

HüBner, Verz. bek. Schmett., 219, '\$816.

1289. delicata Grote, Trans. Am. Ent. Soc., v, 92, 1874; Sмith, C. 148.

Atl. syn. interna Grote.

States.

\section{DIPTERYGIA Stephens.}

Stephens, Ill. Brit. Ent., Haust., ii, 167, 1829.

1290. scabriuscula Linneus, Syst. Nat., 516, 1758; SмITH, C. 155.

syn. pinastri Linneus.

Atl. States, Col., Eur.

\section{ACTINOTIA Hübner.}

HüBNer, Verz. bek. Schmett., 244, 1816.

1291. ramosula Guenée, Spec. Gén., vi, 114, 1852; SмITH, C. 167.

*1292. stewarti Grote, Can. Ent., vii, 28, 1875; Sмптн, C. 167 .

Atl. States.

Cal.

U.S.

1293. glabella Morrison, Proc. Bost. Soc. Nat. Hist., xvii, 153, 1874; SмIтH, C. 197.

*1294. triquetra Grote, Pap., iii, 78, 1883; Sмптн, C. 197.

1295. pyramidoides Guenée, Spec. Gén., vi, 413, 1852; SмITH, C. 197.

Atl. States, Col.

a. inornata Grote, Proc. Ent. Soc. Phil., iii, 86, 1864.

b. conspersa Riley, 3d Rept. Ins. Mo., 75, 1871.

1296. tragopoginis Linnfeus, Faun. Suec., 1189, 1761; SwITH, C. 197.

Atl. States, Eur. syn. repressus Grote. 


\section{HELIOTROPHA Lederer.}

\section{Lederer, Noct. Eur., 118, 1857.}

1297. reniformis Grote, Can. Ent., vi, 14, 1874; SмITH, C. 173 .

a. atra Grote, Proc. Acad. Nat. Sci. Phil., 200, 1874.

*1298. obtusa Sirth, Jn. N. Y. Ent. Soc., x, 45, 1902.

Atl. States.

N. H.

\section{PRODENIA Guenée.}

Guenée, Spec. Gén., v, 159, 1852.

1299. commelinæ Sмiтн \& Аввот, Lep. Ins. Ga., ii, 189, 1797; Sмith, C. 169.

Atl. States.

Atl. States, Cal., Col.

1300. ornithogalli Guenée, Spec. Gén., v, 163, 1852; SмITH, C. 169.

syn. Tineatella HaRver.

a. eudiopta Guenée, Spec. Gén., v, 164, 1852;

Smith, C. 170.

syn. flavimedia Harvey.

b. præfica Grote, Can. Ent., vii, 44, 1875.

1301. eridania Cramer, Pap. Exot., iv, pl. 358, f. E, 1782; SмIтH, C. 169.

So. States,

So. Am.

syn. phytolacce Sмiтн \& Aввот, derupta MorRISON, nigrofasciata Hulst.

\section{LAPHYGMA Guenée.}

\section{Guenée, Spec. Gén., v, 156, 1852.}

1302. frugiperda Sмгтн \& Аввот, Lep. Ins. Ga., ii, 191, 1797; Sмiтн, C. 168.

Atl. States,

syn. macra GuenéE, signifera WALKER, plagiata WALKER, autumnalis RILEY.

a. obscura Riley, 8th Rept. Ins. Mo., 49, 1876.

b. fulvosa Riley, 8th Rept. Ins. Mo., 49, 1876.

\section{LUSSA Grote.}

Grote, Can. Ent., xv, 127, 1883.

1303. nigroguttata Grote, Can. Ent., xv, 127, 1883; SMITH, C. 167.

*1304. inflexa Morrison, Proc. Acad. Nat. Sci. Phil., 65,1875 ; Smith, C. 168.

Fla.

Fla. 
MAGUSA Walker.

WAlker, Cat. Brit. Mus., xi, 762, 1857.

1305. dissidens Felder, Reise Novara, pl. 108, f. 50, 1872; Smith, C. 329; Dyar, Proc. Ent. Soc. Wash., iv, 453, 1901.

syn. divaricata Grote, angustipennis МöschLer, divida Möschler.

Atl. States, So. Am.

\section{PSEUDANARTA Hy. Edwards.}

Hy. Edwards, Proc. Cal. Acad. Sci., vi, 133, 1875; Copanarta Grote, Abh. nat. Ver. Brem., xiv, 112, 1895.

*1306. aurea Grote, Bull. Geol. Surv. Terr., v, 205, 1879; SмITH, C. 149.

1307. flava Grote, Trans. Am. Ent. Soc., v, 91, 1874; Sмith, C. 140.

syn. crocea Hy. Edwards.

1308. singula Grote, Can. Ent., xii, 215, 1880; Sмrтh, C. 148 .

1309. flavidens Grote, Bull. Geol. Surv. Terr., v, 205, 1879; Sмiтh, C. 149.

1310. falcata Neumoegen, Pap., iii, 141, 1883; Sмith, C. 149 .

Tex.

N.-W. Pac. States, Col., Ariz.

Tex., Ariz., Col. Col., N. Mex.

Ariz., Mex.

\section{HOMOHADENA Grote.}

Grote, Bull. Buff. Soc., i, 180, 1873.

1311. candida Smith, Proc. U. S. Nat. Mus., xxii, 478, 1900 .

1312. badistriga Grote, Trans. Am. Ent. Soc., iv, 20, 1872; Snith, C. 158.

Atl. States Col.

1313. infixa Walker, Cat. Brit. Mus., ix, 178, 1856; Sмith, C. 157.

syn. Kappa Grote.

1314. retroversa Morrison, Proc. Bost. Soc. Nat. Hist., xvii, 157, 1874; Smith, C. 157.

1315. induta Harvey, Bull. Buff. Soc., ii, 274, 1874; Suith, C. 157.

1316. incomitata Harvey, Bull. Buff. Soc., iii, 6, 1875; Smith, C. 156.

1317. stabilis Surth, Ent. News, vii, 29, 1896.

So. Atl.

States.

Miss.

Tex.

Tex.

Alberta.

Ariz. 
1319. figurata Harvey, Can. Ent., vii, 117, 1875; SMITH, C. 157.

Col., Nev., Cal.

*1320. chorda Grote, Can. Ent., xii, 256, 1880; Sмith, C. 157.

Col.,

Cal.

*1321. epipaschia Grote, Trans. Kans. Acad. Sci., viii, 49, 1882; SмITH, C. 157.

Kans., N. Mex.

Ariz.

1322. vulnerea Grote, Can. Ent., xv, 29, 1883; Sмith, C. 157.

*1323. deserta Suith, Proc. U. S. Nat. Mus., xiii, 402, 1890; C. 157.

\section{ONCOCNEMIS Lederer.}

Lederer, Noct. Eur., 94, 1857.

1324. hayesi Grote, Bull. Buff. Soc., i, 106, 1873; Sмiтh, C. 158.

Col., Cal.,

B. C.

Col.

1325. dayi Grote, Bull. Buff. Soc., i, 105, 1873; SмIтH, C. 158 .

1326. fasciatus Sмгтн, Ins. Life, i, 18, 1888; C. 159.

*1327. behrensi Grote, Bull. Buff. Soc., ii, 65, 1874; Sмith, C. 160.

1328. mirificalis Grote, Bull. Geol. Surv. Terr., v, 207, 1879; Sмith, C. 158.

Col., Cal.

Cal.

Nev.,

Cal.

Col.

Col.

1330. umbrifascia Sмith, Trans. Am. Ent. Soc., xxi, 64,1894 .

1331. levis Grote, Can. Ent., xii, 254, 1880; Sмiтh, C. 159 .

1332. augustus Harvey, Bull. Buff. Soc., iii, 73, 1875; SмITH, C. 159.

1333. saundersiana Grote, Can. Ent., viii, 29, 1876; Sмiтh, C. 160.

*1334. pernotata Grote, Can. Ent., xv, 25, 188 ; Sмith, C. 160 .

1335. homogena Grote, Bull. Geol. Surv. Terr., iii, 800, 1874; Sмiтh, C. 160.

1336. occata Grote, Trans. Am. Ent. Soc., v, 114, 1874; Sмith, C. 160.

Tex., Col., Cal.

Nev.,

Cal.

C. 161 .

syn. picina Grote, vorax BeHr.

1338. chandleri Grote, Bull. Buff. Soc., i, 107, 1873;

- Sмith, C. 161. 
1339. riparia Morrison, Can. Ent., vii, 213, 1875; Sinth, C. 161.

N. Y., Mass.

*1340. extremis Smith, Ent. Amer., vi, 30, 1890: C. 160. B. C.

1341. atrifasciata Morrison, Proc. Acad. Nat. Sci. Phil., 431, 1875: SмITH, C. 159.

1342. terminalis Sмrтн, Ins. Life, i, 19, 1888; C. 159.

*1343. simplex Surth, Ins. Life, i, 20, 1888; C. 159.

1344. iricolor Sмптн, Ins. Life, i, 19, 1888; C. 160.

1345. glennyi Grote, Bull. Buff. Soc., i, 141, 1873; Sмiтh, C. 160.

*1346. meadiana Morrison, Proc. Acad. Nat. Sci. Phil., 60, 1875; Sмith, C. 160.

1347. major Grote, Pap., i, 33, 1881; SмitiH, C. 162. syn. aqualis Grote, curvicollis Grote.

1348. colorado Smith, Ent. News, iv, 100, 1892: Trans. Am. Ent. Soc., xxi, 66, 1894; C. 161.

1349. corusea Sмrth, Jn. N. Y. Ent. Soc., vii, 40, 1899.

1350. melalutea Smith, Jn. N. Y. Ent. Soc., vii, 39, 1899.

1351. melantho Sмrтн, Jn. N. Y. Ent. Soc., vii, 37, 1899.

1352. pohono Sмiтh, Jn. N. Y. Ent. Soc., vii, 38, 1899.

*1353. pudorata Smith, Trans. Am. Ent. Soc., xxi, 63, 1894.

*1354. viriditincta Smith, Trans. Am. Ent. Soc., xxi, $66,1894$.

1355. ciliata Smith, Proc. U. S. Nat. Mus., xxii, 478, 1900 .

*1356. barnesii Sмith, Jn. N. Y. Ent. Soc., vii, 37, 1899.

*1357. oblita Grote, Bull. Geol. Surv. Terr., iii, 117 , 1877; Sмith, C. 162.

1358. cibalis Grote, Can. Ent., xii, 244, 1880; Sмптн, C. 162 .

*1359. balteata Suith, Jn. N. Y. Ent. Soc., x, 43, 1902.

*1360. regina Svith, Jn. N. Y. Ent. Soc., x, 44, 1902.

1361. atricollaris HARvey, Bull. Buff. Soc., ii, 273, 1874; SMITH, C. 162.

1362. griseicollis Grote, Can. Ent., xiv, 19, 1882; SмITH, C. 163.

No. Atl

States.

Col.

Utah.

Col.

Col.

Ariz.

Ariz., Col.

Cal.

Col.

Cal.

Col.

Cal.

Cal.

B. C.

B. C.

Ariz.

Wyo.

Nev.

Col.

Col.

N. W. Terr

Tex., Ariz. Col.

Ariz.

Cal.

*1363. aterrima Grote, Can. Ent., xi, 199, 1879; Sмith, C. 163. 
1364. flagrantis SмIтH, Ins. Life, v, 330, 1893.

Cal.

1365. exemplaris Suith, Trans. Am. Ent. Soc., xxi, 64,

Cal. 1894.

1366. extranea Smith, Trans. Am. Ent. Soc., xxi, 68, 1894.

1367. nigrocaput Syith, Trans. Am. Ent. Soc., xxi, 67, 1894.

1368. refecta Sмiтн, Trans. Am. Ent. Soc., xxi, 65, 1894.

Col.

Col.

Col.

\section{LEPIPOLYS Guenée.}

Guenée, Spec. Gén., vi, 173, 1852.

1369. perscripta Guenée, Spec. Gén., vi, 174, 1852; SмIth, C. 259.

Atl. States, Col., Cal.

\section{ADITA Grote.}

\section{Grote, Bull. Buff. Soc., ii, 63, 1874.}

1370. chionanthi Sмгтн \& Aввот, Lep. Ins. Ga., ii, 195, 1797; Sмith, C. 158.

Atl. States, Col.

\section{COPIPANOLIS Grote.}

Grote, 6th Rept. Peab. Acad. Sci., app., 25, 1874.

*1371. borealis Snith, Proc. U. S. Nat. Mus., xv, 61, 1892; C. 112.

1372. cubilis Grote, 6th Rept. Peab. Acad. Sci., app., 25, 1874; Sмith, C. 112.

1373. fasciata Surth, Proc. U. S. Nat. Mus., xv, 61, 1892; C. 113.

Minn.

No. Atl.

States.

Mo.,

Tex.

Fla.

\section{EUTOLYPE Grote.}

Grote, Proc. Acad. Nat. Sci. Phil., 189, 1874.

1375. rolandi Grote, Proc. Acad. Nat. Sci. Phil., 198, 1874; Smith, C. 112.

syn. vernalis Morrison.

1376. bombyciformis Smith, Proc. U.S. Nat. Mus., xv, 58,1892 ; C. 112.

1377. grandis Smith, Can. Ent., xxx, 321, 1898.

Atl.

States.

1378. depilis Grote, Pap., i, 48, 1881; Sмith, C. 112.

*1379. damalis Grote, Bull. Geol. Surv. Terr., v, 208, 1880; Smith, C. 112.

Mass.,

Mo.

Mo.

Atl. States.

Cal. 
PSAPHIDIA Walker.

Walker, Cat. Brit. Mus., xxxii, 447, 1865; Dicopis Grote.

1380. grotei Morrison, Bull. Buff. Soc., i, 274, 1874; Sмith, C. 111.

No. Atl.

States.

1381. resumens Walker, Cat. Brit. Mus., xxxii, 448, 1865 ; Smith, C. 111.

Atl.

States.

syn. viridescens WALKER, muralis GROTE.

*1382. electilis Morrison, Proc. Bost. Soc. Nat. Hist., xviii. 114, 1875; Smith, C. 111.

Pa.

1383. thaxterianus Grote, Bull. Buff. Soc., ii, 196, 1874; Sмith, C. 111; Dyar, Jn. N. Y. Ent. Soc., ix, 84, 1901.

\section{CERAPODA Smith.}

Surth, Trans. Am. Ent. Soc., xxi, 68, 1894.

1384. stylata Smith,Trans. Am. Ent. Soc., xxi, 69,1894.

\section{FOTA Grote.}

Grote, Can. Ent., xiv, 174, 1882.

1385. armata Grote, Can. Ent., xiv, 175, 181, 1882; Sмith, C. 183.

1386. minorata Grote, Can. Ent., xiv, 181,1882; SMITH C. 183.

Col.

Atl.

States.

Ariz.

Ariz.

1387. crassipes Suith, Jn. N. Y. Ent. Soc., x, 48, 1902. Ariz., Cal.

\section{CRIMONA Smith.}

Smith, Jn. N. Y. Ent. Soc., x, 49, 1902.

*1388. pallimedia Smith, Jn. N. Y. Ent. Soc., x, 49, 1902.

Cal.

\section{RHYNCHAGROTIS Smith.}

Sмiтн, Bull. 38, U. S. Nat. Mus., 13, 1890.

1389. gilvipennis Grote, 6th Rept. Peab. Acad. Sci., app., 24, 1874; ऽмптн, С. 50.

No. Atl.

States.

No. U. S., Cal.

No. Atl. States, Col. 
1392. minimalis Grote, No. Am. Ent., i, 45, 1879; Sмiтh, C. 52.

Me., Col.

1393. anchocelioides Guenée, Spec. Gén., v, 384, 1852; SMith, C. 52.

syn. cupida Grote, velata WaLKer.

No. Atl.

States, a. brunneipennis Grote, Can. Ent., vii, 187, 1875.

1394. belfragei Sмптн, Bull. 38, U. S. Nat. Mus., 20, 1890; C. 53.

1395. placida Grote, Ann. Lye. Nat. Hist. N. Y., xi, 305, 1876; Sмiтh, C. 52.

Rocky Mits.

Tex.

Rocky Mts.,

No. U. S.

1396. variata Gkote, Bull. Buff. Soc., iii, 83, 1876; Sмith, C. 53.

Rocky Mts.,

B. C., Ariz.

syn. varix Grote, orbis Grote.

1397. alternata Grote, Proc. Ent. Soc. Phil., iii, 526, 1864; Smith, C. 53.

1398. trigona Sмiтh, C. 53, 1893.

Atl. States, Col.

Col., Cal.,

Oreg.

Cal.

1399. cupidissima Grote, Can. Ent., vii, 101, 1875; Sмith, C. 56.

*1400. bimarginalis Grote, Ann. Mag. Nat. Hist., 53, 1883: Sмith, C. 54.

1401. vittifrons Grote, Proc. Ent. Soc. Phil., iii, 527, 1864; SMITH, C. 54.

1402. inelegans Sмiтh, Trans. Am. Ent. Soc., xvii, 43, $1890 ;$ C. 54.

1403. mirabilis Grote, No. Am. Ent., i, 39, 1879; Sмiтh, C. 54.

N. Mex.

Col.

Cal.

Col.,

Ariz.

Cal.

1404. exsertistigma Morrison, Proc. Bost. Soc. Nat. Hist., xvii, 166, 1874; Sмrth, C. 55.

syn. observabilis Grote.

1405. formalis Grote, Bull. Buff. Soc., ii, 61, 1874; Sмiтh, C. 55.

a. facula Grote, Bull. Buff. Soc., iii, 82, 1876. syn. insularis Grote, emarginata Grote.

*1406. carissima Harvey, Grote, Check List, 25, 1875; Sirth, C. 54.

*1407. lætula Grote, Bull. Buff. Soc., iii, 83, 1876; Sмith, C. 56.

syn. distracta Sмiтh.

1408. discoidalis Grote, Bull. Buff. Soc., iii, 82, 1876; Sirth, C. 56.

Pac.

States.

Cal.

Pac.

States.

$4630-$ No. $52-02-9$

Nev.,

Oreg. 
1409. crenulata Sмrth, Proc. U. S. Nat. Mus., x, 451, 1887; C. 56.

Pac. States.

*1410. confusa Smith, Proc. U. S. Nat. Mus., x, 452, Wash. 1887: C. 56.

*1411. costata Grote, Bull. Buff. Soc., iii, 80, 1876; SMITH, C. 55.

syn. binominalis SмITH.

ac. States.

ADELPHAGROTIS Smith.

Sмiтh, Bull. 38, U. S. Nat. Mus., 38, 1890.

*1412. stellaris Grote, Can. Ent., xii, 153, 1880; SмIтн, C. 57 .

*1413. indeterminata Walker, Cat. Brit. Mus., xxxiii, 750,1875 ; SмIтH, C. 57.

syn. innotabilis Grote, washingtoniensis Grote.

*1414. quarta Grote, Bull. Geol. Surv. Terr., vi, 258, 1883: Sмith, C. 57.

1415. prasina Fabricius, Mant. Ins., ii, 169, 1787; Sinth, C. 57.

syn. herbacea GuenéE.

1416. apposita Grote, Bull. Geol. Surv. Terr., iv, 170, 1878; Sмiтн, C. 58.

Nev., Wash.

Pac. States.

Cal.

No. Atl.

States, Rocky Mts., Eur.

Pac. States, Col.

\section{PLATAGROTIS Smith.}

Sмiтh, Bull. 38, U. S. Nat. Mus., 43, 1890.

1417. speciosa HüBnER, Eur. Schmett., Noct., 491, 1815; SмITH, C. 58.

syn. perquirita Morrison, baileyana Grote, mixta WALKER.

a. arctica Zetterstedt, Ins. Lapl., 339, 1839.

1418. pressa Grote, Trans. Am. Ent. Soc., v, 90, 1874; SмITH, C. 59.

1419. condita Guenée, Spec. Gén., vi, 78, 1852; SмIth, C. 59 .

syn. trabalis Grote.

*1420. sincera Herrich-Schaeffer, Eur. Schmett., ii, 412, 1851: Smith, C. 59.

1421. imperita Hübner, Zutr. exot. Schmett., f. 447 , 1823; SмIтн, C. 59.
No. Atl. States, Eur.

Atl.

States.

Atl.

States.

Lab.

No. Atl.

States. 
EUERETAGROTIS Smith.

Smith, Bull. 38, U. S. Nat. Mus., 47, 1900.

1422. sigmoides Guenée, Spec. Gén., v, 325, 185\%; SMITH, C. 60.

1424. attenta Grote, Can. Ent., vi, 131, 1874; Sмптн, C. 60 .

\section{ABAGROTIS Smith.}

Sмiтh, Bull. 38, U. S. Nat. Mus., 50, 1890.

1425. erratica Sмптн, Bull. 38, U. S. Nat. Mus., 50, 1890; C. 60.

Cal.

\section{SEMIOPHORA Stephens.}

Stephens, Ill. Brit. Ent., Haust., ii, 138, 1829.

1426. elimata Guenée, Spec. Gén., v, 333, 1852; Surth, C. 61 .

syn. dilucidula Morrison.

Atl. States

a. badicollis Grote, Bull. Buff. Soc., i, 136, 1873.

b. janualis Grote, Bull. Geol. Surv. Terr., iv, $169,1878$.

1427. opacifrons Grote, Bull. Geol. Surv. Terr., iv, 170,1878 ; SMITH, C. 61.

No. Atl. States.

No. Atl. States.

Can.

\section{PACHNOBIA Guenée.}

Guenée, Spec. Gén., v, 341, 1852.

*1430. monochromatea Morrison, Proc. Bost. Soc. Nat. Hist.. xvii, 165, 1874; Sмmтн, C. 62.

1431. littoralis Packard, Proc. Bost. Soc. Nat. Hist., xi, 36, 1868; Smith, C. 62.

a. pectinata Grote, Proc. Acad. Nat. Sci. Phil., 207, 1874; Smith, C. 63.

syn. ferruginoides Sмптн.

1432. carnea Thunberg, Mus. Acad. Nat. Ups., Diss., iv, 56, 1788; Sмiтн, C. 64 .

Aretic

a. cinerea STAudinger, Stett. ent. Zeit., xxii, 369. 1861 .

Am. 
1433. cinerascens Suпth, Trans. Am. Ent. Soc., xviii,

Cal. 103. 1891: C. 64 .

1434. wockei Möschler, Wien. ent. Mon., vi, 130, 1862; SмITH, C. 64.

N. H.

Lab.

syn. scropulana Morrison.

*1435. okakensis Packard, Proc. Bost. Soc. Nat. Hist., xi, 38, 1867; Sмmтн, C. 64.

N. H., Lab.

Col.

*1436. elevata Smith, Trans. Am. Ent. Soc., xviii, 104, 1891; C. 64.

1437. salicarum W ALKER, Cat. Brit. Mus., xi, 717, 1857; Sмuth, C. 63.

syn. orilliana GROTE, claviformis MoRrison.

*1438. manifesta Morrison, Proc. Bost. Soc. Nat. Hist., xviii, 116, 1875; SмIтh, C. 62.

*1439. hæsitans Walker, Cat. Brit. Mus., x, 329, 1856; SмITH, C. 63.

1440. fishii Grote, Bull. Gecl. Surv. Terr., iv, 175, 1878; Sмiтh, C. 64.

METALEPSIS Grote.

Grote, Check list Noct., 25, 1875; Pseudoglæa Grote.

*1441. cornuta Grote, Bull. Buff. Soc., ii, 68, 1874; SмITH, C. 210.

*1442. blanda Grote, Bull. Buff. Soc., iii, 86, 1875; Sмith, C. 210.

No. Atl.

States.

Atl. States.

Rocky

Mts.

Me.

Cal.

Pac. States, Col., Tex. syn. tradata Grote, decepta Grote.

SETAGROTIS Smith.

Sмith, Bull. 38, U. S. Nat. Mus., 59, 1890.

*1443. planifrons Surth, Trans. Am. Ent. Soc., xvii, 42, 1890; C. 65.

B. C.

1444. radiatus Sмrтh, Proc. U. S. Nat. Mus., xxii, 418, 1900.

1445. quebecensis Smith, Proc. U. S. Nat. Mus., xxii, 417,1900 .

1446. elata Sмrтh, Jn. N. Y. Ent. Soc., vi, 106, 1898.

Col.

1447. terrifica Smith, Trans. Am. Ent. Soc., xxi, 42, 1894.

Col.

1448. congrua Smith, Trans. Am. Ent. Soc., xvii, 43, 1890 ; C. 65 . 
1449. vernilis Grote, Can. Ent., xi, 57, 1879; Sмith, C. 65 .

*1450. infimatis Grote, No. Am. Ent., i, 93, 1880; Sмiтн, C. 65.

\section{AGROTIS Ochsenheimer.}

Ochsenheimer, Schmett. Eur., iv, 66, 1816.

1451. badinodis Grote, Can. Ent., vi, 13, 1874; SмIth, C. 65 .

1452. violaris Grote \& Robinson, Trans. Am. Ent. Soc., i, 353, 1868; Sмith, C. 66.

1453. aurulenta Sмгтн, Bull. 38, U. S. Nat. Mus., 215, $1890 ;$ C. 66.

1454. ypsilon RottenbUrg, Naturf., xli, 141, 1776; Sмith, C. 66.

syn. suffusa Denis \& SChIffermüller, telifer $a$ Harris, idonea Cramer.

1455. geniculata Grote \& Robinson, Trans. Am. Ent. Soc., i, 349, 1868; Smith, C. 66.

1456. docilis Grote, Bull. Geol. Surv. Terr., vi, 259, 1882; Sмith, C. 68.

syn. ingeniculata Sмrтн, Bull. 38, U. S. Nat. Mus., 216, 1890; C. 67.

*1457. bollii Grote, Bull. Geol. Surv. Terr., vi, 160, 1882; Sмiтh, C. 67.

*1458. dapsilis Grote, Bull. Geol. Surv. Terr., vi, 582, 1883; Sмith, C. 67.

*1459. nanalis Grote, Can. Ent., xiii, 131, 1881; Sмiтh, C. 67 .

*1460. hero Morrison, Proc. Bost. Soc. Nat. Hist., xviii, 238, 1876; Sмiтh, C. 67.

*1461. tenuicola Morrison, Proc. Bost. Soc. Nat. Hist., xvii, 163, 1874; Sмith, C. 67.

\section{PERIDROMA Hübner.}

HüBner, Verz. bek. Schmett., 227, 1816.

1462. occulta Linnæus, Syst. Nat., iv, 514, 1767; Sмith, C. 68.

*1463. præfica Morrison, Proc. Bost. Soc. Nat. Hist., xviii, 117, 1875; Sмith, C. 68.

1464. astricta Morrison, Proc. Bost. Soc. Nat. Hist., xvii, 135, 1874; Smith, C. 68.
Col., Nev., Cal.

Cal., Wash.

Atl.

States.

Pa.,

N. Y.

Col., Ariz., Neb.

U. S., Eur.

Atl. States.

Col.

Tex.

Fla.

Nev.

Mass.

N. Y.

No.

U. S.

Rocky

Mts.

No. Atl.

States, Col. 
1465. nigra Sмiтh, Trans. Am. Ent. Soc., xxi, 43, 1894.

Col.

*1466. grandipennis Grote, Ann. Mag. Nat. Hist., 54, 1883; SмITH, (.. 69.

1467. margaritosa Haworth, Lep. Brit., 157, 1810.

a. saucia Hübner, Samml. Eur. Schmett., Noct., 378, 1816; SмITH, C. 69.

syn. inermis HARRIS, ortonii PACKARD.

1468. incivis Guenée, Spec. Gén., v, 274, 1852; Suith, C. 70 . syn. alabamæ Grote.

1469. pellucidalis Grote, Bull. Geol. Surv. Terr., vi, 567,1882 ; Sмiтh, C. 69.

Atl. States, Cal.

Tex.,

Col.

Tex. Sмiтh, C. 69.

1471. demutabilis Smith, Ins. Life, v, 328, 1893.

*1472. tenuescens Sмiтh, Bull. 38, U. S. Nat. Mus., 73, 1890; C. 70.

1473. simplaria Morrison, Proc. Bost. Soc. Nat. Hist., xvii, 164, 1874; SмIтh, C. 70.

1474. digna Morrison, Proc. Bost. Soc. Nat. Hist., xviii, 115,$1875 ;$ SмIтh, C. 70.

syn. niqrovittata GROTE.

\section{NOCTUA Linnæus.}

Linneus, Syst. Nat., 508, 1758.

1475. smithii Snellen, Tijd. voor Ent., xxxix, 157, 1896; Smith, Jn. N. Y. Ent. Soc., vi, 99, 1898.

1476. normaniana Grote, Trans. Am. Ent. Soc., v, 89, 1874; SMITH, C. 71.

syn. obtusa SPEYER.

1477. esuralis Grote, Can. Ent., xiii, 131, 1881; Sмrтн, C. $72 ;$ Jn. N. Y. Ent. Soc., vi, 102, 1898.

1478. bicarnea Guenée, Spec. Gén., v, 329,1852; Sмith, C. 71 .

syn. plagiata WALKER.

1479. treatii Grote, Can. Ent., vii, 186, 1875; Sмгтн, C. 71; Jn. N. Y. Ent. Soc., vi, 103, 1898.

*1480. conchis Grote, No. Am. Ent., i, 43, 1879; Sмrth, C. 71 .

No. Atl. States.

Atl.

States.

Wash.

Atl. States, Col.

Mass.

Col., N. Mex.

1481. c-nigrum Linneus, Syst. Nat., 516, 1758; Sмith, C. 72 .

Atl. States, Eur. 
1482. hospitalis Grote, Can. Ent., xiv, 184, 1882; Sмiтн, C. 72; Jn. N. Y. Ent. Soc., vi, 100, 1898.

1483. jucunda Walker, Cat. Brit. Mus., x, 399, 1856; SмIтн, C. 72.

syn. percomflua Grote.

1484. phyllophora Grote, Bull. Buff. Soc., ii, 61, 1874; Sмith, C. 72 .

No. Atl.

syn. eriensis Grote.

1485. rubifera Grote, Can. Ent., viii, 207, 227, 1875 ; Smith, C. 73; Jn. N. Y. Ent. Soc., vi, 100, 1898.

1486. oblata Morrison, Proc. Bost. Soc. Nat. Hist., xviii, 116, 1875; Smith, C. 73.

syn. hilliana Harver.

1487. rosaria Grote, Bull. Geol. Surv. Terr., iv, 172, 1878; Sмmtн, C. 73; Jn. N. Y. Ent. Soc., vi, $102,1898$.

1488. rava Herrich-Schaeffer, Schmett. Eur., vi, 59, 1850; Sмiтh, C. 73.

syn. umbrata PACKARD.

1489. fennica Tauscher, Eversmann, Bull. Soc. Imp. Mosc., i, 13, 1837; Svith, C. 74.

syn. intractata WALKER.

1490. plecta Linneus, Faun. Suec., 321, 1761; Sмгтн, C. 74 .

syn. vicaria WALKER.

1491. collaris Grote \& Robinson, Trans. Am. Ent. Soc., i, 348, 1868; Smith, C. 74.

*1492. juncta Grote, Bull. Geol. Surv. Terr., iv, 171, 1878; Smith, C. 74.

syn. patefacta Sмrтн, Ent. News, vi, 333, 1895.

1493. haruspica Grote, Bull. Buff. Soc., ii, 212, 1875; SMITH, C. 74.

syn. grandis SPEYER.

1494. inopinatus Smith, Jn. N. Y. Ent. Soc., vi, 103, 1898.

*1495. sierræ Harvey, Can. Ent., viii, 37, 1876; Smith, C. 75 .

No.

U.S.

Pac. States,

Col.

Lab.,

Nova Scotia.

No. Atl.

States, Eur.

No. Atl.

States.

Nova Scotia,

Alberta.

No. U.S.

1496. clandestina Harris, Ins. Inj. Veg., 448, 1862; Smith, C. 75.

syn. unicolor WALKER, nigreeps WALKER.

1497. clemens Smith, Trans. Am. Ent. Soc., xvii, 44, 1890 ; C. 75 .

Cal.

Col.,

Alberta.

Cal. .

Col.

Atl. States, Rocky Mts. 
1498. pyrophiloides Harver, Can. Ent., viii, 37, 1876; Sмith, C. 78.

*1499. subporphyrea Walker, Cat. Brit. Mus., xiv, 1658, 1858; Sмнтн, C. 76.

1500. havilæ Grote, Bull. Geol. Surv. Terr., vi, 157, 1880; Sмith, C. 76.

Cal.

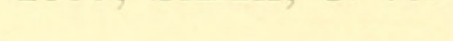

1501. piscipellis Grote, Can. Ent., x, 233, 1878; Sмith, C. 76 .

1502. atrifrons Grote, Bull. Buff. Soc., i, 97, 1873; Sмiтн, C. 77.

1503. plebeia Sмrтн, Jn. N. Y. Ent. Soc., vi, 105, 1898.

1504. atricincta Smith, Ent. News, vi, 333, 1895.

*1505. pallidicollis Grote, Bull. Geol. Surv. Terr., vi, 154, 1880; Sмiтh, C. 77.

1506. substrigata Sмптн, Ent. News, vi, 352, 1895.

1507. flavotincta Surth, Trans. Am. Ent. Soc., xxi, 45, 1898.

1508. calgary Sмптн, Jn. N. Y. Ent. Soc., vi, 101, 1898.

1509. exuberans Sмнтн, Jn. N. Y. Ent. Soc., vi, 103, 1898.

1510. bolteri Sмптн, Jn. N. Y. Ent. Soc., vi, 104, 1898.

1511. суnica ऽмитн, Jn. N. Y. Ent. Soc., vi, 101, 1898.

*1512. tepperi Smith, Proc. U. S. Nat. Mus., x, 452, 1887; C. 77.

1513. vocalis Grote, Can. Ent., xi, 56, 1879; Sмiтh, C. 77 .

syn. invenusta Grote.

1514. lubricans Guenée, Spec. Gén., v, 323, 1852; Sмiтн, C. 77.

syn. associans WALKER, illapsa WALKER.

a. beata Grote, Ann. Mag. Nat. Hist., (5), xi, 54, 1883.

*1515. spreta Surth, Jn. N. Y. Ent. Soc., x, 36, 1902.

Fia.

PRONOCTUA Smith.

Sмith, Trans. Am. Ent. Soc., xxi, 44, 1894.

1516. typica Smith, Trans. Am. Ent. Soc., xxi, 45, 1894.

Col. 


\section{CHORIZAGROTIS Smith.}

Sмiтh, Bull. 38, U. S. Nat. Mus., 98, 1890.

1517. auxiliaris Grote, Bull. Buff. Soc., i, 196, 1872; SMITH, C. 78.

1518. introferens Grote, Proc. Acad. Nat. Sci. Phil., 423, 1873; SMITH, C. 78.

1519. agrestis Grote, Bull. Geol. Surv. Terr., iii, 118, 1877; SMITH, C. 78.

syn. mercenaria Grote.

1520. soror Sirth, Proc. U. S. Nat. Mus., x, 453, 1887; C. 78 .

1521. inconcinna Harvey, Bull. Buff. Soc, iii, 5, 1875; SмITH, C. 78.

*1522. terrealis Grote, Trans. Kans. Acad. Sci., viii, 47, 1882; SмIтн, C. 79.

1523. immixta Grote, Bull. Geol. Surv. Terr., vi, 259, 1882; SмITH, C. 79.

1524. balanitis Grote, Bull. Buff. Soc., i, 97, 1873; Smith, C. 79.

Col., Tex., Cal.

Col., Tex., Cal.

Rocky Mts., Tex., Cal.

Mont.

Tex.

Ariz., Tex., Col.

N. Mex.

Tex.

Col.,

B. C.

RHIZAGROTIS Smith.

1525. albalis Grote, Bull. Geol. Surv. Terr., iv, 175, 1878; Smith, C. 80.

1526. cloanthoides Grote, Bull. Geol. Surv. Terr., vi, 153, 1880; SMITH, C. 80.

1527. abnormis Sмптн, Trans. Am. Ent. Soc., xvii, 41, 1890: C. 79 .

*1528. proclivis Smith, Proc. U. s. Nat. Mrs., x, 453, 1887; C. 79 .

*1529. acclivis Morrison, Ann. Lyc. Nat. Hist. N. Y., xi, 93, 1875; Smith, C. 79.

syn. opaca HARveY.

1530. albicosta Smith, Proc. U. S. Nat. Mus., x, 451, 1887; C. 80.

Col.

Col.

Cal.

Ariz.

Ariz., Tex., Col.

Rocky

Mts.

Rocky

Mts. 1887; C. 90.

Col. .

N. Mex. 1882; Smith, C. 80.

1533. lagena Grote, Can. Ent., vii, 26, 1875; Smith, Rocky Mts.,
C. 80. 
*1534. atha Strecker, Lep. Rhop. Het., suppl. 2, 6, Wash. 1898.

\section{FELTIA Walker.}

Watker, Cat. Brit. Mus., ix, 203, 1856.

1535. robustior Sмптн, Can. Ent., xхxi, 206, 1899.

Man.

*1536. olivia Morrison, Proc. Bost. Soc. Nat. Hist., xviii, 238, 1876; Sмrтh, C. 80.

1537. longidens Sмrтн, Bull. 38, U. S. Nat. Mus., 217, 1890; C. 81.

1538. subgothica Haworth, Lep. Brit., 224, 1810; Smith, C. 81; Jn. N. Y. Ent. Soc., x, 36, 1902; Slingerland, Can. Ent., xxvii, 301, 1895; xxviii, 295, 1896.

*1539. edentata Surth, Jn. N. Y. Ent. Soc., x, 38, 1902.

1540. jaculifera Guenée, Spec. Gén., v, 262, 1852. Sмiтн, C. 81.

Utah.

N. Mex.

No.

U. S.

syn. tricosa LINTNER.

a. herilis Grote, Bull. Buff. Soc., i, 99, 1873; SMITH, C. 82.

1541. pectinicornis Sмrth, Bull. 38, U. S. Nat. Mus., 114,1890; C. 82.

*1542. evanidalis Grote, Bull. Geol. Surv. Terr., iv, 172, 1878; SмIтн, C. 82.

Wash.

Atl. States, Col.

Tex.

Cal.

*1543. circumdata Grote, Ann. Mag. Nat. Hist., (5), xi, 53, 1883; Sмптн, C. 82.

1544. gladiaria Morrison, Proc. Bost. Soc. Nat. Hist., xvii, 162, 1874; SмIтн, C. 82.

syn. morrisoniana RILEY.

1545. venerabilis WaLker, Cat. Brit. Mus., x, 328, 1856; Sмith, C. 83.

1546. gravis Grote, Bull. Buff. Soc., ii, 155, 1874; Sмith, C. 83.

syn. vapularis Grote.

1547. vancouverensis Grote, Bull. Buff. Soc., i, 134, 1873; SмITH, C. 83.

syn. hortulana Morrison, semiclarata Grote, agilis Grote.

1548. æneipennis Grote, Bull. Buff. Soc., iii, 81, 1876; Smith, C. 83.

syn. clodiana Grote.

N. Mex.

Atl. States.

U.S.

Cal.

Pac. States.

1549. volubilis Harvey, Bull. Buff. Soc., ii, 118, 1874; Smith, C. 84.

Pac. States.

U. S.

syn. stigmosa Morrison. 
1550. annexa Treitschke, Schmett. Eur., v, 154, 1825; Sмith, C. 84.

Atl. States, So. Am.

syn. decernens W ALKER.

1551. malefida Guenée, Spec. Gén., v, 267, 1852; SмITH, C. 84.

U.S. So. Am.

\section{POROSAGROTIS Smith.}

Sмith, Bull. 38, U. S. Nat. Mus., 123, 1890.

1552. vetusta W ALKer, Cat. Brit. Mus., ix, 78, 1856; SMITH, C. 85.

Atl. States, Col. syn. muræmula Grote \& Robinson.

1553. catenula Grote, No. Am. Ent., i, 44, 1879; Rocky Mts., SмITH, C. 85.

1554. texana Grote, Proc. Ent. Soc. Phil., ii, 273, 1863; Sмiтh, C. 86.

syn. obesula Sмrтh, Proc. U. S. Nat. Mus., x, 456,$1887 ;$ C. 85 .

1555. satiens Surth, Trans. Am. Ent. Soc., xvii, 45, 1890; C. 85.

1556. mimallonis Grote, Bull. Buff. Soc., i, 98, 1873; Sмiтth, C. 85 .

syn. mifipennis Grote.

*1557. fusca Boisduval, Icon. Hist. Lep., pl. 48, f. 4, 1834; Sмith, C. 86.

syn. septentrionalis Möschler, patula WALKER.

1558. tripars W ALKER, Cat. Brit. Mus., ix, 78, 1856; Sмith, C. 86.

syn. worthingtoni Grote.

1559. rileyana Morrison, Proc. Bost. Soc. Nat. Hist., xvii, 166, 1874; Smith, C. 86.

1560. orthogonia Morrison, Proc. Bost. Soc. Nat. Hist., xviii, 239, 1876; Sмгтн, C. 87.

1561. dædalus Sмiтth, Bull. 38, U. S. Nat. Mus., 217, $1890 ;$ C. 87.

*1562. dollii Grote, Can. Ent., xiv, 216, 1882; Sмiтh, C. 87 .

1563. milleri Grote, Bull. Buff. Soc., iii, 78, 1875; SмIтH, C. 87.

1564. pluralis Grote, Bull. Geol. Surv. Terr., iv, 174, 1878; Snith, C. 87.
Cal.

Tex., Col., Mont.

Col.,

B. C.

Mont., Col., Can., N. Y.

Lab., Rocky Mts.

N. Y., Ind.

Atl. States, Rocky Mts.

Rocky Mts.

Col.

Ariz.

Cal.

Nev.,

Col. 


\section{PARAGROTIS Pratt.}

Carneades Grote (not Bates), Can. Ent., xv, 4, 1883.-F. C. Pratt.

1565. edictalis Smrth, Trans. Am. Ent. Soc., xxi, 40,

Col. 1894.

1566. siccata Smith, Trans. Am. Ent. Soc., xxi, 46, 1894.

Col.

1567. wilsonii Grote, Bull. Buff. Soc., i, 135, 1873; SмIтн, C. 88.

Cal. ,

Col.

syn. specialis Grote, xqualis Harver.

1568. lacunosa Grote, Bull. Geol. Surv. Terr., iv, 172, 1878; Sмith, C. 88.

Cal.

1569. segregata Sмгтн, Trans. Am. Ent. Soc., xxi, 47, 1894.

Col.

1570. lætificans Smith, Trans. Am. Ent. Soc., xxi, 48, 1894.

1571. recula Harver, Can. Ent., viii, 37, 1876: Smith, C. 88.

1572. cicatricosa Grote \& Robinson, Proc. Ent. Soc. Phil., iv, 492, 1865; Smith, C. 88.

1573. neomexicana Sмгтн, Bull. 38, U. S. Nat. Mus., 218, 1890; C. 88.

1574. quadridentata Grote \& Robinson, Proc. Ent. Soc. Phil., iv, 491, 1865; Smith, C. 89.

1575. niveilinea Grote, Can. Ent., xiv, 216, 1882; SMITH, C. 89.

Col.

Oreg., Col.

Col.

N. Mex.

Col.,

Oreg.

Rocky Mts., Tex.

*1576. insertans Smith, Trans. Am. Ent. Soc., xvii, 45. 1890; C. 89.

B. C.

1577. brevipennis Sмrтh, Proc. U. S. Nat. Mus., x, 455, 1887; C. 89.

Cal., Col.

1578. oblongostigma Smith, Proc. U. S. Nat. Mus., x. 454, 1887; C. 89.

Mont. ,

Col.

1579. plagigera Morrison, Proc. Bost. Soc. Nat. Hist., xvii, 163, 1874; Sмith, C. 89.

No.

U. S.

*1580. agema Strecker, Lep. Rhop. Het., suppl. 2, 5, 1899.

Col.

1581. olivalis Grote, No. Am. Ent., i, 43, 1879: Sмrтt, C. 89 .

Col.,

Utah.

1582. ridingsiana Grote, Bull. Buff. Soc., ii, 305, 1875; Sмith, C. 90.

Rocky

Mts.

*1583. dargo Strecker, Lep. Rhop. Het., suppl. 1, 6, Col. 1898. 
1584. pugionis Sмiтh, Proc. U. S. Nat. Mus., xxii, 419, Col. 1900.

1585. flavidens Sмптн, Proc. U. S. Nat. Mus., x, 455, 1887; C. 90.

Rocky

Mts,

1586. loya Sмгтн, Proc. U. S. Nat. Mus., xxii, 422, 1900.

1587. bicollaris Grote, Bull. Geol. Surv. Terr., iv, 173, 1878; Sмiтh, C. 90.

Cal.

Cal., Nev., Ariz.

Col., Nev., Kans., Neb. 56,1875 ; Sмiтh, C. 90. syn. bochus Morrison.

1589. sponsa Sмiтh, Proc. U. S. Nat. Mus., x, 457, 1887; C. 90.

1590. cogitans Surth, Trans. Am. Ent. Soc., xvii, 46, 1890 ; C. 90.

*1591. achor Strecker, Lep. Rhop. Het., suppl. 2, 5, 1899.

1592. stigmatalis Sirth, Proc. U. S. Nat. Mus., x ii. $425,1900$.

1593. hollemani Grote, Can. Ent., vi, 156, 1874; Smith, C. 91.

Wash.

Cal.,

Col.

Col.

Col.

Cal.,

Ariz., Col.

Col.

1894. collocata Smith, Trans. Am. Ent. Soc., xxi, 50, 1894.

1595. nevada Surth, Proc. U. S. Nat. Mus., xxii, 420, 1900.

*1596. atristrigata Sмiтн, Ent. Amer., vi, 76, 1890; C. 91.

1597. biclavis Grote, Bull. Geol. Surv. Terr., v, 206, 1879; Sмith, C. 91.

1598. perpolita Morrison, Proc. Bost. Soc. Nat. Hist., xviii, 237, 1876; Sмrth, C. 91.

1599. fumalis Grote, Bull. Buff. Soc., i, 98, 1873; Sirth, C. 91.

syn. permunda Morrison.

1600. perfusca Grote, Pap., iii, 77, 1883; Sмiтh, C. 91.

1601. punctigera WALKer, Cat. Brit. Mus., xxxii, 661, 1865 ; Sмiтh, C. 92.

syn. pastoralis Grote.

1602. finis Sмiтh, Proc. U. S. Nat. Mus., x, 457, 1887; C. 92 .

1603. velleripennis Grote, Sixth Rept. Peab. Acad. Sci., app., 25, 1874; SмIтн, C. 92.

Nev.

B. C.

Ariz.

No. Atl. States, Col.

Atl.

States.

Cal., Col., Ariz.

Pac. States, Rocky Mts.

Mont.

Atl. States, Col. 
1604. atomaris Sмrтh, Trans. Am. Ent. Soc., xvii, 47, 1890; C. 92.

Cal.,

Col.

1605. flaviscapula Sмгтн, Proc. U. S. Nat. Mus., xxii, $422,1900$.

1606. exculta Smith, Proc. U. S. Nat. Mus., xxii, 424, 1900 .

1607. excogita Smith, Proc. U. S. Nat. Mus., xxii, 423, 1900 .

1608. gagates Grote, Can. Ent., vii, 68, 1875; Sмгтн, C. 92 .

1609. nævulus Sмптн, Proc. U. S. Nat. Mus., xxii, 424, 1900 .

1610. citricolor Grote, Can. Ent., xii, 154, 1880; Sмith, C. 92.

1611. acornis Smith, Ent. News, vi, 335, 1895.

1612. megastigma Sмптн, Proc. U. S. Nat. Mus., xxii, $425,1900$.

1613. mœrens Grote, Can. Ent., xv, 4, 1883; Sмith, C. 93.

1614. misturata SмIтH, Bull. 38, U. S. Nat. Mus., 156, 1890 ; C. 92.

1615. mitis Smith, Trans. Am. Ent. Soc., xxi, 49, 1894.

1616. candida Sмrтh, Trans. Am. Ent. Soc., xxi, 49, 1894.

1617. contagionis Smith, Proc. U. S. Nat. Mus., xxii, 421, 1900 .

Col.,

Nev.

*1618. dolis Grote, No. Am. Ent., i, 91, 1880; Sмiтh, C. 93.

1619. falerina Sмrтн, Proc. U. S. Nat. Mus., xxii, 429, 1900.

1620. scandens Riley, First Rept. Ins. Mo., 76, 1869; SmIth, C. 93.

Atl. States, Col.

*1621. detesta Suith, C. 93, 1893.

1622. remota Smith, Trans. Am. Ent. Soc., xvii, 48, 1890; C. 93.

Col.

Col.

1623. detersa Walker, Cat. Brit. Mus., ix, 212, 1856; Smith, C. 93.

syn. pitychrous Grote, personata Morrison.

*1624. infracta Morrison, Proc. Bost. Soc. Nat. Hist., xviii, 115, 1875; Smith, C. 93.

Col.

Cal.,

Col.

Atl. States, Col.

Col., Tex.

*1625. gian Strkcker, Lep. Rhop. Het., suppl. 1, 6 , 1898.

Ariz. 
*1626. azif Strecker, Lep. Rhop. Het., suppl. 1, 6,

N. Y. 1898.

1627. luteola SмIтh, Proc. U. S. Nat. Mus., x, 457,

Ariz. 1887; C. 94.

*1628. serricornis Surth, Proc. U. S. Nat. Mus., x, 458, 1887; C. 94.

*1629. tetrica Surth, Proc. U. S. Nat. Mus., x, 458, 1887: C. 94.

1630. vulpina SмrтH, Ent. News, vi, 335, 1895.

1631. bostoniensis Grote, Proc. Acad. Nat. Sci. Phil., 203, 1874; Smith, C. 94.

1632. cænis Grote, No. Am. Ent., i, 44, 1879; Sмith, C. 94 .

1633. muscosa Grote, Can. Ent., xv, 26, 1883; Sмптн, C. 94 .

1634. medialis Snrth, Proc. U. S. Nat. Mus., x, 459, 1887; C. 95.

1635. feniseca Harver, Bull. Buff. Soc., iii, 74, 1875; Sмiтн, C. 95.

1636. audentis Sмmтн, Trans. Am. Ent. Soc., xxi, 51, 1894.

syn. annir STREcker, Lep. Rhop. Het., suppl. $1,6,1898$.

1637. cona Strecker, Lep. Rhop. Het., suppl. 1, 6, 1898.

1638. enteridis Smith, Proc. U. S. Nat. Mus., xxii, 427, 1900 .

1639. vallus Sмrтн, Proc. U. S. Nat. Mus., xxii, 430, 1900.

1640. termessus Smrth, Proc. U. S. Nat. Mus., xxii, 426,1900 .

*1641. alko Strecker, Lep. Rhop. Het., suppl. 2, 5, 1899.

1642. dakota Smith, Proc. U. S. Nat. Mus., xxii, 442, Dak. 1900 .

1643. sessile Smith. Proc. U. S. Nat. Mus., xxii, 431. 1900 .

1614. relaxus Smith, Proc. U. S. Nat. Mus., xxii, 432, 1900.

So. Cal.

Tex.,

Nev.

Alberta.

Atl.

States.

Col.

N. Mex.

Col.

Tex.,

Col.

Cal.

Col.

Col.

Wash.

B. C.

Wyo.

Col.

Col.

Cal.

1645. luteositus Sмнтн, Proc. U. S. Nat. Mus., xxii, 433, 1900 . 
*1646. extranea Smith, Proc. U. S. Nat. Mus., x, 459, 1887; C. 95.

*1647. trifasciata Smith, Proc. U. S. Nat. Mus., x, 460, 1887; C. 95.

1648. bifasciata Sмiтh, Proc. U. S. Nat. Mus., x, 460 , 1887; C. 95.

Mont.

Oreg.

Ariz.

1649. messoria Harris, Rep. Ins. Mass., 324, 1841; Sмmtн, C. 96; Proc. U. S. Nat. Mus., xxii, 434, 1900 .

syn. spissa Guenée, cochrani Riley, repentis Grote \& Robinson, displiciens Walker, reticens WALKER, ordinata WALKER, inextricata WALKER, indirecta W ALKER, septentrionalis WALKER, inducta WALKER.

1650. incubita Smrth, Proc. U. S. Nat. Mus., xxii, 435, 1900 .

Wash.,

Cal.

16.51. terrenus Sмптн, Proc. U. S. Nat. Mus., xxii, 436 , 1900 .

1652. pleuritica Grote, Check List, 47, 1875; Sмrтн, C. 97.

No. Atl.

States.

Cal. 1900 .

1654. territorialis Sirth, Proc. U. S. Nat. Mus., xxii, $436,1900$.

Col., Wash.

1655. fulda Sмrth, Proc. U. S. Nat. Mus., xxii, 437, 1900 .

Cal.

*1656. drewseni Staudinger, Stett. ent. Zeit., xviii, 302, 1857; SMITH, C. 97.

1657. rubefactalis Grote, Bull. Geol. Surv. Terr., vi, 154, 1880; SмITH, C. 97.

Greenl.

Wash.,

Col.

1658. perturbata Sмптн, Bull. 38, U. S. Nat. Mus., 222. 1890; C. 97.

Col.

1659. brunneigera Grote, Bull. Buff. Soc., iii, 80, 1875 : Simth, C. 98.

Pac. States. Col., La.

1660. incallida Symth, Trans. Am. Ent. Soc., xvii, 50, 1890 ; C. 98.

Cal.

1661. lutulenta Surth, Trans. Am. Ent. Soc., xvii, 50, 1890; C. 98.

Cal., Col.

*1662. comosa Morrison, Proc. Bost. Soc. Nat. Hist., xviii, 238, 1876; Smith, C. 95.

Col.

*1663. fauna Morrison, Proc. Bost. Soc, Nat. Hist., xviii, 237, 1876; Syith, C. 98.

Cal. 
1664. itodes Sмiтh, Proc. U. S. Nat. Mus., xxii, 438, Ariz. 1900 .

1665. lagganæ Sмiтн, Proc. U. S. Nat. Mus., xxii, 439, Alberta. 1900.

1666. ontario Sмiтh, Proc. U. S. Nat. Mus., xxii, 440, 1900.

1667. testula Sмrтh, Proc. U. S. Nat. Mus., xxii, 440, 1900.

1668. difformis Sмiтh, Proc. U. S. Nat. Mus., xxii, 441, 1900 .

1669. choris Harvey, Can. Ent., viii, 37, 1876; SмIth, C. 97.

1670. sculptilis Harvey, Bull. Buff. Soc., ii, 271, 1874; SмIтн, C. 95.

syn. xyliniformis SмITH.

1671. conjuncta Sмгтн, Bull. 38, U. S. Nat. Mus., 221, 1890 ; C. 98.

1672. pallipennis Suпth, Proc. U. S. Nat. Mus., x, 461 , 1887; C. 104.

1673. recticincta Surth, Ent. News, vi, 334, 1895.

1674. annulipes Sмгтн, Trans. Am. Ent. Soc., xvii, 48, 1890 ; C. 98.

1675. pedalis Sмгтн, Bull.38, U. S. Nat. Mus., 220, 1890; C. 98 .

1676. lineifrons Sмiтh, Bull. 38, U. S. Nat. Mus., 219, $1890 ;$ C. 98.

1677. kervillei Sмгтн, Proc. U. S. Nat. Mus., xxii, 443, 1900.

*1678. teleboa Sмгтн, Bull. 38, U. S. Nat. Mus., 219, 1890.

1679. murdockii Suith, Trans. Am. Ent. Soc., xvii, 49, 1890; C. 99.

1680. quinquelinea Sмrтh, Trans. Am. Ent. Soc., xvii, 49, 1890; C. 99.

1681. friabilis Grote, Can. Ent., vii, 187,1875; SмIтh, C. 99 .

1682. fuscigera Grote, Can. Ent., vi, 155, 1874; Sмith, C. 99 .

*1683. orbicularis Sмiтh, Proc. U. S. Nat. Mus., x, 460, 1887; C. 99.

Can.

Alberta.

Oreg.

Nev.

Tex.,

N. Mex.

N. Mex.,

Col.

Col.,

B. C.

Alberta.

Oreg.

Col.

Col.

Tex.

N. Mex., Col.

Utah,

B. C.

Cal.

No. U. S.

Cal., Col.

Nev.

$4630-$ No. $52-02-10$ 
*1684. micronyx Grote, Bull. Geol. Surv. Terr., iv, 171, 1878; Sмmтн, C. 99.

Cal.

1685. atropulverea Sмrth, Proc. U. S. Naț. Mus., xxii, 428, 1900.

Col.

*1686. numa Strecker, Lep. Rhop. Het., suppl. 1, 5, 1898.

1687. ternarius Sмrтh, Proc. U. S. Nat. Mus., xxii, 444, 1900.

1688. compressipennis Sмiтh, Proc. U. S. Nat. Mus., xxii, 429, 1900 .

1689. holoberba Sмiтh, Proc. U. S. Nat. Mus., xxii, 443 , 1900 .

1690. objurgata Sмiтh, Proc. U. S. Nat. Mus., xxii, 448, 1900.

1691. cariosus Sмrтh, Proc. U. S. Nat. Mus., xxii, 449, 1900.

1692. intrita Morrison, Proc. Bost. Soc. Nat. Hist., xvii, 164, 1874; Snith, C. 99.

*1693. mollis Walker, Cat. Brit. Mus., x, 331, 1856; Sмiтh, C. 100.

syn. fernaldi Morrison.

*1694. opipara Morrison, Proc. Bost. Soc. Nat. Hist., xvii, 165, 1874; Sмrтh, C. 100.

syn. labraioriensis STAUdINGER.

*1695. tristicula Morrison, Proc. Acad. Nat. Sci. Phil., 429, 1875; Sмrth, C. 100.

1696. munis Grote, No. Am. Ent., i, 38, 1879; Sмith, C. 100 .

syn. sublatis Grote.

*1697. dissona Möschler, Wien. ent. Mon., iv, 365, 1860; Smith, C. 101.

1698. vetusta Walker, Cat. Brit. Mus., xxxii, 662, 1865; Smith, C. 101.

syn. tetra WALKER, euroides GRote, perpura Morrison.

1699. titubatis Smith, Trans. Am. Ent. Soc., xxi, 51, 1894.

Oreg.,

Col.

*1700. reuda Strecker, Lep. Rhop. Het., suppl. 1, 6, 1898.

Wash.

1701. noctuiformis SмIтH, Proc. U. S. Nat. Mus., xxii, 445,1900 .

Cal., Wash. 
1702. infausta WaLker, Cat. Brit. Mus., xxxiii, 729, 1865: Sмith, C. 101.

syn. rufula SмITH.

1703. basiflava Sмiтth, Trans. Am. Ent. Soc., xvii, 52, 1890; C. 101.

1704. alticola Smith, Trans. Am. Ent. Soc., xvii, 51, $1890 ;$ C. 101.

*1705. satis Harvey, Can. Ent., viii, 36, 1876; SмIth, C. 102 .

1706. rena Sмiтh, Trans. Am. Ent. Soc., xvii, 53, 1890; C. 102 .

1707. insulsa Walker, Cat. Brit. Mus., ix, 234, 1856; Sмith, C. 102.

syn. insignata WALKER, expulsa WALKER, declarata W ALKER, decolor MorRison, campestris GRoTe.

a. verticalis Grote, Bull. Brook. Ent. Soc., iii, 29,1880 .

1708. albipennis Grote, Bull. Buff. Soc., iii, 118, 1877; Sмith, C. 103.

syn. nigripennis Grote.

*1709. spectanda Surth, Trans. Am. Ent. Soc., xvii, 5t, 1890; C. 103.

1710. neotelis Sмiтh, Proc. U. S. Nat. Mus., xxii, 446 , 1900 .

1711. tessellata Harris, Rep. Ins. Mass., 324, 1841; Sмiтh, C. 103.

syn. maizi Fitch, atropurpurea GRote.

1712. intrusa Smith, Proc. U. S. Nat. Mus., xxii, 446, 1900 .

1713. atrofusca Sмiтh, Proc. U.S. Nat. Mus., xxii, 447, 1900 .

1714. malis Sмптн, Proc. U. S. Nat. Mus., xxii, 450, 1900 .

*1715. colla Strecker, Lep. Rhop. Het., suppl. 1, 6, 1898.

1716. basalis Grote, No. Am. Ent., i, 38, 1879; Sмith, C. 104 .

*1717. solitaria Sмiтн, Stett. ent. Zeit., xlvi, 223, 1885; C. 104 .

1718. nostra Sмптн, Trans. Am. Ent. Soc., xvii, 55, 1890; C. 104.
B. C., Col., N. Mex.

B. C., Col.

Cal. Col.

Cal., Nev., Mont.

Cal.

U. S.

Atl. States, Rocky Mts.

Cal.

Wash. Col.

U. S.

Cal.

Col.

Man.

Col.

Col.

Lab.

Cal. 
1719. ochrogaster GuenéE, Spec. Gén., v, 327, 1852; Sirth, C. 104.

svn. illata WALKER, cinereomaculata MorrIson, gularis Grote, turris Grote.

1720. idahoensis Grote, Bull. Geol. Surv. Terr., iv, 171, 1878; SмIтн, C. 105.

Rocky

Mts.

Cal., Col. 1890; C. 105 .

Lab., Greenl.

Col.

1723. fœminalis Sмгтн, Proc. U. S. Nat. Mus., xxii, $454,1900$.

1724. obeliscoides Guenée, Spec. Gén., v, 293, 1852; Sмптн, C. 105.

syn. sexatilis Grote.

1725. infusa Sмiтн, Can. Ent., xxxiv, 30, 1902.

1726. perexcellens Grote, Bull. Geol. Surv. Terr., vi, 156, 1880; Sмiтн, C. 106.

syn. infelix Sмiтh.

*1727. abar Strecker, Lep. Rhop. Het., suppl. 2, 5, 1899.

*1728. islandica Staudinger, Stett. ent. Zeit., xviii, 232, 1857; SмITh, C. 106.

1729. henrietta Smith, Proc. U. S. Nat. Mus., xxii, 152 , 1900.

1730. vanidicus Smith, Proc. U. S. Nat. Mus., xxii, 453 , 1900.

1731. acutifrons Sмгтн, Proc. U. S. Nat. Mus., xxii, $458,1900$.

1732. nordica Sмгтн, Proc. U. S. Nat. Mus., xxii, 455, 1900.

1733. factoris Sмrтh, Proc. U. S. Nat. Mus., xxii, 456, 1900.

*1734. colata Grote, Can. Ent., xiii, 131, 1881; Sмiтh, C. 106.

*1735. lewisi Grote, Bull. Buff. Soc., i, 137, 1873; Sмiтh, C. 106.

1736. divergens W ALKer, Cat. Brit. Mus., x, 327, 1856; Smith, C. 107.

syn. versipellis Grote.

1737. redimicula Morrison, Proc. Bost. Soc. Nat. Hist., xvii, 165, 1874; Sмith, C. 107.

No. Atl. States, Rocky Mts. Man., Wyo.

Pac. States, Col.

Col.

Iceland.

Cal., Ariz.

Ariz., Wash.

Cal., Oreg.

B. C.

Col.

Oreg., Cal.

Col.

No. U. S.

No. Atl. States, Col.

1738. servitus Smith, Ent. News, vi, 336, 1895.

Col., Alberta. 
1739. fusimacula Sмгтн, Can. Ent., xxxiv, 125, 1902.

Cal.

1740. pindar Smith, Proc. U. S. Nat. Mus., xxii, 451, 1900.

*1741. atrifera Grote, Bull. Geol. Surv. Terr., iv, 173, 1878; Sмith, C. 107.

Utah.

Cal., Col., Me.

*1742. strigilis Grote, Bull. Buff. Soc., iii, 81, 1876; SMITH, C. 107.

1743. tesselloides Grote, Bull. Geol. Surv. Terr., vi, 566, 1880; Sмiтh, C. 107.

1744. cæsius Sмптн, Proc. U. S. Nat. Mus., xxii, 457, 1900.

1745. silens Grote, Can. Ent., vii, 67, 1875; Sмith, C. 107.

1746. laminis Sмгтн, Proc. U. S. Nat. Mus., xxii, 460, 1900.

1747. selenis Sмптн, Proc. U. S. Nat. Mus., xxii, 459 , 1900.

*1748. perlentans W ALKer, Cat. Brit. Mus., x, 352, 1856; Sмith, C. 108.

B. C.

Cal., Ariz., Col.

Cal.

Cal., Ariz., Col.

Cal.

Cal.

N. Y.

\section{EUCOPTOCNEMIS Grote.}

Grote, Bull. Buff. Soc., ii, 13, 1874.

1749. fimbriaris Guenée, Spec. Gén., v, 172, 1852; Sмiтh, C. 109.

syn. obvia W ALKER.

RICHIA Grote.

Grote, Can. Ent., xix, 44, 1887.

1750. chortalis Harvey, Bull. Buff. Soc., ii, 272, 1875; Sмith, C. 108.

a. atratrix Harvey, Bull. Buff. Soc., iii, 74, 1875.

1751. parentalis Grote, No. Am. Ent., i, 44, 1879; SмIтH, C. 108.

a. decipiens Grote, No. Am. Ent., i, 45, 1879.

*1752. distichoides Grote, Trans. Kans. Acad. Sci., viii, 48, 1883; Sмiтh, C. 109.

Tex. Rocky Mits.

Col., N. Mex.

N. Mex.

\section{ANYTUS Grote.}

Grote, Bull. Buff. Soc., i, 144, 1873.

1753. privatus WALKer, Cat. Brit. Mus, xi, 521, 1857 ; Sмith, C. 109.

Atl. States, Col. syn. sculptus Grote.

a. planus Grote, Can. Ent., xiv, 183, 1882. 
*1754. theodora Schaus, Trans. Am. Ent. Soc., xxi, 223, 1894 (of this genus?).

Ariz., Mex.

175.5. atristrigatus Smith, Proc. U. S. Nat. Mus., xxii, 460,1900 .

1756. profundus SмrTH, Can. Ent., xxxii, 218, 1900.

1757. obscurus Smiтh, Can. Ent., xxxii, 218, 1900.

Tex.

Man.

Alberta.

\section{UFEUS Grote.}

Grote, Bull. Buff. Soc., i, 101, 1873.

*1758. sagittarius Grote, Pap., iii, 31, 1883; Sмптн, C. 190.

1759. plicatus Grote, Bull. Buff. Soc., i, 102, 1873; SмITH, C. 190.

syn. barometricus Goossens, Le Nat., iii, 380, 1881.

1760. unicolor Grote, Bull. Geol. Surv. Terr., iv, 179, 1878; Smith, C. 190.

\section{Cal.}

No. Atl. States, Col., Cal.

$$
\text { Ill., }
$$
Col.

*1761. faunus Strecker, Lep. Rhop. Het., suppl. 1, 9, 1898.

1762. satyricus Grote, Bull. Buff. Soc., i, 101, 1873; SмiтH, C. 191.

N. Mex.

No. Atl. States.

AGROTIPHILA Grote.

Grote, Ann. Lyc. Nat. Hist. N. Y., xi, 107, 1875.

1763. alaskæ Grote, Bull. Buff. Soc., iii, 84, 1876; Sмiтн, C. 110.

1764. incognita Smith, Trans. Am. Ent. Soc., xxi, 52, 1894.

*1765. staudingeri Möschler, Wien. ent. Mon., vi, 132, 1862; SмITH, C. 110.

Alaska.

syn. montana Morrison.

1766. rigida Smith, Trans. Am. Ent. Soc., xviii, 133, 1891; C. 110.

1767. maculate Sмrth, Trans. Am. Ent. Soc., xxi, 53, 1894.

B. C.

Lab., N. H., Col.

Col.

B. C.

1768. colorado Smith, Trans. Am. Ent. Soc., xviii, 133, 1891: C. 110.

*1769. velata Strecker, Lep. Rhop. Het., suppl. 1, 9, 1898.

\section{PTEROSCIA Morrison.}

Morrison, Proc. Bost. Soc. Nat. Hist., xvii, 155, 1874.

*1770. atrata Morrison, Proc. Bost. Soc. Nat. Hist.,

N. H. xvii, 156, 1874; Smith, C. 191. 
MAMESTRA Ochsenheimer.

Ochsenheimer, Schmett. Eur., iv, 76, 1816.

1771. discalis Grote, Bull. Geol. Surv. Terr., iii, 797, 1877: SмITH, C. 114.

1772. rogenhoferi Möschler, Stett. ent. Zeit., xxxi, 269, 1870; SMITH, C. 114.

1773. nimbosa Guenée, Spec. Gén., vi, 77, 1852; SмITH, C. 114.

1774. imbrifera Guenée, Spec. Gén., vi, 76, 1852; SмITH, C. 114.

1775. purpurissata Grote, Proc. Ent. Soc. Phil., iii, 82, 1864; Sмith, C. 114.

1776. juncimacula Sмiтн, Bull. Brook. Ent. Soc., v, 67, $1882 ;$ ' C. 114.

1777. insolens Grote, Bull. Buff. Soc., ii, 65, 1874; Sмiтh, C. 115.

syn. arietis Grote, earina Morrison.

1778. leucogramma Grote, Bull. Buff. Soc., i, 140, 1873; SмITH, C. 115.

1779. lepidula Sмrth, Proc. U. S. Nat. Mus., x, 463, 1887; C. 115.

1780. determinata Siıтн, Proc. U. S. Nat. Mus., xiv, 209, 1891; C. 115.

1781. meditata Grote, Bull. Buff. Soc., i, 104, 1873; Sмiтн, C. 115.

1782. lustralis Grote, Can. Ent., vii, 223, 1875; Sмiтh, C. 115 .

syn. suffusa Sмiтh, Proc. U. S. Nat. Mus., x, 474, 1887; C. 203.

1783. detracta W ALKer, Cat. Brit. Mus., xi, 733, 1857; Sмiтth, C. 116.

Atl. States, syn. claviplena Grote.

1784. gnata Grote, Can. Ent., xiv, 170, 1882; Sмith, C. 116 .

1785. distincta HüBNer, Samml. exot. Schmett., i, 1810; Sмith, C. 116.

syn. vitis French.

1786. crotchii Grote, Bull. Brook. Ent. Soc., iii, 29, 1880; Smith, C. 116.

N. Mex.

Atl.

States.

Atl. States, Col., Ariz.

a. fusculenta Sмiтt, Proc. U. S. Nat. Mus., xiv, $213,1891$.

1787. farnhami Grote, Bull. Buff. Soc., i, 103, 1873; Sмith, C. 116.

Ariz., N. Mex.

Atl. States, Col.

Col., Oreg., Cal.

Col. 
1788. liquida Grote, Pap., i, 58, 1881; Sмгтн, C. 116.

1789. capsularis Guenée, Spec. Gén., vi, 22, 1852; Sмiтh, C. 117.

syn. propulsa WALKER.

*1790. vittula Grote, Trans. Kans. Acad. Sci., viii, 48, 1882; Sмптн, C. 117.

1791. prodeniformis Sмiтh, Proc. U. S. Nat. Mus., ix, 464,1887 ; C. 117.

1792. atlantica Grote, Bull. Buff. Soc., ii, 12, 1874; Sмith, C. 117.

syn. discolor SPEYer.

1793. radix W Alker, Cat. Brit. Mus., x, 332, 1856; Smith, C. 117.

syn. dimmocki Grote, desperata Sмith.

*1794. canadensis Surth, Proc. U. S. Nat. Mus., x, 464, 1887; C. 118.

*1795. nevadæ Grote, Bull. Buff. Soc., iii, 84, 1876; Sмith, C. 118.

1796. subjuncta Grote \& Robinson, Trans. Am. Ent. Soc., ii, 198, 1868; SмIтH, C. 118.

1797. gussata Svirth, Ent. News, vi, 337, 1895.

1798. ingravis Sмiтн, Ent. News, vi, 337, 1895; ix, 250, 1898.

1799. invalida Sмiтн, Proc. U. S. Nat. Mus., xiv, 225, 1891; C. 119.

1800. grandis Borsduval, Guenée, Ind. Méth., 120, 1840; Sмптн, C. 118.

syn. libera W ALKER.

1801. trifolii RotTemburg, Naturf., ix, 131, 1776; Sмith, C. 119.

syn. chenopodii FABricius, albifusa WALKER, glancovaria WALKER, major SPEYER.

a. oregonica Grote, Can. Ent., xiii, 230, 1881.

1802. u-scripta Sмrтн, Proc. U. S. Nat. Mus., xiv, 228, 1891; C. 119.

1803. rosea Harvey, Bull. Buff. Soc., ii, 119, 1874; Sмith, C. 120.

1804. larissa Sмiтh, Ent. News, vi, 338, 1895.

1805. congermana Morrison, Can. Ent., vi, 106, 1874; Simth, C. 120.

*1806. rubefacta Morrison, Can. Ent., vi, 249, 1874; Sмith, C. 120.
Wash., Oreg., Cr.

Atl. States, Col.

N. Mex.

Ariz., N. Mex.

Atl.

States.

No. U. S.,

Cal.

New

Bruns.

Cal.

Atl. States, Col.

Alberta.

Alberta.

Pac. States, Col.

No. U. S.

U. S., Eur.

Cal.,

Col.

No. U. S.

Alberta.

No. Atl. States, Col.

No. Atl. States. 
1807. picta Harris, Rep. Ins. Mass., 329, 1847; SмITH, C. 120 .

syn. exusta GUENÉE, contraria W ALKER.

1808. cristifera Walker, Cat. Brit. Mus., xv, 1654, 1858; Sмiтh, C. 121.

syn. Tubens Grote.

1809. assimilis Morrison, Bull. Buff. Soc., ii, 119, 1874; Smith, C. 121.

a. pulverulenta Sмiтh, Proc. U. S. Nat. Mus., x, $468,1887$.

1810. latex Guenée, Spec. Gén., vi, 78, 1852; Smith, C. 121 . syn. demissa WALKer.

*1811. passa Morrison, Proc. Bost. Soc. Nat. Hist., xvii, 139, 1874; Sмmth, C. 122.

1812. adjuncta Boisduval, Guenée, Ind. Méth., 243, 1841; Smith, C. 122.

1813. variolata Sмгтн, Proc. U. S. Nat. Mus., x, 467, 1887; C. 122.

*1814. glaciata Grote, Can. Ent., xiv, 170, 1882; SмITH, C. 122.

1815. minorata Sмith, Proc. U. S. Nat. Mus., x, 467, 1887; C. 122.

*1816. defessa Grote, Can. Ent., xii, 88, 1880; Sмith, C. 122 .

1817. chartaria Grote, Bull. Buff. Soc., i, 138, 1873; Sмith, C. 122.

*1818. repentina Morrison, Proc. Bost. Soc. Nat. Hist., xviii, 118, 1875; SмIтн, C. 122.

*1819. brachiolum Harver, Can. Ent., viii, 6, 1876; Smith, C. 122.

*1820. beanii Grote, Can. Ent., ix, 87, 1877; Smith, C. 122 .

1821. rugosa Morrison, Proc. Bost. Soc. Nat. Hist., xviii, 119, 1875; Sмiтh, C. 122.

1822. ligitima Grote, Proc. Ent. Soc. Phil., iii, 82, 1864; Sмith, C. 122.

1823. lilacina Harvey, Bull. Buff. Soc., ii, 119, 1874; Sirth, C. 122.

syn. illabefacta Morrison.

1824. noverca Grote, Can. Ent., x, 236, 1878; Sмiтh, C. 124 .
Atl. States, Col.

No. U. S.

No. Atl. States.

No. Atl. States.

Cal.

No. Atl.

States.

Wash.

Ariz.,

Col.

Cal.,

Col.

Cal.

Cal., Wash., Col.

N. J.

Tex.,

Ariz.

Ill., Tex.,

Col.

Me,

No.

U. S.

No. Atl. States, Col., N. Mex.

Cal., Col., Ariz., Neb. 
1825. goodellii Grote, Can. Ent., vii, 223, 1875; Sмптн, C. 124 .

1826. quadrata Sмrтh, Proc. U. S. Nat. Mus., xiv, 248, 1891; C. 124.

1827. obscura Sмптн, Proc. U. S. Nat. Mus., x, 468, 1891; C. 124.

1828. ectypa Morrison, Proc. Bost. Soc. Nat. Hist., xviii, 118, 1875: Smith, C. 124.

syn. bella Grote.

1829. renigera Stephens, Ill. Brit. Ent., Haust., ii, 16, 1829; Sмптн, C. 124.

syn. herbimacula Guenée, infecta WaLker.

1830. stricta Walker, Cat. Brit. Mus., xxxiii, 728, 1865 ; SмITH, C. 125.

syn. ferrea Grote.

a. cinnabarina Grote, Proc. Bost. Soc. Nat. Hist., xvi, 241, 1874.

*1831. spiculosa Grote, Can. Ent., xvi, 28, 1883; SмITH, C. 125.

1832. olivacea Morrison, Proc. Bost. Soc. Nat. Hist., xvii, 143, 1874; Sмith, C. 125.

a. obscurior Smith, Proc. U.S. Nat. Mus., x, 465, 1887.

b. comis Grote, Bull. Geol. Surv. Terr., iii, 85, 1877 .

syn. davena Sмптн, Trans. Am. Ent. Soc., xxvii, 237, 1901; lucina Smith, Trans. Am. Ent. Soc., xxvii, 236, 1901; altua SмIтH, Trans. Am. Ent. Soc., xxvii, 236, 1901; megarena Surth, Trans. Am. Ent. Soc., xxvii, 236, 1901; petita Smith. Trans. Am. Ent. Soc., xxvii, 239, 1901.

c. rectilinea Sмith, Proc. U. S. Nat. Mus., x, 465, 1887; C. 125.

syn. circumcincta Smith, Proc. U. S. Nat. Mus., xiv, 253, 1891; C. 125; obnigra SмIтH, Trans. Am. Ent. Soc., xxvii, 238, 1901.

*1833. vau-media Sмith, Proc. U. S. Nat. Mus., x, 466 , 1887; C. 126.

*1834. incurva Smith, Proc. U. S. Nat. Mus., x, 466 , 1887 ; C. 126.

1835. quadrilineata Grote, Bull. Buff. Soc., i, 140, 1873; Smith, C. 126.

1836. marinitincta Harver, Bull. Buff. Soc., ii, 273 , 1875; Sмiтн, C. 126.
No. Atl.

States.

Cal.

$W$ is.

N. J., W. Va.

No. Atl. States, Col., Eur.

Pac. States.

Ariz.

No.

U. S.

Col.

Col., Ariz., N. Mex.

Ariz., Cal.

Tex. 
1837. laudabilis Guenée, Spec. Gén., vi, 30, 1852; SмIтн, C. 126.

syn. indicans WALKER, strigicollis WALLEN-

So. Atl.

States,

Col., Cal.

a. illaudabilis Grote, Can. Ent., vii, 27, 1875.

1838. albogutta Grote, Bull. Buff. Soc., iii, 85, 1877; SMITH, C. 126.

N. Mex.,

Oreg., Cal.

1839. cuneata Grote, Bull. Buff. Soc., i, 139, 1873; SмIтн, C. 127.

1840. sutrina Grote, Pap., i, 5, 1881; Smith, C. 127; Ent. News, ix, 230, 1898.

1841. quadrannulata Morrison, Proc. Acad. Nat. Sci. Phil., 430, 1875; SмIтн, C. 127.

1842. lorea Guenée, Spec. Gén., v, 126, 1852; Smith, C. 127 .

syn. ligata W ALKer, dodgei Grote.

1843. erecta Walker, Cat. Brit. Mus., x, 264, 1856; Sirth, C. 127.

syn. constipata WaLKer, innexa Grote.

1844. longiclava Smith, Proc. U. S. Nat. Mus., xiv, 265, 1891; C. 128.

1845. anguina Grote, Can. Ent., xiii, 129, 1881; Sмith, C. 128 .

1846. languida Sмith, Trans. Am. Ent. Soc., xxi, 54, 1894.

1847. hadeniformis Surth, Trans. Am. Ent. Soc., xxi, 55,1894 .

1848. fuscolutea Sмiтh, Trans. Am. Ent. Soc., xxi, 55, 1894.

1849. segregata SмIтн, Trans. Am. Ent. Soc., xxi, 56, 1894 .

1850. vicina Grote, Bull. Buff. Soc., ii, 156, 1874; Sмith, C. 128.

syn. teligera Morrison, acutipennis Grote.

1851. pensilis Grote, Proc. Acad. Nat. Sci. Phil., 199, 1874; Sмith, C. 128.

*1852. impolita Morrison, Proc. Bost. Soc. Nat. Hist., xvii, 140, 1874; Smith, C. 129.

1853. plicata Sмrтh, Ent. News, ix, 243, 1898.

*1854. ferrealis Grote, Can. Ent., xv, 29, 1883; Sмith, C. 128 .

Pac. States,

N. Y.

Col.

Neb.,

Tex., Col.

Atl.

States, Col.

Tex.

Col.

No. Atl. States, Col.

Col.

Col.

Col.

B. C.

Atl. States, Cal.

Pac. States, Col.

Can.

Col.

Mont. 
*1855. subdita Möschler, Wien. ent. Mon., iv, 363,

Lab. 1860; Sмith, C. 129.

1856. cervina Sмiтh, Ent. News, ix, 247, 1898.

1857. neoterica Sмптн, Ent. News, ix, 244, 1898.

Man.

1858. nugatis Sмmтн, Ent. News, ix, 240, 1898.

1859. mystica Smith, Ent. News, ix, 242, 1898.

1860. intentata Sмптн, Ent. News, ix, 245, 1898.

Man.

1861. ectrapela Smith, Ent. News, ix, 249, 1898.

Mont., Neb.

Man.

Col.

B. C.

*1862. doira Strecker, Lep. Rhop. Het., suppl. 1, 7, 1898.

Utah.

1863. griseata Sмптн, Proc. U. S. Nat. Mus., xxii, 467, 1900 .

1864. senatoria Sмптн, Proc. U. S. Nat. Mus., xxii, 461, 1900 .

1865. dilatata Smith, Proc. U. S. Nat. Mus., xxii, 464, 1900 .

1866. yakima Smrth, Proc. U. S. Nat. Mus., xxii, 464, 1900.

1867. roseosuffusa Sмгтн, Proc. U. S. Nat. Mus., xxii, 466,1900 .

1868. rainierii Sмптн, Proc. U. S. Nat. Mus., xxii, 462, 1900 .

1869. florida Sмrth, Proc. U. S. Nat. Mus., xxii, 465, 1900 .

1870. bolteri Sмгтн, Proc. U. S. Nat. Mus., xxii, 463, 1900 .

1871. mutilata Smith, Ent. News, ix, 246, 1898.

*1872. selana Strecker, Lep. Rhop. Het., suppl. 1, 7, 1898.

*1873. mania Strrecker, Lep. Rhop. Het., suppl. 2, 5, 1899.

Col.

Ariz.

N. Mex.

Wash.

Ariz.

Wash.

Fla.

N. Mex.

B. C.

Tex.

Col.

*1874. tacoma Strecker, Lep. Rhop. Het., suppl. 3, 31,1900 .

1875. nævia Sмiтн, Ent. News, ix, 248, 1898.

Col.

1876. negussa Sмrтн, Can. Ent., xxxii, 219, 1900.

Alberta.

*1877. circumvadis Smith, Jn. N. Y. Ent. Soc., x, 42, 1902 .

Alberta.

*1878. vau-orbicularis Smith, Jn. N. Y. Ent. Soc., x, 42,1902 .

Oreg. 
ADMETOVIS Grote.

Grote, Bull. Buff. Soc., i, 133, 1873.

1879. oxymorus Grote, Bull. Buff. Soc., i, 133, 1873; Sмiтh, C. 113.

1880. similis BARNES. Cal., Col.

BARATHRA Hübner.

HüBner, Verz. bek. Schmett., 218, 1816; Copimamestra Grote.

1881. occidentata Grote, Ann. Mag. Nat. Hist. (5), xi, N. Mex. 53, 1883; Sмiтh, C. 113.

1882. curialis Sмiтh, Proc. U. S. Nat. Mus., x, 470, Me., 1887; C. 113. N. H.

NEURONIA Hübner.

HüBNer, Verz. bek. Schmett., 215, 1816.

1883. americana Sмiтh, Trans. Am. Ent. Soc., xxi, 59, Mont. 1894 .

\section{DARGIDA Walker.}

Walker, Cat. Brit. Mus., ix, 201, 1856; Eupsephopæctes Grote.

1884. procinctus Grote, Bull. Buff. Soc., i, 138, 1873; Cal., Oreg., Smith, C. 170.

\section{MORRISONIA Grote.}

Grote, Bull. Buff. Soc., ii, 53, 1874; Sмгтн, Proc. U. S. Nat. Mus., xv, 64, 1892.

1885. sectilis Guenée, Spec. Gén., v, 141, 1852; Smith, C. 232 .

No. Atl.

syn. evicta Grote.

States.

a. vomerina Grote, Bull. Buff. Soc., i, 84, 1873.

*1886. infidelis Grote, Can. Ent., xi, 206, 1879; Smith, Mich. C. 232 .

1887. rileyana Sмгтн, Ent. Amer., vi, 212, 1890; C. Mo., 231.

Tex.

1888. bisulca Grote, Can. Ent., xiii, 230, 1881; Sмiтh, Ariz. C. 232 .

1889. mucens HüBner, Verz. bek. Schmett., 243, 1816; Sмith, C. 231.

syn. spoliata WALKER.

Atl.

States.

1890. confusa HüBner, Verz. bek. Schmett., 243, 1816; Simth, C. 232.

syn. infructuosa W ALKER, multifaria W ALKER. 


\section{XYLOMIGES Guenée.}

Guenée, Spec. Gén., v, 147, 1852.

1891. hiemalis Grote, Bull. Buff. Soc., ii, 71, 1874; Sмiтн, C. 233.

syn. californica BEHR.

1892. simplex W WLker, Cat. Brit. Mus., xxxii, 618, 1865; SмIтн, C. 233.

Pac. States, syn. crucialis HaRver.

1893. curialis Grote, Bull. Buff. Soc., i, 143, 1873; Sмптн, C. 233.

1894. dolosa Grote, Can. Ent., xii, 88, 1880; Sмiтth, C. 234.

1895. rubrica Harvey, Can. Ent., x, 58, 1878; Smith, C. 234 .

Col.

Cal.

No. Atl. States, Col.

Cal.,

Oreg.

1896. perlubens Grote, Can. Ent., xiii, 132, 1881; Sмiтн, C. 234.

syn. subapicalis Smith.

*1897. pulchella Sirth, Trans. Am. Ent. Soc., xxi, 81, 1894.

1898. ochracea Riley, Proc. U. S. Nat. Mus., xv, 74 , 1892; SмITH, C. 234.

1899. candida Smith, Trans. Am. Ent. Soc., xxi, 79 , 1898.

1900. patalis Grote, Bull. Buff. Soc., i, 144, 1873; Sмптн, C. 234.

syn. Aletcheri Grote.

1901. cognata Surth, Trans. Am. Ent. Soc., xxi, 78, 1894.

B. C., Oreg., Col.

*1902. peritalis Sмгтн, Proc. U. S. Nat. Mus., xv, 68, 1892; C. 233.

Col.,

Oreg.

Col.

1903. indurata Smith, Trans. Am. Ent. Soc., xxi, 80, 1894.

1904. pallidior Sмптн, Jn. N. Y. Ent. Soc., vii, 227, 1899.

*1905. tabulata Grote, Bull. Geol. Surv. Terr., iv, 181, 1878; Sмith, C. 234.

B. C.

Cal.

B. C.

Pac.

States.

B. C.

N. Y.

\section{SCOTOGRAMMA Smith.}

Smith, Proc. U.S. Nat. Mus., x, 469, 1887.

1906. submarina Grote, Can. Ent., xv, 4, 1883; Sмith, Ariz., Mont.. C. 129 . 
1907. densa Sмптн, Ins. Life, v, 329, 1893.

Cal., Col.

a. megæra Sмгтн. Jn. N. Y. Ent. Soc., vii, 44, 1899.

1908. infuscata Sмrтн, Jn. N. Y. Ent. Soc., vii, 42, 1899.

1909. discolor Sмrтth, Jn. N. Y. Ent. Soc., vii, 42, 1899.

1910. uniformis Sмiтh, Trans. Am. Ent. Soc., xxi, 58, 1894.

1911. luteola Surth, Trans. Am. Ent. Soc., xxi, 57, 1894.

1912. perplexa Sмiтн, Proc. U. S. Nat. Mus., x, 469, 1887 ; C. 129.

1913. inconcinna Sмiтн, Proc. U. S. Nat. Mus., x, 469, 1887; C. 130.

1914. umbrosa Smith, Proc. U. S. Nat. Mus., x, 470, 1887; C. 130.

Col.

Col.

B. C.

B. C.

Col.

Col.

Col.,

Ariz.

1915. phoca Möschler, Wien. ent. Mon., viii, 197. 1864; Sмith, C. 129.

Lab., Col.

syn. promulsa Morrison.

1916. sedilis Sмгтн, Jn. N. Y. Ent. Soc., vii, 43, 1899. *1917. stretchii Hv. Edwards, Can. Ent., xix, 146, 1887; Smith, C. 130.

1918. conjugata Sмгтн, Jn. N. Y. Ent. Soc,, vii, 41, 1899.

\section{ULOLONCHE Smith.}

Smith, Proc. U. S. Nat. Mus., x, 471, 1887.

*1919. niveiguttata Grote, Bull Buff. Soc., i, 140, 1873; SMITH, C. 130.

Cal., Ariz.

1920. orbiculata Sмıтн, Proc. U. S. Nat. Mus., xiv, 266, 1891; C. 131.

Col.

1921. modesta Morrison, Proc. Bost. Soc. Nat. Hist., xvii, 114, 1874; Smith, C. 130.

Atl. States.

1922. fasciata Sмith, Proc. U. S. Nat. Mus., x, 471, 1887; C. 130.

1923. disticha Morrison, Proc. Bost. Soc. Nat. Hist., xvii, 217, 1874; Smith, C. 130.

1924. dilecta Hy. Edwards, Pap., iv, 123, 1884; Sмith, C. 154 .

Col.

Ariz.

Col.

N. Mex.

Tex.

Col.,

Ariz.

ANARTA Ochsenheimer.

Ochsenheimer, Schmett. Eur., iv, 90, 1816.

1925. etacta Sмiтh, Proc. Wash. Acad. Sci., ii, 493, 1900.

Alaska, 
*1926. mimula Grote, Trans. Kans. Acad. Sci., viii, 48, 1883; Smith, C. 295.

*1927. mimuli Behr, Bull. Cal. Acad. Sci., 62, 1885; SMITH, C. 295.

*1928. funebris HüBner, Schmett. Eur., Noct., f. 433, 1804; Smith, C. 295.

1929. acadiensis Bethune, Trans. Nov. Sc. Ins. Nat. Sci., ii, 84, 1869; SмIтH, C. 292.

N. Mex

Cal.

Lab.

Nova

Scotia.

1930. cordigera Thunberg, Mus. Nat. Acad. Ups., Diss., vi, 72, 1788; Sumth, C. 292.

Can., Lab., Col. syn. luteola Grote \& Robinson.

1931. melanopa Thunberg, Diss. Ent., ii, 42, 1791; Arctic Am., Sмith, C. 292.

Col.

syn. nigrolunata PACKARD.

1932. melaleuca Thunberg, Diss. Ent., ii, 42, 1791; Sмiтн, C. 292.

syn. bicycla PACKARD.

1933. quadrilunata Grote, Proc. Bost. Soc. Nat. Hist., xvi, 244, 1874; SмIтH, C. 293.

1934. schœnherri Zetterstedt, Ins. Lap., 950, 1840; Sмптн, C. 293.

syn. leucocycla STAUdinger.

1935. richardsoni Curtis, Ross Narr. Second Voy. N.-W. Pass., app., 72, 1834; Sмгтн, C. 293.

a. lanuginosa Smith, Proc. Wash. Acad. Sci., ii, 492, 1900.

*1936. impingens W alker, Cat. Brit. Mus., xi, 700, 1857; Sмmтн, C. 294.

syn. nivaria Grote, curta MorRison, perpura Morrison.

*1937. secedens W Alker, Cat. Brit. Mus., xii, 913, 1857; Sмith, C. 294.

*1938. membranacea Morrison, Ann. N. Y. Lyc. Nat. Hist., xi, 101, 1875; Sмrтн, C. 294.

Lab.

Col.

Lab.,

Greenl.

Lab., Alaska.

Col.

Can.

N. H.

*1939. lapponica Thunberg, Diss. Ent., ii, 42, 1792; SMITH, C. 294.

syn. amissa LeFèBre.

*1940. kelloggi Hy. Edwwards, Proc. Cal. Acad. Sci., vi, 133, 1875; Smith, C. 295.

Cal.

1941. zetterstedti Staudinger, Stett. ent. Zeit., 294, 1857; Sмiтн, C. 295.

Lab., Lapl.

*1942. quieta Hübner, Schmett. Eur., Noct., 485, 1805; Sмrтн, C. 295.

Arctic

Am.

syn. constricta WALKER, rigida WALKER. 
TRICHOCLEA Grote.

Grote, Pap., iii, 30, 1883; Sмith, C. 209.

1943. edwardsii Sмrтh, Proc. U. S. Nat. Mus., x, 478,

Cal. 1887; C. 209.

1944. decepta Grote, Pap., iii, 30, 1883; Smith, C. 209.

Ariz.

1945. postica Smith, Trans. Am. Ent. Soc., xviii, 115, 1891; C. 209.

Cal. , Col.

a. antica Sмrth, Trans. Am. Ent. Soc., xviii, 116 , 1891; C. 209.

TRICHOPOLIA Grote.

Grote, Pap., iii, 76, 1883.

1946. serrata Sumth, Proc. U. S. Nat. Mus., xxii, 479 , 1900.

*1947. dentatella Grote, Pap., iii, 76, 1883; SмIth, C. 164 .

1948. ptilodonta Grote, Pap., iii, 77, 1883; SмIтн, C. 164 .

Tex.

Ariz.

Ariz.

EUPOLIA Smith.

Smith, Trans. Am. Ent. Soc., xxi, 69, 1894.

1949. licentiosa Surth, Trans. Am. Ent.Soc., xxi, 70, Utah. 1894.

\section{NEPHELODES Guenée. \\ Guenée, Spec. Gén., v, 130, 1852.}

1950. minians Guenée, Spec. Gén., v, 130, 1852; Sмith, C. 172.

syn. expansa WALKER, sobria WALKER.

a. violans Guenée, Spec. Gén., v, 130, 1852.

syn. subdolens WALKER.

1951. pectinatus Smith, Can. Ent., xxxii, 221, 1900.

Atl. States.

\section{HELIOPHILA Hiibner.}

Hübner, Tent., 1806; Leucania Ochsenheimer, Schmett. Eur., iv, 81, 1816; Smith, Proc. U. S. Nat. Mus., xxv, 159, 1902.

*1952. Iutina Sмiтh, Proc. U. S. Nat. Mus., xxv, 176, Fla. 1902.

syn. velutina Smith (not Eversmann), Proc.

U. S. Nat. Mus., xxii, 480, 1900.

1953. unipuncta Haworth, Lep. Brit., ii, 177, 1810; Sмith, C. 189. 
1954. pseudargyria Guenée, Spec. Gén., v, 74, 1852; SiITH, C. 189.

a. callida Grote, New Check List, 30, 1882.

*1955. pilipalpis Grote, Proc. Bost. Soc. Nat. Hist., xviii, 415, 1875; Sмптн, C. 189.

1956. subpunctata Harvey, Bull. Buff. Soc., iii, 8, 1875; Sмith, C. 189.

syn. complicata Strecker, Lep. Rhop. Het., suppl. 1, 9, 1898.

1957. luteopallens Sмiтh, Proc. U. S. Nat. Mus., xxv, $180,1902$.

1958. minorata Syith, Trans. Am. Ent. Soc., xxi, 75 , 1894.

1959. oxygale Grote, Can. Ent., xiii, 14, 1881; Sмптн, C. 185 .

1960. rubripallens Sмгтн, Proc. U. S. Nat. Mus., xxv, $182,1902$.

*1961. pertracta Morrison, Proc. Bost. Soc. Nat. Hist., xviii, 120, 1875; Sмiтh, C. 186.

1962. rubripennis Grote \& Robinson, Trans. Am. Ent. Soc., iii, 179, 1870; Sмith, C. 186.

1963. albilinea HüBner, Samml. exot. Schmett., f. 337, 1816; Sмiтh, C. 186.

syn. harveyi GRots.

1964. obscurior Sirth, Proc. U. S. Nat. Mus., xxv, $185,1902$.

1965. diffusa Walker, Cat. Brit. Mus., ix, 94, 1856; SмmTh, C. 186.

syn. moderata WALKER.

*1966. limitata Suith, Proc. U. S. Nat. Mus., xxv, 187, 1902.

1967. tetra Sмiтh, Proc. U. S. Nat. Mus., xxv, 187, 1902.

1968. neptis Sмгтн, Proc. U. S. Nat. Mus., xxv, 188, 1902.

1969. ligata Grote, Trans. Am. Ent. Soc., v, 115, 1875; SMITH, C. 187.

*1970. flabilis Grote, Can. Ent., xiii, 15, 1881; Sмптн, C. 189.

1971. rimosa Grote, Can. Ent., xiv, 216, 1882; Sиiтh, C. 189.

Atl. States.

Cal.,

Oreg.

Col.

Col., Utah.

$\mathrm{Pa}$.

So.

States.

Atl.

States.

Man.

Atl.

States.

Tex.

Ariz.

Col.

Tex., Col., Fla.

N. Y.

Me.

Cal.

1972. dia Grote, Can. Ent., xi, 29, 1879; Sмптн, C. 187. 
1973. megadia Sмrтн. Proc. U. S. Nat. Mus., xxv, 191, 1902 .

1974. heterodoxa Surth, Trans. Am. Ent. Soc., xxi, 75, 1894.

1975. insueta Guenḱe, Spec. Gén., v, 81, 1852; Sмith, C. 188 .

syn. adonea Grote, mimica Strecker, Lep. Rhop. Het., suppl. 2, 6, 1899.

1976. extincta Guenée, Spec. Gén., v, 79, 1852; Suith, C. 187.

syn. linita Guenée, scirpicola Guenée, amygdalina Harver.

1977. juncicola Guenée, Spec. Gén., v, 83, 1852; Sмith, C. 188.

syn. adjuta Grote.

1978. multilinea WALKER, Cat. Brit. Mus., ix, 97, 1856; Sмith, C. 187.

syn. lapidaria Grote.

1979. commoides Guenée, Spec. Gén., v, 86, 1852; Sirth, C. 188.

1980. phragmitidicola Guenée, Spec. Gén., v, 89, 1852; Smith, C. 187.

a. texana Morrison, Proc. Bost. Soc. Nat. Hist., xvii, 211, 1874.

1981. imperfecta Sмiтh, Trans. Am. Ent. Soc., xxi, 76, 1894.

1982. anteroclara Sirth, Proc. U. S. Nat. Mus., xxv, 200,1902 .

1983. calgariana Sмiтh, Proc. U. S. Nat. Mus., xxv, 201, 1902 .

*1984. stolata Surth, Trans. Am. Ent. Soc., xxi, 76, 1894.

*1985. oregona Suith, Proc. U. S. Nat. Mus., xxv, 202, 1902.

1986. roseola Surth, Trans. Am. Ent. Soc., xxi, 75, 1894.

1987. farcta Grote, Can. Ent., xiii, 15, 1881; Sмith, C. 188 .

1988. palliseca Sмiтh, Proc. U. S. Nat. Mus., xxv, 203, 1902.

\section{NELEUCANIA Smith.}

Sмith, Proc. U. S. Nat. Mus., xxv, 203, 1902.

1989. niveicosta Sмiтh, Proc. U. S. Nat. Mus., xxv, 205, 1902.
Pac. States, Ariz.

Cal., B. C., Minn.

Atl. States, Col.

Atl.

States.

Ala.,

Tex.

Atl.

States.

Atl. States, Col.

Atl. States, Col.

Ariz.

Alberta.

Alberta.

Ariz.

Oreg.

B. C.

Cal.

Cal., Col.

Col. 
1990. bicolorata Grote, Pap., i, 154, 1881; Sмith, C. 186.

Ariz., Col.

1991. citronella Sмiтh, Proc. U. S. Nat. Mus., xxv, $206,1902$.

1992. patricia Grote, Bull. Brook. Ent. Soc., iii, 46 , 1880; Sмith, C. 186.

Col., N. Mex.

*1993. prægracilis Grote, Bull. Geol. Surv. Terr., iii, 119, 1877; SмIтH, C. 185.

Rocky

Mts.

\section{ZOSTEROPODA Grote.}

Grote, Bull. Buff. Soc., ii, 67, 1874.

1994. hirtipes Grote, Bull. Buff. Soc., ii, 68, 1874; SмITH, C. 190.

Cal.

TRICHORTHOSIA Grote.

Grote, Pap., iii, 31, 1883.

*1995. parallela Grote, Pap., iii, 31, 1883; Smith, C. 210.

N. Mex.

\section{ORTHODES Guenée.}

Guenée, Spec. Gén., v, 371, 1852.

1996. crenulata Butler, Ann. Mag. Nat. Hist., (6), vi, 97, 1890; Sмith, C. 198.

Atl.

States.

1997. cynica Guenée, Spec. Gén., v, 375, 1852; Sмith, C. 190 .

syn. candens Guenée, tecta W AlKer.

1998. vecors Guenée, Spec. Gén., v, 376, 1852; Sirth, C. 199 .

syn. enervis Guenée, nimia Guenée, togata W ALKER, velata W ALKER, prodeuns W ALKER, griseocincta HaRveY, nitens Grote.

1999. virgula Grote, Pap., iii, 76, 1883; Sмiтh, C. 200.

2000. irrorata Sмгтн, Proc. U. S. Nat. Mus., x, 478 , 1887; C. 200.

Atl. States, Col.

Atl. States.

Ariz., Col.

Wash.,

B. C.

Cal. Sмiтt, C. 200.

*2002. agrotiformis Grote, Can. Ent., xiii, 14, 1881; SMith, C. 200.

*2003. calceolarius Strecker, Lep. Rhop. Het., suppl. $3,33,1900$.

*2004. imora Strecker, Lep. Rhop. Het., suppl. 1, 8, 1898.

\section{Col.}

N. Y.

Wis. 
*2005. akalus Strecker, Lep. Rhop. Het., suppl. 2, 6, Col. 1899.

HIMELLA Grote.

Grote, Proc. Acad. Nat. Sci. Phil., 200, 1874; Smith, C. 200.

2006. contrahens WaLker, Can. Nat. Geol., v, 255, 1860; Sмith, C. 200.

syn. thecata Morrison.

2007. intractata Morrison, Proc. Bost. Soc. Nat. Hist., xvii, 160, 1874; Sмiтh, C. 201.

syn. fidelis Grote.

*2008. conar Strecker, Lep. Rhop. Het., suppl. 1, 7 . 1898.

syn. quadristigma Surth, Proc. U. S. Nat. Mus., xxii, 480, 1900.

\section{CROCIGRAPHA Grote.}

Grote, Can. Ent., vii, 57, 1875; Sмiтh, C. 201.

2009. normani Grote, Can. Ent., vi, 115, 1874; Sмith, C. 201.

No. Atl. States.

GRAPHIPHORA Hübner.

Hübner, Tent., 1806; Tæniocampa Guenée, Ann. Soc. Ent. Fr., viii, 477, 1839.

2010. carminata Snith, Ent. Amer., vi, 121, 1890; C. 202.

2011. trifascia Sмrтh, Trans. Am. Ent. Soc., xviii, 118, 1891; C. 202.

2012. culea Guenée, Spec. Gén., v, 404, 1852; Smith, C. 202.

syn. modifica Morrison.

2013. consopita Grote, Pap., i, 154, 1881; Sмiтh, C. 202.

2014. rufula Grote, Bull. Buff. Soc., ii, 64, 1874; Smith, C. 203.

2015. oviducta Guenée, Spec. Gén., v, 357, 1852; Smith, C. 203.

syn. capsella Grote, orobia Harvey.

2016. utahensis Sмiтh, Proc. U. S. Nat. Mus., x, 473, 1887; C. 203.

2017. curtica Sмiтh, Ent. Amer., vi, 122, 1890; C. 203.

2017. 1. suffusa Sirth, Proc. U. S. Nat. Mus., x, 174, 1887; C. 203.
No. Atl.

States, Col.,

N. Mex.

Atl.

States.

N. Mex., Utah, Ariz.
Col.

Col.

Atl.

States.

Ariz.

Cal.,

Col.

Atl.

States.

Utah.

Cal.

Col.,

Ariz. 
2018. incincta Morrison, Proc. Bost. Soc. Nat. Hist., xvii, 133, 156, 1874; Sмптн, C. 203.

Mass., Ill., Col.

2019. pectinata Sмгтн, Proc. U. S. Nat. Mus., x, 475, 1887; C. 204.

2020. annulimacula Sмrтн, Trans. Am. Ent. Soc., xviii, 117, 1891; C. 204.

2021. uniformis SMIth, Proc. U. S. Nat. Mus., x, 472, 1887; C. 202.

2022. palilis Harvey, Bull. Buff. Soc., ii, 273, 1875; Sмiтh, C. 202.

2023. columbia Sмrтh, Proc. U. S. Nat. Mus., x, 472, 1887; C. 202.

2024. furfurata Grote, Proc. Acad. Nat. Sci. Phil., 201, 1874; Sмith, C. 201.

2025. perbrunnea Grote, Can. Ent., xi, 28, 1879; SMITH, C. 202.

2026. peredia Grote, Pap., iii, 32, 1883; Sмrth, C. 201.

*2027. perforata Grote, Pap., iii, 73, 1883; Sмith, C. 203.

*2028. obtusa Smith, Proc. U. S. Nat. Mus., x, 474, 1887; C. 204.

Cal.

Tex.

Ariz.

Tex.

B. C.

U. S.

Cal.

No. Atl.

States.

Ariz.

Ariz.

*2029. terminata Smith, Proc. U. S. Nat. Mus., x, 475, 1887; C. 204.

So.

Cal.

2030. reliqua Sмгтн, Jn. N. Y. Ent. Soc., vii, $226,1899$.

*2031. præses Grote, Bull. Geol. Surv. Terr., v, 202, 1879; SмITH, C. 206.

*2032. revicta Morrison, Proc. Bost. Soc. Nat. Hist., xviii, 241, 1875; Smith, C. 206.

2033. ferrigera Sмiтн, Trans. Am. Ent. Soc., xxi, 78, 1894.

Col.

Cal.

IIl.

B. C., Oreg.

2034. flaviannula Sмrтh, Jn. N. Y. Ent. Soc., vii, 225, 1899.

*2035. saturnus Strecker, Lep. Rhop. Het., suppl. 3, 31,1900 .

*2036. subfuscula Grote, Proc. Bost. Soc. Nat. Hist., xvi, 244, 1873; Smith, C. 204.

Col.

Wis.

Oreg.,

Mont.

*2037. arthrolita Harvey, Bull. Buff. Soc., ii, 275, 1874; Smith, C. 204.

2038. vindemialis Guenée, Spec. Gén., v, 344, 1852; SMITH, C. 205.

Cal.

Fla. ? 
2039. pacifica Harvey, Bull. Buff. Soc., ii, 120, 1874; Sмнтн, C. 205.

Col., Cal.

2040. alia Guenée, Spec. Gén., v, 352, 1852; Smith, C. 205 .

syn. instabilis Fitch, insciens WaLker.

a. hibisci Guenée, Spec. Gén., v, 355, 1852.

syn. comfluens Morrison.

*2041. alurina Sмiтh, Jn. N. Y. Ent. Soc., x, 47, 1902.

2042. rubrescens W Alker, Cat. Brit. Mus., xxxii, 671, 1865; Snith, C. 206.

Atl. States.

syn. venata SмITH.

2043. subterminata Sмiтh, Proc. U. S. Nat. Mus., x, 476, 1887; C. 206.

No. Atl.

States.

No. Atl.

States.

III.,

Iowa.

C. 206.

Ga.

*2045. styracis Guenée, Spec. Gén., v, 357, 1852; SмITH, C. 206.

*2046. planalis Grote, Ann. Mag. Nat. Hist., (5), xi, 53, 1883; Smith, C. 206.

STRETCHIA Hy. Edwards.

Hy. Edwards, Proc. Cal. Acad. Sci., v, 267, 1874; Acerra Grote.

2047. normalis Grote, Bull. Buff. Soc., ii, 162, 1874;

Cal.

Smith, C. 207.

2048. plusiiformis Hy. Edwards, Proc. Cal. Acad. Sci., V, 267, 1874; SмmTh, C. 208.

Cal., Col., Nev., Oreg.

syn. muricina Grote, Bull. Buff. Soc., iii, 85, 1875; inferior Smith, Proc. U. S. Nat. Mus., $\mathrm{x}, 477,1887$.

2049. behrensiana Grote, Can. Ent., vii, 71, 1875; Sмith, C. 208.

2050. variabilis Smith, Trans. Am. Ent. Soc., xviii, 119, 1891; C. 208.

2051. addenda Surth, Ent. Amer., vi, 122, 1890; C. 208; Jn. N. Y. Ent. Soc., vii, 225, 1899.

*2052. pulchella Harver, Can. Ent., viii, 54, 1876; Snith, C. 208; Jn. N. Y. Ent. Soc., vii, 225, 1899.

Cal.

Col.

Cal.

Cal.

2053. erythrolita Grote, Can. Ent., xi, 208, 1879; SMITH, C. 208.

2054. transparens Grote, Bull. Geol. Surv. Terr., vi, 583, 1881; Sminh, C. 208.

Wash.,

Cal.

syn. hamifera Grote, Can. Ent., xx, 130, 1888;

Smith, C. 218. 
2055. mys Dyar (fore wings dark purple-brown, slightly hoary, unspotted; hind wings whitish, rosy tinged at the edges).

\section{PERIGONICA Smith.}

Sмiтh, Ent. Amer., vi, 123, 1890.

2056. angulata Sмгтн, Ent. Amer., vi, 124, 1890; C. 209.

2057. tertia DYAR (markings of angulata, antennæ of fulminans).

Cal.

Cal.,

Oreg.

2058. fulminans Sмптн, Ent. Amer., vi, 124, 1890; C. 209.

\section{PERIGRAPHA Lederer. \\ Lederer, Noct. Eur., 136, 1857.}

*2059. prima Surth, Trans. Am. Ent. Soc., xviii, 119, 1891; C. 209.

Cal.

\section{TRICHOLITA Grote.}

Grote, Bull. Buff. Soc., ii, 211, 215, 1875.

2060. signata Walker, Can. Nat. Geol., v, 253, 1860; SMITH, C. 172.

No. Atl.

States.

syn. semiaperta Morrison.

2061. fistula Harvey, Can. Ent., x, 56, 1878; SiIth, C. 173 .

2062. inconspicua Grote, Can. Ent., xv, 129, 1883; Sмiтн, C. 173.

*2063. notata Strecker, Lep. Rhop. Het., suppl. 1, 9. 1898.

*2064. syrissa Strecker, Lep. Rhop. Het., suppl. 2, 6, 1899.

\section{COBALIODES Dyar.}

Cobalos Sмith (not Cobalus Hüвner), Jn. N. Y. Ent. Soc., vii, 223, 1899.

2065. franciscanus Smith, Jn. N. Y. Ent. Soc., vii, 224,

Cal. 1899.

2066. angelicus Sмrтн, Jn. N. Y. Ent. Soc., vii, 223, 1899.

Cal.

\section{CLEOCERIS Boisduval.}

Boisduval, Ind. Méth., 93, 1829.

2067. populi Strecker, Lep. Rhop. Het., suppl. 1, 8, 1898. 
*2068. onychina Guenée, Spec. Gén., vi, 48, 1852; No. Am. Sмith, C. 215.

2069. elda French, Can. Ent., xix, 5, 1887; Sмmth, Cal. C. 215 .

2070. rectifascia Sмгтн, Trans. Am. Ent. Soc., xviii, 109, 1891; C. 215.

2071. curvifascia Sмiтh, Trans. Am. Ent. Soc., xviii, 109, 1891; C. 215.

\section{APOROPHILA Guenée.}

Guenée, Ind. Méth., Ann. Soc. Ent. Fr., x, 246, 1841.

*2072. yosemitæ ('rote, Bull. Buff. Soc., i, 113, 1873; SMITH, C. 163.

\section{PLEROMA Smith.}

Smith, Trans. Am. Ent. Soc., xviii, 114, 1891.

2073. obliquata Smith, Trans. Am. Ent. Soc., xviii, 114, 1891; C. 235 .

Col.,

Cal.

2074. bonuscula Sмrтh, Can. Ent., xxx, 325, 1898.

Col.

*2075. conserta Grote, Pap., i, 58, 1881; Smith, C. 235.

Wash.

*2076. apposita Surth, Trans. Am. Ent. Soc., xxi, 81, 1894.

B. C.

\section{LITHOMOIA Hübner.}

HüBNer, Verz. bek. Schmett., 244, 1816.

2077. germana Morrison, Bull. Buff. Soc., ii, 192, 1874; Smith, C. 235.

No. Atl.

States.

\section{XYLINA Ochsenheimer.}

Ochsenhermer, Schmett. Eur., iv, 85, 1816; Simith, Trans. Am. Ent. Soc., xxvii, 1, 1900; Lithophane HǘnNER, Verz. bek. Schmett., 242, 1816.

2078. disposita Morrison, Bull. Buff. Soc., ii, 116, No. Atl. 1874; Sмiтh, C. 227.

States.

2079. petulca Grote, Sixth Rept. Peab. Acad. Sci., 31, No. Atl. 1874; Sмith, C. 227.

States.

2080. contenta Grote, Can. Ent., xii, 216, 1880: Surth, Cal., C. 224 .

Wash.

syn. pomona Sмrтh, Jn. N. Y. Ent. Soc., vii, $230,1899$.

2081. puella Sмnтh, Trans. Am. Ent. Soc., xxvii, 30, 1900.

*2082. dentilinea Smith, Jn. N. Y. Ent. Soc., vii, 229, Ariz., 1899. 
2083. longior Sмrтн, Jn. N. Y. Ent. Soc., vii, 230, 1899.

2084. torrida Sмiтн, Jn. N. Y. Ent. Soc., vii, 228, 1899. 2085. itata Sмптн, Jn. N. Y. Ent. Soc., vii, 231, 1899.

*2086. hemina Grote, Bull. Geol. Surv. Terr., v, 202, 1879 ; Smith, C. 227.

*2087. gausapata Grote, Pap., iii, 77, 1883; Sмith. C. 227.

2088. dilatocula Surth, Trans. Am. Ent. Soc., xxvii, 42,1900 .

*2089. patefacta Walker, Cat. Brit. Mus., xiv, 1733, 1858; SмIтH, C. 231.

2090. antennata WALker, Cat. Brit. Mus., xiv, 1733, 1858; Sмiтн, C. 228.

syn. cinerea RILEy.

2091. laticinerea Grote, Bull. Buff. Soc., ii, 27, 1874; SMITH, C. 229.

2092. grotei Riley, Pap., ii, 102, 1882; Smith, C. 229. syn. cinerosa Grote (not Guenée).

a. winnipeg Sмrth, Trans. Am. Ent. Soc., xxvii, 31, 1900 .

2093. ferrealis Grote, Sixth Rept. Peab. Acad. Sci., 32, 1874; Sмiтн, C. 227.

2094. signosa Walker, Cat. Brit. Mus., xi, 627, 1857; SMitH, C. 227.

2095. innominata SмIтH, C. 227.

2096. amanda Surth, Trans. Am. Ent. Soc., xxvii, 24, 1900.

2097. bethunei Grote \& Robinson, Trans. Am. Ent. Soc., i, 354, 1868; Smith, C. 227.

2098. oriunda Grote, Bull. Buff. Soc., ii, 160, 1874; SмIтH, C. 224.

2099. semiusta Grote, Sixth Rept. Peab. Acad. Sci., 24, 1874; Smith, C. 228.

2100. fagina Morrison, Bull. Buff. Soc., ii, 115, 1874; SMITH, C. 228.

*2101. oregonensis Harver, Can. Ent., viii, 55, 1876; Sмith, C. 228.

2102. georgii Grote, Can. Ent., vii, 88, 1875; Sмптн, C. 228 .
Col.

Pac. States.

Col.

No. Atl.

States.

Cal.

Wash.,

Cal.

Can.

Atl.

States.

Atl.

States.

Atl. States.

Atl.

States.

No. Atl.

States.

No. Atl. States, Col.

No.

U. S.

No. Atl.

States.

Can.,

Wis.

No. Atl.

States.

Mass.,

N. Y.

Oreg., Cal., Col.

No. Atl.

States. 
2103. holocinerea Sмiтt, Trans. Am. Ent. Soc., xxvii, 28, 1900 .

2104. emarginata SмIтн, Trans. Am. Ent. Soc., xxvii, 28,1900 .

*2105. viridipallens Grote, Can. Ent., ix, 215, 1877; Sмiтн, C. 229.

2106. unimoda Lintner, Ent. Cont., iv, 96, 1878; Sмith, C. 229.

2107. tepida Grote, Bull. Buff. Soc., ii, 27, 1874; SMITH, C. 229.

2108. baileyi Grote, Can. Ent., ix, 86, 1877; Smith, C. 229.

2109. querquera Grote, Sixth Rept. Peab. Acad. Sci., 34, 1874; Sмith, C. 229.

2110. lepida Lintner, Ent. Cont., iv, 95, 1878; Smith, C. 230 .

2111. thaxteri Grote, Bull. Buff. Soc., ii, 196, 1874; Sмith, C. 230.

2112. pexata Grote, Sixth Rept. Peab. Acad. Sci., 35, 1874; SMith, C. 230.

a. washingtonia Grote, Pap., iii, 74, 1883.

2113. capax Grote \& Robinson, Trans. Am. Ent. Soc., i, 355, 1868; Sмiтh, C. 230.

\section{EUHARVEYA Grote.}

Grote, Can. Ent., xxvi, 81, 1894.

2114. carbonaria Harver, Can. Ent., viii, 55, 1876; Sмith, C. 230.

\section{LITHOLOMIA Grote.}

Grote, Can. Ent., vii, 206, 1875.

2115. napæa Morrison, Proc. Bost. Soc. Nat. Hist., xvii, 152, 1874; Smith, C. 226.

2116. dunbari Harvey, Can. Ent., viii, 52, 1876; Sмiтh, C. 226.

\section{CALOCAMPA Stephens.}

Stephens, Ill. Brit. Ent. Haust., ii, 174, 1829.

2117. brucei Smith, Ent. News, iii, 252, 1892; Trans. Am. Ent. Soc., xxi, 82, 1894.

2118. nupera Lintwer, Bull. Buff. Soc., ii, 188, 1874; SMith, C. 235.
Pac.

States.

Col.

Mass.,

N. Y.

No. Atl. States.

No. Atl,

States.

N. Y.

Mo.,

N. Y.

No. Atl.

States.

No. Atl.

States.

No. Atl.

States,

Wash.

No. Atl.

States, Col.

Oreg., Cal., Col.

No. Atl. States, Col., Cal.

B. C.

Col. 
2119. thoracica Putnam-Cramer, Ent. Amer., ii, 142 , 1886; SмITh, C. 236.

No.

U.S.

2120. cineritia Grote, Proc. Acad. Nat. Sci. Phil., 210, 1874; Sмith, C. 236.

No. Atl.

States.

2121. curvimacula Morrison, Bull. Buff. Soc., ii, 191, 1874; Sмith, C. 236.

No.

U. S.

*2121.1. brillians Ottolengui, Jn. N. Y. Ent. Soc., x, $78,1902$.

Me.,

N. H.

\section{CUCULLIA Schrank.}

Schrank, Faun. Boica, ii, 157, 1802.

2122. convexipennis Grote \& Robinson, Trans. Am. Ent. Soc., ii, 201, 1868; Smith, C. 236.

2123. montanæ Grote, Can. Ent., xv, 178, 1882; SмIтH, C. 237 .

2124. similaris Smith, Proc. U. S. Nat. Mus., xv, 40, 1892; C. 237.

2125. obscurior Sirth, Proc. U. S. Nat. Mus., xv, 40, 1892; C. 237.

2126. postera Guenée, Spec. Gén., vi, 133, 1852; Sмiтh, C. 237.

2127. asteroides Guenée, Spec. Gén., vi, 133, 1852; SMITH, C. 237.

2128. florea Guenée, Spec. Gén., vi, 133, 1852; Smith, C. 237 .

2129. lætifica Lintner, Grote, Check List Noct., 24, 1875; SMITH, C. 237.

syn. cita Grote, hartmanni French.

2130. dorsalis Sмiтh, Proc. U. S. Nat. Mus., xv, 46, 1892; C. 238.

2131. speyeri Lintner, Ent. Cont., iii, 168, 1874; SMITH, C. 238.

2132. intermedia Speyer, Stett. ent. Zeit., xxxi, 400, 1870 ; SмITh, C. 238.

2133. cinderella Sмгтн, Proc. U. S. Nat. Mus., xv, 48, 1892: C. 238.

Atl.

States.

Col.,

Mont.

Col.

Col.

Atl.

States.

Atl.

States.

Atl.

States.

Tex.,

Ariz.

Col.

Col.

Atl.

States.

Col.

Cal.

2134. serraticornis Lintner, Ent. Cont., iii, 174, 1874; SMITH, C. 238.

2135. bistriga SмIтh, Proc. U. S. Nat. Mus., xv, 47, 1892; C. 238.

Col.

2136. albida Sмiтh, Trans. Am. Ent. Soc., xxi, 84, 1894.

Col. 
COPICUCULLIA Smith.

Smith, Trans Am. Ent. Soc., xxi, 84, 1894.

*2137. eulepis Grote, Bull. Buff. Soc., iii, 86, 1875; SMith, C. 236.

Oreg.,

Cal.

2138. antipoda Strecker, Lep. Rhop. Het., 129, 1875; Sмith, C. 236.

Col.,

Ariz.

*2139. alfarata Strecker, Lep. Rhop. Het., suppl. 1, $9,1898$.

Fla.

2140. astigma Smith, Trans. Am. Ent. Soc., xxi, 85,

Col. 1894 .

2141. propinqua Smith, Trans. Am. Ent. Soc. , xxi, 85 ,

Col. 1894.

RANCORA Smith.

Smith, Trans. Am. Ent. Soc., xxi, 83, 1894.

2142. solidaginis BEHr, Strecker, Lep. Rhop. Het., 94, 1874; Snith, C. 239.

Cal., B. C. syn. strigata Smith, Trans. Am. Ent. Soc., xxi, 83, 1894.

*2143. matricaria BEHR, Strecker, Lep. Rhop. Het., 94, Cal. 1874.

\section{LATHOSEA Grote.}

Grote, Bull. Geol. Surv. Terr., vi, 270, 1882.

2144. pullata Grote, Bull Geol. Surv. Terr., vi, 270, 1882; Sмith, C. 163.

Oreg., Col.

2145. ursina Smith, Can. Ent., xxxi, 324, 1898.

Col.

\section{ASTEROSCOPUS Boisduval.}

Boisduval, Ind. Méth., 59, 1829.

2146. borealis Sмiтн, Can. Ent., xxxi, 25, 1899.

Man.

\section{BELLURA Walker.}

WAlker, Cat. Brit. Mus., xxxii, 465, 1865; Arzama Walker.

2147. gortynides Walker, Cat. Brit. Mus., xxxii, 465, 1865; SмIтH, C. 181.

syn. densa WALKER, vulnifica Grote, melanopyga Grote.

2148. diffusa Grote, Bull. Geol. Surv. Terr., iv, 179, 1878; Sмith, C. 181. 


\section{SPHIDA Grote.}

Grote, Bull. Geol. Surv. Terr., iv, 179, 1878.

2149. obliqua Walker, Cat. Brit. Mus., xxxii, 428, 1865; SмITH, C. 181.

syn. obliquata Grote \& Robinson.

NONAGRIA Ochsenheimer.

Ochsenhermer, Schmett. Eur., iv, 82, 1816.

2150. permagna Grote, Pap., iii, 73, 1883; Sмптн, C. 182.

2151. subflava Grote, Pap., ii, 95, 1882; Sмiтh, C. 182.

*2152. oblonga Grote, Pap., ii, 96, 1882; Sмiтh, C. 182.

2153. subcarnea Kellicott, Can. Ent., xv, 175, 1883; Sмith, C. 182.

*2154. læta Morrison, Proc. Bost. Soc. Nat. Hist., xviii, 120, 1875; Sмiтh, C. 182.

*2155. inquinata Guenée, Spec. Gén., v, 104, 1852; Sмith, C. 183.

OMMATOSTOLA Grote.

Grote, Bull. Buff. Soc., ii, 112, 1873.

2156. lintneri Grote, Bull. Buff. Soc., ii, 112, 1873; SмiтH, C. 185.

N. Y., N. J.

2157. popofensis Sмптн, Proc. Wash. Acad. Sci., ii, 492, Alaska. 1900.

ACHATODES Guenée.

Guenée, Spec. Gén., v, 132, 1852.

2158. zeæ Harris, Ins. Inj. Veg., 319, 1841; Sirth, C. 179.

\section{GORTYNA Ochsenheimer.}

Ochsenheimer, Schmett., Eur., iv, 82, 1816.

2159. albilunata Sмiтh, Trans. Am. Ent. Soc., xxvi, 14, 1899.

syn. lunata Syith (not Freyer), Trans. Am. Ent. Soc., xviii, 110, 1891.

*2160. u-album Guenée, Spec. Gén., v, 345, 1852; Sмrтн, C. 174; Trans. Am. Ent. Soc., xxvi, 15, 1899. 
2161. velata Walker, Cat. Brit. Mus., xxxii, 671, 1865; Sмrth, C. 174; Trans. Am. Ent. Soc., xxvi, Atl. 20,1899 .

syn. sera Grote \& Robinson.

2162. nictitans Borkhausen, Naturg. Europ. Schmett., iv, 463, 1792; Smith, C. 174.

syn. erythrostigma HAwORTH, lucens FrEYER. a. americana SPEYER, Stett. ent. Zeit., xxxvi, 152, 1875 .

syn. atlantica Sumth, Trans. Am. Ent. Soc., xxvi, 18, 1899.

b. pacifica Smith, Trans. Am. Ent. Soc., xxvi, 19, 1899.

c. interoceanica Smiтн, Trans. Am. Ent. Soc., xxvi, 17,1899 .

*2163. erepta Grote, Bull. Geol. Surv. Terr., vi, 267, 1881; SмIтн, C. 175.

2164. juvenilis Grote, Bull. Geol. Surv. Terr., vi, 267, 1881; Surth, C. 174; Trans. Am. Ent. Soc., xxvi, 20,1899 .

2165. immanis Guenée, Spec. Gén., v, 128, 1852; Surth, C. 175; Trans. Am. Ent. Soc., xxvi, 21, 1899.

*2166. stramentosa GuenéE, Spec. Gén., v, 129, 1852; Smith, C. 175; Trans. Am. Ent. Soc., xxvi, 22, 1899.

2167. obliqua Harver, Can. Ent.. viii, 53, 1876; Syith, C. 175; 'Trans. Am. Ent. Soc., xxvi, 23, 1899.

2168. medialis Snith, Trans. Am. Ent. Soc., xxi, 74, 1894; xxvi, 24, 1899.

syn. pallescens Surth, Trans. Am. Ent. Soc., xxvi, 25, 1899.

2169. senilis Sмrтн, Trans. Am. Ent. Soc., xxi, 73, 1894; xxvi, 25, 1899.

2170. serrata Grote, No. Am. Ent., i, 94, 1880; Sмith, C. 179; Trans. Am. Ent. Soc., xxvi, 26, 1899.

States.

Atl.

States.

Cal.

Kans.

Col.,

Kans.

No.

U. S.

No. Atl.

States.

Atl.

States.

No. Pac. States, Col.

Col.

Col.

$$
\text { PAPAIPEMA Smith. }
$$

Smith, Trans. Am. Ent. Soc., xxvi, 2, 1899.

2171. cerina Grote, Proc. Acad. Nat. Sci. Phil., 200, 1874; Sмith, C. 176.

2172. inquæsita Grote \& Robinson, Trans. Am. Ent. Soc., i, 344, 1868; Smith, C. 176.

Kans.,

Me.

No. Atl.

States.

2173. speciosissima Grote \& Robinson, Trans. Am. Ent. Soc., i, 342, 1868; Surth, C. 177; Trans.

No. Atl. States. 
2174. rigida Grote, Can. Ent., ix, 87, 1877; Sмith, C. 176.

No. Atl.

States.

2175. harrisii Grote, Bull. Geol. Surv. Terr., vi, 268, 276,$1882 ;$ Sмith, C. 177.

No. Atl.

States.

Man.

2176. verona Sмiтh, Trans. Am. Ent. Soc., xxvi, 32, 1899.

2177. baptisiæ Bird, Can. Ent., xxxiv, 109, 1902.

Atl. States.

2178. purpurifascia Grote \& Robinson, Trans. Am. Ent. Soc., i, 341, 1868; Smith, C. 176.

2179. nitela Guenée, Spec. Gén., v, 124, 1852; Sмith, C. 178 .

a. nebris Guenée, Spec. Gén., v, 124, 1852.

2180. nelita Strecker, Lep. Rhop. Het., suppl. 1, 8, 1898; Sмiтh, Trans. Am. Ent. Soc., xxvi, 35, 1899 .

syn. ærata Lyman, Can. Ent., xxxiii, 319, 1901.

2181. necopina Grote, Can. Ent., viii, 25, 1876; Sмith, C. 179 .

2182. limpida Guenée, Spec. Gén., v, 124, 1852; Sмith, C. 178 .

2183. cerussata Grote \& Robinson, Proc. Ent. Soc. Phil., ii, 431, 1864; SмIтн, C. 178.

2184. frigida Sмгтн, Trans. Am. Ent. Soc., xxvi, 39, 1899.

2185. unimoda Sмiтh, Trans. Am. Ent. Soc., xxi, 73, 1894; xxvi, 39, 1899.

2186. angelica Sмiтh, Trans. Am. Ent. Soc., xxvi, 40, 1899.

2187. cataphracta Grote, Proc. Acad. Nat. Sci. Phil., 81, 1864; Sмith, C. 176.

2188. impecuniosa Grote, Bull. Geol. Surv. Terr., vi, 267, 1882; SмIтн, C. 176.

2189. circumlucens Sмiтh, Trans. Am. Ent. Soc., xxvi, 43,1899 .

2189. 1. duovata Brrd, Can. Ent., xxxiv, 115, 1902.

2190. rutila Guenée, Spec. Gén., v, 123, 1852; Sмiтh, C. 177 .

*2190. 1. insulidens BIRD, Can. Ent., xxxiv, 112, 1902.

2191. appassionata Harvey, Can. Ent., viii, 155, 1876; SMITH, C. 178.

2192. marginidens Guenée, Spec. Gén., v, 123, 1852; Sмiтh, C. 177.

Atl.

States.

Atl.

States.

No. Atl.

States.

N. Y.

No. Atl.

States.

No. Atl. States.

Man.

Col.

Cal.

No. Atl.

States.

Mass.,

N. Y.

Atl.

States.

N. Y.

Atl.

States.

B. C.

Can.

No. Atl. States. 
2193. furcata SмIтн, Trans. Am. Ent. Soc., xxvi, 46, 1899.

Atl.

States.

Ill.

*2194. latia Strecker, Lep. Rhop. Het., suppl. 2, 6, 1899.

\section{OCHRIA Hübner.}

HüBner, Verz. bek. Schmett., 233, 1816.

2195. sauzælitæ Grote, Bull. Buff. Soc., ii, 216, 1875; Sмith, C. 179.

*2196. buffaloensis Grote, Can. Ent., ix, 88, 1877; Sмith, C. 179.

\section{PYRRHIA Hübner.}

HüBner, Verz. bek. Schmett., 262, 1816.

2197. umbra Hüfnagel, Berl. Mag., iii, 294, 1767; Smith, C. 216.

Atl. States, Col.

Rocky Mts.

*2198. stilla Grote, No. Am. Ent., i, 45, 1880; Sмith,

C. 216 .

Cal.

N. Y.

a. exprimens Walker, Cat. Brit. Mus., xi, 687 , 1857.

svn. anqulata Grote.

No. Atl. States, Eur.

B. C.

No. Atl.

States.

\section{JODIA Hübner.}

HüBNER, Verz. bek. Schmett., 234, 1816.

2202. rufago HüBnER, Zutr. exot. Schmett., f. 61, 1818; SMITH, C. 223.

syn. honesta WALKER.

Atl.

States.

\section{BROTOLOMIA Lederer.}

Lederer, Noct. Eur., ii, 64, 1852; Mesolomia Smith, C. 171.

2203. iris Guenée, Spee. Gén., vi, 64, 1852; Smith, C. 171 .

No. Atl. States. 
TRIGONOPHORA Hübner.

Hü BNer, Verz. bek. Schmett., 217, 1816.

2204. periculosa Guenée, Spec. Gén., vi, 65, 1852; SмITH, C. $17 i$.

No. Atl. States, Col.

a. v-brunneum Grote, Check List Noct., 23, 1875 .

CONSERVULA Grote.

Grote, Check List Noct., 11, 1875.

2205. anodonta Guenée, Spec. Gén., vi, 63, 1852; Suith, C. 170 .

No. Atl. States.

\section{EUCIRRCEDIA Grote.}

Grote, Can. Ent., vii, 206, 1875.

2206. pampina Guenée, Spec. Gén., v, 402, 1852; SмIтH, C. 224.

No. Atl. States.

\section{SCOLIOPTERYX Germar.}

Germar, Syst. Gloss. Prod., 14, 1812.

2207. libatrix Linneus, Syst. Nat., 507, 1758; SмIтн, C. 224.

U.S.,

Eur.

\section{CHEPHORA Grote \& Robinson.}

Grote \& Robinson, Trans. Am. Ent. Soc., ii, 199, 1868.

2208. fungorum Grote \& Robinson, Trans. Am. Ent. Soc., ii, 220, 1868; Sмiтh, C. 211.

\section{PSEUDORTHOSIA Grote.}

Grote, Bull. Buff. Soc., ii, 161, 1874.

2209. variabilis Grote, Bull. Buff. Soc., ii, 161, 1874; SмITH, C. 211.

Cal., Col.

\section{PSEUDOGLAA Grote. \\ Grote, Can. Ent., viii, 18, 1876.}

*2210. blanda Grote, Bull. Buff. Soc., iii, 86, 1875; Pac. States, Sмith, C. 210.

syn. trdata Grote, decepta Grote.

\section{ANCHOCELIS Guenée.}

Guenée, Ann. Soc. Ent. Fr., viii, 483, 1839.

2211. digitalis Grote, Bull. Geol. Surv. Terr., vi, 584, 1882; Sмith, C. 215 ,

No. Atl. States, 


\section{SELICANIS Smith.}

Smith, Proc. U. S. Nat. Mus., xxii, 481, 1900.

2212. cinereola Sмптн, Proc. U. S. Nat. Mus., xxii, 481, Col. 1900 .

\section{TAPINOSTOLA Lederer.}

\section{Lederer, Noct. Eur., 123, 1857.}

2213. orientalis Grote, Bull. Geol. Surv. Terr., vi, 583, 1882; SMrth, C. 184.

No. Atl.

States.

Mich.

*2214. variana Morrison, Proc. Acad. Nat. Sci. Phil., 432, 1875; Sмrth, C. 184.

\section{FAGITANA Walker.}

Walker, Cat. Brit. Mus., xxxii, 645, 1865; Pseudolimacodes Grote.

*2215. obliqua Sмiтh, Jn. N. Y. Ent. Soc., viii, 174, 1900. Fla.

2216. littera Guenée, Spec. Gén., v, 71, 1852; Simth, Atl. C. 356.

syn. lucidata WALKER, niveicostatus Grote.

\section{COSMIA Ochsenheimer.}

Ochsenheimer, Schmett. Eur., iv, 84, 1816; Enargia Hüвner, Verz. bek. Schmett., $235,1816$.

2217. paleacea Esper, Schmett. Eur., pl. 122, f. 504, 1788; SмIтн, C. 214.

U. S. .

Eur.

syn. discolor Walker, infumata Grote.

2218. punctirena Sмгтн, Can. Ent., xхxii, 222, 1900.

Col.

\section{ORTHOSIA Ochsenheimer.}

Ochsenheimer, Schmett. Eur., iv, 79, 1816.

2219. purpurea Grote, Bull. Buff. Soc., ii, 125, 1874;

Cal.

SMITH, C. 217.

a. crispa Harver, Bull. Buff. Soc., ii, 276, 1875.

*2220. decipiens Grote, Bull. Geol. Surv. Terr., vi, 269, 1881; Sмiтн, C. 217.

2221. ralla Grote \& Robinson, Trans. Anı. Ent. Soc., i, 346, 1868; Smith, C. 217.

Ind.

2222. bicolorago Guenée, Spec. Gén., v, 397, 1852; Sмiтн, C. 218.

syn. spurcata W ALKER.

a. ferruginoides Guenée, Spec. Gén., v, 389, 1852.

2223. euroa Grote \& Robinson, Trans. Am. Ent. Soc., iv, 431, 1873; Smith, C. 218.

Atl. States.

Col. 
2224. inops Grote, Bull Geol. Surv. Terr., vi, 270, 1881: SмIтн, C. $21^{\mathbf{} 8 .}$

Me.

2225. aurantiago Guenée, Spec. Gén., v, 394, 1852; SмIтH, C. 219.

syn. illiterata Grote, differta Morrison, illinoisensis FrENCH.

*2226. americana Morrison, Proc. Acad. Nat. Sci. Phil., 434, 1875; Sмirth, C. 219.

*2227. posticata Harvey, Bull. Buff. Soc., iii, 8, 1875; Sirth, C. 219.

*2228. citima Grote, Pap., iii, 74, 1883; Sмrth, C. 219.

2229. conradi Grote, Bull. Geol. Surv. Terr., v, 203, 1879; Sмith, C. 219.

2230. helva Grote, Bull. Buff. Soc., ii, 310, 1875; Sмiтh, C. 219.

2231. lutosa Andrews, Can. Ent., ix, 99, 1877; Sмith, C. 220 .

*2232. belangeri Morrison, Proc. Bost. Soc. Nat. Hist., xvii, 149, 1874; Sмith, C. 220.

*2233. immaculata Morrison, Proc. Acad. Nat. Sci. Phil., xvii, 149, 1874; SмIтн, C. 220.

*2234. chlorophora Hübner, Samml. exot. Schmett., i, 1806; Sмith, C. 220.

Atl. States.

N. Y.

Tex.

Ariz.

Atl.

States.

Atl. States, Col.

Atl.

States, Ariz.

Can.

Nev.

So. States.

PARASTICHTIS Hïbner.

HüBner, Verz. bek. Schmett., 212, 1816.

2235. discivaria WALKER, Cat. Brit. Mus., ix, 27, 1856; Sмith, C. 217.

syn. gentilis Grote.

a. perbellis Grote, Bull. Buff. Soc., ii, 144, 1874.

\section{SCOPELOSOMA Curtis.}

Curtis, Brit. Ins., xiv, 635, 1838.

2236. indirecta W ALKer, Cat. Brit. Mus., x, 468, 1857 ; SмIтн, C. 225.

syn. græfiana Grote.

2237. moffatiana Grote, Br:ll. Geol. Surv. Terr., vi, 538, 1882; Sмiтh, C. 225.

No. Atl. States.

No. Atl.

States.

No. Atl.

States.

2238. pettiti Grote, Can. Ent., vii, 188, 1875; Sмiтh, C. 225 .

No. Atl.

States.

2239. ceromatica Grote, Bull. Buff. Soc., ii, 70, 1874; SмITH, C. 225.

No. Atl. States. 
2240. tristigmata Grote, Can. Ent., ix, 156, 1877; SмITH, C. 225.

No. Atl. States.

2241. walkeri Grote, Proc. Ent. Soc. Phil., ii, 439, 1864; SмIтH, C. 225.

2242. sidus Guenée, Spec. Gén., v, 386, 1852; Smith, C. 226 . syn. vimulenta Grote.

2243. morrisoni Grote, Bull. Buff. Soc., ii, 70, 1874; Smith, C. 226.

2244. devia Grote, Proc. Acad. Nat. Sci. Phil., 209, 1874; Sмith, C. 226.

Atl. States.

Atl. States.

No. Atl. States.

No. Atl.

States.

ORRHODIA Hübner

HüBneR, Verz. bek. Schmett., 231, 1816.

2245. californica Surth, Trans. Am. Ent. Soc., xviii, 113, 1891: C. 223.

Cal.

\section{GLAEA Hübner.}

HüBner, Tent., 1806.

2246. viatica Grote, Sixth Rept. Peab. Acad. Sci., 29, 1874; Sмith, C. 221.

2247. inulta Grote, Sixth Rept. Peab. Acad. Sci., 30, 1874; Sмith, C. 221.

2248. olivata Harvey, Bull. Buff. Soc., ii, 120, 1874; SMITH, C. 221.

2249. sericea Morrison, Proc. Bost. Soc. Nat. Hist., xvii, 151, 1874; Sмiтh, C. 222.

*2250. signata French, Can. Ent., xi, 76, 1879; Sмith, C. 221.

Atl.

States.

Atl.

States.

Cal.

Atl.

States.

Atl.

States.

\section{EPIGL $\nRightarrow$ A Grote.}

Grote, Bull. Geol. Surv. Terr., iv, 181, 1878.

2251. pastillicans Morrison, Proc. Bost. Soc. Nat. Hist., xvii, 151, 1874; Sмптн, C. 222.

2252. tremula Harvey, Bull. Buff. Soc., ii, 276, 1874; SмITH, C. 222.

*2253. venustula Grote, Can. Ent., vii, 84, 1875; Sмith, C. 222 .

2254. apiata Grote, Sixth Rept. Peab. Acad. Sci., 30, 1874; Sмith, C. 222.

No. Atl. States.

Tex.

Md.

No. Atl.

States.

Atl.

2255. decliva Grote, Sixth Rept. Peab. Acad. Sci., 30, 1874; Suith, C. 222.

States. syn. deleta Grote. 
HOMOGL $Æ A$ Morrison.

Morrison, Proc. Bost. Soc. Nat. Hist., xviii, 240, 1875.

2256. hircina Morrison, Proc. Bost. Soc. Nat. Hist., xviii, 240,1875 ; Smith, C. 220.

No. Atl. States.

2257. carnosa ('rote, Can. Ent., ix, 21, 70, 1877; Sмith. C. 220 .

No. Atl.

States.

\section{MESOGONA Boisduval.}

Boisduval, Guenée, Ind. Méth., 144, 1840.

*2258. oxalina HüBner, Samml. eur. Schmett., iv, 219, 1823; SмIтH, C. 211.

N. Y. ? Eur.

syn. intexta HARveY.

CALYMNIA Hübner.

HüBNer, Verz. bek. Schmett., 235, 1816.

2259. orina Guenée, Spec. Gén., vi, 10, 1852; Sмith, C. 212.

syn. canescens BeHr, Bull. Cal. Acad. Sci., iii, 61, 1885; Sмiтh, C. 214.

a. calami Harver, Can. Ent., viii, 54, 1876.

\section{ZOTHECA Grote.}

Grote, Bull. Buff. Soc., ii, 68, 1874.

2260. tranquila Grote, Bull. Buff. Soc., ii, 69, 1874; SMITH, C. 212.

syn. sambuci BeHR.

a. viridula Grote, Bull. Geol. Surv. Terr., iv, 180, 1878.

IPIMORPHA Hübner.

HüBNeR, Verz. bek. Schmett., 238, 1816.

2261. pleonectusa Grote, Bull. Buff. Soc., i, 191, 1873; SмITH, C. 212.

Atl. States, Col., Utah. syn. xquilinea Sмптн.

*2262. subvexa Grote, Can. Ent., viii, 189, 1876; Sмптн, C. 212. Col.

TRILEUCA Grote.

Grote, Proc. Am. Phil. Soc., xxi, 166, 1883.

*2263. buxea Grote, Can. Ent., xiii, 230, 1882; Sмith, C. 213 .

*2264. dentalis Sмrth, Trans. Am. Ent. Soc., xviii, 123, 1891; C. 213.

Tex.

Tex. 
*2265. gulnare Strecker, Proc. Dav. Acad. Sci., ii, 274, 1878; SмITH, C. 213.

ATETHMIA Hübner.

HüBner, Verz. bek. Schmett., 238, 1816.

2266. subusta HüBner, Zutr. exot. Schmett., ii, 205, 1818; SмITH, C. 213.

Fla., Tex., So. Am.

2267. rectifascia Grote, Proc. Bost. Soc. Nat. Hist., xvi, 242, 1874; SмIth, C. 214.

Atl.

States.

Fla.,

Tex.

TRICHOCOSMIA Grote.

Grote, Can. Ent., xv, 6, 1883.

2269. inornata Grote, Can. Ent., xv, 6, 1883; SмIth, C. 210.

Ariz.

\section{CEA Grote.}

Grote, Pap., iii, 78, 1883.

*2270. immaculata Grote, Pap., iii, 87, 1883; Sмith, C. 214 .

Ariz.

TRISTYLA Smith.

Sмiтh, Ins. Life, v, 332, 1893.

2271. alboplagiata Sмптн, Ins. Life, v, 332, 1893.

Cal.

ANTAPLAGA Grote.

Grote, Can. Ent., ix, 71, 1877.

2272. dimidiata Grote, Can. Ent., ix, 71, 1877; Sмiтн, C. 265 .

*2273. sexseriata Grote, Pap., i, 176, 1882; Sмith, C. 265 .

*2274. biundulata ZelLer, Verh. zool.-bot. Ges. Wien. xxii, 502, 1872; SмIтH, C. 265.

*2275. composita Hy. Edwards, Pap., iv, 44, 1884; Ariz. SMITH, C. 266.

*2276. thoracica Hr. Edwards, Pap., iv, 44, 1884; Ariz. Sмiтн, C. 265.

2277. koebelei KILEY, Ins. Life, v, 333, 1893.

Cal.

GROTELLA Harvey.

Harvey, Bull. Buff. Soc., ii, 278, 1874.

2278. septempunctata Harvey, Bull. Buff. Soc., ii, 278 , 1874: Sмптн, C. 266. 
2279. dis Grote, Ann. Mag. Nat. Hist., (5). XI, 55 1883; Sмптн, C. 266.

N. Mex., Ariz.

PIPPONA Harvey.

Harvey, Bull. Buff. Soc., iii, 9, 1875.

2280. bimatris Harvey, Bull. Buff. Soc, iii, 10, 1875; Sмптн, C. 266.

BESSULA Grote.

Grote, Pap., i, 176, 1881.

*2281. luxa Grote Pap., i, 176, 1881; Sмith, C. 266.

OXYCNEMIS Grote.

Grote, Can. Ent., xiv, 182, 1882.

2282. perfundis Sмith, Trans. Am. Ent. Soc., xxi, 87, 1894.

*2283. advena Grote, Can. Ent., xiv, 182, 1882; Sмith, C. 267 .

2284. sectilis Sмгтн, Trans. Am. Ent. Soc., xxi, 86, 1894.

*2285. nivalis Surth, Trans. Am. Ent. Soc., xxi, 87, 1894.

2286. gracillima Grote, Can. Ent., xiii, 231, 1881; SмITH, C. 162.

2287. fusimacula Sмiтн, Jn. N. Y. Ent. Soc., x, 50, 1902.

N YCTEROPH $Æ$ TA Smith.

Smith, Bull. Brook. Ent. Soc., iv, 45, 1882; Epinyctis Grote.

2288. luna Morrison, Proc. Bost. Soc. Nat. Hist., xviii, 122, 1875; Sмith, C. 267.

syn. magdalena Hulst, notatella Grote.

Rocky

Mts.

\section{COPABLEPHARON Harvey.}

Harvey, Can. Ent., x, 56, 1878.

*2289. grandis Strecker, Lep. Rhop. Het., 129, 1875; Sмiтh, C. 267.

syn. subflavidens Grote, Can. Ent., xiv, 169, 1882.

2290. longipenne Grote, Can. Ent., xiv, 169, 1882; SMITH, C. 267.

2291. album Harvey, Can. Ent., vii, 35, 1876; SмIth, C. 268 .

Oreg., Col., Mont. 
2292. absidum Harvey, Bull. Buff. Soc., ii, 275, 1874; Sмiтh, C. 267.

Cal., Rocky Mts.

ÆDOPHRON Lederer.

Lederer, Noct. Eur., 180, 1857.

*2293. pallens Tepper, Trans. Am. Ent. Soc., x, 215, 1882; Sмiтн, C. 268.

So.

Cal.

\section{THYREION Smith.}

Smith, Trans. Am. Ent. Soc., xviii, 121, 1891.

*2294. snowi Grote, Proc. Acad. Nat. Sci. Phil., 422, 1875 ; Sмith, C. 268.

2295. rosea Smith, Trans. Am. Ent. Soc., xviii, 121, 1891; C. 268.

\section{CHLORIDEA Westwood.}

Westwoon, Lib. Nat. Hist., xxxvii, 198, 1841.

2296. virescens Fabricius, Spec. Ins., ii, 217, 1781; Sмiтh, C. 268.

syn. rhexiæ Sмгтн \& Аввот, spectanda STRECKER.

*2297. subflexa Guenée, Spec. Gén., ii, 175, 1852; SмIтH, C. 269.

No.

Am.

HELIOCHEILUS Grote.

Grote, Proc. Ent. Soc. Phil., iv, 328, 1865.

2298. paradoxus Grote, Proc. Ent. Soc. Phil., iv, 329, 1865; SмIтн, C. 269.

So. Atl. States, Col.

Fla. 680, 1865; SмIтH, C. 269.

HELIOTHIS Ochsenheimer.

Ochsenheimer, Schmett. Eur., iv, 91, 1816.

2300. armiger HüBner, Samml. eur. Schmett., Noct., 370, 1810; SмITH, C. 270.

a. umbrosus Grote, Proc. Ent. Soc. Phil., i, 219, 1863; Sмith, C. 270.

2301. phlogophagus Grote \& Robinson, Trans. Am. Ent. Soc., i, 180, 1868; Suith, C. 270.

syn. interjacens Grote.

a. luteitinctus Grote, Proc. Acad. Nat. Sci. Phil., 426,1875 .

2302. scutosus Fabricius, Mant. Ins., ii, 142, 1787; Sмiтh, C. 271. syn. nuchalis Grote. 
2303. sauvis Hy. Edwards, Pap., iv, 45, 1884; Sмrth, C. 271 .

Rocky Mts.

DERRIMA Walker.

WA Lker, Cat. Brit. Mus., xii, 770, 1857.

2304. stellata Walker, Cat. Brit. Mus., xxii, 770, 1857 ; SмITH, C. 271.

Atl. States.

a. henrietta Grote, Proc. Ent. Soc. Phil., iii, 3 , 1864.

CHAM $A C L E A$ Grote.

Grote, Can. Ent., xv, 76, 1883.

*2305. pernana Grote, Pap., i, 155, 1881; Sмmтн, C. 271.

Ariz.

\section{RHODOPHORA Guenée.}

Guenée, Spec. Gén., vi, 170, 1852; Alaria Westwood (not Schrank), Oxylos Grote, Check List Noct., 19, 1875.

2306. gauræ Sмптн \& Аввот, Lep. Ins. Ga., ii, 197, 1797; SмIтH, C. 272.

So. States, Col.

syn. matutina HüBNER.

2307. florida Guenée, Spec. Gén., vi, 171, 1852; SмIтH, C. 272 .

*2308. felicitata Smith, Trans. Am. Ent. Soc., xxi, 80, 1894.

2309. citronellus Grote \& Robinson, Trans. Am. Ent. Soc., iii, 180, 1870; Sмптн, C. 272.

Atl. States.

Utah.

Tex., Col.

RHODOSEA Grote.

Grote, Can. Ent., xv, 5, 1883.

2310. julia Grote, Can. Ent., xv, 5, 1883; Sмmтн, C. 272.

New Mex., Ariz.

RHODODIPSA Grote.

Grote, Bull. Geol. Surv. Terr., iii, 797, 1877.

2311. volupia Fiтch, Trans. N. Y. Sta. Agr. Soc., 900, 1857; SмITH, C. 273.

Col.,

Tex.

*2312. miniana Grote, Pap., i, 175, 1881; Smith, C. 273.

2313. masoni Sмmтн, Ent. News, vii, 284, 1896.

N. Mex.

Col.

Col.

*2314. aden Strecker, Lep. Rhop. Het., suppl. 1, 11, 1898.

TRIOCNEMIS Grote.

Grote, Pap., i, 77, 1881.

2315. saporis Grote, Pap., i, 77, 1881; Smith, C. 273. Col., Wash.. Cal. 
PSEUDACONTIA Smith.

Smith, Trans. Am. Ent. Soc., x, 246, 1882.

2316. crustaria Morrison, Proc. Acad. Nat. Sci. Phil., 70,1875 ; Sмith, C. 273.

Neb.,

Col.

\section{GRAPERIA Grote.}

Grote, Abh. nat. Ver. Brem., xiv, 109, 1895; Heliodora Neumoegen (not Heliodore STÅL), Can. Ent., xxiii, 125, 1891.

*2317. magnifica Neumoegen, Can. Ent., xxiii, 125, Tex. 1891; Sмптн, C. 273.

\section{PORRIMA Grote.}

Grote, Bull. Geol. Surv. Terr., iii, 798, 1877.

2318. regia Strecker, Lep. Rhop. Het., 121, 1876; Kans., Tex., SмITH, C. 279.

Col.

2319. sanguinea Geyer, Zutr. exot. Schmett., f. 613, 1832; Sмith, C. 279.

So.

States.

syn. carmosina Neunoegen.

2320. gloriosa Strecker, Lep. Rhop. Het., 132, 1876; Sмiтн, C. 280.

TRICHOSELLUS Grote.

Grote, Rev. Check List, 36, 1890.

*2321. cupes Grote, Trans. Am. Ent. Soc., v, 113, 1875; Pac. States, Sмптн, C. 280.

Tex., Col.

syn. crotchii Hr. EDwards.

EUPANYCHIS Grote.

Grote, Rev. Check List, 34, 1890.

2322. spinosæ GuenÉe, Spec. Gén., vi, 182, 1852; SмIтн, C. 281.

Atl.

States.

syn. hirtella Grote \& Robinson.

CANIDIA Grote.

Grote, Rev. Check List, 36, 1890.

2323. scissa Grote, Proc. Bost. Soc. Nat. Hist., xviii, 451, 1876; Smith, C. 285.

Fla.

SCHINIA Hübner.

Hüвner, Verz. bek. Schmett., 281, 1816; Sмrtтh, Trans. Am. Ent. Soc., x, 225, 1883.

2324. chrysellus Grote, Bull. Buff. Soc., ii, 76, 1874; SMITH, C. 274.

Tex.,

N. Mex., Col. 
2325. lanul Strecker, Lep. Rhop. Het., 132, 1877; Sмптн, C. 285.

syn. velaris Grote, ochreifascia SмIтH, C. 274.

*2326. hulstia Tepper, Trans. Am. Ent. Soc., x, 228, 1883; Sмiтh, C. 274.

Tex., Col.

232\%. aleucis Harver, Can. Ent., vii, 117, 1875; Sмith, C. 275 .

2328. cumatilis Grote, Proc. Ent. Soc. Phil., iv, 330, 1865; Sмптн, C. 275.

Tex.

Col., N. Mex.

*2329. tenuescens Grote, Can. Ent., xv, 128, 1883; Sмiтh, C. 275.

*2330. biundulata Smith, Trans. Am. Ent. Soc., xviii, 129, 1891; C. 275.

2331. sexplagiata Sмгтн, Trans. Am. Ent. Soc., xviii, 124, 1891; C. 275.

syn. pyraloides Strecker, Lep. Rhop. Het., suppl. 1, 9, 1898.

2332. trifascia HüBner, Zutr. exot. Schmett., f. 33 , 1818; Sмith, C. 275.

syn. lineata WALKER.

*2333. gracilenta Hübner, Zutr. exot. Schmett., f. 5, 1818; Sмiтh, C. 276.

syn. oleagina Morrison.

2334. simplex Surth, Trans. Am. Ent. Soc., xviii, 129, 1891 ; C. 276.

*2335. arefacta Hy. Edwards, Pap., iv, 123, 1884; SмIтH, C. 276.

2336. unimacula Sмiтh, Trans. Am. Ent. Soc., x, 229, $1882 ;$ C. 276.

2337. obliqua Sмrth, Trans. Am. Ent. Soc., x, 229, 1882; C. 276.

*2338. bifascia HüBner, Zutr. exot. Schmett., f. 55, 1818; Sмith, C. 276.

2339. nundina Drury, Ill. Exot. Ent., i, 36, 1770; Sмith, C. 276.

syn. nigrirena Наwовтн.

*2340. parmeliana Hy. Edwards, Pap., ii, 14, 1882; SмIтн, C. 277.

2341. acutilinea Grote, Can. Ent., x, 232, 1878; SмIтH, C. 277 . syn. separata Grote.

*2342. balba Grote, Pap., i, 156, 1881; Sмith, C. 277.

Atl. States, Col.

$$
\text { So. }
$$

States.

Col.

Fla.

Col.

Ariz.

Ga., Ariz., Col.

Atl.

States.

Md.

Rocky

Mts.

Ariz. 
*2343. coercita Grote, Pap., i, 156, 1881; Sмmth, C. 277.

Ariz.

*2344. walsinghami Hr. Edwards, Pap., i, 20, 1881; Smith, C. 278.

Oreg:

2345. brucei SмrтH, Trans. Am. Ent. Soc., xviii, 125, 1891; C. 278.

2346. lynx Gunnée, Spec. Gén., vi, 185, 1852; Sмrth, C. 278 .

2347. roseitincta Harvey, Bull. Buff. Soc., ii, 278, 1875; SмIтH, C. 278.

syn. exaltata Hy. EDwards.

2348. saturata Grote, Bull. Buff. Soc., ii, 74, 1874; SмmTH, C. 278.

syn. mbiginosa STRECKER.

2349. diffusa Sмrтн, Trans. Am. Ent. Soc., xviii, 125, 1891; C. 279.

2350. sordidus Smith, Trans. Am. Ent. Soc., x, 230, 1883; C. 279.

2351. tertia Grote, Proc. Acad. Nat. Sci. Phil., 212, 1874; SмIтH, C. 279.

2352. albafascia Sмгтн, Trans. Am. Ent. Soc., x, 231 , 1883; C. 279 .

2353. jaguarina Guenée, Spec. Gén., vi, 184, 1852; SMITH, C. 280.

2354. arcifera Guenée, Spec. Gén., vi, 184, 1852; Sмith, C. 280.

syn. spraguei Grote.

*2355. petulans Hr. Edwards, Pap., iv, 123, 1884; Sмith, C. 281.

*2356. crenilinea Surth, Trans. Am. Ent. Soc., xviii, 129, 1891; C. 281.

*2357. lupatus Grote, Can. Ent., vii, 224, 1875; Sмiтн, C. 281.

2358. packardii Grote, Proc. Ent. Soc. Phil., iii, 528, 1864; Sмith, C. 281.

Col.

Atl.

States.

Tex.,

Col.

Atl. States,

Cal.

Col.

Ala.,

Tex.

Tex.

Utah,

Col.

So. States,

Col.

Atl.

States.

Fla.

Tex.

Tex.

Tex., Col.,

Ariz.

syn. mortua Grote, nobilis Grote.

*2359. bicuspida Smith, Trans. Am. Ent. Soc., xviii, 127, 1891; C. 282.

2360. thoreaui Grote \& Robinson, Trans. Am. Ent. Soc., iii, 181, 1868; Sмiтн, C. 282.

Tex.

So.

States.

236\%. marginata HaworTH, Lep. Brit., 374, 1810; SмIтH, C. 282.

Atl.

States.

s.yn. rioulosa GuenéE, divergens W ALKER, contracta W ALKER, designata W ALKER. 
*2362. imperspicua Strecker, Lep. Rhop. Het., 122, 1876; SмIтH, C. 276.

Tex.

syn. digitalis Surth, Trans. Am. Ent. Soc., xviii, 128, 1891; C. 283.

*2363. constricta Hy. Edwards, Pap., ii, 128, 1882; SмITH, C. 283.

N. C.

*2364. septentrionalis W ALKER, Cat. Brit. Mus., xv, 1744, 1858; Sмiтh, C. 284.

*2365. tuberculum HüBner, Zutr. exot. Schmett., f. 517, 1823; SмIтн, C. 283.

syn. dorsilutea WALKER.

2366. brevis Grote, Proc. Ent. Soc. Phil., iii, 530, 1864; SмIтн. C. 283.

a. atrites Grote, Proc. Ent. Soc. Phil., iii, 530, 1864 .

*2367. concinna Sмiтh, Trans. Am. Ent. Soc., xviii, 128, 1891; C. 284.

2368. errans Sмгтн, Trans. Am. Ent. Soc., x, 235, 1883; C. 284 .

*2369. inclara Strecker, Lep. Rhop. Het., 122, 1876; SмITH, C. 284.

*2370. limbalis Grote, Proc. Acad. Nat. Sci. Phil., 421, 1875; SмITH, C. 284.

2371. meskeana Grote, Can. Ent., vii, 234, 1875; Sмптн, C. 284.

syn. fastidiosa STrecker, rufimedia Grote.

2372. ultima Sтrecker, Lep. Rhop. Het., 122, 1876; Sмiтн, C. 285.

2373. ligeæ Sмгтн, Ins. Life, v, 331, 1893.

2374. intrabilis SмIтн, Ins. Life, v, 331, 1893.

2375. ciliata Sмптн, Proc. U. S. Nat. Mus., xxii, 488, 1900.

2376. oculata Sмiтh, Proc. U. S. Nat. Mus., xxii, 488, 1900 .

2377. reniformis Sмiтh, Proc. U. S. Nat. Mus., xxii, 487,1900 .

*2378. labe Strecker, Lep. Rhop. Het., suppl. 1, 10, 1898.

Atl. States, Col.

Tex.

Ariz.

Tex.

Kans.

Tex.,

Fla.

Tex.

Cal.

Cal.

N. Mex.

Ariz.

Col.

Tex.

*2379. hanga Strecker, Lep. Rhop. Het., suppl. 1, 9, 1898.

Tex.

*2380. ar Strecker, Lep. Rhop. Het., suppl. 1, 10, 1898.

Tex. 
*2381. nubila Strecker, Lep. Rhop. Het., 122, 1876;

Tex. Sмith, C. 284.

*2382. approximata Strecker, Lep. Rhop. Het., suppl. $1,10,1898$.

*2383. dolosa Strecker, Lep. Rhop. Het., suppl. 1, 9, 1898.

*2384. neglecta Strecker, Lep. Rhop. Het., suppl. 1, Col. 10,1898 .

*2385. tanena STREcker, Lep. Rhop. Het., suppl. 1, 10, 1898.

*2386. obscurata Strecker, Lep. Rhop. Het., suppl. 1, $10,1898$.

*2387. lora Strecker, Lep. Rhop. Het., suppl. 1, 10, Tex. 1898.

*2388. siren Strecker, Lep. Rhop. Het., 122, 1876; Tex. Sмith, C. 285.

\section{DASYSPOUD EA Smith.}

Sмiтн, Trans. Am. Ent. Soc., x, 213, 1883.

2389. lucens Morrison, Proc. Acad. Nat. Sci. Phil.,69, 1875 ; SMith, C. 286.

Rocky Mts.

a. luxuriosa Grote, Can. Ent., xiv, 175, 1882.

2390. meadii Grote, Bull. Buff. Soc., i, 121, 1873; Sirth, C. 286.

Mont., Col.

PSEUDANTHECIA Smith.

Sмiтн, Trans. Am. Ent. Soc., x, 213, 1880.

2391. tunida Grote, Bull. Brook. Ent. Soc., iii, 30, 1880; Sмith, C. 286.

Col.

\section{PALADA Smith.}

Sмiтh, Proc. U. S. Nat. Mus., xxii, 486, 1900.

2392. scarletina Sмгтн, Proc. U. S. Nat. Mus., xxii, $487,1900$.

Cal.

STYLOPODA Smith.

Smith, Trans. Am. Ent. Soc., xviii, 131, 1891.

2393. cephalica Smith, Trans. Am. Ent. Soc., xviii, 131, 1891; C. 286.

Cal.

SYMPISTIS Hübner.

Hübner, Verz. bek. Schmett., 257, 1816; Euros Hy. Edwards.

*2394. proprius Hy. Edwards, Pap., 1, 19, 1881; Sмiтh,

Cal. C. 286 , 


\section{MELANOPORPHYRIA Grote.}

Grote, Bull. Buff. Soc., ii, 75, 1874.

2395. immortua Grote, Bull. Buff. Soc., ii, 75, 220, 1874; Sмith, C. 287.

Mass., N. Y., Col.

*2396. prorupta Grote, Trans. Am. Ent. Soc., iv, 294, 1873; Sмiтн, C. 287.

Cal., Oreg.

syn. venusta Hy. EDwards.

2397. oregona Hy. Edwards, Proc. Cal. Acad. Sci., vi, 135,1875 ; Sмттн, C. 287.

Col., Nev., Oreg.

\section{DYSOCNEMIS Grote.}

Grote, Rev. Check List, 34, 1890.

2398. belladonna Hy. Edwards, Pap., i, 20, 1881; Sмiтh, C. 287.

\section{PSEUDOTAMILA Smith.}

Sмith, Trans. Am. Ent. Soc., x, 238, 1883.

2399. vanella Grote, Can. Ent., xi, 197, 1877; Sмıтн, C. 287.

*2400. perminuta Hy. Edwards, Pap., i, 21, 1881; SмIth, C. 287.

\section{MELICLEPTRIA Hübner.}

HüBNER, Verz. bek. Schmett., 262, 1816.

*2401. celeris Grote, Bull. Buff. Soc., i, 148, 1873; Sмith, C. 288.

2402. pulchripennis Grote, Proc. Bost. Soc. Nat. Hist., xvi, 241, 1874; SмIтth, C. 288.

syn. languida Hy. Edwards.

*2403. graefiana Tepper, Trans. Am. Ent. Soc., x, 245, 1883; Sмiтh, C. 288.

2404. villosa Grote, Proc. Ent. Soc. Phil., iii,531,1864; Sмith, C. 288.

syn. pauxillus Grote.

a. persimilis Grote, Bull. Buff. Soc., i, 117, 1873.

2405. honesta Grote, Pap., i, 77, 1881; Sмiтh, C. 289.

*2406. sueta Grote, Bull. Buff. Soc., i, 117, 1873; Sмith, C. 289 .

syn. californicus Grote.

*2407. vacciniæ Hy. Edwards. Proc. Cal. Acad. Sci., vi, 134, 1875; Sмiтh, C. 289.
Nev., Cal.

Cal.

So.

Cal.

Cal., Col.

So.

Cal.

Col.,

Cal.

Oreg.

Col.,

Cal.

Cal. 
2408. septentrionalis Hy. Edwards, Pap., iv, 45, 1884; SмIтH, C. 289.

HELIOLONCHE Grote.

Grote, Bull. Buff. Soc., i, 115, 1873.

2409. modicella Grote, Bull. Buff. Soc., i, 116, 1873; Cal., Col. Sмiтtн, C. 289.

Utah.

OMIA Hübner.

HÜвNer, Verz. bek. Schmett., 244, is16.

2410. nesæa Sмптн, Ins. Life, v, 332, 1893.

Cal.

\section{HELIOPHANA Grote.}

Grote, Bull. Buff. Soc., ii, 220, 1875.

*2411. mitis Grote, Bull. Buff. Soc., i, 116, 1873; SмITH, C. 290.

Tex.,

Miss.

syn. obliquata SмiтH.

2412. amaryllis Sмiтн, Trans. Am. Ent. Soc., xviii, 130, 1891; C. 290.

*2413. bina Guenée, Spec. Gén., vi, 186, 1852; Sмrth, C. 290 .

Cal.

Neb.,

N. Y.

\section{HELIODES Guenée.}

Gi vée, Ann. Soc. Ent. Fr., x, 61, 1841.

2414. restrictalis Smith, Proc. U. S. Nat. Mus., xxii, 485,1900 .

Cal.

2415. angelica Ммптн, Proc. U. S. Nat. Mus., xxii, 484, 1900.

Cal.

\section{HELIOSEA Grote.}

Grote, Bull. Buff. Soc., ii, 220, 1875.

*2416. pictipennis Grote, Bull. Buff. Soc., ii, 220, 1875; SмIтн, C. 289.

Cal.

XANTHOTHRIX Hy. Edwards.

Hy. Edwards, Pac. Coast Lep., no. 29, 1878.

2417. ranunculi Hy. Edwards, Pac. Coast Lep., no. 29, 1878; Smith, C. 290.

Cal.

2418. neumoegeni Hr. Edwards, Pap., i, 101, 1881; Smith, C. 290.

Cal.

$4630-$ No. $52-02-13$ 
AXENUS Grote.

Grote, Bull. Buff. Soc., i, 153, 1873.

2419. arvalis Grote, Bull. Buff. Soc., i, 152, 1873; SMITH, C. 291.

Cal., Col., Ariz.

a. ochraceus Hy. Edwards, Proc. Cal. Acad. Sci., vi, 136,1875 .

b. amplus Hy. Edwards, Proc. Cal. Acad. Sci., vi, 136,1875 .

HELIACA Herrich-Schaeffer.

Herrich-Schaeffer, Schmett. Eur., ii, 370, 1853.

2420. diminutiva Grote, Bull. Buff. Soc., i, 148, 1873; Sмптн, C. 291.

Cal., Nev., Col.

Col.

2421. fasciata Hy. Edwards, Proc. Cal. Acad. Sci., vi, 134, 1875; Sмптн, C. 281.

*2422. dubitans Tepper, Trans. Am. Ent. Soc., vi, 134 , 1875; SмITH, C. 291.

Nev.

2423. nexilis Morrison, Proc. Acad. Nat. Sci. Phil., 102, 1875; SмITH, C. 291.

Col., Cal.

Col.

2424. elaborata Hy. Edwards, Pap., i, 21, 1881; SuIth. C. 291.

\section{EUPSEUDOMORPHA Dyar. \\ Dyar, Can. Ent., xxv, 28, 1893.}

*2425. brillians Neumoegen, Can. Ent., xii, 67, 1880; Neumoegen \& Dyar, Jn. N. Y. Ent. Soc., ii, 23, Tex. 1894.

XANTHOPASTIS Hübner.

Aübner, Verz. bek. Schmett., 211, 1816.

2426. timais Cramer, Pap. Exot., pl. 275, f. B, 1782; Sмптн, C. 180.

syn. regnatrix GROTE.

PSYCHOMORPHA Harris.

Harris, Am. Jn. Sci., xxxvi, 319, 1839.

2427. epimenis Drury, Ill. Exot. Ent., iii, pl. 39, f. 2, 1780; Neumoegen \& Dyar, Jn. N. Y. Ent. Soc.. ii, $19,1894$.

Atl. States.

EUTHISANOTIA Huibner.

Hübner, Zutr. exot. Schmett., iii, 12, 1825; Eudryas BoIsduval.

2428. unio Hübner, Zutr. exot. Schmett., iii, 12, 839 , 840, 1825; Neunoegen \& Dyar, Jn. N. Y. Ent. Soc., ii, 24, 1894. 
2429. brevipennis Stretch, Zyg. Bomb. No. Am., 151, 1874; Neunoegen \& Dyar, Jn. N. Y. Ent. Soc.

Cal.

ii, 25,1894 .

2430. grata FABricius, Syst. Ent., iii, 457, 1793; Neunoegen \& Dyar, Jn. N. Y. Ent. Soc., ii, 25, 1894.

syn. assimilis BoIsduvaL.

\section{CIRIS Grote.}

Grote, Proc. Ent. Soc. Phil,, ii, 65, 1863.

2431. wilsoni Grote, Proc. Ent. Soc. Phil., ii, 65, 1863; Neunoegen \& Dyar. Jn. N. Y. Ent. Soc., ii, 25, Tex. 1894.

\section{NOROPSIS Guenée.}

\section{Guenée, Spec. Gén., v, 117, 1852.}

2432. hieroglyphica Cramer, Pap. Exot., pl. 147, f. D, 1779; SмIтн, C. 180.

syn. festiva Fabricius, elegams HüBNER, fastuosa Guenée.

\section{FENARIA Grote.}

Grote, Pap., ii, 132, 1882.

2433. longipes Druce, Biol. Cent. Am., Lep. Het., i, $334,1889$.

Ariz. ,

Mex.

2434. sevorsa Grote, Pap.. ii, 132, 1882; Neunoegen \& DYar, Jn. N. Y. Ent. Soc., ii, 19, 1894.

Tex., Fla. syn. xdessa Druce, Biol. Cent. Am., Lep. Het., i, 334, 1889.

\section{ACHERDOA Walker.}

Ariz., Mex.

Walker, Cat. Brit. Mus., xxxii, 451, 1865; Varina Neumoegen.

2435. ferraria Walker, Cat. Brit. Mus., xxxii, 4.51, Fla. 1865; Neunoegen \& Dyar, Jn. N. Y. Ent. Soc., ii, 59,1894 .

syn. ornata Neumoegen.

AON Neumoegen.

Neumoegen, Ent. News, iii, 258, 1893.

2436. noctuiformis Neumoegen, Ent. News, iii, 258, 1893; Neumoegen \& Dyar, Jn. N. Y. Ent. Soc., Tex. ii, $60,1894$. 


\section{CIRRHOPHANUS Grote.}

Grote, Can. Ent., iv, 187, 1872.

2437. triangulifer Grote, Can. Ent., iv, 187, 1872; SмITh, C. 261.

So. States.

2438. dyari Cockerell, Can. Ent., xxxi, 288, 1899. N. Mex.

2439. duplicatus Smith, Trans. Am. Ent. Soc., xviii, Col. 112, 1891; C. 261.

\section{TRICHOCALA Ottolengui.}

Kallitrichia Otтolengur (not Callitriche Poli), Can. Ent., xxx, 107, 1898.-R. Ottolengui.

*2440. coronides Druce, Biol. Cent. Am., Lep. Het., i, $328,1889$.

Ariz. , Mex.

syn. pendula Ottolengui, Can. Ent., xxx, 108, 1898.

*2441. albavena Otтolengui, Can. Ent., xxx, 107, 1898.

Ariz.

*2442. smithii Druce, Biol. Cent. Am., Lep. Het., i, 329, 1889. (May be 2463.)

Ariz., Mex.

a. sagittalba Otтolengui, Can. Ent., xxx, 108, 1898.

\section{BASILODES Guenée.}

\section{Guenée, Spec. Gén., vi, 358, 1852.}

2443. pepita Guenée, Spec. Gén., vi, 358, 1852; Snith, C. 261 .

So. Atl.

States.

2444. chrysopis Grote, Pap., i, 154, 1881; Sмmтн, C. Rocky Mts. 261.

2445. territans Hy. Edwards, Pap., iv, 45,1884 ; SмIтн,

Ariz. C. 261 .

*2446. howardi Hy. Edwards, Pae. Coast Lep., 25, 1877; SмIтH, C. 261.

*2447. mirabilis Neumoegen, Pap., iv, 94, 1884; Smith, C. 262 .

*2447. 1. arizonae French, Can. Ent., xxi, 161, 1889; Sirth, C. 248.

Ariz.

Ariz.

Ariz.

\section{STIRIA Grote.}

Grote, Bull. Buff. Soc., ii, 73, 1874.

2448. rugitrons Grote, Bull. Buff. Soc., ii, 75, 1874; SмITH, C. 262.

Kans.

Col.

*2449. consuela Strecker Lep. Rhop. Het., suppl. 3, Ariz. 34, 1900. 
*2450. sulphurea Neumoegen, Pap., ii, 135, 1882; Smith,

Ariz. C. 262.

*2451. nanata Neumoegen, Pap., iv, 95, 1884; Simth, C. 262 .

\section{STIBADIUM Grote.}

Grote, Bull. Buff. Soc, ii, 74, 1874.

2452. spumosum Grote, Bull. Bufl. Soc., ii, 74. 1874; Sмiтн, C. 262.

So. Atl. States, Col.

2458. aureolum Hr. EDwards, Pap., ii, 126, 1882;

Ariz. SMITH, C. 262.

*2454. curiosum Neumoegen, Pap., iii, 141, 1883; SмITH, C. 262.

2455. navium Harver, Bull. Buff. Soc., iii, 10, 1875; SмITH, C. 263.

N. Mex.

Ariz.

Tex.

\section{PLAGIOMIMICUS Grote.}

Grote, Bull. Buff. Soc., i, 182, 1873.

2456. pityochromus Grote, Bull. Buff. Soc., i, 182, 1873; SмITH, C. 263.

So. Atl. States, Col.

2457. triplagiatus Sнтн, Ent. Amer., vi, 139, 1890: N. Mex. C. 163.

2458. tepperi Morrison, Proc. Acad. Nat. Sci. Phil., 68. 1875 ; SмIтн, C. 263.

syn. richi Grote.

2459. expallidus Grote, Pap., ii, 185, 1882; Sмгтн, C. 264 .

*2460. viridifera Grote, Can. Ent., xiv, 217, 1882; Smith, C. 264.

\section{FALA Grote.}

Grote, Proc. Acad. Nat. Sci. Phil., 425, 1875.

*2461. ptycophora Grote, Proc. Acad. Nat. Sci. Phil., 426, 1875; SмITH, C. 264.

\section{NARTHECOPHORA Smith.}

Smith, Proc. U. S. Nat. Mus., xxii, 485, 1900.

2462. pulverea Sмrтн, Proc. U. S. Nat. Mus., xxii, 486 , 1900.

$$
\text { Tex., }
$$$$
\text { Col. }
$$

Mont., Col.

Ariz.

Cal.

Ariz.

Ariz.,

Oreg. 


\section{PLUSIODONTA Guenée.}

Guenée, Spec. Gén., vi, 359, 1852.

2464. compressipalpis Guenée, Spec. Gén., vi, 359, 1852; SмIтH, C. 260.

Atl.

syn. insigmis WALKER.

States.

\section{GONODONTA Hübner.}

Hübner, Verz. bek. Schmett., 263, 1816.

2465. unica Neumoegen, Can. Ent., xxiii, 125, 1891; Smith, C. 259; Dyar, Proc. U. S. Nat. Mus., xxiii, 27.2, 1900.

*2466. nutrix Cramer, Pap. Exot., iv, pl. 312, f. B, 1782; Guenée, Spec. Gén., vi, 370, 1852.

Fla.

2467. canadensis Bethune, Proc. Ent. Soc. Phil., iv, 213, 1865; Sмптн, C. 259.

syn. purpurascens WALKER, sobria WALKER.

\section{CALPE Treitsehke.}

Treitschke, Schmett. Eur., v, 2, 168, 1825.
No. Atl.

States.
Fla., So. Am.

\section{PANCHRYSIA Huibner.}

Hüвner, Verz. bek. Schmett., 252, 1816; Dera W Alker, Cat. Brit. Mus., xii, 962, 1857.

*2468. morigera Hy. Edwards, Ent. Amer., ii, 169, 1887; Sмнтн, C. 247.

Col.

2469. purpurigera WALKer, Cat. Brit. Mus., xiv, 1791, 1858; SMITH, C. 246.

Atl. States, Col.

*2470. palligera Grote, Pap., i, 35, 1881; Sмгтн, C. 247.

Cal., Col.

2471. ornata Ottolengut, Can. Ent., xxx, 106, 1898.

N. Mex.

POLYCHRYSIA Hübner.

HüBner, Verz. bek. Schmett., 251, 1816.

2472. moneta Fabricius, Mant. Ins., 162, 1787; STAUDinger \& Rebel, Cat. Lep. Eur., i, no. 2521, 1901.

a. esmeralda OBerthur, Étud. d'Ent., v, 85, 1880.

syn. trabea Smin, Ent. News, vii, 29, 1896.

2473. formosa Grote, Proc. Ent. Soc. Phil., iv, 323, 1865 ; SмIтH, C. 249.

Alberta, Eur.

Atl. States. 


\section{PLUSIA Hübner.}

Hübner, Tent., 1806; Ochsenhermer, Schmett. Eur., iv, 89, 1816.

2474. ærea HüBNer, Schmett. Eur., iv, pl. 56, f. 27 , 1810; Sмiтн, C. 247.

Atl. States, Col.

2475. æroides Grote, Proc. Ent. Soc. Phil., iii, 83, 1864: SмIтH, C. 247.

Atl. States, Col.

2476. balluca Geyer, Zutr. exot. Schmett., f. 681 , 1835: SмITH, C. 248.

No. Atl.

States.

Wash., Cal.

2477. metallica Grote, Bull. Buff. Soc., ii, 371, 1875; SмIтH, C. 248.

syn. scapularis Hy. Edwards, Pap., ii, 127, 1882; lenzi French, Can. Ent., xxi, 161, 1889; SмIтH, C. 253.

\section{EUCHALCIA Hübner.}

HüBner, Verz. bek. Schmett., 251, 1816.

2478. contexta Grote, Bull. Buff. Soc., i, 193, 1873; Sмith, C. 248.

Atl. States.

2479. festucæ Linneus, Syst. Nat., 513, 1758; STAUDinger \& Rebel, Cat. Lep. Eur., i, no. 2546 , 1901.

a. putnami Grote, Bull. Buff. Soc., i, 146, 1873; SмITH, C. 248.

2480. venusta Walker, Cat. Brit. Mus., xxxiii, 836, 1865; SмIтн, C. 248.

syn. striatella Grote.

\section{EOSPHOROPTERYX Dyar.}

Dyar, Jn. N. Y. Ent. Soc., x, 80, 1902.

2481. thyatiroides Gunnée, Spec. Gén., vi, 337, 1852; Sмith, C. 249.

\section{A UTOGRAPHA Hibner.}

Hёвner, Verz. bek. Schmett., 251, 1816.

2482. mappa Grote \& Robinson, Trans. Am. Ent. Soc. ii, 204, 1868; SuIth, C. 249.

2483. bimaculata Stephens, Ill. Brit. Ent., Haust., iii. 104, 1832; Sмптн, C. 249.

*2484. solida Ottolengui, Jn. N. Y. Ent. Soc., x, 64, 1902.

2485. biloba Stephens, Ill. Brit. Ent., Haust., iii, 104, 1832; SмIтн, C. 249.
Atl. States Eur.

Atl. States.

Atl.

No. Atl.

States.

Atl. States.

Tex., Mex.

U. S. States. 
2486. verruca Fabricius, Ent. Syst., iii, 2, 81, 1794; SMITH, C. 250.

Atl. States,

syn. omega HüBner, oo Cramer, omicrom So. Am.

HüBNER, questionis TreITschKE, rutila WALKER.

2487. rogationis Guenée, Spec. Gén., vi, 344, 1852; SмITH, C. 250.

Atl. States,

syn. hamifera WaLker, dyaus Grote, includens W ALKER, culta LinTNER.

2488. precationis Guenée, Spec. Gén., vi, 344, 1852; SмIтH, C. 251.

Col., So. Am.

2489. egena Guenée, Spec. Gén., vi, 328, 1852; Sмith, C. 251.

2490. labrosa Grote, Proc. Acad. Nat. Sci. Phil., 207, 1874; Smith, C. 251.

2491. flagellum W ALKer, Cat. Brit. Mus., xii, 909, 1857; SмIтн, C. 251.

syn. monodon Grote, insolita SMith, Ent. News, vii, 30, 1896.

2492. gamma Linn жus, Faun. Suec., 1171, 1761; Sиттн, C. 251 .

Can.. Pac. States.

a. pseudogamma Grote, Can. Ent., vii, 208, 1875; SмITH, C. 251.

b. californica Speyer, Stett. ent. Zeit., xxxvi, 164,1875 .

syn. mesea Hy. EDwards.

2493. ou Guenée, Spec. Gén., vi, 348, 1852; Smith, C. 252 .

syn. fratella Grote, Bull. Buff. Soc., ii, 161, 1874: SмIтH, C. 252.

*2494. rubidus Ottolengui, Jn. N. Y. Ent. Soc., x, 67, 1902.

*2495. pedalis Grote, Can. Ent., vii, 204, 1875; Sмrth, C. 252 .

2496. brassicæ Riley, Second Rept. Ins. Mo., 110, 1870; SMITH, C. 253.

syn. echinocystis BEHR.

*2497. abrota Druce, Biol. Cent. Am., Lep. Het., i, 333, 1889; ii, 504, 1898.

Fla.,

Mex.

2498. oxygramma Geyer, Zutr. exot. Schmett., f. 769, 1830; Sмmтн, C. 253.

So. States, So. Am.

syn. indiqna WaLker, Cat. Brit. Mus., xxii, 901, 1857; SмITH, C. 257.

*2500. albavitta Ottolengui, Jn. N. Y. Ent. Soc., x, 75,1902 .

Cal. 
2501. alias Otтolengut, Jn. N. Y. Ent. Soc., x, 69, 1902 .

No. Atl. States.

2502. octoscripta Grote, Bull. Buff. Soc., ii, 72, 1874; SмITH, C. 254.

No. Atl. States. syn. octosignata Grote.

*2503. altera Ottolengut, Jn. N. Y. Ent. Soc., x, 69, 1902.

*2504. v-alba Otтolengut, Jn. N. Y. Ent. Soc., x, 73, 1902 .

2505. rectangula Kirby, Faun. Bor. Am., iv, 306, 1837; SMITH, C. 254.

N. Y. Can.

Wyo.

No. Atl. States.

syn. mortuorum GuenÉe, spec. Gén., vi, 353, 1852: SмIтH, C. 254.

*2506. u-aureum Gunnée, Spec. Gén., vi, 353, 1852: SмITH, C. $254 .^{1}$

*2507. arctica Möschler, Verh. zool.-bot. Ges. Wien, $285,1884 .^{1}$

2508. vaccinii Hy. Edwards, Ent. Amer., iii, 170, 1886; SмITH, C. $254 .^{1}$

No. Atl. States.

2509. selecta Walker, Cat. Brit. Mus., xii, 912, 1857 ; SMITH, C. 255.

No. Atl.

States.

syn. viridisignata Grote.

*2510. variana Ottolengut, Jn. N. Y. Ent. Soc., x, 70, 1902.

2511. epsilon Ottolengut, Proc. Wash. Acad. Sci., ii, $494,1901$.

2512. angulidens Sмптн, Trans. Am. Ent. Soc., xviii, 111. 1891: C. 255.

2513. ottolenguii DYAR.

svn. arctica Ottolengui (not Möschler), Jn.

N. Y. Ent. Soc., x, 66, 1902.

*2514. celsa Hy. Edwards, Pap., i, 101, 1891; SмIth, C. 255 .

2515. epigæa Grote, Proc. Acad. Nat. Soc. Phil., 208, 1874; SмITH, C. 255.

N. Y., Mass., Col.

*2516. surena Grote, Bull. Geol. Surv. Terr., vi, 585, 1882; SмIтH, C. 255.

2517. ampla WAlker, Cat. Brit. Mus., xii, 910, 1857; Sмith, C. 256.

N. Bruns.

Alaska.

Col.

Alaska.

Oreg.

Me.

No. Atl. States, Col.

syn. alterna Strecker, Proc. Acad. Nat. Sci. Phil., xxxvii, 178, 1885. 
2518. basigera WALKer, Cat. Brit. Mus., xxxiii, 836, 1865 ; SмITH, C. 255.

syn. laticlavia Morrison.

States.

2519. falcigera Kirby, Faun. Bor. Am., iv, 308, 1837; SMITH, C. 254.

a. simplex Guenér, Spec. Gén., vi, 346, 1852; SмIтH, С. 256.

2520. pasiphæia Grote, Bull. Buff. Soc., i, 146, 1873; SмITH, C. 256.

Pac. States.

*2521. zeta Ottolengui, Jn. N. Y. Ent. Soc., x, 70, N.-W. Terr. 1902.

*2522. excelsa Ottolengui, Jn. N. Y. Ent. Soc., x, 71, 1902.

*2523. pallida Ottolengui, Jn. N. Y. Ent. Soc. x, 71, 1902.

2524. corrusca Strecker, Proc. Acad. Nat. Sci. Phil., 178, 1885; Sмптн, C. 257.

No. U.S.

Newfoundl.

Col. Wash.

*2525. omicron Afzelius, Life Linn., 1823: ऽмiтH, C. $257 .{ }^{1}$

N. Y.

B. C.

*2526. speciosa Ottolengui, Jn. N. Y. Ent. Soc., x, 73, 1902.

*2527. simplicima Ottolengui, Jn. N. Y. Ent. Soc., x, $74,1902$.

2528. sackeni Grote, (an. Ent., ix, 135, 1877; Sмнтн, C. 257 .

*2529. snowi Hy. Edwards, Pap., iv, 44, 188t; Smith, C. 257 .

Wash.

Col.

Col. .

N. Mex.

*2530. diasema Boisduval, Eur. Lep. Ind. Méth., 93, 1829 ; Sмith, C. 256.

Lab., Col.

2531. accurata Hy. Edwards, Pap., ii, 127, 1882: SмIтH, C. 257 .

Wash.

¿YNGRAPHA Hübner.

Hübner, Verz. bek. Schmett., 250, 1816; Caloplusia Smith.

2532. parilis Hübner, Schmett. Eur., Noct., iii, 422, 1800; Smith, C. 256.

Arctic

$\mathrm{Am}$.

syn. quadriplaga WALKER.

2533. ignea Grote, Proc. Ent. Soc. Phil., ii, 274, 1863; SмITH, C. 258.

Col.

${ }^{1}$ This name falls by ḩomonymy even if it represent a different species from omicrom Hübner [2486]. See Fée, Life Linnæus in Mém. Soc. R. d. Sci. de Lille, 1831. 
2534. hochenwarthi Hochenwarth, Act. Soc. Berl., vi 337. 1785: Sмith, C. 258.

Aretic Am. syn. divergens Fabricius.

2535. devergens HüBner, Schmett. Eur., Noct., iii, 500, 1800: Sмптн, C. 259.

Col., Lab.

syn. alticola Walker, Cat. Brit. Mus., xii, 912, 1857; SмIтH, C. 258.

\section{ABROSTOLA Ochsenheimer.}

Ochsenheimer, Schmett. Eur., iv, 88, 1816.

2536. urentis Gunnée, Spec. Gén., vi, 322, 1852; Sмiтh, C. 246.

Atl. States.

Atl. States.

\section{BEHRENSIA Grote.}

Grote, Can. Ent., vii, 70, 1875.

2538. conchiformis Grote, Can. Ent., vii, 71, 1875; Cal., Sмith, C. 246.

Oreg.

DIASTEMA Guenée.

Guenée, Spec. Gén., vi, 317, 1852; Nepistu Walker, Plagiola Grote.

*2539. tigris Guenée, Spec. Gén., vi, 317, 1852; Sмmтh, Fla. C. 245 .

syn. lineata WALKER.

\section{OGDOCONTA Butler.}

Butler, Ann. Mag. Nat. Hist., (6), vii, 462, 1891.

2540. cinereola Guenée, Spec. Gén., vi, 316, 1852; Sмith, C. 245.

syn. atomaria WALKER.

*2541. carneola Surth, Trans. Am. Ent. Soc., xviii, N. Mex. 110,1891 ; C. 246.

\section{PAETES Huibnér.}

HüBner, Verz. bek. Schmett., 248, 1816; Ingura Guenée.

2542. declinata Grote, Can. Ent., xi, 208, 1878; Surth, C. 240 .

Cal.,

Col.

2543. burseræ DYar, Proc. Ent. Soc. Wash., iv, 455,

Fla. 1901.

2544. delineata Guenée, Spec. Gén., vi, 311, 1852; Sirth, C. 240. 
2545. abrostoloides Guenée, Spec. Gén., vi, 311, 1852;

SNITH, C. 240.

Atl. States.

*2546. flabella Grote, Can. Ent., xi, 208, 1879; Sмнтн, C. 240 .

Kans.

2547. pygmæa Hübner, Zutr. exot. Schmett., f. 109, 1818; Smith, C. 240; Grote, Abh. nat. Ver. Brem., xiv, 101, 1895.

syn. fuscescens WALKER, abrostella WALKER, propilata Grote.

2548. oculatrix Guenée, Spec. Gén., vi, 313, 1852; SмIтH, C. 241.

Atl. States.

*2549. cristatrix Guenée, Spec. Gén., vi, 313, 1852; Smith, C. 241. U.S.

\section{EUTELIA Hiibner.}

HüBner, Verz. bek. Schmett., 259, 1816.

*2550. pulcherrima Grote, Proc. Ent. Soc. Phil., iv,326, 1865; Sмith, C. 239. syn. dentifera WALKER.

\section{MARASMALUS Grote.}

Grote, Trans. Am. Ent. Soc, iv, 89, 1872.

2551. inficita Walker, Cat. Brit. Mus., xxxiii, 818, 1865; Sмiтh, C. 239.

syn. histrio Grote.

2552. ventilator Grote, Trans. Am. Ent. Soc., iv, 89, 1872: SмIтH, C. 239.

Guenée, Spec. Gén., v, 406, 1852; Chytoryza Grote.

2553. orbica Morrison. Proc. Bost. Soc. Nat. Hist., xvii, 216, 1874; Sмmтн, C. 244.

Tex., Kans. syn. tecta Grote.

\section{PTERATHOLIX Grote.}

Grote, Trans. Am. Ent. Soc., iv, 298, 1873.

2554. bullula Grote, Trans. Am. Ent. Soc., iv, 299, 1873; SмIтH, C. $24 \dot{4}$.

So. States. 


\section{ALABAMA Grote.}

Grote, Abh. nat. Ver. Brem., xiv, 123, 1895.

2555. argillacea HüBner, Zutr. exot. Schmett., f. 399, 1820; SмIтн, C. 243.

So. Atl. States.

syn. xylina SAY, grandipuncta GUEnÉE, bipunctina GuenéE.

\section{ANOMIS Huibner.}

\section{Hübner, Verz. bek. Schmett., 249, 1816.}

2556. erosa HüBner, Zutr. exot. Schmett., f. 287, 1818; SuIth, C. 241.

So. Atl. States.

So. Atl. States.

Gulf States.

Tex.

*2559. conducta Walker, Cat. Brit. Mus., xiii, 990, 1857; SмIтн, C. 242.

syn. hostia HARveY.

SCOLECOCAMPA Guenée.

Guenée, Spec. Gén., v, 131, 1852.

2560. liburna Geyer, Zutr. exot. Schmett., f. 963, 1823; Smith, C. 191. syn. ligni Guenéf.

EUCALYPTERA Morrison.

Morrison, Ann. Lyc. Nat. Hist. N. Y., xi, 104, 1875.

*2561. obscura Grote, Can. Ent., xv, 7, 1883; Sмmth, C. 192 .

Ariz.

2562. bipuncta Morrison, Ann. Lyc. Nat. Hist. N. Y., xi, 104, 1875; SмIтн, C. 191.

Atl.

Coast.

2563. pectinicornis SмIтн, Jn. N. Y. Ent. Soc., vii, 232,

Ariz. 1899.

2564. strigata Sмiтн, Jn. N. Y. Ent. Soc., x, 45, 1902.

Tex. 


\section{REABOTIS Smith.}

Eyes naked; legs unarmed save for the usual spurs on tibiæ, closely scaled; palpi long, curved, far exceeding the head, closely scaled, median joint a little thickened centrally, terminal joint slender, cylindrical; tongue moderate only; primaries trigonate, costa a little depressed, inner and outer margins rounded; secondaries, cell-rather short, vein 5 as strong as the others and close to 4 on a short spur from the median.-JoHn B. Sмiтh.

*2565. immaculalis Hulst, Trans. Am. Ent. Soc., xiii, $154,1886$.

Mont.

\section{CILLA Grote.}

Grote, No. Am. Ent., i, 100, 1880.

2566. distema Grote, No. Am. Ent., i, 100, 1880; Sмiтh, C. 193.

Tex.

AMOLITA Grote.

Grote, Bull. Buff. Soc, ii, 158, 1874.

2567. fessa Grote, Bull. Buff. Soc., ii, 158, 1874 ; Sмптн, C. 193.

Atl. States.

RIVULA Guenée.

Guenée, Spec. Gén., viii, 47, 1854.

2568. propinqualis GuenéE, Spec. Gén., viii, 49, 1854; SMITH, C. 384.

Atl. States.

\section{PSEUDORGYIA Harvey.}

Harvey, Bull. Buff. Soc., ii, 283, 1875.

2569. versuta Harver, Bull. Buff. Soc., ii, 284, 1875; SMITH, C. 386.

*2570. russula Grote, Pap., iii, 75, 1883; Sмптн, C. 386.

Tex.

Ariz.

\section{DORYODES Guenée.}

Guenée, Spec. Gén., x, 233, 1857.

2571. bistriaris Geyer, Zutr. exot. Schmett., f. 775. 1823: SмIтH, C. 192.

Atl.

Coast.

syn. acutaria Herrich-SchaEfFer, divisa WALKER, promptella WALKER.

2572. spadaria Guenée, Spec. Gén., x, 234, 1857; SMITH, C. 192.
Fla. 
PHIPROSOPUS Grote.

Grote, Trans. Am. Ent. Soc., iv, 90, 1872.

2573. callitrichoides Grote, Trans. Am. Ent. Soc., iv, 90, 1872; Smith, C. 192.

syn. nastuaria ZELLER.

ANEPISCHETOS Smith.

Sмiтh, Proc. U. S. Nat. Mus., xxii, 482, 1900.

2574. bipartita Smith, Proc. U. S. Nat. Mus., xxii, 482, 1900.

Fla.

DIALLAGMA Smith.

Smith, Proe. U. S. Nat. Mus., xxii, 483, 1900.

2575. lutea Sмiтн, Proc. U. S. Nat. Mus., xxii, $¥ 88,1900$.

Fla.

\section{PLEONECTYPTERA Grote.}

Grote, Trans. Am. Ent. Soc., iv, 23, 1872.

2576. pyralis HüBner, Zutr. exot. Schmett., f. 127, 1818; Sмiтн, C. 362 .

So. Atl.

States.

syn. irrecta WALKER, Anccalis ZeLLer.

2577. geometralis Grote, Trans. Am. Ent. Soc., iv, 24 1872; SмIтн, C. 362.

So.

States.

*2578. habitalis W alker, Cat. Brit. Mus., xvi, 39, 1859; Sмiтн, C. 363.

syn. phalænalis Grote.

So.

States.

Cal.

Col.,

Ariz.

Ariz.

Ariz.

Tex.

Tex.

*2584. obliqualis Hr. Edwards, Ent. Amer., ii, 171 , 1886; Sмiтн, C. 363. 
A N NAPHILA Grote.

Grote, Bull. Buff. Soc., i, 149, 1873.

*2585. casta Hy. Edwards, Ent. Amer., iv, 114. 1890; SмITH, C. 296.

2586. superba Hy. Enwards, Proc. Cal. Acad. Sci., vi, 139, 1875: SмIтн, C. 296.

*2587. divinula Grote, Bull. Geol. Surv. Terr., iv, 183 , 1878; Sмith, C. 296.

2588. diva Grote, Bull. Buff. Soc., i, 150, 1873; SмIth, C. 296 .

Oreg.

Cal.

Cal.

Cal.

*2589. pustulata Hy. Edwards, Pap., i, 23, 1881; SмIth, C. 297 .

Ariz.

*2590. domina Hy. Edwaros, Proc. Cal. Acad. Sci., vi, 138, 1875 ; SмITH, C. 297.

Cal.

*2591. germana Hy. Edwards, Proc. Cal. Acad. Sci., vi, 138, 1875: SмIтн, C. 296.

2592. decia Grote, Can. Ent., vii, 47, 1875; Sмнтн, C. 296.

syn. amicula Hr. EDwards.

*2593. depicta Grote, Bull. Buff. Soc., i, 159, 1873; SмIтH, C. 296.

2594. salicis Hy. Eowards, Pap., i, 23, 1881; SмiтH, C. 297.

syn. arvalis Hy. EDwards.

*2595. lithosina Hy. Edwards, Proc. Cal. Acad. Sci., vi, 137, 1875; Sмптн, C. 297.

Cal.

2596. mera Harvey, Bull. Buff. Soc., ii, 277, 1875: SMITH, C. 297.

Cal.

Cal.

Cal.

Cal.

2597. danistica Grote, Bull. Buff. Soc., i, 151, 1873; Sмith, C. 297.

Nev. Cal.

INCITA Grote.

Grote, Abh. nat. Ver. Brem., xiv, 112, 1895.

2598. aurantiaca Hy. Edwards, Pap., i, 23,1881; SмIтн, C. 297.

Cal.

TRICHOTARACHE Grote.

Grote, Can. Ent., vii, 48, 1875.

*2599. assimilis Grote, Can. Ent., vii, 48, 1875; SмIтH, C. 298. 


\section{EUSTROTIA Hibner.}

Hübner, Verz. bek. Schmett., 253, 1816; Erastria Ochsenhemer (not Hǘner).

*2600. malaca Grote, Trans. Am. Ent. Soc., iv, 296 , 1873; SмIтH, C. 309.

2601. albidula Guenée, Spec. Gén., vi, 230, 1852; SмITH, C. 309.

Atl. States.

*2602. secta Grote, Can. Ent., xi, 199, 1879; Sмптн, C. 310 .

2603. flaviguttata Grote, Can. Ent., xiv, 187, 1882; SMith, C. 310.

2604. concinnimacula Guenée, Spec. Gén., vi, 238, 1852; Sмптн, C. 310.

Pa.

a. parvimacula Grote, No. Am. Ent., i, 66, 1880.

2605. synochitis Grote \& Robinson, Trans. Am. Ent. Soc., i, 357, 1868; Smith, C. 310.

Mass.

Tex.

Atl.

States.

2606. musta Grote \& Robinson, Trans. Am. Ent. Soc., i, 358, 1868; SмIтн, C. 311.

2607. muscoscula Guenée, Spec. Gén., vi, 230, 1852; SMITH, C. 311.

Atl. States.

Atl.

States.

Atl.

States.

*2608. retis Grote. Can. Ent., xi, 198, 1879; Sмmтн, C. 311.

*2609. distincta Grote, Pap., ii, 184, 1882; Smith, C. 311.

2610. caduca Grote, Can. Ent., viii, 207, 1876; SмIтH, C. 311 :

Pa.

2611. propera Grote, Pap., ii, 132, 184, 1882; Sмгтн, C. 311.

2612. apicosa Haworth, Lep. Brit., 261, 1812; Sмнтн, C. 311.

syn. nigritula Guenée.

2613. carneola Guenée, Spec. Gén., vi, 228, 1852; SмIтн, C. 312.

syn. biplaga WALKER.

*2614. strigulataria Sмrтh, Jn. N. Y. Ent. Soc., viii, 173,1900 .

*2615. dividua Grote, No: Anı. Ent., i, 46, 1880: Sмiтн, C. 312.

2616. æria Grote, Pap., i, 11, 1881; Sмiтн, C. 312.

Atl.

States.

Fla.

Atl.
states.

Ariz.

Atl.

States.

Tex.

Wis., Ala. 4630 -No. $52-02-14$ 
2617. includens Walker, Cat. Brit. Mus., xii, 813, No. Atl. 1857 ; SмIтн, С. 312. States.

syn. nomma Morrison, pentia Morrison, mariz GRoTe.

\section{GA LGULA Guenée. \\ Guenée, Spec. Gén., vi, 239, 1852.}

2618. hepara Guenée, spec. Gén., vi, 239, 18.52; SмITH, C. 314.

Atl.

syn. externa WALKER.

a. partita Guenée, Spec. Gén., vi, 239, 1852. syn. vesca Morrison, subpartitr Guenée.

\section{ESCARIA Grote. \\ Grote, Pap., ii, 186, 1882.}

2619. clauda Grote, Pap., ii, 186, 1882; Sмmtн, C. 302.

Ariz.

\section{AZENIA Grote.}

Grote, Pap., i1, 186, 1882.

2620. implora Grote, Pap., ii, 186, 1882; Sмгтн, C. 302.

*2621. edentata Grote, Can. Ent., xv, 25, 1883; Sмith, C. 302 . States.

Ariz.

Ariz.

LITHACODIA Hübner.

HÜBNER, Verz. bek. Schmett., 205, 1816.

2622. bellicula Hübner, Zutr. exot. Schmett., f. 85, 1818; Sмith, C. 309.

Atl. States, Col.

\section{PROTHYMIA Hübner.}

HüBNER, Verz. bek. Schmett., 282, 1816.

2623. rhodarialis Walker, Cat. Brit. Mus., xix, 860, 1859; SмITH, C. 307.

Atl. States.

syn. coccineifascia Grote.

2624. semipurpurea Walker, Cat. Brit. Mus., xxxiii, 803, 1865: SмITH, C. 307.

syn. comfinisalis WaLKER, rosalba Grote.

*2625. plana Grote, Pap., ii, 184, 1882; Smith, C. 307.

2626. orgyiæ Grote, Trans. Am. Ent. Soc., v, 116, 1875 ; SмITH, C. 307.

syn. subolivacea Harver.
Ali. Stales.

Ariz.

Tex. 
EXYRA Grote.

Grote, Check List Noct., 26, 1875.

2627. semicrocea Guenée, Spec. Gén., vi, 241, 1852; SMith, C. 306.

2628. ridingsii Riley, Trans. St. Louis Acad. Sci., iii, 240, 1874; Smith, C. 306.

syn. nigrocaput Morrison.

*2629. fax Grote, Trans. Am. Ent. Soc., iv, 295, 1873; Smith, C. 306.

Atl.

States.

So.

States.

So.

States.

2630. rolandiana Grote, Psyche, ii, 38, 1877; Sмrth, C. 306.

Atl.

States.

XANTHOPTERA Guenée.

Guenée, Spec. Gén., vi, 240, 1852.

2631. nigrofimbria Guenée, Spec. Gén., vi, 241, 1852; SMITH, C 303.

So. Atl.

States.

Ariz.

*2632. clausula Grote, Pap., ii, 186, 1882; Smith, C. 303.

2633. semiflava Guenée, Spec. Gén., vi, 241, 1852; Sмiтн, C. 303.

So. States.

*2634. subcitrinalis Hulst, Trans. Am. Ent. Soc., xiii, 157, 1886; Sмiтh, C. 304.

Ariz.

\section{THALPOCHARES Lederer.}

Lederer, Verh. zool.-bot. Ges. Wien, iv, 368, 1853.

*2635. ætheria Grote, No. Am. Ent., i, 47, 1879; Smith, C. 313.

Fla.

\section{EUMESTLETA Butler.}

Butler, Ent., xxv, 189, 1892.

2636. flammicincta Walker, Cat. Brit. Mus., xxxiii, 801, 1865; SмIтн, C. 313.

Tex.,

Fla.

$$
\text { syn. patula Morrison, patmelis Grote. }
$$

2637. carmelita Morrison, Proc. Acad. Nat. Sci. Phil., 434, 1875; Sмith, C. 313.

Tex., Miss., Cal.

2638. mundula Zeller, Verh. zool.-bot. Ges. Wien, xxii, 460, 1872; Sмптн, C. 313.

2639. daria Druce, Biol. Cent. Am., Lep. Het., ii, 497, 1898; Sмrth, Proc. U. S. Nat. Mus., xxii, 490, 1900 .

*2640. orba Grote, Can. Ent., ix, 68, 1877; Smith, C. 314. 
*2641. fortunata Grote, Can. Ent., xiv, 171, 1882;

Ariz.

SмmTH, C. 314.

*2642. perita Grote, Can. Ent., xiv, 171, 1882; Sмmth, Ariz. C. 314.

GYROS Hy. Edwards.

Hy. Edwards, Pap., i, 177, 1881.

*2643. muirii Hy. Edwards, Pap., i, 22, 117, 1881; Cal. SмIтH, C. 315.

\section{TRIPUDIA Grote.}

Grote, Can. Ent., ix, 70, 1877.

2644. flavofasciata Grote, Can. Ent., ix, 70, 1877; Rocky Mts., SMITH, C. 314. Tex., Ala. syn. versutus Hy. EDwards.

2645. quadrifera ZelLer, Verh. zool.-bot. Ges. Wien, xxiv, 425, 1874; Sмiтh, C. 315.

2646. limbata Hy. Edwards, Pap., i, 22, 1881; Sмrth, C. 315 .

2647. opipara Hy. Edwards, Pap., i, 117, 1881; Sмith, C. 315 .

2648. luda Druce, Biol. Cent. Am., Lep. Het., ii, 491, 1898: Sмiтh, Proc. U. S. Nat. Mus., xxii, 489, 1900 .

*2649. basicinerea Grote, Bull. Geol. Surv. Terr., vi, 563,1882 ; SмIтн, C. 315.

2650. lixivia Grote, Can. Ent., xiv, 173, 1882; Sмith, C. 315 .

2651. luxuriosa Sмrтн, Proc. U. S. Nat. Mus., xxii, 490, 1900 .

2652. balteata Sмгтн, Proc. U. S. Nat. Mus., xxii, 489, 1900 .

Tex., Mo., Mex.

Tex., Mex.

Tex.

Ariz., Mex.

Ariz.

Ariz.

Ariz.

Ariz.

\section{METOPONIA Duponchel.}

Duponchel, Cat. Lep. Méth. Eur., iii, 45, 1844.

2653. obtusa Herrich-SCHAEFFer, Samml. ausser. Schmett., f. 210, 1844; Sмiтh, C. 316.

2654. perflava Harvey, Bull. Buff. Soc., iii, 11, 1875; SмITH, C. 316.

2655. macula Sмптн, Trans. Am. Ent. Soc., xviii, 132, 1891; C. 316.

So. Atl. States.

Tex.

N. Mex. 
CHAMYRIS Guenée.

Guenée, Spec. Gén., vi, 225, 1852.

2656. cerintha Treitschke, Schmett. Eur., v, 240, 1825; SмITH, C. 301.

Atl. States.

TORNACONTIA Smith.

Smith, Trans. Am. Ent. Soc., xxvii, 55, 1900.

2657. sutrix Grote, Can. Ent., xii, 154, 1880; SмIтн, C. 299.

Rocky

Mts.

2658. megocula Surth, Trans. Am. Ent. Soc., xxvii, 58, 1900 .

So.

Cal.

THERASEA Grote.

Grote, Abh. nat. Ver. Brem., xiv, 118, 1895; Conacontic Smiтh, Trans. Am. Ent. Soc., xxvii, 55, 1900.

2659. flavicosta Smith, Trans. Am. Ent. Soc., xxvii, 58, 1900 .

Rocky Mts.

2660. angustipennis Grote, Proc. Acad. Nat. Sci. Phil., 426, 1875 ; Sмiтн, C. 299.

Rocky Mts., Cal., Tex.

\section{TARACHE Hübner.}

HüBner, Verz. bek. Schmett., 261, 1816.

2661. terminimacula Grote, Bull. Buff. Soc., i, 153, 1873 ; Sмптн, C. 301.

2662. delecta W ALKer, Cat. Brit. Mus., xii, 799, 1857; Smith, C. 301.

syn. metallica Grote.

2663. flavipennis Grote, Bull. Buff. Soc., i, 153, 1873; SMith, C. 298.

2664. abdominalis Grote, Can. Ent., ix, 157, 1877; Sмith, C. 298.

2665. lactipennis Hapvey, Bull. Buff. Soc., iii, 10, 1875; Sмith, C. 300.

2666. major Suгth, Trans. Am. Ent. Soc., xxvii, 64, 1900.

2667. expolita Grote, Pap., ii, 131, 1882; Sмith, C. 298.

2668. lan eolata Grote, Can. Ent., xi,198, 1879; Sмiтh, C. 299 .

*2669. gonella Strecker, Lep. Rhop. Het., suppl. 1, 11, 1898; Smith, Trans. Am. Ent. Soc, xxvii, 66, 1900.

Atl.

States.

Atl.

States.

Pac.

States.

Tex.,

Kans.

Tex.

Col.

Ariz.

Tex.

Ariz., N. Mex. 
*2670. sedata Hy. Edwards, Pap., i, 23, 1881; Sмmth, C. 300 .

Ariz.,

Tex.

2671. nuicola Sмmтh, Trans. Am. Ent. Soc., xxvii, 67, 1900 .

2672. lucasi Smith, Trans. Am. Ent. Soc., xxvii, 68, 1900 .

2673. biplaga Guenée, Spec. Gén., vi, 218, 1852; SмIтH, C. 298.

Tex.

Cal.

2674. aprica Hübner, Schmett. Eur., Noct., f. 371, 1803; Sмптн, C. 298.

*2675. areli Strecker, Lep. Rhop. Het., suppl. 1, 11, 1898.

2676. erastrioides Guenée, Spec. Gén., vi, 218, 1852; SMITH, C. 299.

2677. quadriplaga Smiтh, Trans. Am. Ent. Soc., xxvii, $72,1900$.

2678. schwarzi Surth, Trans. Am. Ent. Soc., xxvii, 73, 1900 .

2679. arida Smith, Trans. Am. Ent. Soc., xxvii, 73, 1900 .

2680. coquilletti Smith, Trans. Am. Ent. Soc., xxvii, 74,1900 .

2681. neocula Sмптн, Trans. Am. Ent. Soc., xxvii, 75, 1900 .

2682. cretata Grote \& Robinson, Trans. Am. Ent. Soc., iii, 181, 1868; SмIтн, C. 300.

2683. behrii Sмптн, Trans. Am. Ent. Soc., xxvii, 76 , 1900.

2684. elegantula Harver, Can. Ent., viii, 55, 1876; Sмith, C. 300.

syn. arizonx Hr. EDwARDs, seminivealis Hulst.

2685. virginalis Grote, Can. Ent., xiii, 15, 1881; Sмптн, C. 300 .

2686. binocula Grote, Can. Ent., vii, 224, 1875; Sмптн, C. 300 .

2687. meskei Surth, Trans. Am. Ent. Soc., xxvii, 79, 1900 .

2688. tenuicola Morrison, Proc. Bost. Soc. Nat. Hist., xvii, 218, 1874; Sмmтн, C. 299.

2689. libedis Snmth, Trans. Am. Ent. Soc., xxvii, 80, 1900.

So.

States.

So.

States.

Rocky

Mts.

Atl.

States.

Tex.,

N. Mex.

Ariz.

Col., Ariz.

Cal.

N. Mex.

Tex.,

Col.

Cal.

Rocky

Mts.

Ariz.

Ariz.,

Tex.

Tex.

Tex.

Col.,

N. Mex. 
2690. neomexicana Sмrтн, Trans. Am. Ent. Soc., xxvii, Tex. 81,1900 .

2691. candefacta HüBNer, Zutr. exot. Schmett., f. 587 , 1823; Sмптн, C. 299.

syn. debilis WALKER.

2969. ardoris Hübner, Zutr. exot. Schmett., f. 551, 1823; SмIтH, C. 301.

*2693. niveicollis Smith, Jn. N. Y. Ent. Soc., x, 51, 1902 .

*2694. semiatra Sмrтн, Jn. N. Y. Ent. Soc., x, 52, 1902.

*2695. tenuescens Smith, Jn. N. Y. Ent. Soc., x, 53, 1902.

States.

Ga.

Cal.

Ariz.

Fla.

FRUVA Grote.

Grote, Can. Ent., ix, 69, 1877.

2696. tortricina Zeller, Verh. zool.-bot. Ges. Wien, xхіi, 461, 1872; Smith, C. 306.

Tex.

Kans.

syn. fasciatella Grote, obsoleta Grote; SMith, C. 302; inomata Grote.

*2697. acerba Hr. Edwards, Pap., i, 24, 1881; Sмiтh, C. 302 .

*2698. modesta Hr. Edwards, Pap., iv, 124, 1884; SMith, C. 302.

2699. apicella Grote, Trans. Am. Ent. Soc.,iv, 21,1872; Sinth, C. 302.

syn. truncatula ZeLLer, accepta Hy. Edwards.

*2700. parvula Walker, Cat. Brit. Mus., xxxiii, 779, 1865; SмITH, C. 303.

syn. georgica Grote.

*2701. deleta Hy. Edwards, Pap., iv, 124, 1884; Sмith, C. 303.

Nev., Can.

SPRAGUEIA Grote.

Grote, Check List Noct., 25, 1875.

2702. onagrus Gunnée, Spec. Gén.. v1, 205, 1852; Smith, C. 304 .

So. States.

2703. leo Guenée, Spec. Gén., vi, 205, 1852; Surth, C. 304 .

So.

States.

*2704. magnifica Grote, Pap., ii, 183, 1882; Sмrth,

Ariz. C. 304 .

2705. plumbifimbriata Grote, Can. Ent., ix, 68, 1877; SMITH, C. 304.

Tex.

*2706. obatra Morrison, Proc. Bost. Soc. Nat. Hist., xviii, 124, 1875 ; Smith, C. 304. 
2707. dama Guenée, Spec. Gén., vi, 205, 1852; Sмith, C. 305 .

syn. trifariana WALKER.

*2708. transmutata Walker, Cat. Brit. Mus., xxxiii, 776, 1865: SмIтн, C. 305.

syn. pardalis Grote.

2709. funeralis Grote, Pap., i, 158, 1881; Sмmth, C. 305.

2710. sordida Grote, Can. Ent., xiv, 217, 1882; Sмiтh, C. 305 .

2711. guttata Grote, Can. Ent., vii, 224, 1875; Sмrth, C. 305 .

Ariz.

So.

States.

Fla.

Tex.

Tex.

2712. floridensis Guenée, Spec. Gén., vi, 192, 1852;

\section{CALLOPISTRIA Hübner.}

HüBNer, Verz. bek. Schmett., 216, 1816. Surth, C. 309.
*2713. strena Grote, Abh. nat. Ver. Brem., xiv, 119, 1895 .

METATHORASA MOOre.

Moore, Proc. Zool. Soc. Lond., 374, 1881.

*2714. argentilinea Walker, Cat. Brit. Mus., xii, 863, 1857; Sмiтh, C. 308.

So. Atl. States.

2715. monitifera Guenée, Spec. Gén., vi, 295, 1852; Sirth, C. 308.

Atl. States.

\section{EUHERRICHIA Grote. \\ Grote, Pap., ii, 122, 1882.}

2716. mollissima Guenée, Spec. Gén., vi, 294, 1852; SMith, C. 308.

Atl.

States.

$$
\text { syn. rubicunda WALKER. }
$$

*2717. granitosa Guenée, spec. Gén., vi, 195, 1852; Sмiтh, C. 308.

*2718. cervina Hy. Edwards, Ent. Amer., vi, 114, 1890; Sмith, C. 308.
So.

States.

Cal.,

Col.

\section{CYDOSIA Westwood.}

Westwood, Nat. Lib. Exot. Moths, xxxvii, 193, 1841; Sмrтh, Proc. U. S. Nat. Mus., xi, 187, 1888; Penthetria Hy. Edwards, Pap., i, 80, 1881; Tantura Kinby, Cat. Lep. Het., i, 86, 1892.

2719. imitella Stretch, Zyg. Bomb. No. Am., i, 163, 1873; Neumoegen \& Dyar, Jn. N. Y. Ent. Soc., So. i, 154, 1893; Druce, Biol. Cent. Am., Lep. Het., States. ii, $402,1897$. 
2720. aurivitta Grote \& Robinson, Trans. Am. Ent. Soc., ii, 186, 1868; Neunoegen \& Dyar, Jn. N. Y. Ent. Soc., i, 154, 1893.

2721. majuscula Hr. Enwards, Pap., i, 80, 1881; NeuMOEgEN \& DYAR, Jn. N. Y. Ent. Soc., i, 113, 1893; Dyar, Jn. N. Y. Ent. Soc, vi, 41, 1898.

\section{CERATHOSIA Smith.}

Smith, Ent. Amer., iii, 79, 1887.

2722. tricolor Smith, Ent. Amer., iii, 79, 1887; Grote, Ent. Amer., iv, 121, 1888; Smith, Ent. Amer., iv, 122, 1888; Grote, Can. Ent., xxi, 37, 1889; Smith, Ent. Amer., v, 8, 119, 1889; Hurst, Ent. Amer., v, 118, 1889; Neumoegen \& Dyar, Jn. N. Y. Ent. Soc., i, 155, 1893; Dyar, Psyche, viii, 154,1897 .

\section{HORMOSCHISTA Möschler.}

Möschler, Abh. Senck. Ges., 221, 1890.

2723. pagenstecheri Möschler, Abh. Senck. Ges., 221, 1890.

So.

States.

So,

States.

Tex.

\section{PHALANOSTOLA Grote.}

Grote, Trans. Am. Ent. Soc., iv, 302, 1873.

2724. larentioides Grote, Trans. Am. Ent. Soc., iv, 302, 1873; Sмiтн, C. 377.

So. Atl.

a. citima Grote, Trans. Am. Ent. Soc., iv, 303, 1873.

\section{PANGRAPTA Hübner.}

HüBNER, Verz. bek. Schmett., 343, 1816.

2725. decoralis HüBnER, Zutr. exot. Schmett., f. 93, 1818; Sмiтh, C. 377.

Atl. States.

syn. geometroides GuenéE, epionoides GuenéE, elegantalis FITCH, recusans W ALKER.

\section{SYLECTRA Hübner.}

HüBner, Verz. bek. Schmett., 341, 1816.

2726. erycata Cramer, Pap. Exot., pl. 287, f. D, 1782: SMith, C. 376.

Fla., So. Am. syn. mirandalis HüBNER. 
HYAMIA Walker.

Walker, Cat. Brit. Mus., xvi, 234, 1858; Spargaloma Grote.

2727. sexpunctata Grote, Trans. Am. Ent. Soc., iv, 300, 1873; Dyar, Jn. N. Y. Ent. Soc., iv, 145, 1896.

Atl. States.

2728. perditalis Walker, Cat. Brit. Mus., xvi, 234, 1858; SмITH, C. 346.

syn. semilineata W ALKER, umbrifascia Grote.

*2729. punctipennis Grote, Can. Ent., xv, 122, 1883; SMITH, C. 376.

Ariz.

MELANOMMA Grote.

Grote, Trans. Am. Ent. Soc., v, 117, 1875; Hulst, Trans. Am. Ent. Soc., xxiii, 294, 1896.

2730. auricinctaria Grote, Trans. Am. Ent. Soc., v, 117, 1875; Bull. Geol. Surv. Ter., iv, 674, 1878; Dyar, Can. Ent., xxx, 257, 1898.

ARGILLOPHORA Grote.

Grote, Bull. Buff. Soc., i, 124, 1873; Sмптн, C. 375.

*2731. furcilla Grote, Bull. Buff. Soc., i, 124, 1873;

Ala. SмITH, C. 375.

\section{PARORA Smith.}

Smith, Proc. U. S. Nat. Mus., xxii, 491900.

2732. texana Sмrтh, Proc. U. S. Nat. Mus., xxii, 491, 1900 .

Tex.

HOMOPYRALIS Grote.

Grote, Proc. Acad. Nat. Soc. Phil., 213, 1874.

2733. discalis Grote, Can. Ent., viii, 206, 1876; Sмrth, C. 374 .

2734. contracta Walker, Can. Nat. Geol., v, 258, 1869; SMITH, C. 374.

Atl. States.

Atl. syn. zomata WALKER, tactus GroTe.

States.

2735. tantillus Grote, Proc. Acad. Nat. Sci. Phil., 214, 1874; SмIтH, C. 375.

2736. monodia DYAR (like tantillus, but blacker, nearly uniform, the lines fine, white, punctate).

2737. miserulata Grote, Can. Ent., xiv, 185, 1882; N. Mex. SмIтн, C. 375. 


\section{AGASSIZIA Behr.}

Behr, Trans. Am. Ent. Soc., iii, 23, 1870.

*2738. urbicola Benr, Trans. Am. Ent. Soc., iii, 23, Cal. 1870; Sмiтн, C. 366.

ISOGONA Guenée.

Guenée, Spec. Gén., vii, 322, 1852; Entoreuma Grote.

*2739. natatrix Guenée, Spec. Gén., vii, 323, 1852; SMITH, C. 365.

So. Atl.

syn. tenuis Grote, Trans. Am. Ent. Soc., iv, States. $22,1872$.

HYPSOROPHA Hibner.

Hübner, Verz. bek. Schmett., 249, 1816.

2740. monilis Fabricius, Spec. Ins., ii, 219, 1782; SMITH, C. 260.

So. States.

2741. hormos HüBner, Zutr. exot. Schmett., f. 27 , 1818; SмIтH, C. 260.

So. Atl.

States.

HYBLAEA Fabricius.

Fabricius, Ent. Syst., iii, 2, 127, 1793.

2742. puera Cramer, Pap. Exot., pl. 103, f. D, 1779; Sмiтh, C. 316.

Fla.. Antilles. syn. saga Fabricius, mirificum STRECKER.

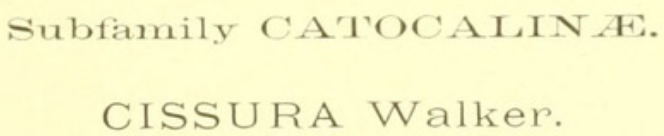

Walker, Cat. Brit. Mus., ix, 153, 1856; Synedoida Hy. Edwards.

2743. spadix Cramer, Pap. Exot., pl. 275, f. F, 1780; Tex. Sмith, C. 320.

syn. vegeta Morrison; Smith, C. 207, 320.

*.2744. mucronata Grote, Can. Ent., xv, 121, 1883;

Ariz. Sмith, C. 321.

2745. inepta Hr. Edwards, Pap., i, 27, 1881; Smith, C.

Col. 321.

syn. morbosa Hy. Edwards.

*2746. biformata Hr. Edwards, Pac. Coast Lep., no. 29,

Cal. 9, 1878; Sмith, C. 321.

2747. scropulosa Hy. Edwards, Pac. Coast Lep., no. 29. 9, 1878; Sмiтh, C. 321. 
2748. insperata Grote, Can. Ent., xiv, 176, 1882; Ariz. SмIтH, C. 321.

2749. ægrotata Hy. Edwards, Pap., iv, 47, 1884; Ariz. Sмiтh, C. 321.

2750. sabulosa Hy. Enwards, Pap., i, 26, 1881; Sмiтh, Col. C. 321 .

*2751. cervina Hy. Edwards, Pap., ii, 129, 1882; Sмith, C. 320 .

2752. subtermina Sмгтн, Proc. U. S. Nat. Mus., xxii, 492,1900 .

Ariz.

Cal.

\section{ULOSYNEDA Smith.}

Differs from Cissura by the plump woolly body, woolly thoracic vestiture, short weak legs, shorter palpi, narrower primaries and pectinated male antennæ; allied with Cienurgia.—Јон B. Sмiтн.

2753. valens Hy. Edwards, Pap., i, 119, 1881; Sмith, C. 321.

Utah, Col.

\section{DRASTERIA Hübner.}

Hübner, Verz. bek. Schmett., 280, 1816.

2754. erechtea Cramer, Pap. Exot., pl. 275, f. E, 1782; SMith, C. 316.

Atl. States, Col. syn. sobria W ALKER, narrata W ALKER, patibilis W ALKER, agricola GROTE \& ROBINSON, mundula Grote \& Robinson.

2755. crassiuscula НАwовтн, Lep. Brit., 259, 1810; Smith, C. 317. syn. erichto Guenée.

a. ochrea Grote, Bull. Buff. Soc., i, 155, 1873.

b. distincta Neumoegen, Pap., iii, 143, 1883.

2756. cærulea Grote, Bull. Buff. Soc., i, 155, 1873; Sмiтh, C. 318. syn. aquamarina Felder.

2757. conspicua Sмrтн, Can. Ent., xxxii, 224, 1900.

Pac. States.

Alberta.

\section{ENURGIA Walker.}

Walker, Cat. Brit. Mus., xiv, 1491, 1858; Litosea Grote.

2758. convalescens Guenée, Spec. Gén., vii, 289, 1852; Sirth, C. 318. syn. socors WALKER, purgata WALKER.

2759. adversa Grote, Can. Ent., vii, 49, 1875; Sмiтh, C. 318 .

States.

Cal. 
EÚCLIDIA Ochsenheimer.

Ochsenhemer, Schmett. Eur., iv, 96, 1816.

2760. cuspidea HüBner, Zutr. exot. Schmett., f. 69, 1818; Sмiтh, C. 319.

Atl. States.

Oreg.

*2761. annexa Hy. Edwards, Ent. Amer., vi, 115, 1890; Sмith, C. 319.

2762. intercalcaris Grote, Bull. Geol. Surv. Terr., vi, 563, 1882; SмITH, C. 319.

2763. diagonalis Dyar, Jn. N. Y. Ent. Soc., vi, 41, 1898.

PANULA Guenée.

Guenée, Spec. Gén., vii, 59, 1852.

2764. inconstans Guenée, Spec. Gén., vii, 59, 1852; Sмith, C. 320.

*2765. remigipila GuenÉe, Spec. Gén., vii, 60, 1852; Sмith, C. 320.

\section{MELIOPOTIS Hübner.}

HüBner, Verz. bek. Schmett., 260, 1816.

2766. fasciolaris HüBner, Zutr. exot. Schmett., f. 443 , 1823; Smith, C. 326.

syn. hunearis GuenéE.

2767. nigrescens Grote \& Rominson, Proc. Ent. Soc. Phil., vi, 20, 1866; SMmth, C. 326.

So. States.

Fla.?
So. States?

Antilles.

Tex.,

Col.

Tex.,

Col.

Atl.

States.

Tex.

III.,

Tex.

Tex.

Ariz.

2773. perlæta Hy. Edwards, Pap., ii, 14, 1882; Sumth, C. 327 . 
2774. jucunda Hübner, Zutr. exot. Schmett., f. 81, 1818; Sмптн, C. 328.

Atl. States, Col.

syn. cinis Guenée, agrotipennis Harver, hadeniformis BeHr, Trans. Am. Ent. Soc., iii, 25,1870 ; :мптн, С. 327.

2775. sinualis Harvey, Can. Ent., ix, 94, 1877; Sмiтh, C. 328 .

\section{HYPOGRAMMA Guenée.}

Guenée, Spec. Gén., vii, 34, 1852.

*2776. andromedæ Guenée, Spec. Gén., vii, 84, 1852; Smith, C. 328.

Ga.

\section{CIRRHBOLINA Grote.}

Grote, Trans. Am. Ent. Soc., v, 117, 1875.

2777. deducta Morrison, Proc. Bost. Soc. Nat. Hist., xvii, 220, 1874; Smith, C. 325.

syn. pavitensis Morrison.

2778. mexicana BeHr, Trans. Am. Ent. Soc., iii, 27. 1870 ; Sмiтh, C. 325.

S. - W.

U.S.

syn. incandescens Grote.

a. vulpina Hy. Edwards, Pap., ii, 14, 1882.

*2779. perfecta Hy. Edwards, Pap., iv, 46, 1884; SмIтH, C. 326.

*2780. tetrica Hy. Edwards, Pac. Coast Lep., no. 29, 10, 1878; SмITH, C. 326.

Tex.

Ariz.

Cal.

\section{SYNEDA Guenée.}

\section{Guenée, Spec. Gén., vii, 71, 1852.}

2781. graphica HüBner, Zutr. exot. Schmett., f. 11. 1818: Sмith, C. 322.

Atl. syn. capticola WALKER.

a. media Morrison, Proc. Bost. Soc. Nat. Hist., xviii, $125,1875$.

2782. divergens Behr, Trans. Am. Ent. Soc., iii, 27, 1870 ; Sмith, C. 323.

*2783. petricola Walker, Cat. Brit. Mus., xiv, 1462, 1858: Sмiтн, C. 323.

States.

2784. alleni Grote, Can. Ent., ix, 215, 1877; Sмiтh, C. 323.

$$
\text { syn. saxea Hy. Edwards. }
$$

2785. adumbrata BeHr, Trans. Am. Ent. Soc., iii, 27, 1870; SмiтH, C. 323.

Rocky

Mts.

No. Atl.

States, Col.

Cal., Rocky Mts 
2786. seposita Hy. Edwards, Pap., i, 25, 1881; Sмith, C. 323.

Col.,

Utah.

2787. socia BeHl, Trans. Am. Ent. Soc., iii, 27, 1870; SмIтH, C. $32:$.

Cal.,

Col.

2788. ochracea Benr, Trans. Am. Ent. Soc., iii, 25, 1870; Smith, C. 324.

Cal.

*2789. mirifica Hy. Edwards, Pac. Coast Lep., no. 29, 8, 1878 ; SмmTH, C. 324.

2790. tejonica Benr, Trans. Am. Ent. Soc., iii, 26, 1870; Sмith, C. 324.

Nev.

Cal. ,

Col.

2791. ingeniculata Morrison, Proc. Acad. Nat. Sci. Phil., 435, 1875; SмITH, C. 325.

Tex.

2792. hastingsii Hy. Evwards, Pac. Coast Lep., no. 29, 8, 1878; Sмiтh, C. 324.

a. perpallida Hy. Edwards, Pap., i, 25, 1881.

*2793. maculosa Benr, Trans. Am. Ent. Soc., iii, 26, 1870 ; SмIтн, C. 324.

*2794. faceta Hy. Enwards, Pap., i, 119, 1881; Sмiтh, C. 324 .

2795. howlandii Grote, Proc. Ent. Soc. Phil., iii, 533, 1864; SмITH, C. 324.

syn. stretchii BEHR.

2796. edwardsii Beнr, Trans. Am. Ent. Soc., iii, 28, 1870; Sмith, C. 325.

*2797. nubicola Behr, Trans. An. Ent. Soc., iii, 25, 1870; SмIтн, C. 324.

Oreg. .

Cal.

Cal.

Fla,

Rocky Mts.,

Cal.

Cal.

Cal.

*2798. perplexa Hy. Edwards, Pap., iv, 47, 1884; SмITH, C. 325.

Ariz.

*2799. hudsonica Grote \& Robinson, Proc. Ent. Soc. Phil., iv, 494, 1865; Smith, C. 322.

Can., Mont.

*2800. athabasca Neumoegen, Pap., iii, 143, 1883; SMITH, C. 322.

B. C.

*2801. occulta Hy. Edwards, Pap., i, 118, 1881; Sмith, C. 323.

*2802. fumosa STrecker, Lep. Rhop. Het., suppl. 1, 12, 1898.

*2803. flavofasciata STREскеR, Lep. Rhop. Het., suppl. 1, 12, 1898.

*2804. nigromarginata Strecker, Lep. Rhop. Het., suppl. 1, 11, 1898.

Tex.

Ariz.

Ariz.

Ariz.

*2805. decepta Strecker, Lep. Rhop. Het., suppl. 1, 11, 1898. 


\section{CATOCALA Sehrank.}

\section{Schrank, Faun. Boica, ii, 2, 158, 1802.}

2806. epione Drury, Ill. Exot. Ent., i, 46, 1773; Sirth, C. 347 .

Atl.

States.

2807. sappho Strecker, Lep. Rhop. Het., 95, 1874; SмITH, C. 352.

So. States, IIl.

2808. agrippina Strecker, Lep. Rhop. Het., 95, 1874; SMITH, C. 352.

So.

States.

*2809. subviridis Harvey, Can. Ent., ix, 193, 1877; SмITH, C. 353.

Tex.

2810. lacrymosa Guenée, Spec. Gén., vii, 93, 1852; Sмiтh, C. 352.

a. ulalume Strecker, Lep. Rhop. Het., 132, 1877; SмITH. C. 352.

b. paulina Hy. Enwards, Bull. Brook. Ent. Soc., iii, 54,1880 .

c. emilia Hr. Edwards, Pap., i, 117, 1881.

d. evelina French, Pap., i, 110, 1881.

e. zelica French, Pap., i, 111, 1881.

2811. viduata Guenée, Spec. Gén., vii,94,1852; Smith, (). 352 .

syn. mastosa Hulst, guenéei Grote.

*2812. moderna Grote, Can. Ent., xxxii, 191, 1900.

2813. vidua Sмгтн \& A ввот, Lep. Ins. Ga., ii, 181, 1797; Smith, C. 351.

syn. desperata Guenée.

*2814. dejecta Strecker, Bull. Brook. Ent. Soc., ii, 97, 1880; SмITH, C. 351.

2815. retecta Grote, Trans. Am. Ent. Soc., iv, 4, 1872; Smith, C. 351.

Atl. States.

So. Atl.

States.

Tex.

Atl.

States.

So. Atl.

States.

Atl.

a. luctuosa Hulst, Bull. Brook. Ent. Soc., vii, 32, States. $53,1884$.

2816. flebilis Grote, Trans. Am. Ent. Soc.., iv, 4, 1872.

Atl. States.

2817. robinsonii Grote, Trans. Am. Ent. Soc.. iv, 20, 1872; Smith, C. 351.

Atl. a. curvata French, Pap., i, 218, 1881.

*2818. barnesii French, Can. Ent., xxxii, 190, 1900.

States.

2819. obscura Strecker, Lep. Rhop. Het., 19, 1873; Sмiтн, C. 353.

a. simulatilis Grote, Trans. Am. Ent. Soc., v, 95, States. 1873. 
2820. residua Grote, Proc. Bost. Soc. Nat. Hist., xvi, 242, 1874; SмIтн, C. 353.

Atl.

States.

2821. insolabilis Guenée, Spec. Gén., vii, 94, 1852; SмITH, C. 353.

Atl.

States.

Atl.

States.

C. 353 .

a. lucetta Hr. Edwards, French, Cat. Ill., 4, 1882.

2823. judith Strecker, Lep. Rhop. Het., 95, 1874; Smith, C. 350.

syn. levettei Grote.

a. miranda Hy. Edwards, Pap., i, 118, 1881.

2824. tristis Edwards, Proc. Ent. Soc. Phil., ii, 511, 1864; SuIth, C. 347.

*2825. elda Behrens, Can. Ent., xix, 199, 1887; Sмптн, C. 347 .

2826. relicta W ALKer, Cat. Brit. Mus., xiii, 1192, 1857; Smith, C. 346.

a. bianca Hy. Edwards, Bull. Brook. Ent. Soc., iii, 54,1880 .

b. phrynia Hr. Edwards, Bull. Brook. Ent. Soc., iii, 54,1880 .

2827. cara Guenée, Spec. Gén., vii, 87, 1852; Sмrth, C. 344.

a. sylvia Hy. Edwards, Bull. Brook. Ent. Soc., iii, 57,1880 .

b. carissima Hulst, Bull. Brook. Ent. Soc., ii, 97, 1880 .

2828. amatrix HüBNER, Samml. exot. Schmett., ii, 1810; SмITH, C. 344.

Atl. States, Col.

a. nurus Walker, Cat. Brit. Mus., xiii, 1195, 1857; Sмith, C. 345.

2829. marmorata Edwards, Proc. Ent. Soc. Phil., ii, 508, 1864; Sмith, C. 340.

2830. concumbens WaLker, Cat. Brit. Mus., xiii, 1198, 1857; SмITH, C. 344.

Atl.

States.

Atl.

States.

Oreg.

Atl.

States,

Oreg.,

Col.

Atl.

States.

U. S.

Atl.

States.

a. diana Hy. Edwards, Bull. Brook. Ent. Soc., iii, 57, 1880.

b. hillii Grote, Pap., iii, 43, 1883.

2831. californica Edwards, Proc. Ent. Soc. Phil., ii, Cal. 509, 1864; Sмптн, C., 343.

a. perdita Hy. Edwards, Strecker, Lep. Rhop. Het., 100, 1874.

b. cleopatra Hr. Edwards, Strecker, Lep. Rhop. Het., 99, 1874.

$4630-$ No. $52-02-15$ 
*2832. frenchii Poling, Can. Ent., xxxiii, 125, 1901.

B. C.

*2833. jessica Hy. Edwards, Pac. Coast Lep., no. 25, 1877; SмIтH, C. 341.

Cal.

*2834. hippolyta Hy. Edwards, Proc. Cal. Acad. Sci., vi, 211, 1875; Sмптн, C. 341.

Cal.

*2835. portia Hy. Edwards, Bull. Brook. Ent. Soc., ii, 94, 1880; SмIтH, C. 341.

2836. luciana Hy. Edwards, Strecker, Lep. Rhop. Het., 99, 1874; Sмith, C. 343.

syn. nebraskix Dodge.

a. somnus Dodge, Can. Ent., xii, 40, 1881.

*2837. babayaga Strecker, Pap., iv, 73, 1884; Sмгтн, C. 346 .

2838. arizonæ Grote, Can. Ent., v, 163, 233, 1873; Sмiтh, C. 345.

*2838. 1. texanæ French, Can. Ent., xxxiv, 98, 1902.

2839. aspasia Strecker, Lep. Rhop. Het., 94, 1874; SMITH, C. 345.

a. sara French, Can. Ent., xv, 163, 1883.

2840. walshii Edwards, Proc. Ent. Soc. Phil., ii, 509, 1864; Sмith, C. 345.

*2841. junctura Walker, Cat. Brit. Mus., xiii, 1196, 1857; Syith, C. 345.

*2842. cassandra Hy. Edwards, Proc. Cal. Acad. Sci., vi, 214, 1875; SмIтH, C. 345 .

2843. stretchii BeHr, Trans. Am. Ent. Soc., iii, 24, 1870; Sмith, C. 341.

*2844. augusta Hy. Edwards, Proc. Cal. Acad. Sci., vi, 184, 1875; SмIтH, C. 341.

Cal.

Col., Kans., Neb.

Ariz.

Ariz.

Tex.

Col.

Tex.

Atl. States.

Col.

Cal.

Cal.

*2845. rosalinda Hy. Edwards, Bull. Brook. Ent. Soc., iii, 55, 1880; SмIтh, C. 341.

Col.,

Kans.

2846. pura Hulst, Bull. Brook. Ent. Soc., ii, 96, 1880; SмITH, C. 341.

Rocky

Mts.

*2847. semirelicta Grotf, Sixth Rept. Peab. Acad. Sci., 35,1874 ; Sмптн, C. 342.

Atl.

States.

2848. unijuga Walker, Cat. Brit. Mus., xiii, 1194, 1857; Swith, C. 340.

Atl.

States.

Atl.

States. C. 341 .

2850. meskei Grote, Can. Ent., vi, 161, 233, 1873; Sмith, C. 340.

Atl.

States. 
2851. mariana Hy. Edwards, Strecker, Lep. Rhop. Cal. Het., 99, 1874; Sмптн, C. 342.

a. francesca Hy. Edwards, Bull. Brook. Ent. Soc., iii, 57, 1880.

2852. groteiana BaIley, No. Am. Ent., i, 21, 1879; SмITH, C. 342.

Atl.

States.

Col.,

N. Mex.

93, 1880; Sмith, C. 343.

Atl.

States.

Cal., Col. Sмiтh, C. 341.

a. zillah Strecker, Lep. Rhop. Het., 129, 1877.

b. verecunda Hulst, Bull. Brook. Ent. Soc., vii, 45,1884 .

c. allusa Hulst, Bull. Brook. Ent. Soc., vii, 45, 1884.

2856. irene Behr, Trans. Am. Ent. Soc., iii, 24, 1870; Sмiтh, C. 343.

Cal.,

Col.

a. virgilia Hy. Edwards, Bull. Brook. Ent. Soc., iii, $56,1880$.

b. volumnia Hy. Edwards, Bull. Brook. Ent. Soc., iii, 56, 1880.

c. valeria Hy. Edwards, Bull. Brook. Ent. Soc, iii, $56,1880$.

2857. parta Guenée, Spec. Gén., vii, 84, 1852; Sипth, C. 340 .

Atl.

States.

a. perplexa Strecker, Lep. Rhop. Het., 38, 1874.

b. petulans Hulst, Bull. Brook. Ent. Soc., vii, 43,1884 .

2858. coccinata Grote, Trans. Am. Ent. Soc., iv, 6, 1872; Sмith, C. 338.

a. sinuosa Grote, Bull. Brook. Ent. Soc., i, 77, 1879.

2859. circe Strecker, Lep. Rhop. Het., 121, 1876; Smith, C. 338.

2860. aholibah Strecker, Lep. Rhop. Het., 72, 1874; Sмith, C. 339.

Pac. States,

Col.

*2861. chiricahua Poling, Can. Ent., xxxiii, 127, 1901.

Ariz.

*2862. violenta Hy. Edwards, Bull. Brook. Ent. Soc.,

Atl.

States.

Tex. iii, 58, 1880; Sмith, C. 337.

Col. 
2863. verilliana Grote, Can. Ent., vii, 185, 1875;

SмIтth, C. 337.

Rocky

a. ophelia Hy. Edwards, Bull. Brook. Ent. Soc, Mts. ii, 95, 1880.

b. votiva Hulst, Bull. Brook. Ent. Soc., vii, 41, 1884 .

2864. ultronia HüBner, Zutr. exot. Schmett., f. 347, 1818; Sмith, C. 338.

Atl. States,

a. celia Hy. Edwards, Bull. Brook. Ent. Soc., iii, 58, 1880.

b. mopsa Hy. Edwards, Bull. Brook. Ent. Soc., iii, 58, 1880.

c. adriana Hy. Edwards, Bull. Brook. Ent. Soc., iii, 57, 1880.

d. herodias Strecker, Lep. Rhop. Het., 121, 1876.

2865. ilia Cramer, Pap. Exot., pl. 33, f. B, 1779; Sмiтн, C. 339.

a. zoe Behr, Trans. Am. Ent. Soc., iii, 24, 1870.

b. uxor Guenée, Spec. Gén., vii, 92, i852; Sмiтh, C. 339.

syn. umbrosa Worthington, confusa WorthINGTON, decorata WORTHINGTON, obsoleta WoRTHINGTON, dupiicata WoRTHINGTON, conspicua Worthington.

e. osculata Hulst, Bull. Brook. Ent. Soc., vii, 43,1884 .

2866. innubens Guenée, Spec. Gén., vii, 98, 1852;

SMith, C. 348.

a. flavidalis Grote, Trans. Am. Ent. Soc., v, 95, 1874; Sмптн, C. 349.

b. hinda French, Pap., i, 111, 1881.

c. scintillans Grote, Proc. Ent. Soc. Phil., vi, $28,1866$.

2867. nebulosa Edwards, Proc. Ent. Soc. Phil., ii, 510, 1864; Sмптн, C. 350.

2868. piatrix Grote, Proc. Ent. Soc. Phil., iii, 88, 1865; Sмiтh, C. 350.

Atl. States.

Atl.
States.

Atl.
States.

Col.

Atl.

States.

Atl.

States.

2869. dionyza Hy. Edwards, Pap., iv, 124, 1884; SMITH, C. 350.

Ariz.

2870. neogama Sмiтн \& Аввот, Lep. Ins. Ga., ii, 175, 1797; Sмith, C. 349.

Atl.

a. communis Grote, Trans. Am. Ent. Soc., iv, 9,1872 .

b. snoviana Grote, List. Noct., 41, 1876; Sмптн, C. 350 . 
2871. subnata Grote, Proc. Ent. Soc. Phil., iii, 326, 1865; Sмith, C. 350.

Atl.

States.

2872. cerogama Guenée, Spec. Gén., vii, 96, 1852; Smith, C. 337; Dyar, Can. Ent., xxvi, 21, 1894.

syn. aurella Fischer, eliza Fischer.

a. bunkeri Grote, Can. Ent., viii, 230, 1876.

2873. palæogama Guenée, Spec. Gén., vii, 97, 1852; Sмiтh, C. 349.

a. annida FAGER, Can. Ent., xiv, 120, 1882.

b. phalanga Grote, Proc. Ent. Soc. Phil., iii, 86, 1865 .

2874. consors Sмгтн \& Аввот, Lep. Ins. Ga., ii, 177, 1797; Sмiтh, C. 336.

Atl.

States.

Atl.

States.

So. Atl.

States.

Atl.

States.

Sмiтh, C. 348.

a. permanans Hulst, Bull. Brook. Ent. Soc., vii, $50,1884$.

2876. delilah Strecker, Lep. Rhop. Het., 96, 1874; Smith, C. 337.

IIl., Tex., Ariz. syn. adoptiva Grote.

*2877. desdemona Hy. Edwards, Pap., ii, 15, 1882; Sмith; C. 337.

*2878. calphurnia Hy Edwards, Bull. Brook. Ent. Soc., iii, 59, 1880; Sмiтh, C. 337.

2879. adromache Hy. Edwards, Ent. Amer., i, 50, 1885; Suith, C. 336.

2880. frederici Grote, Trans. Am. Ent. Soc., iv, 14, 1872; Sмith, C. 336.

Ariz.

Kans.

Cal.

Tex.,

N. Mex., Col.

2881. illecta Walker, Cat. Brit. Mus., xiii, 1205, 1857; Smith, C. 336, Beutenmüller, Jn. N. Y. Ent. Soc., ix, 189, 1902 .

syn. magdalena STRECKER.

2882. serena Edwards, Proc. Ent. Soc. Phil., ii, 510, 1864; Sмith, C. 348.

Ill., Neb., Tex.

2883. amestris Strecker, Lep. Rhop. Het., 96, 1874; Sмiтh, C. 336.

syn. anna Grote.

a. wescottii Grote, Can. Ent., x, 195, 1878.

2884. antinympha HüBner, V erz. bek. Schmett., 278, 1816; Sмith, C. 347 . 
2885. badia Grote \& Robinson, Proc. Ent. Soc. Phil., vii, 22, 1868; SмIтh, C. 348.

Atl. States.

2886. cœlebs Grote, Trans. Am. Ent. Soc., v, 96, 1874; Sмптн, C. 348.

Can.

a. phœbe Hr. Edwards, Pap., iv, 125, 1384.

2887. habilis Grote, Trans. Am. Ent. Soc., iv, 11, 1872; Sмith, C. 348.

Atl. a. basalis Grote, Can. Ent., viii, 230, 1876.

States.

2888. clintonii Grote, Proc. Ent. Soc. Phil., iii, 89, 1865; Sмith, C. 335.

a. helene Pilate, Pap., ii, 31, 1882.

2889. abbreviatella Grote, Trans. Am. Ent. Soc., iv, 14, 1872; Sмiтh, C. 335.

Miss.

Val.

2890. whitneyi Dodge, Can. Ent., vi, 125, 1874; Sмrth, C. 375 .

Ohio,

Neb.

2891. nuptialis WALKer, Cat. Brit. Mus., iii, 1206,1857; Sмiтh, C. 335.

Miss.

Val.

syn. myrrha STRECKER.

2892. polygama Guenée, Spec. Gén., vii, 105, 1852; Sмiтth, C. 332.

syn. blandula Hulst; Suith, C. 335.

a. cratægi SAUnders, Can. Ent., viii, 72, 1876;

Sмith, C. 334.

b. mira Grote, Can. Ent., viii, 230, 1876.

2893. pretiosa Lintner, Can. Ent., viii, 121, 1876; Sмith, C. 334.

Atl. States.

2894. amasia Sмптн \& Аввот, Lep. Ins. Ga., ii, 178, 1797; Sмiтн, C. 333.

syn. sancta Hulst; Smith, C. 334 .

a. virens French, Can. Ent., xviii, 162, 1886.

*2895. cordelia Hy. Edwards, Bull. Brook. Ent. Soc., iii, 59, 1880; Sмптн, C. 334 .

Tex.,

Fla.

2896. chelidonia Grote, Pap., i, 159, 1881; Sмптн, C. 333.

2897. similis Edwards, Proc. Ent. Soc. Phil., ii, 511, 1864; Sмiтh, C. 333.

Atl. States. syn. formula Grote.

a. aholah Strecker, Lep. Rhop. Het., 96, 1874.

b. isabella Hr. Edwards, Bull. Brook. Ent. Soc., iii, 60, 1880. 
2898. fratercula Grote \& Robinson, Proc. Ent. Soc. Phil., vi, 24, 1866; Surth, C. 332 (as micronympha GUENÉE).

a. atarah Strecker, Lep. Rhop. Het., 97, 1874.

b. jaquenetta Hy. Edwards, Bull. Brook. Ent. Soc., iii, 60, 1880.

c. ouwah Poling, Can. Ent., xxxiii, 128, 1901.

d. timandra Hy. Edwards, Bull. Brook. Ent. Soc., iii, 60,1880 .

e. hero Hy. Edwards, Pap., iv, 125, 1874.

f. gisela Meyer, Bull. Brook. Ent. Soc., ii, 96, 1880 .

*2899. olivia Hy. Edwards, Bull. Brook. Ent. Soc., ii, 95, 1880; Sмiтh, C. 331.

2900. præclara Grote \& Robinson, Proc. Ent. Soc. Phil., vi, 25, 1866; Sмптн, C. 332.

2901. dulciola Grote, Pap., i, 5, 1881; Sмrth, C. 334.

2902. grynea Cramer, Pap. Exot., iii, pl. 208, f. H, 1782; Sмith, C. 332.

a. constans Hulst, Bull. Brook. Ent. Soc., vii, 37,1884 .

*2903. alabamæ Grote, Proc. Acad. Nat. Sci. Phil., 427, 1875; Sмiтh, C. 332.

*2904. titania Dodge, Ent. News, xi, 472, 1900.

2905. gracilis Edwards, Proc. Ent. Soc. Phil., ii, 511, 1864; Sмптн, C. 331.

a. sordida Grote, Can. Ent., ix, 170, 1877.

2906. minuta Edwards, Proc. Ent. Soc. Phil., ii, 512, 1864; Sмith, C. 331.

a. parvula Edwards, Proc. Ent. Soc. Phil., ii, 512, 1864.

b. mellitula Hulst, Bull. Brook. Ent. Soc., vii, 35, 1884.

2907. amica HÜBnER, Zutr. exot. Schmett., f. 27, 1818; Smith, C. 330.

syn. androphila Guenée.

a. lineella Grote, Trans. Am. Ent. Soc., iv, 18, 1872 .

b. nerissa Hy. Edwards, Bull. Brook. Ent. Soc., iii, 61,1880 .

*2908. jair Strecker, Ent. News, viii, 116, 1897.
Atl. States, Ariz., Col., Cal.

Tex.

Atl.

States.

Ohio, Ill.

Atl.

States.

Ala.

Mo.

Atl.

States.

Atl.

States.

Atl.

States.

Fla. 
ALLOTRIA Hübner.

HUbner, Verz. bek. Schmett., 280, 1816.

2909. elonympha Hübner, Zutr. exot. Schmett., i, f. 29, 1818; SмIтн, C. 330.

Atl. States.

\section{ANDREWSIA Grote.}

Grote, New Check List, 41, 1882.

2910. messalina Guenée, Spec. Gén., vii, 107, 1852; Simth, C. 330.

So. Miss. Vall.

syn. belfragiana HARver, jocasta STRECKER.

EUPARTHENOS Grote.

Grote, Ann. N. Y. Lyc. Nat. Hist., xi, 301, 1876.

2911 nubilis HüBnER, Samml. exot. Schmett., ii, 1816; Sмiтн, C. 330.

Atl. States, a. apache Poling, Can. Ent., xxxiii, 129, 1901.

Ariz.

HYPOCALA Guenée.

Guenée, Spec. Gén., vii, 73, 1852.

2912. andremona Cramer, Pap. Exot., iv, pl. 358, f. C, 1782; Merrick, Faun. Haw., i, 159, 1899.

Tex., So. Am.

syn. hillii Lintner, Ent. Cont., iv, 103, 1878;

Sмiтh, C. 318.

\section{LiTOCALA Harvey.}

Harvey, Bull. Buff. Soc., ii, 280, 1875.

2913. sexsignata Harvey, Bull. Buff. Soc., ii, 280, 1875; SMith, C. 322.

Rocky Mts., Cal.

a. deserta Hy. Edwards, Pap., i, 25, 1881.

TOXOCAMPA Guenée.

Guenée, Ann. Soc. Ent. Fr., x, 75, 1841.

2914. victoria Grote, Bull. Buff. Soc., ii, 163, 1874; SмiтH, C. 355.

No. U.S., Col.

PHOBERIA Hübner.

HüBner, Verz. bek. Schmett., 267, 1816.

2915. atomaris HüBNER, Zutr. exot. Schmett., f. 75, 1818; Sмith, C. 355.

syn. orthosioides GuenéE, forrigens W ALKER, ingenua WALKER.
Atl. States. 
*2916. indiscreta Hy. Edwards, Ent. Amer., ii, 170,

Cal. 1866; Sмith, C. 355.

\section{HOMOPHOBERIA Morrison.}

Morrison, Proc. Bost. Soc. Nat. Hist., xviii, 125, 1875.

*2917. cristata Morrison, Proc. Bost. Soc. Nat. Hist., N. J.? xviii, 125,1875 ; SмmTH, C. 355.

\section{SIAVANA Walker.}

Walker, Cat. Brit. Mus., xiii, 1009, 1857; Harveya Grote. 2918. repanda WALker, Cat. Brit. Mus., xiii, 1009, 1857; SмIтH, C. 361.

syn. auripennis Grote.

PALINDIA Guenée.

Guenée, Spec. Gén., vi, 274, 1852.

2919. dominicata Guenée, Spec. Gén., vi, 276, 1852; SмmTH, C. 361.

Tex., So. Am.

$\mathrm{Pa}$.

Atl. States. 1818; Sмith, C. 361.

syn. mbricosta Guenée, cressonï Grote. a. carneicosta Guenée, Spec. Gén., vii, 325, 1852.

syn. scissa W ALKER, combinata WALKER.

b. roseicosta Guenée, Spec. Gén., vii, 325, 1852.

\section{PARALLELIA Hïbner.}

HüBner, Verz. bek. Schmett., 269, 1816.

2921. bistriaris HüBNer, Zutr. exot. Schmett., f. 63, 1818; Sмith, C. 360.

Atl. States. syn. amplissima WALKER.

\section{AGNOMONIA Hübner.}

HüBNer, Zutr. Exot. Schmett., iii, 10, 1823.

2922. anilis Drury, Ill. Exot. Ent., ii, 21, 1797; SмIтH, C. 360 . 
REMIGIA Guenée.

Guenée, Spec. Gén., vii, 313, 1852.

2923. repanda FABricius, Ent. Syst., iii, 133, 1793. syn. latipes Guenée, perlata WaLker, indentata Harvey, texana Morrison.

a. disseverans WaLker, Cat. Brit. Mus., xiv, $1495,1858$.

b. marcida Guenée, Spec. Gén., vii, 317, 1852. syn. hexastylus Harver.

\section{GRAMMODES Guenée.}

Guenée, Spec. Gén., vii, 275, 1852.

2924. smithii Guenée, Spec. Gén., vii, 266, 1852; Sмith, C. 319.

2925. similis Guenée, Spec. Gén., vii, 267, 1852; Sмith, C. 319.

a. apicalis Guenée, Spec. Gén., vii, 267, 1852.

2926. consobrina Guenée, Spec. Gén., vii, 268, 1852; Smith, C. 319.

Atl. States, So. Am.

\section{EPIDROMIA Guenée.}

Guenée, Spec. Gén., vii, 325, 1852.

*2927. delinquens W ALKer, Cat. Brit. Mus., xiv, 1423, 1858; Druce, Biol. Cent. Am., Lep. Het., i, 381, 1890.

POAPHILA Guenée.

Guenée, Spec. Gén., vii, 299, 1852.

2928. quadrifilaris Hübner, Zutr. exot. Schmett., f. 569, 1823; Sмiтh, C. 358.

2929. deleta Guenée, Spec. Gén., vii, 300, 1852; Sмith, C. 358.

syn. obsoleta Grote.

2930. sylvarum Guenée, Spec. Gén., vii, 300, 1852; SмITH, C. 358.

*2931. erasa Guenée, Spec. Gén., vii, 301, 1852; Sмith, C. 359 .

*2932. herbicola Guenée, Spec. Gén., vii, 301, 1852; Sмith, C. 359.

*2933. contempta Guenée, Spec. Gén., vii, 302, 1852; Sмптн, C. 358.

*2934. flavistriaria HüBNer, Zutr. exot. Schmett., f. 555,1823 ; Sмгтн, C. 359.

So.

States.

So.

States.

So.

States.

Fla., So. Am.
Atl.

States.

So.

States.

So.

States.

So.

States.

So.

States.

So.

States.

So.

States. 
*2935. pacalis Walker, Cat. Brit. Mus., xiv, 1475, Fla.

1858; Sмith, C. 359.

syn. irrorata GRote.

*2936. placata Grote, Bull. Geol. Surv. Terr., iv, 184, 1878; Sмith, C. 359.

*2937. perplexa Boisduval, Guenée, Spec. Gén., vii, 302, 1852; SмITH, C. 359.

"2938. revoluta Walker, Cat. Brit. Mus., xiv, 1472, 1858; Sмith, C. 360.

"2939. turbata Walker, Cat. Brit. Mus., xiv, 1834, 1858; Sмiтh, C. 260 (to Perigea).

\section{PHURYS Guenée.}

GuenÉe, Spec. Gén., vii, 303, 1852.

2940. vinculum Guenée, Spec. Gén., vii, 304, 1852; Sмiтh, C. 357.

2941. herbarum Guenée, Spec. Gén., vii, 303, 1852; Sмith, C. 357. syn. bifasciata Bates.

*2942. ovalis Grote, Pap., iii, 75, 1883; Sмith, C. 357. 2943. lima Guenée, Spec. Gén., vii, 305, 1852; Smith, C. 357 .

syn. obversa WALKER, dissocians W ALKER.

2944. bistrigata HüBner, Zutr. exot. Schmett., f. 111, 1818; Sмiтh, C. 357.

2945. perspicua Walker, Cat. Brit. Mus., xvi, 1477, 1858; Sмith, C. 358.

syn. glans Grote.

CELIPTERA Guenée.

Guenée, Spec. Gén., vii, 308, 1852.

2946. frustulum Guenée, Spec. Gén., vii, 308, 1852; SмITH, C. 355.

syn. discissa Walker, elongatus Grote.

*2947. bucetum Grote, Trans. Kans. Acad. Sci., viii, 50, 1883; Sмith, C. 356.

Atl.

States.

N. Mex.

ANTICARSIA Hübner.

HüBner, Verz. bek. Schmett., 340, 1816.

2948. gemmatilis HübNER, Zutr. exot. Schmett., f. 153, 1818; Sмiтh, C. 365.

Atl. States.

2949. ferruginea Sмгтн, Jn. N. Y. Ent. Soc., viii, 174, 1900.

Fla. 


\section{ANTIBLEMMA Hübner.}

Hübner, Verz. bek. Schmett., 341, 1816.

2950. inexacta W ALKer, Cat. Brit. Mus., xxxiii, 1038, 1865: SмIтH, C. 366.

syn. canalis Grote.

So. States, So. Am., Ariz.

a. guttula Hy. Edwards, Pap., ii, 129, 1882.

b. minorata Sмптн, Proc. U. S. Nat. Mus., xxii, $493,1900$.

c. fasciata Sмrтн, Proc. U. S. Nat. Mus., xxii, 494,1900 .

\section{LITOPROSOPUS Grote.}

Grote, Trans. Am. Ent. Soc., ii, 309, 186.

2951. futilis Grote \& Robinson, Trans. Am. Ent. Soc., ii, 202, 1868; Suith, C. 245.

Fla.,

$\mathrm{Ga}$.

\section{OPHIDERES Boisduval.}

*2952. materna Linndeus, Syst. Nat., 12th ed., 2, 840, 1767; SмITH, C. 354 .

Fla., So. Am.

syn. hybrida Fabricius, calaminea Cramer.

\section{STRENOLOMA Grote.}

Grote, No. Am. Ent., i, 99, 1880; Spiloloma Grote (not Spilosoma Stephens), Bull. Buff. Soc., i, 127, 1873.

2953. Iunilinea Grote, Buff. Bull. Soc., i, 127, 1873; Sмith, C. 354 .

So. Atl. States.

\section{CAMPOMETRA Guenée.}

Guenée, Spec. Gén., vii, 25, 1852; Eubolina Harvey; Smith, Proc. U. S. Nat. Mus., xxii, 101, 1899 (for 2956 and 2958).

2954. fraterna Sмптн, Proc. U. S. Nat. Mus., xxi, 104, 1899.

2955. minor Smith, Proc. U. S. Nat. Mus., xxi, 104, 1899.

2956. impartialis Harver, Bull. Buff. Soc., ii, 281, 1875; SMITH, C. 372.

2957. amella Guenée, Spec. Gén., vii, 25, 1852; Surth, C. 372 .

Tex.

syn. integerrima WALKER, stylobata HARVEY.

2958. meskei Hy. Edwards, Pap., ii, 128, 1882; Sмптн, C. 372 .

Ariz.

Tex.

Tex., Fla.

Tex. 
2959. mima Harvey, Can. Ent., viii, 155, 1876; Sмith, C. 372 .

Tex., Col., Ariz.

2960. bilineata Sмгтн, Proc. U. S. Nat. Mus., xxi, 102, 1899.

2961. cinctipalpis Sмrтн, Proc. U. S. Nat. Mus., xxi, $103,1899$.

Tex.

Fla.

TRAMA Harvey.

Harvey, Bull. Buff. Soc., iii, 13, 1875.

2962. detrahens WALker, Cat. Brit. Mus., xiv, 1834, 1858; Sмith, C. 364.

So.

States.

syn. arrosa Harvey.

2963. hinna Geyer, Zutr. exot. Schmett., f. 971, 1837; Sмith, C. 364.

So. States.

Ariz.

*2964. griseipennis Grote, Can. Ent., xiv, 183, 1882; Sмiтн, C. 365.

\section{MATIGRAMMA Grote.}

Grote, Trans. Am. Ent. Soc., iv, 22, 1872.

2965. pulverilinea Grote, Trans. Am. Ent. Soc., iv, 22, 1872; Sмiтh, C. 375.

2966. pulversoa WatKer, Cat. Brit. Mus., xxxiii, 994, 1865; SмIтн, C. 375.

2967. rubrosuffusa Grote, Can. Ent., xiv, 172, 1882; Sмith, C. 375.

CAPNODES Guenée.

Guenée, Spec. Gén., vii, 374, 1852.

2968. punctivena Sмith, Jn. N. Y. Ent. Soc., vii, 175, 1900.

*2969. californica Behr, Trans. Am. Ent. Soc., iii, 23, 1870; Sмiтh, C. 365.

So. States.

Tex.

Ariz.

Fla.

Cal.

KAKOPODA Smith.

Sмгтн, Jn. N. Y. Ent. Soc., viii, 175, 1900.

*2970. cincta Sмrтth, Jn. N. Y. Ent. Soc., viii, 176, 1900.

Fla.

YRIAS Guenée.

Guenée, Spec. Gén., vii, 21, 1852.

2971. clientis Grote, Can. Ent., xiv, 236, 1882; Sмith, C. 374 . 
2972. volucris Grote, Can. Ent., xv, 3,1883; Sмith, C. 374 .

2973. repentis Grote, Pap., i, 165, 1881; Sмiтh, C. 374.

2974. crudelis Grote, Can. Ent., xv, 237, 1882; Sмгтн, C. 374 .

Ariz.

Ariz.

Ariz., Tex., Cal.

\section{EGRYRLON Smith.}

Smith, Jn. N. Y. Ent. Soc., viii, 176, 1900.

*2975. filaria Sмrтth, Jn. N. Y. Ent. Soc., viii, 177, 1900.

Fla.

\section{ZALE Hübner.}

HüBNer, Verz. bek. Schmett., 275, 1816.

2977. horrida HüBner, Zutr. exot. Schmett., f. 31, 1818; Sмith, C. 367.

Atl. States.

\section{SELENIS Guenée.}

Guenée, Spec. Gén., vii, 361, 1852.

2978. monotropa Grote, Can. Ent., vii, 207, 1876; SмIтH, C. 373.

\section{PHEOCYMA Huibner.}

HüBNer, Verz. bek. Schmett., 275, 1816.

2979. lunifera Hübner, Zutr. exot. Schmett., f. 97, 1818; Sмith, C. 368.

Atl. syn. lineola WALKer.

*2980. umbrina Grote, Can. Ent., xv, 3, 1883; Suith, C. 368 .

*2981. termina Grote, Can. Ent., xv, 129, 1883; Sмith, C. 368 .

YPSIA Guenée.

Guenée, Spec. Gén., vii, 16, 1852.

2983. undularis Drury, Ill. Exot. Ent., i, pl. 9, f. 4, 1770; Sмith, C. 372.

Atl. States.

a. æruginosa Guenée, Spec. Gén., vii, 17, 1852. syn. plenipennis WALKER.

b. umbripennis Grote, Can. Ent., viii, 109, 1877.

\section{PSEUDANTHRECIA Grote.}

Grote, Bull. Buff. Soc., ii, 46, 1874.

2984. coracias Guenée, Spec. Gén., vii, 19, 1852; Sмith, C. 373 .

Atl. States.

*2985. cornix Guenée, Spec. Gén., vii, 19, 1852; Smith, C. 373 . 


\section{HOMOPTERA Boisduval. ${ }^{a}$}

Boisduval (not Latreille) in Guérin, Icon. Règ. An., pl. 89, 1829; Guenée, Spec. Gén., vii, 8, 1852.

2986. lunata Drury, Ill. Exot. Ent., i, 40, 1770; SмITH,

C. 368 .

Atl.

a. edusa Drury, Ill. Exot. Ent., ii, pl. 24, f. 4, 1773. States. syn. putrescens Guenée, saundersii Bethune, viridans WALKER, involuta WALKER.

*2987. nigricans Bethune, Proc. Ent. Soc. Phil., iv, 214, 1864; SмIтH, C. $369 .^{b}$

No. Atl.

States.

2988. rosæ Behr, Trans. Am. Ent. Soc., iii, 28, 1870;

Cal. Sмith, C. 369.

2989. rubi Hy. Edwards, Pap., i, 28, 1881; Sмith, C. 369 .

Cal.,

Ariz.

*2990. minerea Guenée, Spec. Gén., vii, 15, 1852; Sмiтн, C. 369.

Atl.

States.

2991. calycanthata Sмптн \& Aввот, Lep. Ins. Ga., ii, 207, 1797; SмITH, C. 370.

Atl.

States.

Atl.

2992. cingulifera W Alker, Cat. Brit. Mus., xiii, 1056, 1857; SмIтн, C. 370.

syn. intenta WaLKer, woodii Grote.

States.

*2993. salicis Benr, Trans. Am. Ent. Soc., iii, 28, 1870; Sмith, C. 370.

Cal.

*2994. albofasciata Bethune, Can. Jn., x, 256, 1865; Sмith, C. 370.

2995. edusina Harver, Bull. Buff. Soc., iii, 14, 1875; Sмith, C. 370.

a. atritincta HArver, Bull. Buff. Soc., iii, 14, 1875 .

*2996. galbanata Morrison, Proc. Acad. Nat. Sci. Phil., 435, 1875; SмITH, C. 370.

*2997. uniformis Morrison, Can. Ent., vii, 148, 1875; SмITH, C. 371.

*2998. cinerea Morrison, Can. Ent., vii, 148, 1875; Sмith, C. 371.

*2999. penna Morrison, Proc. Bost. Soc. Nat. Hist., xviii, 241,1875 ; Sмmтh, C. 371.

Neb.

Can.

Tex.

3000. unilineata Grote, Can. Ent., viii, 108, 1876; SмIтн, C. 371.

Ga.

Mass.

Miss.

Vall.

Atl.

States. 
3001. obliqua Guenée, Spec. Gén., vii, 16, 1852; Sмпth, C. 371.

3002. duplicata Bethune, Can. Jn., x, 257,1865; Sмптн, C. 371.

All. States. Atl. States.

*3003. benesignata Harvey, Bull. Buff. Soc., iii, 14, 1875 ; Sмнтн, C. 371.

Can.

*3004. declarans Walker, Cat. Brit. Mus., xiii, 1057, 1857; Sмiтн, C. 371.

E. Fla.

LATEBRARIA Guenée.

Guenée, Spec. Gén., vii, 159, 1852.

3005. amphipyroides Guenée, Spec. Gén., vii, 159, 1852.

Tex., So. Am.

\section{EREBUS Latreille.}

Latreille, Gen. Crust. Ins., 365, 1810.

3006. odora Linn eus, Syst. Nat., 505, 1758; Smith, C. 366.

syn. agarista Cramer.

Atl. States, Col., Cal., So. Am.

THYSANIA Dalman.

Dalman, Vet. Akad. Handl., 407, 1824.

3007. zenobia Cramer, Pap. Exot., pl. 115, f. A, 1779; Sмiтн, C. 367.

Fla., So. Am.

\section{Subfamily HYPFNIN AE. \\ EPIZEUXIS Hübner.}

Hübner, Verz. bek. Schmett., 346, 1816; Sмith, Bull. 48, U. S. Nat. Mus., 15, 1895.

3008. americalis Guenée, Spec. Gén., viii, pl. 6, f. 5, 1854; Smith, C. 379; Bull. 48, U. S. Nat. Mus., Atl. 23,1895 . States.

syn. scriptipennis W ALKER.

3009. æmula HüBner, Samml. exot. Schmett., iii, 1815; Sмiтн, C. 379.

Atl. States.

syn. mollifera W ALKER, herminioides WALKER, effusalis WALKER, concisa WALKER.

*3910. nigellus Strecker, Lep. Rhop. Het., suppl. 3, 36,1900 .

3011. suffusalis Sмrтн, Jn. N. Y. Ent. Soc., vii, 233, 1899. 
3012. lubricalis Geyer, Zutr. exot. Schmett., f. 665, 1832; Smith, C. 377.

Atl. States, Col.

syn. phæalis Guenée, surrectalis WaLKer.

a. occidentalis Smith, Bull. Brook. Ent. Soc., vii, 5,1884 .

3013. denticulalis Harver, Bull. Buff. Soc.,ii, 283, 1875; SмIтн, C. 378.

3014. scobialis Grote, No. Am. Ent., i, 95, 1880; Sмiтh, C. 378.

3015. laurentii Smith, Ent. News, iv, 83, 1893.

3016. rotundalis WALKer, Cat. Brit. Mus., xxxiv, 1144, 1865: Sмiтt, Bull. 48, U. S. Nat. Mus., 20, 1895. syn. borealis SuIth, forbesii French.

3017. majoralis Sмiтн, Bull. 48, U. S. Nat. Mus., 25 1895 .

3018. gopheri Sмmтн, Can. Ent., xxxi, 94, 1899.

Atl. States.

Atl. States.

N. C.

Atl. States, Col.

Atl. States.

Fla.

\section{ZANCLOGNATHA Lederer.}

Lemerer, Noct. Eur., 211, 1857; Smith, Bull. 48, U. S. Nat. Mus., 27, 1895; Pityolita Grote, Bull. Buff. Soc., i, 39, 1873; Megachyte Grote, Trans. Am. Ent. Soc., iv, 306, 1873; Cleptomita Grote, Trans. Am. Ent. Soc., iv, 301, 1873.

3019. lævigata Grote, Trans. Am. Ent. Soc., iv, 95, 1872; Sмith, Bull. 48, U. S. Nat. Mus., 36, 1895. Atl. a. modestalis Fiтch (median space entirely brown).

b. reversata DYAR (basal and terminal spaces brown).

c. obsoleta Sмiтн, Bull. Brook. Ent. Soc., vii, 5, 1884; C. 382.

3020. pedipilalis Guenée, Spec. Gén., viii, 57, 1854; Sмгтн, C. 381; Bull. 48, U. S. Nat. Mus., 39, 1895.

3021. cruralis Guenée Spec. Gén., viii, 58, 1854; Sмith, C. 382 ; Bull. 48, U. S. Nat. Mus., 40, 1895 .

syn. jachusalis W ALKER.

3022. obscuripennis Grote, Trans. Am. Ent. Soc., iv, 98, 309, 1872: Smith, C. 382; Bull. 48, U. S. Nat. Mus., 41, 1895.

3023. protumnusalis W ALKer, Cat. Brit. Mus., xvi, 104, 1859; Sмith, C. 383; Bull. 48, U. S. Nat. Mus., States. 42,1895 .

syn. minimalis Grote.

$4630-$ No. $52-02-16$

Atl.

States.

Atl.

States.

Atl.

States.

Atl.

States. 
3024. ochreipennis Grote, Trans. Am. Ent. Soc., iv, 98, 1872; Sмrth, C. 382; Bull. 48, U. S. Nat. Mus., Atl. 44,1895 .

3025. marcidilinea Grote, Trans. Am. Ent. Soc., iv, 93, 1872; Smith, C. 382; Bull. 48, U. S. Nat. Mus., 43,1895 .

3026. lituralis HüBner, Zutr. exot. Schmett., f. 19, 1818; Smith, C. 380; Bull. 48, U. S. Nat. Mus., 32,1895 .

3027. theralis Walker, Cat. Brit. Mus., xix, 855, 1859; Smith, C. 380; Bull. 48, U. S. Nat. Mus., 33, 1895. States. syn. deceptricalis ZELLER.

a. gypsalis Grote, Bull. Brook. Ent. Soc., iii, 65, 1880.

3028. inconspicualis Grote, Can. Ent., xv, 30, 1853; Sirth, C. 380; Bull. 48, U. S. Nat. Mus., 35, 1895.

*3029. minoralis Sirth, Bull. 48, U. S. Nat. Mus., 34, 1895 .

Atl. States.

Atl. States. Atl. States.

N. Y.

*3030. atrilineella Grote, Trans. Am. Ent. Soc., iv, 301, 1873; Sмптн, C. 383; Bull. 48, U. S. Nat. Mus., 38, 1895.

\section{HORMISA Walker.}

Walker, Cat. Brit. Mus., xvi, 74, 1859; Sмmth, Bull. 48, U. S. Nat. Mus., 45, 1895; Pallachira Grote, Can. Ent., ix, 197, 1877.

3031. absorptalis Walker, Cat. Brit. Mus., xvi, 74, 1859; Sмптн, C. 380 ; Bull. 48, U. S. Nat. Mus., Atl. 46,1895 . States. syn. nubilifascia Grote.

*3032. litophora Grote, Bull. Buff. Soc., i, 86, 1873; Smith, C. 380; Bull. 48, U. S. Nat. Mus., 48, 1895 .

*3033. linearis Grote, Can. Ent., xv, 121, 1883; Smith, C. 381 .

3034. bivittata Grote, Can. Ent., ix, 198, 1877; Smith, C. 383 ; Bull. 48, U. S. Nat. Mus., 48,-1895.

3035. orciferalis Walker, Cat. Brit. Mus., xvi, 235, So. Atl. 1859; Smith, C. 386; Bull. 48, U. S. Nat. Mus., States. 49,1895 . syn. pupillaris Grote, hartii French. 
PHILOMETRA Grote.

Grote, Trans. Am. Ent. Soc., iv, 99, 1872; Sмmтн, Bull. 48, U. S. Nat. Mus., 50, 1895.

3036. metonalis Walker, Cat. Brit. Mus., xvi, 236, 1859; Sмrth, Buli. 48, U. S. Nat. Mus., 51, 1895.

Atl.

syn. goasalis W ALKER; SMITH, C. 383; longilabris Grote.

3037. eumelusalis WaLker, Cat. Brit. Mus., xvi, 105,

1859; Sмrth, C. 384; Bull. 48, U. S. Nat. Mus.,

Atl.

53,1895 .

syn. serraticomis Grote.

3038. hanhami Sмптн, Can. Ent., xхxi, 207, 1899.

Man.

\section{CHYTOLITA Grote.}

Grote, Trans. Am. Ent. Soc., iv, 309, 1873; Sмrth, Bull. 48, U. S. Nat. Mus., 54, 1895 .

3039. morbidalis Guenée, Spec. Gén., viii, 56, 1854; Smith, C. 382; Bull. 48, U. S. Nat. Mus., 56, Atl. 1895 .

a. petrealis Grote, Can. Ent., xii, 219, 1880; Sмiтh, Bull. 48, U. S. Nat. Mus., 56, 1895.

b. punctiformis Sмптн, Bull. 48, U. S. Nat. Mus., 37,1895 .

States.

States.

HYPENULA Grote.

Grote, Can. Ent., viii, 27, 1876; Sмптн, Bull. 48, U. S. Nat. Mus., 76, 1895.

3040. cacuminalis Walker, Cat. Brit. Mus., xvi, 37, 1859; Smith, C. 389; Bull. 48, U. S. Nat. Mus., 77,1895 .

So. States.

syn. biferalis WALKER, opacalis GRoTE.

\section{RENIA Guenée.}

Guenée, Spec. Gén., vii, 91, 1854; Smith, Bull. 48, U. S. Nat. Mus., 65, 1895.

3041. salusalis WaLKer, Cat. Brit. Mus., xvi, 197, 1859; Sмптн, C. 387; Bull. 48, U. S. Nat. Mus., 68, 1895. syn. brevirostralis GRote.

3042. discoloralis Guenée, Spec. Gén., viii, 82, 1854; Smith, C. 386 ; Bull. 48, U. S. Nat. Mus., 69, 1895. syn. fallacialis WALKER, generalis WALKER, thraxalis W ALKER.

3043. fraternalis Sмптн, Bull. 48, U. S. Nat. Mus., 70, 1895.
Atl. States, Col.

Atl. States.

Fla.,

Ga. 
3044. sobrialis W ALKen, Cat. Brit. Mus., xvi, 228, 1859; Sмiтh, C. 387; Bull. 48, U.S. Nat. Mus., 71, 1895; Dyar, Proc. U. S. Nat. Mus., xxiii, 280, 1901.

Atl. States, Col. syn. restrictalis Grote.

a. larvalis Grote, Trans. Am. Ent. Soc., iv, 20, 1872; Sмith, C. 387; Bull.48, U. S. Nat. Mus., 72,1895 .

3045. clitosalis W ALKER, Cat. Brit. Mus., xvi, 108, 1859; Sмrтt, C. 388; Bull. 48, U. S. Nat. Mus., 72, 1895.

syn. centralis Grote.

3046. factiosalis W ALKER, Cat. Brit. Mus., xvi, 37, 1859; Sмптн, C. 388; Bull. 48, U. S. Nat. Mus., 73, 1895. syn. plenilinealis Grote, alutalis Grote.

3047. pulverosalis Sмптн, Bull. 48, U. S. Nat. Mus., 75, 1895 .

3048. flavipunctalis Geyer, Zutr. exot. Schmett., f. 701, 1832; Sмiтh, C. 388; Bull. 48, U. S. Nat. Mus., 74, 1895.

syn. phalerosalis W ALKER, helinsalis W ALKER, belfragei Grote, pastoralis Grote.
Atl. States.

Atl. States, Col.

Col.

Atl. States.

\section{BLEPTINA Guenée.}

Guenée, Spec. Gén., viii, 66, 1854; Smith, Bull. 48, U. S. Nat. Mus., 57, 1895.

3049. caradrinalis Guenée, Spec. Gén., vii, 67, 1854; Sмrth, C. 389; Bull. 48, U. S. Nat. Mus., 58, 1895 .

syn. cloniasalis WALKER.

3050. inferior Grote, Trans. Am. Ent. Soc., iv, 94, 1872; Sмrтн, C. 389; Bull. 48, U. S. Nat. Mus., 61, 1895. a. medialis Sмrth, Bull. 48, U. S. Nat. Mus., 60, 1895 .
Atl. States, Rocky Mts., Ariz.

\section{So.} States.

TETANOLITA Grote.

Grote, Trans. Am. Ent. Soe., iv, 305, 1873; Sмıтн, Bull. 48, U. S. Nat. Mus., 61, 1895.

3051. foridana Sмптн, Bull. 48, U. S. Nat. Mus., 63, 1895 .

Fla., Tex.

3052. mynesalis Walker, Cat. Brit. Mus., xix, 860, 1859; Sмптн, C. 389; Bull. 48, U. S. Nat. Mus., 63,1895 .

So. Atl. States.

syn. lixalis Grote.

3053. palligera SмrтH, Bull. Brook. Ent. Soc., vii, 6, 1884; C. 385 ; Bull. 48, U. S. Nat. Mus., 64, Cal. 1895 . 
HETEROGRAMMA Guenée.

Guenée, Spec. Gén., viii, 91, 1854; Sмптн, Bull. 48, U. S. Nat. Mus., 78, 1895.

3054. pyramusalis Walker, Cat. Brit. Mus., xvi, 106, 1859; Sмiтh, C. 385; Bull. 48, U. S. Nat. Mus., Atl. 79,1895 .

syn. gyasalis WALKER, murigena Grote.

\section{GABERASA Walker.}

Walker, Cat. Brit. Mus., xxxiv, 1197, 1865; Sмгтн, Bull. 48, U. S. Nat. Mus., 80, 1895.

3055. ambigualis Walker, Cat. Brit. Mus., xxxvi, 1198, 1865; Sмптн, C. 395; Bull. 48, U. S. Nat.

Atl. Mus., 81, 1895 .

States.

syn. bifidalis Grote, indivisalis Grote.

\section{DIRCETIS Grote.}

Grote, Bull. Geol. Surv. Terr., iv, 186, 1878; Sмптн, Bull. 48, U. S. Nat. Mus., 82, 1895.

3056. vitrea Grote, Bull. Geol. Surv. Terr., iv, 186, 1878; SмIтH, C. 396.

So. Atl.

States.

3057. pygmæa Grote, Bull. Geol. Surv. Terr., iv, 187, 1878; Sмrth, C. 396.

Fla., Tex.

\section{PALTHIS Hübner.}

HÜвner, Verz. bek. Schmett., 342, 1816; Sмiтh, Bull. 48, U. S. Nat. Mus., 84, 1895.

3058. angulalis HüBner, Schmett. Eur., Pyral. f. 107, 1796; Smith, C. 385 ; Bull. 48, U. S. Nat. Mus., Atl. 86,1895 .

syn. aracinthusalis WALKER.

3059. asopialis Guenée, Spec. Gén., viii, 96, 1854; Smith, C. 385; Bull. 48, U. S. Nat. Mus., 87, 1895 .

\section{CAPIS Grote.}

Grote, Can. Ent., xiv, 20, 119, 1882; Sмптн, Bull. 48, U. S. Nat. Mus., 88, 1895.

3060. curvata Grote, Can. Ent., xiv, 20, 1882; Sмптн, C. 386 .

No. Atl.

States.

\section{SALIA Hübner.}

Hüвner, Verz. bek. Schmett., 338, 1816; Sмiтh, Bull. 48, U. S. Nat. Mus., 89, 1895.

3061. salicalis Denis \& Schiffermüller, Syst. Verz. Wien, 122, 1776; W Alker, Cat. Brit. Mus., xvi, 19, 1858; Staudinger \& Rebel, Cat. Lep. Eur., i, no. $2790,1901$.

syn. salicis Sмiтн, Bull. 48, U. S. Nat. Mus., $91,1895$.
Tex: Eur. 
3062. interpuncta Grote, Trans. Am. Ent. Soc., iv, 93, 1872; Sмiтн, C. 384; Bull. 48, U. S. Nat. Mus.,

Atl. States, 90,1895 .

syn. saligna Zeller, rufa Grote, Can. Ent., xv, 31, 1883; SмIтн, C. 384.

\section{LOMANALTES Grote.}

Grote, Bull. Buff. Soc., i, 13, 1873; Sмгтн, Bull. 48, U. S. Nat. Mus., 109, 1895. 3063. eductalis WaLker, Cat. Brit. Mus., xvi, 36, 1859; SMITH, C. 390.

Atl. syn. læctulus Grote.

States.

BOMOLOCHA Hübner.

Hüвner, Verz. bek. Schmett., 343, 1816; Sмптн, Bull. 48, U. S. Nat. Mus., 91, 1895.

3064. manalis Walker, Cat. Brit. Mus., xvi, 33, 1859; Sмiтн, C. 390; Bull. 48, U. S. Nat. Mus., 95, 1895.

3065. baltimoralis Guenée, Spec. Gén., viii, 34, 1854; Smith, C. 390; Bull. 48, U. S. Nat. Mus., 96, 1895.

Atl. States. syn. benignalis WaLKer, laciniosa ZELLER.

3066. bijugalis WaLker, Cat. Brit. Mus., xvi, 32, 1859; Sirth, C. 391; Bull. 48, U. S. Nat. Mus., 97, 1895.

syn. fecialis Grote, pallialis ZelLer.

3067. scutellaris Grote, Can. Ent., v, 225, 1873; Sмптн, C. 390 ; Bull. 48, U. S. Nat. Mus., 98, 1895.

3068. abalinealis Walker, Cat. Brit. Mus., xvi, 31, 1859; Smith, C. 391; Bull. 48, U. S. Nat. Mus., 100,1895 .

3069. madefactalis Guenée, Spec. Gén., viii, 35, 1854; Snith, C. 391; Bull. 48, U. S. Nat. Mus., 102, 1895 .

syn. achatinalis Zeller; SMITH, C. 391; damnosalis WALKER, caducalis WaLKER, Cat. Brit. Mus., xvi, 35, 1859; Sмптн, C. 393; profecta Grote.

3070. sordidula Grote, Trans. Am. Ent. Soc., iv, 296, 1873; Smith, C. 392; Bull. 48, U. S. Nat. Mus., 103,1895 .

*3071. mitographa Grote, Trans. Am. Ent. Soc., iv,

- 296, 1873; Suith, C. 392.

3072. toreuta Grote, Trans. Am. Ent. Soc., iv, 24, 1872; Sмrтн, C. 392; Bull. 48, U. S. Nat. Mus.,

Atl. States.

Atl. States.

Atl. States.

Atl. States.

Atl. States. 105,1895 .

syn. albisignalis ZELLER.

3073. deceptalis Walker, Cat. Brit. Mus., xvi, 30, 1859; Sмith, C. 393; Bull. 48, U. S. Nat. Mus., 101,1895 . 
3074. edictalis W ALKer, Cat. Brit. Mus., xvi, 28, 1859; Smith, C. 393; Bull. 48, U. S. Nat. Mus., 106, Atl. 1895 .

syn. lentiginosa Grote, velliferd Grote.

3075. citata Grote, Trans. Am. Ent. Soc., iv, 101, 1872; Suith, Bull. 48, U. S. Nat. Mus., 107, 1895.

syn. trituberalis ZelLer, idreusalis SMITH (not WALKER), C. 392.

3076. umbralis Sмıтн, Bull. Brook. Ent. Soc., vii, 41, 1884; C. 392; Bull. 48, U. S. Nat. Mus., 104, 1895.

3077. vega Sмптн, Proc. U. S. Nat. Mus., xxii, 494, 1900 .

*3078. annulalis Grote, Check List Noct., 45, 1876; Smith, C. 391: Bull. 48, U. S. Nat. Mus., 108, 1895 .

*3078. 1. idæusalis WaLker, Cat. Brit. Mus., xix, 839, 1859; Sмiтh, Bull. 48, U. S. Nat. Mus., 108, 1895.

States.

Fla.

N. Mex.

Tex.

U.S. PLATHYPENA Grote.

Grote, Bull. Buff. Soc., i, 38, 1873; Sмiтh, Bull. 48, U. S. Nat. Mus., 110, 1895.

3079. scabra Fabricius, Ent. Syst., suppl. 4, 448, 1794; Sмiтн, C. 395; Bull. 38, U. S. Nat. Mus., 111. Atl. 1895 .

syn. erectalis Guenée, palpalis Haworth, crassatus Haworth, obesalis STEPHEns.

a. subrufalis Grote, Trans. Am. Ent. Soc., iv, $102,1872$. States.

HYPENA Schrank.

Schrank, Faun. Boica, ii, 2, 163, 1802; Sмrith, Bull. 48, U. S. Nat. Mus., 112, 1895.

3080. humuli Harris, Cat. Ins. Mass., 74, 1855; Sмith, 394: Bull. 48, U. S. Nat. Mus., 112, 1895.

syn.evanidalis RoBINson, germanalis W ALKER.

a. olivacea Grote, Can. Ent., v, 226, 1873.

b. albopunctata Tepper, Bull. Brook. Ent. Soc., iv, 2, 1881.

3081. californica Behr, Trans. Am. Ent. Soc., iii, 23, 1870: Sмith, C. 394: Bull. 48, U. S. Nat. Mus., 116,1895 .

a. decorata Sмıтн, Bull. Brook. Ent. Soc., vii, 4, 1884 .

3082. modesta Sмiтн, Bull. 48. U. S. Nat. Mus., 117, 1895 .
Atl. States, Col.

Pac.

States.

Cal. 


\section{Family NYCTEOLID A.}

(C.=Neumoegen \& Dyar, Jn. N. Y. Ent. Soc., i, 117, 1893.)

NYCTEOLA Hübner.

Hübner, Tent., 2, 1806; Kirby, Cat. Lep. Het., i, 369, 1892.

3083. revayana Scopoli, Ann. Nat. Hist., v, 116, 1772;

Kirby, Cat. Lep. Het., i, 369, 1892.

Eur.,

syn. ramosana HüBNER, dilutana HüBNER, undulana HüBNER, degenerana HüBNER, punctana HüBNER, stonimus CURTIs, duplana Fabricius, rivagana FabriciUs, fasciatanum Retzius, glaucana Lampa.

a. lintnerana SPEYER, Stett. ent. Zeit., Xxxv, 170, 1875; Neumoegen \& Dyar, C. 117.

b. columbiana Hy. Edwards, Proc. Cal. Acad. Sci., v, 184, 1874.

c. cinereana Neunoegen \& Dyar, Jn. N. Y. Ent. Soc., i, 117, 1893.

3084. proteella Dyar, Jn. N. Y. Ent. Soc., vi, 40, 1898.

Atl. States.

\section{Family PERICOPID A.}

\section{(C. =Neumoegen \& Dyar, Jn. N. Y. Ent. Soc., ii, 26, 1894.)}

\section{DARITIS Walker.}

Walker, Cat. Brit. Mus., iii, 618, 1855.

3085. howardi Hy. Edwards, Ent. Amer., ii, 165, 1887;

Neumoegen \& Dyar, C. 26; Druce, Biol. Cent.

Ariz. Am., Lep. Het., ii, 387, 1897.

\section{COMPOSIA Hübner.}

HüBner, Verz. bek. Schmett., 179, 1822.

3086. fidellissima Herrich-Schaeffer, Corr.-Blatt. Reg., xx, 131, 1866; Neumoegen \& Dyar, C. 26. syn. olympia Butler.

\section{GNOPH ELA Walker.}

W Alker, Cat. Brit. Mus., ii, 330, 1854.

3087. latipennis Borsduval, Ann. Soc. Ent. Fr., (2), $\mathrm{x}, 320,1852$; Neumoegen \& Dyar, C. 27.

Pac. States, Rocky Mts.

syn. hopfferi Grote \& Robinson.

a. discreta Stretch, Surv. W. 100th Mer., Wheeler, 802, 1878.

syn. arizonæ French, morrisoni Druce.

b. vermiculata Grote \& Robinson, Proc. Ent. Soc. Phil., ii, 334, 1863.

syn. continua HY. EDwards. 
3088. clappiana Holland, Ent. News, ii, 156, 1891;

Neumoegen \& Dyar, C. 27.

Col.,

Ariz.

Family DIOPTID E.

(C.=Neumoegen \& Dyar, Jn. N. Y. Ent. Soc., ii, 111, 1894.)

PHRYGANIDIA Packard.

Packard, Proc. Ent. Soc. Phil., iv, 348, 1864.

3089. californica Packard, Proc. Ent. Soc. Phil., iv, 348, 1864; Neumoegen \& Dyar, C. 111.

\section{Family NOTODONTID E.}

(C.=PACkard, Monog. Not., Mem. Nat. Acad. Sci., vii, 87-284, 1895.)

\section{APATELODES Packard.}

Packard, Proc. Ent. Soc. Phil., iii, 253, 1864; Packard, C. 99.

3090. torrefacta Sмiтн \& Аввот, Lep. Ins. Ga., 151,

1797; PACKARD, C. 100.

Atl.

a. floridana Hy. Enwards, Ent. Amer., ii, 13, States.

1886.

3091. angelica Grote, Proc. Ent. Soc. Phil., iii, 322, 1864; PaCkard, C. 103.

syn. hyalinopuncta PACKARD.

States.

a. indistincta Hr. Edwards, Ent. Amer., ii, 13,

1886.

MELALOPHA Hübner.

Hübner, Tent., 1, 1806; Packard, C. 123.

3092. apicalis WaLker, Cat. Brit. Mus., v, 1058, 1855; PACKARD, C. 125.

U.S.

syn. vau Fitch, indentata PACKARd.

a. ornata Grote \& Robinson, Trans. Am. Ent.

Soc., ii, 191, 1868.

syn. incarcerata BoIsduvaL.

b. astoriæ Hy. Eowards, Ent. Amer., ii, 14, 1886.

c. bifiria Hy. Edwards, Ent. Amer., ii, 167, 1886.

3093. inornata Neumoegen, Pap., ii, 134, 1882; PACKARD, C. 130.

3094. inclusa HüBner, Zutr. exot. Schmett., 36, 1825; PACKARD, C. 131.

Ariz.

syn. americana HARRIs.

a. inversa Packard, Proc. Ent. Soc. Phil., iii, $352,1864$.

syn. palla French.

b. jocosa Hy. Edwards, Ent. Amer., ii, 10, 1886. 
3095. strigosa Grote, Bull. Geol. Serv. Terr., vi, 532, 1882; Packard, C. 130.

No. Atl.

a. luculenta Hy. Edwards, Ent. Amer., ii, 10, 1886.

3096. albosigma Fiтch, Second Rept. Ins. N. Y., 274, 1855 ; Packard, C. 138.

a. specifica Dyar, Can. Ent., xxiv, 180, 1892.

3097. brucei Hy. Edwards, Ent. Amer., i, 17, 1885; PaCkard, C. 137. States.

a. multnoma Dyar, Can. Ent., xxiv, 179, 1892. syn. alethe Neumoegen \& Dyar.

\section{DATANA Walker.}

Walker, Cat. Brit. Mus., v, 1060, 1855; PACkard, C. 105.

3098. ministra Drury, Ill. Exot. Ent., ii, 25, 1773; PaCkard, C. 106.

Atl. States.

3099. californica Dyar, Ent. Amer., vi, 127, 1890; PACKARD, C. 108.

Cal.

3100. angusii Grote \& Robinson, Proc. Ent. Soc. Phil., vi, 9, 1866; Packard, C. 110.

Atl.

States.

3101. drexelii Hy. Edwards, Pap., iv, 25, 1884; PaCKARD, C. 112.

Atl.

States.

3102. major Grote \& Robinson, Proc. Ent. Soc. Phil., vi, 12, 1866; PaCKard, C. 113.

Atl.

States.

3103. palmii Beutenmüller, Psyche, vi, 297, 1890; Packard, C. 116.

Atl.

States.

3104. floridana Graef, Bull. Brook. Ent. Soc., ii, 37, 1879; PaCkaRd, C. 115.

Fla.

*3105. modesta Beutenmüller, Psyche, vi, 297, 1890; PaCkard, C. 117.

3106. perspicua Grote \& Robinson, Proc. Ent. Soc. Phil., iv, 489, 1865; Packard, C. 119. a. messillæ Cockerell, Psyche, viii, 41, 1897.

*3107. robusta Strecker, Lep. Rhop. Het., 131, 1872; PaCkard, C. 119.

3108. integerrima Grote \& Robinson, Proc. Ent. Soc. Phil., vi, 12, 1866; PaCkard, C. 120.

Atl.

States.

3109. chiriquensis DYaR, Jn. N. Y. Ent. Soc., iii, 167; 1895.

Ariz.,

Mex.

3110. contracta Walker, Cat. Brit. Mus., v, 1062, 1855; Packard, C. 122; Beutenmüller, Ent. News, i, 144, 1890. 
HYPER ESCHRA Butler.

Butler, Ann. Mag. Nat. Hist., (5), vi, 65, 1880; Dyar, Trans. Am. Ent. Soc., xxiv, $16,1897$.

3111. stragula Grote, Proc. Ent. Soc. Phil., iii, 93, U. S. 1864; Packard, C. 165; Schaus, Trans. Ent.

Soc. Lond., 330, 1901.

syn. scitipennis WaLKER.

a. manitou Neumoegen \& Dyar, Jn. N. Y. Ent. Soc., i, 35, 1893.

b. pacifica Benr, Proc. Cal. Acad. Sci., (2), iii, $206,1892$.

3112. georgica Herrich-Schaeffer, Samml. ausser. Schmett., 66, 1856; PACKARD, C. 153.

Atl. States.

3113. tortuosa Tepper, Bull. Brook. Ent. Soc., iv, 2, 1881; PaCKard, C. 153.

Col.,

Ariz.

\section{ODONTOSIA Hübner.}

HüBner, Verz. bek. Schmett., 145, 1818; Dyar, Trans. Am. Ent. Soc., xxiv, 16, 1897.

3114. elegans Strecker, Proc. Acad. Nat. Sci. Phil., 285, 1884; Packard, C. 156; Schaus, Trans. Ent. Soc. Lond., 329, 1901.

Rocky

Mts.,

Can.

a. grisea Strecker, Proc. Acad. Nat. Sci. Phil., 286, 1884; Neunoegen \& Dyar, Trans. Am.

Ent. Soc., xxi, 184, 1894.

syn. notaria Hy. EDwards.

\section{PTILODON Hübner.}

Hübner, Tent., 1, 1806; Dyar, Trans. Am. Ent. Soc., xxiv, 16, 1897.

*3115. americana Harver, Can. Ent., ix, 95, 1877;

Packard, C. 156 (=Eur. sp., capucina Lin-

Atl.

NæUS?).

\section{NOTODONTA Ochsenheimer.}

Ochsenhemer, Schmett. Eur., ii, 45, 1810; Dyar, Trans. Am. Ent. Soc., xxiv, 15, 1897.

3116. basitriens Walker, Cat. Brit. Mus., v, 1000, 1855; Packard, ('. 152; Schaus, Trans. Ent. Soc. Lond., 330, 1901.

3117. simplaria Graef, Bull. Brook. Ent. Soc., iii, 95; 1881; PaCKard, C. 167.

Atl. States.

No. Afl.

States.

\section{PHEOSIA Hübner.}

HüBner, Verz. bek. Schmett., 145, 1816; Packard, C. 157.

3118. dimidiata Herrich - Schaefrer, Ausser. Atl. States, Schmett., 66, 1856; Packard, C. 158; Schaus, Rocky Mts., Trans. Ent. Soc. Lond., 331, 1901. 
3119. portlandia Hy. Edwards, Ent. Amer., ii, 168, 1886; PACKARD, C. 158.

No. Pac.

syn. descherei Neumoegen.

States.

LOPHODONTA Packard.

Packard, Proc. Ent. Soc. Phil., iii, 358, 1864; C. 146.

3120. ferruginea Packard, Proc. Ent. Soc. Phil., iii, 357, 1864; C. 150; Schaus, Trans. Ent. Soc. Lond., 330, 1901.

3121. angulosa Sмrтн \& Аввот, Lep. Ins. Ga., 165, 1797; PACKARD, C. 147.

Atl.

States.

Atl.

States.

\section{EUNYSTALEA Grote.}

Grote, Abh. natur. Ver. Bremen, xiv, 7, 1895; Dyar, Trans. Am. Ent. Soc., xxiv, $14,1897$.

*3122. indiana Grote, Pap., iv, 7, 1884; Schaus, Trans.

Ent. Soc. Lond., 326, 1901.

Fla.

\section{NADATA Walker.}

Walker, Cat. Brit. Mus., v, 1062, 1855; Packard, C. 141.

3123. gibbosa Sмптн \& Aввот, Lep. Ins. Ga., ii, 163, U. S.

1797; PACKard, C. 142.

a. doubledayi Packard, Proc. Ent. Soc. Phil., iii, 365, 1864 .

b. rubripennis Neumoegen \& Dyar, Jn. N. Y.

Ent. Soc., i, 24, 1893.

c. oregonensis Butler, Ann. Mag. Nat. Hist., (5), viii, 317, 1881.

d. behrensii Hy. Edwards, Ent. Amer., i, 49, 1885 .

\section{NERICE Walker.}

Walker, Cat. Brit. Mus., v, 1076, 1855; Packard, C. 169.

3124. bidentata Walker, Cat. Brit. Mus., v, 1076 , 1855; Packard, C. 171; Schaus, Trans. Ent. Soc. Lond., 267, 1901.

Atl. States.

\section{SYMMERISTA Hübner.}

Hübner, Verz. bek. Schmett., 248, 1816; Packard, C. 177.

3125. albifrons Sмптн \& Аввот, Lep. Ins. Ga., ii, 159, 1797; PACKARD, C. 179.

Atl. States, Rocky Mts.

a. albicosta Hübner, Eur. Schmett., Noct., f. $440,1804$.

b. suavis Barnes, Can. Ent., xxxiii, 53, 1901.

*3125. 1. plagiata Walker, Cat. Brit. Mus., xxxii, 427, 1865; Neumoegen \& Dyar, Jn. N. Y. Ent.

Can. Soc., ii, 173, 1894 (type lost). 
HIPPIA Möschler.

Möschler, Verh. zool. -bot. Ges. Wien, xxvii, 693, 1878; Schaus, Trans. Ent. Soc. Lond., 287, 1901.

3126. packardii Morrison, Ann. Lyc. Nat. Hist. N. Y., Tex. xi, 92, 1375; РaCKARD, C. 183.

\section{DASYLOPHIA Packard.}

Packard, Proc. Ent. Soc. Phil., iii, 362, 1864; C. 172.

3127. anguina Sмгтн \& Aввот, Lep. Ins. Ga., 167, 1797; PACKarD, C. 174.

Atl. States, syn. cuculifera HerRich-SCHAEFFER, punctata WALKER, cana WALKER, signata WALKER.

a. puntagorda Stosson, Can. Ent., xxiv, 129, 1892.

b. saturata BArnes, Can. Ent., xxxiii, 53, 1901.

3128. thyatiroides WALKER, Trans. Ent. Soc. Lond., (3), i, 79, 1862; Packard, C. 177.

Atl.

syn. interna PACKARD, tripartita WALKER.

*3129. seriata Druce, Biol. Cent. Am., Lep. Het., i, $235,1887$.

syn. melanopa Barnes, Can. Ent., xxxiii, 54, 1901.

\section{LITODONTA Harvey.}

Harvey, Can. Ent., viii, 5, 1876; Packard, C. 220.

3130. hydromeli Harvey, Can. Ent., viii, 5, 1876;

Tex.

Packard, C. 253.

a. fusca Harver, Can. Ent., viii, 110, 1876.

\section{HETEROCAMPA Doubleday.}

Doubleday, Entom., 97, 1841; Packard, C. 220.

*3131. lineata Druce, Biol. Cent. Am., Lep. Het., i, pl. 25, f. $11,1887$.

3132. astarte Doubleday, Ent., 57, 1841; Packard, C. 247; Schaus, Trans. Ent. Soc. Lond., 302, 1901. States.

Ariz., Mex. syn. varia WaLKER, menas HaRris.

3133. obliqua Packard, Proc. Ent. Soc. Phil., iii, 368, 1864; C. 242.

Mex., Fla.?

So.

States.

a. trouvelottii PaCkard, Proc. Ent. Soc. Phil., iii, 368, 1864.

syn. brunnea Grote \& Robinson.

No. Atl. States. 
3134. picta Felder, Reise Nov., pl. 97, f. 19, 1874;

Schaus, Trans. Ent. Soc. Lond., 303, 1901.

So.

syn. chapmani Grote, Bull. U. S. Geol. Surv. Terr., vi, 258, 1891; PACKard, C. 251; perolivata Packard, Mem. Nat. Acad. Sci., vii, 246,1895 .

3135. lunata Hy. Edwards, Pap., iv, 64, 1884; PackARD, C. 248.

syn. plumosa Hy. Edwards.

3136. umbrata W ALKER, Cat. Brit. Mus., v, 1023, 1855; Packard, C. 249; Schaus, Trans. Ent. Soc. Lond., 302, 1901 (pulverea sp. distinct).

syn. semiplaga WaLker, pulverea Grote \& Robinson, athereo Harris.

3137. manteo Doubleday, Ent., 58, 1841; Packard, C. 224; Dyar, Ent. News, iv, 262, 1893.

syn. cinerascens WALKER, subalbicans GROTE.

3138. subrotata Harvey, Bull. Buff. Soc., i, 263, 1874; PACKaRd, C. 252.

syn. celtiphaga Harver, superba Hy. Edwards.

3139. belfragei Grote, Can. Ent., xi, 209, 1879; PACKARD, C. 250.

3140. biundata WALKER, Cat. Brit. Mus., v, 1025, 1855; PACKARD, C. 235.

syn. olivatus Packard, mollis WaLKer.

3141. guttivitta W ALKER, Cat. Brit. Mus., v, 992, 1855; PACKard, C. 230.

syn. albiplaga WALKER, mucorea HERRICHSChaEfFer, harrisii PACKARD, intederminata WALKER, doubledayi SCUDDER, cinereus PACKARD.

3142. bilineata Packard, Proc. Ent. Soc. Phil., iii, 359, 1864; C. 218.

syn. turbida W ALKER, associata W ALKER, ulmi Harris.

States.

Ariz.,

Mex.

Atl.

States.

Atl.

States.

Tex.

Tex.

Atl. States.

Atl. States.

Atl. States.

\section{MISOGADA Walker.}

Walker, Cat. Brit. Mus., xxxii, 449, 1865; Schaus, Trans. Ent. Soc. Lond., 300, 1901.

3143. unicolor Packard, Proc. Ent. Soc. Phil., iii, 373, 1864; C. 254.

Atl. States.

syn. marina PACKARD, cinerea Schaus (not PACKARD), sobria WALKER.

EUHYPARPAX Beutenmüller.

Beutenmüller, Bull. Am. Mus. Nat. Hist., v, 19, 1893; Packard, C. 187.

*3144. rosea Beutenmüller, Bull. Am. Mus. Nat. Hist., v, 19, 1893; PaCkard, C. 188.

Col. 


\section{IANASSA Walker.}

Walker, Cat. Brit. Mus., v, 1101, 1855; Packard, C. 188; Dicentria HerrichShaeffer, Ausser. Schmett., i, 11, 1855; Schaus, Trans. Ent. Soc. Lond., 296, 1901.

3145. lignicolor Walker, Cat. Brit. Mus., v, 1101, 1855; PaCKaRd, C. 189.

Atl. syn. virgata PaCkard, lignigera WaLKer.

3146. coloradensis Hr. Edwards, Ent. Amer., i, 17, 1885; Packard, C. 210. States.

Col., N. Mex.

3147. pallida Strecker, Lep. Rhop. Het., suppl. 2, 5, 1899.

Col., Oreg.

\section{SCHIZURA Doubleday.}

Doubleday, Ent., 59, 1841; Packard, C. 192.

3148. ipomœæ Doubleday, Ent., 59, 1841; Packard, U.S. C. 194 .

syn. biguttatus PaCkard, confusa WaLker, ducens WALKER, corticed WALKER, compta W ALKER, nigrosignata WALKER.

a. telifer Grote, No. Am. Ent., 99, 1880.

b. cinereofrons Packard, Proc. Ent. Soc. Phil., iii, 366, 1864.

syn. ustipennis WALKER.

3149. concinna Sмгтн \& Аввот, Lep. Ins. Ga., ii, 169, U.S. 1797; РACKard, C. 212.

syn. nitida PACKARD.

3150. semirufescens Walker, Cat. Brit. Mus., xxxii, 450, 1865; Schaus, Trans. Ent. Soc. Lond., 296, Atl. 1901.

syn. eximia Grote; Packard, C. 210.

a. perangulata Hy. Edwards, Pap., ii, 125, 1882. States.

3151. unicornis Sнiтн \& Аввот, Lep. Ins. Ga., ii, 170, Col.

U.S. 1797; PaCkard, C. 203.

syn. edmandsii PACKARD, humilis WALKER, conspecta Hy. Edwards.

3152. apicalis Grote \& Robinson, Proc. Ent. Soc. Phil., vi, 15, 1886; Packard, C. 203.

Atl. States.

3153. badia Packard, Proc. Ent. Soc. Phil., iii, 361, 1864; C. 208.

Atl. States. syn. significata W ALKER.

3154. leptinoides Grote, Proc. Ent. Soc. Phil., iii, 323, 1864; Packard, C. 199.

Atl. States. syn. mustelina PaCKard. 
HYPARPAX Hübner.

Hübner, Samml. exot. Schmett., ii, 1824; Packard, C. 184.

3155. aurora Sмгтн \& Аввот, Lep. Ins. Ga., ii, 173, 1797; PACKaRd, C. 184.

Atl. States.

syn. rosea WALKER, venusta WALKER.

3156. venus Neumoegen, Can. Ent., xxiv, 226, 1892; PACKARD, C. 187.

Col.

3157. perophoroides Strecker, Proc. Acad. Nat. Sci. Fla. Phil., 152, 1876; PACKARD, C. 187.

syn. aurostriata Graef.

a. tyria Sloosson, Ent. News, v, 198, 1894.

*3158. aonides Strecker, Lep. Rhop. Het., suppl. 2, 4, 1899.

\section{CERURA Schrank.}

Schrank, Faun. Boica, ii, 152, 1802; Packard, C. 263; Dyar, Trans. Am. Ent. Soc., xxiv, $10,1897$.

3159. scitiscripta W ALKer, Cat. Brit. Mus., xxxii, 408, 1865; PACKARD, C. 276.

Atl. States, Mex.

a. multiscripta Riley, Trans. St. Louis Acad.

Sci., iii, 241, 1875 .

b. candida Lintner, Ent. Cont, iv, 57, 1878.

3160. occidentalis Lintner, Ent. Cont., iv, 82, 1878;

Packard, C. 268.

States.

\section{HARPYIA Ochsenheimer.}

Ochsenhermer, Schmett. Eur., iii, 19, 1810; Dyar, Trans. Am. Ent. Soc., xxiv, 10, 1897.

3161. borealis Borsduval, in Guérin, Icon. Règ. An., pl. 88, f. 5, 1829; Рackard, C. 264.

3162. cinerea Walker, Cat. Brit. Mus., xxxii, 407, 1865; PACKARD, C. 273.

a. cinereoides Dyar, Can. Ent., xxii, 253, 1890.

b. placida Dyar, Psyche, vi, 291, 1892.

c. paradoxa Benr, Bull. Cal. Acad. Sci., 64, 1885.

3163. nivea Neumoegen, Can. Ent., xxiii, 124, 1891; Packard, C. 273.

a. meridionalis DYar, Psyche, vi, 291, 1892;

Kunzé, Jn. N. Y. Ent. Soc., vi, 188, 1898.

3164. scolopendrina Borsduval, Ann. Soc. Ent. Belg., xii, 86, 1870; Packard, C. 270.

syn. aquilonaris Lintner.

a. modesta Hudson, Can. Ent., xxiii, 197, 1891.

b. albicoma Strecker, Proc. Acad. Nat. Sci. Phil., 284, 1884.
Atl. States. U. S. Ariz., Mont.

No. U. S. 


\section{FENTONIA Butler.}

Butler, Trans. Ent. Soc. Lond., 20, 1881; Dyar, Trans. Am. Ent. Soc., xxiv, 10, 1897.

3165. marthesia Cramer, Pap. Exot., pl. 98, f. A, 1779; PACKARD, C. 257.

Atl.

syn. tesella PaCkard, turbida WALKER.

States.

a. elongata Grote, Trans. Am. Ent. Soc., i, 182, 1867.

syn. dorothea DyAR, Can. Ent., xxviii, 176, 1896.

GLUPHISIA Boisduval.

Boisduval, Ind. Méth., 88, 1840; Packard, C. 89.

3166. septentrionalis WaLker, Cat. Brit. Mus., v, 1038, 1855; PaCKaRd, C. 90.

U.S.

syn. clandestina WALKER, trilineata PACKARD.

a. ridenda Hy. Edwards, Ent. Amer., ii, 11, 1886; PaCKard, C. 93.

b. quinquelinea Dyar, Ent. News, iii, 158, 1892.

3167. wrightii Hy. Edwards, Ent. Amer., ii, 11, 1886; PACKARD, C. 93.

S. -W.

U.S.

syn. albofascia Hr. EDwards.

a. rupta Hy. Edwards, Ent. Amer., ii, 12, 1886.

b. formosa Hy. EDwards, Ent. Amer., ii, 12, 1886.

3168. severa Hy. Edwards, Ent. Amer., ii, 167, 1886; PACKARD, C. 96.

No.

U.S.

a. danbyi Neumoegen, Can. Ent., xxiv, 225, 1892.

b. avimacula Hudson, Ent. News, ii, 155, 1891.

c. slossonii Packard, Mem. Nat. Acad. Sci., vii, 97,1895 .

3169. lintneri Grote, Can. Ent., ix, 85, 1877; PACKARD, C. 96.

\section{ELLIDA Grote.}

Grote, Can. Ent., viii, 125, 1876; Packard, C. 168.

3170. caniplaga Walker, Cat. Brit. Mus., ix, 1856; PACKaRd, C. 169.

Atl. States.

syn. transversata WALKER, gelida GROTE.

\section{HEMICERAS Guenée.}

Guenée, Spec. Gén., vii, 379, 1852; Schaus, Trans. Ent. Soc. Lond., 333, 1901.

3171. cadmia Guenée, Spec. Gén., vii, 383, 1852;

Sмith, Bull. 44, U. S. Nat. Mus., 260, 1893.

So.

syn. obliquitinea WALKER.

States.

$4630-$ No, 52-02-17 
- CARGIDA Schaus.

Schaus, Trans. Ent. Soc. Lond., 267, 1901.

*3172. pyrrha Druce, Biol. Cent. Am., Lep. Het., ii, $459,1898$.

Ariz., Mex.

CRINODES Herrich-Schaeffer.

Herrich-Schaeffer, Ausser. Schmett., i, 11, 1855; Schaus, Trans. Ent. Soc. Lond., 276,1901 .

*3172. 1. beskei HüBNer, Samml. exot. Schmett., ii, 1824; Schaus, Trans. Ent. Soc. Lond., 276, 1901.

Ariz., Mex.

\section{Family THYATIRID E.}

$$
\text { (C.=Sмiтh, Bull. 44, U. S. Nat. Mus., 27-29, 1893.) }
$$

HABROSYNE Hübner.

Hübner, Verz. bek. Schmett., 236, 1816; Hampson, Moths Ind., i, 178, 1892.

3173. scripta Gosse, Can. Nat., 249, 1840; Sмптн, C. 27; Dyar, Can. Ent., xxvii, 129, 1895.

*3174. chatfeldii Grote, Abhl. natur. Ver. Brem., xiv, 10,1895 .

3175. rectangulata Otтolengui, Ent. News, viii, 25, 1897; Wrnn, Ent. News, viii, 99, 1897.

\section{PSEUDOTHYATIRA Grote.}

Grote, Proc. Ent. Soc. Phil., iii, 539, 1865; Sмптн, C. 28.

3176. cymatophoroides Guenée, Spec. Gén.,v, 13, 1852; SмITH, C. 25.

3177. expultrix Grote, Proc. Ent. Soc. Phil., ii, 58, 1863; SмIтh, C. 28.

Atl. States.

Atl. States.

THYATIRA Hübner.

HüBner, Verz. bek. Schmett., 236, 1816.

3178. mexicana Hy. Edwards, Pap., iv, 16, 1884.

syn. superba Barnes, Can. Ent., xxviii, 55, 1901.

\section{EUTHYATIRA Smith.}

Sмiтh, List. Lep. Bor. Am., 34, 1891; C. 27.

3179. Iorata Grote, Pap., i, 75, 1881; Sмiтh, C. 27.

3180. pudens Guenée, Spec. Gén., v, 13, 1852; Smith, C. 29; Dyar, Can. Ent., xxvii, 129, 1895.

Ariz., Mex. No. Atl. States. No. Pac. States.

Atl. States, Rocky Mts.

a. anticostiensis Grote, Can. Ent., xviii, 215, note, 1886 .

b. pennsylvanica Sмiтh, Jn. N. Y. Ent. Soc., x, 34, 1902 .
No. Pac. States.

No. Atl. States. 
3181. semicircularis Grote, Pap., i, 75, 1881; Sмпт, C. 29 .

No. Pac.

States.

Fla.

*3182. candida Snith, Ent. Amer., vi, 179, 1890; C. 29.

No. Pac.

*3183. tema Strecker, Lep. Rhop. Het., suppl. 1, 5, 1898.

States.

\section{BOMBYCIA Huibner.}

Hübner, Tent., 1, 1816; Sмith, C. 29; Dyar, Can. Ent., xxvii, 129, 1895.

*3184. improvisa Hy. Edwards, Proc. Cal. Acad. Sci.,

v, 189, 1873; Sмiтн, C. 29.

Pac.

syn. tearlii Hy. EDwards.

States.

\section{Family LIPARID A.}

(C.=Neumoegen \& Dyar, Jn. N. Y. Ent. Soc., ii, 28-30, 57-60, 1894.)

\section{GYN $A$ PHORA Hübner.}

Hübner, Verz. bek. Schmett., 161, 1822; Dyar, Can. Ent., xxix, 15, 1897.

3185. rossii Curtis, Ross Second Voyage, app., 70,

1835; Neunoegen \& Dyar, C. 59.

3186. grœnlandica Homeyer, Zweite deut. Nordp.Fahrt, ii, 469, 1874; Neunoegen \& Dyar, C. 59.

\section{NOTOLOPHUS Germar.}

Germar, Syst. Gloss. Prod., 35, 1812; Neumoegen \& Dyar, C. 28.

3187. antiqua Linneus, Syst. Nat., i, 503, 1758; NeU- No. U. S. MOEGEN \& DYAR, C. 28.

Eur.

syn. nova Fitch.

a. badia Hy. Enwards, Proc. Cal. Acad. Sci., v,

188, 1874; Neunoegen \& Dyar, C. 29.

*3188. oslari Barnes, Can. Ent., xxxii, 45, 1900.

Col.

syn. libera Strecker, Lep. Rhop. Het., suppl. 3, 29, 1900.

\section{HEMEROCAMPA Dyar.}

Dyar, Can. Ent., xxix, 15, 1897.

3189. vetusta Boisdural, Ann. Soc. Ent. Fr., x, 322 ,

Cal.

1852; Neumoegen \& Dyar, C. 29.

a. cana Hr. Edwards, Pap., i, 61, 1881.

b. gulosa Hy. Edwards, Pap., i, 61, 1881.

3190. leucostigma Sмiтн \& Аввот, Lep. Ins. Ga., ii,

pl. 79, 1797; Neunoegen \& Dyar, C. 30.

Atl.

syn. leucographa Geyer, intermedia Fitch,

borealis Fitch, obliviosa Hy. Edwards. 
3191. inornata Beutenuüller, Psyche, v, 300, 1890; Neumoegen \& Dyar, C. 30; Dyar, Psyche, ix, Atl. $143,1900$.

syn. falcata Schaus, Jn. N. Y. Ent. Soc., iv, 153, 1896; Druce, Biol. Cent. Am., Lep. Het., ii, 411, pl. 79, f. 7, 1897.

3192. definita Packard, Proc. Ent. Soc. Phil., iii, 332, 1864; NeUM'Egen \& Dyar, C. 29. States.

\section{OLENE Hübner.}

Hübner, Zutr. exot. Schmett., ii, 19, 1823; Neumoegen \& Dyar, C. 30.

3193. achatina Sмгтн \& Аввот, Lep. Ins. Ga., ii, pl. 77, 1797; Neumoegen \& Dyar, C. 57.

Atl.

syn. parallela Grote \& RoBinson.

a. tephra Hübner, Samml. exot. Schmett., i, 1805; Neumoegen \& Dyar, C. 57.

syn. obliquata Grote \& Robinson.

b. cinnamomea Grote \& Robinson, Proc. Ent. Soc. Phil., vi. $6,1866$.

3194. leucophæa Sмгтн \& Аввот, Lep. Ins. Ga., ii, pl. 78, 1797; Neunoegen \& Dyar, C. 57.

Atl.

a. basiflava Packard, Proc. Ent. Soc. Phil., iii, $332,1864$.

b. atrivenosa Palm, Jn. N. Y. Ent. Soc, i, 21, 1893.

c. manto Strecker, Lep. Rhop. Het., suppl. 3, 29,1900 .

3195. plagiata W ALker, Cat. Brit. Mus.,iv, 199, 1855;

Neunoegen \& Dyar, C. 58. States.

syn. atomaria WALKER, clintonii GROTE \& ROBINSON.

States.

PORTHETRIA Hübner.

Hübner, Verz. bek. Schmett., 160, 1822; Neumoegen \& Dyar, C. 58.

3196. dispar Linneus, Syst. Nat., i, 501, 1758; FerNaLD, Gypsy Moth, 257, 1896.

Mass., Eur.

\section{EUPROCTIS Hübner.}

Hüвner, Verz. bek. Schmett., 159, 1822; Kirby, Cat. Lep. Het., i, 442, 1892; Dyar, Can. Ent., xxix, 16, 1897.

3197. chrysorrhœa Linnæus, Syst. Nat., 502, 1758; Kibby, Cat. Lep. Het., i, 442, 1892; Fernald \& Atl. States. Kirkland, Brown Tail Moth, Sp. Bull. Mass. Mass., Eur. Agr. Coll., 1897. 
DOA Neumoegen \& Dyar.

Neumoegen \& Dyar, Jn. N. Y. Ent. Soc., ii, 171, 1894.

3198. ampla Grote, Can. Ent., x, 232, 1878; NeumoeGEN \& DYAR, Jn. N. Y. Ent. Soc., i, 155, 1893.

Ariz., Col.

\section{LEUCULODES Dyar.}

Leucula Hulst (not Guenée), Trans. Am. Ent. Soc., xxiii, 317, 1896.

3199. lacteolaria Hulst, Ent. Amer., ii, 51, 120, 1887.

Ariz.

$$
\text { Family LASIOCAMPID A. }
$$

(C.=Neumoegen \& Dyar, Jn. N. Y. Ent. Soc., ii, 152-160, 1894.)

\section{GLOVERIA Packard.}

Packard, Rep. Peab. Acad., iv, 89, 1872; Neumoegen \& Dyar, C. 159.

3200. dolores Neumoegen \& Dyar, Ent. News, iv, 290. 1893 ; C. 159.

Col.

3201. arizonensis Packard, Rep. Peab. Acad., iv, 90,

Ariz. 1872; Neumoegen \& Dyar, C. 159.

syn. dentata Hy. EDwards.

3202. medusa Strecker, Ent. News, ix, 13, 1898.

Cal.

*3203. gargamella Strecker, Proc. Acad. Nat. Sci.

Ariz.

Phil., 286, 1884; Neumoegen \& Dyar, C. 159.

3204. psidii Sallé, Ann. Soc. Ent. Fr., (2), v, 16, 1857; Kirby, Cat. Lep. Het., 834, 1892.

Ariz., Mex.

3205. diazoma Grote, Pap., i, 175, 1881; Neunoegen

Ariz. \& DYAR, C. 159.

3206. howardi Dyar, Jn. N. Y. Ent. Soc., iv, 22, 1896.

Ariz.

\section{ARTACE Walker.}

W ALKer, Cat. Brit. Mus., vi, 1491, 1855.

3207. punctistriga Walker, Cat. Brit. Mus., vi, 1491, 1855; Neumoegen \& Dyar, C. 157.

So. Atl.

States. syn. mbripalpis FELDER.

\section{TOLYPE Hübner.}

Hübner, Verz. bek. Schmett., 189, 1822; Neumoegen \& Dyar, C. 157.

3208. velleda Stolt, Suppl. Cram. Pap. Exot., pl. lii, f. 4, 1791; Neumoegen \& Dyar, C. 158. 
3210. distincta French, Can. Ent., xxii, 45, 1890; Neumoegen \& Dyar, C. 158.

3211. laricis Fiтch, Second Report Ins. N. Y., 262, 1856; Neumoegen \& Dyar, C. 158. syn. minuta Grote.

3212. brevicrista Dyar, Can. Ent., xxviii, 246, 1895. N. Mex. HYPOPACHA Neumoegen \& Dyar.

Neumoegen \& Dyar, Jn. N. Y. Ent. Soc., i, 29, 1893.

*3213. grisea Neumoegen, Pap., ii, 134, 1882; NeuMOEGEN \& DYAR, C. 157.

Ariz.

\section{MALACOSOMA Hübner.}

HüBner, Verz. bek. Schmett., 192, 1822; Kirby, Cat. Lep. Het., i, 819, 1892; Dyar, Can. Ent., xxx, 6, 1898.

3214. americana Fabricius, Syst. Ent., iii, 433, 1793; Neumoegen \& Dyar, C. 155.

Atl. States.

syn. decipiens WALKER, frutetorum BolsDUVAL.

3215. fragilis Stretch, Pap., i, 64, 1881; Neumoegen \& DYAR, C. 155.

a. incurva Hy. Edwards, Pap., ii, 125, 1882.

syn. discolorata Neumoegen.

b. mus Neumorgen, Can. Ent., xxv, 4, 1893.

c. constrictina Neumoegen \& Dyar. Jn. N. Y. Ent. Soc., i, 30, 1893.

syn. lutescens Neumoegen \& Dyar.

d. perlutea Neumoegen \& Dyar, Jn. N. Y. Ent. Soc., i, 31, 1893.

3216. pluvialis Dyar, Can. Ent., xxv, 42, 1893; NEUMOEGEN \& DYAR, C. 156.

3217. ambisimilis Dyar, Can. Ent., xxv, 40, 1893; Neunoegen \& Dyar, C. 156.

3218. californica Packard, Proc. Ent: Soc. Phil., iii, 357, 1864; Neumoegen \& Dyar, 'C. 156.

syn. pseudoneustria BoIsduval.

3219. constricta Stretch, Pap., i, 65, 1881; NeUMOEGEN \& DYAR, C. 157.

syn. californica WaLkER (not PACKARD).

a. strigosa Stretch, Pap., i, 67, 1881.
No. Pac.

States.

Cal.

Rocky Mts. to Cal.

Cal.

Cal. 
3220. tigris Dyar, Proc. Ent. Soc. Wash., v, 38, 1902. Rocky Mts.

3221. disstria HüBner, Verz. bek. Schmett., 122, 1822; U. S. Neumoegen \& Dyar, C. 154.

syn. Arupacearum Boisduval.

a. sylvatica Harris, Rep. Ins. Mass., 271, 1841.

b. thoracicoides Neumoegen \& Dyar, Jn. N. Y.

Ent. Soc., i, 30, 1893.

c. erosa Stretch, Pap., i, 64, 1881.

d. sylvaticoides Neumoegen \& Dyar, Jn. N. Y.

Ent. Soc., i, 30, 1893.

e. thoracica Stretch, Pap., i, 68, 1881.

$f$. perversa Neumoegen \& Dyar, Jn. N. Y. Ent. Soc., i, 30, 1893.

HETEROPACHA Harvey.

Harvey, Bull. Buff. Soc. Nat. Sci., i, 262, 1874; Neumoegen \& Dyar, C. 153.

3222. rileyana Harver, Bull. Buff. Soc. Nat. Sci., i, Miss. 262, 1874; Neumoegen \& Dyar, C. $154 . \quad$ Vall.

\section{EPICNAPTERA Rambur.}

Rambur, Cat. Lep. And., 344, 1866; Neumoegen \& Dyar, C. 152.

3223. americana HARRIs, Rep. Ins. Mass., 273, 1841; U.S. Neumoegen \& Dyar, C. 153.

syn. occidentis WALKER, carpinifolia BoIsDUVAL.

a. ferruginea Packard, Proc. Ent. Soc. Phil., iii, 386, 1864; Neumoegen \& Dyar, C. 153.

b. roseata Stretch, Zyg. Bomb. N. A., pl. 4, f. 12,1872 .

syn. mildei Stretch.

c. californica Packard, Rep. Peab. Acad., iv, 91, 1872.

d. dyari Rivers, Can. Ent., xxv, 144, 1893.

Family BOMBYCID A.

\section{BOMBYX Linnæus.}

Linneus, Syst. Nat., i, 499, 1758.

3224. mori Linneus, Syst. Nat., i, 499, 1758; Neu(Cultivated.) MOEgEn \& Dyar, Jn. N. Y. Ent. Soc., ii, 118, 1894. 


\section{Family PLATYPTERYGID A.}

(C.= Neumoegen \& Dyar, Jn. N. Y. Ent. Soc., ii, 61-62, 1894.)

EUDEILINEA Packard.

Packard, Rept. Peab. Acad., v, 68, 1873; Neumoegen \& Dyar, C. 61.

3225. herminiata Guenée, Spec. Gén., x, 58, 1857;

Neumoegen \& Dyar, C. 61.

Atl.

a. biseriata Packard, Fifth Rept. Peab. Acad. States.

Sci., 68, 1873.

ORETA Walker.

Walker, Cat. Brit. Mus., v, 1116, 1855; Neumoegen \& Dyar, C. 61.

3226. rosea WaLker, Cat. Brit. Mus., v, 1164, 1855;

Neumoegen \& Dyar, (). 61.

Atl.

syn. americana HERRICH-SCHAEFFER, formula States.

Grote.

a. marginata WALker, Cat. Brit. Mus., v, 1165, 1855 .

3227. irrorata Packard, Proc. Ent. Soc. Phil., iii, 377, 1864; Neumoegen \& Dyar, C. 61.

Atl. States.

*3228. adona Strecker, Lep. Rhop. Het., suppl. 3, 30, 1900 .

Fla.

\section{DREPANA Schrank.}

Schrank, Fauna Boica, ii, (2), 155, 1802; Kirby, Cat. Lep. Het., i, 730, 1892. 3229. arcuata W ALKER, Cat. Brit. Mus., v, 1164, 1855; Neumoegen \& Dyar, C. 62.

\section{FALCARIA Haworth.}

Haworth, Lep. Brit., ii, 147, 1809; Neumoegen \& Dyar, C. 62.

3231. bilineata Packard, Proc. Ent. Soc. Phil., iii, 376, 1864; Neumoegen \& Dyar, C. 62. a. levis Hudson, Can. Ent., xxv, 24, 1893. 


\section{Family GEOMETRID A.}

By George D. Hutst.

(C.=Packard, Mon. Geom., Rept. U. S Geol. Surv. Terr., Hayden, x, 1876.)

$$
\text { Subfamily DYSPTFRIDINAE. }
$$

DYSPTERIS Hübner.

HüBner, Verz. bek. Schmett., 286, 1818; Herrich-Schaeffer, Auss. Schmett., i, 27, 1854; Guenée, Spec. Gén., ix, 361, 1857; Packard, C. 368; Hulst, Trans. Am. Ent. Soc., xxiii, 250, 1896.

3232. abortivaria Herrich - Schaeffer, Auss. Schmett., f. 346,1855 ; PACKARD, C. 368; French, Trans. Dept. Agr. Ill., xv, 238, 1877.

\section{CYSTEOPTERYX Hulst.}

Hulst, Trans. Am. Ent. Soc., xxiii, 250, 1896.

*3233. viridata Packard, Fifth Rept. Peab. Acad. Sci., 56, 1873; C. 182 .

Atl.

States.

NYCTOBIA Hulst.

Hulst, Trans. Am. Ent. Soc., xxiii, 251, 1896.

3234. limitata Walker, Cat. Brit. Mus., xxi, 487, 1860; Packard, C. 457; Hulst, Ent. News, vi, 43,1895 .

syn. lobophorata WaLker, Cat. Brit. Mus., Xxv, 1347, 1862; vernata PACKARD, Fifth Rept. Peab. Acad. Sci., 57, 1873; C. 183; Grote, Can. Ent., ix, 27, 1877.

3235. fusifasciata W ALkER, Cat. Brit. Mus., xxv, 1258, 1862; Hulst, Ent. News, vi, 43, 1895.

syn. longipennis Walker, Cat. Brit. Mus., xxxv, 1671, 1866; Grote \& Robinson, Trans. Am. Ent. Soc., ii, 82, 1868; anguilineata. Grote, Ann. Lyc. Nat. Hist. N. Y., viii, pl. 15A, f. 16, 1867; Packard, C. 184.

*3236. nigroangulata STREcker, Lep. Rhop. Het., suppl. 2, 10, 1899.

\section{CLADORA Hulst.}

Hulst, Trans. Am. Ent. Soc., xxiii, 251, 1896.

3237. atroliturata WALker, Cat. Brit. Mus., xxv, 1710, 1862; Grote \& Robinson, Tr. Am. Ent. Soc., ii, 83, 1868; Hulst, Ent. News, vi, 43, 1895. syn. geminata Grote \& Robinson, Proc. Ent. Soc. Phil., vi, 29, 1866; Packard, C. 184.
Atl. States.

Atl. States.

Pac. States.

Atl. States. 
OPHEROPTERA Hübner.

Hübner, Verz. bek. Schmett., 321, 1818; Packard, C. 197; Hulst, Trans. Am. Ent. Soc., xxiii, 151, 1896; Cheimatobia Stephens, Nom. Brit. Ins., 44, 1829; Westwood \& Humphreys, Brit. Moths, ii, 57, 1849.

3238. boreata Hübner, Schm. Eur., f. 414, 1820; PACKARD, C. 198; Drмmock, Psyche, iv, 243, 1885; Hulst, Tr. Am. Ent. Soc., xxiii, 252, 1896; Hofmann, Gross. Sch. Eur., 199, 1894; Kirby, Arctic No. Am., Eur. Eur. Butt., 388, 1882.

PARAPTERA Hulst.

Hulst, Trans. Am. Ent. Soc., xxiii, 252, 1896.

*3239. danbyi Hulst, Trans. Am. Ent. Soc., xxiii, 252, 1896.

No. Pac. States.

\section{RACHELA Hulst.}

Hulst, Trans. Am. Ent. Soc., xxiii, 253, 1896.

3240. bruceata Hulst, Ent. Amer., ii, 123, 1886.

3241. hyperborea Hulst, Trans. Am. Ent. Soc. yxiii, $254,1896$.

3242. occidentalis Hulst, Trans. Am. Ent. Soc., xxiii, $254,1896$.

*3243. latipennis Hulst, Trans. Am. Ent. Soc., xxiii, $254,1896$.

Subfamily HYDRIOMFININ $A$.

PALEACRITA Riley.

Riley, Trans. Acad. Sci. St. Louis, iii, 273, 1875; Hulst, Trans. Am. Ent. Soc., xxiii, $257,1896$.

*3244. longiciliata Hulst, Can. Ent., xxx, 113, 1898.

Cal.

3245. vernata Peck, Mass. Mag., 323, 415, 1795; Packard, C. 402; Riter, Rep. Ins. Mo., i, 109; ii, 94 ; vi, 28 ; vii, 80 ; viii, 13,1874 ; SAUNDERs, Ins. Inj. Fr., 61, 1883; Packard, Bull. U. S. Ent. Comm., vii, 61, 1882; Riley, Rept. U. S. Ent. No. Atl. States.

Alaska.

No. Pac. States.

Cal.
Atl. States, Col., Cal. Comm., iii, 157, 170, 1882; French, Ill. Rept., vii, 110, 239, 1877; Hulst, Ent. Amer., iv, 51, 1888.

syn. sericeiferata WaLker, Cat. Brit. Mus., xxv, 1697, 1862; PaCkard, C. 454; Hulst, Ent. News, vi, 42, 1895; autumnata PACKARD, C. 400.

a. merriccata DYAR (dark gray, the discal dot large, white, dark edged; other markings broken and reduced). 


\section{ALSOPHILA Hübner.}

HüBner, Verz. bek. Schmett., 320, 1818; Stephens, Cat. Brit. Lep., 160, 1850; Hulst, Trans. Am. Ent. Soc., xxiii. 257, 1896; Anisoptery, $x$, Stephens, Cat. 116, 1829; Packard, C. 399; Kirby, Eur. Butt., 356, 1881; Hofmann, Gr. Schm. Eur., 146,1894 .

3247. pometaria Harris, Inj. Ins. Mass., 333, 1841; Riley, Rept. Ins. Mo., ii, 97; vi, 29; vii, 80; viii, 13, 1874; Packard, Guide Stud. Ins., 324, 1869; C. 402; Mann, Can. Ent., viii, 164, 1876; JaEger, N. A. Ins., 175, 1871; Saunders, Ins. Inj. Fr., 65, 1883; Riley, Rept. U. S. Ent. Comm., iii, 150, 1882; French, Ill. Rept., vii, 238, 1877; Hulst, Ent. Amer., iv, 56, 1888; Ent. News, vi, 42, 1895 ; Hinds, Can. Ent., Xxxiii, 185, 1901; Dyar, Pysche, ix, 262, 1901.

syn. restituens Walker, Cat. Brit. Mus., xxv, $1697,1862$.

\section{EUDULE Hübner.}

Hübner, Zutr. exot. Schmett., ii, 14, 1825; Neumoegen \& Dyar, Jn. N. Y. Ent. Soc., i, 118, 1893; Hulst, Trans. Am. Ent. Soc., xxiii, 157, 1896; Ameria Walker, Cat. Brit. Mus., ii, 554, 1854; Euphanessa Packand, Proc. Ent. Soc. Phil., iii, 1021864.

3248. mendica WALKer, Cat. Brit. Mus., ii, 576, 1854; PaCKard, Proc. Ent. Soc. Phil., iii, 102, 1864; C. Atl. 33; Saunders, Can. Ent., iii, 227, 1871; ClemStates. Ens, Proc. Ent. Soc. Phil., i, 543, 1860; Riley, Rept. Ins. Mo., ix, 6, 1877; Ent. Amer., i, 170, 1885; Snith, Ent. Amer., i, 179, 1885; Butler, Trans. Ent. Soc. Lond., 371, 1877; Hulst, Ent. Amer. i, 167, 1885, ii, 221, 1887; STretch, Zyg. Bomb. N. A., 53, 1872; Lucock, Can. Ent., xxx, 248, 1898; Dyar, Psyche, ix, 189, 1901.

syn. biseriata Herrich-Schaeffer, Auss. Schm., f. 441, 1858.

3249. meridiana Slosson, Ent. Amer., v, 7, 1889.

*3250. hyalina Hulst, Can. Ent., xxx, 114, 1898.

3251. unicolor Robinson, Ann. N. Y. Lyc. Nat. Hist., ix, 153, 1869: NeuMOEgeN \& Dyar, Jn. N. Y. Ent. Soc., i, 118, 1893.

\section{Atl.} States, Col. 
PHILOPSIA Hulst.

Hulst, Trans. Am. Ent. Soc., xxiii, 259, 1896.

3253. nivigerata WaLker, Cat. Brit. Mus., xxiv, 1259 , 1862; Packard, C. 185; Hulst, Ent. News, vi, 43,1895 .

syn. inæqualiata PACKARd, C. 180.

AGIA Hulst.

Hulst, Trans. Am. Ent. Soc., xxiii, 159, 1896.

*3254. eborata Hulst, Trans. Am. Ent. Soc., xxiii, 260 , 1896.

Atl. States.

TALLEDEGA Hulst.

Hulst, Trans. Am. Ent. Soc., xxiii, 260, 1896.

3255. montanata Packard, Sixth Rept. Peab. Acad. Sci., 40, 1874; C. 181.

No. U.S.

syn. nocticolata Hulst, Bull. Brook. Ent. Soc., iv, $26,1881$.

3256. tabulata Hulst, Trans. Am. Ent. Soc., xxiii, 26, 1896.

N. -W. U. S.

SCELIDACANTHA Hulst.

Hulst, Trans. Am. Ent. Soc., xxiii, 261, 1896.

3257. triseriata Packard, Sixth Rept. Peab. Acad. Sci., 39, 1874; C. 195.

3258. virginata Graef, Bull. Brook. Ent. Soc., iii, 96, 1880.

Col., Ariz., Cal.

\section{CARSIA Hübner.}

Hübner, Verz. bek. Schmett., 336, 1818; Guenée, Spec. Gén., ix, 493, 1857; MeyRICK, Trans. Ent. Soc. Lond., 69, 1892; Hulst, Trans. Am. Ent. Soc., xxiii, 261, 1896; Larissa Curtis, Brit. Ent., vii, 324, 1830; Celma Stephens, Ill. Brit. Ent., Haust., iii, 242, 1831 .

3259. paludata Thunberg, Mus. Acad. Nat., 76, 1788; Packard, C. 186; Möschler, Verh. zool.-bot. Ges. Wien, 301, 1884; Hofmann, Gr. Schm. Eur., 197, 1894.

Arctic Am., Eur.

syn. sororiata HüBNER, sororaria HerRICHSchaeffer, primaria Eversmann, Bull. Mose., ii, 639, 1851; boreata PACKARD, alpinata PACKARD.

a. imbutata HüBnER, Schm. Eur., pl. 68, f. 405, 1796; Packard, C. 186; Westwood \& Humphreys, Brit. Moths, ii, 43, 1849. 


\section{NANNIA Hulst.}

Hulst, Trans. Am. Ent. Soc., xxiii, 262, 1896.

3260. refusata Walker, Cat. Brit. Mus., xxiii, 891, 1861; Hulst, Ent. News, vi, 43, 1895.

No. Atl. States.

syn. harveiata PACKARD, C. 193.

*3261. morensata Hulst, Trans. Am. Ent. Soc., xxiii, $262,1896$.

Miss.

Vall.

HETEROPHLEPS Herrich-Schaeffer.

Herrich-Schaeffer, Ausser. Schmett., 62, 1854; Packard, C. 192.

3262. triguttaria Herrich - Schaeffer, Ausser. U. S. Schmett., f. 202, 185̆4; PaCKard, C. 193.

syn. quadrinotata WaLker, Cat. Brit. Mus., xxvi, 1759, 1862; Hulst, Ent. News, vi, 105, 1895; Schaus, Proc. Zool. Soc. Lond., 647, 1896; hexaspilata WaLker, Cat. Brit. Mus., xxxv, 1653, 1866: Hulst, Ent. News, vi, 42,1895 .

\section{CHLOROCLYSTIS Hübner.}

Hübner, Verz. bek. Schmett., 323, 1818; Meyrick, Trans. Ent. Soc. Lond., 65, 1892; Hulst, Trans. Am. Ent. Soc., xxiii, 263, 1896.

*3263. inconspicua Hulst, Trans. Am. Ent. Soc., xxiii, Cal. $264,1896$.

GYMNOCELIS Mabille.

Mabille, Ann. Soc. Ent. Fr., 77, 1869; Meyrick, Trans. Ent. Soc. Lond., 65, 1892; Hulst, Trans. Am. Ent. Soc., xxiii, 264, 1896.

*3264. inferior Hulst, Trans. Am. Ent. Soc., xxiii, 264, Cal. 1896.

*3265. gypsata Grote, Can. Ent,, xiv, 188, 1882.

Ariz.

3266. desperata Hulst, Trans. Am. Ent. Soc., xxiii,

Tex. $264,1896$.

3267. minuta Hulst, Trans. Am. Ent. Soc., xxiii, 265, 1896.

So.

Cal.

\section{TEPHROCLYSTIS Hübner.}

HüBner, Verz. bek. Schmett., 323, 1818; Meyrick, Trans. Ent. Soc. Lond., 65, 1892; Hulst, Trans. Am. Ent. Soc., xxiii, 265, 1896; Dyscymatoge Hüвner, Tarachia Hüвner, Arcyonia HüBner, Leucocora HüBner, Eupithecia Curtis, Brit. Ent., ii, 64, 1825; Packard, C. 47; v. Gumprenberg, Nov. Act. Halle, lii, 153, 1888; Meyrick, Trans. Ent. Soc. Lond., 192, 1892; Nycterosea Hulst, Trans. Am. Ent. Soc., xxiii, $263,1896$.

*3268. misturata Hulst, Trans. Am. Ent. Soc., xxiii, U. S. $266,1896$. 
3269. nebulosa Hulst, Trans. Am. Ent. Soc., xxiii, $266,1896$.

Atl. States.

*3270. scriptaria Herrich-Schaeffer, Schm. Eur., iii, 121, 1847; Guenée, Spec. Gén., ix, 312, 1857; Möschler, Stett. ent. Zeit., 122, 1883; v. GumpPenberg, Nov. Act. Halle, lii, 180, 1888; HofMann, Gross. Schm. Eur., 215, 1894.

3271. implicata Walker, Cat. Brit. Mus., xxiv, 1241, 1862; Packard, C. 64; Hulst, Ent. Amer., iii, 114, 1887; Ent. News, vi, 70, 1895.

3272. luteata Packard, Proc. Bost. Soc. Nat. Hist., xi, 46, 1867; C. 57; v. Gumppenberg, Nov. Act. Halle, lii, 252, 1888.

syn. palpate PaCKard, Fifth Report Peab. Acad. Sci., 58, 1873; C. 57.

*3273. hyperboreata Staudinger, Stett. ent. Zeit., 400, 1861; v. Gumppenberg, Nov. Act. Halle, lii, $187,1888$.

*3274. edna Hulst, Trans. Am. Ent. Soc., xxiii, 266, 1896.

*3275. subcolorata Hulst, Can. Ent., xxx, 114, 1898.

3276. ornata Hulst, Trans. Am. Ent. Soc., xxiii, 267, 1896.

3277. miserulata Grote, Proc. Ent. Soc. Phil., ii, 32 , 1863; Packard, C. 52; Bull. U. S. Ent. Comm., vii, 248, 1881; Coquillett , Pap., i, 56, 1881; Riley, Ins. Life, iii, 345, 1891; Hulst, Ent. News, vi, 70, 1895 ; v. Gumprenberg, Nov. Act. Halle, lii, 173, 1888.

a. californiata v. Gumppenberg, Nov. Act. Halle, lii, 174, 1888.

*3278. interruptofasciata PACKaRd, Fifth Rept. Peab. Acad. Sci., 59, 1873; C. 52; Coquillett, Ill. Rept., xi, 23, 1881; Pap., i, 56, 1881; SAunders, Ins. Inj. Fr., 352, 1885; v. Gumppenbera, Nov. Act. Halle, lii, 174, 1888.

*3279. leucata Hulst, Trans. Am. Ent. Soc., xxiii, 267, 1896.

3280. niveifascia Hulst, Can. Ent., xxx, 115, 1898.

*3281. inornata Hulst, Trans. Am. Ent. Soc., xxiii, $276,1896$.

Lab.

N.-E. ,

U. S.

No. Atl.

States.

Greenl.

Col.

Ariz.

Rocky Mts., No. Cal.

Atl. States.

Cal.

Atl.

States.

Rocky

Mts.

N. Mex.,

Oreg.

Atl.

States. 
*3282. albicapitata PaCkard, C. 48; v. Gumppenberg, Nov. Act. Halle, lii, 254, 1888.

Can., Col.

*3283. insolabilis Hulst, Jn. N. Y. Ent. Soc., viii, 215, Ariz. 1901.

3284. rotundopuncta Packard, Proc. Bost. Soc. Nat. Hist., xiii, 395, 1871; v. Gumprenberg, Nov. Act. Halle, lii, 245, 1888.

syn. rotundopunctata PACKARD, C. 55.

*3285. annulata Hulst, Trans. Am. Ent. Soc., xxiii, $267,1896$.

*3286. borealis Hulst, Can. Ent., xxx, 114, 1898.

*3287. latipennis Hulst, Can. Ent., xxx, 114, 1898.

3288. plumbaria Hulst, Can. Ent., xxxii, 112, 1900.

*3289. flavigutta Hulst, Trans. Am. Ent. Soc., xxiii, $268,1896$.

*3290. coloradensis Hulst, Trans. Am. Ent. Soc., xxiii, 268, 1896.

*3291. sierræ Hulst, Trans. Am. Ent. Soc., xxiii, 268, 1896.

*3292. cretata Hulst, Trans. Am. Ent. Soc., xxiii, 269, 1896.

*3293. brunneipennis Hulst, Trans. Am. Ent. Soc., xxiii, 263, 1896.

3294. absinthiata CLERCK, Icones, vi, 9, 1759; LINNæUS, Faun. Suec., 339, 1761; HüBNER, Schmett. Eur., 453, 1820; v. Gumppenberg, Nov. Act. Halle, lii, 246, 1888; Hofmann, Gr. Schm. Eur., 218, 1894.

syn. minutata Treitschke, Schm. Eur., vi, (2), 105, 1828; notata Stephens, Ill., iii, 286, 1831; elongata HaworTH, Brit. Ent., 358, 1829; absynthiata Gunnée, Spec. Gén., ix, 340, 1857; Crewe, Ent. Ann., 140, 1861; Snellen, Tidj. v. Ent., 137, 1866; Packard, C. 49; Goodell, Can. Ent., ix, 62, 1877; Möschler, Verh. zool.-bot. Ges. Wien, 319, 1884; coagulata GuEnéE, geminata PACKARD.

3295. fumosa Hulst, Trans. Am. Ent. Soc., xxiii, 269, 1896.

3296. longipalpata Packard, Geom. Moths., C. 56, 1876.

N. Mex., Cal.

Cal.

Manitoba. Can.

Atl. States。

Col.

Col.

Col.

Cal.

Cal.

U.S., Eur.

Ati. States.

Pac. States. 
*3297. mæstosa Hulst, Trans. Am. Ent. Soc., xxiii, $269,1896$.

*3297. 1. lachrymosa Hulst, Can. Ent., xxxii, 103, 1900.

Col.

*3298. nimbicolor Hulst, Trans. Am. Ent. Soc., xxiii, $269,1896$.

3299. perfusca Hulst, Can. Ent., xxx, 116, 1898.

3300. zygænidata Packard, C. 51; v. GumpPenberg, Nov. Act. Halle, lii, 249, 1888.

3301. plenoscripta Hulst, Can. Ent., xxxii, 103, 1900.

3302. nimbosa Hulst, Trans. Am. Ent. Soc., xxiii, $269,1896$.

*3302. 1. bolteri Hulst, Can. Ent., xxxii, 102, 1900.

*3303. longidens Hulst, Trans. Am. Ent. Soc., xxiii, $270,1896$.

*3303. 1. tenebrescens Hulst, Can. Ent., xxxii, 103, 1900.

*3304. multistrigata Hulst, Trans. Am. Ent. Soc., xxiii, $270,1896$.

*3305. multiscripta Hulst, Trans. Am. Ent. Soc., xxiii, $270,1896$.

*3306. laisata Strecker, Lep. Rhop. Het., suppl. 2, $11,1899$.

*3307. stellata Hulst, Trans. Am. Ent. Soc., xxiii, 270, 1896.

3308. flebilis Hulst, Proc. Wash. Acad. Sci., ii, 497, 1900 .

*3309. obscurior Hulst, Trans. Am. Ent. Soc., xxiii, $271,1896$.

3310. bivittata Hulst, Trans. Am. Ent. Soc., xxiii, $271,1896$.

*3311. golgata Strecker, Lep. Rhop. Het., suppl. 2, 11, 1899.

3312. behrensata Packard, C. 59; Hulst, Ent. Amer., iv, $49,1886$.

*3313. unicolor Hulst, Trans. Am. Ent. Soc., xxiii, $271,1896$.

Oreg.

No. Rocky Mts., Cal.

Utah, Wash.

Atl. States, Col.

Wyo.

Cal.,

Ariz.

Tex.

Col.

Tex.

Col.,

Utah.

Col.

Cal.

Col.

Alaska.

Cal.

Cal.

Nev.

Cal.

Col., Cal.

3314. subapicata Guenée, Spec. Gén., ix, 331, 1857; Packard, C. 62; Grote, Can. Ent., xv, 27, 1883;

Cal. v. Gumppenberg, Nov. Act. Halle, lii, 240, 1888. syn. occidentalis Packard, Proc. Bost. Soc. Nat. Hist., xiii, 404, 1871. 
3315. a.cutipennis Hulst, Can. Ent., xxx, 115, 1898.

Cal.

3316. cestata Hulst, Trans. Am. Ent. Soc., xxiii, 271,

Cal. 1896.

*3317. nevadata Packard, Proc. Bost. Soc. Nat. Hist., xiii, 395,1871 ; C. 61 ; v. Gumprenberg, Nov. Act. Halle, lii, 229, 1888.

*3318. implorata Hulst, Trans. Am. Ent. Soc., xxiii, $272,1896$.

3319. raveocostaliata PACKard, C. 60; v. GumpPenBerg, Nov. Act. Halle, lii, 217, 1888.

Pac.

States.

Cal.

Pac.

States.

\section{CYSTEOPHORA Hulst.}

Hulst, Jn. N. Y. Ent. Soc., viii, 215, 1901.

3320. pervertipennis Hulst, Jn. N. Y. Ent. Soc., viii, 215, 1901; Dyar, Proc. Ent. Soc. Wash., iv, 457,1901 .

Fla.

\section{EUCYMATOGE Hübner}

HüBner, Verz. bek. Schmett., 325, 1818; Meyrick, Trans. Ent. Soc. Lond., 67, 1892; Hulst, Trans. Am. Ent. Soc., xxiii, 272, 1896; Hypepirritis HüBner, Orthonana Hübner, Horisma HüBner, Verz. bek. Schmett., 329, 331, 1818; Phibalapteryx Stephens, Cat., 138, 1829; Packard, C. 168; Collix Guenée, Spec. Gén., x, 357, 1857; Kirby, Eur. Butt., 368, 1882.

3321. tenuata Hulst, Bull. Brook. Ent. Soc., iii, 45, Col. 1880.

*3322. gelidata Möschler, Wien ent. Monats., iv, 47, 1860; Stett. ent. Zeit., 122, 1883; PaCKard, C. 64; Staudinger, Cat. Lep. Eur., 195, 1871; v. Gumppenberg, Nov. Act. Halle, lii, 201, 1888.

3323. anticaria W ALKer, Cat. Brit. Mus., xxv, 1241 , 1862; Packard, C. 64; Hulst, Ent. News, vi, 70,1895 .

syn. explanata WaLker, Cat. Brit. Mus., xxv, 1242, 1862; Packard, C. 64; Hulst, Ent. News, vi, 70, 1895; strattonata PACKARD, Fifth Rept. Peab. Acad. Sci., 60, 1883; C. 58 ; v. Gumppenberg, Nov. Act. Halle, lii, 230,1888 .

*3324. graefii Hulst, Trans. Am. Ent. Soc., xxiii, 273, 1896.

Labr.

Atl.

States.

3325. grandis Hulst, Trans. Am. Ent. Soc., xxxii, $273,1896$.

Wash.

Wash.,

Oreg. $4630-$ No. $52-02-18$ 
*3326. gille tei Hulst, Can. Ent., xxx, 116, 1898.

Col.

3327. intestinata Guenée, Spec. Gén., ix, 432, 1857; U.S. Packard, C. 170; Hulst, Ent. News, vi, 43, 1895; v. Gumppenberg, Nov. Act. Halle, lii, $153,1888$.

syn. impleta Walker, Cat. Brit. Mus., xxxv, 1683, 1866; indoctrinata W ALKER, Cat. Brit. Mus., xxvi, 1722, 1862.

*3328. vitalbata Denis \& Schiffermüller, Syst. Verz. Wien, 109, 1776; HüBnER, Schmett. Eur., 269, 1820; Treitschke, Eur. Schmett., vi, (2), 66, 1828; Duponchel, Hist. Nat., viii, 197, 1838; Guenée, Spec. Gén., ix, 437, 1857; Walker, Cat. Brit. Mus., xxv, 1337, 1862; Hulst, Trans. Am. Ent. Soc., xxiii, 272, 1896; v. GuMPPENBerg, Nov. Act. Halle, lii, 145, 1888; HofMANN, Gr. Schmett. Eur., 210, 1894.

\section{VENUSIA Curtis.}

Curtis, Brit. Ent., 759, 1839; Meyrick, Trans. Ent. Soc. Lond., 75, 1892; Hulst, Trans. Am. Ent. Soc., xxiii, 273, 1896.

3329. cambrica Curtis, Brit. Ins., xvi, 1839; Wood, Ind. Ent., suppl., 1724, 1839; Lederer, Verh. U. S., Eur. zool.-bot. Ges. Wien, xix, 101, 1853; Hulst, Ent. News, vi, 70, 1895; Hofmann, Gr. Schm. Eur., 204, 1894.

syn. cambricaria Guenée, Spec. Gén., ix, 440, 1857; Packard, C. 85; Möschler, Verh. zool.-bot. Ges. Wien, 303, 1884; emutaria Duponchel, Hist. Nat., suppl., 4, 1842; Borsduval, Ind. Méth., 203, 1840; Herrich-Schaeffer, Schm. Eur., 258, 1856; nebulosaria FreYer, Beit. Ges. Eur. Schm., 546, 1831; scitularia W ALKer, Cat. Brit. Mus., xxi, 406, 1860; Hulst, Ent. Amer., iii, $114,1887$.

3330. duodecemlineata Packard, Proc. Bost. Soc. Nat. Hist., xvi, 19,1874; C. 84; Butler, Pap., i, 222, 1881.

3331. comptaria W ALKer, Cat. Brit. Mus., xxi, 406,1860; Hulst, Ent. News, vi, 70, 1895.

Can., Eur.

syn. condensata W ALKer, Cat. Brit. Mus., xxv, 1273, 1862; PACKARD, C. 166; inclinataria Walker, Cat. Brit. Mus., xxvi, 1727, 1862; inclinata Hulst, Sm. List Lep. Bor. Am., no. 3929, 1891: perlineata PACKARD, Proc. Bost. Soc. Nat. Hist., xvi, 19, 1874; C. 83. 


\section{EUCHCEA Hïbner.}

Hü bner, Verz. bek. Schmett., 298, 1818; Meyrick, Trans. Ent. Soc. Lond., 74, 1892; Hulst, Trans. Am. Ent. Soc., xxiii, 274, 1896; Meyrick, Proc. Linnæan Soc. N. S. Wales, ii, 811, 1887; Hydrœlia HüBner, Verz. bek. Sch., 322, 1818; Kirby, Eur. Butt., 389, 1882; Trichodezia W Arren, Nov. Zool., ii, 119, 1895.

3332. albovittata Guenée, Spec. Gén., ix, 520, 1857; Packard, C. 189; Hulst, Ent. News, vi, 42, 1895. Atl. State syn. propriaria Walker, Cat. Brit. Mus., xxv, 1293, 1862; reciprocata W ALKER, Cat. Brit. Mus., xxv, 1294, 1862.

a. albofasciata Grote, Proc. Ent. Soc. Phil., ii, 66, 1863; Trans. Kans. Acad. Sci., viii, 51, 1878; Can. Ent., viii, 28, 1876; PACKARd, C. 166.

3333. californiata Packard, Proc. Bost. Soc. Nat. Hist., xiii, 404, 1871; C. 189.

3334. cretaceata Packard, Sixth Rept. Peab. Acad. Sci., 40, 1874; Proc. Bost. Soc. Nat. Hist., xvi, pl. 1, to Alaska.

f. 3, 1874; C. 63; Butler, Pap., i, 223, 1881; v. Gumppenberg, Nov. Act. Halle, lii, 249, 1888.

33.5. lucata Guenée, Spec. Gén., ix, 437, 1857; PaCKARD, C. 326.

III.,

Man.

Atl. States.

1866; Hulst, Ent. News, vi, 105, 1895.

syn. albogilvaria Morrison, Proc. Bost. Soc.

Nat. Hist., xvi, 194, 1874; PaCKard, C. 325;

triseriata Packand, Sixth Rept. Peab. Acad.

Sci., 50, 1874; C. 325.

a. brunneifasciata PACKARD, C. 324, 1876.
Pac.

States.

U.S.

\section{EPIRRITA Hübner.}

Hübner, Tent., 1810; Packard, C. 82; Hulst, Trans. Am. Ent. Soc., xxiii, 274, 1896; Asthena Hübner, Verz. bek. Schmett., 310, 1818; Packard, C. 324; Merrick, Trans. Ent. Soc. Lond., 74, 1892; Hulst, Trans. Am. Ent. Soc., xxiii, 274, 1896; Oporima Hübner, Verz. bek. Schmett., 321, 1818; Minoa Treitsch ke, Schm. Eur., vi, (2), 248, 1827; Staudinger, Cat. Lep. Eur., 178, 1871; v. Gumppenberg, Nov. Act. Halle, xlix, 365, 1887; Oporabia Stephens, Ills., iii, 273, 1831; Guenée, Spec. Gén., ix, 261, 1857.

3337. dilutata Denis \& Schiffermüller, Syst. Verz. Wien, 109, 1776; Packard, C. 87; Fitch, Fifth Rept. Ins. N. Y., 842, 1858; Bruck, Pap., ii, 82, 1882; Hofmann, Gr. Sch. Eur., 205, 1894.

Atl. States, Col., Eur.

syn. dilutaria Freyer, impluviata BorkHAUSEN, Eur. Schmett., v, 291, 1794; inscriptata Donovan, Nat. Hist., xv. pl., 517, 1816; fimbriata Haworth, Lep. Brit., 320, 1829.

a. autumnata Guenée, Spec. Gén., x, 264, 1857. 


\section{CORYPHISTA Hulst.}

Hulst, Trans. Am. Ent. Soc., xxiii, 275, 1896.

*3338. meadii Packard, Sixth Rept. Peab. Acad. Sci., Pac. States, 41, 1874; Rept. Geol. Surv. Terr., v, 551, 1875. New Mex.

syn. meadiata PaCKard, C. 176.

3329. badiaria Hy. Edwards, Ent. Amer., i, 50, 1885; v. Gumppenberg, Nov. Act. Halle, lii, 136, 1888 .

Pac.
States,
Col.

HYDRIA Hübner.

Hübner, Tent., 1810; Packard, C. 171; Calocalpe Hübner, Verz. bek. Schmett., 330, 1818; Meyrick, Trans. Ent. Soc. Lond., 70, 1892; Hulst, Trans. Am. Ent. Soc., xxiii, 275, 1896; Eucosmia Stephens, Ills., iii, 265, 1831; Staudinger, Cat. Lep. Eur., 78, 1871; v. Gumppenberg, Nov. Act. Halle, lii, 139, 1888.

3340. undulata Linneus, Syst. Nat., 524, 1758; U. S., Fiтch, Fourteenth Rept. Ins. N. Y., 355, 1870; Eur. Packard, C. 172; Möschler, Verh. zool.-bot. Ges. Wien, 301, 1884; Hulst, Ent. Amer., ii, 162, 1886; v. Gumppenberg, Nov. Act. Halle, lii, 140, 1888; Hofmann, Gr. Sch. Eur., 200, 1894; Dyar, Psyche, ix, 9, 1900.

\section{CATOCLOTHIS Hulst.}

Hulst, Trans. Am. Ent. Soc., xxiii, 275, 1896; Cyclica Grote (not Latreille), Can. Ent., xiv, 174, 1882; Hulst, Trans. Am. Ent. Soc., xxiii, 275, 1896.

*3341. frondaria Grote, Can. Ent., xiv, 174, 1882; xv,

Ariz. $27,1883$.

\section{PHILEREME Hübner.}

Hübner, Verz. bek. Schmett., 330, 1818; Packard, C. 174; Meyrick, Trans. Ent. Soc. Lond., 70, 1892; Hulst, Trans. Am. Ent. Soc., xxiii, 276, 1896; Scotosia Stephens, Brit. Ins., 44, 1829; Lederer, Verh. zool.-bot. Ges. Wien, 252, 1853; v. GumpPenberg, Nov. Act. Halle, lii, 137, 1888; Hofmann, Gr. Sch. Eur., 200, 1894.

3342. ealiforniata Packard, Proc. Bost. Soc. Nat. Hist., xiii, 399, 1871; C. 175.

Cal.

*3343. multivagata Hulst, Bull. Brook. Ent. Soc., iv, 26,1881 .

Ont., Col.,

B. C.

*3344. nigrescens Hulst, Can. Ent., xxxii, 104, 1900.

Oreg.

*3345. formosa Hulst, Trans. Am. Ent. Soc., xxiii, 276, 1896.

Col.,

Man.

*3346. optimata Strecker, Lep. Rhop. Het., suppl. 2, Wash. 11, 1899 . 


\section{PHYLACE Hulst.}

Hulst, Trans. Am. Ent. Soc., xxiii, 277, 1896.

3347. luteolata Hulst, Trans. Am. Ent. Soc., xxiii, $277,1896$.

Rocky

Mts.

\section{EUSTROMA Hübner.}

HüBner, Verz. bek. Schmett., 335, 1818; Meyrick, Trans. Ent. Soc. Lond., 71, 1892; Hulst, Trans. Am. Ent. Soc.; xxiii, 277, 1896; Euphia HüBner, Verz. bek. Schmett., 336, 1818; Electra Stephens, Cat. 135, 1829; Steganolophia Stephens, Cat. 135, 1829; Westwood \& Humphreys, Brit. Ins., ii, 39, 1849.

3348. diversilineata Hübner, Samml. exot. Schm., i, 1, 2, 3, 4, 1806; Packard, C. 128; French, Trans. Atl. Dep. Agr. Ill., xv, 237, 1877; Bruce, Ent. Amer., States. iii, 50, 1887; Saunders, Can. Ent., ii, 74, 1870. a. gracilineata Guenée, Spec. Gén., x, 476, 1857.

3349. testata Linneus, Faun. Suec., 1262, 1761; Packard, C. 122; Möschler, Verh. zool.-bot. Ges. Wien, 302, 1884.

syn. achatinata HüBner, Schm. Eur., 301, 1796; Packard, C. 122.

3350. populata Linnæus, Syst. Nat., 525, 1758; PACKard, C. 124; Möschler, Wien. ent. Mon., iv, 375, 1860; Stett. ent. Zeit., 120, 1883; Verh. zool.bot. Ges. Wien, 302, 1884; Hofmann, Gr. Schm. Eur., 201, 1894; Hulst, Ent. News, vi, 43, 1895. syn. dotata CLERCK, propulsata WALKER, molliculata WALKer; PACKARD, C. 132; packardata Lintner, Ent. Cont., iv, 113, 1878. a. remotata WALkER, Cat. Brit. Mus., xxv, 1388 , 1862; Packard, C. 132.

b. similis Walker, Cat. Brit. Mus., xxv, 1425, 1862.

c. cervinifascia Walker, Cat. Brit. Mus., xxv, 1184, 1862; PACKARD, C. 131.

*3351. destinata Möschler, Wien. ent. Mon., iv, 46, 1860; Stett. ent. Zeit., 120, 1883; PACKARD, Proc. Bost. Soc. Nat. Hist., xi, 48, 1867.

a. lugubrata Möschler, Wien. ent. Mon., 136, 1862; Staudinger \& Rebel, Cat. Lep. Eur., i, no. 3295 a, 1901.

3352. prunata Linneus, Syst. Nat., 526, 1758; РАCKard, C. 116; Hofmann, Gr. Schm. Eur., 200, 1894.

syn. ribesiaria BoIsDUVAL, triangulatum PACKARD, montanatum PACKARD.

Atl. States, Eur. No. U. S., Eur.

No. U.S. 
3353. nubilata Packard, Proc. Bost. Soc. Nat. Hist., xiii, 400, 1871.

Pac. States.

syn. semiatratum Hulst, Bull. Brook. Ent. Soc., iv, 26, 1881.

3354. atrocolorata Grote, Ann. N. Y. Lyc. Nat. Hist., viii, 31, 1867; PACKard, C. 121.

Atl. States.

3355. explanata Walker, Cat. Brit. Mus., xxv, 1422, 1862; Hulst, Ent. News, vi, 44, 1895.

Atl. States, Col.

Atl.

3356. cunigerata Walker, Cat. Brit. Mus., xxvi, 1726, 1862; Packard, C. 114; Hulst, Ent. News, vi, 44,1895 .

syn. disjunctaria PACKARD.

\section{NEOLEXIA Hulst.}

Hulst, Trans. Am. Ent. Soc., xxiii, 278, 1896.

3357. xylina Hulst, Trans. Am. Ent. Soc., xxiii, 278, 1896.

*3358. speciosa Hulst, Trans. Am. Ent. Soc., xxiii, $279,1896$.

No. U.S.

Alberta, Can.

RHEUMAPTERA Hübner.

Hübner, Tent., 1810; Packard, C. 150; Cosmorhoe Hübner, Plemyria, Hübner; MeyRick, Trans. Ent. Soc. Lond., 71, 1892; Hulst, Trans. Am. Ent. Soc., xxiii, 279, 1896; Epirrhoe Hüвner, Eulypa Hübner, Melanippe Duponchel.

3359. hastata Linnfus, Syst. Nat., 527, 1758; PACKArd, C. 164; Möschler, Verh. zool.-bot. Ges. Wien, 306, 1884; Strecker, Surv. Dept. Mo., Ruffner, app., 1861, 1878; Dпммоск, Psyche, iv, 243, 1855; Hulst, Ent. News, vi, 73, 1895. a. gothicata Guenée, Spec. Gén., x, 388, 1857; Packard, Proc. Bost. Soc. Nat. Hist., xi, 46, 1867.

syn. furcifascia Walker, Cat. Brit. Mus., xxv, 1294, 1862; hecate Butler, Ann. Mag. Nat. Hist., (5), i, 448, 1878; Ill. Lep. Het. B. M., iii, $55,1879$.

b. hastulata HüBNer, Eur. Schmett., 356, 1820. c. subhastata Nolcken, Verh. zool.-bot. Ges. Wien, xx, 68, 1870.

d. thulearia Herrich-Schaffrer, Eur. Schmett., iii, 156, 1850; Guenée, Spec. Gén., ix, 389, 1857; Walker, Cat. Brit. Mus., xxv, 1282, 1862 .

e.mœstata NoLcken, Verh. zool.-bot. Ges. Wien, xx, 68, 1870 .

syn. hastulata Guenée (not Hübner), Spec. Gén., ix, 389, 1857: Staudinger, Stett. ent. Zeit., 397, 1861.

No. U.S., Eur. 
3360. tristata Linn eus, Syst. Nat., 526, 1758; РАCKARD, C. 162; Möschler, Verh. zool.-bot. Ges. Can., Eur. Wien, 306, 1884; Hofmann, Gr. Schm. Eur., 207,1894 .

syn. limbopunctata Nolckes, Lep. Faun., i, $270,1868$.

3361. sociata Borkhausen, Eur. Schmett., v, 432 , 1794: Staudinger, Cat. Lep. Eur., 188, 1871.

syn. substriata H A WORTH, degenerata HAWORTH, alchemillata SCHIFFERMÜLLER, alchemillaria Freyer, rivata DUPONCHeL.

*3362. luctuata Denis \& Schiffermüller, Syst. Verz. Wien, 316, 1776 (not desc.); Hübner, Bei. Ges. Schm., ii, 4, 3, T, 1792; Staudinger \& Rebel, Cat. Lep. Eur., i, no. 3444, 1901.

syn. luctuaria Herrich-SchaEfFer, transversata Thunberg, lugubrata STAudinger, Cat. Lep. Eur., 189, 1871; Packard, C. 161.

a. obductata Möschler, Wien. ent. Mon., 374 , 1860; Hulst, Ent. News, vi, 70, 1895.

b. concordata Walker, Cat. Brit. Mus., xxv, 1295,1862 .

c. kodiakata Packard, Proc. Bost. Soc. Nat. Hist., xvi, 23, 1874.

*3363. delimitata Warren, Nov. Zool., ii, 114, 1895.

3364. georgii Hulst, Trans. Am. Ent. Soc., xxiii, 280, 1896.

3365. rubrosuffusata Packard, Proc. Bost, Soc. Nat. Hist., xiii, 402, 1871; C. 143; Butler, Pap., i, 223,1881 .

\section{ZENOPHLEPS Hulst.}

Hulst, Trans. Am. Ent. Soc., xxiii, 280, 1896.

3366. lignicolorata Packard, Sixth Rept. Peab. Acad. Sci., 42, 1874; Proc. Bost. Soc. Nat. Hist., xvi, pl. 1, f. 11, 1874; C. 138; Hulst, Ent. News, vi, $104,1696$.

*3367. obscurata Hulst, Trans. Am. Ent. Soc., xxiii, 281 , 1896.

No. U.S., Eur.

No. Atl. States.

U.S. No. U. S., Pac. States.

Pac. States.

Pac.

States.

Cal.

\section{ENCHORIA Hulst.}

Hulst, Trans. Am. Ent. Soc., xxiii, 281, 1896.

*3368. osculata Hulst, Trans. Am. Ent. Soc., xxiii, 281 , 1896.

So.

Cal.

3369. albifasciata PACKard, Proc. Bost. Soc. Nat. Hist.,

Cal. xvi, pl. 1, f. 5, 1874; C. 97. 


\section{PERCNOPTILOTA Hulst.}

Hulst, Trans. Am. Ent. Soc., xxiii, 282, 1896.

3370. fluviata Hübner, Eur. Schm., 280, 1820; РACKARd, C. 78; Millik̀re, Ann. Soc. Linn. Lyon, 50, 1868; Krrby, Eur. Butt., 365, 1882; Möschler, Ver. zool.-bot. Ges. Wien, 304, 1884; Hofmann, Gr. Sch. Eur., 205, 1894; Hulst, Ent. News, vi, 70, 1895; Dyar, Psyche, viii, 429, 1899.

syn. fluviaria HerRICH-SCHAEFFER, gemmata HüBNer, gemmaria HerRICH-SCHAEFFER, angustata HAwORTH, exagitata WALKER, Cat. Brit. Mus., xxv, 1331, 1862; peracuta WaLker, Cat. Brit. Mus., xxv, 1421, 1862; obruptata WaLker, Cat. Brit. Mus., Xxv, 1713, 1862; signataria W ALKER, Cat. Brit. Mus., xxv, 1718, 1862; alternata WALKER, Cat. Brit. Mus., xxxv, 1681, 1866; pigrata WaLKEr, Cat. Brit. Mus., xxxv, 1681, 1866; mediata WaLker, Cat. Brit. Mus., xxv, 1338 , 1862; intrusata Walker, Cat. Brit. Mus., xxv, 1339, 1862; lapillata Guenée, Spec. Gén., ix, 430, 1857; baccata Gunnée, Spec. Gén., ix, 430, 1857; ? plemyrata FELder, Reise Nov., pl. 132, f. 15, 1874.

\section{MESOLEUCA Hübner.}

HüBner, Verz. bek. Schmett., 326, 1818; Hulst, Trans. Am. Ent. Soc., xxiii, 282, 1896; Glaucopteryx HüBner, Packard, C. 66; Melanthia Duponchel, Hist. Nat., viii, 252, 1829; Borsduval, Gen. Ind., 216, 1840; Stephens, List. Ins. Br. Mus., 213, 1850; Camptogramma Stephens, Ill., iii, 263, 1831; Guenée, Spec. Gén., ix, 422, 1857; Walker, Cat. Brit. Mus., xxv, 1323, 1862; Westwood \& Humphreys, Brit. Moths, ii, 51, 1849.

3371. ruficilliata Guenée, Spec. Gén., ix, 382, 1857; Packard, C. 153; Emmons, Nat. Hist. N.Y. Agr., v, 249,1854 .

3372. gratulata Walker, Cat. Brit. Mus., xxv, 1273 , 1862; Packard, C. 166; Hulst, Ent. News, vi, 43,1895 .

syn. brunneicitiata PACKARD, Sixth Rept. Peab. Acad. Sci., 42, 1874; C. 152.

3373. cæsiata Denis \& Schiffervüller, Syst. Verz. Wien, 112, 1776; Borkhausen, Eur. Schmett., v, 351, 1794; Packard, C. 67; Kirby, Eur. Butt., 383, 1882; Möschlek, Stett. ent. Zeit., 122, 1883; Verh. zool.-bot. Ges. Wien, 305, 1884; Butler, Pap., i, 222, 1881; Hofmann, Gr. Schm. Eur., 205, 1894; Grote, Bull. Geol. Surv. Terr., Hayden, vi, 591, 1882.

syn. cæsaria Freyer, infrequentata HaworTH, aurata PACKARD.

$$
\text { No. S. }
$$

Pac. States.

No. U. S., Eur. 
a. annosata Zetterstedt, Ins. Lap., 962, 1840.

b. glaciata Germar, Faun. Ins. Eur., xv, f. 18, 1835; Zetterstedt, Ins. Lap., 959, 1840.

c. gelata Guenée, Spec. Gén., x, 271, 1857.

d. inventaria Grote, Bull. Geol. Surv. Terr., Hayden, vi, 591, 1882.

3374. lacustrata Guenée, Spec. Gén., ix, 395, 1857 ; Packard, C. 158.

No. U. S.,

Eur.

3375. implicata Guenée, Spec. Gén., x, 284, 1857; PACKARD, C. 71.

Cal.,

Wis.

syn. multilineata PACKARD.

3376. intermediata Guenée, Spec. Gén., x, 395, 1857; Packard, C. 157; Dyar, Psyche, viii, 438, 1899.

*3377. brunneomaculata BAtes, Can. Ent., xviii, 74, 1886.

3378. variata Denis \& Schiffermüller, Syst. Verz. Wien, 110, 1776; Staudinger \& Rebel, Cat. Lep. Eur., i, no. 3306, 1901; Dyar, Proc. Wash. Acad. Sci., ii, 495, 1900.

3379. truncata Hufnagel, Berl. Mag., iv, 602, 1769; Packard, C. 105; Staudinger \& Rebel, Cat. Lep. Eur., i, no. 3319, 1901; STrecker, Surv. Dept. Mo., suppl., 1864, 1878.

syn. centumotata Schulz, mesata Denis \& SCHIFFERMÜLler, mesaria HerrichSCHAEFFER, commanotata HAwORTH, staurata STePhens, ? infuscata TengströM, Cat. 30, 320, 1869; mulleolata Huls'r, Bull. Brook. Ent. Soc., iv, 26, 1881; ? transversata Kellicott, Bull. Buff. Soc., v, 45, 1886; Hulst, Ent. News, vi, 106, 1895 (type lost). a. brunneata PAckard, Proc. Bost. Soc. Nat. Hist., xi, 47. 1861; C. 108.

b. suspectata Möschler, Stett. ent. Zeit., xxv, 160, 1874; xxxv, 121, 1884; PaCkard, C. 130.

3380. immanata Haworth, Lep. Brit., 323, 1810; Staudinger \& Rebel, Cat. Lep. Eur., i, no. $3320,1901$.

syn. atrifasciata Hulst, Ent. Amer., iii, 214, 1887; Ent. News, vi, 43, 1895.

a. marmorata Haworth, Lep. Brit., 324, 1810. syn. amenata STEPHENs, passeraria FreYer, ? citrata LINNæUS.

b. unicolorata Staudinger, Cat. Lep. Eur., 184, 1871.

Atl.

States.

Mass.

Alaska, Eur.

No. U. S., Eur.

No. U.S., Eur. 
3381. silaceata HüBner, Samml. ausser. Schmett. u. Vögel, 100, 1793; Staudinger \& Rebel, Cat. Mont., Lep. Eur., i, 307, 1901.

a. deflavata Staudinger, Cat. Lep. Eur., 191, 1871: Stett. ent. Zeit., 122, 1883; МöschLER, Verh. zool.-bot. Ges. Wien, 306, 1884.

3382. albolineata Packard, Fifth Rept. Peab. Acad., 55,1873 ; C. 120.

3383. hersiliata Guenée, Spec.Gén., x, 464, 1857; PACKARd, C. 111; Hulst, Ent. News, vi, 43, 1895. Eur.

syn. Alammifera Walker, Cat. Brit. Mus., xxiv, $1184,1862$.

*3384. ethela Hulst, Trans. Am. Ent. Soc., xxiii, 283 , 1896.

3385. abacta Hulst, Can. Ent., xxx, 117, 1898.

No. Atl.

States.

Col.

3386. vasaliata Guenée, Spec. Gén., x, 407, 1857; Packard, C. 167; Hulst, Ent. News, vi, 103 , 1895 .

syn. rigidata WALKer, Cat. Brit. Mus., xxvi, 1727, 1862; PACKARD, C. 133.

a. niveifascia Hulst, Can. Ent., xxx, 115, 1898; Jn. N. Y. Ent. Soc., viii, 216, 1901.

HYDRIOMENA Hübner.

Hübner, Verz. bek. Schmett., 322, 1818; Packard, C. 90; Meyrick, Proc. Linn. Soc. N. S. Wales, ii, 819, 1887; Trans. Ent. Soc. Lond., 72, 1892; Hulst, Trans. Am. Ent. Soc., xxiii, 283, 1^96; Euphyia HüBner, ?Perizoma HüBNer, ?Eutephria HüвNer, Chloroclysta HüBner, Dysstroma HüBner, Verz. bek. Schmett., 333, 1818 ; Harpalyce Stephens, Ypsiptes Stephens, Emmelesia Stephens, Cat. ii, 147, 1829; Mrsia Stephens, Polyphrasia Stephens, Euthalia Stephens, Thera Stephens, Ills., iii, 271, 1831; Phasyle Duponchel, Cat. Méth., 254, 1844; Ceratodalia Packard, C.' 322 .

3387. sordidata Fabricius, Erit. Syst., 185, 1794; PACKARD, C. 96; Möschler, Verh. zool.-bot. Ges. Wien, 306, 1884; Hofmann, Gr. Schm. Eur., 209, 1894.

syn. rectangulata FABRICIUS, bicolorata BORKHAUSEN, birivata BORKHAUSEN.

a. elutata HüBner, Schmett. Eur., 224, 1820?; Staudinger \& Rebel, Cat. Lep. Eur., i, no. 3485a, 1901.

b. nubilifasciata Packard, Proc. Bost. Soc. Nat. Hist., xiii, 398, 1871; C. 98.

c. quinquefasciata Packard, Proc. Bost. Soc. Nat. Hist., xiii, 379, 1871.

d. viridata Packard, Proc. Bost. Soc. Nat. Hist., xvi, 21, 1874.

e. bistriolata Zeller, Verh. zool.-bot. Ges. Wien, xxii, 493, 1873: PaCKaRd. C. 94.

$f$. glaucata Packard, Proc. Bost. Soc. Nat. Hist., xvi, 20, 1876.

No. U.S., Eur. 
3388. autumnalis Strömeyer, Kgl. Vid. Skr.-Sel., 85, 1783; Staudinger \& Rebel, Cat. Lep. Eur., i, no. $3486,1901$.

syn. trifasciata Borkhausen, impluviata Denis \& Schiffermüller, Syst. Verz. Wien, 109, 1776 (not desc.); pluviata Guenée, divisaria Walker, Cat. Brit. Mus., xxi, 489, 1860; renunciata W ALKER, Cat. Brit. Mus., xxv, 1187, 1862; frigidata W ALKER, Cat. Brit. Mus., xxv, 1729, 1862; Hulst, Ent. News, xi, 43, 1895.

3389. pernotata Hulst, Can. Ent., xxx, 117, 1898.

3390. tæniata STEPHens, Ills., iii, 299, 1831; STAUDInger \& Rebel, Cat. Lep. Eur., i, no. 3324, 1901; Hulst, Ent. News, vi, 103, 1895.

syn. arctata ZELLER, arctaria HERRICHSCHAEFFER, albimacularia Freyer, explagiata Walker, Cat. Brit. Mus., xxv, 1728, 1862; PACKARD, C. 133; basaliata W ALKER, Cat. Brit. Mus., xxv, 1184, 1862; PACKARD, C. 154; fulvida Butler.

3391. californiata Packard, Proc. Bost. Soc. Nat. Hist., xiii, 396, 1871; C. 94.

*3392. speciosata Packard, Proc. Bost. Soc. Nat. Hist., xvi, 22, 1874; C. 102.

*3393. reflata Grote, Can. Ent., xiv, 186, 1882.

3394. similaris Hulst, Trans. Am. Ent. Soc., xxiii, $284,1896$.

3395. contracta Packard, Fifth Rept. Peab. Acad., 56, 1873; C. 89.

*3396. sparsimacula Hulst, Trans. Am. Ent. Soc., xxiii, $285,1896$.

3397. banavahrata STrecker, Lep. Rhop. Het., suppl. 2, 11, 1899 .

3398. occidens Hulst, Can. Ent., xxx, 180, 1898.

*3399. herbicolata Hulst, Trans. Am. Ent. Soc., xxiii, $285,1896$.

*3400. floridata W Alker, Cat. Brit. Mus., xxv, 1719, 1862; Hulst, Ent. News, vi, 105, 1895 (type lost).

3401. multiferata W ALKER, Cat. Brit. Mus., xxv, 1715, 1862; Packard, C. 81.

3402. latirupta WALKer, Cat. Brit. Mus., xxxv, 1684, 1866; PaCkard, C. 169; Hulst, Ent. News, vi, 43,1895 .

syn. lascinata Zeller, Verh. zool.-bot. Ges. Wien, 205, 1873.

Pac. States, Ariz., Mont.

Tex., Cal., Ariz.

Rocky Mts.

Col.,

Nev.

Me.

Cal.

Cal.

Oreg.

Cal.

Fla.

No.

U. S.

U. S. 
*3403. curvilinea Hulst, Trans. Am. Ent. Soc., xxiii, 286,1896 .

*3404. immediata Grote, Can. Ent., xiv, 184, 1882 (type lost).

3405. costiguttata Hulst, Trans. Am. Ent. Soc., xxiii, $286,1896$.

3406. custodiata Guenée, Spec. Gén., ix, 491; 1857; Walker, Cat. Brit. Mus., xxv, 1438, 1862; Hulst, Ent. News, vi, 104, 1895.

syn. gueneata PACKARD, C. 141.

*3407. excurvata Grote, Can. Ent., xv, 123, 1883.

syn. gueneata PACKARD, C. 323.

*3408. mirabilata Grote, Can. Ent., xv, 123, 1883.

*3409. unangulata Наworth, Lep. Brit., 332, 1829; Packard, C. 159; Hofmann, Gr. Schm. Eur., 207, 1894; Hulst, Ent. News, vi, 70, 1896.

syn. unangularia Herrich-Schaeffer, congregata W ALKER, Cat. Brit. Mus., xxv, 1264, 1862.

*3410. amorata Hulst, Can. Ent., xxxii, 104, 1900.

3411. neomexicana Hulst, Trans. Am. Ent. Soc., xxiii, $285,1896$.

3412. grandiosa Hulst, Can. Ent., xxx, 118, 1898.

3413. australata Hulst, Ent. Amer., i, 205, 1886.

*3414. albata Hulst, Trans. Am. Ent. Soc., xxiii, 284, 1896.

*3415. elisata Strecker, Lep. Rhop. Het., suppl. 2, 11, 1899.
Brit. Col.

N. Y.

Cal., Oreg.

Pac. States, Rocky Mts.

Mont., B. C.

Rocky Mts. U. S., Eur.

Cal. Rocky Mts., Cal., Fla. Fla., Ariz .

Fla.

Ariz.

Atl. States.

\section{TRIPHOSA Stephens.}

Stephens, Cat., 44, 1829; Packard, C. 177; v. Gumppenberg, Nov. Act. Halle, lii, 129, 1888; Hofmann, Gr. Schm. Eur., 199, 1894; Hulst, Tr. Am. Ent. Soc., xxiii,
287, 1896.

3416. dubitata Linneus, Syst. Nat., 524, 1758; PaCKard, C. 177; Staudinger \& Rebel, Cat. Lep. Eur., i, no. 3259, 1901.

No. Atl. States, Eur.

3417. progressata WALKER, Cat. Brit. Mus., xxv, 1348, 1862; Butler, Pap., i, 223, 1881; Hulst, Ent. News, vi, 43, 1895 .

syn. indubitata Grote, Bull. U. S. Geol. Surv. Terr., vi, 591, 1882; dubitata PACKaRd (not Linneus), C. 177; Haryey, Bull. Buff. Soc., i, 264, 1874; Möschler, Verh. zool.-bot. Ges. Wien, 301, 1884.

a. pustularia Hy. Edwards, Ent. Amer., i, 50,
No. Pac States. 


\section{CENOCALPE Hübner.}

HüBner, Verz. bek. Schmett., 330, 1818; Hulst, Trans. Am. Ent. Soc., xxiii, 287, 1896: Corythea Duponchel, Cat. Méth., 257, 1844; Stammodes Guenée, Spec. Gén., ix, 515, 1857; v. Gumppenberg, Nov. Act. Halle, lxix, 345, 1887.

3418. aurata Grote, Can. Ent., xiv, 186, 1882.

Rocky Mts.

3419. magnoliata Guenée, Spec. Gén., ix, 455, 1857; U. S.

Hy. Edwards, Proc. Cal. Acad. Sci. vi, 89, 1875; Packard, C. 70; Moffat, Can. Ent., xvi, 38, 1884; Hulst, Ent. News, vi, 70, 1895.

syn. ziczacata W ALKer, Cat. Brit. Mus., xxv, 1185, 1862; placidata Walker, Cat. Brit. Mus., xxv, 1186, 1862; quadripunctata Packard, Proc. Bost. Soc. Nat. Hist., xiii, $402,1871$.

a. cumatilis Grote \& Robinson, Ann. N. Y. Lyc. Nat. Hist., viii, 460, 1867; Grote, Can. Ent., xvi, 38, 1884; Packard, Proc. Bost. Soc. Nat. Hist., xvi, 20, 1874.

*3420. oxygramma Hulst, Trans. Am. Ent. Soc., xxiii, $288,1896$.

3421. carnata Packard, Sixth Rept. Peab. Acad. Sci., 43, 1874; Proc. Bost. Soc. Nat. Hist., xvi, pl. 1, f. 9,1874 .

syn. carneata PACKard, C. 142.

*3422. phlebeculata Guenée, Spec. Gén., ix, 419, 1857; Walker, Cat. Brit. Mus., xxv, 1309, 1862; Packard, C. 149; Hulst, Ent. News, vi, 104, 1895 (type lost).

3423. alaskæ Hutst, Trans. Am. Ent. Soc., xxiii, 287, 1896.

3424. parinotata ZeLLer, Verh. zool.-bot. Ges. Wien, xxii, 495, 1872; Packard, C. 155.

3425. polygrammata Hulst, Trans. Am. Ent. Soc., xxiii, 288, 1896.

3426. gibbocostata Walker, Cat. Brit. Mus., xxv, 1388, 1862; Hulst, Ent Am., iii, 9, 1887; Ent. News, vi, 42, 1895.

syn. costinotata Walker, Cat. Brit. Mus., xxv, 1701, 1862; strigularia Minot; PACKARD, C. 170; Winn, Can. Ent., xxiii, 97, 1891; seneiformis HaRver, Buff. Bull., i, 265, 1873 .

*3427. annellata Hulst, Ent. Amer., ii, 191, 1887.

*3428. morrisata Hulst, Ent. Amer., ii, 190, 1887.

*3429. cœnonymphata Hulst, Can. Ent. xxxii, 104, 1900.

Cal.

Pac. States.

Cal.

Alaska.

Tex.,

Fla.

Rocky

Mts.

Atl.

States.

Pac. States.

Ariz.

Col.,

Cal.

3430. fervifactaria Grote, Pap., i, 177, 1881.

Rocky Mts. 
3431. formosata Strecker, Surv. Dept. Mo., Ruffner, Rocky app., $1864,1878$. Mts.

syn. dryadata Hulst, Bull. Brook. Ent. Soc., iii, 43, 1880; sponsata Grote, Can. Ent., xiv, $215,1882$.

*3432. seifertii Neumoegen, Pap., ii, 125, 1882.

Ariz.

3433. tessellata Packard, Rept. Geol. Surv. Terr., v, 522, $1873 ;$ C. 261 .

Ariz.

3434. topazata Strecker, Lep. Rhop. Het., suppl. 2, Rocky Mts., 9, 1899 .

Alaska.

EMPLOCIA Herrich-Schaeffer.

Herrich-Schafffer, Ausser. Schmett., 34, 1855; Hulst, Trans. Am. Ent. Soc., xxiii, 288,1896 .

3435. inconstans GEYer, Zuträge Exot. Schmett., f. 861,1825 .

N. Mex., Ariz.

syn. cephisaria Grote, Pap., i, 177, 1881; Hulst, Trans. Am. Ent. Soc., xxiii, 289, 1896.

MARMOPTERYX Packard.

- Packard, Rept. Geol. Surv. Terr., v, 552, 1873; C. 259; Hulst, Trans. Am. Ent. Soc., xxiii, 289, 1896; Marmoroptery $x$ v. Gumppenberg, Nov. Act. Halle, xlix, 332, 1887.

3436. marmorata Packard, Proc. Bost. Soc. Nat. Hist., Rocky Mts., xiii, 393, 1871; C. 260.

Cal.

*3437. odonata Hulst, Trans. Am. Ent. Soc., xxiii, Col. $289,1896$.

\section{GYPSOCHROA Hübner.}

Hübner, Verz. bek. Schmett., 336, 1818; v. Gumppenberg, Nov. Act. Halle, xlix, 368, 1887; Hulst, Trans. Am. Ent. Soc., xxiii, 290, 1896; Cidaria Treitschke, Schm. Eur., vi, 2, 242, 1828; Meyrick, Trans. Ent. Soc. Lond., 211, 1886; HofMANn, Gr. Schm. Eur., 201, 1894.

3438. designata Hufnagel, Berl. Mag., iv, 612, 1769: Packard, C. 144; Möschler, Verh. zool. U. S., bot. Ges. Wien, 304, 1884; Goodell, Can. Eur. Ent., xii, 235, 1880; Hofmann, Gr. Schm. Eur., $205,1894$.

syn. propugnata Denis \& SCHIfFermüLLER, propugnaria TREITschKe.

3439. sitellata Guenée, Spec. Gén., x, 298, 1857; Walker, Cat. Brit. Mus., xxv, 1210, 1862.

syn. hasitata Guenée, Spec. Gén., x, 444, 1857; Hulst, Ent. News, vi, 43, 1895; Dyar, Psyche, ix, 59, 1900; impauperata W ALKER, Cat. Brit. Mus., xxv, 1363, 1862; albosignata Packard, Fifth Rept. Peab. Acad., 61, 1873; C. 174 ; v. Gumpeenberg, Nov. Act. Halle, lii, 141, 1888. 


\section{EURHINOSEA Packard.}

Packard, Proc. Bost. Soc. Nat. Hist., xvi, 34, 1873; Hulst, Trans. Am. Ent. Soc., xxiii, 290, 1896.

*3440. flavaria Packard, Proc. Bost. Soc. Nat. Hist., Cal. xvi, 35, 1873 .

syn. flavata Packard, C. 129.

*3441. leoninata Packard, Proc. Bost. Soc. Nat. Hist., xiii, 401, 1871; C. 119; Hulst, Ent. News, vi, 104,1895 .

*3442. mancipata Guenée, Spec. Gén, x, 468, 1857; Packard, C. 113; Hulst, Ent. News, vi, 104, 1895 .

syn. subochreata Pack ard, Proc. Bost. Soc. Nat. Hist., xiii, 400, 1871.

\section{PSYCHOPHORA Curtis.}

Cuntis, App. Ross Second Voy., 73, 1835; Hulst, Trans. Am. Ent. Soc., xxiii, 290, 1896.

3443. sabinii Curtis, App. Ross Second Voy., 73, 1835; Hulst, Trans. Am. Ent. Soc., xxiii, 290, 1896; Greenl., Ent. News, vi, 70, 1895. Lab.

syn. frigidaria Guenée, Spec. Gén., x, 269, 1857; phocata Möschler, Wien. ent. Mon., vi, 9, 1862; PACKARD, C. 76; sabinaria PACKARD, C. 75 .

a. polaris HuLst (both wings uniform brownish gray, the fore wings darker).

b. immaculata SkInner, Proc. Acad. Nat. Sci. Phil., 159, 1892; Hulst, Ent. News, vi, 70, 1895 .

3443. 1. fasciata SkInner, Ent. News, xiii, 141, 1902.

Alaska.

TRICHOCHLAMYS Hulst.

Hulst, Trans. Am. Ent. Soc., xxiii, 291, 1896.

*3444. polata HüBNER, Zutr. exot. Schmett., f. 805 , 1825; Staudinger, Stett. ent. Zeit., 395, 1861; Packard, C. 73; Möschler, Verh. zool.-bot. Ges. Wien, 305, 1884; Hofmann, Gr. Schm. Eur., 205,1894 .

syn. polaria Herrich-SCHAEFFER, Eur. Schmett., iii, 162, 1847; Christoph, Wien. ent. Mon., 313, 1858; Hulst, Ent. News, vi, 106, 1895; punctipes Curtis, App. Ross Second Voy., 73, 1835.

a. brullei Lefèbre, Ann. Soc. Ent. Fr., 399, 1836;

STAUdinger, Stett. ent. Zeit., 306, 1857;

Walker, Cat. Brit. Mus., xxv, 1284, 1862.

3445. lacteata PACKaRd C. $143,1876$.

Pac. States. 
ERSEPHILA Hulst.

Hulst, Trans. Am. Ent. Soc., xxiii, 291, 1896.

3446. grandipennis Hulst, Trans. Am. Ent. Soc., xxiii, $291,1896$.

Pac. States, Col.

3447. indistincta Hulst, Can. Ent., xxx, 119, 1898.

Pac. States, Col.

\section{PETROPHORA Hïbner.}

Hübner, Tentamen, 1810; Packard, C. 103; Hulst, Trans. Am. Ent. Soc., xxiii, 292, 1896; Xanthorhoe HüBner, Verz. bek. Schmett., 327, 1818; Meyrick, Proc. Linn. Soc. N. S. Wales, ii, 862, 1887; Trans. Ent. Soc. Lond., 76, 1892; Calostygia HüBner, Melamydris Hü Bner, Plerocymia HüBner, Amøba HüBner, Ochyria HüBner, Onychia Hübner, Scotopteryx Hübner, Ortholitha Hübner, Mesotype Hübner, Verz. bek. Schm., 328-338, 1818; v. Gumppenberg, Nov. Act. Halle, lii, 142, 1888; Eubolia Duponchel, Hist. Nat., viii, 162, 1829; Larentia Duponchel, Hist. Nat., viii, 358, 1829; Meyrick, Tr. Linn. Soc. N. S. Wales, 77, 1883; Zerynthia Curtis, Brit. Ent., vii, 296, 1830; Cymazonita Sodoffsky, Bull. Imp. Soc. Mosc., 126, 1837; Eusebia Duponchel, Cath. Méth., 249, 1844; Coremia Guenée, Spec. Gén., x, 408, 1857; Walker, Cat. Brit. Mus., xxv, 1304, 1862.

*3448. volucer Hulst, Trans. Am. Ent. Soc., xxiii, 293, 1896.

Rocky Mts.

*3449. incursata HüBner, Schmett. Eur., f. 351, 1803; Staudinger \& Rebel, Cat. Lep. Eur., i, no. No. U. S., $3361,1901$. Eur.

syn. disceptaria Fischer, incursaria HerrichSchaeffer, decrepitata Zetterstedt, decrepitaria HerRICH-SCHAEFFER, Schm. Eur., iii, 159, 1847; polygrapharia BorsDuval, Ind. Méth., 203, 1840, Guenée, Spec. Gén., x, 282, 1857.

*3450. abrasaria Herrich-Schaeffer, Neu. Schmett., 27, vi, 137, 1856; PACKard, C. 139; Möschler, Verh. zool.-bot. Ges. Wien, 304, 1884.

syn. ligularia Guenée, baicalcata Bremer, nigrofasciata PACKARD.

No. U. S., Eur.

*3451. illocata Hulst, Trans. Am. Ent. Soc., xxiii, 293 , 1896.

3452. borealis Hulst, Trans. Am. Ent. Soc., xxiii, 292, 1896.

3453. nemorella Hulst, Trans. Am. Ent. Soc., xxiii, $293,1896$.

3454. glacialis Hulst, Can. Ent., xxx, 119, 1898.

Or., Alaska.

Alaska.

Pac. Coast.

Alaska. a. longula Hulst, Can. Ent., xxx, 119, 1898; Dyar, Can. Ent., xxx, 203, 1898.

*3455. algidata Möschler, Stett. ent. Zeit., xxxv, 162, 1874; xliv, 121, 1883; Packard, C. 150.
Lab. Anticosti. 
3456. munitata HüBNer, Schm. Eur., f. 346, 1803; Staudinger \& Rebel, Cat. Lep. Eur., i, no. $3327,1901$.

syn. munitaria Herrich-SCHAEFFER, Eur. Schmett., iii, 167, 1847; PACKARD, C. 136; decoloraria EsPER, arcticaria GERMAR, collinaria Metzner, Stett. ent. Zeit., 238, 1846; strigata PACKARD, californiata PACKARD,

a. labradorensis Packard, Proc. Bost. Soc. Nat. Hist., xi, 46, 1867; Möschler, Verh. zool.bot. Ges. Wien, 302, 1884.

*3457. ferrugata Clerck, Icones, vi, 14, 1759; STAUDinger \& Rebel, Cat. Lep. Eur., i, no. 3369, 1901.

syn. ferrugaria Borkhausen; Packard, C. 146; unidentaria HaworTH.

3458. spadicearia Denis \& Schiffermüller, Syst. Verz. Wien, 113, 1776; Staudinger \& Rebel, Cat. Lep. Eur., i, no. 3369, 1901.

syn. fermugata HüBner (not ClereK), ferrugaria HaworTH (not BorkHAUsen), alchenillaria EsPER, freyeraria STAUDANGER, Cat. Lep. Eur., no. 524, 1861.

3459. montanata Denis \& Schiffermüller, Syst. Verz. Wien, 113, 1776; Staudinger \& Rebel, Cat. Lep. Eur., i, no. 3363, 1901.

syn. montanaria TreitschKe, implicata VILLIERs, ocellata FABricius.

a. lapponica Staudinger, Cat. Lep. Eur., 186, 1871; Möschler, Verh. zool. -bot. Ges. Wien, 303, 1884 .

*3460. convallaria Guenée, Spec. Gén., x, 410, 1857; Packard, C. 149; Hulst, Ent. News, vi, 104 , 1895 .

3461. defensaria Guenée, Spec. Gén., x, 411, 1857; PACKARD, C. 149.

*3462. anticostiata STRECKER, Lep. Rhop. Het., suppl. 2, 11, 1899 .

3463. fluctuata Linn eus, Syst. Nat., 527, 1758; PACKArd, C. 155; Staudinger \& Rebel, Cat. Lep. Eur., i, no. 3344, 1901; Hulst, Ent. News, vi,

No. U. S., Eur.

No. U. S.,

Eur.
No. U. S., Eur.

$$
\text { , }
$$


LOXOFIDONIA Packard.

Packard, C. 223; Hulst, Trans. Am. Ent. Soc., xxiii, 294, 1896; Thyone Merrick, Trans. N. Zeal. Ins., xvi, 61, 1883; Asaphodes Meyrick, Trans. N. Zeal. Ins., xviii, 184, 1885; Trans. Ent. Soc. Lond., 76, 1892.

*3464. acidaliata Packard, Sixth Rept. Peab. Acad. Col. Sci., 48, 1874; C. 224; Strecker, Surv. Dept. Mo., suppl., 1862, 1878.

Subfamily MONOTAXIINAE.

MONOTAXIS Hulst.

Hulst, Can. Ent., xxx, 120, 1898.

3465. semipectinata Hulst, Can. Ent., xxx, 120, 1898.

Ariz.

Subfamily MONOCTFNIIN AE.

SYNOMILA Hulst.

Hulst, Trans. Am. Ent. Soc., xxiii, 295, 1896.

3466. subochreata Hulst, Ent. Amer., ii, 187, 1887.

PAOTA Hulst.

Rocky Mts., Oreg.

Hulst, Trans. Am. Ent. Soc., xxiii, 295, 1896.

*3467. fultaria Grote, Can. Ent., xiv, 174, 1882.

\section{HAMATOPSIS Hübner.}

HüBner, Verz. bek. Schmett., 301, 1818; Packard, C. 218; Hulst, Trans. Am. Ent. Soc., xxiii, 295, 1896.

3468. grataria FABRicius, Ent. Syst., suppl., 112, 1798; Packard, C. 219; Riley, Rept. Ins. Mo., i, 179, Atl. 1869; Bowles, Can. Ent., xv, 165, 1883; Dyar, States. Psyche, ix, 155, 1901.

syn. saniaria HüBNER, successaria WALKER, Can. Nat., v, 262, 1862; Cat. Brit. Mus., xxv, 1617, 1862; Grote, Can. Ent., ix, 29, 1878.

Subfamily STFRRHINAE.

\section{ERASTRIA Hïbner.}

HüBner, Tentamen, 1810; Calothysanis HüBner, Verz. bek. Schmett., 301, 1818; Meyrick, Trans. Ent. Soc. Lond., 91, 1892; Hulst, Trans. Am. Ent. Soc., xxiii, 297, 1896; Timandra Duponchel, Bradypeies Stephens; Packard, C. 316.

3469. amaturaria WALker, Cat. Brit. Mus., xxxv, Atl. 1634, 1866; PaCKARD, C. 317; Ins. Life, iv, 382, States. 1892; Kellicotт, Can. Ent., xxiv, 242, 1892.

*3470. viridipennaria Guenée, Spec. Gén., x, 3, 1857; Hulst, Ent. News, vi, 104, 1895. 


\section{PIGIA Guenée.}

Guenée, Spec. Gén., x, 19, 1857; Hulst, Trans. Am. Ent. Soc., xxiii, 297, 1896.

*3471. multilineata Hulst, Ent. Amer., ii, 188, $1887 . \quad$ Ariz.

\section{EUACIDALIA Packard.}

Packard, Fifth Rept. Peab. Acad., 69, 1873; C. 318; Hulst, Trans. Am. Ent. Soc., xxiii, 298, 1896.

3472. sericeata PACkARd, Fifth Rept. Peab. Acad., 69, 1873; C. 318.

Fla. to Ariz.

\section{PROSOPARIA Grote.}

Grote, Can. Ent., xv, 130, 1883; Hulst, Trans. Am. Ent. Soc., xxiii, 298, 1896.

*3473. perfuscaria Grote, Can. Ent., xv, 130, 1883.

Ariz.

\section{MYCTEROPHORA Hulst.}

Hulst, Trans. Am. Ent. Soc., xxiii, 298, 1896.

*3474. monticola Hulst, Trans. Am. Ent. Soc., xxiii, $299,1896$.

Cal.

*3475. longipalpata Hulst, Trans. Am. Ent. Soc., xxiii, $299,1896$.

Cal.

*3476. slossoniæ Hulst, Can. Ent., xxx, 120, 1898.

N. H., Man.

DEPTALIA Hulst.

Hulst, Trans. Am. Ent. Soc., xxiii, 299, 1896.

3477. insularia Guenée, Spec. Gén., ix, 469, 1857; Packard, C. 335; Hulst, Ent. Amer., iii, 175, Atl. 1887; Ent. News, vi, 71, 1895.

States.

syn. asthenaria WALKER, Cat. Brit. Mus., xxii, 737, 1861; invariata WALKER, Cat. Brit. Mus., xxv, 1596, 1862; imparata Walker, Cat. Brit. Mus., xxv, 1598, 1862 . persimilata Grote.

\section{COSYMBIA Hübner.}

Hübner, Verz. bek. Schmett., 302, 1818; Cyclophora Hüвner (not Montfort), Tentamen, 1810; Hulst, Trans. Am. Ent. Soc., xxiii, 300, 1896; Leucophthalmia HüBner, Verz. bek. Sch., 302, 1818; Meyrick, Trans. Ent. Soc. Lond., 91, 1892; Codonia HüBner, Verz. bek. Schmett., 302, 1818; Pyctis HüBner, Verz. bek. Schmett., 309, 1818; Ephyra Duponchel, Hist. Nat., viii, 20, 1829; Pack ARD, C. 361; Zonosoma Lederer, Verh. zool.-bot. Ges. Wien, 194, 1853.

3478. culicaria Guenée, Spec. Gén., ix, 407, 1857; So. Atl. Packard, C. 365; Hulst, Ent. Amer., ii, 221, States. 1887; Ent. News, vi, 72, 1895, 
3479. myrtaria Guenée, Spec. Gén., ix, 408, 1857 ; Packard, C. 364; Goodell, Can. Ent., ix, 62, 1877; Hulst, Ent. News, vi, 70, 1896.

syn. ignotaria WALKer, Cat. Brit. Mus., xxv, 1576,1862 .

3480. lumenaria HüBNER, Zutr. exot. Schmett., f. 757 , 1832; Packard, C. 365; Hulst, Ent. News, vi, 106,1895 .

syn. pendulinaria Guenée; Packard, C. 363; quadriannulata WaLker, Cat. Brit. Mus., Xxv, $1595,1862$.

*3481. umatillaria Strecker, Lep. Rhop. Het., suppl. 2, 9, 1899.

3482. serrulata PACKARd, Fifth Rept. Peab. Acad. Sci., 73, 1873; C. 366.

*3483. dataria Hulst, Ent. Amer., ii, 186, 1887.

Atl. States.

Fla.

Atl. States, Ariz.

Cal.

Atl. States.

Atl. States.

syn. tremularia Walker, Cat. Brit. Mus., XXV, 1614, 1862; purpurissata GRoTe.

SYNELYS Hulst.

Hulst, Trans. Am. Ent. Soc., xxiii, 300, 1896.

3486. alabastaria HüBNER, Zutr. exot. Schmett., ii, f. 311, 1825?; Hulst, Ent. News, vi, 72, 1895, vi, $106,1895$.

syn. reconditaria WALKER, Cat. Brit. Mus., xxiii, 786, 1861; Packard, C. 357; Grote, Trans. Am. Ent. Soc., ii, 82, 1868; Hulst, Ent. News, vi, 72, 1895; ennucleata PACKard (not Guenée), C. 347; Goodell, Can. Ent., xi, 194, 1879; Can. Ent., xii, 236, 1880.

3487. ennucleata Guenée, Spec. Gén., ix, 505, 1857; Hulst, Ent. News, vi, 72, 1895; Dyar, Psyche, ix, 165,1901 .

syn. restrictata WaLKer, Cat. Brit. Mus., xxii, 722, 1861; mensurata W ALKER, Cat. Brit. Mus., xxxv, 1621, 1866; continuaria Walker, Cat. Brit. Mus., xxxv, 1622, 1866.

*3488. pergracilis Hulst, Can. Ent., xxx, 121, 1898.

*3489. nigrocandida Hulst, Can. Ent., xxx, 121, 1898.

Atl. States.

Atl. States, Rocky Mts.

Fla.

Fla. 
*3490. timandrata Walker, Cat. Brit. Mus., xxii, 724, Fla. 1861; Packard, C. 355; Hulst, Ent. News, vi, 72,1895 .

syn. rufilineata Walker, Cat. Brit. Mus., xxiii, $783,1861$.

3491. ordinata WALker, Cat. Brit. Mus., xxii, 722, 1861; Packard, C. 565; Hulst, Ent. News, vi, 71,1895 .

syn. puraria WaLker, Cat. Brit. Mus., xxiii, 796, 1861; Hulst, Ent. News, vi, 71, 1895; candidaria PACKARD, C. 349.

3492. subquadrata Guenée, Spec. Gén., ix, 459, 1857; Walker, Cat. Brit. Mus., xxii, 729, 1861; Hulst, Ent. News, vi, 73, 1895.

syn. obluridata Hulst, Ent. Amer., ii, 185, 1887.

*3493. umbilicata Guenée, Spec. Gén., ix, 504, 1857; W Alker, Cat. Brit. Mus., 727, 1861; Hulst, Ent. News, vi, 72, 1895 .

syn. indoctaria W alker. Cat. Brit. Mus., xxii, 731, 1861.

\section{XYSTROTA Hulst.}

Hulst, Trans. Am. Ent. Soc., xxiii, 301, 1896.

3494. hepaticaria Guenée, Spec. Gén., ix, 471, 1857 ; Packard, C. 352; Hulst, Ent. Amer., ii, 222, 1887, iv, 49, 1888.

syn. rubromarginaria PACKARD, fermenimaria Zeller, Verh. zool.-bot. Ges. Wien, 478, 1873; PACKaRD, C. 360 ; rubromarginata PaCkard, C. 339.

WAUCHULA Hulst.

Hulst, Jn. N. Y. Ent. Soc., viii, 216, 1901.

3495. rubrotincta Hulst, Jn. N. Y. Ent. Soc., viii, 216, 1901.

U. S. Fla., Tex. So. States.

Fla.

Fla.
Tex.


3498. purata Guenée, Spec. Gén., ix, 488, 1857;

Walker, Cat. Brit. Mus., xxii, 720, 1861; PACK-

Atl. Ard, C. 353; Hulst, Ent. Amer., ii, 222, 1887. States. syn. cacuminata Morrison, cacuminaria PACKARD, C. 346.

*3499. compensata Walker, Cat. Brit. Mus., xxii, 724, 1861; Packard, C. 354.

Tex., Fla.

3500. ancellata Hulst, Ent. Amer., ii, 186, 1887. Rocky Mts. 3501. fuscata Hulst, Ent. Amer., ii, 187, 1887. Rocky Mts.

*3502. albidula Hulst, Trans. Am. Ent. Soc., xxiii, 301, 1896.

\section{SCELOLOPHIA Hulst.}

Hulst, Trans. Am. Ent. Soc., xxiii, 301, 1896.

*3503. formosa Hulst, Trans. Am. Ent. Soc., xxiii, 302, 1896.

Tex.

CHAROMMAT EA Hulst.

Hulst, Trans. Am. Ent. Soc., xxiii, 302, 1896.

*3504. ella Hulst, Trans. Am. Ent. Soc., xxiii, 302, 1896.

a. ellatina Hulst, Trans. Am. Ent. Soc., xxiii, $303,1896$.

Fla.

\section{LEPTOMERIS Hübner.}

Hübner, Verz. bek. Schmett., 310, 1818; MeYrick, Trans. Ent. Soc. Lond., 89, 1892; Hulst, Trans. Am. Ent. Soc., xxiii, 303, 1896; Craspedia HüBner, Verz. bek. Schmett., 312, 1818; Dosithea Duponchel, Hist. Nat., viii, 43, 1829.

3505. gemmata PaCkard, C. 320, 1876.

3506. lautaria HüBner, Zutr. exot. Schmett., 539, 1820 ?; Hulst, Ent. News, vi, 72, 1895.

syn. myrmidonata Guenée, Spec. Gén., ix, 487, 1857; PACKaRd, C. 353; minutularia Hulst, Bull. Brook. Ent. Soc., iii, 44, 1880.

*3507. occidentaria Packard, Proc. Bost. Soc. Nat. Hist., xvi, 29, 1874; C. 321.

syn. occidentata PACKARD.

*3508. roseotincta Hulst, Trans. Am. Ent. Soc., xxiii, 303, 1896.

3509. æmulata Hulst, Trans. Am. Ent. Soc., xxiii, 303, 1896.

3510. quinquelinearia PaCkard, Proc. Bost. Soc. Nat. Hist., 389, 1871; Rept. Geol. Surv. Terr., v, 554, 1873; C. 348; Butler, Pap., i, 221, 1881.
Rocky Mts. So. States.

Pac. States, Col.

Fla.

Fla.

U. S. 
3511. sentinaria HüBner, Zutr. exot. Schmett., f. 823, No. U. S. 1837; Packard, C. 342.

syn'. spuraria CHRIsTOPH, gracitior ButLer,

Ann. Mag. Nat. Hist., (6), xii, 18, 1893.

3512. magnetaria Guenée, Spec. Gén., ix, 450, 1857; Packard, C. 350; Hulst, Ent. Amer., ii, 222, 1886.

syn. mbrolinearia PACKARD, mibrolineata PaCkard, C. 343.

*3513. frigidaria Möschler, Wien. ent. Monat., iv, 44, 1860; Packard, C. 340; Hulst, Ent. News, vi, Aretic 71,1895 .

syn. defixaria WALKer, Cat. Brit. Mus., xxiii, 796, 1861; impauperata WALKer, Cat. Brit. Mus., xxv, 1363, 1862; ?arcticaria W ALKER, Cat. Brit. Mus., xxvi, 1594, 1862; Hulst, Ent. News, vi, 105, 1895 (type lost); okakaria PACKARD.

3514. ostentaria Walker, Cat. Brit. Mus., xxiii, 784, 1861; PACKARD, C. 355.

Pac. States.

Am.

Fla., Tex.

3515. plantagenaria Hulst, Ent. Amer., ii, 185, 1887. *3516. nigrodiscalis Hulst, Can. Ent., xxx, 158, 1898. Fla. to Ariz. Me.

*3517. placidaria Guenée, Spec. Gén., ix, 469, 1857; Packard, C. 352; Hulst, Ent. News, vi, 105 No. Am. 1895 (type lost).

\section{EOIS Hïbner.}

Hübner, Verz. bek. Schmett., 308, 1818; Packard, C. 319; Meyrick, Trans. Ent. Soc. Lond., 86, 1892; Hulst, Trans. Am. Ent. Soc., xxiii, 304, 1896; Arrhostia Hüвner, Verz. bek. Schmett., 311, 1818; Ptychopoda Stephens, Cat. 150, 1829; Hyria Stephens, Cat. 150, 1829; Guenée, Spec. Gén., ix, 428, 1857; Carphoxera Riley, Ins. Life, iv, 112, 1892.

3518. parvularia Hulst, Ent. Amer., iii, 213, 1887.

Tex.

3519. ptelearia RILEy, Ins. Life, iv, 112, 1892; iv, 271, U.S. 1892; v, 40, 1892; Wright, Ins. Life, v, 271, 1892.

*3520. scintillaria Hulst, Ent. Amer., i11, 213, 1887.

Fla.

3521. demissaria HüBner, Zutr. exot. Schmett., 563, U. S. 1825; PaCKARD, C. 351.

syn. ferrugata Packard, C. 321; Möschler, Verh. zool. -bot. Ges. Wien, 304, 1884; bonifata Hulst, Ent. Amer., ii, 187, 1886.

a. russata Hulst, Ent. Amer., ii, 187, 1886. syn. eremiata Hulst, Ent. Amer., ii, 187, 1886; ?inclusaria W alker, Cat. Brit. Mus., xxv, 1596, 1862; Hulst, Ent. News, vi, 105, 1895 (type lost). 
3522. purpurascens Hulst, Can. Ent., xxxii, 105, 1900. Fla.

*3523. hilliata Hulst, Ent. Amer., ii, 187, 1886. Fla.

*3524. flavescens Hulst, Trans. Am. Ent. Soc., xxiii, $304,1896$.

3525. lævitaria HüBNER, Zutr. exot. Schmett., f. 873, 1820 ?; Guenée, Spec. Gén., ix, 471, 1857; Walker, Cat. Brit. Mus., xxii, 719, 1861. syn. floridata PACKARD, C. 319.

3526. microphysa Hulst, Trans. Am. Ent. Soc., xxiii, $305,1896$.

So.

Cal.

*3527. delicata Hulst, Trans. Am. Ent. Soc., xxiii, 305, 1896.

3528. peralbata Packard, Fifth Rept. Peab. Acad. Sci., 70, 1873; C. 332; Strecker, Surv. Dept. Mo. Ruffner, app., 1862, 1878.

syn. longipennata PACKARD, Fifth Rept. Peab. Acad. Sci., 71, 1873; C. 332; Hulst, Ent. Amer., ii, 221, 1887.

3529. nimbicolor Hulst, Trans. Am. Ent. Soc., xxiii, $305,1896$.

syn. floridaria Hulst (not Packard), Ent. Amer., iii, 215, 1888; foridata Hulst, Trans. Am. Ent. Soc., xxiii, 306, 1896.

3530. ossularia HüBNer, Zutr. exot. Schmett., f. 909, 1837; Hulst, Ent. Amer., ii, 221, 1887; Ent. News, vi, 73, 1895.

syn. ossulata PACKARD. C. 329; temnaria Guenée; Packard, C. 352; sublataria Guenée, Spec. Gén., ix, 474, 1857; PackARD, C. 352; magniferaria W ALKER, Cat. Brit. Mus., xxiii, 784, 1861; Рackard, C. 356; favillifera WaLker, Cat. Brit. Mus., XXXv, 1624, 1866; PACKARD, C. 359; violacearia Walker, Cat. Brit. Mus., xxiii, 786, 1861; PACKARD, C. 357 ; repletaria WALKER, Cat. Brit. Mus., xxxv, 1624, 1866; PACKARD, C. 359 .

*3531. granitaria Packard, Proc. Bost. Soc. Nat. Hist., xiii, 390, 1871; C. 330.

3532. lanceolata Hulst, Trans. Am. Ent. Soc., xxiii, $305,1896$.

3533. balistraria Guenée, Spec. Gén., ix, 453, 1857; PACKARd, C. 351.

syn. perirrorata PACKARD, Fifth Rept. Peab. Acad. Sci., 71, 1873; C. 331.

N. Mex.

Tex.

Fla.

U. S.

Cal.

N. Mex., Cal., Fla.

So. States, Col., Ariz. 
*3534. rufescens Hulst, Trans. Am. Ent. Soc., xxiii, $305,1896$.

*3535. pallida Hulst, Trans. Am. Ent. Soc., xxiii, 306, 1896.

3536. eburneata GuenÉe, Spec. Gén., ix, 474, 1857; Walker, Cat. Brit. Mus., xxii, 734, 1861; Hulst, Ent. News, vi, 73, 1895.

syn. tacturata Walker, Cat. Brit. Mus., xxii,

721, 1861; PaCkard, C. 353.

3537. suavata Hulst, Jn. N. Y. Ent. Soc., viii, 217, 1901; Dyar, Psyche, ix, 106, 1900.

3538. lacteolata Lintner, Ent. Cont., iv, 112, 1878.

3539. obfusaria WaLker, Cat. Brit. Mus., xxiii, 786, 1861; Packard, C. 357.

syn. punctofimbriata PACKARD, Fifth Rept. Peab. Acad. Sci., 70, 1873; C. 333; Hulst, Ent. News, vi, 71, 1895.

*3540. crossii Hulst, Can. Ent., xxxii, 105, 1900.

*3541. volucrata Hulst, Ent. Amer., ii, 186, 1887.

*3542. quæsitata Hulst, Bull. Brook. Ent. Soc., iii, 45, 1880.

*3543. micropterata Hulst, Jn. N. Y. Ent. Soc., viii, $217,1901$.

*3544. rotundopennata PACKaRD, C. 337.

*3545. persimilis Hulst, Can. Ent., xxx, 158, 1898.

3546. inductata Guenée, Spec. Gén., ix, 494, 1857; Packard, C. 340; Hulst, Ent. News, vi, 71, 1895; Dyar, Psyche, ix, 226, 1901.

syn. consecutaria Walker, Cat. Brit. Mus., xxxv, 1623, 1866; РACKARD, C. 358; sobrid W AlKer, Cat. Brit. Mus., xxxv, 1624, 1866; PACKARD, C. 359; ? suppressaria WALKER, Cat. Brit. Mus., xxvi, 1594, 1862; Hulst, Ent. News, vi, 105, 1895 (type lost).

*3547. hanhamii Hulst, Can. Ent., xxx, 158, 1898. *3548. productata Packard, C. 334, 1876.

*3549. australis Hulst, Trans. Am. Ent. Soc., xxiii, $306,1896$.

3550. sideraria Guenée, Spec. Gén., ix, 450, 1857; Packard, C. 350; Hulst, Ent. Amer., ii, 222, 1887; PACKard, C. 341.

syn. californiaria PACKARD, californiata PACKARD, pacificaria PACKARD.

No.Atl. States. No. U.S. Atl. States.

Man.

Atl. States.

Fla.

No.

U.S. 
*3550. 1. refractaria W ALKer, Cat. Brit. Mus., xxiii, $785,1861$.

East Fla.

3551. anticaria W Alker, Cat. Brit. Mus., xxvi, 1593, 1862; Hulst, Ent. News, vi, 72, 1895.

Atl.

syn. subalbaria Packard, Proc. Bost. Soc.

Nat. Hist., xvi, 28, 1873 ; C. 344.

*3551. 1. basipunctaria Walker, Cat. Brit. Mus., xxiii, $785,1861$.

States.

East

Fla.

\section{EMMILTIS Hübner.}

Hǘnner, Verz. bek. Schmett., 309, 1818; Meyrick, Trans. Ent. Soc. Lond., 86, 1892; Hulst, Trans. Am. Ent. Soc., xxiii, 306, 1896; Anthometria Borsduval, Ind. Méth., 231, 1840; v. Gumppenberg, Nov. Act. Halle, xlix, 392, 1887.

3552. sparsaria Walker, Cat. Brit. Mus., xxvi, 1596, 1862; Hulst, Ent. News, vi, 42, 1895.

Tex.,

Fla.

syn. psilogrammaria Zeller, Verh. zool. -bot.

Ges. Wien, xxii, 490, 1872; Packard, C. 430.

\section{PENTOPODA Hulst.}

Hulst, Trans. Am. Ent. Soc., xxiii, 307, 1896.

*3553. miranda Hurst, Trans. Am. Ent. Soc., xxiii, $307,1896$.

\section{SIGELA Hulst.}

Hulst, Trans. Am. Ent. Soc., xxiii, 308, 1896.

3554. penumbrata Hulst, Trans. Am. Ent. Soc., xxiii, 308, 1896.

Fla., Cal.

LOPHOSIS Hulst.

Hulst, Trans. Am. Ent. Soc., xxiii, 308, 1896.

*3555. labeculata Hulst, Ent. Amer., ii, 187, 1887.

Col., Ariz.

\section{GONIACIDALIA Packard.}

Packard, Fifth Rept. Peab. Acad. Sci.,68, 1873; C. 312; Hulst, Trans. Am. Ent. Soc., xxiii, 308, 1896.

3556. furciferata Packard, Fifth Rept. Peab. Acad. Sci., 68, 1873; C. 312.

Tex.

\section{Subfamily GFOMF'TRIN AE.}

ANNEMORIA Packard.

Packard, Proc. Bost. Soc. Nat. Hist., xvi, 30, 1874; C. 375; Hulst, Trans. Am. Ent. Soc., xxiii, 312, 1896.

3557. bistriaria PaCkard, C. 378; Hulst, Ent. Amer., Rocky ii, 140, 1886; iii, 193, 1888. Mts. syn. undinaria Strecker, Surv. Dept. Mo., Ruffner, app., 1862, 1878. 
3558. faseolaria Gunnée, Spec. Gén., ix, 351, 1857;

Walker, Cat. Brit. Mus., xxii, 534, 1861.

Cal.

syn. fasceolaria PACKARD, C. 375; fasciolaria

Hulst, Ent. Amer., ii, 141, 1886; perviri-

daria PACKard, C. 379.

*3559. græfiaria Hulst, Ent. Amer., ii, 123, 1886.

3560. unitaria Packard, Proc. Bost. Soc. Nat. Hist.,

Nev., Cal.

xvi, 30, 1874; C. 376.

Nev.

\section{CHLOROCHLAMYS Hulst.}

Hulst, Trans. Am. Ent. Soc., xxiii, 312, 1896.

3561. chloroleucaria Guenée, Spec. Gén., ix, 351,1857; Packard, C. 370; Goodell, Can. Ent., xii. 235. 1880; Hulst, Bull. Brook. Ent. Soc., ii, 78, 1879; Ent. News, vi, 71, 1895.

syn. indiscriminaria WALKER, Cat. Brit.

Mus., xxvi, 1556, 1862; PACKARD, C. 375; densaria Walker, Cat. Brit. Mus., xxv, 1557, 1862; PACKARD, C. 375; deprivata Walker, Cat. Brit. Mus., xxvi, 1559, 1862 ; PACKard, C. 396.

3562. phyllinaria ZelLer, Verh. zool.-bot. Ges. Wien, 479, 1872; Hulst, Ent. Amer., ii, 141, 1886;

Ent. News, vi, 71, 1895.

Atl. States, Cal.

$$
\text { syn. zelleraria PACKARd, C. } 370 .
$$

\section{NEMORIA Hübner.}

Hübner, Verz. bek. Schmett., 285, 1818; Packard, C. 372; Meyrick, Trans. Ent. Soc. Lond., 93, 1892; Hulst, Trans. Am. Ent. Soc., xxiii, 312, 1896; Chlorissa STePhens, West. \& Hump., Brit. Moths, ii, 78, 1849.

3563. pistaceata Guenée, Spec. Gén., ix, 348, 1857; Packard, C. 374; Hulst, Ent. News, vi, 71, 1895. Atl. syn. superata Walker, Cat. Brit. Mus., xxxv, 1612, 1866; PACKARD, C. 396.

3564. subcroceata WaLker, Cat. Brit. Mus., xxv, 1557, 1862; Packard, C. 372; Dyar, Psyche, viii, 386, 1899 .

3565. dyarii Hulst, Can. Ent., xxxii, 105, 1900. States.

*3566. auranticolorata STrEcker, Lep. Rhop. Het., suppl. 2, 8, 1899.

Rocky Mts., Cal.

*3567. euchloraria Guenée, spec. Gén., ix, 355, 1857; Packard, C. 396.

Atl.

States.

Atl. States.

Fla.

Atl.

States. 


\section{EUCROSTIS Hübner.}

Hübner, Verz. bek. Schmett., 283, 1818; Packard, C. 369; Meyrick, Trans. Ent. Soc. Lond., 94, 1892; Hulst, Trans. Am. Ent. Soc., xxiii, 313, 1896.

3568. incertata WALker, Cat. Brit. Mus., xxv, 1557, 1862; Packard, C. 372; Hulst, Ent. News, vi, 71,1895 .

syn. oporaria Zeller, Verh. zool.-bot. Ges. Wien, 481, 1872; gratata PACKaRd, C., pl. 10, f. 79,1876 .

3569. viridipennata Hulst, Trans. Am. Ent. Soc., xxiii, 314, 1896; Dyar, Psyche, ix, 287, 1901.

Atl. States.

\section{CHLOROPTERYX Hulst.}

Hulst, Trans. Am. Ent. Soc., xxiii, 314, 1896.

*3570. tepperaria Hulst, Ent. Amer., ii, 122, 1886.

So. States.

\section{RACHEOSPILA Guenée.}

Guenée, Spec. Gén., ix, 372, 1857; Packard, C. 384; Hulst, Trans. Am. Ent. Soc., xxiii, 314, 1896.

3571. lixaria Guenée, Spec. Gén., ix, 374, 1857; PACKARD, C. 384; Hulst, Ent. News, vi, 71, 1895.

syn. inclusaria WaLker, Cat. Brit. Mus., xxii, 508, 1861; Hulst, Ent. News, vi, 105, 1895; Packard, C. 395; congruata Walker, Cat. Brit. Mus., xxii, 511, 1861; extremaria Walker, Cat. Brit. Mus., xxii, 584, 1861; mubrolineata Packard, Fifth Rept. Peab. Acad. Sci., 74, 1873; C. 390; cupidenaria Grote, Can. Ent., xii, 218, 1880.

*3572. jaspidiaria Hulst, Ent. Amer., ii, 122, 1886.

Fla.

*3573. hollandaria Hulst, Ent. Amer., ii, 122, 1886. Atl. States.

*3574. viridipurpurea Hulst, Can. Ent., xxx, 159, 1898.

Fla.

3575. saltusaria Hulst, Ent. Amer., ii, 122, 1886; Dyar, Psyche, ix, 118, 1900.

Fla.

Fla.

\section{SYNCHLORA Guenée.}

Guenée, Spec. Gén., ix, 375, 1857; Packard, C. 379; Hulst, Trans. Am. Ent. Soc., xxiii, 314, 1896; Eunemoria PAckand, Fifth Rept. Peab. Acad. Sci., 76, 1873.

3576. hulstiana Dyar, Proc. Ent. Soc. Wash., iv, 457, Fla. 1901. 
3577. louisa Hulst, Can. Ent., xxx, 159, 1898.

Fla.

3578. ærata Fabricius, Syst. Ent., suppl., 238, 1798; Atl. hulst, Ent. News, vi, 71, 1895; Aurivillius, Tidsk. Ent., xviii, 166, 1898.

syn. glaucaria Guenée, Spec. Gén., ix, 377, 1857; Packard, C. 392; Hulst, Ent. Amer., ii, 141, 1886; Dyar, Psyche, ix, 93, 1900; mimicata W ALKer, Cat. Brit. Mus., xxxv, 1600, 1866; PACKARD, C. 395; rubivora Riley, First Rept. Ins. Mo., 139, 1869; rubivoraria PACKARD, C. 382; SAUNDERS, Ins. Inj. Fruits, 316, 1883; French, Trans. Dept. Agr. Ill., xv, 238, 1877; albolineata Packard, Fifth Rept. Peab. Acad. Sci., 75, 1873; gracillaria PACKARD, Fifth Rept. Peał. Acad. Sci., 77, 1873.

*3579. viridipallens Hulst, Trans. Am. Ent. Soc., xxiii, $315,1896$.

3580. denticulata WALKer, Cat. Brit. Mus., xxii, 536, 1861; Hulst, Ent. News, vi, 71, 1895.

syn. excurvaria Packard, Fifth Rept. Peab. Acad. Sci., 76, 1873; C. 381; Dyar, Ent. News, v, 62, 1894.

3581. liquoraria Guenée, Spec. Gén., ix, 375, 1857; Packard, C. 383; Hulst, Ent. Amer., ii, 141, 1886; Ent. News, vi, 71, 1895.

syn. tricoloraria Packard, Proc. Bost. Soc. Nat. Hist., xvi, 30, 1874; C. 381.

*3582. texana Hulst, Can. Ent., xxx, 160, 1898.

3583. rubrifrontaria Packard, Fifth Rept. Peab. Acad. Sci., 75, 1873; C. 383.

3584. xysteraria Hulst, Ent. Amer., ii, 121, 1886.

3585. dominicaria Guenée, Spec. Gén., ix, 367, 1857; W Alker, Cat. Brit. Mus., xxii, 566,1861 ; Husst, Ent. News, vi, 71, 1895.

Tex.

Atl. States.

Fla.

Col., Ariz.

U. S.

U. S.

Fla.

\section{CHLOROSEA Packaid.}

Packard, Proc. Bost. Soc. Nat. Hist., xvi, 30, 1874; C. 376; Hulst, Trans. Am. Ent. Soc., xxiii, 315, 1896.

*3586. nevadaria Packard, Proc. Bost. Soc. Nat. Hist., xvi, 31, 1874; C. 378.

Rocky Mts., Pac. States. 


\section{APLODES Guenée.}

Guenée, Spec. Gén., ix, 376, 1857; Packard, C. 385; Hulst, Trans. Am. Ent. Soc., xxiii, 315, 1896; Hipparchiscus Walsh, Proc. Bost. Soc. Nat. Hist., ix, 300, 1864.

3587. mimosaria Guenée, Spec. Gén., ix, 377, 1857; Packard, C. 388; Hulst, Ent. News, vi, 71, 1895; Ent. Amer., ii, 139, 1886; Dyar, Psyche, viii, $310,1899$.

syn. tractaria Walker, Cat. Brit. Mus., xxii, 540, 1861; venusta Walsh, Proc. Bost. Soc. Nat. Hist., ix, 301, 1864; approximaria Packard, Fifth Rept. Peab. Acad. Sci., 73, 1873; C. 391; Bull. U. S. Ent. Comm., vii, 49, 1881; lataria PACKARD, Fifth Rept. Peab. Acad. Sci., 74, 1873; C. 391; coniferaria PaCkard, Am. Nat., xviii, 933, 1884.

*3588. catachloa Hulst, Can. Ent., xxx, 160, 1898.

3589. rubrifrontaria PACKARD, Fifth Rept. Peab. Acad. Sci., 76, 1873; C. 386.

syn. packardaria Grote, New Check List, 46, 1882.

3590. bistriaria HüBner, Zutr. exot. Schmett., f. 103, 1818; Packard, C. 564; Hulst, Ent. News, vi, 71,1895 .

syn. bifilata Walker, Cat. Brit. Mus., xxvi, 1585, 1862; bmunearia PACKARD, C. 388.

Fla.

Atl. States.

Atl. States, Brit. Col.

Atl. States.

\section{ANAPLODES Packard.}

Packard, C. 392; Hulst, Trans. Am. Ent. Soc., xxiii, 316, 1896.

3591. zygotaria Hulst, Ent. Amer., ii, 121, 1886.

Tex.

3592. viridicaria Hulst, Bull. Brook. Ent. Soc., iii, 41, 1880; Ent. Amer., ii, 140, 1886.

Col., a. albaria Grote, Can. Ent., xv, 126, 1883.

Ariz.

*3593. obliqua Hulst, Can. Ent., xxx, 161, 1898.

Col.

syn. billonaria Strecker, Lep. Rhop. Het., suppl. 2, 8, 1899.

*3594. rubromarginaria Packard, C. 389; Hulst, Ent. News, vi, 71, 1895.

3595. arizonaria Grote, Can. Ent., xv, 125, 1883.

syn. festaria Hulst, Ent. Amer., ii, 121, 1886.

3596. pistacearia PACKARD, C. 392, 1876.

*3597. junctolinearia Graef, Bull. Brook. Ent. Soc., iii, 87, 1881; Hulst, Ent. Amer., ii, 140, 1886.

Atl. States.

Cal.,

Ariz.

Rocky Mts.

Rocky

Mts.

3598. remotaria Walker, Cat. Brit. Mus., xxii, 530, 1861; Hulst, Ent. News, vi, 71, 1895.

Atl.

a. consequaria Hr. Edwards, Pap., iv, 19, 1884. 
3599. iridaria Guenée, Spec. Gén., ix, 344, 1857; Packard, C. 394; Hulst, Ent. News, vi, 71, 1895. syn. rectaria Grote, Can. Ent., ix, 157, 1877; Hulst, Ent. News, vi, 71, 1895.

3600. illustraria Hulst, Ent. Amer., ii, 121, 1886. syn. iridaria PaCKard (not Guenée), C. pl. 10, f. 93,1876 .

\section{Subfamily FHRNALDFILINAE. FERNALDELLA Hulst.}

Hulst, Trans. Am. Ent. Soc., xxiii, 318, 1896.

3601. fimetaria Grote \& Robinson, Trans. Am. Ent. Soc., iii, 182, 1870; Grote, Bull. Buff. Soc., i, 88, 1873; Packard, C. 228; Hulst, Ent. Amer., iii, $9,1887$.

syn. halesaria Zeller, Verh. zool.-bot. Ges.

Wien, xxii, 488, 1872; xxv, 125, 1875.

a. partitaria Grote, Can. Ent., xv, 130, 1883.

3602. stalachtaria STREckER, Surv. Dept. Mo., Ruffner, suppl., 1863, 1878; Hulst, Ent. Amer., iii, 9, 1887.

a. alternaria Grote, Can. Ent., xv, 27, 1883.

Subfamily FiNNOMIN AE.

EPELIS Hulst.

Hulst, Trans. Am. Ent. Soc., xxiii, 324, 1896.

3603. truncataria Walker, Cat. Brit. Mus., xxv, 1034, 1862; Packard, C. 230; v. Gumppenberg, Nov. Act. Halle, xlix, 388, 1894; Hulst, Ent. News, vi, 12, 1895; Dyar, Psyche, ix, 298, 1902.

syn. faxonii Mrnot, Proc. Bost. Soc. Nat. Hist., xi, 83, 1869; PACKARd, C. 232.

\section{EUFIDONIA Packard.}

Packard, C. 225; Hulst, Trans. Am. Ent. Soc., xxiii, 324, 1896; v. Gumppenberg, Nov. Act. Halle, xlix, 397, 1887.

3604. notataria Walker, Cat. Brit. Mus., xxi, 407, 1860; Packard, C. 226; Goodell, Can. Ent., xiv, 199, 1882; Hulst, Ent. News, vi, 12, 1895.

syn. discospilata Walker, Cat. Brit. Mus., xxiv, 1034, 1862.

a. fidoniata W ALker, Cat. Brit. Mus., xxiv, 1183, 1862; v. Gumpennerg, Nov. Act. Halle, xlix, 398, 1887.

syn. bicolorata Minot, Proc. Bost. Soc. Nat. Hist., xi, 83, 1869; quadripunctaria MorrIson, Proc. Bost. Soc. Nat. Hist., xvi, 199, 1874 .
Rocky Mts., Cal.

Cal.

Rocky Mts.

Rocky Mts.

Atl. States, Col. Atl. States. 
ORTHOFIDONIA Packard.

Packard, C. 235; Hulst, Trans. Am. Ent. Soc., xxiii, 324, 1896.

3605. exornata Walker, Cat. Brit. Mus., xxiv, 1187, 1862; Packard, C. 236; v. Gumppenberg, Nov. Atl. Act. Halle, xlix, 400, 1887; Hulst, Ent. News, States. vi, 42,1895 .

syn. albifusata WALker, Cat. Brit. Mus., xxvi, $1728,1862$.

3606. semiclarata W ALkER, Cat. Brit. Mus., xxxv, 1653 , 1866; Packard, C. 302; Hulst, Ent. News, v, Atl. $304,1894$. States.

syn. viatica Harvey, Buff. Bull. Soc., i, 265, 1874.

3608. vestaliata Guenée, Spec. Gén., x, 59, 1857; PACKARD, C. 301.

Atl. States, Col.

syn.junctaria WaLKER, Can. Nat., vi, 39, 1861; Cat. Brit. Mus., xxvi, 1593, 1862; Grote, Can. Ent., ix, 27, 1877.

*3609. elsinora Hulst, Jn. N. Y. Ent. Soc., viii, 218, 1900 .

\section{DASYFIDONIA Packard.}

Packard, C. 233; Hulst, Trans. Am. Ent. Soc., xxiii, 23, 325, 1896.

3610. avuncularia Guenée, Spec. Gén., x, 145, 1857; Packard, C. 234; v. Gumppenberg, Nov. Act. Halle, xlix, 386, 1887.

Col. to Cal.

Cal.

\section{HELIOMATA Grote.}

Grote, Proc. Ent. Soc. Phil., vi, 29, 1866; Packard, C. 190; v. Gumppenberg, Nov. Act. Halle, xlix, 368, 1887; Hulst, Trans. Am. Ent. Soc., xxiii, 325, 1896.

3611. infulata Grote, Proc. Ent. Soc. Phil., ii, 67, 1863; PaCkard, C. 191.

Atl. States.

*3612. elaborata Grote, Proc. Ent. Soc. Phil., ii, 67, 1863; PACKARd, C. 191.

3613. cycladata Grote, Proc. Ent. Soc. Phil., vi, 30, 1866; Packard, C. 192; Dyar, Psyche, ix, 177, 1901 .

Va.

Atl. States, Mont.

MELLILLA Grote.

Grote, Bull. Buff. Soc., i, 12, 1873; Hulst, Trans. Am. Ent. Soc., xxiii, 325, 1896.

3614. inextricata WaLkER, Cat. Brit. Mus., xxiv, 1038, 1862; Packard, C. 295; Hulst, Ent. News, v, Atl. $304,1894$.

a. xanthometata Walker, Cat. Brit. Mus., xxiv, 1038, 1862.

syn, snoviaria PACKard, C. 222. 
3615. chamæchrysaria Grote, Bull. Buff. Soc., i, 13, 1873; Can. Ent., x, 152, 1878.

Atl.

syn. rilevaria PACKARD, C. 221.

States.

\section{CHLORASPILATES Packard.}

Packard, C. 211; Hulst, Trans. Am. Ent. Soc., xxiii, 326, 1896.

3616. bicoloraria Packard, C. 212; Grote, Can. Ent., Rocky xiv, 109, 1882. Mts. a. arizonaria Grote, Pap., ii, 80, 1882.

3617. profugaria Herrich - Schaeffer, Ausser. No. Am. Schmett., 66, f. 410,1855 ; PACKARD, C. 212.

\section{PSYSOSTEGANIA Warren.}

Warren, Nev. Zool., i, 406, 1894; Hulst, Trans. Am. Ent. Soc., xxiii, 326, 1896.

3618. pustularia Guenée, Spec. Gén., x, 49, 1857;

Packard, C. 310: U. S. Ent. Comm., vii, 112,

Atl.

1881: Saunders, Can. Ent., iii, 225, 1871;

States.

Hulst, Ent. News, v, 304, 1894.

\section{GUENERIA Packard.}

Packard, C. 307; Hulst, Trans. Am. Ent. Soc., xxiii, 326, 1896.

3619. basiaria Walker, Cat. Brit. Mus., xxvi, 1508,

Atl.

1862; Hulst, Ent. News, v, 304, 1896.

States.

syn. basiata PACKaRd, C. 308; incoloraria

W Alker, Cat. Brit. Mus., xxvi, 1509, 1862;

Packard, C. 498; congrue Walker, Cat.

Brit. Mus., xxxv, 1623, 1866; Packard, C.

358.

\section{DEILINIA Hübner.}

Hübner, Verz. bek. Sc'imett., 310, 1818; Packard, C. 305; Meyrick, Trans. Ent. Soc.

Lond., 108, 1892; Hulst, Trans. Am. Ent. Soc., xxiii, 327, 1896; Sphecodes Hübner

(not Latreille), Tentamen, 1806; Cabera Treitschke, Schmett. Eur., vi, 1, 343,

1827; Stephens, Brit. Ins., 44, 1829; Duponchel, Lép. Fr., viii, (v), 5, 1830;

Lederer, Verh. zool.-bot. Ges. Wien, 200, 1853; Guenée, Spec. Gén., x, 52, 1857.

*3620. borealis Hulst, Trans. Am. Ent. Soc., xxiii, Alberta. $327,1896$.

*3621. elimaria Hulst, Ent. Amer., ii, 186, 1882.

Col., Man.

*3622. quadrifasciaria Packard, Fifth Rept. Peab. Acad. Sci., 62, 1873; C. 205.

Rocky

Mts.

3623. variolaria Guenée, Spec. Gén., x, 56, 1857; Packard, C. 306; Hulst, Ent. News, v, 304, 1894.

syn. intentata W ALKer, Cat. Brit. Mus., xxiii, 870, 1861; Packard, C. 306. 
3624. erythremaria Guenée, Spec. Gén., x, 56, 1857; PACKARD, C. 306.

Atl. States.

3625. exanthemata Scopoli, Ent. Car., 218, 552, 1763; Staudinger, Cat. Lep. Eur., 155, 1871.

Can., Eur.

syn. exanthemaria Denis \& SCHIFFERMÜLLER, Syst. Verz. Wien., 107, 5, 1776; STAUDINGER \& Rebel, Cat. Lep. Eur., i, no. 3714 , 1901; Hulst, Trans. Am. Ent. Soc., xxiii, 327. 1896; striaria HüBNER, arenosaria HAwORTH, approximaria HAwORTH.

*3626. pacificaria PACKard, C. 307, 1876.

*3627. nevadaria Hulst, Ent. Amer., iii, 217, 1888.

3628. fœminaria Guenée, Spec. Gén., x, 149, 1857; Walker, Cat. Brit. Mus., xxiv, 1029, 1862; Hulst, Ent. News, vi, 104, 1896.

syn. celataria Hulst, Ent. Amer., iii, 216, 1888; ?monicaria Guenée, Spec. Gén., x, 100, 1857 (type lost).

3629. falcataria Packard, Proc. Bost. Soc. Nat. Hist., xvi, 32, 1874; C. 423.

3630. carnearia Hulst, Ent. Amer., iii, 216, 1888.

3631. bifilata Hulst, Bull. Brook. Ent. Soc., iii, 44, 1880 .

3632. perpallidaria Grote, Can. Ent., xiv, 185, 1882; Can. Ent., xv, 25, 1883.

Brit. Col.

Nev., Cal.

Col.

Cal.

Pac.

States.

Cal.

Rocky

Mts.

Col., Cal., Brit. Col.

3633. litaria Hulst, Ent. Amer., ii, 211, 1887.

Rocky Mts., Cal.

3634. pulveraria Hulst, Can. Ent., xxx, 161, 1898.

Brit. Col.

3635. quadraria Grote, Can. Ent., xiv, 185, 1882.

Cal., Col., Nev.

3636. liberaria Walker, Cat. Brit. Mus., xx, 239, 1860; Hulst, Ent. Amer., iii, 10, 1887; Ent. Atl. News, vi, 15, 1895; Packard, C. 297.

syn. integraria Walker, Cat. Brit. Mus., xxiii, 889, 1861: lintneraria PACKARD, Sixth Rept. Peab. Acad. Sci., 44, 1874;

C. 209; Goodell, Can. Ent., x, 40, 1878.

3637. nigroseriata Packard, Proc. Bost. Soc. Nat. Hist., xvi, 40, 1878; C. 246.

No.

U. S.

3638. behrensaria Hulst, Ent. Amer., ii, 210, 1887; Ent. News, vi, 15, 1895.

syn. ?unicalcaria Guenée, Spec. Gén., x, 100,

1857; PaCKard, C. 275.

a. cervinicolor Hulst, Can. Ent., xxx, 161, 1898.

3639. fumosa Hulst, Trans. Am. Ent. Soc., xxiii, 328, 1896. 
*3640. solamata Hulst, Jn. N. Y. Ent. Soc., viii, 217, 1901.

Man.

EPISEMASIA Hulst.

Hulst, Trans. Am. Ent. Soc., xxiii, 328, 1896.

*3641. morbosa Hulst, Trans. Am. Ent. Soc., xxiii, $328,1896$.

3642. cervinaria Packard, Fifth Rept. Peab. Acad. Sci., 81, 1873; C. 532.

SCIAGRAPHIA Hulst.

Hulst, Trans. Am. Ent. Soc., xxiii, 329, 1896.

3643. sublacteolaria Hulst, Ent. Amer., ii, 189, 1887. *3644. colorata Grote, Can. Ent., xv, 7, 1883.

3645. maculifascia Hulst, Trans. Am. Ent. Soc., xxiii, $329,1876$.

*3646. flavivenata Hulst, Can. Ent., xxx, 163, 1898.

3647. granitata Guenée, Spec. Gén., x, 85, 1857; Packard, C. 285; Hulst, Ent. News, v, 304 , 1894; Dyar, Ent. News, v, 63, 1894.

syn. contemptata Guenée, Spec. Gén., x, 86, 1857; PaCkard, C. 294; haliata Guenée, Spec. Gén., x, 97, 1857; Packard, C. 356; dispuncta Walker, Cat. Brit. Mus., xxi, 405, 1861; Packard, Rept. Geol. Surv. Terr., v, 553, 1875; inordinaria WALKER, Cat. Brit. Mus., xxi, 488, 1860; Grote, Can. Ent., ix, 27, 1877; retractaria WALKER, Cat. Brit. Mus., xxiii, 785, 1861; PaCkard, C. 356; submarmorata WaLker, Cat. Brit. Mus., xxiii, 887, 1861; exauspicata W ALKER, Cat. Brit. Mus., xxiii, 889, 1861; irregulata Walker, Cat. Brit. Mus., xxiii, 890, 1861; ordinata WaLker, Cat. Brit. Mus., xxiv, 1038, 1862; exnotata WALKER, Cat. Brit. Mus., xxiv, 1186, 1862; abruptata W ALKER, Cat. Brit. Mus., xxv, 1326, 1862; PACKARD, Fifth Rept. Peab. Acad. Sci., 88, 1873; fissinotata Walker, Cat. Brit. Mus., xxvi, 1595, 1862; subapicaria W ALKER, Can. Nat., vi, 40, 1861; Cat. Brit. Mus., xxvi, 1641 , 1862; retinotata WaLKer, Cat. Brit. Mus., xxvi, 1642, 1862; quadrisignata W ALKER, Cat. Brit. Mus., xxxv, 1665, 1866; sexmaculata Packard, Proc. Bost. Soc. Nat. Hist., xi, 44, 1867; succosata ZeLLER, Verh. zool.bot. Ges. Wien, xxii, 485, 1872; unimodaria Morrison, Proc. Bost. Soc. Nat. Hist., xvi, 196,1874 . 
3648. denticulata Grote, Can. Ent., xv, 133, 1883;

Hulst, Ent. Amer., ii, 223, 1887.

Rocky

syn. sexpunctata BAtes, Can. Ent., xviii, 75, 1886.

3649. muscariata Guenée, Spec. Gén., x, 98, 1857; Packard, C. 274; Hulst, Ent. News, vi, 104, 1895 .

Col.,

Nev.,

Cal.

syn. delectata Hulst, Ent. Amer., ii, 190, 1887.

3650. punctolineata Packard, Fifth Rept. Peab. Acad. Sci., 64, 1873; C. 284.

Rocky

Mts.

3651. heliothidata Guenée, Spec. Gén., x, 79, 1857; Walker, Cat. Brit. Mus., xxiii, 891, 1861; Hulst, Ent. News, v, 305, 1894; Dyar, Psyche, ix, 203, 1901.

syn. ocellinata Guenée, Spec. Gén., x, 85, 1857; Zeller, Verh. zool.-bot. Ges. Wien, xxii, 486, 1872; PACKARD, C. 283 ; restorata Walker, Cat. Brit. Mus., xxii, 726, 1861; subcolumbata WALker, Cat. Brit. Mus., xxvi, 1676, 1862; duplicata PaCkARD, Fifth Rept. Peab. Acad. Sci., 65, 1873.

3652. californiaria Packard, Proc. Bost. Soc. Nat. Hist., xiii, 392, 1871; xvi, 27, 1874; Rept. Geol. Surv. Terr., v, 553, 1873.

syn. californiata Packard, C. 281; Grote, Can. Ent., xv, 8, 1883; pallidata Packard, Fifth Rept. Peab. Acad. Sci., 64, 1873.

3653. respersata Hulst, Bull. Brook. Ent. Soc., iii, $42,1880$.

*3654. nubiculata PaCkard, C. 267; Hulst, Ent. Amer., ii, $224,1886$.

Pac. States, Rocky

Mts.

syn. colata Grote, Pap., i, 167, 1881.

3655. irrorata PaCka Rd, C. 273; Butler, Pap., i, 222, 1882; Dyar, Ent. News, v, 63, 1894.

Col., Ariz., Cal.

3656. neptaria Guenée, Spec. Gén., x, 99, 1857; Walker, Cat. Brit. Mus., xxiii, 957, 1861.

syn. neptata Packard, C. 273; Grote, Can. Ent., xv, 8, 1883; Hulst, Ent. Amer., ii, 223, 1887; flavofasciate Packard, Proc. Bost. Soc. Nat. Hist., xiii, 394, 1871; cinereata Bates, Can. Ent., xviii, 75, 1886.

*3657. hebitata Hulst, Bull. Brook. Ent. Soc., iv, 34, 1881.

Col., Ariz.,

Wash.

3658. sinuata PackArd, Sixth Rept. Peab. Acad. Sci., 45,1874 ; C. 271.

Pac. States, Col. 
3659. snoviata PaCKard, C. 268.

syn. subminiata PACKARD (not PACKARD), Sixth

Pa., Kans.

Rept. Peab. Acad. Sci., 49, 1874.

3660. pervolata Hulst, Bull. Brook. Ent. Soc., iii, 42, 1880.

Col.,

Ariz.

Col.,

Ariz.

Sci., 47, 1874.

syn. meadiata Packard, C. 269.

3662. continuata WaLker, Cat. Brit. Mus., xxv, 1445, 1862; Hulst, Ent. Amer., iii, 114, 1887; Ent. News, vi, 12, 1895.

syn. orillata Walker, Cat. Brit. Mus., xxvi, 1740, 1862; PACKARD, C. 265; strigularia

Walker, Cat. Brit. Mus., xxvi, 1675, 1862; Packard, C. 211; excurvata PACKARd, Sixth Rept. Peab. Acad. Sci., 47, 1874; curvata Grote, Bull. Brook. Ent. Soc., iii, 47, 1880; cruciata Grote, Trans. Kans. Acad. Sci., viii, 56, 1883; Ann. Mag. Nat. Hist., (5), xi, $55,1883$.

a. atrofasciata PACKARD, C. 264.

$366^{2}$. spodopterata Hulst, Can. Ent., xxx, 162, 1898. 3664. mellistrigata Grote, Bull. Buff. Soc., i, 12, 1873; Hulst, Ent. Amer., ii, 224, 1887; Packard, C. 269 .

a. trifasciata Packard, Sixth Rept. Peab. Acad. Sci., 46, 1874; C. 270.

3665. subminiata Packard, Proc. Bost. Soc. Nat. Hist., xvi, 25, 1874; C. 272.

Atl. and Pac. States.

Cal., Col.

No.

U. S.

Mont., Cal.

\section{PHILOBIA Duponchel.}

Duponchel, Hist. Nat., vii, 195, 1829; Hulst, Trans. Am. Ent. Soc., xxiii, 330, 1896.

3666. notata Linnæus, Syst. Nat., 523, 1758; Hulst, Trans. Am. Ent. Soc., xxiii, 330, 1896; STAU Dinger \& Rebel, Cat. Lep. Eur., i, no. 3782 , Atl. States, Eur. 1901.

syn. notaria Denis \& SCHIFFermüller, Syst. Verz. Wien, v, 104, 1776.

3667. enotata Guenée, Spec. Gén., x, 69, 1857; PACKARD, C. 288; Hulst, Ent. News, v, 305, 1894; Trans. Am. Ent. Soc., xxiii, 330, 1896.

syn. æmulataria WALker, Cat. Brit. Mus., xxiii, 884, 1861; Zeller, Verh. zool.-bot. Ges. Wien, xxii, 487, 1872; sectomaculata Morrison, Proc. Bost. Soc. Nat. Hist., xvi, 198, 1874; notata Cramer (not Linneus), Pap. Exot., iv, pl. 371, f. F., 1782. 


\section{MACARIA Curtis.}

Curtis, Brit. Ent., vi, 132, 1826; Packard, C. 279; Hofmann, Gr. Schm. Eur., 175, 1894; Hulst, Trans. Am. Ent. Soc., xxiii, 330, 1896.

3668. infimata Guenée, Spec. Gén., x, 81, 1857 ; Walker, Cat. Brit. Mus., xxiii, 907, 1861; Hulst, Ent. News, v, 305, 1894.

syn. gnophosaria Guenée, Spec. Gén., x, 99, 1857; Packard, C. 275; infectata Walker, Cat. Brit. Mus., xxv, 1332, 1862; seductata Walker, Cat. Brit. Mus., xxvi, 1654, 1862; crsiaria Hulst, Ent. Amer., iii, 217, 1887.

3669. s-signata Packard, Fifth Rept. Peab. Acad. Sci., 63, 1873; C. 280; Grote, Can. Ent., xv, 7, 127, 1883.

3670. pictipennata Hulst, Can. Ent., xxx, 162, 1898.

*3671. labradoriata Möschler, Stett. ent. Zeit., 118, 1883.

*3672. sabularia Guenée, Spec. Gén., x, 105, 1857; Packard, C. 276; Hulst, Ent. News, vi, 105, 1896 (type lost).

3673. eremiata Guenée, Spec. Gén., x, 109, 1857 ; PACKARD, C. 278; Hulst, Ent. News, vi, 12, 105, 1895.

syn. retectata WALKER, Cat. Brit. Mus., xxiii, 959, 1861; gradata W ALKER, Cat. Brit. Mus., xxiii, 968, 1861; retentata WALKER, Cat. Brit. Mus., xxiii, 968, 1861; subcinctaria Walker, Cat. Brit. Mus., xxvi, 1655, 1862.

3674. hypæthrata Grote, Pap., i, 167, 1881.

3675. æquiferaria WALker, Cat. Brit. Mus., xxiii, 886 , 1861; Packard, C. 295; Hulst, Ent. Amer., iii, 114, 1888; Ent. News, v, 305, 1894.

syn. postrema WALKER, Cat. Brit. Mus., xxiii, 887, 1861: PACKARD, C. 295; morosaria Walker, Cat. Brit. Mus., xxiii, 942, 1861; galbiniata Zeller, Verh. zool.-bot. Ges. Wien, xxii, 484, 1872; PaCkard, C. 290.

3676. minorata Packard, Fifth Rept. Peab. Acad. Sci., 66, 1873; C. 291.

3677. grassata Hulst, Bull. Brook. Ent. Soc., iv, 33, 1881; Ent. Amer., ii, 223, 1887.

*3678. præatomata Haworth, Lep. Brit., 345, 1810; Packard, C. 291; Hulst, Ent. Amer., ii, 223, 1887.

syn. consepta W ALker, Cat. Brit. Mus., xxiii, $941,1861$.

Rocky Mts., Cal.

Col., Ariz.

Lab.

No.

Am.

Atl. States.

Rocky Mts.

Atl. States, Ariz.

Atl.

States.

Atl.

States.

Atl. States. 
a. bisignata WALKER, Cat. Brit. Mus., xxxv, 1655 , 1866; PaCKard, C. 290.

syn. consimilata ZeLLer, Verh. zool.-bot. Ges.

Wien, xxii, 483, 1872.

*3679. quadrisignata Walker, Cat. Brit. Mus., xxxv, $1655,1866$.

No.

Am.

3680. simulata Hulst, Ent. Amer., ii, 188, 1887.

Tex., Ariz.

syn. similate Hulst, Trans. Am. Ent. Soc., xxiii, 331, 1896.

3681. mendicata Hulst, Ent. Amer., ii, 189, 1887.

N. Mex., Ariz.

3682. septemfluaria Grote, Pap., i, 41, 1881; Hulst, Ent. Amer., ii, 223, 1887; Ent. News, v, 304, Atl. States. 1894.

syn. ?quadrinotata HerRICH - SCHAEFFER, Auss. Schmett., f. 347, 1855; septemlinearia Grote.

3683. glomeraria Grote, Pap., i, 41, 1881; Can. Ent., xiii, 139, 1881; Pap., ii, 84, 1882; Hulst, Ent. News, v, 304, 1894.

*3684. teucaria Strecker, Lep. Rhop. Het., suppl. 2, 8, 1899 .

*3685. ancillaria Strecker, Lep. Rhop. Het., suppl. 2, 8, 1899 .

*3686. lapitaria STREcker, Lep. Rhop. Het., suppl. 2, 8,1899 .

Atl. States.

Wash.

Fla.

Tex.,

Mex.

Col.

Can.

*3687. 1. dispuncta Walker, Cat. Brit. Mus., xxi, 405, 1860 .

CYMATOPHORA Hübner.

Hübner, Tent., 1810; Packard, C. 427; Harvey, Bull. Buff. Soc., i, 276, 1873; Diastictis Hübner, Verz. bek. Schmett., 288, 1818; Meyrick, Trans. Ent. Soc. Lond., 103, 1892; Hulst, Trans. Am. Ent. Soc., xxiii, 331, 1896; Itama HüBNer, Verz. bek. Schmett., 299, 1818; Rhyparia HüBner, Verz. bek. Schmett., 305, 1818; Dryocetis HüBner, Verz. bek. Schmett., 316, 1818; Speranza Curtis, Brit. Ent., v, 222, 1825; Grammatophora Stephens, Cat., 126, 1829; Halia Duponchel, Hist. Nat., vii, 537, 1829; Guenée, Spec. Gén., x, 91, 1857; Hofmann, Gr. Schm. Eur., 188, 1894; Thamnonoma Lederer, Verh. zool.-bot. Ges. Wien, 233, 1853; PAckard, C. 249; Tephrina Guenée, Spec. Gén., x, 96, 1857; Eumacaria Packard, Fifth Rept. Peab. Acad. Sci., 67, 1874; C. 298; Eufitchia PACKARD, C. 247; Catastictis v. GuMPPenBERG, Nov. Act. Halle, lxix, 370, 1887.

*3688. deleta Hulst; Jn. N. Y. Ent. Soc., viii, 218, 1901.

Atl. States.

*3689. virginalis Hulst, Jn. N. Y. Ent. Soc., viii, 218, 1901. 
3690. ribearia Fiтєн, Trans. N. Y. Agr. Soc., viii, 466, Atl. 1848; Third Rept. Ins. N. Y., 427, 1856; W ALsH, States.

Pract. Ent., 22, 1865; SAunders, Rept. Ent. Soc. Ont., 374, 1874; Can. Ent., vi, 138, 1874; Ins. Inj. Fruits, 345, 1883; PACKARD, C. 248; Riley, Rept. Ins. Mo., ix, 3, 1877: Lintner, Ent. Cont., iii, 166, 1872; Hulst, Ent. News, vi, 104,1895 .

syn. sigmaria Guenée, Spec. Gén., ix, 184, 1857; Walker, Cat. Brit. Mus., xxiv, 1068, 1862; annisaria WaLker, Can. Nat., v, 260, 1860; aniusaria WALKER, Cat. Brit. Mus., xxvi, 1507, 1862; Packard, C. 497; grossulariata SaUnders, Rept. Ent. Soc. Ont., xii, 83, 1881.

*3691. sulphurea Packard, Fifth Rept. Peab. Acad. Sci., 77, 1873 .

syn. sulphuraria PACKARD, C. 255.

3692. occiduaria Packard, Sixth Rept. Peab. Acad. Sci., 52, 1874; C. 473.

3693. flavicaria PACKARD, C. 256.

*3694. fascioferaria Hulst, Ent. Amer., ii, 191, 1887.

3695. brunneata Thunberg, Diss. Ent., i, 9, 1784; Staudinger \& Wocke, Cat. Lep. Eur., i, no. 2451, 1871; Staudinger \& Rebel, Cat. Lep. Eur., i, no. 4018, 1901; Packard, C. 256.

syn. pinetaria HüBNER, quinquaria HüBNER, sylvaria CuRTIs, cembraria Motschulsky, ferruginaria PACKARD.

*3696. crocearia Hulst, Ent. Amer., ii, 211, 1887.

3697. ella Hulst, Trans. Am. Ent. Soc., xxiii, 332, 1896.

*3698. cervinaria Blanchard, Gay's Hist. Chile, Zool., vii, 89, 1852; Hulst, Ent. News, v, 305, 1894.

syn. eversaria Guenée, Spec. Gén., ix, 93,

1857; Walker, Cat. Brit. Mus.. xx, 116, 1860; rithusaria WaLKer, Cat. Brit. Mus., xx, 162, 1860; tegularia W ALKER, Cat. Brit. Mus., xx, 228, 1860.

a. gausaparia Grote, Pap., i, 41, 1881.

*3699. nicetaria Guenée, Spec. Gén., x, 107, 1857; Hulst, Ent. News, v, 305, 1894.

No. U. S.

Pac. States. No. Atl. States.

No. U.S.

No. U. S., Eur.

Tex.

Wash.

Fla., Tex., Ariz., So. Am.

svn. proditata W $\triangle$ LKER, Cat. Brit. Mus., xxii, 633, 1861: confinaria WALKER, Cat. Brit. Mus., xxiii, 959, 1861; cyclata WALKER, Cat. Brit. Mus., xxvi, 1669, 1862; liboraria W Alker, Cat. Brit. Mus., xxvi, 1495, 1862; lucidiferata WaLker, Cat. Brit. Mus., xxvi, 1574, 1862; vagaria WALKER, Cat. Brit. Mus., xxvi, 1685, 1862. 
*3700. solitaria W Alker, Cat. Brit. Mus., xxii, 631, Fla. 1861; Hulst, Ent. News, v, 306, 1894.

syn. stabilitata W ALKer, Cat. Brit. Mus., xxii, 632, 1861; repugnata WALKER, Cat. Brit. Mus., xxvi, 1577, 1862.

a. inaptata WAlker, Cat. Brit. Mus., xxiii, 886, 1861; PaCkard, C. 297.

*3701. helena Hulst, Trans. Am. Ent. Soc., xxiii, 332, 1896.

*3702. nervata Guenée, Spec. Gén., x, 85, 1857; Walker, Cat. Brit. Mus., xxiii, 910, 1861.

syn. tractata Walker, Cat. Brit. Mus., xxiii, 890, 1861; PaCKard, C. 296.

3703. inceptaria Walker, Cat. Brit. Mus., xxvi, 1667, 1862; Hulst, Ent. News, vi, 11, 1895; SuINgerland, Rural New Yorker, 497, 1896.

syn. argillacearia PACKARD, Sixth Rept. Peab. Acad. Sci., 48, 1874; C. 258; modestaria Hulst, Ent. News, vi, 11, 1895.

*3704. evagaria Hulst, Can. Ent., xxxii, 106, 1900.

3705. subcessaria Walker, Cat. Brit. Mus., xxiii, 945, 1861; Packard, C. 254; Hulst, Ent. News, v, $306,1894$.

syn. perarcuata WaLker, Cat. Brit. Mus., xxiv, $1264,1862$.

a. coortaria Hulst, Ent. Amer., ii, 191, 1887.

3706. bitactata Walker, Cat. Brit. Mus., xxiv, 1264, 1862; Hulst, Ent. News, v, 306, 1894.

syn. quadrilinearia Packard, Proc. Bost. Soc.

Nat. Hist., xvi, 26, 1874; C. 252.

*3707. packardaria Möschler, Stett. ent. Zeit., 119, 1883.

3708. wauaria Linneus, Syst. Nat., 522, 1758; STAUDinger \& Rebel, Cat. Lep. Eur., i, no. 4013, 1901.

syn. wavaria FABricius, Syst. Ent., iii, 2, 150, 1794; Packard, C. 253; Hofmann, Gr. Schm. Eur., 189, 1894; vamaria Schrank, Faun. Boica, ii, 2, 24, 1802; wawaria HerRICH-SchaEfFEr; Möschler, Verh. zool.bot. Ges. Wien, 301, 1884; fuscaria THuNBERG, Diss. Ent., iv, 58, 1794; v-nigraria Haworth, Lep. Brit., 282, 1829; atrosignata WALKER, Cat. Brit. Mus., xxv, 1457, 1862; circumflexaria EvErsmann, Bull. Mosc., iii, 226, 1848.

Col., Alberta, Minn., Ont.

U. S.

$$
\text { U.S. }
$$

Lab.

No. U.S., Eur. 
3709. pustularia HüBNer, Zutr. exot. Schmett., f. 879, 1837; Packard, C. 564; Hulst, Ent. News, vi, 106, 1895 .

syn. latifermugata WALKer, Cat. Brit. Mus., xxvi, 1640, 1862; PaCkard, C. 296; Hulst, Ent. News, v, 304, 1894; brunneata PACKARD, Fifth Rept. Peab. Acad. Sci., 67, 1873; Rept. Geol. Surv. Terr., v, 553, 1873; brunnearia Packard, C. 298; Goodell, Can. Ent., x, 66, 1878; Kellicotт, Can. Ent., xvii, 32,1885 .

3710. graphidiaria Hulst, Ent. Amer., ii, 190, 1887.

3711. octolineata Hulst, Ent. Amer., ii, 189, 1887.

*3712. particolor Hulst, Can. Ent., xxx, 163, 1898.

*3713. marinaria Strecker, Lep. Rhop. Het., suppl. 2, 9, 1899.

*3714. floridensis Hulst, Can. Ent., xxx, 164, 1898.

*3715. decorata Hulst, Trans. Am. Ent. Soc., xxiii, $333,1896$.

*3716. sericeata Hulst, Can. Ent., xxx, 191, 1898.

3717. olivalis Hulst, Can. Ent., xxx, 191, 1898.

3718. benigna Hulst, Can. Ent., xxx, 191, 1898.

*3719. pervelata WaLKer, Cat. Brit. Mus., xxvi, 1760, 1862; Packard, C. 276; Hulst, Ent. News, vi, 105, 1895 (type lost).

3720. rectifascia Hulst, Trans. Am. Ent. Soc., xxiii, $333,1896$.

3721. guenearia PaCkard, C. 252, 1876.

3722. tenebrosata Hulst, Ent. Amer., ii, 189, 1887.

*3723. subalbaria Hulst, Trans. Am. Ent. Soc., xxiii, $333,1896$.

3724. minuta Hulst, Trans. Am. Ent. Soc., xxiii, 334, 1896.

*3725. maricopa Hulst, Can. Ent., xxx, 164, 1898.

3726. abbreviata W ALKer, Cat. Brit. Mus., xxvi, 1673, 1862; Packard, C. 210; Hulst, Ent. News, vi, $105,1896$.

syn. florida Hulst, Trans. Am. Ent. Soc., xxiii, 334, 1896.

*3727. crassata Hulst. Trans. Am. Ent. Soc., xxiii, $333,1896$.

Ariz., N. M., Mex., Tex.

Ariz.

Fla.

Wash.

Fla.

Col.

Ariz., Col.

? Tex.

Cal.

Ga.

Wash.

Cal.

Ariz.

U. S.

Tex., Ariz.

Ariz.

Atl.

States.

Col. 
*3728. deceptata Hulst, Trans. Am. Ent. Soc., xxiii, $334,1896$.

*3729. pallidula Hulst, Trans. Am. Ent. Soc., xxiii, $334,1896$.

*3730. subacuta Hulst, Trans. Am. Ent. Soc., xxiii, $335,1896$.

*3731. cinereola Hulst, Trans. Am. Ent. Soc., xxiii, $335,1896$.

3732. umbriferata Hulst, Ent. Amer., ii, 189, 1887. syn. umbrifasciate Hulst, Trans. Am. Ent. Soc., xxiii, 332, 1896.

3733. inquinaria Hulst, Ent. Amer., ii, 189, 1887.

3734. denticulodes Hulst, Trans. Am. Ent. Soc., xxiii, $332,1896$.

*3735. festa Hulst, Trans. Am. Ent. Soc., xxiii, 335, 1896.

*3736. subfalcata Hulst, Trans. Am. Ent. Soc., xxiii, $335,1896$.

*3737. bicolorata Fabricius, Syst. Ent., suppl., 149, 1794; Guenée, Spec. Gén., x, 77, 1857; Packard, C. 294; Walker, Cat. Brit. Mus., xxiii, $883,1861$.

*3738. distribuaria HüBner, Zutr. exot. Schmett., f. 585, 1825; Packard, C. 293; Hulst, Ent. News, v, 305, 1896.

syn. oppositaria Guenée, Spec. Gén., x, 76, 1857; PaCKaRd, C. 293; proxanthata Walker, Cat. Brit. Mus., xxvi, 1642, 1862; Packard, C. 297; antaurate Walker, Cat. Brit. Mus., xxvi, 1686, 1862.

a. transitaria WALker, Cat. Brit. Mus., xxiii, 886, 1861; PACKard, C. 295.

*3739. donotaria Walker, Cat. Brit. Mus., xxvi, 1673. 1862 (type lost).

3739. 1. speciosa Hulst, Trans. Am. Ent. Soc., xxiii, 332, 1896. NYCTIPHANTA Hulst.

Hulst, Trans. Am. Ent. Soc., xxiii, 336, 1896.

*3740. lætula Hulst, Trans. Am. Ent. Soc., xxiii, 336,

Ariz. 1896.

\section{APOLEMA Hulst.}

Hulst, Trans. Am. Ent. Soc., xxiii, 336, 1896.

*3741. carata Hulst, Ent. Amer., ii, 211, 1887.

Col., Cal., N. Mex.

Col., Cal.

N. Y.,

Col.

Col.

Col..

Man.

Fla..

Cal.

Alberta.

Atl.

States.

Ga.

N. Mex.

Fla. 


\section{EUASPILATES Packard.}

Paekard, Sixth Rept. Peab. Acad. Sci., 45, 1874; C. 203; Hulst, Trans. Ent. Soc., xxiii, 337, 1896.

3742. spinataria Packard, Sixth Rept. Peab. Acad. Sci., 45, 1874; Rept. Geol. Surv. Terr., v, 551, 1875; C. 204; STrecker, Surv. Dept. Mo., RuffRocky ner, App. SS, 1863, 1878; Bruce, Ent. Amer., iii, $49,1887$.

\section{ANTHELIA Hulst.}

Hulst, Trans. Am. Ent. Soc., xxiii, 337, 1896.

*3743. taylorata Hulst, Trans. Am. Ent. Soc., xxiii. 337, 1896.

Mts.

Brit.

Col.

SYMPHERTA Hulst.

Hulst, Trans. Am. Ent. Soc., xxiii, 338, 1896.

3744. julia Hulst, Trans. Am. Ent. Soc., xxiii, 338, 1896.

Atl. States, Rocky Mts.

Col.

*3745. coloradensis Hulst, Trans. Am. Ent. Soc., xxiii, 338, 1896.

3746. marcessaria Guenée, Spec. Gén., x, 92, 1857; Packard, C. 251; Hulst, Ent. Amer., iii, 9, 1887.

a. cineraria PACKARd, Proc. Bost. Soc. Nat. Hist., xiii, 392, 1871.

3747. tripunctaria Packard, Proc. Bost. Soc. Nat. Hist., xvi, 26, 1874; C. 250; Butler, Pap., i, 222, 1882; Hulst, Ent. News, vi, 11, 1895.

Cal.,

Brit.

syn. ? Torquinaria Guenée, Spec. Gén., x, 101,

1857: Walker, Cat. Brit. Mus., xxiii, 958,

1861; Hulst, Ent. Amer., iii, 9, 1887; Ent.

News, vi, 11, 1895 (type lost).

\section{HOMOCHLODES Hulst.}

Hulst, Trans. Am. Ent. Soc., xxiii, 339, 1896.

3־78. fritillaria Guenée, Spec. Gén., x, 136, 1857; Packard, C. 489; Hulst, Ent. News, v, 306, No. Atl. 1894.

States.

syn. discoventa Walker, Cat. Brit. Mus., xxi, 404, 1860; Packard, C. 243; Grote, Can. Ent., ix, 28, 1877; Hulst, Ent. News, v, 306, 1894; latispargaria W ALKer, Can. Nat., vi, 41, 1861; Cat. Brit. Mus., xxv, 1387, 1862; immersata WALKER, Cat. Brit. Mus., xxiv, 1228, 1862.

*3749. famulata Hulst, Ent. Amer., ii, 191, 1887.

Ont. 
THALLOPHAGA Hulst.

Hulst, Trans. Am. Ent. Soc., xxiii, 339, 1896.

*3750. fautaria Hulst, Ent. Amer., iii, 216, 1888; Ent. News, v, 306, 1894.

Cal., Col., B. C.

\section{ETHYCTERA Hulst.}

Hulst, Trans. Am. Ent. Soc., xxiii, 339, 1896.

*3751. electa Hulst, Trans. Am. Ent. Soc., xxiii, 339, 1896.

*3752. lineata Hulst, Can. Ent., xxx, 192, 1898.

Cal.

Col.

\section{AP $Æ C A S I A$ Hulst.}

Hulst, Trans. Am. Ent. Soc., xxiii, 340, 1896.

3753. detersata Guenée, Spec. Gén., x, 105, 1857; Packard, C. 243.

Col.

*3754. deductaria WALker, Cat. Brit. Mus., xx, 237, 1860; Hulst, Ent. News, vi, 13, 1895.

No. Atl. States.

syn. atropunctata PACKARD, Sixth Rept. Peab. Acad. Sci., 50, 1874; C. 244; Grote, Can. Ent., xii, 219, 1880; fernaldi Grote, Can. Ent., x, 17, 1878 .

3755. defluata Walker, Cat. Brit. Mus., xxiii, 984, 1861; Packard, C. 245; Hulst, Ent. News, vi, 71,1895 .

syn. subaquaria WALKer, Cat. Brit. Mus., xxvi, 1660, 1862; PACKARD, C. 247.

*3756. mercedulata Strecker, Lep. Rhop. Het., suppl. $2,9,1899$.

*3757. extremaria Walker, Cat. Brit. Mus., xxiii, 984, 1861; Packard, C. 247; Hulst, Ent. News, vi, 42,1895 .

syn. ordinaria W ALKER, (at. Brit. Mus., xxiv, 1068, 1861.

No. Atl. States.

Cal.

Atl. States.

\section{CATOPYRRHA Hübner.}

HüBner, Verz. bek. Schmett., 300, 1818; Guenée, Spec. Gén., x, 182, 1857; Walker,

Cat. Brit. Mus., xxiv, 1064, 1861; Hulst, Trans. Am. Ent. Soc., xxiii, 340, 1896.

*3758. ferruginosaria Packard, Proc. Bost. Soc. Nat. Col. Hist., xiii, 388, 1871; C. 426. 
3759. coloraria Fabricius, Syst. Ent., suppl., 96, 1798; Packard, C. 206; Hulst, Ent. Amer., iii, 10 , 1887; Ent. News, vi, 15, 1895.

syn. accessaria HüBner, Zutr. exot. Schmett., f. 503, 1820?; cmentaria HüBNer, Eur. Schmett., pl. 10, f. 48, 1830?; Duponchel, Hist. Nat., viii, 128, 1829; atropunctaria Walker, Cat. Brit. Mus., xxvi, 1673, 1862; Packard, C. 210.

a. olenusaria WALKer, Cat. Brit. Mus., xxvi, 1675, 1862; PaCkard, C. 216.

b. dissimilaria HüBner, Samml. exot. Schmett., i, 1806; PaCkard, C. 208.

c. sphæromacaria Harvey, Bull. Buff. Soc., ii, 284, 1875; PaCKard, C. 207.

d. perolivata Hulst, Trans. Am. Ent. Soc., xxiii, $340,1896$.

ENEMERA Hulst.

Hulst, Trans. Am. Ent. Soc., xxiii, 340, 1896.

3760. juturnaria Guenée, Spec. Gén., x, 147, 1857; Packard, C. 241; Butler, Pap., i, 222, 1881; Dyar, Ent. News, v, 63, 1894; Hulst, Ent. News, vi, 104, 1895.

a. californiaria PACKARD, Proc. Bost. Soc. Nat. Hist., xiii, 394, 1871; C. 241.

3761. viridirufaria Neumoegen, Pap., i, 145, 1881.

Rocky Mts., Pac. States, Alaska.

\section{CARIPETA Walker.}

Walker, Cat. Brit. Mus., xxvi, 1524, 1862; PAckard, C. 237; Hulst, Trans. Am. Ent. Soc., xxiii, 341, 1896; Parennomos PACKard.

*3762. ida Hulst, Trans. Am. Ent. Soc., xxiii, 341, 1896.

Col.

*3763. græfiaria Hulst, Ent. Amer., ii, 192, 1887.

Ariz.

3764. divisata WaLker, Cat. Brit. Mus., xxvi, 1525, 1862: Packard, C. 237; Hulst, Ent. News, vi, $12,105,1895$.

Ariz.

syn. albopunctata Morrisox, Proc. Bost. Soc.

Nat. Hist., xvi, 202, 1874.

3765. angustiorata WaLKer, Cat. Brit. Mus., xxvi, 1524, 1862; Packard, C. 238; Am. Nat., xviii, 1095, 1884; Hulst, Ent. Amer., iii, 9, 1887.

Atl. States.

syn. piniaria PaCKard, New or Little Known Ins., $15,1870$.

a. latiorata W ALker, Cat. Brit. Mus., xxvi, 1525, 1862; Packard, C. 239.

Atl. States. 
*3766. aretaria WaLker, Cat. Brit. Mus., xx, 258, 1860; Hulst, Ent. News, vi, 12, 1895.

Va. to

Ga.

Col., N. Mex.

Pa.

*3768. seductaria Strecker, Lep. Rhop. Het., suppl. $2,9,1899$.

PHENGOMMAT $Æ$ A Hulst.

Hulst, Trans. Am. Ent. Soc., xxiii, 341, 1896.

3769. edwardsata Hulst, Ent. Amer., i, 203, 1886.

Col., Ariz., Cal.

3770. gertruda Hulst, Trans. Am. Ent. Soc., xxiii, $342,1896$.

Col.

*3771. dissimilis Hulst, Can. Ent., xxx, 215, 1898.

Col.

\section{PLATEA Herrich-Schaeffer.}

Herrich-Schafffer, Ausser. Schmett., 29, 1855; Hulst, Trans. Am. Ent. Soc., xxiii, 342, 1896; Grote, Proc. Ent. Soc. Phil., ii, 344, 1865; Gorylodes Guenée, Spec. Gén., x, 179, 1857; Packard, C. 201.

3772. californiaria Herrich - Schaeffer, Ausser. Cal. Schmett., f. 537,1855; W ALKer, Cat. Brit. Mus., xxvi, 1673,1862 .

syn. uncanaria Guenée, Spec. Gén., x, 180, 1857; Packard, C. 201.

a. personaria Hy. Edwards, Pap., i, 120, 1881.

3773. trilinearia Packard, Proc. Bost. Soc. Nat. Hist., xvi, 24, 1874; C. 202; Hulst, Ent. Amer., iii, $11,1887$.

Tex., Col.,

Ariz.,

Nev.

a. dulcearia Grote, Bull. Brook. Ent. Soc., iii, 46,1880 .

3774. diva Hulst, Trans. Am. Ent. Soc., xxiii, 343, 1896.

So.

Cal.

*3775. demorsaria Strecker, Lep. Rhop. Het., suppl. $2,9,1899$.

Wash.

\section{ENYPIA Hulst.}

Hulst, Trans. Am. Ent. Soc., xxiii, 343, 1896.

3776. venata Grote, Can. Ent., xv, 133, 1883.

Pac. States.

*3777. perangulata Hulst, Trans. Am. Ent. Soc., xxiii, $242,1896$.

Col.,

Ariz. 
PHILEDIA Hulst.

Hulst, Trans. Am. Ent. Soc., xxiii, 343, 1896.

3778. punctomacularia Hulst, Ent. Amer., iii, 214, 1888; Hopkins, Bull. 21, n. s., U. S. Dept. Agr., 18, 1899 (without name).

NEPYTIA Hulst.

Hulst, Trans. Am. Ent. Soc., xxiii, 344, 1896.

3779. nigrovenaria PACKARD, C. 454.

3780. semiclusaria Walker, Cat. Brit. Mus., xxvi, 1506, 1862; Hulst, Ent. News, vi, 42, 1895.

Pac. States. syn. pulchraria Мrлot, Proc. Bost. Soc. Nat. Hist., xiii, 170, 1896; РACKARD, C. 452; pellucidaria Packard, Fifth Rept. Peab. Acad. Sci., 78, 1873; Morrison, Psyche, i, 68, 1875; pinaria PACKARD, New or Little Known Ins., 14, 1870; Drмmock, Psyche, iv, 272,1885 .

a. canosaria W ALKer, Cat. Brit. Mus., xxvi, 1675, 1862: PACKARD, C. 210.

*3781. fumosaria Strecker, Lep. Rhop. Het., suppl. 2, 10, 1899 .

Pac. States.

No.

U. S.

Fla.,

Ill.

*3782. phantasmaria Strecker, Lep. Rhop. Het., suppl. 2, 10, 1899 .

3783. umbrosata Packard, Proc. Bost. Soc. Nat. Hist. xvi, 23, 1874; C. 453.

Wash.

Pac.

States.

\section{A LCIS Curtis.}

Curtis, Brit. Ent., iii, 303, 1825; Hulst, Trans. Am. Ent. Soc., xxiii, 344, 1896 Hesperumia Packard, Fifth Rept. Peab. Acad. Sci., 79, 1873; Proc. Bost. Soc. Nat. Hist., xvi, 37, 1873.

3784. sulphuraria Packard, Fifth Rept. Peab. Acad. U.S. Sci., 79, 1873; C. 477. syn. ochreata PACKARD, Proc. Bost. Soc. Nat. Hist., xvi, 37, 1873.

a. baltearia Hulst, Bull. Brook. Ent. Soc., iii, 43, 1880.

b. unicoloraria Hulst, Ent. Amer., i, 208, 1886.

3785. multilineata PACKARd, Fifth Rept. Peab. Acad. Sci., 65, 1873; C. 287; Hulst, Ent. Amer., ii, $223,1887$.

syn. patriciata Grote, Can. Ent., xv, 129, 1883.

3786. dislocaria Packard, C. 282; Grote, Can. Ent., xv, 8, 1883 .

N.-E. U. S., Rocky Mts.

Iowa, Tex., Col.

3787. metanemaria Hulst, Ent. Amer., ii, 188, 1887. 3788. depromaria Grote, Can. Ent., xv, 87, 1883.

Ariz., Cal. Rocky Mts. Cal. 
3790. atrolinearia Hulst, Ent. Amer., iii, 214, 1888.

3791. spododea Hulst, Trans. Am. Ent. Soc., xxiii, 345, 1896.

3792. dissonaria Hulst, Trans. Am. Ent. Soc., xxiii, $345,1896$.

*3793. guttata Hulst, Jn. N. Y. Ent. Soc., viii, 219, 1901.

*3794. dejecta Hulst, Trans. Am. Ent. Soc., xxiii, 345, 1896.

3795. quinquelinearia PACKARD, Sixth Rept. Peab. Acad. Sci., 51, 1874; C. 432.

3796. obliquaria Grote, Can. Ent., xv, 124, 1883.

3797. imitata Walker, Cat. Brit. Mus., xxi, 395, 1860; Hulst, Ent. News, vi, 42, 1895.

syn. californiaria PAckard, Proc. Bost. Soc.

Nat. Hist., xiii, 388, 1869; C. 411.

3798. mæstosa Hulst, Can. Ent., xxx, 193, 1898.

3799. latifasciaria PACKARd, Proc. Bost. Soc. Nat. Hist., xvi, 33, 1873; C. 447; Bull. U. S. Ent. Comm., vii, 49,1881 .

3800. haydenata PACKARD, C. $445,1876$.

*3801. luridula Hulst, Trans. Am. Ent. Soc., xxiii, 346, 1896.

3802. latipennis Hulst, Trans. Am. Ent. Soc., xxiii, $346,1896$.

\section{PARAPHIA Guenée.}

Atl. States, Col.

Col.

Col.

N. Y.,

$\mathrm{Pa}$.

Col., Cal., Ariz.

Tex.

Col., Cal. ,

Ariz.

Cal.

Nev.

Iowa.

Cal.,

Wash.

Rocky Mts.

Ga..

Fla.

Wash.

Guenée, Spec. Gén., ix, 271, 1857; Packard, C. 415; Hulst, Trans. Am. Ent. Soc., xxiii, 346, 1896; Amilapis Guenée, Spec. Gén., x, 62, 1857.

3803. subatomaria Wood, Ind. Ent., 241, f. 1673, 1839; Packard, C. 417; Hulst, Ent. News, vi, 73, 1895.

Atl. syn. nubecularia GuENÉE, mammuraria States.

Guenée, impropriata WaLker, Cat. Brit.

Mus., xxiii, 888, 1861; exsuperata W ALKER,

Cat. Brit. Mus., xxvi, 1655, 1862.

a. unipuncta Haworth, Lep. Brit., 345, 1820 ?;

PaCKard, C. 416.

syn. unipunctata GuEnÉE, triplipunctaria

Fiтch, Trans. N. Y. Agr. Soc., xviii, 825, 1860 .

b. deplanaria Guenée, Spec. Gén., ix, 272, 1857;

Packard, C. 418; Hutst, Ent. News, vi, 73,

1895 .

syn. fidoniata Walker, Cat. Brit. Mus., xxiii, $924,1861$.

$4630-$ No. $52-02-21$ 


\section{SPODOLEPIS Hulst.}

Hulst, Trans. Am. Ent. Soc., xxiii, 347, 1896.

3804. substriaria Hulst, Trans. Am. Ent. Soc., xxiii, $347,1896$.

N. Y., N. J.

STENOTRACHELYS Guenée.

Guenék, Spec. Gén., ix, 290, 1857; Packard, C. 448; Hulst, Trans. Am. Ent. Soc., xxiii, $347,1896$.

3805. approximaria HüBNER, Samml. exot. Schmett., i, 1806; PaCkard, C. 449.

3806. permagnaria PACKARD, C. 450, 1876.

So. Atl. States.

Mo.

\section{LYTROSIS Hulst.}

Hulst, Trans. Am. Ent. Soc., xxiii. 348, 1896.

3807. unitaria Herrich-Schaeffer, Ausser. Schmett., f. 204, 1855; Packard, C. 447; Bull. U. S. Ent. Comm., vii, 49, 1881.

\section{MERIS Hulst.}

Hulst, Trans. Am. Ent. Soc., xxiii, 348, 1896.

*3808. alticola Hulst, Trans. Am. Ent. Soc., xxiii, 348, 1896.

Col.

$$
\text { PTEROTAE Hulst. }
$$

Hulst, Trans. Am. Ent. Soc., xxiii, 349, 1896.

*3809. cariosa Hulst, Trans. Am. Ent. Soc., xxiii, 349, 1896.

\section{IXALA Hulst.}

Hulst, Trans. Am. Ent. Soc., xxiii, 349, 1896.

3810. desperaria Hulst, Ent. Amer., ii, 210, 1887. a. unicoloraria Hulst, Ent. Amer., iii, 217, 1888.

Cal.

\section{PTEROSPODA Dyar.}

Spodoptera Hulst (not Guenée), Trans. Am. Ent. Soc., xxiii, 350, 1896. *3811. opuscularia Hulst, Ent. Amer., ii, 210, 1887. Cal.

3812. kunzei Hulst, Can. Ent., xxx, 192, 1898. Ariz.

\section{SOMATOLOPHIA Hulst.}

Hulst, Trans. Am. Ent. Soc., xxiii, 350, 1896.

*3813. umbripennis Hulst, Trans. Am. Ent. Soc., xxiii, $350,1896$. 
Morrison, Proc. Bost. Soc. Nat. Hist., xvii, 217, 1875; Packard, C. 214; Hulst, Trans. Am. Ent. Soe., xxiii, 351, 1896.

3814. scolopacinarius Guevée, Spec. Gén., x, 360, 1857;
Packard, C. 565; Hulst, Ent. News, vi, 103, 1896.

syn. mubiginosus Morrison, Proc. Bost. Soc.

Nat. Hist., xvii, 218, 1875; PACKARD, C. 214.

a. cinctarius Hulst, Ent. Amer., ii, 192, 1887.

3815. abjectarius Hulst, Ent. Amer., ii, 192, 1887.

So. Atl.

States.

EXELIS Guenée.

Guenée, Spec. Gén., ix, 323, 1857; Patridiva Walker, Cat. Brit. Mus., xxvi, 1688, 1862.

3816. pyrolaria Guenée, Spec. Gén., ix, 324, 1857; So. Atl.

Packard, C. 565; Hulst, Ent. News, vi, 103, States.

1895; Ent. Amer., iv, 50, 1888.

syn. teusaria Walker, Cat. Brit. Mus., xxvi, 1689, 1862; approximaria PACKARD, C. 215;

Hulst, Ent. Amer., iii, 11, 1887; infumataria Grote, Can. Ent., ix, 90, 1877.

\section{SYNGLOCHIS Hulst.}

Hulst, Trans. Am. Ent. Soc., xxiii, 351, 1896.

*3817. perumbraria Hulst, Trans. Am. Ent. Soc., xxiii, Cal. $352,1896$.

\section{GLAUCINA Hulst.}

Hulst, Trans. Am. Ent. Soc., xxiii, 352, 1896.

3818. pygmeolaria Grote, Can. Ent., xv, 24, 1883; Hulst, Ent. Amer., iii, 11, 1887.

3819. escaria Grote, Can. Ent., xv, 24, 1883; Hulst, Ent. Amer., iii, 11, 1887.

Ariz.

Col., Ariz.

*3820. incopriata Hulst, Ent. Amer., ii, 210, 1887.

Cal., Ariz.

\section{HOLOCHROA Hulst.}

Hulst, Trans. Am. Ent. Soc., xxiii, 352, 1896.

3821. dissociaria Hulst, Ent. Amer., ii, 192, 1887.

Tex., Cal.

\section{CENOCHARIS Hulst.}

Hulst, Trans. Am. Ent. Soc., xxiii, 353, 1896.

*3822. eupitheciaria Grote, Can. Ent., xv, 24, 1883. 
3823. elongata Hulst, Trans. Am. Ent. Soc., xxiii, 353, 1896.

Tex., Ariz.

3824. interruptaria Grote, Can. Ent., xiv, 185, 1883; Hulst, Ent. Amer., iii, 11, 1887; iv, 49, 1888.

Col., Ariz., Cal.

*3825. ochrofuscaria Grote, Can. Ent., xiv, 186, 1883; Ariz. Hulst, Ent. Amer., iii, 11, 1887.

\section{ATHALODES Hulst.}

Hulst, Trans. Am. Ent. Soc., xxiii, 354, 1896.

*3826. packardaria Hulst, Ent. Amer., iii, 217, 1888.

Cal.

\section{CHESIADODES Hulst.}

Hulst, Trans. Am. Ent. Soc., xxiii, 354, 1896.

*3827. morosata Hulst, Trans. Am. Ent. Soc., xxiii, $354,1896$.

\section{SELIDOSEMA Hübner.}

HüBner, Verz. bek. Schmett., 299, 1818; Lederer, Verh. zool.-bot. Ges. Wien, 232, 1853; Packard, C. 240; Meyrick, Trans. Ent. Soc. Lond., 105, 1892; Hulst, Trans. Am. Ent. Soc., xxiii, 354, 1896; Adactylotis HüBner, Verz. bek. Schmett., 303, 1818.

*3828. muricolor Hulst, Trans. Am. Ent. Soc., xxiii, $\mathrm{Pa}$. $355,1896$.

3829. wrightiarium Hulst, Ent. Amer., iii, 215, 1888. Cal. *3830. fuliginarium Hulst, Ent. Amer., iii, 215, 1888. Ill., Tex. *3831. delicatum Hulst, Can. Ent., xxxii, 106, 1900. Cal.

3832. lachrymosum Hulst, Can. Ent., xxx, 194, 1898. syn. homopteroides Hulst, Jn. N. Y. Ent. Soc., viii, 219, 1901.

*3833. pulmonarium Grote, Pap., i, 167, 1881.

Col., Ariz., N. Mex.

*3834. clivinarium Guenée, Spec. Gén., ix, 245, 1857; Packard, C. 455; Hulst, Ent. News, vi, 105, Cal. 1895 .

*3835. separatarium Grote, Can. Ent., xv, 124, 1883. Ariz. 3836. nigrescens Hulst, Can. Ent., xxx, 214, 1898.

Tex.

*3837. laminarium Strecker, Lep. Rhop. Het., suppl. $2,10,1899$.

Cal. 
3838. humarium Guenée, Spec. Gén., ix, 246, 1857; Packard, C. 435; Hulst, Ent. News, vi, 41, 72, 1895.

Atl. States, N. Mex., Cal.

syn. intrarium Guenée, Spec. Gén., ix, 246, 1857; defectarium Guenée, Spec. Gén., ix, 247, 1857; moniarium WALKER, Cat. Brit. Mus., xxi, 345, 1860; transfixarium Walker, Cat. Brit. Mus., xxi, 347, 1860; albiginarium W ALKer, Cat. Brit. Mus., xxi, 348, 1860; ephyrarium WaLKer, Cat. Brit. Mus., xxi, 349,1860; intractarium W ALKER, Cat. Brit. Mus., xxi, 349, 1860; erosiatum WaLker, Cat. Brit. Mus., xxvi, 1719, 1862; illaudatum W ALKER, Cat. Brit. Mus., xxi, 397, 1860; ejectarium WALKER, Cat. Brit. Mus., xxii, 489,1861 ; expressarium W ALKER, Cat. Brit. Mus., xxvi, 1657, 1862.

3839. umbrosarium Hübner, Samml. exot. Schmett., i, 1806; Packard, C. 439.

syn. ?porcellarium Guenée, Spec. Gén., ix, 252, 1857; Walker, Cat. Brit. Mus., xxi, 350, 1860; Packard, C. 455; Hulst, Ent. News, vi, 42, 105, 1895.

a. gnophosarium Guenée, Spec. Gén., ix, 251, 1857; W Alk ER, Cat. Brit. Mus., xx, 350, 1860.

*3840. excelsarium Strecker, Lep. Rhop. Het., suppl. $2,10,1899$.

*3841. albescens Hulst, Trans. Am. Ent. Soc., xxiii, $355,1896$.

Atl. States.

Wash.

Wash.

\section{MERICISCA Hulst.}

Hulst, Trans. Am. Ent. Soc., xxiii, 356, 1896.

3842. gracea Hulst, Trans. Am. Ent. Soc., xxiii, 356, 1896.

Col.

\section{CLEORA Curtis.}

Curtis, Brit. Ent., ii, 88, 1825; Packard, C. 450; Meyrick, Trans. Ent. Soc. Lond., 105, 1892; Warren, Nov. Zool., i, 434, 1894; Hulst, Trans. Am. Ent. Soc., xxiii, 356, 1896; Boarmia Treitschke, Schmett. Eur., vi, 1, 87, 1827; Duponchel, Hist. Nat., vii, 4, 327, 1829; Herrich-Schaeffer, Schm. Eur., iii, 76, 1847; Lederer, Verh. zool.-bot. Ges. Wien, 177, 1853; Meyrick, Trans. New Zeal. Ins., 99, 1883; 65, 1884; Trans. Ent. Soc. Lond., 211, 1886.

3843. furfuraria Hulst, Ent. Amer., iii, 214, 1888.

Col.

3844. dataria Grote, Can. Ent., xiv, 173, 1882.

Rocky Mts.

*3845. opacaria Hulst, Bull. Brook. Ent. Soc., iv, 27, 1881.

Col.,

N. Mex.

*3846. lixaria Grote, Trans. Kans. Acad. Sci., viii, 52, 1882.

Rocky Mts. 
3847. cribrataria Guenée, Spec. Gén., ix, 260, 1857 ; PACKARD, C. 424.

Atl. States.

3848. indicataria WALker, Cat. Brit. Mus., xxi, 346 , 1860; Hulst, Ent. News, vi, 41, 1895.

Atl.

syn. filaria Walker, Cat. Brit. Mus., xxi, 347,1860 ; PACKARD, C. 456 ; polygrammaria PACKARD, C. 439.

*3849. rufaria Grote, Can. Ent., xv, 125, 1883.

3850. pampinaria Guenée, Spec. Gén., ix, 245, 1857; Packard, C. 432; French, Pap., i, 82, 1881; Hulst, Ent. News, vi, 41, 1895.

syn. sublunaria Guenée, Spec. Gén., ix, 248, 1857; PaCKaRd, C.442; frugallaria Guenée, Spec. Gén., ix, 246,1857; Walker, Cat. Brit. Mus., xxi, 342, 1860; collecta W ALkEr, Cat. Brit. Mus., xxi, 397,1860; tinctaria W ALKER, Cat. Brit. Mus., xxi, 486, 1860; fraudulentaria Zeller, Verh. zool.-bot. Ges. Wien, xxii, 492, 1872; PACKARD, C. 432.

*3851. configurata Hulst, Can. Ent., xxx, 195, 1898.

3852. formosata Hulst, Trans. Am. Ent. Soc., xxiii, $357,1896$. States.

Ariz.

Atl. States.

Col.

Col., Cal.

3853. correllatum Hulst, Trans. Am. Ent. Soc., xxiii, $355,1896$.

Col., Cal.,

Oreg.

Fla.,

Tex.

3855. larvaria Guenée, Spec. Gén., ix, 247, 1857; Packard, C. 437; Hulst, Ent. News, vi, 34, 1895.

syn. ? convergaria Walker, Cat. Brit. Mus., xxi, 488, 1860 (type lost); plumosaria PACKARD, Sixth Rept. Peab. Acad. Sci., 51, 1874; C. 431 .

3856. subaustralis Hulst, Can. Ent., xxx, 194, 1898. 3857. pedicellata Hulst, Can. Ent., xxx, 194, 1898.

Fla.

Fla.

\section{MELANOLOPHIA Hulst.}

Hulst, Trans. Am. Ent. Soc., xxiii, 357, 1896.

3858. canadaria Guenée, Spec. Gén., ix, 263, 1857; Packard, C. 425; Hulst, Ent. News, vi, 42, Miss., Oreg., Wash., Man. 1895 .

syn. signataria W ALker, Cat. Brit. Mus., xxi, 350, 1860; mperfectaria W ALKER, Cat. Brit. Mus., xxi, 407, 1860; contribuaria WALKER, Cat. Brit. Mus., xxi, 407, 1860. 
ETHALOPTERA Hulst.

Hulst, Trans. Am. Ent. Soc., xxiii, 358, 1896.

3859. intextata Walker, Cat. Brit. Mus., xxi, 398, 1860; Hulst, Ent. News, vi, 42, 1895.

Atl.

States.

syn. anticaria WALKer, Cat. Brit. Mus., xxi, 406, 1860; Packard, C. 423; Hulst, Ent. News, vi, 42, 1895; submurraria WALKER, Cat. Brit. Mus., xxi, 406, 1860.

\section{GLENA Hulst.}

Hulst, Trans. Am. Ent. Soc., xxiii, 358, 1896.

*3860. cognataria HüBner, Zutr. exot. Schmett., f. 549 , 1825; Packard, C. 421; Hulst, Ent. News, vi, Atl. 42,1895 .

syn. acidaliaria Walker, Cat. Brit. Mus., xxvi, 1684, 1862; infixaria WALKER, Cat. Brit. Mus., xxvi, 1685, 1862.

3861. texanaria Hulst, Ent. Amer., iii, 46, 1888. Fla., Tex. syn. ? minimaria Guenée, Spec. Gén., ix, 279,1857 .

\section{ECTROPIS Hübner.}

Hüвner, Verz. bek. Schmett., 316, 1818; Meyrick, Trans. Ent. Soc. Lond., 104, 1892; Hulst, Trans. Am. Ent. Soc., xxiii, 358, 1896; Tephrosia Guenée, Ind. Gén., 198, 1840; Packard, C. 420.

3862. crepuscularia Denis \& Schiffermüller, Syst. Verz. Wien, 101, 1776; PACKard, C. 428; U.S., Staudinger \& Rebel, Cat. Lep. Eur., i, no. Eur. 3903, 1901; Goodell, Can. Ent., x, 67, 1878; Möschler, Verh. zool.-bot. Ges. Wien, 300, 1884; Dimmock, Psyche, iv, 271, 1885; Hulst, Ent. News, vi, 41, 72, 1895 .

syn. consonaria Haworth, defessaria FreY, occiduaria GUENÉE, signaria WALKER, spatiosaria WALKER, intrataria WALKER, cineraria Walker, Cat. Brit Mus., xxi, 488, 1860; fumataria Мгот.

a. abraxaria WALker, Cat. Brit. Mus., xxi, 403, 1860; Hulst, Ent. News, vi, 72, 1895.

syn. divisaria Walker, Cat. Brit. Mus., xxi, 489, 1860; Packard, C. 458; Bowles, Can. Ent., xv, 166, 1883; fernaldaria Hulst, Ent. Amer., iii, 215, 1888.

*3863. grisearia Grote, Can. Ent., xv, 124, 1883.

Ariz. 


\section{EPIMECIS Hïbner.}

Hübner, Verz. bek. Schmett., 315, 1818; Grote, Can. Ent., viii, 206, 1876; Hulst, Trans. Am. Ent. Soc., xxiii, 359, 1896; Bronchelia Guenée, Spec. Gén., ix, 286, 1857; Walker, Cat. Brit. Mus., xxi, 450, 1860.

3864. virginaria Cramer, Pap. Exot., iii, pl. 275, f. G, 1782; Hulst, Ent. News, vi, 106, 1895.

syn. hortaria Fabricius, Syst. Ent., iii, (2), States. 138, 31, 1793; PaCkard, C. 443; Hulst, Ent. News, vi, 104, 1895; liriodendraria Sмптн \& Аввот, Lep. Ins. Ga., pl. 102, 1797; disserptaria WaLker. Cat. Brit. Mus., xxi, 451, 1860; amplaria WALKER, Cat. Brit. Mus., xxi, 405, 1860.

a. dendraria Guenée, Spec. Gén., ix, 289, 1857; Walker, Cat. Brit. Mus., xxi, 451, 1860. syn. gravilinearia Andrews, Can. Ent., x, 108, 1878.

\section{LYCIA Hübner.}

HüBner, Verz. bek. Schmett., 319, 1818; Hulst, Trans. Am. Ent. Soc., xxiii, 359, 1896; Amphidasis Treitschke, Schm. Eur., vi, 1, 229, 1827; Duponchel, Hist. Nat., vii, 4, 268, 1829; Herrich-Schaeffer, Eur. Schmett., iii, 99, 1847; Lederer, Verh. zool.-bot. Ges. Wien, 218, 1853; Kirby, Eur. Butt., 332, 1882; Amphidasys GuenÉe, Spec. Gén., ix, 206, 1857; Walker, Cat. Brit. Mus., xxi, 305, 1860; Hofmann, Gr. Schm. Eur., 179, 1894.

3865. ursaria WAlker, Can. Nat., v, 261, 1860; PACKARD, C. 414; Bull. U. S. Ent. Comm., vii, 121, Atl. 1881; Möschler, Verh. zool.-bot. Ges. Wien, States. 300, 1884; Bowles, Can. Ent., viii, 7, 1876.

3866. virginaria Grote, Can. Ent., xii, 220, 1880; Hulst, Ent. News, vi, 41, 1895.

3867. cognataria Gunnée, Spec. Gén., ix, 208, 1857; Packard, C. 413; Bowles, Can. Ent., iii, 11, 1871; Edwards \& Elliot, Pap., iii, 136, 1883; Goodell, Can. Ent., x, 67, 1878; PutnamCramer, Bull. Brook. Ent. Soc., vi, 48, 1885; Lintner, Ann. Rept. N. Y. Sta. Ent., 98, 1885; Saunders, Ins. Inj. Fru., 349, 1883; Diммоск, Psyche, iv, 271, 1885; Hulst, Ent. News, vi, 41,1895 .

syn. sperataria Walker, Cat. Brit. Mus., xxi, 307,1860 .

\section{PHAOURA Hulst.}

Hulst, Trans. Am. Ent. Soc., xxiii, 359, 1896.

3868. mexicanaria Grote, Trans. Kans. Acad. Sci., viii, 51, 1882; Hulst, Ent. News, vi, 41, 1895.

Col.

Atl. States.

*3869. cristifera Hulst, Trans. Am. Ent. Soc., xxiii, 360, 1896.

Col.

Col. 
NACOPHORA Hulst.

Hulst, Trans. Am. Ent. Soc., xxiii, 360, 1896.

*3870. minima Hulst, Trans. Am. Ent. Soc., xxiii, 360,

Col.

1896.

*3871. ypsilon Forbes, Rept. Ent. Ill., xiv, 95, 1885; Lugger, Rept. Ent. Minn., 189, 1898.

Atl. States syn. carolotta Hulst, Trans. Am. Ent. Soc., xxiii, 361, 1896.

*3872. phigaliaria Guenée, Spec. Gén., ix, 225, 1857; Packard, C. 328; Hulst, Ent. News, vi, 41, Atl. 1895 .

syn. pænulataria Grote, Proc. Ent. Soc. Phil., ii, 31, 1864; Can. Ent., viii, 153, 1876.

3873. quernaria Sмiтh \& Aввот, Lep. Ins. Ga., ii, 205, pl. 103, 1797; Packard, C. 411; Emions, Nat. Hist. N. Y. Agr., v, 245, 1854; Hulst, Ent. Amer., iv, 50, 1888; Ent. News, vi, 41, 1895 .

a. atrescens Hulst, Can. Ent., xxx, 162, 1898.

*3874. cupidaria Grote, Proc. Ent. Soc. Phil., iii, 534, 1864; Packard, C. 412; Hulst, Ent. Amer., iv, States. 50, 1888; Ent. News, vi, 41, 1895.

Atl. States.

Fla.

\section{CERATONYX Guenée.}

Guenée, Spec. Gén., ix, 193, 1857; Walker, Cat. Brit. Mus., xxi, 296, 1860.

*3875. satanaria Guenée, Spec. Gén., ix, 194, 1857;

Ga. PACKARD, C. 565.

\section{APOCHEIMA Hübner.}

Hübner, Verz. bek. Schmett., 319, 1818; Guenée, Spec. Gén., ix, 203, 1857; MeyRICK, Trans. Ent. Soc. Lond., 121, 1892; Hulst, Trans. Am. Ent. Soc., xxiii, 361, 1896; A pochima Herrich-Schaeffer, Eur. Schmett., iii, 98, 1847; Lederer, Verh. zool.-bot. Ges. Wien, 218, 1853; Ithusia HüBner, Verz. bek. Schmett., 319, 1818; Nyssia Duponchel, Hist. Nat., vii, 283, 1829; Guenée, Spec. Gén., ix., 198, 1857.

3876. rachelæ Hulst, Trans. Am. Ent. Soc., xxiii, 362, 1896.
Col.

Alaska.

\section{CONIODES Hulst.}

Hulst, Trans. Am. Ent. Amer., xxiii, 353, 1896.

3877. plumigeraria Hulst, Ent. Amer., iii, 216, 1888; Coquillett, Bull. U. S. Dept. Agr., n. s., vii, 64, 1897; Hulst, Can. Ent., xxx, 214, 1898.

Col., Cal., Brit. Col. 
JUBARELLA Hulst.

Hulst, Can. Ent., xxx, 192, 1898.

*3878. danbyi Hurst, Can. Ent., xxx, 192, 1898.

Brit. Col.

\section{PHIGALIA Duponchel.}

Duponchel, Hist. Nat., vii, 296, 1829; Lederer, Verh. zool.-bot. Ges. Wien, 177, 1853; Guenée, Spec. Gén., ix, 195, 1857; Packard, C. 406; Raphidodemas Hulst, Trans. Am. Ent. Soc., xxiii, 362, 1896.

*3879. nevadaria Hulst, Trans. Am. Ent. Soc., xxiii, $362,1896$.

Nev., Col.

3880. olivacearia Morrison, Proc. Bost. Soc. Nat. Hist., xvi, 200, 1874; Hulst, Ent. Amer., iv, 51, 1888 .

3881. titea Cramer, Pap. Exot., iii, 275, f. C, 1782; Packard, C. 442; Hulst, Ent. News, vi, 41, 1896.

syn. titearia Guenée, Spec. Gén., ix, 248, 1857; Walker, Cat. Brit. Mus., xxi, 345, 1860; revocata WaLker, Cat. Brit. Mus., xxvi, 1527, 1862; strigataria Мinot, Proc. Bost. Soc. Nat. Hist., xiii, 84, 1869; PACKARd, C. 407; Bruce, Pap., ii, 81, 1882; French, Trans. Dept. Agr. Ill., xv, 241, 1877; ? cinctaria French, Can. Ent., x, 157, 1878; Hulst, Ent. Amer., iv, 51, 1888.

*3882. denticulata Hulst, Jn. N. Y. Ent. Soc., viii, 219, 1901.

Atl. States.

Atl. States.

\section{ERANNIS Hübner.}

Hübner, Verz. bek. Schmett., 320, 1818; Meyrick, Trans. Ent. Soc. Lond., 81, 1892; Hulst, Trans. Am. Ent. Soc., xxiii, 363, 1896; Agriopis HüBner, Verz. bek. Schmett., 320, 1818; Hybernia Latreille, Fam. Nat., 477, 1825; Packard, C. 408; Meyrick, Trans. Ent. Soc. Lond., 120, 1892; Hibernia Duponchel, Hist. Nat., vii, 4, 301, 1829; Herrich-Schaeffer, Eur. Schmett., iii, 58, 1847; Lederer, Verh. zool.-bot. Ges. Wien, 213, 1853; Hofmann, Gr. Schm. Eur., 176, 1894.

3883. defoliaria Clerck, Icones, 7, 4, 1764: StaUDINGER \& Rebel, Cat. Lep. Eur., i, no. 3802, 1901.

Eur., a. vancouverensis Hulst, Trans. Am. Ent. Soc., B. C. xxiii, 363, 1896.

3884. tiliaria HARris, Inj. Ins. Mass., 341, 1841; PACKard, C. 409; Saunders, Can. Ent., xiv, 282, 1882; Ins. Inj. Fruits, 111, 1883; Fiтch, Third Rept. Ins. N. Y., 343, 1856; J AEgER, N. Am. Ins., 175, 1871; Coquillett, Rept. Ent. Ill., x, Atl. States, Rocky 149, 1880; xi, 25, 1881. 
*3885. coloradata Hulst, Trans. Am. Ent. Soc., xxiii, $363,1896$.

Col.

\section{CINGILIA Walker.}

Walker, Trans. Ent. Soc. Lond., (3), i, 76, 1862; Dyar, Can. Ent., xxvi, 69, 1894; Hulst, Trans. Am. Ent. Soc., xxiii, 364, 1896; Caterva Grote, Can. Ent., viii, 205, 1876; Vestigifera v. Gumppenberg, Nov. Act. Halle, lii, 369, 1888.

3886. catenaria Drury, Ill. Exot. Ent., i, 17, 1770; Cramer, Pap. Exot., iii, 61, pl. 228, f. E, 1782; Emmons, Nat. Hist. N. Y. Agr., v, 249, 1854; Packard, C. 217; Comstock, Rept. Dept. Agr., 274, 1880; Coquillett, Pap., i, 56, 1881; Harris, Ins. Inj. Mass., 459, 1852; Dyar, Psyche, ix, $250,1901$.

syn. humeralis Walker, Trans. Ent. Soc. Lond., (3), i, 76, 1862; ? devinctaria Guenée, Spec. Gén., x, 222, 1857; WaLker, Cat. Brit. Mus., xxiv, 1137, 1862.

\section{EUCATERVA Grote.}

Grote, Pap., ii, 80, 1882; Hulst, Trans. Am. Ent. Soc., xxiii, 364, 1876.

3887. vararia Grote, Pap., ii, 80, 1882; Can. Ent., Ariz. xiv, 109, 1882; HAY, Bull. Geol. Surv., vi, 564, Atl. States, Col. 1882; Dyar, Ent. News, v, 63, 1894.

a. sabesaria Grote, Pap., ii, 143, 1882.

PHILTR $Æ$ A Hulst.

Hulst, Trans. Am. Ent. Soc., xxiii, 364, 1896.

3888. elegantaria Hy. Edwards, Pap., i, 121, 1881.

Tenn., La., Tex., Ariz., Cal.

\section{ACANTHOPHORA Hulst.}

Hulst, Trans. Am. Ent. Soc., xxiii, 365, 1896.

3889. graefij Hulst, Trans. Am. Ent. Soc., xxiii, 365, 1896.

Tex.

TRACHEOPS Hulst.

Hulst, Trans. Am. Ent. Soc., xxiii, 365, 1896.

*3890. bolteri Hulst, Trans. Am. Ent. Soc., xxiii, 366 , 1896. 
DYSCIA Hübner.

Hübner, Verz. bek. Schmett., 314, 1818; Hulst, Trans. Am. Ent. Soc., xxiii, 366, 1896; Psednothrix HüBNer, Verz. bek. Schmett., 319, 1818, Scodiona Borsduval, Ind. Méth., 185, 1840; Lederer, Verh. zool.-bot. Ges. Wien, 235, 1853; Guenée, Spec. Gén., x, 139, 1857; Walker, Cat. Brit. Mus., xxiv, 1021, 1862; Napuca Walker, Cat. Brit. Mus., xxvi, 1693, 1862; Pseudosiona Butler, Ann. Mag. Nat. Hist., (6), xii, 18, 1893.

3891. orciferata WaLker, Cat. Brit. Mus., xxvi, 1693, 1862; Packard, C., pl. 13, f. 57; Hulst, Ent. No. Amer., ii, 223, 1887; Ent. News, vi, 14, 1895. U. S. a. labradoriata Möschler, Stett. ent. Zeit., 118, 1883; Staudinger \& Rebel, Cat. Lep. Eur., i, no. $3786,1901$.

syn. aberrata Hy. Edwards, Pap., iv, 47, 1887;

taylori Butler, Ann. Mag. Nat. Hist., (6), xii, 18, 1893.

LYCHNOSEA Grote.

Grote, Trans. Kans. Acad. Sci., viii, 52, 1882; Hulst, Trans. Am. Ent. Soc., xxiii, $367,1896$.

3892. helviolaria Hulst, Bull. Brook. Ent. Soc., iv, 33, Col., N.Mex., 1881; Ent. Amer., ii, 50, 1882. Ariz.

syn. aulularia Grote, Trans. Kans. Acad. Sci., viii, 52, 1882.

3893. intermicata W ALker, Cat. Brit. Mus., xxiv, 1076, 1862; Hulst, Ent. News, vi, 42, $105,1895$.

So. Atl.

syn. pervaria PaCkard, Fifth Rept. Peab. Acad.

States.

Sci., 62, 1873; C. 206.

a. interminaria Grote, Can. Ent., ix, 90, 1877.

*3894. runcinaria STrecker, Lep. Rhop. Het., suppl. 2,

Col. 7, 1899 .

STERGAMMAT $A$ A Hulst.

Hulst, Trans. Am. Ent. Soc., xxxiii, 368, 1896.

*3895. inornata Hulst, Trans. Am. Ent. Soc., xxiii, 368, Col. 1896.

\section{MELEM $Æ$ A Hulst.}

Hulst, Trans. Am. Ent. Soc., xxiii, 368, 1896.

*3896. magdalena Hulst, Trans. Am. Ent. Soc., xxiii, 368, 1896.

Col.

*3897. morsicaria Hulst, Ent. Amer., i, 203, 1896.

Tex. 
ANAGOGA Hübner.

Hübner, Verz. bek. Schmett., 294, 1818; Packard, C. 486; Hulst, Trans. Am. Ent. Soc., xxiii, 369, 1896; Azinophora Stephens, Cat. 126, 1829; Numeria Duponchel, Hist. Nat., vii, 4, 107, 1829; Westwood \& Humphreys, Brit. Moths, ii, 24, 1849; Hofmann, Gr. Schm. Eur., 170, 1892.

3898. pulveraria Linneus, Syst. Nat., 521, 1758; Guenée, Spec. Gén., x, 137, 1857; Staudinger \& Rebel, Cat. Lep. Eur., i, no. 3715, 1901. Eur., No. a. occiduaria W ALKER, C'at. Brit. Mus., xxiii, 1016, 1861; Packard, C. 487; Hulst, Ent. Amer., ii, 51, 1886; Ent. News, vi, 12, 1895. syn. plagifasciata Walker, Cat. Brit. Mus., xxvi, 1508, 1862; PACKaRD, C. 487.

\section{NEOTERPES Hulst.}

Hulst, Trans. Am. Ent. Soc., xxiii, 369, 1896.

3899. ephelidaria Hulst, Ent. Amer., ii, 120, 1886. a. kunzei Hulst, Can. Ent., xxx, 215, 1898.

*3900. snoviaria Hulst, Ent. Amer., iii, 213, 1887.

3901. edwardsata Packard, Proc. Bost. Soc. Nat. Hist., xiii, 383, 1871; C. 478; Strecker, Surv. Dept. Mo., Ruffner, app. SS, 1863, 1878.

Rocky Mts.

Rocky Mts.

Cal., Ariz., Alaska.

\section{SICYA Guenée.}

Guenée, Spec. Gén., ix, 104, 1857; Packard, C. 479; Hulst, Trans. Am. Ent. Soc., xxiii, $370,1896$.

3902. macularia Harris, Lake Superior, Agassiz, 392,

U.S.

1850; Packard, C. 480; Hulst, Ent. News, vi, 14,1895 .

syn. solfataria Guenée, Spec. Gén., ix, 104, 1857; Walker, Cat. Brit. Mus., xx, 134, 1860; sublimaria Guenée, Spec. Gén., ix, 105, 1857; calipusaria WALKER, Cat. Brit. Mus., xx, 120, 1860 .

a. truncataria Guenée, Spec. Gén., ix, 104, 1857. syn. argyllaria WALkER, Cat. Brit. Mus., xx, 121, 1860; crocearia PACKARD, Proc. Bost.

Soc. Nat. Hist., xvi, 36, 1874.

b. faustinaria Strecker, Lep. Rhop. Het., suppl. $2,7,1899$. 


\section{THERINA Hübner.}

HüBner, Verz. bek. Schmett., 283, 1818; Packard, C. 492; Hulst, Trans. Am. Ent. Soc., xxiii, 370, 1896; Hylæa Hüвner (not $a$ ), Tentamen, 1810; Ellopia Treitschke, Schmett. Eur., vi, 1, 89, 1827; Packard, C. 492.

3903. vitraria Grote, Trans. Kans. Acad. Sci., viii, 51, 1882.

Rocky Mts.

*3904. punctata Hulst, Can. Ent., xxx, 215, 1899.

*3905. fatuaria STrEcker, Lep. Rhop. Het., suppl. 2, 8, 1899 .

*3906. læta Hulst, Can. Ent., xxxii, 107, 1900.

3907. pellucidaria Grote \& Robinson, Ann. N. Y. Lyc. Nat. Hist., viii, 25, 1867; Packard, C. 495; Grote, Can. Ent., xiv, 108, 1882; Hulst, Ent. Amer., ii, 51, 1886; Ent. News, vi, 14, 1895; Dyar, Psyche, ix, 21, 1900.

3908. endropiaria Grote \& Robinson, Ann. N. Y. Lye. Nat. Hist., viii, 26, 1867; Packard, C. 495; Goodell, Can. Ent., xi, 194, 1879; Grote, Can. Ent., xiv, 109, 1882; Hulst, Ent. Amer., ii, 51, 1886: Dyar, Psyche, viii, 407, 1899.

3909. athasiaria WALkER, Cat. Brit. Mus., xx, 163, 1860; Hulst, Ent. News, vi, 14, 1895; Dyar, Psyche, ix, 10, 1900.

syn. siccaria WALKER, Cat. Brit. Mus., xxvi, 1547, 1866; seminudata WALKER, Cat. Brit. Mus., xxvi, 1508, 1862; seminudaria PACKARD, C. 495; bibularia Grote \& Robinson, Ann. Lyc. Nat. Hist. N. Y., viii, 24, 1867.

3910. fiscellaria Guenée, Spec. Gén., ix, 133, 1857; Walker, Cat. Brit. Mus., xx, 161, 1860; Hulst, Ent. Amer., ii, 50, 1886; Ent. News, vi, 14, 1895. syn. Alagitiaria Guenée, Spec. Gén., ix, 133, 1857; panisaria Walker, Cat. Brit. Mus., $\mathrm{xx}, 163,1860$; rqualiaria WALKer, Cat. Brit. Mus., xx, 164, 1860.

3911. fervidaria HüBner, Zutr. exot. Schmett., f. 409, 1818; Packard, C. 493; Hulst, Ent. Amer., ii, 50, 1886; Ent. News, vi, 14, 1895.

syn. pultaria Guenée, Spec. Gén., ix, 131, 1857; PaCKard, C. 496; sciata WaLKER, Cat. Brit. Mus., xxvi, 1510, 1862; invexata W Alker, Cat. Brit. Mus., xxvi, 1512, 1862. a. somniaria Hulst, Ent. Amer., i, 308, 1886; Fletcher, Rept. Exp. Farms Can., 176, 1891; Riley, Ins. Life, iii, 360, 1891.
Col.

Can.

N. Mex.

Atl.

States.

Atl.

States.

Atl.

States.

Atl. States, Col.

Atl. States. 
3912. lugubrosa Hulst, Can. Ent., xxxii, 106, 1900.

B. C.

*3912. 1. cavillaria Hulst, Ent. Amer., i, 203, 1886.

Ariz.

\section{METROCAMPA Latreille.}

Latreille, Cons. Gen., 366, 1810; Fam. Nat., 477, 1825; Packard, C. 490; Meyrick, Trans. Ent. Soc. Lond., 111, 1892; Hulst, Trans. Am. Ent. Soc., xxiii, 370, 1896; Campæa Lamarck, Hist. Nat., iii, 568, 1817.

3913. prægrandaria Guenée, Spec. Gén., ix, 128, 1857;

Walker, Cat. Brit. Mus., xx, 157, 1860; Hulst,

No.

Ent. News, vi, $104,1895$.

syn. perlata Guenée, Spec. Gén., ix, 128, 1857; Strecker, Surv. Dept. Mo., Ruffner, app. SS, 1863, 1878; Butlep, Pap., ii, 21, 1881: Möschler, Verh. zool.-bot. Ges. Wien, 298, 1884; perlaria PACKARD, C. 491; viridoperlata PACKARD, Proc. Bost. Soc. Nat. Hist., xvi, 38, 1874.

\section{SLOSSONIA Hulst.}

Hulst, Can. Ent., xxx, 216, 1898.

3914. rubrotincta Hulst, Can. Ent., xxx, 217, 1898.

Cal.

3915. latipennis Hulst, Can. Ent., xxx, 217, 1898.

Fla.

\section{EUGONOBAPTA Warren.}

Warren, Nov. Zool., i, 405, 1894; Hulst, Trans. Am. Ent. Soc., xxiii, 371, 1896. 3916. nivosaria Guenée, Spec. Gén., ix, 499, 1857. Atl. States.

syn. nivosata PaCKard, C. 338; Hulst, Ent.

News, v, 304, 1894.

*3917. constans Hulst, Can. Ent., xxx, 216, 1898.

Ariz.

*3918. ochreata Hulst, Can. Ent., xxx, 216, 1898.

Ariz.

*3919. brunneolineata Hulst, Jn. N. Y. Ent. Soc., viii,

Fla. 218, 1901.

\section{RIPULA Guenée.}

Guenée, Spec. Gén., ix, 34, 1857; Hulst, Trans. Am. Ent. Soc., xxiii, 371, 1896. 3920. vestalis Hulst, Can. Ent., xxx, 215, 1898.

Fla.

*3921 virginaria Hulst, Ent. Amer., i, 202, $1886 . \quad$ Fla. 


\section{ENNOMOS Treitschke.}

Treitschke, Schm. Eur., vi, 1, 3, 1827; Duponchel, Hist. Nat., vii, 4, 126, 1829; Boisduval, Ind. Gén., 182, 1840; Duponchel, Cat., 218, 1844; Westwood \& Humphreys, Brit. Moths, 2, 81, 1849; Guenée, Spec. Gén., ix, 173, 1857; Walker, Cat. Brit. Mus., xx, 204, 1860; Hofmann, Gr. Schm. Eur., 171, 1894; Hulst, Trans. Am. Ent. Soc., xxiii, 371, 1896; Eugonia Hü BNER (not $a$ ), Verz. bek. Schmett., 291, 1818; Packard, C. 527; Kirby, Eur. Butt., 298, 1882; Odoptera Sodoffsky, Bull. Imp. Soc. Mose., 125, 1837; Stephens, Cat. Brit. Ins., 165, 1850.

3922. subsignarius HüBner, Samml. exot. Schmett., ii, 1806; Graef, Rept. Brook. Hort. Soc., -, 1862; Packard, C. 528; Am. Nat., ii, 333, 1868; Bull. U. S. Ent. Comm., vii, 62, 1881; Grсте, Bull. Geol. Surv. Terr., Hayden, vi, 588, 1882; Dodge, Can. Ent., xiv, 30, 1882; French, Trans. Dept. Agr. Ill., xv, 243, 1877; Saunders, Ins. Inj. Fruits, 111, 1883; Walsh, Pract. Ent., i, $57,1866$.

syn. niveosericeata Jones, Proc. Ent. Soc. Phil., i, 31, 1861.

3923. magnarius Guenée, Spec. Gén., ix, 174, 1857; Walker, Cat. Brit. Mus., xx, 205, 1860; Hulst, Ent. Amer., ii, 49, 1884; iv, 49, 1886; Dпммоск, Atl.
States,
Col. Psyche, iv, 272, 1885; Snellen, Neder. Ent. Ver., xxix, 137, 1874.

syn. alniaria PACKARd (not Linn eus), C. 529; Bull. U. S. Ent. Comm., vii, 92, 1881; autumnaria Möschler (not WerNEBURG), Verh. zool.-bot. Ges. Wien, 299, 1884; lutaria Walker, Cat. Brit. Mus., xxxv, 1552, 1866; PACKARD, C. 531.

*3924. ochreatus Hulst, Can. Ent., xxx, 218, 1898.

No. U. S.

\section{XANTHOTYPE Warren.}

Warren, Nov. Zool., i, 463, 1894; Hulst, Trans. Am. Ent. Soc., xxiii, 372, 1896. 3925. crocataria Fabricius, Ent. Syst., suppl., 146, 1794; Packard, C. 474; Rept. Geol. Surv. Terr., v, 554, 1873; Saunders, Rept. Ent. Soc. Ont., ii, 87, 1870; Ins. Inj. Fruits, 348, 1883; FrenCH, Trans. Dept. Agr. Ill., xv, 243, 1877; Forbes, Trans. Dept. Agr. Ill., xxi, 80, 1883; DYAR, Ent. News, v, 62, 1894; v. Gumppenberg, Nov. Act. Halle, xlix, 396, 1887; Dyar; Psyche, ix, $226,1901$.

syn. citrina HüBNER, Zutr. exot. Schmett., f. 499,1825 .

a. cælaria Hulst, Ent. Amer., i, 208, 1886.

\section{PLAGODIS Hübner.}

Hübner, Verz. bek. Schmett., 294, 1818; Packard, C. 465; Hulst, Trans. Am. Ent. Soc., Xxiii, 372, 1896; Eurymene Duponchel, Hist. Nat., vii, 185, 1829; KIrby, Eur. Butt., 302, 1882; Hofmans, Gr. Schm. Eur., 173, 1894.

*3926. kempii Hulst, Jn. N. Y. Ent. Soc., viii, 220, 1901. 
3927. serinaria HerRICH-SCHAEFFER, A usser. Schmett., f. 365, 1855; PaCkard, C. 469; Hulst, Ent. Amer., ii, 52, 1886; Ent. News, vi, 14, 1895. syn. subprivata W ALKer, Cat. Brit. Mus., xxvi, 1509, 1862; floscularia Grote, Pap., i, 40, 1881; Can. Ent., xiv, 109, 1889; Pap., ii, 83,1882 .

a. rosaria Grote, Bull. Buff. Soc., iii, 131, 1876. 3928. keutzingi Grote, Can. Ent., viii, 112, 1876; viii, $154,1876$.

syn. keutaingaria PACKARD, C. 468.

a. nigrescaria Hulst, Ent. Amer., ii, 212, 1887; Packard, C. pl. 13, f. 54.

3929. fervidaria Herrich-Schaeffer, Ausser. Schmett., f. 203, 1855; Packard, C. 467; Rept. U.S. Ent. Comm., 328, 1886; Hulst, Ent. News, vi, 104,1895 .

syn. excurvaria Morrison, Bull. Buff. Soc., i, $189,1873$.

3930. alcoolaria Guenée, Spec. Gén., ix, 146, 1857; PACKARD, C. 469.

No. Atl.

States.

No. Atl.

States.

No. Atl.

States.

No. Pac

States.

3933. approximaria Dyar, Can. Ent., xxxi, 266, 1899.

HYPERITIS Guenée.

Guenée, Spec. Gén., ix, 117, 1857; Packard, C. 460; Hulst, Trans. «m. cnt. Soc., xxiii, 373, 1896; Probole Herrich-Schaeffer (not Wesmael), Ausser. Schmett., 83,1855 .

3934. amicaria Herrich-Schaeffer, Ausser. Schm., f. 361,1855 ; Hulst, Ent. Amer., ii, 52, 1886; Atl. iii, 114, 1887; Ent. News, vi, 40, 1895; Dyar, States. Ent. News, v, 62, 1894.

syn. nyssaria Guenée, Spec. Gén., ix, 118, 1857: PaCkard, C. 461; exsimaria Guenée, Spec. Gén., ix, 118, 1857; persinuaria Guenée, insinuaria Guenée, subsinuaria Guenée, laticincta Walker, Cat. Brit. Mus., xxi, 295, 1860; neoninaria W ALKER, Cat. Brit. Mus., xx, 186, 1860; neonaria Packard, C. 461; æesionaria Walker, Cat. Brit. Mus., xx, 183, 1860.

a. alienaria Herrich-Schatefer, Ausser. Schm.,

f. 364,1855 ; PaCKard, C. pl. 11 , f. 38.

b. nepiasaria WALKer, Cat. Brit. Mus., xx, 146, 1860; Packard, C. pl. 13, f. 42.

4630 - No. $52-02-22$ 
*3935. mollicularia Zeller, Verh. zool.--bot. Ges. Wien, xxxviii, 481, 1872; PACKard, C. 485.

3936. trianguliferata Packard, Proc. Bost. Soc. Nat. Hist., xiii, 384, 1871; C. 549; French, Can. Ent., xviii, $105,1886$.

3937. notataria Hulst, Ent. Amer., i, 203, 1886.

*3938. indiscretata Hy. Edwards, Pap., iv, 48, 1884. Tex. Pac. States, Col. Col., Cal., Alberta.

N. Mex.

\section{ANIA Stephens.}

Stephens, Ill., iii, 321, 1831; Westwood \& Humphreys, Brit. Moths, ii, 80, 1849; Hulst, Trans. Am. Ent. Soc., xxiii, 373, 1896; Microgonia Herrich-Schaeffer, Ausser. Schmett., 28, 1855; Nematocampa Guenée, Spec. Gén., ix, 120, 1857; PAckARD, C. 471.

3939. limbata Haworth, Lep. Brit., 346, 1829; Hulst, Ent. Amer., ii, 52, 1886.

Atl.

syn. vestitaria Herrich-Schaeffer, Ausser.

Schmett., f. 368, 1855; resistaria HERRICH-

Schaeffer, Ausser. Schmett., 41, 1855;

Guenée, Spec. Gén., ix, 121, 1857;

Walker, Cat. Brit. Mus., xx, 147, 1860; filimentaria Guenée, Spec. Gén., ix, 120, 1857; Packard, C. 471; French, Trans. Dept. Agr. Ill., xv, 242, 1877; Coquillett,

Trans. Dept. Agr. Ill., xviii, 148, 1880.

a. expunctaria Grote, Can. Ent., iv, 101, 1872; xiv, 110, 1882.

\section{GONODONTIS Hübner.}

Hübner, Verz. bek. Schmett., 287, 1818; Meyrick, Trans. Ent. Soc. Lond., 115, 1892; Hulst, Trans. Am. Ent. Soc., xxiii, 373, 1896; Epirranthis HüBNER, Verz. bek. Schmett., 296, 1818; Packard, C. 498; Odontoptera Stephens, Ill., iii, 162, 1831; Guenée, Spec. Gén., ix, 164, 1857; Lederer, Verh. zool.-bot. Ges. Wien, 204, 1853 ; Westwoon \& Humphreys, Brit. Moths, ii, 11, 1849; Kirby, Eur. Butt., 298, 1882; Metarranthis Warren, Nov. Zool., i, 436, 1894.

*3940. hilumaria Hulst, Ent. Amer., i, 206, 1886.

3941. hypochraria HerRich-SchaEFFEr, Ausser. Schmett., f. 207, 1855; PaCKard, C. 504; Hulst, Ent. News, vi, 15, 1896; Butler, Ann. Mag. Rocky Mts. Nat. Hist., (5), viii, 30, 1881; Dyar, Ent. News, v, 61, 1894; Psyche, viii, 415, 1899.

syn. refractaria Guenée, Spec. Gén., ix, 125, 1857; Walker, Cat. Brit. Mus., xx, 151, 1860; mestusata WaLker, Cat. Brit. Mus., $\mathrm{xx}, 154,1860$.

a. lateritiaria GuenÉe, Spec. Gén., ix, 125, 1857 ; Walker, Cat. Brit. Mus., xx, 151, 1860. syn. foedaria WALKer, Cat. Brit. Mus., xxxv, 1548, 1866; РАCKARD, C. 523; indeclinata Walker, Cat. Brit. Mus., xxiii, 888, 1861.

b. homuraria Grote, Trans. Am. Ent. Soc., ii, 80, 1875; Pap., ii, 100, 1882; Can. Ent., ix, $89,1877$. 
3943. warneri Harvey, Bull. Buff. Soc., ii, 121, 1874; Grote, Cat. Ent., xiv, 106, 1881; Hulst, Ent.。 News, vi, 40, 1895; Ent. Amer., ii, 50, 1886; Ent. News, vi, 15, 1895.

syn. apiciaria PACKard, C. 502.

3944. duaria Guenée, Spec. Gén., ix, 135, 1857; Packard, C. 502; Hulst, Ent. News, vi, 15, 1895; Dyar, Psyche, ix, 371, 1902.

No.

Atl.

States.

syn. hamaria Guenée, Spec. Gén., ix, 136, 1857; agreasaria WALKer, Cat. Brit. Mus., xx, 252, 1860; PACKARD, C. 537; adustaria

Walker, Cat. Brit. Mus., xxxv, 1545, 1866.

a. pilosaria PACKARD, C. 501, 1876.

*3945. barnesii Hulst, Trans. Am. Ent. Soc., xxiii, 374, 1896.

3946. formosa Hulst, Trans. Am. Ent. Soc., xxiii, $375,1896$.

Atl. States, Col.

Col.

Col. Cal., Nev.

Atl.

3947. obfirmaria HüBner, Samml. exot. Schmett., ii, 1806; Packard, C. 499.

States.

Tex.

3948. distycharia Guenée, Spec. Gén., ix, 83, 1857; W Alker, Cat. Brit. Mus., xx, 104, 1860; Hulst, Ent. News, vi, 13, 1895.

syn. cayennaria PACKARD (not Guenée), C. 533.

*3949. antidiscaria Walker, Cat. Brit. Mus., xxvi, 1513, 1862; PaCKard, C. pl. 13, f. 54; Hulst, Ent. Amer., iii, 113, 1887; Ent. News, vi, 14, 1895 .

syn. Zentaria Hulst, Ent. Amer., i, 257, 1886.

\section{EUCHLANA Hübner.}

HüBNER, Verz. bek. Schmett., 293, 1818; Meyrick, Trans. Ent. Soc. Lond., 112, 1892; Hulst, Trans. Am. Ent. Soc., xxiii, 275, 1896; Endropia Guenée, Spec. Gén., ix, 122, 1857; PACKARD, C. 499.

*3950. geniculata Hulst, Ent. Amer., i, 204, 1886.

Col. *3951. argillaria Hulst, Ent. Amer., i, 204, 1886.

*3952. galbanaria Hulst, Ent. Amer., i, 204, 1886.

*3953. manubriaria Hulst, Ent. Amer., i, 207, 1886.

3954. serrata Drury, Ill. Exot. Ent., ii, pl. 20, f. 4, 1770; Emmons, Nat. Hist. N. Y. Agr., v, pl. 40, f. 6, 1854; Grote, Can. Ent., viii, 152, 1876; Hulst, Ent. News, vi, 105, 1895; Dyar, Psyche, ix, 130,1900 .

syn. serrataria PACKARD, C. 517; concisaria

W Alker, Cat. Brit. Mus., xxvi, 1551, 1862;

PACKARD, C. 530.

Ariz., Cal.

Ariz.

Col.

Atl.

States. 
3956. obtusaria HüBNER, Schm. Eur., f. 390, 1835 ?; Packard, C. 516; Hulst, Ent. News, vi, 40, 1895. Atl. syn. propriaria WaLKer, Cat. Brit. Mus., xx, 249, 1860; decisaria WALKer, Cat. Brit. Mus., $x x, 47,1860$.

a. tigrinaria Guenée, Spec. Gén., ix, 123, 157;

WaLker, Cat. Brit. Mus., xx, 149, 1860.

3957. effectaria WALker, Can. Nat., v, 260, 1860; Cat. Brit. Mus., xxvi, 1504, 1862: PACKard, C. 514; Butler, Pap., i, 220, 1881; Hulst, Ent. News, vi, 40,1895 .

a. muzaria Walker, Cat. Brit. Mus., xx, 154, 1860; PaCkard, C. 516.

*3958. occantaria Hulst, Ent. Amer., i, 207, 1886.

*3959. amethystaria Strecker, Lep. Rhop. Het., suppl. $2,6,1899$.

3960. johnsonaria Fiтch, Trans. N. Y. Agr. Soc., xiii, 530, 1853; Hulst, Ent. News, vi, 106, 1895.

syn. bilinearia PACKARD, New and Little Known Ins., 13, 1870; C. 511; Emmons, Nat. Hist. N. Y. Agr., v, 249, 1854; French, Trans. Dept. Agr. Ill., xv, 243, 1877; Brdce, Ent. Amer., iii, 47, 1887.

a. mollisaria Hulst, Ent. Amer., i, 206, 1886.

b. minoraria Hulst, Ent. Amer., i, 206, 1886.

3961. amœnaria Guenée, Spec. Gén., ix, 124, 1857; Packard, C. 509; Grote, Can. Ent., xiv, 108, 1882; Hulst, Ent. Amer., ii, 50, 1886.

syn. deplanaria WALKer, Cat. Brit. Mus., xxvi, 1510, 1862; РACKARD, C. 498; arefactaria Grote \& Robinson, Ann. N. Y. Lye. Nat. Hist., viii, 13, 1867.

*3962. vinulentaria Grote \& Robinson, Ann. N. Y. Lyc. Nat. Hist., viii, 15, 1867; PaCkard, C.506; Hulst, Ent. News, vi, 40, 1895.

3963. astylusaria W ALKer, Cat. Brit. Mus., xx, 152, 1860; Hulst, Ent. News, vi, 40, 1895.

syn. madusaria WaLker, Cat. Brit. Mus., xx, 153, 1860; Packard, C. 508; Butler, Pap., i, 220, 1881; Grote \& Robinson, Trans. Am. Ent. Soc., ii, 81, 1868; Can. Ent., xiv, 108, 1882; oponearia WaLKER, Cat. Brit. Mus., xx, 153, 1860; vinosaria Grote \& Robinson, Ann. N. Y. Lye. Nat. Hist., viii, $17,1867$.

a. tiviaria W ALKER, Cat. Brit. Mus., xx, 250, 1860.

Nev., Wash.

Fla.

Atl. States.

Atl.

States.

Atl. States.

Atl. States.

Atl.
States. 
3964. marginata Мinot, Proc. Bost. Soc. Nat. Hist., xi, 169, 1869; PaCKard, C. 505.

Atl.

States.

Atl.

States.

Wien., 103, 6, 1776; PACKARD, C. 513; DYAR,

Psyche, ix, 344, 1902 (prectinria).

syn. deductaria WaLKer, Cat. Brit. Mus., xx,

$151,1860$.

*3966. sirenaria Strecker, Lep. Rhop. Het., suppl. 2, 7, 1899.

3967. sesquilinearia Grote, Can. Ent., xv, 125, 1883.

3968. falcata Packard, Proc. Bost. Soc. Nat. Hist., xvi, 39, 1874; C. 557; Butler, Pap., i, 220, 1881.

*3969. abnormalis Hulst, Jn. N. Y. Ent. Soc., viii, 220, 1901.

\section{EUTRAPELA Hübner.}

HüBner, Tentamen, 1810; Selenia HüBner, Verz. bek. Schmett., 292, 1818; PAckard, C. 524; Meyrick, Trans. Ent. Soc. Lond., 113, 1892; Hofmann, Gr. Schm. Eur., 171, 1894; Hulst, Trans. Am. Ent. Soc., xxiii, 376, 1896; Krrby, Eur. Butt., 300, 1882 .

3970. alciphearia WALker, Cat. Brit. Mus., xx, 184, 1860; Hurst, Ent. Amer., iii, 113, 1887; Dyar, No. Psyche, viii, 395, 1899.

3971. kentaria Grote, Trans. Am. Ent. Soc., i, 359, 1865; iv, 1, 1867; Pap., ii, 100, 1882; Hulst, Ent. Amer., ii, 162, 1886; iii, 113, 1887; BrucE, Ent. Amer., iii, 47, 1887; Pap., ii, 81, 1882.

*3972. perangulata Hulst, Trans. Am. Ent. Soc., xxiii, $376,1896$.

U.S.

Atl.

States.

Ariz.

Cal.

Man.

\section{EPIPLATYMETRA Grote.}

Grote, Can. Ent., v, 145, 1873; viii, 153, 1876; Hulst, Trans. Am. Ent. Soc., xxiii, $376,1896$.

3973. coloradaria Grote \& Robinson, Ann. Lyc. Nat. Col. Hist. N. Y., viii, 12, 1867; Can. Ent., xiv, 107, 1882; Packard, C. 550; Strecker, Surv. Dept. Mo., Ruffner, App. SS, 1863, 1878.

*3974. grotearia Packard, C. 553, 1876; Grote, Can. Ent., xv, 125, 1883.

Rocky syn. vidularia Grote, Can. Ent., xiv, 173, 1882; xv, 25, 1883; Hulst, Ent. Amer., ii, $49,1886$.

\section{SYNAXIS Hulst.}

Hulst, Trans. Am. Ent. Soc., xxiii, 377, 1896.

*3975. fuscata Hulst, Can. Ent., xxx, 217, 1898.

Col.

*3976. pallulata Hulst, Ent. Amer., ii, 211, 1887.

Oreg.

*3977. oblentaria Grote, Can. Ent., xv, 126, 1883.

Cal., Ariz. 
PHERNE Hulst.

Hulst, Trans. Am. Ent. Soc., xxiii, 377, 1896.

3978. parallelia Packard, Proc. Bost. Soc. Nat. Hist., xvi, 38, 1874 .

syn. paralleliaria PaCKARd, C. 551; Hulst, Ent. Amer., i, 202, 1886; ii, 48, 1886.

*3979. jubararia Hulst, Ent. Amer., ii, 120, 1886.

Wash.

3980. placearia Guenée, Spec. Gén., i, 132, 1857; Packard, C. 497; Hulst, Ent. News, vi, 104, Cal. 1895 .

syn. mellitularia Hulst, Ent. Amer., i, 202, 1896.

\section{METANEMA Guenée.}

Guenée, Spec. Gén., ix, 171, 1857; Packard, C. 542; Hulst, Trans. Am. Ent. Soc., xxiii, 378, 1896.

3981. inatomaria Guenée, Spec. Gén., ix, 171, 1857; U.S. Packard, C. 543; Bruce, Ent. Amer., iii, 47, 1887.

3982. determinata Walker, Cat. Brit. Mus., xxxv, 1551, 1866; Hulst, Ent. News, vi, 14, 1895.

syn. camaria PACKARD, Fifth Rept. Peab. States. Acad. Sci., 80, 1873; C. 542.

*3983. subpunctata Hulst, Can. Ent., xxx, 218, 1898. Cal.

3984. excelsa Strecker, Surv. Dept. Mo., Ruffner, App. SS, 1863, 1878.

Rocky

a. simpliciaria Grote, Can. Ent., xv, 127, 1883; Mts. Hulst, Ent. Amer., ii, 48, 1886.

*3985. vanusaria Strecker, Lep. Rhop. Het., suppl. $2,6,1899$.

N. Mex.

3986. quercivoraria Guenée, Spec. Gén., ix, 172, 1857; Packard, C. 544; Ins. Inj. For. Trees, 51, 1881; Hulst, Ent. News, vi, 14, 1895.

Atl. States.

syn. rliaria WaLker, Cat. Brit. Mus., xx, 260, 1860; trilinearia PACKARD, C. 542.

*3987. incongruaria Hulst, Ent. Amer., ii, 212, 1887.

Ont.

3988. textrinaria Grote \& Robinson, Ann. N. Y. Lye. Nat. Hist., viii, 15, 1867; Packard, C. 507; Am. Nat., xviii, 934, 1884; Grote, Pap., ii, 100, 1882; Hulst, Ent. Amer., ii, 49, 1896.

*3989. forficularia Guenée, Spec. Gén., ix, 172, 1857 (type lost).
Atl. States.

Cal. 


\section{PRIOCYCLA Guenée.}

Guenée, Spec. Gén., ix, 90, 1857; Walker, Cat. Brit. Mus., xx, 114, 1860; Pryocycla Hulst, Trans. Am. Ent. Soc., xxiii, 378, 1896.

3990. armantaria Herrich-SchaEfFer, Ausser. Schmett., f. 373, 1855; Packard, C. 510; Rept. Dept. Agr. 83, 1871; Saunders, Can. Ent., iii, 130, 1871; Ins. Inj. Fruits, 354, 1883; Fiтch, Rept. Ins. N. Y., xiii, 522, 1869.

*3991. decoloraria Hulst, Ent. Amer., i, 207, 1886. Atl. States.

*3992. jucundaria Strecker, Lep. Rhop. Het., suppl. Atl. States. $2,7,1899$. Md.

\section{SNOWIA Neumoegen.}

Neumoegen, Pap., iv, 95, 1884; Hulst, Trans. Am. Ent. Soc., xxiii, 379, 1896. *3993. montanaria Neumoegen, Pap., iv, 96, 1884.

Col.

STENASPILATES Packard.

Packard, C. 212, 1876; Hulst, Trans. Am. Ent. Soc., xxiii, 379, 1896.

3994. zalissaria Walker, Cat. Brit. Mus., xx, 187, Fla, 1860; Packard, (. 522; Hulst, Ent. Amer., iii, $113,1888$.

*3995. inviolata Hulst, Can. Ent., xxx, 218, 1898.

Ariz.

*3996. radiosaria Hulst, Ent. Amer., i, 206, 1886.

Ariz.

*3997. muricolor Hulst, Trans. Am. Ent. Soc., xxiii, $379,1896$.

3998. meskearia Packard, C. 213, 1876; Hulst, Ent. Amer., ii, 141, 1887.

Tex.

Rocky Mts.

syn. arizonaria Hy. Edwards, Pap., ii, 130, 1882.

a. albomacularia Hy. Edwards, Pap., ii, 130, 1882.

3999. albidula Hulst, Can. Ent., xxiii, 107, 1900.

\section{MARMAREA Hulst.}

Hulst, Trans. Am. Ent. Soc., xxiii, 379, 1896.

*4000. occidentalis Hulst, Trans. Am. Ent. Soc., xxiii, $380,1896$.

Cal., Ariz.

a. peplarioides Hulst, Can. Ent., xxx, 218, 1898. 


\section{AZELINA Guenée.}

Guenée, Spec. Gén., ix, 156, 1857; Pack Ard, C. 520; Meyrick, Trans. N. Zeal. Inst., 106, 1883; Hulst, Trans. Am. Ent. Soc., xxiii, 380, 1896.

4001. ancetaria Hübner, Samml. exot. Schmett., ii, U. S. 1806.

syn. hubneraria Guenée, Spec. Gén., ix, 159,

1857; Packard, Proc. Bost. Soc. Nat. Hist., xiii, 386, 1871; Butler, Ann. Mag. Nat. Hist., (5), viii, 33, 1881; hubnerata PACKARD, C. 520; honestaria W ALKER, Cat. Brit. Mus., $\mathrm{xx}, 258,1860$.

a. peplaria HÜBNER, Zutr. exot. Schmett., f. 709, 1832; Hulst, Ent. Amer., ii, 49, 1886; Ent. News, vi, 14, 1895 . syn. stygiaria WALKer, Cat. Brit. Mus., xxxv, 1548, 1866; atrocolorata Hulst, Ent. Amer., i, $205,1885$.

b. morrisonata Hy. Edwards, Pap., i, 121, 1881; Hulst, Ent. Amer., ii, 249, 1886.

4002. behrensata Packard, Proc. Bost. Soc. Nat. Hist., xiii, 386, 1871; C. 521.

Cal.

\section{SYSSAURA Hübner.}

Hübner, Verz. bek. Schmett., 150, 1818; WArren, Nov. Zool., i, 458, 1894; Patalene Herrich-Schaeffer, Ausser. Schmett., 80, 1855; Microsemia Herrich-Schaeffer, Ausser. Schmett., 83, 1855; Hyperytha GuenÉe, Spec. Gén., i, 99, 1857; Walker, Cat. Brit. Mus., xx, 124, 1860; Hypsoridra Butuer, Proc. Zool. Soc. Lond., 492, 1878; Drepanodes Packard, C. 537.

4003. siculata GuenÉe, Spec. Gén., ix, 67, 1857; Hulst, Ent. News, vi, 103, 1895.

syn. perizomaria Hulst, Ent. Amer., i, 205, 1886.

*4004. syzygyaria Hulst, Ent. Amer., ii, 121, 1886.

4005. infensata Guenée, Spec. Gén., ix, 68, 1857 ; Hulst, Ent. News, vi, 12, 1895.

syn. ephyrata Guenée, Spec. Gén., ix, 69, 1857; olyzonaria WaLker, Cat. Brit. Mus., xx, 69, 1860; requosus Grote \& Robinson, Ann. Lyc. Nat. Hist. N. Y., viii, 22, 1867; sesquilinea Grote, Can. Ent., ii, 114, 1870.

a. biclaria Walker, Cat. Brit. Mus., xx, 73, 1860 .

syn. amearia Walker, Cat. Brit. Mus., xx, 73, 1860; puber Grote \& Robinson, Ann. Lyc. Nat. Hist. N. Y., viii, 20, 1867; Grote, Can. Ent., xiv, 107, 1882; varus Grote \& Robinson, Ann. Lyc. Nat. Hist. N. Y., viii, 21, 1867; PACKARD, C. 538; juniperaria Packard, First Rept. Ins. Mass., 22, 1871.
Va., Mont., Ariz.

Fla. So. Atl. States. 


\section{CABERODES Guenée}

Guenée, Spec. Gén., ix, 135, 1857; Packard, C. 531; Warren, Nov. Zool., i, 487, 1894; Hulst, Trans. Am. Ent. Soc., xxiii, 381, 1896.

*4006. juncturaria Guenée, Spec. Gén., ix, 88, 1857;

Walker, Cat. Brit. Mus., xx, 102, 1860; Hulst, S. - E.

Ent. News, vi, 103, 1895.

syn. incopularia Guenée, Spec. Gén., ix, 89,

1857; Walker, Cat. Brit. Mus., xx, 112, 1860; effascinaria Hulst, Ent. Amer., i, 204,1886 .

4007. confusaria HüBNER, Samml. exot. Schmett., i, U.S. 1806; Packard, C. 534: Bruce, Ent. Amer., iii, 47, 1887; Hulst, Ent. News, vi, 13, 1895; French, Trans. Dept. Agr. Ill., xv, 244, 1877. syn. remissaria Guenée, imbraria Guenée, superaria Guenée, ineffusaria Guenée, floridaria Guenée, phasianaria Guenée, interlinearia Guenée, Spec. (Gén., ix, 137-140, 1857: varadaria W ALKER, Cat. Brit. Mus., xx, 251, 1860; ? arburaria WALKER, Cat. Brit. Mus., xx, 102, 1860; amyrisaria WALKer, myandaria WALKer, Cat. Brit. Mus., xx, 164, 1860.

a. metrocamparia Guenée, Spec. Gén., ix, 137, 1857.

syn. ? eldanaria Walker, Cat. Brit. Mus., xx, $170,1860$.

b. minima Hulst, Can. Ent., xxx, 219, 1898.

4008. majoraria Guenée, Spec. Gén., ix, 138, 1857; Packard, C. 536; Hulst, Ent. News, vi, 13, 1895. U. S.

syn. pandaria Walker, Cat. Brit. Mus., xx, 173, 1860; PACKaRd, C. 534.

*4008.1. subochrearia Hulst, Can. Ent., xxxii, 107, 1900.

Atl. States, Col.

N. J.

OXYDIA Guenée.

Guenée, Spec. Gén., ix, 52, 1857; Hulst, Trans. Am. Ent. Soc., xxiii, 382, 1896. *4009. zonulata Hulst, Ent. Amer., i, 201, 1886.

Tex.

4010. vesulia Cramer, Pap. Exot., iii, pl. 240, f. B, Fla. 1782; Walker, Cat. Brit. Mus., xx, 53, 1860; Hulst, Ent. News, vi, 13, 1895.

syn. vesuliata Gunnée, Spec. Gén., ix, 60, 1857; Hulst, Ent. Amer., ii, 47, 1886; peosinata Guenée, distichata Guenée, nimbata Guenée, Spec. Gén., ix, 59, 1857; saturniata GuenéE, agliata Guenée, gastropachata Guenée, spec. Gén., ix, 62, 1857; Walker, Cat. Brit. Mus., xx, 55, 1860; transponens Walker, Cat. Brit. Mus., xx, 20, 1860; vitiligata Felder, Reise Nov., Lep., pl. 122, f. $17,1873$. 
TETRACIS Guenée.

Guenée, Spec. Gén., ix, 140, 1857; Packard, C. 546; Hulst, Trans. Am. Ent. Soc., xxiii, 382, 1896.

4011. crocallata Guenée, Spec. Gén., ix, 141, 1857;

Packard, C. 548; Goodell, Can. Ent., xi, 193, Atl.

1879; Minot, Can. Ent., ii, 28, 1869; Bruce, States.

Ent. Amer., iii, 47, 1887; Hulst, Ent. News, vi, 13,1895 .

syn. allediusaria Walker, Cat. Brit. Mus., $\mathrm{xx}, 253,1860$.

a. aspilata Guenée, Spec. Gén., ix, 141, 1857;

W AlKer, Cat. Brit. Mus., xx, 173, 1860.

4012. hyperborea Hulst, Proc. Wash. Acad. Sci., ii, 496, 1900; Journ. N. Y. Ent. Soc., viii, 220, 1901.

Alaska.

\section{SABULODES Guenée.}

Guenée, Spec. Gén., ix, 42, 1857; Hulst, Trans. Am. Ent. Soc., xxiii, 382, 1896; Cherodes Guenée (not White), Spec. Gén., ix, 35, 1857; Antepione Packard, C. 484; Procherodes Grote, Ann. Mag. Nat. Hist., (5), xi, 55, 1883.

4013. sulphurata Packard, Fifth Rept. Peab. Acad. Sci., 79, 1873; C. 484.

Atl.

a. imitata Hy. Edwards, Pap., iv, 48, 1884.

4014. arcasaria WALker, Cat. Brit. Mus., xx, 131, 1860. syn. depontanata Grote, Proc. Ent. Soc. Phil., iii, 90, 1864; PaCkard, C. 483.

4015. novellata Hulst, Ent. Amer., i, 204, 1886.

Ariz.

4016. lorata Grote, Proc. Ent. Soc. Phil., iii, 91, 1864; Can. Ent., xiv, 107, 1882; Minot, Can. Ent., ii, 28, 1869; Packard, C. 547; Goodell, Can. Ent., ix, 62, 1876; Bruce, Ent. Amer., iii, 47, 1887.

4017. truxaliata Guenée, Spec. Gén., ix, 142, 1857; Packard, C. 554; Hulst, Ent. Amer., ii, 47, 1886.

4018. cervinaria Packard, Proc. Bost. Soc. Nat. Hist., xiii, 386, 1871; C. 552; Hulst, Ent. Amer., ii, $47,1886$.

4019. aurantiacaria PACKARd, Proc. Bost. Soc. Nat. Hist., xvi, 34, 1874; C. 551; Hulst, Ent. Amer., ii, $47,1886$.

4020. caberata Guenée, Spec. Gén., ix, 45, 1857; Walker, Cat. Brit. Mus., xx, 34, 1860; Hulst, States.

Atl. States.

Ent. News, v, 303, 1894; vi, 13, 1895. syn. xgrotata Guenée, Spec. Gén., ix, 141, 1857; Packard, C. 555; Butler, Pap., i, 221, 1881; ?forficaria Guenée, Spec. Gén., ix, 172, 1857; PACKard, C. 545 (type lost); arsenaria W Alker, Cat. Brit. Mus., xx, 260, 1860. 
*4021. nonangulata Strecker, Lep. Rhop. Het., suppl. $2,6,1899$.

4022. anfractata Hulst, Ent. Amer., i, 202, 1886.

4023. catenulata Grote, Trans. Kans. Aead. Sci., viii, 56, 1883; Ann. Mag. Nat. Hist., (5), xi, 55, 1883.

4024. nubilata Packard, Proc. Bost. Soc. Nat. Hist., xiii, 381, 1871; C. 558.

*4025. furciferata Packard, Fifth Rept. Peab. Acad. Sci., 68, 1873; C. 559.

4026. transversata Drury, Ill. Exot. Ent., i, 16, 1770; PaCkard, C. 559; Bull. U. S. Ent. Comm., vii, 112, 1881; French, Trans. Dept. Agr. Ill., xv, 244, 1877; Goodell, Can. Ent., xii, 236, 1880; Emmons, Nat. Hist. N. Y. Agr., v, 249, 1854; Bruce, Ent. Amer., iii, 47, 1887; Hulst, Ent. News, vi, 13, 1895; Drar, Psyche, ix, 273, 1901. syn. transmutans WaLker, Cat. Brit. Mus., $\mathrm{xx}, 17,1860$; contingens W ALKER, Cat. Brit. Mus., $\mathrm{xx}, 18,1860$; transfindens W ALKER, Cat. Brit. Mus., xx, 26, 1860.

a. goniata Guenée, Spec. Gén., ix, 38, 1857. syn. transvertens Walker, Cat. Brit. Mus., $\mathrm{xx}, 16,1860$.

b. transposita Walker, Cat. Brit. Mus., xx, 15, 1860 .

c. incurvata Guenée, Spec. Gén., ix, 37, 1857; Walker, Cat. Brit. Mus., xx, 15, 1860.

4027. politia Craver, Pap. Exot., ii, pl. 140, f. E, 1776; Fabricius, Sp. Ins., ii, 253, 64, 1781; Mant. Ins., ii, 96, 100, 1787; Ent. Syst., iii, 2, 163, 123, 1794; Leach, Zool. Miss., 80, 1817; Guenée, Spee. Gén., ix, 30, 1857; Walker, Cat. Brit. Mus., xx, 7, 1860; Hulst, Ent. Amer., ii, 47, 1886; Ent. News, v, 303, 1894; W Arren, Nov. Zool., i, 399, 1894.

syn. politiata Guenée, Spec.Gén., ix, 30, 1857; complicata Guenée, Spec. Gén., ix, 30, 1857; WaLKer, Cat. Brit. Nus., xx, 7, 1860; illiturbata Guenée, Spec. Gén., ix, 130, 1857; illiturata W ALKer, Cat. Brit. Mus., xx, 8, 1860; floridata Grote, Can. Ent., xv, 6, 1883 .
Tex.

Rocky Mts., Cal.

Rocky Mts., Cal.

Cal.

Atl.

States.

Atl.

States.

Fla. 
ABBOTANA Hulst.

Hulst, Trans. Am. Ent. Soc., xxiii, 383, 1896.

4028. clemataria Sмiтн \& Aввот, Lep. Ins. Ga., ii, 201, 1797; Packard, C. 561; Bruce, Ent. Amer., iii, 47, 1887; Hulst, Ent. Amer., ii, 47, 1886;

Dyar, Psyche, ix, 142, 1900.

syn. transferens W alker, Cat. Brit. Mus., xx, $19,1860$.

a. transducens Walker, Cat. Brit. Mus., xx, 18, 1860 .

MECOCERAS Guenée.

Guenée, Spec. Gén., ix, 388, 1857; Walker, Cat. Brit. Mus., xxii, 606, 1861; Hulst, Trans. Am. Ent. Soc., xxiii, 385, 1896.

4029. nitoris Cramer, Pap. Exot., iii, pl. 275, f. A, Fla.

1776; Walker, Cat. Brit. Mus., xxii, 606, 1860;

Dyar, Psyche, ix, 69, 1900.

syn. nitocraria HüBNER, Samml. exot. Schmett., ii, 1806; Guenée, Spec. Gén., ix, 389, 1857; peninsularia Grote, Pap., iii, $79,1883$.

\section{ALMODES Guenée.}

Guenée, Spec. Gén., ix, 389, 1857; Walker, Cat. Brit. Mus., xxii, 607, 1861; Hulst, Trans. Am. Ent. Soc., xxiii, 385, 1896.

*4030. terraria Guenée, Spec. Gén., ix, 390, 1857; Fla.

Walker, Cat. Brit. Mus., xxii, 608, 1861; Hulst, Ent. News, vi, 73, 1896; Warren, Nov. Zool., i, 376, 1894.

syn. stellidaria Guenée, Spec. Gén., x, 450, 1857; squamigera Felder, Reise Novara, pl. 126, f. 11, 1874; balteolata HERrICH-SCHAEFFER, Corr.-Blatt. Reg., xxiv, 190, 1870; Möschler, Abh. Senck. G'es., xvi, 272, 1890; assecoma Druce, Biol. Cent. Am., Lep. Het., ii, 79, 1892; calvina Druce, Biol. Cent. Am., Lep. Het., ii, 79, 1892; rivularia Grote, Pap., iii, 79, 1883.

\section{Subfamily PALYADINA \\ PALYAS Guenée.}

Guenée, Spec. Gén., ix, 395, 1857; Walker, Cat. Brit. Mus., xxiii, 612, 1861; WarRen, Nov. Zool., i, 402, 1894; Hulst, Trans. Am. Ent. Soc., xxiii, 384, 1896. 


\section{PHRYGIONIS Hübner.}

Hübner, Verz. bek. Schmett., 307, 1818; Warren, Nov. Zool., i, 394, 1894; Hulst, Trans. Am. Ent. Soc., xxiii, 384, 1896; Byssodes Guenée, Spec. Gén., ix, 399, 1857; Walker, Cat. Brit. Mus., xxii, 617, 1861; Hulst, Trans. Am. Ent. Soc., xxiii, 384, 1896.

4032. argenteostriata STrecker, Proc. Acad. Nat. Sci. Fla. Phil., 152, 1876; Hulst, Ent. Amer., ii, 222, 1886; Dyar, Proc. Ent. Soc. Wash., iv, 458, 1901. syn. cerussata Grote, Pap., ii, 101, 1882; obrussata Grote, Can. Ent., xiv, 111, 1882; xV $, 6,1883$.

\section{Subfamily SPH AECHLODIN AE. \\ SPH $Æ C E L O D E S$ Guenée.}

Guenée, Spec. Gén., x, 116, 1857; Walker, Cat. Brit. Mus., xx, 213, 1860; Hulst, Trans. Am. Ent. Soc., xxiii, 367, 1896; Brotis HüBNER (not $a$ ), Verz. bek. Schmett., $303,1818$.

4033. vulneraria HüBNER, Zutr. exot. Schmett., f. 319 , 1825; Guenée, Spec. Gén., x, 117, 1857; W alker, Cat. Brit. Mus., xx, 214, 1860; Grote, Can. Ent., viii, 154, 1876; xii, 116, 1880; Hulst, Can. Ent., xviii, 136, 1886.

syn. floridensis Holland, Pap., iv, 72, 1884.

Subfamily MHLANCHROIIN AE.

MELA NCHROIA Hübner.

Hü BNer, Verz. bek. Schmett., 173, 1818.

4034. regnatrix Grote, Ann. N. Y. Lyc. Nat. Hist., viii, 441, 1867.

4035. cephise Cramer, Pap. Exot., iv, pl. 381, f. E, 1782; Grote, Proc. Ent. Soe. Phil., vi, 306, 1867; Hy. Edwards, Ent. Amer., ii, 9, 1886; Cockerell, Can. Ent., xxv, 26, 1893.

Atl. States.

4036. geometroides WaLker, Cat. Brit. Mus., ii, 387, 1854; Grote, Proc. Ent. Soc. Phil., vi, 307, 1867 .

Cuba, Fla. ?

Ariz.,

Fla.,

So.

Am.

Tex., Mex., Fla.

syn. mors Lucas, Hist. Nat. Cuba, 663, 1857.

$$
\text { Subfamily BRFPHIN } A \text {. }
$$

BREPHOS Ochsenheimer.

Ochsenheimer, Schmett. Eur., iv, 96, 1816.

4037. infans Möschler, Wien. ent. Mon., vi, 134, 1862; Smith, Bull. 44, U. S. Nat. Mus., 396, 1893; Brainerd, Can. Ent., xxix, 272, 1897; No. Atl. States.

Lyman, Can. Ent., xxx, 49, 1898; Staudinger \& Rebel, Cat. Lep. Eur., i, no. 2855, 1901.

syn. hamadryas HARRIs. 
*4038. melanis Borsduvar, Ann. Soc. Ent. Belg., xii, Cal. 88, 1868; Sмгтн, Bull. 44, U. S. Nat. Mus., 396, 1893.

*4039. californicus Boisduval, Ann. Soc. Ent. Belg., xii, 88, 1868; Sмптн, Bull. 44, U. S. Nat. Mus., 396, 1893.

\section{LEUCOBREPHOS Grote.}

Grote, Bull. Buff. Soc. Nat. Sci., ii, 53, 1874.

*4040. brephoides Walker, Cat. Brit. Mus., xi, 702, 1857; Sмrth, Bull. 44, U. S. Nat. Mus.. 397, 1893.

syn. moyi Grote, resoluta ZELLeR.

*4041. middendorfi Ménétries, Schrenk's Reise, 66, 1859; Sмптн, Bull. 44, U. S. Nat. Mus., 397, 1893; Staudinger \& Rebel Cat. Lep. Eur., i, no. 2857.1901.

\section{Family EPIPLEMID E.}

\section{PHILAGRAULA Hulst.}

Huist, Trans. Am. Ent. Soc., xxiii, 310, 1896.

*4042. slossoniæ Hulst, Trans. Am. Ent. Soc., xxiii, 310, 1896.

No.

U.S.

Cal.

Canada.

Fla.

\section{CALLIZZIA Packard.}

Packard, Rept. Geol. Surv. Terr., Hayden, x, 314, 1876; Hulst, Trans. Am. Ent. Soc., xxiii, 309, 1896.

4043. amorata PACKA RD, Rept. Geol. Surv. Terr., No. U. S., Hayden, x, 315, 1876 .

Ariz., Col.

\section{CALLEDAPTERYX Grote.}

Grote, Trans. Am. Ent. Soc., ii, 119, 1868; Hulst, Trans. Am. Ent. Soc., xxiii, 310, 1896.

4044. dryopterata Grote, Trans. Am. Ent. Soc., ii, 120, 1868; Packard, Rept. Geol. Surv. Terr.,

Atl. Hayden, x, 313, 1876.

syn. erosiata Packard, Rept. Geol. Surv.

Terr., Hayden, x, pl. 3, f. 14, 1876.

\section{SCHIDAX Hübner.}

Hübner, Verz. bek. Schmett., 315, 1818; Guenée, Spec. Gén., x, 39, 1857; Walker, Cat. Brit. Mus., xxiii, 853, 1861.

*4045. coronaria STREcker, Lep. Rhop. Het., suppl. Fla. 2, 8, 1899. 


\title{
Superfamily TINEOIDEA.
}

\author{
Family NOLID \&.
}

(C.= Hampson Cat. Lep. Phal. Brit. Mus.. ii, 1900.)

CELAMA Walker.

Walker, Cat. Brit. Mus., xxxii, 500, 1865; Hampson, C. 5.

4046. triquetrana Fiтch, First Rept. Ins. N. Y., 244, 1856; Sмith, Bull. 44, U. S. Nat. Mus., 193, 1893; Dyar, Jn. N. Y. Ent. Soc., vi, 42, 1898; Hampson, C. no. 34.

syn. trinotata WALKER, sexmaculata GROTE.

4047. minna Butler, Ann. Mag. Nat. Hist., (5), viii, 315, 1881; Hampson, C. no. 36. syn. hyemalis STRETCH.

4048. sorghiella Riley, Rept. Dept. Agr., 188, 1882; Hampson, C. no. 33.

Atl. States.

4049. pustulata Walker, Cat. Brit. Mus., xxxiii, 795, 1865; Hampson, C. no. 26.

Pac. States.

syn. nigrofasciata ZeLLER, obaurata MorRISON.

4050. cilicoides Grote, Bull. Buff. Soc., i, 175, 1873; Hampson, C. no. 27.

*4051. anfracta Hy. Edwards, Pap., i, 12, 1881; Hampson, C. no. 152.

*4051. 1. aphyla Hampson, C. no. 15, 1900.

Atl. States.

So. Atl. States.

Atl.

States.

Cal.

Cal.

\section{NOLA Leach.}

Leach, Edinb. Eneycl., ix, 135, 1815; Snellen, Tidj. voor Ent., xviii, 61, 1874; Hampson, C. 31.

4052. clethræ Dyar, Can. Ent., xxxi, 62, 1899; НАмPson, C. no. 46.

4053. ovilla Grote, Can. Ent., vii, 221, 1875; НАмpson, C. no. 45.

4054. apera Druce, Biol. Cent. Am., Lep. Het., ii, 404, 1897; Hampson, C. no. 76. syn. involuta DYAR, Jn. N. Y. Ent. Soc., vi, $42,1898$.

a. exposita Dyar, Jn. N. Y. Ent. Soc., vi, 43, 1898.

b. lagunculariæ Dyar, Proc. Ent. Soc. Wash., iv, $465,1901$.
At1.

States.

Atl.

States.

Ariz., Cal., Mex., Fla. 


\section{RCSELIA Hübner.}

HüBner, Verz. bek. Schmett., 397, 1827; Hampson, C. 51.

4055. minuscula Zeller, Verh. zool.-bot. Ges. Wien, Atl. xxii, 455, 1872; Hampson, C. no. 142. States.

syn. minor Dyar, Can. Ent., xxxi, 64, 1899. a. phylla Dyar, Jn. N. Y. Ent. Soc., vi, 43, 1898; Can. Ent., xxxi, 61, 1899.

4056. fuscula Grote, Pap., i, 76, 1881.

Col.

syn. conspicue Dyar, Jn. N. Y. Ent. Soc., vi, $43,1898$.

4057. dentata Dyar, Can. Ent., xxxi, 64, 1899; НАмPAriz. son, C. no. 133.

\section{NIGETIA Walker.}

Walker, Cat. Brit. Mus., xxxiv, 1505, 1865; Hampson, C. 50.

4058. formosalis WaLker, Cat. Brit. Mus., xxxiv, Atl. 1506, 1865; Hampson, C. no. 104; Proc. Zool. States. Soc. Lond., 290, 1899.

syn. melanopa ZELLER.

\section{Family LACOSOMID E.}

(C. = Neumoegen \& Dyar, Jn. N. Y. Ent. Soc., ii, 120, 1894.)

CICINNUS Blanchard.

Blanchard, Gay's Hist. Chile, Zool., vii, 66, 1852; Neumoegen \& Dyar, C. 120. 4059. melsheimeri Harris, Rep. Ins. Mass., 290, 1841;

Neumoegen \& Dyar, C. 120. Atl. syn. egenaria WALKER.

\section{LACOSOMA Grote.}

Grote, Proc. Ent. Soc. Phil., iii, 77, 1864; Neumoegen \& Dyar, C. 120. 4060. chiridota Grote, Proc. Ent. Soc. Phil., iii, 78, 1864: Neumoegen \& Dyar, C. 120.

Atl. States. 4061. arizonicum Dyar, Jn. N. Y. Ent. Soc., vi, 44, 1898. Ariz.

\section{Family PSYCHID Æ.}

(C.=Neumoegen \& Dyar, Jn. N. Y. Ent. Soc., ii, 111-120, 1894.)

\section{OIKETICUS Guilding.}

Guilding, Trans. Ent. Soc. Lond., xv, 375, 1837; Neumoegen \& Dyar, C. 118. 4062. abbotii Grote, No. Am. Ent., i, 52, 1880; NeU- Fla. MOEGEN \& DYAR, C. 118. 
4063. townsendi Cockerell, Ann. Mag. Nat. Hist., (6),

N. Mex.

xv, 208, 1895; Dyar, Can. Ent., xxvii, 242, 1895.

*4064. davidsoni Hy. Edwards, Proc. Cal. Acad. Sci.

Cal. vii, 142, 1877; Dyar, Ent. News, iv, 320, 1893.

THYRIDOPTERYX Stephens.

Stephens, Ill. Brit. Ent., Haust., iv, 387, 1834; Neumoegen \& Dyar, C. 118.

4065. ephemeræformis HaworTh, Lep. Brit., 72, 1803;

Neumoegen \& Dyar, C. 118.

Atl.

syn. coniferarum PACKARD.

4066. meadii Hy. Edwards, Pap., i, 116, 1881; NeuMOEGEN \& DYAR, C. 119.

So.

Cal.

\section{PLATECETICUS Packard.}

Packard, Guide Stud. Ins., 291, 1869; Neumoegen \& Dyar, C. 119.

4067. gloveri Packard, Guide Stud. Ins., 291, 1869; Fla.

Neumoegen \& Dyar, C. 119.

syn. edwardsii HeYLAERTs.

EURYCYTTARUS Hampson.

Hampson, Ill. Lep. Het. Brit. Mus, viii, 66, 1891; Neumoegen \& Dyar, C. 119.

4068. confederata Grote \& Robinson, Trans. Am. Ent. Soc., ii, 191, 1868; Neunoegen \& Dyar, C. 119.

Atl.

States.

4069. carbonaria Packard, Ent. Amer., iii, 51, 1887;

Tex.

Neumoegen \& Dyar, C. 119.

\section{CHALIA Moore.}

Moore, Ann. Mag. Nat. Hist., (4), xx, 345, 1877; Neumoegen \& Dyar, C. 120.

*4070. rileyi Heylaerts, Ann. Soc. Ent. Belg., xxviii, 208, 1884; Neumoegen \& Dyar, C. 120.

Atl.

States.

4071. fragmentella Hr. Edwards, Proc. Cal. Acad. Sci.,

Pac. vii, 142, 1877; Dyar, Ent. News, iv, 320, 1893.

States.

syn. coniferella Hr. Edwards.

SOLENOBIA Zeller.

Zeller, Linn. Ent., vii, 332, 1852; Clemens, Tin. Nor. Am., 181, 1872.

4072. walshella Clemens, Proc. Ent. Soc. Phil., i, 132, 1862; Packard, Guide Stud. Ins., 346, 1869;

Chambers, Can. Ent., v, 74, 1873; vii, 125, 1875;

States.

viii, 19, 1876.

4630 -No. $52-02-23$ 


\section{HYALSCOTES Butler.}

Butler, Ann. Mag. Nat. Hist., (5), viii, 314, 1881.

*4073. fumosa Butler, Ann. Mag. Nat. Hist., (5), viii, 314, 1881; Neumoegen \& Dyar. C. i, 114.

Cal.

\section{EDONIA Kirby.}

Kirby, Cat. Lep. Het., i, 524, 1892; Dyar, Can. Ent., xxv, 301, 1893.

* 4074. exigua Hy. Edwards, Pap., ii, 125, 1882; Dyar, Ariz.

Can. Ent., xxv, 301, 1893.

\section{Family COCHLIDIID A.}

\section{(C. = Neumoegen \& Dyar, Jn. N. Y. Ent. Soc, ii, 64-76, 109, 1894.}

SIBINE Herrich-Schaeffer.

Herrich-Schateffer, Samml. ausser. Schmett., i, 7, 1855.

4075. stimulea Clemens, Proc. Acad. Nat. Sci. Phil., Atl. xi, 158, 1860; Neumoegen \& DYaR, C. 72; DYaR \& Morton, Jn. N. Y. Ent. Soc., iv, 1, 1896.

syn. ephippiatus Harris.

\section{EUCLEA Hübner.}

HÜBNER, Verz. bek. Schmett., 149, 1822.

4076. nanina Dyar, Jn. N. Y. Ent. Soc., vii, 247, 1899. Fla.

syn. nana DYAR (not HERrich-SCHAEFFER), Ent. News, ii, 61, 1891; Neumoegen \& DYAR, C. 67.

4077. delphinii Borsdural, Cuvier An. King., pl. ciii, f. 6, 1832; Neumoegen \& Dyar, C. 67; Dyar, Jn. N. Y. Ent. Soc., v, 57, 1897.

syn. strigata BoIsduval, quercicola HerrichSChaEFFer, tardigrada Clemens, ferruginea PaCkARD, argentatus Wetherby, Cin. Quart. Jn. Sci., ii, 366, 1875.

a. querceti Herrich-Schaeffer, Samml. ausser. Schmett., f. 174, 1854.

syn. bifida PACKARD.

b. interjecta Dyar, Ent. News, ii, 61, 1891.

c. viridiclava WALKer, Cat. Brit. Mus., v, 1154 , 1855 .

syn. monitor PACKARD.

d. elliotii Pearsall, Ent. Amer., i, 209, 1887.

e. pænulata Clemens, Proc. Acad. Nat. Sci. Phil., xii, 159, 1860. 
4078. incisa Harvey, Can. Ent., viii, 5, 1876; NeuMOEGEN \& DYAR, C. 68.

4079. indetermina Borsduval, Cuv. An. King., pl. ciii, f. 1, 1832; Neumoegen \& Dyar, C. 68; Dyar, Jn. N. Y. Ent. Soc., v, 10, 1897.

syn. vernata PACKARD.

4080. chloris Herrich-Schaeffer, Samml. ausser. Schmett., i, f. 146, 1854; Neumoegen \& Dyar, C. 72; Dyar, Jn. N. Y. Ent. Soc., v, 61, 1897. Tex. syn. viridis Reakirt, fraterna Grote.

MONOLEUCA Grote \& Robinson.

Grote \& Robinson, Trans. Am. Ent. Soc., ii, 187, 1869; Neumoegen \& Dyar, C. 69.

4081. subdentosa Dyar, Trans. Am. Ent. Soc., xviii, Fla. 156, 1891; Neumoegen \& Dyar, C. 69.

4082. semifascia Walker, Cat. Brit. Mus., v, 1151, 1855; Neunoegen \& Dyar, C. 69.

4083. sulfurea Grote, No. Am. Ent., i, 60, 1880; Neumoegen \& Dyar, C. 69.

*4084. obliqua Hr. Edwards, Ent. Amer., ii, 10, 1886; Neumoegen \& Dyar, C. 69.

So. Atl. States.

Fla.

Fla.

\section{ADONETA Clemens.}

Clemens, Proc. Acad. Nat. Sci. Phil., xii, 158, 1860.

4085. spinuloides Herrich-Schaeffer, Samml. ausser. Schmett., i, f. 187, 1854; Neumoegen \& Dyar, C. 71: Dyar, Jn. N. Y. Ent. Soc., v, 5, 1897. States. syn. voluta Clemens, ferrigera WALKER, nebulosus Wetherby, Cin. Quart. Jn. Sci:, ii, 370,1875 .

a. leucosigma Packard, Proc. Ent. Soc. Phil., iii, 345, 1864; Neumoegen \& Dyar, C. 72.

4086. pygmæa Grote \& Robinson, Trans. Am. Ent. Soc., ii, 189, 1868; Neumolgen \& Dyar, C. 71.

Tex.

\section{SISYROSEA Grote.}

Grote, Can. Ent., viii, 112, 1876; Neumoegen \& Dyar, C. 69.

4087. textula Herrich-Schaeffer, Ausser. Schmett., f. 184, 1854; Dyar, Jn. N. Y. Ent. Soc., iv, 185, 1896.

syn. inorrata Grote \& Robinson. 
NATADA Walker.

Walker, Cat. Brit. Mus., v, 1108, 1855.

4088. nasoni-Grote, Can. Ent., viii, 112, 1876; Dyar,

Jn. N. Y. Ent. Soc., vii, 61, 1899.

Atl.

syn. daona Druce, rude Hy. Edwards.

States.

\section{PHOBETRON Hübner.}

Hübner, Verz. bek. Schmett., 398, 1827; Neumoegen \& Dyar, C. 70.

4089. pithecium Smith \& Aввот, Lep. Ins. Ga., ii, 74,

1897; Neumoegen \& Dyar, C. 70; Dyar, Jn.

Atl.

N. Y. Ent. Soc., iv, 178, 1896.

syn. abbotana HüBNER, nigricans PACKARD, hyalinus WALSH, tetradactylus WALSH, nondescriptus Wetherby, Cin. Quart. Jn. Sci., ii, 371, 1875.

\section{ISOCH $Æ$ TES Dyar.}

Dyar, Jn. N. Y. Ent. Soc., vii, 208, 1899.

4090. beutenmülleri Hy. Edwards, Can. Ent., xix, 145

1887; Neumoegen \& Dyar, C. 71.

Atl.

States.

\section{ALARODIA Möschler.}

Möschler, Abhl. Sencken. Ges., xiv, 3 Heft, 35, 1886.

4091. slossoniæ Packard, Ent. News, iv, 169, 1893;

Fla.

Neumoegen \& Dyar, C. 111; Dyar, Jn. N. Y.

States.

Ent. Soc., v, 122, 1897; vi, 158, 1898.

\section{PROLIMACODES Sehaus.}

Schaus, Jn. N. Y. Ent. Soc., iv, 56, 1896.

4092. scapha Harris, Rep. Ins. Mass., 303, 1841; Neumoegen \& Dyar, C. 73; Dyar, Jn. N. Y. Ent. Soc., iv, 172, 1896.

Atl.

syn. undifera WALKER.

*4093. trigona Hy. Edwards, Pap., ii, 12, 1882; NEU-

Ariz.

MOEGEN \& DYAR, C. 73.

syn. telligii Barnes, Can. Ent., xxiii, 46, 1900.

\section{COCHLIDION Hübner.}

Hübner, Tentamen, 1806; Apoda Neumoegen \& Dyar, C. 73.

4094. biguttata Packard, Proc. Ent. Soc. Phil., iii,

Atl. 341, 1864; Neumoegen \& Dyar, C. 73; Dyar, States, Jn. N. Y. Ent. Soc., v, 167, 1897.

syn. tetraspilaris W ALKER. 
4095. rectilinea Grote \& Robinson, Trans. Am. Ent. Soc., ii, 188, 1868; Neunoegen \& Dyar, C. 73. Atl.

a. latomia Harvey, Can. Ent., ix, 75, 1875; NeUStates. MOEGEN \& DYAR, C. 74.

4096. y-inversa Packard, Proc. Ent. Soc. Phil., iii, 461, 1864; Neunoegen \& Dyar, C. 74; Dyar \& Morton, Jn. N. Y. Ent. Soc., iii, 151, 1895.

Atl.

States.

a. parallela Hy. Edwards, Ent. Amer., ii, 10, 1886.

\section{LITHACODES Packard.}

Packard, Proc. Ent. Soc. Phil., iii, 345, 1864.

4097. fasciola Herrich-Schaeffer, Ausser. Schmett., i, f. 186, 1854; Neumoegen \& Dyar, C. 76; Dyar, Jn. N. Y. Ent. Soc., v, 1, 1897.

syn. divergens Walker, Trans. Ent. Soc. Lond., 82, 1862; Schaus, Proc. Zool. Soc. Lond., 650, 1896.

a. laticlavia Clemens, Proc. Acad. Nat. Sci. Phil., xii 157, 1860.

Atl.

States.

PACKARDIA Grote \& Robinson.

Grote \& Robinson, Ann. Lye. Nat. Hist. N. Y., viii, 373, 1866; Neumoegen \& Dyar, C. 76 .

4098. elegans Packard, Proc. Ent. Soc. Phil., iii, 342, 1864; Neunoegen \& Dyar, C. 76; Dyar, Jn. Atl.

N. Y. Ent. Soc., vi, 5, 1898. States. syn. nigripunctata GoodelL.

a. fusca Packard, Proc. Ent. Soc. Phil., iii, 343, 1864.

4099. geminata Packard, Proc. Ent. Soc. Phil., iii, 343, 1864; Neumoegen \& Dyar, C. 109; Dyar, Jn. N. Y. Ent. Soc., vi, 2, 1898.

4100. albipunctata PACKard, Proc. Ent. Soc. Phil., iii, 344, 1864; Neumoegen \& Dyar, C. 109. syn. goodellii Grote.

a. ocellata Grote, Proc. Ent. Soc. Phil., iv, 322, 1864.

Atl. States. States.

HETEROGENEA Knoch.

Knoch, Beitr. Ins., iii, 60, 1793; Neumoegen \& Dyar, C. 74.

4101. shurtleffii Packard, Proc. Ent. Soc. Phil., iii, 346, 1864; Neumoegen \& Dyar, C. 74; Dyar, Jn. N. Y. Ent. Soc., vi, 241, 1898. 
KRON $A$ A Reakirt.

Reakirt, Proc. Ent. Soc. Phil., iii, 347, 1864; Neumoegen \& Dyar, C. 75.

*4102. minuta Reakirt, Proc. Ent. Soc. Phil., iii, 251,

1864; Neumoegen \& Dyar, C. 75.

Atl.

States.

TORTRICIDIA Packard.

Packard, Proc. Ent. Soc. Phil., iii, 347, 1864; Neumoegen \& Dyar, C. 75.

4103. fiskeana Dyar, Ent. News, x, 333, 1900.

Atl. States.

4104. græfii PaCkard, Ent. Amer., iii, 52, 1887.

Tex.

4105. flexuosa Grote, No. Am. Ent., i, 60, 1880; Dyar,

Jn. N. Y. Ent. Soc., vi, 94, 1898.

Atl.

a. cæsonia Grote, No. Am. Ent., i, 60, 1880; States.

Neumoegen \& Dyar, C. 74.

4106. testacea Packard, Proc. Ent. Soc. Phil., iii, 348,

1864; Neumoegen \& Dyar, C. 75; Dyar, Jn.

N. Y. Ent. Soc., vi, 151, 1898.

a. crypta Dyar, Proc. U. S. Nat. Mus., xxv, 395, 1902.

4107. pallida Herrich-Schaffrer, Ausser. Schmett., f. 183, 1854; Neumoegen \& Dyar, C. 75; Dyar, Jn. N. Y. Ent. Soc., vi, 155, 1898.

a. flavula Herrich-Scha EFFEr, Ausser.Schmett. . f. 185,1854 .

\section{Family MEGALOPYGID A.}

(C.=Neumoegen \& Dyar, Jn. N. Y. Ent. Soc., ii, 109-110, 1894.)

CARAMA Walker.

Walker, Cat. Brit. Mus., iv, 843, 1855; Neumoegen \& Dyar, C. 109.

4108. cretata Grote, Proc. Ent. Soc. Phil., iii, 524, 1864; Neumoegen \& Dyar, C. 110; Dyar, Jn.

Atl.

States.

Col.

Atl.

States.

N. Y. Ent. Soc., x, 54, 1902.

syn. pura Butler, Trans. Ent. Soc. Lond., 64,

1878; Dyar, Can. Ent., xxvii, 14, 1895.

\section{MEGALOPYGE Hübner.}

Hübner, Verz. bek. Schmett., 185, 1822; Neumoegen \& Dyar, C. 110.

4109. opercularis Sмгтн \& Aввот, Lep. Ins. Ga., ii, 53,

1797; Neumoegen \& Dyar, C. 110.

Atl. States.

syn. lanuginosa Clemens, subcitrina WALKER

So. Atl.

States. 


\section{LAGOA Harris.}

Harris, Rep. Ins. Mass., 205, 1841; Dyar, Can. Ent., xxix, 67, 1897.

4110. crispata Packard, Proc. Ent. Soc. Phil., iii, 335,

1864; Neumoegen \& Dyar, C. 110.

Atl. States.

4111. pyxidifera Sмгтн \& Aввот, Lep. Ins. Ga., ii, pl. 54, 1797; Neumoegen \& Dyar, C. 110.

So. Atl.

States.

\section{TROSIA Hübner.}

Hüвner, Verz. bek. Schmett., 196, 1822; Dyar, Jn. N. Y. Ent. Soc., vii, 173, 1899. 4112. obsolescens Dyar, Jn. N. Y. Ent. Soc., vii, 173, Ariz. 1899.

\section{Family DALCERID A.}

\section{DALCERIDES Neumoegen \& Dyar.}

Neumoegen \& Dyar, Can. Ent., xxv, 121, 1893; Dyar, Jn. N. Y. Ent. Soc., vi, 232, 1898. *4113. ingenita Hr. Edwards, Pap., ii, 12, 1882; NEUMOEGEN \& Dyar, Jn. N. Y. Ent. Soc., ii, 111,

Ariz. 1894.

\section{Family EPIPYROPIDA.}

\section{EPIPYROPS Westwood.}

Westwoon, Trans. Ent. Soc. Lond., 522, 1876; Krrby, Cat. Lep. Het., i, 490, 1892. 4114. barberiana Dyar, Proc. Ent. Soc. Wash., v, 43, N. Mex. 1902.

\section{Family PYROMORPHID AE.}

(C.=Neumoegen \& Dyar, Jn. N. Y. Ent. Soc., ii, 63, 1894.)

\section{ACOLOITHUS Clemens.}

Clemens, Proc. Acad. Nat. Soc. Phil., 539, 1860; Neumoegen \& Dyar, C. 63.

4115. falsarius Clemens, Proc. Acad. Nat. Sci. Phil.,

540, 1860; Neumoegen \& Dyar, C. 63.

Atl.

syn. samborni PACKARD.

4116. rectarius Dyar, Jn. N. Y. Ent. Soc., vi, 44, $1898 . \quad$ Ariz.

PYROMORPHA Herrich-Schaeffer.

Herrich-Schaeffer, Ausser. Schmett., i, p. 6, 1854; Neumoegen \& Dyar, C. 63.
4117. dimidiata
Herrich - SCHAEFFER,
Ausser.
Atl.

Schmett., f. 222, 1855; Neumoegen \& Dyar, States.

C. 63 .

syn. perlucidula Clemens. 
*4118. centralis Walker, Cat. Brit. Mus., ii, 288, 1854 . Mex., Fla. ? syn. notha Hy. Edwards, Ent. Amer., i, 128, 1885.

\section{TRIPROCRIS Grote.}

Grote, Bull. Buff. Soc., i, 35, 1873; Neumoegen \& Dyar, C. 63.

4119. fusca Hy. Edwards, Pap., iv, 43, 1884; Neumoe-

Ariz. GEN \& DYAR, C. 64 .

4120. rata Hy. Edwards, Pap., ii, 124, 1882; Neumoe

Ariz. GEN \& DYAR, C. 64.

4121. latercula Hy. Edwards, Pap., ii, 124, 1882; NeUMOEGEN \& DYAR, C. 64.

4122. constans Hy. Edwards, Pap., i, 81, 1881; NeUMOEGEN \& DYAR, C. 64.

a. sancta Neumoegen \& Dyar, Jn. N. Y. Ent. Soc., ii, 64, 1894.

4123. smithsonianus Clemens, Proc. Acad. Nat. Sci. Phil., 540, 1860; Neumoegen \& Dyar, C. 64; Dyar, Proc. Ent. Soc. Wash., v, 33, 1902.

4124. marteni French, Pap., iii, 191, 1883; NeumoeGEN \& DYAR, C. 65.

Ariz.

Ariz.

N. Mex.

Rocky Mts., Tex.

Rocky

Mts.

*4125. aversus Hy. Edwards, Pap., iv, 13, 1884.

Mex., Ariz.

4126. lustrans Beutenmüller, Bull. Am. Mus. Nat. Hist., vi,367,1894; Neumoegen \& Dyar,C.172.

Col., Mex.

\section{HARRISINA Packard.}

Packard, Proc. Essex Ins., iv, 31, 1864; Neumoegen \& Dyar, C. 65.

4127. coracina Clemens, Proc. Acad. Nat. Sci. Phil., 539, 1860; Neumoegen \& Dyar, C. 65.

Tex., syn. nigrina GraEF.

4128. metallica Stretch, Ent. Amer., i, 102, 1885; NeuMOEGEN \& DYAR, C. 66.

Tex., Ariz.

4129. americana Guérin-Méneville, Icon. Règ. An. Ins., 500, 1829; NeuMoegen \& Dyar, C. 65.

Atl. States

syn. texana STRETCH.

a. australis Stretch, Ent. Amer., i, 102, 1885;

Neumoegen \& Dyar, C. 65.

\section{Family CHALCOSIDA.}

GINGLA Walker.

\section{Walker, Cat. Brit. Mus., xxxi, 128, 1864.}

4130. laterculæ DYAR, Jn. N. Y. Ent. Soc., viii, 32, 1900.

Ariz. 


\section{Family THYRIDA.}

(C.=Hampson, Proc. Zool. Soc. Lond., 603-633, 1897.)

\section{THYRIS Laspeyres.}

Laspeyres, Ill. Mag., ii, 39, 1803; Hampson, C. 606.

4131. maculata Harris, Am. Jn. Sci., xxxvi, 313, 1836; Hampson, C. 607.

Atl.

States.

syn. perspicua WALKER.

4132. lugubris Borsduval, Spec. Gén., pl. 14, f. 11, 1852 ; i, 490, 1874; Hampson, C. 607.

Atl.

States.

syn. sepulchralis BoIsDuvaL, nevadx OBER THUR.

DYSODIA Clemens.

Clemens, Proc. Acad. Nat. Sci. Phil., 389, 1860; Hampson, C. 608.

*4133. vitrina Boisduval, Mon. Zyg., pl. 1, f. 5, 1829; U. S. Hampson, C. 609.

4134. oculatana Clemens, Proc. Acad. Nat. Sci. Phil., U. S. 349, 1860; Hampson, C. 609.

syn. plena WaLker, fasciata Grote \& RoBInson, montana Hy. Edwards, aurea PAGENSTECHER.

*4135. granulata Neumoegen, Pap., iii, 137, 1883.

Ariz.

*4136. speculifera SEPP, Surin. Vlind., iii, pl. 135, 1830; HAMPson, 609.

Fla., So. Am.

syn. requalis WALKER, flagrata WALKER, thyridina FELDER, floridana HuLst.

\section{HEXERIS Grote.}

Grote, Can. Ent., vii, 176, 1875; Hampson, C. 627.

4137. enhydris Grote, Can. Ent., vii, 176, 1875; HaMPSON, C. 627.

syn. reticulina BeutenMüLLER.

BELNOPTERA Herrich-Schaeffer.

Herrich-Schaeffer, Ausser. Schmett., 76, 1858; Hampson, C. 628.

*4138. fratercula Pagenstecher, Iris, v, 95, 1892:

Cal. Hampson, C. 629.

\section{MESKEA Grote.}

Grote, Can. Ent., ix, 114, 1877; Hampson, C. 631.

4139. dyspteraria Grote, Can. Ent., ix, 115, 1877; Hampson, C. 632.

Fla. 
THYRIDOPYRALIS Dyar.

Dyar, Jn. N. Y. Ent. Soc., ix, 23, 1901.

4140. gallærandialis DyAR, Jn. N. Y. Ent. Soc., ix, 23, Fla. 1901.

\section{Family COSSID A.}

(C.=Neumoegen \& Dyar, Jn. N. Y. Ent. Soc., ii, 160-166, 1894.)

ZEUZERA Latreille.

Latreille, Dict. Hist. Nat., xxiv, 186, 1804; Neumoegen \& Dyar, C. 160.

4141. pyrina Linneus, Faun. Suec., 306, 1701; NeuMOEGEN \& DYAR, C. 160.

Atl. States, Eur.

syn. hypocastrina PODA, resculi Linnaus, hilaris Fourcroy decipiens KIrBY.

\section{COSSUS Fabricius.}

Fabricius, Ent. Syst., iii, (2), 8, 1794; Neumoegen \& Dyar, C. 161.

4142. centerensis Lintner, Can. Ent., ix, 129, 1877; NeuMOEgEN \& DYar, C. 161.

Atl. States.

4143. undosus Lintner, Rept. N. Y. Sta. Mus., xxx, 243, 1878; Neumoegen \& Dyar, C. 161.

Rocky syn. brucei French.

4144. populi Walker, Cat. Brit. Mus., vii, 1515, 1856; NeUMoegen \& Dyar, C. 162.

syn. angreai BAILEY.

a. ore Strecker, Proc. Acad. Nat. Sci. Phil., 282, 1893; NeunOEgEN \& Dyar, C. 162.

*4145. perplexus Neumoegen \& Dyar, Jn. N. Y. Ent. Soc., i, 31, 1893.

Col.

*4146. mucidus Hy. Edwards, Pap., ii, 126, 1882; NeuAriz. MOEGEN \& DYAR, C. 162.

\section{PRIONOXYSTUS Grote.}

Grote, Check List, 63, 1882; Neumoegen \& Dyar, C. 163.

4147. robiniæ PEck, Mass. Agr. Rept., v, 67, 181s;

U. S. Neumoegen \& Dyar, C. 163.

syn. plagiatus WALKER, crepera GROTE, reticulatus Lintrer, aabolicus STRECKER, Lep.

Rhop. Het., suppl. 1, 5, 1898.

a. quercus Ehrman, Can. Ent., xxv, 251, 1893. 
4148. macmurtrei Guérin-Méneville, Icon. Règ. An. Ins., pl. 85, f. 2, 1829; Neumoegen \& Dyar, C. 163.

syn. querciperda Fiтch.

INGUROMORPHA Hy. Edwards.

Hy. Edwards, Ent. Amer., iii, 182, 1887.

4149. basalis Walker, Cat. Brit. Mus., vii, 1523, 1856; Neumoegen \& Dyar, C. 163.

Fla.,

Mex. syn. slossoni Hy. EDwards.

4150. arbeloides Dyar, Ent. News, x, 129, 1899.

Ariz.

\section{COSSULA Bailey.}

Balley, Pap., ii, 93, 1882; Neumoegen \& Dyar, C. 163.

4151. magnifica STrecker, Proc. Acad. Nat. Sci. Phil., 151, 1876; Neumoegen \& Dyar, C. 163.

Fla.,

Mex. syn. magnifica BAILeY, norax Druce, Biol. Cent. Am., Lep. Het., ii, 450, pl. 89, f. 6, 1891.

HYPOPTA Hiibner.

Hübner, Verz. bek. Schmett., 195, 1822; Neumoegen \& Dyar, C. 164.

4152. manfredi Neunoegen, Pap., iii, 139, 1884.

4153. theodori Dyar, Cat. Ent., xxv, 220, 1893.

4154. bertholdi Grote, Bull. Brook. Ent. Soc., iii, 45, 1880; Rivers \& Dyar, Psyche, viii, 10, 1897.

*4155. ethela Neumoegen \& Dyar, Jn. N. Y. Ent. Soc., i, 32, 1893.

4156. henrici Grote, Pap., ii, 131, 1882.

*4157. cornelia Neumoegen \& Dyar, Jn. N. Y. Ent. Soc., i, 32, 1893.

*4158. edwardi Neumoegen \& Dyar, Jn. N. Y. Ent. Soc., i, 32, 1893.

*4159. nanus Strecker, Proc. Acad. Nat. Sci. Phil., 151, 1876; Neumoegen \& Dyar, C. 166.

4160. anna Dyar, Ent. News, ix, 214, 1898.

*4161. itzalana STrecker, Lep. Rhop. Het., suppl. 3, 30,1900 .
Ariz.,

N. Mex.

Ariz., N. Mex.

Col. ,

Cal.

Col.

Ariz., N. Mex.

Col.

Col.

Col.

Fla.

Ariz. 
Family SESIID A.

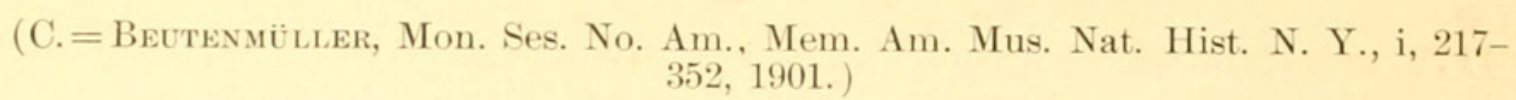

MELITTIA Hïbner.

Hübner, Verz. bek. Schmett., 128, 1816; Beutenmüller, C. 231.

4162. satyriniformis HüBner, Zutr. exot. Schmett., f. U. S. 453, 1825; Beutenuüller, C. 232.

syn. cucurbitæ HARRIS, ceto WestwOOD, amona Hy. Edwards.

4163. snowii Hy. Edwards, Pap., ii, 53, 1882; BeutenMÜLLER, C. 234.

4164. gloriosa Hr. Edwards, Bull. Brook. Ent. Soc., iii, 71, 1880; Beutenmüller, C. 235 .

Kans.

So. Cal.,

Ariz.

*4165. grandis Strecker, Can. Ent., xiii, 156, 1881; Beutenuüller, C. 235.

Ariz.,

Tex.

*4166. magnifica Beutenmüller, Bull. Am. Nat. Hist., Tex. xii, 151, 1899; C. 236.

\section{G $\nRightarrow$ A Beutenmüller.}

Beutenuüller, Bull. Am. Mus. Nat. Hist., viii, 115, 1896; C. 236.

*4167. emphytiformis WaLKer, Cat. Brit. Mus., viii, 43, (Unknown.) 1856; Beutenmüller, C. 237.

*4168. solituda Hy. Edwards, Pap., i, 182, 1881; Tex., Beutenmüllek, C. 238.

EUHAGENA Hy. Edwards.

Hy. Edwards, Pap., i, 181, 1881; Beutenuüller, C. 238.

4169. nebraskæ Hy. Edwards, Pap., i, 181, 1881; Nebr., Beutenmüller, C. 239.

AlCOTHOE Hy. Edwards.

Hy. Edwards, Pap., ii, 53, 1882; Beutenmüller, C. 239.

4170. caudata Harris, Am. Jn. Arts \& Sci., xxxvi, 311, 1839; Beutenmüller, C. 240.

Atl.

a. walkeri Neumoegen, Ent. News, v, 331, 1894.

4171. korites Druce, Biol. Cent. Am., Lep. Het., i, 34, 1884; Beutenmüller, C. 241. 
SANNINA Walker.

WAlker, Cat. Brit. Mus., viii, 64, 1856; Beútenmüller, C. 242.

4172. uroceriformis Walker, Cat. Brit. Mus., viii, 64, So. Atl. 259, 1856; Beutenmüller, C. 242.

syn. quinquecaudata Ridings.

\section{PODOSESIA Möschler.}

Möschler, Stett. ent. Zeit., xxxvii, 312, 1876; Beutenmüller, C. 243.

4173. syringæ Harris, Am. Jn. Arts \& Sci., xxxvi, 311, 1838; Beutenuüller, C. 244.

Atl. States

syn. longipes Möschler.

4174. fraxini Lugger, Psyche, vi, 109. 1891; BeutenMÜLLER, C. 245.

Mont., Dak.

\section{MEMYTHRUS Nevman.}

Newman, Sphinx Vesp., Ess., 1832; Beutenuüller, C. 245.

*4175. tricinctus Harris, Am. Jn. Arts \& Sci., xxx, 310, 1839; Beutenmüller, C. 247.

Atl.

States.

*4176. denotatus Hy. Edwards, Pap., ii, 55, 1882; Beutenmüller, C. 248.

Rocky

Mts.

4177. robiniæ Hy. Edwards, Bull. Brook. Ent. Soc., iii, 72, 1880; Beutenuüller, C. 248.

Nev., Cal.,

Wash.

4178. cupressi Hy. Edwards, Pap., i, 183, 1881; Beutenyüller, C. 249.

Utah, Col.,

Ariz.

*4179. polistiformis Harris, Am. Pom. Soc., 10, 1854; Beutenmüller, C. 249.

Atl.

States.

*4180. scepsiformis Hy. Edwards, Pap., i, 183, 1881; BeutenMülLer, C. 250.

So. Atl

States.

Atl.

States.

Fla.

Beutenmüller, C. 251.

4183. asilipennis Boisduval, Guér. Règ. An., ii, 496, 1829; Beutenmüller, C. 252.

syn. vespipenne Herrich-Schaeffer, denudatum HARRIS, bombyciformis W ALKER.

4184. dollii Neumoegen, Ent. News, v, 330, 1894; BeuTENMÜLLER, C. 252.

a. castaneum BeutenyüLler. Bull. Am. Mus. Nat Hist., ix, 213, 1897.

Atl. States. 
*4185. seminole Neumoegen, Ent. News, v, 330, 1894; Fla. Beutenmüller, C. 253.

*4186. admirandus Hy. Enwards, Pap., ii, 54,1882; Beu- Tex. TENMÜLLER, C. 254.

\section{PALMIA Beutenmuiller.}

Beutenmüller, Bull. Am. Mus. Nat. Hist., viii, 123, 1896; C. 254.

*4187. præcedens Hr. Edwards, Pap., iii, 155, 1883; N. C. BeutenMüller, C. 255.

\section{AEGERIA Fabricius.}

Fabricius, Ill. Mag., vi, 288, 1807; Beutenmüller, C. 255.

4188. apiformis CLerck, Icon., pl. 4, f. 2, 1759; BEU. TENMÜLLER, C. 256.

No. U. S., Eur.

syn. vespiformis HuFnaGeL, crabroniformis

Denis \& SCHIFFERMÜLLER.

*4189. pacifica Hy. Edwards, Pap., i, 180, 1881; BeuTENMÜLler, C. 259.

Pac. States, Mont.

No.

U. S.

4190. tibialis Harris, Am. Jn. Arts \& Sci., xxxvi, 306, 1839; BeutenMüller, C. 259.

syn. flavitibia WaLKer, minimum Neumoegen.

\section{BEMBECIA Hübner.}

Hübner, Verz. bek. Schmett., 128, 1816; Beutenmüller, C. 260.

4191. marginata Harris, Am. Jn. Arts \& Sci., xxxvi, 309, 1839; Beutenmüller, C. 260.

No. U.S.

syn. pleciaformis W ALKER, odyneripennis

W alker, mbi Riley, flavipes Hulst.

a. albicoma Hulst, Bull. Brook. Ent. Soc., vi, 8, 1883.

\section{VESPAMIMA Beutenmiiller.}

Beutenmüller, Bull. Am. Mus. Nat. Hist., vi, 87, 1894; C. 262.

4192. sequoiæ Hy. Edwards, Pap., i, 181, 1881; BeuTENMÜLLER, C. 263.

Cal., Wash.

syn. pinorum BeHRens.

\section{PARHAMONIA Beutenmüller.}

Beutenmüller, Bull. Am. Mus. Nat. Hist., viii, 124, 1896; C. 264.

4193. pini Kellicotr, Can. Ent., xiii, 5, 1881; BeuTENMÜLLER, C. 264.

No. Atl.

States. 
SANNINOIDEA Beutenmüller.

Beutenaüller, Bull. Am. Mus. Nat. Hist., viii, 126, 1896; C. 265.

4194. exitiosa SAY, Jn. Acad. Nat. Sci. Phil., iii, 216, 1823: BeutenMüLler, C. 266.

Atl.

syn. persica Thonas, pepsidiformis HüBNer, States.

xiphixformis BoIsDuvaL.

a. fitchii Hy. Edwards, Pap., ii, 55, 1882.

b. edwardsii Beutenmüller, Bull. Am. Mus. Nat. Hist., xii, 160, 1899.

c. luminosa Neumoegen, Ent. News, v, 331, 1894.

4195. opalescens Hr. Edwards, Pap., i, 199, 1881; BeutenMüller, C. 271.

Pac.

syn. pacifica RILEY.

4196. græfii Hy. Edwards, Pap., i, 183, 1881; BeUTENMÜLLER, C. 271.

States.

a. barnesii Beutenmüller, C. 272, 1901.

Col., Nev., Wash.

\section{ALBUNA Hy. Edwards.}

Hy. Edwards, Pap., i, 186, 1881; Beutenmïller, C. 272.

4197. pyramidalis WALker, Cat. Brit. Mus., viii, 40, U. S. 1856; BeutenmüLler, C. 273.

syn. hylotomiformis WALKER, vancowverensis Hy. EDwards.

a. montana Hy. Edwards, Pap., i, 188, 1881.

syn. tanaceti Hr. Edwards.

b. rubescens Hulst, Bull. Brook. Ent. Soc., iii, 76,1881 .

c. coloradensis Hy. Edwards, Pap., i, 189, 1881. syn. torva Hy. EDwands.

4198. fraxini Hy. Edwards, Pap., i, 185, 1881; BeuTENMÜLLER, C. 275 .

syn. morrisonii Hy. EDwards.

\section{SESIA Fabricius.}

Fabricius, Syst. Ent., 549, 1775; Beutenmüller, C. 275.

4199. mellinipennis Borsduval, Spec. Gén., ii, pl. 14,

f. 12, 1836; Beutenmüller, C. 279.

Cal.,

Col.

syn. resplendens Hy. Edwards, artemisiæ $\mathrm{Hy}$.

Edwards, senecioides Hy. EDwards.

*4200. giliæ Hy. Edwards, Pap., i, 200, 1881; BeUTENMÜLler, C. 279.

Rocky

Mts.

syn. vitrina Neumoegen, deceptiva BeutenMÜLLER. 
4201. rileyana Hy. Edwards, Pap., i, 187, 1881; BeuTENMÜLLER, C. 280.

Atl. \& Pac.

syn. brunneipennis Hy. Edwards, hyperici States, Mont. Hy. Edwards.

*4202. mimuli Hy. Edwards, Pap., i, 200, 1881; BeuTENMÜLLER, C. 281.

4203. rutilans Hy. Edwards, Pap., i, 186, 1881; BeUTENMÜLLER, C. 281.

syn. aureola Hy. EDwards, hemizonæ Hy. EDwards, hupini Hy. Edwards, perplexa Hy. Edwards, impropria Hy. Edwards, washingtonia Hy. Edwards, madariæ Hy. EDWARDS.

4204. arctica Beutenmüller, Can. Ent., xxxii, 277, 1900; C. 283.

*4205. neglecta Hy. Edwards, Pap., i, 197, 1881; BeUTENMÜLLER, C. 283.

*4206. refulgens Hy. Edwards, Pap., i, 199, 1881; BeuTENMÜLLER, C. 283.

4207. bassiformis Walker, Cat. Brit. Mus., viii, 39, 1856; Beutenmüller, C. 284.

syn. lustrans Grote, consimitis Hy. Edwards, bollii Hy. Edwards, eupatorii Hy. EDwards, sexfasciata Hy. EDwards, infirma Hy. EDWARDS, imitata Hy. EDWARDS.

4208. tipuliformis Clenck, Icones, pl. 4, f. 1, 1759; BEUTENMÜLLER, C. 285.

4209. arizonæ Beutenmüller, Jn. N. Y. Ent. Soc., vi, 240, 1898; C. 288.

*4210. morula Hy. Edwards, Pap., i, 196, 1881; BeuTENMÜLLER, C. 288.

*4211. novaroensis Hy. Edwards, Pap., i, 199, 1881; Beutenmüller, C. 289.

*4212. rubrofascia Hy. Edwards, Pap., i, 191, 1881; BeutenMüller, C. 289.

*4213. bolteri Hy. Edwards, Pap., iii, 155, 1883; BeuTENMÜLLER, C. 290.

*4214. fulvipes Harris, Am. Jn. Arts \& Sci., xxxvi, 312, 1839; Beutenyüller, C. 290.

*4215. saxifragæ Hy. Edwards, Pap., i, 190, 1881; Beutenmüller, C. 291.

\section{Col.}

U. S.

Alaska.

Cal.,

Wash.

Ga.

Atl. States, Col.

U. S., Eur., etc.

Tex.,

Ariz.

Tex.

Cal.,

Wash.

Ga.

Atl. States.

No. Atl. States. syn. henshawii Hy. Edwards.

Lab., Col. 
4216. pictipes Grote \& Robinson, Trans. Am. Ent. Soc., ii, 182, 1868; Beutenuüller, C. 291.

syn. inusitata Hy. EDwards.

4217. albicornis Hy. Edwards, Pap., i, 201, 1881; Beutenmüller, C. 292.

U. S.

syn. proxima Hr. Edwards, modesta KelliCOTT, BeutenMüller, C. 344.

*421 . americana Beutenmüller, Bull. Am. Mus. Nat. Hist., viii, 136, 1896; C. 293.

Nev.,

B. C.

4219. culiciformis Linnaus, Syst. Nat., 493, 1758; BeutenMüLler, C. 294.

Alaska,

Eur,

Ga.

*4220. tepperi Hy. Edwards, Pap., i, 203, 1881; BeuTENMÜLLER, C. 294.

4221. acerni Clemens, Proc. Acad. Nat. Sci. Phil., 14, 1860; BeutenMüller, C. 294.

syn. acericolum Germar.

4222. corni Hy. Edwards, Pap., i, 190, 1881; BeuTENMÜLLER, C. 296.

Atl.

States.

Tex.

Soc., iii, 72, 1880; Beutenyüller, C. 296.

4224. pyri Harris, N. E. Farmer, ix, 2, 1830; BeuTENMÜLLER, C. 297.

syn. koebelei Hy. Edwards.

4225. scitula Harris, Am. Jn. Arts \& Sci., xxxvi, 313, 1839; Beutenmüller, C. 298.

syn. gallivorum Westwood, hospes WALSH, zmula Hy. Edwards.

*4226. ithacæ Beutenmüller, Bull. Am. Mus. Nat. Hist., ix, 215, 1897; C. 299.

4227. corusca Hy. Edwards, Pap., i, 193, 1881; BeuTENMÜLLER, C. 299.

4228. decipiens Hr. Edwards, Pap., i, 197, 1881; BeutenMüLler, C. 300.

Atl.

States.

Atl.

States.

Atl.

States.

N. Y.

Tex.

Col. ,

Tex.

syn. imperfecta Hy. Edwards, nicotianx Hy. EDwards.

4229. rubristigma Kellicotт, Can. Ent., xxiv, 211, 1892; Beutenmüller, C. 301.

Atl.

States.

4230. querci Hy. Edwards, Pap., ii, 98, 1882; BeuTENMÜLLER, C. 301.

Ariz.

syn. quercus Hr. Edwards.

*4231. prosopis Hy. Edwards, Pap., ii, 99, 1882; BEUTENMÜLLER, C. 302.

Ariz.

4630 - No. $52-02-24$ 
*4232. tecta Hr. Edwards, Pap., ii, 56, 1882; BeUAriz. TENMÜLLER, C. 302.

*4233. candescens Hy. Edwards, Pap., ii, 123, 1882; Ariz. Beutenmüller, C. 303.

*4234. sigmoidea Hy. Edwards, Pap., ii, 56, 1882; BeutenMüller, C. 303.

N. H., Mass.

4235. tacoma Beutenmüller, Jn. N. Y. Ent. Soc., vi, 240, 1898; C. 304.

*4236. texana Hy. Edwards, Pap., i, 204, 1881; BeuTENMÜLLER, C. 304.

syn. wittfeldii Hr. EDwards.

4237. seminole Beutenmüller, Jn. N. Y. Ent. Soc,, viii, 255, 1899; C. 305 .

*4238. palmii Beutenmüller, Jn. N. Y. Ent. Soc., x, 126,1902 .

*4239. marcia Beutenmüller, Jn. N. Y. Ent. Soc., vii, 254, 1889; C. 305.

4240. præstans Hy. Edwards, Pap., ii, 98, 1882; BeUTENMÜLleR, C. 306.

4241. fragariæ Hy. Edwards, Pap., i, 202, 1881; BEUTENMÜLLER, C. 307.

syn. orthocarpi Hy. EDwaros.

*4242. behrensii Hy. Edwards, Pap., ii, 123, 1882; BeutenMüller, C. 307.

Wyo.,

Wash.

Fla.,

Tex.

Fla.

Ariz.

Fla.

Wash.

Rocky

Mts.

syn. elda Hy. EDwards, helianthi Hr. EDwards.

*4243. mariona Beutenmüller, C. 308, 1901.

Col.

4244. polygoni Hy. Evwards, Pap., i, 202, 1881; BeUTENMÜLLER, C. 308.

*4245. achillæ Hy. Edwards, Pap., i, 203, 1881; BeuTENMÜLlER, C. 308.

syn. eremocarpi Hy. EDwaRds.

*4246. floridensis Grote, Can. Ent., vii, 174, 1875; BEUTENMÜLLER, C. 309.

4247. geliformis Walker, Cat. Brit. Mus., viii, 46, 1856; BeutenMüller, C. 309.

Cal.

Cal.

Fla.

Fla., Antilles.

4248. sapygæformis WALKER, Cat. Brit. Mus., viii, 45, 1856; Beutenmüller, C. 310.

Fla.

4249. animosa Hy. Edwards, Pap., iii, 156, 1883; BEUAriz. TENMÜLLER, C. 310.

*4250. pyralidiformis Wa KKer, Cat. Brit. Mus., viii, 44, 1856 ; Beutenuë Ller, C. 310. 
*4251. sanborni Hy. Edwards, Pap., i, 185, 1881; BeuMass.

TFNMÜLLER, C. 311.

4252. ruficornis Hy. Edwards, Pap., i, 184, 1881; BeuTENMÜLLER, C. 311.

*4253. subærea Hr. Edwards, Pap., iii, 156, 1883; BeuSo.
States.

Ariz. TENMÜLLER, C. 312.

*4254. nigra Beutenmüller, Bull. Am. Mus. Nat. Hist., vi, 95, 1894; C. 312 .

Col.,

Utah.

Col.

*4255. verecunda Hy. Edwards, Pap., i, 190, 1881; BEuTENMÜLLER, C. 312.

*4256. edwardsii Beutenmüller, Bull. Am. Mus. Nat.

Col. Hist., vi, 92, 1894; C. 313.

\section{CALESESIA Beutenmüller.}

Beutenyüller, Jn. N. Y. Ent. Soc., vii, 256, 1899; C. 314.

4257. coccinea Beutenmüller, Jn. N. Y. Ent. Soc., N. Mex. vi, 241, 1898; C. 314 .

\section{PARANTHRENE Huibner.}

Hübner, Verz. bek. Schmett., 128, 1816; Beutenuüller, C. 314.

*4258. maculipes Grote \& Robinson, Trans. Am. Ent.

Tex. Soc., ii, 184, 1868; Beutenmüller, C. 315.

*4259. heucheræ Hy. Edwards, Pap., i, 205, 1881; BEUTENMÜLLER, C. 315 .

Cal., Tex.

syn. potentillæ Hr. Edwards.

4260. palmii Neumoegen, Ent. News, ii, 108, 1891; Ariz. Beutenmüller, C. 316.

4261. canescens Hy. Edwards, Pap., i, 205, 1881; BeUTENMÜLLER, C. 316.

Kans.,

Col.

*4262. mexicanus Beutenmüller, Bull. Am. Mus. Nat. Hist., ix, 216, 1897; C. 316.

N. Mex.

Family PYRALID A.

Subfamily PYRAUETIN AE

By C. H. Fernald.

GLAPHRIA Hübner.

Hüвner, Zutr. exot. Schmett., ii, 29, 1823; Druce, Biol. Cent. Am., Lep. Het., ii, 267, 1895; Homophysa Guenée, Spec. Gén., viii, 364, 1854; Lederer, Wien. ent. Mon., vii, 454, 1863; Hampson, Proc. Zool. Soc. Lond., 607, 1898.

4263. glaphyralis Guenée, Spec. Gén., viii, 366, 1854. No. Atl. syn. stipatalis Walker, Cat. Brit. Mus., States. xxxiv, 1460, 1865; allolineata Grote \& Robinson, Tr. Am. Ent. Soc., i, 28, 1867. 
4264. sesquistrialis Hübner, Zutr. exot. Schm., ii, 29, Mo., Kans., 1823. Tex.

syn. dimotalis Walker, Cat. Brit. Mus., xxxiv, 1346, 1865 .

*4265. invisalis Guenée, Spec. Gén., viii, 361, 1854.

syn. lentifualis Zeluer, Verh. zool.-bot. Ges.

Wien, xxii, 525, 1872.

*4266. psychicalis Hulst, Tr. Am. Ent. Soc., xiii, 149, 1886.

4267. reluctalis Hulst, Tr. Am. Ent. Soc., xiii, 156, 1886.

4268. fulminalis Lederer, Wien. ent. Mon., vii, 487, 1863 .

*4269. peremptalis Grote, Can. Ent., x, 28, 1878.

So. States, So. Am.

Atl. States.

Ariz.

Atl. States.

Mass.

SCYBALISTA Lederer.

Lederer, Wien. ent. Mon., vii, 455, 1863; Hampson, Proc. Zool. Soc. Lond., 608, 1898; Eupoca Warren, Ann Mag. Nat. Hist., (6), viii, 63, 1891.

*4270. restionalis Lederer, Wien. ent. Mon., vii, 455, 1863. U. S.,
So. Am.

SYMPHYSA Hampson.

Hampson, Proc. Zool. Soc. Lond., 609, 1898.

*4271. reniculalis Zeller, Verh. zool.-bot. Ges. Wien, xxii, 526, 1872.

4272. eripalis Grote, Can. Ent., x, 29, 1878. syn. salutalis Hulst, Trans. Am. Ent. Soc., xiii, $150,1886$.

\section{LIPOCOSMA Lederer.}

Lederer, Wien. ent. Mon., vii, 448, 1863.

4273. sicalis WaLker, Cat. Brit. Mus., xix, 942, 1859. Atl. States. syn. perfusalis Walker, Cat. Brit. Mus., xxxiv, $1226,1865$.

*4274. fuliginosalis Fernald, Ent. Am., iv, 37, 1888.

Mo.,

Tex.

Iowa, Tex., Oreg., Cal.

\section{HYMENIA Hübner.}

HüBner, Verz. bek. Schmett., 360, 1826; Мeyrick, Tr. Ent. Soc. Lond., 441, 1890; Zinckenia Zeller, Lep. Caffr., 55, 1852; Hampson, Proc. Zool. Soc. Lond., 623, 1898; Spoladea Guenée, Spec. Gén., viii, 224, 1854.

4275. perspectalis Hübner, Schm. Eur., Pyr., f. 101, U. S., So. Am., 1796; Guenée, Spec. Gén., viii, 226, 1854.

syn. animalis Guenée, Spec. Gén., viii, 226,

So. Afr.,

Austr.

1854; exportalis Guenée, Spec. Gén., viii, 227, 1854; primordialis ZeLLER, Lep. Caffr., 56,1852 ; rhinthonalis WaLKER, Cat. Brit. Mus., xix, 932, 1859; phrasiusalis WALKER, Cat. Brit. Mus., xix, 944, 1859. 
4276. fascialis Cramer, Pap. Exot., iv, 236, 1782.

syn. angustalis Fabricius, Mant. Ins., ii, 222,

1787; recurvalis Fabricius, Ent. Syst., iii, 2, 237, 1794; diffascialis HüBNER, Verz. bek. Schmett., 361, 1826: albifascialis BoISDUvaL, Faun. Ent. Mad., 119, 1834.
U. S., So. Am., So. Eur., So. Afr., Austr.

\section{DESMIA Westwood.}

Westwood, Mag. Zool., ix, 1832; Guenée, Spec. Gén., viii, 188, 1854; Clemens, Proc. Acad. Nat. Sci. Phil., 215, 1860; Lederer, Wien. ent. Mon., vii, 433, 1863.

4277. funeralis Hübner, Schm. Eur., Pyr., f. 103 , 1796.

syn. maculalis Westwood, Mag. Zool., ix, pl. 2. 1832; Clemens, Proc. Acad. Nat. Sci. Phil., 215, 1860 .

a. subdivisalis Grote, Can. Ent., iii, 126, 1871.

4278. tages Cramer, Pap. Exot., ii, 2, 1777; Dyar, Journ. N. Y. Ent. Soc., ix, 22, 1901.

syn. tagesalis Guenée, Spec. Gén., viii, 291, 1854; propinqualis Möschler, Verh. zool.bot. Ges. Wien, xxxi, 430, 1881.
Atl.

States.

\section{SYNCLERA Lederer.}

Lenerer, Wien. ent. Mon., vii, 444, 1863; Moore, Lep. Cey., iii, 315, 1866.

4279. traducalis Zeller, Lep. Caffr., 54, 1852; Moore, Lep. Cey., iii, 316, 1866.

syn. retinalis Lederer, Wien. ent. Mon., i, 100, 1857; jarbusalis WALKer, Cat. Brit. Mus., xvii, 352, 1859; mivocalis WaLKER, Cat. Brit. Mus., xvii, 499, 1859; coitalis Walker, Cat. Brit. Mus., xix, 964, 1859; chlorophasma Butcer, Proc. Zool. Soc. Lond., 493, 1878.
Fla., W. I., So. Am.

\section{ERCTA Walker.}

Walker, Cat. Brit. Mus., xvii, 425, 1859; Hampson, Proc. Zool. Soc. Lond., 636, 1898; Spanista Lederer not Förster), Wien. ent. Mon., vii, 445, 1863; Hydriris Meyrick, Tr. Ent. Soc. Lond., 443, 1885.

*4280. ornatalis Duponcher, Hist. Nat. Lép. Fr., viii, 2, 207, 1831 .

syn. saturnalis T'reitschke, Schm. Eur., x, 3, 29, 1835; deciusalis W ALKER, Cat. Brit. Mus., xix, 905, 1859; invenustalis WALKER, Cat. Brit. Mus., xxxiv, 1431, 1865; fratema Fla., W. I., So. Am., So. Afr., So. Asia.

Butler, Ann. Mag. Nat. Hist., (4), xvi, 415,1875 .

Fla., W. I., So. Am., So. Eur., So. Afr., Austr. 


\section{MARASMIA Lederer.}

Lederer, Wien. ent. Mon., vii, 385,-1863; Hampson, Proc. Zool. Soc. Lond., 6., 1898; Dolichosticha Merrick, Tr. Ent. Soc. Lond., 304, 1884; Epimima Merric Tr. Ent. Soc. Lond., 235, 1886; Lasiacme WArren, Ann. Mag. Nat. Hist., (6), „2vii, $176,1896$.

*4281. cochrusalis Walker, Cat. Brit. Mus., xix, 959, Fla., W. I., 1859.

syn. azionalis WaLker, Cat. Brit. Mus., xix, So. Am. 985, 1859; ruptalis WALKER, Cat. Brit. Mus., xxxiv, 1391, 1865.

4282. trapezalis Guenée, Spec. Gén., viii, 200, 1854. syn. creonalis WaLker, Cat. Brit. Mus., xviii, 579 , 1859; neoclesalis W ALKER, Cat. Brit. Mus., xviii, 635, 1859; suspicalis WALKER, Cat. Brit. Mus., xviii, 667,1859 ; convectalis Walker, Cat. Brit. Mus., xxxiv, 141, 1865; bifurcalis Snellen, Tijd. v. Ent., 219, 1880.

4283. floridalis Fernald, Journ. N. Y. Ent. Soc., ix, $49,1901$.

\author{
Fla., Tex., \\ W.I., \\ So. Am., \\ So. Afr.. \\ So. Asia.
}

Fla.

\section{ANANIA Hübner.}

Hü вner, Zutr. exot. Schmett., iii, 27, 1823; Syngamia Guenée, Spec. Gén., viii, 187, 1854; Lederer, Wien. ent. Mon., vii, 434, 1863.

4284. florella Cramer, Pap. Exot., iv, pl. 348, f. L. Fla., W. I., 1781. So. Am.

\section{SAMEA Guenée.}

Guenée, Spec. Gén., viii, 193, 1854; Lederer, Wien. ent. Mon., vii, 379, 1863; Hampson, Proc. Zool. Soc. Lond., 647, 1898.

4285. ecclesialis Guenée, Spec. Gén., viii, 194, 1854. syn. castellalis Guenée, Spec. Gén., viii, 195, 1854; luccusalis WalKer, Cat. Brit. Mus., xix, 937, 1859; disertalis W ALKER, Cat. Brit. Mus., xxxiv, 1302, 1865.

*4286. multiplicalis Guenée, Spec. Gén., viii, 227, 1854. syn. discessalis Walker, Cat. Brit. Mus., xxxiv, 1302, 1865; nicausalis W ALKER, Cat. Brit. Mus., xvii, 464, 1859.
Fla., W. I.. So. Am.

Fla., W. I., So. Am.

\section{DIASTICTIS Hübner.}

Hüвner, Zutr. exot. Schmett., i, 21, 1818; Bocchoris Moore, Lep. Cey., iii, 27I, 1886; Hampson, Proc. Zool. Soc. Lond., 649, 1898.

4287. argyralis HüBner, Zutr. exot. Schmett., i, 21, fig. 113, 1818.

Atl.

a. ventralis Grote \& Robinson, Tr. Am. Ent. States. Soc., i, 21, 1867.

4288. fracturalis Zelcer, Verh. zool.-bot. Ges. Wien, xxii, 509, 1872 . 
*4289. cæcalis W Arren, Ann. Mag. Nat. Hist., (6), ix, $434,1892$.

*4290. talis Grote, Can. Ent., x, 26, 1878.

Ala.

\section{PILOCROCIS Lederer.}

Lederer, Wien. ent. Mon., 430, 1863; Hampson, Proc. Zool. Soc. Lond., 655, 1898; Ceratoclasis Lederer, Wien. ent. Mon., vii, 430, 1863.

4291. ramentalis Lederer, Wien. ent. Mon., vii, 430, 1863.

syn. perfuscalis Hulst, Tr. Am. Ent. Soc., xiii, $159,1886$.

*4292. tripunctata Fabricius, Ent. Syst., iii, 2, 217, 1794.

N. Y., Fla., So. Am.

syn. campalis Guenée, Spec. Gén., viii, 345, 1854; cubanalis Guenée, Spec. Gén., viii, 345, 1854; memmialis WALKER, Cat, Brit, Mus., xviii, 731, 1859.

*4393. plumbicostalis Grote, Can. Ent., iii, 103, 1871. 4294. inguinalis Guenée, Spec. Gén., viii, 346, 1854. syn. thoasalis WALKer, Cat. Brit. Mus., xviii, 610, 1859: anticostalis Grote, Can. Ent., iii, 104, 1871: levalis Hulst, Tr. Am. Ent. Soc., xiii, 152, 1896.

*4295. tristigmalis Hampson, Proc. Zool. Soc. Lond., 59.1898.

\section{CONCHYLODES Guenée,}

Ala, Fla.

Ala., Fla, So, Am.

Fla.

Guenée, Spec. Gén., viii, 288, 1854; Lederer, Wien. ent. Mon., vii, 442, 1863; Hampson, Proc. Zool. Soc. Lond., 674, 1898; Ledereria Snellen, Tijd, v. Ent., 256, 1875 .

*4296. diphteralis GEYER, Zutr. exot. Schmett., iv, 24, f. 691,1832 .

Fla., Tex., W. I.

4297. platinalis Guenée, Spec. Gén., viii, 282, 1854. syn. ovulalis Guenée, Spec. Gén., viii, 283, 1854 ; erinalis Wakler, Cat. Brit. Mus., xvii, 474, 1859; magicalis FeLder, Reise Nov., pl. 135, f. 6,1874 ; concinnalis HAMPson, Proc. Zool. Soc. Lond., 675, 1898.

So. Atl. States, W. I., So. Am.

\section{DICHOGAMA Lederer.}

Lederer, Wien, ent. Mon., vii, 396, 1863; Hampson, Proc. Zool. Soc. Lond., 676, 1898; Carbacha W Alker, Cat. Brit. Mus., xxiv, 1379, 1865; Pleurasympieza MöschLER, Abh. Senck. Ges., 146, 1890.

4297. 1. redtenbacheri Lederer, Wien. ent. Mon., vii, Fla., 396, 1863; Dyar, Can. Ent., xxii, 271, 1900. 
4297. 2. amabilis Möschler, Abh. Senck. Ges., 296, 1890; Dyar, Jn. N. Y. Ent. Soc., ix, 20, 1901. Iila., W. I.

4297. 3. bergii Möschler, Abh. Senck. Ges., 297, 1890; Fla.,

Dyar, Jn. N. Y. Ent. Soc., ix, 21, 1901. W. I.

\section{LAMPROSEMA Hiibner.}

\section{HüBner, Zutr. exot. Schmett., ii, 21, 1823.}

*4298. lunulalis HüBner, Zutr. exot. Schmett., ii, 21. 1823; Gunéée, Spec. Gén., viii, 205, 1854.

Tex., N. Mex.

HEDYLEPTA Lederer.

Lederer, Wien. ent. Mon., vii, 409, 1863.

*4299. indicata Fabricius, Syst. Ent., 640, 1775.

syn. vulgalis Guenér, Spec. Gén., viii, 202, 1854; sabalis Watker, Cat. Brit. Mus., xviii, 631, 1859; moliusalis WaLker, Cat. Brit. Mus., xviii, 703, 1859; comnexalis Walker, Cat. Brit. Mus., xxxiv, 1394, 1865 ; reductalis WaLker, Cat. Brit. Mus., xxxiv, 1412,1865 .

\section{BLEPHAROMASTIX Lederer.}

Lederer, Wien. ent. Mon., vii, 422, 1863.

4300 . ebulealis Gunnée, spec. Gén., viii, 196, 1854.

4301. aplicalis Guenée, Spec. Gén., viii, 229, 1854.

syn. xeniolalis Hulst, Trans. Am. Ent. Soc., xiii, $159,1886$.

4302. ranalis Guenée, Spec. Gén., viii, 243, 1854.

syn. archasialis WALKER, Cat. Brit. Mus., xvii, 365, 1859; ofellusalis WALKER, Cat. Brit. Mus., xviii, 732, 1859; olliusalis Walker, Cat. Brit. Mus., xix, 982, 1859; strictalis WaLKer, Cat. Brit. Mus., xxxiv, 1392, 1865; qracilis Grote \& RoBINson, Trans. Am. Ent. Soc., i, 25, 1867; datisalis Druce, Biol. Cent. Am., Lep. Het., ii, 269, 1895 .

4303. magnalis Guenée, Spec. Gén., viii, 230, pl. ix, f. 6,1854 .

Fla., W. I., So. Am., So. Africa, So. Asia.
Fla., W. I.

Tex., W. I.

U. S., W. I., So. Am.

syn. medealis Walker, Cat. Brit. Mus., xvii, 353, 1859; belusalis WALKER, Cat. Brit. Mus., xviii, 582, 1859; curtalis WaLKER, Cat. Brit. Mus., xxxiv, 1305, 1865.

Fla., Tex., W. I. 
4304. stenialis Guenée, Spec. Gén., viii, 231, 1854.

syn. acestealis WaLker, Cat. Brit. Mus., xvii, 352, 1859; phamealis Warker, Cat. Brit. Mus., xvii, 368, 1859; sagratis Druce, Biol. Cent. Am., Lep. Het., ii, 270, 1895.

\section{ASCIODES Guenée.}

Guenée, Spec. Gén., viii, 374, 1854.

4305. gordialis Guenée, Spec. Gén., viii, 374, 1854; DYAR, Journ. N. Y. Ent. Soc., ix, 20, 1901.

syn. quietalis Walker, Cat. Brit. Mus., xix, 825, 1859; confusalis Hulst, Trans. Am. Ent. Soc., xiii, 158, 1886.

4306. anormalis Guenée, Spec. Gén., viii, 352, 1854; Dyar, Journ. N. Y. Ent. Soc., ix, 20, 1901. svn. alvinalis Guenée, Spec. Gén., viii, 352, 1854: helcitalis Walker, Cat. Brit. Mus., xviii, 574, 1859; orphnealis WALKER, Cat. Brit. Mus., xviii, 736, 1859; dracusalis Walker, Cat. Brit. Mus., xix, 983, 1859; subxqualis Walker, Cat. Brit. Mus., xxxiv, 1394,1865 .

\section{PANTOGRAPHA Lederer.}

Lederer, Wien. ent. Mon., vii, 387, 1863.

4307. limata Grote \& Robinson, Ann. Lyc. Nat. Hist. N. Y., viii, 464, 1867; Fernald, Can. Ent., xvi. 26,1884 .

syn. suffusalis Druce, Biol. Cent. Am., Lep. Het., ii, 240, 1895 .

\section{SYLEPTA Hübner.}

HüBnER, Verz. bek. Schmett., 356, 1826.

*4308. penumbralis Grote, Can. Ent., ix, 106, 1877.

4308. 1. fluctuosalis Lederer, Wien. ent. Mon., vii. 473, 1863: Dyar, Proc. Ent. Soc. Wash., iv, 460, 1901.

4309. obscuralis Lederer, Wien. ent. Mon., vii, 472, 1863.

*4310. elevata Fabricius, Ent. Syst., iii, 2, 216, 1794. syn. elevalis Guenée, Spec. Gén., viii, 319, 1854 .
So. Atl.

States,

W. I., Mex.,

So. Am.

Fla., W. I., So. Am.

Fla., W. I., So. Am.

Me., Mass.,

Va., Minn., Mex., So. Am.
Ohio, Fla. Fla., So. Am.

Fla.

Fla., W. I., So. Am. 
LYGROPIA Lederer.

Lederer, Wien. ent. Mon., vii, 381, 1863.

*4311. rivulalis Hampson, Proc. Zool. Soc. Lond., 727 ,

1898.

*4312. chromalis Guenée, Spec. Gén., viii, 204, 1854. Fla., So. Am. syn. principalis Lederer, Wien. ent. Mon., vii, 471,1863 .

\section{AGATHODES Guenée.}

Guenée, Spec. Gén., viii, 207, 1854; Hampson, Proc. Zool. Soc. Lond., 730, 1898; Stenurges Lederer, Wien. ent. Mon, vii, 416, 1863.

4313. monstralis Guenée, Spec. Gén., viii, 209, 1854. Fla., W. I., syn. designalis Gunnée, Spec. Gén., viii, 209, Mex., So. Am. 1854; Aloridalis Hulst, Trans. Am. Ent. Soc., xiii, 156, 1886.

\section{PARADOSIS Zeller.}

Zeller, Lep. Caffr., 58, 1854.

4314. flegia Cramer, Pap. Exot., ii, 66, 1777; Dyar, Can. Ent., xxxii, 117, 1900.

Fla., W. I., So. Am. syn. flegialis Poer, Cent. Lep. Cuba, Dec. i, 1832; phantasmalis Guenée, Spec. Gén., viii, 310, 1854; villosalis Zeluer, Lep. Caffr., 58, 1854 .

\section{DIAPHANIA Hübner.}

HüBner, Zutr. exot. Schmett., i, 20, 1818; Eudioptis HüBner, Zutr. exot. Schmett., ii, 24, 1823; Margaronia HüBner, Verz. bek. Schmett., 358, 1826; Phakellura Guilding, Phil. Mag., vii, 206, 1830; Glyphodes Guenée, Spec. Gén., viii, 292, 1854.

*4315. olealis Felder, Reise Nov., pl. 135, f. 35, 1874. Fla., So. Am.

4316. nitidalis Stoll, Pap. Exot., iv, 160, 1781; suppl., 110, 1790; Guenée, Spec. Gén., viii, 299, 1854; Riley, Mo. Rep., ii, 64, 1870; Saunders, Ins. Inj. to Fruits, 367, 1889; Lintner, N. Y. Rep., So. States, W. I., So. Am. xi, 126, 1896; Chittenden, Bull. no. 19, n. s., U. S. Dept. Ag., 41, 1899.

syn. vitralis HüBNER, Zutr. exot. Schmett., 20, 1818; fumosalis Guenée, Spec. Gén., viii, 300, 1854; praxial is Druce, Biol. Cent. Am., Lep. Het., ii, 231, 1895.

4317. infimalis Guenée, Spec. Gén., viii, 298, 1854; Dyar, Jn. N. Y. Ent. Soc., ix, 20, 1901.

*4318. arguta Lederer, Wien. ent. Mon., vii, 478, 1863.

No. Am.,? So. Am.

4319. niveocilia Hampson, Proc. Zool. Soc. Lond., 728, 1898.
Fla., W. I., So. Am. 
43ะ0. hyalinata Linneus, Syst. Nat., ed. 12, i, 874,

1767; Fabricius, Ent. Syst., iii, 2, 213, 1794;

U.S.,

Saunders, Can. Ent., xv, 56, 1883; Ashmead, Antilles,

Bull. 14, U. S. Dept. Ag., 26, 1887; SAunders, So. Am.

Ins. Inj. to Fruits, 365, 1889; Lintrer, N. Y.

Rep., xi, 134, 1896; Cомsтоск, Man., 231, 1895.

syn. marginalis Stoll, Pap. Exot., iv, 160,

1781; lucemalis HüBNER, Schm. Eur., Pyr.,

20,pl. 17,f. 108, 1796; hyalinatalis Guenée,

Spec. Gén., viii, 296, 1854; Comstock, Rep.

U. S. Dept. Ag., 218, 1879.

4321. quadristigmalis Guenée, Spec. Gén., viii, 304, 1854; Riley, Ins. Life, i, 22, 1888.

Atl. States,

W. I.,

So. Am.

Fla., Tex.,

W. I.,

So. Am.

syn. batesi Felder, Reise Nov., pl. 135, f. 29,

1874; alitalis Hulst, Trans. Am. Ent. Soc., xiii, $157,1886$.

\section{METREA Grote.}

Grote, Pap., ii, 73, 1882; Hampsox, Proc. Zool. Soc. Lond., 757, 1898.

4323. ostreonalis Grote, Pap., ii, 73, 1882.

Can., Me.,

syn. urticaloides Fyles, Can. Ent., xxvi, 184,

Mass., Pa. 1894.

OMMATOSPILA Lederer.

Lederer, Wien. ent. Mon., vii, 443, 1863; Hampson, Proc. Zool. Soc. Lond., 759, 1898; Thelda WALker, Cat. Brit. Mus., xxxiv, 1221, 1865.

*4324. narcæusalis Walker, Cat. Brit. Mus., xix, 972, Tex., W. I., 1859.

syn. nummulalis Lederer, Wien. ent. Mon., vii, $444,1863$.

HELLULA Guenée.

Guenée, Spec. Gén., viii, 415, 1854; Lederer, Wien. ent. Mon., vii, 351, 1863; Hennemann, Kleinschm., i, 2, 44, 1865; Hampson, Proc. Zool. Soc. Lond., 760, 1898.

4325. undalis Fabricius, Ent. Syst., iii, 2, 226, 1794; Hübner, Schm. Eur., Pyr., 19, pl. 14, f. 93, 1796: Treitschke, Schm. Eur., vii, 128, 1829; Duponchel, Hist. Nat. Lép. Fr., viii, 160, 1831; Heinemann, Kleinschm., i, 2, 45, 1865; Hampson, Proc. Zool. Soc. Lond., 760, 1898; Chittenden, Bull. no. 19, n. ser., U. S. Dept. Agr., 54, 1899; Bull. no. 23, n. ser., U. S. Dept. Agr., 53, 1900 .

syn. alcomalis Walker, Cat. Brit. Mus., xix, 827. 1859; exemptalis W ALKER, Cat. Brit. Mus., xxxiv, 1313, 1865; rogatalis Hulst, Tr. Am. Ent. Soc., xiii, 149, 1886.
So. States, So. Eur., Africa, India. 
MIMORISTA Warren.

W Arren, Ann. Mag. Nat. Hist., (6), vi, 476, 1890.

4326. flavidissimalis Grote, Can. Ent., ix, 105, 1877.

Tex.

TERASTIA Guenée.

Guenée, Spec. Gén., viii, 211, 1854; Hampson, Proc. Zool. Soc. Lond., 181, 1899.

4327. meticulosalis Guenée, Spec. Gén., viii, 212, 1854; Fla., W. I., Dyar, Jn. N. Y. ent. soc., ix, 21, 1901.

syn. subjectalis Lederer, Wien. ent. Mon., Ceylon,Java, P. I. vii, 480, 1863; quadratalis WALKER, Cat. Brit. Mus., xxxiv, 1527, 1865; coligenalis Hulst, Tr. Am. Ent. Soc., xiii, 156, 1886.

\section{LANIIFERA Hampson.}

Hampson, Proc. Zool. Soc. Lond., 184, 1899.

*4328. cyclades Druce, Biol. Cent. Am., Lep. Het., ii, 220,1895 .

Ariz., Mex.

\section{EVERGESTIS Hübner.}

Hüвner, Verz. bek. Schmett., 354, 1826; Hampson, Proc. Zool. Soc. Lond., 185, 1899; Mesographe HüBner, Verz. bek. Schmett., 354, 1826; Homochroa HüBner, Verz. bek Schmett., 358, 1826; Scopolia HüBner, Verz. bek. Schmett., 368, 1826; Orobena Guenée, Spec. Gén., viii, 376, 1854; Parædis Grote, Check List, 51, 1882.

4329. funalis Grote, Bull. U. S. Geol. Surv., iv, 670, 1878; Cockerell, Ent. News, x, 68, 1899.

N. Mex., Cal.

*4330. obliqualis Grote, Ann. Mag. Nat. Hist., (5), xi, 56, 1883; Proc. Kans. Ac. Sci., viii, 56, 1883.

N. Mex.

*4331. simulatilis Grote, No. Am. Ent., 94, 1880.

Ariz., Col.

syn. brunneogrisea Hy. Edwards, Ent. Am., ii, $171,1886$.

4332. napæalis Hulst, Tr. Am. Ent. Soc., xiii, 145, 1886.

4333. dyaralis Fernald, Jn. N. Y. Ent. Soc., ix, 49, 1901; Dyar, Proc. Ent. Soc. Wash., iv, $460,1901$.

4334. rimosalis Guenée, Spec. Gén., viii, 371, 1854; Thomas, Ill. Rep., iv, 37, 1880; Riley, Rep. U. S. Dep. Agr., 126, 1883.

4335. extimalis Scopoli, Ent. Carn., 241, 1763; MeyRIck, Handb. Brit. Lep., 424, 1895.

syn. margaritalis Denis \& SCHIFFERMÜLLER, Syst. Verz. Wien, 123, 1776; emcalis Ḧ̈вnek, Eur. Schm., Pyr., 28, pl. 9, f. 55, 1796; comsimilis Warren, Ann. Mag. Nat. Hist., (6), ix, 433, 1892.

\section{Cal.}

Fla., So. Am.

Va., Cal., Wash.

Ariz., N. Mex. 
4336. straminalis HüBNER, Vög. \& Schm., 82, 1792;

Meyrick, Handb. Brit. Lep., 424, 1895.

U. S.,

Eur.

syn. elutalis Hübner, Eur. Schm., Pyr., 26, pl. 10 , f. 62,1796 ; stramentalis Ḧ̈BNER, Verz. bek. Schmett.,354, 1826; TreitschKE, Schm. Eur., vii, 76, 1829; Duponchel, Hist. Nat. Lép. Fr., viii, 2, 102, 1831; Heinemann, Kleinschm., i, 2, 95, 1865; eunusalis Walker, Cat. Brit. Mus., xviii, 756,1859 .

\section{CROCIDOPHORA Lederer.}

Lederer, Wien. ent. Mon., vii. 386, 1863.

4337. serratissimalis Zecler, Verh. zool.-bot. Ges. Wien, xxii, 521, 1872.

Atl. syn. subdentalis Grote, Bull. Buff. Soc., i, 173, 1873.

*4338. pustuliferalis Lederer, Wien. ent. Mon., vii, Fla. $477,1863$.

4339. tuberculalis Lederer, Wien. ent. Mon., vii, $476,1863$.

\section{STENOPHYES Lederer.}

Lederer, Wien. ent. Mon., vii, 388, 1863.

4340. huronalis Guenée, Spec. Gén., viii, 198, 18.54. syn. zinghalis WALker, Cat. Brit. Mus., xvii, 355, 1859; serinalis WALKER, Cat. Brit. Mus., xvii, 468, 1859.

\section{POLYGRAMMODES Guenée.}

Guenée, Spec. Gén., viii, 344, 1854; Hampson, Proc. Zool. Soc. Lond., 196, 1899.

*4341. hirtalis Guenée, Spec. Gén., viii, 344, 1854. Tex.,So.Am.

syn. Tybialis Walker, Cat. Brit. Mus., xviii, 624, 1859; amatalis WALKER, Cat. Brit. Mus., xviii, 625, 1859; capitalis Grote, Bull. U. S. Geol. Surv., vi, 272, 1881.

\section{NOMOPHILA Hübner.}

HüBner, Verz. bek. Schmett., 368, 1826; Meyrick, Handb. Brit. Lep., 410, 1895; Hampson, Proc. Zool. Soc. Lond., 201, 1899.

4342. noctuella Denis \& SChiffermüller, Syst. Verz. Wien, 136, 1776; Felt, Can. Ent., xxv, 129, 1893: Merrick, Handb. Br. Lep., 410, 1895; Hampson, Proc. Zool. Soc. Lond., 201, 1899. syn. hybriaalis HüBnER, Schm. Eur., Pyr., 29, pl. 17, f. 114, 1796; indistinctalis WALKER, Cat. Brit. Mus., xxvii, 59, 1863; helvolalis MaAssen, Stübel's Reise, 170, 1890.
U.S., Eur. Asia, So. Am. 
PACHYZANCLA Meyrick.

Meyrick, Tr. Ent. Soc. Lond., 315, 1884.

*4343. periusalis Walker, Cat. Brit. Mus., xviii, 623, 1859.

U. S., Brazil.

4344. bipunctalis Fabricrus, Ent. Syst., iii, 2, 232, 1794.

syn. agrotalis ZelLer, Lep. Caffr., 38, 1852; Ga., Fla., W. I., So. Am? So. Afr. mutualis Zeller, Lep. Caffr., 40, 1852; verminalis Guenée, Spec. Gén., viii, 348, 1854; detritalis Guenée, Spec. Gén., viii, 347, 1854; lycialis Walker, Cat. Brit. Mus., xviii, 572, 1859; phileatis WaLkne, Cat. Brit. Mus., xviii, 596, 1859; repetitalis Grote, Rep. U. S. Dept. Agr., 270, 1880; Hampson, Proc. Zool. Soc. Lond., 204, 1899.

\section{LOXOSTEGE Hübner.}

Hübner, Verz. bek. Schmett., 352, 1826; Meyrick, Tr. Ent. Soc. Lond., 452, 1890; Handb. Brit. Lep., 418, 1895; Emmelia GEYer, Zutr. exot. Schmett., v, 8, 1837; Phlyctenodes Guené, Spec. Gén., viii, 173, 1854; Hampson, Proc. Zool. Soc. Lond., 207, 1899; Spilodes Guenée, Spec. Gén., viii, 379, 1854; Dosara Walker, Cat. Brit. Mus., xix, 828, 1859; Ephelis Lederer, Wien. ent. Mon., vii, 356, 1863; Eurycreon Lederer, Wien. ent. Mon., vii, 376, 1863.

4345. dasconalis Walker, Cat. Brit. Mus., xviii, 773, 1859 .

*4346. coloradensis Grote \& Robinson, Tr. Am. Ent. Soc., i, 25, 1867.

syn. pergilvalis Hulst, Tr. Am. Ent. Soc., xiii, $151,1886$.

4347. chortalis Grote, Bull. Buff. Soc., i, 89, 1873.

4348. aureolalis Hulst, Tr. Am. Ent. Soc., xiii, 156, 1886.

syn. cyralis Druce, Biol. Cent. Am., Lep. Het., ii, 204,1895 .

4349. obliteralis W ALKER, Cat. Brit. Mus., xxxiv, 1392, 1865; Chittenden, Bull. no. 27, n. ser., U. S. Dept. Agr., 102, 1901.

syn. marculenta Grote \& Robinson, Tr. Am. Ent. Soc., i, 23, 1867.

*4350. mancalis Lederer, Wien. ent. Mon., vii, 464, 1863.

syn. marculenta ZelLer, Verh. zool.-bot. Ges. Wien, xxii, 507, 1872.

4351. helvialis WALKer, Cat. Brit. Mus., xviii, 772, 1859.

syn. thycesalis Walker, Cat. Brit. Mus., xix, 981, 1859; apertalis WALKER, Cat. Brit. Mus., xxxiv, 1393, 1865; citrina Grote \& Robinson, Tr. Am. Ent. Soc., i, 23, 1867.
N. Y., Ill., Tex., Col.

Tex., Col., Ariz.

Me. to Cal.

Col., Ariz., Mex

Can., Mass., N. Y., Ill.

Va., Fla., Mo.

Atl. States. 
*4352. bifidalis Fabricius, Ent. Syst., iii, 2, 232, 1794. syn. inornatalis WaLker, Cat. Brit. Mus., xxxiv, 1456, 1865; evanidalis BERgSTRASSER, Deutsche ent. Zeits., xix, 134, 1875; obsole. talis Bergstrasser, Deutsche ent. Zeits., xix, 135, 1875; orbitalis FELder, Reise Nov., pl. 134, f. 32, 1874.

4353. flavalis Fernald, Ins. Life, vi, 255, 1894.

N. Mex., W. I., So. Am.

Cal.

U.S., So. Am.

syn. crinisalis W ALKer, Cat. Brit. Mus., xviii, 798, 1859; siriusalis WALKER, Cat. Brit. Mus., xviii, 563, 1859; diotimealis W ALKER, Cat. Brit. Mus., xviii, 785, 1859; crinitalis Lederer, Wien. ent. Mon., vii, 376, 1863; Zeller, Verh. zool.-bot. Ges. Wien, 519, 1872; communis Grote, Can. Ent., viii, 99, 1876.

a. rantalis Guenée, Spec. Gén., viii, 405, 1855; Zeller, Verh. zool.-bot. Ges. Wien, xxii, 519, 1872: Bergstrasser, Deutsche ent. Zeits., xix, 132, 1875; Snow, Psyche, iii, 127, 1880. syn. murcialis W ALKer, Cat. Brit. Mus., xviii, 746,1859 ; licealis Walk er, Cat. Brit. Mus., xviii, 563, 1859; nestusalis W ALKER, Cat. Brit. Mus., xviii, 784, 1859; thoonalis Walker, Cat. Brit. Mus., xviii, 785, 1859; intractella WaLKer, Cat. Brit. Mus., xxvii, 55, 1863; posticata Grote \& Robinson, Trans. Am. Ent. Soc., i, 22, 1867; occidentalis Packard, Ann. Lyc. Nat. Hist. N. Y., x, $260,1873$.

4355. allectalis Grote, Can. Ent., ix, 107, 1877.

Tex.

syn. perplexalis Fernatd, Can. Ent., xvii, 57,1885 .

4356. lepidalis Hulst, Trans. Am. Ent. Soc., xiii, 146 , 1886.

*4357. baccatalis Hulst, Can. Ent., xxiv, 63, 1892.

4358. sticticalis Linneus, Faun. Suec., 352, 1761; Treitschke, Schm. Eur., vii, 64, 1829; Duponcher, Hist. Nat. Lép. Fr., viii, 96, 1831; HerRICH-SCHAEFfer, Schm. Eur. iv, 34, 1848; HeInemann, Kleinschm. .i, 2,90,1865; Zeller, Verh. zool.-bot. Ges. Wien, xxii, 518, 1872; MeYrick, Handb. Brit. Lep., 418, 1895.

syn. fuscalis Hübner, Eur. Schmett., Pyr., 29 , pl. 7, f. 45, 1796 ; tetragomalis HaWoRTH, Lep. Brit., 385, 1811; sordida Butlen, Tr. Ent. Soc. Lond., 432, 1886.

Mont. Col.

Tex.

Rocky Mts., Cal., Eur. 
4359. commixtalis Walker, Cat. Brit. Mus., xxxiv, 1759,1865 .

Eur., No. Am.

syn. indotatellus Walker, Cat. Brit. Mus., xxv, 1752, 1866; septentrional is TENGSTRöM, Cat.,358,1869; cereral is ZeLLen, Verh. zool. bot. Ges. Wien, xxii, 517, 1872.

4360. offumalis Hulst, Trans. Am. Ent. Soc., xiii, 150, 1886.

*4361. indentalis Grote, Ann. Mag. Nat. Hist., (5), xi, $57,1883$.

*4362. albiceralis Grote, Bull. U. S. Geol. Surv.,iv, 678, 1878.

4363. oberthuralis Fernald, Ins. Life, vi, 255, 1894.

*4364. labeculalis Hulst, Trans. Am. Ent. Soc., xiii, 152, 1886.

*4365. thallophilalis Hulst, Trans. Am. Ent. Soc., xiii, $154,1886$.

*4366. annaphilalis Grote, Can. Ent., xiii, 34, 1881.

*4367. anartalis Grote, Can. Ent., x, 27, 1878.

syn. Iulualis Hulst, Trans. Am. Ent. Soc., xiii, $150,1886$.

4368. linealis Fernatd, Ins. Life, vi, 255, 1894.

4369. macluræ Riley, Ins. Life, v, 155, 1893.

*4370. flavifimbrialis W ARren, Ann. Mag. Nat. Hist., (6), ix, 174, 1892 .

*4371. succandidalis Hulst, Trans. Am. Ent. Soc., xiii, $153,1886$.

*4372. oblectalis Hulst, Trans. Am. Ent. Soc., xiii, 154 , 1886.

*4373. ophionalis Walker, Cat. Brit. Mus., xvii, 316, 1859.

4374. nasonialis Zeller, Verh. zool.-bot. Ges. Wien, xxiii, 209, 1873.

4375. sesquialteralis ZeLLer, Verh. zool.-bot. Ges. Wien, xxiii, 209, 1873.

4376. vibicalis Zeluer, Verh. zool.-bot. Ges. Wien, xxiii, 208, 1873.
Cal.

N. Mex.

Col.

Ariz., Cal.

Ariz.

Mont.,

Cal.

Cal.

Cal.

Cal.

Mo., Tex.

Cal.

Dak.

Ariz.

Tex.

Tex.

Tex.

Tex. 


\section{DIASEMIA Hübner.}

Hübner, Verz. bek. Schmett., 348, 1826; Stephens, Ill. Brit. Ent., Haust., iv, 37, 1834; Guenée, Spec. Gén., viii, 233, 1854; Lederer, Wien. ent. Mon., vii, 418, 1863; Heinemann, Kleinschm., i, 2, 98, 1865; Meyrick, Handb. Brit. Lep., 404, 1895; Hampson, Proc. Zool. Soc. Lond., 213, 1899.

4377. ramburialis Duponchel, Hist. Nat. Lép. Fr., viii, 2, 343, 1831; Fischer v. Röslerstama, Microlep., 281, 1841; Herrich-Schaeffer, Schm. Eur., iv, 26, 1848; Guenée, Spec. Gén., viii, 234, 1854; Heinemann, Kleinschm., i, 2, 98, 1865; Leech, Brit. Pyr., 45, 1886; Merrick, Handb. Brit. Lep., 404, 1895; Hampson, Ind. Moths, iv, 411, 1896.

syn. melalencalis Walker, Cat. Brit. Mus., xvii, 402, 1859; leodocusalis W ALKER, Cat. Brit. Mus., xix, 947, 1859; reconditalis W ALKer, Cat. Brit. Mus., xxxiv, 1325, 1865; leucophralis WaLker, Cat. Brit. Mus., xxxiv, 1326, 1865.

4378. nigralis Fernald, Can. Ent., xxiv, 178, 1892.

*4379. janassialis WALKer, Cat. Brit. Mus., xvii, 337, 1859 .

syn. hariolalis Hulst, Trans. Am. Ent. Soc., xiii, 149, 1886.

*4380. plumbosignalis Fernald, Ent. Am., iv, 37, 1888.

4381. roseopennalis Hulst, Trans. Am. Ent. Soc., xiii, 148, 1886.

*4382. elegantalis W ARren, Ann. Mag. Nat. Hist., (6), ix, 440, 1892.

*4383. magdalena Fernald, Can. Ent., xxiv, 122, 1892.

So. Atl.

States,

Eur.,

Austr.
Fla.

Fla.

Can., Col., Va., N. C., Ariz.

Cal.

Fla., Tex.

\section{LIOPASIA Möschler.}

Möschler, Verh. zool.-bot. Ges. Wien, xxxi, 426, 1881; Hampson, Proc. Zool. Soc. Lond., 215, 1899.

*4384. teneralis Lederer, Wien. ent. Mon., vii, 462, Cal. 1863.

\section{CONDYLORRHIZA Lederer.}

Lederer, Wien. ent. Mon., vii, 393, 1863; Hampson, Proc. Zool. Soc. Lond., 218, 1899. *4385. vestigialis Guenée, Spec. Gén., viii, 321, 1854. La., Tex. syn. tritealis WaLker, Cat. Brit. Mus., xviii, 597, 1859; mestoralis WALKER, Cat. Brit. Mus., xviii, 729,1859; oratalis Hulst, Trans. Am. Ent. Soc., xiii, 158, 1886. 


\section{THOLERIA Hübner.}

HüBner, Zutr. exot. Schmett., ii, 27, 1823; Verz. bek. Schmett., 354, 1826; Mecyna Guenée, Spec. Gén., viii, 406, 1854; Meyrick, Trans. Ent. Soc. Lond., 451, 1890; Handb. Brit. Lep., 417, 1895; Hampson, Proc. Zool. Soc. Lond., 223, 1899.

4386. reversalis Guenée, Spec. Gén., viii, 409, 1854; Dyar, Proc. Ent. Soc. Wash., iv, 461, 1901.

Atl. States,

\section{CALAMOCHROUS Lederer.}

Lederer, Wien. ent. Mon., vii, 386, 1863.

*4387. straminea Warren, Ann. Mag. Nat. Hist., (6), ix, 393, 1892 . W. I.

\section{CYBALOMIA Lederer.}

Lederer, Wien. ent. Mon., vii, 420, 1863; Hampson, Proc. Zool. Soc. Lond., 229, 1899; Hypolais Guenée (not Kaup), Spec. Gén., viii, 239, 1854.

*4388. extorris Warren, Ann. Mag. Nat. Hist., (6), ix, West. $395,1892$.

Cal.

1. belialis Druce, Biol. Cent. Am., Lep. Het., ii, 557, 1899; Dyar, Proc. U. S. Nat. Mus., xxv, 397, 1902 .

\section{MONOCONA Warren.}

Warren, Ann. Mag. Nat. Hist., (6), ix, 173, 1892; Hampson, Proc. Zool. Soc. Lond., $232,1899$.

*4389. rubralis Warren, Ann. Mag. Nat. Hist., (6), ix,

Cal. 174,1892 .

\section{AUTOCOSMIA Warren.}

Warren, Ann. Mag. Nat. Hist., (6), ix, 432, 1892; Hampson, Proc. Zool. Soc. Lond., $233,1899$.

*4390. nexalis Hulst, Tr. Am. Ent. Soc., xiii, 150, Tex., Col., 1886. Cal.

syn. concinna Warren, Ann. Mag. Nat. Hist., (6), ix, 433, 1892.

\section{TITANIO Hübner.}

Hübner, Verz. bek. Schmett., 350, 1826; Meyrick, Tr. Ent. Soc. Lond., 453, 1890; Hampson, Proc. Zool. Soc. Lond., 235, 1899.

4391. pollinalis Denis \& SCHIfFermüller, Syst. Verz. Wien, 124, 1776; Treitschke, Schm. Eur., vii, 202, 1829; Duponchel, Hist. Nat. Lép. Fr., viii, 2, 250, 1831; Herrich-Schaefrer, Schm. Eur., iv, 16, 1848; Guenée, Spec. Gén., viii, 149, 1854; Hennemann, Kleinschm., i, 2, 52, 1865 .

syn. bigutta Esper, Eur. Schmett., iv, 163, 5, 1786; melissalis WaLker, Cat. Brit. Mus., xv11, 331, 1859; flavinotalis Grote, Can. Ent., xiii, 34, 1881. 
4392. ephippialis Zetтerstedt, Ins. Lap., 972, 1840; Möschler, Wien. ent. Mon., iv, 377, 1860; Wocke, Stett. ent. Zeit., xxiii, 34, 1862; xxv, 191, 1864 .

syn. frigidalis Guenée, Spec. Gén., viii, 157 , 1854; scandinavialis Guenée, Spec. Gén., viii, 156,1854 .

*4393. dapalis Grote, Can. Ent., xiii, 17, 1881.

Cal.

4394. proximalis Fernald, Ins. Life, vi, 256, 1894.

Cal.

*4395. immerens Harver, Can. Ent., vii, 160, 1875.

Cal,

*4396. bububattalis Hulst, Tr. Am. Ent. Soc., xiii, $149,1886$.

4397. helianthiales Murtfeldt, Can. Ent., xxix, 71, Mo., Tex. 1897.

\section{METASIA Guenée.}

Guenée, Spec. Gén., viii, 251, 1854; Hampson, Proc. Zool. Soc. Lond., 236, 1899. 4398. argalis Fernald, Ins. Life, vi, 256, $1894 . \quad$ Cal. 4399. quadristrigalis FernaLd, Ins. Life, vi, 257, $1894 . \quad$ Cal.

\section{PERISPASTA Zeller.}

Zeller, Verh. zool.-bot. Ges. Wien, xxv, 333, 1875.

4400. cæculalis Zeller, Verh. zool.-bot. Ges. Wien, xxv, 333, 1875 .

syn. immixtalis Grote, Can. Ent., xiii, 232,

1881.

\section{PHLYCT $Æ$ NIA Hiibner.}

HüBner, Verz. bek. Schmett., 359, 1826; Stephens, Ill. Brit. Ent., Haust., iv, 42, 1834;

Meyrick, Trans. Ent. Soc. Lond., 446, 1890; Handb. Brit. Lep., 408, 1895.

4401. ferrugalis HüBner, Eur. Schmett., Pyr., 27, pl. 9, f. 54, 1796; 'Treiтschке, Schm. Eur., vii, 94, 1829; Duponchel, Hist. Nat. Lép. Fr., viii, U. S., Eur., 138, 1831; Stephens, Ill. Brit. Ent., Haust., iv, Asia. 53, 1834; Herrich-Schaeffer, Schm. Eur., iv, 39, 1848; Guenée, Spec. Gén., viii, 398, 1854; Hennemann, Kleinschm., i, 2, 76, 18.5; Meyrick, Handb. Brit. Lep., 409, 1895.

syn. mbigalis Guenée, Spec. Gén., viii, 398, 1854: C'Hittenden, Bull. no. 27, n. ser.. U. S. Dept. Agr., 7, 1901; martialis Guenée, Spec. Gén., viii, 398, 1854; hypatialis Walker, Cat. Brit. Mus., xix, 1014, 1859: oblunatis Lederer, Wien. ent. Mon., vii, 469, 1863; harveyana Grote, Can. Ent., ix, 104, 1877. 
*4402. profundalis PACKARd, Ann. Lye. Nat. Hist. N. Y., $\mathrm{x}, 261,1873$.

Cal., B. C.

4403. inquinatalis Zeller, Isis, xiii, 205, 1846; Herrich-Schaeffer, Schm. Eur., iv, 41, 1848; Guenée, Spec. Gén., viii, 395, 1854.

Lab., N. Eur., Alps.

syn. glacialis Packard, Proc. Bost. Soc. Nat. Hist., xi, 52, 1866.

4404. itysalis WaLker, Cat. Brit. Mus., xix, 828, 1859 .

Lab., Can., Col.

syn. variegata WALKER, Cat. Brit. Mus., xxvii, 76, 1863; turmalis Grote, Can. Ent., xiii, 33, 1881; hyperborealis Möschler, Stett. ent. Zeit., xxxv, 163, 1874.

*4405. radiosalis Möschler, Stett. ent. Zeit., xliv, 123, 1883.

4406. washingtonalis Grote, Bull. U. S. Geol. Surv., vi, 578, 1882 .

syn. invinctalis Hulst, Tr. Am. Ent. Soc., xiii, $152,1886$.

*4407. externalis Warren, Ann. Mag. Nat. Hist., (6), ix, 296, 1892 .

*4408. indistinctalis W ARren, Ann. Mag. Nat. Hist., (6), ix, 394, 1892 .

4409. acutella WALker, Cat. Brit. Mus., xxxv, 1753, 1866.

syn. venalis Grote, Can. Ent., x, 24, 1878.

4410. terrealis Treitschke, Schm. Eur., vii, 110, 1829; Heinemann, Kleinschm., i, 2, 69, 1865; MeyRICK, Handb. Brit. Lep., 409, 1895.

syn. mysippusalis Walker, Cat. Brit. Mus., xviii, 564, 1859; humilalis Lederer, Wien. ent. Mon., vii, 464, 1863.

4411. extricalis Guenée, Spec. Gén., viii, 338, 1854. syn. dionalis Walker, Cat. Brit. Mus., xviii, 758, 1859; nisoecalis WALKER, Cat. Brit. Mus., xviii, 771, 1859; intricatalis LEDERER, Wien. ent. Mon., vii, 469, 1863; oppilatis Grote, Can. Ent., xii, 36, 1880.

4412. helvalis WALker, Cat. Brit. Mus., xviii, 757, 1859 .

No. Atl.

syn. oscitalis Grote, Can. Ent., xii, 36, 1880; gyralis Hulst, Tr. Am. Ent. Soc., xiii, 152, 1886.

4413. tertialis GuenÉe, Spec. Gén., viil, 364, 1854. S. Lab.

Wrash.

U.S.

U.S.

No. Atl.

States.

No. U. S.,

Eur.

Atl. States.

States, Col.

syn. plectilis Grote \& Robinson, Tr. Am. Ent. Soc., i, 27, 1867; syringicola PACKard, Rep. Mass. Bd. Agr., 250, 1870.

Atl. States. 
CINDAPHIA Lederer.

Lederer, Wien. ent. Mon., vii, 438, 1863.

4414. bicoloralis Gunnée, Spec. Gén., viii, 205, 1854. syn. julialis WaLker, Cat. Brit. Mus., xvii, Atl. States, So. Am. 389, 1859; incensalis LEDERER, Wien. ent. Mon., vii, 439, 1863; amiculatalis BERG, Stett. ent. Zeit., xxxvii, 343, 1876; pulchripictalis Hampson, Ann. Mag. Nat. Hist., (6), xvi, 341, 1895.

\section{EPICORSıA Hübner.}

HüBner, Zutr. exot. Schmett., i, 24, 1818; Verz. bek. Schmett., 355, 1826.

4415. mellinalis HüBNER, Zutr. exot. Schmett., i, 24, f. 137, 138, 1818; DYar, Journ. N. Y. Ent. Soc., ix, 21,1901 .

syn. adipodalis Guenée, Spec. Gén., viii, 336, 1854; butyrosa Butler, Proc. Zool. Soc. Lond., 493, 1878.

\section{PYRAUSTA Sehrank.}

Schrank, Faun. Boica, ii, 2, 1802; Treitschke, Schm. Eur., vii, 162, 1829; DuponChel, Hist. Nat. Lép. Fr., viii, 2, 209, 1831; Stephens, Ill. Brit. Ent., Haust., iv, 33, 1834; Merrick, Trans. Ent. Soc. Lond., 449, 1890; Handb. Brit. Lep., 411, 1895; Hampson, Proc. Zool. Soc. Lond., 252, 1899.

*4416. vacunalis Grote, Can. Ent., xiii, 33, 1881.

Cal.

4417. pertextalis Lederer, Wien. ent. Mon., vii, 466, 1863.

Me. to

Tex.

syn. gentilis Grote, Bull. Buff. Soc., i, 173, 1873; thesealis ZelLer, Verh. zool.-bot. Ges. Wien, 514, 1872.

*4418. fissalis Grote, Bull. U. S. Geol. Surv., vi, 273, 1881.

*4419. æglealis W ALKer, Cat. Brit. Mus., xviii, $565,1859$. syn. quinquelinealis Grote, Bull. Buff. Soc., ii, 231,1875 .

4420. thestealis Walker, Cat. Brit. Mus., xviii, 733, 1859.

syn. magistralis Grote, Bull. Buff. Soc., i, 173, 1873; gulosalis Hulst, Trans. Am. Ent. Soc., xiii, $155,1886$.

4421. theseusalis Walker, Cat. Brit. Mus., xviii, 562, 1859.

syn. feudalis Grote, Bull. Buff. Soc., ii, 231, 1875 .

*4422. langdonalis Grote, Can. Ent., ix, 10, 1877.
Fla., W. I., So. Am.
No. Atl.

States.

No. Atl.

States.

No. Atl.

States.

Atl. States. 
4423. oxydalis Guenée, Spec. Gén., viii, 328, 1854. syn. Alavidalis Guenée, Spec. Gén., viii, 329, 1854 ; lacoalis Walker, Cat. Brit. Mus., xviii, 733, 1859; cinctipedalis W ALKER, Cat. Brit. Mus., xxxiv, 1391, 1865.

*4424. phyllisalis W aLKer, Cat. Brit. Mus., xix, 936, 1859.

*4425. elealis W ALKer, Cat. Brit. Mus., xvii, 351, 1859. syn. tredialis W ALKer, Cat. Brit. Mus., xviii, $732,1859$.

*4426. orphisalis Walker, Cat. Brit. Mus., xvii, 310, 1859 .

syn. adipaloides Grote \& Robinson, Trans. Am. Ent. Soc., i, 27, 1867.

*4427. fuscimaculalis Grote, Can. Ent., x, 25, 1878.

syn. Alavicoloralis Grote, Can. Ent., x, 25, 1878; confovealis Hulst, Trans. Am. Ent. Soc., xiii, $151,1886$.

4428. trimaculalis Grote, Can. Ent., x, 24, 1878.

4429. gracilalis Hulst, Tr. Am. Ent. Soc., xiii, 151, 1886.

*4430. hædulalis Hulst, Tr. Am. Ent. Soc., xiii, 152, 1886.

*4431. submedialis Grote, Can. Ent., viii, 111, 1876. syn. dissectalis Grote, Can. Ent., xii, 36, 1880; pilalis Hulst, Tr. Am. Ent. Soc., xiii, $151,1886$.

*4432. venalalis Hulst, Tr. Am. Ent. Soc., xiii, 151, 1886.

*4433. obumbratalis Lederer, Wien. ent. Mon., vii, $467,1863$.

4434. mustelinalis Packard, Ann. Lye. Nat. Hist. N. Y., x, 262, 1873.

syn. catenulalis Grote, Can. Ent., ix, 105, 1877; monulalis Hulst, Tr. Am. Ent. Soc., xiii, $154,1886$.

*4435. singularis Lederer, Wien. ent. Mon., vii, 475, 1863.

4436. fumalis Gunnée, Spec. Gén., viii, 358, 1854. syn. orasusalis Watker, Cat. Brit. Mus., xviii, 784, 1859; badipennis Grote, Bull. Buff. Soc., i, 88, 1873.
Atl. States, So. Am.

Tex.

Pa.

No. Atl.

States.

Tex.

Tex.

Tex., Ariz., Cal.

Tex.

Can.,

III.,

Fla.,

Ariz.

N. Y.

No. Am.

Cal.

No. Am.?, Brazil.

Atl. States. 
4437. illibalis HüBner, Zutr. exot. Schmett., i, 19, f. $95,96,1818$.

Atl.

syn. arsaltealis W ALKER, Cat. Brit. Mus., xviii, 564, 1859; euphasalis WaLKer, Cat. Brit. Mus., xix, 1008, 1859; guttulosa WALKER, Cat. Brit. Mus., xxvii, 78, 1863; fascialis WaLker, Tr. Ent. Soc. Lond., (3), i, 127, 1862; subjectalis LEDERER, Wien. ent. Mon., vii, 480, 1863; magniferalis WALKER, Can. Nat. \& Geol., vi, 41, 1861.

*4438. octosignalis Hulst, Tr. Am. Ent. Soc., xiii, 153, 1886.

States.

Tex.,

Cal.

4439. penitalis Grote, Can. Ent., viii, 98, 1876.

syn. nelumbialis Sмптн, Ent. Am., vi, 89, 1890.

4440. inconcinnalis Lederer, Wien. ent. Mon., vii, $467,1863$.

syn. crocotalis Grote, Pap., i, 167, 1881; festalis Hulst, Tr. Am. Ent. Soc., xiii, $153,1886$.

4441. futilalis Lederer, Wien. ent. Mon., vii, 467, 1863.

syn. erectalis Grote, Can. Ent., viii, 99, 1876.

4442. fumoferalis Hulst, Tr. Am. Ent. Soc., xiii, 154. 1886.

4443. unifascialis PACKARD, Ann. Lye. Nat. Hist. N. Y., $\mathrm{x}, 261,1873$.

syn. subolivalis Packard, Ann. Lyc. Nat. Hist. N. Y., x, 261, 1873; hircinalis Grote, Bull. Buff. Soc., ii, 232, 1875; obnigralis Húlst, Tr. Am. Ent. Soc., xiii, 153, 1886.

*4444. torvalis Möschler, Wien. ent. Mon., viii, 198, 1864.

syn. getida McLachlan, Jn. Linn. Soc., xiv, $115,1880$.

4445. fodinalis Lederer, Wien. ent. Mon., vii, 461, 1863.

syn. socialis Grote, Can. Ent., ix, 107, 1877.

4446. semirubralis PaCKard, Ann. Lyc. Nat. Hist. N. Y., $\mathrm{x}, 263,1873$.

4447. perrubralis Packard, Ann. Lyc. Nat. Hist. N. Y., $\mathrm{x}, 264,1873$.

syn. scurralis Hulst, Tr. Am. Ent. Soc., xiii, 155, 1886; postrubralis HaMPSON, Proc. Zool. Soc. Lond., 262, 1899.

So. Atl. States.

Ill., Tex., Col., Ariz.

Atl. States.

No. U. S., Cal.

No. U. S., Cal.

Lab.,

No. Greenl.

No. U.S., Cal.

Cal.

Manitoba, Ariz., Cal. 
4448. phœnicealis HÜBner, Zutr. exot. Schmett., i, 22, f. $115,116,1818$.

syn. opalizalis Guenée, Spec. Gén., viii, 172, 1854; insignitalis Guenée, Spec. Gén., viii, 173, 1854; Alegialis W ALKER, Cat. Brit. Mus., xvii, 316, 1859; panopealis W ALKER, Cat. Brit. Mus., xvii, 318, 1859; eratalis W ALKER, Cat. Brit. Mus., xviii, 578, 1859; onythesal is Walker, Cat. Brit. Mus., xviii, 734, 1859.

*4449. toralis Grote, Pap., i, 178, 1881.

4450. acrionalis W ALKer, Cat. Brit. Mus., xix, 925, 1859 .

syn. acuphisalis W ALKer, Cat. Brit. Mus., xix, 926, 1859; proceralis Lederer, Wien. ent. Mon., vii, 460, 1863; sumptuosalis W ALKER, Cat. Brit. Mus., xxxiv, 1281, 1865; hamespica Grote \& Robinson, Trans. Am. Ent. Soc., i, 19, 1867.

a. rufifimbrialis Grote, Can. Ent., xiii, 34, 1881.

4451. rubricalis Hübner, Schm. Eur., Pyr., 22, pl. 16, f. $106,1796$.

syn. similatis Lederer, Wien. ent. Mon., vii, 460,1863 ; nescalis WaLker, Cat. Brit. Mus., xvii, 315, 1859; californicalis PACKARD, Ann. Lyc. Nat. Hist. N. Y., x, 260, 1873.

*4452. tatalis Grote, Can. Ent., ix, 106, 1877.

4453. borealis Packard, Proc. Bost. Soc. Nat. Hist., xi, 53, 1867.

syn. matronalis Grote, Bull. Buff. Soc., ii, $231,1875$.

4454. insequalis Guenée, Spec. Gén., viii, 447, 1854. syn. subsequalis Guenée (not HerRICHSchaeffer), Spec. Gén., viii, 177, 1854; madetesalis WaLker, Cat. Brit. Mus., xix, 946, 1859; repletalis W ALKER, Cat. Brit. Mus., xxxiv, 1285, 1865; efficitalis W ALKER, Cat. Brit. Mus., xxxiv, 1287, 1865.

4455. generosa Grote \& Robinson, Trans. Am. Ent. Soc., i, 20, 1867.

*4456. flavofascialis Grote, Bull. U. S. Geol. Surv., vi, 577,1882 .

4457. laticlavia Grote \& Robinson, Trans. Am. Ent. Soc., i, 17, 1867.

Atl. States, W. I., So. Am., India, China, Australia.

N. Mex.

Atl.

States.

Cal.

Tex.

Lab., Can., Me.

Atl. States.

Pa.,

Ill.

N. Mex.

Pa., Tex., Cal. a. cinerosa Grote \& Robinson, Trans. Am. Ent. Soc., i, 18, 1867. 
4458. tyralis Guenée, Spec. Gén., viii, 169, 1854.

Ill., Fla., Tex.

syn. erosnealis WaLker, Cat. Brit. Mus., xvii, 311, 1859; diffissa Grote \& Robinson, Trans. Am. Ent. Soc., i, 19, 1867; bellulalis Hulst, Trans. Am. Ent. Soc., xiii, 149, 1886.

*4459. coccinea Warren, Ann. Mag. Nat. Hist., (6), ix, 176,1892 .

4460. costimaculalis Fernald, Journ. N. Y. Ent. Soc., ix, 50, 1901.

4461. inornatalis Fernald, Can. Ent., xvii, 57, 1885. syn. rosa Druce, Biol. Cent. Am., Lep. Het., ii, 206,1895 .

4461. 1. signatalis Walker, Cat. Brit. Mus., xxxiv, 1282,1865 .

syn. vimulenta Grote \& Robinson, Trans. Am. Ent. Soc., i, 17, 1867.

4462. volupialis Grote, Bull. U. S. Geol. Surv., iii, $799,1877$.

4463. augustalis Grote, Bull. U. S. Geol. Surv., vi, 273,1881 .

Cal.

Fla.

Fla., Tex.,

Mex.

IIl., Mo., Ala., Tex.

Col.

Col., Ariz., Cal.

U. S.

*4464. subnicalis Warren, Ann. Mag. Nat. Hist., (6), ix, 177, 1892 .

4465. atropurpuralis Grote, Can. Ent., ix, 104, 1877.

4466. lethalis Grote, Can. Ent., xiii, 33, 1881.

Tex.

Cal.

*4467. nicalis Grote, Bull. U. S. Geol. Surv., iv, 671, 1878.

syn. uxorculalis Hulst, Trans. Am. Ent. Soc., xiii, 153, 1886.

*4468. marginalis Walker, Cat. Brit. Mus., xxxiv, 1459,1865 .

Manitoba, Me.

syn. stenopteralis Grote, Can. Ent., x, 26, 1878.

4469. unimacula Grote \& Robinson, Trans. Am. Ent. Soc., i, 14, 1867.

*4470. commortalis Grote, Can. Ent., xiii, 233, 1881.

*4471. versicolor Warren, Ann. Mag. Nat. Hist., (6), ix, 175,1892 .

4472. funebris Ströм, Kgl. Norske Vid. Selsk. Skr., iv, 339, 1768; ScHören, Stett. ent. Zeit., xl, Manitoba, Nev., Coì., Cal. 399, 1879.

syn. octomaculata Linnsus, Mant. Plant. Alt., 540, 1771; glomeralis W ALKER, Cat. Brit. Mus., xvii, 330, 1859. 
4473. niveicilialis Grote, Bull. Buff. Soc., ii, 232, 1875. Mass., N. Y. *4473. 1. abdominalis Zeller, Verh. zool.-bot. Ges. No. Am. Wien, xxii, 515, 1872; Hampson, Proc. Zool. Soc. Lond., 273, 1899 (type probably lost).

\section{EUSTIXIA Hübner.}

Hübner, Zutr. exot. Schmett., ii, 24, 1823; Thelcteria Lederer, Wien. ent. Mon., vii, 350, 1863; Hampson, Proc. Zool. Soc. Lond., 275, 1899.

4474. pupula HüBner, Zutr. exot. Schmett., ii, 24, f. $327,328,1823$.

Atl. States.

4475. octonalis ZeLler, Verh. zool.-bot. Ges. Wien, xxiii, 211, 1873.

Atl. States.

syn. sexmaculatis Grote, Can. Ent., viii, 98, 1876.

CORNIFRONS Lederer.

Lederer, Wien. ent. Mon., ii, 147, 1858; Hampson, Proc. Zool. Soc. Lond., 276, 1899.

4476. simalis Grote, Bull. U. S. Geol. Surv., iv, 670, 1876.

Mont., Oreg.

*4477. pulveralis Warren, Ann. Mag. Nat. Hist., (6), Nev. ix, $435,1892$.

\section{NOCTUELIA Guenée.}

Guenée, Spec. Gén., viii, 113, 1854; Hampson, Proc. Zool. Soc. Lond., 278, 1899. 4478. thalialis Walker, Cat. Brit. Mus., xviii, 582, Tex., W. I., 1859 . So. Am.

syn. perweiana Walker, Cat. Brit. Mus., xxxiii, 804, 1865; gelidalis WaLker, Cat. Brit. Mus., xxxiv, 1229, 1865; novalis Grote, Can. Ent., viii, 156, 1876; costcemaculalis Snellen, Tijd.v. Ent., xxx, 54, 1887.

4479. castanealis Hulst, Tr. Am. Ent. Soc., xiii, 157, 1886.

*4480. nuchalis Grote, Bull. U. S. Geol. Surv., iv, 675, 1878 .

4481. elautalis Grote, Pap., i, 168, 1881. Tex.

syn. magnalis Hulst, Tr. Am. Ent. Soc., xiii, $147,1886$.

*4482. simplex Warren, Ann. Mag. Nat. Hist., (6), xvi, 474,1895 .

\section{LINEODES Guenée.}

Guenée, Spec. Gén., viii, 234, 1854; Hampson, Proc. Zool. Soc. Lond., 283, 1899; Scoptonoma Zeller, Verh. zool.-bot. Ges. Wien, xxiii, 328, 1873.

4483. contortalis Guenée, Spec. Gén., viii, 236, 1854. Tex., Fla., So. Am. 
4484. integra Zeller, Verh. zool.-bot. Ges. Wien, xxiii, 328, 1873; Dyar, Jn. N. Y. Ent. Soc., ix, 22,1901 .

Mo., Tex., Cal., So. Am.

Tex.

*4485. interrupta Zelcer, Verh. zool.-bot. Ges. Wien, xxiii, 329, 1873.

4486. triangulalis Möschler, Abn. Senck. Ges., xv, 305, 1889: Dyar, Jn. N. Y. Ent. Soc., ix, 22, 1901 .

Subfamily NY MPHUI,INAE.

By C. H. Fernald.

NYMPHULA Sehrank.

Schrank, Faun. Boica., ii, 2, 162, 1802; Treitschke, Schm. Eur., vii, 127, 1829; Duponchel, Hist. Nat. Lép. Fr., viii, 158, 1831; Herrich-Schaeffer, Schm. Eur., iv, 10, 1848; Meyrick, Handb. Brit. Lep., 402, 1895; Hampson, Trans. Ent. Soc. Lond., 138, 1897; Hydrocampa Latreille, Fam. Nat. Règ. An., 478, 1825; Parapoynx Hübner, Verz. bek. Schmett., 362, 1826; Synclita Lederer, Wien. ent. Mon., vii, 448, 1863; Nymphxёlla Grote, No. Am. Ent., i, 97, 1880.

4487. icciusalis WaLker, Cat. Brit. Mus., xix, 971, 1859 .

syn. faulalis Walker, Cat. Brit. Mus., xix, 973, 1859; formosalis Clemens, Proc. Acad. Nat. Sci. Phil., 217, 1860; Packard, Am. Nat., xviii, 824, 1884; genuialis LEDERER, Wien. ent. Mon., vii, 451, 1863; pacalis Grote, Pap., i, 17, 1881.

4488. nebulosalis Fernald, Ent. Amer., iii, 127, 1887.

*4489. gyralis Hulst, Trans. Am. Ent. Soc., xiii, 159, 1886.

syn. dentilinea Hampson, Trans. Ent. Soc. Lond., 139, 1897.

4490. ekthlipsis Grote, Can. Ent., viii, 111, 1876.

4491. allionealis WaLker, Cat. Brit. Mus., xvii, 453, 1859 .

syn. itealis WaLker, Cat. Brit. Mus., xvii, 458, 1859; cretacealis Lederer, Wien. ent. Mon., vii, 484, 1863; aptalis LEDERER, Wien. ent. Mon., vii, 485, 1863; plenilinealis Grote, Pap., i, 17, 1881.

4492. badiusalis WaLker, Cat. Brit. Mus., xix, 955, 1859.

syn. curviferalis Walker, Cat. Brit. Mus., xxxiv, 1331, 1865; albalis Robinson, Ann. Lyc. Nat. Hist. N. Y., ix, 153, 1869.
Atl. States, So. Am.

Fla.

Atl.

States.

Me., Mass.,

N. Y., Can.

Ga., Fla.,

Wis.
Atl.

States. 
4493. obscuralis Grote, Pap., i, 18, 1881.

Me., Mass.,

syn. ? redyuscongalis Clemens, Proc. Acad.

Nat. Sci. Phil., 216, 1860.

N. Y., Pa., Wis.

4494. cannalis Quanntance, Bull. Fla. Ex. Sta., no. 45, $68,1898$.

Fla.

4495. maculalis Clemens, Proc. Acad. Nat. Sci. Phil., 218,1860 .

Atl. States.

syn. seminivella Walker, Cat. Brit. Mus., xxxv, 1717, 1866; dipsar Grote, No. Am. Ent., i, 97, 1880.

4496. obliteralis Walker, Cat. Brit. Mus., xvii, 399, 1859 .

syn. obscuralis Möschler, Verh. zool.-bot. Ges. Wien, 432, 1876; proprialis Fernald, Ent. Am., iv, 37, 1888.

\section{ELOPHILA Hübner.}

Hübner, Tent., 2, 1806; Cataclysta Hübner, Verz. bek. Schmett., 363, 1826; Stephens, Ill. Brit. Ent., Haust., iv, 39, 1834; Herrich-Schaeffer, Schm. Eur., iv, 7, 1848; Guenée, Spec. Gén., viii, 263, 1854; Lederer, Wien. ent. Mon., vii, 453, 1863; Heinemand, Kleinschm., i, 2, 106, 1865; 'Meyrick, Handb. Brit. Lep., 402, 1895; Hampson, Trans. Ent. Soc. Lond., 147, 1897; Chrysendeton Grote, Pap., i, 16, 1881; Anydraula Meyrick, Trans. Ent. Soc. Lond., 427, 1885.

*4497. magnificalis Hübner, Eur. Schmett., Pyr., f. $104,1796$.

Mid.

syn. lamialis Walker, Cat. Brit. Mus., xvii, 436, 1859; helopalis Clemens, Proc. Acad.

Nat. Sci. Phil., 218, 1860.

4498. claudialis WaLker, Cat. Brit. Mus., xvii, 437, 1859. States.

syn. medicinalis Grote, Pap., i, 15, 1881.

4499. bifascialis Robinson, Ann. Lyc. Nat. Hist. N. Y., ix, 154,1869 .

4500. fulicalis Clemens, Proc. Acad. Nat. Sci. Phil., $217,1860$.

Fla.

syn. angulatalis Lederer, Wien. ent. Mon., vii, 486, 1863; confusalis WALKER, Cat. Brit. Mus., xxxiv, 1334, 1865.

*4501. avernalis Grote, Trans. Kans. Acad. Sci., viii, 53, N. Mex. 1853.

Tex.

Me., Mass., Pa., N. Mex.

\section{OLiGostigmA Guenée.}

Guenée, Spec. Gén., viii, 260, 1854; Hampson, Tr. Ent. Soc. Lond., 167, 1897.

4502. juncealis Gunnée, Spec. Gén., viii, 261, 1854.

Fla.

syn. seminealis Walker, Cat. Brit. Mus.,

xvii, 430, 1859. 
DIATHRAUSTA Lederer.

Lederer, Wien. ent. Mon., 438, 1863; Hampson, Tr. Ent. Soc. Lond., 205, 1897.

4503. reconditalis Walker, Cat. Brit. Mus., xix, 943, Mass., N. Y., 1859 .

syn. minualis Walker, Cat. Brit. Mus., xxxiv, 1297, 1865; octomaculalis FERNALD, Ent. Amer., iii, 127, 1887.

\section{Subfamily SCOPARIINAE. \\ By C. H. Fernald. \\ SCOPARIA Haworth.}

Haworth, Lep. Brit., iii, 498, 1811; Heinemann, Kleinschm., i, 2, 20, 1865; MeyRick, Handb. Brit. Lep., 419, 1895; Hampson, Tr. Ent. Soc. Lond., 229, 1897; Eudorea Curtis, Brit. Ent., vi, 170, 1825; Stephens, Ill. Brit. Ent., Haust., iv, 298, 1834; Zeller, Linn. Ent., i, 265, 1846.

*4504. lugubralis WALKER, Cat. Brit. Mus., xxxiv, 1498, 1865 .

*4505. nominatalis Hulst, Tr. Am. Ent. Soc., xiii, 148, Vancouver. 1886.

*4506. atropicta Hampson, Tr. Ent. Soc. Lond., 233,1897.

4507. basalis Walker, Cat. Brit. Mus., xxxiv, 1497, 1865 .

syn. biplagialis Walker, Cat. Brit. Mus., xxxiv, 1499, 1865; libella Grote, Bull. U. S. Geol. Surv., iv, 675, 1878.

*4508. rectilinea Zeller, Verh. zool.-bot. Ges. Wien, xxiv, 5, 1874.

Can.

syn. refugalis Hulst, Tr. Am. Ent. Soc., xiii, $148,1886$.

*4509. delphusa Druce, Biol. Cent. Am., Lep. Het., ii, 279,1895 .

4510. centuriella Denis \& SchiffermüLler, Syst. Verz. Wien., 319, 1776.

syn. borealis Lefèbre, Ann. Soc. Ent. Fr., 400, 1835; numeralis ZETTERSTEDT, Ins.LAp., 971, 1840; quadratella-ZETTERSTEDT, Ins. Lap., 997, 1840; crecalis W ALKER, Cat. Brit. Mus., xvi, 36, 1858; caliginosalis W ALKER, Cat. Brit. Mus., xxxiv, 1460, 1865; ninguidalis Hulst, Tr. Am. Ent. Soc., xiii, 147, 1886.

W. States, Mex.

Eur., Lab., Can., U. S. 
Subfamily PYRAIIN AE.

By C. H. Fernald.

AGLOSSA Latreille.

Latreille, Préeis Char. Gén. Ins., 145, 1796; Hist. Nat. Crust. Ins., iii, 414, 1802 v, 323, 1803; xiv, 229, 1805; Duponchel, Hist. Nat. Lép. Fr., viii, 2, 61, 183 । Stephens, Ill. Brit. Ent., Haust., iv, 22, 1834; Herrich-Schaeffer, Schm. Eur., ir, 119, 1848; Guenée, Spec. Gén., viii, 125, 1854; Hernemann, Kleinschm., i, 2, 13, 1865; Meyrick, Handb. Brit. Lep., 428, 1895; Hampson, Trans. Ent. Soc. Lond., $505,1896$.

4511. cuprealis HüBner, Verz. bek. Schmett., 348, 1826; Treiтschке, Schm. Eur., vii, 38, 1829;

U. S., Eur.

Duponchel, Hist. Nat. Lép. Fr., viii, 2, 61, 1831; Stephens, Ill. Brit. Ent., Haust., iv, 23, 1834; Herrich-Schaeffer, Schm. Eur., iv, 119, 1848; Heinemann, Kleinschm., i, 2, 14, 1865; Meyrick, Handb. Brit. Lep., 428, 1895.

syn. caprealis HüBner, Schmett. Eur., Pyr。, f. 153, 1800; domalis Guenée, Spec. Gén., viii, 128, 1854; enthealis Hulst, Trans. Am. Ent. Soc., xiii, $160,1886$.

4512. cestalis Hulst, Trans. Am. Ent. Soc., xiii, 164, 1886.

HYPSOPYGIA Hübner.

Hübner, Verz. bek. Schmett., 348, 1826; Stephens, Ill. Brit. Ent., Haust., iv, 26, 1834; Hampson, Trans. Ent. Soc. Lond., 507, 1896.

4513. costalis Fabricius, Syst. Ent., 644, 1775; STEPHens, Ill. Brit. Ent., Haust., iv, 27, 1834; Heinemann, Kleinschm., i, 2, 15, 1865; MeyEur., RIck, Handb. Brit. Lep., 427, 1895.

syn. fimbrialis Denis \& SCHIFFERMülLer, Syst. Verz. Wien, 124, 1776.

a. hyllalis W Alker, Cat. Brit. Mus., xvii, 265, 1859.

\section{PYRALIS Linnæus.}

Linnæus, Syst. Nat., i, 533, 1758; Stephens, Ill. Brit. Ent., Haust., iv, 24, 1834; Meyrick, Handb. Brit. Lep., 426, 1895; Hampson, Trans. Ent. Soc. Lond., 507, 1896; Asopia Treitschke, Schm. Eur., vi, 2, 316, 1828.

*4514. cuprina Zeller, Verh. zool.-bot. Ges. Wien, xxii, $497,1872$.

Mo., Tex.

*4514. 1. costiferalis Walker, Cat. Brit. Mus., xxxv, $1977,1866$.

Me., N. J., N. C.

syn. costigeralis WALKER (not W ALKER), Cat.

Brit. Mus., xxxiv, 1226, 1865.

*4515, electalis Hulst, Trans. Am. Ent. Soc., xiii, 146, 1886.

Ariz. 
4516. farinalis Linneus, Syst. Nat., i, 533, 1758; Stephens, Ill. Brit. Ent., Haust., iv, 25, 1834; Hübner, Pyr., f. 95, 1796; Treitschke, Schm. Eur., vii, 147, 1829; Duponchel, Hist. Nat. Lép. Fr., viii, 193, 1831; Hzrrich-SchaEFFEr, Schm. Eur., iv, 121, 1848; Guenée, Spec. Gén., viii, 119, 1854; Hennemann, Kleinschm., i, 2, 16, 1865; Merrick, Handb. Brit. Lep., 427, 1895 .
U. S., Eur., Asia.

\section{HERCULIA Walker.}

Walker, Cat. Brit. Mus., xix, 807, 1859; Hampsox, Trans. Ent. Soc. Lond., 517, 1896; Cisse Walker, Cat. Brit. Mus., xxvii, 125, 1863; Buzala Walker, Cat. Brit. Mus., xxvii, 129, 1863; Ocrasa Walker, Cat. Brit. Mus., xxxiv, 1212, 1865; Lixa Walker, Cat. Brit. Mus., xxxiv, 1254, 1865; Bejuda WAlker, Cat. Brit. Mus., xxxiv, 1273, 1865; Pseudasopia Grote, Bull. Buff. Soc., i, 172, 1873.

*4517. binodulalis Zeller, Verh. zool.-bot. Ges. Wien, Tex. xxii, 501, 1872.

4518. thymetusalis WaLker, Cat. Brit. Mus., xviii, $565,1859$.

Can., Mass., N. Y.

syn. devialis Grote, Bull. Buff. Soc., ii, 229, 1875 .

*4519. cohortalis Grote, Can. Ent., x, 233, 1878.

4520. intermedialis WALKER, Trans. Ent. Soc. Lond., (3), i, 118, 1862.

syn. sodalis W ALker, Char. Lep. Het., 60, 1869 ; squamealis Grote, Bull. Buff. Soc., i, $172,1873$.

4521. olinalis Guenée, Spec. Gén., viii, 118, 1854; Zeller, Verh. zool.-bot. Ges. Wien, xxii, 499, 1872.

syn. trentomalis Lederer, Wien. ent. Mon., vii, 458, 1863.

*4522. planalis Grotf, No. Am. Ent., i, 95, 1880. syn. enniculalis Hulst, Tr. Am. Ent. Soc., xiii, 147, 1886; occidentalis Hulst, Tr. Am. Ent. Soc., xiii, 147, 1886.

4523. himonialis ZeLLER, Verh. zool.-bot. Ges. Wien, xxii, 500, 1872.

\section{OMPHALOCERA Lederer.}

Lederer, Wien. ent. Mon., vii, 339, 1863.

4524. cariosa Lederer, Wien. ent. Mon., vii, 339, 1863.

4525. dentosa Grote, Bull. U. S. Geol. Surv., vi, 272, 1881.
U. S.

Can.

N. E., N. Y.. West. States.

Col.

Mass.
So. Atl. Sta., So. Am.

U. S. 
Subfamily CHRYSAUGINAE.

By C. H. Fernald.

SALOBRANA Walker.

Walker, Cat. Brit. Mus., xxviii, 446, 1863; Hampson, Proc. Zool. Soc. Lond., 649, 1897; Clydonopteron Riley, Am. Ent., iii, 287, 1880.

4526. tecomæ Riley, Am. Ent., iii, 288, 1880.

Mo., W. I., So. Am.

ECTOPERIA Zeller.

Zeller, Verh. zool.-bot. Ges. Wien, xxv, 331, 1875; Ragonot, Ann. Soc. Ent. Fr., $494,1891$.

4527. sincera Zeller, Verh. zool.-bot. Ges. Wien, Tex. xxv, 332, 1875 .

TOSALE Walker.

Walker, Oat. Brit. Mus., xxviii, 447, 1863; Ragonot, Ann. Soc. Ent. Fr., 499, 1891; Hampson, Proc. Zool. Soc. Lond., 652, 1897; Fabatana Walker, Cat. Brit. Mus., xxxiv, 1265, 1865; Siparocera Grote, Ann. Lyc. Nat. Hist. N. Y., xi, 128, 1875.

4528. oviplagalis Walker, Cat. Brit. Mus., xxxiv, $1265,1865$.

Atl. States,

syn. nobitis Grote, Ann. Lyc. Nat. Hist. Tex., W. I., N. Y., xi, 128, 1875; anthocioides Grote \& So. Am. Robinson, Trans. Am. Ent. Soc., i, 15, 1867.

\section{PARACHMA Walker.}

Walker, Cat. Brit. Mus., xxxiv, 1263, 1865; Hampson, Proc. Zool. Soc. Lond., 659, 1897; Zazaca Walker, Cat. Brit. Mus., xxxiv, 1269, 1865; Perseis Ragonot, Ann. Soc. Ent. Fr., 538, 1891.

*4529. ochracealis Walker, Cat. Brit. Mus., xxxiv, Fla., Tex. 1263,1865 .

syn. auratalis W ALker, Cat. Brit. Mus., xxxiv, 1269, 1865; culiculalis Hulst, Tr. Am. Ent. Soc., xiii, 147, 1886.

ARTA Grote.

Grote, Bull. Buff. Soc., ii, 229, 1875; Hampson, Proc. Zool. Soc. Lond., 669, 1897: Heliades Ragonot, Ann. Soc. Ent. Fr., 534, 1891.

4530. statalis Grote, Bull. Buff. Soc., ii, 230, 1875.

syn. epiconalis Ragonot, Ann. Soc. Ent. Fr.,

N.Y., Ariz., Fla. 536, 1891; mulleolella Hulst, Ent. Am., iii, 133, 1887.

4531. olivalis Grote, Can. Ent., x, 24, 1878.

Tex. 


\section{CONDYLOLOMIA Grote.}

Grote, Bull. Buff. Soc., i, 176, 1873; Ragonot, Ann. Soc. Ent. Fr., 510, 1891; Намpson, Proc. Zool. Soc. Lond., 673, 1897.

*4532. participialis Grote, Bull. Buff. Soc., i, 177, 1873. Mass., Pa.

\section{GALASA Walker.}

Walker, Cat. Brit. Mus., xxxv, 1801, 1866; Hampson, Proc. Zool. Soc. Lond., 674, 1897; Cordylopeza Zeller, Verh. zool.-bot. Ges. Wien, xxiii, 206, 1873.

4533. rubidana W ALKER, Cat. Brit. Mus., xxxv, 1802 , 1866.
Atl. States, W. I.

syn. nigrinodis ZeLLER, Verh. zool.-bot. Ges. Wien, xxiii, 206, 1873.

\section{ACALLIS Ragonot.}

Ragonot, Ann. Soc. Ent. Fr., 540, 1891; Hampson, Proc. Zool. Soc. Lond., 677, 1897.

*4534. griphalis Hulst, Trans. Am. Ent. Soc., xiii, 146, Tex., Ariz., 1886.

Col.

syn. fernaldi Ragonot, Ann. Soc. Ent. Fr., 540, 1891; angustipennis WARren, Ann. Mag. Nat. Hist., (6), vii, 494, 1891.

CHALINITIS Ragonot.

Ragonot, Ann. Soc. Ent. Fr., 528, 1891; Hampson, Proc. Zool. Soc. Lond., 684, 1897.

*4535. olealis Ragonot, Ann. Soc. Ent. Fr., 529, $1891 . \quad$ Fla.

$$
\begin{aligned}
& \text { Subfamily SCHCHNOIINA. } \\
& \text { By C. H. Fernald. }
\end{aligned}
$$

AMESTRIA Ragonot.

Ragonot, Ann. Soc. Ent. Fr., 545, 1891; Hampson, Proc. Zool. Soc. Lond., 904, 1895.

*4536. oculiferalis Ragonot, Ann. Soc. Ent. Fr., 546, Tex. 1891.

\section{PATISSA Moore.}

Moore, Lep. Ceyl., iii, 388, 1886; Hampson, Proc. Zool. Soc. Lond., 910, 1895. 4537. xantholeucalis Guenée, Spec. Gén., viii,253,1854. Ga., Fla. syn. fasciella Fernald, Ent. Am., iii, 38, 1887.

*4538. flavicostella Fernald, Ent. Am., iii, 38, $1887 . \quad$ Fla.

*4539. vestaliella Zeller, Verh. zool.-bot. Ges. Wien, Fla., xxii, 532, 1872.

Tex. $4630-$ No. $52-02-26$ 


\section{SCIRPOPHAGA Treitschke.}

Treitsch ke, Schm. Eur., ix, 1, 55, 1832; Herrich-Schaeffer, Schm. Eur., iv, 52, 1848; Zeller, Chil. et Cram., 1, 1863; Heinemann, Kleinschm., i, 2, 110, 1865; Hampson, Proc. Zool. Soc. Lond., 912, 1895.

*4540. albinella Crajer, Pap. Exot., iv, pl. 372, f. D, 1781.

So. Am. Fla.

syn. nivea Walker, Cat. Brit. Mus., xxviii, $524,1863$.

4541. perstrialis HüBNER, Zutr. exot. Schmett., iii, 18, 1825 .

syn. serriradiellus Walker, Cat. Brit. Mus., xxvii, 161,1863; macrinellus ZelLer, Stett. ent. Zeit., xxvii, 152, 1866; Hor. Soc. Ent. Ross., xiii, $10,1877$.

\section{SCHENOBIUS Duponchel.}

Duponchel, Cat. Lép. Eur., 312, 1844; Zeller, Chil. et Cram., 3, 1863; Heinemann, Kleinschm., i, 2, 111, 1865; Fernald, Ent. Am., iv, 135, 1888; Meyrick, Handb. Brit. Lep., 400, 1895; Hampson, Proc. Zool. Soc. Lond., 915, 1895.

4542. sordidellus Zincken, Germ. Mag., iv, 247, 1821; Zeller, Chil. et Cram., 4, 1863; Fernald, Ent. Am., iv, 136, 1888.

4543. unipunctellus Robinson, Ann. Lyc. Nat. Hist. N. Y., ix, 314, 1870; Fernald, Ent. Am., iv, $156,1888$.

4544. tripunctellus Robinson, Ann. Lye. Nat. Hist. N. Y., ix, 314, 1870; Fernald, Ent. Am., iv, $136,1888$.

4545. melinellus Clemens, Proc. Acad. Nat. Sci. Phil., 205, 1860; Robinson, Ann. Lyc. Nat. Hist. N. Y., ix, 313, 1870; Fernald, Ent. Am., iv, 137, 1888. a. dispersellus Robinson, Ann. Lyc. Nat. Hist. N. Y., ix, 313, 1870; Fernald, Ent. Am., iv, $138,1888$.

b. albicostellus Fernald, Ent. Am., iv, 138, 1888.

*4546. clemensellus Robinson, Ann. Lyc. Nat. Hist. N. Y., ix, 313, 1870; Fernald, Ent. Am., iv, 138, 1888.

syn. aquilellus Clemens (not Hübner), Proc. Acad. Nat. Sci. Phil., 205, 1860.

4547. forficellus Thunberg, Diss., v, 98, 1794; StauDInger \& Rebel, Cat. Lep. Eur., ii, no. 188, 1901.

syn. longirostrellus Clemens, Proc. Acad. Nat. Sci. Phil., 205, 1860; Robinson, Ann. Lyc. Nat. Hist. N. Y., ix, 312, 1870; Fernald, Ent. Am., iv, 139, 1888.

*4548. maximellus Fernald, Can. Ent., xxiii, 30, 1891.
Ga., Fla., IIl.

Fla., Ill., Tex.

Tex.

Atl.

States.

Me. to Tex.

Atl,

States.

Eur.,

Eastern States.
Tex. 
Subfamily CRAMBINAE.

(C.=Fernald, The Crambidæ of No. Am., Sp. Bull. Mass. Agr. Coll., Jan., 1896.)

UINTA Hulst.

Hulst, Ent. Am., iv, 116, 1888; Fernald, C. 12, 1896.

*4549. oreadella Hulst, Ent. Am., iv, 116, 1888; FER- Col. NALD, C. 13, 1896.

\section{MESOLIA Ragonot.}

Ragonot, Ann. Soc. Ent. Fr., 282, 1888; Hampson, Proc. Zool. Soc. Lond., 962, 1895.

*4550. incertella Zincken, Germ. Mag., iv, 253, 1821; Zeller, Chil. et Cram., 14, 1863; Robinson, Ann. Lyc. Nat. Hist. N. Y., ix, 315, 1870; FerN. C., Ga., NALD, C. $15,1896$.

IIl.

syn. olivella Grote, Bull. U. S. Geol. Surv., vi, $274,1881$.

PRIONAPTERYX Stephens.

Stephens, Ill. Brit. Ent., Haust., iv, 316, 1834; Zelder, Chil. et Cram., 13, 1863; Hampson, Proc. Zool. Soc. Lond., 963, 1895; Fernald, C. 13, 1896; Nuarace Walker, Cat. Brit. Mus., xxvii, 188, 1863.

4551. nebulifera Stephens, Ill. Brit. Ent., Haust., iv, Tex. 317. 1834; Wood, Ind. Ent., f. 1484, 1854; Zeller, Chil. et Cram., 13, 1863; Fernald, C. $14,1896$.

4552. achatina Zeller, Chil. et Cram., 13, 1863; Fernald, C. 14, 1896.

Tex., Ariz.

*4552. 1. cuneolalis Hulst, Tr. Am. Ent. Soc., xiii, 166, 1886; Fernald, C. 15, 1896.

Tex.

\section{EUGROTEA Fernald.}

Fernald, C. 16, 1896.

*4553. dentella Fernald, C. 16, 1896.

Fla.

\section{PSEUDOSCHENOBIUS Fernald.}

Fernald, Smith's List Lep. Bor. Am., 85, 1891; C. 17, 1896.

4554. opalescalis Hulst, Trans. Am. Ent. Soc., xiii, 167, 1886; Fernald, C. 18, 1896.

Ariz., Cal. syn. griseosparsa Hampson, Proc. Zool. Soc. Lond., 964, 1895. 
RAPHIPTERA Hampson.

Hampson, Proc. Zool. Soc. Lond., 962, 1895.

4555. minimella Robinson, Ann. Lyc. Nat. Hist. N. Y., ix, 315, 1870; Felt, Gr.-Eat. Ins., 88, 1894; Fernald, C. 23, 1896.

*4556. argillaceëlla PAckard, Proc. Bost. Soc. Nat. Hist., xi, 54, 1867; Fernald, C. 24, 1896.

N. Y., Pa., Ill., Tex.

Lab.

\section{CRAMBUS Fabricius.}

Fabricius, Ent. Syst., suppl., 464, 1798; Latreille, Hist. Nat. Crust. Ins., iii, 416, 1802; xiv, 247, 1805; Leach, Ed. Ency., ix, 135, 1815; Curtis, Brit. Ent., iii, 109, 1826; Stephens, Ill. Brit. Ent., Haust., iv, 317, 1834; Herrich-Schaeffer, Schm. Eur., iv, 52, 1848; Zeller, Chil. et Cram., 14, 1863; Heinemann, Kleinschm., i, 2, 117, 1865; Meyrick, Trans. Ent. Soc. Lond., 481, 1890; Handb. Brit. Lep., 388, 1895; Fernald, C. 18, 1896; Tetrachila Hübner, Tent., 1806; Palparia Haworth, Lep. Brit., 481, 1811; Argyrotenchia HüBNER, Verz. bek. Schmett., 364, 1826; Eucarphia HüBNer, Verz. bek. Schmett., 364, 1826; Catoptria HüBner, Verz. bek. Schmett., 364, 1826; Chrysoteuchia HüBNER, Verz. bek. Schmett., 366, 1826; Thisanotia HüBner, Verz. bek. Schmett., 467, 1826; Exoria HüBner, Verz. bek. Schmett., 467, 1826; Carvanca Walker, Cat. Brit. Mus., ix, 119, 1856; Myeza Walker, Cat. Brit. Mus., xxvii, 190, 1863: Arequipa Walker, Cat. Brit. Mus., xxvii, 195, 1863; Calamotropha Zeller, Chil. et Cram., 8, 1863.

4557. satrapellus Zincken, Germ. Mag., iv, 247, 1821; Zeller, Chil. et Cram., 16, 1863; Felt, Gr.-Eat. Ins., 89, 1894; Fernald, C. 22, 1896.

Ga.,

Fla.,

Tex.

syn. aculeitellus Walker, Cat. Brit. Mus., xxvii, 158, 1863; elegantellus WaLker, Cat. Brit. Mus., xxvii, 179, 1863.

4558. hastiferellus Walker, Cat. Brit. Mus., xxvii, 155, 1863; Fernald, C. 22, 1896.

N. S., Pa., Fla., La.

syn. quinquareatıs Zeller, Hor. Soc. Ent. Ross., xiii, 38, 1877; extorralis Hulst, Trans. Am. Ent. Soc., xiii, 165, 1886.

*4559. occidentalis Grote, Can. Ent., xii, 16, 1880; Can. Ent., xiii, 66, 1881; Fernald, C. 23, 1896.

4560. hamellus Thunberg, Diss. Ent., 97, 1794; Herrich-SchaEfFer, Schm. Eur., iv, 53, 1848; Wood, Ind. Ent., f. 1491, 1854; StaInton, Man., ii, 181, 1859; Zeller, Chil. et Cram., 17, 1863; Hennemann, Kleinschm., i, 2, 119, 1865; Meyrick, Handb. Brit. Lep., 389, 1895; FerNALD, C. $25,1896$.

syn. ensigerella HüBner, Schm. Eur., Tineæ, pl. liv, f. 367 (false 667), 1803?; ZINCKEN, Germ. Mag., ii, 53, 1817; Treitschke, Schm. Eur., ix, 1, 79, 1832; Duponchel, Hist. Nat. Lép., x, 57, 1836.

4561. cypridalis Hulst, Trans. Am. Ent. Soc., xiii, 165, 1886; Fernald, C. 26, 1896.
Cal.

Eur., Me.

Utah. 
*4562. carpenterellus Packard, Rep. Hayd. Surv., 548, 1873; Fernald, C. 26, 1896.

Mts. of

Col.

4563. pascuellus Linn eus, Syst. Nat., 535, 1758; Faun. Suec., 355, 1761; FABricius, Syst. Ent., 658, 1775; Hüвner, Schm. Eur., Tineæ, pl. v, f. 51, 1796; Zincken, Germ. Mag., ii, 49, 1817; Treitschке, Schm. Eur., ix, 1, 75, 1832; Stephens, Ill. Brit. Ent., Haust., iv, 320, 1834; Herrich-Scha efFer, Schm. Eur., iv, 53, 1848; Zeller, Chil. et Cram., 20, 1863; Heinemann, Kleinschm., i, 2, 120, 1865; Meyrick, Handb. Brit. Lep., 390, 1895; Fernald, C. 27, 1896.

syn. floridus Zeller, Verh. zool.-bot. Ges. Wien, xxii, 537, 1872; FeLt, Gr.-Eat. Ins., $78,86,1894$.

4564. girardellus Clemens, Proc. Acad. Nat. Sci. Phil., 204, 1860; Felt, Gr.-Eat. Ins., 73, 86, 1894; Fernald, C. 28, 1896.

syn. nivihumellus Walker, Cat. Brit. Mus., xxvii, 159, 1863.

4565. leachellus Zincken, Germ. Mag., iii, 114, 1818; Felt, Gr.-Eat. Ins., 71, 85, 1894; Fernald, C. $29,1896$.

syn. pulchellus Zelcer, Chil. et Cram., 18, 1863; Verh. zool.-bot. Ges. Wien, xxii, 535,1872 .

4566. unistriatellus Packard, Proc. Bost. Soc. Nat. Hist., xi, 54, 1867; Felt, Gr.-Eat. Ins., 85, 1894; Fernald, C. 30, 1896.

syn. exesus Grote, Can. Ent., xii, 16, 1880; No. Am. Ent., i, 68, 1880.

4567. præfectellus Zincken, Germ. Mag., iv, 249, 1821: Fernald, C. 31, 1896.

syn. involutellus Clemens, Proc. Acad. Nat. Sci. Phil., 203, 1860.

*4568. dissectus Grote, Can. Ent., xii, 16, 1880; Fernald, C. 31, 1896.

4569. bidens Zeller, Verh. zool. -bot. Ges. Wien, xxii, 535, 1872; Fernald, C. 32, 1896.

Me. to

Cal.

Labr.,

Atl. States,

Minn.,

Cal.

Can.,

Atl. States,

Col.

Me.,

N. Y.

Mass.,

N. Y.

4570. labradoriensis Christoph, Stett. ent. Zeit., xix,

Labr.,

Ont., 314, 1858; Möschler, Wien. ent. Mon., iv, 379, 1860; Zeller, Chil. et Cram., 21, 1863;

Oreg. Fernald, C. 32, 1896. 
4571. dumetellus Hübner, Eur. Schmett., Tineæ, pl. Iviii, f. 389, 390, 1803?; Treitschke, Schmett. Eur., ix, 1, 80, 1832; Stephens, Ill. Brit. Ent., Haust, iv, 321, 1834; Herrich-Schaeffer, Schmett. Eur., iv, 54, 1848; Zeller. Chil. et Cram., 24, 1863; Heinemann, Kleinschm., i, 2, 122, 1865; Meyrick, Handb. Brit. Lep., 391, $1895 ;$ Fernald, C. 33, 1896.

syn. pratella HüBner, Eur. Schmett., Tineæ, pl. v, f. 29, 1796; trichusalis HuLst, Trans. Am. Ent. Soc., xiii, 165, 1886.

*4572. gausapalis Hulst, Trans. Am. Ent. Soc., xiii, 167, 1886; Fernald, C. 34, 1896.

4573. laqueatellus Clemens, Proc. Acad. Nat. Sci. Phil., 203, 1860; Zeller, Chil. et Cram., 24,1863; Verh. zool. -bot. Ges. Wien, xxii, 538, 1872; FeLt, Gr.Eat. Ins., 79, 89, 1894; Fernald, C. 35, 1896.

syn. semifusellus WaLker, Cat. Brit. Mus., xxvii, 159, 1863.

*4574. alboclavellus Zeller, Chil. et Cram., 19, 1863; Verh. zool.-bot. Ges. Wien, xxii, 538, 1872; Felt, Gr.-Eat. Ins., 77, 88, 1894; Fernald, C. 36,1896 .

4575. agitatellus Clemens, Proc. Acad. Nat. Sci. Phil., 203, 1860; FeLt, Gr.-Eat. Ins., 88, 1894; FerNALD, C. $37,1896$.

syn. saltuellus ZeLLer, Chil. et Cram., 22, 1863.

4576. multilinellus Fernald, Ent. Am., iii, 37, 1887.

syn. multilineëllus Fernald, C. 37, 1896.

4577. albellus Clemens, Proc. Acad.Nat. Sci. Phil., 204, 1860; FeLt, Gr.-Eat. Ins., 76, 88, 1894; FERNALD, C. 38, 1896.

4578. pusionellus Zeller, Chil. et Cram., 16, 1863; Stett. ent. Zeit., xxxiii, 470, 1872; Hor. Soc. Ent. Ross., xiii, 33, 1877; Fernald, C. 39, 1896.

4579. hortuellus Hübner, Eur. Schm., Tineæ, 29, pl. vii, f. 46, 1796; Zrncken, Germ. Mag., ii, 62, 1817; Treitschke, Schm. Eur., ix, 1, 84, 1832; Stephens, Ill. Brit. Ent., Haust., iv, 322, 1834; Herrich-Schaeffer, Schm. Eur., iv, 59, 1848; Zeller, Chil. et Cram., 24, 1863; Heinemann, Kleinschm., i, 2, 125, 1865; Meyrick, Handb. Brit. Lep., 391, 1895; Fernald, C. 40, 1896.

syn. cespitella Hüвner, Eur. Schm., Tineæ, 29, pl. vii, f. 45, 1796; topiarius Zeller, Stett. ent. Zeit., xxvii, 155, 1866; Grote, Can. Ent., xii, 17, 1880; Felt, Gr.-Eat. Ins., 75, 87, 1894; Scudder, Ins. Life, vii, 1, 1894.
Eur., Tex., Col., Rocky Mts. north of Mont.

Sierra Nev. Mts., Cal.

Me., Mass., N. Y., Ohio, Ill., Ky., La., Tex.

Atl.

States.

No. Atl. States, Tex.

Fla.

N. Atl. States.

Cal.

Eur., Me., Mass., N. Y., Cal. 
4580. perlellus Scopoli, Ent. Carn., 243, 1763; FaBriCIUs, Ent. Syst., iii, 2, 292, 1794; HüBNER, Schm. Eur., Tineæ, pl. vi, f. 40, 1796; Zincken, Germ. Mag., ii, 97, 1817; Treitschke, Schm. Eur., ix, 1, 129, 1832; Herrich-Schaeffer, Schm. Eur., iv, 66, 1848; Zeller, Stett. ent. Zeit., ix, 313, 1849; Chil. et Cram., 49, 1863; Heinemann, Kleinschm., i, 2, 143, 1865; Meyrick, Hand. Brit. Lep., 393, 1895; Fernald, C. 43, 1896.

syn. argentella Fabricius, Syst. Ent., 658, 1775; Ent. Syst., iii, 2, 296, 1794; Ent. Syst., suppl., 471,1798; Stephens, Ill, Brit. Ent., Haust., iv, 319, 1834; argyreus STEPHens, Ill. Brit. Ent., Haust., iv, 318, 1834; arbustorum STEPHENs, Ill. Brit. Ent.,Haust., iv, 319, 1834; innotatellus WALKER, Cat. Brit. Mus., xxvii, 156, 1863; Felt, Gr.-Eat. Ins., 74, 87, 1894; sericinellus ZeLLer, Chil. et Cram., 49, 1863; Grote, Can. Ent., xiii, 66, 1881; inornatellus Clemens, Proc. Ent. Soc. Phil., ii, 418, 1864.

4581. turbatellus W ALKer, Cat. Brit. Mus., xxvii, 196, 1863; Felt, Gr.-Eat. Ins., 86, 1894; Fernald, C. 44,1896 .

syn. bipunctellus ZeLLer, Chil. et Cram., 23, 1863; Robinson, Lyc. Nat. Hist. N. Y., ix, $316,1870$.

4582. elegans Clemens, Proc. Acad. Nat. Sci. Phil., 204, 1860; Zeller, Stett. ent. Zeit., xxxiii, 473 , 1872; Felt, Gr.-Eat. Ins., 74, 86, 1894; FerNALD, C. $45,1896$.

4583. myellus HüBner, Eur. Schm., Tineæ, pl. vi, f. 37, 1796; Herrich-Schaeffer, Schm. Eur., iv, 64, 1848; Heinemann, Kleinschm., i, 2, 133, 1865; Meyrick, Handb. Brit. Lep., 392, 1895; FerNALD, C. $46,1896$.

syn. conchellus Treitschke, Schm. Eur., ix, 1, 97, 1832; latiradiellus W ALKER, Cat. Brit. Mus., xxvii, 157, 1863; intermuptus Grote, Can. Ent., ix, 101, 1877.

*4584. luctuellus Herrich-SCha Effer, Schm. Eur., vi, 145, 1852; Fernald, C. 47, 1896.

4585. vulgivagellus Clemens, Proc. Ac. Nat. Sci. Phil., 204, 1860; SaUnders, Can. Ent., xiii, 199, 1881; Riley, Rept. Dept.Agr., 179, 1881-82; Lintner, Rep. Ins. N. Y., i, 127, 1882; Fernald, Stand. Nat. Hist., ii, 433, 1884; Felt, Gr.-Eat. Ins., 69, 85, 1894; Fernald, C. 47, 1896.

syn. aurifimbrialis WALKer, Cat. Brit. Mus., xxvii,157,1863; chalybirostris ZeLler, Chil. et Cram., 40, 1863.

Can., N. Y., Pa., Ohio, Ill.

Atl.

States.

Eur., N. S., Me.

Eur., Labr., Wash.

No. U. S., Cal. 
4586. biothanatalis Hulst, Trans. Am. Ent. Soc., xiii, Cal. 166, 1886; Fernald, C. 49, 1896.

syn. behrensellus Fernald, Ent. Am., iii, 37, 1887.

4587. ruricolellus Zeller, Chil. et Cram., 40, 1863; Felt, Gr.-Eat. Ins., 67, 1894; Fernald, C. 49 , 1896.

*4588. anceps Grote, Can. Ent., xii, 18, 1880; Fernald, C. $50,1896$.

No. Atl. States.

Cal. Atl. States.

Atl. States.

Col.

Tex.

*4592. bolterellus Fernald, Ent. Amer., iii, 37, 1887; C. 53,1896 .

*4593. hulstellus Fernald, Can. Ent., xvii, 56, 1885; Felt, Gr.-Eat. Ins., 83, 1894; Fernald, C. 53 , 1896.

4594. attenuatus Grote, Can. Ent., xii, 18, 1880; Fernald, C. 54, 1896.

Br. Col., Cal.

So.

Cal. C. $55,1896$.

Tex., Haiti. Fernald, C. 55, 1896.

*4597. trichostomus Christoph, Stett. ent. Zeit., xix, 313, 1858; Möschler, Wien. ent. Mon., iv, 379, 1860; Zeller, Chil. et Cram., 28, 1863; Fernald, C. 56, 1896.

syn. albisinuatella Packard, Proc. Bost. Soc. Nat. Hist., xi, 53, 1867. 
4598. truncatellus Zetterstedt, Ins. Lap., 995, 1840; Zeller, Chil. et Cram., 28, 1863; Heinemann, Kleinschm., i, 2, 128, 1865.

syn. Tieniqiellus Zelder, Stett. ent. Zeit.. iv, 139, 1843; abstrusellus WALKer, Cat. Brit. Mus., xxvii, 158, 1863; mufinalis W ALKER, Cat. Brit. Mus., xxxiv, 1133, 1865.

*4599. oregonicus Grote, Can. Ent., xii, 17, 1880; Fernald, C. 56, 1896.

4600. bonifatellus Hulst, Ent. Am., iii, 135, 1887; Fernatd, C. 57, 1896.

4601. mutabilis Clemens, Proc. Acad. Nat. Sci. Phil., 204, 1860; FeLt, Gr.-Eat. Ins., 64, 83, 1894; Fernatd, C. 57, 1896.

syn. fuscicostellus Zeluer, Chil. et Cram., 44, 1862.

4602. hemiochrellus Zeller, Hor. Soc. Ent. Ross., xiii, 49, 1877; Fernald, C. 58, 1896.

*4603. undatus Grote, Can. Ent., xiii, 35, 1881; FerNALD, C. 58, 1896.

4604. trisectus Walker, Cat. Brit. Mus., ix, 119, 1856; Fernatd, C. 59, 1896.

syn. interminellus Walker, Cat. Brit. Mus., xxvii, 156, 1863; Fett, Gr.-Eat. Ins., 62, 83 , 1894; exsiccatus Zeller, Chil. et Cram., 37, 1863; Lintner, Rep. Ins. N. Y., i, 149, 1882; Osborn, Rep. Dept. Agr., 154, 1887; biliturellus Zelter, Verh. zool.-bot. Ges. Wien, xxiv, $7,1874$.

*4605. laciniellus Grote, Can. Ent., xii, 18, 1880; Fernald, C. 60, 1896.

*4606. dimidiatellus Grote, Ann. Mag. Nat. Hist., (5), ii, 57, 1883; Fernald, C. 61, 1896.

4607. caliginosellus Clemens, Proc. Acad. Nat. Sci. Phil., 204, 1860; FELT, Gr.-Eat Ins., 61, 82, 1894; Fernald, C. 61, 1896.

4608. zeëllus Fernald, Can. Ent., xvii, 55, 1885; Forbes, Third Ill. Rep., 12, 15, 1885; Fernald, C. 62,1896 .

syn. refotalis Hulst, Tr. Am. Ent. Soc., xiii, $166,1886$.

4609. luteolellus Clemens, Proc. Acad. Nat. Sci. Phil., 203, 1860; Felt, Gr.-Eat. Ins., 61, 82, 1894; Fernald, C. 64, 1896.

syn. duplicatus Grote, Can. Ent., xii, 79, 1880.

a. ulæ Cockereld, Ent. Mon. Mag., xxiv, 272, 1885; Fernald, C. $65,1896$.
No. Eur.,

Hudson

Bay.

Oreg.

Col.

Can. to

Tex.

Tex.

Cal.

Atl. States,

Col., B. C.

Me.

Col.,

N. Mex.

Atl.

States.

Atl.

States.

Col.

Me. to Cal.

Ariz. .

Col. 
*4610. inornatellus W ALKer, Cat. Brit. Mus., xxiv, 157, 1863 .

THAUMATOPSIS Morrison.

Morrison, Proc. Bost. Soc. Nat. Hist., xvii, 161, 1874; Propexus Grote, Can. Ent., xii, 79,1880 .

*4611. magnifica Fernald, Can. Ent., xxiii, 30, 1891; C. 66,1896 .

4612. pexella Zeller, Chil. et Cram., 48, 1863; FerNALD, C. 66, 1896.

syn. macropterellus Zeller, Chil. et Cram., 48, 1863; longipalpus Morrison, Proc. Bost. Soc. Nat. Hist., xvii, 161, 1874.

4613. edonis Grote, Can. Ent., xii, 19, 1880; Fernald, C. 67,1896 .

4614. repanda Grote, Can. Ent., xii, 79, 1880; FErNALD, C. 67, 1896.

*4615. striatella Fernald, C. 68, 1896.

4616. pectinifer Zeller, Hor. Soc. Ent. Ross., xiii, 51 1877; Fernald, C. 68, 1896.

\section{EUFERNALDIA Hulst.}

Hulst, Jn. N. Y. Ent. Soc., viii, 224, 1901.

4617. argenteonervella Hulst, Jn. N. Y. Ent. Soc., viii, 224, 1901.
Ariz.
Ga., Mo., Col.

Col.

N. C.,

Kans.

Tex., Ariz., Kans., Col.

No. Ill.

Tex.

\section{OMMATOPTERYX Kirby.}

Kirby, Handb. Lep., 274, 1897; Eromere Hübner (not HüBner, Verz. bek. Schm., 256), Verz. bek. Schm., 366, 1826; Zeller, Chil. et Cram., 52, 1863; Leech, Brit. Pyr., 87, 1886; Hampson, Proc. Zool. Soc. Lond., 948, 1895; Euchromius Guenée (not Euchromia Hü BNer), Ind. Méth., 86, 1845; Meyrick, Trans. Ent. Soc. Lond., 479, 1890; Handb. Brit. Lep., 396, 1895; Fernald, C. 68, 1896.

4618. ocellea Haworth, Lep. Brit., 486, 1811; Stephens, Ill. Brit. Ent., Haust., iv, 316, 1834; Zeller, Chil. et Cram., 54, 1863; Leech, Brit. Pyr., 87, 1886; Meyrick, Handb. Brit. Lep., 396, 1895; Hampson, Moths Ind., iv, 24, 1896; Fernald, C. 69, 1896.

syn. funiculella Treitschke, Schm. Eur., ix, 1, 200, 1832; Zeller, Isis, vi, 175, 1839; cyritella Costa, Faun. Nap. Lep., 2, 1832-36; cyrilli Zeller, Isis, xiv, 760, 1847; HerRICH-SchaEFFER, Schm. Eur., iv, 67, 1848; texana Robinson, Ann. Lyc. Nat. Hist. N. Y., ix, 155, 1870; catifornicalis PACKARd, Ann. Lye. Nat. Hist. N. Y., x, 264, 1873. 


\section{ARGYRIA Hübner.}

HüBner, Zutr. exot. Schmett., i, 28, 1818; Verz. bek. Schmett., 372, 1826; WALkER, Cat. Brit. Mus., xxx, 976, 1864; Fernald, C. 70, 1896; Urola Walker, Cat. Brit, Mus., xxvii, 181, 1863; Catharylla Zeller, Chil. et Cram., 50, 1863; Ptychopseustis Merrick, Trans. Ent. Soc. Lond., 521, 1889.

4620. nivalis Drury, Ill. Exot. Ent., ii, 25, 1773; FerNald, No. Am. Ent., 100, 1880; Felt, Can. Ent., Atl. xxvii, 96, 1894; Fernald, C. 71, 1896.

States.

syn. argentata Emmons, Nat. Hist. N. Y. Agr., v, pl. 40, 1854; michrochysella WALKER, Cat. Brit. Mus., xxvii, 181, 1863; mummulalis Zeller, Chil. et Cram., 51, 1863.

4621. argentana Martyn, Psyche, pl. xxxii, f. 95, 1797; Fernald, C. 71, 1896.

syn. nummulalis HüBNer, Zutr. exot. Schmett., i, 30, f. 185, 186, 1818; Fernald, No. Am. Ent., 101, 1880; subcenescens W ALKER, Cat. Brit. Mus., xxvii, 182, 1863; fuscipes ZELLER, Chil. et Cram., 51, 1863.

4622. auratella Clemens, Proc. Acad. Nat. Sci. Phil., 204, 1860; Fernald, C. 72, 1896.

Pa., Ga., Fla., Ill.

Me. to Cal.

Fla., Tex., W. I., So. Am.

4623. lacteëlla FABricius, Ent. Syst., iii, 2, 313, 1794; Hedemann, Stett. ent. Zeit., lv, 300, 1894; FerNALD, C. 72, 1896.

syn. albana Fabricius, Ent. Syst., Suppl., 476, 1798; Hedemann, Stett. ent. Zeit., Iv, 300, 1894; pussillalis HüBNER, Zutr. exot. Schm., i, 28, 1818; abronalis WALKER, Cat. Brit. Mus. xix, 969, 1859; Tusella Zeller, Chil. et Cram., 51, 1863; rufisignella ZelLer, Verh. zool. -bot. Ges. Wien, xxii, 542, 1872 ; pontiella Zeller, Hor. Soc. Ent. Ross., xiii, 59, 1877.

\section{DIATRAEA Guilding.}

Guilding, Trans. Soc. Enc. Arts, xlvi, 143, 1832; Zeller, Hor. Soc. Ent. Ross, xvi, 8, 1881; Fernald, Ent. Am., iv, 119, 1888; Hampson, Proc. Zool. Soc. Lond., 953, 1895; Fernald, C. 73, 1896.

4624. saccharalis FABRICIUs, Ent. Syst., iii, 2, 238, 1794; Comstock, Rept. Dept. Agr., 1880, 240, 1881; RILEY \& Howard, Ins. Life, iii, 64, 1890; HowARD, Ins. Life, iv, 95, 1891; Bruner, Rep. Neb. St. Bd. Ag., 262, 1891; Fernald, C. 74, 1896. syn. leucaniellus WaLker, Cat. Brit. Mus., xxvii, 161, 1863; lineosellus WaLker, Cat. Brit. Mus., xxvii, 162, 1863; obliteratellus Zeller, Chil. et Cram., 8, 1863; crambidoides Grote, Can. Ent., xii, 15, 1880.
So. States,

W. I., Cent. \& So. Am., Hawaii. 
*4625. alleni Fernald, Ent. Am., iv, 120, 1888; C. 75, Me. 1896.

*4626. differentialis Fernald, Ent. Am., iv, 120, 1888; C. 76,1896 .

4627. idalis FernaLd, C. $76,1896$.

N. J., Ga.

\section{CHILO Zincken.}

Zrncken, Germ. Mag., ii, 33, 1817; Stephens, Ill. Brit. Ent., Haust., iv, 330, 1834; Treitschke, Schm. Eur., ix, 1, 60, 1832; Westwood, Syn. Gen. Brit. Ins., 114, 1839; Herrich-Schaeffer, Schm. Eur., iv, 50, 1848; Zeller, Chil. et Cram., 6, 1863; Heinemann, Kleinschm., i, 2, 112, 1865; Meyrick, Trans. Ent. Soc. Lond., 480, 1890; Handb. Brit. Lep., 397, 1895; Hampson, Proc. Zool. Soc. Lond., 954, 1895; Fernald, C. 77, 1896; Epina Walker, Cat. Brit. Mus., xxxv, 1707, 1866; Donacoscaptes Zeller, Hor. Soc. Ent. Ross, xiv, 1877; Diphryx Grote, Bull. U. S. Geol. Surv., vi, 273, 1881.

4628. plejadellus Zincken, Germ. Mag., iv, 251, 1821; Pa., Ga., Zeller, Chil. et Cram., 26, 1863; Fernald, C. La., Wis. 78,1896 .

syn. sabulifera Walker, Cat. Brit. Mus., xxvii, 185, 1863; prolatella Grote, Bull. U. S. Geol. Surv., vi, 273, 1881; oryaceёllus Riley, Rep. Dep. Agr., 1 5, 1882.

4629. densellus Zeluer, Hor. Soc. Ent. Ross., xvi, 5, 1881; Fernald, C. 79, 1896.

Fla., Tex., III.

syn. multilineatella Hulst, Ent. Am., iii, 134, 1887.

4630. squamulellus Zeller, Hor. Soc. Ent. Ross., xvi, 5, 1881; Fernald, C. 79, 1896.

4631. comptulatalis Hulst, Tr. Am. Ent. Soc., xiii, 167, 1886; Fernald, C. 80, 1896.

4632. forbesellus Fernald, C. 80, 1896.

\section{CHALCÖ̈LA Zeller.}

Zeller, Verh. zool.-bot. Ges. Wien, xxii, 528, 1872; Hampson, Proc. Zool. Soc. Lond., 958, 1895.

4633. iphitalis Walker, Cat. Brit. Mus., xvii, 444, 1859. So. States. syn. aurifera ZelLer, Verh. zool.-bot. Ges. Wien, xxii, 529, 1872.

\section{DICYMOLOMIA Zeller.}

Zeller, Verh. zool.-bot. Ges. Wien, xxii, 530, 1872; Hampson, Proc. Zool. Soc. Lond., $959,1895$.

4634. julianalis Walker, Cat. Brit. Mus., xvii, 438, 1859. So. States.

syn. decora Zeller, Verh. zool.-bot. Ges. Wien, xxii, 531, 1872. 
4635. metalliferalis Packard, Ann. Lyc. Nat. Hist.

Cal.

N. Y., x, 265, 1873.

syn. sauberi Hedemann, Verh. Ver. Hamb., v, Anhang, 3, 1880.

4636. pegasalis WaLKer, Cat. Brit. Mus., xvii, 438, 1859 .

So. States, W. I.

syn. principatis WaLker, Cat. Brit. Mus., xxxiv, 1333, 1865; egressalis W ALKER, Cat. Brit. Mus., xxxiv, 1335, 1865; robinsonii Grote, Can. Ent., iii, 181, 1871.

$$
\text { Subfamily GALLFRIIN A.. }
$$

MELISSOBLAPTES Zeller.

Zeller, Isis, 180, 1839.

*4636. 1. fuscolimbellus Ragonot, Diag. Nouv. Phye. Gall., 20, 1887.

GALLERIA Fabricius.

Fabricius, Suppl. Ent., 419, 1798.

4636. 2. mellonella Linnæus, Syst. Nat., 537, 1758; Staudinger \& Rebel, Cat. Lep. Eur., ii, no. 11, 1901.

syn. cereana Linneus, cerella Fabricius, obliquella WALKER.

\section{PARALIPSA Butler.}

Butler, Ann. Mag. Nat. Hist., (5), iv, 454, 1879.

4636. 3. fulminalis ZelLer, Verh. zool. -bot. Ges. Wien, xxii, $560,1872$.

*4636. 4. furellus Zeller, Verh. zool.-bot. Ges. Wien, xxiii, 212, 1873.

*4636. 5. decorella Hulst, Can. Ent., xxiv, 63, 1892.

Eur.,

U. S.

\section{APHOMIA Hiibner.}

HüBner, Verz. bek. Schmett., 369, 1816.

4636. 6. sociella Linnæus, Syst. Nat., 534, 1758; STAUDinger \& Rebel, Cat. Lep. Eur., ii, no. 8, 1901.

Eur., U.S. syn. colonella Linneus, tribunella SCHIFFerMÜLLER.

\section{ACHROIA Huibner.}

HüBner, Verz. bek. Schmett., 163, 1816.

4636. 7. grisella Fabricius, Ent. Syst., iii, 2, 289, 1794; Staudinger \& Rebel, Cat. Lep. Eur., ii, no. 3 , Eur., U. S, 1901. 


\title{
Subfamily FPIPASCHIIN $A$ E.
}

By George D. Hulst.

\author{
EPIPASCHIA Clemens.
}

Clemens, Proc. Acad. Sci. Phil., 14, 1860; Grote, Proc. Bost. Soc. Nat. Hist., xix, 262, 1877; Bull. Geol. Surv. Terr., iv, 685, 1878; N. Am. Ent., i, 9, 1879; Meyrick, Trans. Ent. Soc. Lond., 62, 1884; 187, 1887; Hulst, Ent. Amer., v, 50, 1889; Hampson, Trans. Ent. Soc. Lond., 463, 465, 1896; Mochlocera Grote, Can. Ent., viii, 151, 1876; Bull. Geol. Surv. Terr., iv, 686, 1878; N. Am. Ent., i, 9, pl. 2, f. 2, 1879; Meyrick, Trans. Ent. Soc. Lond., 187, 1887; Catamola Meyrick, Trans. Ent. Soc. Lond., 63, 280, 1884; 187, 1887; Astropometis Meyrick, Trans. Ent. Soc. Lond., 67, 1884; 187, 1887.

4637. superatalis Clemens, Proc. Acad. Sci. Phil., 14, 1860; Grote, Proc. Bost. Soc. Nat. Hist., xix, 262, 1877; Bull. Geol. Surv. Terr., iv, 686, 1878; N. Am. Ent., i, 9, pl. 1, f. 1, 1879; Hulst, Ent. U. S., east of plains, Amer., v, 51, 1889.

syn. borealis Grote, Bull. Buff. Soc., i, 177, 1873; ii, 77, 1874; Proc. Bost. Soc. Nat. Hist., xix, 262, 1877; olivalis Hulst, Trans. Am. Ent. Soc., xiii, 160, 1886.

*4638. interruptella Ragonot, Ann. Soc. Ent. Fr., Séances, Oct. 10, p. cl, 1888.

4639. zelleri Grote, Can. Ent., viii, 157, 1876; Proc. Bost. Soc. Nat. Hist., xix, 264, 1877; Bull. Geol. Surv. Terr., iv, 686, 1878; No. Am. Ent., i, pl. 2, Ont., Col. f. 2, 1879; Hulst, Ent. Amer., v, 52, 1889.

\section{CACOZELIA Grote.}

Grote, Proc. Bost. Soc. Nat. Hist., xix, 264, 1887; Bull. Geol. Surv. Terr., iv, 687, 1878; No. Am. Ent. i, 10, pl. 2, f. 3, 1879; Meyrick, Trans. Ent. Soc. Lond., 65, 1984; 187, 1887; Hulst, Ent. Amer., v, 63, 1889.

4640. basiochrealis Grote, Proc. Bost. Soc. Nat. Hist., xix, 264, 1877; Bull. Geol. Surv. Terr., iv, 687, 1878; No. Am. Ent., i, 10, pl. 2, f. 3, 1879; Hulst, Ent. Amer., v. 62, 1889.

\section{JOCARA Walker.}

Walker, Cat. Brit. Mus., xxvii, 115, 1863; Hampson, Trans. Ent. Soc. Lond., 460, 1896; Toripalpus Grote, Proc. Bost. Soc. Nat. Hist., xix, 265, 1877; Hulst, Ent. Amer., v, 62, 1889; Hampson, Trans. Ent. Soc. Lond., 460, 1896; Titanoceros MerRICK, Trans. Ent. Soc. Lond., 62, 1884; Hampson, Trans. Ent. Soc. Lond., 460, 1896; Winona Hulst, Ent. Amer., iv, 113, 1887.

4641. incrustalis Hulst, Ent. Amer., iii, 130, 1887; v, 62, 1889; Dyar, Proc. U. S. Nat. Mus., xxiii, 283,1900 .

4642. breviornatalis Grote, Proc. Bost. Soc. Nat. Hist., xix, 265, 1877; Bull. Geol. Surv. Terr., iv, 688, 1878; No. Am. Ent., i, 10, pl. 2, f. 4, 1879; Hulst, Ent. Amer., v, 63, 1889.

Col., Fla.

Gulf States, Col.

4643. dentilineella Hulst, Jn. N. Y. Ent. Soc., viii, Ariz. 221, 1900. 
ONEIDA Hulst.

Hulst, Ent. Amer., v, 63, 1889; Hampson, Tr. Ent. Soc. Lond., 455, 1896. 4644. Iunulalis Hulst, Ent. Amer., iii, 130, 1887; v, N. Y.. 64,1889 .

Ont.

4645. luniferella Hulst, Can. Ent., xxvii, 53, 1895.

Col.

YUMA Hulst.

Hulst, Ent. Amer., v, 65, 1889.

4646. trabalis Grote, Pap., i, 18, 1881; Hulst, Ent. Amer., v, 63, 1889; Ragonot, Mon. Phyc., pl. Tex., 3 , f. 23,1893 .

syn. adulatalis Hulst, Ent. Amer., iii, 129, 1887; v, 65, 1889.

TALLULA Hulst.

Hulst, Ent. Amer., iv, 114, 1888; v, 72, 1889; Hampson, Trans. Ent. Soc. Lond., $458,1896$.

4647. atrifascialis Hulst, Trans. Am. Ent. Soc., xiii, Gulf States, 160, 1886; Ent. Amer., iv, 115, 1888; v, 73, 1889; Col.

Hampson, Trans. Ent. Soc. Lond., 456, 1896.

\section{BENTA Walker.}

Walker, Cat. Brit. Mus., xxvii, 112, 1863; Hampson, Trans. Ent. Soc. Lond., 456, 1896; Saluda Hulst, Ent. Amer., iv, 113, 1888; v, 66, 1889; Hampson, Trans. Ent. Soc. Lond., 456, 1896.

4648. asperatella Clemens, Proc. Acad. Nat. Sci. Phil., 207, 1860; Grote, Bull. Geol. Surv. Terr., iv, 691, 1878; Hulst, Ent. Amer., iv, 113, 1888; v, 67,1889 .

syn. expandens Walker, Cat. Brit. Mus., xxvii, 112, 1863; Hulst, Trans. Am. Ent. Soc., xvii, 221, 1890; fuscolotella Ragonot, Ann. Soc. Ent. Fr., Séances, cli, Oct. 10,1888.

4649. malanogrammos Zeller, Ver. zool.-bot. Ges. Wien, xxii, 546, pl. 3, f. 24a, b, 1872; Grote, Bull. Geol. Surv. Terr., iv, 689, 1877; Hulst, Ent. Amer., v, 67, 1889.

a. diluculella Grote, No. Am. Ent., i, 60, 68, pl. 5, f. 10, 1880; Rep. Dept. Agr., 263, 1880.

syn. talleolalis Hurst, Trans. Am. Ent. Soc., xiii, 160, 1886; Ent. Amer., iii, 22, 1887; v, 67,1889 .

4650. floridella Hulst, Jn. N. Y. Ent. Soc., viii, 221, 1901.

46.51. speciosella Hulst, Jn. N. Y. Ent. Soc., viii, 222, 1901.
Ont., Eastern \&Gulf States, Tex., Col., Wis., Ariz.

N. Y., Fla., Tex., Col.

Fla.

Fla. 


\section{LANTHAPE Clemens.}

Clemens, Proc. Acad. Sci. Phil., 207, 1860; Hulst, Ent. Amer., v, 66, 1889; Hampson, Trans. Ent. Soc. Lond., 456, 1896.

4652. platanella Clemens, Proc. Acad. Sci. Phil., 207, 1860; Grote, Bull. Geol. Surv. Terr., iv, 691, Eastern 1878; Hulst, Ent. Amer., iv, 114, 1888; v, 66, U. S., Col. 1889 .

\section{TIOGA Hulst.}

Hulst, Ent. Amer., iv, 113, 1888; v, 69, 1889; Hampson, Trans. Ent. Soc. Lond., $455,1896$.

4653. aplastella Hulst, Ent. Amer., iv, 113, 1888; $\mathrm{v}, 69,1889$.

Tex., Col., Fla.

WANDA Hulst.

Hulst, Ent. Amer., iv, 114, 1888; v, 69, 1889; Hampson, Trans. Ent. Soc. Lond., $456,1896$.

4654. baptisiella Fernald, Ent. Amer., iii, 128, 1887; Hulst, Ent. Amer., iv, 114, 1888; v, 70, 1889.

N. Y., Mo.

4655. tiltella Hulst, Ent. Amer., iv, 114, 1888; v, 70, 1889.

Tex.

\section{TETRALOPHA Zeller.}

Zeller, Isis, 880, 1848; Grote, Bull. Geol. Surv. Terr., iv, 688, 1878; No. Am. Ent., i, 10, pl. 2, f. 5, 1879; Hulst, Ent. Amer., v, 69, 1889; Hampson, Trans. Ent. Soc. Lond., 456, 1896; Katona Hulst, Ent. Amer., iv, 113, 1888; v, 69, 1889; Loma Hulst, Ent. Amer., iv, 114, 1888; v, 69, 1889.

*4656. nephelotella Hulst, Ent. Amer., iv, 114, 1888; $\mathrm{v}, 70,1889$.

Pa.,

Tex.

4657. robustella ZeLler, Isis, 881, 1848; Grote, Bull. Geol. Surv. Terr., iv, 690, 1878; Hulst, Ent. Tex., Amer., v, 71, 1889.

4658. militella Zeller, Isis, 880, 1848; Grote, Bull. Geol. Surv. Terr., iv, 689, 1878; Hulst, Ent. Amer., v, 71, 1889.

*4659. formosella Hulst, Can. Ent., xxxii, 169, 1900. Tex.

*4660. slossonii Hulst, Can. Ent., xxvii, 53, 1895. Fla.

4661. euphemella Hulst, Ent. Amer., iv, 113, 1888; v, 71,1889 .

Col.

Tex.

4662. humerella Ragonot, Ann. Soc. Ent. Fr., Séances, cli, Oct. 10, 1888.

\section{POCOCERA Zeller.}

Zeller, Isis, 874, 1848; Hampson, Tr. Ent. Soc. Lond., 456, 1896.

4663. variella Ragonot, Ann. Soc. Ent. Fr., Séances, Tex. cli, Oct. 10, 1888.

syn. melanographella RAGonot, Ann. Soc. Ent, Fr., Séances, clii, Oct. 10, 1888, 
4664. subcanalis WALKER, Cat. Brit. Mus., xxvii, 56,

Tex. 1863.

syn. texanella Ragonot, Ann. Soc. Ent. Fr., Séances, clii, Oct. 10, 1888.

\section{ATTACAPA Hulst.}

Hulst, Ent. Amer., v, 71, 1889; Hampson, Trans. Ent. Soc. Lond., 456, 1896. 4665. callipeplella Hutst, Ent. Amer., iv, 114. 1888; v, Tex., $71,1889$.

DYARIA Neumoegen.

Neumoegen, Can. Ent., xxv, 214, 1893.

4666. singularis Neumoegen, Can. Ent., xxv, 214, 1893; DYAR, Can. Ent., xxxii, 284, 1900. (= Canodomus hocking $\because i$ WALSINGHAM ?)

Subfamily PHYCITINA.

By George D. Hulst.

(C.=Ragoxoт, Mon. Phyc. Gall., Romanoff, Mém. Lép., vii, 1893.)

TRACHYCERA Ragonot.

RAGONOT, C. 2, 1893.

*4667. pallicornella Ragonot, Diag. N. Am. Phyc., 119,

Tex. 1890; C. 2.

\section{SARASOTA Hulst.}

Hulst, Jn. N. Y. Ent. Soc., vii, 222, 1901.

4668. plumigerella Hulst, Jn. N. Y. Ent. Soc., vii, 222, 1901.

Me. ? 
*4672. minutulella Hulst, Ent. Amer., iii, 136, 1887; Ragonot, C. 48.

*4673. texanella Hulst, Can. Ent., xxiv, 60, 1892. Tex.

*4674. zonulella Ragonot, Ent. Amer., v, 117, 1889; C. 49 .

4675. leucophæella Hulst, Can. Ent., xxiv, 60, 1892.

Col.

4676. bistriatella Hulst, Ent. Amer., iii, 136, 1887: RAGONOT, C. 51.

syn. bilineatella Ragonot, Diag. N. Am. Phyc., N. Y., D. C., Iowa, Fla., Wis., Col. 3, 1887; C. 48; immundella Hulst, Trans. Am. Ent. Soc., xvii, 117, 1890; Ragonot, C. 49 .

*4677. grossipunctella Ragonot, Diag. Nov. Gen. Sp. Phyc., 8, 1887; C. 51.

*4678. alatella Hulst, Ent. Amer., iii, 135, 1857; RAGONOT, C. 52.

syn. rectistrigella $\mathrm{R}_{\mathrm{AGONOT} \text {. }}$

*4679. dulciella Hulst, Can. Ent., xxxii, 176, 1900.

*4680. corniella Ragonot, Diag. N. Am. Phye., 2, 1887; C. 53.

syn. coniella Hulst, Sm. List. Lep. Bor. Amer., no. 4254, 1891.

*4681. duplipunctella Ragonot, Diag. N. Am. Phyc., 2, 1857 ; C. 56.

Tex.

Ill.

Col. 
*4686. demotella Grote, Pap., i, 14, 1881; Bull. Geol. Surv. Terr., vi, 590, 1882; Ragonot, C. 103.

4687. angusella Grotr, No. Am. Ent., i, 51, 1880; Bull. Geol. Surv. Terr., vi, 590, 1880; Ragonot, C. 104 .

4688. caryæ Grote, Pap., i, 13, 1881; Hulst, Trans. Am. Ent. Soc., xvii, 122, 1890; Ragonot, C. 105.

syn. minimella Ragonot.

*4689. nigrosignella Hulst, Trans. Am. Ent. Soc., xvii, 123, 1890; Ragonot, C. 105.

*4690. caryivorella Ragonot, Diag. N. Am. Phyc., 4, 1887; C. 108.

syn. carycevorella Hulst, Trans. Am. Ent. Soc., xvii, 121, 1890; canjivorella Hulst, Sm. List Lep. Bor. Amer., no. 4262, 1891.

*4691. cirroferella Hulst, Can. Ent., xxiv, 60, 1892.

4692. rubrifasciella Packard, Ann. Lyc. Nat. Hist. N. Y., x, 267. 1873; Ragonot, C. 106.

4693. betulella Hulst, Trans. Am. Ent. Soc., xvii, 125, 1890; Ragonot, C. 107.

4694. comptoniella Hulst, Trans. Am. Ent. Soc., xvii, 125, 1890; Ragonot, C. 108.

4695. hebescella Hulst, Trans. Am. Ent. Soc., xvii, 126, 1890: Ragonot, C. 109.

*4696. fructetella Hulst, Can. Ent., xxiv, 59, 1892.
Ont. to

N. Y.

Ont.,

N. Y.

Mass., N. Y., Ill., Tex.

Tex.

Mo.

Tex., Col.

N. Eng.. N. Y., Col.

N. Y., N. H., Col.

N. Eng.,

N. Y.

N. J., Tex., Ill., Wis.

Tex., Ariz. Col.

\section{MINEOLA Hulst.}

Hulst, Trans. Am. Ent. Soc., xvii, 126, 1890; Ragonot, C. 86.

*4697. scitulella Hulst, Can. Ent., xxxii, 169, 1900.

Col.

4698. tricolorella Grote, Bull. Geol. Surv. Terr., iv, 694, 1878; Ragonot, C. 93.

Cal., Nev., Me.

4699. rubescentella Hulst, Can. Ent., xxxii, 169, 1900.

Tenn.

4700. amplexella Ragonot, Diag. N. Am. Phyc., 3, 1887 ;

Atl. States. C. 97.

*4701. caliginelia Hulst, Ent. Amer., iii, 131, 1887; v, 156, 1889; Ragonot, C. 115.

Cal., Ariz., N. Mex. syn. comptella Ragonot.

4702. juglandis Le Baron, Ins. Ills., ii, 123, 1872; Atl. States. Ragonot, C. 120.

4703. vaccinii Riley, Can. Ent., xvi, 237, 1884; RagoNOT, C. 121.

N. Eng., N. J., Tex. 
4704. indigenella Zeller, Isis, 651, 1848; Ragonot, Atl. States. C. 118 .

syn. nebulo W ALsH, selatella HuLst.

a. nebulella Riley, Ins. Mo., iv, 41, 1872; RAgONOT, C. 118.

\section{ULOPHORA Ragonot.}

Ragonot, Ann. Soc. Ent. Fr., Séances, 7, 1890; Hulst, Trans. Am. Ent. Soc., xvii, 222, 1890; RagONot, C. 155.

*4705. grotei Ragonot, Ann. Soc. Ent. Fr., Séances, p. N. C. vii, 1890; Hulst, Trans. Am. Ent. Soc., xvii, 222, 1890; Ragonot, C. 156.

\section{PIESMOPODA Zeller.}

Zeller, Isis, 606, 683, 1848; Hulst, Trans. Am. Ent. Soc., xvii, 132, 1890; Ragonot, C. 158 .

*4706. subrufella Hulst, Ent. Amer., iii, 132, 1887;

Fla.

Ragonot, C. 166.

*4707. filiolella Hulst, Ent. Amer., iv, 117, 1888; Fla., Ragonot, C. 166.

\section{PHYCITOPSIS Ragonot.}

Ragonot, Diag. No. Am. Phyc., 4, 1887; Hulst, Trans. Am. Ent. Soc., xvii, 133, 1890; RAGONoT, C. 185.

*4708. flavicornella Ragonot, Diag. No. Am. Phyc., 4, Tex. 1887; C. 185.

\section{DIORYCTRIA Zeller.}

Zeller, Isis, 732, 1846; 585, 1848; Heinemann, Pyr., 148, 1865; Ragonot, Ent. Mon. Mag., xxii, 52, 1885; C. 187.

*4709. clarioralis Walker, Cat. Brit. Mus., xxvii, 54, 1863; Hulst, Trans. Am. Ent. Soc., xvii, 136, 1890; Ragonot, C. 193.

*4710. aurantiacella Grote, Trans. Kans. Acad. Sci., Col., N. Mex., viii, 57, 1883; Ann. Mag. Nat. Hist., (5), xi, 57, Ariz. 1883; Ragonot, C. 194. syn. miniatella Ragonot.

4711. abietella Denis \& Schiffermüller, Syst. Verz. Wien, x, 138, 1776; Staudinger \& Rebel, Cat. Lep. Eur. ii, no. 700, 1901; Ragonot, C. 198.

U. S., Fla.? syn. decuriella HüBNER, sylvestrella RATZEBURG, abietivorella Grote.

*4712. reniculella Grote, No. Am. Ent., i, 67, 1880; Ragonot, C. 200.
Atl. States, Col., Wash., Europe.

Atl. States. 
MONOPTILOTA Hulst.

Hulst, Can. Ent., xxxii, 13, 1900.

4713. nubilella Hulst, Can. Ent., xxxii, 13, 1900.

Md., Fla.,

Ala.

4714. actualis Hulst, Trans. Am. Ent. Soc., xiii, 161,

Col. 1886; Ragonot, C. 203.

\section{PINIPESTIS Grote.}

Grote, Can. Ent., x, 19, 1878; Bull. Geol. Surv. Terr., iv, 699, 1878; Hulst, Trans. Am. Ent. Soc., xvii, 136, 1890.

4715. zimmermanni Grote, Can. Ent., ix, 161, 1877; x, 19, 1878; Packard, Ins. Inj. to Shade Trees, N. Y., 182, 1881; Grote, No. Am. Ent., i, 11, pl. 2, f. $\mathrm{Pa}$. 10, 1879; Zimmermann, Can. Ent., x, 20, 1878; Ragonot, C. 190.

*4716. amatella Hulst, Ent. Amer., iii, 131, 1887; Ragonot, C. 191.

*4717. pygmæella Ragonot, Diag. No. Am. Phyc., 5, 1887 ; C. 192.

*4718. albovittella Hulst, Trans. Am. Ent. Soc., xvii, 138, 1890; Ragonot, C. 193.

N. Mex., Col.

syn. gulosella Hulst, Trans. Am. Ent. Soc., xvii, 126, 1890; Ragonot, C. 109 ; elegantella Hulst, Can. Ent., xxvii, 59, 1895.

*4719. umbripennis Hulst, Can. Ent., xxvii, 57, 1895.

Col.

\section{TACOMA Hulst.}

Hulst, Ent. Amer., iv, 115, 1888; Trans. Am. Ent. Soc., xvii, 139, 1890; Ragonot, C. 205 .

4720. feriella Hulst, Ent. Amer., iv, 115, 1888; RAGO-

Tex. NOT, C. 205.

\section{DASYPYGA Ragonot.}

Ragonot, Diag. No. Am. Phyc., 5, 1887; Hulst, Trans. Am. Ent. Soc., xvii, 138, 1890; Ragonot, C. 206.

*4721. alternosquamella Ragonot, Diag. No. Am. Phyc., Cal., 5, 1887; C. 206.

Ariz.

a. stictophorella Ragonot, Diag. No. Am. Phyc.,

5, 1887; C. 206.

\section{PROMYLEA Ragonot.}

Ragonot, Diag. No. Am. Phyc., 5, 1887; Hulst, Trans. Am. Ent. Soc., xvii, 139, 1890; RAgONOT, C. 207.

*4722. lunigerella Ragonot, Diag. No. Am. Phyc., 5, Vancouver 1887; C. 208. 


\section{GLYPTOCERA Ragonot.}

Ragonot, Ent. Amer., v, 114,1889; Ann. Soc. Ent. Fr., Séances, Jan. 8, vii, 1890; Hulst, Trans. Am. Ent. Soc., xvii, 140, 1890; Ragonot, C. 209.

*4723. consobrinella Zeller, Verh. zool. -bot. Ges. Wien, 528,1872 ; Ragonot, C. 210.

Fla.,

Tex.

\section{ORTHOLEPIS Ragonot.}

Ragonot, Diag. No. Am. Phye., 6, 1887; Hulst, Trans. Am. Ent. Soc., xvii, 140, 1890; RAGONOT, C. 214.

*4724. jugosella Ragonot, Diag. No. Am. Phyc., 6, 1887;

Cal. ? C. 214 .

\section{POLOPEUSTIS Ragonot.}

RAGONOT, C. 232, 1893.

*4725 annulatella Zetterstedt, Ins. Lap., 997, 1840; Ragonot, C. 233.

Lab., Eur.

syn. altensis Wocke; Möschler, Verh. zool.bot. Ges. Wien, 309, 1884.

\section{A MBESA Grote.}

Grote, No. Am. Ent., i, 98, 1880; Hulst, Trans. Am. Ent. Soc., xvii, 141, 1890; Ragoмот, C. 237; Pristophora Ragonot, Ann. Soc. Ent. Fr., 229, 1887; C. 242.

*4726. walsinghami Ragonot, Diag. No. Am. Phyc., 6 , 1887: C. 239.

4727. lætella Grote, No. Am. Ent., i, 98, 1880; RagoNOT, C. 240.

*4728. lallatalis Hulst, Trans. Am. Ent. Soc., xiii, 161, 1885: Ragonot, C. 241.

syn. denticulella Ragonot, mrucei Hulst, Can. Ent., xxvii, 55, 1895.

*4729. niviella Hulst, Ent. Amer., iv, 117, 1888; RAGONOT, C. 241.
Col.

Ariz.

Col.

Col.,

Nev.

Col.

\section{NEPHOPTERYX Hiibner.}

Hübner, Verz. bek. Schmett., 370, 1818; Zeller, Isis, 731, 732, 1846; 585, 1848; Herrich-Schaeffer, Eur. Schm., iv, 78, 1849; Heinemann, Pyr., 149, 1865; Grote, Bull. Geol. Surv. Terr., iv, 695, 1878; No. Am. Ent., i, 11, 1879; Merrick, Proc. Linn. Soc. N. S. Wales, iii, 201, 1878; Ragonot, Ent. Mon. Mag., xxii, 19, 1885; Hulst, Trans. Am. Ent. Soc., xvii, 142, 1890; Ragonot, C. 241.

4730. scobiella Grote, No. Am. Ent., i, 51, 1880; RAGONOT, C. 266.

Tex.

N. Mex.

syn. decimerella Hulst.

4731. pergratialis Hulst, Trans. Am. Ent. Soc., xiii, 162, 1886; Ragonot, C. 267.

syn. grotella Ragonot.

*4732. modestella Hulst, Can. Ent., xxxii, 170, 1900.
Ga.,

Fla. 
4733. furfurella Hulst, Ent. Amer., iii, 131, 1887; RAGONOT, C. 269.

Fla.,

Tex.

4734. ovalis Packard, Ann. N. Y. Lyc. Nat. Hist., x, 269, 1873; Grote, No. Am. Ent., i, 11, pl. 2, f. 9, 1880; Ragonot, C. 269.

syn. latifasciella PACKARD.

a. geminipunctella Ragonot, Diag. No. Amer. Phyc., 7, 1887; C. 269.

*4735. rhypodella Hulst, Ent. Amer., iii, 137, 1887; RAGONOT, C. 270. syn. curvatella Ragonot.

*4736. fasciolalis Hulst, Trans. Am. Ent. Soc., xiii, 162, 1886; RaGONOT, C. 271.

*4737. hypochalciella Ragonot, Diag. No. Am. Phyc., 7, 1887; C. 272 .

*4738. rubrisparsella Ragonot, Diag. No. Am. Phyc., 6, 1887; C. 284.

syn. mufibasella Ragonot; croceella Hulst.

*4739. crassifasciella Ragonot, Diag. No. Am. Phyc., 8, 1887; C. 285.

*740. inquilinella Ragonot, Diag. No. Am. Phyc., 8, 1887: C. 290.

*4741. gilvibasella Hurst, Trans. Am. Ent. Soc., xvii, 145, 1890; C. 289.

*4742. subtinctella Ragonot, Diag. No. Am. Phyc., 7 , 1887; C. 302.

TLASCALA Hulst.
Ill., Cal.,

Tex.

East. U. S., Col., Cal., Tex.

Cal., Nev., Brit. Col.

Wash.

Tex.

Cal.

Wis.

Tex.

Cal.

Hulst, Trans. Am. Ent. Soc., xvii, 146, 1890; Ragonot, C. 255.

*4743. finitella Walker, Cat. Brit. Mus., xxvii, 53, N. Sco., Fla., 1863; Ragonot, C. 282.

Col.

4744. reductella Walker, Cat. Brit. Mus., xxvii, 62, 1863; Ragonot, C. 283.

S. C., Ohio, N. Y.

syn. gleditschiella FernaLd.

MEROPTERA Grote.

Grote, Can. Ent., xiv, 29, 1882; Hulst, Trans. Am. Ent. Soc., xvii, 148, 1890; Ragonot, C. 321; Oreana Hulst, Ent. Amer., iv, 115, 1888.

*4745. mirandella Ragonot, Mon. Phyc. Gall., i, 313, 1893.

4746. pravella Grote, Bull. Geol. Surv. Terr., iv, 694, 1878; RAGONOT, C. 314.

East. U.S., Col., Ont.

*4747. uvinella Ragonot, Diag. No. Am. Phyc., 8, 1887;

U. S. ?

C. 315 . 
*4748. unicolorella Hulst, Ent. Amer., iii, 136, 1887; C. 315 ,

Ont., Wash.

*4749. canescentella Hulst, Trans. Am. Ent. Soc., xvii, 149, 1890; Ragonot, C. 319.

Tex.

\section{SALEBRIA Zeller.}

Zeller, Isis, 733, 1846; 779, 1848; Heinemann, Pyr., 155, 1865; Grote, Bull. Geol. Surv. Terr., iv, 695, 1878; No. Am. Ent., i, 11, 1879; Ragonot, Ent. Mon. Mag., xxii, 19, 1885; Hulst, Trans. Am. Ent. Soc., xvii, 149, 1893; Ragonot, C. 327.

*4750. pumilella Ragonot, Diag. No. Am. Phyc., 8, 1887; C. 344.

4751. nubiferella Ragonot, Diag. No. Am. Phyc., 8, 1887; C. 344 .

*4752. turpidella Ragonot, Mon. Phyc. Gall., i, 346, pl. 13 , f. $24,1893$.

4753. annulosella Ragonot, Diag. No. Am. Phyc., 7, 1887; C. 346.

*4754. tenebrosella Hulst, Ent. Amer., iii, 136, 1887; Ragonot, C. 347.

syn. quercicolella RaGonot.

*4755. delectella Hulst, Can. Ent., xxvii, 57, 1895.

4756. lævigatella Hulst, Can. Ent., xxiv, 61, 1892.

*4757. afflictella Hulst, Can. Ent., xxxii, 170, 1900.

*4758. nigricans Hulst, Can. Ent., xxxii, 171, 1900.

4759. contatella Grote, No. Am. Ent., i, 49, 1880; RAgOnot, C. 348.

Col., Tex.,

N. Mex.,

Ariz.

Tex.,

Col.

Mass.,

Col.

Mass., Tex., Col.

S. C.,

Tex.

Col.

Col.

N. J.

Ariz.

East. U. S., Col., Can.

syn. ?subcrsiella Clemens, Proc. Acad. Sci. Phil., 206, 1860.

a. quinquepunctella Grote, No. Am. Ent., i, 50, 68 , pl. 5, f. 6,1880 ; RA ONOT, C. 348 .

syn. ?virgatella Clemens, Proc. Acad. Sci.

Phil., 206, 1860.

b. inconditella Ragonot, Mon. Phyc. Gall., i, 348, pl. 15 , f. 2, 1893.

4760. celtidella Hulst, Trans. Am. Ent. Soc., xvii, 155, 1890; Ragonot, C. 354.

N. Eng.,

N. Y., Fla.

*4761. pudibundella Ragonot, Mon. Phyc. Gall., i, 350, 1893.

Col.

4762. georgiella Hulst, Can. Ent., xxvii, 57, 1895.

Fla.

*4763. subfuscella Ragonot, Diag. No. Am. Phyc., 8, 1887; C. 351.

*4764. slossonella Hulst, Can. Ent., xxxii, 170, 1900.

Tex.

Fla.

*4765. lacteella Hulst, Can. Ent., xxxii, 171, 1900. 
4766. semiobscurella Hulst, Trans. Am. Ent. Soc., xvii, 151, 1890: Ragonot, C. 352.

4767. basilaris Zeller, Ver. zool.-bot. Ges. Wien, xxii, 548, pl. 3, f. 23, 1872; Grote, No. Am. Ent., i, 51, 1880; RaGonot, C. 353.

*4768. aliculella Hulst, Ent. Amer., iii, 135, 1887; RAgONOT, C. 367.

syn. oberthurella RaGONOT.

*4769. bifasciella Hulst, Ent. Amer., iii, 132, 1887; RAgONOT, C. 366.

*4770. odiosella Hulst, Ent. Amer., iii, 132, 1887; RAGONOT, C. 366.

*4771. carneella Hulst, Ent. Amer., iii, 131, 1887; RAGONOT, C. 367.

*4772. purpurella Hulst, Can. Ent., xxiv, 61, 1892.

\section{PASSADENA Hulst.}

Hulst, Can. Ent., xxxii, 171, 1900.

4773. constantella Hulst, Can. Ent., xxxii, 171, 1900.

\section{MYRLAA Ragonot.}

RAgonot, Mon. Phyc. Gall., i, 394, 1893.

*4774. tarmitalis Hulst, Trans. Am. Ent. Soc., xiii, 163, 1886; Ragonot, C. 401.

4775. delassalis Hulst, Trans. Am. Ent. Soc., xiii, 161, 1886; Ragonot, C. 402.

syn. fernaldi RaGonot.

\section{LAODAMIA Ragonot.}

Ragonot, Nouv. Gén. Spec. Phyc., 22, 1888; Hulst, Trans. Am. Ent. Soc., xvii, 156, 1890; Ragonot, C. 403.

4776. fusca Haworth, Lep. Brit., 493, 1828; WestwOOD \& Humphreys, Brit. Moths, ii, 232, pl. 115, f. 29, 1849; Wallengren, Pyr., 1036, 1859; Grote, No. Am. Ent., i, 11, pl. 2, f. 7, 1879; Möschler, Stett. ent. Zeit., 393, 1880; Ver. zool.-bot. Ges. Wien, 309, 1884; Frey, Lep. Schw., 274, 1880; Ragonot, C. 408.

syn. spadaceella ZnNcken, carbonariella Fischer, posticella Zetterstedt, janthinella DuPONChel, mostella WALKer, undulatella Walker, Cat. Brit. Mus., xxxv, 171i, 1866; cacabella Hulst.

a. frigidella PaCkard, Proc. Bost. Soc. Nat. Hist., 53. 1866; Ragonot, C. 408.
N. Y., Tex., Col.

Mass., Col., Tex.

Ariz.

Ariz.

Tex., Col.

Me.,

Mass.

Ill.

S. C.

Col.

Col., Ariz.,

N. Mex.

Arctic Am., Eur. 


\section{ELASMOPALPUS Blanchard.}

Blanchard, Gay, Hist. Chili, Zool., vii, 104, 1852; Hulst, Trans. Am. Ent. Soc., xvii, 157, 1890; RAgONot, C. 418.

*4777. decoralis Walker, Cat. Brit. Mus., xxvii, 42, U. S. 1863; Ragonot, C. 420.

syn. metagrammalis WALKER, decorellus Hulst, Sm. List Lep. Bor. Am., no. 4341, 1902 .

4778. petrellus Zeller, Isis, 771, 1846; Ragonot, C. 421.

syn. erectalis WALKER, rubiginella WALKER, rufinalis WAIKER, hapsella HuLst, obsipella Hulst.

*4779. floridellus Hulst, Trans. Am. Ent. Soc., xvii, 158, 1890; Ragonot, C. 422.

*4780. melanellus Hulst, Trans. Am. Ent. Soc., xvii, 157, 1890; Ragonom, C. 424.

4781. lignosellus Zeller, Isis, 883, 1848; Ragonot, C. 425 .

N. C., Ga., Fla., Tex., Col., So. Am.

Fla., Ariz.

Fla.

Atl. States, So. Am.

syn. angustellus Blanchard.

a. incautellus Zeller, Verh. zool.-bot. Ges.

Wien, xxii, 544, 1872; Ragonot, C. 425.

b. tartarellus Zeller, Verh. zool.-bot. Ges.

Wien, xxii, 544, 1872; Ragonot, C. 425.

syn. carbonellus HuLst.

\section{SELAGIA Hübner.}

HüBner, Verz. bek. Schmett., 371, 1818; Zeller, Isis, 732, 1846; 752, 1848; Heișemann, Pyr., 153, 1865; Ragonot, Ent. Mon. Mag., xxii, 19, 1885; Hulst, Trans. Am. Ent. Soc., xvii, 159, 1890; Ragonot, C. 467.

*4782. australella Hulst, Can. Ent., xxxii, 174, 1900.

Tex.

*4783. lithosella Ragonot, Diag. No. Am. Phyc., 9, 1887; C. 474.

Ariz.

\section{PYLA Grote.}

Grote, Check List, 55, 66, 1882; Pap., i, 18, 1881; Ragonot, Diag. No. Am. Phyc., 9, 1887; Hulst, Trans. Am. Ent. Soc., xvii, 161, 1890; Ragonot, C. 481.

4784. scintillans Grote, Pap., i. 18, 1881; Ragonot, C. 482 .

Cal.,

Nev.

*4785. metalicella Hulst, Can. Ent., xxvii, 54, 1895.

Col.

*4786. bistriatella Hulst, Can. Ent., xxvii, 54, 1895.

Cal.

*4787. incorruscella Hulst, Can. Ent., xxvii, 55, 1895 Col.

*4788. æneella Hulst, Can. Ent., xxvii, 55, 1895 Col.

*4789. æneoviridella Ragonot, Diag. No. Am. Phyc., 8, N. Y. 1887; C. 482. 
ANORISTIA Ragonot.

Ragonot, Ann. Soc. Ent. Fr., 236, 1887; C. 486.

*4790. olivella Hulst, Ent. Am., iv, 117, 1888; RAGONOT, C. 487.

EPISCHNIA Hiibner.

HüBner, Verz. bek. Schmett., 370, 1818; Zeller, Isis, 178, 1839; 585, 644, 737, 1848;

Herrich-Schaeffer, Eur. Sehm., iv, 89, 1849; Heinemann, Pyr., 171, 1865; MeyRick, Proe. Linn. Soc. N. S. Wales, iv, 229, 1879; Ragonot, Ent. Mon. Mag., xxii, 19, 1885; Hulst, Trans. Am. Ent. Soc., xvii, 162, 1890; Ragonot, C. 493; Pima

Hulst, Ent. Amer., iv, 114, 1888; Trans. Am. Ent. Soc., xvii, 164, 1890.

*4791. ruderella Ragonot, Diag. No. Am. Phyc., 9, 1887; C. 514 .

Cal.

*4792. albiplagiatella PACkard, Ann. N. Y. Lyc. Nat. Hist., x, 269, 1873; Ragonot, C. 518.

syn. fosterella Hulst.

4793. boisduvaliella Guenée, Ann. Soc. Ent. Fr., 318, 1845; Ragonot, C. 518.

syn. farrella Curtis, Ann. Soc. Nat. Hist., iv, 114. 1850; Ragonot, C. 518; lafauryella Comstock, leucoloma SNeLlen.

a. tabulella Ragonot, Mon. Phyc. Gall., 519, 1893.

*4794. albocostalis Hulst, Trans. Am. Ent. Soc., xiii, 164, 1886; Ragonot, C. 519.

Cal.

*4795. subcostella Ragonot, Diag. No. Am. Phyc., 10, 1887: C. 520.

*4796. fulvirugella Ragonot, Diag. No. Am. Phyc., 10, 1887; C. 521.

Col.

Mass.

Mont., Col.,

Tex., Cal.

*4797. incanella Hulst, Can. Ent., xxvii, 56, 1895.

Utah.

*4798. granitella Ragonot, Diag. No. Am. Phye., 9, 1887; C. 523.

Col., Cal.

Col.

Col.,

Cal.

GETULiA Ragonot.

*4799. flavidorsella Ragonot, Diag. No. Am. Phyc., 9, 1887; C. 528.

Ariz., Mex.

MEGASIS Guenée.

Guenée, Ann. Soc. Ent. Fr., 309, 1845; Heinemann, Pyr., 170, 1865; Hulst, Trans. Am. Ent. Soc., xvii, 164, 1890; Ragonot, C. 537.

*4800. edwardsialis Hulst, Trans. Am. Eñt. Soc., xiii, 163, 1886; Ragonot, C. 545.

Cal., Nev., Col. syn. polyphemella Ragonot.

*4801. excantalis Hulst, Trans. Am. Ent. Soc., xiii, Cal. 1886 ; C. 547.

syn. pullatella Ragonot. 
4802. atrella Hulst, Trans. Am. Ent. Soc., xvii, 166, Col. 1890: Ragonot, C. 548.

4803. cinctella Hulst, Can. Ent., xxxii, 172, 1900.

Cal.

\section{LIPOGRAPHIS Ragonot.}

Ragonot, Diag. No. Am. Phyc., 10, 1887; Hulst, Trans. Am. Ent. Soc., xvii, 166,1890; RAGONOT, C. 562.

*4804. humilis Ragonot, Diag. No. Am. Phyc., 11, Cal. 1887; C. 563.

*4805. fenestrella Packard, Ann. N. Y. Lyc. Nat. Hist.. x, 259, 1873: Ragonot, C. 564 .

*4806. leoninella PaCkard, Ann. N. Y. Lyc. Nat. Hist. x, 259, 1873; Ragonot, C. 565 .

Cal.

Cal., Col., Nebr.

\section{ETIELLA Zeller.}

Zeller, Isis, 179, 1839; 733, 1846; Heinemann, Pyr., 154, 1865; Meyrick, Proc. Linn. Soc. N. S. Wales, iii, 203, 1878; vii, 156, 1882; Hulst, Trans. Am. Ent. Soc., xvii, 169, 1890; Ragonot, C. 569; Ramphodes Guenée, Ann. Soc. Ent. France, 319, 1845; Zeller, Hor. Soc. Ent. Ross., xvi, 177, 1880; Mella Walker, Cat. Brit. Mus., xix, 1017, 1859; Asara Walker, Cat. Brit. Mus., xxvii, 79, 1863; Modiana Walker, Cat. Brit. Mus., xxvii, 83, 1863; Alata Walker, Cat. Brit. Mus., xxvii, 108, 1863; Aruche W Alker, Cat. Brit. Mus., xxvii, 201, 1863.

4807. zinckenella Treitschke, Schm. Eur., ix, 1, 201, 1832; Staudinger \& Rebel, Cat. Lep. Eur.,

Can., U. S., Eur.

ii, no. 510, 1901; Ragonot, C. 572.

syn. etiella Treitschke, majorella Costa, colonellus COSTA, dymnusalis WALKER, albocostalis WALKER, scittivitalis WALKER, anticalis WALKER, indicatalis WALKER, hastiferella WALKER, heraldella GuEnÉE, madagascariensis SAALMÜLLER, sabulinus Butler, spartiella Bond.

*4808. schisticolor Zeller, Hor. Soc. Ent. Ross., xvi, 178, 1881; Ragonot, C. 574.

Cal., Col., Ariz.

syn. villosella Hulst.

*4809. rubribasella Hulst, Trans. Am. Ent. Soc., xvii 170, 1890; Ragonot, C. 572.

Fla.,

Col.

\section{HYPOCHALCIA Hübner.}

HüBner, Verz. bek. Schmett., 367, 1818; Zeller, Isis, 585, 1848; Herrich-Schaeffer, Eur. Schm., iv, 85, 1849; Heinemann, Pyr., 165, 1865; Ragonot, Ent. Mon. Mag., xxii, 18, 1885; Hulst, Trans. Am. Ent. Soc., xvii, 168, 1890; Ragonot, C. 578.

*4810. hulstiella Ragonot, Diag. No. Am. Phyc., ii, Tex. 1887; C. 603.

\section{SARATA Ragonot.}

Ragonot, Diag. No. Am. Phyc., 11, 1887; C. 614.

*4811. nigrofasciella Ragonot, Diag. No. Am. Phyc., 11, 1887; C. 615 . 
*4812. tephrella RaGonot, C. $616,1893$.

Wash.

*4813. perfuscalis Hulst, Trans. Am. Ent. Soc., xiii,161,

Cal.

1886; Ragonot, C. 616.

syn. dnoposella Ragonot.

*4914. cinereella Hulst, Can. Ent., xxxii, 172, 1900.

Col.

\section{MELITARA Walker.}

Walker, Cat. Brit. Mus., xxvii, 136, 1863; Hulst. Trans. Am. Ent. Soc., xvii, 171, 1890; Megaphycis Grote, Can. Ent., xiv, 29, 1882.

4816. prodenialis WALKER, Cat. Brit. Mus., xxvii, 137 , 1863; Hulst, Trans. Am. Ent. Soc., xvii, 171, 1890 .

Fla., Tex., Col., W. I.

syn. bollii Zeller. Verh. zool.-bot. Ges. Wien, 550, pl. 3, f. 21, 1872; Grote, Can. Ent., xiv, 29, 1882; Snellen, Tidsk. Ent., xxx, 64, pl. 5, f. 64, 6, 6a, 1886.

4817. dentata Grote, Can. Ent.,viii, 158, 1876; xiv, 29, 1882; Hulst, Trans. Am. Ent. Soc., xvii, 172, 1890; Kellogg, Kans. Univ. Quar., i, 40, pl. 8, 1892.

4818. junctolineella Hulst, Can. Ent., xxxii, 173, 1900.

4819. fernaldialis Hulst, Trans. Am. Ent. Soc., xiii, 163, 1886; xvii, 172, 1890.

Col.

Tex., Col.

Ariz.

Mex.

\section{YOSEMETIA Ragonot.}

New generic name proposed by Ragonot in manuscript for graciella Hulst.

4820. graciella Hulst, Ent. Amer., iii, 134, 1887; Trans. Am. Ent. Soc., xvii, 173, 1890.

a. longipennella Hulst, Ent. Amer., iv, 117, 1888.

\section{ZOPHODIA Hübner.}

HüBner, Verz. bek. Schmett., 370, 1818; Zeller, Isis, 176, 1839; 679, 1848; Herrich-Schaeffer, Eur. Schm., iv, 90, 1849; Heinemann, Pyr., 189, 1865; Merrick, Trans. Linn. Soc. N. S. Wales, vii, 156, 1882; Ragonot, Ent. Mon. Mag., xxii, 19, 1885; Hulst, Trans. Am. Ent. Soc., xvii, 172, 1890; Dakruma Grote, Bull. Geol. Surv. Terr., iv, 702, 1878; No. Am. Ent., i, 11, 1879; Pap., i, 152, 1882; Riley, Pap., i, 108, 1882 .

4821. grossulariæ RILey, Rept. Ins. Mo., i, 140, 1869; Pap., i, 108, 1881; Packard, Guide Stud. Ins., 331, 1869; French, Rept. Dept. Agr. Ill., vii, 251, 1877; Grote, No. Am. Ent., i, 11, pl. 2, f. 12, 1880; i, 68, 1880; Pap., i, 142, 1881; Hulst, Trans. Am. Ent. Soc., xvii, 173, 1890.

syn. turbitella Grote, Bull. Geol. Surv. Terr., iv, 702, 703, 1878.

*4822. dilatifasciella Ragonot, Diag. No. Am. Phyc., 13, 1887; Hulst, Trans. Am. Ent. Soc., xvii, 174,1890 .

N.-E.

U. S.,

Can.

Ariz. , Mex. 
*4823. packardella Ragonot, Diag. No. Am. Phyc., 12, 1887: Hulst, Trans. Am. Ent. Soc., xvii, 173, 1890.

4824, glaucatella Hulst, Ent. Amer., iv, 117, 1888; Trans. Am. Ent. Soc., xvii, 174, 1890.

Tex., N. Mex.

4825. bella Hulst, Can. Ent., xxiv, 61, 1892. 4826. fuscatella Hulst, Can. Ent., xxxii, 173, 1900. Mass. Cal. 4827. epischnioides Hulst, Can. Ent., xxxii, 173, 1900.

N. Mex.

\section{ECCOPSIA Ragonot.}

New generic name proposed by Ragonot in manuscript for serratilineella RAGonot.

4828. serratilineella Ragnot, Diag. No. Am. Phyc., Cal. 15, 1887; Hulst, Trans. Am. Ent. Soc. xvii, 179,1890 .

\section{EUZOPHERA Zeller.}

Zeller, Stett. ent. Zeit., xxviii, 377, 1867; Ragonot, Ent. Mon. Mag., xxii, 30, 1885;

MeYrick, Proc. Linn. Soc. N. S. Wales, iv, 239, 1879; vii, 156, 1882; Hulst, Trans.

An. Ent. Soc., xvii, 174, 1890; Stenoptycha Zeller (not Agassiz), Stett. ent. Zeit.,

154, 1863; Heinemann, Pyr., 190, 1865; Melia Heinemann (not Billberg), Pyr., 209,1865 .

*4829. ostricolorella Hulst, Trans. Am. Ent. Soc., xvii, 175,1890 .

4830. nigricantella Ragonot, Diag. No. Am. Phyc., 14, 1887; Hulst, Trans. Am. Ent. Soc., xvii, 177,1890 .

*4831. franconiella Hulst, Trans. Am. Ent. Soc., xvii, $177,1890$.

4832. semifuneralis Walker, Cat. Brit. Mus., xxvii, 57, 1863; Hulst, Trans. Am. Ent. Soc., xvii, 175,1890 .

syn. impletella Zeluer, Hor. Soc. Ent. Ross., xvi, 234, pl. 12, f. 37, 1881; pallulella Hulst, Trans. Am. Ent. Soc., xvii, 175, 1890.

*4833. æglæella Ragonot, Diag. No. Am. Phyc., 14, 1887; Hulst, Trans. Am. Ent. Soc., xvii, 177, 1890 .

N. Y.

Ariz.

N. H.

U. S.

syn. aglæella Hutst, Sm. List Lep. Bor. Am., no. $4379,1891$.

*4834. inornatella Hulst, Can. Ent., xxxii, 173, 1900.

N. J.

4835. ochrifrontella Zeller, Verh. zool--bot. Ges. Wien, 337, 1875; Hulst, Trans. Am. Ent. Soc., 177,1890 .

Utah.

syn. ferruginella Ragonot, Diag. No. Am. Phyc., 14, 1887.

East. U. S., Tex. 


\section{SENECA Hulst.}

Hulst, Trans. Am. Ent. Soc., xvii, 177, 1890.

*4836. tumidulella Ragonot, Diag. No. Am. Phyc., 13, 1887; Hulst, Trans. Am. Ent. Soc., xvii, 178, 1890.

\section{VITULA Ragonot.}

Ragonot, Diag. No. Am. Phyc., 14, 1887; Hulst, Trans. Am. Ent. Soc., xvii, 178, 1890.

4838. edmandsii Packard, Proc. Essex Inst., iv, 120, 1864; Guide Stud. Ins., 331, pl. 3, f. 2, 1869; East. U. S., Hulst, Ent. Amer., v, 156, 1889; Trans. Am. Tex. Ent. Soc., xvii, $178,1890$.

syn. dentosella Ragonot, Diag. No. Am. Phyc., $14,1887$.

4839. basimaculella Ragonot, Diag. No. Am. Phyc., 15, 1887; Hulst, Trans. Am. Ent. Soc., xvii, Fla. $179,1890$.

\section{LAOSTICHA Ragonot.}

New generic name proposed by Ragonot in manuscript for ephestiella RAGONOT.

*4841. ephestiella Ragonot, Diag. No. Am. Phyc., 13, Ariz. 1887; Hulst, Trans. Am. Ent. Soc., xvii, 185, 1890 .

\section{LATILIA Ragonot.}

Ragonot, Ann. Soc. Ent. Fr., Séances, Jan. 8, p. viii, 1890; Hulst, Trans. Am. Ent. Soc., xvii, $182,1890$.

4842. coccidivora Comstock, No. Am. Ent., i, 25, pl. 4, 1879; Rept. U. S. Dept. Agr., 241, 1880; Packard, Ins. Inj. to Shade Trees, 54, 1881; Hulst, Trans. Am. Ent. Soc., xvii, 182, 1890. syn. pallida Constock, Rept. U. S. Dept. Agr., 243, 1880.

a. hulstii Cockerell, Am. Nat., xxxi, 588, 1897.
East. U. S., Tex., N. Mex., Ariz.

N. Mex.

\section{CANARSIA Hulst.}

Hulst, Trans. Am. Ent. Soc., xvii, 179, 1880.

4843. ulmiarrosorella Clemens, Proc. Acad. Sci. Phil., 205, 1860; Grote, Bull. Geol. Surv. Terr., iv, 698, 1878; Hulst, Trans. Am. Ent. Soc., xvii,

East. U. S., Tex., Ont. $180,1890$.

syn. pneumatella Hulst, Ent. Amer., iii, 137, 1887; ulmella Ragonot, Diag. No. Am. Phyc., 13, 1887; fuscatella Hulst, Ent. Amer., iv, 118, 1888.

*4844. gracilella Hulst, Can. Ent., xxxii, 174, 1900. 
4845. hammondi Riley, Rept. Ins. Mo., iv, 46, f. 21, 1872; Index Repts. Ins. Mo., 80, 1881; French, Rept. Dept. Agr. Ill., xv, 252, 1877; Hulst, Trans. Am. Ent. Soc., xvii, 181, 1890.

\section{STAUDINGERIA Ragonot.}

Ragonot, Ann. Soc. Ent. Fr., 249, 1887; Hulst, Trans. Am. Ent. Soc., xvii, 185, 1890.

4846. albipennella Hulst, Ent. Amer., iii, 133, 1887;

Trans. Am. Ent. Soc., xvii, 186, 1890.

Cal.,

Ariz.

\section{HETEROGRAPHIS Ragonot.}

Ragonot, Ent. Mon. Mag., xxii, 31, 1885; Hulst, Trans. Am. Ent. Soc., xvii, 186, 1890; Mona Hulst, Ent. Amer., iv, 115, 1888.

4847. morrisonella Ragonot, Diag. No. Am. Phyc., 11, 1887; Hulst, Trans. Am. Ent. Soc., xvii, 186, 1890 .

Tex., Col.,

N. Mex.,

Ariz.

a. coloradensis Ragonot, Diag. No. Am. Phyc., 12, 1887; Hulst, Trans. Am. Ent. Soc., xvii, $186,1890$.

b. olbiella Hulst, Ent. Amer., iv, 116, 1888; Trans. Am. Ent. Soc., xvii, 186, 1890.

4848. arizonella Hulst, Jn. N. Y. Ent. Soc., viii, 222, 1901.

Ariz.

\section{HULSTEA Ragonot.}

New generic name proposed by Ragonot in manuscript for undulatella Clemens.

*4849. undulatella Clemens, Proc. Acad. Sci. Phil., 205, 1860; Grote, Bull. Geol. Surv. Terr., iv, 698, 1878; PACKARD, Ins. Inj. to Shade Trees, 69, 1881; Hulst, Trans. Am. Ent. Soc., xvii, U. S., Ont., Queb. 187,1890 .

syn. propriella Walker, Cat. Brit. Mus., xxxv, 1716, 1866.

*4850. texanella Hulst, Can. Ent., xxxii, 174, 1900.

Tex.

\section{HONORA Grote.}

Grote, Bull. Geol. Surv. Terr., iv, 702, 1878; No. Am. Ent., i, 11, 1879; Hulst, Trans. Am. Ent. Soc., xvii, 187, 1890.

4851. mellinella Grote, Bull. Geol. Surv. Terr., iv, 702, 1878; No. Am. Ent., i, 11, pl. 2, f. 11, 1879; Hulst, Trans. Am. Ent. Soc., xvii, 188, 1890.

Tex., Col., N. Mex., Cal.

syn. ochrimaculella Ragonot, Diag. No. Am. Phyc., 12, 1887; Hulst, Trans. Am. Ent. Soc. xvii, $189,1890$.

*4852. sciurella Ragonot, Diag. No. Amı. Phyc., 12, 1887; Hulst, Trans. Am. Ent. Soc., xvii, 189, 1890 . 
*4853. subsciurella Ragonot, Diag. No. Am. Phyc.,

Col.

12, 1887; Hulst, Trans. Am. Ent. Soc., xvii, $189,1890$.

4854. luteella Hulst, Jn. N. Y. Ent. Soc., viii, 223,

Ariz. 1901.

4855. cinerella Hulst, Jn. N. Y. Ent. Soc., viii, 223,

Ariz. 1901.

4856. dulciella Hulst, Jn. N. Y. Ent. Soc., viii, 223, Fla. 1901.

*4857. montinatatella Hulst, Ent. Amer., iii, 134. 1887; v, 156, 1889; Trans. Am. Ent. Soc., xvii, 189, Cal., Nev. 1890.

syn. canicostella Ragonot, Diag. No. Am. Phyc., 12, 1887.

*4858. fumosella Hulst, Can. Ent., xxxii, 174, 1900.

N. J.

\section{DOLICHORHIN:A Ragonot.}

Ragonot, Nouv. Gén. Spec. Phyc., 28, 1888; Hulst, Trans. Am. Ent. Soc., xvii, 190, 1890; Macrorrhinia Ragonot (not Macrorhimes Latreille), Diag. No. Am. Phyc, $13,1887$.

4859. aureofasciella RAgonot, Diag. No. Am. Phyc., 13, 1887; Hulst, Trans. Am. Ent. Soc., xvii, 190,1890 .

Tex., Cal.

Ariz.

Col.

DIVIANA Ragonot.

Ragonot, Nouv. Gén. Spec. Phyc., 27, 1888; Hulst, Trans. Am. Ent. Soc., xvii, $190,1890$.

*4860. eudoriella Ragonot, Nouv. Gén. Spec. Phyc., N. C. 27, 1888; C. pl. 23, f. 12, 1893; Hulst, Trans. Am. Ent. Soc., xvii, 190, 1890.

OCALA Hulst.

Hulst, Can. Ent., xxiv, 61, 1892.

*4861. dryadella Hulst, Can. Ent., xxiv, 61, 1892.

Fla.

PALATKA Hulst.

Hulst, Can. Ent., xxiv, 62, 1892.

*4862. nymphæella Hulst, Can. Ent., xxiv, 62, 1892.

Fla.

\section{EURYTHMIDIA Ragonot.}

New generic name proposed by Ragonot in manuscript for ignidorsella RAGONOT. *4863. igniàorsella Ragonot, Diag. No. Am. Phyc., 16, Ariz. 1887; Hulst, Trans. Am. Ent. Soc., xvii, 196, 1890 . $4630-$ No. $52-02-28$ 


\section{HOMFOSOMA Curtis.}

Curtis, Brit. Ent., iv, 311, 1834; Stephens, Ills., iv, 311, 1834; Zeller, Isis, 585, 599, 1848; Hor. Soc. Ent. Ross., xvi, 237, 1881; Westwood \& Humphreys, Brit. Moths, ii, 233, 1849; Herrich-Schaeffer, Eur. Schm., iv, 103, 1849; Heinemann, Pyr., 196, 1865; Grote, Bull. Geol. Surv. Terr., iv, 703, 1878; No. Am. Ent., i, 12, 1879; Meyrick, Proc. Linn. Soc. N. S. Wales, iii, 214, 1878; vii, 159, 1882; Ragonot, Ent. Mon. Mag., xxii, 26, 1885; Hulst, Trans. Am. Ent. Soc., xvii, 191, 1890; Phycidea ZeLLer, Isis, 178, 1839; Lotria Guenée, Ann. Soc. Ent. Fr., 320, 1845.

4864. impressale Hulst, Trans. Am. Ent. Soc., xiii, 163, 1886; xvii, 191, 1890.

4865. electellum Hulst, Ent. Amer., iii, 137, 1887; Trans. Am. Ent. Soc., xvii, 193, 1890.

syn. texanellum Ragonot, Diag. No. Am. Phyc., 15, 1887.

*4866. opalescellum Hulst, Ent. Amer., iii, 138, 1887; Trans. Am. Ent. Soc., xvii, 192, 1890.

syn. temiipunctellum Ragonot, Diag. No. Am. Phyc., 15, 1887.

4867. illuvellum Ragonot, Nouv. Gén. Spec. Phyc., 33. 1888; Hulst, Ent. Amer., v, 155, 1889; Trans. Am. Ent. Soc., xvii, 192, 1890.

syn. candidellum Hulst, Ent. Amer., iv, 118, 1888.

4868. uncanale Hulst, Trans. Am. Ent. Soc., xiii, 162, 1886; xvii, 192, 1890.

*4869. albiscentellum Ragonot, Diag. No. Am. Phyc., 15, 1887; Hulst, Trans. Am. Ent. Soc., xvii, 192,1890 .

4870. stypicellum Grote, Bull. Geol. Surv. Terr., iv, 703, 1878; No. Am. Ent., i, 12, pl. 2, f. 13, 1879; Hulst, Trans. Am. Ent. Soc., xvii, 193, 1890.

4871. mucidellum Ragonot, Diag. No. Am. Phyc., 15, 1887; Hulst, Trans. Am. Ent. Soc., xvii, 193. 1890.

*4872. anguliferellum Ragonot, Diag. No. Am. Phyc., 16, 1887; Hulst, Trans. Am. Ent. Soc., xvii, 192,1890 .
Cal.,

Ariz.

Tex., Iowa, N. Mex., Col.

Tex., Cal.

Col., Ariz. , Mex.

Fla., Col., Nev.

Cal.

N.-E. U. S., Tex.

Tex., Col., N. Mex. Cal. No. Am.

\section{EPHESTIA Guenée.}

Guenée, Ann. Soc. Ent. Fr., 319, 1845; Zeller, Isis, 588, 592, 1848; HerrichSchaeffer, Eur. Schm., iv, 110, 1849; Heinemann, Pyr., 201, 1865; Meyrick, Proc. Linn. Soc. N. S. Wales, iii, 215, 1878; iv, 234, 1879; vii, 160, 1882; Hulst, Trans. Am. Ent. Soc., xvii, 197, 1890.

4873. fuscofasciella Ragonot, Diag. No. Am. Phyc., Mo., Tex., 17, 1887; Hulst, Trans. Am. Ent. Soc., xvii, 198, Col., N. Mex. 1890 : 
4874. kuehniella Zeller, Stett. ent. Zeit., 476, 1879; SNellen, Tidsk. Ent., xxviii, 237, pl. 8, 1885; Thompson, Ent., xx, 66, 1887; Barrett, Ent., xxiii, 255, 1887; Rnley, Ins. Life, i, 315, 1888; ii, 166,1889 ; v, 141, 276, 1892; vi, 44, 290, 1893; Onerod, Ins. Life, i, 314, 1889; Fletcher. Ins. Life, ii, 187, 1889; Can. Ent., xxii, 41, 1890; Bell, Am. Nat., 200, 1890; Hulst, Trans. Am. Ent. Soc., xvii, 198, 1890; Danyoz, Mem. Lab. Par. Veg., 1, 1893; Howard, Ins. Life, vii, 417, 1895; Johnson, Rep. Ent. Ill., xix, app., 1896; Chittenden, Dept. Agr., Farm. Bull., 45, 8, f. 4, 5, 1896; Ragonot, C., pl. 2, f. 19, 1893; Staudinger \& Rebel, Cat. Lep. Eur., ii, no. $254,1901$.

syn. gitonella Druce; ?sericariumiscotT, Proc.

Zool. Soc. Lond., 207, 1859.

*4875. cautella WaLker, Cat. Brit. Mus., xxvii, 73, 1863; Staudinger \& Rebel, Cat. Lep. Eur., ii, no. 271. 1901.

syn. cahiritella Zeller, passulella Barr, desuetella WALKER.

*4876. figulilella Gregson, Ent., v, 385, 1865; STAUDinger \& Rebel, Cat. Lep. Eur., ii, no. 258, 1901 .

syn. ficulella BARRETT, milleri ZELLER.

4877. rileyella Ragonot, Diag. No. Am. Phyc., 17, 1887; Hulst, Trans. Am. Ent. Soc., xvii, 198, 1890.

4878. nigrella Hulst, Trans. Am. Ent. Soc., xvii, 200, 1890.

4879. elutella HüBNER, Eur. Schm., pl. 24, 163, 1820; Zincken, Germ. Mag., iii, 175, 1818; Treitschke, Schm. Eur., ix, 1, 194, 1832; Duponcher, Hist. Nat., x, 279, 1836; Stephens, Ills., iv, 304, 1834; Wood, Ind. Ent., 1454, 1839; Zeller, Isis, 592 , 1848; Herrich-Schaeffer, Eur. Schm. . iv, 110, 1849; Westwood \& Humphreys, Brit. Moths, ii, 229, pl. 115, f. 7, 1849; Heinemann, Pyr., 201, 1865; Morris, Brit. Moths, iii, pl. 79, f. 18, 1872; Meyrick, Proc. Linn. Soc. N. S. Wales, iii, 215, 1878; Trans. Ent. Soc. Lond., 261, 1887; Zeller, Verh. zool. -bot.Ges. Wien, 338,1876; Möschler, Stett. ent. Zeit., 393, 1880; Verh. zool. -bot. Ges. Wien, 310, 1884; Wallengren, Skand. Pyr., 1053, 1872; Snellen, Vlind. Neth., ii, 1, 162, 1882; Frey, Lep. Schw., 279, 1880; Christoph, Hor. Soc. Ent. Ross., xii, 224, 1876; Hulst, Trans. Am. Ent. Soc. xvii, 200, 1890; Ragonot, C., pl. 2, f. 20, 1893; Staudinger \& Rebel, Cat. Lep. Eur. ii, no. 283, 1901.

syn. mefa Haworth, elutea Haworth, angusta HAWORTH. 
EPHESTIODES Ragonot.

Ragonot, Diag. No. Am. Phyc., 16, 1887; Hulst, Trans. Am. Ent. Soc., xvii, 194, 1890 4880. gilvescentella Ragonot, Diag. No. Am. Phyc., 16, 1887; Hulst, Trans. Am. Ent. Soc., xvii, $194,1890$.

4881. infimella Ragonot, Diag. No. Am. Phyc., 16, 1887; Hulst, Trans. Am. Ent. Sor., xvii, 194, Cal., Ariz. 1890 .

4882. nigrella Hulst, Journ. N. Y. Ent. Soc., viii, $224,1901$.

*4883. erythrella Ragonot, Diag. No. Am. Phyc., 16, 1887; Hulst, Trans. Am. Ent. Soc., xvii, 195, 1890 .

EURYTHMIA Ragonot.

Ragonot, Diag. No. Am. Phyc., 16, 1887; Hulst, Trans. Am. Ent. Soc., xvii, 195, 1890.

4884. hospitella Zelcer, Verh. zool.-bot. Ges. Wien, Tex., N. Mex., xxii, 338, 1872; Hulst, Trans. Am. Ent. Soc., Ariz., Col. xvii, 196,1890 .

syn. quantulella Hulst, Ent. Am., iii, 134, 1887.

*4885. coloradella Hulst, Can. Ent., xxxii, 175, 1900.

Cal.

\section{MANHATTA Hulst}

Hulst, Trans. Am. Ent. Soc., xvii, 196, 1890; Hornigia Ragonot (not ${ }^{\alpha}$ ), Diag. No. Am. Phyc., 16, 1887.

4886. ostrinella Clemens, Proc. Acad. Sci. Phil., 206, 1860 . Pa., Tex.

syn. obtusangulella Ragonot, Diag. No. Am. Phyc., 16, 1887; Hulst, Trans. Ent. Soc., xvii, $197,1890$.

\section{MOODNA Hulst.}

Hulst, Trans. Am. Ent. Soc., xvii, 193, 1890.

*4887. lugubrella Ragonot, Diag. No. Am. Phyc., 17, 1887; Hulst, Trans. Am. Ent. Soc., xvii, 197, Cal. 1890 .

4888. pelviculella Hulst, Trans. Am. Ent. Soc., xvii, $194,1890$.

N. Y. Pa.

\section{UNADILLA Hulst.}

Hulst, Trans. Am. Ent. Soc., xvii, 197, 1890.

*4889. erronella Zeller, Hor. Soc. Ent. Ross., xvi, 238, pl. 12, f. 42, 1881.

N. Mex., Cal.

syn. nasutella Hulst, Trans. Am. Ent. Soc., xvii, 197, 1890. 


\section{PLODIA Guenée.}

Guenée, Ann. Soc. Ent. Fr., 322, 1845; Heinemann, Pyr., 202, 1865; Ragonot, Ent. Mon. Mag., xxii, 25, 1885; Hulst, Trans. Am. Ent. Soc., xvii, 200, 1890.

4890. interpunctella HübNER, Eur. Schm., 310, 1827;

Treitschke, Schm. Eur., ix, 1, 106, 1832;

U. S.,

Duponchel, Hist. Nat., x, 280, 5, 1834; Suppl.,

iv, 121 , pl. 60, f. 6, 1842; Zeller, Isis, 598, 1848;

Herrich-SchaffFer, Eur. Schm., iv, 110, 1855;

Stainton, Man., ii, 169, 1859; Heinemann,

Pyr., 202, 1865; Zeller, Verh. zool.-bot. Ges.

Wien, 336, 1875; Möschler, Verh. zool.-bot.

Ges. Wien, 310, 1884; Snellen, Vlind. Neth.

Micro., i, 163, 1882; Frey, Lep. Schw., 279,

1880; Ragonot, Ent. Mon. Mag., xxii, 25, 1885;

Riley \& Howard, Ins. Life, v, 2, 277, 1890;

Hulst, Trans. Am. Ent. Soc., xvii, 201, 1890;

Stevenson, Rept. Ent. Soc. Ont., xxv, 57, 1894;

Chittenden, U. S. Dept. Agr., Farmers' Bull., xxxix, 9, f. 6, 1897; Staudinger \& Rebel, Cat.

Lep. Eur., ii, no. 253, 1901.

syn. zеæ Fiтch, Rep. Ins. N. Y., 320, pl. 4,

f. 1. 1858; Clemens, Proc. Acad. Sci. Phil.,

206,1860 .

\section{Subfamily ANEIRA.STINAE.}

\section{By George D. Hulst.}

\section{RAGONOTIA Grote.}

Grote, Can. Ent., xxii, 75, 1888; Hulst, Trans. Am. Ent.Soc., xvii, 204, 1890; (it: Ragonot (not Grote), Diag. No. Am. Phyc., 17, 1887.

*4891. dotalis Hulst, Trans. Am. Ent. Soc., xiii, 164, Cal., 1886; xvii, 205, 1890; Ragonot, Mon. Phyc., i, Ariz. pl. 2, f. 22,1890 .

syn. discigerella Ragonot, Diag. No. Am.

Phyc., 17, 1887.

*4892. saganella Hulst, Trans. Am. Ent. Soc., xvii,

Col. $205,1890$.

URULA Hulst.

Hulst, Can. Ent., xxxii, 175, 1900.

$\begin{array}{ll}\text { 4893. incongruella Hulst, Can. Ent., xxxii, 175, 1900. } & \text { Col., } \\ \text { Ariz. }\end{array}$

A URORA Ragonot.

Ragonot, Diag. No. Am. Phyc., 18, 1887; Hulst, Trans. Am. Ent. Soc., xvii, 209, 1890. *4894. longipalpella Ragonot, Diag. No. Am. Phyc., No. Am. 18, 188:; Hulst, Trans. Am. Ent. Soc., xvii, 210,1890 . 
4895. nigrocinereella Hulst, Can. Ent., xxxii, 176, Tex. 1900 .

4896. nigromaculella Hulst, Journ. N. Y. Ent. Soc., Ariz. viii, $224,1901$.

ALTOONA Hulst.

Hutst, Ent. Amer., iv, 116, 1888; Trans. Am. Ent. Soc., xvii, 206, 1890. * 4897. opacella Hulst, Ent. Amer., iii, 138, 18s7; Trans. Am. Ent. Soc., xvii, $207,1890$.

Tex.

\section{ATASCOSA Hulst.}

Hulst, Trans. Am. Ent. Soe., xvii, 210, 1890.

*4898. glareosella Zelcer, Verh. zool.-bot. Ges. Wien, 553, 1872; Hulst, Trans. Am. Ent. Soc., xvii, Tex. 211,1890 .

syn. bicolorella Hulst, Trans. Am. Ent. Soc., xvii, $210,1890$.

*4899. floscella Hulst, Trans. Am. Ent. Soc., xvii, 210, 1890.

\section{CA YUGA Hulst.}

Hurst, Ent. Amer., iv, 116, 1888; Trans. Am. Ent. Soc., xvii, 208, 1890.

4900. gemmatella Hulst, Ent. Amer., iii, 134, 1887; Ill., Col., Trans. Am. Ent. Soc., xvii, 209, 1890. Cal.

a. bistriatella Hulst, Trans. Am. Ent. Soc., xvii, 209,1890 .

MARICOPA Hulst.

Hulst, Trans. Am. Ent. Soc. xvii, 205, 1890.

*4901. lativittella Ragonot, Diag. No. Am. Phyc., 18, 1887; Hulst, Trans. Am. Ent. Soc., xvii, 206, 1890 .

*4902. albocostella Hulst, Can. Ent., xxxii, 176, 1900.

Ariz.

Tex.

\section{TRIVOLUSIA Dyar.}

Volusia Hulst (not Desvoiny), Trans. Am. Ent. Soc., xvii, 206, 1890.-H. G. Dyar.

*4903. roseopennella Hulst, Trans. Am. Ent. Soc., xvii, $206,1890$.

*4903. 1. pallidipennata Hulst, Can. Ent., xxvii, 56, Col. 1895.

\section{SALURIA Ragonot.}

Ragonot, Ann. Soc. Ent. Fr., 258, 1887; Hulst, Trans. Am. Ent. Soc., xvii, 211, 1890

*4904. ostreella Ragonot, Diag. No. Am. Phyc., 18,

Ariz. 1887; Hulst, Trans. Am. Ent. Soc., xvii, 211, 1890. 
*4905. tetradella Zeller, Verh. zool.-bot. Ges. Wien, 552, 1872; Hulst, Trans. Ent. Soc., xvii, 207, Tex., 1890.

*4906. rostrella Ragonot, Diag. No. Am. Phyc., 18, 1887: Mon. Phyc., i, pl. 1, f. 3, 1893; Hulst, Trans. Am. Ent. Soc., xvii, 211, 1890.

*4907. dichrocella Ragonot, Ent. Amer., v, 113, 1889; Hulst, Trans. Am. Ent. Soc., xvii, $207,1890$.

Cal.

4908. ardiferella Hulst, Ent. Amer., iv, 11s, 1888; Trans. Am. Ent. Soc., xvii, 208, 1890.

\section{MARTIA Ragonot.}

Ragonot, Diag. No. Am. Phyc., 18, 1887; Hulst, Trans. Am. Ent. Soc., xviii, 209, 1890. *4909. arizonella Ragonot, Diag. No. Am. Phyc., 18, Ariz. 1887: Hulst, Trans. Am. Ent. Soc., xvii, 209, 1890 .

\section{NAVASOTA Ragonot.}

Ragonot, Diag. No. Am. Phyc., 18, 1887; Hulst, Trans. Am. Ent. Soc., xvii, 212, 1890. *4910. hebetella Ragonot, Diag. No. Am. Phyc., 18, 1887; Hulst, Trans. Am. Ent. Soc., xvii, 212, 1890 .

Tex.

\section{PEORIA Ragonot.}

Ragonot, Diag. No. Am. Phyc., 19, 1887; Hulst, Trans. Am. Ent. Soc., xvii, 213, 1890.

4911. approximella Walker, Cat. Brit. Mus., xxxv, $1722,1866$.

syn. hrmatica Zeller, Verh. zool.-bot. Ges. Wien, 555, 1872; Hulst, Trans. Am. Ent. Soc., xvii, 218, 1890; roseatella PACKARD, Ann. N. Y. Lyc. Nat. Hist., x, 270, 1873; Grote, Bull. Geol. Surv. Terr., iv, 704, 1878; No. Am. Ent., i, 12, pl. ii, f. 14, 1879.

4912. bipartitella Ragonot, Diag. No. Am. Phyc., 19, 1887; Hulst, Trans. Am. Ent. Soc., xvii, 214, 1890 .

*4913. albidella Hulst, Can. Ent., xxxiii, 175, 1900. Tex., Col., Ont.

\section{HYPSOTROPA Zeller.}

Zeller, Isis, 591, 1848; Heinemann, Pyr., 200, 1865; Hulst, Trans. Am. Ent. Soc., xvii, $212,1890$.

*4914. luteicostella Ragonot, Diag. No. Am. Phyc., 19, 1887; Hulst, Trans. Am. Ent. Soc., xvii, 212, Fla. 1890 . 


\section{WEKIVA Hulst.}

Hulst, Trans. Am. Ent. Soc, xvii, 215, 1890.

*4915. nodosella Hulst, Trans. Am. Ent. Soc., xvii, $215,1890$.

\section{HOMOSASSA Hulst.}

Hulst, Trans. Am. Ent. Soc., xvii, 214, 1890.

4916. ella Hulst, Ent. Amer., iii, 138, 1887; Trans. Am. Ent. Soc., xvii, 214, 1890.

\section{DANNEMORA Hulst.}

Hulst, Trans. Am. Ent. Soe., xvii, 212, 1890.

*4917. edentella Hulst, Trans. Am. Ent. Soc., xvii, $213,1890$.

Fla.

Fla.

\section{BANDERA Ragonot.}

Ragonot, Diag. No. Am. Phyc., 19, 1887; Hulst, Trans. Am. Ent. Soc., x vii, 202, 1890.

*4918. binotella Zeller, Verh. zool.-bot. Ges. Wien, xvii, 202, 1890.

*4919. cupidinella Hulst, Ent. Amer., iv, 118, 1888; Trans. Am. Ent. Soc., xvii, 203, 1890.

Fla.

\section{xxii, 554, 1872; Hulst, Trans. Am. Ent. Soc.,}

\section{Tex., N. Mex.}

Col.,

N. Mex.

*4920. subluteella Ragonot, Diag. No. Am. Phyc., 19, 1887; Hulst, Trans. Am. Ent. Soc., xvii, 202, 1890 .

\section{TAMPA Ragonot.}

Ragonot, Diag. No. Am. Phyc., 19, 1887; Hulst, Trans. Am. Ent. Soc., xvii, 203, 1890.

4921. dimediatella Ragonot, Diag. No. Am. Phyc., 20, 1887; Hulst, Trans. An. Ent. Soc., xvii, 203,1890 .

Fla.,

Tex.

\section{STATINA Ragonot.}

Ragonot, Diag. No. Am. Phyc., 19, 1887; Hulst, Trans. Am. Ent. Soc., xvii, 216, 1890.

*4922. roseotinctella Ragonot, Diag. No. Am. Phyc., 19, 1887; Hulst, Trans. Am. Ent. Soc., xvii, 216,1890 .

*4923. gaudiella Hulst, Trans. Am. Ent. Soc., xvii, $216,1890$.

\section{PETALUMA Hulst.}

Hulst, Ent. Amer., iv, 116, 1888; Trans. Am. Ent. Soc., xvii, 215, 1890.

4924. illibella Hulst, Ent. Amer., iii, 138, 1887; Trans.

Am. Ent. Soc., xvii, 216, 1890.

Fla.,

Tex.

Cal.

syn. puricostella Ragonot, Diag. No. Am. Phyc., 20, 1887.

4925. inspergella Ragonot, Diag. No. Am. Phyc., 20, 1887; Hulst, Trans. Am. Ent. Soc., xvii, 216, 1890 .

Tex., Col., Ariz. 


\section{CALERA Ragonot.}

Ragonot, Nouv. Gén. Spec. Phyc., 50, 1888; Hulst, Trans. Am. Ent. Soc., xvii, 217, 1890.

*4926. punctilimbella Ragonot, Nouv. Gén. Spec. Phyc., 50, 1888; Hulst, Trans. Am. Ent. Soc., xvii, 217,

N. C., 1890.

lowa.

\section{CENOCHROA Ragonot.}

Ragonot, Diag. No. Am. Phye., 20, 1887; Hulst, Trans. Am. Ent. Soc., xvii, 217, 1890.

*4927. californiella Ragonot, Diag. No. Am. Phyc., 20,

Cal.,

1887; Mon. Phyc. Gall., pl. 3, f. 3, 1893; Hulst,

Trans. Am. Ent. Soc., xvii, 217, 1890.

Ariz.,

Col.

\section{CHIPOTA Hulst.}

Hulst, Can. Ent., xxiv, 62, 1892; Osceola Hulst (not Burd), Sm. List Lep., 85, 1891. *4928. perlepidella Hulst, Can. Ent., xxiv, 62, 1892.

Fla.

\section{Family PTEROPHORID A.}

(C.=Fernald, Pter. No. Am., Spec. Bull. Hatch. Exp. Sta., Mass. Agr. Coll., 1898.)

\section{TRICHOPTILUS Walsingham.}

Walsingham, Pter. Cal. \& Oreg., 62, 1880; Tutt, Mon. Pter. Brit., 77, 1891; Meyrick, Handb. Brit. Lep., 430, 1895; Hofmann, Pteroph., 121, 1895; Fernald, C. 13, 1898.

*4929. pygmæus Waisingham, Pter. Cal. \& Oreg., 64, Cal. 1880; Fernald, C. 14, 1898.

*4930. ochrodactylus Fish, Can. Ent., xiii, 142, 1881; Fernald, C. $15,1898$.

4931. lobidactylus Frтch, Trans. N. Y. Agr. Soc., xiv, 847, 1854; Fernald, C. 15, 1898; Dyar, Psyche, viii, $249,1898$.

\section{Tex}

syn. californicus Walsingham, Pter. Cal. \& Oreg., 60, 1880.

N. Eng., N. Y., Col., Cal.

\section{OXYPTILUS Zeller.}

Zeller, Isis, viii, 765, 1841; Linn. Ent. vi, 342, 1852; Herrich-Schaeffer, Schm. Eur., v, 270, 1854; Wallengren, Fjäderm., 14, 1859; Heinemann \& Wocke, Kleinschm., ii, 2, 789, 1876; Meyrick, Trans. Ent. Soc. Lond., 8, 1886; 485, 1890; Tutt, Mon. Pter. Brit., 60, 1891; Merrick, Handb. Brit. Lep., 431, 1895; Hofmanu, Pteroph., 95, 1895; Fernald, C. 16, 1898.

4932. periscelidactylus Fiтch, Trans. N. Y. Agr. Soc., xiv, 843, 1854; Riley, Rep. Ins. Mo., i, 137, Atl. 1869; Am. Ent., ii, 234, 1870; Zeller, Stett. States. ent. Zeit., xxii, 178, 1871; PACKard, Guide, 356, 1872; Zeller, Verh. zool.-bot. Ges. Wien, xxiii, 319, 1873; Saunders, Can. Ent., v, 99, 1873; Warsingham, Pter. Cal. \& Oreg., 25, 1880; Saunders, Ins. Inj. Fruits, 268, 1889 ; Comstock, Man., 238, 1895; Sмiтн, Econ. Ent., 318, 1896; Fernald, C. $17,1898$. 
4933. delawaricus Zeller, Verh. zool.-bot. Ges. Wien, xxiii, 320,1873; Walsingham, Pter. Cal. \& Oreg., 29, 1880; Fernald, C. 19, 1898; Dyar, Proc. U. S. Nat. Mus., xxv, 397, 1902.

*4934. ningoris Walsingham, Pter. Cal. \& Oreg., 26, 1880; Fernald, C. 20, 1898.

4935. tenuidactylus Fitch, Trans. N. Y. Agr. Soc., xiv, 848, 1854; Fernald, C. 20, 1898; Dyar, Psyche, viii, 249, 1898.

syn. niqrociliatus ZelLer, Verh. zool.-bot. Ges. Wien, xxiii, 322, 1873; WaLsingham, Pter. Cal. \& Oreg., 31, 1880; Saunders, Ins. Inj. Fruits, 314, 1889; delavaricus Forbes, Rep. Ent. Ill., xiv, 91, 1885.

Cal., Oreg.

No. Atl. States, Col., Cal. Atl. States, Col.,Cal.

\section{PLATYPTILIA Hübner.}

Hübner, Verz. bek. Schmett., 429, 1826; Heinemanx \& Wocke, Kleinschm., ii, 2, 783, 1876; Meyrick, Trans. Ent. Soc. Lond., 9, 1886; 485, 1890; Tutт, Mon. Pter. Brit., 22, 1891; Meyrick, Handb. Brit. Lep., 432, 1895; Hofmann, Pteroph., 36, 1895; Fernald, C. 22, 1898; Platyptilus Zeller, Isis, viii, 764, 1841; Linn. Ent., vi, 326, 1852; Herrich-Schaeffer, Schm. Eur., v, 366, 1854; Wallengren, Fjäderm., 11, 1859.

*4936. pica Walsingham, Pter. Cal. \& Oreg., 21, 1880; Fernald, C. 24, 1898.

4937. cosmodactyla HüBner, Schm. Eur., Aluc., pl.vii, f. 35, 36, 1823; Treitschke, Schm. Eur., ix, 2, 235, 1833; Stephens, Ill. Brit. Ent., Haust., iv, 377, 1834; Wood, Ind. Ent., f. 1649, 1854; HerRICH-SchaEFFer, Schm. Eur., v, 369, 1854; Heinemann \& Wocke, Kleinschm., ii, 2, 788, 1876; Walsingham, Pter. Cal. \& Oreg., 23, 1880; Jordan, Ent. Mon. Mag., xviii, 117, 1881; Leech, Brit. Pyr., 56, 1886; Meyrick, Handb. Brit. Lep., 433, 1895; Hofmann, Pteroph., 65, 1895; Fernald, C. 25, 1898; Tutt, Ent. Rec., xi, 238, 1899; Dyar, Proc. U. S. Nat. Mus., xxv, $399,1902$.

syn. punctidactyla Haworth, Lep. Brit., iii, 479, 1811; WooD, Ind. Ent., f. 1648, 1854; ulodactyla Zetterstedt, Ins. Lap., 1012, 1840.

4938. marmarodactyla DyaR (near cosmodactyla, but smaller, expanse 17-18 mm., fore wing smooth, even gray, reddish tinted, a rounded orange and whitish patch covering basal half of first feather and resting on fissure; scale tuft on third feather of hind wing not triangular). 
4939. acanthodactyla HüBner, Eur. Schmett., Aluc., pl. v, f. 23, 24, 1818; Treiтschке, Schm. Eur., ix, 2, 234, 1833; Herrich-Schaeffer, Schm. Eur., v, 369, 1854; Hennemann \& Wocke, Kleinschm., ii, 2, 788, 1876; SNellen, Vlind. Nederl., ii, 2, 1023, 1882; Leech, Brit. Pyr., 56, 1886: Hofmann, Pteroph., 61, 1895; Meyrick, Handb. Brit. Lep., 433, 1895; Fernald, C. 25 , 1898; Walsingham, Ent. Mon. Mag., xxxiv, 192, 1898; Tutт, Ent. Rec., xi, 238, 1899.

*4940. edwardsii Fish. Can. Ent., xiii, 72, 1881; Fernald, C. 25, 1898.

4941. carduidactyla Riley, Rep. Ins. Mo., i, 180, 1869; Fernald, C. 26, 1898.

syn. cardui Zeller, Stett. ent. Zeit., xxxii, 179, 1871; Verh. zool.-bot. Ges. Wien, xxiii, 318, 1873: Walsinghan, Pter. Cal. \& Oreg., 7, 1880; Riler, Gen. Ind., 83, 1881; W ALsingham, Ent. Mon. Mag., xxxiv, 192, 1898.

4942. percnodactyla Walsingham, Pter. Cal. \& Oreg., 8, 1880; Fernald, C. 27, 1898.

*4943. shastæ W alsingham, Pter. Cal. \& Oreg., 14, 1880; Fernald, C. 28, 1898.

4944. fragilis Walsingham, Pter. Cal. \& Oreg., 16, 1880; Fernald, C. 28, 1898.

4945. orthocarpi Walsingham, Pter. Cal. \& Oreg., 11, 1880; Fernald, C. 29, 1898.

4946. albida Walsingham, Pter. Cal. \& Oreg., 10, 1880; Fernald, C. 29, 1898.

*4947. albidorsella W alsingham, Pter. Cal. \& Oreg., 13, 1880; Fernald, C. 30, 1898.

*4948. grandis W alsingham, Pter. Cal. \& Oreg., 6, 1880; Fernald, C. 30, 1898.

4949. cooleyi Fernald, Pter. No. Am., 30, 1898.

4950. modesta Walsingham, Pter. Cal. \& Oreg., 18, 1880; Fernald, C. 31, 1898.

4951. petrodactyla WaLker, Cat. Brit. Mus., xxx, 940, 1864: Walsingham, Pter. Cal. \& Oreg., 20, 1880; Fernald, C. 31, 1898.

*4952. adusta Walsingham, Pter. Cal. \& Oreg., 5, 1880; Fernald, C. 32, 1898.

*4953. albiciliata Walsingham, Pter. Cal. \& Oreg., 17 , 1880; Fernald, C. 32, 1898.

*4954. albicans Fish, Can. Ent., xiii, 71, 1881; FerNALD, C. 32, 1898.
Eur.,

N. Y., Cal.,

Oreg.

Me.,

Mass.

U.S.

Cal.

Cal.

Cal.

Oreg.

Cal.

Oreg.

Cal.

Cal.

Col., Cal.

Ariz.,

Cal.

Arctic

Am.

Cal.

Cal.

Nev. 
4955. tesseradactyla Linvæus, Faun. Suec., 370, 1761; Heinemann \& Wocke, Kleinschm., ii, 2, 787, 1876: Zeller, Stett. ent. Zeit., xxxix, 162, 1878; Barrett, Ent. Mon. Mag., xxxiii, 25, 1897; Fernatd, C. 33, 1898.

syn. fischeri ZELLER, Isis, viii, 781, 1841; Tengström, Bidr., 155, 1847; Zeller, Linn. Ent., vi, 337, 1852; Herrich-SchaEFFEr, Schm. Eur., v, 369, 1854.

4956. marginidactyla Fiтch, Trans. N. Y. Agr. Soc., xiv, 848, 1854; Fernald, C. 34, 1898.

Eur., Mass., Col., Cal.

syn. nebulxdactylus Fiтch, Trans. N. Y. Agr. Soc., xiv, 849, 1854; bertrami Roessler, Wien. ent. Mon., viii, 54, 1864; Zeller, Stett. ent. Zeit., xxxiv, 135, 1873; HerneMANN \& W OCKE, Kleinschm., ii, 2, 784, 1876; Walsinghay, Pter. Cal. \& Oreg., 3, 1880; Snellen, Vlind. Nederl., ii, 2, 1017, 1882; Porritt, Ent. Mon. Mag., xxii, 103, 1885; xxiii, 163, 1886; Leech, Brit. Pyr., 52, 1886; Tutr, Mon. Pter. Brit., 31, 1891; Meyrick, Handb. Brit. Lep., 434, 1895; Hofmann, Pteroph., 55, 1895; bischoffii Zeller, Stett. ent. Zeit., xxviii, 333, 1867; Verh. zool.-bot. Ges. Wien, xxiii, 317, 1873; cervinidactylus Packard, Ann. Lye. Nat. Hist. N. Y., x, $266,1873$.

\section{ALUCITA Linnæus.}

Linneus, Syst. Nat., 542, 1758; Walsingham, Ent. Mon. Mag., 33, 41, 1897; FerNALD, C. 36, 1898; Aciptilia HüBner, Verz. bek. Schmett., 430, 1826; Aciptilus Zeller, Isis, viii, 768, 1841; Wallengren, Fjäderm., 23, 1859; Pterophorus MeyRICk, Trans. Ent. Soc. Lond., 10, 1885; 489, 1890; Handb. Brit. Lep., 435, 1895.

4957. walsinghami Fernald, Pter. No. Am., 36, $1898 . \quad$ Col.

*4958. belfragei Fish, Can. Ent., xiii, 142, 1881; Tex. Fernald, C. 37, 1898.

4959. montana Walsingham, Pter. Cal. \& Oreg., 59, 1880; Fernald, C. 37, 1898.

Cal., N. Y.

4960. cinerascens Walsingham, Pter. Cal. \& Oreg., 57, 1880; Fernald, C. 39, 1898; Dyar, Proc. U. S. Nat. Mus., xxv, 399, 1902.

Cal., Col.

\section{PTEROPHORUS Geoffroy.}

Geoffroy, Hist. Abr. Ins., ii, 90, 1762; W Allengren, Fjäderm., 20, 1859; Tutt, Mon. Pter. Brit., 110, 1891; Hofmann, Pteroph., 131, 1895; Fernald, C. 39, 1898; Oidæmatophorus Wallengren, Fjäderm., 19, 1859; Leioptilus Wallengren, Fjäderm., 21, 1859; Lioptilus Meyrick, Trans. Ent. Soc. Lond., 10, 1886; Alucita MeYRICK, Trans. Ent. Soc. Lond., 487, 1890; Handb. Brit. Lep., 438, 1895.

*4961. fishii Fernald, Can. Ent., xxv, 95, 1893; C. 40, Nev. 1898. 
4962. homodactylus WaLker, Cat. Brit. Mus., xxx, 941, 1864; Walsinghan, Pter. Cal. \& Oreg., 50, 1880; Coquillett, Pap., ii, 62, 1882; FerNALD, C. 41, 1898.

4963. brucei Fernald, Pte". No. Am., 42, 1898.

Cal.,

Oreg.

4964. elliottii Fernald, Can. Ent., xxv, 95, 1893; C. 42, 1898; Dyar, Psyche, viii, 250, 1898.

*4965. subochraceus Walsingham, Pter. Cal. \& Oreg., 53, 1880; Fernald, C. 43, 1898.

Col.

N. Y

Mass.,

Cal.

$\mathrm{Ky}$.

So.

Oreg.

1880; Fernald, C. 43, 1898.

Fla.

*4968. bipunctatus Möschler, Ab. Senck. nat. Ges., xv, 346, 354, 1890; Walsinghà, Proc. Zool. Soc. Lond., 496, 1891; 61, 1897.

syn. microdactylus Hedemann, stett. ent. Zeit., lvii, 9, 1896.

*4969. stramineus Walsinghay, Pter. Cai. \& Oreg. 41, 1880; Fernald, C. 44, 1898.

So.

Oreg.

Cal.

*4970. angustus Walsinghan, Pter. Cal. \& Oreg., 43, 1880; Fernald, C. 44, 1898.

4971. sulphureodactylus Packard, Ann. Lyc. Nat. Hist. N. Y., x, 266, 1873; Fernald, C. 44, 1898;

Cal.,

Col.

Dyar, Proc. U. S. Nat. Mus., xxv, 398, 1902.

syn. sulphureus Walsingham, Pter. Cal. \& Oreg., 48, 1880.

*4972. mathewianus Zeller, Verh. zool.-bot. Ges. Wien, xxiv, 23, 1874; Fernald, C. 45, 1898.

Vanc., Id.

4973. paleaceus Zeller, Verh. zool.-bot. Ges. Wien, xxi1i, 326, 1873; Walsingham, Pter. Cal. \& Oreg., 41, 1880; Möschler, Ab. Senck. Ges., xv, 346 , 354, 1890: W alsingham, Proc. Zool. Soc. Lond., 495, 1891; Fernald, C. 45, 1898.

syn. sericidactylus Murtfeldt, Am. Ent., iii, 235,1880 .

*4974. agraphodactylus WALKer, Cat. Brit. Mus., xxx, 941, 1864; Walsingham, Pter. Cal. \& Oreg., 46, 1880; Proc. Zool. Soc. Lond., 496, 1891; Proc. Zool. Soc. Lond., 6, 1897; Fernald, C. $47,1898$.

syn. aspilodactylus WALKER, Cat. Brit. Mus., xxx, 941, 1864; Butler, Proc. Zool. Soc. Lond., 495, 1878; Walsinghay, Proc. Zool. Soc. Lond., 496, 1891.

W. I., Ohio, Ill., Mo., Tex., Oreg. Cal.

W. I., So. Oreg. 
*4975. inconditus Walsingham, Pter. Cal. \& Oreg., 44, 1880; Fernald, C. 47, 1898.

Cal.,

D. C.

*4976. parvus Walsingham, Pter. Cal. \& Oreg., 55, 1880; Fernald, C. 48, 1898.

Ariz., Cal.

4977. kellicottii Fish, Can. Ent., xiii, 141, 1881; Fernald, C. 49, 1898.

4978. rhynchosiæ Dyar, Psyche, viii, 249, 1898.

4979. grandis Fish, Can. Ent.. xiii. 141, 1881; FerNALD, C. 50, 1898.

4980. rileyi Fernald, Pter. No. Am., 50, 1898.

4981. monodactylus Linnæus, Syst. Nat., i, 542, 1758; Wallengren, Fjäderm., 20, 1859; Heinemann \& Wocke, Kleinschm., ii, 2, 801, 1876; WaLsINGHaм, Pter. Cal. \& Oreg., 39, 1880; SNellen, Vlind. Nederl., ii, 1048, 1882; South, Ent., xviii, 277, 1885; Tutт, Mon. Pter. Brit., 111, 1891; Meyrick, Handb. Brit. Lep., 439, 1895; Hofmann, Pteroph., 133, 1895; Fernald, C. 51, 1898.

syn. pterodactyla Hübner, Eur. Schmett., Aluc., pl. 1, f. 4, 1803; Тreitschке, Schm. Eur., ix, 2, 246, 1833; Zeller, Isis, viii, 846, 1841; Linn. Ent., vi, 377, 1852; HerrichSchaEfFer, Schm. Eur.. v, 379, 1854; cineridactylus Fitch, Trans. N. Y. Agr. Soc., xiv, 848, 1854; novosidactylus Fitch, Trans. N. Y. Agr. Soc., xiv, 849, 1854; pergracilidactylus Packard, Ann. Lyc. Nat. Hist. N. Y.., x, 265, 1873.

4982. cretidactylus Fitch, Trans. N. Y. Agr. Soc., xiv, 849, 1854; Fernald, Can. Ent., xxv, 96, 1893; C. 52, 1898; Dyar, Psyche, viii, 250, 1898.

syn. occidentalis Walsingham, Pter. Cal. \&

Oreg., 37, 1880.

4983. eupatorii Fernald, Can. Ent., xxv, 96, 1893; C. 52, 1898; Dyar, Psyche, viii, 250, 1898.

syn. cretidactylus ZELLER, Verh. zool.-bot. Ges. Wien, xxiv, 22, 1874; Walsingham, Pter. Cal. \& Oreg., 35, 1880; Kellicott, Bull. Buff. Soc., iv, 2, 1882.

*4984. guttatus Walsingham, Pter. Cal. \& Oreg., 36, 1880; Fernald, C. 53, 1898.

*4985. cineraceus Fish, Can. Ent., xiii, 73, 1881; FerNALD, C. 54, 1898.

*4986. baroni Fish, Can. Ent., xiii, 73, 1881; FerNALD, C. $54,1898$.

Fla.

Cal.

Cal.

Eur., No. Africa, W. Asia, Maine to Cal.

N. Y., Cal.

N. Y., Cal., Vanc. Id.

Cal.

Wash.

Cal. 
*4987. gratiosus Fish, Can. Ent., xiii, 73, 1881; FERNALD, C. 54, 1898.

*4988. lugubris Fish, Can. Ent., xiii, 140, 1881; Fernald, C. 55, 1898.

4989. grisescens Walsinghan, Pter. Cal. \& Oreg., 34, 1880; Fernald, C. 55, 1898.

Cal.

Cal.

So.

Oreg:

4990. inquinatus Zelcer, Verh. zool.-bot. Ges. Wien, xxiii, 325, 1873; Coquillett, Pap., ii, 61, 188.; Hedemann, Stett. ent. Zeit., lvii, 9, 1896; Walsingham, Proc. Zool. Soc. Lond., 59, 1897; Ala., Tex., Mo., Col., Ariz. , W. I. Fernald, C. 56, 1898.

syn. ambrosix Murtandot, Am. Ent., iii, 236, 1880.

\section{STENOPTILIA Hübner.}

HüBner, Verz. bek. Schmett., 430, 1826; Zeller, Isis, viii, 766, 1841; Meyrick, Trans. Ent. Soc. Lond., 487, 1890; Handb. Brit. Lep., 440, 1895; Hofmans, Pteroph., 68, 1895; Fernald, C. 57, 1898.

*4991. pumilio Zeller, Verh. zool.-bot. Ges. Wien, Tex. xxiii, 324, 1873; Walsingham, Proc. Zool. Soc. Lond., 495, 1891; 58, 1897; Fernald, C. 58, 1898. syn. gitvidorsis (part) Hedemann, Stett. ent. Zeit., lvii, 8, 1896.

4992. pterodactyla Linveus, Faun. Suec., 371, 1761; Wallengren, Fjäderm., 18, 1859; Heinemann Eur., \& Wocke, Kleinschm., ii, 2, 797, 1876; SNeLlen, N. Y. Vlind. Nederl., ii, 1040, 1882; Leech, Brit. Pyr., 61, 1886; Tutw, Mon. Pter. Brit., 100, 1891; MEYRICK, Handb. Brit. Lep., 440, 1895; Fernald, C. 58, 1898 .

syn. fuscus Retzius, Gen. et Spec., 35, 1783; Zeller, Isis, viii, 841, 1841; Linn. Ent., vi, 371, 1852; Herrich-Schaeffer, Schm. Eur., v, 375, 1854; Hofmann, Pter., 82, 1895; ptilodactyla HüBNER, Eur. Schmett., Aluc., pl. 3, f. 16, 1803; Treitschke, Schm. Eur.,ix, 2, 244,1833; fuscodactyla HaworTH, Lep. Brit., 476, 1811.

4993. exclamationis Walsingham, Pter. Cal. \& Oreg., 32, 1880; Fernald, C. 59, 1898.

Cal.,

Oreg.

*4994. mengeli Fernald, No. Am. Pter., 60, 1898. No. Greenland.

*4995. semicostata Zeller, Verh. zool. -bot. Ges. Wien, Tex. xxiii, 323, 1873; Fernald, C. 60, 1898.

4996. coloradensis Fernald, No. Am. Pter., 61, 1898.

Col. 


\title{
Family ORNEODIDA.
}

ORNEODES Latreille.

Latreille, Préc. Gén. Ins., 148, 1796; Hist. Nat. Crust. Ins., iii, 418, 1802; Treitschk e, Schm. Eur., ix, 2, 254, 1833; Meyrick, Trans. Ent. Soc. Lond., 490, 1890; Handb. Brit. Lep., 442, 1895; Fernald, C. 61, 1898; Alucita (part) Linveus, Syst. Nat., 542, 1758; Stei'hens, Ill. Brit. Ent., Haust., iv, 334, 1834; Zeller, Isis, viii, 867, 1841; Herrich-Schaeffer, Schm. Eur., v, 386, 1854; Wallengren, Fjäderm., 25, 1859; Heinemann \& Wocke, Kleinschm., ii, 2, 811, 1876; Ripidophora HüBner, Tentamen, 1806; Euchiradia HüBner, Verz. bek. Schm., 431, 1826.

4997. hexadactyla Linneus, Syst. Nat., 542, 1758; Wood, Ind. Ent., f. 1653, 1854; Hernemann \& Wocke, Kleinschm., ii, 2, 813, 1876; W ALsINGHam, Pter. Cal. \& Oreg., 66, 1880; Snellen, Vlind. Nederl., ii, 2, 1060, 1882; South, Ent., xvi, 74, 1883: Leech, Brit. Pyr., 69, 1886: Tutt, Mon. Pter. Brit., 158, 1891; Merrick, Handb. Brit. Lep., 442, 1895; Fernald, C. 62, 1898.

Eur., N. Y.. Mo., Cal., Col., Oreg., Can., Manitoba. syn. polydactyla HüBner, Eur. Schmett., Aluc., pl. vi, f. 28, 1816; Treitschке, Schm. Eur., ix, 2, 257, 1833; montana Cockerell, Ent. Mon. Mag., xxv, 213, 1889.

\section{Family TORTRICID E.}

\author{
By C. H. Fernald, \\ Subfamily OLF'TIRFU'TIN AE.
}

EVETRIA Hübner.

HüBner, Verz. bek. Schmett., 378, 1826; Meyrick, Handb. Brit. Lep., 470, 1895; Retinia Guenée, Ann. Soc. Ent. Fr., (2), iii, 180, 1845; Heinemann, Kleinschm., i, $1,93,1863$.

4998. frustrana Comstock, Rept. Dept. Agr., 1879, 236, 1880; Scudder, Pine Moth of Nantucket, 4, 1883.

Mass., N. Y., Va.

*4999. rigidana Fernald, Rept. Dept. Agr., 1879, 237, N. Y. 1880 .

5000. comstockiana Fernald, Can. Ent., xi, 157, 1879; Comstock, Rept. Dept. Agr., 1879, 235, 1880.

N. Y.,

Md.

*5001. turionana HüBnER, Eur. Schmett., Tort., ff. 220 , 221, 1818; Frölich, En. Tort. Würt., 69, 1828; Treitschke, Schm. Eur., viii, 137, 1830; Dupon-

Eur., CHEl, Hist. Nat. Lép. Fr., ix, 233, 1834; Ratzeburg, Forst. Ins., i, 207, 1839; HerrichSchaeffer, Schm. Eur., iv, 222, 1851; HerneManN, Kleinschm., i, 1, 94, 1863.

syn. turionella Wilkinson, Brit, Tort., 222, 1859 , 
*5002. sylvestrana Curtis, Ann. Mag. Nat. Hist., (2), v, 3, 1850; Wilkinson, Brit. Tort., 220, 1859.

Eur., Oreg.

Eur., Oreg.

Brit. Tort., 219, 1859; Hennemann, Kleinschm., i, 1, 95, 1863; Meyrick, Handb. Brit. Lep., 471, 1895 .

syn. pudendana Herrich-Schaeffer, Schm. Eur., iv, 222, 1851.

*5004. subcervinana Walsingham, Ill. Lep. Het. Brit. Mus., iv, 25, 1879.

\section{POLYCHROSIS Ragonot.}

Ragonot, Ann. Soc. Ent. Fr., lxiii, 208, 1894.

5005. botrana Schiffermüller, Syst. Verz. Wien, 131, 1776; Herrich-Schaesfer, Schm. Eur., iv, 225, 1851 .

syn. vitisana JACQUIN, Coll., ii, 97, 1788; reliquana HüBner, Verz. bek. Schmett., 381, 1816; Treitschke, Schm. Eur., x, 3, 146, 1835; Wilkinson, Brit. Tort., 280, 1859: viteana Cremens, Proc. Acad. Nat. Sci. Phil., 359, 1860; vitivorana PACKARD, Guide Stud. Ins., 336, 1869; Riley, Rep. Ins. Mo., i, 133, 1869; Walsh \& Riley, Am. Ent., i, 177,1869 .

Oreg.

Atl. States, Eur.

BACTRA Stephens.

Stephens, Ill. Brit. Ent., Haust., iv, 124, 1834; Wilkinson, Brit. Tort., 144, 1859; Meyrick, Handb. Brit. Lep., 456, 1895.

5006. lanceolana HüBNER, Schm. Eur.,Tort.,f. 80,1800; Treitschke, Schm. Eur., viii, 324, 1830; DuponChel, Hist. Nat. Lép. Fr., ix, 239, 1834; HerRICH-SCHAEFFER, Schm. Eur., iv, 243, 1851; WILKinson, Brit. Tort., 145, 1859; HeInemann, Kleinschm., i, 1, 134, 1863.

syn. dibeliana HüBner, Schm. Eur., Tort., f. 272, 1823; lanceana Frölich, En. Tort. Würt., 98, 1828.

a. verutana ZELLer, Verh. zool.-bot. Ges. Wien, $\mathrm{xxv}, 247,1875$.

5007. furfurana HAworTH, Lep. Brit., 466, 1811; WILKINSON, Brit. Tort., 147, 1859; HeInemann, Kleinschm., i, 1, 135, 1863; ZelLer, Verh. zool. -

U. S., W. I., Eur., Asia, Africa, Australia, N. Z.

Eur., Mass. bot. Ges. Wien, xxv, 247, 1875.

syn. acutana Eversmann, Faun. Volg. Ural., 529, 1844; Zamana ZELLER, Isis, 257, 1846; scirpana Herrich-Schaeffer, Schm. Eur., iv, $243,1851$.

*5008. inquadrana Walsingham, Trans. Ent. Soc. Lond., $134,1884$.

Ariz.

$4630-$ No. $52-02-29$ 


\section{EXARTEMA Clemens.}

Clemens, Proc. Acad. Nat. Sci. Phil., 356, 1860; Meyrick, Handb. Brit. Lep., 457, 1895.

*5009. fagigemmeanum Chambers, Can. Ent., x, 74, 1878.

*5010. nitidanum Cremens, Proc. Acad. Nat. Sci. Phil., 356, 1860; Proc. Ent. Soc. Phil., v, 133, 1865.

5011. ferrugineanum Riley, Trans. St. Louis Acad. Sci., iv, 317, 1881.

5012. monetiferanum RILeY, Trans. St. Louis Acad. Sci., iv, 317, 1881.

*5013. sericoranum Walsingham, Ill. Lep. Het. Brit. Mus., iv, 36, 1879.

*5014. zellerianum Fernald, Trans. Am. Ent. Soc., x, $29,1882$.

syn. nitidanum Zeller (not Clemens), Verh. zool.-bot. Ges. Wien, xxv, 270, 1875.

5015. permundanum Clemens, Proc. Acad. Nat. Sci. Phil., 356, 1860; Proc. Ent. Soc. Phil., v, 134, 1865; Zeller, Verh. zool.-bot. Ges. Wien, xxv, 273,1875 .

syn. meanderana WALker, Cat. Brit. Mus., xxviii, 341, 1863.

*5016. olivaceanum Fernald, Trans. Am. Ent. Soc., x, $71,1882$.

5017. concinnanum Clemens, Proc. Ent. Soc. Phil., v, 134,1865 .

syn. fredana Clemens, Proc. Ent. Soc. Phil., $\mathrm{v}, 135,1865$.

*5018. versicoloranum Clemens, Proc. Acad. Nat. Sci. Phil., 357, 1860.

syn. appendiceum Zeller, Verh. zool.-bot. Ges. Wien, xxv, 275, 1875.

*5019. punctanum Walsingham, Ill. Lep. Het. Brit. Mus., iv, 87, 1879.

syn. versicolorana (Lemens (part), Proc. Ent. Soc. Phil., v, 136, 1865.

*5020. atrodentanum Fernald, Trans. Am. Ent. Soc., $\mathrm{x}, 71,1882$.

Ohio, Ill., Tex.

5021. fasciatanum Clemens, Proc. Acad. Nat. Sci. Phil., 357, 1860; Proc. Ent. Soc. Phil., v, 134, 1865 .

No. Atl.

States.

syn. decisana W Alker, Cat. Brit. Mus., xxviii, 340, 1863; albofasciatum Zelcer, Verh. zool.-bot. Ges. Wien, xxv, 272, 1875. 
*5022. corylanum Fernald, Trans. Am. Ent. Soc., x, 71,1882 .

5023. exoletum Zeller, Verh. zool.-bot. Ges. Wien, $\mathrm{xxv}, 270,1875$.

Atl. States.

Mass.,

N. Y.

Atl.

5024. inornatanum Clemens, Proc. Acad. Nat. Sci. Phil., 357, 1860; Proc. Ent. Soc. Phil., 134, 1865. syn. clavana WALKer, Cat. Brit. Mus., xxviii, 395, 1863; quadrifidum ZeLLer, Verh. zool.'bot. Ges. Wien, xxv, 268, 1875 .

*5025. malanum Fernald, Trans. Am. Ent. Soc., x. 72, 1882.

5026. footianum Fernald, Bull. Buff. Soc., iv, 53, 1882.

5027. ferriferanum WaLKer, Cat. Brit. Mus., xxviii, 343, 1863; Walsingham, Ill. Lep. Het. Brit. Mus., iv, 37, 1879.

syn. gratiosana Clemens, Proc. Ent. Soc. Phil., v, 134, 1865; usticana ZéLLer, Verh. zool.-bot. Ges. Wien, xxv, 293, 1875.

\section{OLETHREUTES Hïbner.}

Hübner, Tent., 2, 1806; Penthina Treitschke, Schm. Eur., viii, 21, 1830; Sericoris Treitschke, Schm. Eur., viii, 142, 1830.

*5028. intermistana Clemens, Proc. Ent. Soc. Phil., v, Lab. 140,1865

syn. tessellana Packard, Proc. Bost. Soc. Nat. Hist., xi, 58, 1867.

*5029. septentrionana Curtis, App. Ross Second Voyage N.-W. Pass., 77, 1831.

Aretic Am. Lab.

syn. primariana Walker, Cat. Brit. Mus., xxviii, 336, 1863; fulvifrontana PACKARD, Proc. Bost. Soc. Nat. Hist., xi, 59, 1867.

*5030. frigidanả Packard, Bost. Soc. Nat. Hist., xi, 57 , 1867.

5031. nimbatana Clemens, Proc. Acad. Nat. Sci. Phil., 346,1860 .

syn. contrariana Walker, Cat. Brit. Mus., xxviii, $374,1863$.

5032. consanguinana W aLsingham, Ill. Lep. Het. Brit. Mus., iv, 30, 1879.

5033. capreana HüBner, Eur. Schmett., Tort., f. 250, 1818; Treitschke, Schm. Eur., viii, 27, 1830; Heinemann, Kleinschm., i, 1, 106, 1863.

N. Y.,

Ill.

N. Y.

Va.

syn. capræana WILKInson, Brit. Tort., 23, 1859; mostana Wocke, Stett. ent. Zeit., xxiii, 52,1862 .

Lab., N. H.

No. Atl

States.

Cal.

Eur., Lab. 
5034. dimidiana Sodoffsky, Bull. Mosc., 73, 1830; Treitschke, Schm. Eur., x, 3, 46,1835; HerrichSchaefFer, Schm. Eur., iv, 228, 1851; WILKINSON, Brit. Tort., 28, 1859; HeInemann, Kleinschm., i, 1, 109, 1863.

syn. atropunctana ZetTerstedt, Ins. Lap., 977, 1840; ochromelana Guenée, Ann. Soc. Ent. Fr., (2), iii, 152, 1845 .

5035. hartmanniana Linnæus, Faun. Suec., 345, 1761; Treitschke, Schm. Eur., viii, 91, 1830; Duponchel, Hist. Nat. Lép. Fr., ix, 201, 1834; Herrich-Schaeffer, Schm. Eur., iv, 227, 1851; Wilkinson, Brit. Tort., 19, 1859; Heinemann, Kleinschm., i, 1, 106, 1863.

syn. lineana Schiffermüller, Syst. Verz.

Wien, 131, 1776; scriptana HüBNER, Schm. Eur., Tort., f. 110, 1800; FröLICH, En. Tort. Würt., 57, 1828; Stephens, Ill. Brit. Ent., Haust., iv, 86, 1834.

a. albeolana Zeller, Verh. zool.-bot. Ges. Wien, XXv, 262, 1875 .

*5036. griseoalbana Walsingham, Ill. Lep. Het., iv, 38, 1879 .

*5037. conditana Walsingham, Ill. Lep. Het., iv, 31, 1879 .

5038. hebesana WaLker, Cat. Brit. Mus., xxviii, 342, 1863; Walsingham, Ill. Lep. Het. Brit. Mus., iv, 31,1879 .

syn. inexpertana Walker, Cat. Brit. Mus., xxviii, 394, 1863; fullerea Riley, Am. Ent., ii, $204,371,1870$.

5039. cyanana Murtfeldt, Am. Ent., iii, 14, 1880.

*5040. interruptolineana Fernald, Trans. Am. Ent. Soc., x, 70, 1882.

*5041. hemidesma ZeLLer, Verh. zool.-bot. Ges. Wien, $\mathrm{xxv}, 261,1875$.

*5042. murina Packard, Proc. Bost. Soc. Nat. Hist., xi, $60,1867$.

5043. osmundana Fernald, Can. Ent., xi, 156, 1879.

5044. malachitana Zeluer, Verh. zool.-bot. Ges. Wicn, xxv, 292, 1875.

5045. roseomaculana Herrich-SchaEffer, Schm. Eur., iv, $229,1851$.

syn. Tieniqiana Heinemann, Kleinschm., i, 1, 111, 1863.

Pa. to Kans.

Mass.,

N. H.

Me., Mass., Cal.

Labrador.

Me., Mass., $\mathrm{Pa}$.

Pa., Mo., Tex., So.Am. ?

Eur., Labrador. 
*5046. costimaculana Fernald, Trans. Am. Ent. Soc., $\mathrm{x}, 70,1882$.

Me.,

Mass.

5047. chionosema ZeLLer, Verh. zool.-bot. Ges. Wien, $\mathrm{xxv}, 265,1875$.

Atl.

States.

*5048. melanosticta Walsingham, Trans. Ent. Soc. Lond., 500, 1895.

Col.

5049. duplex Walsingham, Trans. Ent. Soc. Lond., 501,1895 .

5050. nubilana Clemens, Proc. Ent. Soc. Phil., v, 140, 1865; PaCkard, Guide Stud. Ins., 333, 1869.

Col.

Pa.,

Wis.

*5051. vetulana Walsingham, Ill. Lep. Het., iv, 32, 1879.

*5052. auricapitana Walsingham, Ill. Lep. Het., iv, 33, 1879.

5053. agilana Clemens, Proc. Acad. Nat. Sci. Phil., $359,1860$.

*5054. albiciliana Fernald, Trans. Am. Ent. Soc., x, $70,1882$.

*5055. chalybeana Walsingham, Ill. Lep. Het., iv, 34, 1879.

5056. coruscana Clemens, Proc. Acad. Nat. Sci. Phil., 346,1860 .

syn. ferrolineana W ALKER, Cat. Brit. Mus., xxviii, 395, 1863; argyralana Zelter, Verh. zool.-bot. Ges. Wien, xxv, 277, 1875.

5057. constellatana ZeLler, Verh. zool.-bot. Ges. Wien, xxv, 279, 1875 .

*5058, major Walsingham, Trans. Ent. Soc. Lond., $502,1895$.

*5059. mengelana Fernald, Ent. News, v, 131, 1894.

5060. rivulana Scopoli, Ent. Carn., 237, 1763; SchifFervüller, Syst. Verz. Wien, 131, 1776; Heinemann, Kleinschm., i, 1, 123, 1863.

syn. rivellana Fabricius, Syst. Ent., 654, 1775 ;

FröLICH, En. Tort. Würt., 62, 1828; conchana Hübner, Sêhm. Eur., Tort., f. 106, 1800; Haworth, Lep. Brit., 460, 1811; Treitschke, Schm. Eur., viii, 148, 1830; Duponchel, Hist. Nat. Lép. Fr., ix, 208, 1834; Herrich-Schafferer, Schm. Eur., iv, 213, 1851; Wilkinson, Brit. Tort., 266, 1859 .

Tex.,

Cal.

Pa., N. Y.

Pa.

Me.

Oreg., Cal.

Me., N. Y., $\mathrm{Pa}$.

Me. to

Wis.

Col.

Greenl.

Eur., Cal., Oreg. 
*5061. urticana Hübner, Schm. Eur., Tort., f. 65, 1800; Haworth, Lep. Brit., 460, 1811; Treitschke, Schm. Eur, , viii, 145, 1830; Herrich-SchaEFFER, Schm. Eur., iv, 215, 1851; WILKInson, Brit. Tort., 267, 1859; Heinemann, Kleinschm., i, 1, $126,1863$.

*5062. astrologana ZeLLÉr, Verh. zool.-bot. Ges. Wien, XXv, 281, 1875 .

*5063. puncticostana Walker, Cat. Brit. Mus., xxviii, 339, 1863; Walsingham, Ill. Lep. Het., iv, 33, 1879 .

5064. instrutana Clemens, Proc. Ent. Soc. Phil., v, 135,1865 .

syn. poana Zeller, Verh. zool.-bot. Ges. Wien, xxv, 282, 1875.

5065. turfosana Herrich-Schaeffer, Schm. Eur., iv, 217, 1851; Heinemann, Kleinschm., i, 1, 114, 1863.

*5066. campestrana ZelLer, Verh. zool.-bot. Ges. Wien, $\mathrm{xxv}, 282,1875$.

5067. fuscalbana ZelLer, Verh. zool. bot. Ges. Wien, xxv, 284, 1875 .

*5068. glaciana Möschler, Wien. ent. Mon., iv, 380, 1860.

*5069. dealbana Walker, Cat. Brit. Mus., xxviii, 374, 1863; Walsingham, Ill. Lep. Het., iv, 34, 1879.

*5070. dilutifuscana Walsingham, Ill. Lep. Het. Brit. Mus., iv, 33, 1879.

5071. bipartitana Clexiens, Proc. Acad. Nat. Sci. Phil., 346, 1860; Packard, Guide Stud. Ins., 333, 1869. syn. cæsialbana ZelLer, Verh. zool.-bot. Ges. Wien, xxv, 285, 1875.

*5072. similisana W ALKer, Cat. Brit. Mus., xxviii, 373, 1863.

*5073. impudens Walsingham, Trans. Ent. Soc. Lond., 135,1884 .

*5074. inquietana WaLker, Cat. Brit. Mers., xxviii, 378, 1863.

5075. niveiguttana Grote, Bull. Buff. Soc., i, 91, 1873. Mass., N. Y., Pa., Mo.

No. Atl.

States.

Mass.,

N. C.

Aretic

Am.

U.S.

No. Atl.

Me.,
Mass.

Me., Mass.,

Lab.,

Ont.

Me.,

Mo.

Oreg.

No.

Eur.,

Tex.

Nova Scotia, Me. States.

Nur., Lab., ss. 
5076. schulziana Fabricius, Gen. Ins., 293, 1777; ZETTERSTEDT, Ins. Lap., 983, 1840; WILKINSON, Brit. Tort., 276, 1859; Heinemann, Kleinschm., i, 1, 120, 1863.

syn. pinetana HüBner, Schm. Eur., Tort., f. 57, 1800; ahrensiana GeYer, Eur. Schm., Tort., ff. 337, 338, 1834; bentleyana Donovan, Nat. Hist. Brit. Ins., x, pl. 357, f.1,1801; ainckenana FröLICH, En. Tort. Würt., 71, 1828; Treitschke, Schm. Eur., viii, 143, 1830; Duponchel, Hist. Nat. Lép. Fr., ix, 225, 1834; Herrich-Schaeffer, Schm. Eur., iv, 210, 1851.

\section{PHACASIOPHORA Grote.}

Grote, Bull. Buff. Soc., i, 90, 1873.

5077. confixana Walker, Cat. Brit. Mus., xxviii, 340, 1863; Walsingham, Ill. Lep. Het., iv, 36, 1879.

Atl. States. syn. perductana Walker, Cat. Brit. Mus., xxviii, 341, 1863; mutabilana Clemens, Proc. Ent. Soc. Phil., v, 135, 1865; Grote, Bull. Buff. Soc., i, 90, 1873; Zeller, Verh. zool.-bot. Ges. Wien, xxv, 276, 1875.

\section{PSEUDOGALLERIA Ragonot.}

Ragonot, Ann. Soc. Ent. Fr., (6), iv, Bull. 1, 1885.

5078. inimicella Zeller, Verh. zool.-bot. Ges. Wien, Atl. States.

Eur., Aretic Am.

\section{Hites.}

\section{xxii, $559,1872$.}

\section{EUCOSMA Hübner.}

Hübner, Zutr. exot. Schmett., ii, 28, 1823; Pædisca Treitschke, Schmett. Eur., viii, 188, 1830; Heinemann, Kleinschm., i, 1, 142, 1863.

5079. circulana HüBner, Zutr. exot. Schmett., ii, ff. 363, $364,1823$.

So. Atl. States.

syn. scintillana Clemens, Proc. Ent. Soc. Phil., v, 142, 1865; Packard, Guide Stud. Ins., 337, 1869; dodecana ZelLer, Verh. zool.-bot. Ges. Wien, xxv, 311, 1875.

*5080. quinquemaculana Robinson, Trans. Am. Ent. Soc., ii, 284, 1869.

syn. robinsonana Grote, Can. Ent., iv, 101, 1872; quintana ZeLLer, Verh. zool.-bot. Ges. Wien, xxv, 304, 1875.

5081. bolanderana Walsingham, Ill. Lep. Het., iv, 42, 1879.

*5082. agassizii Robinson, Trans. Am. Ent. Soc., ii, $284,1869$. 
5083. ridingsana Robinson, Trans. Am. Ent. Soc., ii, $285,1869$.

Tex.,

Col.,

a. argentifurcatana Grote, Can. Ent., viii, 206,

Can. 1876.

b. hipeana Grote, Can. Ent., viii, 207, 1876.

*5084. fernaldana Grote, No. Am. Ent., 98, 1880.

5085. crambitana Walsingham, Ill. Lep. Het., iv, 43, 1879.

5086. monogrammana ZelLer, Verh. zool.-bot. Ges. Wien, xxv, 313, 1875.

*5087. larana Walsingham, Ill. Lep. Het., iv, 43, 1879.

*5088. luridana W alsingham, Ill. Lep. Het., iv, 44, 1879.

*5089. argentialbana Walsingham, Ill. Lep. Het., iv, 44, 1879 .

5090. albiguttana ZeLler, Verh. zool.-bot. Ges. Wien, xxv, 313, 1875 .

*5091. atomosana Walsingham, Ill. Lep. Het., iv, 42, 1879.

*5092. agricolana Walsingham, Ill. Lep. Het., iv, 42, 1879.

*5093. basipunctana Walsingham, IIl. Lep. Het., iv, 40, 1879.

*5094. subplicana Walsingham, IIl. Lep. Het., iv, 41, 1879.

*5095. primulana Walsingham, Ill. Lep. Het., iv, 45, 1879.

5096. cataclystiana Walker, Cat. Brit. Mus., xxviii, 378, 1863; Walsingham, Ill. Lep. Het., iv, 46, 1879 .

syn. ochreana Clemens, Proc. Ent. Soc. Phil., iii, 520, 1864; Packard, Guide, 337, 1869.

5097. ochraceana Fernald, Jn. N. Y. Ent. Soc., ix, 51, 1901.

*5098. comatulana Zeller, Verh. zool.-bot. Ges. Wien, $\mathrm{xxv}, 316,1875$.

*5099. occipitana Zeller, Verh. zool.-bot. Ges. Wien, xxv, 315, 1875.

*5100. numerosana Zeller, Verh. zool.-bot. Ges. Wien, xxv, 317, 1875.

5101. giganteana RiLey, Trans. St. Louis Acad. Sci., iv, 318, 1881.

Ky., Col.

Cal.

Tex.

Cal.

Cal.

Tex.

Tex.

Cal.

Cal., Oreg., Ariz.

Cal.

Cal., Oreg.

Cal.

Me., Va., Tex., Cal.

Fla.

Tex.

Tex.

Tex.

N. H., IIl., Iowa, Kans. 
*5102. perdricana Walsingham, IIl. Lep. Het., iv, 49, 1879.

*5103. glomarana Walsingham, Ill. Lep. Het., iv, 49, 1879.

*5104. fulminana Watsingham, Ill. Lep. Het., iv, 50, 1879 .

Cal.

Tex,

Tex., Ill., Cal.

Cal.

*5105. irroratana Walsingham, Ill. Lep. Het., iv, 48, 1879.

5106. bipunctella WALKer, Cat. Brit. Mus., xxvii, 202, 1863; Walsingham, Ill. Lep. Het., iv, 47, 1879. syn. worthingtoniana Fernald, Can. Ent., x, $83,1878$.

*5107. grandiflavana Walsingham, Ill. Lep. Het., iv, 47,1879 .

*5108. subflavana Walsingham, IIl. Lep. Het., iv, 48, 1879 .

*5109. shastana Walsingham, Ill. Lep. Het., iv, 46, 1879.

*5110. biquadrana W ALsingham, Ill. Lep. Het., iv, 45, 1879 .

*5111. maculatana Walsingham, Ill. Lep. Het., iv, 48, 1879 .

*5112. palpana W alsingham, Ill. Lep. Het, iv, 54, 1879.

*5113. radicana Walsingham, Ill. Lep. Het., iv, 53, 1879 .

*5114. passerana Walsingham, Ill. Lep. Het., iv, 49, 1879.

*5115. canana Walsingham, Ill. Lep. Het., iv, 50, 1879. 5116. lineana Fernald, Journ. N. Y. Ent. Soc., ix, 50, 1901.

*5117. culminana Walsingham, IIl. Lep. Het., iv, 38, 1879 .

5118. rectiplicana Walsingham, Ill. Lep. Het., iv, 40, 1879 .

*5119. terracoctana Walsingham, Ill. Lep. Het., iv, 39, 1879.

*5120. albangulana WaLsingham, Ill. Lep. Het., iv, 40, 1879 .

5121. juncticiliana Walsingham, Ill. Lep. Het., iv, 75, Me. to Cal. 1879.

*5122. pulveratana Walsingham, Ill. Lep. Het., iv, 45, 1879.

Tex., Cal., Ariz. 
*5123. nigralbana Walsingham, IIl. Lep. Het., iv, 41, 1879.

Me.,

Cal.

5124. abbreviatana Walsingham, Ill. Lep. Het., iv, 54, 1879.

Mass., Pa.,

D. C.

Fla.,

Tex.

$\mathrm{xxv}, 305,1875$.

5126. abruptana WaLsingham, III. Lep. Het., iv, 53, 1879.

Va.,

Tex.

5127. solicitana WALKer, Cat. Brit. Mus., xxviii, 387, 1863; Walsingham, Ill. Lep. Het., iv, 55, 1879.

syn. packardiana Clemens, Proc. Ent. Soc.

Phil., ii, 417, 1864; tephrinana ZelLer,

Verh. zool.-bot. Ges. Wien, xxv, 309, 1875.

*5128. transmissana Walker, Cat. Brit. Mus., xxviii, 375, 1863; Walsingham, Ill. Lep. Het., iv, 52, 1879 .

5129. strenuana WaLker, Cat. Brit. Mus., xxviii, 383, 1863; Walsingham, Ill. Lep. Het., iv, 52, 1879. syn. exvagana WALKER, Cat. Brit. Mus., xxviii, 383, 1863; Alavocellana Clemens, Proc. Ent. Soc. Phil., v, 138, 1865; subversana Zeller, Verh. zool.-bot. Ges. Wien, xxv, 318, 1875 .

5130. perplexana Fernatd, Jn. N. Y. Ent. Soc., ix, 51, 1901.

5131. nisella Clerck, Icon., pl. 12, f. 6, 1759; LiNnæUs, Faun. Suec., 357, 1761; WiLkinson, Brit. Tort., 78, 1859; Heinemann, Kleinschm., i, 1, 158, 1863; Merrick, Handb. Brit. Lep., 493, 1895 .

*5132. hirsutana Walsingham, Ill. Lep. Het., iv, 50, 1879.

*5133. improbana Walker, Cat. Brit. Mus., xxviii, 337, 1863; Walsingham, Ill. Lep. Het., iv, 51, 1879. syn. diffinana W ALKer, Cat. Brit. Mus., xxviii, $378,1863$.

*5134. trigeminana Stephens, Ill. Brit. Ent., Haust., iv, 94, 1834; Wilkinson, Brit. Tort., 94, 1859.

syn. argyrana Stephens, Ill. Brit. Ent., Haust., iv, 95, 1834; precilana Guenée, Ann. Soc. Ent. Fr., (2), iii, 177, 1845; HerrichSchaeffer, Schm. Eur., iv, 241, 1851; Heinemann, Kleinschm., i, 1, 152, 1863.

*5135. vertumnana ZeLLer, Verh. zool.-bot. Ges. Wien, xxv, 310, 1875.

No. Atl. States.

No. Atl.

States.

Atl.

States.

Fla.

Eur.,

Can.

Cal.,

Oreg.

Hudson

Bay.

Eur., Cal., Oreg.

N. Y.,

Tex. 
5136. celtisana Riley, Trans. St. Louis Acad. Sci., iv, $319,1881$.

*5137. matutina Grote, Bull. Buff. Soc., i, 92, 1873.

5138. illotana W alsingham, Ill. Lep. Het., iv, 39, 1879.

5139. scudderiana Clemens, Proc. Acad. Nat. Sci. Phil., 358, 1860.

syn. saligneana Clemens, Proc. Ent. Soc. Phil., v, 141, 1865; Packard, Guide Stud. Ins., 337, 1869; Riley, Rep. Ins. Mo., ii, 134, 1870; affusana Zeller, Verh. zool.bot. Ges. Wien, xxv, 307, 1875.

5140. desertana Zeller, Verh. zool.-bot. Ges. Wien, $\mathrm{xxv}, 306,1875$.

5140. 1. obfuscana Riley, Proc. Ent. Soc. Wash., i, 33, $1888 .{ }^{a}$

*5141. tripartitana ZeLler, Verh. zool.-bot. Ges. Wien, xxv, 308, 1875.

5142. otiosana Clemens, Proc. Acad. Nat. Sci. Phil., $354,1860$.

syn. inclinana ZelLer, Verh. zool.-bot. Ges. Wien, xxv, 301, 1875.

5143. similana HüBner, Vög. \& Schm., f. 71, 1792; Eur. Schm., Tort., f. 41, 1800; Frölich, En. Tort. Würt., 47, 1828.

syn. bimaculana Donovan, Nat. Hist. Brit. Ins., xiii, pl. 459, 1808; HeInemann, Kleinschm., i, 1, 145, 1863; Zeller, Verh. zool.-bot. Ges. Wien, xxv, 302, 1875; dissimilana Treitschke, Schm. Eur., x, 3, 103, 1835; F. v. Röslerstami, Ber. Sch., 170, 1839; Herrich-Schaeffer, Schm. Eur., iv, 239, 1851; cervana Eversmann, Faun. Volg. Ural., 507, 1844.

5144. dorsisignatana Clemens, Proc. Acad. Nat. Sci. Phil., 353, 1860.

syn. similana Clemens, Proc. Acad. Nat. Sci. Phil., 353, 1860; distigmana W ALKER, Cat. Brit. Mus., xviii, 384, 1863; clavana ZELLER, Verh. zool.-bot. Ges. Wien, xxv, 303, 1875 ; graduatana Walsingham, III. Lep. Het., iv, 54, 1879.

*5145. adamantana Guenée, Ann. Soc. Ent. Fr., (2), iii, 303,1845 .

Tex.

Tex.

Oreg.

No. Atl. States.

Tex., N. Y.

Atl. States.

Tex.

So. Atl. States.

Eur., Me., Mass.

Atl. States.

N. J.

$a$ Riley's type specimen closely resembles desertana Zeller, but the dark marks are more diffuse, especially the patch near tornus, which is gray, showing no black scales.-Harrison G. Dyar. 
*5146. argenteana Walsingham, Trans. Ent. Soc. Lond., Col. 504,1895 .

*5147. aspidana Walsingham, Trans. Ent. Soc. Lond., Ariz. $140,1884$.

*5148. biplagata Walsingmam, Trans. Ent. Soc. Lond., $507,1895$.

*5149. caniceps Walsingham, Trans. Ent. Soc. Lond., $137,1884$.

*5150. carolinana Walsingham, Trans. Ent. Soc. Lond., 509,1895 .

*5151. castaneana Walsingham, Trans. Ent. Soc. Lond., 511,1895 .

5152. corosana Walsingham, Trans. Ent. Soc. Lond., $139,1884$.

*5153. dilatana Walsinghay, Trans. Ent. Soc. Lond., 510,1895 .

Col.

Mont.

N. C.

Col.

Mont.

Ariz.

*5154. emaciatana Walsingham, Trans. Ent. Soc. Lond.,

Ariz. 137, 1884.

*5155. fuscosparsa Walsingham, Trans. Ent. Soc. Lond., 507,1895 .

*5156. hyponomeutana Walsingham, Trans. Ent. Soc. Lond., 502, 1895.

*5157. invicta Walsingham, Trans. Ent. Soc. Lond., 509, 1895 .

*5158. mediostriata Walsingham, Trans. Ent. Soc. Lond., 508, 1895.

5159. morrisoni Walsinghay, Trans. Ent. Soc. Lond., 138, 1884.

*5160. ragonoti Walsingham, Trans. Ent. Soc. Lond., 503,1895 .

*5161. serpentana W alsingham, Trans. Ent. Soc. Lond., 504,1895 .

*5162. smithiana Walsingham, Trans. Ent..Soc. Lond., 506, 1895 .

Col.

Col.

Col.

Col.

Mont.

Col.

Cal.

Col.

THIODIA Hübner.

HüBner, Verz. bek. Schmett., 391, 1826; Walsingham, Proc. Zool. Soc. Lond., 125, 1897; Semasia Herrich-Schaeffer, Schm. Eur., iv, 244, 1851; Heinemann, Kleinschm., i, 1, 166, 1863.

5163. radiatana Walsinghà, Ill. Lep. Het., iv, 55, 1879.

Nova Scotia, Me., N. Y.

5164. olivaceana Riley, Trans. St. Louis Acad. Sci., III. iv, 320, 1881. 
5165. formosana Clemens, Proc. Acad. Nat. Sci. Phil., 360, 1860; Packard, Guide Stud. Ins., 338, 1869.

syn. sagittana W.ALKER, Cat. Brit. Mus., xxviii, 386, 1863; stercoreana ZelLer, Verh. zool.-bot. Ges. Wien, xxv, 290, 1875.

*5166. corculana Zeller, Verh. zool.-bot. Ges. Wien, xxiv, 11, 1874.

5167. aspidiscana HüBNER, Eur. Schmett., Tort., f. 256, 1818; Frölich, En. Tort. Würt., 96, 1828; Treitschке, Schm. Eur., viii, 210, 1830; Stephens, Ill. Brit. Ent., Haust., iv, 120, 1834; Duponchel, Hist. Nat. Lép. Fr., ix, 275, 1834; Herrich-Schaeffer, Schm. Eur., iv, 247, 185.1; Heinemann, Kleinschm., i, 1, 120, 1863.

syn. dahlbomiana Zetrerstedt, Ins. Lap., $897,1840$.

*5168. ferruginana Fernald, Trans. Am. Ent. Soc., x, 72,1882 .

5169. succedana Schiffermüller, Syst. Verz. Wien, 129, 1776; Frölich, En. Tort. Würt., 95, 1828; Treitschk E, Schm. Eur., viii, 211, 1830; Duponchel, Hist. Nat. Lép. Fr., ix, 302, 1834; Herrich-Schaeffer, Schm. Eur., iv, 252, 1851; Hemnemann, Kleinschm., i, 1, 193, 1863.

syn. asseclana HüBner, Schm. Eur., Tort., f. 194, 1800; decorana HaworTH, Lep. Brit., 437, 1811; ulicetana Haworth, Lep. Brit., 458, 1811; lanceolana Stephens, Ill. Brit. Ent., Haust., iv, 121, 1834.

a. gallicana Herrich-SchaEfFer, Schm. Eur., iv, 252,1851 .

b. conjunctana Möschler, Berl. ent. Zeit., 140, 1866.

*5170. rœssleri Zeller, Verh. zool.-bot. Ges. Wien, xxv, 291, 1875 .

5171. vestaliana Zecler, Verh. zool.-bot. Ges. Wien, $\mathrm{xxv}, 286,1875$.

*5172. elongana Walsingham, Ill. Lep. Het., iv, 56, 1879 .

*5173. tarandana Möschler, Stett. ent. Zeit., xxiv, 165, 1874.

No. Atl.

States.

Eur.,

Oreg.

ancouve
Island.

Eur.,

Oreg.

No. Atl.

States. 
*5176. spiculana Zeller, Verh. zool. -bot. Ges. Wien, Tex. xxv, 289, 1875.

5177. striatana Clemens, Proc. Acad. Nat. Sci. Phil., $349,1860$.

syn. albicepsana Walker, Cat. Brit. Mus., xxviii, 379, 1863; trivittana ZELLER, Verh. zool.-bot. Ges. Wien, xxv, 287, 1875.

5178. tenuiana Walsingham, IIl. Lep. Het., iv, 59, 1879.

States.

*5179. clavana Fernald, Trans. Am. Ent. Soc., x, 72, 1882.

*5180. pallidicostana Walsingham, Ill. Lep. Het., iv, $62,1879$.

*5181. griseocapitana Walsingham, Ill. Lep. Het., iv, $61,1879$.

*5182. taleana Grote, Can. Ent., x, 54, 1878.

*5183 perangustana Walsingham, Ill. Lep. Het., iv, $58,1879$.

5184. amphorana Walsingham, Ill. Lep. Het., iv, 63, 1879.

*5185. decempunctana Walsingham, Ill. Lep. Het., iv, 58,1879 .

5186. helianthana Riley, Trans. St. Louis Acad. Sci., iv, 319, 1881.

*5187. columbiana Walsingham, Ill. Lep. Het., iv, 57, 1879 .

5188. scalana Walsingham, Ill. Lep. Het., iv, 57, 1879.

*5189. signatana Clemens, Proc. Ent. Soc. Phil., iii, $514,1864$.

syn. variana Clemens, Proc. Ent. Soc. Phil., iii, 520, 1864; aceriella Clemens, Tin., No. Am. 178, 1872; subnisana Zeller, Verh. zool.-bot. Ges. Wien, xxv, 294, 1875.

5190. lapidana W alsingham, Ill. Lep. Het.,iv, 58, 1879.

*5191. sublapidana WaLsingham, Ill. Lep. Het., iv, 59, 1879.

*5192. parvana Walsingham, Ill. Lep. Het., iv, 60, 1879.

*5193. stramineana WaLsingham, Ill. Lep. Het., iv, 60, 1879.

*5194. minimana Wa dsingham, Ill. Lep. Het., iv, 60, 1879.

Cal.,

Nev.

Mass.

Cal.

Cal.

III.

Cal.

Oreg.,

Col.

Oreg.

Md.,

Tex.

Oreg.

Cal., Oreg.

Atl.

States.

Oreg。

Oreg.

Oreg.

Col.

Cal. 
5195. infuscana Walsinghay, IIl. Lep. Het., iv, 62, Cal. 1879.

*5196. refusana Walker, Cat. Brit. Mus., xxviii, 382, 1863; Walsingham, Ill. Lep. Het. Brit. Mus., iv, 63,1879 .

*5197. perstructana Walker, Cat. Brit. Mus., xxviii, 343, 1863; Walsingham, Ill. Lep. Het. Brit. Mus., iv, 64, 1879.

*5198. offectalis Hulst, Trans. Am. Ent. Soc., xiii, 166, 1886.

Can.

Hudson

Bay.

syn. bucephaloides Walsingham, Ins. Life, iii, $465,1891$.

5199. apacheana W alsinghay, Trans. Ent. Soc. Lond., $149,1884$.

*5200. montanana Walsingham, Trans. Ent. Soc. Lond., $143,1884$.

*5201. obliterana Walsinghay, Trans. Ent. Soc. Lond., 513,1895 .

Col., N. Mex., Cal.

Ariz.

Mont.

Ariz., Col.

5202. ochreicostana Walsingham, Trans. Ent. Soc. Lond., 141, 1884.

Mont.

*5203. ochrocephala Walsinghay, Trans. Ent. Soc. Lond., 513, 1895.

Col.

*5204. octopunctana WalsinghaM, Trans. Ent. Soc. Lond., 512, 1895.

*5205. transversa Walsingham, Trans. Ent. Soc. Lond., 514,1895 .

\section{EPISIMUS Walsingham.}

Walsingham, Proc. Zool. Soc. Lond., 501, 1891; 122, 1897.

5206. augmentanus Zeller, Hor. Soc. Ent. Ross., xiii, 158, 1877; Walsingham, Proc.Zool.Soc. Lond., 502, 1891; 123, 1897; DYaR, Proc. Ent. Soc. Wash., iv., 468, 1901.

5207. argutanus Clemens, Proc. Acad. Nat. Sci. Phil., 358, 1860; Drar, Proc. Ent. Soc. Wash., iv, $469,1901$.

syn. allutana ZelLer, Verh. zool.-bot. Ges.

Wien, xxv, 295, 1875.

\section{EXENTERA Grote.}

Grote, Can. Ent., ix, 227, 1877.

5208. apriliana Grote, Can. Ent., ix, 227, 1877.

Fla.,

W. I.
Can. to Fla., Tex., W. I.

Col.

Col. 
HYSTRICOPHORA Walsingham.

Walsingham, Ill. Lep. Het., iv, 64, 1879.

*5209. leonana Walsingham, Ill. Lep. Het. Brit. Mus., iv, $65,1879$.

a. aurantiana WALsInghaM, Ill. Lep. Het., iv, $65,1879$.

\section{PROTEOPTERYX Walsingham.}

Waisingham, Ill. Lep. Het., iv, 68, 1879.

5210. emarginana Walsinghai, Ill. Lep. Het. Brit. Mus., iv, 68, 1879.

*5211. oregonana Walsingham, Ill. Lep. Het. Brit. Mus., iv, 62, 1879.

5212. cressoniana Clemens, Proc. Ent. Soc. Phil., iii, 514,1864 .

Cal., Ariz.

Oreg.

N. Y., $\mathrm{Va}$.

5213. deludana Clemens, Proc. Ent. Soc. Phil., iii, 513,1864 .

So. Atl. States.

5214. spoliana Clemens, Proc. Ent. Soc. Phil., iii, $513,1864$.

So. Atl.

States.

*5215. resuptana Walker, Cat. Brit. Mus., xxviii, 376 , 1863; Walsinghà, Ill. Lep. Het., iv, 44, 1879.

*5216. virginiana Clemens, Proc. Ent. Soc. Phil., iii, $512,1864$.

5217. costomaculana Clemens, Proc. Acad. Nat. Sci. Phil., 349, 1860.

syn. bipustulana Walker, Cat. Brit. Mus., xxviii, 316, 1863.

*5218. pulchellana Clemens, Proc. Ent. Soc. Phil., iii, 511, 1864.

\section{PROTEOTERAS Riley.}

Riley, Trans. St. Louis Acad. Sci., iv, 321, 1881.

5219. æsculanum Riler, Trans. St. Louis Acad. Sci., iv, 321, 1881.

EPINOTIA Hübner.

HüBNer, Verz. bek. Schmett., 377, 1826.

5220. incarnana Haworth, Lep. Brit., 435, 1811; STEPHens, Ill. Brit. Ent., Haust., iғ. 120, 1834.

syn. dealbana Frölich, En. Tort. Würt., 51, 1828; Herrich-Schaeffer, Schm. Eur., iv, 232, 1851; Wilkinson, Brit. Tort., 120, 1859; Hernemann, Kleinschm., i, 1, 207, 1863; minorana TreitschKe, Schm. Eur., viii, 48, 1830; Duponchel, Hist. Nat. Lép. Fr., ix, 573, 1834.
N. Y., Mo., Tex.

Nova Scotia, $\mathrm{Pa}$. Va.

Me., Pa.

Va,

Eur., Cal. 
*5221. fasciolana Clemens, Proc. Ent. Soc. Phil., iii, 511,1864 .

syn. blakeana Grote, Bull. Buff. Soc., i, 91, 1873.

5222. lagopana WaLsinghim, Ill. Lep. Het., iv, 71, 1879.

*5223. liturana W alsingham, Ill. Lep. Het., iv, 71, 1879.

*5224 purpuriciliana Walsingham, Ill. Lep. Het., iv, $72,1879$.

5225. salicicolana Clemens, Proc. Ent. Soc. Phil., iii, 514,1864 .

5226. saliciana Clemens, Proc. Ent. Soc. Phil., iii, 515, 1864.

5227. crispana Cenmens, Proc. Ent. Soc. Phil., v, 137 1865 .

5228. augustana HüBner, Schm. Eur., Tort., f. 205, 1818; Treitschke, Schm. Eur., viii, 221, 1830; Duponchel, Hist. Nat. Lép. Fr., ix, 486, 1834; Zeller, Isis, 247, 1846; Herrich-Schaeffer, Schm. Eur., iv, 272, 1851; Heinemann, Kleinschm., i, 1, 219, 1863.

syn. cmuciana Zetterstedt, Ins. Lap., 981, 1840; pullana Eversuann, Faun. Volg. Ural., 512, 1844; direptana Walker, Cat. Brit. Mus., xxviii, 338, 1863; vilisana WALKER, Cat. Brit. Mus., xxviii, 338, 1863.

5229. pinicolana Zeller, Isis, 242, 1846; HerrichSchaeffer, Schm. Eur., iv, 207, 1851; HeineMANN, Kleinschm., i, 1, 210, 1863.

syn. occultana WiLkinson, Brit. Tort., 223, 1859.

*5230. biangulana Walsingham, Ill. Lep. Het., iv, 71, 1879.

*5231. nebulosana Packard, Proc. Bost. Soc. Nat. Hist., xi, $61,1866$.

5232. claypoleana Riley, Psyche, iii, 364, 1882; Am. Nat., xvi, 913, 1882; Pap., iii, 191, 1883; РАCKARD, Rept. U. S. Ent. Com., v, 654, 1890; Lintner, Rept. N. Y. St. Ent., xii, 214, 1897.

syn. instrutana Claypole (not Clemens), Proc. Am. Assoc. Adv. Sci., 269, 1882; Riley, Am. Nat., xv, 1009, 1881.

5233. ratzeburgiana SAXESEN, Forst-Ins., ii, 227, 1840; Fernald, Rept. Dept. Agr., 378, 1884; РaCKARD, Rept. U. S. Ent. Com., v, 845, 1890.

$4630-$ No. $52-02-30$
Me., Mass., N. Y., Pa.

Cal., Ariz., Mont.

Cal.

Cal.

III.

Ill.

No. Atl.

States.

Eur.,

Hudson

Bay,

Cal.

Eur., N. Y., Wis.

Oreg.

Lab.

N. Y., Pa., Ohio.

Me.,

Eur. 
*5234. pyricolana Murtfeldt, Bull. no. 23, U. S. Dept. Agr., 52, 1891.

5235. lindana Fernald, Can. Ent., xxiv, 178, 1892.

*5236. medioplagata Walsingham, Trans. Ent. Soc. Lond., 516, 1895.

Mo.

Can., Mass.

Col.

TMETOCERA Lederer.

Lederer, Wien. ent. Mon., iii, 367, 1859; Heinemann, Kleinschm., i, 1, 206, 1863; Meyrick, Handb. Brit. Lep., 476, 1895.

5237. ocellana Schiffermüller, Syst. Verz. Wien, 130, 1776; Fabricius, Mant. Ins., ii, 228, 1787; Treitschke, Schm. Eur., viii, 40, 1830; HerRICH-SCHAEFFER, Schm. Eur., iv, 233, 1851; Wilkinson, Brit. Tort., 118, 1859; Lederer, Wien. ent. Mon., iii. 368, 1859; Hernemann, Kleinschm., i, 1, 206, 1863; Zeller, Verh. zool.bot. Ges. Wien, xxv, 267, 1875 .

syn. Tuscana FABricius, Ent. Syst., 255, 1793; Frölich, En. Tort. Würt., 50, 1828; DuponCHel, Hist. Nat. Lép. Fr., ix, 203, 1834; comitana HüBner, Schm. Eur., Tort., f. 16, 1800; pyrifoliana Clemens, Proc. Acad. Nat. Sci. Phil., 357, 1860; oculana HARris, Inj. Ins., 482, 1862; Saunders, Can. Ent., iii, $13,1871$.

\section{EUDEMIS Hübner.}

Hübner, Verz. bek. Schmett., 382, 1826; Meyrick, Handb. Brit. Lep., 476, 1895.

5238. vacciniana Packard, Guide Stud. Ins., 338, 1869; Glover, Rept. U. S. Dept. Agr., 85, 1870 ; Smith, Bull. no. 4, U. S. Dept. Agr., 10, 1884; SAUNNo.
U. S.,
Eur. DERs, Inj. Ins., 369, 1889.

syn. ? luctiferana WALKer, Cat. Brit. Mus., xxviii, 342, 1863.

\section{ANCYLIS Hübner.}

Hübner, Verz. bek. Schmett., 376, 1826; Мeyrick, Handb. Brit. Lep., 477, 1895; Phoxopteris Treitschke, Schm. Eur., vii, 232, 1829; Duponchel, Hist. Nat. Lép. Fr., ix, 22, 1834.

5239. mediofasciana Clemens, Proc. Ent. Soc. Phil., iii, 511, 1864; Zeller, Verh. zool.-bot. Ges. Wien, xxv, 248, 1875.

No.
U. S.,
Cal.

5240. nubeculana Clemens, Proc. Acad. Nat. Sci. Phil., 349, 1860; Zeller, Verh. zool.-bot. Ges. Wien, Me., Mass., N. Y. xxv, 249, 1875; Riley, Rept. U. S. Dept. Agr., No. Atl. States. $239,1878$.

*5241. subæquana Zeller, Verh. zool.-bot. Ges. Wien, $\mathrm{xxv}, 254,1875$. 
*5242. discigerana Walker, Cat. Brit. Mus., xxviii, $384,1863$.

No. Atl. States.

5243. semiovana ZelLer, Verh. zool.-bot. Ges. Wien, $\mathrm{xxv}, 250,1875$.

Me.,

N. Y.

Mo.

5244. murtfeldtiana Riley, Trans. St. Louis Acad. Sci., iv, $323,1881$.

5245. lundana Fabricius, Gen. Ins., 294, 1777; Donovan, Nat. Hist. Brit. Ins., xi, pl. 374, f. 1, 1804; Haworth, Lep. Brit., 452, 1811; Frölich, En. Tort. Würt., 99, 1828; Wilkinson, Brit. Tort., 138,1859 .

syn. badiana Schiffermüller, Syst. Verz.

Wien, 126, 1776; Treitschke, Schm. Eur., viii, 243, 1830; Duponchel, Hist. Nat. Lép. Fr., ix, 343, 1834; Herrich-SchaEFFER, Schm. Eur., iv, 285, 1851; Heinemann, Kleinschm., i, 1, 225, 1863; corylana HüBNER, Vög. \& Schm., f. 63, 1792; Schm. Eur., Tort., f. 53, 1800.

*5246. spiræifoliana Clemens, Proc. Acad. Nat. Sci. Phil., 348, 1860.

syn. metamelana Walker, Cat. Brit. Mus., xxviii, 385, 1863; discoferana W ALKER, Cat. Brit. Mus., xxviii, 386, 1863.

5247. laciniana ZeLLer, Verh. zool.-bot. Ges. Wien, $\mathrm{xxv}, 253,1875$.

5248. burgessiana Zexler, Verh. zool. -bot. Ges. Wien, xxv, 252, 1875 .

*5249. dubiana Clemens, Proc. Ent. Soc. Phil., iii, 512, 1864.

*5250. floridana Zelcer, Verh. zool.-bot. Ges. Wien, xxv, 258, 1875 .

*5251. amblygona Zeller, Verh. zool. -bot. Ges. Wien, $\mathrm{xxv}, 259,1875$.

5252. comptana Frölich, En. Tort. Würt., 99, 1828; Duponchel, Lép. Fr., suppl., 187, 1844; HerRICH-SchaEFFER, Schm. Eur., iv, 286, 1851; Wilkinson, Brit. Tort., 141, 1859; Heinemann, Kleinschm., i, 1, 225, 1863; Zeller, Verh. zool.bot. Ges. Wien, xxv, 257, 1875.

syn. comflexana WALKer, Cat. Brit. Mus., xxviii, 384, 1863; fragariæ W ALSH \& RILEY, Am. Ent. i, 89, 1869; Riley, Rep. Ins. Mo., i, 142, 1869; PACKARD, Guide Stud. Ins., $340,1869$.

*5253. angulifasciana Zeller, Verh. zool.-bot. Ges. Wien, xxv, 256, 1875.

Me., Mass., Ohio. 
5254. platanana Clemens, Proc. Acad. Nat. Sci. Phil., $349,1860$.

syn. marcidana ZeLLer, Verh. zool.-bot. Ges. Wien, xxv, 260, 1875.

5255. divisana Walker, Cat. Brit. Mus., xxviii, 385, 1863; Walsingham, Ill. Lep. Het., iv, 74, 1879.

5256. apicana W Alker, Cat. Brit. Mus., xxxv, 1795, 1866; Walsingham, Ill. Lep. Het., iv, 73, 1879.

5257. cornifoliana Riley, Trans. St. Louis Acad. Sci., iv, 324, 1881.

*5258. muricana Walsingham, Ill. Lep. Het., iv, 74, 1879.

5259. uncana HüBNER, Schmett. Eur., Tort., f. 76, 1800; Haworth, Lep. Brit., 451, 1811; Frölich, En. Tort. Würt. 101, 1828; Treitschke, Schm. Eur., viii, 237, 1830; Duponchel, Hist. Nat. Lép. Fr., ix, 335, 1834; Herrich-Schaeffer, Schm. Eur., iv, 286, 1851; Wilkinson, Brit. Tort., 137, 1859.

syn. geminana Donovan, Nat. Hist. Brit. Ins., xi, 29, 1804; uncella Heinemann, Kleinschm., i, 1, 224, 1863.

5260. biarcuana Stephens, Cat., ii, 178, 1829; WILkinson, Brit. Tort., 136, 1859; Heinemann, Kleinschm., i, 1, 223, 1863.

syn. cuspidana Stephens, Ill. Brit. Ent., Haust., iv, 113, 1834; crenana Duponchel, Hist. Nat. Lép. Fr., ix, 334, 518, 1834; Aluctigerana Herrich-Schaeffer, Schm. Eur., iv, $286,1851$.

*5261. goodelliana Fernald, Trans. Am. Ent. Soc., x, 69,1882 .

*5262. plagosana Clemens, Proc. Ent. Soc. Phil., ii, 417,1864 .

5263. pacificana Walsingham, Ill. Lep. Het., iv, 73, 1879.

*5264. cometana Walsingham, IIl. Lep. Het., iv, 74, 1879.

*5265. loricana Grote, Can. Ent., xii, 218, 1880.

*5266. tineana HüBNER, Schm. Eur., Tort., f. 81, 1800; Herrich-Schaeffer, Schm. Eur., iv, 284, 1851; Heinemann, Kleinschm., i, 1, 223, 1863.

syn. ocellana Clemens, Proc. Ent. Soc. Phil., iii, 510, 1864; leucophaleratana PACKARD, Proc. Bost. Soc. Nat. Hist., xi, 56, 1866.

5267. kincaidiana Fernald, Proc. Wash. Acad. Sci, ii, 500, 1900.
Pa., Mo., Tex.

Nova Scotia, Mass.

Nova Scotia, Mass., Oreg. Mass., Pa., Kans.

D. C.

Eur., N. H.

Eur., Cal.

N. Eng.

Lab.

Cal., Oreg.

Cal.

Ohio.

Eur., Lab., Me., Mass.

Alaska. 


\section{ENARMONIA Hïbner.}

Hüвner, Verz. bek. Schmett., 375, 1826; Meyrick, Handb. Brit. Lep., 472, 1895; Grapholita Treitsch Ke, Schm. Eur., vii, 232, 1829; Grapholitha Herrich-Sch AEfFer, Schm. Eur., iv, 253, 1851; Lederer, Wien. ent. Mon., iii, 330, 1859; Heinemann, Kleinschm., i, 1, 177, 1863.

5268. caryana Fiтch, N. Y. Agr. Rept., xvi, 459, 1856. Atl. States. syn. caryce Shrmer, Trans. Am. Ent. Soc., ii, 394, 1869.

5269. prunivora Walsh, Rept. Ent. Ill., i, 80, 1868.

5270. interstinctana Clemens, Proc. Acad. Nat. Sci. Phil., 351, 1860; Zeller, Verh. zool.-bot. Ges. Wien, xxv, 296, 1875 .

syn. scitana W ALker, Cat. Brit. Mus., xxviii, 413, 1863; distema Grote, Bull. Buff. Soc., i, $92,1873$.

5271. bracteatana Fernald, Rept. U. S. Dept. Agr., $1880,265,1881$.

*5272. conversana Walsingham, Ill. Lep. Het., iv, 66, 1879 .

5273. albimaculana Fernald, Can. Ent., xi, 157, 1879.

5274. Iunatana W Alsingham, Ill. Lep. Het., iv, $66,1879$.

*5275. tristrigana Clemens, Proc. Ent. Soc. Phil., v, 133, 1865 .

Ill., Mo., Minn.

Atl.

States.

Cal.

Oreg.

Me.

Oreg

Mass.,

Va.

5276. americana Walsinghair, IIl. Lep. Het., iv, 67, 1879 .

Cal.

*5277. cæruleana Walsingham, Ill. Lep. Het., iv, 66, 1879 .

*5278. vitrana W alsingham, Ill. Lep. Het., iv, 65, 1879.

Oreg.

*5279. lautana Clemens, Proc. Ent. Soc. Phil., v, 139, 1865 (as tautana, typ. err.).

Va.,
Tex.

Va.,
Tex.

syn. perfluana Zecler, Verh. zool.-bot. Ges. Wien, xxv, 299, 1875.

5280. gallæsaliciana RrLeY, Trans. St. Louis Acad. Sci., iv, 320, 1881.

Oreg.

*5281. trossulana Walsingham, Ill. Lep. Het., iv, 67, 1879.

*5282. packardi Zeller, Verh. zool.-bot. Ges. Wien, xxv, 300, 1875.

N. Y., Mo., Tex.

Cal.

Tex. 
*5283. parmatana Clemens, Proc. Acad. Nat. Sci. Phil.,

Pa. $352,1860$.

*5284. duodecemstriata Walsingham, Trans. Ent. Soc.

Ariz. Lond., 146, 1884.

*5285. sebastianiæ Riley, Proc. Ent. Soc. Wash., ii, 214, 1892.

*5286. larimana Walsingham, Trans. Ent. Soc. Lond., 518,1895 .

\section{ECDYTOLOPHA Zeller.}

Zeller, Verh. zool.-bot. Ges. Wien, xxv, 266, 1875.

5287. insiticiana ZeLLer, Verh. zool.-bot. Ges. Wien, $\mathrm{xxv}, 266,1875$.

Mass. to Col.

\section{HEMIMENE Hiibner.}

Hübner, Verz. bek. Schmett., 378, 1826; Meyrick, Handb. Brit. Lep., 499, 1895; Dichrorampha Guenée, Ann. Soc. Ent. Fr., (2), iii, 185, 1845; Lederer, Wien. ent. Mon., iii, 369, 1859; Heinemann, Kleinschm., i, 1, 229, 1863.

*5288. incanana Clemens, Proc. Acad. Nat. Sci. Phil., 351,1860 .

*5289. simulana Clemens, Proc. Acad. Nat. Sci. Phil., 351, 1860; PACKARD, Guide Stud. Ins., 337, 1869.

syn. aurisignana Zes.ler, Verh. zool.-bot. Ges. Wien, xxv, 319, 1875.

5290. alpinana Treitschke, Schm. Eur., viii, 230, 1830; Duponchel, Hist. Nat. Lép. Fr., ix, 322, 1834; Herrich-Schaeffer, Schm. Eur., iv, 271, 1851; Wilkinson, Brit. Tort., 105, 1859; Heinemann, Kleinschm., i, 1, 230, 1863.

syn. politana Guenée, Ann. Soc. Ent. Fr., (2), iii, 185, 1845; WILKInson, Brit. Tort., 104, 1859 .

5291. plumbana Scopoli, Ent. Carn., no. 592, 1763; Heinemann, Kleinschm., i, 1, 239, 1863.

Pa. So. Atl. States.

Eur., Oreg.

syn. petiverella Schiffermüller, Syst. Verz. Wien, 136, 1776; zachana TReitschке, Schm. Eur., viii, 217, 1830; Duponchel, Hist. Nat. Lép. Fr., ix, 282, 1834; ulicana Guenée, Ann. Soc. Ent. Fr.,(2), iii, 185, 1845; Wilkinson, Brit. Tort., 228, 1859; blepharana Herrich-Schaeffer, Schm. Eur., iv, $254,1851$.

5292. radicolana Walsingham, Ill. Lep. Het., iv, 75, 1879 . 


\section{LIPOPTYCHA Lederer.}

Lederer, Wien. ent. Mon., iii, 370, 1859; Meyrick, Handb. Brit. Lep., 503, 1895.

5293. maculana Fernald, Jn. N. Y. Ent. Soc., ix, 51, Fla. 1901.

\section{PAMMENE Hiibner.}

Hübner, Verz. bek. Schmett., 378, 1826; Meyrick, Handb. Brit. Lep., 505, 1895 Phthoroblastis Lederer, Wien. ent. Mon., iii, 370, 1859.

*5294. texanana Walsinghay, Ill. Lep. Het., iv, 70, 1879 . Tex.

MELISSOPUS Riley.

Riley, Trans. St. Louis Acad. Sci., iv, 322, 1881.

5295. latiferreanus Walsingham, Ill. Lep. Het., iv, 70, 1879; Riley, Trans. St. Louis Acad. Sci., iv, Me. to $322,1881$.

\section{CYDIA Hübner.}

Hübner, Verz. bek. Schmett., 375, 1826; Walsingham, Proc. Zool. Soc. Lond., 130, 1897; Carpocapsa Treitschke, Schm. Eur., vii, 231, 1829; Lederer, Wien. ent. Mon., iii, 368, 1859; Hernemann, Kleinschm., i, 1, 193, 1863.

5296. pomonella Linneus, Syst. Nat., x, 538, 1758; STephens, Ill. Brit. Ent., Haust., iv, 119, 1834; U.S., Eur.

Wilkinson, Brit. Tort., 236, 1859; Harris, Inj. Ins., 484, 1862; Hennemann, Kleinschm., i, 1, $194,1863$.

syn. pomonana Schiffermüller, Syst. Verz. Wien,126,1776; HüBner, Schm. Eur., Tort., f. 30,1800 ; Haworth, Lep. Brit., 457, 1811; Frölich, En. Tor. Würt., 78, 1828; Treitschke, Schm. Eur., viii, 161, 1830; Duponchel, Hist. Nat. Lép. Fr., ix, 248, 1834: Herrich-Schaeffer, Schm. Eur., iv, 251, 1851; pomana FABricius, Ent. Syst., iii, $279,1793$.

5297. saltitans Westwood, Proc. Ashmol. Soc., iii, $137,1857$.

syn. deshaisiana Lucas, Ann. Soc. Ent. Fr., pl. $16,1858$.

*5298. toreuta Grote, Bull. Buff. Soc., i, 92, 1873. Pa., Va.,

5298. 1. ninana Riley, Sm. List Lep. Bor. Am., no. Ariz. $5025,1891 .^{a}$

$a$ In Riley's types the fore wings are leaden gray with a pale carneous ray in cell and a narrower bent one on submedian fold. Transverse posterior line black and shining plumbeous, from middle of costa bent at middle almost at right angles ending above tornus. Space beyond bright rose pink, costal edge carneous white with several bent brown-black bars, fringe shining plumbeous. Hind wings blackish, fringe pale.-Harrison G. Dyar. 
Subfamily TORTIRICINA.

\section{ALCERIS Hübner.}

Hü BNer, Verz. bek. Schmett., 384, 1826; Teras Treitsch ke, Schm. Eur., vii, 233, 1829; Lederer, Wien. ent. Mon., iii, 149, 1859; Heinemann, Kleinschm., i, 1, 10, 1863.

5299. effractana FröLich, En. Tort. Würt., 27, 1828; Treitschke, Schm. Eur., viii, 249, 1830; F. v. Röslerstami, Ber. Sch., 144, 1839; HerrichSchaeffer, Schm. Eur., iv, 154, 1849; HeineMANN, Kleinschm., i, 1, 12, 1863.

svn. scabrana Fabricius (not SCHIFFERMüLLER), Sp. Ins., no. 54, 1781; caudana Haworth (not Fabricius), Lep. Brit., no. 46, 1811; HüBner, Schm. Eur., Tort., f. 232, 1818; indecorana ZetTerstedt, Ins. Lap., $989,1840$.

*5300. peculiana ZeLLer, Verh. zool.-bot. Ges. Wien, XXv, 210, 1875 .

*5301. subnivana W ALKer, Cat. Brit. Mus., xxviii, 376 , 1863; Walsingham, Ill. Lep. Het., iv, 1, 1879. syn. deflectana Robinson, Trans. Am. Ent. Soc., ii, 283, 1869; Zeller, Verh. zool.-bot. Ges. Wien, xxv, 211, 1875 .

5302. trisignana Robinson, Trans. Am. Ent. Soc., ii, $282,1869$.

5303. boscana Fabricius, Ent. Syst., iii, 2, 269, 1794; Duponchel, Hist. Nat. Lép. Fr., ix, 131, 1834; Herrich-Schaeffer, Schm. Eur., iv, 147, 1849; Wilkinson, Brit. Tort., 163, 1859; Heinemann, Kleinschm., i, 1, 20, 1863; МеҮrick, Handb. Brit. Lep., 523, 1895.

syn. cerusana Hübner, Schm. Eur., Tort., f. 63, 1800; Treitschke, Schm. Eur., viii, 182, 1830.

a. parisiana Guenée, Ann. Soc. Ent. Fr., (2), iii, 145, 1845; Herrich-Schaeffer, Schm. Eur., iv, 147, 1849; placidana RoBinson, Trans. Am. Ent. Soc., ii, 282, 1869.

5304. niveana FABRICIUS, Mant. Ins., ii, 233, 1787; Frölich, En. Tort. Würt., 19, 1828; HeineManN, Kleinschm., i, 1, 22, 1863.

syn. treveriana HüBner, Schm. Eur., Tort., f. 100, 1800; Treitschk e, Schm. Eur., viii, 93, 1830; Fischer v. Röslerstama, Ber. Sch., 43, 1838; treveriana Duponchel, Hist. Nat. Lép. Fr., ix, 135, 1834; HerrichSchaEfFEr, Schm. Eur., iv, 151, 1849; cemsana Duponcher, Hist. Nat. Lép. Fr., ix, 532, 1834 .
Eur.,

Vane. Id.

Tex.

Atl.

States.

N. Y.,

Va.

No.

Atl. States,

Eur.

Eur.,

Can. 
*5305. nigrolinea Robinson, Trans. Am. Ent. Soc., ii, $281,1869$.

Can., Me., Vanc. Id.

syn. senescens Zelier, Verh. zool.-bot. Ges. Wien, xxiv, 9, 1874 .

*5306. ferruginiguttana Fernald, Trans. Am. Ent. Soc., $\mathrm{x}, 65,1882$.

*5307. brewsteriana Robinson, Trans. Am. Ent. Soc., ii, $283,1869$.

Col.

Me.,

N. Y.

Mass.,

N. Y. 1869 .

5309. hastiana Linneus, Syst. Nat., x, 532, 1758; Faun. Suec., no. 1328, 1761; Fabricius, Syst. Ent., 650, 1775; Frölich, En. Tort. Würt., 23, 1828; Wilkinson, Brit. Tort., 171, 1859 ; HeineManN, Kleinschm., i, 1, 14, 1863.

syn. logiana FABricius, Syst. Ent., 651, 1775; scabrana Schiffermüller, Syst. Verz. Wien, 130, 1776; Treitschke, Schm. Eur., viii, 255, 1830; elevana Fabricius, Ent. Syst., 269, 1793.

a. divisana HüBNER, Eur. Schmett., Tort., f. 198, 1800; Robinson, Trans. Am. Ent. Soc., ii, $280,1869$.

b. flavivittana Clemens, Proc. Ent. Soc. Phil., iii, 516, 1864; Robinson, Trans. Am. Ent. Soc., ii, $280,1869$.

c. perspicuana Robinson, Trans. Am. Ent. Soc., ii, $280,1869$.

d. maculidorsana Clemens, Proc. Ent. Soc. Phil., iii, 516, 1864; Robinson, Trans. Am. Ent. Soc., ii, 281,1869 .

e. inana Robinson, Trans. Am. Ent. Soc., ii, $281,1869$.

f. albistriana W ood, Ind. Ent., 1069, 1854.

g. ptychogrammos Zeller, Verh. zool.-bot. Ges. Wien, xxv, 213, 1875.

h. hudsoniana Walker, Cat. Brit. Mus., xxviii, $290,1863$.

i. caliginosana WALKer, Cat. Brit. Mus., xxviii, 309, 1863.

"5310. pulverosana Walker, Cat. Brit. Mus., xxviii. 291, 1863; Walsingham, Ill. Lep. Het., iv, 3, 1879 .

Hudson Bay.

syn. implexana Walker, Cat. Brit. Mus., xxviii, 338, 1863. 
5311. maccana Treitschke, Schm. Eur., suppl., x, 3, Eur., 133, 1835; Herrich-Schaeffer, Schm. Eur., iv, 149, 1849; Wilkinson, Brit. Tort., 171, 1859; Hennemann, Kleinschm., i, 1, 16, 1863.

Me., Oreg.

syn. erebana Guenée, Ann. Soc. Ent. Fr., (2), iii, 146,1845 .

5312. logiana Schiffermüller, Syst. Verz. Wien, 130, 1776; HüBner, Schm. Eur., Tort., f. 64, 1800; Herrich-Schaeffer, Schm. Eur., iv, 143,1849 .

syn. tristana HüBner, Schm. Eur., Tort., f. 50, 1800; Herrich-Schaeffer, Schm. Eur., iv, 142, 1849; WILkinson, Brit. Tort., 167, 1859; Heinemann, Kleinschm., i, 1, 17, 1863; trigonana STEPHens, Ill. Brit. Ent., Haust., iv, 1834.

a. viburnana Clemens, Proc. Acad. Nat. Sci. Phil., 347, 1860; Robinson, Trans. Am. Ent. Soc., ii, 281, 1869.

b. famula Zeller, Verh. zool.-bot. Ges. Wien, xxv, 214, 1875 .

*5313. permutana Duponchel, Hist. Nat. Lép. Fr., ix, 449, 1834; Herrich-SchaefFer, Schm. Eur., iv, 141, 1849; Wilkinson, Br. Tort., 174, 1859; Heinemann, Kleinschm., i, 1, 19, 1863.

*5314. nivisellana Walsingham, Ill. Lep. Het., iv, 2, 1879 .

5315. schalleriana Linnæus, Faun. Suec., no. 1339,1761; Haworth, Lep. Brit., no. 73, 1811; HüBNER, Eur. Schm., Tort., ff. 288, 289, 1823; TreITSCHKE, Schm. Eur., viii, 265, 1830; Duponchel, Hist. Nat. Lép. Fr., ix, 152, 1834; HerrichSchaeffer, Schm. Eur., iv, 144, 1849; WILkinson, Brit. Tort., 165, 1859; HeInemann, Kleinschm., i, 1, 19, 1863.

syn. latifasciana Haworth, Lep. Br., no. 65, 1811; Stephens, Ill. Brit. Ent., Haust., iv, 159, 1834; erutana HERRICH-SCHAEFFER, Schm. Eur., iv, 143, 1849.

5316. ferrugana Schiffermüller, Syst. Verz. Wien, 128, 1776; Treitschke, Schm. Eur., viii, 263, 1830; Heinemann, Kleinschm., i, 1, 25, 1863; Zeller, Verh. zool.-bot. Ges. Wien, xxv, 212, 1875 .

syn. gallicolana Clemens, Proc. Ent. Soc. Phil., iii, 516, 1864; semiannula RoBinson, Trans. Am. Ent. Soc., ii, 282, 1869.

Eur., Me., Ill., Cal.

Me., N. Y. Cal., Oreg. Eur., Me.

Eur., Atl. States. 
5317. simpliciana Walsingham, Ill. Lep. Het., iv, 2, 1879 .

*5318. oxycoccana Packard, Guide Stud. Ins., 334, 1869. 5319. minuta Robinson, Trans. Am. Ent. Soc., ii, 276 , 1869 .

syn. malivorana Le Baron, Rept. Ins. Ill., i, 16, 1870; vaccinivorana PACKARD, New or Little Known Insects, 1870; Rept. Agr. Mass., 241, 1870; variolana ZeLLer, Verh. zool.-bot. Ges. Wien, xxv, 212, 1875.

a. cinderella Riley, Rept. Ins. Mo., iv, 46, 1872.

5320. foliana W ALsingham, Ill. Lep. Het., iv, 3, 1879;

Dyar, Proc. U. S. Nat. Mus., xxv, 399, 1902.

*5321. fishiana Fernald, Trans. Am. Ent. Soc., x, 66, 1882.

*5322. chalybeana Fernald, Trans. Am. Ent. Soc., x, $65,1882$.

5323. cervinana Fernald, Trans. Am. Ent. Soc., x, 65, 1882.

5324. americana Fernald, Trans. Am. Ent. Soc., x, 66,1882 .

*5325. angusana Fernald, Can. Ent., xxiv, 178, 1892.

*5326. comandrana Fernald, Can. Ent., xxiv, 121, 1892.

5327. variana Fernald, Rept. U. S. Ent. Com., v, $847,1890$.

SYNNOMA Walsingham.

Walsingham, Ill. Lep. Het, iv, 24, 1879.

*5328. lynosyrana Walsingham, Ill. Lep. Het., iv, 24, 1879.
N. H.,

Oreg.

Me., Mass.

So. Atl.

States.

Cal., Col.,

Ariz.

Me.

Me.,

N. Y.

Mass.,

Ga.

Mass.,

Cal.

Me.

Mass., Pa.,

Tex.

Me.

\section{EPAGOGE Hübner.}

Hübner, Verz. bek. Schmett., 389, 1826; Meyrick, Handb. Brit. Lep., 527, 1895; Dichelia Guenée, Ann. Soc. Ent. Fr., (2), iii, 141, 1845; Heinemann, Kleinschm., i, 1, $50,1863$.

5329. pulcherrimana Walsingham, Ill. Lep. Het., iv, Tex. 19, 1879.

5330. caryæ Robinson, Trans. Am. Ent. Soc., ii, 270, 1869.

Pa., Ill., Tex. 
5331. sulfureana Clemens, Proc. Acad. Nat. Sci. Phil., 353, 1860; Robinson, Trans. Am. Ent. Soc., ii, 273, 1869; Zeller, Verh. zool.-bot. Ges. Wien, Xxv, 230, 1875 .

syn. gratana WALKER, Cat. Brit. Mus., xxviii, 359, 1863; fulvoroseana Clemens, Proc. Ent. Soc. Phil., iii, 516, 1864; virginiana Clemmens, Proc. Ent. Soc. Phil., iii, 517, 1864; gallivorana Clemens, Proc. Ent. Soc. Phil., iii, 517, 1864; gracilana W ALSINGHAM, Ill. Lep. Het., iv, 18, 1879.

a. belfrageana Zeller, Verh. zool.-bot. Ges. Wien, xxv, 232, 1875 .

*5332. demissana Walsingham, IIl. Lep. Het., iv, 19, 1879 .

*5333. californiana Walsingham, Ill. Lep. Het., iv, 21, 1879 .

5334. tunicana Walsingham, III. Lep. Het., iv, 20, 1879.

Tex.

Tex.

Cal.

Cal.

CENOPIS Zeller.

Zeller, Verh. zool.-bot. Ges. Wien, xxv, 239, 1875.

5335. reticulatana Clemens, Proc. Acad. Nat. Sci. Phil., 353, 1860; Robinson, Trans. Am. Ent. Soc., ii, 272, 1869; Zeller, Verh. zool.-bot. Ges. Wien, xxv, 233,1875 .

syn. subauratana Walker, Cat. Brit. Mus., xxviii, 289, 1863; directana WaLKer, Cat. Brit. Mus., xxviii, 309, 1863.

a. mesospila ZeLler, Verh. zool.-bot. Ges. Wien, $\mathrm{xxv}, 233,1875$.

5336. pettitana Robinson, Trans. Am. Ent. Soc., ii, 269, 1369; Zeller, Verh. zool.-bot. Ges. Wien, xxv, 240,1875 .

5337. diluticostana Walsinghay, Ill. Lep. Het., iv, 18, 1879 .

Atl. States.

syn. quercana Fernald, Trans. Am. Ent. Soc., $\mathrm{x}, 69,1882$.

*5338. niveana Walsingham, Ill. Lep. Het., iv, 19, 1879.

*5339. groteana Fernald, Trans. Am. Ent. Soc., x, 69, 1882.

5340. testulana Zeller, Verh. zool.-bot. Ges. Wien, Xxv, 241, 1875.

*5341. cana Robinson, Trans. Am. Ent. Soc., ii, 276 , 1869 .

Can.

Ohio.

Atl.

States.

Atl. States.

Tex.

N. Y., Pa. 


\section{CAPUA Stephens.}

Stephens, Ill. Brit. Ent., Haust., iv, 171, 1834; Westwood, Intr. Class. Ins., i, 109, 1839; Wilkinson, Brit. Tort., 112, 1859; Meyrick, Handb. Brit. Lep., 527, 1895.

5342. furcatana WALKER, Cat. Brit. Mus., xxviii, 319, 1863; Robinson, Trans. Am. Ent. Soc., ii, 270, N. Y., Pa., 1869; Zeller, Verh. zool.-bot. Ges. Wien, xxv, Ohio. 232, 1875; Walsingham, Ill. Lep. Het., iv, 21 , 1879 .

5343. lentiginosana Walsingham, Ill. Lep. Het., iv, Tex. 22,1879 .

\section{CELOSTATHMA Clemens.}

\section{Clemens, Proc. Acad. Nat. Sci. Phil., 355, 1860.}

5344. discopunctana Clemens, Proc. Acad. Nat. Sci. Phil., 355, 1860; Robinson, Trans. Am. Ent. Soc., ii, 276, 1869; Zeller, Verh. zool.-bot. Ges. Wien, xxv, 234, 1875.

\section{SPARGANOTHIS Hübner.}

HüBner, Verz. bek. Schmett., 386, 1826; Meyrick, Handb. Brit. Lep., 528, 1895; Enectra Guenée, Ann. Soc. Ent. Fr., (2), iii, 142, 1845; Zeller, Verh. zool.-bot. Ges. Wien, xxv, 228, 1885.

5345. pilleriana Schiffermüller, Syst. Verz. Wien, 126, 1776; FABricius, Mant. Ins., ii, 227, 1877; Ent. Syst., iii, 2, 251, 1794; Hübner, Schm. Eur., Tort., f. 172, 1800; Treitschke, Schm. Eur., viii, 83, 1830; Duponchel, Hist. Nat. Lép. Fr., ix, 91, 1834; Guenée, Ann. Soc. Ent. Fr., (2), iii, 142, 1845; Duponchel, Cat. Méth., 1845; Herrich-SchaEFFer, Schm. Eur., iv, 162, 1849; Wilkinson, Brit. Tort., 40, 1859; Heinemann, Kleinschm., i, 1, 50, 1863.

syn. vitana FAbricius, Ent. Syst., iii, 2, 249, 1794; - Tuteolana HüBnER, Eur. Schmett., Tort., f. $136,1800$.

5346. rudana Walsingham, Ill. Lep. Het., iv, 16, 1879.

Cal., Oreg.

5347. senecionana Walsingham, 11l. Lep. Het., iv, 17, Cal., Oreg. 1879.

5348. puritana Robinson, Trans. Amer. Ent. Soc., ii, 271, 1869; Zeller, Verb. zool.-bot. Ges. Wien, $\mathrm{xxv}, 229,1875$.

syn. unifasciana Clemens (not Duponchel),

Proc. Ent. Soc. Phil., iii, 516, 1864.

No. Atl.

States. 
5349. xanthoides W ALKer, Cat. Brit. Mus., xxvii, 190, 1863; xxviii, 290, 1863; Walsingham, Ill. Lep. Het., iv, 20, 1879.

Atl. States, B. C.

syn. breviornatana Clemens, Proc. Ent. Soc. Phil., v, 140, 1865; Robinson, Trans. Am. Ent. Soc., ii, 269, 1869.

5350. irrorea Robinson, Trans. Am. Ent. Soc., ii, 274 , 1869.

Me., Mass., N. Y., Col.

5351. inconditana Walsingham Ill. Lep. Het., iv, 16, 1879 .

Cal., Oreg.

5352. violaceana Robinson, Trans. Am. Ent. Soc., ii, 271, 1869; Zeller, Verh. zool.-bot. Ges. Wien, xxv, 229,1875 .

*5353. flavibasana Fernald, Trans. Am. Ent. Soc., x, 69,1882 .

Tex., IIl.

5354. distincta Walsingham, Trans. Ent. Soe. Lond., 126,1884 . Ariz.

*5355. striata Walsingham, Trans. Ent. Soc. Lond., $126,1884$.

Me., Mass., N. Y., Wis.

Mont.

ARCHIPS Hübner.

HüBner, Tent., 2, 1806; Walsingham, Proc. Zool. Soc. Lond., 133, 1897; Caccecia Hübner, Verz. bek. Schmett., 388, 1826; Heinemann, Kleinschm., i, 1, 32, 1863.

5356. rosaceana HarRIs, Inj. Ins., 1st ed., 348, 1841; 3d ed., 481, 1862; Fiтch, Rep. Ins. N. Y., iii, 28, 1859; Clemens, Proc. Acad. Nat. Sci. Phil., 347, 1860; Robinson, Trans. Am. Ent. Soc., ii, 262, 1869; PaCKard, Guide Stud. Ins., 335, 1869; Zeller, Verh. zool.-bot. Ges. Wien, xxv, $215,1875$.

syn. vicariana Walker, Cat. Brit. Mus., xxviii, 287, 1863; gossypiana PACKARD, Guide Stud. Ins., 335, 1869; arcticana Möschler, Stett. ent. Zeit., xxxv, 164, 1874.

5357. purpurana Clemens, Proc. Ent. Soc. Phil., 136, 1865; Robinson, Trans. Am. Ent. Soc., ii, 263, 1869; Zeller, Verh. zool.-bot. Ges. Wien, xxv, 215,1875 .

syn. gurgitana Robinson, Trans. Am. Ent. Soc., ii, 263, 1869; lintneriana Grote, Trans. Am. Ent. Soc., iv, 424, 1873.

5358. infumatana ZeLLer, Verh. zool.-bot. Ges. Wien, $\mathrm{xxv}, 216,1875$.
No. U.S., Col.

No. Atl.

States.

Wis., Mo. 
5359. rosana Linndeus, Syst. Nat., x, 530, 1758; HAworth, Lep. Brit., no. 96, 1811; Geyer, Schm. Eur., Tort., f. 302, 1830; WILkinson, Brit. Tort., 63, 1859; Heinemann, Kleinschm., i, 1, 34, 1863.

syn. ameriana Linneus, Syst. Nat., x, 531, 1758; Fabricius, Syst. Ent., 647, 1775; lævigana Schiffermüller, Syst. Verz. Wien, 129, 1776; Fabricius, Ent. Syst., 253, 1793; Treitschke, Schm. Eur., viii, 62, 1830; Stephens, Ill. Brit. Ent., Haust., iv, 74, 1834; Fischer v. Röslerstami, Ber. Schm., 17, 1838; Herrich-SchaEFFEr, Schm. Eur., iv, 159, 1849; variana FABRICIUs, Mant. Ins., ii, 231, 1787; oxyacanthana Hübner, Schm. Eı r., Tort., f. 117, 1800; Haworth, Lep. Brit., no. 97, 1811; DuponChel, Hist. Nat. Lép. Fr., ix, 74, 1834; acerana HüBNER, Schm. Eur., Tort., f. 118, 1800; FröLich, En. Tort. Würt., 31, 1828; Duponcher, Hist. Nat. Lép. Fr., ix, 76, 1834; branderiana HaworTH, Lep. Brit., no. 94, 1811; fuscana Haworth, Lep. Brit., no. 95, 1811; nebulana STEPHens, Ill. Brit. Ent., Haust., iv, 74, 1834.

5360. cerasivorana Fiтch, N. Y. Agr. Rep., 382, 1856; Robinson, Trans. Am. Ent. Soc., ii, 275, 1869; Zeller, Verh. zool.-bot. Ges. Wien, xxv, 217, 1875 .

5361. rileyana Grote, Trans. Am. Ent. Soc., ii, 121, 1868: Robinson, Trans. Anı. Ent. Soc., ii, 271, 1869; Riley, Rep. Ins. Mo., i, 153, 1869; ZeLLER, Verh. zool.-bot. Ges. Wien, xxv, 221, 1875. syn. fervidana Walker (not Clemens), Cat. Brit. Mus., xxviii, 313, 1863.

5362. parallela Robinson, Trans. Am. Ent. Soc., ii, 267, 1869.

5363. zapulata Robinson, Trans. Am. Ent. Soc., ii, 264, 1869.

5364. obsoletana WALker, Cat. Brit. Mus., xxviii, 288, 1863; Walsingham, Ill. Lep. Het., iv, 11, 1879.

No. U. S., Cal.

Ga., Tex., Mo.

Me. to Ill.

IIl., Mo.

Atl. States.

syn. transiturana W aLkER, Cat. Brit. Mus., xxviii, 312, 1863; Walsingham, Ill. Lep. Het., iv, 8, 1879; vesperana Clemens, Proc. Ent. Soc. Phil., v, 136, 1865; Robinson, Trans. Am. Ent. Soc. ii, 266, 1869; sanbornana Robinson, Trans. Am. Ent. Soc., ii, 265, 1869.

Eur., N. Y. 
5365. argyrospila WALKER, Cat. Brit. Mus., xxviii, 373, 1863; Walsingham, Ill. Lep. Het., iv, 8, 1873.

syn. furvana Robinson, Trans. Am. Ent. Soc., ii, 265, 1869; Zellen, Verh. zool.-bot. Ges. Wien, xxv, 13, 1875; v-signatana PACKARD, Rept. Agr. Mass., 238, 1870.

a. vividana DYar, Proc. Ent. Soc. Wash., v, 78, 1902; Proc. U. S. Nat. Mus., xxv, 400, 1902.

5366. semiferana WaLker, Cat. Brit. Mus., xxviii, 336, 1863; Walsingham, Ill. Lep. Het., iv, 7, 1879. syn. Aaccidana Robinson, Trans. Am. Ent. Soc., ii, 277, 1869; Zeller, Verh. zool. -bot. Ges. Wien, xxv, 13, 1875.

5367. negundana Dyar, Proc. Ent. Soc. Wash., v, 78, 1902; Proc. U. S. Nat. Mus., xxv, 401, 1902.

5368. fervidana Clemens, Proc. Acad. Nat. Sci. Phil., $347,1860$.

syn. paludana Robinson, Trans. Am. Ent. Soc., ii, $275,1869$.

*5369. magnoliana Fernald, Can. Ent., xxiv, 121, 1892.

5370. georgiana WaLker, Cat. Brit. Mus., xxviii, 372, 1863; Grote, Bull. Buff. Soc., i, 15, 1873; Walsingham, Ill. Lep. Het., iv, 9, 1879.

5371. fractivittana Clemens, Proc. Ent. Soc. Phil., v, 136, 1865; Robinson, Trans. Am. Ent. Soc., ii, 265,1869 .

syn. fumosa Robinson, Trans. Am. Ent. Soc., ii, 268,1869 .

5372. grisea Robinson, Trans. Am. Ent. Soc., ii, 268, 1869.

5373. afflictana W ALker, Cat. Brit. Mus., xxviii, 337, 1863; Walsingham, Ill. Lep. Het., iv, 14, 1879. syn. fuscolineana Clemens, Proc. Ent. Soc. Phil., v, 137, 1865; RoBinson, Trans. Am. Ent. Soc., ii, 266, 1869.

5374. musculana HüBNER, Schm. Eur., Tort.,f. 98, 1800; Frölich, En. Tort. Würt., 34, 1828; 'Treitschke, Schm. Eur., viii, 175, 1830; Duponchel, Hist. Nat. Lép. Fr., ix, 381, 1834; Herrich-SchaefFER, Schm. Eur., iv, 168, 1849; Wilkinson, Brit. Tort., 56, 1859; Heinemann, Kleinschm., i, $1,39,1863$.

syn. trifasciana Haworth, Lep. Brit., no. 100, 1811.
No. U. S., Cal., Col.

Atl. States, Col.

Atl. States, Col.

Mass., N. Y., $\mathrm{Pa}$.

N. Y.

So. Atl. States, Brazil.?

So. Atl. States.

Tex., Ohio, Mo.

No. U. S., Cal.

Eur.,

Oreg. 
5375. virescana Clemens, Proc. Ent. Soc. Phil., v, 140, 1865 .

syn. sescuplana Zeller, Verh. zool.-bot. Ges. Wien, xxv, 220, 1875.

*5376. glaucana W alsingham, Ill. Lep. Het., iv, 13, 1879. 5377. clemensiana Fernald, Can. Ent., xi, 155, 1879.

*5378. retiniana Walsingham, Ill. Lep. Het., iv, 12, 1879

5379. persicana Fitch, N. Y. Agr. Rept., 357, 1856.

syn. blandana Clemens, Proc. Ent. Soc. Phil., iii, 515, 1864; fragariana PACKARD, Guide Stud. Ins. 335, 1869; conigerana Zeller, Verh. zool.-bot. Ges. Wien, xxv, 227, 1875.

5380. melaleucana Walker, Cat. Brit. Mus., xxviii, 335, 1863; Robinson, Trans. Am. Ent. Soc., ii, 271, 1869: Zeller, Verh. zool.-bot. Ges. Wien, xxv, 223,1875; Walsingham, Ill. Lep. Het., iv, 10,1879 .

syn. invexana WaLker, Cat. Brit. Mus., xxviii, 358, 1863; semifuscana Clemens, Proc. Ent. Soc. Phil., iii, 519, 1864.

*5381. dissitana Grote, No. Am. Ent., i, 29, 1879.
Me. to Cal., Ariz.

So. Oreg.

Me., Mass., N. Y., Wis.

Cal.

No. Atl. States.

No. Atl. States.

Me. to Ohio.

\section{PLATYNOTA Clemens.}

Clemens, Proc. Acad. Nat. Sci. Phil., 347, 1860; Zeller, Verh. zool.-bot. Ges. Wien, xxv, 235, 1875 .

5382. flavedana Clemens, Proc. Acad. Nat. Sci. Phil., 348, 1860; Robinson, Trans. Am. Ent. Soc., ii, 278, 1869; Zeller, Verh. zool.-bot. Ges. Wien, $\mathrm{xxv}, 236,1875$.

syn. concursana Walker, Cat. Brit. Mus., xxviii, 324, 1863; laterana RoBinson, Trans. Am. Ent. Soc., ii, 278, 1869.

5383. rostrana Walker, Cat. Brit. Mus., xxviii, 290, 1863; Walsingham, Ill. Lep. Het., iv, 5, 1879.

syn. restitutana WaLker, Cat. Brit. Mus., Atl. States. xxviii, 292, 1863; comnexana WaLKER, Cat. Brit. Mus., xxviii, 293, 1863.

*5384. tinctana Walker, Cat. Brit. Mus., xxviii, 289, 1863.

5385. labiosana Zeller, Verh. zool.-bot. Ges. Wien, xxv, 237, 1875; Dyar, Proc. U. S. Nat. Mus.,

Fla., Santo Dom., Venezuela.

Tex.

Tex., Col. $\mathrm{xxv}, 402,1902$. $4630-$ No. $52-02-31$ 
5386. exasperatana Zeluer, Verh. zool.-bot. Ges. Wien, xxv, 238, 1875.

*5387. sentana Clemens, Proc. Acad. Nat. Sci. Phil., 348, 1860; Robinson, Trans. Am. Ent. Soc., ii, 277, 1869; ZelLer, Verh. zool.-bot. Ges. Wien, xxv, 235,1875 .

*5388. metallicana Walsingham, Trans. Ent. Soc. Lond., 497, 1895.

*5389. nigrocervina Walsingham, Trans. Ent. Soc. Lond., 495, 1895.

*5390. semiustana Walsingham, Trans. Ent. Soc. Lond., 128,1884 .
Me., N. Y., Tex.

Me. to

Tex.

Fla,

Col.

N. C.

\section{PANDEMIS Hübner.}

Hübner, Verz. bek. Schmett., 388, 1826; Hernemann, Kleinschm., i, 1, 35, 1863; Meyrick, Handb. Brit. Lep., 533, 1895.

5391. limitata Robinson, Trans. Am. Ent. Soc., ii, $264,1869$.

Pa.,

Mo.

*5392. lamprosana Robinson, Trans. Am. Ent. Soc., ii, $264,1869$.

Atl. States.

*5393. albaniana W ALker, Cat. Brit. Mus., xxviii, 288, Hudson Bay, 1863; Walsingham, Ill. Lep. Het., iv, 11, $1879 . \quad$ Cal.

TORTRIX Linnæus.

Linneus, Syst. Nat., x, 1, 530, 1758; Meyrick, Handb. Brit. Lep., 534, 1895.

5394. alleniana Fernald, Trans. Am. Ent. Soc., x, 68, 1882.

5395. citrana Fernald, Ent. Amer., v, 18, 1889; Bull. no. 18, n. ser., U. S. Dept. Agr., 99, 1898.

5396. pallorana Robinson, Trans. Am. Ent. Soc., ii, $266,1869$.

Me.

Cal.

Atl. States,

Mont.

*5397. lata Robinson, Trans. Am. Ent. Soc., ii, 266, 1869 .

Mass., Pa., III.

*5398. houstonana Grote, Bull. Buff. Soc., i, 18, 1873.

syn. retana Walsingham, Ill. Lep. Het., iv, $13,1879$.

5399. quercifoliana Fiтch, N. Y. Agr. Rep., 826, 1858.

syn. trifurculana Zeller, Verh. zool.-bot. Ges. Wien, xxv, 226, 1875.

5400. albicomana Clemens, Proc. Ent. Soc. Phil., v, 137, 1865; Robinson, Trans. Am. Ent. Soc., ii, 273, 1869; Zeller, Verh. zool.-bot. Ges. Wien, xxv, $227,1875$. 
5401. bergmanniana Linn eus, Syst. Nat., x, 531, 1758; Schifferü̈ller, Syst. Verz. Wien, 126, 1776 ; Fabricius, Ent. Syst., iii, 273, 1793; Frölich, En. Tort. Würt., 76, 1828; Treitschke, Schm. Eur., viii, 121,1830; Geyer, Schm. Eur., Tort., f, 340, 1834; Duponchel, Hist. Nat. Lép. Fr., ix, 114, 1834; Stephens, Ill. Brit. Ent., Haust., iv, 173, 1834; Herrich-SchaEfFer, Schm. Eur., iv, 170, 1849; Wilkinson, Brit. Tort., 153, 1859; Heinemann, Kleinschm., i, 1, 48, 1863; Zeller, Verh. zool.-bot. Ges. Wien, xxiv, 11, 1874.

syn. rosana HüBner, Schm. Eur., Tort., f. 137, 1800 .

5402. peritana Clemens, Proc. Acad. Nat. Sci. Phil., 356, 1860; Robinson, Trans. Am. Ent. Soc., ii, 277,1869 .

syn. inconclusana WALKer, Cat. Brit. Mus., xxviii, 318, 1863.

*5403. franciscana Walsinghay, Ill. Lep. Het., iv, 13, 1879.

*5404. fucana Walsinghay, Ill. Lep. Het., iv, 12, 1879.

5ั40.5. ivana Fernalio. Jn. N. Y. Ent. Soc., ix, 51, 1901.

$\because 5+05$. 1. semicirculana Fernald, Trans. Am. Ent. Soc., $\mathrm{x}, 68,1882$.

5\$06. fumiferana Clemens, Proc. Ent. Soc. Phil., v, 139,1865 .

syn. niqridia RobIsson, Trans. Am. Ent. Soc., ii, 268, 1869.

5407. packardiana Fernald, Rept. U. S. Ent. Com., v, 849, 1890; Bull. no. 12, U. S. Dept. Agr., 20, 1886.

5408. conflictana Walker, Cat. Brit. Mus., xxviii, 323 , 1863; Walsinghay, Ill. Lep. Het., iv, 10, 1879.

5t09. osseana Scopoli, Ent. Carn., 238, 1763; HerneMANN, Kleinschm., i, 1, 54, 1863.

syn. quadripunctana HaworTH, Lep. Brit. no. 237, 1811; pratana HüBNER, Schm. Eur., Tort., ff. 227, 228, 1818; FröLICH, En. Tort. Würt., 67, 1828; Treitschke, Schm. Eur., viii, 101, 1830; Duponchel, Hist. Nat. Lép. Fr., ix, 446, 1834; Herrich-SCHAEFFER, Schm. Eur., iv, 178, 1849; WILKINSON, Br. Tort., 257, 1859; boreana ZeTterstedT, Ins. Lap., 980, 1840 .

*5410. niveosana Packard, Proc. Bost. Soc. Nat. Hist., xi, $55,1866$.
Eur.,

Vanc. Id.

Atl. States.

Cal.

Oreg.

Fla.

Col.

No. U. S.

Me.

No. Atl.

States.

Eur., Lab., Alaska.

Lab. 
5411. argentana CLerck, Icon., pl. 11, f. 14, 1759; Schiffermüller, Syst. Verz. Wien, 127, 1776; Hübner, Schm. Eur., Tort., f. 86, 1800.

syn. goïana Linneus, Faun. Suec., 349, 1761; gouana Linneus, Syst. Nat., xii, 879, 1767; Fabricius, Sp. Ins., 283, 1781; Frölich, En. Tort. Würt., 67, 1828; Treitschке, Schm. Eur., viii, 102, 1830; Duponcher, Hist. Nat. Lép. Fr., ix, 444, 1834; HerrichSchaEfFer, Schm. Eur., iv, 177, 1849; Hennemann, Kleinschm., i, 1, 54, 1863; govana FABricius, Syst. Ent., 651, 1775: magnana HüBner, Schm. Eur., Tort., ff. 225, 226, 1818; margaratalis HüBNER, Schm. Eur., Pyr., f. 48, 1796; georgiella Hulst, Ent. Am., iii, 136, 1887.

*5412. basiplagana Walsingham, Ill. Lep. Het., iv, 23, 1879 .

5413. trigonana Walsingham, Ill. Lep. Het., iv, 22, 1879.

5414. horariana Walsingham, Ill. Lep. Het., iv, 22, 1879.

5415. möschleriana Wocke, Stett. ent. Zeit., 45, 1862. syn. algidana Möschler, Wien. ent. Mon., vi, 138, 1862; Robinson, Trans. Am. Ent. Soc., ii, 272, 1869; Packard, Guide Stud. Ins., $334,1869$.

*5416. arizonana Walsingham, Trans. Ent. Soc. Lond., $124,1884$.

*5 $\$ 17$. indivisana WaLker, Cat. Brit. Mus., xxviii, 344 , $985,1863$.

Eur., Cal., Nev., Alaska.

Tex.

Cal.

Oreg.

Lab., White Mts., Alask?.

Ariz.

Hudson Bay.

\section{EULIA Hübner.}

HüBner, Verz. bek. Schmett., 392, 1826; Lophoderus. STephens, Cat. Brit. Ins., ii, 184, 1829; Ill. Brit. Ent., Haust., iv, 143, 1834; Westwood, Class. Ins., i, 108, 1839; HerneMANN, Kleinschm., i, 1, 41, 1863.

5418. ministrana Linneus, Syst. Nat., x, 531, 1758; Schifferuüller, Syst. Verz. Wien, 128, 1776 ; Haworth, Lep. Brit., no. 10, 1811; Frölich, En. Tort. Würt., 42, 1828; Treitschke, Schm. Eur., No. Atl. States., Eur. viii, 89, 1830; Duponchel, Hist. Nat. Lép. Fr., ix, 96, 1834; Herrich-Schaefrer, Schm. Eur., iv, 175, 1849; Wilkinson, Brit. Tort., 17, 1859; Hennemann, Kleinschm., i, 1, 43, 1863.

syn. ferrugana HüBnER, Eur. Schmett., Tort., f. 56, 1800; Duponchel, Hist. Nat. Lép. Fr., ix, 478, 1834; subfascianus STEPHENS, Ill. Brit. Ent., Haust., iv, 144, 1834. 
5419. quadrifasciana Fernald, Trans. Am. Ent. Soc., $\mathrm{x}, 67,1882$.

*5420. juglandana Fernald, Can. Ent., xi, 155, 1879.

5421. triferana Walker, Cat. Brit. Mus., xxviii, 314, 1863; Walsingham, Ill. Lep. Het., iv, 15, 1879. syn. incertana Clemens, Proc. Ent. Soc. Phil., v, 138, 1865; Robinson, Trans. Am. Ent. Soc., ii, 278, 1869 .

5422. amatana Dyar, Jn. N. Y. Ent. Soc., ix, 24, 1901.

5423. politana Haworth, Lep. Brit., no. 229, 1811; Wilkinson, Brit. Tort., 271, 1859; Heinemann, Kleinschm., i, 1, 41, 1863; FernaLd, Rept. U. S. Dept. Agrr., 1880, 264, 1881.

syn. sylvana Treitschke, Schm. Eur., viii, 109, 1830; Fischer v. Röslerstami, Ber. Schm., 40, 1838; Herrich-SCHAEFFER, Schm. Eur., iv, 162, 1849; pulchellana Stephens, Ill. Brit. Ent., Haust., iv, 135, 1834 .

5424. velutinana WaLker, Cat. Brit. Mus., xxviii, 313, 1863.

syn. Tutosana Clemens, Proc. Ent. Soc. Phil., v, 138, 1865; Robinson, Trans. Am. Ent. Soc., ii, 279, 1869.

*5425. gloverana Walsingham, Ill. Lep. Het., iv, 14, 1879.

5426. coloradana Fernald, Trans. Am. Ent. Soc., x, 67,1882 .

*5427. mariana Fernald, Trans. Am. Ent. Soc., x, 67, 1882.

5428. alisellana Robinson, Trans. Am. Enc. Soc., ii, 267,1869 .

\section{AMORBIA Clemens.}

Clemens, Proc. Acad. Nat. Sci. Phil., 352, 1860; Hendecastema Walsingham, Ill. Lep. Het., iv, 4, 1879.

5429. humerosana Clemens, Proc. Acad. Nat. Sci. Phil., 352, 1860; Robinson, Trans. Am. Ent. Soc., ii, 275,1869 .

5430. cuneana Walsingham, Ill. Lep. Het., iv, 4, 1879.

N. Y.,

Cal.

Col.

Fla.

Ohio.
Atl. States.
Eur., No. States.

a. abumbrana WaLsinghà, Ill. Lep. Het., iv, 5 ,

No.

Atl.

States.

Cal. 1879. 
Subfamily PHAI,ONIIN A.

PHALONIA Hübner.

Hübner, Verz. bek. Schmett., 393, 1826; Meyrick, Handb. Brit. Lep., 545, 1895; Cochylis Treitschne, Schm. Eur., vii, 233, 1829; viii, 272, 1830; Duponchel, Hist. Nat. Lép. Fr., ix, 23, 1834; Stephens, Ill. Brit. Ent., Haust., iv, 185, 1834; Conchylis Sonoffsky, Bull. Imp. Soc. Mose. (Sep.), 20, 1837; Lederer, Wien. ent. Mon., iii, 273, 1859; Heinemand, Kleinschm., i, 1, 68, 1863.

*5431. floccosana Walker, Cat. Brit. Mus., xxviii, 358, 1863; Walsingham, Ill. Lep. Het., iv, 27, 1879.

Nova Scotia, $\mathrm{Pa}$.

syn. confusana Robinson, Trans. Am. Ent. Soc., ii, 274, 1869.

*5432. vitellinana Zecler, Verh. zool. - bot. Ges. Wien, xxv, 243, 1875 .

*5433. straminoides Grote, Bull. Buff. Soc., i, 16, 1873.

*5434. scissana Walker, Cat. Brit. Mus., xxviii, 360, 1863; Walsingham, IIl. Lep. Het., iv, 28, 1879.

5435. smeathmanniana FABRICIUs, Sp. Ins., 278, 1781; Frölich, En. Tort. Würt., 39, 1828; Treitschk E, Schm. Eur., viii, 274, 1830: Duponchel, Hist. Nat. Lép. Fr., ix, 413, 1834; Herrich-SchaEfFer, Schm. Eur., iv, 185, 1851; Wilkinson, Brit. Tort., 313, 1859; Hernemann, Kleinschm., i, 1, $80,1863$.

syn. fabriciana HüBner, Schm. Eur., Tort., f. 149, 1800; Haworth, Lep. Brit., 401, 1811; stachydana Herrich-SCHAEFFER, Schm. Eur., iv, 185, 1851.

5436. kindermanniana Treitschke, Schm. Eur., viii, 276, 1830; Duponchel, Hist. Nat. Lép. Fr., ix, 415, 1834; F. v. Röslerstamm, Ber. Schm., 18, 1838; Herrich-Schanffer, Schm. Eur., 184, 1851; Heinemann, Kleinschm., i, 1, 80, 1863.

5437. deutschiana Zetterstedt, Ins. Lap., 981, 1840; Wocke, Stett. ent. Zeit., 48, 1862; 204, 1864.

syn. lutulentana Herrich-Schaffere, Neu. Schm., p. 5, f. 35, 1856; Laharpe, Tort., 40, 1857; fuscostrigana Clemens, Proc. Ent. Soc. Phil., ii, 417, 1864; chalcana PACKARD, Proc. Bost. Soc. Nat. Hist., xi, 56, 1866.

*5438. felix Walsingham, Trans. Ent. Soc. Lond., 498, 1895 .

5439. rutilana HüBner, Schm. Eur., Tort., f. 249, 1818; Frölich, En. Tort. Würt., 74, 1828; Herrich-Schaeffer, Schm. Eur., iv, 182, 1851; Wilkinson, Brit. Tort., 318, 1859; Heinemann, Kleinschm., i, 1, 78, 1863; Riley, Rep. U. S. Dept. Agr., 1878, 247, 1879.

Me., N. H., Mass.

N. Y.

Nova Scotia.

Eur., Me., Cal.

Eur., Cal.

Eur., Lab.

Col.

Eur., Me., N. Y. 
5440. dorsimaculana Robinson, Trans. Am. Ent. Soc., ii, 285, 1869.

Pa.,

Tex.

syn. angustana Clemens (not Hübner), Proc. Acad. Nat. Sci. Phil., 354, 1860.

*5441. promptana Robinson, Trans. Am. Ent. Soc., ii, $286,1869$.

*5442. fernaldana Walsingham, Ill. Lep. Het., iv, 27, 1879 .

*5443. seriatana Zeller, Verh. zool.-bot. Ges. Wien, xxv, 244, 1875 .

*5444. intactana W alsingham, Ill. Lep. Het., iv, $27,1879$.

*5445. angulatana Robinson, Trans. Am. Ent. Soc., ii, $286,1869$.

5446. argentilimitana Robinson, Trans. Am. Ent. Soc., ii, 287, 1869; Zeller, Verh. zool.-bot. Ges. Wien, xxv, 242, 1875.

*5447. parallelana Walsingham, Ill. Lep. Het., iv, 28, 1879.

*5448. transversana Walsingham, Ill. Lep. Het., iv, 28, 1879 .

*5449. labeculana Robrnson, Trans. Am. Ent. Soc., ii, $287,1869$.

*5450. lepidana Clemens, Proc. Acad. Nat. Sci. Phil., 355, 1860; Robinson, Trans. Am. Ent. Soc., ii, $287,1869$.

*5451. interruptofasciata Robinson, Trans. Am. Ent. Soc., ii, 287, 1869.

5452. bunteana Robinson, Trans. Am. Ent. Soc., ii, 288, 1869; Zeller, Verh. zool.-bot. Ges. Wien, $\mathrm{xxv}, 245,1875$.

5453. œnotherana Riley, Trans. St. Louis Acad. Sci., iv, $316,1881$.

5454. erigeronana Riley, Trans. St. Louis Acad. Sci., iv, 316, 1881.

*5455. hospes Walsingham, Trans. Ent. Soc. Lond., $131,1884$.

*5456. latipunctana Walsingham, Ill. Lep. Het.. iv 29, 1879.

*5457. dilutana W alsinghan, Ill. Lep. Het., iv, 29, 1879.

*5458. nana Haworth, Iep. Brit., 439, 1811; Stephens, Ill. Brit. Ent., Haust., iv, 182, 1834.

Pa.,

Tex.

Cal.

Oreg.

Tex.

Cal.

Pa. to

Tex.

Mass., Pa..

Tex.

Cal.

Cal.

$\mathrm{Pa}$.

$\mathrm{Pa}$.

Pa.

Atl.

States.

Atl.

States.

Tex.

N. C.

Cal.

Oreg.

Eur., Nova Scotia.

syn. carneana Guenée, Ann. Soc. Ent. Fr., (2), iii, 298, 1845; ochreaalbana WALKER, Cat. Brit. Mus., xxviii, 375, 1863. 
*5459. campicolana Walsingham, Ill. Lep. Het., iv, 29, Cal. 1879.

*5460. parvimaculana Walsingham, Ill. Lep. Het., iv, $30,1879$.

*5461. glaucofuscana Zeller, Verh. zool.-bot. Ges. Wien, xxv, 245, 1875.

Oreg.

Tex.

5462. dubitana HüBner, Schm. Eur., Tort., f. 82, 1800; Frölich, En. Tort. Würt., 52,1828; Treitschke, Schm. Eur., viii, 283, 1830; Duponchel, Hist. Nat. Lép. Fr., ix, 420, 1834; Stephens, Ill. Brit. Ent., Haust., iv, 183, 1834; HerrichSchaeffer, Schm. Eur., iv, 192, 1851; WILKinson, Brit. Tort., 298, 1859; Heinemann, Kleinschm., i, 1, 90, 1863.

syn. albidana WALKer, Cat. Brit. Mus., xxxv, $1807,1866$.

5463. comes Walsingham, Trans. Ent. Soc. Lond., $129,1884$.

*5464. dorsistriatana Walsingham, Trans. Ent. Soc. Lond., 132, 1884.

*5465. edwardsiana Walsingham, Trans. Ent. Soc. Lond., 128, 1884.

Eur.,

Nova Scotia.

Ariz.

Ariz.

Ariz.

*5466. fulvotinctana Walsingham, Trans. Ent. Soc. Lond., 132, 1884.

Ariz.

COMMOPHILA Hübner.

HüBner, Verz. bek. Schmett., 392, 1826; Meyrick, Handb. Brit. Lep., 555, 1895; Phtheochroa Stephens, Cat. Brit. Ins., ii, 191, 1829; Ill. Brit. Ent., Haust., iv, 184, 1834; Lederer, Wien. ent. Mon., iii, 279, 1859; Willkinson, Brit. Tort., 280, 1859; Heinemann, Kleinschm., i, 1, 90, 1863.

5467. macrocarpana Walsingham, Trans. Ent. Soc.

Cal. Lond., 499, 1895.

*5468. saxicolana Walsingham, Ill. Lep. Het., iv, 29, 1879

PSEUDOCONCHYLIS Walsingham.

Walsingham, Trans. Ent. Soe. Lond., 133, 1884.

5469. laticapitana W ALsingham, Trans. Ent. Soc. Lond., $133,1884$.

Cal.

PHARMACIS Hiibner.

HüBNer, Zutr. exot. Schmett., ii, 111, 1823.

5470. sartana Hübner, Zutr. exot. Schmett., ii, 111, Pa. to Fla. 1823.

*5471. bimaculana Robinson, Trans. Am. Ent. Soc., ii, 285, 1869; Zeller, Verh. zool.-bot. Ges. Wien, Tex. Mo. xxv, 243, 1875 . 


\section{HYSTEROSIA Stephens.}

Stephens, List Brit. Mus., x, 85, 1852; Walsingham, Trans. Ent. Soc. Lond., 498, 1895; Idiographis Lederer, Wien. ent. Mon., iii, 242, 1859.

5472. inopiana Haworth, Lep. Brit., 469, 1811; StePHENs, Ill. Brit. Ent., Haust., iv, 192, 1834; No. U.S., Eur. Wilkinson, Brit. Tort., 100, 1859; Nolcken, Stett. ent. Zeit., xxx, 283, 1869.

syn. centrana Herrich-SchaEfFer, Schm. Eur., iv, 205, 1851; Lederer, Wien. ent. Mon., iii, 246, 1859; Heinemann, Kleinschm., i, 1, 38, 1863 .

*5473. fulviplicana Walsingham, Ill. Lep. Het., iv, 25, Cal. 1879 .

*5474. ægrana Walsingham, Ill. Lep. Het., iv, 26, 1879.

Oreg.

*5475. aureoalbida Warsingham, Trans. Ent. Soc. Lond., Col. $498,1895$.

\section{CARPOSINA Herrich-Schaeffer.}

Herrich-Schaeffer, Eur. Schmett., v, 38, 1855; Fernald, Can. Ent., xxv, 96, 1893. *5475. 1. crescentella Walsingham, Trans. Am. Ent. (Unknown.) Soc., x, 189, 1882.

Family YPONOMEUTID A.

(C.=Dyar, Can. Ent., xxxii, 37-41, 84-86, 1900.)

MARTYRINGA Busck.

Busck, Jn. N. Y. Ent. Soc, x, 96, 1902.

5476. latipennis Walsingham, Trans. Am. Ent. Soc., x, 190, 1882; Busck, Jn. N. Y. Ent. Soc., x, 96,1902 .

\section{YPONOMEUTA Latreille.}

Latreille, Gen. Crust. Ins., iv, 222, 1796; Dyar, C. 38.

5477. multipunctella Clemens, Proc. Acad. Nat. Sci. Phil., 8, 1860; Tin. No. Am., 95, 1872; СнамBers, Can. Ent., iv, 42, 1872; Zerler, Verh. zool.-bot. Ges. Wien, xxiii, 228, 1873; Riley, Proc. Am. Ass. Adv. Sci., 617, 1880; Dyar, C. 38.

syn. ordinatellus WALKER, euonymella CHAMBERs, orbimaculella CHAMBERs, wakarusa GAUMER.

MIEZA Walker.

Walker, Cat. Brit. Mus., ii, 527, 1854; Dyar, C. 39.

5478. subfervens Walker, Cat. Brit. Mus., ii, 528, Atl. States. 1854; Dyar, C. 39.

Tex. 
5479. psammitis Zeller, Verh. zool.-bot. Ges. Wien, Xxii, 562, 1872; DYAR, C. 39.

5480. igninix Walker, Cat. Brit. Mus., ii, 527, 1854; DYAR, C. 39.

syn. crassinervella ZELLER.

\section{ATTEVA Walker.}

Walker, Cat. Brit. Mus., ii, 526, 1854; Eta Grote, Proc. Ent. Soe. Phil., v, 230, 1865; Dyar, C. 39.

5481. aurea Fiтch, Third Rept. Ins. N. Y., 168, 1856; DYAR, C. 39.

syn. compta Clemens.

5482. gemmata Grote, Bull. Buff. Soc., i, 93, 1873; Chapman, Jn. N. Y. Ent. Soc., v, 127, 1897; DYAR, C. 39.

syn. fastuosa Zeller, Hor. Soc. Ent. Ross., xiii, 225, 1877; Walsingham, Proc. Zool. Soc. Lond., 113, 1897; floridana NEUMOEGEN.

TRICHOSTIBAS Zeller.

Zeller, Stett. ent. Zeit., 150, 1863; Dyar, C. 39.

5483. calligera Zeller, Hor. Soc. Ent. Ross., xiii, 231, 1877; DYAR, C. 40.

Fla.

syn. parvula Hy. Edwards.

EUCERATIA Walsingham.

Walsingham, Proc. Zool. Soc. Lond., 310, 1881.

5484. securella Walsingham, Proc. Zool. Soc. Lond. $311,1881$.

5485. castella Walsingham, Proc. Zool. Soc. Lond., 3101881.

ARAOLEPIA Walsingham.

Walsingham, Proc. Zool. Soc. Lond., 303, 1881.

5486. subfasciella Walsingham, Proc. Zool. Soc. Lond., $303,1881$.

Cal.

PERICLYMENOBIUS Wallengren.

Wallengren, Ent. Tidsk., i, 63, 1880.

5487. frustellus Walsingham, Proc. Zool. Soc. Lond., Cal. 309, 1881.

5488. canariellus Walsingham, Proc. Zool. Soc. Lond.,

Cal.

Cal. 309, 1881.

5489. dentiferellus Walsingham, Proc. Zool. Soc. Lond., 308, 1881.

Cal. 
TRACHOMA Wallengren.

Wallengren, Ent. Tidsk., i, 61, 1880.

5490. instabilella Mans, Verh. zool.-bot. Ges. Wien,

Cail.

v, 351, 1866, pl. 1, f. 5; W alsinghan, Proc. Zool.

Soc. Lond., 301, 1881.

5491. falciferella W alsingham, Proc. Zool. Soc. Lond.,

Cal. $307,1881$.

5492. senex Walsingham, Ins. Life, i, 288, 1889.

Col.

CALANTICA Zeller.

Zeller, Isis, 801, 1847.

5493. polita Walsingham, Proc. Zool. Soc. Lond., 302, Cal. 1881.

\section{PTEROLONCHE Zeller.}

Zeller, Isis, 845, 1847; Herrich-Schaeffer, Syst. Bearb. Schmett. Eur., v, 40, 1855. *5494. lineata Walsingham, Ins. Life, i, 288, 1889.

Ariz.

\section{CEROSTOMA Latreille.}

Latreille, Nat. Hist. Ins., iii, 416, 1802; Meyrick, Handb. Brit. Lep., 697, 1895; Dyar, C. 41; Pluteloptera Chambers, Jn. Cin. Soc. Nat. Hist., ii, 181, 1879.

5495. sublucella Walsingham, Proc. Zool. Soc. Lond., Cal. 308, 1881.

5496. cervella Walsingham, Proc. Zool. Soc. Lond.,307, 1881.

5497. subsylvella W alsingham, Ins. Life, i, 287, 1889.

5498. aleutianella Beutenmüller, Can. Ent., xxi, 27, 1889.

5499. koebelella Dyar, Cat. Ent., xxxii, 40, 1900.

5500. radiatella Donovan, Nat. Hist. Brit. Ins., iii, 77, 1816; Wocke, Cat. Lep. Eur. ii, no. 1639, 1871; Walsingham, Proc. Zool. Soc. Lond., 307, 1881; Ins. Life, i, 287, 1889.

syn. ochrella Chambers, Jn. Cin. Soc. Nat. Hist., ii, 181, 1880; variella HüBner, fissella HüBNER, lutarella HüBNER, byssinella HüвNER, paralella PANZER, radiatus HaWORTH, fissus HawORTH, quinquepunctatus $\mathrm{H}_{\mathrm{A}}$ wORTH, lutosus HawORTH, flaviciliatus Haworth, unitella TreitschKe, fulvella Duponchel, mifimetrellus Stephens.

5501. rubrella Dyar, Proc. U. S. Nat. Mus., xxv, 404, 1902 .

Coì. 


\section{EIDO Chambers.}

Chambers, Can. Ent., v, 72, 1873; Jn. Cin. Soc. Nat. Hist., ii, 202, f. 18, 1879; Venilia Chambers (not Duponchel), Can. Ent., iv, 207, 1872.

*5502. albapalpella Chambers, Can. Ent., iv, 208, 1872; $\mathrm{v}, 72,1873$.

syn. albopalpella Riley, Sm. List Lep. Bor. Am., no. 5543, 1891.

\section{PLUTELLA Sehrank.}

Schrank, Fauna Boica, ii, 2, 169, 1802.

5503. maculipennis Curtis, Brit. Ent., pl. 420, 1832; Walsingham \& Durrant, Ent. Mo. Mag., xxxiii, $173,1897$.

syn. cruciferarum Zeller, Stett. ent. Zeit., 281, 1843; Chambers, Bull. Geol. Surv. Terr., iv, 161, 1878; Walsingham, Proc. Zool. Soc. Lond., 304, 1881; Fletcher, Rept. Ex. Far. Can., 165, 1890; Ormerod, Jn. Roy. Agr. Soc. Engl., 1891; limbidipenella Clemens, mollipedella Clemens, brasiella Fitch, mylostella PACKARD, aylostella Chambers, dubiosella Beutenmüller, Can. Ent., xxi, 27, 1889; Dyar, C. 40.

5504. porrectella Linndeus, Syst. Nat., 546, 1758; Wecke, Cat. Lep. Eur., ii, no. 1624, 1871; Chambers, Bull. Geol. Surv. Terr., iv, 161, 1878; Walsingham, Proc. Zool. Soc. Lond., 305, 1881 .

syn. hesperidella HüBNER, vittatus Fabricius, hesperidis Haworth, vigilacella Clemens.

5505. omissa Walsingham, Ins. Life, i, 258, 1889.

5506. vanella Walsingham, Proc. Zool. Soc. Lond., $305,1881$.

*5507. albidorsella Walsingham, Proc. Zool. Soc. Lond., 305, 1881.

5508. interrupta Walsingham, Proc. Zool. Soc. Lond, $304,1881$.

*5509. multimaculella Chambers, Bull. Geol. Surv. Terr., iv, 89, 1878; Hagen, Pap., iv, 99, 1884; Busck, Jn. N. Y. Ent. Soc., x, 97, 1902.

\section{GLYPHIPTERYX Hübner.}

Hüвner, Verz. bek. Schmett., 421, 1816; Dyar, C. 84.

5510. bifasciata Walsingham, Proc. Zool. Soc. Lond.,

Cal. Cal., Eur.

U. S., Eur.

Cal.

Cal.

Oreg.

Tex.

Cal. 
*5511. unifasciata Walsingham, Proc. Zool. Soc. Lond., Cal. $322,1881$.

5512. quinqueferella Walsingham, Proc. Kool. Soc. Lond., 322, 1881.

5513. impigritella Clemens, Proc. Ent. Soc. Phil., ii, 9, 1862; 'Tin. No. Am., 214, 1872.

syn. exoptatella Chambers, Cin. Quart. Jn. Sci., ii, 234, 1875; Chambers, Can. Ent., xiii, 193,1881 .

5514. circumscriptella Chambers, Jn. Cin. Soc. Nat. Hist., iii, 291, 1880.

5515. californiæ Walsingham, Proc. Zool. Soc. Lond., 320, 1881; Chambers, Can. Ent., xiii, 193, 1881.

Cal.

Tex.

Atl. States.

Cal.

5516. regalis Walsingham, Proc. Zool. Soc. Lond., 319, 1881.

5517. quadragintapunctata DYAR, Can. Ent., xxxii, 8t, 1900 .

*5518. montisella Chambers, Cin. Quart. Jn. Sci., ii, 292, 1875; Bull. Geol. Surv. Terr., iv, 148, 1878.

Col.

syn. montinella Chambers, Can. Ent., ix, 14, 1877.

\section{CHOREUTIS Hübner.}

Hübner, Verz. bek. Schmett., 373, 1816; Zeller, Verh. zool.-bot. Ges. Wien, xxv, 320, 1875; Fernald, Can. Ent., xxxii, 240, 1900; Kearfott, Jn. N. Y. Ent. Soc., x, $106,1902$.

5519. inflatella Clemens, Proc. Ent. Soc. Phil., ii, 5, Atl. States. 1863; Dyar, C. 85; Fernald, Can. Ent., xxxii, 242,1900 .

a. virginiella Clemens, Proc. Ent. Soc. Phil., iii, Atl. States. 505, 1864; Fernald, Can. Ent., xxxii, 243, 1900 .

5520. dyarella Kearfot', Jn. N. Y. Ent. Soc., x, 112, 1902.

5521. onustana WALker, Cat. Brit. Mus., xxx, 996, 1864 .

syn. ohioensis ZerLer, Verh. zool.-bot. Ges. Wien, xxv, 220, 1875.

5522. gnaphaliella Kearfott, Journ. N. Y. Ent. Soc., $\mathrm{x}, 113,1902$.

5523. carduiella Kearfott, Journ. N. Y. Ent. Soc., x, $116,1902$.

a. busckiella Kearfott, Journ. N. Y. Ent. Soc., $\mathrm{x}, 120,1902$.

Cal.

No. Atl. States.

U.S.

N. J., Fla. 
5524. silphiella Grote, Pap., i, 40, 1881. Cal., Col. syn. gemmalis Hulst, Trans. Am. Ent. Soc., xiii, 148, 1886.

5525. sororculella Dyar, Can. Ent., xxxii, 86, 1900. Col.

5526. occidentella Dyar, Can. Ent., xxxii, 86, 1900. Cal.

5527. coloradella Kearfott, Journ. N. Y. Ent. Soc., $\mathrm{x}, 123,1902$.

5528. extrincicella Dyar, Can. Ent., xxxii, 86, 1900. Wis.

5529. leucobasis Fernald, Can. Ent., xxxii, 242, 1900. No. Atl. States.

HEMEROPHILA Hübner.

Hübner, Tent., 1806; Fernald, Can. Ent., xxxii, 239, 1900.

*5530. vicarilis Zelier, Verh. zool.-bot. Ges. Wien, xxv, 322, 1875 .

Tex.

5531. dyari Busck, Journ. N. Y. Ent. Soc., vii, 242 1900 .

Fla.

\section{BRENTHIA Clemens.}

Clemens, Proc. Acad. Nat. Sci. Phil., 172, 1860; Fernald, Can. Ent., xxxii, 32, 1900

5532. pavonacella Clemens, Proc. Acad. Nat. Sci. Phil., 172, 1860; Tin. No. Am., 134, 1872; ZeLAtl. LER, Verh. zool.-bot. Ges. Wien, xxv, 323, 1875; States.

Chambers, Can. Ent., x, 76, 1878; WalsingHaM, Proc. Zool. Soc. Lond., 529, 1891; 120, 1897; Fernald, Can. Ent., xxxii, 243, 1900.

syn. amphicarpecana CHambers.

\section{WALSINGHAMIA Riley.}

Riley, Proc. Ent. Soc. Wash., i, 157, 1889; Fernald, Can. Ent., xxxii, 244, 1900.

5533. diva Riley, Proc. Ent. Soc. Wash., i, 158, 1889.

Fla.

*5534. slossonia Fernald, Can. Ent., xxxii, 244, 1900.

Fla.

\section{SETIOSTOMA Zeller.}

Zeller, Verh. zool.-bot. Ges. Wien, xxv, 324, 1875; Fernald, Can. Ent., xxxii, 244,

5535. xanthobasis Zeller, Verh. zool.-bot. Ges. Wien, $\mathrm{xxv}, 324,1875$.

Atl. States.

5536. fernaldella Riley, Proc. Ent. Soc. Wash., i, 155, 1889.

Cal. 
ORCHEMIA Guenée.

Guenée, Ind. Méth., 58, 1845; Fernald, Can. Ent., xxxii, 238, 1900.

5537. diana HüBner, Eur. Schmett., Tort., pl. 44, f. U.S. 247, 1823; Fernald, Can. Ent., xxxii, 238, 1900. syn. decoranaZeTterstedt, luridana W ALKER. a. betuliperda Dyar, Proc. U. S. Nat. Mus., xxv, 403, 1902 .

\section{THELETHIA Dyar.}

Dyar, Can. Ent., xxv, 301, 1893; C. 86.

*5538. extranea Hy. Edwards, Ent. Amer., iii, 181, Ariz. 1888; DYar, C. 86.

\section{Family GELECHIID A.}

\section{By August Busck.}

\section{METZNERIA Zeller.}

\section{Zeller, Isis, 197, 1839.}

5539. lappella Linneus, Syst. Nat., 537, 1758; STAUDinger \& Rebel, Cat. Lep. Eur., ii, no. 2491,

Atl. States, Eur.

\section{PALTODORA Meyrick.}

Meyrick, Handb. Brit. Lep., 571, 1895.

5540. striatella HüBNER, Eur. Schmett., 288, 1820; Walsinghay, Ins. Life, i, 82, 1888; Staudinger \& Rebel, Cat. Lep. Eur., ii, no. 2935, 1901.

5541. pallidistrigella Chambers, Can. Ent., vi, 244, 1874; Bull. Geol. Surv. Terr., iv, 92, 1878; WaLsingнам, Ins. Life, i, 81, 1888.

5542. magnella Busck, Proc. U. S. Nat. Mus., xxv, $776,1903$.

5543. cilialineella Chambers, Can. Ent., vi, 242, 1874; Bull. Geol. Surv. Terr., iv, 91, 1878.

Cal.,

Eur.

Tex.

Col.

Tex.

5544. dietziella Busck, Proc. U. S. Nat. Mus., xxv, $777,1903$.

5545 . canicostella Walsingham, Ins. Life, i, 82, 1888.

Cal.

5546. anteliella Busck, Proc. U. S. Nat. Mus., xxv, 778 ,

N. J. 1903.

5547. sabulella Walsingham, Ins. Life, i, 83, 1888.

Cal.

5548. similiella Chambers, Can. Ent., iv, 193, 1872; vi, 242, 1873.

Atl.

syn. piscipellis Zeller, Verh. zool.-bot. Ges.

Wien, xxiii, 277, 1873. 
5549. tophella Walsingham, Ins. Life, i, 83, 1888.

Cal.

5550. pallidella Chambers, Can. Ent., vi, 245, 1874;

Col.

Bull. Geol. Surv. Terr., iv, 92, 1878; WaLsingнам, Ins. Life, i, 81, 1888.

5551. modesta Walsingham, Ins. Life, i, 82, 1888.

Cal.

\section{SITOTROGA Heinemann.}

Heinemann, Schmett. Deut. u. Schweiz, 287, 1870.

5552. cerealella Olivier, Encl. Méth.,Ent., i,121,1819; Glover, Rept. Dept. Agr., 67, 1854; Clemens, U. S., Eur. Proc. Acad. Nat. Sci. Phil., 168, 1860; StaUDinger \& Rebel, Cat. Lep. Eur., ii, no. 2902, 1901.

\section{AUTONEDA Busck.}

Neda Chambers (not Mulsant), Can. Ent., vi, 243, 1874.

5553. plutella Chambers, Can. Ent., vi, 244, 1874; vii, 105, 1875; Bull. U. S. Geol. Surv. Terr., iii, 157, Ky. 1878 .

\section{TELPHUSA Chambers.}

Chambers, Can. Ent., iv, 182, 1872; Xenolechia Meyrick, Handb. Brit. Lep., 583, 1895.

*5554. longifasciella Clemens, Proc. Ent. Soc. Phil., ii, 12, 121, 1863; Chambers, Can. Ent., iv, 174, 1872.

Atl. States.

syn. curvistrigella Chambers, Can. Ent., iv, 133, 1872; obliquifasciella CHambers, Jn. Cin. Soc. Nat. Hist., ii, 182, 1879.

5555. quinquecristatella Chambers, Bull. Geol Surv. Terr., iv, 88, 146, 1878.

5556. latifasciella Chambers, Cin. Quart. Jn. Sci., ii, 251,1875 .

5557. quercinigracella Chambers, Can. Ent., iv, 170, 1872 .

syn. fragmentella ZelLer, Verh. zool.-bot. Ges. Wien, xxiii, 71, 1873; quercinigrxella Chambers, Bull. U. S. Geol. Surv. Terr., iv, 146,1878 .

5558. palliderosacella Chambers, Bull. U. S. Geol. Surv. Terr., iv, 90, 1878.

5559. querciella Chambers, Can. Ent., iv, 127, 147, 207, 1872; Busck, Proc. U. S. Nat. Mus., xxv, $787,1903$.

*5560. basistrigella Zeller, Verh. zool.-bot. Ges. Wien, xxiii, 270, 1873.

5561. basifasciella Zeller, Verh. zool.-bot. Ges. Wien, xxini, 269, 1873.
Ky. ?

Ky., М̆o.

Atl.

Atl. States.

Atl. States.

Tex.

Tex., N. J. States. 
5562. betulella Busck, Proc. U. S. Nat. Mus., xxv. $787,1903$.

5563. belangerella Chambers, Can. Ent., vii, 210, 1875. syn. oronella Walsingham, Trans. Am. Ent. Soc., x, 179, 1882; РАскаRD, Fifth Rept. U. S. Ent. Comm., 630, 1890; orella Dietz, Smith's List Ins. N. J., 474, 1900.

5564. glandiferella Zelder, Verh. zool.-bot. Ges. Wien, xxiii, 275, 1873; Walsingham, Proc. Zool. Soc. Lond., 72, 1897.

syn. sella Chambers, Can. Ent., vi, 238, 1874; glandifera Chambers, Can. Ent., ix, 14, 1877.

*5565. alexandriæella Chambers, Can. Ent., iv, 149, 1872.

*5566. fasciella Chambers, Can. Ent., vi, 149, 1872.
Va., D. C.

Atl. States.

Tex.

Ky.

Ky.

\section{AGNIPPE Chambers.}

Chimbers, Can. Ent., iv, 194, 1872.

5567. biscolorella Chambers, Can. Ent., iv, 195, 1872; vii, 106, 1875; ix, 231, 1877.

568. fuscopulvella Chambers, Can. Ent., iv, 195, 1872. Ky. Ky. syn. biscolorella Chambers, Bull. Geol. Surv. Terr., iv, 128, 1878.

\section{NEALYDA Dietz.}

Dietz, Ent. News, xi, 350, 1900.

5. 59. pisoniæ Busck, Proc. U. S. Nat. Mus., xxiii, 229, 1900- Dyar, Proc. Ent. Soc. Wash., iv, 470 , 1901.

5570. bifidella Dietz, Ent. News, xi, 351, 1900; Dyar, Proc. U. S. Nat. Mus., xxv, 406, 1902.

5571. kinzelella Busck, Proc. U. S. Nat. Mus., xxiii, 230, 1900; DYar, Proc. Ent. Soc. Wash., iv, 471,1901 .

Fla.

Col

Fla.

\section{CHRYSOPORA Clemens.}

Clemens, Proc. Acad. Nat. Sci. Phil., 362, 1860; Nomia Clemens, Proc. Acad. Nat.

Sci. Phil., 167, 1860; Nannodia Hernemann, Schmett. Deut. u. Schw., 284, 1870.

5572. lingulaceila Clenens, Proc. Acad. Nat. Sci. Phil., 167, 1860; Tin. No. Am., 124, 1872.

Atl. syn. hemanella Chambers, Can. Ent., iv, 67, 169, 1872; x, 52, 1878; armeniella FREY \& Boll, Stett. ent. Zeit., xxxix, 249, 1878. States. $4630-$ No. $52-02-32$ 
5573. hermanella Fabricius, Spec. Ins., ii, 509, 1781; Staudinger \& Rebel, Cat. Lep. Eur., ii, no. Can., $2896,1901$.

\section{LEUCE Chambers.}

Chambers, Can. Ent., vii, 9, 51, 1875; Næra Chambers (not Sowerby), Can. Ent., vii, $9,1875$.

5574. fuscocristatella Chambers, Can. Ent., vii, 9, 34, Tex. 51,1875 .

syn. belfragesella Chambers, Jn. Cin. Soc. Nat. Hist., ii, 183, 1879.

\section{ARISTOTELIA Hübner.}

Hübner, Verz. bek. Schmett., 424, 1816; Eucatoptus Walsingham, Proc. Zool. Soc. Lond., 69, 1897.

5575. roseosuffusella Clemens, Proc. Acad. Nat. Sci. Phil., xii, 162, 434, 1860; Proc. Ent. Soc. Phil., ii, 121, 1863; iii, 508, 1864; Chambers, Can. Ent., iv, 69, 148, 169, 193, 1872; Bull. U. S. Geol. Surv. 'Terr., iii, 125, 141, 1877; Can. Ent., ix, 14, 1877; Bull. Geol. Surv. Terr., iv, 110, 1878; Jn. Cin. Soc. Nat. Hist., ii, 183, 1880; Murtfeldt, Can. Ent., vi, 222, 1874; U. S. Dept. Agr., Div. Ent., Bull. 23, 53,1891; Zeller, Verh. zool.-bot. Ges. Wien, xxiii, 272, 1873; Walsingham, Trans. Am. Ent. Soc., x, 180, 1882: Proc. Zool. Soc. Lond., 66, 1897; Dietz, Smith's List Ins. N. J., 474, 1900; Busck, Proc. U. S. Nat. Mus., xxiii, 226, 1900.

syn. rosasuffusella Chambers, Cin. Quart. Jn. Sci., ii, 290, 1875; bellela W ALKER, Cat. Brit. Mus., xxix, 595, 1864.

5576. pudibundella ZeLLer, Verh. zool. -bot. Ges. Wien, xxiii, 273, 1873; Walsingham, Trans. Am. Ent. Soc., x, 181, 1882; Proc. Zool. Soc. Lond., 66, 1897 ; Busck, Proc. U. S. Nat. Mus., xxiii, 226, 1900 .

syn. intermediella Chanmers, Bull. Geol. Surv. Terr., iv, 89, 1878; WalsinghaM, Trans. Ent. Soc. Lond., x, 180, 1882; Murtaeldt, U. S. Dept. Agr., Div. Ent., Bull. 23, 53, 1891; DreTz, Smith's List Ins. N. J., 475, 1900 .

5577. molestella Zeluer, Verh. zool.-bot. Ges. Wien, xxiii, $274,1873$.

Atl. States.

Atl. States.

Tex. 
5578. rubidella Clemens, Proc. Acad. Nat. Sci. Phil., xii, 163, 434, 1860; Proc. Ent. Soc. Phil., ii, 121, Atl. 1863; Walsingham, Trans. Am. Ent. Soc., x, 180, 1882; Proc. Zool. Soc. Lond., 70, 1897; Dietz, Smith's List Ins. N. J., 475, 1900.

syn. mbensella Chambers, Can. Ent., iv, 193, 1872: Murtfeldt, Can. Ent., vi, 222, 1874; U. S. Dept. Agr., Div. Ent., Bull. 23, 54, 1891; pudibundella Chambers, Can. Ent., ix, 23,1877 .

5579. fungivorella Clemens, Proc. Ent. Soc. Phil., iii, 507, 1874; Walsh, Proc. Ent. Soc. Phil., vi, 273, 1866; PaCKard, Guide Stud. Ins., 350, 1869.

States.

*5579. 1 salicifungiella Clemens, Proc. Ent. Soc. Phil. iii, 508, 1864.

5580. ivæ Busck, Proc. U. S. Nat. Mus., xxiii, 225, 1900; Dyar, Proc. Ent. Soc. Wash., iv, 470, 1901 .

5581. bifasciella Busck, Proc. U. S. Nat. Mus., xxv, $799,1903$.

5582. elegantella Chanbers, Can. Ent., vi, 239, 1872; ix, 23, 1877 .

Atl.

States.

III.

Fla.

Ariz.

Tex.,

Mo.

syn. superbella Chavibers, Can. Ent., vii, 32, 1875 .

5583. argentifera Busck, Proc. U. S. Nat. Mus., xxv, $800,1903$.

5584. cockerella Busck, Pruc. U. S. Nat. Mus., xxv, $800,1903$.

5585. absconditella Walker, Cat. Brit. Mus., xxix, 595, 1864; Walsingham, Trans. Am. Ent. Soc., x, 181, 1882; DIexz, Smith's List Ins. N. J., $475,1900$.

syn. palpiannulella Chambers, Can. Ent., iv, 68,1872 .

5586. minimella Chambers, Can. Ent., vi, 243, 1874.

5587. physaliella Chambers, Can. Ent., iv, 173, 1872; Cin. Quart. Jn. Sci., ii, 238, 1875; Bull. Geol. Surv. Terr., iii, 128, 1877.

5588. disconotella Chambers, Bull. Geol. Surv. Terr., iv, $86,1878$.

5589. gilvolinella Clemens, Proc. Ent. Suc. Phil., ii, 119, 1863; Tin. No. Am., 223, 1872.

5590. kearfottella Busck, Proc. U. S. Nat. Mus., xxv, 803, 1903.

5591. quinquepunctella Busck, Proc. U. S. Nat. Mus., Cal.

N. Mex.

Atl. States.

Tex.

Ky.

$\mathrm{Ky}$.

Pa.

Pa., N. J.

Pa. xxv, 804, 1903. 
HELICE Chambers.

Chambers, Can. Ent., v, 187, 1873.

5592. pallidochrella Chambers, Can. Ent., v, 188, 230, 1873; vii, 105, 1875; ix, 231, 1877; Busck, Jn. Ky.

N. Y. Ent. Soc., x, 89, 1902.

syn. palidochrella Chambers, Can. Ent., ix, 15, 1877; gleditschizella Chambers, Can. Ent., ix, 232, 1877.

\section{EVIPPE Chambers.}

Chambers, Can. Ent., v, 185, 1873; Phrtusa Chambers, Can. Ent., vii, 106, 1875.

5593. prunifoliella Chambers, Can. Ent., v, 186, 1873; vii, 105, 1875; ix, 23, 1877; WalsinghaM, Trans. Am. Ent. Soc., x, 177, 1882; Murteledt, Can. Ent., xv, 94, 1883.

5594. leuconota Zeller, Verh. zool.-bot. Ges. Wien, xxiii, 268, 1873.

Tex., Ky..

syn. plutella Chambers, Can. Ent., vii, 106, 1875; Walsingham, Trans. Am. Ent. Soc., x, 177, 1882; Murteledt, Can. Ent., xv, $94,1883$.

\section{EUCORDYLEA Dietz.}

Dietz, Ent. News, xi, 349, 1900.

5595. atrupictella Dietz, Ent. News, xi, 350, 1900.

Pa., Can.

RECURVARIA Haworth.

Haworth, Lep. Brit., 547, 1829; Evagora Clemens, Proc. Acad. Nat. Sci. Phil., 165, 1860; Eidothoa Chambers, Can. Ent., v, 186, 1873; Sinoe Chambers, Can. Ent., v, 231, 1873; Aphanaula Merrick, Handb. Brit. Lep., 579, 1895.

5596. apicitripunctella Clenens, Proc. Acad. Nat. Sci. Phil., 165. 1860; Walsingham, Trans. Am. Ent. Soc., x, 182, 1882 . Atl. States.

syn. abietisella Packard, Rept. Dept. Agr., 150, 1883; Fifth Rept. U. S. Ent. Comm., 876,1890 .

5597. variella Chambers, Can. Ent., iv, 174, 1872; vi, 241,1874 .

Atl. States.

5598. colubrinæ Busck, Proc. U. S. Nat. Mus., xxv, 810, 1903.

5599. obliquestrigella Chambers, Can. Ent., iv, 65, 1872. syn. obliquistrigella Chambers, Can. Ent., iv, 145,1872 ; vii, 106,1875 ; ix, 24, 1877; x, 50, 1878.

5600. cratægella Busck, Proc. U. S. Nat. Mus., xxv, $811,1903$.

Ky. D. C.

Tex.

Ky.

Pa. . 
5601. robiniella FiтcH, Rept. Ins. N. Y., v, 334, 1859; Chambers, Can. Ent., iii, 55, 163, 183, 1871.

Atl.

syn. fuscopallidella Chambers, Can. Ent., vii, 105, 1875; ix, 24, 1877; Rept. Dept. Agr., 225, 1879; robinizfoliella CHambers, Rept. Dept. Agr., 224, 1879.

5602. quercivorella Chambers, Can. Ent., iv, 173, 1872. syn. gilviscopella Zelter, Verh. zool.-bot. Ges. Wien, xxiii, 266, 1873; gilvoscopella Chambers, Bull. Geol. Surv. Terr., iv, 144, 1878.

5603. dorsivittella Zelcer, Verh. zool. -bot. Ges. Wien, xxiii, 267, 1873; Walsingham, Proc. Zool. Soc. Lond., 66, 1897; Dietz, Smith's List Ins. N. J., 475,1900 .

syn. vagatiocella Chambers, Can. Ent., v, 187. 229, 1873; vii, 105, 1875.

5604. cristatella Chambers, Cin. Quart. Jn. Sci., ii, 241, 1875; Walsingham, Trans. Am. Ent. Soc., $\mathrm{x}, 179,182,1882$.

5605. nigra Busck, Proc. U.S. Nat. Mus., xxv, 814, 1903.

States.

Ky., Tex., Atl. States.

Ky., Tex., Atl. States, W. I.

Ky.

TRYPANISMA Clemens.

Clemens, Proc. Acad. Nat. Sei. Phil., 168, 1860.

5606. prudens Clemens, Proc. Acad. Nat: Sei. Phil., $168,1860$.

Atl. States.

syn. quinqueanmulella Chambers, Can. Ent., iv, 191,1872 .

5607. fagella Busck, Proc. U. S. Nat. Mus., xxv, 816, 1903.

EPITHECTIS Meyrick.

Meyrick, Handb. Brit. Lep., 580, 1895; Taygete Chambers (not Taygetis Hüвner), Can. Ent., v, 231, 1873.

5608. attributella WALKer, Cat. Brit. Mus., xxix, 593, 1864: Walsingham, Trans. Am. Ent. Soc., x, Atl. 182,1882 .

syn. difficilisella Chambers, Can. Ent., iv, 65, 1872; v, 187, 231, 1873; vii, 105, 1875; viii, 19, 1876; Cin. Quart. Jn. Sci., ii, 289, 1875.

5609. bicostomaculella Chambers, Bull. Geol. Surv. Terr., iii, 127, 1877.

5610. sylvicolella Busck, Proc. U. S. Nat. Mus., xxv, 818, 1903.

States.

5611. subsimella Clemens, Proc. Acad. Nat. Sci. Phil., 173,1860 .

Col.

N. Y.

Pa.

5612. saundersella Chambers, Can. Ent., viii, 173, 1876.

Ky. 
5613. gallægenitella Clemens, Proc. Ent. Soc. Phil., III. ii, 420, 1864; iii, 506, 1865; Chambers, Bull. Geol. Surv. Terr., iv, 143, 1878.

syn. geminella Riley, Can. Ent., iii, 195, 1871.

PARALECHIA Busck.

Busck, Proc. U.S. Nat. Mus., xxv, 820, 1903.

5614. pinifoliella Chambers, Jn. Cin. Soc. Nat. Hist., ii, 181, 1880; Comstock, Fifth Rept. U. S. Ent. Comm., 793, 1890; Dietz, Smith's List Ins. N.J., 475,1900 .

5615. cristifasciella Chambers, Bull. Geol. Surv. Terr., iv, $87,1878$.

syn. inscripta Walsingham, Trans. Am. Ent. Soc., x, 180, 1882; Dietz, Smith's List Ins. N. J., $474,1900$.

PHTHORIM $Æ$ A Meyrick.

Meyrick, Ent. Mon. Mag., xxxviii, 103, 1902.

5616. operculella Zecter, Verh. zool.-bot. Ges. Wien, xxiii, 262, 1873; Howard, U. S. Dept. Agr., Farmer's Bull., 120, 23, 1900.

syn. terrella WALKER (not Fischer v. RösLERsтамм), Cat. Brit. Mus., xxx, 1024, 1864; solanella Boisduval, Jn. Soc. C'ent. Hort. Fr., (2), viii, 713, 1874; tabacella RAgonot, Bull. Soc. Ent. Fr., 147,1879; Staudinger \& Rebel, Cat. Lep. Eur., ii, no. 2636, 1901.

5617. glochinella Zelcer, Verh. zool.-bot. Ges. Wien, xxiii, 263, 1873; Chambers, Bull. Geol. Surv. Terr., iv, 144, 1878.

syn. solaniella Chambers, Can. Ent., v, 176, 1873; Cin. Quart. Jn. Sci., ii, 239, 1875; cinerella Murteledt, Can. Ent., xiii, 244, 1881; inconspicuella Murtaeldt, Can. Ent., xV, $139,1883$.

5618. striatella Murtfeldt,Can. Ent., xxxii, 163, 1900.

*5619. marmorella Chambers, Cin. Quart. Jn. Sci., ii, $239,1875$.

Atl. States.

Ky., Atl. States.

So. States, Eur.

Tex.,

Mo.

Mo., Cal.

Ky.

GNORIMOSCHEMA Busck.

Busck, Proc. U. S. Nat. Mus., xxiii, 227, 1900.

5620. gallæsolidaginis RILEy, Rept. Ins. Mo., i, 173, 1869; ii, 20, 132, 134, 1870; Chambers, Can. Ent., viii, 19, 1876; ix, 14, 1877; Cin. Quart. Jn. Sci., ii, 289, 1875; Bull. Geol. Surv. Terr., iii, 1, 28, 141, 1877; Kellicott. Can. Ent., x, 201, 1878; Dietz, Smith's List Ins. N. J., 474, 1900 .
Atl. States. 
5621. gallæasteriella KelLicott, Can. Ent., x, 203, 1878.

Atl. States, Can.

syn. galladiplopappi Fyles, Can. Ent., xxii, $248,1890$.

5622. baccharisella Busck, Proc. U. S. Nat. Mus., xxv, $825,1903$.

5623. coquillettella Busck, Proc. U. S. Nat. Mus., xxv, $405,1902$.

*5624. albimarginella Chambers, Cin. Quart. Jn. Sci., ii, 291,1875 .

syn. albomarginella Chambers, Bull. Geol. Surv. Terr., iv, 141, 1878.

5625. semicyclionella Busck, Proc. U. S. Nat. Mus., xxv, 828, 1903.

*5626. pallidochrella Chambers, Can. Ent., iv, 126, 129 , 147, 1872; Busck, Proc. U. S. Nat. Mus., xxv, 828, 1903; Jn. N. Y. Ent. Soc., x, 90 note, 1902.

5627. dudiella Busck, Proc. U. S. Nat. Mus., xxv, 828, 1903.

5628. serratipalpella Chambers, Bull. Geol. Surv. Terr., iii, 123, 1877.

5629. pedmontella Chambers, Bull. Geol. Surv. Terr., iii, $123,1877$.

5630. triocellella Chambers, Bull. Geol. Surv. Terr., iii, $127,1877$.

syn. triocelella Chambers, Bull. Geol. Surv. Terr., iv, 87, 1878.

5631. octomaculella Chambers, Cin. Quárt. Jn. Sci., ii, 291, 1875; Bull. Geol. Surv. Terr., iii, 128, 1877.

5632. ochreostrigella Chambers, Bull. Geol. Surv. Terr. . iii, 126, 1877.

*5633. collinusella Chambers, Bull. Geol. Surv. Terr., iii, $128,1877$.

5634. saphirinella Chambers, Cin. Quart. Jn. Sci., ii, $250,1875$.

N. Mex.

Ky.

Col.

Col., N. Mex,

Col.

Col.

Cal.,

Col.

Col.

Col.

Col.,

D. C.

syn. sapharinella Chambers, Bull. Geol. Surv.

Terr., iv, 147, 1878.

5635. florella Busck, Proc. U. S. Nat. Mus., xxv, 832, 1903.

5636. banksiella Busck, Proc. U. S. Nat. Mus., xxv, 832, 1903.

5637. batanella Busck, Proc. U. S. Nat. Mus., xxv, 833,1903 .

Ariz.

N. Y.

N. J. 
5638. lavernella Chambers, Can. Ent., vi, 242, 1874. syn. pleysalivorella Chambers, Cin. Quart. Jn. Sci., ii, $238,1878$.

*5639. scutellariæella Chambers, Can. Ent., v, 175, 1873.

5640. tetradymiella Busck, Proc. U.S. Nat. Mus., xxv, 834,1908 .

5641. terracottella Busck, Proc. U.S. Nat. Mus., xxiii, 227, 1900; Dyar, Proc. Ent. Soc. Wash., iv, 471, 1901.

GLAUCE Chambers.

Chambers, Can. Ent., vii, 11, 1875.

*5642. pectenalæella Chambers, Can. Ent., vii, 12, 1875; Busck, Proc. U. S. Nat. Mus., xxv, 783, 1903.

NEODACTYLOTA Busck.

Busck, Proc. U. S. Nat. Mus., xxv, 835, 1903.

5643. snellenella WalsinghaM, Ins. Life, i, 83, 1888; Proc. Zool. Soc. Lond., 522, 1891; 523, 1897; Busck, Proc. U. S. Nat. Mus., xxiii, 228. 1900.

5644. barberella Busck, Proc. U. S. Nat. Mus., xxv, 836, 1903.

\section{DEOCLONA Busek.}

Busck, Proc. U. S. Nat. Mus., xxv, 837, 1903.

5645. yuccasella Busck, Proc. U. S. Nat. Mus., xxv, 837, 1903.

\section{PROSTOMEUS Busck.}

Busck, Proc. U. S. Nat. Mus., xxv, 837, 1903.

5646. brunneus Busck, Proc. U. S. Nat. Mus., xxv, 838 , 1903.

\section{POLYHYMNO Chambers.}

Chambers, Can. Ent., vi, 246, 1874.

5647. luteostrigella Chambers, Can. Ent., vi, 247, 1874; Jn. Cin. Soc. Nat. Hist., ii, 203, 1880; Beutenmüller, Ent. Amer., v, 37, 1889; Walsingham, Trans. Ent. Soc. Lond., pl. 7, f. 78, 1891; Proc. Zool. Soc. Lond., 77, 1897; Busck, Jn. N. Y. Ent. Soc., viii, 236, 1900.

syn. fuscostrigella Chambers, Can. Ent., viii, $30,1876$.

5648. acaciella Busck, Jn. N. Y. Ent. Soc., viii, 235, 1900.

5649. sexstrigella Chambers, Can. Ent., vi, 248, 1874; Busck, Jn. N. Y. Ent. Soc., viii, 236, 1900.
Atl. States.

$\mathrm{K}_{y}$.

Cal.

Fla.

Tex., $\mathrm{Ky}$.

Ariz.

Col.

Cal.

Fla.

So. Atl.

States.

Tex.

Tex. 
MENESTA Clemens.

Clemens, Proc. Acad. Nat. Sci. Phil., 213, 1860; Hyale Снambers, Cin. Quart. Jn. Sci., ii, $242,1880$.

5650. tortriciformella Clemens, Proc. Acad. Nat. Sci. Phil., 213, 1860; Walsingham, Proc. Zool. Soc. Atl.

Lond., 319, 1881; Ins. Life, ii, 154, 1889. States. syn. liturella Walker, Cat. Brit. Mus., xxix, 591, 1864; compliella Chambers, Cin. Quart. Jn. Sci., ii, 242, 1875.

5651. melanella Murtfeldt, Ins. Life, ii, 304, 1890.

Mo.

*5652. albaciliæella ChavBers, Can. Ent., x, 77, 1878. Ohio, N. J. syn. argenticilixella Chambers, Bull. Geol. Surv. Terr., iv, 162, 1878.

\section{STROBISIA Clemens.}

Clemens, Proc. Acad. Nat. Sci. Phil., 164, 1860.

5653. irridipennella Clemens, Proc. Acad. Nat. Sci. Phil., 165, 1860; Chambers, Can. Ent., iv, 89, 1872; Frey \& Boll, Stett. ent. Zeit., xxxix, 251, 1878; Dietz, Smith's List Ins. N. J., 474, 1900. syn. aphroditella Chambers, Can. Ent., iv, 88, 1872; proserpinella FreY \& BoLL, Stett. ent. Zeit., xxxix, 251, 1878.

5654. emblemella Clemens. Proc. Acad. Nat. Sci. Phil., 164, 1860; Chambers, Can. Ent., iv, 89, 1872; Frey \& Boll, Stett. ent. Zeit., xxxix, 251, 1878. Atl. States. syn. vemustella Chambers, Can. Ent., iv, 90, 1872 .

TRICHOTAPHE Clemens.

Atl. States.

Clemens, Proc. Acad. Nat. Sci. Phil., 166, 1860; Begoe Chambers, Can. Ent., iv, 24, 1872; Epicorthylis Zeluer, Verh. zool.-bot. Ges. Wien, xxiii, 248, 1873; Malacotricha Zeller, Verh. zool.-bot. Ges. Wien, xxiii, 282, 1873.

5655. flavocostella Clemens, Proc. Acad. Nat. Sci. Phil., 162, 1860; Proc. Ent. Soc. Phil., i, 131, 1862; Zeller, Verh. zool.-bot. Ges. Wien, xxiii, Atl. 279, 1873; Coquillett, Rept. State Ent. Ill., x, $153,1881$.

syn. Alavicostella Walsingham, Trans. Am. Ert. Soc., x, 184, 1882.

5656. inserrata Walsinghay, Trans. Am. Ent. Soc., x, $184,1882$. States.

5657. serrativittella Zeller, Verh. zool.-bot. Ges. Wien, xxiii, 280, 1873; Chambers, Can. Ent., ix, 24, 1877; Walsinghay, Trans. Am. Ent. Soc., x, 184, 1882.

syn. plutella Chambers, Can. Ent., vi, 238, 1874. 
5658. costarufoella Chambers, Can. Ent., vi, 240, 1874. Tex.

syn. costorufoella Сhambers, Bull. Geol. Surv. Terr., iv, 142, 1878.

5659. alacella Clemens, Proc. Ent. Soc. Phil., i, 132, 1862; Dietz, Smith's List Ins. N. J., 474, 1900.

syn. ochripalpella ZeLLer, Verh. zool.-bot. Ges. Wien, xxiii, 279, 1873; Walsingham, Trans. Am. Ent. Soc., x, 183, 1882; goodellella Chambers, Jn. Cin. Soc. Nat. Hist., iii, $289,1881$.

5660. purpureofusca Walsingham, Trans. Am. Ent. Soc., x, 184, 1882.

5661. nonstrigella Chambers, Bull. Geol. Surv. Terr. iv, $92,1878$.

5662. juncidella Clemens, Proc. Acad. Nat. Sci. Phil., 166, 1860; Walsingham, Trans. Am. Ent. Soc., $\mathrm{x}, 183,1882$.

syn. pallipalpis Walker, Cat. Brit. Mus., xxix, 596, 1864; dubitella Chambers, Can. Ent., iv, 90, 128, 1872; Murtfeldt, Can. Ent., vi, 221, 1874; hallipalpis RILEY, Smith's List Lep. Bor. Anı., no. 5394, 1891.

5663. melantherella Busck, Proc. U. S. Nat. Mus., xxiii, 232, 1900; DYar, Proc. Ent. Soc. Wash., iv, 472, 1901.

5664. setosella Clemens, Proc. Acad. Nat. Sei. Phil., 166, 1860; Zeller, Verh. zool.-bot. Ges. Wien, xxiii, $282,1873$.

syn. costolutella Chambers, Can. Ent., iv, 209, 1872; ix, 24, 1877: bilobella Zeluer, Verh. zool.-bot. Ges. Wien, xxii, 280, 1873.

5665. inversella Zeluer, Verh. zool.-bot. Ges. Wien, xxiii, 248, 1873; Chambers, Can. Ent., x, 54, 1878; Jn. Cin. Soc. Nat. Hist., ii, 198, 1880.

5666. condaliavorella Busck, Proc. U. S. Nat. Mus., xxiii, 232, 1900; Dyar, Proc. Ent. Soc. Wash., iv, $473,1901$.

5667. chambersella Murtfeldt, Can. Ent.,vi,222,1874; xiii, 242, 1881; Chamsers, Cin. Quart. Jn. Sci., ii, 240,1875 .

syn. inæquepulvella Chambers, Cin. Quart. Jn. Sci., ii, 239, 1875.

*5668. lactiflosella Chambers, Bull. Geol. Surv. Terr., iv, $89,1878$.

Fla.

Tex.

Fla.

Mo.,

Atl.

States.

Tex.

5669. trimaculella Сhambers, Can. Ent., vi, 238, 1874.

Tex. 
*5670. bidiscomaculella Chambers; Can. Ent., vi, 241, Tex. 1874 .

5671. fernaldella Busck, Proc. U. S. Nat. Mus., xxv, $915,1903$.

*5672. georgiella W ALker, Cat. Brit. Mus., xxxv, 1827, 1866: Walsingham, Proc. Zool. Soc. Lond., 312, 1891; Busck, Jn. N. Y. Ent. Soc., x, 94, 1902.

Me.

Ga.

\section{GLYPHIDOCERA Walsingham.}

Walsingham, Proc. Zool. Soc. Lond., 531, 1891.

5673. floridanella Busck, Proc. Ent. Soc. Wash., iv, $474,1901$.

5674. æquepulvella Chambers, Can. Ent., iv, 192, 1872; vi, 230, 1874; Cin. Quart. Jn. Sci., ii, 246, 1875; Bull. Geol. Surv. Terr., iii, 125, 141, 1877; Busck, Proc. Ent. Soc. Wash., iv, 475, 1901.

Fla.

Ky., Tex., Cal., Col.

\section{ANORTHOSIA Clemens.}

Clemens, Proc. Acad. Nat. Sci. Phil., 156, 1860; Sagaritis Chambers, Can. Ent., iv, 225,1874 .

5675. punctipennella Clemens, Proc. Acad. Nat. Sci. Phil., 161, 1860; Chambers, Can. Ent., iv, 225, 1872; vi, 245, 1874; Walsingham, Trans. Ent. Atl. Soc. Lond., 110, 1891.

*5676. gracilella Chambers, Can. Ent., iv, 226, 1874 States.

\section{ENCHRYSA Zeller.}

Zeller, Verh. zool.-bot. Ges. Wien, xxiii, 82, 1873.

*5677. dissectella Zecler, Verh. zool.-bot. Ges. Wien, Ohio. xxiii, 283, 1873.

YPSOLOPHUS Fabricius.

Fabricius, Ent. Syst., suppl., 421, 1798.

5678. ligulellus HüBner, Zutr. exot. Schmett., f. 143, 1818.

syn. pometella Harris, Camb. Chron., Jul. 17, 1853; Fiтch, Jn. N. Y. Agr. Soc., iv, 36, 1853; contubernatellus Fitch, Trans. N. Y. Agr. Soc., xiii, 178, 1854; pancigutellus Clemens, Proc. Ent. Soc. Phil., ii, 123, 1863: Alavivittellus Clemens, Proc. Ent. Soc. Phil., ii, 429, 1864; reedella Chambers, Can. Ent., iv, 222, 1872; quercipomonella CHамBers, Can. Ent., iv, 222, 1872; ruderella Chambers, Bull. Geol. Surv. Terr., iv, 167, 1878. 
5679. punctidiscellus Clemens, Proc. Ent. Soc. Phil., ii, 123, 1863; Zeller, Verh. zool.-bot. Ges. Wien. xxiii, $285,1873$.

syn. stramineellus Chaybers, Can. Ent., iv, $224,1872$.

5680. touceyellus Busck.

syn. trimaculellus Chambers (not Fitch), Can. Ent., vi, 243, 1874; Bull. Geol. Surv. Terr., iv, 92 1878; W alsingham, Proc. Zool. Soe. Lond., 526, 1891.

5681. bipunctellus W alsingham, Trans. Am. Ent. Soc., $x, 186,1882$.

*5682. trinotellus Coquillett, Pap., iii, 81, 1883; PaCkARD, Fifth Rept. U. S. Ent. Comm., 640, 1890.

5683. citrifoliellus Chambers, Jn. Cin. Soc. Nat. Hist., ii, 184, 1880; Сомsтоск, Rept. U. S. Dept. Agr., 205,1880 .

5684. caryæfoliellus Chambers, Can. Ent., iv, 224, 1872 .

5685. ventrellus Fiтch, Trans. N. Y. Agr. Soc., xiii, $234,1853$.

syn. unicipunctellus Clemens, Proc. Ent. Soc. Phil., ii, 123, 1863; Zeller, Verh. zool.-bot. Ges. Wien, xxiii, 286, 1873; W ALsinghaM, Trans. Am. Ent. Soc., x, 186, 1882.

5686. eupatoriellus Chambers, Can. Ent., iv, 221, 1872; ix, $23,1877$.

syn. dolabella Zeluer, Verh. zool.-bot. Ges. Wien, xxiii, 288, 1873.

*5687. malifoliellus Fiтch, Trans. N. Y. State Agr. Soc., xiii, $233,1853$.

*5688. quercicellus Chambers, Can. Ent., iv, 223, 1872. syn. querciella Chambers, Bull. Geol. Surv. Terr., iv, 83, 1878.

*5689. roseocostellus Walsinghan, Trans. Am. Ent. Soc., x, 185, 1882.

*5690. bimaculellus Chambers, Bull. Geol. Surv. Terr., iii, 122, 1877; Jn. Cin. Soc. Nat. Hist., ii, 184, 1880 .

*5691. grisseellus Chambers, Can. Ent., vi, 245, 1874.

*5692. rusticus Walsingham, Proc. Zool. Soc. Lond., 525,$1891 ; 86,1897$.

Tex., Ky.

Mass.

III.

Fla.

Ky., Tex.,

Mo.

Atl. States.

Atl. States, Ky., Tex.

N. Y.

Ky.

Mo.

Col.

Tex.

Tex., W. I. 


\section{ANARSIA Zeller.}

Zeller, Isis, 190, 1839.

5693. lineatella Zeller, Isis, 190, 1839; Staudinger \& Rebel, Cat. Lep. Eur., ii, no. 2999, 1901; Chambers, Can. Ent., iv, 208, 1872; Dietz, Smith's List Ins. N. J., 475, 1900.

syn. pruniella Clemens, Proc. Acad. Nat. Sci. Phil., 169, 1860; Chambers, Can. Ent., iv, 208, 1872; vi, 243,1874 .

*5694. suffusella Chambers, Can. Ent., vi, 243, 1874.

U. S., Eur.

Tex.

Fla.

Tex., Ky., Atl. States. Tex., Atl. States.

N. J.

Atl. States.

Atl. States, Col.

5700. concinusella Chambers, Cin. Quart. Jn. Sci., ii, 253,1875 .

syn. concinnisella Chambers, Bull. Geol.

Surv. Terr., iii, 127, 1877.

\section{ANACAMPSIS Curtis.}

Cuntis, Brit. Ent., Expl. pl. 189, 1827; Tachyptilia Heinemann, Schm. Deut. u. Schw., ii, 321, 1870.

5701. innocuella Zeller, Verh. zool.-bot. Ges. Wien, xxiii, 249, 1873; Dyar, Proc. U. S. Nat. Mus., xxv, 406, 1902 .

Col., Tex. 
5702. rhoifructella Clemens, Proc. Acad. Nat. Sci. Phil., 163, 1860; Proc. Ent. Soc. Phil., ii, 121, 1863: Chambers, Can. Ent., iii, 68, 1872; ZeLLER, Verh. zool.-bot. Ges. Wien, xxiii, 252, 1873; Coquillett, Pap., iii, 99, 1883; Dietz, Smith's List Ins. N. J., 474, 1900.

syn. consonella ZeLLer, Verh. zool.-bot. Ges. Wien, xxiii, 251, 1873; Walsinghay, Trans. Am. Ent. Soc., x, 183, 1882; quadrimaculella Chambers, Can. Ent., vi, 237, 1874; ochreocostella Chambers, Bull. Geol. Surv. Terr., iv, $91,1878$.

5703. crescentifasciella Chaмbers, Can. Ent., vi, 237, 1874; Cin. Quart. Jn. Sci., ii, 255, 1875; Bull. Geol. Surv. Terr., iv, 90, 1878.

5704. niveopulvella Chambers, Can. Ent., vii, 210, 1875 .

5705. argyrothamniella Busck, Proc. U. S. Nat. Mus., xxiii, 231, 1900; Dyar, Proc. Ent. Soc. Wash., iv, 474,1901 .

5706. lagunculariella Busck, Proc. U. S. Nat. Mus., xxiii, 230, 1900; Dyar, Proc. Ent. Soc. Wash., iv, 474,1901 .

5707. cyclella Busck, Proc. U. S. Nat. Mus., xxv, 848. 1903.

5708. paltodoriella Busck, Proc. U. S. Nat. Mus., xxv, 848, 1903.

5709. fullonella ZELLER, Verh. zool.-bot. Ges. Wien, xxiii, $276,1873$.

syn. rufusella Chambers, Can. Ent., vi, 240, 1874; refusella Walsingham, Trans. Am. Ent. Soc., x, 184, 1882; rubescens W ALsINGHaM, Proc. Zool. Soc. Lond., 319, 1881; subruberella Chambers, Can. Ent., vi, 240, 1874; Cin. Quart. Jn. Sci., ii, 254, 1875.

5710. lupinella Busck, Can. Ent, xxxiii, 14, 1901.

5711. agrimoniella Clemens, Proc. Acad. Nat. Sci. Phil., 162, 434, 1860; Proc. Ent. Soc. Phil., ii, 120, 1863; ZelLer, Verh. zool.-bot. Ges. Wien, xxiii, 275, 1873; Dietz, Smith's List Ins. N. J., 474, 1900; Besck, Can. Ent., xxxiii, 15, 1901.

syn. aduncella Zeller, Verh. zool.-bot. Ges. Wien, xviii, 614, 1868; aderusella RILEY, Smith's List Lep. Bor. Am., no. 5299, 1891.

5712. tristrigella Walsingham, Trans. Am. Ent. Soc., x, 181, 1882; Coquillett, Pap., iii, 91, 1883; Сомsтоск, Fifth Rept. U. S. Ent. Comm., 639, 1890; Busck, Can. Ent., xxxiii, 15, 1901.
Atl. States, Mo., Tex.

Tex.

Can., Vanc. Id., Ariz.

Fla.

Fla.

Ariz.

N. Mex.

Tex.

Can.

Atl. States.

Ill.,

Kans. 
5713. levipedella Clemens, Proc. Ent. Soc. Phil., ii, 4, 1863; Frey \& Boll, Stett. ent. Zeit., xxxix, 251, Atl. 1878; Busck, Can. Ent., xxxiii, 15, 1901.

States.

\section{GELECHIA Hübner.}

Hübner, Verz. bek. Schmett., 415, 1816; Catastega a Clemens, Proc. Ent. Soc. Phil., i, 87, 1861; Cirrha Chambers, Can. Ent., iv, 146, 1872; Oeseis Chambers, Cin. Quart. Jn. Sci., ii, 255, 1875; Pseudochelaria Dietz, Ent. News, xi, 252, 1900.

5714. cercerisella Chambers, Can. Ent., iii, 108, 129, 147, 1872; Walsingham, Trans. Am. Ent. Soc., $\mathrm{x}, 177,1882$.

syn. olympiadella Zelier, Verh. zool.-bot. Ges. Wien, xxiii, 259, 1873; Chambers, Can. Ent., ix, 24, 1877.

5715. quinella Zeller, Verh. zool.-bot. Ges. Wien, xxiii, 260, 1873; ('Hambers, Can. Ent., ix, 23, 1877 .

5716. arizonella Busck, Proc. U. S. Nat. Mus., xxv, $856,1903$.

5717. coloradensis Busck, Proc. U. S. Nat. Mus., xxv, $857,1903$.

5718. trialbamaculella CHambers, Cin. Quart. Jn. Sci., ii, 250,1875 .

syn. epigzella Chambers, Jn. Cin. Soc. Nat. Hist., 1ii, 289, 1881.

5719. confusella Chambers, Cin. Quart. Jn. Sci., ii, 251,1875 .

syn. persicæella Murtaelot, Rept. Mich. State Agr. Col., 1899; Can. Ent., xxxii, 164,1900 .

5720. bimaculella Chambers, Can. Ent., iv, 108, 129, 147,1872 .

syn. ternarella Zeluer, Verh. zool.-bot. Ges. Wien, xxiii, 264, 1873; sylvacolella СнамBers, Bull. Geol. Surv. Terr., iv, 86, 1878.

5721. continuella ZELLER, Isis, 198, 1839; STAUDINGER \& Rebel, Cat. Lep. Eur., ii, no. 2597, 1901; Möschler, Wien. ent. Mon., 200, 1864; Grote, (in. Ent., iv, 126, 1872.

syn. trimaculella PACKARd, Proc. Bost. Soc. Nat. Hist., xi, 61, 1867; albomaculella Chambers, Can. Ent., vii, 209, 1875.

5722. ribesella Chambers, Cin. Quart. Jn. Sci., 1i, 290, 1875; Bull. Geol. Surv. Terr., iii, 128, 1877; Dyar, Proc. U. S. Nat. Mus., xxv, 407, 1902.
So. Atl. States.

Tex.

Ariz.

Col.

Tex., Atl. States.

Mich.

Tex., Ky., D. C:

Lab., Can., Eur.

a This genus, with the species 5777,5807 , and 5830 , are referable to the Tortricidæ.-Harrison G. Dyar. 
5723. trophella Busck, Proc. U. S. Nat. Mus., xxv, $860,1903$.

Col.

5724. lugubrella Fabricius, Ent. Syst., iii, 2, 299, 54. 1794; Staudinger \& Rebel, Cat. Lep. Eur., ii, no. $2617,1901$.

5725. albilorella ZelLer, Verh. zool.-bot. Ges. Wien, xxiii, 261, 1873.

syn. trifasciella Chambers, Cin. Quart. Jn. Sci., ii, 252, 1875; Can. Ent., ix, 24, 1877.

5726. dentella Busck, Proc. U. S. Nat. Mus., xxv, 862, 1903.

5727. sistrella Busck, Proc. U. S. Nat. Mus., xxv, 862 , 1903.

5728. abdominella Busck, Proc. U. S. Nat. Mus., xxv, $863,1903$.

5729. basquella Chambers, Can. Ent., vii, 92, 124, 1875 .

syn. bosquella Chambers, Bull. U. S. Geol. Surv. Terr., iv, 87, 1878; Walsingham, Trans. Am. Ent. Soc., x, 178, 1882; Proc. Zool. Soc. Lond., 75, 1897; costipunctella Möschler, Abh. Senck. Ges., xvi, 344, 1889; Walsingham, Proc. Zool. Soc. Lond., $519,1892$.

5730. paulella Busck, Proc. U. S. Nat. Mus., xxv, 865, 1903.

5731. unifasciella Busck, Proc. U. S. Nat. Mus., xxv, $865,1903$.

*5732. packardella (hambers, Bull. Geol. Surv. Terr., iii, $143,1877$.

5733. aristella Busck, Proc. U. S. Nat. Mus., xxv, 866 , 1903.

5734. thoracealbella Chambers, Can. Ent., vi, 255, 1874; Cin. Quart. Jn. Sci., ii, 252, 1875.

"5735. minimaculella Chambers, Can. Ent., vi, 235, 1874. syn. minimmaculella Chambers, Bull. Geol. Surv. Terr., iv, 145, 1878.

5736. ochreosuffusella Снambers, Can. Ent., vi, 236, 1874; Cin. Quart. Jn. Sci., ii, 255, 1875.

syn. depressostrigella Chambers, Can. Ent., vi, 236, 1874; Bull. Geol. Surv. Terr., iii, 142, 1878; depussostrigella Chambers, Cin.Quart. Jn. Sci., ii, 255, 1875.

5737. striatella Busck, Proc. U. S. Nat. Mus., xxv, 868,1903 .

Me.,

Eur.

Tex.,

Ariz.

Ariz.

Ariz.

Ariz.

Tex., Atl. States, W. I.

Cal., Ariz.

Ariz.

Col.

Ariz.

Tex.

Tex.

Tex. Col.

Ariz. 
5738. ochreostrigella Chambers, Cin. Quart. Jn. Sci., ii, 247, 1875; Can. Ent., x, 54, 1878.

5739. hibiscella Busck, Proc. U. S. Nat. Mus., xxv, 869, 1903.

5740. cockerelli Busck, Proc. U. S. Nat. Mus., xxv, 871, 1903.

Cal.

D. C.

N. Mex.,

Ariz.

5741. variabilis Busck, Proc. U. S. Nat. Mus., xxv, $871,1903$.

Col.,

Cal.

Col.

5742. trilineella Chambers, Bull. Geol. Surv. Terr., iii, $125,1877$.

5743. bianulella Chambers, Cin. Quart. Jn. Sci., ii, 225,1875 .

syn. ocellella Chanbers, Bull. Geol. Surv. Terr., iii, 126, 1877; ocelella CHAMBERs, Bull. Geol. Surv. Terr., iv, 145, 1878.

5744. discoocellella Chambers, Can. Ent., iv, 194, 1872. syn. discoocelella Chambers, Can. Ent., vi, 231, 1874; discoocella Chambers, Cin. Quart. Jn. Sci., ii, 237, 1875; discooecella CoquILLett, Pap., iii, 98, 1883; diseocella Dietz, Smith's List Ins. N. J., 474, 1900; violaceofusca Zeller, Verh. zool.-bot. Ges. Wien, xxiii, 258, 1873.

5745. anarsiella Chambers, Bull. Geol. Surv. Terr., iii, 126, 1877; Dyar, Proc. U. S. Nat. Mus., xxv, 407, 1902 .

5746. pravinominella Chambers, Can. Ent., x, 50, 1878; Dyar, Proc. U. S. Nat. Mus., xxv, 407, 1902.

syn. quadrimacalella CHAmBers (not CHAMBers), Cin. Quart. Jn. Sci., ii, 290, 1875; Bull. Geol. Surv. Terr., iii, 128, 1877.

5747. barnesiella Busck, Proc. U. S. Nat. Mus., xxv, $875,1903$.

5748. lindenella Busck, Proc. U. S. Nat. Mus., xxv, 876, 1903.

Ky., Tex., Ill., Kans., Atl. States.

Col.

Col.

Col.

Col.

5749. dyariella Busck, Proc. U. S. Nat. Mus., xxv, 877, 1903.

5750. albisparsella Chambers, Can. Ent., iv, 92, 128, 1872.

syn. platanella Chambers, Can. Ent., iv, 146, 1872.

5751. unctulella Zeller, Verh. zool.-bot. Ges. Wien, xxiii, 257, 1873.

Tex., Col., Ariz.

$4630-$ No. $52-02-33$ 
5752. obscuroocelella Chambers, Cin. Quart. Jn. Sci., ii, 254,1875 .

syn. obscuræecella RILey, Smith's List Lep. Bor. Am., no. 5424, 1891.

5753. versutella Zeller, Verh. zool.-bot. Ges. Wien, xxiii, 253, 1873.

*5754. lynceella ZelLer, Verh. zool.-bot. Ges. Wien, xxiii, $255,1873$.

5755. bicostomaculella Chambers, Can. Ent., iv, 127, 147, 1872; Dietz, Smith's List Ins. N. J., 474, 1900 .

syn. quercifoliella Chambers, Can. Ent., iv, 206, 1872; v, 174, 1873; qibbosella Chanbers (not Stainton), Can. Ent., v, 72, 1873.

5756. nigrimaculella Busck, Proc. U.S. Nat. Mus., xxv, 880, 1903.

5757. maculimarginella Chambers, Can. Ent., vi, 241. 1874.

syn. maculomarginella Chambers, Bull. Geol. Surv. Terr., iv, 144, 1878.

5758. biminimaculella Chambers, Cin. Jn. Nat. Hist., ii, $183,1880$.

5759. pseudoacaciella Chambers, Can. Ent., iv, 9, 107, 129, 147, 1872; Cin. Quart. Jn. Sci., i, 208, 1874; Psyche, iii, 65, 1880.

syn. cacella ZeLler. Verh. zool.-bot. Ges. Wien, xxiii, 252, 1873.

5760. serotinella Busck, Proc. U. S. Nat. Mus., xxv, $882,1903$.

5761. vernella Murtfeldt, Can. Ent., xv, 139, 1883. syn. formosella Murtaeld (not Hübner), Can. Ent., xiii, 243, 1881.

5762. sequax Haworth, Lep. Brit., 552, 1829; StaUDINGER \& REBel, Cat. Lep. Eur., ii, no. 2741,1901; Zeller, Verh. zool.-bot. Ges. Wien, xxiii, 265, 1873 .

*5763. occidentella Chambers, Cin. Quart. Jn. Sci., ii, 246,1875 .

5764. mediofuscella Clemens, Proc. Ent. Soc. Phil., ii, $11,121,1863$.

syn. vagella WaLker, Cat. Brit. Mus., xxix, 596, 1864; Walsingham, Trans. Am. Ent. Soc., x, 178, 1882; fuscoochrella Chambers, Can. Ent., iv, 106, 1872: liturosella ZeLLer, Verh, zool, -bot. Ges. Wien, xxiii, 265, 1873.

Tex., Col., Wyo.

Tex.

Ky., Atl. States.

N. Y.

Tex., Atl.

States.

Tex.,

Mo.

Atl. States, Tex., Ky.

Atl. States. Col.

Mo., Atl. States.

Mass., Eur.

Cal.

Tex., Ky. . Atl. States. 
5765. walsinghami Dietz, Ent. News, xi, 352, 1900; Walsingham \& Durrant, Ent. Mo. Mag., Pa. xxxviii, 28, 1902.

*5766. pennsylvanica Dietz, Ent. News, xi, 353, 1900; Walsingham \& Durrant, Ent. Mo. Mag., xxxviii, 29, 1902.

*5767. tephriasella Chambers, Can. Ent., iv, 68, 1872; Cin. Quart. Jn. Sei., ii, 253, 1875; Walsingham, Trans. Am. Ent. Soc., x, 181, 1882.

5768. conclusella Walker, Cat. Brit. Mus., xxix, 593, 1864; Walsingham, Trans. Am. Ent. Soc., x, $179,1882$.

syn. grissefasciella Chambers, Cin. Quart. Jn. Sci., ii, 253, 1875.

5769. rileyella Chambers, Can. Ent., iv, 106, 147, 1872; Busck, Proc. U. S. Nat. Mus., xxv, 887, 1903.

5770. nundinella Zeluer, Verh. zool.-bot. Ges. Wien, xxiii, 256, 1873.

syn. beneficentella Murtfeldt, Can. Ent., xiii, $245,1881$.

5771. monumentella Chambers, Bull. Geol. Surv. Terr., iii, $125,1877$.

5772. obscurosuffusella Chambers, Bull. Geol. Surv. Terr., iv, 90, 1878.

5773. petasitis Pfaffenzeller, Stett. ent. Zeit., xxviii, 79, 1867; Staudinger \& Rebel, Cat. Lep. Eur., ii, no. 2588, 1901; Walsingham, Trans. Am. Ent. Soc., $\mathrm{x}, 178,1882$.

5774. panella Busck, Proc. U. S. Nat. Mus., xxv, 889, 1903.

5775. abella Busck, Proc. U. S. Nat. Mus., xxv, 889, 1903.

5776. fuscotæniaella Chambers, Bull. Geol. Surv. Terr., iv, $89,1878$.

syn. fuscotanniella RILEY, Smith's List Lep. Bor. Am., no. 5473, 1891; fuscolinianella Riley, Smith's List Lep. Bor. Am., no. 5370 , 1891.

*5777. aceriella Clemens, Proc. Ent. Soc. Phil., i, 87, 1861.

*5778. adaptella WaLker, Cat. Brit. Mus., xxix, 590 1864.

*5779. albistrigella Chambers, Can. Ent., iv, 171, 1872; Hagen, Pap., iv, 98, 1884.

Col.

Tex., Mo.,

Atl. States.

Atl.

Ky.

Ky.

States.

Tex.

Atl. States, Eur.

Ariz.

Col.

Tex., Col.

$\mathrm{Pa}$.

Can.

Ky.

*5780. ambrosiæella Chambers, Cin. Quart. Jn. Sci., ii, 239,1875 . 
*5781. amorphæella Chambers, Bull. Geol. Surv. Terr., iii, $126,1877$.

*5782. angustipennella Clemens, Proc. Ent. Soc. Phil., ii. $119,1863$.

*5783. argentialbella Chambers, Can. Ent.,vi, 241, 1874.

*5784. attritella WaLker, Cat. Brit. Mus., xxix, 592, 1864.

*5785. aurimaculella Chambers, Can. Ent., iv, 172, 1872. syn. discomaculella Chambers, Can. Ent., iv, 172, 1872; Cin. Quart. Jn. Sci., ii, 239, 1875.

*5786. badiomaculella Chambers, Can. Ent., iv, 192, 1872.

*5787. bistrigella Chambers, Can. Ent., iv, 92, 147, 1872 .

*5788. brumella Clemens, Proc. Ent. Soc. Phil., ii, 416, 1864 .

*5789. canopulvella Chambers, Bull. Geol. Surv. Terr., iv, $91,1878$.

*5790. capiteochrella Chambers, Cin. Quart. Jn. Sci., ii, $252,1875$.

*5791. caryævorella PaCkard, Rept. Dept. Agr., 1885, $331,1886$.

*5792. cassella W ALKer, Cat. Brit. Mus., xxix, 594, 1864 .

*5793. decemmaculella Chambers, Cin. Quart. Jn. Sci., ii, 290, 1875; Bull. Geol. Surv. Terr., iii, 128, 1877 .

*5794. brackenridgella Busck.

syn. detersella Clemens (not Zeller), Proc. Acad. Nat. Sci. Phil., 164, 1860.

*5795. discoannulella Chambers, Cin. Quart. Jn. Sci., ii, 254,1875 .

*5796. discostrigella Chambers, Cin. Quart. Jn. Sci., ii, 248,1875 .

*5797. flavicorporella Walsingham, Trans. Am. Ent. Soc., x, 177, 1882.

*5798. flexurella Clemens, Proc. Acad. Nat. Sci. Phil., 163, 1860; Proc. Ent. Soc. Phil., ii, 122, 1863.

*5799. fuscoluteella Chambers, Can. Ent., iv, 106, 129, $147,1872$.

*5800. fuscomaculella Chambers, Can. Ent., iv, 170, 1872 .

*5801. fuscopunctella Clemens, Proc. Ent. Soc. Phil., ii, 12, 121, 1863 .

(Unknown.)

Cal.

Mass.

Pa.

Ky.

Ky.

Pa.? 
*5802. gilvomaculella Clemens, Proc. Ent. Soc. Phil., ii, $12,121,1863$.

*5803. glycyrrhizæella Chambers, Bull. Geol. Surv. Terr., iii, 124, 1877.

*5804. grisella Chambers, Can. Ent., iv, 171, 1872.

*5805. griseaella Chambers, Can. Ent., iv, 88, 1872.

Pa. ?

Col.

Ky.

Can.

syn. griseella Chambers, Bull. Geol. Surv. Terr., iv, 14t, 1878.

*5806. griseochrella Chambers, Cin. Quart. Jn. Sci., ii, 247,1875 .

*5807. hamameliella Clemens, Proc. Ent. Soc. Phil., i, 87, 1861.

*5808. labradorica Möschler, Can. Ent., iv, 125, 1872.

*5809. labradoriella Clemens, Proc. Ent. Soc. Phil., ii, $12,120,1863$.

*5810. lacteusochrella Chambers, Cin. Quart. .Jn. Sci., ii, 244,1875 .

*5811. liturella WALKer, Cat. Brit. Mus., xxix, 591, 1864 .

*5812. maculatusella Chambers, Cin. Quart. Jn. Sci., ii, 245.1875 .

*5813. milleriella Chambers, Cin. Quart. Jn. Sci., ii, 253,1875 .

*5814. mimella Clenens, Proc. Acad. Nat. Sci. Phil., 163, 1860; Proc. Ent. Soc. Phil., ii, 121, 1863.

*5815. obscurella Chambers, Can. Ent., iv, 170, 1872.

*5816. obscurusella Chambers, Can. Ent., iv, 106, 128, $148,1872$.

syn. fuscopulvella Chambers, Can. Ent., iv, $170,1872$.

*5817. ocherfuscella Chambers, Cin. Quart. Jn. Sci., ii, 249,1875 .

syn. ochreofuscella Chambers, Bull. Geol. Surv. Terr., iv, 145, 1878.

*5818. ornatifimbriella Clemens, Proc. Ent. Soc. Phil., ii, $420,1864$.

*5819. pallidegrisseella Chambers, Can. Ent., vi, 237, 1875 .

*5820. palpialbella Chambers, Cin. Quart. Jn. Sci., ii, (Unknown.) 253,1875 .

syn. palpialella Riley, Smith's List Lep. Bor.

Am., no. 5441, 1891. 
*5821. parvipulvella Chambers, Can. Ent., vi, 242, 1874.

Tex,

*5822. pullifimbriella Clemens, Proc. Ent. Soc. Phil., ii, 120, 1863.

Pa. ?

*5823. pullusella Chambers, Can. Ent., vi, 237, 1874.

Tex.

*5824. punctiferella Clemens, Proc. Ent. Soc. Phil., ii, $119,1863$.

*5825. simpliciella Chambers, Cin. Quart. Jn. Sci., ii, $238,1875$.

*5826. subalbusella Chambers, Can. Ent., vi, 242, 1874.

*5827. suffusella Chambers, Can. Ent., iv, 171, 1872.

*5828. thoraceochrella Chambers, Can. Ent., iv, 169 , 1872 .

*5829. thoracestrigella Chambers, Cin. Quart. Jn. Sci., ii, 245,1875 .

Pa.?

Ky.

Tex.

Ky.

Ky.

Cal.

*5830. timidella Clemens, Proc. Ent. Soc. Phil., i, 87, 1861.

*5831. unistrigella Chambers, Can. Ent., v, 176, 1873.

*5832. versicolorella Chambers, Can. Ent., iv, 127, 147, 1872 .

*5833. wacoella Chambers, Can. Ent., vi, 237, 1874.

Minn.

Ky.

Ky.

Tex.

\section{Family XYLORICTID E.}

STENOMA Zeller.

\section{Zeller, Isis, 195, 1839.}

5834. schlægeri Zeller, Linn. Ent., ix, 372, 1854; x, 158, 1855; Verh. zool.-bot. Ges. Wien, xxiii, 246, 1873; Walsingham, Ins. Life, ii, 152, 1889.

Atl. States.

5835. leucillana Zeller, Linn. Ent., ix, 370, 1854; Walsingham, Ins. Life, ii, 153, 1889.

5836. humilis Zeller, Linn. Ent., x, 156, 1855; WALSINGHAM, Ins. Life, ii, 154, 1889.

syn. nubeculosa Zeller, Verh. zool.-bot. Ges. Wien, xxiii, 245, 1873; W ALsingham, Trans. Am. Ent. Soc., x, 175, 1882; canusella Chambers, Can. Ent., vi, 235, 1874.

5837. crambitella Walsingham, Ins. Life, ii, 154, 1889.

Ariz.

5838. furcata Walsingham, Ins. Life, ii, 153, 1889.

Ariz.

*5839. algidella WaLker, Cat. Brit. Mus., xxix, 710, 1864; Walsingham, Ins. Life, ii, 153, 1889. 
IDE Chambers.

Chambers, Jn. Cin. Soc. Nat. Hist., ii, 180, 1879; Walsingham, Ins. Life, ii, 155, 1889.

*5840. osseella Walsingham, Ins. Life, ii, 155, 1889.

Cal.

5841. vestalis Zeller, Verh. zool.-bot. Ges. Wien, xxiii, 247, 1873; Walsinghay, Ins. Life, ii, 155, 1889 .

Tex., Fla., S. C.

syn. albella Chambers, Can. Ent., vi, 234, 1874.

5842. lithosina Zeller, Verh. zool.-bot. Ges. Wien, xxiii, 244, 1873; Walsingham, Ins. Life, ii, 155, 1889.

syn. tortricella Chambers, Can. Ent., vi, 235, 1874: Bull. Geol. Surv. Terr., iii, 122, 141, 1877.

\section{Family CECOPHORIDA.}

EUMEYRICKIA Busck.

Busck, Jun. N. Y. Ent. Soc., x, 94, 1902.

5843. trimaculella Fiтch, Rep. Ins. N. Y., ii, 233, 1856; Busck, Jn. N. Y. Ent. Soc., x, 94, 1902. syn. albapulvella Chambers, Can. Ent., vii, 147, 1875; haustellata WaLsingHAM, Trans. Am. Ent. Soc., x, 173, 1882.

\section{CRYPTOLECHIA Zeller.}

Zeller, Lep. Micr., 106, 1852; Walsingham, Ins. Life, ii, 150, 1889.

5844. sparsiciliella Clemens, Proc. Ent. Soc. Phil., ii, 430, 1863; Tin. No. Am., 255, 1872.

Atl. States.

syn. contrariella WaLker, Cat. Brit. Mus., xxix, 771, 1864: Walsinghay, Proc. Zool. Soc. Lond., 85, 1880; atropicta Zeller, Verh. zool.-bot. Ges. Wien, xxv, 343, 1875; sparsicella Chambers, Bull. Geol. Surv. Terr., iv, $129,1878$.

5845. concolorella Beutenmüller, Ent. Amer., iv, 30, 1888; Walsingham, Ins. Life, ii, 152, 1889.

5846. cretacea Zeller, Verh. zool.-bot. Ges. Wien, xxiii, 243, 1873; Walsingham, Trans. Am. Ent. Soc., x, 176,1882 .

*5847. ferruginosa Zeller, Verh. zool.-bot. Ges. Wien, xxiii, 243, 1873.

*5848. obscuromaculella Chambers, Bull. Geol. Surv. Terr., iv, 86, 1878.

*5849. obsoletella Zeller, Verh. zool.-bot. Ges. Wien, xxiii, 242, 1873.

Nev.

Tex.

Ohio.

Tex.

Ohio.
No. Atl.

States. 
*5850. piperatella 'Lerler, Verh. zool.-bot. Ges. Wien, xxiii, 239, 1873.

5851. quercicella Clemens, Proc. Acad. Nat. Sci. Phil., 212, 1860; Tin. No. Am., 159, 1872; Zeller, Verh. zool.-bot. Ges. Wien, xxiii, 240, 1873; Walsingham, Ins. Life, ii, 151, 1889.

syn. cressomella Chambers, Bull. Geol. Surv. Terr., iv, 85, 1878; faginella CHambers, Can. Ent., iv, 131, 1872; vi, 231, 1874; Bull. Geol. Surv. Terr., iv, 84, 1878; cryptolechiella Chambers, Can. Ent., iv, 91, 131, 1872; Bull. Geol. Surv. Terr., iv, 84, 1878; dubitatella Zeluer, Hor. Soc. Ent. Ross., $262,1887$.

5852. reflexella Clemens, Proc. Acad. Nat. Sci. Phil., 212, 1860; Tin. No. Am., 149, 1872; W ALsINGTex. Atl. States. НАм, Ins. Life, ii, 151, 1889.

syn. reflexa Chambers, Bull. Geol. Surv. Terr., iv, 137, 1878.

\section{MACHIMIA Clemens.}

Clemens, Proc. Acad. Nat. Sci. Phil., 211, 1860; Tin. No.Am., 147, 1872.

5853. tentoriferella Clemens, Proc. Acad. Nat. Sci. Phil., 212, 1860; Tin. No. Am., 148, 1872; ZELLER, Verh. zool.-bot. Ges. Wien, 238, 1873; Chambers, Bull. Geol. Surv. Terr., iv, 84, 1878. syn. confertella Walker, Cat. Brit. Mus., xxix, 563, 1864; Walsingham, Proc. Zool. Soc. Lond., 312, 1881; fernaldella CHAMbers, Bull. Geol. Surv. Terr., iv, 83, 1878.

\section{DEPRESSARIA Haworth.}

Haworth, Lep. Brit., 505, 1812; Clemens, Tin. No. Am., 229, 1872; Busck, Proc. U. S. Nat. Mus., xxiv, 731-749, 1902.

5854. atrodorsella Clemens, Proc. Ent. Soc. Phil., ii, 124, 1863; Tin. No. Am., 230, 1872; Packard, Guide Stud. Ins., 349, 1869; Chambers, Can. Atl. States. Ent., iv, 91, 1872; Robinson, Ann. Lye. Nat. Hist. N. Y., ix, 156, 1868; Zeller, Verh. zool. bot. Ges. Wien, xxiii, $233,1873$.

5855. umbraticostella Walsingham, Proc. Zool. Soc. Lond., 318, 1881.

*5856. thoracenigræella Chambers, Cinn. Quart. Jn. Sci., ii, $246,1875$.

5857. gracilis WaLsinghaM, Ins. Life, i, 257, 1899.

Cal. Col.

Atl. States.

Cal.

Tex., Col. 
5\$58. pulvipennella, Clemens, Proc. Ent. Soc. Phil., ii, 421, 1864: Tin. No. Am., 244, 1872; Robinson, Ann. Lyc. Nat. Hist. N. Y., ix, 157, 1868; Chambers, Can. Ent., iv, 91, 1872.

syn. eupatoriella Chambers, Bull. Geol. Surv. Terr., iv, 82, 1878; solidaginis WALsINGHAM, Ins. Life, i, 255, 1889.

5859. arnicella Walsinghan, Proc. Zool. Soc. Lond., $314,1881$.

5860. argillacea W alsingham, Proc. Zool. Soc. Lond., $313,1881$.

5861. sanguinella Busck, Proc. U. S. Nat. Mus., xxiv, 739, 1902 .

5862. applana Fabricius, Gen. Ins., 294, 1777; STAUDINGer \& Rebel, Cat. Lep. Eur., ii, no. 3233, 1901; Walsingham, Trans. Am. Ent. Soc., x, $175,1882$.

syn. applanella Fischer v. Röslerstamm, cinctella HüBner, clemensella Chambers, Can. Ent., ix, 103, 1877.

5863. ciliella Stainton, Cat. Brit. Ins., Tin., 17, 1849; Staudinger \& Rebel, Cat. Lep. Eur., ii, no. 3234, 1901; Walsingham, Proc. Zool. Soc. Lond., 316, 1881.

5864. fernaldella Walsingham, Ins. Life, i, 256, 1889.

5865. psoraliella Walsingham, Proc. Zool. Soc. Lond.. $317,1881$.

5866. novimundi Walsinghan, Ins. Life, i, 256, 1889.

*5867. thoracefasciella Chambers, Can. Ent., x, 50, 1878; Cin. Quart. Jn. Sci., ii, 246, 1875.

5868. klamathiana Walsingham, Proc. Zool. Soc. Lond., 314, 1881.

5869. ciniflonella Zeller, Isis, 280, 1846; Staudinger \& Reber, Cat. Lep. Eur., ii, no. 3221, 1901.

5870. nebulosa Zeller, Verh. zool.-bot. Ges. Wien, xxiii, 237, 1873.

5871. fulva Walsingham, Trans. Am. Ent. Soc., x, $175,1882$.

5872. amyrisella Busck, Jn. N. Y. Ent. Soc., viii, 247, 1901.

5873. muricolorella Busck, Proc. U. S. Nat. Mus., xxiv, 741, 1902.
Atl. States.

Cal.

Cal.

Ariz.

D. C..

Eur.

Cal.,

Eur.

Mass., Can.

Cal.

Col., Cal.

Cal.

Cal.

B. C.,

Eur.

Mass.

(Unknown.)

Fla.

Col. 
5874. curvilineella Beutengüller, Ent. Amer., v, 10, 1889 .

5875. senicionella Busck, Proc. U. S. Nat. Mus., xxiv, $742,1902$.

syn. seniciella Busck, Proc. U. S. Nat. Mus., xxiv, 743, 1902.

*5876. sabulella Walsinghan, Proc. Zool. Soc. Lond., $313,1881$.

*5877. arenella Denis \& Schiffermüller, Syst. Verz. Wien, 137, 1776; Staudinger \& Rebel, Cat. Lep. Eur., ii, no. 3204, 1901. syn. gilvella HüBNER.

5878. canadensis Busck, Proc. U. S. Nat. Mus., xxiv, $744,1902$.

*5879. lythrella Walsingham, Ins. Life, i, 257, 1889.

5880. posticella Walsingham, Proc. Zool. Soc. Lond., $315,1881$.

5881. nubiferelia Walsingham, Proc. Zool. Soc. Lond., $316,1881$.

5882. robiniella Packard, Guide Stud. Ins., 349, 1869; Chambers, Can. Ent., iv, 107, 1874; Cin. Quart. Jn. Sci., ii, 208, 1875.

syn. hilarella Zeller, Verh. zool.-bot. Ges. Wien, xxiii, 234, 1873.

5883. lecontella Clemens, Proc. Acad. Nat. Sci. Phil., 174, 1860; Tin. No. Am., 137, 1872; Chambers, Can. Ent., iv, 146, 1874; Robinson, Ann. N. Y. Lye. Nat. Hist., ix, 157, 1868.

5884. emeritella Stainton, Trans. Ent. Soc. Lond., v, 167, 1849; Staudinger \& Rebel, Cat. Lep. Eur., ii, no. 3283, 1901; Walsingham, Proc. Zool. Soc. Lond., 318, 1881.

5885. togata Walsingham, 'Ins. Life, i, 254, 1889.

5886. betulella Busck, Proc. U. S. Nat. Mus., xxiv, 746 , 1902.

5887. nervosa Haworth, Lep. Brit., 506, 1829; StaUDinger \& Rebel, Cat. Lep. Eur., ii, no. 3306, 1901; Walsingham, Proc. Zool. Soc. Lond., 317, 1881.

syn. apiella Hübner, daucella Treitschke.

5888. barberella Busck, Proc. U. S. Nat. Mus., xxiv, 747,1902 。

Can.

N. Y.,

Can.

D. C., Va.

Cal.

Cal. Eur.

III.

Cal., Col.

Cal.

So. Atl. States.

N. Y.,

$\mathrm{Pa}$.

Cal., Eur.

Cal., Oreg.

$\mathrm{Pa}$.

Eur.

Ariz. 
5889. heracliana De Geer, Mém. Ins., ii, 407, 1771; Zeller, Isis, 305, 1839; Linn. Ent., ix, 312, 1854; Staudinger \& Rebel, Cat. Lep. Eur., ii, no. $3280,1901$.

syn. heraclei Retzius, Gen. Degeerii, 45, 1783; umbellana Fabricius, Ent. Syst., iii, 286. 1775; umbellella Zetterstedt, Ins. Lap., 999, 1840; pastinacella Duponchel, Hist. Nat., viii, 153, 1836; ontariella BETHune, Can. Ent., ii, 3, 19, 1870.

*5890. groteella Robinson, Ann. Lyc. Nat. Hist. N. Y., ix, 157, 1868.

5891. cinereocostella Clemens, Proc. Acad. Nat. Sci. Phil., ii, 422, 1864; Tin. No. Am., 245, 1872: Chambers, Can. Ent., iv, 91, 1872; Robinson, Atl. States, Eur. Ann. Lye. Nat. Hist. N. Y., ix, 155, 1868.

syn. clausella WALKer, Cat. Brit. Mus., xxix, 564, 1864; Walsingham, Proc. Zool. Soc. Lond., 312, 1881; Ins. Life, i, 255, 1889.

*5892. scabella ZeLler, Verh. zool.-bot. Ges. Wien. xxiii, 236,1873 .

Atl. States. Pa., Va.

Ohio.

\section{SEMIOSCOPSIS Hübner.}

HüBner, Verz. bek. Schmett., 402, 1816; Enicostoma Stephens, Cat. Brit. Ins., 296, 1829; Epigraphia Stephens, Cat. Brit. Ins., 304, 1829.

5893. packardella Clemens, Proc. Ent. Soc. Phil., ii, 125, 1863; Tin. No. Am., 231, 1872; W ALsingNo. Atl. HaM, Trans. Am. Ent. Soc., x, 174, 1882. States. syn. eruditella Grote, No. Am. Ent., i, 53, 1880.

5894. allenella Walsinghay, Trans. Am. Ent. Soc., x, $174,1882$.

No. Atl.

States.

*5895. inornata Walsingham, Trans. Am. Ent. Soc., x, (Unknown.) $174,1882$.

\section{ETHMIA Hübner.}

Hübner, Verz. bek. Schmett., 163, 1816; Walsingham, Proc. Zool. Soc. Lond., 88, 1897; Psecadia Hüвner, Verz. bek. Schmett., 412, 1816.

5896. albicostella Beutenmüller, Ent. Amer., v, 9, 1889 .

5897. albistrigella Walsingham, Proc. Zool. Soc. Lond., 89,1880 .

Col.

Cal., Col.

5898. arctostaphylella Walsingham, Proc. Zool. Soc. Lond., 88, 1880.

5899. discostrigella Chambers, Bull. Geol. Surv. Terr.. iii, 122, 144, 1877; Walsingham, Ins. Life, i, $149,1888$.
Rocky

Mts. 
5900. subcærulea Walsingham, Proc. Zool. Soc. Lond.,

Cal. $89,1880$.

5901. hagenella Chambers, Bull. Geol. Surv. Terr., iv, $80,1878$.

5902. apicipunctella Chambers, ('an. Ent., vii, 8, 1875.

5903. marmorea Walsingham, Ins. Life, i, 149, 1888.

5904. mirusella Chavbers, Can. Ent., vi, 233, 1874; Bull. Geol. Surv. Terr., iii, 121, 141, 1877.

5905. monticola Walsinghay, Proc. Zool. Soc. Lond., $87,1880$.

5906. obscurella Beutenmüller, Ent. Amer., iv, 129, 1888.

5907. semilugens Zeller, Verh. zool.-bot. Ges. Wien, xxii, 561, 1872; Chambers, Cin. Quart. Jn. Sci., ii, 258,1875 .

syn. multipunctella Chambers, Can. Ent., vi, $233,1874$.

5908. semiopaca Grote, Bull. U. S. Geol. Surv., vi, $275,1881$.

Ariz., Col.

5909. plumbeella Beutenmüller, Ent. Amer., v, 9, 1889.

*5910, chambersella DYAR.

syn. texanella Chambers (not Chambers), Jn. Cin. Soc. Nat. Hist., ii, 179, 1880; WALSINGHAM, Ins. Life, i, 149, 1888.

*5911. trifurcella Chambers, Can. Ent., v, 12, 1873; Bull. Geol. Surv. Terr., iv, 80, 1878.

Tex.

Tex.

5912. longimaculella Chambers, Can. Ent., iv, 43, 1872. syn. walsinghamella BeutenMüLler, Ent. Amer., v, 9, 1889.

5913. zelleriella Chambers, Bull. Geol. Surv. Terr., iv, $80,1878$.

syn. texanella Chambers, Jn. Cin. Soc. Nat. Hist., ii, 2, 1880; Walsingham, Ins. Life, i, $149,1888$.

5914. fuscipedella Walsingham, Ins. Life, i, 150, 1888.

5915. confusella Walker, Cat. Brit. Mus., xxviii, 531, 1863; Walsingham, Proc. Zool. Soc. Lond., 88, 1897.

N. C., Iowa.

Fla., Antilles. 
TRICLONELLA Busek.

Busck, Jn. N. Y. Ent. Soc., viii, 236, 1901.

5916. pergandeella Busck, Jn. N. Y. Ent. Soc., viii, $237,1901$.

5917. villella Busck, Jn. N. Y. Ent. Soc., viii, 238, 1901.

D. C.

Md.

\section{EUCLEMENSIA Grote.}

Grote, Can. Ent., x, 69, 1878; Hamadryas Clemens (not HüBner), Tin. No. Am., 245,1872 .

5918. bassettella Clemens, Proc. Ent. Soc. Phil., ii, 423, 1864; Tin. No. Am., 246, 1872; Chambers, Can. Ent., x, 53, 1878; vi, 231, 1874; Cin. Quart. Jn. Atl. Sci., ii, $115,1875$.

5919. schwarziella Busck, Jn. N. Y. Ent. Soc., viii, 239, 1901.

Ariz.

\section{EPICALLIMA Dyar.}

Callima Clemens (not Kallima Westwood), Proc. Acad. Nat. Sci. Phil., 166, 1860.

5920. argenticinctella Clemens, Proc. Acad. Nat. Sci. Phil., 167, 1860; Tin. No. Am., 12, 46, 123, 1872; Chambers, Can. Ent., v, 188, 1873; Cin. Quart. Atl. Jn. Sci., ii, 114, 1875.

\section{ECOPHORA Latreille.}

Latreille, Gen. Crust. Ins., iv, 222, 1796.

*5921. boreasella Chambers, Can. Ent., v, 189, 1873; Cin. Quart. Jn. Sci., 1i, 114, 292, 1875; Bull. States.

Geol. Surv. Terr., iii, 129, 141, 1877.

*5922. borkhausenii ZeLLER, Isis, 192, 1839; Verh. zool. bot. Ges. Wien, xxiii, 290, 1873; STAUdIngER \& Rebel, Cat. Lep. Eur., ii, no. 3384, 1901.

*5923. coloradella Walsinghay, Ins. Life, i, 148, 1888. *5924. determinatella Zeller, Verh. zool.-bot. Ges. Wien, xxiii, 289, 1873.

Ky.

syn. australisella CHAMBErs, Can. Ent., vii, 124, 1875; ix, 24, 1877; Cin. Quart. Jn. Sci., ii, 114,1875 .

*5925. dimidiella Walsingham, Ins. Life, i, 148, 1888. 5926. pseudospretella Stannton, Cat. Brit. Ins., Tin., 14, 1849; Staudinger \& Rebel, Cat. Lep. Eur., ii, no. 3358, 1901; Walsingham, Ins. Life, i, Eur., D. C. Col. Tex. 149, 1888. 
*5927. quadrimaculella Chambers, Cin. Quart. Jn. Sci., Col. ii, 292, 1875; Bull. Geol. Surv. Terr., iii, 129, 1877 .

*5928, shalleriella Chambers, Cin. Quart. Jn. Sci., ii, 114,1875 .

Ky.

*5929. thoracella Walsingham, Ins. Life, i, 147, 1888. Col.

*5930. constrictella ZELLER, Verh. zool. -bot. Ges. Wien, xxiii, 291, 1873.

\section{CHAMBERSIA Riley.}

Riley, Smith's List Lep. Bor. Am., 103, 1891; Blepharocera Chambers (not Blanchard), Bull. Geol. Surv. Terr., iii, 144, 1877.

*5931. haydenella Chambers, Bull. Geol. Surv. Terr., iii, $145,1877$.

Col.

\section{DASYCERA Haworth.}

Haworth, Lep. Brit., 524, 1829; Stephens, Cat. Brit. Ins., 297, 1829; Clemens, Proc. Ent. Soc. Phil., ii, 428, 1864.

*5932. newmanella Clemens, Proc. Ent. Soc. Phil., ii, Va. 428, 1864; Tin. No. Am., 252, 1872; Zeller, Verh. zool. bot. Ges. Wien, xxiii, 289, 1873.

*5933. nonstrigella Chambers, Bull. Geol. Surv., iv, 92, 1878.

BABAIAXA Busck.

Busck, Jn. N. Y. Ent. Soc., x, 95, 1902.

5935. delliella Fernald, Can. Ent., xxiii, 29, 1891.

Tex.

Family BLASTOBASIDE.

\section{PLOIOPHORA Dietz.}

Dietz, Trans. Am. Ent. Soc., xxvii, 102, 1900.

5936. ampla Dietz, Trans. Am. Ent. Soc., xxvii, 103, 1900 .

5937. fidella Dietz, Trans. Am. Ent. Soc., xxvii, 103, 1900 .

$\mathrm{Pa}$ 。

Pa.

\section{PIGRITIA Clemens.}

Clemens, Proc. Acad. Nat. Sci. Phil., 172, 1860; Dietz, Trans. Am. Ent. Soc., xxvii, 104,1900 .

5938. confusella Dietz, Trans. Am. Ent. Soc., xxvii, 104,1900 .

Pa., N. J.

*5939. purpurella Dietz, Trans. Am. Ent. Soc., xxvii, $105,1900$.

Atl. States.

*5940. basilarella Dietz, Trans. Am. Ent. Soc., xxvii, 105,1900 . 
5941. laticapitella Clemens, Proc. Acad. Nat. Sci. Phil., 173, 1860; Tin. No. Am., 41, 136, 1872; Walsingham. Trans. Am. Ent. Soc., x, 190, States. 1882; Dietz, Trans. Am. Ent. Soc., xxvii, 106, 1900 .

syn. aufugella ZeLter, Verh. zool.-bot. Ges. Wien, xxiii, 300, 1873; anfugella Dietz, Trans. Am. Ent. Soc., xxvii, 119, 1900; luteopulvella Chambers, Can. Ent., vii, 73, 1875 .

5942. mediofasciella Dietz, Trans. Am. Ent. Soc., xxvii, 107, 1900 .

5943. ornatella Dietz, Trans. Am. Ent. Soc., xxvii, $107,1900$.

5944. angustipennella Dietz, Trans. Am. Ent. Soc., xxvii, 108, 1900.

5945. tristella Dietz, Trans. Am. Ent. Soc., xxvii, 108, 1900.

5946. spoliatella Dietz, Trans. Am. Ent. Soc., xxvii, $110,1900$.

*5947. arizonella Dietz, T? . Am. Ent. Soc., xxvii, $109,1900$.

5948. obscurella Dietz, Trans. Am. Ent. Soc, xxvii, Pa.

Pa.

Pa.

Pa. $110,1900$.

EPIGRITIA Dietz.

Dietz, Trans. Am. Ent. Soc., xxvii, 110, 1900.

5949. pallidotinctella Dietz, Trans. Am. Ent. Soc., Pa. xxvii, 111, 1900.

5950. heidemannella Dietz, Trans. Am. Ent. Soc. Pa. xxvii, 111, 1900.

DRYOPE Chambers.

Chambers, Can. Ent., vi, 49, 1874; Dietz, Trans. Am. Ent. Soc., xxvii, 114, 1900.

*5951. occidentella Dietz, Trans. Am. Ent. Soc., xxvii,

Cal. $115,1900$.

*5952. tenebrella Dietz, Trans. Am. Ent. Soc., xxvii,

$\mathrm{Pa}$. $116,1900$.

*5953. minnicella Dietz, Trans. Am. Ent. Soc., xxvii,

Ga. 116, 1900.

5954. grisella Dietz, Trans. Am. Ent. Soc., xxvii, $116,1900$.

Pa., Mo., S. Dak.

*5955. fuscosuffusella Dietz, Trans. Am. Ent. Soc., Mo. xxvii, 117, 1900 . 
5956. ochrocomella Clemens, Proc. Ent. Soc. Phil., ii, 126, 1864; Tin. No. Am., 232, 1872; Dietz, Trans, Am. Ent. Soc., xxvii, 117, 1900.

syn. murtfeldtella Chambers, Can. Ent., vi, 50, 1874; ochroeomella Dietz.

*5957. canariella Dietz, Trans. Am. Ent. Soc., xxvii, 118, 1900.

Cal.

*5958. discopunctella Dietz, Trans. Am. Ent. Soc., xxvii, 118, 1900.

*5959. ochreella Clemens, Proc. Ent. Soc. Phil., ii, 126 , 1864; Tin. No. Am., 232, 1872; Dietz, Trans. Am. Ent. Soc., xxvii, 118, 1900.

*5960. fenyesella Dietz, Trans. Am. Ent. Soc., xxvii, $119,1900$.

Dietz, Trans. Am. Ent. Soc., xxvii, 112, 1900.

5961. dorsomaculella Dietz, Trans. Am. Ent. Soc., xxvii, 112, 1900 .

5962. equitella Diexz, Trans. Am. Ent. Soc., xxvii, $112,1900$.

*5963. fraternella Dietz, Trans. Am. Ent. Soc., xxvii, $113,1900$.

*5964. argyreella Dietz, Trans. Am. Ent. Soc., xxvii, $113,1900$.

\section{HYPATIMA Hübner.}

HÜBNER, Verz. bek. Schmett., 415, 1816.

*5965. subsenella Zeller, Verh. zool.-bot. Ges. Wien, xxiii, 302, 1873.

Pa.

Atl. States.

Cal.

Pa.

*5966. confectella Zecler, Verh. zool.-bot. Ges. Wien, xxiii, 303, 1873.

Tex.

Tex.

BLASTOBASIS Zeller.

Zeller, Linn. Ent., x, 171, 1855; Verh. zool.-bot. Ges. Wien, xxiii, 295, 1873; Walsingham, Proc. Zool. Soc. Lond., 91, 1897.

5967. guilandinæ Busck, Proc. U. S. Nat. Mus, xxiii, Fla. $234,1900$.

*5968. sciaphiella Zeller, Verh. zool.-bot. Ges. Wien, xxiii, 295, 1873; Chambers, Can. Ent., ix, 71,

Tex. 1877; Busck, Jn. N. Y. Ent. Soc., x, 96, 1902.

*5969. subtractella W ALKER, Cat. Brit. Mus., xxix, 592, 1864. 


\section{HOLCOCERA Clemens.}

Clemens, Proc. Ent. Soc. Phil., ii, 121, 1863.

5970. chalcofrontella Clemens, Proc. Ent. Soc. Phil., ii, 122, 1863: Tin. No. Am., 226, 1872; Zeller, Verh. zool.-bot. Ges. Wien, xxiii, 95, 1873; Chambers, Can. Ent., iv, 65, 1872; vi, 246, 1874; Cin. Quart. Jn. Sci., ii, 256, 1875.

*5971. fluxella ZeLLer, Verh. zool.-bot. Ges. Wien, xxiii, 301, 1873.

5972. gigantella Chambers, Can. Ent., viii, 219, 1876; Bull. Geol. Surv. Terr., iii, 149, 1877.

*5973. gilbociliella Clemenens, Proc. Ent. Soc. Phil., ii, 122, 1863: Tin. No. Am., 227, 1872; Zeller, Verh. zool.-bot. Ges. Wien, xxiii, 95, 1873.

5974. iceryæella Riley, Rept. Comm. Agr., 1886, 485, 1887.

*5975. modestella Clemens, Proc. Ent. Soc. Phil., ii, 122, 1863; Tin. No. Am., 229, 1872.

*5976. purpurocomella Clemens, Proc. Ent. Soc. Phil., ii, 122, 1863; Tin. No. Am., 229, 1872.

5977. quisquiliella ZELLer, Verh. zool.-bot. Ges. Wien, xxiii, 298, 1873.

*5978, retectella Zeller, Verh. zool.-bot. Ges. Wien, xxiii, 297, 1873.

5979. glandulella Riley, Can. Ent., iii, 18, 1871; iv, 17, 38, 62, 65, 1872; Rep. Ins. Mo., iv, 144, 1871; Chambers, Cïn. Quart. Jn. Sci., ii, 256, 1875.

*5980. nubilella Zeller, Verh. zool. bot. Ges. Wien, xxiil, 297, 1873; xxv, 345, 1875; W ALsinghaM, Trans. Am. Ent. Soc., x, 191, 1882.

*5981. triangularisella Chambers, Cin. Quart. Jn. Sci., ii, 256, 1875; Can. Ent.. 1x, 71, 1877.

*5982. livorella Zeller, Verh. zool-bot. Ges. Wien, xxiii, 299, 1873.

syn. livolella Riley, Smith's List Lep. Bor. Am., 104, 1891.

*5983. fuscopulvella Chambers, Bull. U. S. Geol. Surv., iv , 132, 1878 (not described). ${ }^{a}$

*5984. fractilinea Zeller, Verh. zool.-bot. Ges. Wien, xxiil, $298,1873$.

Atl.

States.

Tex.

Col.

Atl.

States.

Australia.

Atl.

States.

Atl.

States.

Tex.

Tex.

Atl.

States.

Tex.

Ky.

Tex.

(Unknown.)

Tex.

a Chambers credits Clemens with this species, but I have not found it in his writings.

$4630-$ No. $52-02-34$ 
*5985. clemensella Chambers, Can. Ent., vi, 246, 1874. Tex.

5986. maligemmella Murtfeldt, Mo. Agr. Exp. Sta., Bull. 42, 1895; Steduan, Can. Ent., xxx, 109, 1898; Busck, Jn. N. Y. Ent. Soc., x, 96, 1902.

\section{Family ELACHISTID Æ.}

\section{COLEOPHORA Hiibner.}

Hübner, Tent., 1806; Clemens, Tin. No. Am., 210, 1872.

*5989. accordella Walsingham, Trans. Ent. Soc. Lond., $436,1882$.

*5990. æneusella Chambers, Can. Ent., vi, 128, 1874.

syn. Xmusella Riley, Smith's List Lep. Bor. Am., 105, 1891; xnusella Chambers, Bull. Geol. Surv. Terr., iv, 135, 1878.

*5991. acutipennella Walsinghay, Trans. Ent. Soc. Lond., 440, 1882.

*5992. albacostella Chambers, Can. Ent., vii, 95, 1875; Bull. Geol. Surv. Terr., iv, 93, 1878.

*5993. argentialbella Chàbers, Can. Ent., vi, 128, 1874 ; $\mathrm{x}, 112,1878$.

*5994. chambersella DYAR.

syn. artemisicolella CHAMBers (not BrUAND), Bull. Geol. Surv. Terr., iii, 133, 144, 1877.

5995. atriplicivora Cockerell, Ann. Mag. Nat. Hist., (7), ii, 403, 1898.

5996. auropurpurella Chambers, Can. Ent., vi, 130, 1874 .

*5997. basistrigella Chambers, Bull. Geol. Surv. Terr., iii, 133,1877 .

5998. bella Walsingham, Trans. Ent. Soc. Lond., 439, 1882.

*5999. biminimaculella Chambers, Bull. Geol. Surv. Terr., iv, 94, 1878 .

*6000. bipunctella W alsingham, Trans. Ent. Soc. Lond., $440,1882$.

6001. bistrigella Chambers, Can. Ent., vii, 75, 1875; ix, 14, 72, 1877; x, 112, 1878; Jn. Cin. Soc. Nat. Hist., ii, 7, 1880; Bull. Geol. Surv. Terr., iii, 133, 1877 .

*6002. cœnosipennella Clemens, Proc. Acad. Nat. Sci. Phil., 5, 1860; Tin. No. Am., 88, 1872.

Cal.

Ky.

Cal.

Tex.

Ky.

Col.

N. Mex.

Can.

Col.

Cal.

Tex.

Tex.

Tex.,

Col.

Pa. 
6003. caryæfoliella Clemens, Proc. Ent. Soc. Phil., i, Pa.

78, 1861; Tin. No. Am., 166, 1872; Chambers,

Can. Ent., x, 112, 1878 .

syn. mufoluteella Chambers, Can. Ent., vi, 129 , 1874 .

*6004. castipennella Walsingham, Trans. Ent. Soc. Lond., 441, 1882.

Cal.

Mass. Mass. Bd. Agr., 239, 1870.

6006. cæspititiella Zeller, Isis, 208, 1839; STAUdinger \& Rebel, Cat. Lep. Eur., ii, no. 3845, 1901.

syn. sternipennella ZETTERSTEDT, lacunxcolella Duponchel, cilizochrella Chambers, Can. Ent., vi, 129, 1874; cispiticella Hulst, Ent. Amer., vi, 40, 1890; cespititiella RILEY, Smith's List Lep. Bor. Am., 105, 1891.

6007. cinerella Chambers, Bull. Geol. Surv. Terr., iv, $93,1878$.

*6008. concolorella Clemens, Proc. Ent. Soc. Phil., ii, 6, 1863; Tin. No. Am., 211, 1872; Chambers, Can. Ent., vi, 129, 1874.

6009. cornella Walsinghay, Trans. Ent. Soc. Lond., $432,1882$.

6010. spissicornis Haworth, Lep. Brit., 537, 1829; Staudinger \& Rebel, Cat. Lep. Eur., ii, no. $3680,1901$.

syn. fabriciella Villiers, mayrella ZeLLer, trochitipennella CosTa, cormscipennella Clemens, Proc. Acad. Nat. Sci. Phil., 4, 1860; Tin. No. Am., 88, 1872; Zeller, Verh. zool.-bot. Ges. Wien, xxiii, 311, 1873.

*6011. corylifoliella Clemens, Proc. Ent. Soc. Phil., i, 79, 1863; Tin. No. Am., 166, 1872.

*6012. cratipennella Clemens, Proc. Ent. Soc. Phil., iii, 506, 1864; Tin. No. Am., 258, 1872.

*6013. cretaticostella Clemens, Proc. Acad. Nat. Si. Phil., 5, 1860; 'Tin. No. Am., 89, 1872; ChaмBERs, Can. Ent., vii, 124, 1875.

*6014. currucipennella Zeller, Isis, 207, 1839; STÁUDinger \& Rebel, Cat. Lep. Eur., ii, no. 3791, 1901: W alsinghay, Trans. Ent. Soc. Lond., 430, Eur., Ky.

Ky.

Pa.

Cal.

Atl. States, Eur.

Pa.

$\mathrm{Pa}$.

Pa. 1882.

syn. tristrigella HeInemann \& Wocke.

*6015. discostriata WalsinghaM, Trans. Ent. Soc.

Cal. Lond., 435, 1882. 
*6016. fletcherella Fernald, Can. Ent., xxiv, 122, 1892;

Fletcher, Rept. Exp. Farms, 1891, 196, 1892;

Can.

Slingerland, Bull. 92, Corn. Exp. Sta., 1895.

6017. fagicosticella Chambers, Can. Ent., vi, 129, 1874;

$\mathrm{x}, 111,1878$.

syn. fagicorticella Chambers, Bull. Geol. Surv., iv, 135, 1878; fragicorticella RILEY, Smith's List Lep. Bor. Am., 106, 1891.

*6018. fuscostrigella Chambers, Bull. Geol. Surv., iv, $93,1878$.

6019. gigantella Chambers, Can. Ent., vi, 128, 1874; $\mathrm{x}, 110,1878$.

6020. glaucella Walsingham, Trans. Ent. Soc. Lond., 433, 1882.

*6021. infuscatella Clemens, Proc. Acad. Nat. Sci. Phil., 5, 1860; Tin. No. Am., 89, 1872.

*6022. inornatella Chambers, Jn. Cin. Soc. Nat. Hist., ii, 185,1879 .

*6023. irroratella Walsingham, Trans. Ent. Soc. Lond., 434, 1882.

*6024. laricella HüBner, Schm. Eur., 427, 1827; STAUDinger \& Rebel, Cat. Lep. Eur., ii, no. 3633 , 1901.

syn. laricinella RATzEBURG.

*6025. laticornella Clemens, Proc. Acad. Nat. Sci. Phil., 5, 1860; Tin. No. Am., 88, 1872.

*6026. leucochrysella Clemens, Proc. Ent. Soc. Phil., ii, 6, 1863; Tin. No. Am., 211, 1872; WAlsingHaM, Trans. Am. Ent. Soc., x, 194, 1882.

*6027. lineapulvella Chambers, Can. Ent., x, 111, 1878. Ky.

6028. lynosyridella Walsingham, Trans. Ent. Soc. Lond., 437, 1882.

6029. luteocostella Chambers, Cin. Quart. Jn. Sci., ii, 294, 1875; Bull. Geol. Surv. Terr., iii, 133, 1877.

Tex.

Can.

Cal.

$\mathrm{Pa}$.

Tex.

Cal.

Eur.. U. S. ?

$\mathrm{Pa}$.

Pa.

syn. argentella Chambers, Can. Ent., x, 112, 1878: argentialbella CHAMBERs (not CHAMBErs), Can. Ent., vii, 75, 1875; Bull. Geol. Surv. Terr., iii, 133, 1877.

6030. malivorella Riley, Rept. Comm. Agr., 48, 1878; Walsinghay, Trans. Am. Ent. Soc., x, 194, 1882.

syn. multipulvella CHanbers, Bull. U.S. Geol.

Surv. Terr., iv, 93, 1878. 
*6031. nigralineella Chambers, Can. Ent., viii, 172,

$\mathrm{K}_{y}$.

1876.

syn. nigerlinella Chambers, Bull. Geol. Surv., iv, $136,1878$.

6032. nigrostriata Walsingham, Trans. Ent. Soc. Lond., 438, 1882.

Oreg.

$\mathrm{Ky}$. $94,1878$.

*6034. pruniella Clemens, Proc. Ent. Soc. Phil., i, 79, 1861; Tin. No. Am., 167, 1872; Zeller, Verh. Atl. zool.-bot. Ges. Wien, xxiii, 309, 1873.

States.

syn. occidentis Zeller, Verh. zool.-bot. Ges.

Wien, xxiii, 309, 1873; occidentalis RILEY,

Smith's List Lep. Bor. Am., 106, 1891.

6035. ochrostriata Walsingham, Trans. Ent. Soc. Lond., 437, 1882.

6036. octagonella Walsingham, Trans. Ent. Soc. Lond., $431,1882$.

*6037. ostryæ Clemens, Proc. Ent. Soc. Phil., i, 79, 1861; Tin. No. Amı., 167, 1872.

6038. portulacæ Cockerell, Ann. Mag. Nat. Hist., (7), ii, 328, 1898.

*6039. quadrilineella Chambers, Bull. Geol. Surv. Terr., iv, 94, 1878.

*6040. querciella Clemens, Proc. Ent. Soc. Phil., i, 80, 1861; Tin. No. Am., 168, 1872.

*6041. rosacella Clemens, Proc. Ent. Soc. Phil., ii, 426, 1864: Tin. No Am., 251, 1872; Packard, Guide Stud. Ins., 350, 1869.

*6042. rosæfoliella Clemens, Proc. Ent. Soc. Phil., ii, 426, 1864; Tin. No. Am., 250, 1872; PACKarD̀, Guide Stud. Ins., 350, 1869.

*6043. shaleriella Chambers, Cin. Quart. Jn. Sci.,ii, 116, 1875 .

*6044. sparsipulvella Chambers, Cin. Quart. Jn. Sci., ii, 294, 1875; Bull. Geol. Surv. Terr., iii, 133, 1877.

6045. suædicola Cockereld, Ann. Mag. Nat. Hist., (7), ii, 403, 1898.

*6046. tenuis Walsingham, Trans. Ent. Soc. Lond., 436 , 1882.

*6047. texanella Chambers, Bull. Geol. Surv. Terr., iv,

Cal.

Fla.

Atl. States.

N. Mex.

$\mathrm{Ky}$.

Pa.

Pa.

Atl.

States.

Ky.

Col.

N. Mex.

Cal.

Tex. 93, 1878. 
*6048. tiliæfoliella Clemens, Proc. Ent. Soc. Phil., i, 79, 1861; Tin. No. Am., 168, 1872.

6049. trilineella Chambers, Can. Ent., vii, 95, 1875. Ky.

*6050. unicolorella Chambers, Can. Ent., vi, 129, 1874; x, $111,1878$.

*6051. veroniæella Chambers, Can. Ent., x, 114, 1878.

*6052. viburnella Clemens, Proc. Ent. Soc. Phil., i, 79 , 1861; Tin. No. Am., 167, 1872.

*6053. viridicuprella Walsingham, Trans. Ent. Soc. Lond., 432, 1882.

6054. viscidiflorella Walsingham, Trans. Ent. Soc. Lond., 439, 1882.

*6055. wythiæ Walsingham, Trans. Ent. Soc. Lond., 434,1882 .

*6056. zelleriella Chambers, Can. Ent., vi, 128, 1874.

$\mathrm{Ky}$.

Ky., Mo

$\mathrm{Pa}$.

Cal.,

Oreg.

Cal.

Cal.

$\mathrm{Ky}$

COLEOTECHNISTES Chambers.

Chambers, Rept. Dept. Agr., 206, 1879.

6057. citriella Снambers, Rept. Dept. Agr., 206, 1879.

Fla.

BATRACHETRA Stainton.

Stajnton, Ins. Brit., Tin., iii, 230, 1854; Clemens, Tin. No. Am., 264, 1872.

*6058. præangusta Haworth, Ins. Brit., iii, 230, 1854; Staudinger \& Rebel, Cat. Lep. Eur., ii, no. Eur. 3460, 1901; Chambers, Bull. Geol. Surv. Terr., iii, 134, 1877; Can. Ent., ix, 145, 1877.

6059. rileyi Walsingham, Trans. Am. Ent. Soc., x, 198, 1882.

Gulf States.

6060. salicipomonella Clemens, Proc. Ent. Soc. Phil., v, 142, 1867; vi, 273, 1868; Tin. No. Am., 265, 1872; Zeller, Verh. zool.-bot. Ges. Wien, xxiii, 313, 1873; Packard, Guide Stud. Ins., 352, 1869; Chambers, Can. Ent., ix, 145, 1877.

6060. 1. striolata Zeller, Verh. zool.-bot. Ges. Wien, xxiii, 313, 1873.

Atl.

States.

syn. pulvella Chambers, Can. Ent., viii, 171, 1876; clemensella Chambers, Bull. Geol. Surv. Terr., iii, 134, 1877; Can. Ent., ix, $146,1877$.

COSMOPTERYX Hübner.

Hübner, Verz. bek. Schmett., 424, 1816; Clemens, Tin. No. Am., 99, 1872. *6061. chalybæella WaLsingham, Ins. Life, i, 289, 1889.

Tex. 
*6062. clemensella Stanton, Tin. No. Am., 39, 100, Pa. ? 1872: Ent. Week. Int., ix, 31, 1860; FreY \& Boll, Stett. ent. Zeit., xxxvii, 214, 1876.

*6063. delicatella Waisinghà, Ins. Life, i, 290, 1889. N. C. *6064. fernaldella Walsinghay, Trans. Am. Ent. Soc., $\mathrm{x}, 197,1882$.

6065. floridanella Beutenuüller, Ent. Amer., v, 10, 1889.

syn. nigrapunctella Busck, Proc. U. S. Nat. Mus., xxiii, 235, 1900.

6066. gemmiferella Clemens, Proc. Acad. Nat. Sci. Phil., 10, 1860; Tin. No. Am., 99, 1872; СнамBers, Cin. Quart. Jn. Sci., ii, 231, 1875; Frey \& Boll, Stett. ent. Zeit., xxxvii, 214, 1876; Walsingham, Proc. Zool. Soc. Lond., 536, 1891.

6067. іроmœæ Busck, Proc. U. S. Nat. Mus., xxiii, 235, 1900; Dyar, Proc. Ent. Soc. Wash., iv, 478, 1901.

6068. attenuatella Walker, Cat. Brit. Mus., xxx, 1019, 1864: Walsingham, Proc. Zool. Soc. Lond., 105, 1897.

syn. lespedes⿱ Walsingham, Trans. Am. Ent. Soc., x, 198, 1882; Proc. Zool. Soc. Lond., 536,1891 .

6069. minutella Beutenmüller, Ent. Amer., v, 10, 1889.

*6070. montisella Chambers, Cin. Quart. Jn. Sci., ii, 297, 1875; Bull. Geol. Surv. Terr., iii, 124, 1877.

(Unknown.)

Fla.

Atl. States.

Fla.

So.

States.

Fla.

Col.

*6071. nitens Walsingham, Ins. Life, i, 289, 1899.

Tex.

6072. pulcherrimella Chambers, Cin. Quart. Jn. Sci., ii, 231, 1875; Walsingham, Ins. Life, i, 289, $\mathrm{Ky}$. 1889 .

*6073. quadrilineella Chambers, Bull. Geol. Sur. Terr., iv, 95, 1878; Walsingham, Ins. Life, i, 290, 1889.

*6074. unicolorella WaLsinghaM, Ins. Life, i, 291, 1889.

Cal.

\section{SCELORTHUS Busck.}

Busck, Jn. N. Y. Ent. Soc., viii, 239, 1901.

6075. pisoniella Busck, Jn. N. Y. Ent. Soc., viii, 240, 1901.

\section{ELACHISTA Treitschke.}

Treitschke, Schm. Eur., ix, 2, 177, 1833; Clemens, Tin. No. Am., 255, 1872; Cosmoites Clemens, Proc. Acad. Nat. Sci. Phil., 8, 1860.

*6076. albapalpella Chanbers, Jn. Cin. Soc. Nat. Hist., Mass. iii, $294,1880$. 
*6077. duplicatella Dyar.

Tex.

syn. bicristatella Chambers (not Chambers), Jn. Cin. Soc. Nat. Hist., ii, 187, 1879.

*6078. brachyelytrifoliella Clemens, Proc. Acad. Nat. Sci. Phil., 425, 1860; Tin. No. Am., 248, 1872.

Pa.

6079. concolorella Сhambers, Can. Ent., vii, 55, 1875. Ky.

*6080. cristatella Chambers, Can. Ent., viii, 172, 1876.

*6081. illicitella Clemens, Proc. Acad. Nat. Sci. Phil., 9, 1860; Tin. No. Am., 98, 1872; Chambers, Bull. Geol. Surv. Terr., iv, 139, 1878.

*6082. inornatella Chambers, Can. Ent., vii, 93, 1875.

*6083. maculosella Clemens, Proc. Acad. Nat. Sci. Phil., 9, 1860; Tin. No. Am., 98, 1872; ChamBers, Bull. Geol. Surv., iv, 139, 1878.

*6084. madarella Clemens, Proc. Acad. Nat. Sci. Phil., 9, 1860; Tin. No. Am., 98, 1872; Chambers, Bull. Geol. Surv. Terr., iv, 139, 1878.

*6085. metallifera Walsingham, Trans. Am. Ent. Soc., $\mathrm{x}, 200,1882$.

*6086. orichalcella Clenenens, Proc. Ent. Soc. Phil., ii, 430, 1864; Tin. No. Am., 256, 1872; PaCkard, Guide Stud. Ins., 352, 1869.

6087. parvipulvella Chambers, Can. Ent., vii, 56, 1875.

6088. præmaturella Clemens, Proc. Acad. Nat. Sci. Phil., 172, 1860; Tin. No. Am., 133, 1872; СнамBers, Can. Ent., vi, 76, 1874; Bull. Geol. Surv. Terr., iii, 143, 1877.

*6089. pusilla Frey \& Boll, Stett. ent. Zeit., xxxvii, $215,1876$.

*6090. staintonella Chambers, Bull. Geol. Surv. Terr., iv, 96, 1878 .

*6091. texanella Chambers, Bull. Geol. Surv. Terr., iv, $96,1878$.

*6092. texanica Frey \& Boll, Stett. ent. Zeit., xxxvii, $216,1876$.

*6093. unifasciella Chambers, Can. Ent., vii, 147, 1875.

*6094. bicristatella Chambers, Can. Ent., vii, 210, 1875.

*6095. curvilineella Chambers, Can. Ent., iv, 172, 1872.

Mass. ?

Pa.

Ky.

Pa.

Tex.

Tex.

Tex.

Tex.

Ky. ?

Ky.

Ky. 
LYMN ECIA Stainton.

Stainton, Cat. Brit. Tin., suppl., 4, 1851.

6096. phragmitiella Starnton, Cat. Brit. Tin., suppl., 4, 1851: Staudinger \& Rebel, Cat. Lep. Eur., ii, no. 3592, 1901; Merrick, Hand. Brit. Lep., 675, 1895; Busck, Proc. Ent. Soc. Wash., iv, Atl. States, Eur. $421,1901$.

\section{LITHARIAPTERYX Chambers.}

Chambers, Can. Ent., viii, 217, 1876; Jn. Cin. Soc. Nat. Hist., ii, 203, 1880.

6097. abroniæella Chambers, Can. Ent., viii, 217, 1876;

Col. Bull. Geol. Surv. Terr., iii, 124, 149, 1877; DYAR,

Proc. U. S. Nat. Mus., xxv, 410, 1902.

\section{LAMPROLOPHUS Busck.}

Busck, Jn. N. Y. Ent. Soc., viii, 241, 1900.

6098. lithella Busck, Jn. N. Y. Ent. Soc., viii, 241, 1900.

Fla.

\section{HELIODINES Stainton.}

Stainton, Ins. Brit. Lep., 243, 1854; Walsingham, Ins. Life, iv, 384, 1892; Proc. Zool. Soc. Lond., 108, 1897.

6099. bella Chambers, Can. Ent., vii, 73, 1875; ix, 72, 1877; Bull. Geol. Surv. Terr., iii, 114,1877; WaLSINGHAM, Ins. Life, iv, 384, 1892.

Ky., Tex., Col., Cal.

Cal.

*6100. extraneella W alsingham, Proc. Zool. Soc. Lond., 323, 1881; Ins. Life, iv, 385, 1892.

*6101. sexpunctella Walsingham, Ins. Life, iv, 385, 1892.

*6102. tripunctella Walsinghay, Ins. Life, iv, 384, 1892.

*6103. unipunctella W aLsinghaM, Ins. Life, iv, 385, 1892.

\section{SCYTHRIS Hübner.}

HüBner, Verz. bek. Schmett., 414, 1816; Meyrick, Handb. Brit. Lep., 685, 1895; Galanthia HüBner, Verz. bek. Schmett., 417, 1816; Butalis Treitschke, Schm. Eur., ix, 2, 108, 1833 .

6104. albapennella Chambers, Can. Ent., vii, 11, 1875.

Tex.

6105. albilineata Walsingham, Ins. Life, i, 116, 1888.

Ariz.

*6106. aterrimella W ALker, Cat. Brit. Mus., xxix, 590,

Can. 1864. 
6107. basilaris Zeller, Linn. Ent., x, 230, 1855; Stainton, Tin. No. Am., 40, 1872; W alsingham, Ins. Life, i, 114, 1888.

syn. Alavifrontella Clemens, Proc. Acad. Nat. Sci. Phil., 169, 1860; Tin. No. Am., 126, 1872; Chambers, Can. Ent., vi, 8, 1874; Zeller, Verh. zool.-bot. Ges. Wien, xxiii, $292,1873$.

6108. eboracensis ZELLER, Linn. Ent., x, 205, 1855; Verh. zool.-bot. Ges. Wien, xxiii, 294, 1873.

*6109. fuscicomella Clemens, Proc. Acad. Nat. Sci. Phil., 169, 1860; Tin. No. Am., 126, 1872; Chambers, Can. Ent., vi, 8, 1874; Zeller, Verh. zool.-bot. Ges. Wien, xxiii, 292, 1873.

6110. impositella ZeLLer, Linn. Ent., x, 241, 1855; Walsingham, Ins. Life, i, 113, 1888.

syn. matutella Clemens, Proc. Acad. Nat. Sci. Phil., 169, 1860; Tin. No. Am., 40, 127, 1872; Zeller, Verh. zool.-bot. Ges. Wien, xxiii, 292, 1873; Walsingham, Ins. Life, i, 113, 1888; monstratella Walker, Cat. Brit. Mus., xxix, 594, 1864; Walsingham, Ins. Life, i, 113, 1888; dorsipallidella Chambers, Can. Ent., vii, 10, 1875; buristriga Сhambers, Can. Ent., vii, 10, 1875; brevistriga СнамBers, Bull. Geol. Surv. Terr., iv, 93, 133, 1878; brevistrigella Chambers, Can. Ent., vii, 54, 1875; immaculatella Chambers, Can. Ent., vii, 10, 1875: Bull. Geol. Surv. Terr., iii, 144, 1877.

6111. ochristriata Walsingham, Ins. Life, i, 115, 1888.

6112. perspicelella W ALsinghaM, Ins. Life, i, 114, 1888.

*6113. pilosella Zelder, Verh. zool.-bot. Ges. Wien, xxiii, $293,1873$.

6114. plausipennella Chambers, Can. Ent., vii, 10, 1875. syn. planipennella Chambers, Bull. Geol. Surv. Terr., iv, 134, 1878.

611.. suffusa Walsingham, Ins. Life, i, 114, 1888.

6116. trivinctella ZeLLer, Verh. zool.-bot. Ges. Wien, xxiii, 292, 1873; Chambers, Bull. Geol. Surv. Terr., iv, 93, 1878.

HELIOZELA Herrich-Schaeffer.

Herrich-Schaeffer, Schmett. Eur., v, 56, 1855.

6117. æsella Chambers, Can. Ent., ix, 108, 1877.

*6118. gracilis Zeller, Verh. zool.-bot. Ges. Wien, xxiii, 314, 1873 .

Ky.

N. Y., Tex.

$\mathrm{Pa}$.

Atl. States.

Cal.

Cal.

Mass.

Tex.

Cal.

Tex.

Tex. 


\section{IDIOGLOSSA Walsingham.}

Walsingham, Proc. Zool. Soc. Lond., 272, 1881; Idiostoma Murtfeldt, Can. Ent., xv, 139, 1883; Metamorpha Frey \& Boll (not HüBner), Stett. ent. Zeit., xxxix, 277, 1878; Walsingham, Can. Ent., xv, 239, 1883.

6119. miraculosa Frey \& Boll, Stett. ent. Zeit., Tex. xxxix, $278,1878$.

syn. americella Walsingham, Trans. Am. Ent. Soc., x, 199, 1882.

\section{ANTISPILA Hübner.}

HüBNER, Verz. bek. Schmett., 419, 1816.

6120. ampelopsiella Chambers, Can. Ent., vi, 168, 197, Ky. 1874; ix, 195, 1877; xi, 126, 1879.

*6121. cornifoliella Clemens, Proc. Acad. Nat. Sci. Phil., 11, 1860; Tin. No. Am., 103, 1872; Chambers, Can. Ent., vi, 166, 170, 198, 1874; FreY \& Boll, Stett. ent. Zeit., хххіх, 253, 1878; СнамBERs, Psyche, iii, 63, 1880.

6122. eugeniella Busck, Proc. U. S. Nat. Mus., xxiii, 236,1900 .

*6123. hydrangiæella Chambers, Can. Ent., vi, 170, 1874; ix, 195, 1877; xi, 126, 1879.

6124. isabella Clemens, Proc. Acad. Nat. Sci. Phil., 209, 1860; Tin. No. Am., 142, 1872; Chambers, Cın. Ent., vi, 167, 198, 1874.

syn. issabella Chambers, Bull. Geol. Surv. Terr., iv, 129, 1878.

6125. nyssæfoliella Clemens, Proc. Acad. Nat. Sci. Phil., 11, 1860; Tin. No. Am., 102, 1872; СнамBErs, Psyche, iii, 63, 1880.

Fla.

Ky.

Pa.

*6126. viticordifoliella Clemens, Proc. Acad. Nat. Sci. Phil., 209, 1860; Tin. No. Am., 142, 1872; СнамBErs, Can. Ent., vi, 169, 198, 1874; FreY \& Boll, Stett. ent. Zeit., xхxix, 253, 1878; СнамBERs, Psyche, iii, 63, 1880.

\section{STILBOSIS Clemens.}

Clemens, Proc. Acad. Nat. Sci. Phil., 170, 1860; Tin. No. Am., 40, 129, 1827.

6127. tesquella Clemens, Proc. Acad. Nat. Sci. Phil., 170, 1860; Walsingham, Trans. Am. Ent. Soc., Atl. $\mathrm{x}, 197,1882$.

syn. quinquecristatella CHAMBers, Jn. Cin. Soc. Nat. Hist., iii, 293, 1880; tesquatella Chambers, Bull. Geol. Surv. Terr., iv, 162. 1878. 


\section{CYCLOPLASIS Clemens.}

Cómmens, Proc. Ent. Soc. Phil., ii, 420, 1864; Tin. No. Am., 246, 1872; Walsingham, Proc. Zool. Soc. Lond., 143, 1897.

6128. panicifoliella Clemens, Proc. Ent. Soc. Phil., ii, 422, 1864; Tin. No. Am., 248, 1872; DYar, Proc. Ent. Soc. Wash.. iv, 479, 1901.

Atl. States, Fla.

Tex.

*6129. bipunctella Chambers, Jn. Cin. Soc. Nat. Hist., ii, $187,1879$.

THEISOA Chambers.

Chambers, Can. Ent., vi, 75, 1874.

*6130. constrictella Zeller, Verh. zool. -bot. Ges. Wien, xxiii, 291, 1873; Chambers. Bull. Geol. Surv. Terr., iv, $165,1878$.

syn. bifasciella Chambers, Can. Ent., vi, 75, 1874; vii, 93,1875 ; ix, $24,1877$.

*6131. multifasciella Chambers, Can. Ent., vii, 93, 1875.

Tex.

\section{CHRYSOPELEIA Chambers.}

Chambers, Can. Ent., vi, 72, 1874; Exa Chambers, Can. Ent., vi, 73, 1874

*6132. ostryæella Chambers, Can. Ent., vi, 74, 1874; Ky. viii, 172,1876 ; xi, 9,1879 .

*6133. purpuriella Chambers, Can. Ent., vi, 73, 1874; Ky. xi, 9, 1879; Psyche, iii, 64, 1880.

*6134. quadricristatella Chambers, Jn. Cin. Soc. Nat. Tex. Hist., ii, $186,1879$.

\section{ERIPHIA Chambers. ${ }^{a}$}

Eriphia Chambers (not Latremle), Can. Ent, vii, 55, 1875.

*6135. concolorella Chambers, Can. Ent., vii, 55, 94, Ky. 1875; Bull. Geol. Surv. Terr., iii, 137, 1877.

*6136. albalineella Chambers, Bull. Geol. Surv. Terr., iv, 95,1878 .

*6137. nigrilineella Chambers, Bull. Geol. Surv. Terr., iv, $96,1878$.

\section{COPTODISCA Walsingham.}

Walsingham, Ent. Mo. Mag., xxxi, 41, 1895; Proc. Zool. Soc. Lond., 143, 1897; Aspidisca Clemens (not Ehrenberg), Proc. Acad. Nat. Sci. Phil., 209, 1860; Tin. No. Am., 143, 1872.

6138. diospyriella Chambers, Can. Ent., vi, 217, $1874 . \quad$ Ky. 
6139. condaliæ Busck, Proc. U. S. Nat. Mus., xxiii,

Fla. 242, 1900 .

6140. ella Chambers, Can. Ent., iii, 224, 1871; vi, 152, Ky. 218,1874 .

6141. lucifluella Clemens, Proc. Acad. Nat. Sci. Phil., Pa. 209. 1860; Tin. No. Am., 143, 1872; Chambers, Can. Ent., iii, 224, 1871; vi, 218, 1874; Psyche, iii, 64,1880 .

*6142. juglandiella Chambers, Can. Ent., vi, 151, 218, 1874.

*6143. ostryæfoliella Clemens, Proc. Ent. Soc. Phil., i, 82, 1861; Tin. No. Am., 171, 1872.

6144. saliciella Chambers, Proc. Ent. Soc. Phil., i, 82, 1861; Tin. No. Am., 171, 1872; Chambers, Pysche, iii, 147, 1880.

6145. splendoriferella Clemens, Proc. Acad. Nat. Sci. Phil., 12, 1860; Tin. No. Am., 105, 1872; ChaмBers, Can. Ent., iii, 23, 1871; v, 50, 1873; vi, 149, 219, 1874; Stalnton, Ent. Mo. Mag., ix, 18,1872 .

syn. pruniella Clemens, Proc. Ent. Soc. Phil., i, 82, 1861; saccatella PACK ARD, Guide Stud. Ins., 355, 1869; Chambers, Can. Ent., iii, $223,1871$.

EPERMENIA Hübner.

Hübner, Verz. bek. Schmett., 418, 1816; Chauliodus Treitschke (not Schneider), Schm. Eur., ix, 2, 31, 1833.

*6146. canicinctella Clemens, Proc. Ent. Soc. Phil., ii, Pa. 129, 1863; Tin. No. Am., 236, 1872.

6147. pimpinella Murtfeldt, Can. Ent., xxxii, 162, Mo. 1900 .

\section{MOMPHA Hübner.}

HüBner, Verz. bek. Schmett., 414, 1816; Laverna Curtis, Brit. Ent., 16, 1859; Wilsonia Clemens, Proc. Ent. Soc. Phil., iii, 428, 1864.

*6148. albella Chambers, Cin. Quart. Jn. Sci., ii, 295, Col. 1875 .

*6149. albopalpella Chambers, Cin. Quart. Jn. Sci., ii, Col. $295,1875$.

*6150. argentimaculella Murtfeldt, Can. Ent., xxxii, Mo. $161,1900$.

*6151. bifasciella Chambers, Can. Ent., viii, 158, 1876. 
6152. brevivittella Clemens, Proc. Ent. Soc. Phil., ii, 428, 1864; Tin. No. Am., 254, 1872.

Atl.

svn. anotherivorella Chambers, Jn. Cin. Soc. States.

Nat. Hist., iii, 293, 1880; W alsinghaM, Trans. Am. Ent. Soc., x. 169, 1882; anotheraseminella Chambers, Can. Ent., viii, 138, 1876 ; xi, $6,1879$.

*6153. circumscriptella Zelcer, Verh. zool.-bot. Ges. Wien, xxiii, 312, 1873; Chambers, Can. Ent., $\mathrm{x}, 239,1878$.

*6154. coloradella Chambers, Bull. Geol. Surv. Terr., iii, $136,1877$.

6155. decorella Stephens, Ill. Brit. Ent., Haust., iv, 213, 1835; Staudinger \& Rebel, Cat. Lep. Eur., ii, no. 3580, 1901; WalsinghaM, Trans. Am. Ent. Soc., x, 196, 1882.

svn. unifasciella Chambers, Can. Ent., viii, $159,1876$.

*6156. definitella Zeller, Verh. zool.-bot. Ges. Wien, xxiii, 311, 1873.

syn. unicristatella CHaMbers, Can. Ent., vii, 32,1875 ; ix, 74, 1877.

6157. eloisella Clemens, Proc. Acad. Nat. Sci. Phil., 171, 1860; Tin. No. Am., 131, 1872; Chambers, Can. Ent., ix, 74, 1877; Walsinghay, Trans. Am. Ent. Soc., x, 195, 1882.

syn. magnatella Zelcer, Verh. zool. -bot. Ges. Wien, x xiii, 315,1873; Chambers, Can. Ent., ix, 73. 1877; anotheræella CHambers, Can. Ent., vii, 30, 1875; lyonetiella CHAMBERs, Can. Ent., vii, 30, 51, 1875.

6158. erransella Chambers, Can. Ent., vi, 52, 1874; vii, 52, 1875; ix, 187, 1877.

syn. unomaculella Chambers, Can. Ent., vii, 94, 1875; xi, 9, 1879.

*6159. gleditschiæella Chambers, Can. Ent., viii, 135, 171, 1876; x, 232, 1878; xiii, 173, 1881; Psyche, iii, 66,1880 .

*6160. grandisella Chambers, Cin. Quart. Jn. Sci., ii, $296,1875$.

*6161. ignobilisella Chambers, Can. Ent., vii, 33, 51, 1875 ; xi, 8, 1879.

6162. luciferella Clemens, Proc. Acad. Nat. Sci. Phil., 171, 1860; Tin. No. Am., 130, 1872; W ALSINGHaм, Trans. Am. Ent. Soc., x, 196, 1882.

Col.

Eur.,

Cal.

Tex.

Pa.

$\mathrm{K} y$.

Ky.

Col.

Tex.

Pa.,

$\mathrm{Ky}$.

syn. cephalonthiella Chambers, Can. Ent., iii, 221, 1871; vii, 53, 1875; xi, 10, 1879. 
*6163. minimella Chambers, Jn. Cin. Soc. Nat. Hist., iii, 294,1880 .

6164. murtfeldtella Chambers, Cin. Quart. Jn. Sici., ii, 237, 1875; Can. Ent., viii, 159, 1876; ix, 13, 1877 ; xi, 5, 1879.

Mass.

Mo.,

Col.,

Tex.

syn. albocapitella Chambers, Can. Ent., vii, 33, 1875; Bull. Geol. Surv. Terr., iii, 144, 1877; grissæella Chambers, Cin. Quart. Jn. Sci., ii, 295, 1875; Bull. Geol. Surv. Terr., iii, 141, 1877; obscumesella Chambers, Can. Ent., vii, 53, 1875; parvicristatella СнамBers, Can. Ent., vii, 34, 1875.

6165. rufocristatella Chambers, Can. Ent., vii, 33, 1875.

*6166. subiridescens Walsingham, Trans. Am. Ent. Soc., x, 194, 1882.

6167. subbistrigella HaworTH, Lep. Brit., 581, 1829; Staudinger \& Rebel, Cat. Lep. Eur., ii, no. 3582, 1901; Walsingham, Trans. Am. Ent. Soc., x, 196,1882 .

6168. sexnotella Chambers, Bull. Geol. Surv. Terr., iv, 88, 1878: Hagen, Pap., iv, 99, 1884; Вusck, Jn. N. Y. Ent. Soc., x, 97, 1902.

\section{HOMALEDRA Busek.}

Busck, Proc. U. S. Nat. Mus., xxiii, 237, 1900.

6169. heptathalama Busck, Proc. U. S. Nat. Mus., xxiii, $237,1900$.

6169. 1. sabalella Chambers, Jn. Cin. Soc. Nat. Hist., ii, 7,1880 .

\section{ENDROSIS Hiibner.}

HübNer, Verz. bek. Schmett., 401, 1816.

6170. lacteella Denis \& SCHIfFermüller, Syst. Verz. Wien, 139, 1776; Staudinger \& Rebel, Cat. Lep. Eur., ii, no. 3051, 1901.

Eur., Cal. syn. kennicotella Clemens, Proc. Acad. Nat. Sci. Phil., 165, 1860; Tin. No. Am., 119, 1872; Chambers, Cin. Quart. Jn. Sci., ii, 244,1875 .

\section{LEUCOPHRYNE Chambers.}

Chambers, Can. Ent., vii, 210, 1875.

6171. tricristatella Chambers, Can. Ent., vii, 211, 1875.

Can.

DOUGLASIA Stainton.

Stainton, Ins. Brit., Lep. Tin., 179, 1854.

*6172. obscurofasciella Chambers, Jn. Cin. Soc. Nat. Hist., iii, 291, 1880. 
AROTURA Walsingham.

Walsingham, Ins. Life, i, 116, 1888.

6173. eburnea Walsingham, Ins. Life, i, 117, 1888.

Ariz.

\section{APHIGALIA Dyar.}

Phigalia Chambers (not Duponchel), Can. Ent., vii, 107, 1875.

*6174. albella Chambers, Can. Ent., vii, 107, 1875.

Tex.

*6175. ochreomacuiella Chambers, Can. Ent., vii, 107, 1875 .

Tex.

SCHRECKENSTEINIA Hiibner.

Hübner, Verz. bek. Schmett., 419, 1816.

6176. felicella Walsingham, Pter. Cal. Oreg., 2, 1880.

6177. erythriella Clemens, Proc. Acad. Nat. Sci. Phil., 171, 1860; Tin. No. Am., 40, 132, 1872; FreY \& Boll, Stett. ent. Zeit., xxxvii, 214, 1876.

61،8. festaliella HüBNER, Schm. Eur., 449, 1827; Staudinger \& Rebel, Cat. Lep. Eur., ii, no. 3405, 1901; Walsingham, Pter. Cal. Oreg., 1, 1880; Trans. Am. Ent. Soc., x, 197, 1882; DYAR. Psyche, vii, 252, 1895 (as basilaris).

\section{WALSHIA Clemens.}

Clemens, Proc. Ent. Soc. Phil., ii, 418, 1864.

6179. amorphella Clemens, Proc. Ent. Soc. Phil., ii, 419, 1864; Tin. No. Am., 241, 1872; Riley, Rep. Ins. Mo., ii, 132, 1869; Proc. Ent. Soc. Wash., i, 30, 1886 .

syn. miscecalonella Chambers, Can. Ent., vii, 34, 1875; miscecolorella Chambers, Can. Ent., vii, 51, 1875; Bull. Geol. Surv. Terr., iii, 144, 1877; Walsingham, Trans. Am. Ent. Soc., x, 197, 1882.

\section{BRACHILOMA Clemens.}

Clemens, Proc. Ent. Soc. Phil., ii, 126, 1863.

*6180. unipunctella Clemens, Proc. Ent. Soc. Phil., ii, 126, 1863; Tin. No. Am., 232, 1872.

Cal., Oreg. Atl. States.

No. U. S., Eur.

Atl. States.

\section{EULYONETIA Chambers.}

Chambers, Jn. Cin. Soc. Nat. Hist., ii, 188, 1879.

*6181. inornatella Chambers, Jn. Cin. Soc. Nat. Hist., ii, $188,1879$. 
CACELICE Busck.

Busck, Jn. N. Y. Ent. Soc., x, 93, 1902.

6182. permolestella Busck, Jn. N. Y. Ent. Soc., x, $\mathrm{Ky}$. 93, 1902.

Family TINEID \&.

NEPTICULA von Heyden.

Von Heyden, Berich. Vers. Naturf. Mainz, 201, 1842.

*6183. amelanchierella Clemens, Proc. Ent. Soc. Phil., i, 84, 1861; Tin. No. Am., 174, 1872; PaCkARD, Guide Stud. Ins., 356, 1869.

*6184. anguinella Clemens, Proc. Ent. Soc. Phil., i, 85, 1861; Tin. No. Am., 175, 1872.

*6185. apicialbella Chambers, Can. Ent., v, 127, 1873; Cin. Quart. Jn. Sci., ii, 118, 1875.

No. Atl. States.

$\mathrm{Pa}$.

Ky.

$\mathrm{K} y$.

*6186. badiocapitella Chambers, Can. Ent., viii, 160, 1876.

*6187. belfrageella Chambers, Can. Ent., vii, 75, 1875.

*6188. bifasciella Clemens, Proc. Ent. Soc. Phil., i, 133, 1862: Tin. No. Am. 183, 1872; Chambers, Can. Ent., v, 146, 1873.

*6189. castaneæfoliella Chambers, Cin. Quart. Jn. Sci., ii, 117, 1875; Psyche, iii, 66, 1880; Jn. Cin. Soc. Nat. Hist., ii, 193, 1879.

*6190. caryæfoliella Clemens, Proc. Ent. Soc. Phil., i, 84, 1861; Tin. No. Am., 174, 1872.

*6191. clemensella Chambers, Can. Ent., v, 125, 1873.

6192. condaliafoliella Busck, Proc. U. S. Nat. Mus., xxiii, 238, 1900.

*6193. corylifoliella Clemens, Proc. Ent. Soc. Phil., i, 83, 1861; Tin. No. Am., 173, 1872; PACKArd, Guide Stud. Ins., 356, 1869.

*6194. cratægifoliella Clemens, Proc. Ent. Soc. Phil., i, 83, 1861; Tin. No. Am., 173, 1872.

6195. dallasiana Frey \& Boll, Stett. ent. Zeit., xxxvii, 228, 1876.

*6196. fuscocapitella Chambers, Can. Ent., v, 128, 1873.

Tex.

Pa.

$\mathrm{Ky}$.

Pa.

Ky., Pa.

Fla.

Pa.

$\mathrm{Pa}$.

Tex.

Ky. $4630-$ No. $52-02-35$ 
*6197. fuscotibiella Clemens, Proc. Ent. Soc. Phil., i, Pa. 133, 1861; Tin. No. Am., 182, 1872; Chambers, Can. Ent., v, 128, 1873; Cin. Quart. Jn. Sci., ii, 114,1875 .

syn. cillixfuscella Chambers, Can. Ent., v, 128, 1873; Cin. Quart. Jn. Sci., ii, 117, 1875; furcotibiella Riley, Smith's List Lep. Bor. Am., 111, 1891.

*6198. grandisella Chambers, Jn. Cin. Soc. Nat. Hist., ii, $193,1879$.

*6199. juglandifoliella Clemens, Proc. Ent. Soc. Phil., i, 84, 1861; Tin. No. Am., 173, 1872; Bull. Geol. Surv. Terr., iv, 105, 1878.

*6200. latifasciella Chambers, Bull. Geol. Surv. Terr., iv, $106,1878$.

*6201. maculosella Chambers, Jn. Cin. Soc. Nat. Hist., ii, $193,1879$.

6202. maximella Chambers, Can. Ent., v, 126, 1873.

*6203. minimella Chambers, Can. Ent., v, 127, 1873.

6204. myricafoliella Busck, Proc. U. S. Nat. Mus., xxiii, 238, 1900 .

*6205. nigriverticella Chambers, Cin. Quart. Jn. Sci., ii, 118,1875 .

*6206. nyssæfoliella Chambers, Psyche, iii, 66, 1880.

*6207. ochrefasciella Chambers, Can. Ent., v, 128, 1873.

*6208. ostryæfoliella Clemens, Proc. Ent. Soc. Phil., i, $83,1861$.

6209. platanella Clemens, Proc. Ent. Soc. Phil., i, 173, 183, 1861; v, 146, 1865; Chambers, Can. Ent., v, 125, 1873; Packard, Guide Stud. Ins., 356, 1869 .

*6210. platea Clemens, Proc. Ent. Soc. Phil., i, 85, 1861; Tin. No. Am., 175, 1872.

Tex.

Pa.

Ky.

Tex.

Ky.

Ky.

Fla.

$\mathrm{Ky}$.

Ky.

Ky.

$\mathrm{Pa}$.

Pa.

Pa.

*6211. pomivorella PaCkard, Am. Nat., vi, 685, 1872; Rept. Mass. Agr. Soc., 238, 1870; W ALsingham, Mass. Proc. Zool. Soc. Lond., 83, 1880; Busck, Can. Ent., xxxiii, 52, 1901.

*6212. populetorum Frey \& Boll, Stett. ent. Zeit., xxxix, $276,1878$.

6213. prunifoliella Clemens, Proc. Ent. Soc. Phil., i, 84, 1861; Tin. No. Am., 174, 1872; Chambers, Can. Ent., v, 127, 1873.

*6214. pteliæella Chambers, Psyche, iii, 137, 1880; 276, 1881. 
*6215. quercicastanella Chambers, Can. Ent.,v, 127,1873; x, 105, 1878; xi, 93, 1879; Psyche, iii, 66, 1880.

Ky.

*6216. quercipulchrella Chambers, Bull. Geol. Surv. Terr., iv, 105, 1878.

*6217. resplendensella Chambers, Cin. Quart. Jn. Sci., ii, 118, 1875 .

*6218. rosæfoliella Clemens, Proc. Ent. Soc. Phil., i, 85, 1861; Tin. No. Am., 176, 1872.

*6219. rubifoliella Clemens, Proc. Ent. Soc. Phil., v, 146, 1865; Tin. No. Am., 152, 1872.

6220. saginella Clemens, Proc. Ent. Soc. Phil., i, 85, 1861; Tin. No. Am., 175, 271, 1872; Chambers, Can. Ent., xi, 93, 1879.

*6221. serotinæella Chambers, Can. Ent., v, 126, 1873.

*6222. thoracealbella Chambers, Can. Ent., v, 127, 1873.

*6223. unifasciella Chambers, Cin. Quart. Jn. Sci., ii, 119,1875 .

*6224. villosella Clemens, Proc. Ent. Soc. Phil., i, 84, 1861; Tin. No. Am., 174, 1872.

*6225. virginiella Clemens, Proc. Ent. Soc. Phil., i, 83, 1861; Tin. No. Am., 172, 1872.

Ky.

$\mathrm{Ky}$.

Pa.

Pa.

Pa.

Ky.

Ky.

Ky.

Pa.

Pa.

TRIFURCULA Zeller.

Zeller, Linn. Ent., iii, 330, 1848; Trifurcella Chambers, Bull. Geol. Surv. Terr., iv, $165,1878$.

*6226. obrutella Zellex, Verh. zool.-bot. Ges. Wien, Tex. xxiii, 316, 1873.

OPOSTEGA Zeller.

Zeller, Isis, 214, 1839.

6227. accessoriella Frey \& Boll, Stett. ent. Zeit.,

Tex. xxxvii, 216, 1876.

*6228. albogallierella Clemens, Proc. Ent. Soc. Phil., Pa. i, 131, 1862; Tin. No. Am., 180, 1872.

6229. bosqueella Chambers, Bull. Geol. Surv. Terr., iv, $106,1878$.

6230. nonstrigella СнамвеRs. Jn. Cin. Soc. Nat. Hist., iii, $296,1880$.

*6231. quadristrigella Chambers, Cin. Quart. Jn. Sci., ii, 106,1875 .

Tex.

Ky.

Ky. . 


\section{BUCCULATRIX Zeller.}

Zeller, Linn. Ent., iii, 286, 1848; Clemens, Tin. No. Am., 108, 1872.

6232. albicapitella Chambers, Can. Ent., vii, 125, 1875.

Can.

6233. ambrosiæfoliella Chambers, Cin. Quart. Jn. Sci., ii, 119, 1875; Can. Ent., xiv, 153, 1882.

Ky.

*6234. agnella Clemens, Proc. Acad. Nat. Sci. Phil., 211, 1860; Tin. No. Am., 147, 1872.

*6235. angustata Frey \& Boll, Stett. ent. Zeit., xxxvii, 218, 1876.

6236. canadensisella Chambers, Can. Ent., vii, 146, 1875 .

6237. capitialbella Chambers, Can. Ent., v, 150, 1873.

6238. coronatella Clemens, Proc. Acad. Nat. Sci. Phil., 13, 1860; Tin. No. Am., 109, 1872; Chambers, Can. Ent., v, 151, 1873.

*6239. immaculatella Chamвers, Can. Ent., vii, 54, 1875.

6240. ivella Busck, Proc. U. S. Nat. Mus., xxiii, 243, 1900 .

*6241. litigiosella Zeller, Verh. zool.-bot. Ges. Wien, xxv, 354, 1875 .

6242. luteella Chambers, Can. Ent., v, 151, 1873; xi, 93, 1879.

6243. magnella Chambers, Can. Ent., vii, 54, 1875.

$\mathrm{Pa}$.

Tex.

Can.

Ky.

Pa.

Tex.

Fla.

Tex.

Ky.

Tex.

*6244. niveella Chambers, Can. Ent., vii, 54, 1875.

*6245. packardella Chambers, Can. Ent., v, 151, 1873; Cin. Quart. Jn. Sci., ii, 120, 1875.

6246. pomifoliella Clemens, Proc. Acad. Nat. Sci. Phil., 211, 1860; Tin. No. Am., 146, 1872; Chambers, Can. Ent., v, 150, 1873; Riley, Rep. Ins. Mo., iv, 149, 1872; Zeller, Verh. zool.-bot. Ges. Wien, xxv, 353, 1875; Walsingham, Trans. Am. Ent. Soc., x, 204, 1882.

syn. pomomella Packard, Guide Stud. Ins., 7th ed., 354, 1880: curvilineatella PACKARD, Guide Stud. Ins., 354, 1869; Chambers, Can. Ent., iii, 184, 1871.

*6247. quinquenotella Chanbers, Cin. Quart. Jn. Sci., ii, 120,1875 .

Ky.

*6248. rileyi Frey \& Boll, Stett. ent. Zeit., xxxvii, $219,1876$.

Tex. 
*6249. staintonella Chambers, Bull. Geol. Surv. Terr., Col. iv, $133,1878$.

syn. albella Chambers (not Stainton), Bull. Geol. Surv. Terr., iii, 141, 1877.

6250. thuiella PaCKARD, Am. Nat., v, 152, 1871; Rrley, Rep. Ins. Mo., iv, 51, 1872.

6251. trifasciella Clemens, Proc. Ent. Soc. Phil., v, 147, 1866; Tin. No. Am., 272, 1872; Chambers, Can. Ent., v, 149, 1873; Cin. Quart. Jn. Sci., ii, 120,1875 .

syn. obscurofasciella Chambers, Can. Ent., v, $150,1873$.

\section{LITHOCOLLETES Hübner.}

HüBNER, Verz. bek. Schmett., 423, 1816.

*6252. hageni Frer \& Boll, Stett. ent. Zeit., xxxir, 208, 1873; Chambers, Cin. Quart. Jn. Sci., i, 201, 1874; Bull. Geol. Surv. Terr., iv, 100, 1878.

syn. necospinusella Chambers, Bull. Geol.

Surv. Terr., iv, 100, 1878.

6253. fitchella Clemens, Proc. Acad. Nat. Sci. Phil., Atl. States.

Pa. 207, 1860; Tin. No. Am., 139, 1872; Chambers, Can. Ent., iii, 183, 1871; Cin. Quart. Jn. Sci., i, 207, 1874; PaCkar!, Guide Stud. Ins., 353, 1869; Chambers, Bull. Geol. Surv. Terr., iii, 139, 1877; Can. Ent., xi, 90, 1879; Frey \& Boll, Stett. ent. Zeit., xxxix, 26, 1878.

syn. quercifoliella Fitch, Fifth Rept. Ins. N. Y., 327, 1859; quercitorum FREY \& BOLL, Stett. ent. Zeit., xxxiv, 207, 1873; Zeller, Verh. zool.-bot. Ges. Wien, xxv, 140, 1875; Chambers, Cin. Quart. Jn. Sci., i, 201, 1874; ii, 229, 1875; Bull. Geol. Surv. Terr., iii, $139,141,1877$.

6254. rileyella Chambers, Cin. Quart. Jn. Sci., ii, 236, 1875; Walsinghay, Ins. Life, ii, 25, 1889.

Mass. ?

$\mathrm{Pa}$.

syn. temuistrigate Frey \& Boll, Stett. ent.

Zeit., xxxvii, 225, 1876; xxxix, 26, 1878.

6255. insignis WalsinghaM, Ins. Life, ii, 117, 1889.

6256. clemensella Chambers, Can. Ent., xi, 91, 1879; W alsingham, Ins. Life, ii, 25, 1889.

6257. lucidicostella Clemens, Proc. Acad. Nat. Sci. Phil., 318, 1859; Tin. No. Am., 39, 64, 66, 1872; Chambers, Cin. Quart. Jn. Sci., ii, 102, 1875; Can. Ent., iii, 57, 1871.

syn. ludicostella Riler, Smith's List Lep. Bor. Am., 109, 1891. 
6258. argentifimbriella Clemens, Proc. Acad. Nat.

$\mathrm{Pa}$.

Sci. Phil., 318, 321, 1859; Tin. No. Am., 39, 64,

70, 1872; Chambers, Can. Ent., iii, 57, 85, 1871;

Cin. Quart. Jn. Sci., i, 201, 1874; ii, 229, 1875;

Frey \& Boll, Stett. ent. Zeit., xxxiv, 209, 1873;

Walsingham, Ins. Life, iii, 325, 1891.

syn. fuscocostella Chambers, Cin. Quart. Jn. Sci., ii, 102, 1875; Walsingham, Ins. Life, ii, 25,1889 .

6259. quercialbella Fiтch, Rep. Ins. N. Y., v, 328, 1859; Chambers, Can. Ent., iii, 57, 1871; WalsingHAM, Ins. Life, ii, 25, 1890; iii, 325, 1891.

syn. longirostrata FREY \& Boll, Stett. ent. Zeit., xxxiv, 209, 1873; Chambers, Cin. Quart. Jn. Sci., ii, 229, 1875; W ALsinghaM, Ins. Life, ii, 25, 1891; quercibella СнамBers, Cin. Quart. Jn. Sci., ii, 202, 1875; Walsingham, Ins. Life, ii, 77, 1889; quercipulchella СнамвеRs, Bull. Geol. Surv. Terr., iv, 120, 1878; PACKard, Bull. Ent. Comm., vii, 53, 1881; WalsinghaM, Ins. Life, ii, 77, 1889; quercipulchella Rrley, Smith's List Lep. Bor. Am., 109, 1891.

*6260. subaureola Frey \& Boll, Stett. ent. Zeit., xxxix, 262, 1878; Walsingham, Ins. Life, ii, 25, 1889; iii, $325,1891$.

*6261. caryæalbella Chambers, Can. Ent., iii, 58, 85, $182,206,1871$.

syn. caryalbelia Walsingham, Ins. Life, iii, 328, 1891.

6262. lucetiella Clemens, Proc. Acad. Nat. Sci. Phil., 319, 322, 1859; Tin. No. Am., 65, 73, 1872; Chambers, Can. Ent., iii, 56,1871 ; W alsingham, Ins. Life, ii, 52, 1889.

syn. xniqmatella FreY \& Boll, Stett. ent. Zeit., xxxiv, 219, 1873; Chambers, Cin. Quart. Jn. Sci., i, 206, 1874.

*6263. albanotella Chambers, Cin. Quart. Jn. Sci., ii, $191,1875$.

6264. alniella ZelLer, Linn. Ent., i, 229, 1846; STAUDinger \& Rebel, Cat. Lep. Eur., ii, no. 4118, 1901; Frey \& Boll, Stett. ent. Zeit., xxxiv, 210, 1873; Chambers, Cin. Quart. Jn. Sci., i, 201, 1874; ii. 229.1875

Atl. States.

Tex.

$\mathrm{Ky}$.

Pa.

Ky.

Eur., U.S.? 
6265. ostensackenella FiтcH, Rept. Ins. N. Y., v, 338, N. Y. 1859: Chambers, Can. Ent., iii, 183, 1871.

syn. ornatella Chambers, Can. Ent., iii, 161, 1871; iv, 107, 1872; xi, 91, 1879; ZELLER, Verh. zool.-bot. Ges. Wien, xxv, 347, 1875; Frey \& Boll, Stett. ent. Zeit., xxxiv, 217, 1873; Walsingham, Ins. Life, ii, 53, 1889 .

6266. gemmea Frey \& Boll, Stett. ent. Zeit., xxxiv, 218, 1873; Chambers, Cin. Quart. Jn. Sci., i, 206, 339, 1874; ii, 227, 1875; WaLsinghaм, Ins. Life, ii, 53, 1889.

6267. robiniella Clemens, Proc. Acad. Nat. Sci. Phil., 318, 1859; 209, 1860; Tin. No. Am., 66, 1872; Chambers, Can. Ent., iii, 54, 87, 163, 183, 185, 1871; iv, 9, 117, 1872; Cin. Quart. Jn. Sci., ii, 228, 1875: Bull. Geol. Surv. Terr., iii, 137, 1877; Jn. Cin. Soc. Nat. Hist., ii, 91, 1879; Zeller, Verh. zool.-bot. Ges. Wien, xxv, 348, 1875: Frey \& Boll, Stett. ent. Zeit., xxxix, 275,1878 .

syn. pseudacaciella FiтcH, Rept. Ins. N. Y., $\mathrm{v}, 335,1859$.

*6268. uhlerella Fiтch, Rept. Ins. N. Y., v, 337, 1859; Walsingham, Ins. Life, ii, 53, 1889.

syn. amorphæella CHambers, Bull. Geol. Surv. Terr., iii, 132, 137, 1877; amorphx Frey \& Boll, Stett. ent. Zeit., xxxix, $275,1878$.

6269. morrisella Fiтch, Rept. Ins. N. Y., v, 336, 1859; W alsinghaM, Ins. Life, ii, 52, 1889.

syn. texanella ZelLer, Verh. zool.-bot. Ges. Wien, xxv, 349, 1875; Frey \& Boll, Stett. ent. Zeit., xxxix, 275, 1878; amphicarpæella Chambers, Bull. Geol. Surv. Terr., iii, 137, 1877.

6270. blancardella FABRICIUs, Syst. Ent., iii, 327, 1775; Staudinger \& Rebel, Cat. Lep. Eur., ii, no.

Atl. States, Eur. 4144, 1901.

syn. pomifoliella ZeLLer, Isis, 218,1839; WALsingham, Trans. Am. Ent. Soc., x, 202, 1882; mespilella HAwORTH, cratrgella CLEMens, Proc. Acad. Nat. Sci. Phil., 324, 1859; deceptusella Chambers, Can. Ent., xi, 73, 1879 .

6271. faginella Zeller, Linn. Ent., i, 204, 1846; Staudinger \& Rebel, Cat. Lep. Eur., ii, no. 4149, 1901; Walsinghay, Ins. Life, iii, 327 , 1891.

syn. triguttella Stainton. 
6272. incanella Walsingham, Ins. Life, ii, 81, 1889.

Cal.

6273. alnicolella Walsingham, Ins. Life, ii, 80, 1889.

Cal.

*6274. alni Walsingham, Ins. Life, iii, 326, 1891.

Col.

syn. alnivorella Chambers (not Ragonot), Cin. Quart. Jn. Sci., ii, 302, 1875; Bull. Geol. Surv. Terr., iii, 139, 1877.

*6275. ostryæfoliella Clemens, Proc. Acad. Nat. Sci. Phil., 322, 1859; Tin. No. Am., 67, 71, 1872; Chambers, Can. Ent., iii, 85, 1871; Cin. Quart. Jn. Sci., i, 202, 1874; Can. Ent., xi, 91, 1879; Walsingham, Ins. Life, ii, 53, 1889.

syn. mirifica Frey \& Bold, Stett. ent. Zeit., xxxiv, 212, 1873.

*6276. minutella Frey \& Boll, Stett. ent. Zeit., xxxix, 263, 1878.

6277. diaphanella Frey \& Boll, Stett. ent. Zeit., xxxix, $265,1878$.

*6278. scudderella Frey \& Bold, Stett. ent. Zeit., xxxiv, 212, 1873; Chambers, Cin. Quart. Jn. Sci., ii, 230, 1875; Bull. Geol. Surv. Terr., iv, 156, 1878; Can. Ent., xi, 72, 1879.

*6279. obsoleta Frey \& Boll. Stett. ent. Zeit., xxxiv, 211, 1873; Chambers, Cin. Quart. Jn. Sci., i, 202,1874 .

syn. obsoletella Chambers, Bull. Geol. Surv. Terr., iv, 155, 1878.

*6280. obscuricostella Clemens, Proc. Acad. Nat. Sci. Phil., 321, 1859; Tin. No. Am., 64, 71, 1872; Chambers, Can. Ent., iii, 85, 1871; xi, 92, 1879.

syn. virginella Chambers, Can. Ent., iii, 84, 1871.

6281. æriferella Clemens, Proc. Acad. Nat. Sci. Phil., 320, 1859; Tin. No. Am., 64, 68, 1872; Chambers, Can. Ent., iii, 183, 1871; Cin. Quart. Jn. Sci., ii, 104,1875 .

*6282. sexnotella Chambers, Jn. Cin. Soc. Nat. Hist., ii, $189,1879$.

6283. argentinotella Clemens, Proc. Acad. Nat. Sci. Phil., 321, 1859; Tin. No. Am., 66, 78, 1872; Chambers, Can. Ent., iii, 148, 1871; xi, 89, 1879; Frey \& Boll, Stett. ent. Zeit., xxxiv, 214, 1873; Chambers, Cin. Quart.Jn. Sci.,i, 202, 1874; ii, 101,1875 .

*6284. occitanica Frer \& Boll, Stett. ent. Zeit., xxxvii, 224, 1876; xxxix, 270, 1878.

Tex. 
*6285. amœna Frer \& Boll, Stett. ent. Zeit., xxxix, 269,1878 .

6286. celtifoliella Chambers, Can. Ent., iii, 128, 1871; WaLsingham, Ins. Life, ii, 52, 1889.

Atl. States.

syn. nonfasciella Chambers, Can. Ent., iii, 108,

1871; Cin.Quart. Jn. Sci., i, 201, 1874; celtisella Chambers, Can. Ent, ,iii, 129, 1871; Cin. Quart. Jn. Sci., i, 201, 1874; Frey \& Boll, Stett. ent. Zeit., xxxix, 274, 1878; Chambers, Jn. Cin. Soc. Nat. Hist., ii, 190, 1879; pusillifoliella Frey \& Boll, Stett. ent. Zeit., xxxix, $274,1878$.

6287. cincinnatiella Chambers, Can. Ent., iii, 144, 149, 1871; Cin. Quart. Jn. Sci., i, 149, 1874; Bull. Geol. Surv. Terr., iii, 141, 1877.

6288. caryæfoliella Clemens, Proc. Acad. Nat. Sci. Phil., 323, 1859; Tin. No. Am., 65, 74, 1872; Chambers, Can. Ent., iii, 109. 165, 1871; Frey \& Boll, Stett. ent. Zeit., xxxix, 273, 1878.

syn. juglandiella Clemens, Proc. Ent. Soc. Phil., i, 81, 1861; Tin. No. Am., 170, 1872; Chambers, Can. Ent., iii, 165, 1871; vii, 126, 1875; xi, 91, 1879; PACKARD, Guide Stud. Ins., 353, 1869.

*6289. macrocarpella Frey \& Boll, Stett. ent. Zeit., xxxix, 261, 1878.

6290. umbellulariæ WaLsinghaM, Ins. Life, ii, 78, 1889.

Ohio.

Atl. States.

6291. gaultheriella W ALsinghaM, Ins. Life, ii, 79, 1889.

6292. ledella Walsinghà, Ins. Life, ii, 79, 1889.

6293. nemoris Walsingham, Ins. Life, ii, 116, 1889.

6294. ulmella Chambers, Can. Ent., iii, 148, 1871; Cin. Quart. Jn. Sci., i, 202, 1874; ii, 101, 1875; FreY \& Boll, Stett. ent. Zeit., xxxiv, 214, 1873; Walsingham, Ins. Life, ii, 24, 1889.

syn. modesta Frey \& Boll, Stett. ent. Zeit., xxxvii, 274, 1876; xxxix, 274, 1878.

*6295. conglomeratella Zeller, Verh. zool.-bot. Ges. Wien, xxv, 346, 1875; Walsingham, Ins. Life, ii, 24,1889 .

syn. bicolorella Chambers, Bull. Geol. Surv. Terr., iv, 103, 1878; obtusilobx Frey \& Boll, Stett. ent. Zeit., xxxix, 265, 1878.

*6296. quercivorella Chambers, Can. Ent., xi, 145, 1879; Walsingham, Ins. Life, ii, 24, 1889.

Tex.

Cal.

Oreg., Cal.

Cal.

Cal.

Atl.

States.

Tex.

Ky.

6297. australisella Chambers, Bull. Geol. Surv. Terr., iv, $103,1878$.

Tex. 
6298. solidaginis Frey \& Boll, Stett. ent. Zeit., Tex. xxxvii, $223,1876$.

syn. solidaginisella Chambers, Jn. Cin. Soc. Nat. Hist., ii, 12, 1880.

6299. grindeliella WaLsingham, Ins. Life, iii, 327, 1891. Cal.

*6300. chambersella WalsinghaM, Ins. Life, ii, 78, 1889. syn. quinquenotella Chambers (not Frex), Jn. Cin. Soc. Nat. Hist., ii, 189, 1879.

6301. basistrigella Clemens, Proc. Acad. Nat. Sci. Phil., 321, 1859; Tin. No. Am., 39, 65, 69, 1872; Chambers, Can. Ent., iii, 48, 166, 182, 1871; Cin. Quart. Jn. Sci., i, 205, 1874; Walsingham, Ins. Life, ii, 25, 1889.

syn. intermedia Frey \& Boll, Stett. ent. Zeit., xxxiv, 210, 1873; Chambers, Cin. Quart. Jn. Sci., ii, 230, 1875.

*6302. auronitens Frey \& Boll, Stett. ent. Zeit., xxxiv, 216, 1873.

6303. desmodiella Clemens, Proc. Acad. Nat. Sci. Phil., 220, 1859; Tin. No. Am., 65, 68, 1872; ChaмBers, Can. Ent., iii, 127, 152, 1871; Jn. Cin. Soc. Nat. Hist., ii, 189, 1879; Walsingham, Trans. Am. Ent. Soc., x, 202, 1882.

syn. gregariella Murtfeldt, Can. Ent., xiii, 245, 1881; xv, 139, 1883; W ALSINGHAM, Proc. Zool. Soc. Lond., 146, 1897.

6304. toxicodendri Frey \& Boll, Stett. ent. Zeit., xxxix, 273, 1878.

6305. aceriella Clemens, Proc. Acad. Nat. Sci. Phil., 325, 1859; Tin. No. Am., 65, 75, 1872; ChaMBers, Can. Ent., iii, 130, 1871.

62,06. guttifinitella Clemens, Proc. Acad. Nat. Sci. Phil., 324, 1859: Tin. No. Am., 65, 76, 1872; Chambers, Can. Ent., iii, 110, 1871; Cin. Quart. Jn. Sci., i, 201, 1874; Bull. Geol. Surv. Terr., iv, 102, 1878; Jn. Cin. Soc. Nat. Hist., ii, 82, 1879 .

syn. xesculisella Chambers, Can. Ent., iii, 112, 1871; Walsingham, Ins. Life, ii, 52, 1889; resculella RiLEY, Smith's List Lep. Bor. Am., 109, 1891.

*6307. obstrictella Clemens, Proc. Acad. Nat. Sci. Phil., 322, 1859; Tin. No. Am., 64, 73, 1872; ChamBers, Can. Ent., iii, 83, 1871; Bull. Geol. Surv. Terr., iv, 102, 1878.

Atl.

States.

Mass.

Atl. States.

Tex.

Pa.

Atl. States.

Pa. 
6308. corylisella Chambers, Can. Ent., iii, 111, 127, 1871 .

Wis., $\mathrm{Ky}$.

syn. comyliella Chambers, Can. Ent., xi, 90, 1879 .

*6309. oregonensis Walsingham, Ins. Life, ii, 117, 1889.

6310. tilieacella Chambers, Can. Ent., iii, 56, 1871.

syn. tilixella Chambers, Cin. Quart. Jn. Sci., ii, 203, 1875; tiliella Walsingham, Ins. Life, iii, 328, 1891.

*6311. symphoricarpella Chambers, Cin. Quart. Jn. Sci., ii, 98,1875 .

*6312. bolliella DYAR.

Oreg.

Ky.

svn. symphoricarpella FREY \& BOLL (not (Hambers), Stett. ent. Zeit., xxxix, 271, 1878.

*6313. fragilella Frey \& Boll, Stett. ent. Zeit., xxxix, 270, 1878; Walsingham, Ins. Life, ii, 51, 1889.

Tex.

syn. trifasciella FreY \& BOLL (not $\mathrm{HA}^{-}$ worth), Stett. ent. Zeit., xxxiv, 215, 1873; Chambers, Cin. Quart. Jn. Sci., i, 205, 1874; Walsingham, Ins. Life, iii, 326, 1891.

*6314. affinis FreY \& Boll, Stett. ent. Zeit., xxxvii, 222, 1876; xxxix, 270, 1878; Walsinghay, Ins. Life, ii, 51, 1889.

6315. mariæella Chambers, Cin. Quart. Jn. Sci., ii, 99, 1875; Can. Ent., xi, 92, 1879; Walsingham, Trans. Am. Ent. Soc., x, 201, 1882.

syn. mariella Riley, Smith's List Lep. Bor. Am.. 109, 1891.

*6316. tritæniella Chambers, Can. Ent., iii, 110, 184, 1871; v, 48, 1873; xi, 89, 1879; WALSINGHAM, Ins. Life, ii, 53, 1889.

svn. consimilelia Frey \& Boll, Stett. ent. Zeit., xxxiv, 217, 1873; Chambers, Cin. Quart. Jn. Sci., ii, 230, 1875; Walsingham, Ins. Life, ii, 51, 1889.

*6317. fasciella Walsingham, Ins. Life, iii, 326, 1891. $\mathrm{Ky}$.

syn. unifasciella CHAmbers (not Tengström), Cin. Quart. Jn. Sci., i1, 103, 1875.

*6318. castaneæella Chambers, Cin. Quart. Jn. Sci., ii, 104. 1875 .

syn. castanella Walsingham, Ins. Life, iii, $329,1891$.

*6319. bostonica Frey \& Boll, Stett. ent. Zeit., xxxiv, 216, 1873; Chambers, Cin. Quart. Jn. Mass. Sc1., i, 206, 1874; i1, 230, 1875. 
*6320. ignota Frey \& Boll, Stett. ent. Zeit., xxxiv, 215, 1873; Chambers, Cin. Quart. Jn. Sci., i, 206,1874 ; ii, $230,1875$.

syn. helianthisella Chambers, Cin. Quart. Jn. Sci., i, 205, 1874; helianthivorella CHaMBers, Cin. Quart. Jn. Sci., ii, 100, 1875.

6321. ambrosiella Chambers, Can. Ent., iii, 127, 1871: Cin. Quart. Jn. Sci., ii, 100, 1875; Frey \& Boll, Stett. ent. Zeit., xxxvii, 221, 1876; xxxix, 267, 1878; Walsingham, Ins. Life, ïi, 54, 1889.

*6322. elephantopodella Frer \& Boll, Stett. ent. Zeit., xxxix, 268, 1878.

6323. verbesinella Busck, Proc. U. S. Nat. Mus., xxiii, $247,1900$.

*6324. actinomeridis Frer \& Boll, Stett. ent. Zeit., xxxix, 268, 1878.

*6325. eppelsheimii Frer \& Boll, Stett. ent. Zeit., xxxix, 272, 1878.

6326. bethuniella Chambers, Can. Ent., iii, 109, 1871; Cin. Quart. Jn. Sci., ii, 103, 1875; Can. Ent., xi, $89,1879$.

*6327. lebertella Frey \& Boll, Stett. ent. Zeit., xxxix, 266,1878 .

*6328. betulivora Walsingham, Ins. Life, iii, 326, 1891.

*6329. bifasciella Chambers, Bull. Geol. Surv. Terr., iv, $101,1878$.

*6330. tubiferella Clemens, Proc. Acad. Nat. Sci. Phil., 208, 1860; Tin. No. Am., 140, 1872; Chambers, Can. Ent., iii, 165, 183, 1871; WalsinghaM, Ins. Life, ii, 24, 77, 1889; iii, 329, 1891.

6331. populiella Chambers, Bull. Geol. Surv. Terr., iv, 101, 1878.

6332. atomariella Zeller, Verh. zool.-bot. Ges. Wien, xxv, 350, 1875; Walsingham, Ins. Life, ii, 54, 1889.

6333. salicifoliella Clemens, Proc. Ent. Soc. Phil., i, 81, 1861; Tin. No. Am., 169, 1872; Packard, Guide Stud. Ins., 353, 1869; Chambers, Can. Ent., iii, 163, 185, 1871; Cin. Quart. Jn. Sci., ii, 302, 1875; Bull. Geol. Surv. Terr., iii, 139, 1877; Walsingham, Ins. Life, ii, 54, 1889.

Ohio, Ky.

Atl. States.

Ky.

Pa.

Mass.

Atl. States. 
6334. hamadryella Clemens, Proc. Acad. Nat. Sci. Phil., 324, 1859; Tin. No. Am., 65, 77, 1872; Chambers, Can. Ent., iii, 55, 164, 182, 1871; Cin. Quart. Jn. Sci., ii, 201, 1875; FreY \& Boll, Stett. ent. Zeit., xxxix, 62, 1878.

syn. alternatella ZelLer, Verh. zool.-bot. Ges.

Wien, xxv, 351, 1875; alternata CHAMBERs, Bull. Geol. Surv. Terr., iv, 153, 1878.

*6335. ostryarella Chambers, Can. Ent., iii, 111, 1871.

*6336. lysimachiæella Chambers, Cin. Quart. Jn. Sci., ii, 100, 1875; Walsingham, Ins. Life, ii, 77, 1889.

Atl. States.

Ky.

$\mathrm{Ky}$ ?

BEDELLIA Stainton.

Stainton, Cat. Brit. Tin., 226, 1849.

6337. somnulentella ZeLLer, Isis, 849, 1847; STAUDinger \& Rebel, Cat. Lep. Eur., ii, no. 4107 , 1901: Chambers, Bull. Geol. Surv. Terr., iv, $131,1878$.

syn. staintonella Clemens, Proc. Acad. Nat. Sci. Phil., 8, 1860; Proc. Ent. Soc. Phil., i, 147, 1862; convolvulella FABRICIUs, sommulatella Riler, Smith's List Lep. Bor. Am., 108, 1891.

6338. minor Busck, Proc. U. S. Nat. Mus., xxiii, 243, 1900 .

\section{CHILOCAMPYLA Busck.}

Busck, Proc. U. S. Nat. Mus., xxiii, 248, 1900.

6339. dyariella Busck, Proc. U. S. Nat. Mus., xxiii, 249, 1900 .

EUCOSMOPHORA Walsingham.

Walsingham, Proc. Zool. Soc. Lond., 148, 1897.

6340. sideroxyloniella Busck, Proc. U. S. Nat. Mus., xxiii, 250, 1900.

Atl. States, Eur.

Fla.

Fla.

Fla.

\section{GRACILARIA Haworth.}

Haworth, Lep. Brit., 527, 1829; Parectopa Clemens, Tin. No. Am., 144, 1872.

6341. aceriella Chambers, Jn. Cin. Soc. Nat. Hist., iii, Mass. 295,1880 .

6342. acerifoliella Chambers, Cin. Quart. Jn. Sci., ii, Col. 299, 1875; Bull. Geol. Surv. Terr., iii, 132, 1877.

6343. alnicolella Chambers, Cin. Quart. Jn. Sci., ii, 299, 1875; Bull. Geol. Surv. Terr., iii, 132, 1877.

Col. 
6344. alnivorella Chambers, Cin. Quart. Jn. Sci., ii, 298, 1875; Bull. Geol. Surv. Terr., iii, 132, 1877; Can. Ent., ix, 15, 1877.

6345. astericola Frey \& Bold, Stett. ent. Zeit., xxxiv, 204, 1873; Chambers, Cin. Quart. Jn. Sc., ii, 200,1875 .

6346. atomosella Zeller, Verh. zool.-bot. Ges. Wien, xxiii, 309, 1873.

*6347. behrensella Chambers, Can. Ent., viii, 32, 1876. 6348. belfrageella Chambers, Can. Ent., vii, 92, 1875.

6349. blandella Clemens, Proc. Ent. Soc. Phil., iii, 505, 1864; Tín. No. Am., 257, 1872; Chambers, Can. Ent., v, 13, 47, 1873.

*6350. bosquella Chambers, Can. Ent., viii, 33, 1876; Bull. Geol. Surv. Terr., iii, 132, 1877.

6351. coroniella Clemens, Proc. Ent. Soc. Phil., ii, 421, 1864; v, 145, 1866; Tin. No. Am., 243, 1872; Walsingham, Trans. Am. Ent. Soc., x, 192, 1882.

6352. violacella Clemens, Proc. Acad. Nat. Sci. Phil., 7, 1860; Tin. No. Am., 93, 1872; Chambers, Can. Ent., iv, 26, 1872; v, 46, 1873; Cin. Quart. Jn. Sci., i, 208, 1874; Zeller, Verh. zool.-bot. Ges. Wien, xxiii, 108, 1873.

syn. desmodifoliella Clemens, Proc. Ent. Soc. Phil., v, 145, 1865; Tin. No. Am., 268, 1872; FreY \& Boll, Stett. ent. Zeit., xxxvii, 212, 1876.

6353. plantaginisella Chambers, Can. Ent., iv, 10, $1872 ; \mathrm{v}, 46,1873$.

syn. geiella Chambers, Cin. Quart. Jn. Sci., i, 200, 1874; erigeronella Chambers, Can. Ent., ix, 127, 1877; Bull. Geol. Surv. Terr., iv, 148,1878 .

6354. elongella Linneus, Faun. Suec., no. 1436, 1761; Staudinger \& Rebel, Cat. Lep. Eur., ii, no. 4056, 1901; Walsingham, Trans. Am. Ent. Soc., $\mathrm{x}, 193,1882$.

syn. signipennella HÜBNER, roscipennella

TreitschKe, inconstans StaInton, straminella Stainton, olongella Riley, Smith's List Lep. Bor. Am., 105, 1891.

6355. falconipennella HüBNER, Schm. Eur., 317, 1827; Staudinger \& Rebel, Cat. Lep. Eur., ii, no. 4050, 1901; Zeller, Linn. Ent., ii, 323, 1846;

Pac. States, Eur.

Atl. States.

Ky.

Verh. zool.-bot. Ges. Wien, xxiii, 307, 1873.

Eur., Tex. 
6356. fasciella Chambers, Cin. Quart. Jn. Sci., ii, 98, 1875; Can. Ent., vii, 93, 1875; ix, 123, 194, 1877; Ky. xi, 118, 1879; Walsingham, Trans, Am. Ent. Soc., $\mathrm{x}, 201,1882$.

syn. quinquenotella Chambers, Can. Ent., ix, 126, 194, 1877.

*6357. fulgidella Clemens, Proc. Acad. Nat. Sci. Phil., 6, 1860; Proc. Ent. Soc. Phil., v, 145, 1865; Tin. No. Am., 92, 1872.

6358. fuscoochrella Beutenuüller, Ent. Am., v, 10, 1889.

6359. juglandiella Chambers, Can. Ent., iv, 28, 88, $1872 ; \mathrm{v}, 15,47,1873$.

syn. juglandisnigrzella Chanbers, Bull. Geol. Surv. Terr., iv, 149, 1878.

6360. negundella Chambers, Can. Ent., viii, 18, 1876; Bull. Geol. Surv. Terr., iii, 132, 1877; Psyche, iii, 66,1880 .

6361. nigristrigella Beutenyüller, Ent. Am., iv, 30, 1888.

syn. muptostrigella Beutenyüller, Ent. Am., iv, $30,1888$.

6362. stigmatella Fabricius, Sp. Ins., ii, 295, 34, 1781; Staudinger \& Rebel, Cat. Lep. Eur., ii, no. 4044, 1901; Chambers, Can. Ent., xi, 74, 119, 1879; xii, 24, 1880.

syn. upupxpennella HüBNER, ochracea $\mathrm{H}_{\mathrm{A}}$ worth, purpuriella Chambers, Can. Ent., iv, 27, 1872; v, 46, 1873; ix, 126, 194, 1877.

6363. rhoifoliella Chambers, Can. Ent., viii, 31, 1876.

6364. lespedezæfoliella Clemens, Proc. Acad. Nat. Sci. Phil., 210, 1860; Tin. No. Am., 144, 1872; ChaмBers, Can. Ent., iv, 7, 1872; v, 47, 1873; viii, 19, 1876; Bull. Geol. Surv. Terr., iii, 132, 1877. syn. robiniella Clemens, Proc. Ent. Soc. Phıl., ii, 4, 1863; Tin. No. Am., 207, 1872; СhaмBERs, Can. Ent., iii, 87, 1871; iv, 7, 1872; v, 47, 1873; viii, 33, 1876; Bull. Geol. Surv. Terr., iii, 132, 1877; Walsingham, Trans. Am. Ent. Soc., x, 193, 1882; mirabilis FrEY \& Bolt, Stett. ent. Zeit., xxxiv, 203, 1873; Chambers, Cin. Quart. Jn. Sci., ii, 227, 1875.

6365. salicifoliella Chambers, Can. Ent., iv, 25, 1872; v, 15, 46, 186, 1873; Cin. Quart. Jn. Sci., i, 340, 1874 .

6366. sauzalitoella Chambers, Can. Ent., viii, 32, 1876.

Atl. States, Eur.

Atl. States.

Atl.

States.

Ky.

Cal. 
6367. sassafrasella Chambers, Can. Ent., viii, 33, 1876.

6368. sanguinella Beutenuüller, Ent. Amer., iv, 30, 1888.

6369. shastaella Beutenyüller, Ent. Amer., iv, 30, 1888.

6370. strigifinitella Clemens, Proc. Acad. Nat. Sci. Phil., 6, 1860; Proc. Ent. Soc. Phil., v, 145, 1865; Tin. No. Am., 92, 269, 1872.

6371. duodecemlineella Chambers, Can. Ent., iv, 11, 1872; ix, 124, 1877.

6372. alchimiella Scopoli, Ent. Carn., no. 661, 1763; Staudinger \& Rebel, Cat. Lep. Eur., ii, no. 4040, 1901; W alsingham. Trans. Am. Ent. Soc., $\mathrm{x}, 191,1882$.

syn. swederella Thunberg, franckella HüвNER, hilaripennella TreitschKe, superbifrontella Clemens, Proc. Acad. Nat. Sci. Phil., 5, 1861; Proc. Ent. Soc. Phil., v, 145, 1865; Tin. No. Am., 91, 269, 1872; FreY \& BolL, Stett. ent. Zeit., xxxiv, 202, 1873; Chambers, Cin. Quart. Jn. Sci., i, 200, 1874; ii, 226, 1875; packardella Chambers, Can. Ent., iv, 27, 1872; ix, 194, 1877; Cin. Quart. Jn. Sci., i, 200, 1874; inornatella Chambers, Can. Ent., viii, 31, 1876; xi, 119, 1879; elegantella Frey \& Boll, Stett. ent. Zeit., xxxiv, 202, 1873; Chambers, Cin. Quart. Jn. Sci., ii, $227,1875$.

*6373. populiella Chambers, Cin. Quart. Jn. Sci., ii, 301, 1875; Bull. Geol. Surv. Terr., iii, 132, 1877.

6374. thermopsella Chambers, Cin. Quart. Jn. Sci., ii, 300, 1875; Bull. Geol. Surv. Terr., iii, 132, 1877; DYar, Proc. U. S. Nat. Mus., xxv, 409, 1902.

6375. venustella Clemens, Proc. Acad. Nat. Sci. Phil., 6, 1860; Proc. Ent. Soc. Phil., ii, 10, 1863; v, 145, 1865; Tin. No. Am., 92, 216, 269, 1872.

syn. eupatoriella Chambers, Can. Ent., iv, 9, $1872 ; \mathrm{v}, 44,46,1873$.

*6376. ribesella Chambers, Bull. Geol. Surv. Terr., iii, $132,1877$.

6377. pulchella Chambers, Can. Ent., vii, 186, 1875.

6378. burgessiella ZelLer, Verh. zool.-bot. Ges. Wien, xxiii, 307,1873 .

*6379. auriferella Frex \& Boll, Stett. ent. Zeit., xxxvii, $211,1876$.
Ky.

Cal.

Cal.

$\mathrm{Pa}$.

$\mathrm{K} y$.

Atl. States, Eur.

Col.

Col.

Atl. States.

Col.

Can.

Mass.

Tex. 
*6380. consimilella FreY \& Boll, Stett. ent. Ziet., xxxvii, 210, 1876.

Tex.

Tex. xxxvii, 211, 1876.

*6382. obscuripennella FreY \& Boll, Stett. ent. Zeit., xxxvii, 209, 1876.

6383. burserella Busck, Proc. U. S. Nat. Mus., xxiii, $251,1900$.

6384. sebastianella Busck, Proc. U. S. Nat. Mus., xxiii, $251,1900$.

6385. pnosmodiella Busck, Proc. U. S. Nat. Mus., xxv, $409,1902$.

*6386. strictella Walker, Cat. Brit. Mus., xxix, 591, 1864.

\section{ORNIX Treitschke.}

Treitschke, Schm. Eur., ix, 2, 192, 1833.

6387. geminatella PACKARD, Guide Stud. Ins., 353, 1869; Chambers, Can. Ent., iii, 183, 1871.

syn. prunivorella Chambers, Can. Ent., v, 50, 1873; Cin. Quart. Jn. Sci., ii, 301, 1875; Bull. Geol. Surv. Terr., iii, 133, 141, 1877; Psyche, iii, 67, 1880; Walsingham, Trans. Am. Ent. Soc., x, 194, 1882.

6388. cratægifoliella Clemens, Proc. Acad. Nat. Sci. Phil., 8, 1860; Tin. No. Am., 94, 1872; ChaмBers, Can. Ent., v, 48, 1873.

*6389. boreasella Clemens, Proc. Ent. Soc. Phil., ii, 415, 1864; Tin. No. Am., 237, 1872.

6390. anglicella Stainton, Trans. Ent. Soc. Lond., (2), i, 92, 1850; Staudinger \& Rebel, Cat. Lep. Eur., ii, no. 4097, 1901; WalsinghaM, Trans. Am. Ent. Soc., x, 193, 1882.

syn. fragariz STAINTON.

*6391. festinella Clemens, Proc. Acad. Nat. Sci. Phil., 97, 1860; Tin. No. Am., 94, 1872.

־6392. inusitatumella Chambers, Can. Ent., v, 47, 1873; viii, 19, 1876.

*6393. quercifoliella Chambers, Cin. Quart. Jn. Sci., ii, 116,1875 .

*6394. trepidella Clemens, Proc. Acad. Nat. Sci. Phil., 7, 1860; Tin. No. Am., 94, 1872.

Atl. States.

Pa.

$\mathrm{Pa}$.

Eur., Atl. States.?

Pa.

$\mathrm{Ky}$.

Mo.

Pa.

*6395. quadripunctella Clemens, Proc. Ent. Soc. Phil., i, 86, 1861; Tin. No. Am., 177, 1872.

Pa.

$4630-$ No. $52-02-36$ 


\section{CORISCIUM Zeller.}

ZELLER, Isis, 210, 1839.

6396. albinatella Chambers, Can. Ent., iv, 25, 1872.

Ky.

syn. albanotella Chambers, Can. Ent., ix, 123, 1877; Cin. Quart. Jn. Sci., i, 200, 1874; Bull. Geol. Surv. Terr., iii, 132, 1877.

6397. paradoxum Frey \& Boll, Stett. ent. Zeit., xxxiv, 205, 1873; xxxvii, 212, 1876; Chambers, Cin. Quart. Jn. Sci., i, 200, 1874.

6398. quniquestrigella Chambers, Can. Ent., vii, 75, 1875; ix, 14, 124, 1877; x, 109, 1878.

6399. randiella Busck, Proc. U. S. Nat. Mus., xxiii, 247,1900 .

6400. rhombiferellum Frey \& Boll, Stett. ent. Zeit., xxxvii, 212, 1876.

6401. cuculipenellum HüBner, Ges. eur. Schmett., viii, Tin., vi, Al. B, f. 2, 1831; Staudinger \& Rebel, Cat. Lep. Eur., ii, no. 4083, 1901; FerNALD, Can. Ent., xxv, 96, 1893.

syn. cinerea Haworth, alautella Duponchel.

\section{LEUCANTHIZA Clemens.}

Clemens, Proc. Acad. Nat. Sci. Phil., 327, 1859.

6402. amphicarpeæfoliella Clemens, Proc. Acad. Nat. Sci. Phil., 327, 1859; Tin. No. Am., 85, 87, 1872; Chambers, Can. Ent., iii, 162, 1871.

syn. saundersella Chambers, Can. Ent., iii,205, 1871; xi, 93, 1879.

\section{MARMARA Clemens.}

Clemens, Proc. Ent. Soc. Phil., ii, 6, 1863.

*6403. salictella Clemens, Proc. Ent. Soc. Phil., ii, 7, 1863; Tin. No. Am., 212, 1872.

Atl.

States.

syn. salicella Chambers, Bull. Geol. Surv. Terr., iv, 156, 1878.

6404. guilandinæ Busck, Proc. U. S. Nat. Mus., xxiii, $234,1900$.

\section{LEUCOPTERA Hübner.}

Hübner, Verz. bek. Schmett., 426, 1816; Walsingham, Proc. Zool. Soc. Lond., 141, 272, 1897; Cemiostoma Zeller, Linn. Ent., iii, 272, 1848.

6405. erythrinella Busck, Proc. U. S. Nat. Mus., xxiii, Fla. $239,1900$.

6406. guettardella Busck, Proc. U. S. Nat. Mus., xxiii, 239, 1900.

Fla. 
PROLEUCOPTERA Busck.

Busck, Jn. N. Y. Ent. Soc., x, 98, 1902.

6407. albella Chambers, Can. Ent., iii, 23, 209, 1871; Ky., Col. Dyar, Proc. U. S. Nat. Mus., xxv, 410, 1902.

6408. smilaciella Busck, Jn. N. Y. Ent. Soc., viii, 244, 1901.

Pa.,

D. C.

\section{PHILONOME Chambers.}

Chambers, Can. Ent., vi, 96, 1874.

*6409. clemensella Chambers, Can. Ent., vi, 97, 1874; viii, 136, 1876; ix, 13, 1877; x, 238, 1878.

Ky.

\section{BUSCKIA Dyar.}

Eurynome Chambers (not Leach), Cin. Quart. Jn. Sci., ii, 304, 1875; Bull. Geol. Surv. Terr., iii, 140, 1877; Jn. Cin. Soc. Nat. Hist., ii, 196, 1879.

*6410. albella Chambers, Bull. Geol. Surv. Terr., iii, Col. $140,1877$.

*6411. luteella Chambers, Cin. Quart. Jn. Sci., ii, 304, Col. 1875; Bull. Geol. Surv. Terr., iii, 140, 1877.

\section{CACONOME Dyar.}

Acanthocnemes Chambers (not Acanthocnemis Hawle \& Corda), Bull. Geol. Surv. Terr., iv, 104, 1878.

*6412. fuscoseapulella Chambers, Bull. Geol. Surv. Terr., iv, 104, 1878.

Tex.

\section{LYONETIA Hibner.}

Hübner, Verz. bek. Schmett., 423, 1816; Clemens, Tin. No. Am., 183, 1872.

*6413. alniella Chambers, Cin. Quart. Jn. Sci., ii, 303,

Col. 1875; Bull. Geol. Surv. Terr., iii, 140, 1877.

*6414. apicistrigella Chambers, Cin. Quart. Jn. Sci., ii, Ky. 105,1875 .

*6415. gracilella Chambers, Can. Ent., viii, 34, 1876.

$\mathrm{Ky}$.

*6416. latistrigella Walsingham, Trans. Am. Ent. Soc., x, 203, 1882 .

*6417. nidificansella PaCkard, Guide Stud. Ins., 354, 1869; Chambers, Can. Ent., xi, 75, 1879.

*6418. speculella Clemens, Proc. Ent. Soc. Phil., i, 134, 1861; Tin. No. Am., 184, 1872.

Atl. States.

Atl.

States.

$\mathrm{Pa}$.

\section{PHYLLOCNISTIS Zeller.}

Zeller, Linn. Ent., iii, 264, 1848.

6419. ampelopsiella Chambers, Can. Ent., iii, 207,1871; Cin. Quart. Jn. Sci., ii, 107, 304, 1875; Jn. Cin. Soc. Nat. Hist., ii, 13, 1880; Bull. Geol. Surv. Terr., iii, 140, 1877 . 
6420. populiella Chambers, Cin. Quart. Jn. Sci., ii, 106, Ky. 303, 1875; Can. Ent., viii, 19, 1876; Bull. Geol. Surv. Terr., iii, 140, 147, 1877.

6421. vitifoliella Chambers, Can. Ent., iii, 206, 1871; vi, 169, 1874; Frey \& Boll, Stett. ent. Zeit., xxxix, 26, 1878; Chambers, Psyche, iii, 67, 1880.

Ky., Wis.

6422. vitigenella Clemens, Proc. Acad. Nat. Sci. Phil., 327, 1859; Tin. No. Am., 22, 39, 83, 1872; ChamBers, Can. Ent., iii, 206, 1871; vi, 169, 1874; Zelcer, Verh. zool.-bot. Ges. Wien, xxiii, 314, 1873; Chambers, Psyche, iii, 67, 1880.

*6423. liriodendrella Clemens, Proc. Ent. Soc. Phil., ii, 13, 1863; Tin. No. Am., 220, 1872; Chambers, Can. Ent., iii, 185, 206, 1871.

*6424. magnoliella Chambers, Psyche, iii, 67, 1880.

*6425. liquidambarisella Chambers, Cin. Quart. Jn. Sci., ii, 106,1875 .

*6426. similiacicella Chambers, Jin. Quart. Jn. Sci., ii, 107,1875 .

6427. intermediella Busck, Proc. U. S. Nat. Mus., xxiii, $253,1900$.

6428. erechtiisella Chanbers, Bull. Geol. Surv. Terr., iv, $104,1878$.

syn. insignis Frey \& Boll, Stett. ent. Zeit., xxxvii, 217, 1876.

*6429. magnatella Zeller, Verh. zool. -bot. Ges. Wien, xxiii, 315, 1873.

\section{METRIOCHROA Busck.}

Busck, Proc. U. S. Nat. Mus., xxiii, 244, 1900.

6430. psychotriatella Busck, Proc. U. S. Nat. Mus., xxiii, 245, 1900.

Fla.

TISCHERIA Zeller.

Zeller, Isis, 219, 1839.

*6431. sulphurea Frey \& Boll, Stett. ent. Zeit., xxxix, 256, 1878; Walsingham, Ins. Life, ii, 324, 1890; iii, 387, 1891 .

6432. clemensella Chambers, Bull. Geol. Surv. Terr., iv, 99, 1878; Walsinghay, Ins. Life, ii, 323, 1890; Ky. $\mathrm{Ky}$. Ky. Fla.

Ky., Tex.

Mass. iii, 388, 1891 .

syn. bicolor Frey \& Boll, Stett. ent. Zeit., xxxix, 255, 1878 . 
*6433. concolor Zeller, Verh. zool. -bot. Ges. Wien, xxv, 352, 1875; Frey \& Boll, Stett. ent. Zeit., xxxix, 255, 1878; Walsingham, Ins. Life, ii, 324, 1890.

*6434. castaneæella Chambers, Cin. Quart. Jn. Sci., ii, 111, 1875; W alsingham, Ins. Life, iii, 388, 1891.

Ky. syn. castanella Walsingham, Ins. Life, iii, 389, 1891.

*6435. citrinipennella Clemens, Proc. Acad. Nat. Sci. Phil., 324, 1859; Tin. No. Am., 39, 80, 82, 1872; Chambers, Can. Ent., iii, 208, 1871; WalsingHaM, Ins. Life, ii, 323, 1889.

syn. quercitella Clemens, Proc. Ent. Soc. Phil., ii, 13, 1863; Chambers, Can. Ent., iii, 208, 1871; Frey \& Boll, Stett. ent. Zeit., xxxiv, 221, 1873; xxxix, 254, 1878; Chambers, Cin. Quart. Jn. Sci., ii, 111, 1875; Zeller, Verh. zool.-bot. Ges. Wien, xxv, 146, 1875; Chambers, Bull. Geol. Surv. Terr., iv, 97, 1878; Psyche, iii, 68, 1880; Walsingham, Ins. Life, ii, 324, 1890; quercivorella Chambers, Cin. Quart. Jn. Sci., ii, 109, 1877; Bull. Geol. Surv. Terr., iv, 97, 1878 .

6436. badiiella Chambers, Cin. Quart. Jn. Sci., ii, 109, 111, 1875; Walsingham, Ins. Life, iii, 387, 1891. syn. bodicella Chambers, Can. Ent., vii, 124, 1875 .

*6437. fuscomarginella Chambers, Cin. Quart. Jn. Sci., ii, 110, 1875; Walsingham, Ins. Life, ii, 324, 1890; iii, 388, 1891.

6438. tinctoriella Chambers, Cin. Quart. Jn. Sci., ii, 108, 1875; Walsingham, Trans. Am. Ent. Soc., x, 202, 1882; Ins. Life, ii, 324, 1890; iii, 386, 1891.

*6439. helianthi Frey \& Bold, Stett. ent. Zeit., xxxix, 258, 1878; Walsingham, Ins. Life, ii, 324, 1890.

6440. solidaginifoliella Clemens, Proc. Acad. Nat. Sci., Phil., 326, 1859; Tin. No. Am., 180, 1872; Chaмbers, Can. Ent., iii, 208, 1871; Frey \& Boll, Stett. ent. Zeit., xxxix, 257, 1878; Walsingham, Ins. Life, ii, 324, 1890.

*6441. purinosella Chambers, Cin. Quart. Jn. Sci., ii, 110,1875 .

syn. pruinosella Chambers, Bull. Geol. Surv. Terr., iv, 97, 1878; Frey \& Boll, Stett. ent. Zeit., xxxix, 257, 1878; WALSINGHAM, Ins. Life, ii, 324, 1890.

Ky.

Ky.

$\mathrm{Ky}$.

Tex.

Pa.

Ky.

Atl. States. 
*6442. pulvella Chambers, Bull. Geol. Surv. Terr., iv, $99,1878$.

*6443. heteroteræ FreY \& Boll, Stett. ent. Zeit., xxxix, 257, 1878.

6444. heliopsisella Chambers, Cin. Quart. Jn. Sci., ii, 113, 1875; Walsingham, Proc. Ent. Soc. Lond., 145, 1897; Ins. Life, ii, 325, 1890.

syn. nolckenii FREY \& Boll, Stett. ent. Zeit., xxxvii, 220, 1876; xxxix, 257, 1878.

*6445. longeciliata Frey \& Boll, Stett. ent. Zeit., xxxix, 259, 1878.

6446. ambrosiæella Chambers, Cin. Quart. Jn. Sci., ii, 112, 1875; Walsinghay, Ins. Life, ii, 325, 1890.

Tex.

Tex.

Ky.,

Tex.

Tex.

Ky.

Cal.

6447. ceanothi Walsingham, Ins. Life, ii, 325, 1890.

6448. malifoliella Clemens, Proc. Acad. Nat. Sci. Phil., 208, 1860; Tin. No. Am., 141, 1872; Chambers, Can. Ent., iii, 208, 1871; v, 50, 1873; vi, 150, 1874; Frey \& Boll, Stett. ent. Zeit., xxxiv, 222, 1873; Chambers, Cin. Quart. Jn. Sci., ii, 111, 1875; Frey \& Boll, Stett. ent. Zeit., xxxix, 254, 1878; Walsingham, Ins. Life, ii, 326, 1890; Chambers, Psyche, iii, 68, 1880.

6449. ænea Frey \& Boll, Stett. ent. Zeit., xxxiv, 222, 1873; Chambers, Cin. Quart. Jn. Sci., i, 210, 1874; Bull. Geol. Surv. Terr., iv, 99, 1878; Frey \& Boll, Stett. ent. Zeit., xxxvii, 220, 1876; xxxix, 254, 1878; WaLsingham, Ins. Life, ii, $326,1890$.

*6450. roseticola FreY \& Boll, Stett. ent. Zeit., xxxiv, 223, 1873; Chambers, Cin. Quart. Jn. Sci., i, 210, 1874; ii, 112, 1875; W ALSINGHAM, Ins. Life, ii, 326,1890 .

COPTOTRICHE Walsingham.

Walsingham, Ins. Life, ii, 322, 1890.

6451. zelleriella Clemens, Proc. Acad. Nat. Sci. Phil., 326, 1859; Tin. No. Am., 81, 1872; Chambers, Can. Ent., iii, 208, 1871; Cin. Quart. Jn. Sci., ii, 109, 1875; Zeller, Verh. zool.-bot. Ges. Wien, xxv, 147, 1875; Chambers, Bull. Geol. Surv. Terr., iv, 98, 1878; Walsingham, Ins. Life, iii, 387, 1891.

syn. complanoides FreY \& Boll, Stett. ent. Zeit., xxxiv, 220, 1873; Chambers, Bull. Geol. Surv. Terr., iv, 99, 1878; zellerella Frey \& Boll, Stett. ent. Zeit., xxxiv, 220, 1873; latipennella Chambers, Bull. Geol. Surv. Terr., iv, 97, 1878.

Atl. States.

Atl. States.

Atl. States. 


\section{PODIASA Busck.}

Busck, Proc. U. S. Nat. Mus., xxiii, 240, 1900.

6452. chiococcella Busck, Proc. U. S. Nat. Mus., xxiii, Fla. 240,1900 .

\section{ARGYRESTHIA Hübner.}

HÜBner, Verz. bek. Schmett., 422, 1816.

6453. abdominalis Zeller, Linn. Ent., ii, 270, 1847; Verh. zool.-bot. Ges. Wien, xxiii, 306, 1873.

Tex.

Col.

*6454. altissimella Chambers, Bull. Geol. Surv. Terr., iii, $130,147,1877$.

6455. andereggiella Duponchel, Hist. Nat., xi, 305, 9, 1838; Staudinger \& Rebel, Cat. Lep. Eur., ii, no. 2423, 1901; Clemens, Proc. Acad. Nat. Sci.

Atl. States, Eur. Phil., 7, 1860; Tin. No. Am., 39, 93, 1872; Chambers, Can. Ent., vi, 10, 1874; vii, 145, 1875; Zeller, Verh. zool.-bot. Ges. Wien, xxv, 304, 1875; Chambers, Bull. Geol. Surv. Terr., iii, $131,141,1877$.

syn. oreasella Clemens, Proc. Acad. Nat. Sci. Phil., 7, 1860.

*6456. apicimaculella Chambers, Can. Ent., vi, 11, 1874.

syn. visaliella Chambers, Can. Ent., vi, 145, 1874.

6457. austerella ZelLer, Verh. zool.-bot. Ges. Wien, xxiii, $305,1873$.

syn. undulatella Chambers, Can. Ent., vi, 10, 1874; vii, 145, 1875; ix, 72, 1877.

6458. goedertella Linnæus, Syst. Nat., 541, 1758; Staudinger \& Rebel, Cat. Lep. Eur., ii, no. 2420, 1901; Chambers, Can. Ent., vii, 144, 1875; viii, 19, 1876; Bull. Geol. Surv. Terr., iii, 131, 141, 147,1877 .

syn. goedastella Chambers, Cin. Quart. Jn. Sci., ii, 294, 1875.

6459. mendica Haworth, Lep. Brit., 517, 1829; Staudinger \& Rebel, Cat. Lep. Eur., ii, no. 2397, 1901; Walsingham, Ins. Life, iii, 118, 1891.

*6460. belangerella Chambers, Can. Ent., vii, 145, 1875 .

*6461. cupressella W alsingham, Ins. Life, iii, 118, 1890.

*6462. freyella Walsingham, Ins. Life, iii, 119, 1890. *6463. deletella Zeller, Verh. zool.-bot. Ges. Wien, $\mathrm{Ky}$.

Tex.

Col.,

Eur.

Eur.,

U. S.?

Can.

Cal.

Tex.

Tex. xxiii, 305, 1873. 
*6464. montella Chambers, Bull. Geol. Surv. Terr., iii, $130,1877$.

*6465. plicipunctella Walsingham, Ins. Life, iii, 119, $1890 ; 386,1891$.

(Unknown.)

*6466. pedmontella Chanbers, Bull. Geol. Surv. Terr., iii, 131, 1877.

6467. pygmæella HüBNER, Schm. Eur., 353, 1827; Staudinger \& Rebel, Cat. Lep. Eur., ii, no. $2419,1901$.

*6468. quadristrigella Zeller, Verh. zool.-bot. Ges. Wien, xxiii, 304, 1873; FreY \& Boll, Stett. ent. Zeit., xxxvii, 209, 1876.

*6469. quercicolella Chambers, Bull. Geol. Surv. Terr., iii, $130,1877$.

*6470. subreticulata Walsingham, Trans. Am. Ent. Soc., x, 173, 1882 .

Col.

Col.

Eur.

Tex.

Col.

Atl. States. ?

\section{ACROLEPIA Curtis.}

Curtis, Brit. Ent., xv, 1838; Argiope Chambers, Can. Ent., v, 13, 1873.

*6471. incertella Chambers, Can. Ent., iv, 43, 1872. Ky.

syn. dorsimaculella Chanbers, Can. Ent., v, 13, 174, 1873; Walsinghay, Trans. Am. Ent. Soc., x, 172, 1882.

EUCATAGMA Busck.

Busck, Jn. N. Y. Ent. Soc., viii, 247, 1901.

6472. amyrisella Busck, Jn. N. Y. Ent. Soc., viii, 247, Fla. 1901.

\section{SCARDIA Treitschke.}

Treitschke, Schm. Eur., viii, 291, 1830; Fernaldia Grote, Bull. Geol. Surv. Terr., vi, $274,1882$.

*6473. tessulatella Zeller, Stett. ent. Zeit., vii, 182, Eur. 1846; Staudinger \& Rebel, Cat. Lep. Eur., ii, no. $4521,1901$.

syn. tessalutella Riley, Smith's List Lep. Bor. Am., 95, 190, 1891.

6474. anatomella Grote, Bull. Geol. Surv. Terr., vi, 274, 1882; Walsingham, Trans. Am. Ent. Soc., $\mathrm{x}, 171,1882$.

EUPLOCAMUS Latreille.

Latreille, Gen. Crust. Ins., iv, 223, 1796.

*6475. fuscofasciella Chambers, Cin. Quart. Jn. Sci., ii, 257,1875 .

Ky. 
XYLESTIA Clemens.

Clemens, Proc. Acad. Nat. Sci. Phil., 256, 1859; Walsingham, Proc. Zool. Soc. Lond., $166,1897$.

6476. pruniramiella Clemens, Proc. Acad. Nat. Sci. Phil., 257, 1859; Tin. No. Am., 39, 54, 59, 1872. Atl. syn. congeminatella ZeLLer, Verh. zool.-bot. Ges. Wien, xxiii, 218, 1873; clemensella Chambers, Can. Ent., v, 174, 1873; ix, 208, 1877 .

\section{INCURVARIA Haworth.}

Haworth, Lep. Brit., 559, 1829.

6477. acerifoliella Fiтch, Rep. Ins. N. Y., i, 269, 1854; Clemens, Proc. Acad. Nat. Sci. Phil., 5, 1860; Tin. No. Am., 90, 1872; Walsingham, Ins. Life, i, 147, 1888.

syn. iridella Chambers, Can. Ent., v, 86, 1873; Walsingham, Trans. Am. Ent. Soc., x, 172, 1882.

6478. ænescens Walsingham, Ins. Life, i, 147, 1888. 6479. humilis Walsingham, Ins. Life, i, 146, 1888.

*6480. labradoriella Clemens, Proc. Ent. Soc. Phil., ii, 416, 1864; Tin. No. Am., 238, 1872; WalsingHAM, Ins. Life, i, 147, 1888.

*6481. mediostriatella Clemens, Proc. Ent. Soc. Phil., v, 147, 1866; Tin. No. Am., 273, 1872.

syn. Alavistrigella Walsingham, Trans. Am. Ent. Soc., x, 189, 1882; Ins. Life, i, 147, 1888; auristrigella Chambers, Can. Ent., v, 86, 1873; ix, 207, 1877 .

6482. politella Walsingham, Ins. Life, i, 146, 1888.

6483. punctiferella Walsingham, Ins. Life, i, 145, 1888.

*6484. russatella Clemens, Proc. Acad. Nat. Sci. Phil., 5, 1860; Tin. No. Am., 89, 1872.

syn. tripunctella Walsingham, Proc. Zool. Soc. Lond., 92, 1880; Trans. Am. Ent. Soc., $\mathrm{x}, 172,1882$.

6485. solenobiella Walsingham, Proc. Zool. Soc. Lond. 82, 1880; Ins. Life, i, 146, 1888.

*6486. oregonella Walsinghan, Proc. Zool. Soc. Lond., 91, 1880; Trans. Am. Ent. Soc., x, 172, 1882.

Atl. States.

Oreg.

Cal.

Lab.

Atl. States.

Oreg.

Oreg., Cal.

Atl. States.

Cal.

Oreg. 
TINEOLA Herrich-Schaeffer.

Herrich-Schaeffer, Syst. Bearb. Schmett. Eur., v, 23, 1853.

6487. bisselliella Hummel, Ess. Ent., iii, 13, 1829; Staudinger \& Rebel, Cat. Lep. Eur., ii, no. 4624, 1901; Packard, Am. Nat., i, 423, 1867; Zeller, Verh. zool.-bot. Ges. Wien, xxiii, 223, 1873; Fernald, Can. Ent., xiv, 169, 1882; Walsingham, Trans. Am. Ent. Soc., x, 82, 171, 1882.

syn. crinella Treitschke, destructor Stephens, biselliella ZeLler, Linn. Ent., vi, 166, 1852; Zanariella Clemens, Proc. Acad. Nat. Sci. Phil., 251, 258, 1859.

\section{MONOPIS Hübner.}

HüBner, Verz. bek. Schmett., 401, 1816.

6488. ferruginella HÜBNER, Schm. Eur., 348, 1827; Staudinger \& Rebel, Cat. Lep. Eur., ii, no. $4533,1901$.

syn. crocicapitella Clemens, Proc. Acad. Nat. Sci. Phil., 257, 1859; Walsingham, Trans. Am. Ent. Soc., x, 170, 1882.

6489. rusticella HüBner, Schm. Eur., 339, 1827; StaUDinger \& Rebel, Cat. Lep. Eur., ii, no. 4537, 1901; Zeller, Verh. zool.-bot. Ges. Wien, xxiii, $220,1873$.

syn. vestianella Stephens; Riley, Am. Ent. \& Bot., ii, 90, 1870; Rep. Ins. Mo., iii, 10, 1870.

6490. monachella HüBNER, Schm. Eur., 143, 1827; Staudinger \& Rebel, Cat. Lep. Eur., ii, no. $4536,1901$.

Eur.,

U. S.

Atl. States, Eur.

Eur., U. S.

Eur., Can.

TINEA Linnæus.

Linneus, Syst. Nat., 534, 1758.

6491. acapnopennella Clemens, Proc. Acad. Nat. Sci. Phil., 257, 1859; Tin. No. Am., 233, 1872.

Atl.

syn. auropulvella Chambers, Can. Ent., v, 90, 1873; vii, 125, 1875; viii, 19, 1876; acapuspenella Riley, Smith's List Lep. Bor. Am., 95, 1891.

*6492. apimaculella Chambers, Cin. Quart. Jn. Sci., ii, 257,1875 .

States.

*6493. aurosuffusella Chambers, Can. Ent., v, 87, 1873.

Ky.

*6494. behrensella (hambers, Cin. Quart. Jn. Sci., ii, 249,1875 .

Ky.

Cal. 
*6495. biflavimaculella Clemens, Proc. Acad. Nat. Sci. Phil., 257, 1859; Tin. No. Am., 50, 237, 1872; Atl. Proc. Ent. Soc. Phil., ii, 413, 1864; Zeller, Verh. zool.-bot. Ges. Wien, xxiii, 220, 1873; W alsingham, Trans. Am. Ent. Soc., x, 170, 1882. syn. insignisella WaLker, Cat. Brit. Mus., xxviii, 471, 1863.

6496. bimaculella Chambers, Can. Ent., v, 87, 1873.

*6497. carnariella Clemens, Proc. Acad. Nat. Sci. Phil., 256, 1859; Tin. No. Am., 51, 1872; Chambers, Bull. Geol. Surv. Terr., iv, 166, 1878.

*6498. costosignella Clemens, Proc. Ent. Soc. Phil., ii, 128, 1863; Tin. No. Am., 235, 1872.

*6499. costostrigella Chambers, Can. Ent., v, 87, 1873. *6500. croceoverticella Chambers, Can. Ent., viii, 106, 1876.

*6501. defectella Zeller, Verh. zool.-bot. Ges. Wien, xxiii, 220, 1873.

6502. dorsistrigella Clemens, Proc. Acad. Nat. Sci. Phil., 257, 1859; Tin. No. Am., 50, 1872; ZELLER, Verh. zool.-bot. Ges. Wien, xxiii, 220, 1873; xxv, 342, 1875.

syn. subjunctella Walker, Cat. Brit. Mus., xxvii, 471, 1863; Walsingham, Trans. Am. Ent. Soc., x, 170, 1882.

6503. fuscipunctella Haworth, Lep. Brit., 562, 1829; Staudinger \& Rebel, Cat. Lep. Eur., ii, no. $4583,1901$.

syn. spretella Zeller, nubilipennella Clemens, Proc. Acad. Nat. Sci. Phil., 257, 1859; Tin. No. Am., 58, 1872; friqidella PACKARD, Proc. Bost. Soc. Nat. Hist., xi, 61, 1867; Walsingham, Trans. Am. Ent. Soc., x, $171,1882$.

*6504. fuscomaculella Chambers, Can. Ent., v, 90, 1873. 6505. fuscopulvella Chambers, Can. Ent., v, 90, 1873.

6506. granella Linnæus, Syst. Nat., 537, 1758; STAUDINGER \& Rebel, Cat. Lep. Eur., ii, no. 4555, 1901: Packard, Guide Stud. Ins., 347, 1869; Chambers, Bull. Geol. Surv. Terr., iv, 164, 1878; Walsingham, Trans. Am. Ent. Soc., x, $171,1882$.

syn. variatella Clemens, Proc. Acad. Nat. Sci. Phil., 257, 1859; Chambers, Can. Ent., vii, 126,1875 .

Eur., Lab.

Ky.

Ky.

Eur., Atl. States. 
6507. grumella Zecler, Verh. zool.-bot. Ges. Wien, xxiii, $221,1873$.

*6508. imitatorella Chambers, Can. Ent., viii, 105, 1876. $\mathrm{Ky}$.

*6509. maculabella Chambers, Can. Ent., v, 90, 1873. Ky.

6510. marginimaculella Chambers, Can. Ent., vii, 212, 1875.

Mass.

syn. maculimarginella Chambers, Bull. Geol. Surv. Terr., iv, 164, 1878.

*6511. marginistrigella Chambers, Can. Ent., v, 88, 1873.

$\mathrm{Ky}$.

6512. marmorella Chambers, Can. Ent., vii, 212, 1875.

Can.

6513. minutipulvella Chambers, Can. Ent., vii, 212, 1875 .

Can.

6514. misella Zeller, Isis, 184, 1839; Staudinger \& Reber, Cat. Lep. Eur., ii, no. 4580, 1901; Zeller, Verh. zool.-bot. Ges. Wien, xxiii, 223, 1873.

*6515. misceella Chambers, Can. Ent., v, 86, 1873.

$\mathrm{K}_{y}$.

*6516. niveocapitella Chambers, Cin. Quart. Jn. Sci., ii, 249,1775 .

Can.

Tex.,

Eur.

*6517. obscurostrigella Chambers, Can. Ent., vi, 232, 1874.

6518. oregonella Busck, Jn. N. Y. Ent. Soc., viii, 246, 1900.

*6519. orleansella Chambers, Can. Ent., v, 85, 1873.

Cal.

Tex.

Oreg.

La.

6520. pellionella Linneus, Syst. Nat., 536, 1758; Staudinger \& Rebel, Cat. Lep. Eur., ii, no. 4584, 1901; Walsingham, Trans. Am. Ent. Soc., x, 170, 1882; Fernald, Can. Ent., xiv, 169, 1882.

syn. flavescentella HawORTH, merdella ZELLER, dubiella Stanton, grisseella Chambers, Can. Ent., v, 88, 1873.

6521. seminolella Beutenmüller, Ent. Amer., v, 9, 1889.

*6522. septemstrigella Chambers, Bull. Geol. Surv. Terr., iv, 79, 1878.

*6523. thoracestrigella Chambers, Can. Ent., viii, 106, 1876.

*6524. tricingulatella Clemens, Proc. Ent. Soc. Phil., ii, 128, 1863; Tin. No. Am., 234, 1872.

Fla.

Tex.

Ky. ?

$\mathrm{Pa}$.

*6525. trimaculella Chambers, Can. Ent., v, 88, 1873.

Ky. 
*6526. unomaculella Chambers, Cin. Quart. Jn. Sci., ii, Tex. 258,1875 .

6527. cloacella Haworth, Lep. Brit., 563, 1829; StaUDinger \& Rebel, Cat. Lep. Eur., ii, no. 4556 , 1901.

*6528. straminella Chambers, Can. Ent., v, 86, 1873.

*6529. martinella WALKer, Cat. Brit. Mus., xxviii, $472,1863$.

*6530. afflictella W ALKer, Cat. Brit. Mus., xxx, 1002, 1864.

6531. arcella Fabricius, Gen. Ins., 295, 1777; STAUDinger \& Rebel, Cat. Lep. Eur., ii, no. 4543, 1901.

TRICHOPHAGA Ragonot.

Ragonot, Ann. Soc. Ent. Fr., lxiii, 123, 1894.

6532. tapetzella Linneus, Syst. Nat., 536, 1758; STAUDInger \& Rebel, Cat. Lep. Eur., ii, no. 4539, 1901: Clemens, Tin. No. Am., 258, 1872; ChamBers, Bull. Geol. Surv. Terr., iv, 164, 1878; Fernald, Can. Ent., xiv, 169, 1882.

a. occidentella Chambers. Jn. Cin. Soc. Nat. Sci ii, $193,1879$.

AMADRYA Clemens.

Clemens, Proc. Acad. Nat. Sci. Phil., 260, 1859.

*6533. clemensella Chambers, Can. Ent., vi, 232, 1874; Cin. Quart. Jn. Sci., ii, 256, 1875.

*6534. effrenatella Clemens, Proc. Acad. Nat. Sci. Phil., 260, 1859; Tin. No. Am., 55, 1872; Zeller, Verh. zool.-bot. Ges. Wien, xxiii, 219, 1873;

Eur., U.S.

Eur., U. S.?

Ky.

Can.

Can.

Eur., U. S.? Chambers, Cin. Quart. Jn. Sci., il, 256, 1875.

CYANE Chambers.

Chambers, Can. Ent., v, 112, 1873.

*6535. visaliella Chambers, Can. Ent., v, 113, 1873.

Ky.

PHRYGANEOPSIS Walsingham.

Walsingham, Proc. Zool. Soc. Lond., 301, 1881.

*6536. brunnea Walsingham, Proc. Zool. Soc. Lond., Cal. $302,1881$.

DIACHORISIA Clemens.

Clemens, Proc. Acad. Nat. Sci. Phil., 12, 1860.

*6537. velatella Clemens, Proc. Acad. Nat. Sci. Phil., 13, 1860; Tin. No. Am., 107, 1872.

Pa. 


\section{EUDARCIA Clemens.}

Clemens, Proc. Acad. Nat. Sci. Phil., 10, 1860.

6538. simulatricella Clemens, Proc. Acad. Nat. Sci. Phil., 11, 1860; Tin. No. Am., 102, 1872; WALsinghay, Trans. Am. Ent. Soc., x, 171, 1882.

syn. comentarizella Chambers, Can. Ent., v, 85, 1873; viii, 105, 1876.

TENAGA Clemens.

Clemens, Proe. Ent. Soc. Phil., i, 135, 1862.

*6539. pomiliella Clemens, Proc. Ent. Soc. Phil., i, 136, 1862; Tin. No. Am., 186, 1872.

\section{HYBROMA Clemens.}

Clemens, Proc. Ent. Soc. Phil., i, 137, 1862.

*6540. servulella Clemens, Proc. Ent. Soc. Phil., i, 137, 1862; Tin. No. Am., 187, 1872.

\section{PITYS Chambers.}

\section{Chambers, Can. Ent., v, 110, 1873.}

*6541. fasciella Chambers, Can. Ent. v 111 1873; ix, $207,1877$.

*6542. auricristatella Chambers, Can. Ent., v, 110, 1873.

*6543. fuscocristatella Chambers, Can. Ent., v, 111, 1873.

$\mathrm{Pa}$.

*6544. miscecristatella Chambers, Can. Ent., v, 111. 1873.

Ky.

Ky.

Ky.

Ky.

OENOE Chambers.

Chambers, Can. Ent., vi, 50, 1874.

*6545. hybromella Chambers, Can. Ent., vi, 51, 1874; Jn. Cin. Soc. Nat. Hist., ii, 186, 1879.

Ky.

\section{SEMELE Chambers.}

Chambers, Cin. Quart. Jn. Sci., ii, 243, 1875.

*6546. argentistrigella Chambers, Can. Ent.. v, 89, 1873; viii, $105,1876$.

*6547. argentinotella Chambers, Can. Ent., viii, 104, 1876.

*6548. cristatella Chambers, Cin. Quart. Jn. Sci., ii, 243, 1875; Can. Ent., ix, 208, 1877.

Ky.

Ky.

Ky.

syn. bifasciella Chambers, Can. Ent., viii, 105, 1876; ix, 208, 1877. 
SETOMORPHA Zeller.

Zeller, Micr. Caffr., 93, 1853.

*6549. operosella Zeller, Verh. zool.-bot. Ges. Wien, Mass.? xxiii, $223,1873$.

*6550. inamœnella Zeller, Verh. zool.-bot. Ges. Wien, Mass.? xxiii, 224, 1873.

*6551. ruderella Zeller, Verh. zool.-bot. Ges. Wien, Mass. ? xxiii, $225,1873$.

ADELA Latreille.

Latreille, Gen. Crust. Ins., iv, 224, 1796; Clemens, Tin. No. Am., 249, 1872.

6552. æruginosella W alsinghà, Ins. Life, ii, 285, 1890.

La.

6553. bella Chambers, Can. Ent., v, 73, 1873; ix, 207, 1877; xi, 125, 1879; Walsingham, Ins. Life, ii, 285,1890 .

syn. chalybeis Zeller, Verh. zool.-bot. Ges. Wien, xxiii, 226, 1873; W alsingham, Proe. Zool. Soc. Lond., 79, 1880; iochroa ZELLER, Hor. Soc. Ent. Ross., xiii, 218, 1877.

*6554. bellella Walker, Cat. Brit. Mus., xxviii, 561, 1863; Walsinghan, Proc. Zool. Soc. Lond., 79, 1880; Ins. Life, ii, 284, 1890.

6555. flammeusella Chambers, Can. Ent., viii, 104, 1876; Walsingham, Proc. Zool. Soc. Lond., 79, 1880 .

syn. flamensella Walsinghay, Ins. Life, ii, 284, 1890; lactimaculella WaLsinghaM, Proc. Zool. Soc. Lond., 80, 1880.

6556. punctiferella Walsingham, Ins. Life, ii. 284, 1890.

6557. purpura WaLker, Cat. Brit. Mus., xxviii, 501, 1863; Walsingham, Proc. Zool. Soc. Lond., 79, 1880; Ins. Life, ii, 285, 1890.

syn. biviella ZeLLer, Verh. zool.-bot. Ges. Wien, xxiii, 226, 1873; Chambers, Can. Ent., ix, 206, 1877; xi, 125, 1879.

6558. ridingsella Clemens, Proc. Ent. Soc. Phil., ii, 426, 1864; Tin. No. Am., 250, 1872; Packard, Guide Stud. Ins., 348, 1869; W alsingham, Ins. Life, ii, 285, 1890.

syn. schlaegeri Zeller, Verh. zool.-bot. Ges. Wien, xxiii, 227, 1873; Walsinghay, Trans. Am. Ent. Soc., x, 173, 1882; corruscifasciella Chambers, Can. Ent., v, 74, 1873; ix, 207, 1877; xi, 125, 1879; Walsingham, Proc. Zool. Soc. Lond., 79, 1880.

Atl.

States.

Can.

Cal.

Cal.

No. Atl. States. 
6559. septentrionella Walsingham, Proc. Zool. Soc. Lond., 79, 1880.

Oreg., Cal.

6560. simpliciella W alsingham, Proc. Zool. Soc. Lond., 81, 1880; Ins. Life, ii, 284, 1890.

Oreg.

Cal.

6561. singulella Walsingham, Proc. Zool. Soc. Lond., 80, 1880; Ins. Life, ii, 285, 1890.

*6562. trifasciella Chambers, Can. Ent., viii, 103, 1876. Cal.

6563. trigrapha ZeLLer, Verh. zool.-bot. Ges. Wien, xxv, 342, 1875; Walsingham, Proc. Zool. Soc. Lond., 79, 1880.

syn. fasciella Chambers, Can. Ent., viii, 103, 1876.

PRODOXUS Riley.

Riley, Am. Ent., iii, 155, 1880.

6564. quinquepunctella Chambers, Can. Ent., vii, 7 , 1875; Riley, Am. Ent., iii, 141, 1880.

syn. decipiens Rilex, Amer. Ent., iii, 155, 1880; Proc. Am. Ass. Adv. Sci., 1880, 617, 1881; Am. Nat., xvi, 62, 1882; Ins. Life, iv, 371, 1892; paradoxica Chambers, Jn. Cin. Soc. Nat. Hist., i, 149, 1878.

6565. intermedius Riley, Proc. Am. Ass. Adv. Sci., $1880,617,1881$.

6566. marginatus Riley, Proc. Am. Ass. Adv. Sci., 1880, 617, 1881; Ins. Life, iv, 373, 1892.

6567. y-inversa Riley, Proc. Ent. Soc. Wash., ii, 316 , 1892; Ins. Life, iv, 373, 1892.

6568. reticulata Riley, Proc. Ent. Soc. Wash., ii, 316; 1892; Ins. Life, iv, 374, 1892.

So. Atl. States.

Tex.

Cal.

Cal.

Col.

6569. coloradensis RrLey, Proc. Ent. Soc. Wash., ii, 316, 1892; Ins. Life, iv, 374, 1892.

Col.

a. lautus Cockerell, Psyche, viii, 142, 1897.

b. confluens Cockerell, Psyche, viii, 142, 1897.

6570. pulverulentus Riley, Proc. Ent. Soc. Wash., ii, $315,1892$.

6571. sordidus Riley, Proc. Ent. Soc. Wash., ii, 319 1892.

6572. cinereus Riley, Proc. Am. Assoc. Adv. Sci., 1880, $617,1881$.

Cal.

Cal.

Cal.

6573. ænescens Riley, Proc. Am. Assoc. Adv. Sci., 1880, 617,1881 . 
PRONUBA Riley.

Riley, Fifth Rept. Ins. Mo., 150, 1873; Ins. Life, iv, 360, 1892.

6.77. yuccasella Riley, Fifth Rept. Ins. Mo.,150,1873;

Chambers, Bull. Geol. Surv. Terr., iv, 161, 1878;

So.

Riley, Nature, vi, 444, 1872; Trans. Acad. Nat.

Atl.

Sci. St. Louis, iii, 55, 1873; Bolt, Stett. ent.

Zeit., xxxvii, 401, 1876; Rrley, Am. Ent., iii,

182, 293, 1880; Can. Ent., xii, 263, 1880; Proc.

Am. Assoc. Adv. Sci., 1880, 617, 1881; Ins. Life, iv, 360,1892 .

syn. alba Zeller, Verh. zool.-bot. Ges. Wien, xxiii, 232, 1873; xxv, 340, 1885; HAGEN, Can. Ent., xii, 129, 1880.

6575. maculata Riley, Proc. Am. Assoc. Adv. Sci., 1880, 617, 1881; Proc. Ent. Soc. Wash., ii, 315, 1892; States.

Ins. Life, iv, 368, 1892.

a. apicella DYAR (spots pulverulent, confluent apically, the subbasal ones obsolete).

6576. paradoxa Riley, Proc. Ent. Soc. Wash., i, 154, 1889.

syn. synthetica Riley, Proc. Ent. Soc. Wash., ii, 312, 1892.

NEOLOPHUS Walsingham.

Walsingham, Trans. Ent. Soc. Lond., 141, 1887.

6577. furcatus W Alsinghay, Trans. Ent. Soc. Lond., 141, 1887.

6578. persimplex Dyar, Can. Ent., xxxii, 327, 1900.

Cal.,

Col.

Cal.

\section{EULEPISTE Walsingham.}

Walsingham, Trans. Am. Ent. Soc., x, 169, 1882; Trans. Ent. Soc. Lond., 142, 1887.

6579. cressoni Walsingham, Trans. Am. Ent. Soc., x, Tex. 169, 1882; Trans. Ent. Soc. Lond., 142, 1887.

6580. maculifer Walsingham, Trans. Ent. Soc. Lond., $143,1887$.

6581. cockerelli Dyar, Can. Ent., xxxii, 307, 1900.

Ariz.

Ariz.

HYPOCOLPUS Walsingham.

Walsingham, Trans. Ent. Soc. Lond., 144, 1887.

6582. griseus W Alsingham, Trans. Ent. Soc. Lond., 144, 1887.

D. C., Tex., Ariz.

$4630-$ No. $52-02--37$ 
6583. mortipennellus Grote, Can. Ent., iv, 137, 1872; xviii, 199, 1886; Walsingham, Trans. Am. Ent. So. Soc.. x, 167, 1882; Trans. Ent. Soc. Lond., 150, 1887 .

syn. quadripunctellus Dyar, Can. Ent., xxxii, 307,1900 .

\section{ACROLOPHUS Poey.}

Poex, Cent. Lep. Cuba, 1832; Walsingham, Trans. Ent. Soe. Lond., 147, 1887.

6584. plumifrontellus Clemens, Proc. Acad. Nat. Sci. Phil., 261, 1859; Tin. No. Am., 57, 1872; ZeLLER, Verh. zool.-bot. Ges. Wien, xxiii, 218. 1873; Walsingham, Proc. Zool. Soc. Lond., 513, 1891; Beutenmüller, Ent. Amer., v, 9, 1889.

syn. bombycina ZelLer, Verh. zool.-bot. Ges. Wien, xxiii, 216, 1873; Chanbers, Bull. Geol. Surv. Terr., iv, 79, 1878; WaLsingHaM, Trans. Ent. Soc. Lond., 149, 1887.

6585. cervinus Walsinghay, Trans. Ent. Soc. Lond., 151, 1887; Dyar, Can. Ent., xxxii, 308, 1900. Atl. States.

syn. anqustipennellus BEutenMüLLER, Ent. Amer., iii, 140, 1887.

6586. texanellus Chambers, Bull. Geol. Surv. Terr., iv, 79, 1878; Walsinghan, Trans. Ent. Soc. Lond., 152, 1887.

6587. hulstellus Beutenyüller, Ent. Amer., iii, 139, 1887.

6588. arizonellus Walsingham, Trans. Ent. Soc. Lond., 153, 1887; Dyar, Can. Ent., xxxii, 309, 1900.

Fla.,

Tex.

N. C.,

Tex.

Fla.

Ariz., N. Mex.

6589. simulatus Walsinghay, Trans. Am. Ent. Soc., x, 168, 1882; Trans. Ent. Soc. Lond., 148, 1887.

Tex., Ariz.

\section{ATOPOCERA Walsingham.}

Walsingham, Proc. Zool. Soc. Lond., 169, 1897.

6590. barnesii Dyar, Can. Ent., xxxii, 326, 1900.

Tex.

\section{ANAPHORA Clemens.}

Clemens, Proc. Acad. Nat. Sci. Phil., 260, 1859; Zeller, Verh. zool.-bot. Ges. Wien, xxiii, 214, 1873; Walsingham, Trans. Ent. Soc. Lond., 155, 1887.

6591. propinqua Walsinghà, Trans. Ent. Soc. Lond., $157,1887$.

Fla.

6592. confusellus Dyar, Can. Ent., xxxii, 309, 1900.

So. Atl.

States.

*6593. morrisoni Walsingham, Trans. Ent. Soc. Lond., 157, 1887.

Fla. 
6594. popeanella Clemens, Proc. Acad. Nat. Sci. Phil., 261, 1859; Tin. No. Am., 57, 1872; Walsingнам, Trans. Ent. Soc. Lond., 161, 1887; Proc. Zool. Soc. Lond., 515, 1891; 172, 1897; СнамBers, Can. Ent., iv, 137, 143, 1872; Zeller, Verh. zool.-bot. Ges. Wien, xxiii, 215, 1873.

syn. agrotipennella Grote, Can. Ent., iv, 137, 1872; Murtenedt, Can. Ent., viii, 185, 1876; scardina Zeller, Verh. zool.-bot. Ges. Wien, xxiii, 215, 1873.

6595. tenuis Walsinghay, Trans. Ent. Soc. Lond., $164,1887$.

syn. violaceellus Beutenuüller, Ent. Amer., iii, 139, 1887; Dyar, Can. Ent., xxxiı, 309, 326,1900 .

6596. macrogaster Walsinghà, Trans. Ent. Soc. Lond., 165, 1887.

ORTHOLOPHUS Walsingham.

Walsingham, Trans. Ent. Soc. Lond., 169, 1887.

6597. piger Dyar, Can. Ent., xxxii, 327, 1900.

6598. variabilis Walsingham, Trans. Ent. Soc. Lond., 169, 1887; Dyar, Can. Ent., xxxii, 310, 1900.

Atl. States, Rocky Mts.

So. Atl. States.

Ariz.

Tex.

Rocky Mts., Ariz.

FELDERIA Walsingham.

Walsingham, Trans. Ent. Soc. Lond., 165, 1887. 6599. filicicornis Walsinghà, Trans. Ent. Soc. Lond., $167,1887$.

syn. mexicanellus BeutenvüLLer, Ent. Amer., iv, 29, 1888; filicomis DYAR, Can. Ent., xxxii, $310,1900$.

6600. dorsimacula Dyar, Can. Ent., xxxii, 328, 1900.

PSEUDANAPHORA Walsingham.

Walsingham, Trans. Ent. Soc. Lond., 170, 1887.

6601. davisellus Beutenmüller, Ent. Amer., iii, 139, 1887.

a. minor DYAR (smaller, the pale marks grayer and more contrasted).

6602. arcanella Clemens, Proc. Acad. Nat. Sci. Phil., 262, 1859; Walsingham, Trans. Ent. Soc. Lond., 170, 1887; Dyar, Can. Ent., xxxii, 310, 1900.

6603. mora Grote, Bull. U. S. Geol. Surv. Terr., vi, 257, 1882; Dyar, Can. Ent., xxvii, 15, 1895; xxxii, 310, 1900; Merrick, Proc. Ent. Soc. Wash., v, 40, 1902 .
Ariz., Mex.

Tex., Ariz.

Ariz., Tex.

Atl. States.

Atl. States. 


\section{Superfamily MICROPTERYGOIDEA.}

Family HEPIALID A.

(C. = Neumoegen \& Dyar, Jn. N. Y. Ent. Soc., ii, 166-170, 1894

STHENOPIS Packard.

Packard, Proc. Ent. Soc. Phil., iii, 390, 1864; Neumoegen \& Dyar, C. 166. 6604. argenteomaculatus Harris, Rept. Ins. Mass., 295, No. Atl. 1841; Neumoegen \& Dyar, C. 166. States.

syn. argentata PACKARD, alni Kellicott.

a. purpurascens PACKARD, Bost. Jn. Nat. Hist., vii, 598, 1863.

b. los Strecker, Proc. Acad. Nat. Sci. Phil., 282, 1893.

c. perdita Dyar, Can. Ent., xxy, 327, 1893.

6605. quadriguttatus Grote, Proc. Ent. Soc. Phil., iii, 73, 1864; Neunoegen \& Dyar, C. 167.

No. Atl. States.

syn. semiauratus Neumoegen \& Dyar.

6606. thule Strecker, Lep. Rhop. Het., 105, pl. 12 , f. 6,$1875 ;$ Neumoegen \& Dyar, C. 167.

Can., Wis.

*6607. auratus Grote, Can. Ent., x, 18, 1878; NeUMOEGEN \& DYAR, C. 167.

N. Y., N. H.

\section{HEPIALUS Faoricius.}

Fabricius, Syst. Ent., 589, 1775; Neumoegen \& Dyar, C. 167.

6608. hyperboreus Möschler, Wien. ent. Mon., vi, No. U. S. 129, 1862; Neumoegen \& Dyar, C. 168.

syn. pulcher Grote, meglashani Hy. Edwards.

a. matthewi Hy. Edwards, Proc. Cal. Acad. Sci., v, 265, 1874 .

b. confusus Hy. Edwards, Pap., iv, 122, 1884.

syn, roseicaput NeUMOEGEN \& Dyar.

6609. mustelina Packard, Proc. Ent. Soc. Phil., iii, 393, 1864; Neumoegen \& Dyar, C. 168.

syn. labradorensis PACKARD.

6610. gracilis Grote, Proc. Ent. Soc. Phil., iii, 522, 1864; Neumoegen \& Dyar, C. 168. syn. furcatus Grote.

6611. lembertii Dyar, Ent. News, v, 25, 1894; NEUMOEGEN \& DYAR, C. 168.

6612. sequoiolus Behrens, Can. Ent., viii, 174, 1876; Neumoegen \& DYar, C. 168.

No. Atl.

No. Atl.

States.

States.

Cal.

Pac.

States,

syn. mendocinolus Behrens, 
6613. behrensii Stretch, Zyg. Bomb. No. Am., 105, 1872; Neumoegen \& Dyar, C. 168.

Pac,

States.

syn. tacomix Hy. Edwards.

6614. montanus Stretch, Zyg. Bomb. No. Am., 105, 1872; Neunoegen \& Dyar, C. 170.

Pac. States.

syn. desolatus Strecker, baroni Behrens, anceps Hy. Edwards, rectus Hy. Edwards.

6615. hectoides Boisduval, Ann. Soc. Ent. Belg., xii, 85, 1868; Neumoegen \& Dyar, C. 170.

Cal.

Ariz.

syn. modestus Hy. EDwards, imutilis Hy. EDWARDS.

a. lenzi Behrens, Can. Ent., viii, 175, 1876.

syn. sangaris STRECKER.

*6616. californicus Boisduval, Ann. Soc. Ent. Belg., xii, 85, 1868; Neumoegen \& Dyar, C. 170.

Family MICROPTERYGIDA.

ERIOCEPHALA Curtis.

Cuntis, Brit. Ent., xvi, 1839.

*6617. luteiceps WaLker, Cat. Brit. Mus., xxviii, 494, 1863; Walsinghay, Proc. Zool. Soc. Lond., 83, 1880 .

6618. auricyanea Walsinghay, Trans. Am. Ent. Soc., x, 204, 1882 .

*6619. griseocapitella Walsingham, Ent. Rec., x, 161, 1898.

*6620. aurosparsella Walsinghay, Proc. Zool. Soc. Lond., 83, 1880.

Atl. States.

Atl. States.

Atl. States.

Pac. States.

EPIMARTYRIA Walsingham.

Walsingham, Ent. Rec., x, 161, 1898.

*6621. pardella Walsingham, Proc. Zool. Soc. Lond., 83,1880 .

Pac. States.

*6622. auricrinella W alsingham, Ent. Rec., x, 161, 1898. Atl. States. 



\section{INDEX TO SPECIFIC, GENERIC, AND FAMILY NAMES.}

[Specific names are written in italies; generic and family names in broad-faced type.]

aaroni Skinner, 569.

abacta Hulst, 3385 .

Abagrotis

abalinealis Walker, 3068.

abar Strecker, 1727.

Abbotana.

abbotana Hübner, 4089 (Phobetron).

abbotii Edwards, 5 (Iphidicles).

abbotii Grote, 4062 (Oiketicus).

abbotii Swainson, 668 (Sphecodina).

abbreviata Walker, 3726.

abbreviatana Walker, 5124.

abbreviatella Grote, 2889.

abdominalis Zeller, 6453 (Argyresthia).

abdominalis Grote, 915 (Pygarctia).

abdominalis Zeller, 4473.1 (Pyrausta).

abdominalis Grote, 2664 (Tarache). abdominella Busck, 5728.

abella Busck, 5775.

aberrata Hy. Edwards, 3891.

abietella Schiffermüller, 4711.

abietisella Packard, 5596.

abietivorella Grote, 4711.

abjectarius Hulst, 3815 .

abnormalis Hulst, 3969.

abnormis Smith, 1527.

abortivaria Herrich-Schaeffer, 3232.

abrasaria Herrich-Schaeffer, 3450.

abraxaria Walker, 3862.

abronalis Walker, 4623.

abronixella Chambers, 6097.

abrostella Walker, 2547.

Abrostola ........................

abrostoloides Guenée, 2545.

abrota Druce, 2497.

abrupta Grote, 970.

abruptana Zeller, 5126.

abruptata Walker, 3647.

abscondens Oberthur, 845.
Page.

absconditella Walker, 5585.

absidum Harvey, 2292.

absinthiata Clerck, 3294.

absorptalis Walker, 3031.

abstrusellus Walker, 4598.

348

absynthiata Guenée, 3294

acaciella Busck, 5648.

acadica Edwards, 38 (Pontia).

acadica Edwards, 339 (Thecla).

acadiensis Bethune, 1929.

Acallis . . . . . . . . . . . . . . .

acanootus Scudder, 555.

Acanthocnemes............... . .

acanthodactyla Hübner, 4939.

Acanthophora ....................

acapnopennella Clemens, 6491.

acapuspenella Riley, 6491.

acastus Edwards, 162.

acauda Oberthur, 24.

accepta Hy. Edwards, 2699.

accessaria Hübner, 3759.

accessoriella Frey \& Boll, 6227.

accius Smith \& Abbot, 538.

acclivis Morrison, 1529.

accordella Walsingham, 5989.

accurata Hy. Edwards, 2531.

acera Smith, 1270.

acerana Hübner, 5359.

acerba Hy. Edwards, 2697.

acericola Guenée, 972 (Apatela).

acericolum Germar, 4221 (Sesia).

aceriella Clemens, 5777 (Gelechia).

aceriella Chambers, 6341 (Gracila-

ria).

aceriella Clemens, 6305 (Lithocol-

letes).

aceriella Clemens, 5189 (Thiodia). acerifoliella Chambers, 6342 (Graci-

laria).

acerifoliella Fitch, 6477 (Tischeria). acerni Clemens, 4221.

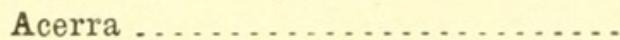

acestealis Walker, 4304.

achaia Grote \& Robinson, 881.

Page. 
Achatia

achatina Smith \& Abbot, 319: (Olene).

achatina Zeller, 4552 (Prionapteryx).

achatinalis Zeller, 3069.

achatinata Hübner, 3349.

Achatodes ....................

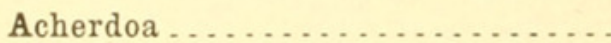

achemon Drury, 679.

acheronta Fabricius, 252.

achillx Hy. Edwards, 4245.

Achlarus .....................

achor Strecker, 1591.

Achroia

Achylodes

acidaliaria Walker, 3860.

acidaliata Packard, 3464.

Aciptilia . . . . . . . . . . . .

Aciptilus . . . . . . . . . . . . .

acis Drury, 364.

Acleris .

acmon Doubleday \& Hewitson, 434.

Acoloithus .....................

Acopa .....................

acornis Smith, 1611.

acrza Drury, 851.

acrionalis Walker, 4450.

Acrobasis

Acrocaula

Acrolepia

Acrolophus

acronyctoides Walker, 960.

actinomeridis Frey \& Boll, 6324.

Actinotia

actualis Hulst, 4714

aculeilellus Walker, 4557.

acuphisalis Walker, 4450.

acutana Eversmann, 5007.

acutaria Herrich-Schaeffer, 2571.

acutella Walker, 4409.

acutifrons Smith, 1731.

acutilinea Grote, 2341.

acutipenella Walsingham, 5991.

acutipennis Grote, 1850 (Mames-

tra).

acutipennis Hulst, 3315 (Tephro-

clystis)

acutissima Grote, 1271.

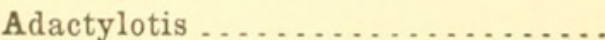

adamantana Guenée, 5145.

adaptella Walker, 5778.

Page.

113

addenda Smith, 2051.

Adela

575

adelina Staudinger, 201.

Adelocephala 75

Adelphagrotis

174

Ææa

xdessa Druce, 2434.

xdon Grote, 1258.

Edophron .

xgaria Strecker, 3687.

Egeria . . . . . . . . . . . . . . . xglxella Ragonot, 4833.

xgleatis Walker, 4419.

xgrana Walsingham, 5474.

xgrotalis Zeller, 4344.

xgrotata Hy. Edwards, 2749 (Cissura).

rgrotata Guenée, 4020 (Sabulodes). shaja Behr, 409.

stiaria Walker, 3986.

xmilea Skinner, 598.

Emilia . . . . . . . . . . . . . . . .
108 
xmula Hübner, 3009.

xmulata Hulst, 3509.

xmulataria Walker, 3667.

xmusella Riley, 5990.

anea Frey \& Boll, 6449.

xneella Hulst, 4788.

reneipennis Grote, 1548.

rneoviridella Ragonot, 4789.

senescens Walsingham, 6478 (Incur-

varia).

xnescens Riley, 6573 (Prodoxus).

xneusella Chambers, 5990.

ænigmatella Frey \& Boll, 6262.

æno Scudder, 295.

ænus Edwards, 464.

xnusella Chambers, 5990.

xqualiaria Grote, 3767 (Caripeta). xquatiaria Walker, 3910 (Therina). xqualis Walker, 4136 (Dysodia). xqualis Harvey, 1567 (Paragrotis). xquepulvella Chambers, 5674.

æquiferaria Walker, 3675.

xquilinea Smith, 2261.

xquosus Grote \& Robinson, 4005. ærata Lyman, 2180 (Papaipema). xrata Fabricius, 3578 (Synchlora). ærea Hübner, 2474.

xreoides Grote, 2475.

æria Grote, 2616.

xriferella Clemens, 6281.

æruginosa Guenée, 2983.

xruginosella Walsingham, 6552.

xsculana Riley, 5219.

xsculella Riley, 6306.

xsculi Linnæus, 4141.

xsculisella Chambers, 6306.

xsella Chambers, 6117.

xsionaria Walker, 3934.

xstiva Harris, 39.

\section{Ethalodes.}

Ethaloptera

xtheria Grote, 2635.

xthra Strecker, 653.

Ethyctera

Ætia

xtna Scudder, 519.

affinis Grote, 906 (Ammalo).

affinis Edwards, 379 (Callophrys). affinis Frey \& Boll, 6314 (Litho-

colletes).

affinis Goeze, 699 (Phlegethontius). afflicta Grote, 1018.

afflictana Walker, 5373.
Page.

affictella Hulst, 4757 (Salebria). afflictella Walker, 6530 (Tinea). affusana Zeller, 5139.

afia Edwards, 419.

afranius Lintner, 623.

Agapema . . . . . . . . . . . . . . 72

Agapetidæ................. $\quad 27$

agarista Cramer, 3006.

Agaristidæ ................... . . 96

agarithe Boisduval, 55.

Agassizia . . . . . . . . . . . . . .

agassizii Robinson, 5082 (Eucosma). agassizii Packard, 922 (Halisidota).

Agathodes .................. agema Strecker, 1580.

Agia . . . . . . . . . . . . . . . . . agilana Clemens, 5053.

agilis Grote, 1547.

agitatellus Clemens, 4575.

aglaella Hulst, 4833.

aglaia Edwards, 119.

Aglais . . . . . . . . . . . . . . .

agliata Guenée, 4010.

Aglossa ... . . . . . . . . . . . . .

agnella Clemens, 6234.

Agnippe . . . . . . . . . . . . . . . . 497

Agnomonia . . . . . . . . . . . . . . 233

agraphodactylus Walker, 4974.

Agraulis . . . . . . . . . . . . .

agreasaria Walker, 3944.

agrestis Grote, 1519.

Agriades . . . . . . . . . . . . . . .

agricola Boisduval, 508 (Anthomaster).

agricola Grote, 2754 (Drasteria).

agricolana Walsingham, 5092.

agrimoniella Clemens, 5711.

Agriopis .

agrippina Strecker, 2808.

agrotiformis Grote, 2002.

agrotipennella Grote, 6594.

agrotipennis Harvey, 2774.

Agrotiphila . . . . . . . . . . . .

Agrotis . . . . . . . . . . . . . . . . 133

ahaton Harris, 523.

aholah Strecker, 2897.

aholibah strecker, 2860.

ahrensiana Geyer, 5076.

ajax Linnæus, 5.

akalus Strecker, 2005.

Alabama

alabamie Grote, 1468 (Peridroma). 
alabastaria Hübner, 3486. alacella Clemens, 5659.

Alaria

Alarodia ..................

alaskix Grote, 1763 (Agrotiphila). alaskix Hulst, 3423 (Conocalpe). alaskensis Holland, 123 (Brenthis). alaskensis Holland, 274 (Erebia). alaskensis Holland, 292 (Eneis).

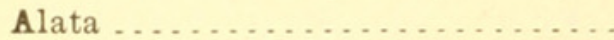
alatella Hulst, 4678.

alautella Duponchel, 6401. alba Grote, 771 (Anisota). alba Strecker, 85 (Eurema). alba Strecker, 70 (Eurymus), alba Edwards, 639 (Hesperia). alba Zeller, 6574 (Pronuba). albacilixella Chambers, 5652. albacostella Chambers, 5992. albafascia Smith, 2352.

albalineella Chambers, 6136. albatis Robinson, 4492 (Nymphula).

albalis Grote, 1525 (Rhizagrotis). albana Fabricius, 4623.

albangulana Walsingham, 5120 .

albaniana Walker, 5393.

albanotella Chambers, 6396 (Coriscium ).

albanotella Chambers, 6263 (Lithocolletes) .

albanus Felder, 9.

albapalpella Chambers, 5502 (Eido). albapalpella Chambers, 6076 (Elachista).

albapennella Chambers, 6104.

albapulvella Chambers, 5843.

albaria Grote, 3592.

albarufa Grote, 1022.

albata Packard, 817 (Clemensia). albata Hulst, 3414 (Hydriomena). albavena Ottolengui, 2441.

albavitta Ottolengui, 2500 .

albella Chambers, 6174 (A phigalia). albella Chambers, 6249 (Bucculatrix).

albella Chambers, 6410 (Busckia). albella Chambers, 5841 (Ide).

albella Chambers, 6148 (Mompha). albella Chambers, 6407 (Proleucoptera).

albellus Clemens, 4577 (Crambus). albeolana Zeller, 5035.
Page.

186 356

albiceralis Grote, 4362.

albiciliana Fernald, 5054.

albiciliata Walsingham, 4953.

albicilla Herrich-Schaeffer, 574.

albicollis Oberthur, 845.

albicoma Hulst, 4191 (Bembecia).

albicoma Strecker, 3164 (Harpyia).

albicomana Clemens, 5400.

albicomis $\mathrm{Hy}$. Edwards, 4217.

albicosta Smith, 1530 (Rhizagrotis).

albicosta Hübner, 3125 (Symmerista).

albicostella Beutenmüller, 5896 (Ethmia).

albicostellus Fernald, 4545 (Schoenobius).

albida Walker, 817 (Clemensia). albida Strecker, 852 (Estigmene). albida Smith, 2136 (Euharveya). albida Walsingham, 4946 (Platyptilia).

albidana Walker, 5462.

albidella Hulst, 4913.

albidentina Walker, 2299.

albidorsella Walsingham, 4947 (Platyptilia).

albidorsella Walsingham, 5507 ( Plutella).

albidula Hulst, 3502 (Cinglis). albidula Guenée, 2601 (Eustrotia). albidula Hulst, 3999 (Stenaspilates). albifascia French, 848.

albifascialis Boisduval, 4276.

albifasciata Packard, 3369.

albifera Walker, 3336.

albifrons Smith \& Abbot, 3125.

albifusa Walker, 1801.

albifusata Walker, 3605.

albiginarium Walker, 3838.

albiguttana Zeller, 5090.

albilinea Hübner, 1963.

albilineata Walsingham, 6105.

albilineellus Fernald, 4595. 
albilorella Zeller, 5725.

albilunata Smith, 2159.

albimaculana Fernald, 5273.

albimacularia Freyer, 3390.

albimarginella Chambers, 5624.

albina Poey, 88 (Eurema).

albina Grote, 1236 (Hadena).

albinatella Chambers, 6396.

albinella Cramer, 4540.

albinic Skinner, 66.

albipenella Hulst, 4846.

albipennis Grote, 1708.

albiplaga Aaron, 174 (Cinclidia).

albiplaga Walker, 3141 (Heterocampa).

albiplagiatella Packard, 4792.

albipuncta Smith, 1089.

albipunctata Packard, 4100.

albiscentellum Ragonot, 4869.

albisignatis Zeller, 3072.

albisinuatella Packard, 4597.

albisparsella Chambers, 5750 .

albistriana Wood, 5309.

albistrigella Walsingham, 5897 (Ethmia).

albistrigella Chambers, 5779 (Gelechia).

albocapitella Hulst, 4685 (Acrobasis).

albocapitella Chambers, 6164 (Mompha).

alboclavellus Zeller, 4574.

albocostaliata Packard, 3484.

albocostalis Walker, 4807 (Etiella). albocostalis Hulst, 4794 (Pima).

albocostella Hulst, 4902.

albofascia Hy. Edwards, 3167.

albofasciata Grote, 3332 (Euchøeca). albofasciata Bethune, 2994 (Homoptera).

albofasciatum Zeller, 5021 (Exartema).

albofasciatus Hewitson, 580 (Eudamus).

albogallierella Clemens, 6228.

albogilvaria Morrison, 3336.

alboguttata Grote, 1838.

albolabes Grote, 1121.

albolineata Grote \& Robinson, 4263 (Glaphyria).

albolineata Packard, 3382 (Mesoleuca).
Page.

albolineata Packard, 3578 (Synchlora).

albomacularia Hy. Edwards, 3998.

albomaculata Stoll, 949.

albomaculella Chambers, 5721.

albomarginella Chambers, 5624.

albopalpella Riley, 5502 (Eido).

albopalpella Chambers, 6149 (Mom-

pha).

alboplagiata Smith, 2271.

albopunctalla Walker, 1095. .

albopunctata Morrison, 3764 (Caripeta).

albopunctata Tepper, 3080 (Hypena).

albosigma Fitch, 3096.

albosignata Packard, 3439.

albovenosa Geoze, 1049.

albovitella Hulst, 4718.

albovittata Guenée, 3332.

album Harvey, 2291.

Albuna . . . . . . . . . . . . . . . .

alcxus Hewitson, 583.

alce Edwards, 444.

alcestis Edwards, 100 (Argynnis).

alcestis Edwards, 338 (Thecla).

alchemillaria Esper, 3458 (Petrophora).

alchemillaria Freyer, 3361 (Rheumaptera).

alchemillata Schiffermüller, 3361.

alchimiella Scopoli, 6372.

alcidamus Cramer, 11.

alcina Skinner, 524.

alciphearia Walker, 3970.

Alcis .

alcmeone Cramer, 53.

alconalis Walker, 4325.

alcoolaria Guenée, 3930.

Alcothoe... . . . . . . . . . . . . . .

Aleptina................... 107

alethe Neumoegen \& Dyar, 3097.

aleucis Harvey, 2327.

aleutianella Beutenmüller, 5498.

alexandra Edwards, 70.

alexandrixella Chambers, 5.565.

Alexicles .................. . .

alferata Strecker, 2139.

alfkenii Grote, 1125.

algens Grote, 1146.

algidana Möschler, 5415.

algidata Möschler, 3455 . 
algidella Walker, 5839.

alia Guenée, 2040.

alias Ottolengui, 2501.

aliaska Scudder, 16.

alicia Edwards, 247.

aliculella Hulst, 4768.

alienaria Herrich-Schaeffer, 3934.

alinda Druce, 766.1.

alisellana Robinson, 5428.

alitalis Hulst, 4322.

alko Strecker, 1641.

allectalis Grote, 4355.

allecto Smith, 1198.

allediusaria Walker, 4011.

allenella Walsingham, 5894.

alleni Fernald, 4625 (Diatræa).

alleni Grote, 2784 (Syneda).

alleniana Fernald, 5394.

allionealis Walker, 4491.

Allotria

allusa Hulst, 2855.

allutana Zeller, 5207.

alma Strecker, 177.

Almodes.

Alni $H_{y}$. Edwards, $922\left(H_{1}\right.$ lisiata). alni Walsingham, 627 (Lithocollealni Walsingham, 6274 (Lithocolletes).

alni Kellicott, 6604 (Sthenopis).

alniaria Packard, 3923.

alnicolella Chambers, 6343 (Gracilaria).

alnicolellaWalsingham, 6273 (Lithocolletes).

alniella Zeller, 6264 (Lithocolletes). alniella Chambers, 6413 (Lyonetia). alnivorella Chambers, 6344 (Gracilaria).

alnivorella Chambers, 6274 (Lithocolletes).

alope Fabricius, 258 (Cercyonis). alope Drury, 688 (Dilophonota).

alpheus Edwards, 611.

alpicola Scopoli, 900.

alpina Quensel, 870.

alpinana Treitschke, 5290.

alpinata Packard, 3259.

also Möschler, 295.

Alsophila...................

altensis Wocke, 4725 .

altera Ottolengui, 2503.

alterna Strecker, 2517.

alternaria Grote, 3602 .
Page.

alternata Grote \& Robinson, 463 (Amblyscirtes).

alternata Chambers, 6334 (Lithocolletes).

alternata Walker, 3370 (Perenoptilota).

alternata Grote, 1397 (Rhynchagrotis).

alternatella Zeller, 6334.

alternosquamella Ragonot, 4721.

alticola Smith, 1229 (Hadena).

alticola Hulst, 3808 (Meris).

alticola Smith, 1704 (Paragrotis).

alticola Walker, 2535 (Syngrapha).

altissimella Chambers, 6454.

Altoona ......................

altua Smith, 1832.

Alucita................... 444, 448

alunata Skinner \& Aaron, 22.

alurina Smith, 2041.

alutalis Grote, 3046.

alvinalis Guenée, 4306.

Alypia ..................... $\quad 97$

Alypiodes .................. $\quad 97$

amabilis Möschler, 4297.1.

amadis Herrich-Schaeffer, 527.

Amadrya ....................

amanda Smith, 2096.

amaryllis Smith, 2412 (Heliopha-

na).

amaryllis Fabrieus, 31 (Tachyris). amasia Smith \& Abbot, 2894.

amatalis Walker, 4341.

amatana Dyar, 5422.

amatella Hulst, 4716.

amatrix Hubner, 2828.

amaturaria Walker, 3469.

Ambesa .......................

ambigua Strecker, 933.

ambigualis Walker, 3055.

ambisimilis Dyar, 3217.

amblygona Zeller, 5251.

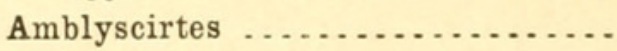

ambrosiæ Murtfeldt, 4990.

ambrosixella Chambers, 5780.

ambrosixfoliella Chambers, 6233 .

ambrosiella Chambers, 6321 (Jithocolletes).

ambrosiella Chambers, 6446 (Tischeria).

amelaina Dyar, 866.

amelanchierella Clemens, 6183. 
amella Guenée, 2957.

Ameria........................ ameriana Linnæus, 5359.

americalis Guenée, 3008.

americana Fernald, 5324 (Acleris). americana Walsingham, 5276 (Ancylis).

americana Harris, 972 (Apatela). americana Harris, 904 (Aretia). americana Harris, 3223 (Epicnaptera).

americana Speyer, 2162 (Gortyna). americana Harris, 4129 (Harrisina). americana D'Urban, 399 (Heodes). americana Harris, 3214 (Malacosoma).

americana Harris, 3094 (Melalopha).

americana Smith, 1883 (Neuronia). americana Herrich-Schaeffer, 3226 (Oreta).

americana Morrison, 2226 (Orthosia).

americana Harvey, 3115 (Ptilodon).

americana Beutenmüller, 4218 (Sesia).

americella Walsingham, 6119.

americus Kollar, 19.

Amestria

amestris Strecker, 2883.

amethystaria Strecker, 3959.

amica Hübner, 2907 (Catocala).

amica Edwards, 410 (Cupido).

amicaria Herrich-Schaeffer, 3934.

amicula Hy. Edwards, 2592.

amiculatalis Berg, 4414.

Amilapis .

amissa Lefebre, 1939.

amisus Hewitson, 579.

\section{Ammalo}

ammon Lucas, 448.

ammoni Behr, 10.

Amœba ................... . .

amøena Frey \& Boll, 6285 (Lithocolletes).

amcena Hy. Edwards, 4162 (Melittia).

amønaria Guenée, 3961.

amœenata Stephens, 3380.

Amolita . . . . . . . . . . . . . . . . amorata Packard, 4043 (Callizzia).
Page.

267

amorata Hulst, 3410 (Hydriomena).

Amorbia . . . . . . . . . . . . . . . . .

amorphx Frey \& Boll, 6268 (Lithocolletes).

amorphx Hy. Edwards, 60 (Zerene).

amorr $^{7}$ sella Chambers, 5781 (Gelechia).

amorphæella Chambers, 6268 (Lithocolletes).

amorphella Clemens, 6179.

Ampelophaga . . . . . . . . . . . . .

ampelophaga Boisduval, 678 (Pholus).

ampelopsiella Chambers, 6120 (Antispila).

ampelopsiella Chambers,

6419

(Phyllocnistis).

ampelos Edwards, 280.

amphicarpæella Chambers, 6269.

amphicarpexana Chambers, 5532.

amphicarpexfoliella Clemens, 6402.

Amphichlora ................ . . $\quad 25$

Amphidasis . . . . . . . . . . . . . 328

Amphidasys . . . . . . . . . . . . . . 328

amphidusa Boisduval, 65.

Amphion .................. . .

amphipyroides Guenée, 3005.

amphorana Walsingham, 5184.

ampla Walker, 2517 (Autographa). ampla Grote, 3198 (Doa).

ampla Dietz, 5936 (Ploiophora).

amplaria Walker, 3864.

amplexella Ragonot, 4700.

ampliata Ménétries, 22.

amplissima Walker, 2921.

321

amplus Hy. Edwards, 2419.

amputatrix Fitch, 1235.

amygdalina Harvey, 1976.

amymone Ménétries, 203.

Amyna . . . . . . . . . . . . . .

amyntas Fabricius, 576.

amyntor Hübner, 721.

amyntula Boisduval, 441.

amyrisaria Walker, 4007.

amyrisella Busck, 5872 (Depressaria).

amyrisella Busck, 6472 (Eucatagma).

Anæa..................... 27 


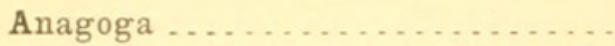

Anaitis

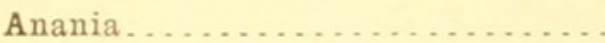

ananius Plotz, 600.

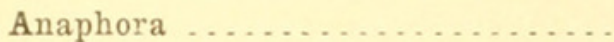

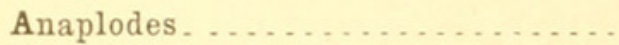

Anarsia .....................

anarsiella Chambers, 5745 .

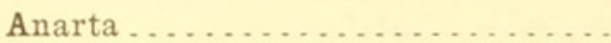

anartalis Grote, 4367.

Anartia .................... . .

anatomella Grote, 6474.

ancellata Walker, 3500.

anceps Grote, 4588 (Crambus).

anceps Hy. Edwards, 6614 (Hepia-

lus).

ancetaria Hübner, 4001.

anchocelioides Guenée, 1393.

Anchocelis . . . . . . . . . . . . . . . .

ancillaria Strecker, 3685.

ancocisconensis Morrison, 1278.

Ancylis

Ancyloxypha ................ andereggiella Duponchel, 6455.

andremona Cramer, 2912

Andrewsia . . . . . . . . . . . . .

andria Scudder, 254.

Androloma ..................

andromacha Hy. Fdwards, 2879

(Catocala).

andromacha Hübner, 286 (Éno-

dia).

andromeda Boisduval, 715 (Sphinx) . andromedx Guenée, 2776 (Hypo-

gramma).

androphila Guenée, 2907.

Andropolia .

Anepischetos.

Anerastinx

anfracta Hy. Edwards, 4051.

anfractata Hulst, 4022.

anfugella Dietz, 5941.

angelica Grote, 3091 (Apatelodes).

angetica Smith, 1071 (Copibry-

ophila).

angelica Smith, 2415 (Heliodes).

angelica Smith, 2186 (Papaipema).

angelicus Smith, 2066 (Cobaliodes).

angelina Boisduval, 47.

anglicella Stainton, 6390.

angrezi Bailey, 4144.

anguilineata Grote, 3235.
Page.

333

267

374

578

302

509

159

\section{angustipennellus Beutenmüller,} 6585 (Acrolophus.)

angustipennis Warren, 4534 (Acallis).

angustipennis Möschler, 1305 (Magusa).

angustipennis Grote, 2660 (Therasea).

angustus Walsingham, 4970.

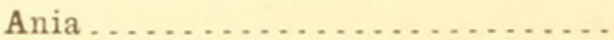

anicia Doubleday \& Hewitson, 151

(Lemonias).

anicia Scudder, 159 (Lemonias).

anilis Drury, 2922.
Fmith \& Abbot, 3127

(Dasylophia).

anguina Grote, 1845 (Mamestra).

anguinella Clemens, 6184.

angulalis Hübner, 3058.

Perigonica)

myulatalis Lederer, 4500.

angulifera Walker, 745 (Callosamia).

yalifera Walker, 922 (Halesi-

dota).

angulifera Walker, 754 (Thauma). anguliferellum Ragonot, 4872.

angulosa Smith \& Abbot, 3121.

angusi Grote, 2822 (Catocala).

\& Robinson. 3100

4879

angustana Clemens, 5440.

culatrix).

ngustata Haworth, 3370 (Percnoptilota).

angustellus Blanchard, 4781.

angustioratr Walker, 3765 (Caripeta).

ingustiorata Grote, 1089.1 (Platysenta).

ingustipennella Clemens, 5782 (Gelechia)

angustipennella Dietz, 5944 (Pigritia). gulatana Robinson, 5445 . 
animalis Guenée, 4275.

animosa Hy. Edwards, 4249.

\section{Anisopteryx}

\section{Anisota}

aniusaria Walker, 3690 .

anna Grote, 880 (Apantesis).

anna Grote, 2883 (Catocala).

anna Dyar, 4160 (Hypopta).

Annaphila .

annaphilatis Grote, 4366.

annellata Hulst, 3427.

Annemoria

annetta Mead, 436.

annexa Hy. Edwards, 2761 (Euclidia).

annexa Treitschke, 1550 (Feltia).

annida Fager, 2873.

annir Strecker, 1636.

annisaria Walker, 3690 .

annonæ Shaw, 684.

annosata Zetterstedt, 3373.

annulalis Grote, 3078.

annulata Hulst, 3285.

annulatella Zetterstedt, 4725.

annulifascia Walker, 923.

annulimacula Smith, 2020.

annulipes Smith, 1674.

annulosella Ragonot, 4753.

annulosum Swainson, 664.

anodonta Guenée, 2205.

\section{Anomis}

Anoristia

anormalis Guenée, 4306.

Anorthodes

Anorthosia

Anosia

antrgon Boisduval, 434.

antæus Drury, 684.

\section{Antaplaga .}

antaurata Walker, 3738

anteliella Busck, 5546.

antennata Smith, 1177 (Hadena).

antennata Walker, 2090 (Xylina).

Antepione ................ . .

anteroclara Smith, 1982.

Anthanassa.

Anthelia

anthocicoides Grote \& Robinson, 4528.

Anthomaster

anthyale Hübner, 66.
Page.

antiacis Boisduval, 418.

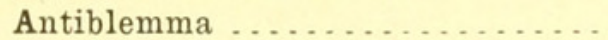

$2: 36$
267

75 -antibubastus Hübner, 447.

antica Walker, 905 (Ammalo).

antica Walker, 914 (Euchætias).

antica Smith, 1945 (Trichoclea).

anticalis Walker, 4807.

anticaria Walker, 3859 (Athaloptera).

anticaria Walker, 3323 (Chlorochlamys).

anticaria Walker, 3551 (Eois).

Anticarsia . . . . . . . . . . . . . . .

anticostalis Grote, 4294

anticostiata Strecker, 3462.

anticostiensis Grote, 3180 (Euthyatira).

anticostiensis Strecker, 21 (Papilio). antidiscaria Walker, 3949.

antigone Strecker, 854.

antilochus Linnæus, 11.

antinympha Hübner, 2884.

antiope Linnæus, 217.

antiphola Walsh, 919.

antipoda Strecker, 2138.

antiqua Linnæus, 3187.

Antispila . . . . . . . . . . . . . . . .

antonia Edwards, 245.

Anydraula . . . . . . . . . . . . . . . . 396

Anytus......................... . . 149

Aon .......................... 195

aonides Strecker, 3158.

apache Poling, 2911.

apacheana Walsingham, 5199.

Apæcasia . . . . . . . . . . . . . 317

apama Edwards, 381.

Apamea .................... 113

apamiformis Grote, 1221.

Apantesis .................... 88

Apatela .................... . . 99

Apatelodes .................. . $\quad 249$

Apatura. . . . . . . . . . . . . . . . 17

apera Druce, 4054.

apertalis Walker, 4351.

Aphanaula ................. . . 500

Apharetra . . . . . . . . . . . . . 105

Aphigalia ................. . . . 544

Aphomia ................. 413

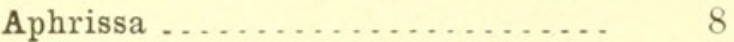

aphrodite Fabricius, 100.

aphroditella Chambers, 5653.

aphyla Hampson, 4051.1. 
apiata Grote, 2254

apicalis Guenée, 2925 (Grammodes).

apicalis Walker, 3092 (Melalopha). apicalis Grote, 1532 (Rhizagrotis). apicalis Grote \& Robinson, 3152 (Schizura).

apicana Walker, 5256. • apicella Grote, 2699 (Fruva). apicella Dyar, 6575 (Pronuba). apicialbella Chambers, 6185. apiciaria Packard, 3943.

apicilineella Chambers, 5699. apicimaculella Chambers, 6456. apicipunctella Chambers, 5902. apicistrigella Chambers, 5699 ( Aproærema).

apicistrigella Chambers, 6414 (Lyonetia).

apicitripunctella Clemens, 5596.

apicosa Harvey, 2612.

apiella Hubner, 5887.

apiforme Linnæus, 4188.

apimaculella Chambers, 6492.

aplastella Hulst, 4653.

aplicalis Guenée, 4301.

Aplocera

Aplodes

Apocheima

Apochima

Apolema

Aporophila

Apostraphia

appassionata Harvey, 2191.

appendiceum Zeller, 5018.

applana Fabricius, 5862.

applanella Fischer v. Röslerstamm, 5862.

apposita Grote, 1416 (Adelphagrotis). apposita Smith, 2076 (Pleroma). approximaria Packard, 3587 (Aplodes).

approximaria Haworth, 3625 (Deilinia).

approximaria Packard, 3816 (Exelis).

approximaria Dyar, 3933 (Plagodis).

approximaria Hubner, 3805 (Stenotrachelys).

approximata Strecker, 878 (Apantesis).
Page.

approximata Strecker, 168 (Lemonias).

approximata Strecker, 2382 (Schinia).

approximella Walker, 4911.

aprica Hubner, 2674.

apriliana Grote, 5208.

Aproærema ..................

aptalis Lederer, 4491.

aqualis Grote, 1347.

aquamarina Felder, 2756.

aquilellus Clemens, 4546.

aquilo Boisduval, 425.

aquilonaris Lintner, 3164.

ar Strecker, 2380.

arabus Edwards, 534.

arachne Edwards, 183.

Arachnis ................ . .

aracinthusalis Walker, 3058.

Aræolepia ..................

arapahoe Reakirt, 406.

araxes Hewitson, 458.

arbeloides Dyar, 4150.

arburaria Walker, 4007.

arbustorum Stephens, 4580.

arcanella Clemens, 6602.

arcasaria Walker, 4014.

arcella Fabricius, 6531.

archasialis Walker, 4302.

archesilea Felder, 199.

archippus Cramer, 239 (Basilarchia). archippus Fabricius, 308 (Anosia).

Archips ..................

Archonias

arcifera Guenée, 2354.

arctaria Herrich-Schæffer, 3390.

arctata Zeller, 3390.

Arctia . . . . . . . . . . . . . . .

arctica Möschler, 2507 (Autographa).

arctica Ottolengui, 2513 (Autographa).

arctica Zetterstedt, 137 (Brenthis). arctica Boisduval, 1235 (Hadena). arctica Zetterstedt, 1417 (Platagrotis).

arctica Beutenmüller, 4204 (Sesia). arcticana Möschler, 5356.

arcticaria Walker, 3513 (Leptomeris) .

arcticaria Germar, 3456 (Petrophora). 
Page.

Arctiidæ

Arctomycis

Arctonotus

arctostaphylella Walsingham, 5898 arcuata Walker, 3229 (Drepana). arcuata Walker, 1167 (Hadena).

Arcyonia ...................

ardea Edwards, 414.

ardema Reakirt, 201.

ardiferelta Hulst, 4908.

ardoris Hubner, 2692.

arefacta Hy. Edwards, 2335.

arefactaria Grote \& Robinson, 3961. areli Strecker, 2675.

arene Edwards, 474

arenella Schiffermüller, 5877 .

arenosaria Haworth, 3625 .

areolatus Smith \& Abbot, 298.

Arequipa . . . . . . . . . . . . .

ares Edwards, 319.

aretaria Walker, 3766.

argalis Fernald, 4398.

argante Fabricius, 54.

arge Drury, 882 (Apantesis).

arge Strecker, 128 (Argynnis).

argentana Martyn, 421 (Argyria).

argentana Clerck, 5411 (Tortrix).

argentata Emmons, 4620 (Argy-

ria).

argentata Packard, 930 (Euschausia).

argentata Packard, 6604 (Sthenopis) .

argentatus Wetherby, 4077 (Euclea).

argenteana Walsingham, 5146.

argentella Chambers, 6029 (Coleophora).

argentella Fabricius, 4580 (Crambus).

argenteomaculatus Harris, 6604.

argenteonervella Hulst, 4617.

argenteostriata Strecker, 4032.

argenteum Kirby, 214.

argentialbana Walsingham, 5089.

argentialbella Chambers, 5993 (Co-

leophora).

argentialbella Chambers, 6029 (Co-

leophora).

argentialbella Chambers, 5783 (Gelechia).

argenticiticella Chambers, 5652. argillacea Packard, 806 (Lexis)

argillacearia Packard, 3703.

argillaceellus Packard, 4556.

argillaria Hulst, 3951.

Argillophora . . . . . . . . . . . .

argiolus Smith \& Abbot, 440.

Argiope . . . . . . . . . . . . . . . .

argus Neumoegen \& Dyar, 753.

arguta Lederer, 4318.

argutana Clemens, 5207.

argyllaria Walker, 3902.

Argynnis . . . . . . . . . . . . . . . .

argyralis Hübner, 4287.

argyrana Stephens, 5134.

argyreella Dietz, 5964.

argyreus Stephens, 4580.

Argyria . . . . . . . . . . . . . .

argyroelana Zeller, 5056.

argyrospila Walker, 5365.

Argyroteuchia . . . . . . . . . . .

argyrothamniella Busck, 5705.

argyrotoxus Behr, 437.

ariadne Edwards, 65.

ariana Boisduval, 258.

aricye Cramer, 51.

arida Smith, 2679.

arietis Grote, 1777.

arioch, Strecker, 1044.

aristella Busck, 5733.

aristodemus Esper, 15.

Aristotelia . . . . . . . . . . . . . . .
Argyresthia arizon $\mathscr{x}$ Grote, 2838 (Catocala). arizonæ French, 3087 (Gnophaela).

$$
4630 \text { - No. } 52-02-38
$$


arizonx Beutenmüller, 4209 (Sesia). arizonæ Hy. Edwards, 2684 (Tarache).

arizonana Walsingham, 5416.

arizonaria Grote, 3595 (Anaplodes). arizonaria Grote, 3616 (Cloraspilates).

arizonaria Hy. Edwards, 3998 (Stenaspilates).

arizonata Grote, 3252.

arizonella Busck, 5716 (Gelechïa). arizonella Hulst, 4848 (Heterographis).

arizonella Ragonot, 4909 (Martia). arizonella Dietz, 5947 (Pigritia).

arizonellus Walsingham, 6588 (Acrolophus).

arizonensis Stretch, 885 (Apantesis). arizonensis Edwards, 236 (Basilarchia).

arizonensis Edwards, 440 (Cyaniris),

arizonensis Packard, 3201 (Gloveria).

arizonensis Edwards, 10 (Papilio). arizonensis Strecker, 764 (Pseudohazis).

arizonicum Dyar, 4061.

armata Grote, 1385.

armataria Guenée, 3990.

armeniella Frey \& Boll, 5572.

armiger Hübner, 2300.

armillata $\mathrm{Hy}$. Edwards, 927.

arna Guenée, 1137.

arnicella Walsingham, 5859.

arogos Boisduval \& Le Conte, 572. arota Boisduval, 386.

Arotura .

arpa Boisduval \& Le Conte, 560.

Arrhostia .....................

arrogaria Hulst, 3932.

arrosa Harvey, 2962.

arsace Boisduval \& Le Conte, 374.

arsaltealis Walker, 4437.

arsenaria Walker, 4020.

Arsilonche ..................

Arta....................

Artace ............................

artemis Packard, 759.

artemisix Hy. Edwards, 4199.

artemisiana Walsingham, 5174.

artemisicolella Chambers, 5994.

arthemis Fabricius, 237. arthrolita Harvey, 2037.

artonis Edwards, 128.

Arucha ................... 428

arvalis Hy. Edwards, 2594 (Annaphila).

arvalis Grote, 2419 (Axenus).

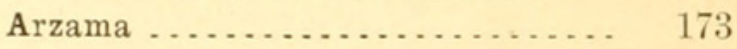

Asaphodes ................... . . 290

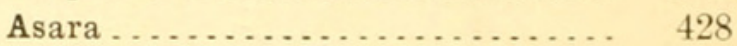

A.sciodes . . . . . . . . . . . . . . . 377

ashtaroth Strecker, 278 (Neominois).

ashtaroth Fischer, 95 (Speyeria). asilipennis Boisduval, 4183.

Asopia

398

asopialis Guenée, 3059.

aspasia Strecker, 2839.

asperatella Clemens, 4648.

aspersa Grote, 850 (Alexicles).

aspersa Morrison, 1266 (Polia).

aspidana Walsingham, 5147.

Aspidisca . . . . . . . . . . . . . . . .

aspidiscana Hübner, 5167.

aspilata Guenée, 4011.

aspilodactylus Walker, 4974.

asseclana Hübner, 5169.

assecoma Druce, 4030.

assimilans Walker, 861.

assimilis Boisduval, 2430 (Euthisanotia).

assimilis Morrison, 1809 (Mamestra).

assimilis Butler, 295 (Oeneis).

assimilis Grote, 2599 (Trichotarache).

assiniboia Lyman, 487.

associans Walker, 1514.

associuta Walker, 3142.

astarte Doubleday and Hewitson, 144

(Brenthis).

astarte Doubleday, 3132 (Heterocampa).

astarte Strecker, 730 (Smerinthus). astarte Fischer, 95 (Speyeria). astenidia Boisduval, 447.

aster Edwards, 435.

astericola Frey and Boll, 6345.

asterius Cramer, 22.

asteroides Guenée, 2127.

Asteroscopus ................

Asthena ................... 275

asthenaria Walker, 3477.

astigma Smith, 2140. 
astinous Drury, 23.

astorix Hy. Edwards, 3092.

astræa Edwards, 69.

astrict: Morrison, 1464.

astrologana Zeller, 5062.

Astropometis.

astur Cramer, 941.

astyanax Fabricius, 236.

astylus Drury, 733.

astylusaria Walker, 3963.

astymone Olivier, 770.

asychis Cramer, 604.

atala Poey, 325.

atalanta Linnæus, 219.

aiarah Strecker, 2898.

Atascosa . . . . . . . . . . . . . .

ate Strecker, 221.

atergatis Doubleday and Hewitson, 310.

aterrima Grote, 1363.

aterrimella Walker, 6106.

Atethmia.

atha Strecker, 1534.

athabasca Neumoegen, 2800.

athasiaria Walker, 3909.

Athena

athena Strecker, 854 .

athereo Harris, 3136.

atlantica Smith, 2162 (Gortyna). atlantica Grote, 1792 (Mamestra). ailantis Edwards, 102.

Atlides

atomaria Walker, 3195.

atomariella Zeller, 6332.

atomaris Walker, 2540 (Ogdoconta). atomaris Smith, 1604 (Paragrotis). atomaris Hübner, 2915 (Phoberia). atomosana Walsingham, 5091.

atomosella Zeller, 6346.

Atopocera . . . . . . . . . . . . . .

atossa Edwards, 126.

atra Grote, 1297.

atrata Hy. Edwards, 954 (Pseudalypia).

atrata Morrison, 1770 (Pteroscia).

atratalis Harvey, 1750.

atrella Hulst, 4802.

atrescens Hulst, 3873.

atriciliata Grote, 1088.

atricincta Smith, 1504.

atricollaris Haworth, 1361.

atricornis Grote, 1257.
Page.

atrifascialis Hulst, 3380 (Mesoleuca).

atrifascialis Hulst, 4647 (Tallula). atrifasciata Morrison, 1341.

atrifera Grote, 1741.

atrifrons Grote, 1502.

atrilineella Grote, 3030.

atripennis Grote, 799.

atriplicivora Cockerell, 5995.

atristrigata Smith, 1596 (Paragrotis).

atristrigatus Smith, 1755 (Anytus). atrites Grote, 2366.

atritincta Harvey, 2995.

atrivenosa Palm, 3194.

atrocolorata Hulst, 4001 (Azelina). atrocoloratum Grote, 3354 (Eustroma).

atrodentana Fernald, 5020. atrodorsella Clemens, 5854. atrofasciata Packard, 3662.

atrofusca Smith, 1713.

atrolinearia Hulst, 3790.

atroliturata Walker, 3237.

atropicta Zeller, 5844 (Cryptolechia).

atropicta Hampson, 4506(Scoparia). atropulverea Smith, 1685.

atropunctana Zetterstedt, 5034.

atropunctaria Walker, 3759.

atropunctata Packard, 3754.

atropurpuralis Grote, 4465.

atropurpurea Grote, 1711.

atrosignata Walker, 3708.

atrupictella Dietz, 5595.

Atrytone

Attacapa ......................

attalus Edwards, 501.

attenta Grote, 1424.

attenuatella Walker, 6068.

attenuatus Grote, 4594.

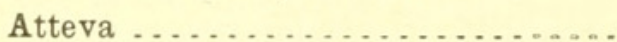

attributella Walker, 5608.

attritella Walker, 5784.

auburniana Harris, 362.

audentis Smith, 1636.

aufugella Zeller, 5941.

auge Linnæus, 779.

augias Hübner, 515.

augmentanus Zeller, 5206.

augusta Hy. Edwards, 2844 (Cato(cala). 
augusta Edwards, 155 (Lemonias).

Aurora .........................

aurora Smith \& Abbot, 3155.

aurosea Neumoegen, 751.

aurosparsella Walsingham, 6620.

aurostriata Graef, 3157.

aurosuffusella Chambers, 6493.

aurotus Fabricius, 736.

aurulenta Smith, 1453.

ausonides Boisduval, 44.

ausonius Lintner, 622.

austerella Zeller, 6457.

australata Hulst, 3413.

australella Hulst, 4782.

australis Grote, 1074 (Baileya).

australis Edwards, 322 (Calephe-

lis).

australis Hulst, 3549 (Eois).

australis Stretch, 4129 (Harrisina). australis Maynard, 11 (Papilio).

australisella Chambers, 6297 (Lithocolletes).

australisella Chambers, 5924 (Eco-

phora).

autholea Boisduval, 885.

Autocosmia ...................

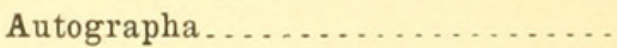

autolycus Edwards, 337.

Automeris ....................

Autoneda . . . . . . . . . . . . . .

autumnalis Cockerell, 65 (Eurymus)

autumnalis Stromeyer, 3388 ( $\mathrm{Hy}$ driomena).

autumnatis Riley, 1302 (Laphygma).

autumnaria Möschler, 3923.

autumnata Guenée, 3337 (Epirrita).

autumnata Packard, 3245 (Paleacrita).

auxiliaris Grote, 1517.

avernalis Grote, 4501.

aversus Hy. Edwards, 4125.

avia Hübner, 870.

avimacula Hudson, 3168.

avuncularia Guenée, 3610.

Axenus ..................... 194

axillaris Grote \& Robinson, 653.

azalex Smith \& Abbot, 681.

Azelina .... . . . . . . . . . . . . . 344

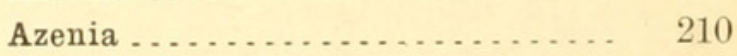

azif Strecker, 1626.

Azinaphora ................. 
azionalis Walker, 4281.

baal Strecker, 99.

Babaiaxa

babayaga Strecker, 2837.

baccata Guenée, 3370.

baccatalis Hulst, 4357.

baccharisella Busck, 5622.

bachmani Kirtland, 311.

Bactra .....................

badia Grote \& Robinson, 2885 (Catocala).

badia Hy. Edwards, 3187 (Notolophus).

badia Packard, 3153 (Schizura).

badiana Schiffermüller, 5245 .

badiaria Hy. Edwards, 3339.

badicollis Grote, 1426.

badiella Chambers, 6436.

badinodis Grote, 1451.

badiocapitella Chambers, 6186.

badiomaculella Chambers, 5786.

badipennis Grote, 4436.

badistriga Grote, 1312.

badiusulis Walker, 4492.

baicalcata Bremer, 3450.

Baileya . . . . . . . . . . . . . .

baileyana Grote, 1417.

baileyi Grote, 2108.

bairdii Edwards, 17.

balba Grote, 2342.

balder Boisduval, 292.

baldur Edwards, 1.

balinitis Grote, 1524.

baliola Morrison, 2160.

balistaria Hübner, 3533.

balluca Gever, 2476.

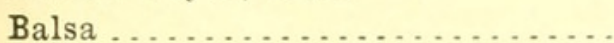

baltearia Hulst, 3784.

balteata Kirtland, 664 (Allopos).

balteata Smith, 1359 (Oncocnemis).

balteata Smith, 2652 (Tripudia).

balteolata Herrich-Schaeffer, 4030.

baltimoralis Guenée, 3065.

banavahrata Strecker, 3397.

Bandera...................

banksiella Busck, 5636.

baptisix Bird, 2177.

baptisiella Fernald, 4654.

baracoa Lucas, 527.

Barathra

barbara Hy. Edwards, 67.

barberella Busck, 5888 (Depressaria).
Page.

barberella Busck, 5644 (Neodactylota).

526

barberiana Dyar, 4114.

barda Hy. Edwards, 881.

barnesi Skinner, 194 (Phyciodes).

barnesiella Busck, 5747.

barnesii Smith, 1033 (A patela).

bamesii Dyar, 6590 (Atopocera).

barnesii French, 2818 (Catocala).

barnesii Hulst, 3945 (Gonodontis).

barnesii Smith, 1189 (Hadena).

barnesii Smith, 1356 (Oncocnemis).

barnesii Beutenmüller, 4196 (Sanninoidea).

barometricus Goossens, 1759.

baroni Edwards, 121 (Argynnis).

baroni Edwards, 258 (Cercyonis).

baroni Behrens, 6614 (Hepialus).

baroni Hy. Edwards, 156 (Lemonias).

baroni Fish, 4986 (Pterophorus).

basatiata Walker, 3390.

basalis Grote, 2887 (Catocala).

basalis Walker, 4149 (Inguromorpha).

107 basalis Grote, 1716 (Paragrotis).

basalis Walker, 4507 (Scoparia).

basiaria Walker, 3619.

basiata Packard, 3619.

basicinerea Grote, 2649.

basifasciella Zeller, 5561.

basiflava Packard, 3194 (Olene).

basiflava Smith, 1703 (Paragrotis).

basigera Walker, 2518.

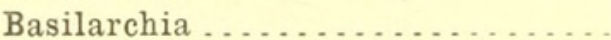

basilarella Dietz, 5940.

basilaris Zeller, 4767 (Salebria).

basilaris Zeller, 6107 (Scythris).

basilinea Schiffermüller, 1208.

Basilodes .

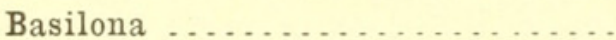

basimaculella Ragonot, 4839.

basiochrealis Grote, 4640.

basiplagana Walsingham, 5412.

basipunctana. Walsingham, 5093.

basipunctaria Walker, 3551.1.

basistrigella Chambers, 5997 (Coleophora)

basistrigella Clemens, 6301 (Lithocolletes).

basistrigella Zeller, 5560 (Telphusa).

basitriens Walker, 3116.

basquella Chambers, 5729. 
bassettella Clemens, 5918.

bassiformis Walker, 4207.

b-ata Goeze, 890.

batabano Lefèbre, 575 .

batanella Busck, 5637.

batesi Felder, 4322 (Diaphania).

batesii Reakirt, 190 (Phyciodes).

bathyllus Smith \& Abbot, 599.

Batrachetra.................

battoides Behr, 429.

beani Skinner, 151 (Lemonias).

beaniana Grote, 2849.

beanii Grote, 1820 (Mamestra).

beanii Neumoegen, 868 (Neoarctia).

beanii Elwes, 295 (Eneis).

beata Grote, 1514.

beckeri Edwards, 33.

Bedellia

Begoe......................

behrensaria Hulst, 3638.

behrensata Packard, 4002 (Azelina).

behrensata Packard, 3312 (Tephroclystis).

behrensella Chambers, 6347 (Gracilaria) .

behrensella Chambers, 6494 (Tinea).

behrensellus Fernald, 4586 (Crambus).

behrensi Grote, 1327 (Oncocnemis).

Behrensia ................. . .

behrensiana Grote, 2049.

behrensii Edwards, 112 (Argynnis). behrensii Stretch, 6613 (Hepialus).

behrensii Hy. Edwards, 3123 (Nadata).

behrensii Hy. Edwards, 4242 (Sesia). behrii Stretch, 888 (Apantesis).

behrii Edwards, 370 (Callipsyche). behrii Edwards, 77 (Eurymus).

behrii Edwards, 418 (Nomiades).

behrii Edwards, 2 (Parnassius).

behrii Smith, 2683 (Tarache).

Bejuda...................

belx Grote, 783.

belangerella Chambers, 6460 (Argyresthia).

belangerella Chambers, 5563 (Telphusa).

belangeri Morrison, 2232.

belfrageana Zeller, 5331.

belfrageella Chambers, 6348 (Gracilaria).
Page.

belfrageella Chambers, 6187 (Nepticula).

belfragei Fish, 4958 (Alucita).

belfragei Grote, 3139 (Chytolita).

belfragei Stretch, 834 (Eubaphe).

belfragei Grote, 3048 (Renia).

belfragei Smith, 1394 (Rhynchagrotis).

534 belfragesella Chambers, 5574.

belfragiana Harvey, 2910.

belialis Druce, 4388.1.

bella Chambers, 6553 (Adela).

bella Walsingham, 5998 (Coleo-

phora).

bella Chambers, 6099 (Heliodines). bella Grote, 1828 (Mamestra).

bella Linnæus, 836 (Utetheisa).

iella Hulst, 4825 (Zophodia).

belladonna Hy. Edwards, 2398

(Dysocnemis).

belladonna Petiver, 220 (Vanessa).

bellela Walker, 6554 (Adela).

bellela Walker, 5575 (Aristotelia).

bellicula Hübner, 2622.

bellona Fabricius, 141.

bellulalis Hulst, 4458.

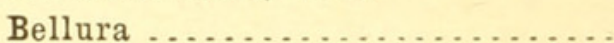

bellus Edwards, 530.

belmaria Ehrman, 832.

belusalis Walker, 4303

Bembecia . -

beneficentella Murtfeldt, 5770.

benesignata Harvey, 3003.

benigna Hulst, 3718(Cymatophora).

benigna Hy. Edwards, 1171 (Hadena).

benignalis Walker, 3065 .

Benta .......................

bentleyana Donovan, 5076.

berenice Cramer, 309.

bergii Möschler, 4297.3.

bergmanniana Linnæus, 5401.

bernardino Edwards, 60.

bertholdi Grote, 4154.

Bertholdia.

bertrami Roessler, 4956.

beskei Hübner, 3172.1 .

Bessula . . . . . . . . . . . . . . .

184

bethunei Grote \& Robinson, 2097.

bethuniella Chambers, 6326.

betulæ Riley, 989. 
Page.

betulella Hulst, 4693 (Acrobasis).

betulella Busck, 5886 (Depressaria). betulella Busck, 5562 (Telphusa).

betuliperda Dyar, 5537.

betulivora Walsingham, 6328.

beutenmuelleri Hy. Edwards, 4090.

bianca Hy. Edwards, 2826.

biangulana Walsingham, 5230 .

bianulella Chambers, 5743.

biarcuana Stephens, 5260.

bibularia Grote \& Robinson, 3909.

bicarnea Guenée, 1478.

biclaria Walker, 4005.

biclavis Grote, 1597.

bicollaris Grote, 1587.

bicolor Harris, 772 (Adelocephala).

bicolor Walker, 865 (Diacrisia).

bicolor Grote, 806 (Lexis).

bicolor Frey \& Boll, 6432 (Tischeria).

bicolorago Guenée, 2222.

bicoloralis Guenée, 4414.

bicoloraria Packard, 3616.

bicolorata Fabricius, 3737 (Cymatophora).

bicolorata Minot, 3604 (Eufidonia).

bicolorata Borkhausen, 3387 ( $\mathrm{Hy}$ driomena).

bicolorata Grote, 1990 (Neleucania).

bicolorella Hulst, 4898 (Atascosa).

bicolorella Chambers, 6295 (Lithocolletes).

bicostomaculella 'Shambers, 5755 (Gelechia).

bicostomaculella Chambers, 5609 (Recurvaria).

bicristatella Chambers, 6077 (Elachista).

bicristatella Chambers, 6094 (Lymnæcia).

bicuspida Smith, 2359.

bicycla Packard, 1932.

bidens Zeller, 4569.

bidentata Walker, 3124 .

bidiscomaculella Chambers, 5670 .

bifascia Hübner, 2338.

bifascialis. Robinson, 4499.

bifasciata Walsingham, 5510 (Glyphipteryx).

bifasciata Smith, 1648 (Paragrotis). bifasciata Bates, 2941 (Phurys).

bifasciella Busck, 5581 (Aristotelia). bifasciella Chambers, 6329 (Lithocolletes).

bifasciella Chambers, 6151 (Mompha).

bifasciella Chambers, 6188 (Nepticula).

bifasciella Hulst, 4769 (Salebria).

bifasciella Chambers, 6548 (Semele).

bifasciella Chambers, 6130 (Theisoa).

biferalis Walker, 3040.

bifida Packard, 4077.

bifidalis Grote, 3055 (Gaberasa).

bifidatis Fabricius, 4352 (Loxostege). bifidella Dietz, 5570 .

bifilata Walker, 3590 (Aplodes).

bifilata Hulst, 3631 (Deilinia).

bifiria Hy. Edwards, 3092.

biflavimaculella Clemens, 6495.

biformata Hy. Edwards, 2746.

bifurcalis Snellen, 4282.

bigutta Schaeffer, 4391.

biguttata Packard, 4094 (Cochlidion).

biguttatus Packard, 3148 (Schizura). bijugalis Walker, 3066.

bilinearia Packard, 3960.

bilineata Smith, 2960 (Campometra).

bilineata Packard, 3231 (Falcaria).

bilineata Packard, 3142 (Heterocampa).

bilineatella Ragonot, 4676.

biliturellus Zeller, 4604.

billonaria Strecker, 3593.

biloba Stephens, 2485.

bilunata Grote, 1101.

bimacula Grote \& Robinson, 555.

bimaculana Donovan, 5143 (Eucosma) .

bimaculana Robinson, 5471 (Pharmacis).

bimaculata Gmelin, 949 (Alypia).

bimaculata Herrich-Schaeffer, 953 (Alypiodes).

bimaculata Stephens, 2483 (Autographa).

bimaculata Saunders, 834 (Eubaphe).

bimaculella Chambers, 5720 (Gelechia).

bimaculella Chambers, 6496(Tinea). 
bimaculella Chambers, 5690 (Ypsolophus).

bimarginalis Grote, 1400.

bimatris Harvey, 2280.

biminimaculella Chambers, 5999

(Coleophora).

biminimaculella Chambers, 5758

(Gelechia).

bina Guenée, 2413.

binocula Grote, 2686.

binodulalis Zeller, 4517.

binominalis Smith, 1411.

binotata Walker, 1155.

binotella Zeller, 4918.

biothanatalis Hulst, 4586.

bipartita Smith, 2574.

bipartitana Clemens, 5071.

bipartitella Ragonot, 4912.

biplaga Walker, 2613 (Erastria).

biplaga Guenée, 2673 (Tarache).

biplagata Walsingham, 5148.

biplagialis Walker, 4507.

bipuncta Morrison, 2562.

bipunctalis Fabricius, 4344.

bipunctatus Möschler, 4968.

bipunctella Chambers, 6129 (Aetia).

bipunctella Walsingham, 6000 (Co-

leophora).

bipunctella Walker,5106 (Eucosma).

bipunctellus Zeller, 4581 (Crambus).

bipunctellus Walsingham, 5681

(Ypsolophus).

bipunctina Guenée, 2555.

bipustulana Walker, 5217.

biquadrana Walsingham, 5110.

birivata Borkhausen, 3387.

bischoffii Edwards, 128 (Argynnis). bischoffii Zeller, 4956 (Platyptilia). biscolorella Chambers, 5567.

bisecta Lintner, 774.

biseliella Zeller, 6487.

biseriata Packard, 3225 (Eudeilinea).

biseriata Herrich-Schaeffer, 3248 (Eudule).

bisignata Walker, 3678.

bisselliella Hummel, 6487.

bistriaria Packard, 3557 (Annemoria).

bistriaria Hübner, 3590 (Aplodes). bistriaris Geyer, 2571 (I)oryodes). bistriaris Hübner, 2921 (Parallelia). bistriatella Hulst, 4900 (Cayuga).
Page.

bistriatella Hulst, 4676 (Myelois). bistriatella Hulst, 4786 (Pyla).

bistriga Smith, 2135.

bistrigata Hübner, 2944.

bistrigella Chambers, 6001 (Coleophora).

bistrigella Chambers, 5787 (Gelechia).

bistriolata Zeller, 3387.

bisulca Grote, 1888.

bitactata Walker, 3706.

biundata Walker, 3140.

biundulata Zeller, 2274 (Antaplaga).

biundulata Smith, 2330 (Schinia).

biviella Zeller, 6557.

bivittata Clemens, 897 (Ectypia).

bivittata Grote, 3034 (Hormisa).

bivittata Hulst, 3310 (Tephroclystis ).

blakeana Grote, 5221.

blakei Grote, 887 (A pantesis).

blakei Maynard, 89 (Eurema).

blancardella Fabricius, 6270.

blanda Grote, 1442 (Metalepsis).

blanda Grote, 2210 (Pseudoglæa).

blandana Clemens, 5379.

blandella Clemens, 6349.

blandula Hulst, 2892.

Blastobasidæ

Blastobasis .

blenina Hewitson, 359.

blepharana Herrich-Schaeffer, 5291.

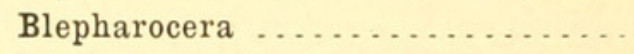

Blepharomastix ..............

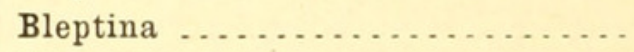

Boarmia. . . . . . . . . . . . .

Bocchoris ...................

bochus Morrison, 1588.

bodicella Chambers, 6436.

boisduvaliana Felder, 82.

boisduraliella Guenée, 4793.

boisduvalii Felder, 53 (Aphrissa).

boisduvalii Duponchel, 137 (Brenthis).

boisduvalii Butler, 848 (Leptarctia). boisduvalii Harris, 288 (Satyrodes). bolanderana Walsingham, 5081.

bolanderi Strecker, 887.

bolliella Dyar, 6312.

bollii Grote, 1457 (Agrotis).

bollii Zeller, 4816 (Melitara).

bollii Hy. Edwards, 4207 (Sesia).

bollii Edwards, 180 (Thessalia). 
bolterellus Fernald, 4592.

bolteri Hy. Edwards, 933 ( Emilia). bolteri Stretch, 909 (Euchretias). bolteri Smith, 1870 (Mamestra). bolteri Smith, 1510 (Noctua). bolteri Hy. Edwards, 4213 (Sesia). bolteri Hulst, 3302.1 (Tephroclystis). bolteri Hulst, 3890 (Tracheops).

Bombycia

Bombycidæ ............... . . bombyciformis Smith, 1376 (Eutolype).

bombyciformis Walker, 4183 (Memythrus).

bombycina Zeller, 6584.

Bombycoidea ................. . . . bombycoides Walker, 725 .

\section{Bombyx}

\section{Bomolocha.}

bonifata Hulst, 3521.

bonifatellus Hulst, 4600.

bonuscula Smith, 2074.

bonusculalis Hulst, 4590.

boopis Behr, 258.

bontes Boisduval, 295.

boothii Curtis, 64.

bore Hübner, 295.

borea Guenée, 1233.

borealis Smith, 2146 (Asteroscopus).

borealis Grote \& Robinson, 321 (Calephelis).

boreatis Smith, 1371 (Copipanolis). borealis Hulst, 3620 (Deilinia).

borealis Grote, 4637 (Epipaschia). borealis Smith, 3016 (Epizeuxis).

borealis Boisduval, 3161 (Harpyia). borealis Fitch, 3190 (Hemerocampa).

borealis Möschler, 872 (Hyphoraia). borealis Hulst, 3452 (Petrophora). borealis Staudinger, 860 (Phragmatobia).

borealis Grote, 38 (Pontia).

borealis Packard, 4453 (Pyrausta). borealis Lefèbre, 4510 (Scoparia).

borealis Hulst, 3286 (Tephroclystis).

boreana Zetterstedt, 5409.

boreasella Chambers, 5921 (Ecophora).

boreasella Clemens, 6389 (Ornix). boreata Packard, 3259 (Carsia).
Page.

boreata Hübner, 3238 (Opheroptera).

borkhausenii Zeller, 5922.

borus Boisduval, 340.

boscana, Fabricius, 5303.

bosquella Chambers, 5729 (Gelechia).

bosquella Chambers, 6350 (Gracilaria).

263

bosquella Chambers, 6229 (Opostega).

bostonica Frey \& Boll, 6319.

bostoniensis Grote, 1631.

botrana Schiffermüller, 5005.

boucardi Druce, 751 (Automeris). Phyciodes).

Brachiloma .................

brachiolum Harvey, 1819.

brachyelytrifoliella Chambers, 6078.

brackenridgella Busck, 5794.

bracteatana Fernald, 5271.

Bradypetes . . . . . . . . . . . . .

branderiana Haworth, 5359.

brannani Stretch, 946.

brasiella Fitch, 5503.

brassicx Riley, 2496.

bredowii Hübner, 243.

bremnerii Edwards, 108.

brenda Edwards, 281.

brennus Godman \& Salvin, 616.

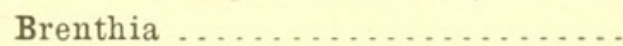

Brenthis

Brephidium.

Brephinæ. .

brephoides Walker, 4040.

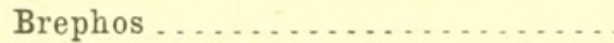

brettoides Edwards, 516.

brettus Boisduval \& Le Conte, 516.

brevicauda Saunders, 21.

brevicornis Walker, 834.

brevicrista Dyar, 3212.

breviomatalis Grote, 4642.

breviornatana Clemens 5349.

brevipennis Stretch, 2429 (Euthisanotia).

brevipennis Smith, 1577 (Paragrotis).

brevirostralis Grote, 3041.

brevis Grote, 2366.

brevistriga Chambers, 6110.

brevistrigella Chambers, 6110.

brevivitella Clemens, 6152. 
brewsteriana Robinson, 5307.

bridghami Grote \& Robinson, 1149.

brillians Ottolengui, 2121.1 (Calocampa).

brillians Neumoegen, 2425 (Eupseudomorpi.a).

brillians Barnes, 1285 (Feralia).

briseis Edwards, 2854.

brizo Boisduval \& Le Conte, 617.

brocha Morrison, 1588.

Bronchelia . . . . . . . . . . . . . . .

brontes Drury, 694 (Diludia).

brontes Denis \& Schiffermüller, 469

(Pamphila).

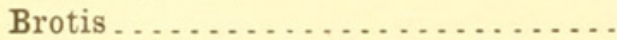

Brotolomia ...................

bruceata Hulst, 3240 .

brucei Hulst, 4728 (Ambesa).

brucei Smith, 2117 (Calocampa).

brucei French, 4143 (Cossus).

brucei Elwes, 273 (Erebia).

brucei French, 654 (Hemaris).

brucei Edwards, 151 (Lemonias).

brucei Hy. Edwards, 3097 (Melalopha).

brucei Hy. Edwards, 867 (Neoarctia).

brucei Edwards, 295 (Eneis).

brucei Edwards, 17 (Papilio).

brucei Fernald, 4963 (Pterophorus). brucei Smith, 2345 (Schinia).

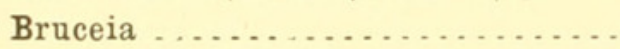

brullei Lefèbre, 3444.

brumella Clemens, 5788.

brumosa Guenée, 1026.

brunnea Stretch, 795 (Ctnucha).

brunnea Grote \& Robinson, 3133

(Heterocampa).

brunnea Strecker, 855 (Hyphantria).

brunnea Walsingham, 6536 (Phryganeopsis).

brunnearia Packard, 3590 (Aplodes).

brunnearia Packard, 3709 (Cymatophora).

brunneata Packard, 3709 (Cymatophora).

brunneata Thunberg, 3695 (Macaria).

brunneata Packard, 3379 (Mesoleuca).

brunneiciliata Packard, 3372.
Page.

brunneicollis Grote, 1391.

brunneicrista Smith, 1281.

brunneifasciata Packard, 3336.

brunneigera Morrison, 1659.

brunneipennis Grote, 1393 (Rhynchagrotis).

brunneipennis Hy. Edwards, 4201 (Sesia).

brunneipennis Hulst, 3293 (Tephroclystis).

brunneogrisea Hy. Edwards, 4331.

brunneolineata Hulst, 3919.

brunneomaculata Bates, 3377.

brunneus Busck, 5646 (Prostomeus).

Bryophila . . . . . . . . . . . . . .

bububattalis Hulst, 4396.

Bucculatrix . . . . . . . . . . . . . .

bucephaloides Walsingham, 5198.

bucephalus Stephens, 515.

bucetum Grote, 2947.

budea Hübner, 855.

buffaloensis Grote, 656 (Hemaris). buffaloensis Grote, 2196 (Ochria).

bullula Grote, 2554.

bunkeri Grote, 2872.

bunteana Robinson, 5452.

burgessi Morrison, 1214.

burgessiana Zeller, 5248.

burgessiella Zeller, 6378.

buristriga Chambers, 6110.

burseræ Dyar, 2543.

burserella Busck, 6383.

Busckia .....................

busckiella Kearfott, 5523.

Butalis...................... 537

butlerii Edwards, 137.

butyrosa Butler, 4415.

buxea Grote, 2263.

Buzala .......................

byssinella Hübner, 5500.

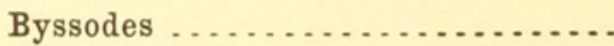

byssus Edwards, 562.

cabelus Edwards, 493.

Cabera ... . . . . . . . . . . . . . . .

caberata Guenée, 4020.

Caberodes ....................

cablei von Reizenstein, 728 .

cacabella Hulst, 4776.

Cacelice ........................ 545

Cacœcia ................... 478

Caconome................... 563

Cacozelia ..................... . 414 
cacuminalis Walker, 3040. cacuminaria Packard, 3498. cacuminata Morrison, 3498. cadarerosa Grote, 906 ( Ammalo). cadaverosa Strecker, 309 (Hypoprepia).

cadmia Guenée, 3171.

caduca Grote, 2610.

caducalis Walker, 3069.

cxсa Strecker, 847.

cxcalis Warren, 4289 (Diastictis). crcalis Walker, 4510 (Scoparia). cxcella Zeller, 5759.

cxculatis Zeller, 4400.

crlaria Hulst, 3925.

cænis Grote, 1632.

cænius Linnæus, 320.

Cænurgia . . . . . . . . . . . . . carulea Grote, 2756 (Drasteria). carulea Godman \& Salvin, 228

(Eunica).

cxruleana Walsingham, 5277.

cxrulescens Holland, 97.

crsaria Freyer, 3373.

cæsialbana Zeller, 5071.

crsiaria Hulst, 3668.

cresiata Denis \& Schiffenmüller, 3373.

crsius Smith, 1744.

crsonia Grote, 4105 (Tortricidia). cxsonia Stoll, 61 (Zerene).

cxspitalis Boisduval, 646.

cxspititiella Zeller, 6006.

cahiritella Zeller, 4875.

caia Linnæus, 904.

caicus Cramer, 689 (Dilophonota). caicus Herrich-Schaeffer, 597 (Tho-

rybes).

cajona Reakirt, 437.

calais Scudder, 291.

calami Harvey, 2259.

calaminea Cramer, 2952.

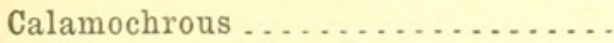

Calamotropha ...............

Calantica.

calanus Hübner, 347.

calceolaria Butler \& Druce, 84 (Eurema)

calceolarius Strecker, 2003 (Orthodes).

calchas Fabricius, 12 (Papilio).

calchas Behr, 430 (Rusticus).

Calephelis
Calera

Page.

Calesesia ..................

calgariana Smith, 1983.

calgary Smith, 1508.

Calidota . . . . . . . . . . . . . . . . .

californix Walsingham, 5515 (Glyphipteryx).

californix Walker, 848 (Leptarctia). californiana Walsingham, 53.33

(Epagoge).

californiana Ménétries, 65 (Eurymus).

californiaria Packard, 3797 (Alcis). californiaria Packard, 3760 (Enemera).

californiaria Packard, 3550 (Eois). californiaria Herrich-Schaeffer, 3772 (Platrea).

californiaria Packard, 3652 (Sciagraphia).

californiata Packard, 3550 (Eois). californiata Packard, 3333 (Euchoeca).

californiata Packard, 3391 (Hydriomena).

californiata Packard, 3456 (Petrophora).

californiata Packard, 3342 (Philereme).

californiata Packard, 3652 (Sciagraphia) .

californiata v. Gumppenberg, 3277 (Tephroclystis).

californica Speyer, 2492 (Autographa) .

californica Behr, 2969 (Capnodes). californica Hy. Edwards, 2831 (Catocala).

californica Doubleday \& Hewitson, 279 (Coenonympha)

californica Dyar, 3099 (Datana).

californica Stretch, 3223 (Epicnaptera).

californica Packard, 851 (Estigmene).

californica Boisduval, 216 (Eugonia).

californica Walker, 922 (Halisidota).

californice Wright, 758 (Hemileuca).

californica Behr, 3081 (Hypena). californica Packard, 859 (Isia).
441

371 
californica Butler, 243 (Liminitis). californica Packard, 3218 (Malacosoma ).

californica Walker, 3219 (Malacosoma).

californica Reakirt, 306 (Mechanitis).

californica Boisduval, 290 (Oeneis). californica Packard, 4618 (Ommatopteryx).

californica Smith, 2245 (Orrhodia). californica Ménétries, 18 (Papilio). californica Stretch, 3118 (Pheosia). californica Packard, 3089 (Phryganidia).

californica Scudder, 471 (Potanthus).

californica Packard, 4451 (Pyrausta).

californica Grote, 742 (Samia).

californica Edwards, 340 (Thecla). . californica Behr, 1891 (Xylomiges).

californicus Boisduval, 4039 (Brephos).

californicus Boisduval, 6616 (Hepialus).

californicus Grote, 2406 (Melicleptria).

californicus Walsingham, 4931 (Trichoptilus).

californiella Ragonot, 4927.

caliginella Hulst, 4701.

caliginosana Walker, 5309.

calignosalis Walker, 4510.

calignosellus Clemens, 4607.

calipusaria Walker, 3902.

Calledapteryx ................

calleta Westwood, 743.

callias Edwards, 272.

Callicista

callida Grote, 1954.

Callidryas .

calligera Zeller, 5483.

Callima ....................

callina Boisduval, 193.

Calliomma . . . . . . . . . . . . . . .

callipeplella Hulst, 4665.

callippe Boisduval, 116.

Callipsyche ..................

Callitriche ...................

callitrichoides Grote, 2573.

Cailizzia
Page.

Callophrys .

Page.

Callopistria

39

Callosamia

216

Calocalpe

Calophasia .................... 119

Caloplusia . . . . . . . . . . . . . . . . 202

Calostygia ................... . . 288

Calothysanis .................. $\quad 290$

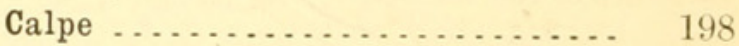

calphurnia Hy. Edwards, 2878.

Calpodes.................... calverleyii Grote, 22.

calvina Druce, 4030.

calycanthata Smith \& Abbot, 2991. calyce Edwards, 36.

Calycopis

Calymnia ....................

cambrica Curtis, 3329.

cambricaria Guenée, 3329.

camerta Cramer, 301 (Cissia).

camertus Cramer, 665 (Triptogon). camillus Edwards, 192.

camina Smith, 1096.

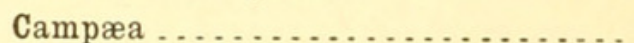
campalis Guenée, 4292.

campestrana Zeller, 5066.

campestris Boisduval, 512 (Hylephila).

campestris Grote, 1707 (Paragrotis). campestris Boisduval, 191 (Phyciodes).

campicolana Walsingham, 5459.

Campometra................

Camptogramma............... camurellus Clemens, 4589.

cana Robinson, 5341 (Cenopis).

cana Walker, 817 (Clemensia).

cana Walker, 3127 (Dasylophia).

cana Martyn, 726 (Lapara).

cana Hy. Edwards, 3189 (Notolophus).

canace Edwards, 195.

canadaria Guenée, 3858.

canadensis Smith \& Dyar, 980 (Apatela).

canadensis Bethune, 2467 (Calpe).

canadensis Guenée, 670 (Deilephila).

canadensis Busck, 5878 (Depressaria).

canadensis Smith, 1794 (Mamestra). canadensis Boisduval, 713 (Sphinx). 
canadensisella Chambers, 6236 canalis Grote, 2950.

canana Walsingham, 5115. canariella Dietz, 5957.

canariellus Walsingham, 5488 .

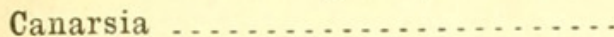

candefacta Hübner, 2691.

candens Guenée, 1997.

candescens Hy. Edwards, 4233.

candida Lintner, 3159 (Cerura).

candida Wright, 475 (Copæodes).

candida Hy. Edwards, 803 (Cram-

bidia).

candida Smith, 3182 (Euthyatira). candida Smith, $131 i$ (Homohadena).

candida Walker, 856 (Hyphantria). candida Smith, 1616 (Paragrotis). candida Smith, 1899 (X ylomiges). candidaria Packard, 3491.

candidellum Hulst, 4867.

canescens Behr, 2259 (Calymnia).

canescens Hy. Edwards, 4261 (Par-

anthrene).

canescentella Hulst, 4749.

caniceps Walsingham, 5149.

canicinctella Clemens, 6146.

canicostella Ragonot, 4857 (Honora).

canicostella Walsingham, 5545 (Paltodora).

Canidia.

caniplaga Walker, 3170.

canjivorella Hulst, 4690.

cannalis Quaintance, 4494.

canningii Walker, 736.

canopulvella Chambers, 5789.

canosaria Walker, 3780.

canthus Boisduval \& Le Conte, 288.

canusella Chambers, 5836.

capax Grote \& Robinson, 2113.

capella Barnes, 152.

Capis

capitalis Grote, 4341.

capiteochrella Chambers, 5790

capitialbella Chambers, 6237.

Capnodes . . . . . . . . . . . . . .

capræana Wilkinson, 5033.

caprealis Hübner, 4511.

capreana Hübner, 5033.

caprotina Drury, 851.

capsella Grote, 2015.
Page.

Caradrina ... . . . . . . . . . . . . .

caradrinalis Guenée, 3079.

caradrinoides Walker, 1103.

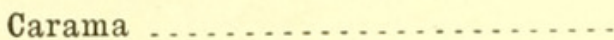

carata Hulst, 3741.

Carbacha . . . . . . . . . . . . . . .

carbonaria Packard, 4069 (Euryeyttarus).

carbonaria Harvey, 2114 (Xylina). carbonariella Fischer, 4776.

carbonellus Hulst, 4781.

carduelis Seba, 221.

cardui Zeller, 4941 (Platyptilia).

cardui Linnæus, 221 (Vanessa).

carduidactyla Riley, 4941.

carduiella Kearfott, 5523.

c-argenteum Scudder, 212.

Cargida

258

Caria on

carina Harvey, 1080.

carinenta Cramer, 312.

cariosa Guenée, 1243 (Hadena).

cariosa Lederer, 4524 (Omphalocera).

cariosa Hulst, 3809 (Pterotæa).

cariosus Smith, 1691 (Paragrotis).

Caripeta . . . . . . . . . . . . . .

carissima Hulst, 2827 (Catocala).

carissima Harvey, 1406 (Rhynchagrotis).

carlota Reakirt, 186.

carlotta Hulst, 3871.

carmelita Morrison, 2637.

carminata Smith, 2010.

carmosina Neumoegen, 2319.

carnaria Packard, 3982.

carnariella Clemens, 6497.

carnata Packard, 3421.

carnea Thunberg, 1422.

Carneades ....................

carneana Guenée, 5458.

carnearia Hulst, 3630.

carneata Packard, 3421.

carneella Hulst, 4771.

carneicosta Guenée, 2920.

carneola Guenée, 2613 (Erastria).

carneola Smith, 2541 (Ogdoconta). 
Page.

carnosa Grote, 2257.

carolina Hy. Edwards, 785 (Eucereon).

carolina Harris, 839 (Haploa). carolina Linnæus, 697 (Phlegethontius).

carolina Skinner, 565 (Phycanassa). carolinana Walsingham, 5150 .

caroliniana Petiver, 61.

carpenterellus Packard, 4562.

carpenterii Edwards, 99.

Carphoxera . . . . . . . . . . . . . .

carpinifolia Boisduval, 3223.

Carpocapsa ................

Carposina .................

Carsia ...................

carus Edwards, 498 (Erynnis).

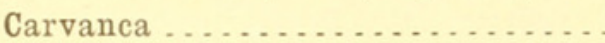

carya Grote, 4688 (Acrobasis).

caryze Shimer, 5268 (Ancylis).

carya Robinson, 5330 (Epagoge).

caryx Harris, 923 (Halisidota).

caryxalbella Chambers, 6251.

caryxfoliella Clemens, 6003 (Coleophora).

caryxfoliella Clemens, 6288 (Lithocolletes).

caryxfoliella Clemens, 6190 (Nepticula).

caryxfoliellus Chambers, 5684 (Y psolophus)

caryævorella Hulst, 4690 (Acrobasis).

caryævorella Packard, 5791 (Gelechia).

caryalbella Walsingham, 6261.

caryana Fitch, 5268.

carye Hübner, 222.

caryivorella Ragonot, 4690.

cassandra Hy. Edwards, 2842.

cassella Walker, 5792.

cassius Morrison, 452.

cassus Edwards, 466.

casta Hy. Edwards, 2585 (Annaphila).

casta Sanborn, 803 (Crambidia).

casta Kirby, 38 (Pontia).

castalis Edwards, 360.

castanea Grote, 1237.

castanexella Chambers, 6318 (Lithocolletes)

castanexella Chambers, 6434 (Tischeria). castanexfoliella Chambers, 6189. castanealis Hulst, 4479.

castaneana Walsingham, 5151. castanella Walsingham, 6318 (Lithocolletes).

castanella Walsingham, 6434 (Tischeria).

castaneum Beutenmüller, 4184.

castanipennella Walsingham, 6004. castella Walsingham, 5485. castellatis Guenée, 4285.

castoria Reakirt, 38.

castro Reakirt, 396.

Catabena

catachloa Hulst, 3588.

Cataclysta . . . . . . . . . . . . . .

cataclystiana Walker, 5096.

catalina Smith, 1187 (Hadena).

catalina Reakirt, 421 (Phædrotes). catalpx Boisduval, 724.

Catamola .....................

cataphracta Grote, 2187.

\section{Catastega}

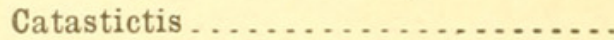

catenaria Cramer, 3886.

catenula Grote, 1553.

catenulatis Grote, 4434.

catenulata Grote, 4023.

Caterva

Catharylla.

catherina Grote, 1428.

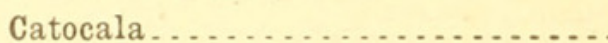

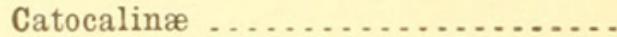

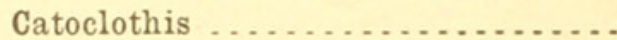

Catoptria . . . . . . . . . . . . .

Catopyrrha .................

catullus Fabricius, 605.

caucasica Herrich-Schaeffer, 900.

caudana Haworth, 5299.

caudatum Harris, 4170.

cautella Walker, 4875.

Cautethia ................. cavillaria Hulst, 3912.1.

cayemaria Packard, 3948.

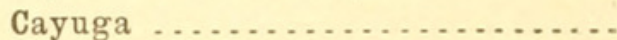

Cea ... . . . . . . . . . . . . . . .

ceanothi Behr, 742 (Samia).

ceanothi Walsingham, 6447 (Tischeria).

cecropia Linnæus, 739.

cecrops Fabricius, 365.

celino Hübner, 295.

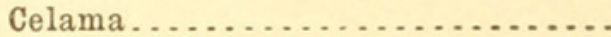


celataria Hulst, 3628 .

celeris Grote, 2401.

celeus Hübner, 696.

celia Skinner, 462 (Amblyscirtes). celia Saunders, 891 (Apantesis). celia Hy. Edwards, 2864 (Catocala).

celiana Robinson, 5308.

celimene Cramer, 294.

\section{Celiptera}

cellus Boisduval \& I.e Conte, 586.

\section{Celma.}

celsa Hy. Edwards, 2514.

celtidella Hulst, 4760.

celtifoliella Chambers, 6286.

celtiphaga Harvey, 3138.

celtis Boisduval \& Le Conte, 244.

celtisana Riley, 5136.

celtisella Chambers, 6286.

cembraria Motschulsky, 3695.

Cemiostoma

\section{Cenopis}

centaurex Rambur, 644.

centerensis Lintner, 4142.

centralis Smith, 1248 (Hadena).

centralis Walker, 4118 (Pyromorpha).

centralis Grote, 3045 (Renia).

centrana Herrich-Schaeffer, 5472.

centumnotata Schulz, 3379.

centuriella Schiffermüller, 4510.

ceos Edwards, 608.

cephatica Grote \& Robinson, 802

(Crambidia).

cephalica Smith, 2393 (Stylopoda). cephalonthiella Chambers, 6162.

cephisaria Grote, 3435.

cephise Cramer, 4035.

ceramica Hübner, 892.

Cerapoda

cerasivorana Fitch, 5360.

cerasivorella Packard, 6005.

Cerathosia.

Ceratocampidæ

Ceratoclasis

Ceratodalia

Ceratomia

Ceratony

cercerisella Chambers, 5714 .

cercyon Burmeister, 687.

Cercyonis.

cerea Hübner, 320.

cerealella Olivier, 5552.
Page.

cerealis Zeller, 4359.

cereana Linnæus, 4636.2.

cerella Fabricius, 4636.2.

ceres Butler, 279.

cereus Doubleday, 320.

cerina Grote, 2171.

cerintha Treitschke, 2656.

cerivana Smith, 1208.

Cerma

cernes Harris, 557 (Limochroes).

cernes Boisduval \& Le Conte, 523

(Thymelicus).

cerogana Guenée, 2872.

ceromatica Grote, 2239.

Cerostoma .......................

cerulea Ehrman, 236.

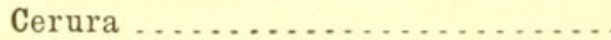

Page.

cerusana Duponchel, 5304 (Acleris). cerusana Hübner, 5303 (Acleris). cerussata Grote, 2183 (Papaipema). cerussata Grote, 4032 (Phrygionis). cervana Eversmann, 5143. cervella Walsingham, 5496 . cerviana Smith, 1208.

cervina Hy. Edwards, 2751 (Cissura).

cervina Hy. Edwards, 2718 (Euherrichia).

cervina Smith, 1856 (Mamestra). cervina Smith, 1130 (Perigea).

cervinana Fernald, 5323.

cervinaria Blanchard, 3698 (Cymatophora).

cervinaria Packard, 3642 (Episemasia).

cervinaria Packard, 4018 (Sabulodes).

cervinicolor Hulst, 3638.

cervinidactylus Packard, 4956.

cervinifascia Walker, 3350.

cervinoides Strecker, 886.

cervinus Walsingham, 6585.

cerysii Kirby, 730.

cespitalis Grote \& Robinson, 900.

cespitella Hübner, 4579.

cespiticella Hulst, 6006.

cespititiella Riley, 6006.

cestalis Hulst, 4512.

cestata Hulst, 3316.

cestus Edwards, 553.

cethura Felder, 47.

ceto Westwood, 4162.

chalcana Packard, 5437. 
chalcedon Doubleday \& Hewitson, 148.

chalcedonia Hübner, 1137.

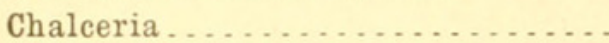

chalcis Behr, 353.

Chalcoela.....................

chalcofiontella Clemens, 5970.

Chalcosidæ

Chalia ... . . . . . . . . . . . . . . .

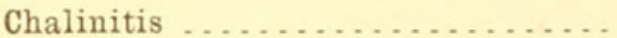

chalybxella Walsingham, 6061.

chalybeana Fernald. 5322 (Acleris). chalybeana Walsingham, 5055 (Olethreutes).

chalybeis Zeller, 6553 .

chalybirostris Zeller, 4585.

chamxchrysaria Grote, 3615.

Chamæclea .................. chambersella Dyar, 5994 (Coleophora).

chambersella Dyar, 5910 (Ethmia). chambersella Walsingham, 6300

(Lithocolletes).

chambersella Murtfeldt, 5667 (Trichotaphe).

Chambersia.

chamonerii Harris, 670.

Chamyris .................

chandleri Grote, 1338.

chapmani Grote, 3134.

chara Edwards, 173.

characta Grote, 1160.

Charadra

chariclea Schneider, 137.

Charidryas

charie Blanchard, 222.

charithonia Linnæus, 304.

charlottii Barnes, 98.

Charommatæa ...............

charon Edwards, 263.

chartaria Grote, 1817.

chatfeldii Grote, 3174.

Chauliodus

Cheimatobia

chelidonia Grote, 2896.

chemnis Fabricius, 550.

chenopodii Fabricius, 1801.

chersis Hübner, 706.

Chesiadodes .

Chesias . .

chicorii Grote \& Robinson, 900.

Chilo

Chilocampyla
Page chiococcella Busck, 6452.

chionanthi Smith \& Abbot, 1370 (Adita).

chionanthi Smith \& Abbot, 698

(Phlegethontius).

chione Curtis, 64.

chionosema Zeller, 5047.

Chipota.

chippewa Edwards, 74.

chiricahua Poling, 2861.

chiridota Grote, 4060.

chiriquensis Dyar, 3109.

chiron Fabricius, 233.

chironias Hübner, 233.

chitone Edwards, 120.

Chlænogramma................

Chloraspilates...............

Chloridea.................... 185

chlorina Skinner, 439.

Chlorippe. . . . . . . . . . . . . . .

chloris Herrich-Schaeffer, 4080.

Chlorissa ...................

Chlorochlamys .............

Chloroclysta ..............

Chloroclystis . . . . . . . . . . . .

chloroleucaria Guenée, 3561.

chlorophasma Butler, 4279.

chlorophora Hübner, 2234.

Chloropteryx...............

Chlorosea..................

chlorostigma Harvey, 1204.

Chlosyne .................... 21

Chœphora ................... 178

chorilus Cramer, 681.

Chœrodes.................... 346

chorda Grote, 1320.

Choreutis ................... 493

choriona Reakirt, 834.

choris Harvey, 1669.

Chorizagrotis . . . . . . . . . . .

chortalis Grote, 4347 (Loxostege). chortalis Harvey, 1750 (Richia).

christina Edwards, 69.

chromalis Guenée, 4312.

Chrysauginæ . . . . . . . . . . . . .

chryseis Olivier, 846.

chryselectra Grote, 1171.

chrysellus Grote, 2324.

Chrysendeton

Chrysobia ................ 34

chrysomelas Hy. Edwards, 68.

Chrysopeleia . . . . . . . . . . . . . .

Chrysophanus ................
396

99

269

300

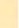

8


chrysopis Grote, 2444.

\section{Chrysopora}

chrysorrhcea Linnæus, 3197.

Chrysoteuchia................... chryxus Doubleday \& Hewitson, 291.

chusca Edwards, 517.

Chytolita $\ldots \ldots \ldots \ldots$
Chytonix $\ldots \ldots \ldots \ldots$
Chytoryza $\ldots \ldots \ldots \ldots$

cibalis Grote, 1358.

cicatricosa Grote \& Robinson, 1572.

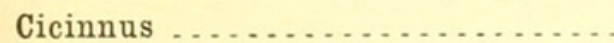

Cidaria...................

cilixochrella Chambers, 6006.

cilialineella Chambers, 5543.

ciliata Smith, 1355 (Oncocnemis).

ciliata Smith, 2375 (Schinia).

cilicoides Grote, 4050.

ciliella Stainton, 5863.

cilium Guenée, 1103.

Cilla

cilla Behr, 424.

cillene Cramer, 90.

cillixfuscella Chambers, 6197.

cimbiciformis Stephens, 656.

cincinnatiella Chambers, 6287 .

Cinclidia

cincta Edwards, 198 (Anthanassa). cincta Smith, 2970 (Kakopoda). cinctaria French, 3881 (Phigalia). cinctarius Hulst, 3814 (Tornos). cinctella Hübner, 5862 (Depressaria).

cinctella Hulst, 4803 (Megasis).

cinctipalpis Smith, 2961.

cinctipedalis Walker, 4423.

cinctipes Grote, 921.

cinctus Tepper, 738.

Cindaphia

cinderella Riley, 5319 (Acleris).

cinderella Smith, 985 (A patela).

cinderella Smith, 2133 (Cucullia).

cinefacta Grote, 1247.

cineraceus Fish, 4985.

cineraria Walker, 3862 (Ectropis). cineraria Packard, 3746 (Sympherta).

cinerascens Walsingham, 4960 (Alucita).

cinerascens Walker, 3137 (Heterocampa).

$$
4630-\text { No. } 52-02-39
$$

Page.

243

107

204

352

286

cinereata Bates, 3656.

cinereella Hulst, 4814.

cinerella Chambers, 6007 (Coleophora).

cinerella Hulst, 4855 (Honora).

cinerella Murfeldt, 5617 (Phthori-

maea).

206 cinereocostella Clemens, 5891.

cinereofrons Packard, 3148.

cinereoides Dyar, 3162.

cinereola Hulst, 3731 (Cymatopho-

ra).

cinereola Guenée, 2540 (Ogdoconta).

cinereola Smith, 2212 (Selicanis).

cinereomaculata Morrison, 1719.

cinereus Packard, 3141 (Heterocampa).

cinereus Riley, 6572 (Prodoxus).

cineridactylus Fitch, 4981.

cineritia Grote, 2120.

cinerosa Grote, 690 (Dilophonota). cinerosa Grote \& Robinson, 4457

(Pyrausta).

cinerosa Grote, 2092 (Xylina).

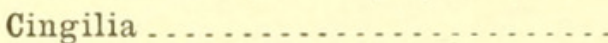

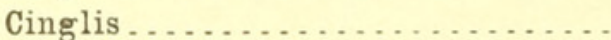

cingulata Fabricius, 699.

cingulifera Walker, 2992.

ciniftonella Zeller, 5869.

cinis Guenée, 2774.

cimnabarina Grote, 1830.

cinnamomea Boisduval, 934.

cipris Cramer, 54.

circx Hy. Edwards, 660.

circe Strecker, 2859.

circulana Hübner, 5079.

circulifera Walker, 964.

circumcincta Smith, 1832. 
circumdata Grote, 1543.

circumflexaria Eversmann, 3708.

circumlucens Smith, 2189.

circumscriptella Chambers, 5514

(Glyphipteryx).

circumscriptella Zeller, 6153 (Mompha).

circumvadis Smith, 1877.

Ciris ................... 195, 437

Cirrha ................... 511

Cirrhbolins ................. 222

Cirrhophanus ................. 196

cirroferella Hulst, 4691.

Cisse. . . . . . . . . . . . . . . . .

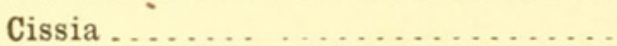

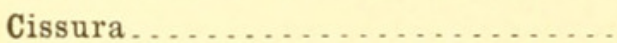

cita Grote, 2129.

citata Grote, 3075.

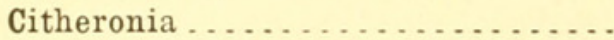

citima Hy. Edwards, 328 (Hypaurotis).

citima Grote, 2228 (Orthosia).

citima Grote, 2724 (Phalænosto-

la).

citra Neumoegen \& Dyar, 857.

citrana Fernald, 5395.

citrata Linnæus, 3380.

citricolor Grote, 1610.

citriella Chambers, 6057.

citrifoliellus Chambers, 5683.

citrina Grote \& Robinson, 4351

(Loxostege).

citrina Hübner, 3925 (Xantho-

type).

cilrinaria Neumoegen \& Dyar, 874. citrinipennella Clemens, 6435.

citronella Smith, 1991 (Neleucania). citronellus Grote, 2309 (Rhodopho-

ra).

civica Grote, 1105.

Cladocera.

Cladora

clandestina Walker, 3166 phisia).

clandestina Harris, 1496 (Noctua). clappiana Holland, 3088.

clappii Maynard, 85.

clara Hy. Edwards, 405 (Cupido). clara Harvey, 1142 (Oligia).

clarescens Guenée, 1002.

clarioralis Walker, 4709.

clarius Boisduval, 1.

clarkix Boisduval, 659.

clarus Grote \& Robinson, 812. clauda Grote, 2619.

claudens Walker, 1153.

claudia Cramer, 92.

clandialis Walker, 4498.

claufacta Walker, 1119.

clausella Walker, 5891.

clausula Grote, 2632

clavana Zeller, 5144 (Eucosma).

clavana Walker, 5024 (Exartema).

clavana Fernald, 5179 (Thiodia).

claviformis Morrison, 1437.

claviplena Grote, 1783.

claypoleana Riley, 5232.

cleis Edwards, 319.

clemataria Smith \& Abbot, 4028.

clemens Smith, 1497.

clemensella Chambers, 6533 (Amadrya).

76 clemensella Chambers, 6060.1 (Batrachetra).

clemensella Stainton, 6062 (Cosmopteryx).

clemensella Chambers, 5862 (Depressaria).

clemensella Chambers, 5985 (Holcocera).

clemensella Chambers, 6256 (Lithocolletes).

clemensella Chambers, 6191 (Nepticula).

clemensella Chambers, 6409 (Philonome).

clemensella Chambers, 6432 (Tischeria).

clemensella Chambers, 6476 (Xylesthia).

clemensellus Robinson, 4546 (Schonobius).

Clemensia ..................

clemensiana Fernald, 5377.

cleobxa Godart, 310.

Cleoceris ...................

168

cleones Boisduval \& Le Conte, 32.

cleopatra Hy. Edwards, 2831.

Cleora .....................

325

Cleptomita.................

clethrx Dyar, 4052.

clientis Grote, 2971.

clintonii Grote, 2888 (Catocala).

clintonii Grote \& Robinson, 3195

(Olene).

clio Edwards, 128 (Argynnis).

clio Packard, 899 (Euverna).

clitosalis Walker, 3045. 
Page.

clitus Edwards, 633.

clivinarium Guenée, 3834.

cloacella Haworth, 6527.

cloanthoides Grote, 1526.

clodiana Grote, 1548.

clodius Ménétries, 1.

cloniasalis Walker, 3049.

clorinda Martyn, 681.

clorinde Godart, 56.

clothilde Edwards, 383.

clotho Fabricius, 674.

cluna Strecker, 1197.

Clydonopteron.............. .

clymena Cramer, 229.

clymene Brown, 838.

clytie Edwards, 367 .

clyton Boisduval \& Le Conte, 248.

cnidia Godart, 54.

c-nigrum Linnæus, 1481.

cnotus Hübner, 682.

coagulata Guenée, 3294.

Cobaliodes

Cobalos ...................

coccidivora Comstock, 4842.

coccinata Grote, 2858.

coccinea Beutenmüller, 4257 (Calesesia).

coccinea Hy. Edwards, 825 (Ptych-

oglene).

coccinea Warren, 4459 (Pyrausta).

coccineifascia Grote, 2623.

cocciniceps Schaus, 829.

Cochlidiidæ

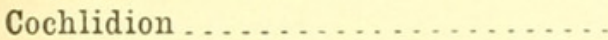

cochrani Riley, 1649.

cochrusalis Walker, 4281.

Cochylis .

cockerella Busck, 5584.

cockerelli Dyar, 6581 (Eulepiste).

cockerelli Busck, 5740 (Gelechia).

cocles Lintner, 250.

cocyta Cramer, 189.

Cocytius.

Codonia

Cœa

coelebs Martyn, 882 (Apantesis).

coelebs Grote, 2886 (Catocala).

coligenalis Hulst, 4327.

Cœlostathma . . . . . . . . . . . . .

comentarixella Chambers, 6538.

cania Hübner, 22:.

Cœnocalpe

Cœnocharis
Cœnochroa

'age.

conomymphata Hulst, 3429.

Cœnonympha . . . . . . . . . . . . . conosipennella Clemens, 6002. coertica Grote, 2343.

cofaqui Strecker, 455.

cogitans Smith, 1590.

cogitata Smith, 1226.

cognata Smith, 1901.

cognataria Hübner, 3860 (Glena).

cognataria Guenée, 3867 (Lycia).

cohortalis Grote, 4519.

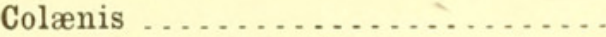

colata Grote, 1734 (Paragrotis).

colata Grote, 3654 (Sciagraphia).

Coleophora . . . . . . . . . . . . .

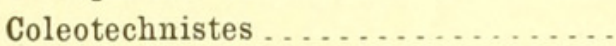

colla Strecker, 1715.

collaris Fitch, 905 (Ammalo).

collaris Walker, 694 (Diludia).

collaris Grote \& Robinson, 1491

(Noctua).

collecta Walker, 3850.

collina Behr, 193.

collinaria Metzner, 3456.

collinusella Chambers, 5633.

Collix ...................... . .

collocata Smith, 1594.

colobrinze Busck, 5598.

colon Edwards, 150.

colona Hübner, 839.

colonella Linnæus, 4636.6 (Aphomia).

colonellus Costa, 4807 (Etiella).

colorada Smith, 1048.

coloradana Fernald, 5426.

coloradaria Grote, 3973.

coloradata Hulst, 3885.

coloradella Kearfott, 5527 (Choreutis).

coloradella Hulst, 4885 (Eurythmia) .

coloradella Chambers, 6154 (Mompha).

coloradella Walsingham, 5923 ( Ecophora).

coloradellus Fernald, 4591 (Crambus ).

coloradensis Hy. Edwards, 4197 (Albuna).

coloratensis Busck, 5717 (Gelechia). coloradensis Ragonot, 4847 (Heterographis). 
coloradensis Hy. Edwards, 3146

(Ianassa).

coloradensis Grote \& Robinson, 4346

(Loxostege).

coloradensis Riley, 454 (Megathymus).

coloradensis Riley, 6569(Prodoxus). coloradensis Putnam-Cramer, 969

(Raphia).

coloradensis Fernald, 4996 (Stenoptilia).

coloradensis Hulst, 3745 (Sympher-

ta).

coloradensis Hy. Edwards, 44 (Synchloe).

coloradensis Hulst, 3290 (Tephroclystis).

Coloradia.

colorado Smith, 1768 (Agrotiphila). colorado Scudder, 487 (Erynnis).

colorado Smith, 1348 (Oneocnemis). coloradus Smith, 711.

coloraria Fabricius, 3759.

colorata Walker, 895 (A pantesis).

colorata Grote, 3644 (Sciagraphia).

columbella Fabricius, 366.

columbia Hy. Edwards, 106 ( Argyn-

nis).

columbia Scudder, 487 (Erynnis).

columbia Smith, 2023 (Graphiphora).

columbia Smith, 741 (Samia).

columbiana Hy. Edwards, 3083

(Nycteola).

columbiana Walsingham, 5187

(Thiodia).

columbina Godart, 92.

Comacla

comacornella Hulst, 4684.

comandrana Fernald, 5326.

comatulana Zeller, 5098.

combinata Walker, 2920.

comes Walsingham, 5463.

cometana Walsingham, 5264.

comis Grote, 1832.

comitana Hübner, 5237.

comma Linnæus, 487 (Erynnis).

comma Walker, 838 (Haploa).

comma Harris, 206 (Polygonia).

commanotata Haworth, 3379.

commelinx Smith \& Abbot, 1299.

commixtalis Walker, 4359.
Page.

commoides Guenée, 1979.

Commophila ..................

commortalis Grote, 4470.

communis Grote, 2870 (Catocala).

communis Grote, 642 (Hesperia).

communis Grote, 4354 (Loxostege).

comosa Morrison, 1662.

compensata Walker, 3499.

complanoides Frey \& Boll, 6451.

complicata Walker, 883 (A pantesis). complicata Strecker, 1956 (Heliophila).

complicata Guenée, 4027 (Sabulodes).

\section{Composia .}

composita Hy. Edwards, 2275.

compressipalpis Guenée, 2464.

compressipennis Smith, 1688.

compta Clemens, 5481 (Atteva).

compta Walker, 3148 (Schizura).

comptana Frölich, 5252.

comptaria Walker, 3331.

comptella Ragonot, 4701.

comptoniella Hulst, 4694.

comptulatalis Hulst, 4631.

comstocki Grote, 1286.

comstockiana Fernald, 5000.

comus Edwards, 532.

comyntas Godart, 442.

cona Strecker, 1637.

Conacontia .................

213

conar Strecker, 2008.

conchana Hübner, 5060.

conchellus Treitschke, 4583.

conchiformis Grote, 2538.

conchis Grote, 1480.

Conchylis . . . . . . . . . . . . . . .

Conchylodes ................

375 concinna Warren, 4390 (Autocosmia).

concinna Smith, 2367 (Schinia). concinna Smith \& Abbot, 3149 (Schizura) .

concinnalis Hampson, 4297.

concinnana Clemens, 5017.

concinnimacula Guenée, 2604.

concinnisella Chambers, 5700.

concinusella Chambers, 5700.

concisa Walker, 3009.

concisaria Walker, 3954.

conclusella Walker, 5768.

concolor Zeller, 6433. 
Page.

concolorella Clemens, 6008 (Coleophora).

concolorella Beutenmüller, 5845

(Cryptolechia).

concolorella Chambers, 6079 (Elachista).

concolorella Chambers, 6135 (Eri-

phia).

concordata Walker, 3362.

concumbens Walker, 2830.

concursana Walker, 5382.

condalix Busck, 6139.

condaliafoliella Busck, 6192.

condaliavorella Busck, 5666.

condensata Walker, 3331.

condita Guenée, 1419.

conditana Walsingham, 5037.

conducta Walker, 2559.

Condylolomia

Condylorrhiza . . . . . . . . . . . . .

confectella Zeller, 5966.

confederata Grote, 4068 (Eurycyttarus. )

confederata Grote, 1118 (Perigea).

confertella Walker, 5853.

configurata Hulst, 3851.

confinaria Walker, 3699.

confine Herrich-Schaeffer, 785.

confinis Walker, 840 .

confinisalis Walker, 2624.

confixana Walker, 5077.

conflexana Walker, 5252.

conflictana Walker, 5408.

confluens Morrison, 2040 (Crocigrapha).

confluens Oberthur, 846 (Eepantheria).

comfluens Cockerell, 6569 (Prodoxus).

confovealis Hulst, 4427.

confragosa Morrison, 1261.

confusa Worthington, 2865 (Catocala).

confusa Lyman, 841 (Haploa).

confusa Hübner, 1890 (Morrisonia).

confusa Smith, 1410 (Rhynchagrotis).

confusa Walker, 3148 (Schizura). confusalis Hulst, 4305 (Asciodes). confusalis Walker, 4500 (Elophila). confusana Robinson, 5431.

confusaria Hübner, 4007.

confusella Waiker, 5915 (Ethmia). confusella Chambers, 5719 (Gelechia).

confusella Dietz, 5938 (Pigritia). confusellus Dyar, 6592 (Anaphora). confusus Hy. Edwards, 6608.

congeminatella Zeller, 6476.

congermana Morrison, 1805.

conglomeratella Zeller, 6295.

congregata Walker, 3409.

congrua Walker, 854 (Fstigmene). congrua Walker, 3619 (Gueneria). congrua Smith, 1448 (Setagrotis).

congruata Walker, 3571.

coniella Ragonot, 4680.

coniferaria Packard, 3587.

coniferarum Smith \& Abbot, 726

(Lapara).

coniferarum Packard, 4065 (Thyridopteryx).

385 coniferella Hy. Edwards, 4071.

conigerana Zeller, 5379.

Coniodes

conjugata Smith, 1918.

conjugens Walker, 1087.

conjuncta Hy. Edwards, 944 (Androloma).

conjuncta Smith, 1671 (Paragrotis). conjunctana Möschler, 5169.

connecta Grote, 1007 (A patela).

connecta Smith, 1070 (Chytonix).

connecta Smith, 1262 (Polia).

connexalis Walker, 4299.

connexana Walker, 5383.

conradi Grote, 2229.

consanguinama Walsingham, 5032.

consecutaria Walker, 3546.

consepta Walker, 3678.

consequaria Hy. Edwards, 3598.

conserta Grote, 2075.

Conservula

consimilata Zeller, 3678.

consimilella Frey \& Boll, 6380

(Gracilaria).

consimilella Frey \& Boll, 6:316

(Lithocolletes).

consimilis Warren, 4335 (Everges-

tis).

consimilis Hy. Edwards, 4207 (Se-

sia) .

consista Walker, 839.

consobrina Guenée, 2926.

consobrinella Zeller, 4723.

consonaria Haworth, 3862. 
consomella Zeller, 5702.

consopita Grote, 2013.

consors Smith \& Abbot, 2874 (Catocala).

consors Smith,-1132 (Perigea).

conspecta Hy. Edwards, 3151.

conspersa Riley, 1295.

conspicua Worthington, 2865 (Catocala).

conspicua Smith, 2757 (Drasteria). conspicua Morrison, 1212 (Hadena). conspicua Edwards, 556 (Limochroes)

conspicua Neumoegen, 917 (Pygarctia).

conspicua Dyar, 4056 (Reselia). constans Hulst, 2902 (Catocala).

constans Hulst, 3917 (Eugonobapta).

constans Hy. Edwards, 4122 (Tri-

procris)

constantella Hulst, 4773.

constellatana Zeller, 5057.

constipata Walker, 1843.

constricta Walker, 1942 (Anarta).

constricta Stretch, 3219 (Malaco-

soma).

constricta Hy. Edwards, 2363

(Schinia).

constrictana Zeller, 5125.

constrictella Zeller, 5930 (Eco-

phora).

constrictella Zeller, 6130 (Theisoa). constrictina Neumoegen \& Dyar,

3215.

consuela Strecker, 2449.

consularis Dyar, 769.

contacta Walker, 1266.

contadina Smith, 1273.

contagionis Smith, 1617.

contatella Grote, 4759.

contempta Boisduval, 2933.

contemptata Guenće, 3647.

contenta Walker, 1221 (Hadena).

contenta Walker, 1232 (Hadena).

contenta Grote, 2080 ( X ylina).

contexta Grote, 2478.

contigua Walker, 964 (Charadra).

contigua Walker, 842 (Haploa).

continens Hy. Edwards, 1127.

contingens Walker, 4026.

continua Hy. Edwards, 3087.

continuaria Walker, 3487 .
Page.

comtimuata Walker, 3662.

continuella Zeller, 5721.

contortalis Guenée, 4483.

contracta Walker, 3110 (Datana).

comtracta Walker, 2734 (Homopyra-

lis).

contracta Packard, 3395 (Hydrio-

mena).

contracta Walker, 2361 (Ipimor-

pha).

contradicta Smith, 1216.

contrahens Walker, 2006.

contraria Walker, 1278 (Hyppa).

contraria Walker, 1807 (Mamestra).

contrariana Walker, 503!.

contrariella Walker, 5844.

contribuaria Walker, 3858.

contubernatellus Fitch, 5678.

convalescens Guenée, 2758.

convallaria Guenée, 3460.

convectalis Walker, 4282.

convergaria Walker, 3855.

conversana Walsingham, 5272 .

convexipennis Grote, 2122.

conviva Harvey, 1104.

comolvulella Fabricius, 6337.

convolvuli Linnæus, 699.

cooleyi Fernald, 4949.

cooperi Behr, 147 (Lemonias).

cooperi Behr, 47 (Synchloe).

coortaria Hulst, 3705.

Copablepharon ................ 184

Copæodes .................. . . 48

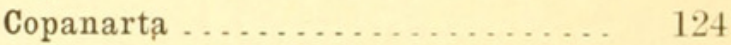

Copibryophila . . . . . . . . . . . 107

Copicucullia . . . . . . . . . . . . . . $\quad 173$

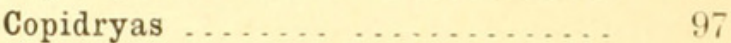

Copipanolis .................. 127

Coptodisca . . . . . . . . . . . . . . 540

Coptotriche ................... 566

coquilletlella Busck, 5623.

coquillettii Smith, 2680.

cora Hübner, 1063.

coracias Guenée, 2984.

coracina Clemens, 4127.

corbis Godman \& Salvin, 24

corculana Zeller, 5166.

cordelia Hy. Edwards, 2895.

cordigera Thunberg, 1930.

Cordylopeza ................. . . 401

Coremia . . . . . . . . . . . . . . . . . 288

coresia Godart, 232.

Coriscium 
Page.

comelia Edwards, 104 (Argynnis). cornelia Neumoegen \& Dvar, 4157

(Hypopta).

comelius Godart, 296.

cornella Walsingham, 6009.

corni Hy. Edwards, 4222.

corniella Ragonot, 4680.

comifotiana Riley, 5257.

cornifoliella Clemens, 6121.

Cornifrons .

cornix Guenée, 2985.

cornuta Grote, 1441.

corollaria Perry, 753.

coronaria Strecker, 4045.

coronatella Clemens, 6238.

coronides Druce, 2440.

coroniella Clemens, 6351.

coronis Behr, 115.

corosana Walsingham, 5152.

correllatum Hulst, 3853.

corrusca Strecker, 2524.

corruscifasciella Chambers, 6558.

corruscipennella Clemens, 6010.

corticea Walker, 3148.

corticosa Guenée, 1057.

corusca Smith, 1349 (Oncocnemis). corusca Hy. Edwards, 4227 (Sesia). coruscana Clemens, 5056.

corvina Boisduval, 797.

corylana Hübner, 5245 (Ancylis).

corylanum Fernald, 5022 (Exartema).

coryliella Chambers, 6308 (Lithocolletes).

coryliella Chambers, 5650 (Menesta).

corylifoliella Clemens, 6011 (Coleophora).

corylifoliella Clemens, 6193 (Nepticula).

corylisella Chambers, 6308.

Coryphista . . . . . . . . . . . . . .

Corythea ..................

coscinia Herrich-Schaeffer, 549.1.

Cosmia

cosmodactyla Hübner, 4937.

Cosmoites

Cosmopteryx

Cosmorhoe

Cosmosoma

Cossidæ

Cossula

Cossus costrmaculalis Snellen, 4478.

costalis Fabricius, 4513 (Hypso-

pygia) .

costalis Doubleday \& Hewitson, 625

(Thanaos).

costarufoella Chambers, 5658.

costata Strecker, 831 (Eubaphe).

costata Grote, 1411 (Rhyncha-

grotis).

394 costiferalis Walker, 4514.1.

costiguttata Hulst, 3405.

costimaculalis Fernald, 4460.

costimaculana Fernald, 5046.

costinotata Walker, 3426.

costipunctella Möschler, 5729.

costolutella Chambers, 5664 .

costomaculana Clemens, 5217.

costorata Haworth, 3463.

costorufoella Chambers, 5658.

costosignella Clemens, 6498.

costostrigella Chambers, 6499.

Cosymbia . . . . . . . . . . . . . . .

cottalis Walker, 4279.

couperii Grote, 419.

coyote Skinner, 593.

crabroniformis Denis \& Schiffermüller, 4188.

Crambidia ....................

Crambidinæ..................

crambidoides Grote, 4624.

crambis Freyer, 295.

crambitana Walsingham, 5085.

crambitella Walsingham, 5837.

Crambodes

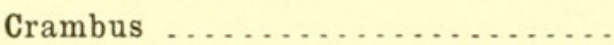

crameri Schaus, 691 (Dilophonota). crameri Ménétries, 675 (Pachylia). crantor Cramer, 679.

Craspedia ................ .

crassata Hulst, 3727 (Cymatophora).

Page.

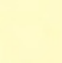

crassatus Haworth, 3079 (Plathypena).

crassifasciella Ragonot, 4739.

crassinervella Zeller, 5480 .

crassipes Smith, 1387.

crassis Herrich-Schaeffer, 1145.

crassiuscula Haworth, 2755.

cratrgella Clemens, 6270 (Litho-

colletes).

cratrgella Busck, 5600 (Recurvaria).

cratrgi Saunders, 2892 (Catocala). 
cratrgi Boisduval \& Le Conte, 385

(Feniseca).

cratrgifoliella Clemens, 6194 (Nepticula) .

cratiegifoliella Clemens, 6388 (Ornix).

cratipennella Clemens, 6012 .

crenana Duponchel, 5260.

crenilinea Smith, 2356.

cremulata Butler, 1996 (Orthodes). cremulata Smith, 1409 (Rhynchagro-

tis).

creola Skinner, 287.

creonalis Walker, 4282.

crepera Grote, 4147.

crepuscularia Schiffermüller, 3862.

crescens Walker, 953.

crescentella Walsingham, 5475.1. crescentifasciella Chambers, 5703.

cresphontes Cramer, 14.

cresphontinus Martyn, 15.

cressonana Grote, 794.

cressonella Chambers, $585 \mathrm{i}$

cressoni Walsingham, 6579 (Eulepiste).

Cressonia . . . . . . . . . . . . . . .

cressoniana Clemens, 5212.

cressonii Grote, 2920 (Panapoda).

cretacea Zeller, 5846.

cretacealis Lederer, 4491.

cretaceata Packard, 3334.

cretata Smith, 981 (Apatela).

cretata Grote, 4108 (Carama).

cretata Grote \& Robinson, 2682

(Tarache).

cretata Hulst, 3292 (Tephroclystis). cretaticostella Clemens, 6013.

cretidactylus Fitch, 4982 (Pterophorus).

cretidactylus Zeller, 4983 (Pterophorus).

creusa Doubleday \& Hewitson, 42. cribrataria Guenée, 3847.

Crimona... . . . . . . . . . . . . .

crinella Treitschke, 6487.

crinisalis Walker, 4354.

crinitalis Lederer, 4354.

Crinodes

arvey, 2219.

crispana Clemens, 5227.

crispatu Packard, 4110.

cristata Grote, 1245 (Hadena).
Page.

cristata Morrison, 2917 (Homophoberia).

cristatella Chambers, 6080 (Elachista).

cristatella Chambers, 5604 (Recurvaria).

cristatella Chambers, 6548 (Semele). cristatrix Guenée, 2549.

cristifasciella Chambers, 5615.

cristifera Walker, 1808 (Mamestra). cristifera Hulst, 3869 (Phæoura).

crocale Edwards, 201.

crocallata Guenée, 4011.

crocataria Fabricius, 3925.

crocea Hy. Edwards, 1307.

crocearia Hulst, 3696 (Cymatophora).

crocearia Packard, 3902 (Sicya). croceella Hulst, 4738.

croceoverticella Chambers, 6500 .

crocicapitella Clemens, 6488.

Crocidophora .................

Crocigrapha ..................

crocotalis Grote, 4440.

crosus Dalman, 666.

71 crossii Hulst, 3540.

crotalariella Busck, 5695.

crotchii Hy. Edwards, 954 (Estigmene).

crotchii Grote, 1786 (Mamestra).

crotchii Hy. Edwards, 2331 (Trichosellus).

crucialis Harvey, 1892.

cruciana Zetterstedt, 5228.

cruciata Grote, 3662.

cruciferam Zeller, 5503 (Plutella). cruciferam Boisduval,38 (Pontia). crudelis Grote, 2974.

cruentaria Hübner, 3759.

cruentus Scudder, 574.

cruralis Guenée, 3021.

crustaria Morrison, 2316.

crypta Dyar, 4106.

Cryptolechia ................

cryptolechiella Chambers, 5851.

crysalus Edwards, 328.

Ctnucha . .

cubanalis Guenée, 4292. cubensis Grote, 937 (Calidota). cubensis Grote \& Robinson, 695

(Diludia).

cubilis Grote, 1372. 
cucomelana Smith, 960.

cucularia Guenée, 3478.

cuculifera Herrich-Schaeffer, 3127.

cuculipennellum Hübner, 6401.

Cucullia

cuculliformis Grote, 1240.

culea Guenée, 2012.

culicaria Guenée, 3478.

culiciformis Linnæus, 4219.

culiculalis Hulst, 4529.

culminana Walsingham, 5117.

culta Lintner, 2487.

cumatilis Grote \& Robinson, 3419

(Conocalpe).

cumatilis Grote, 2328 (Schinia).

cunea Drury, 855.

cuneana Walsingham, 5430.

cuneata Goeze, 894 (Apantesis).

cuneata Grote, 1839 (Mamestra).

cuneolatis Hulst, 4552.1.

cuniferata Walker, 3356.

cunninghami Owen, 128.

cupentina Cramer, 1118.

cupes Grote, 2321.

cupida Grote, 1393.

cupidaria Grote, 3874.

cupidenaria Grote, 3571.

cupidinella Hulst, 4919.

cupidissima Grote, 1399.

Cupido ......................

cupreatis Hübner, 4511.

cupressella Walsingham, 6461.

cupressi Hy. Edwards, 4178 (Me-

mythrus).

cupressi Boisduval, 718 (Sphinx).

cupreus Edwards, 400.

cuprina Zeller, 4514.

curcurbitx Harris, 4162.

curialis Smith, 1882 (Barathra).

curialis Grote, 1893 (Xylomiges).

curiosum Neumoegen, 2454.

currucipennella Zeller, 6014.

curta Morrison, 1936.

curtalis Walker, 4303.

curtica Smith, 2017.

curvata Grote, 3060 (Capis).

curvata French, 2817 (Catocala).

curvata Grote, 1155 (Hadena).

curvata Grote, 3662 (Sciagraphia) .

curvatella Ragonot, 4735.

curvicollis Grote, 1347.

curvifascia Smith, 2071 (Cleoceris).

curvifascia Skinner, 22 (Papilio).
Page.

curviferalis Walker, 4492.

curvilinea Hulst, 3403.

curvilineatella Paokard, 6246.

curvilineella Chambers, 6095 (Coleophora).

curvilineella Beutenmüller, 5874

(Depressaria).

curvimacula Morrison, 2121.

curvistrigella Chambers, 5554 .

cuspidana Stephens, 5260.

Cuspidea ....................

cuspidea Hübner, 2760.

custodiata Guenée, 3406.

cyanana Murtfeldt, 5039.

Cyane..................... 573

Cyaniris.................... 45

Cyathisa .................. 107

Cybalomia . . . . . . . . . . . . . 386

cybele Fabricius, 99.

cycladata Grote, 3613.

cyclades Druce, 4328.

cyclata Walker, 3699.

cyclella Busck, 5707.

Cyclica ....................

cyclica Hy. Edwards, 9!?.

cycloides Guenée, 1103.

Cyclophora ................... . 291

Cycloplasis .................. . . 540

Cydia ...................... 471

Cydosia . . . . . . . . . . . . . . .

cygnus Edwards, 340.

cylindrica Grote, 1207.

Cymatophora................. . .

cymatophoroides Guenée, 3170.

Cymazonita ..................

cymela Cramer, 299.

cymosa Grote, 1237.

cyna Edwards, 446.

cyneas Godman \& Salvin, 178.1.

cynica Smith, 1511 (Noctua).

cynica Guenée, 1997 (Orthodes).

cynoglossum Hy. Edwards, 653.

cynthia Drury, 736.

cypridalis Hulst, 4561.

cypris Edwards, 100.

cyralis Druce, 4348.

cyrilella Costa, 4618.

cyrilli Zeller, 4618.

Cysteophora.

Cysteopteryx...................

dacotah Edwards, 494

dactylina Grote, 975. 
dxdalus Behr, 408 (Cupido). dixdalus Smith, 1561 (Porosagrotis).

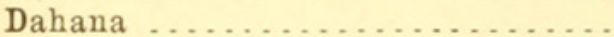

dahlbomiana Zetterstedt, 5167.

dakota Smith, 1642 .

Dakruma

Dalceridæ

Dalcerides .

dallasiana Frey \& Boll, 6195.

dama Guenée, 2707.

damalis Grote, 1379.

damaris Felder, 81 (Pyrisita).

damaris Skinner, 82 (Pyrisita).

damastus Godart, 362.

damnosalis Walker, 3069.

damon Cramer, 362.

danx Cramer, 253.

danbyi Neumoegen, 864 (Diacrisia). danbyi Neumoegen, 3168 (Gluphisia).

danbyi Hulst, 3878 (Jubarella). danbyi Hulst, 3239 (Paraptera). danistica Grote, 2597.

Dannemora .................

daona Druce, 4088.

dapalis Grote, 4393.

daphnis Cramer, 99 (Argynnis).

daphnis Martyn, 100 (Argynnis).

daphnis Gray, 15 (Papilio).

dapsilis Grote, 1458.

dara Kollar, 471.

Dargida

dargo Strecker, 1583.

daria Druce, 2639 (Eumestleta).

daria Godart, 87 (Eurema).

Daritis .

dascomalis Walker, 4345.

Dasycera . . . . . . . . . . . . . .

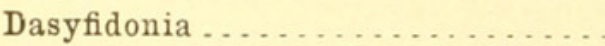

Dasylophia

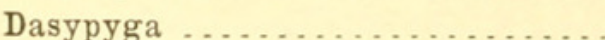

Dasyspoudæa

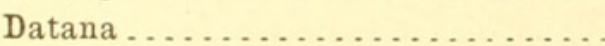

dataria Grote, 3844 (Cleora).

dataria Hulst, 3483 (Cosymbia).

datisalis Druce, 4302.

daucella Treitschke, 5887.

daucus Cramer, 671.

daunia Edwards, 421.

daunus Herbst, 92 (Euptoieta).

daumus Boisduval, 8 (Papilio).

dauria Strecker, 295.

davena Smith, 1832.
Page

davidsoni Hy. Edwards, 4064. davisellus Beutenmüller, 6601.
79

(16)

decoloraria Hulst, 3991 (Priocycla). decolorata Hy. Edwards, 699.

decora Morrison, 966 (Charadra). decora Zeller, 4634 (Dicymolomia). decoralis Walker, 4777 (Elasmopalpus).

decoralis Hübner, 2725 (Pangrapta). decorana Zetterstedt, 5537 (Orchemia).

decorana Haworth, 5169 (Thiodia). decorata Saunders, 895 (A pantesis). 
Page

decorata Worthington, 2865 (Caiocala) .

decorata Hulst, 3715 (Cymatophora).

decorata Smith, 3081 (Hypena). decorella Stephens, 6155 (Mompha). decorella Hulst, 4636.5 (Paralipsa). decorellus Zincken, 4590 (Crambus). decorellus Hulst, 4777 (Elasmopalpus).

decrepitaria Herrich-Schaeffer, 3449. decrepitata Zetterstedt, 3449.

decuriella Hübner, 4711.

deducta Morrison, 2777.

deductaria Walker, 3754 (Apæcasia).

dedrictaria Walker, 3965 (Euchleena).

defecta Grote, 1090.

defectarium Guenée, 3838.

defectella Zeller, 6501.

defensaria Guenée, 3461.

defessa Grote, 1816.

defessaria Freyer, 3862.

definita Packard, 3192 (Hemerocampa).

definita Aaron, 181 (Thessalia).

definitella Zeller, 6156.

defixaria Walker, 3513.

deflavata Staudinger, 3381.

deflectana Robinson, 5301.

deflorata Fabricius, 846.

defloriana Martyn, 894.

defuata Walker, 3755.

defoliaria Clerck, 3883.

degenerana Hübner, 3083.

degenerata Haworth, 3361.

Deidamia

Deilephila

dejecta Hulst, 3794 (Aleis).

dejecta Strecker, 2814 (Catocala).

delassalis Hulst, 4775.

deiavaricus Forbes, 4935.

delaware Edwards, 566.

delawaricus Zeller, 4933.

delecta Walker, 2662.

delectata Hulst, 3649.

delectella Hulst, 4755.

deleta Hulst, 3688 (Cymatophora).

deleta Grote, 2255 (Epiglæa).

deleta Hy. Edwards, 2701 (Fruva).

deleta Guenée, 2929 (Poaphila). deletella Zeller, 6463

delia Cramer, 87.

delicata Hulst, 3527 (Eois).

delicata Grote, 1289 (Trachea).

delicatella Walsingham, 6063.

delicatum Hulst, 3831 (Selidosema).

delila Fabricius, 90.

delilah Strecker, 2876.

delimitata Warren, 3363.

delineata Guenée, 2544.

delinquens Walker, 2927.

delliella Fernald, 5935.

delphinii Boisduval, 4077.

delphusa Druce, 4509.

deludana Clemens, 5213.

Demas

demissa Walker, 1810.

demissana Walsingham, 5332.

demissaria Hübner, 3521.

demoditas Hübner, 87.

demonica Hübner, 226.

demorsaria Strecker, 3775.

demotella Grote, 4686.

demutabilis Smith, 1471.

dendraria Guenée, 3864.

denotata $\mathrm{Hy}$. Edwards, 4176.

densa Walker, 2147 (Bellura).

densa Smith, 1907 (Scotogramma).

densaria Walker, 3561.

densellus Zeller, 4629

dentalis Smith, 2264.

dentata Grote, 1046 (Apharetra).

dentata Hy. Edwards, 3201 Glo-

veria).

dentata Grote, 4817 (Melitara).

dentata Dyar, 4057 (Roeselia).

dentatella Grote, 1947.

dentella Fernald, 4553 (Eugrotea).

dentella Busck, 5726 (Gelechia).

denticulalis Harvey, 3013.

denticulata Hulst, 3882 (Phigalia).

denticulata Grote, 3648 (Sciagraphia).

denticulata Walker, 3580 (Synchlora).

denticulella Ragonot, 4728.

denticulodes Hulst, 3734 .

dentifera Walker, 2550.

dentiferellus Walsingham, 5489 .

dentilinea Hampson, 4489 (Nymphula).

dentilinea Smith, 2082 (Xylina).

dentilineella Hulst, 4643. 
dentosa Grote, 4525 .

dentosella Ragonot, 4838.

denudatr Slosson, 846 (Ecpantheria).

denudata Neumoegen, 765 (Pseudohazis).

denudatum Harris, 4183.

Deoclona ..................

depauperata Oberthur, 845 .

depicta Grote, 2593.

depilis Grote, 1378.

deplanaria Walker, 3961 (Euchlæna).

deplanaria Guenée, 3803 (Paraphia).

depontanata Grote, 4014.

Depressaria.

depressostrigella Chambers, 5736.

deprivata Walker, 3561.

depromaria Grote, 3788.

Deptalia . . . . . . . . . . . . . .

depuiseti Boisduval, 81.

depussostrigella Chambers, 5736 .

deridens Guenée, 964.

deroguta Walker, 2558.

derosa Morrison, 1112.

Derrima.

derupta Morrison, 1301.

descherei Neumoegen, 3119.

desdemona Hy. Edwards, 2877.

deserta Smith, 1323 (Homohadena).

deserta Felder, 82 (Illice).

deserta Hy. Edwards, 2913 (Litocala).

desertana Zeller, 5140.

desertus Hy. Edwards, 792.1 (Lycomorpha).

deshaisiana Lucas, 5297.

designalis Guenée, 4313.

designata Hufnagel, 3438 (Gypsochroa).

designata Walker, 2361 (Schinia).

Desmia.................... .

desmodiella Clemens, 6303.

desmodifoliella Clemens, 6352.

desolatus Strecker, 6614.

desperaria Hulst, 3810.

desperata Kirby, 945 (Androloma).

desperata Guenée, 2813 (Catocala).

desperata Hulst, 3266 (Gymnocelis).

desperata Smith, 1793 (Mamestra).
Page.

destinatum Möschler, 3351.

destructor Stephens, 6487.

desuetella Walker, 4875.

determinata Neumoegen, 889 (A pantesis).

determinata Smith, 1780 (Mamestra).

determinata Walker, 3982 (Metanema).

determinatella Zeller, 5924.

detersa Walker, 1623.

detersata Guenée, 3753.

detersella Clemens, 5794.

detesta Smith, 1621.

detracta Walker, 1783.

detrahens Waiker, 2962.

detritalis Guenée, 4344.

deutschiana Zetterstedt, 5437.

Deva.....................

deva Edwards, 541.

devastatrix Brace, 1232.

devergens Hübner, 2535.

devia Grote, 2244.

devialis Grote, 4518.

devinctaria Guenée, 3886.

dia Grote, 1972.

Diachorisia

573

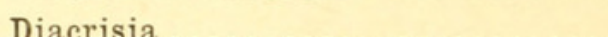

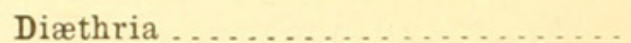

diagonalis Dyar, 2763.

Diallagma . . . . . . . . . . . . .

diana Hy. Edwards, 2830 (Catocala).

diana Packard, 760 (Hemileuca).

diana Hübner, 5537 (Orchemia).

diana Cramer, 94 (Semnopsyche).

diaphanella Frey \& Boll, 6277.

Diaphania . . . . . . . . . . . . . .

diasema Boisduval, 2530.

Diasemia ..................

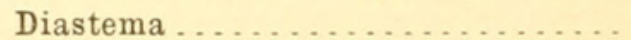

Diastictis . . . . . . . . . . . .

Diathrausta

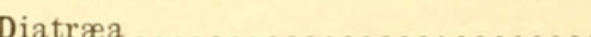

diazoma Grote, 3205.

dibeliana Hübner, 5006.

Dicentria . . . . . . . . . . . . . . .

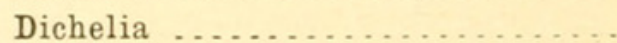

Dichogama ...............

dichrocella Ragonot, 4907.

Dichrorampha ..............

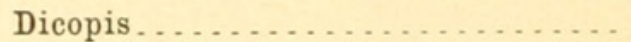

dictimealis Walker, 4354. 
dictynna Walker, 747.

Dicymolomia .....................

Didasys ........................

didonea Smith, 1176.

didyma de Beauvois, 778.

dieckii Neumoegen, 889.

dietziella Busck, 5544.

diffascialis Hübner, 4276.

differentialis Fernald, 4626.

differta Morrison, 2225.

difficilisella Chambers, 5608.

diffinana Walker, 5133.

diffinis Boisduval, 653.

diffissa Grote \& Robinson, 4458.

difflua Geyer, 1233.

difformis Smith, 1668.

diffusa Grote, 2148 (Bellura).

diffusa Walker, 1965 (Heliophila). diffusa Smith, 2349 (Schinia).

diffusilis Harvey, 1266.

digitalis Grote, 2211 (Anchocelis).

digitalis Smith, 2362 (Schinia).

digna Morrison, 1474.

dilara Strecker, 1200.

dilatana Walsingham, 5153.

dilatata Smith, 1865.

dilatifasciella Ragonot, 4822.

dilatocula Smith, 2088.

dilecta Hy. Edwards, 1924.

Dilophonota ..................

dilucidula Morrison, 1426.

diluculella Grote, 4649.

Diludia

dilutana Hübner, 3083 (Nycteola). dilutana Walsingham, 5457 (Pha-

lonia).

dilutaria Freyer, 3337.

dilutata Schiffermüller, 3337.

diluticostana Walsingham, 5337.

dilutifuscana Walsingham, 5070 .

dimediatella Ragonot, 4921.

dimidiana Sodoffsky, 5034 .

dimidiata Grote, 2272 (Antaplaga).

dimidiata Strecker, 848 (Leptarctia).

dimidiata Herrich-Schæffer, 3118

(Pheosia).

dimidiata Herrich-Schæffer, 4117

(Pyromorpha).

dimidiatellus Grote, 4606.

dimidiella Walsingham, 5925.

diminutiva Græf, 834 (Eubaphe).
Page.

\section{dina Hübner, 84.}

dion Edwards, 559.

dionalis Walker, 4411.

dione Fabricius, 882 (Apantesis).

dione Scudder, 390 (Gæides).

dionea Smith, 1190.

dionysius Scudder, 278.

dionyza Hy. Edwards, 2869.

Dioptidæ ..................

Dioryctria . . . . . . . . . . . . . .

diospiryella Chambers, 6138.

Diphryx................... . . .

diphteralis Geyer, 4296.

Diphthera .................. . .

dipsaci Grote \& Robinson, 951

dipteroides Guenée, 1054.

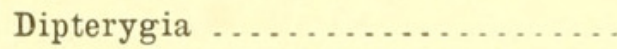

Dircenna . . . . . . . . . . . . . . . 33

Dircetis . . . . . . . . . . . . . 245

directana Walker,5335.

direptana Walker, 5228.

dis Grote, 2279.

disa Thunberg, 270.

discalis Grote, 2733 (Homopyralis). discalis Grote, 1771 (Mamestra).

disceptaria Fischer, 3449.

discessalis Walker, 4286.

discigerana Walker, 5242.

discigerella Ragonot, 4891.

discinigra Walker, 1147.

discippus Fabricius, 145.

discissa Walker, 2946.

discistriga Smith, 1098.

discivaria Walker, 2235.

discoannulella Chambers, 5795.

discocella Dietz, 5744.

discoferana Walker, 5246.

discoidalis Kirby, 268 (Erebia).

discoidalis Skinner, 362 (Mitoura).

discoidalis Grote, 1408 (Rhynchagrotis) .

discolor Walker, 2217 (Cosmia).

discolor Speyer, 1792 (Mamestra).

discolor Smith, 1909 (Scotogramma).

discoloralis Guenée, 3042.

discolorata Neumoegen, 3215.

discomaculella Chambers, 5785.

disconotella Chambers, 5588.

discoocelella Chambers, 5744. 
discoocella Chambers, 5744 . discoocellella Chambers, 5744 . discooecella Coquillett, 5744 . discopunctana Clemens, 5344. discopunctella Dietz, 5958.

discors Grote, 1214.

discospilata Walker, 3604.

discostriata Walsingham, 6015.

discostrigella Chambers, 5899 (Ethmia).

discostrigella Chambers, 5796 (Gelechia).

discoienta Walker, 3748.

discreta Strecker, 3087.

disertalis Walker, 4285 .

disippe Godart, 239.

disjunctaria Packard, 3356.

dislocaria Packard, 3786.

dispar Grote, 4495 (Nymphula).

dispar Smith, 1276 (Polia).

dispar Linnæus, 3196 (Porthetria) .

disparata Hy. Edwards, 945.

dispersellus Robinson, 4545.

displiciens Walker, 1649.

disposita Morrison, 2078.

dispulsa Morrison, 965.

dispuncta Walker, 3687.1(Macaria).

dispuncta Walker, 3647 (Sciagraphia).

dissecta Grote \& Robinson, 1028.

dissectalis Grote, 4431

dissectella Zeller, 5677

dissectus Grote, 4568.

disserptaria Walker, 3864 .

disseverans Walker, 2923.

dissidens Felder, 1305.

dissimilana Treitschke, 5143.

dissimilaria Hübner, 3759.

dissimilis Hulst, 3771.

dissitana Grote, 5381.

dissociana Walker, 2943.

dissociaria Hulst, 3821.

dissona Möschler, 1697.

dissonaria Hulst, 3792.

disstria Hübner, 3221.

distans Grote, 1032.

distema Grote, 5270 (Ancylis).

distema Grote, 2566 (Cilla).

disticha Morrison, 1923.

distichata Guenée, 4010.

distichoides Grote, 1752.

distigma Walsingham, 772.

distigmana Walker, 5144.
Page.

distincta Neumoegen, 2755 (Drasteria).

distincta Grote, 2609 (Eustrotia).

distincta Hübner, 1785 (Mamestra). distincta Walsingham, 5354 (Sparganothis).

distincta French, 3210 (Tolype).

distracta Smith, 1407.

distribuaria Hübner, 3738.

distycharia Guenće, 3948.

diva Grote, 2588 (Annaphila).

diva Hulst, 3774 (Platæa).

diva Riley, 5533 (Walsinghamia).

divaricata Grote, 1305.

divergens Walker, 4097 (Lithacodes).

divergens Walker, 1736 (Paragrotis). divergens Walker, 2361 (Sthinia). divergens Behr, 2782 (Syneda). divergens Fabricius, 2534 (Syngrapha).

diversicolor Morrison, 1165.

diversilineata Grote, 1267 (Polia).

diversilineatum Hübner, 3348 (Eustroma). divesta Grote, 1168.

Diviana ...................

divida Möschler, 1305.

dividua Grote, 2615.

dividula Grote, 2587.

divisa Walker, 2571.

divisana Hübner, 5309 (Acleris).

divisana Walker, 5255 (Ancylis).

divisaria Walker, 3862 (Ectropis).

divisaria Walker, 3388 (Hydrio-

mena).

divisata Walker, 3764.

dnoposella Ragonot, 4813.

Doa ............................

docilis Grote, 1456.

docta Walker, 885.

dodecana Zeller, 5079.

dodgei Butler, 890 (Apantesis).

dodgei Grote, 1842 (Mamestra).

Dodia ......................

doira Strecker, 1862.

dolabella Zeller, 5686.

Dolba

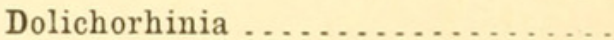

Dolichosticha ................ 374

dolichns Hübner, 329.

dolis Grote, 1618.

dollii Neumoegen, 4184 (Memythrus). 
dollii Grote, 1562 (Porosagrotis). dollii Neumoegen, 710 (Sphinx). dolores Neumoegen \& Dyar, 3200. dolosa Strecker, 2383 (Schinia). dolosa Grote, 1894 (Xylomiges). domalis Guenée, 4511.

domicella Erichson, 641.

domina Hy. Edwards, 2590.

domingonis Butler, 692.

dominicaria Guenée, 3585.

dominicata Guenée, 2919.

Donacoscaptes . . . . . . . . . . . . .

donotaria Walker, 3739.

dorantes Stoll, 579.

dorcas Kirby, 397.

doris Boisduval, 882 (Apantesis). doris Barnes, 755 (Coloradia).

dormitans Guenée, 1076.

dorothea Dyar, 3165 .

dorsalis Smith, 2130.

dorsalutea Walker, 2365.

dorsimacula Dyar, 6600.

dorsimaculana Robinson, 5440.

dorsimaculella Chambers, 6471.

dorsipallidella Chambers, 6110.

dorsisignatana Clemens, 5144.

dorsistriatana Walsingham, 5464 .

dorsistrigella Clemens, 6502.

dorsivittella Zeller, 5603.

dorsomaculella Dietz, 5961.

dorus Edwards, 581.

Doryodes

Dosara

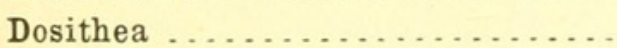

dotalis Hulst, 4891.

dotata Clerck, 3350.

doubledayi Guenée, 1075 (Baileya). doubledayi Scudder, 3141 (Heterocampa).

doubledayi Packard, 3123 (Nadata).

Douglasia ................. . .

draco Edwards, 518.

dracusalis Walker, 4306.

Drasteria . . . . . . . . . . . . .

Drepana....................

Drepanodes ................

drewseni Staudinger, 1656.

drexelii Hy. Edwards, 3101.

drupacearum Boisduval, 3221.

drupiferarum Smith \& Abbot, 701.

drurxi Donovan, 699.

drurii Latreille, 545.

drusius Edwards, 185 (Charidryas).
Page.

drusius Edwards, 594 (Thorybes).

drya Fabricius, 52.

dryadata Hulst, 3431.

dryadella Hulst, 4861.

diyas Edwards, 206.

Dryobota . . . . . . . . . . . . .

Dryocetis . . . . . . . . . . . .

Dryope ...................

dryope Edwards, 343.

dryopterata Grote, 4044.

duaria Guenée, 3944.

dubia Walker, 851

dubiana Clemens, 5249.

dubiella Stainton, 6520.

dubiosella Beutenmüller, 5503.

dubitana Hübner, 546:.

dubitans Walker, 1227 (Hadena).

dubitans Tepper, 2422 (Heliaca)

dubitata Linnæus, 3416 (Triphosa).

dubitata Packard, 3417 (Triphosa).

dubitatella Zeller, 5851.

dubitella Chambers, 5662.

ducens Walker, 3148.

ducta Grote, 1230.

dudiella Busck, 5627.

dugesii Cockerell, 953.

dulcearia Grote. 3773.

dulciella Huist, 4856 (Honora).

dulciella Hulst, 4679 (Myelois).

dulciola Grote, 2901.

dumetellus Hübner, 4571.

chmeti Behr, 313.

dumetorum Boisduval, 380.

dunbari Harvey, 2116.

duodecemlineata Packard, 3330.

duodecemlineella Chambers, 6371.

duodecemstriata Walsingham, 5284.

duovata Bird, 2189.1.

duplana Fabricius, 3083.

duplex Walsingham, 5049.

duplicata Worthington, 2865 (Catocala).

duplicata Neumoegen \& Dyar, 839 (Haploa).

duplicata Bethune, 3002 (Homoptera).

duplicata Packard, 3651 (Sciagraphia).

duplicatus Smith, 2439 (Cirrhophanus).

duplicatus Grote, 4609 (Crambus). duplipunctella Ragonot, 4681.

duryi Edwards, 314. 
dwinellei Hy. Edwards, 148. dyaralis Fernald, 4333.

dyarella Kearfott, 5520 .

dyari Cockerell, 2438 (Cirrhopha-

nus).

dyari Rivers, 3223 (Epicnaptera).

dyari Merrick, 840 (Haploa).

dyari Busck, 5531 (Hemerophila).

Dyaria . . . . . . . . . . . . . . .

dyariella Busck, 6339 (Chilocampyla).

dyariella Busck, 5749 (Gelechia).

dyarii Hulst, 3565 (Nemoria).

dyaus Grote, 2487.

dymas Edwards, 171.

dymnusalis Walker, 4807.

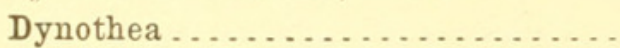

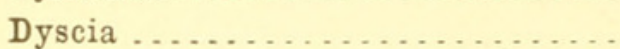

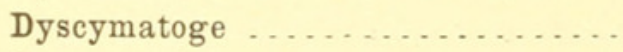

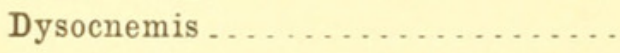

Dysodia . . . . . . . . . . . . . .

dyspteraria Grote, 4139.

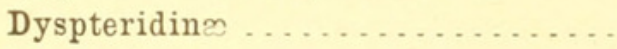

Dyspteris.................

Dysstroma .................

earina Morrison, 1777.

eavesi Hy. Edwards, 242 (Basilarchia).

eavesii Stretch, 896 (Kodiosoma).

eboracensis Zeller, 6108.

eborata Hulst, 3254.

ebriola Poey, 88.

ebulealis Guenée, 4300.

eburnea Walsingham, 6173.

eburneata Guenée, 3536.

ecclesialis Guenée, 4285.

Eccopsia ...................

Ecdytolop'a . . . . . . . . . . . .

echinocystis Behr, 2496.

echo Edwards, 440 (Cyaniris).

echo Smith \& Abbot, 849 (Seirarctia).

Ecpantheria

ectrapela Smith, 1861.

Ectropis . . . . . . . . . . . . . . .

ectypa Morrison, 1828.

Ectypia . . . . . . . . . . . . . .

edentata Grote, 2621 (Azenia).

edentata Smith, 1539 (Feltia).

edentella Hulst, 4917.

edictalis Walker, 3074 (Bomolocha). edictalis Smith, 1565 (Paragrotis). editha Mead, 391 (Gæides).
Page.

editha Boisduval, 159 (Lemonias). edmandsii Packard, 3151(Schizura). edmandsii Packard, 4838 (Vitula). edna Hulst, 3274.

edolata Guenée, 1035.

edonis Grote, 4613.

eductalis Walker, 3063.

edusa Drury, 2986.

edusina Harvey, 2995.

edwardi Neumoegen \& Dyar, 4158. edwardsata Packard, 3901 (Neoterpes).

edvardsata Hulst, 3769 (Phengommatæa).

edwardsi Grote, 786 (Lymire).

edwardsialis Hulst, 4800.

dwardsiana Walsingham, 5465.

edwardsii Boisduval, 944 (Androloma).

edwardsii Stretch, 881 (Apantesis). edwardsii Reakirt, 119 (Argynnis). edwardsii Butler, 688 (Dilophonota).

edwardsii Behr, 70 (Eurymus).

edwardsii Packard, 928 (Hemihyalea).

edwardsii Barnes, 481 (Oarisma). edwardsii Heylaerts, 4067 (Platœceticus).

edwardsii Fish, 4940 (Platyptilia). edwardsii Beutenmüller, 4194 (Sanninoidea).

edwardsii Beutenmüller, 4256 (Sesia).

edwardsii Behr, 46 (Synchloe). edwardsii Behr, 2796 (Syneda). wardsii Saunders, 345 (Thecla). edwardsii Smith, 1943 (Trichoclea). effascinaria Hulst, 4006.

effectaria Walker, 3957. efficitalis Walker, 4454. effractana Frölich, 5299. effrenatella Clemens, 6534. effusatis Walker, 3009. egena Guenée, 2489. egenaria Walker, 4059. egens Walker, 1163. egeremet Scudder, 519. egestis Smith, 1086. eglanterina Boisduval, 764. egle Drury, 910. egleis Boisduval, 130. eglenensis Clemens, 907. 
egressalis Walker, 4636.

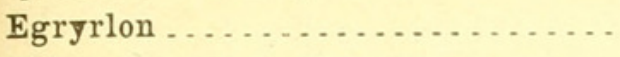

Eido .

Eidothoa

ejectarium Walker, 3838.

elthlipsis Grote, 4490.

elaborata Hy. Edwards, 2424 (Heliaca).

elaborata Grote, 3612 (Heliomata).

Elachista.

Elachistidæ

Elasmopalpus

elata Smith, 1446.

elautalis Grote, 4481.

elda Behr, 2825 (Catocala).

elda French, 2069 (Cleoceris).

elda Hy. Edwards, 4242 (Sesia).

eldanaria Walker, 4007

elealis Walker, 4425.

electa Hulst, 3751 (Aethyctera).

electa Edwards, 105 (Argynnis).

electalis Hulst, 4515.

electellum Hulst, 486.5.

electilis Morrison, 1382.

Electra...................

electra Wright, 756 (Hemileuca).

electra Lintner, 602 (Thorybes).

elegans Clemens, 4582 (Crambus).

elegans Hübner, 2432 (Noropsis).

elegans Strecker, 3114 (Odontosia).

elegans Packard, 4098 (Packardia).

elegans Stretch, 918 (Pygarctia).

elegantalis Warren, 4382 (Diasemia). elegantalis Fitch, 2725 (Pangrapta). elegantaria Hy. Edwards, 3888.

elegantella Chambers, 5582 (Aristotelia).

elegantella Frey \& Boll, 6372 (Gracilaria).

elegantella Hulst, 4718 (Pinipestis). elegantellus Walker, 4557 (Crambus).

elegantula Harvey, 2684.

elephantopodella Frey \& Boll, 6322.

eleuchea Hübner, 235.

elevalis Guenée, 4310.

elevana Fabricius, 5309.

elevata Smith, 1436 (Pachnobia).

elevata Fabricius, 4310 (Sylepta).

elimaria Hulst, 3621.

elimata Guenée, 1426.

elis Strecker, 62.

elisata Strecker, 3415 .
Page.

238

492

500

535

530

426

Ellopia.....................

eloisella Clemens, 6157.

elongana Walsingham, 5172.

elongata Stretch, 888 (Apantesis).

elongata Hulst, 3823 (Conocharis).

elongata Grote, 3165 (Fentonia).

elongata Haworth, 3294 (Tephro-

clystis).

elongatus Grote, 2946 (Celiptera).

elongella Linnæus, 6354.

elonympha Hübner, 2909.

Elophila . . . . . . . . . . . . . . .

elsa Strecker, 712.

elsinora Hulst, 3609.

elutalis Hübner, 4336.

elutata Hübner, 3387.

elutea Haworth, 4879.

elutella Hübner, 4879.

elva Bates, 196.1.

elymi Rambur, 221.

emaciatana Walsingham, 5154.

emaculata Smith, 1038.

emargataria Guenée, 3932.

emarginana Walsingham, 5210.

emarginata Grote, 1405 (Rhyncha-

grotis).

emarginata Smith, 2104 (Xylina).

emblemella Clemens, 5654.

emeritella Stainton, 5884 .

Emesis . . . . . . . . . . . . . . . .

emilia Hy. Edwards, 2810 (Catocala)

emilia Edwards, 70 (Eurymus).

emissa Edwards, 192.

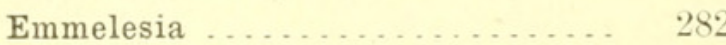

Emmelia .................. . . 382

Emmiltis . . . . . . . . . . . . . . 298

emphytiformis Walker, 4167.

Emplocia . . . . . . . . . . . . . . . . 286

Enargia . . . . . . . . . . . . . . . 179

Enarmonia ................... 469 
Enchoria

Enchrysa

Endropia

endropiaria Grote \& Robinson, 3908.

Endrosis

Enemera

enervata Guenée, 1091.

enervis Guenée, 1998.

enhydris Grote, 4137.

Enicostoma

enixa Grote, 1115.

enniculalis Hulst, 4522 .

ennius Scudder \& Burgess, 625.

Ennominæ

Ennomo

ennucleata Guenée, 3487 (Synelys). ennucleata Packard, 3486 (Synelys).

Enodia ....................

enoptes Boisduval, 427 .

enotata Linnæus, 3667.

ensigerella Hübner, 4560.

enteridis Smith, 1638.

enthea Grote, 1256.

enthealis Hulst, 4511.

Entoreuma

Enypia. . . . . . . . . . . . . . .

eodamus Cramer, 252.

Eois .

eos Edwards, 461.

Eosphoropteryx ..

Epagoge.

Epargyreus

Epelis

Epermenia

ephelidaria Hulst, 3899.

Ephelis

ephemeræformis Stephens, 4065.

Ephestia . . . . . . . . . . . . . .

ephestiella Ragonot, 4841.

Ephestiodes

ephestion Stoll, 236.

ephippialis Zetterstedt, 4392.

ephippiatus Harris, 4075.

Ephyra ..................

ephyrarium Walker, 3838.

ephyrata Guenée, 4005.

Epicallima

epichysis Grote, 1259.

Epicnaptera.

epiconalis Ragonot, 4530.

Epicorsia. . . . . . . . . . . . . .

Epicorthylis
Page.

279

507

339

543

318

$52: 3$

303

336
Epidemas

Page

Epidemia

119

Epidromia

epigra Grote, 2515.

epigxella Chambers, 5718.

epigena Butler, 592.

Epiglæa

181

epigona Herrich-Schaeffer, 592.

Epigraphia

Epigritia.

epilais Walker, 781.

epilobii Harris, 670.

Epimartyria

Epimecis

epimenis Drury, 2427.

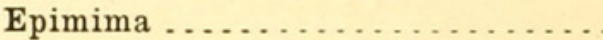

Epina

412

Epinephele

32

Epinotia

464

Epinyctis

184

epione Drury, 2806.

epionoides Guenée, 2725.

Epipaschia

epipaschia Girote, 1321.

Epipaschiiæ

Epiplatymetra

341

Epiplemidæ

350

epipsodea Butler, 273.

Epipyropidæ

Epirranthis

338

Epirrhoe

278

Epirrita...................... 275

Epischnia ................ 427

epischnioides Hulst, 4827.

Episemasia

307

Episimus.

463

Epithectis

epithore Boisduval, 142.

epixanthe Boisduval \& Le Conte, 398.

Epizeuxis

epopea Cramer, 1118.

eppelsheimii Frey \& Boll, 6325.

epsilon Ottolengui, 2511.

epula Boisduval, 193.

epyaxa Strecker, 29.

equitella Dietz, 5962.

Erannis

eraso Guenée, 2931.

Erastria .

erastrioides Guenée, 2676.

eratalis Walker, 4448. 
Page.

Ercta

373

erdmani Möschler, 1145.

erebana Guenée, 5311.

Erebia

Erebus.

erechtea Cramer, 2754.

erechtiisella Chambers, 6428.

erecta Walker, 1843.

erectalis Guenée, 3079 (Bomolocha).

erectalis Walker, 4778 (Elasmopalpus).

erectalis Grote, 4441 (Pyrausta). eremiata Hulst, 3521 (Eois). eremiata Guenée, 3673 (Macaria). eremitoides Strecker, 714. eremitus Hübner, 716. eremocarpi Hy. Edwards, 4245. erepta Guenée, 2163. erica Butler, 1103. ericetorum Boisduval, 639. erichto Guenée, 2755. eridania Cramer, 1301. eriensis Grote, 1484.

erigeronana Riley, 5454 .

erigeronella Chambers, 6353.

erinacea Retzius, 904. erinalis Walker, 4297. erinna Edwards, 128.

Eriocephala. . . . . . . . . . . . eripalis Grote, 4272.

Eriphia .

eriphyle Edwards, 65.

erippus Cramer, 308. erodyle Bates, 202.

\section{Eromene}

\section{Erora}

eros Edwards, 240.

erosa Hübner, 2556 (Anomis). erosa Stretch, 3221 (Malacosoma). erosarium Walker, 3838. erosealis Walker, 4458. erosiata Packard, 4044. errans Skinner, 549 (Prenes). errans Smith, 2368 (Schinia). erransella Chambers, 6158. erratica Smith, 1425. errato Boisduval, 658. erronella Zeller, 4889.

Ersephila.

erucalis Hübner, 4335.

eruditella Grote, 5893.

erutana Herrich-Schaeffer, 5315. erutaria Duponchel, 3329.

Page. erycata Cramer, 2726.

\section{Erycides}

erymus Boisduval, 408.

eryngii $\mathrm{Hy}$. Edwards, 279.

Erynnis .

eryphon Boisduval, 377.

erythella Ragonot, 4883.

erythremaria Guenée, 3624.

erythriella Clemens, 6177.

erythrinella Busck, 6405.

erythrolita Grote, 2053.

erythrostigma Haworth, 2162.

Escaria

escaria Grote, 3819.

esmeralda Oberthur, 2472.

Estigmene .................. . . esurialis Grote, 1477.

etacta Linnæus, 1925.

ethela Edwards, 274 (Erebia).

ethela Neumoegen, 4155 (Hypopta).

ethela Hulst, 3384 (Mesolevca).

ethlius Cramer, 550.

Ethmia

ethrica Smith, 1201.

Etiella . . . . . . . . . . . . . . .

etiella Treitschke, 4807

etolus Boisduval, 656.

Euacidalia . . . . . . . . . . . . . . . . 291

Euaspilates. . . . . . . . . . . . .

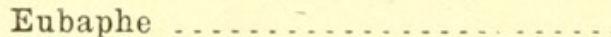

Eubolia .................

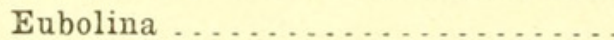

eubule Linnæus, 52.

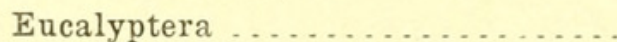

205

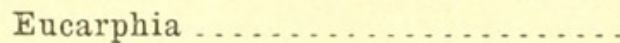

Eucatagma ................. 568

Eucaterva .................. $\quad 331$

Eucatoptus .................. 498

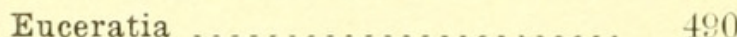

Eucereon .................. 77

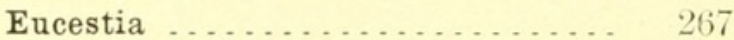

Euchaetes . . . . . . . . . . . . . . . 93

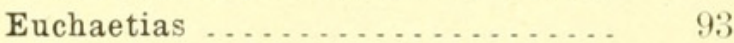

Euchalcia .................. 199

Euchiradia ................. 448

Euchlæna ................. 539

Euchloe ................... 7

euchloria Guenée, 3567.

Euchœca .................... $\quad 275$

Euchromius ................... 410

Eucirrødia . . . . . . . . . . . . . . 178

Euclea .................... . . 354 
euclea Bergstraser, 189.

Euclemensia.

Euclidia

Eucoptocnemis

Eucordylea

Eucosma

Eucosmia

Eucosmophora

Eucrostis .

Eucymatoge

Eudamus

Eudarcia .

Eudeilinea

Eudemis

eudiopta Guenée, 1300.

Eudioptis.

eudora Dvar, 814.

Eudorea

eudoriella Ragonot, 4860.

Eudryas

Eudule.

Eueretagrotis

Euerythra

eufala Edwards, 533.

Eufernaldia

Eufidonia.

Eufitchia

eugeniella Busck, 6122.

Eugonia

Eugonobapta

Eugrotea

Euhagena

Euharveya

Euherrichia

Euhyparpax

eulatia Doubleday \& Hewitson, 243.

eulepis Grote, 2137.

Eulepiste.

Eulia

Eulonche.

Eulyonetia

Eulypa...

Eumacaria

Eumæus

eumelusalis Walker, 3037

Eumestleta

Eumeyrickia

Eunemoria

Eunica

eumus Edwards, 478.

eunusalis Walker, 4336.

Eunystalea
Page euonymella Chambers, 5477.

Eupanychis .................. 187

Euparthenos .................. $\quad 232$

eupatoriella Chambers, 5858 (Depressaria).

eupatoriella Chambers, 6375 (Gracilaria).

eupatoriella Chambers, 5686 ( $\mathrm{Yp}$ solophus).

eupatorii Fernald, 4983 (Pterophorus),

eupatorii Hy. Edwards, 420 (Sesia). euphasalis Walker, 4437.

Euphanessa ................. 267

euphemella Hulst, 4661.

Euphia.................. 277

Euphydryas ................. 17

Euphyes .................... 53

Euphyia............ . . . . . . . . 282

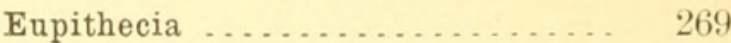

eupitheciaria Grote, 3822.

Euplexia .................... 122

Euplocamus ................. . 568

Eupoca..................... $\quad 372$

Eupolia . . . . . . . . . . . . . . . . 161

Euproctis . . . . . . . . . . . . . . . 260

Eupseudomorpha . . . . . . . . . . . . . 194

Eupseudosoma ............... $\quad 95$

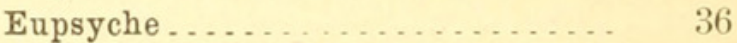

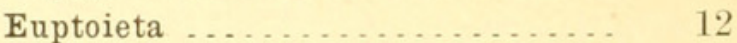

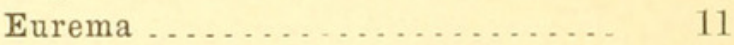

Eurhinosea ................... 287

euroa Grote \& Robinson, 2223.

euroidts.Grote, 1698.

europome Stephens, 66.

europomene Esper, 74.

Euros ....................... . . 191

euryalus Boisduval, 742.

eurycles Latreille, 578.

Eurycreon . . . . . . . . . . . . . . . . . 382

Eurycyttarus .............. . . 353

eurydice Boisduval, 60.

eurymedon Boisduval, 9.

Eurymene .................. 336

Eurymus .................... . . . 9

Eurynome .................... 563

eumnome Edwards, 128.

eurytheme Boisduval, 65.

Eurythmia . . . . . . . . . . . . . . . 436

Eurythmidia ................ 433

eurytris Fabricius, 299.

eurytulus Hübner, 366.

eurytus Fabricius, 299. 
Page.

Euschausia

\section{Eusebia}

\section{Eustixia}

Eustroma.

Eustrotia

Eutelia

Eutephria euterpe Ménétries, 85 (Eurema). euterpe Hy. Edwards, 658 (Lepisesia).

euterpe Herrich-Schaeffer, 780 (Syntomeida).

Euthales

Euthalia

Euthisanotia

Euthyatira

Eutolype.

Eutrapela

Euvanessa

Euverna.

Euzophera.

evadne Godart, 53.

evagaria Hulst, 3704.

Evagora

evanidalis Grote, 1542 (Feltia).

evanidalis Robinson, 3080 ( $\mathrm{Hy}$ pena).

evanidalis Bergstraser, 4352 (Loxostege).

evanidum Grote, 1049.

evelina French, 2810 (Catocala).

evelina French, 1148 (Hadena).

\section{Everes}

Evergestis

eversaria Guenée, 3698.

eversmanni Ménétries, 4.

Evetria evicta Grote, 1885.

\section{Evippe}

evius Boisduval, 412

exacta Hübner, 2557.

exagitata Walker, 3370 .

exaltata Hy. Edwards, 2347.

exanthemaria Denis \& Schiffermül-

ler, 3625 .

exanthemata Scopoli, 3625.

Exartema

exasperatana Zeller, 5386.

exauspicata Walker, 3647.

excxcatus Smith \& Abbot, 731.

excantalis Hulst, 4801.

excelsa Neumoegen, 890 (A pantesis).
95

288

394

277

209

204

282

106

282

194

258

127

341

23

91

430

500

45

380

448

500

\section{exportalis Guenée, 4275.}

exposita Dyar, 4054.

expressa Hy. Edwards, 914.1.

expressarium Walker, 3838.

exprimens Walker, 2197.

Exoria . . . . . . . . . . . . . . . . exornata Möschler, 1222 (Hadena). exomata Walker, 3605 (Orthofidonia).

expallidus Grote, 2459.

expandens Walker, 4648.

expansa Walker, 1950.

explagiata Walker, 3390.

explanata Walker, 3323 (Eucymatoge).

explanatum Walker, 3355 (Eustroma).

xpolita Grote, 2667.

excelsa Ottolengui, 2522 (Autographa)

e.celsa strecker, s9st (Metanema).

exclamationis Walsingham, 4993.

excogita smith, 1607.

excurearia Morrison, 3929 (Plago(iis).

xcurvaria Packard, 3580 (Synchlora)

exemplaris Smith, 1365. (n) 83

, 2197 
expulsa Walker, 1707.

expultrix Grote, 3177.

expunctaria Grote, 3939.

exsiccatus Zeller, 4604.

exsimaria Guenée, 3934.

exsulella Zeller, 4683.

exsuperata Walker, 3803.

externa Walker, 2618.

externalis Warren, 4407.

extersa Walker, 1155.

extimalis Scudder. 4335.

extimia Walker, 1105.

extincta Guenée, 1976 (Heliophila).

extincta Smith, 1269 (Polia).

extorralis Hulst, 4558.

extorris Warren, 4388.

extranea Guenée, 1953 (Heliophila).

extranea Smith, 1366 (Oncocnemis).

extranea Smith, 1646 (Paragrotis).

extranea $\mathrm{Hy}_{\mathrm{y}}$ Edwards, 5538 (Thele-

thia).

extraneella Walsingham, 6100.

extremaria Walker, 3757 (Apreasia).

extremaria Walker, 3571 (Racheo-

spila).

extremis Smith, 1340.

extricalis Guenée, 4411.

extricata Grote, 1036.

extrincicella Dyar, 5528.

exuberans Smith, 1509.

exulis Lefèbre, 1233.

exusta Guenée, 1807.

exvagana Walker, 5129.

Exyra

Fabatana .................

fabia Fabricius, 5:.

fabrefacta Morrison, 1119.

fabriciana Hübner, 5435.

fabriciella Villiers, 6010.

fabricii Boisduval, 753 (Autome-

ris).

fabricii Edwards, 205 (Polygonia). fabricii Kirby, 345 (Thecla).

fabula Grote, 3229 .

faceta Hy. Edwards, 2794.

factiosalis Walker, 3046.

factoris Smith, 1733.

facula Grote, 1405.

fadus Cramer, 664.

fagella Busck, 5607.

fagicorticella Chambers, 6017.
Page.

fagicosticella Chambers, 6017.

fagigemmaxana Chambers, 5009.

fagina Morrison, 2100.

faginella Chambers, 5851 (Cryptolechia).

faginella Zeller, 6271 (Lithocolletes).

Fagitana

Fala

falacer Godart, 347.

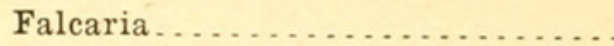

falcate Packard, 3968 (Euchlæna).

falcata Schaus, 3191 (Hemerocampa).

falcata Neumoegen, 1310 (Pseudanarta).

falcataria Packard, 3629.

falciferella Walsingham, 5491 .

falcigera Kirby, 2519.

falconipennella Hübner, 6355.

falcula Grote, 1016.

falerina Smith, 1619.

fallacialis Walker, 3042.

fallax Herrich-Schaeffer, 1060.

fallifera Walker, 3530.

falsa Grote, 1120.

falsarius Clemens, 4115.

famula Zeller, 5312.

famulata Hulst, 3749.

fantasia Butler, 58.

farcta Grote, 1987.

farinalis Linnæus, 4516.

farnhami Grote, 1787.

farrella Curtis, 4793.

fasceolaria Packard, 3558.

400 fascialis Cramer, 4276 (Hymenia). fascialis Walker, 4437 (Pyrausta). fasciata Smith, 2950 (Antiblemma). fasciata Walker, 1031 (Apatela). fasciata Smith, 1373 (Copipanolis). fasciata Swainson, 688 (Dilophonota).

fasciata Grote \& Robinson, 4134

(Dysodia).

fasciata Butler, 267 (Erebia).

fasciata Hy. Edwards, 2421 (Heliaca).

fusciata Strecker, 399 (Heodes).

fusciata Hy. Edwards, 1124 (Perigea).

fasciata Skinner, 3443.1 (Psychophora). 
fasciata Smith, 1922 (Ulolonche). fasciatana Clemens, 5021 (Exartema).

fasciatanum Retzius, 3083 (Nycteola).

fasciatella Grote, 2696.

fasciatus Smith, 1326 (Oncocnemis).

fasciatus Sulzer, 677 (Pholus). fasciella Chambers, 6563 (Adela). fasciella Chambers, 6356 (Gracilaria).

fasciella Walsingham, 6317 (Lithocolletes).

fasciella Fernald, 4537 (Patissa). fasciella Chambers, 6541 (Pitys). fasciella Chambers, 5666 (Telphusa).

fascioferaria Hulst, 3694.

fasciola Herrich-Schaeffer, 4097.

fasciolatis Hulst, 4736.

fasciolana Clemens, 5221.

fasciolaria Hulst, 3559.

fasciolaris Hübner, 2766.

faseolaria Guenée, 3558.

fastidiosa Strecker, 2371.

fastuosa Zeller, 5482 (Atteva).

fastuosa Guenée, 2432 (Noropsis).

fatuaria Strecker, 3905.

faulatis Walker, 4487.

fauna Morrison, 1663.

faunus Edwards, 209 (Polygonia). faunus Strecker, 1761 (Ufeus).

foustina Strecker, 2855.

faustinaria Strecker, 3902.

faustinula Boisduval, 823.

fautaria Hulst, 3750 .

favonius Smith \& Abbot, 336 (Thecla) .

favonius Boisduval \& Le Conte, 335

(Uranotes).

favorita Neumoegen, 890.

fax Grote, 2629.

faxonii Minot, 3603.

fea Edwards, 450.

februalis Grote, 1283.

fecialis Grote, 3066.

fegeus Cramer, 665.

feildeni MeLachlan, 399.

Felderia

felicella Walsingham, 6176.

felicia Poey, 41.
Page.

felicitata Smith, 2308.

felina Grote, 976 (Apatela). felina Druce, 966 (Charadra). felix Walsingham, 5438 .

Feltia 138

Fenaria 195

fenestra Perry, 748.

fenestrella Packard, 4805.

Feniseca

feniseca Harvey, 1635.

fennica Tauscher, 1489.

Fentonia

fenyesella Dietz, 5960.

Feralia.

feriella Hulst, 4720.

fernaldana Grote, 5084 (Eucosma). fernaldana Walsingham, 5442 (Phalonia).

fernaldaria Hulst, 3862.

Fernaldella .....................

fernaldella Walsingham, 6064 (Cosmopteryx).

fernaldella Walsingham, 5864 (Depressaria).

fernaldella Chambers, 5853 (Machimia).

fernaldella Riley, 5536 (Setiostoma).

fernaldella Busck, 5671 (Trichotaphe).

\section{Fernaldellinæ}

303

fernaldi Ragonot, 4534 (Acallis).

fernaldi Grote, 3754 (Apæecasia).

fernaldi Ragonot, 4775 (Myrlea).

fernaldi Morrison, 1693 (Paragròtis).

\section{Fernaldia}

fernaldialis Hulst, 4819.

feronia Linnæus, 231.

ferox Walker, 780.

ferraria Walker, 2435.

ferrea Grote, 1830.

ferrealis Grote, 1854 (Mamestra).

ferrealis Grote, 2093 (X ylina).

ferriferanum Walker, 5027.

ferrigera Walker, 4085 (Adoneta).

ferrigera Smith, 2033 (Graphiphora).

ferrolineana Walker, 5056.

ferrugalis Hübner, 4401.

ferrugana Schiffermüller, 5316 ( Acleris). 
ferrugana Hübner, 5418 (Eulia).

ferrugaria Borkhausen, 3457 (Petrophora).

fermgaria Haworth, 3458 (Petrophora).

ferrugata Packard, 3521 (Eois). fermugata Hübner, 3458 (Petrophora).

fermgata Clerck, 3457 (Pterophora).

fermaginana Fernald, 5168.

fermiginaria Packard, 3695.

ferruginea Smith, 2949 (Anticarsia).

ferruginea Packard, 3223 (Epicnaptera).

ferruginea Packard, 4077 (Euclea). ferruginea Packard, 3120 (Lophodonta).

ferrugineana Riley, 5011.

ferruginella Ragonot, 4835 (Euzophera).

ferruginella Hübner, 6488 (Monopis).

fermginiguttana Fernald, 5306.

ferruginoides Guenée, 2222 (Orthosia).

ferruginoides Smith. 1431 (Pachnobia).

ferruginosa Zeller, 5847 (Cryptolechia).

ferruginosa Walker, 834 (Eubaphe). ferruginosaria Packard, 3758.

ferrunimaria Zeller, 3494.

fervens Walker, 1113.

fervida Staudinger, 860.

fervidana Clemens, 5368 (Archips). fervidana Walker, 5361 (Archips).

fervidaria Herrich-Schaeffer, 3929

(Plagodis).

fervidaria Hübner, 3911 (Therina).

fervifactaria Grote, 3430.

fessa Grote, 2567.

festa Guenée, 1063 (Cerma).

festa Hulst, 3735 (Cymatophora).

festa Hy. Edwards, 692 (Dilophonota).

festaliella Hübner, 6178.

festalis Hulst, 4440.

festaria Hulst, 3595.

festinella Clemens, 6391.

festiva Fabricius, 2432.

festivoides Guenée, 1136.
Page.

festuca Linnzeus, 2479.

festus Hübner, 586 .

feudalis Grote, 4421.

fibulata Morrison, 1152 (Hadena).

fibulate Hufnagel, 3463 (Petrophora).

ficulella Barrett, 4876.

ficus Linnæus, 675.

fidelis Grote, 2007.

fidelissima Herrich-Schaeffer, 3086. fidella Dietz, 5937.

fidicularia Morrison, 1102.

fidoniata Walker, 3604 (Eufidonia). fidoniata Walker, 3803 (Paraphia). fieldeni McLachlan, 399.

figulilella Gregson, 4876.

figurata Drury, 892 (Apantesis).

figurata Harvey, 1319 (Homohadena).

filaria Walker, 3848 (Cleora). filaria Smith, 2975 (Egryrlon). filenus Poey, 447.

filicicornis Walsingham, 6599.

filicomis Dyar, 6599.

filimentaria Guenée, 3939.

filiolella Hulst, 4707.

fimbrialis Denis \& Schiffermüller, 4513.

fimbriaris Guenée, 1749.

fimbriata Haworth, 3337.

fimetaria Grote, 3601.

finis Smith, 1602.

finitella Walker, 4743.

finitima Guenée, 1224 (Hadena).

finitima Smith, 2579 (Pleonectyptera).

fiscellaria Guenée, 3910.

fischeri Zeller, 4955.

Fishea ......................

fishiana Fernald, 5321.

fishii Grote, 1440 (Pachnobia).

fishii Fernald, 4961 (Pterophorus).

fiskeana Dyar, 4103.

fissalis Grote, 4418.

fissella Hübner, 5500.

fissinotata Walker, 3647.

fissus Haworth, 5500.

fistula Harvey, 2061.

fitchella Clemens, 6253.

fitchii $\mathrm{Hy}$. Edwards, 4194.

flabella Grote, 2546.

flabilis Grote, 1970.

flaccidana Robinson, 5366. 
flagellum Walker, 2491.

Alagitiaria Guenée, 3910. flagrantis Smith, 1364

flagrata Walker, 4136.

flamensella Walker, 6555.

flammans Dyar, 826.

flammea Neumoegen, 893.

flammeusella Chambers, 6555.

flammicincta Walker, 2636.

flammifera Walker, 3383.

flava Strecker, 83 (Eurema).

flava Kilian, 900 (Parasemia).

flava Edwards, 38 (Pontia).

flava Grote, 1307 (Pseudanarta).

flavago Fabricius, 2199.

flavalis Fernald, 4353.

flavaria Packard, 3440.

flavata Packard, 3440.

flavedana Clemens, 5382.

flavescens Hulst, 3524.

flavescentella Haworth, 6520.

flaviannula Smith, 2034.

flavibasana Fernald, 5353.

flavicans Goeze, 688.

flavicaria Packard, 3693.

flaviciliatus Haworth, 5500.

flavicollis Smith, 1531.

flavicoloralis Grote, 4427.

flavicornella Ragonot, 4708.

flavicornis Smith, 962.

flavicorporella Walsingham, 5797.

flavicosta Smith, 2659.

flavicostella Fernald, 4538 (Patissa).

flavicostella Walsingham, 5655 (Tri-

chotaphe).

flavidalis Grote, 2866 (Catocala).

flavidalis Guenée, 4423 (Pyrausta).

flavidens Smith, 1585 (Paragrotis).

flavidens Grote, 1309 (Pseudanarta).

flavidissimalis Grote, 4326.

flavidorsella Ragonot, 4799.

flavifimbrialis Warren, 4370.

flavifrontella Clemens, 6107.

flavigutta Hulst, 3289.

flaviguttata Grote, 2603.

flavilinguis Grote, 953.

flavimaculata Harvey, 1103.

flavimedia Harvey, 1300.

flavinotalis Grote, 4391.

flavipennis Grote, 2663.

flavipes Hulst, 4191.

flavipunctalis Geyer, 3048.

flaviscapula Smith, 1605.
Page.

Havistriaria Hübner, 2934.

flavistrigella Walsingham, 6481 .

flavitibia Walker, 4190.

favivenata Hulst, 3646.

flavivittana Clemens, 5309.

flavivittellus Clemens, 5678.

flavocellana Clemens, 5129.

flavocostella Clemens, 5655.

flavofascialis Grote, 4456.

flavofasciaria Packard, 3656.

flavofasciata Barnston, 657 (Lepisesia).

flavofasciata Strecker, 2803 (Syneda).

flavofasciata Grote, 2644 (Tripudia).

flavotincta Cockerell, 72 (Eurymus). flavotincta Smith, 1507 (Noctua).

flavula Herrich-Schaeffer, 4107.

flebitis Grote, 2816 (Catocala).

Alebilis Hulst, 3308 (Tephroclystis).

flegia Cramer, 4314.

flegialis Poey, 4314 (Paradosis).

flegialis Walker, 4448 (Pyrausta).

fletcherella Fernald, 6016.

fletcheri Kemp, 11 (Papilio).

fletcheri Grote, 1900 (Xylomiges) .

flexuosa Walker, 968 (Raphia).

flexuosa Grote, 4105 (Tortricidia).

flexurella Clemens, 5798.

floccalis Zeller, 2576.

floccosa Graeser, 900.

floccosana Walker, 5431.

flora Edwards, 249 (Chlorippe).

flora Wright, 49 (Synchloe).

florea Guenée, 2128 (Rhodophora).

florella Cramer, 4284 (Anania).

florella Busck, 5635 (Gnorimoschema).

florida Hulst, 3726 (Cymatophora). florida Smith, 1869 (Mamestra).

florida Guenée, 2307 (Rhodophora).

floridx Mabille, 470.

floridalis Hulst, 4313 (Agathodes).

floridalis Fernald, 4283 (Marasmia).

floridana Zeller, 5250 (Ancylis).

floridana Hy. Edwards, 3090 (Apatelodes).

floridana Neumoegen, 5482 (Atteva).

floridana Graef, 3104 (Datana). 
floridana Hulst, 4136 (Dysodia). floridana Strecker, 204 (Mestra). floridana Smith, 3051 (Tetanolita). floridanella Beutenmuller, 6055 (Cosmopteryx).

floridanella Busck, 5673 (Glyphidocera).

floridaria Guenée, 4007 (Caberodes).

floridaria Hulst, 3529 (Eois).

floridata Packard, 3525 (Eois).

floridata Walker, 3400 (Hydriomena).

floridata Grote, 4027 (Sabulodes).

floridella Hulst, 4650 (Benta).

floridellus Hulst, 4779 (Elasmopalpus).

floridensis Neumoegen, 53 (Aphrissa).

floridensis Strecker, 240 (Basilarchia).

floridensis Guenée, 2712 (Callopistria).

floridensis Hulst, 3714 (Cymatophora).

floridensis Grote \& Robinson, 656 (Hemaris) .

floridensis Grote, 4246 (Sesia).

floridensis Holland, 4033 (Sphæce-

lodes).

floridiana Walker, 1139.

floridum Grote, 936 (Eupseudosoma).

floridus Zeller, 4563 (Crambus).

florus Edwards, 397.

fioscella Hulst, 4899.

floscularia Grote, 3927.

fluctigerana Herrich-Schaeffer, 5260.

fluctuata Linnæns, 3463.

fluctuosalis Lederer, 4308.1.

fluviaria Herrich-Schaeffer, 3370.

fluviata Hübner, 3370.

fluxella Zeller, 5971.

fodiens Guenée, 1091.

fodinalis Lederer, 4445.

foedana Clemens, 5017.

fœdaria Walker, 3941.

forminalis Smith, 1723.

fominaria Guenée, 3628.

foliana Walsingham, 5320.

footiana Fernald, 5026.

forbesellus Fernald, 4632.

forbesii French, 3016.
Page.

forficaria Guenée, 4020.

forficellus Thunberg, 4547.

forficularia Guenée, 3989.

formalis Grote, 1405.

formosa Hy. Edwards, 3167 (Gluphisia).

formosa Hulst, 3946 (Gonodontis). formosa Hulst, 3345 (Philereme). formosa Grote, 2473 (Polychrysia). formosa Hulst, 3503 (Scelolophia). formosalis Walker, 4058 (Nigetia). formosalis Clemens, 4487 (Nymphula).

formosana Clemens, 5165.

formosata Hulst, 3852 (Cleora).

formosata Strecker, 3431 (Cœnocalpe).

formosella Murtfeldt, 5761 (Gelechia).

formosella Hulst, 4659 (Tetralopha).

formula Grote, 2897 (Catocala). formula Grote, 3226 (Oreta).

fornax Hübner, 230.

forrigens Walker, 2915.

fortis Grote, 1337.

fortunata Grote, 2641.

fosterella Hulst, 4792.

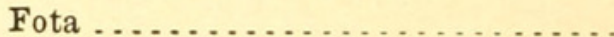

Fotella ...................

fotis Strecker, 373.

f-pallida Strecker, 892.

fractilinea Grote, 1205 (Hadena).

fractilinea Zeller, 5984 (Holcocera).

fractivittana Clemens, 5371.

fracturalis Zeller, 4288.

fragarix Hy. Edwards, 4241 (Albuna).

fragarix Walsh \& Riley, 5252 (Ancylis).

fragarix Stainton, 6390 (Ornix).

fragariana Packard, 5379.

fragicorticella Riley, 6017.

fragilella Frey \& Boll, 6313.

fragilis Guenée, 1009 (Apatela). fragilis Strecker, 831 (Eubaphe).

fragilis Stretch, 3215 (Malacosoma).

fragilis Walsingham, 4944 (Platyptilia).

fragmentella Hy. Edwards, 4071 (Chalia). 
fragmentella Zeller, 5557 (Telphusa).

fragosa Grote, 1111.

francesca Hy. Edwards, 2851.

franciscana Walsingham, 5403.

franciscamus Smith, 2065.

franckella Hübner, 6372.

franckii Neumcegen, 700.1.

franconica Hy. Edwards, 891 (A pantesis).

franconica Slosson, 861 (Phragmatobia).

franconiella Hulst, 4831 .

franklinii Curtis, 425.

fratella Grote, 2493

frater Grote, 968.

fratercula Pagenstecher, 4138 (Belnoptera).

fratercula Grote \& Robinson, 2898 (Catocala).

fraterna Smith, 2954 (Campometra). fraterna Butler, 4280 (Ercta).

fraterna Grote, 4080 (Euclea).

fraternalis Smith, 3043.

fraternella Dietz, 5963.

fraudulentaria Zeller, 3850.

fraxini Hy. Edwards, 4198 (Albuna).

fraxini Lugger, 4174 (Podosesia). frederici Grote, 2880.

freija Thunberg, 138.

frenchii Poling, 2832.

freya Herrich-Schaeffer, 138.

freyella Walsingham, 6462 .

freyeraria Staudinger, 3458.

friabilis Grote, 1681.

frigga Thunberg, 140.

frigida Smith, 977 (Apatela).

frigida Smith, 2184 (Papaipema).

frigida Scudder, 38 (Pontia).

frigidalis Guenée, 4392.

frigidana Packard, 5030.

frigidaria Möschler, 3513 (Leptomeris).

frigidaria Guenée, 3443 (Psychophora).

frigidata Walker, 3388.

frigidella Packard, 4776 (Laodamia).

frigidella Packard, 6503 (Tinea).

frisia Poey, 197.

fritillaria Guenée, 3748.

frondaria Grote, 3341. fructetella Hulst, 4696. frugallaria Guenée, 3850. frugiperda Smith \& Abbot, 1302. frustana Scudder, 4998. frustellus Walsingham, 5487 . frustulum Guenée, 2946. frutetorum Boisduval, 3214.

Fruva.

fucana Walsingham, 5404

fucosa Hübner, 808.

fulda Smith, 1655

fulgens Hübner, 1103 (Caradrina). fulgens Hy. Edwards, 791 (Lycomorpha).

fulgidella Clemens, 6357.

fulicalis Clemens, 4500.

fuliginarium Hulst, 3830.

fuliginosa Strecker, 407 (Cupido).

fuliginosa Linnæus, 860 (Phragmatobia).

fuliginosa Edwards, 403 (Satyrium ).

fuliginosalis Fernald, 4274.

fulla Edwards, 407 (Cupido).

fulla Eversmann, 295 (Oeneis).

fullerea Riley, 5038.

fulliolus Hulst, 399.

fullonella Zeller, 5709.

fulminalis Lederer, 4268 (Glaphyria).

fulminalis Zeller,4636.3 (Paralipsa). fulminana Walsingham, 5104.

fulminans Smith, 2058.

fultaria Grote, 3467 .

fulva Walsingham, 5871 (Depressaria).

fulca Stretch, 896 (Kodiosoma).

fulvella Duponchel, 5500.

fulvescens Hy. Edwards, 354.

fulvia Edwards, 178 (Thessalia). fulvia Dodge, 220 (Vanessa).

fulvicollis Hübner, 787.

fulvicosta Clemens, 839.

fulvida Butler, 3390.

fulvifrontana Packard, 5029.

fulvipes Harris, 4214.

fulviplicana Walsingham, 5473.

fulvirugella Ragonot, 4796.

fulvofasciata Butler, 848.

fulvoflava Walker, 922.

fulvoroseana Clemens, 5331.

fulvosa Riley, 1302.

fulvotinctana Walsingham, 5466 .
Page. 
fumalis Grote, 1599 (Paragrotis). fumalis Guenée, 4436 (Pyrausta). fumataria Minot, 3862 .

fumiferana Clemens, 5406.

fumoferalis Hulst, 4442 .

fumosa Robinson, 5371 (Archips). fumosa Hulst, 3639 (Deilinia).

fumosa Strecker, 862 (Diacrisia). fumosa Strecker, 65 (Eurymus). fumosa Grote, 1173 (Hadena). fumosa Strecker, 653 (Hemaris). fumosa Butler, 4073 (Hyaloscotes). fumosa Strecker, 2802 (Syneda). fumosa Hulst, 3295 (Tephroclystis). fumosalis Guenée, 4316.

fumosaria Strecker, 3781.

fumosella Hulst, 4858.

fumosum Morrison, 1049 (Arsilonche).

fumosus Hulst, 308 (Anosia).

funalis Grote, 4329.

funebris Hübner, 1928 (Anarta). funebris Strömeyer, 4472 (Pyrausta).

funeralis Grote, 1008 (Apatela). funeralis Hübner, 4277 (Desmia). funeralis Grote, 2709 (Spragueia). funeralis Scudder \& Burgess, 634

(Thanaos).

funerea Grote, 903.

fungivorella Clemens, 5579.

fungorum Grote \& Robinson, 2208. funiculella Treitschke, 4618. furcata Smith, 2193 (Papaipema). furcata Walsingham, 5838 (Stenoma).

furcatana Walker, 5342 .

furcatus Grote, 6610 (Hepialus).

furcatus Walsingham, 6577 (Neolophus).

furcifascia Walker, 3359.

furcifera Guenée, 994.

furciferata Packard, 3556 (Goniacidalia).

furciferata Packard, 4025 (Sabulodes).

furcilla Grote, 2731 (Argillophora). furcilla Packard, 957 (Panthea). furcillata Say, 218. furcotibiella Riley, 6197. furellus Zeller, 4636. 4. furfurana Haworth, 5007. furfuraria Hulst, 3843 : furfurata Grote, 2024.
Page.

furfurella Hulst, 4733.

furtious Smith, 1721.

furvana Robinson, 5365.

fusca Grote \& Robinson, 535 (Euphyes).

fusca Stretch, 823 (Illice).

fusca Haworth, 4776 (Laodamia).

fuscu Harvey, 3130 (Litodonta).

fusca Packard, 4098 (Packardia).

fusca Boisduval, 1557 (Porosagrotis).

fusca Hy. Edwards, 4119 (Triproeris).

fuscalbana Zeller, 5067.

fuscalis Hübner, 4358.

fuscama Haw orth, 5359.

fuscaria Thunberg, 3708.

fuscata Hulst, 3501 (Cinglis).

fuscata Hulst, 3975 (Synaxis).

fuscatella Hulst, 4843 (Canarsia).

fuscatella Hulst, 4826 (Zophodia).

fuscescens Walker, 2547.

fuscicaudis Walker, 656.

fuscicomella Clemens, 6109.

fuscicostellus Zeller, 4601.

fuscigera Grote, 1682.

juscimacula Grote, 1140.

fuscimaculalis Grote, 4427.

fuscipedella Walsingham, 5914.

fuscipes Zeller, 4621 (Argyria).

fuscipes Grote, 813 (Comacla).

fuscipunctella Haworth, 6503.

fuscocapitella Chambers, 6196.

fuscocostella Chambers, 6258.

fuscocristatella Chambers, 5574

(Leuce).

fuscocristatella Chambers, 6543

(Pitys).

fuscodactyla Haworth, 4992.

fuscofasciella Ragonot, 4873 (Ephestia).

fuscofasciella Chambers, 6475 (Euplocamus).

fuscolimbellus Ragonot, 4636.1.

fuscolineana Clemens, 5373.

fuscolinianella Riley, 5776.

juscolotella Ragonot, 4648.

fuscolutea Smith, 1848.

fuscoluteella Chambers, 5799.

fuscomaculella Chambers, 5800

(Gelechia).

fuscomaculella Chambers, 6504

(Tinea).

fuscomarginella Chambers, 6437. 
Page.

fuscoochrella Chambers, 5764 (Gelechia).

fuscoochrella Beutenmüller, 6358 (Gracilaria).

fuscopallidella Chambers, 5601.

fuscopulvella Chambers, 5568 ( Agnippe) .

fuscopulvella Chambers, 5816 (Gelechia) .

fuscopulvella Chambers, 5983 (Holcocera).

fuscopulvella Chambers, 6505

(Tinea).

fuscopunctella Clemens, 5801.

fuscosa Neumoegen, 868.

fuscoscapulella Chambers, 6412.

fuscosparsa Walsingham, 5155.

fuscostrigana Clemens, 5437.

fuscostrigella Chambers, 6018 (Coleophora).

fuscostrigella Chambers, 5647 (Polyhymno).

fuscosuffusella Dietz, 5955.

fuscotixnizella Chambers, 5776.

fuscotanniella Riley, 5776.

fuscotibiella Clemens, 6197.

fuscula Grote, 4056.

fusculenta Smith, 1786.

fuscus Retzius, 4992 (Stenoptilia).

fusifasciata Walker, 3235.

fusimacula Barnes, 148 (Lemonias).

fusimacula Smith, 2287 (Oxycne$\mathrm{mis})$.

fusimacula Smith, 1739 (Paragrotis).

futilalis Lederer, 4441.

futilis Grote \& Robinson, 2951.

gabbii Edwards, 260 (Cercyonis).

gabbii Behr, 167 (Lemonias).

Gaberasa

Gæa

Gæides

gagates Grote, 1608.

galactimus Boisduval, 279.

Galanthia

Galasa

galbanaria Hulst, 3952.

galbanata Morrison, 2996.

galbaniata Zeller, 3675.

galbina Clemens, 746.

Galgula

galii Rottemburg, 670.

gallxasteriella Kellicott, 5621.

gallxgenitella Clemens, 5613. gallarandialis Dyar, 4140.

gallasalicana Riley, 5280.

gallæsolidaginis Riley, 5620.

Galleria

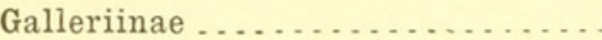

gallicana Herrich-Schaeffer, $5 \mathrm{i} 69$.

gallicolana Clemens, 5316.

gallidiplopappi Fyles, 5621.

gallivorana Clemens, 5331.

gallivorum Westwood, 4225.

galva Strecker, 1062.

gamma Linnæus, 2492.

gardetta De Loche, 283.

gargamelle Strecker, 3203.

garita Reakirt, 479.

garmani Grote, 2044.

garzoni Oberthur, 845.

gasta Strecker, 1045.

gastropachata Guenée, 4010.

gaudiella Hulst, 4923.

gaultheriella Walsingham, 6291.

gaurz Smith \& Abbot, 660 (Lepisesia).

gaurx Smith \& Abbot, 2306 (Rhodophora).

gausapalis Hulst, 4572.

gausaparia Grote, 3698.

gausapata Grote, 2087.

geddesi Neumcegen, 900.

geiella Chambers, 6353.

gelata Lefèbre, 1233 (Hadena).

gelata Guenée, 3373 (Mesoleuca).

Gelechia ......................

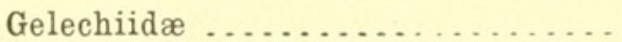

getida Moschler, 883 (Apantesis).

getida Grote, 3170 (Ellida).

getida Guenée, 1233 (Hadena).

gelida McLachlan, 4444 (Pyrausta). gelidalis Walker, 4478.

gelidata Möschler, 3322 .

geliformis Walker, 4247.

geminana Donovan, 5259.

geminata Grote \& Robinson, 3237

(Cladora).
537

401 geminata Packard, 4099 (Packardia).

geminata Packard, 3294 (Tephroclystis).

geminatella Packard, 6387.

geminatus Say, 729 (Smerinthus).

geminella Riley, 5613.

geminipunctella Ragonot, 4734.

gemma Hübner, 296.

gemmalis Hulst, 5524.
413

’’age.

413 
gemmaria Herrich-Schaeffer, 3370. gemmata Hübner, 3370 (Percnoptilota).

gemmata Grote, 5482 (Atteva). gemmata Packard, 3505 (Leptomeris).

gemmatella Hulst, 4900.

gemmatilis Hübner, 2948.

gemmea Frey \& Boll, 6266.

gemmifrrella Clemens, 6066.

generalis Walker, 3042.

generosa Grote \& Robinson, 4455.

genetrix Grote, 1161.

geneura Strecker, 888.

genialis Grote, 1251.

genicula Grote, 3229.

geniculata Grote \& Robinson, 1455

(Agrotis).

geniculata Hulst, 3950 (Euchlæna). genoveva Cramer, 223.

gentilis Grote, 2235 (Parastichtis).

gentilis Grote, 4417 (Pyrausta).

genvialis Lederer, 4487.

genutia Fabricius, 48.

geometralis Grote, 2577.

geometrica Grote, 900.

Geometridæ

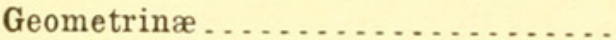

geometroides Walker, 4036 (Melanchroia).

geometroides Guenée, 2725 (Pangrapta).

georgiana Grote, 5370.

georgica Grote, 2700 (Fruva) .

georgica Herrich-Schaeffer, 3112

(Hyperæschra).

georgiella Hulst, 4762 (Salebria). georgiella Hulst, 5411 (Tortrix). georgiella Walker, 5672 (Trichotaphe).

georgii Hulst, 3364 (Rheumaptera). georgii Grote, 2102 (Xylina).

germana Hy. Edwards, 2591 (Annaphila).

germana Morrison, 2077 (Lithomoia).

germanalis Walker, 3080.

geronimo Barnes, 955.

gertruda Hul-t, 3770.

Getulia .

gian Strecker, 1625.

gibbocostata Walker, 3426.

gibbosa Smith \& Abbot, 3123.
Page.

gibbosella Chambers, 5755 .

gigantea Strecker, 73 (Eurymus).

gigantea French, 959 (Panthea).

gigunteana Riley, 5101.

gigantella Chambers, 6019 (Coleophora).

gigantella Chambers, 5972 (Holco-

cera).

gigas Butler, 290.

gilbociliella Clemens, 5973.

gilix Hy. Edwards, 4200.

gillettei Hulst, 3326 (Eucymatoge).

gillettei Barnes, 153 (Lemonias).

gilvella Hübner, 5877.

gilvescentella Ragonot, 4880.

gilvibasella Hulst, 4741.

gilvidorsis Hedemann, 4991.

gilvipennis Grote, 1389.

gilviscopella Zeller, 5602.

gilvolinella Clemens, 5589.

gilvomaculella Clemens, 5802 .

gilvoscopella Chambers, 5602 .

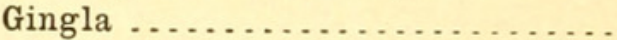

girardellus Clemens, 4564.

gisela Meyer, 2898.

gitonella Druce, 4874.

glabella Morrison, 1293.

glacialis McLachlan, 63(Eurymus).

glacialis Hulst, 3454 (Petrophora).

glacialis Packard, 4403 (Phlyc-

tænia).

glaciana Möschler, 5068.

glaciata Grote, 1814 (Mamestra).

glaciata Germar, 3373 (Mesoleuca).

gladiaria Morrison, 1544.

Glaea ......................

glandifera Chambers, 5564 .

glandiferella Zeller, 5564.

glandulella Riley, 5979.

glans Grote, 2945.

glaphyralis Guenée, 4263.

Glaphyria ..................

glareusella Zeller, 4898.

glaucana Walker, 5376 (Archips).

glaucana Lampa, 3083 (Nycteola).

glaucaria Guenée, 3578.

glaucata Packard, 3387.

glaucatella Hulst, 4824.

Glauce ...................

glaucella Walsingham, 6020.

Glaucina ........................

glaucofuscana Zeller, 5461.

glaucon Edwards, 428. 
Page.

Glaucopteryx

glaucovaria Walker, 1801.

glaucus Linnæus, 11.

gleditschixella Chambers, 5592

(Helice).

gleditschixella Chambers, 6159

(Mompha).

gleditschiella Fernald, 4744.

Glena . . . . . . . . . . . . . . .

glennyi Grote, 1345.

glenwoodii Barnes, 3209.

glochinella Zeller, 5617.

glomeralis Walker, 4472.

glomerana Walsingham, 5103.

glomeraria Grote, 3683.

gloriosa Hy. Edwards, 4164.

glosiosa Strecker, 2320.

gloverana Walsingham, 5425.

gloveri Grote \& Robinson, 956 (Copidryas).

gloveri Packard, 4067 (Platoeceticus). gloveri Strecker, 740 (Samia).

Gloveria....................

Gluphisia................

glycyrrhizxella Chambers, 5803.

Glyphidocera ................

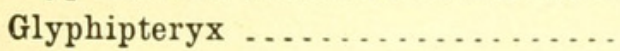

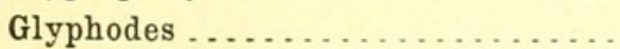

Glyptocera..................

gnaphaliella Kearfott, 5522.

gnata Grote, 1784.

gnatheme Boisduval, 89.

Gnophæla .................

gnophosaria Guenée, 3668 (Macaria).

gnophosarium Guenée, 3839 (Selidosema).

Gnorrimoschema

goasalis Walker, 3036.

godarti Perty, 56 (Gonepteryx).

godartii Boisduval, 326 (Eumaeus). goedartella Linnæus, 6458.

goedastella Chambers, 6458.

goiiana Linnæus, 5411.

golgata Strecker, 3311.

gonella Strecker, 2669.

Gonepteryx .

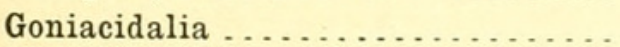

goniata Guenée, 4026.

Gonodonta

Gonodontis .

goodellella Chambers, 5659.

goodelliana Fernald, 5261 (Ancylis).
Page.

goodellianus Grote, 4590 (Crambus). goodellii Grote, 1825 (Mamestra). goodellii Grote, 4100 (Packardia). gopheri Smith, 3018. gordialis Guenée, 4305. gordius Cramer, 703. gorgon Boisduval, 392. gorgone Hübner, 189.

Gortyna .

gortynides Walker, 2147.

Gorytodes

gossypiana Packard, 5356.

gothicata Guenée, 3359.

gouana Linnæus, 5411.

govana Fabricius, 5411.

gozora Boisduval, 440.

gracea Hulst, 3842.

graciella Hulst, 4820.

gracilalis Hulst, 4429.

gracilana Walsingham, 5331.

Gracilaria ...................

gracilella Chambers, 5676 (Anorthosia).

gracilella Hulst, 4844 (Canarsia). gracilella Chambers, 6415 (Lyonetia).

gracilenta Græf, 945 (Androloma). gracilenta Hübner, 2333 (Schinia). gracilineata Guenée, 3348.

gracition Butler, 3511.

gracilis Grote \& Robinson, 4302

(Blepharomastrix).

gracilis Edwards, 2905 (Catocala). gracitis Walsingham, 5857 (Depressaria).

gracilis Zeller, 6118 (Heliozela). gracilis Grote \& Robinson, 655

(Hemaris).

gracilis Grote, 6610 (Hepialus).

gracitis Grote \& Robinson, 212

(Polygonia).

gracillaria Packard, 3578.

gracillima Grote, 2286.

gradata Walker, 3673.

graduatana Walsingham, 5144.

græfiana Tepper, 2403 (Melicleptria).

298 grxfianaGrote, 2236 (Scopelosoma). grxfiaria Hulst, 3559 (Annemoria). grafiaria Hulst, 3763 (Caripeta). grafii Hulst, 3889 (Acanthophora). græfii Grote, 988 (Apatela). græfii Hulst, 3324 (Eucymatoge). 
grefii Hy. Edwards, 196 (Sannin(idea).

grafii Packard, 4104 (Tortricidia).

Græperia ....................

Grais

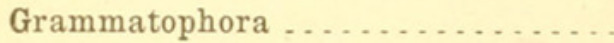

Grammodes ....................

grandiflavana Walsingham, 5107.

grandiosa Hulst, 3412.

grandipennis Hulst, 3446 (Ersephila).

grandipennis Grote, 1466 (Peridroma).

grandipuncta Guenée, 2555.

grandirena Haworth, 2769.

grandis Strecker, 2289 (Copable-

pharon).

grandis Hulst, 3325 (Eucymatoge).

grandis Smith, 1377 (Eutolype).

grandis Ehrman, 217 (Euvanessa).

grandis Boisduval, 1800 (Mames-

tra).

grandis Strecker, 4165 (Melittia).

grandis Speyer, 1493 (Noctua).

grandis Walsingham, 4948 (Platyp-

tilia).

grandis Fish, 4979 (Pterophorus). grandisella Chambers, 6160 (Mom-

pha).

grandisella Chambers, 6198 (Neptic-

ula).

granella Linnæus, 6506.

granitaria Packard, 3531.

granitata Guenée, 3647.

granitella Ragonot, 4798.

granitosa Guenée, 2717.

granulata Neumoegen, 4135.

graphica Ḧ̈bner, 2781.

graphidiaria Hulst, 3710 .

Graphiphora ....................

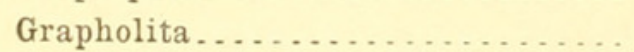

Grapholitha..................

grassata Hulst, 3677.

grata Fabricius, 2430 (Euthisanotia).

grata Hübner, 1141 (Oligia).

gratana Walker, 5331.

grataria Fabricius, 3468 .

gratata Packard, 3568.

gratiosa Reakirt, 82 (Pyrisita).

gratiosana Clemens, 5027.

gratiosus Fish, 4987 (Pterophorus).

gratulata Walker, 3372.

gravilinearia Andrews, 3864.

gravis Grote, 1546 (Feltia).

187

59

311

234

grisea Walker, 1014 (Apatela).

grisea Robinson, 5372 (Archips).

grisea Neumoegen, 3213 (Нypo-

pacha).

grisea Packard, 824 (Illice).

grisea Strecker, 3114 (Odontosia).

griseuella Chambers, 5805 .

grisearic Grote, 3863.

griseata Smith, 1863.

griseicollis Grote, 1362.

griseipennis Grote, 2964.

grisella Fabricius, 4636.7 (Achroia). grisella Dietz, 5954 (Dryope).

grisella Chambers, 5804 (Gelechia). griseoalbaria Walsingham, 5036.

griseocapitana Walsingham, 5181.

griseocapitella Walsingham, 6619 .

griseochrella Chambers, 5806.

griseocincta Harvey, 1998.

griseosparsa Hampson, 4554.

grisescens Walsingham, 4989.

griseus Walsingham, 6582 (Нуроc-

lopus).

grissxella Chambers, 6164.

grisseella Chambers, 5805 (Gele-

chia).

grisseella Chambers, 6520 (Tinea).

grisseella Chambers, 5691 (Ypsolo-

phus).

grissefasciella Chambers, 5768 .

grœnlandica Homeyer, 3186 (Gynæphora).

grcnlandica Zetterstedt, 1233 (Hadena).

grogne Fabricius, 214.

grossipunctella Ragonot, 4677.

grossularix Packard, 4821.

grossulariata Staudinger, 3690.

groteana Bailey, 2852 (Catocala). groteana Fernald, 5339 (Cenopis). grotearia Packard, 3974.

groteella Robinson, 5890.

grotei Boisduvazl, 953 (Alypiodes).

grotei Hy. Edwards, 693 (Cautethia). 
grotei Butler, 653 (Hemaris). grotei Grote \& Robinson, 760 (Hem-

ileuca).

grotei Packard, 790 (Lycomorpha). grotei Morrison, 1380 (Psaphidia). grotei Ragonot, 4705 (Ulophora). grotei Riley, 2092 (Xylina).

Grotella . . . . . . . . . . . . . . . grotella Ragonot, 4731. grumella Zeller, 6507. grunus Boisduval, 327. grynea Cramer, 2902. gryneus Hübner, 362. guadeloupe Strecker, 322. guenearia Packard, 3721. gueneata Packard, 3406 (Hydriomene).

gueneata Packard, 3407 (Hydriomene).

gueneei Grote, 2811.

Gueneria ....................... guettardella Busck, 6406. guilandinæ Busck, 5967 (Blastobasis).

guilandinx Busck, 6404 (Marmara). gularis Grote, 1719.

gulnare Strecker, 2265.

gulosa Hy. Edwards, 3189.

gulosalis Hulst, 4420.

gulosella Hulst, 4718.

gundlachia Poey, 79.

gurgitana Robinson, 5357.

gussata Smith, 1797.

guttata Hulst, 3793 (Alcis).

guttata Boisduval, 873 (Platypre-

pia).

guttata Grote, 2711 (Spragueia). guttatus Walsingham, 4984 (Pterophorus).

guttifera Herrich-Schaeffer, 922.

guttifinitella Clemens, 6306.

guttivitta Walker, 8141.

guttula Hy. Edwards, 2950.

guttulosa Walker, 4437.

gyas Edwards, 445.

gyasalis Walker, 3054.

gyges Hewitson, 197.

Gymnocelis

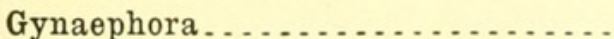

gypsalis Grote, 3027.

gypsata Grote, 3265.

Gypsochroa

gyratis Hulst, 4489 (Nymphula).
Page.

gyralis Hulst, 4412 (Phlyctrenia).

Gyrocheilus ................... . . 28

Gyros ...................... . . $\quad 212$

habilis Grote, 2887.

habitalis Walker, 2578.

Habrodias

Habrosyne................... . . . 258

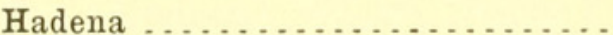

Hadenella . . . . . . . . . . . . . . hadeniformis Smith, 1847 (Mamestra).

hadeniformis Behr, 2774 (Meliopotis).

hxdulalis Hulst, 4430.

hamatica Zeller, 4911.

Hæmatomonis

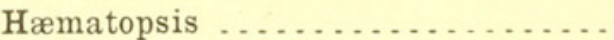

hasitans Walker, 1439.

hasitata Grote, 1027 (A patela).

hasitata Guenée, 3439 (Gypsochroa) .

hagenella Chambers, 5901.

hageni Grote, 723 (Ceratomia).

hageni Edwards, 65 (Eurymus).

hageni Frey \& Boll, 6252 (Lithocolletes).

hahneli Staudinger, 590.

halcyone Edwards, 113.

halesaria Zeller, 3601.

halesus Cramer, 329.

Halia . . . . . . . . . . . . . . . . .

haliata Guenée, 3647.

halicarnix Strecker, 727.

Halisidota . . . . . . . . . . . . . . .

hallipalpis Riley, 5662.

Hamadryas . . . . . . . . . . . . .

hamadryas Harris, 4037.

hamadryella Clemens, 6334.

hamameliella Clemens, 5807.

hamamelis Guenée, 1003.

hamaria Guenée, 3944.

hamellus Thunberg, 4560.

hamifera Walker, 2487 (Autographa).

hamifera Grote, 2054 (Stretchia).

hammondi Riley, 4845.

hamo Lucas, 447.

hampsoni Dyar, 857 .

hanga Strecker, 2379.

hanhami Hulst, 3547 (Eois).

hanhami Smith, 3038 (Philometra).

hanno Stoll, 447. 
Haploa

hapsella Hulst, 4778.

hariolalis Hulst, 4379.

harpalus Edwards, 489.

Harpalyce . . . . . . . . . . . . . . .

Harpyia . . . . . . . . . . . . . . .

harrisii Edwards, 185 (Charidryas). harrisii Scudder, 169 (Cinclidia). harrisii Walsh, 920 (Halisidota). harrisii Dyar, 840 (Haploa).

harrisii Packard, 3141 (Heterocampa).

harrisii Clemens, 725 (Lapara). harrisii Grote, 2175 (Papaipema). harrisii Edwards, 206 (Polygonia). harrisii Boisduval, 902 (Pygoctnucha).

Harrisimemna

Harrisina

hartfordii Hy. Edwards, 67.

hartii French, 3035.

hartmanni French, 2129.

hartmanniana Clemens, 5035.

haruspica Grote, 1493 (Noctua).

haruspica Grote \& Robinson, 4450

(Pyrausta).

harveiata Packard, 3260.

Harveya . . . . . . . . . . . . . . . .

harveyana Grote, 1001 (Apatela). harveyana Grote, 4401 (Phlyctænia).

harveyi Grote, 1963.

hasdrubal Stoll, 685.

hasta Guenée, 985.

hastata Linnæus, 3359.

hastiana Linnæus, 5309.

hastiferella Walker, 4807 (Etiella). hastiferellus Walker, 4558 (Crambus).

hastingsii Hy. Edwards, 2792.

hastulata Guenée, 3359 (Rheumaptera).

hastulata Hübner, 3359 (Rheumaptera).

hastulifera Smith \& Abbot, 973.

hausta Grote, 1159.

haustellata Walsingham, 5843.

havilx Grote, 1500.

haydenata Packard, 3800.

haydenella Chambers, 5931.

haydenii Edwards, 285.

hayesi Grote, 1324.

hayhurstii Edwards, 609.
Page.

haytiellus Zincken, 4596.

hebesana Walker, 5038.

hebescella Hulst, 4695.

hebetella Ragonot, 4910.

hebitata Hulst, 3657.

hebræa Guenée, 1061.

hebraicum Hübner, 1061.

hecate Butler, 3359.

hecla Lefèbre, 63.

hectoides Boisduval, 6615.

Hedylepta .

376

hegesia Cramer, 93.

hegon Scudder, 463.

heidemannella Dietz, 5950.

heiligbrodtii Harvey, 775.

hela Strecker, 63.

helcita Boisduval, 166 (Lemonias).

helcita Hübner, 298 (Neonympha).

helcitalis Walker, 4306.

helena Edwards, 135 (Brenthis).

helena Hulst, 3701 (Cymatophora).

helena Edwards, 74 (Eurymus).

helena Reakirt, 60 (Zerene).

helene Pilate, 2888.

Heliaca ......................

Heliades

helianthana Riley, 5186.

helianthi Walsingham, 4967 (Pterophorus).

helianthi Hy. Edwards, 4242 (Sesia).

helianthi Frey \& Boll, 6439 (Tischeria).

helianthiales Murtfeldt, 4397.

helianthisella Chambers, 6320.

helianthivorella Chambers, 6320 .

Helice ................... 500

Heliconidæ .................. $\quad 32$

Heliocheilus . . . . . . . . . . . . . 185

Heliodes ................... 193

Heliodines . . . . . . . . . . . . . . . . 537

Heliodora . . . . . . . . . . . . . . . 187

Heliolonche................... 193

Heliomata . . . . . . . . . . . . . . . 304

heliopalis Clemens, 4497.

Heliopetes . . . . . . . . . . . . . . . . 61

Heliophana . . . . . . . . . . . . . . . 193

Heliophila................... 161

heliopsiella Chambers, 6444.

helios Edwards, 413.

Helioscota . . . . . . . . . . . . . . . . 113

Heliosea .................... 193

heliothidata Guenée, 3651. 
Heliothis

Heliotropha

Heliozela .

heliusalis Walker, 3048.

helloides Boisduval, 396.

Hellula

helva Grote \& Robinson, 2230.

helvalis Walker, 4412.

helvia Scudder, 160.

helvialis Walker, 4351.

helviolaria Hulst, 3892.

helvolalis Maassen, 4342.

Hemaris . . . . . . . . . . . . . . .

Hemerocampa . . . . . . . . . . .

Hemerophila.

Hemiargus.

hemidesma Zeller, 5041.

Hemihyalea

Hemileuca

Hemimene

hemina Grote, 2086.

hemiochrellus Zeller, 4602.

hemizonæ Hy. Edwards, 4203.

Hendecastema

henrici Grote, 1049 (Arsilonche).

henrici Grote, 4156 (Hypopta).

henrici Grote \& Robinson, 376 (Incisalia).

henrietta Grote, 2304 (Derrima).

henrietta Smith, 1729 (Paragrotis).

henshawi Edwards, 297 (Neonympha).

henshawi Hy. Edwards, 4215 (Sesia).

Heodes

hepara Grote, 2618.

hepaticaria Guenée, 3494.

Hepialidæ

Hepialus

heptathalama Busck, 6169.

hera Harris, 766.

heraclei Retzius, 5889.

heracliana De Geer, 5889.

heraldella Guenée, 4807.

herbacea Guenée, 1415.

herbarum Guenée, 2941.

herbicola Boisduval, 2932.

herbicolata Hulst, 3399.

herbimacula Guenée, 1829

Herculia

herilis Grote, 1540.

hermannella Fabricius, 5573.

Page.

185

123

538

379

\section{hilarella Zeller, 5882.}

hilaripennella Treitschke, 6372.

hilaris Fourcroy, 4141.

hilda Quensel, 295.

Hillia

hilliana Harvey, 1486.

hilliata Hulst, 3523.

hillii Grote, 2830 (Catocala).

hillii Grote, 1153 (Hadena).

hillii Lintner, 2912 (Hypocala).

hilumnaria Hulst, 3940.

Himella . . . . . . . . . . . . . . . . .

himonialis Zeller, 4523.
Page. 
hinda French, 2866.

Page.

hinna Geyer, 2963.

hipeana Grote, 5083.

hippalus Edwards, 596.

Hipparchiscus .

Hippia ........................

hippolyta Edwards, 103 (Argynnis).

hippolyta Hy. Edwards, 2834 (Catocala).

hippolyta Lyman, 217 (Euvanessa).

hircina Morrison, 2256.

hircinalis Grote, 4443.

hirsutana Walsingham, 5132.

hirtalis Guenée, 4341.

hirtella Grote \& Robinson, 2322.

hirtipes Grote, 1994.

historialis Grote, 2582.

Historis . . . . . . . . . . . . . . .

histrio Grote, 2551.

hobomok Harris, 484.

hochenwarthi Hochenwarth, 2534.

hoffmani Strecker, 259.

hoffmanni Behr, 166.

Holcocera ....................

hollandaria Hulst, 3573.

hollandii Edwards, 17.

hollemani Grote, 1593.

holoberba Smith, 1689.

Holochroa .................... .

holocinerea Smith, 2103.

Homaledra ..................

Homochlodes .................. . .

Homochroa ................... . .

homodactylus Walker, 4962.

Homœosoma ..................

homogena Grote, 1335.

Homoglæa . . . . . . . . . . . . . . . .

Homohadena ...................

Homophoberia

Homophysa ........................

Homopryalis .

Homoptera

homopteroides Hulst, 3832.

Homosassa

homuraria Grote, 3941.

honesta Walker, 2202 (Jodia).

honesta Grote, 2405 (Melicleptria).

honestaria Walker, 4001.

Honora ....................... .

hopfferi Grote \& Robinson, 3087.

Horama ....................

horariana Walsingham, 5414 .

horatius Scudder \& Burgess, 627.
Horisma . . . . . . . . . . . . . . . 273

Hormisa . . . . . . . . . . . . . . . . . . 242

hormos Hübner, 2741.

Hormoschista . . . . . . . . . . . . . 217

302

253

Hornigia

436

horrida Hübner, 2977.

hortaria Fabricius, 3864.

hortensis Blanchard, 93.

hortuellus Hübner, 4579.

hortulana Morrison, 1547.

horus Edwards, 540.

hospes Walsingham, 5455.

hospitu Denis \& Schiffermüller, 900.

hospitalis Grote, 1482.

hospitella Zeller, 4884.

hostia Harvey, 2559.

houstonana Grote, 5398.

howardi Hy. Edwards, 2446 (Basi-

lodes).

howardi Hy. Edwards, 3085 (Daritis).

howardi Dyar, 3206 (Gloveria).

howardiSkinner, 568 (Phycanassa)

howlandii Grote, 2795.

hoyi Grote, 4040.

hualapai Neumoegen, 763.

hubbardi Dyar, 816 (Bruceia).

hubbardi Dyar, 775 (Syssphinx).

hübneraria Guenée, 4001.

hübnerata Packard, 4001.

hübneri Plotz, 566.

hudsoniana Walker, 5309.

hudsonica Hy. Edwards, 952 (Alypia).

hudsonica Grote \& Robinson, 2799

(Syneda).

182 hugo Doubleday \& Hewitson, 333.

124

233

371

218

239

440

hugon Godart, 333.

hulda Edwards, 38.

Hulstea ....................

hulstellus Beutenmüller, 6587 (Acrolophus).

hulstellus Fernald, 4593 (Crambus). hulstia Tepper, 2326.

hulstiana Dyar, 3576.

hulstiella Ragonot, 4810.

hulstii Edwards, 241 (Basilarchia).

hulstii Grote, 1223 (Hadena).

hulstii Cockerell, 4842 (Lætilia).

humarium Guenée, 3838.

77 humeralis Walker, 3886.

humerella Ragonot, 4662.

humerosana Clemens, 5429. 
humilalis Lederer, 4410.

humilis Walsingham, 6479 (Incurvaria).

humilis Ragonot, 4804 (Lipographis).

humitis Walker, 3151 (Schizukra). humilis Zeller, 5836 (Stenoma). humuli Harris, 3080 (Hypena). humuli Harris, 335 (Uranotes). huntera Fabricius, 220. hunteri Hübner, 220. huron Edwards, 512. huronalis Guenée, 4340.

Hyale. hyalina Hulst, 3250 (Eudule). hyalinata Linnæus, 4320. hyalinatalis Guenée, 4320. hyalinopuncta Packard, 3091. hyalinus Walsh, 4089 (Phobetron). Hyaloscotes

Hyamia hyantis Edwards, 44.

Hybernia

Hyblæa

Hyboma . . . . . . . . . . . . . hybrida Fabricius, 2952 (Ophideres).

hybrida Butler, 836 (Utetheisa). hybridalis Hübner, 4342.

Hybroma

hybromella Chambers, 6545.

hydaspe Boisduval, 109.

hydrangiella Chambers, 6123.

Hydria

Hydriomena

Hydriomeninæ

Hydriris

Hydrocampa

Hydrœlia

hydromeli Harvey, 3130.

hyemalis Stretch, 4047.

hygixa Heydenreich, 217.

Hylæa

hylæus Drury, 719.

liylas Edwards, 208.

hylax Edwards, 479.

Hylephila

Hylesia

hyllalis Walker, 4513.

hylotomiformis Walker, 4197.

Hymenia hypathrata Grote, 3674.

Hypanartia

354

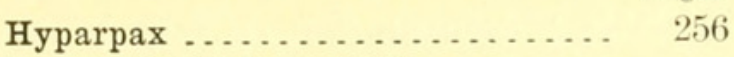

hypatialis Walker, 4401.

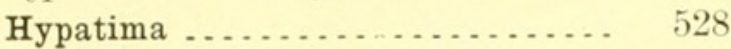

Hypatus. . . . . . . . . . . . . . . . 34

Hypaurotis . . . . . . . . . . . . . . . 35

Hypena . . . . . . . . . . . . . . . . 247

Hypeninæ . . . . . . . . . . . . . . . . 240

Hypenula . . . . . . . . . . . . . . 243

Hypepirritis . . . . . . . . . . . . . 273

Hyperæschra ................ . . . 251

hyperbola slosson, 734 .

hyperborea Curtis, 870 (Hyphoraia).

hyperborea Hulst, 3241 (Rachela).

hyperborea Hulst, 4012 (Tetracis).

hyperborealis Möschler, 4404.

hyperboreata Staudinger, 3273.

hyperboreus Möschler, 6608 (Hepialus).

hyperici Hy. Edwards, 4201 (Sesia). hyperici Boisduval \& Le Conte, 335 (Uranotes).

Hyperitis . . . . . . . . . . . . . . . . . 337

Hyperytha. . . . . . . . . . . . . . . . 344

Hyphantria ............... . . 86

Hyphoraia . . . . . . . . . . . . . . 88

Hypocala . . . . . . . . . . . . . . . . . 232

hypocastrina Poda, 4141.

Hypochalcia . . . . . . . . . . . . . . 428

hypochalciella Ragonot, 4737.

hypochraria Herrich-Schaeffer, 3941.

Hypoclopus .................. . . 577

Hypocrisias . . . . . . . . . . . . . . . . . 94

Hypogramma . . . . . . . . . . . . . 222

Hypolais . . . . . . . . . . . . . . 386

hyponomeutana Walsingham, 5156.

Hypopacha . . . . . . . . . . . . 262

hypophleas Boisduval, 399.

Hypoprepia . . . . . . . . . . . . . 80

Hypopta . . . . . . . . . . . . . . 363

Нурра ... . . . . . . . . . . . . . 121

Hypsopygia . . . . . . . . . . . . . . . 398

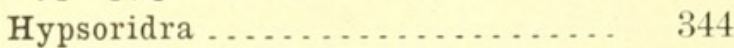

Hypsoropha . . . . . . . . . . . . . . 219

Hypsotropa . . . . . . . . . . . . . . . 439

Hyria . . . . . . . . . . . . . . . 295

Hysterosia. . . . . . . . . . . . . . 489

Hystricophora .............. . . 464

hystriculella Hulst, 4682.

Ianassa . . . . . . . . . . . . . 255

ianthe Edwards, 395.

24 iaspis Guenée, 1067. 
icarioides Boisduval, 408.

icciusalis Walker, 4487.

icelus Lintner, 618.

iceryxella Riley, 5974.

ida Hulst, 3762.

idxusalis Smith, 3075 (Bomolocha).

idæusalis Walker, 3078.1 (Bomolocha).

idaho Edwards, 487.

idahoensis Grote, 1720.

idalia Drury, 95.

idalis Fernald, 4627.

idas Cramer, 589.

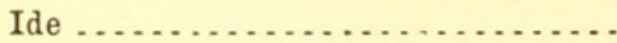

ideata Walker, 3463.

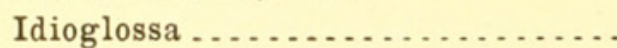

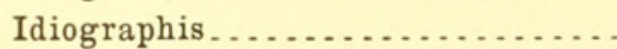

Idiostoma.

idonea Grote, 1243.

iduata Guenée, 3463.

iduna Edwards, 290.

ignea Grote, 2533.

ignidorsella Ragonot, 4863.

igninix Walker, 5480.

ignobilisella Chambers, 6161.

ignota Frey \& Boll, 6320.

ignotaria Walker, 3479.

ilaire Godart, 30.

ilavia Beutenmüller, 361.

ilia Cramer, 2865.

ilioneus Smith \& Abbot, 13.

illabefacta Morrison, 1823.

illapsa Walker, 1514.

illata Walker, 1719.

illaudabilis Grote, 1837.

illaudatum Walker, 3838.

illecta Walker, 2881.

illepida Grote, 1267.

illibalis Hübner, 4437.

illibella Hulst, 4924.

Illice

illicitella Clemens, 6081.

illinois Dodge, 555.

illinoisensis French, 2225.

illita Smith, 1040.

illiterata Grote, 2225.

illiturata Walker, 4027.

illiturbata Guenée, 4027.

illocata Walker, 1277 (Dryobota).

illocata Hulst, 3451 (Petrophora).

illotana Walsingham, 5138.
Page.

illudens Walker, 967.

illustraria Hulst, 3600.

illuviellum Ragonot, 4867.

imbraria Guenée, 4007.

imbrifera Guenée, 1774.

imbutata Hübner, 3259.

imitata Walker, 3797 (Alcis).

imitata Strecker, 170 (Cinclidia).

imitata Hy. Edwards, 4013 (Sabu-

lodes).

imitata Hy. Edwards, 4207 (Sesia).

imitatorella Chambers, 6508.

imitella Stretch, 2719.

immaculalis Harvey, 2583 (Pleonectyptera).

immaculalis Hulst, 2565 (Reabotis).

immaculata Jewett, 772 (Adelocephala).

immaculata Grote, 2270 (Cea).

immaculata Reakirt, 833 (Eubaphe).

immaculata Graef, 936 (Eupseudosoma).

immaculata Morrison, 2233 (Orthosia).

immaculata Skinner \& Aaron, 40 (Pontia).

immaculata Skinner, 3443 (Pschycophora).

immaculatella Chambers, 6239 (Bucculatrix).

immaculatella Chambers, $\quad 6110$ (Scythris).

immanata Haworth, 3380.

immanis Grote, 2165.

immediata Grote, 3404.

immerens Harvey, 4395.

immersata Walker, 3748.

immixta Grote, 1523.

immixtalis Grote, 4400.

immortua Grote, 2395.

immundella Hulst, 4676.

imora Strecker, 2004.

imparata Walker, 3477.

impartialis Harvey, 2956.

impauperata Walker, 3439 (Gypsochroa).

impauperata Walker, 3513 (Leptomeris).

impecuniosa Grote, 2188.

imperator Strecker, 728.

imperaloria Smith \& Abbot, 778. 
Page.

imperfecta Smith, 1981 (Heliophila).

imperfecta Hy. Edwards, 4228 (Sesia).

imperfectaria Walker, 3858 .

imperialis Drury, 778.

imperita Hübner, 1421.

imperspicua Strecker, 2362.

impigritella Clemens, 5513.

impingens Walker, 1936.

impleta Walker, 1039 (Apatela.)

impleta Walker, 3327 (Eucymatoge).

impletella Zeller, 4832.

implexana Walker, 5310.

implicata Guenée,3375(Mesoleuca).

implicata Villiers, 3459 (Petrophora).

implicata Walker, 3271 (Tephroelystis).

implora Grote, 2620.

implorata Hulst, 3318.

impluviata Borkhausen, 3337 (Epirrita).

impluviata Denis \& Schiffermüller, 3388 (Hydriomena).

impolita Morrison, 1852.

impositella Zeller, 6110.

impressa Walker, 1031.

impressale Hulst, 4864.

improba Butler, 140.

improbana Walker, 5133.

impropria Hy. Edwards, 4203.

impropriata Walker, 3803.

improvisa Hy. Edwards, 3184.

impudens Walsingham, 5073.

impulsa Guenée, 1231.

inæqualiata Packard, 3253.

inæquepulvella Chambers, 5667.

inamoenella Zeller, 6550.

inana Robinson, 5309.

inaptata Walker, 3700.

inatomaria Guenée, 3981.

inca Dyar, 1072.

incallida Smith, 1660 (Paragrotis). incallida Walker, 1212 (Hadena). incana Hy. Edwards, 1082 (Acopa). incana Edwards, 258 (Cercyonis). incanana Clemens, 5228.

incandescens Grote, 2778.

incanella Hulst, 4797 (Epischnia). incanella Walsingham, 6272 (Lithocolletes).

incarcerata Boisduval, 3092. incarnana Haworth, 5220.

incarnata Walker, 901.

incarnatorubra Goeze, 882.

incautellus Zeller, 4781.

incensalis Lederer, 4414.

inceptaria Walker, 3703.

incertana Clemens, 5421.

incertata Walker, 3568.

incertella Chambers, 6471 (Acrolepia).

incertella Zincken, 4550 (Mesolia).

incincta Morrison, 2018.

incisa Harvey, 4078.

Incisalia ......................

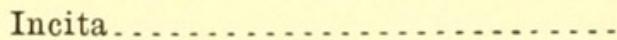

incivis Guenée, 1468.

inclara Smith, 1026 (Apatela).

inclara Strecker, 2369 (Schinia).

inclinana Zeller, 5142.

inclinataria Walker, 3331.

includens Walker, 2487 (Autographa).

includens Walker, 2617 (Erastria). inclusa Hübner, 3094.

inclusaria Walker, 3521 (Eois).

inclusaria Walker, 3571 (Racheospila).

incognita Smith, 1764.

incoloraria Walker, 3619.

incomitata Harvey, 1316.

incompleta Butler, 895.

inconcinna Harvey, 1521 (Chorizagrotis).

inconcinna Smith, 1913 (Scotogramma) .

inconcinnalis Lederer, 4440.

inconclusana Walker, 5402.

inconditana Walsingham, 5351.

inconditella Ragonot, 4759.

inconditus Walsingham, 4975.

incongruaria Hulst, 3987 (Metanema).

incongruella Hulst, 4893 (Urula).

inconspicua Hulst, 3203 (Chloroclystis).

inconspicua Smith, 1154 (Hadena). inconspicua Grote, 2062 (Tricholita).

inconspicualis Grote, 3028.

inconspicuella Murtfeldt, 5617.

inconstans Geyer, 3435 (Emplocia). inconstans Stainton, 6354 (Gracilaria). 
inconstans Grote, 1318 (Homohadena).

inconstans Guenée, 2764 (Panula). incopriaria Hulst, 3820.

incopularia Guenée, 4006.

incomupta Hy. Edwards, 888.

incoruscella Hulst, 4787.

increta Morrison, 1023.

incrustalis Hulst, 4641.

incubita Smith, 1650.

inculta $\mathrm{Hy}$. Edwards, 180.

incursaria Herrich-Schaeffer, 3449. incursata Hübner, 3449.

incurva Hy. Edwards, 3215 (Mala-

cosoma).

incurva Smith, 1834 (Mamestra).

Incurvaria . . . . . . . . . . . . . . .

incurvata Guenée, 4026.

incusalis Grote, 2580.

indeclinata Walker, 3941.

indecorana Zetterstedt, 5299.

indentalis Grote, 4361.

indentata Packard, 3092 (Mela-

lopha).

indentata Harvey, 2923 (Remigia).

indetermina Boisduval, 4079.

indeterminala Walker, 1413 (Adel-

phagrotis).

indeterminata Walker, 3141(Hetero-

campa).

indiana Grote, 3122.

indicans Walker, 1837.

indicata Fabricius, 4299.

indicatalis Walker, 4807.

indicataria Walker, 3848.

indigenella Zeller, 4704.

indigens Walker, 1088.

indigna Walker, 2498.

indirecta Grote, 1157 (Hadena).

indirecta Walker, 1649 (Paragro-

tis).

indirecta Walker, 2236 (Scopelo-

soma).

indiscreta Hy. Edwards, 2916.

indiscretata Hy. Edwards, 3938.

indiscriminaria Walker, 3561.

indistincta Hy. Edwards, 3091

(Apatelodes).

indistincta Hulst, 3447 (Ersephila). indistincta Smith, 1279 (Нyppa).

indistinctalis Walker, 4342 (Nomo-

phila).
Page.

indistinctalis Warren, 4408 (Phlyctænia).

indivisalis Grote, 3055.

indivisana Walker, 5417.

indocilis Walker, 1217.

indoctaria Walker, 3493.

indoctrinata Walker, 3327.

indotatellus Walker, 4359.

indra Reakirt, 20.

indubitata Grote, 3417.

inducta Walker, 1649.

inductata Guenée, 3546.

indurata Smith, 1903.

induta Harvey, 1315.

ineffusaria Guenée, 4007.

inelegans Smith, 1402.

inepta Hy. Edwards, 2745.

inermis Harris, 1467.

ines Edwards, 369.

inexacta Walker, 2950.

inexpertana Walker, 5038.

inextricata Walker, 3614 (Mellilla).

inextricata Walker, 1649 (Paragrotis.).

infans Möschler, 4037.

infausta Walker, 1702.

infecta Walker, 1829.

infectata Walker, 3668.

infelix Smith, 1726 (Paragrotis).

infelix Guenée, 1118 (Perigea).

infensata Guenée, 4005.

inferior Grote, 3050 (Bleptina).

inferior Hulst, 3264 (Gymnocelis).

inferior Smith, 2048 (Stretchia).

infernalis Strecker, 776.

inficita Walker, 2551.

infidelis Grote, 1886.

infimalis Guenée, 4317.

infimata Guenée, 3668.

infimatis Grote, 1450.

infimella Ragonot, 4881.

infirma $\mathrm{Hy}$. Edwards, 4207.

infixa Walker, 1313.

infixaria Walker, 3860.

inflatella Clemens, 5519.

influxa Morrison, 1304.

infracta Morrison, 1624.

infrequentata Haworth, 3373.

infructuosa Walker, 1890.

infulata Grote, 3611.

infumatu Grote, 2217.

infumatana Zeller, 5358. 
infumataria Grote, 3816.

infusa Smith, 1725.

infuscana Walsingham, 5195.

infuscata Tengström, 3379 (Mesoleuca).

infuscata Smith, 1908 (Scotogramma).

infuscatella Clemens, 6021.

ingeniculata Smith, 1456 (Agrotis). ingeniculata Morrison, 2791 (Syneda).

ingenita Hy. Edwards, 4113.

ingens Hy. Edwards, 932.

ingenua Walker, 2915.

ingrata Felder, 82.

ingravis Smith, 1798.

inguinalis Guenée, 4294.

Ingura .

Inguromorpha

203

inimicella Zeller, 5078.

innexa Grote, 1843.

innocuella Zeller, 5701.

innominata Smith, 2095.

innotata Guenée, 988.

innotatellus Walker, 4580.

immubens Guenée, 2866.

inopiana Haworth, 5472.

inopinatus Hy. Edwards, 907 (Ammalo).

inopinatus Smith, 1494 (Noctua).

inops Grote, 2224.

inordinaria Walker, 3647.

inordinata Morrison, 1252.

inornata Edwards, 125 (Argynnis).

inornata Edwards, 284 (Coenonympha).

inornata Grote, 2696 (Fruva).

inornata Beutenmüller, 3191 (Hemerocampa).

imornata Neumoegen, 3093 (Melalopha).

inornata Grote, 1295 (Pyrophila).

inornata Walsingham, 5895 (Semioscopis).

inornata Grote \& Robinson, 4087 (Sisyrosea).

inornata Hulst, 3895 (Stergammatæa).

inornata Hulst, 3281 (Tephroclystis).

inornata Grote \& Robinson, 347 (Thecla).
Page.

inornata Grote, 2269 (Trichocosmia).

inornatalis Walker, 4352 (Loxostege).

inornatalis Fernald, 4461 (Pyrausta). inornatana Clemens, 5024.

inornatella Chambers, 6022 (Coleophora).

inornatella Chambers, 6082 (Elachista).

inornatella Chambers, 6181 (Eulyonetia).

inornatella Hulst, 4834 (Euzophera).

inomatella Chambers, 6372 (Gracilaria).

inornatellus Clemens, 4580 (Crambus).

inornatellus Walker, 4610 (Crambus).

inotabilis Grote, 1413.

inquadrana Walsingham, 5008.

inquasita Grote \& Robinson, 2172.

inquietana Walker, 5074.

inquilinella Ragonot, 4740.

inquinaria Hulst, 3733.

inquinata Guenée, 2155 (Nonagria).

inquinatalis Zeller, 4403.

inquinatus Zeller, 4990 (Pterophorus).

insciens Walker, 2040.

inscripta Walsingham, 5615 (Paralechia).

inscriptata Donovan, 3337.

inscriptum Harris, 669 (Deidamia). insequalis Guenée, 4454.

inserrata Walsingham, 5656.

insertans Smith, 1576.

insignata Cotes \& Swinhoe, 1103

(Caradrina).

insignata Walker, 1227 (Hadena). insignata Walker, 1707 (Paragrotis). insignatilis Guenée, 4448.

insignis Walsingham, 6255 (Lithocolletes).

insignis Frey \& Boll, 6428 (Phyllocnistis).

insignis Walker, 2464 (Plusiodonta). insignisell: Walker, 6495. insignitalis Guenée, 4448. insinuaria Guenée, 3934. 
insipida Strecker, 1108.

insita Walker, 979.

insiticiana Zeller, 5287.

insolabilis Guenée, 2821 (Catocala). insolabilis Hulst, 3283 (Tephroclys-

tis).

insolens Grote, 1777.

insolita Grote, 1043 (Apatela).

insolita Smith, 2491 (Autographa). insolita Lintner, 707 (Sphinx).

insperata Grote, 2748.

inspergella Ragonot, 4925.

instabilella Mann, 5490 .

instabilis Fitch, 2040.

instrutana Claypole, 5232 (Epinotia). instrutana Clemens, 5064 (Olethreu-

tes).

insueta Guenée, 1975.

insularia Guenée, 3477.

insularis Grote, 1405 (Rhynchagrotis).

insularis Vollenhoven, 736 (Philosamia).

insulata Walker, 906.

insulidens Bird, 2190.1.

insulsa Walker, 1103 (Caradrina).

insulsa Walker, 1707 (Paragrotis).

intactana Walsingham, 5444.

integerrima Walker, 2957 (Campometra).

integerrima Grote \& Robinson, 3108

(Datana).

integerrima Harris, 733 (Paonia).

integra Zeller, 4484.

integraria Walker, 3636.

intenta Walker, 2992.

intentata Walker, 3623 (Deilinia).

intentata Smith, 1860 (Mamestra).

intercalcaris Grote, 2762.

interior Scudder, 71.

interjacens Grote, 2301.

interjecta Dyar, 4077.

interlinearia Guenée, 4007.

intermedia Stretch, 877 (Apantesis). intermedia Speyer, 2132 (Cucullia). intermedia Strecker, 440 (Cyaniris). intermedia Kirby, 670 (Deilephila). intermedia Graef, 829 (Eubaphe). intermedia Cockerell, 65 (Eurymus). intermedia Fitch, 3190 (Hemerocampa).

intermedia Frey \& Boll, 6301 (Lithocolletes).
Page.

intermedia Butler, 836 (Utetheisa). intermedialis Walker, 4520 . intermediata Guenée, 3376. intermediella Busck, 6427. intermedius Riley, 6565 (Prodoxus). intermicata Walker, 3893. intermidella Chambers, 5576. interminaria Grote, 3893. interminellus Walker, 4604. intermistana Clemens, 5028. interna Packard, 3128 (Dasylophia).

interna Grote, 1289 (Trachea). interoceanica Smith, 2162. interpositella Frey \& Boll, 6381. interpuncta Grote, 3062. interpunctella Hübner, 4890. interrogationis Fabricius, 205. interrupta Guenée, 991 (Apatela). interrupta Zeller, 4485 (Lineodes). interrupta Walsingham, 5508 (Plutella).

interruptaria Grote, 3824.

interruptella Ragonot, 4638.

intermuptofasciata Robinson, 5451

(Phalonia).

interruptofasciata Packard, 3278

(Tephroclystis).

interruptolineana Fernald, 5040.

interruptomarginata De Beauvois, 838.

interruptus Grote, 4583 (Crambus). interstinctana Clemens, 5270 .

intestinata Guenée, 3327.

intexta Harvey, 2258.

intextata Walker, 3859.

intrabilis Smith, 2374.

intractaria Walker, 3862 (Ectropis). intractarium Walker, 3838 (Selidosema).

intractata Morrison, 2007 (Himella).

intractata Walker, 1489 (Noctua).

intractella Walker, 4354.

intrarium Guenée, 3838.

intricatalis Lederer, 4411.

intrita Morrison, 1692.

introferens Grote, 1518.

intrusa Smith, 1712.

intrusata Walker, 3370.

inulta Grote, 2247.

inusitata Hy. Edwards, 4216.

inusitatumnella Chambers, 6392. 
inusta Guenée, 2268.

inutitis Hy. Edwards, 6615.

invalida Smith, 1799.

invariata Walker, 3477.

inventaria Grote, 3373.

invenusta Grote, 1513.

invenustalis Walker, 4280.

inversa Packard, 3094.

inversella Zeller, 5665.

invexana Walker, 5380.

invexata Walker, 3911.

invicta Walsingham, 5157.

invictalis Hulst, 4406.

inviolata Hulst, 3995.

invisalis Guenée, 4265.

involuta Walker, 2986 (Homoptera).

involuta Dyar, 4054 (Nola).

involutellus Clemens, 4567.

involutum Sepp, 936 (Eupseudosoma).

io Fabricius, 753 (Automeris).

io Boisduval, 733 (Paonias).

iochroa Zeller, 6553.

iole Boisduval, 41 (Nathalis).

iole Grote, 1116 (Perigea).

iole Cramer, 220 (Vanessa).

iowa Scudder, 572.

Iphidicles ................. . . .

iphitalis Walker, 4633.

Ipimorpha . . . . . . . . . . . . .

ipomoex Busck, 6067 (Cosmopteryx).

ipomøx Doubleday, 3148 (Schizura).

ipomøæx Harris, 780 (Syntomeida). irene Boisduval, 122 (Argynnis).

irene Behr, 2856 (Catocala).

irene Fitch, 41 (Nathalis).

irieolor Smith, 1344.

iridaria Guenée, 3599 (Anaplodes). iridaria Packard, 3600 (Anaplodes).

iridella Chambers, 6477.

iris Guenée, 2203.

iroides Boisduval, 372.

irrecta Walker, 2576.

irregulata Walker, 3647.

irresoluta Walker, 1137.

irridipennella Clemens, 5653.

irrorata Hy. Edwards, 817 (Clemensia).

irrorata Packard, 3227 (Oreta).
Page.

irrorata Smith, 2000 (Orthodes). irrorata Grote, 2935 (Poaphila).

irrorata Packard, 3655 (Sciagraphia).

irroratana Walsingham, 5105.

irroratella Walsingham, 6023.

irrorea Robinson, 5350.

irus Godart, 374.

isabella Clemens, 6124 (Antispila). isabella Smith \& Abbot, 859 (Arachnis).

isabella Hy. Edwards, 2897 (Catocala).

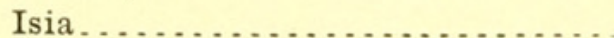

islandica Staudinger, 1728.

ismeria Boisduval \& Le Conte, 186.

Isochætes. . . . . . . . . . . . . . . . 356

Isogona ...................

isola Reakirt, 444.

isophthalma Herrich-Schaeffer, 449. issabella Chambers, 6124.

istapa Reakirt, 366.

Itama

itata Smith, 2085.

itealis Walker, 4491.

ithac: Beutenmüller, 4226.

Ithobalus . . . . . . . . . . . . . . . . .

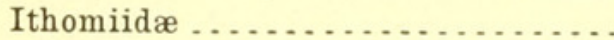

itodes Smith, 1664.

itys Edwards, 341.

itysalis Walker, 4404.

itzalana Strecker, 4161.

iva Busck, 5580.

ivallda Mead, 291.

ivana Fernald, 5405.

ivella Busck, 6240.

Ixala

ixion Linnæus, 664.

jachusalis Walker, 3021.

jaculifera Guenée, 1540.

jada Butler, 53 (Aphrissa).

jada Hewitson, 334 (Eupsyche).

jaguarina Guenée, 2353.

jair Strecker, 2908.

j-album Boisduval \& Le Conte, 215.

jamaicensis Drury, 729.

janais Drury, 200.

janassialis Walker, 4379.

janiphæ Boisduval, 690.

janthinella Duponchel, 4776.

janualis Grote, 1426.

jaquenetta Hy. Edwards, 2898. 
jarbusalis Walker, 4279.

jasminearum Boisduval, 720.

Jaspidia . . . . . . . . . . . . . . .

jaspidiaria Hulst, 3572.

jassieuæ Hübner, 677.

jatrophr Linnæus, 224 (Anartia).

jatrophx Fabrıcius, 684 (Cocytius). jessica Hy. Edwards, 2833 (Catocala).

jessica Barnes, 899 (Euverna).

Jocara ...................

jocasta Strecker, 2910 (Andrewsia). jocasta Smith, 1194 (Hadena).

Jochæra . . . . . . . . . . . . . . . jocosa Guenée, 1282 (Feralia). jocos $\alpha^{*} \mathrm{Hy}$. Edwards, 3094 (Melalopha).

Jodia

johnsomaria Fitch, 3960.

jormlla Westwood, 738.

josephina Godart, 31.

juanita Scudder, 329 (Atlides). juanita Strecker, 661 (Lepisesia). juba Boisduval, 115 (Argynnis). juba Scudder, 487 (Erynnis). jubararia Hulst, 3979.

Jubarella .

jucunda Boisduval \& Le Conte, 88

(Eurema).

jucunda Hübner, 2774 (Meliopotis). jucunda Walker, 1483 (Noctua). jucundaria Strecker, 3992.

judith Strecker, 2823.

juglandana Fernald, 5420.

juglandella Mann, 6359.

juglandiella Chambers, 6142 (Coptodisca).

juglandiella Clemens, 6288 (Lithocolletes).

juglandifoliella Chambers, 6199.

juglandis Smith \& Abbot, 734 (Cressonia).

juglandis Le Baron, 4702 (Mineola). juglandisnigrzella Chambers, 6359. jugosella Ragonot, 4724.

julia Fabricius, 90 (Colænis). julia Grote, 2310 (Rhodosea). julia Hulst, 3744 (Sympherta). julia Edwards, 49 (Synchloe). julialis Walker, 4414. julianulis Walker, 4634. juncealis Guenée, 4502. junceti Zeller, 1103.
Page.

106

kearfottella Busck, 5698 (Aproære$\mathrm{ma})$.

kearfottella Busck, 5590 (Aristotelia).

keewaydin Edwards, 65.

kellicottii Fish, 4977.

kelloggi Hy. Edwards, 1940.

kempii Hulst, 3926.

kennicotella Clemens, 6170.

kentaria Grote, 3971.

kerrvillei Smith, 1677.

keutzingaria Packard, 3928.

keutzingii Packard, 3928.

kincaidiana Fernald, 5267.

kindermanniana Treitschke, 5436.

kinzelella Busck, 5571.

kiowah Reakirt, 529.

klagesii Ehrman, 851.

klamathiana Walsingham, 5868.

klugii Hübner, 305.

kodial: Edwards, 282 (Coenonympha).

kodiak Edwards, 415 (Cupido).

kodiakata Packard, 3362.

Kodiosoma ................... . .

koebelei Riley, 2277 (Antaplaga). 
koebelei Hy. Edwards, 4224 (Sesia). koebelella Dyar, 5499.

korites Druce, 4171.

kreimhild Strecker, 142.

Kricogonia

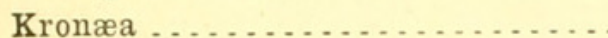

kuehniella Zeller, 4874.

kunzei Hulst, 3899 (Neoterpes).

kunzei Hulst, 3812 (Pterospoda).

labe Strecker, 2378.

labecula Grote, 1094 (Balsa).

labecula Grote, 929 (Hemihyalea).

labeculalis Hulst, 4364.

labeculana Robinson, 5449 .

labeculata Hulst, 3555.

labiosana Zeller, 5385.

labradoriata Möschler, 3891 (Dyscia).

labradoriata Möschler, 3672 (Macaria).

labradorica Möschler, 5808.

labradoriella Clemens, 5809 (Gelechia).

labradoriella Clemens, 6480 (Incurvaria).

labradoriensis Christoph, 4570 (Crambus).

labradoriensis Scudder, 73 (Eurymus).

labradoriensis Packard, 6609 (Hepialus).

labradoriensis Staudinger, 1694

(Paragrotis).

labradoriensis Packard, 3456 (Petrophora).

labrosa Grote, 2490.

labruscæ Linnæus, 674.

lachrymosa Hulst, 3832 (Selidosema).

lachrymosa Hulst, 3297.1 (Tephroclystis).

lacinia Hübner, 201.

laciniana Zeller, 5247.

laciniellus Grote, 4605.

laciniosa Zeller, 3065.

lacoalis Walker, 4423.

Lacosoma .

Lacosomidm

lacrymosa Guenée, 2810.

lactata Smith, 839.

lactea Stretch, 818.

lacteata Packard, 3445.

lacteella Fabricius, 4623 (Argyria).
Page.

lacteella Schiffermüller, 6170 (Endrosis).

lacteella Hulst, 4765 (Salebria).

lacteodactylus Chambers, 4966.

8

358

lacteolata Lintner, 3538.

lacteusochrella Chambers, 5810.

lactiflosella Chambers, 5668.

lactimaculella Walsingham, 6555.

lactipennis Harvey, 2665.

lacunacolella Duponchel, 6006.

lacunosa Morrison, 1568.

lacustrata Guenée, 3374.

ladon Cramer, 440.

Laertias . . . . . . . . . . . . . . .

lata Edwards, 383 (Erora).

leta Boisduval, 828 (Eubaphe).

lata Morrison, 2154 (Nonagria).

lita Hulst, 3906 (Therina).

lietabilis Smith, 1183.

laxtella Grote, 4727.

latifica Smith, 992 (A patela).

latifica Lintner, 2129 (Cucullia).

latificans Smith, 1570.

Lætilia . . . . . . . . . . . . . . . .

lixtula Hulst, 3740 (Cymatophora).

lictula Grote, 1407 (Rhynchagrotis).

latulus Grote, 3063 (Lomanaltes).

lavigana Schiffermüller, 5359.

lavigata Smith, 1079 (Hadenella).

lavigata Grote, 3019 (Zanclognatha).

lavigatella Hulst, 4756.

lavitaria Hübner, 3525.

lafauryella Constant, 4793.

lagena Grote, 1533.

lagganx Smith, 1665.

Lagoa . . . . . . . . . . . . . .

lagopana Walsingham, 5222.

laguncularix Dyar, 4054.

lagunculariella Busck, 5706.

lagus Edwards, 571.

laidon Borkhausen, 284.

lais Edwards, 101.

laisata Strecker, 3306.

lallata Hulst, 3789.

lallatalis Hulst, 4728.

lamana Zeller, 5007.

lamialis Walker, 4497.

lamina Fabricius, 237.

laminarium Strecker, 3837.

laminis Smith, 1746. 
Lamprolophus

lamprosana Robinson, 5392.

Lamprosema . . . . . . . . . . . .

lanariella Clemens, 6487.

lanceana Frölich, 5006.

lanceolana Hübner, 5006 (Bactra). lanceolana Stephens, 5169 (Thiodia).

lanceolaria Grote, 1042.

lanceolata Hulst, 3532 (Eois).

lanceolata Boisduval, 46 (Synchloe). lanceolata Grote, 2668 (Tarache).

langdonalis Grote, 4422.

langtonii Couper, 952.

languida Smith, 1846 (Mamestra). languida $\mathrm{Hy}$. Edwards, 2402 (Melicleptria).

lanice Lintner, 57.

Laniifera

Lanthaphe . . . . . . . . . . . . .

lanuginosa Smith, 1935 (Anarta).

lanuginosa Clemens, 4109 (Megalopyge).

lanul Strecker, 2325.

Laodamia . . . . . . . . . . . . . .

Laosticha . . . . . . . . . . . .

Lapara . . . . . . . . . . . . . .

Laphygma .................

lapidana Walsingham, 5190.

lapidaria Grote, 1978.

lapillata Guenée, 3370.

lapitaria Strecker, 3686.

lappella Linnæus, 5539.

lapponica Thunberg, 1939 (Anarta). lapponica Esper, 138 (Brenthis).

lapponica Staudinger, 74 (Eurymus).

lapponica Thunberg, 870 (Hyphoraia),

lapponica Staudinger, 3459 (Petrophora).

laqueata $\mathrm{Hy}$. Edwards, 937.

laqueatellus Clemens, 4573.

larana Walsingham, 5087.

Larentia . . . . . . . . . . . . . .

larentioides Grote, 2724.

l-argenteum Scudder, 214.

laricella Hübner, 6024.

laricinella Ratzeburg, 6024.

laricis Fitch, 3211.

larimana Walsingham, 5286.

larinia Godart, 223.

Larissa
Page.

larunda Strecker, 171.

larvalis Grote, 3044.

larvaria Guenée, 3855.

larvata Strecker, 312.

lasciniata Zeller, 3402.

Lasiacme ... . . . . . . . . . . . . . . .

Lasiocampidæ . . . . . . . . . . . .

lassauxii Boisduval, 687.

lasus Edwards, 492.

lata Robinson, 5397.

lataria Packard, 3588.

Latebraria . . . . . . . . . . . . . . . . . .

latebricola Grote, 1076.

laterana Robinson, 5382.

latercula $\mathrm{Hy}$. Edwards, 4121.

laterculx Dyar, 4130.

lateritia Hübner, 1225.

lateritiaria Guenée, 3941.

latex Guenée, 1810.

Lathosea . . . . . . . . . . . . . . . .

latia Strecker, 2194.

laticapitana Walsingham, 5469.

laticapitella Clemens, 5941.

laticincta Walker, 3934.

laticinerea Grote, 2091.

laticlavia Morrison, 2518 (Autographa)

laticlavia Clemens, 4097 (Lithacodes).

laticlavia Grote \& Robinson, 4457 (Pyrausta).

laticornella Clemens, 6025.

latifasciana Haworth, 5315.

latifasciaria Packard, 3799.

latifasciata Butler, 848.

latifasciella Packard, 4734 (Nephopteryx).

latifasciella Chambers, 6200 (Nepticula).

latifasciella Chambers, 5556 (Telphusa).

latiferreana Walsingham, 5295.

latiferrugata Walker, 3709.

latiorata Walker, 3765.

latipenella Chambers, 6451.

latipennis Hulst, 3802 (Alcis).

latipennis Stretch, 863 (Diascrisia). latipennis Boisduval, 3087 (Gnophaela).

latipennis Walsingham, 5476 (Martyringa).
Page. 
latipennis Hulst, 3243 (Rachela). latipennis Hulst, 3915 (Slossonia). latipennis Hulst, 3287 (Tephroclystia).

latipes Guenée, 2923.

latipunctana Walsingham, 5456.

latiradiellus Walker, 4583.

latirupta Walker, 3402.

latispargaria Walker, 3748.

latistrigella Walsingham, 6416.

lativittella Ragonot, 4901.

latomia Harvey, 4095.

latreillana Kirby, 798.

laudabilis Guenée, 1837.

laura Edwards, 123.

laurentii Smith, 3015.

laurentina Lyman, 487 (Erynnis).

laurentina Scudder, 71 (Eurymus).

lautana Clemens, 5279.

lautaria Hübner, 3506.

lautus Cockerell, 6569.

Laverna

lavernella Chambers, 5638.

laviana Hewitson, 638.

lavinia Fabricius, 225.

leachellus Zincken, 4565.

leanira Boisduval, 175.

lebertella Frey \& Boll, 6327.

leca Butler, 638.

lecontei Boisduval, 840.

lecontella Clemens, 5883.

leda Edwards, 368.

ledella Walsingham, 6292.

Ledereria

legitima Grote, 1822.

leilia Edwards, 246.

Leioptilus

lembertii Dyar, 6611.

Lemonias.

lena Boisduval, 848 (Leptarctia).

lena Edwards, 612 (Pholisora).

lentaria Hulst, 3949.

lentifusalis Zeller, 4265.

lentiginosa Grote, 3074.

lentiginosana Walsingham, 5343.

lenzi Behrens, 6615 (Hepialus).

lenzi French, 2477 (Plusia).

leo Guenée, 2703.

leoducusalis Walker, 4377.

leonana Walsingham, 5209.

leonardus Harris, 504.

leoninata Packard, 3441.

leoninella Packard, 4806.
Page.

lepida Lintner, 3110.

lepidalis Hulst, 4356.

lepidana Clemens, 5450.

lepidula Grote, 1055 (Jaspidia).

lepidula Smith, 1779 (Mamestra).

Lepipolys .................... 127

Lepisesia .................. . . 63

Lepitoreuma ................. $\quad 99$

leporina Linnæus, 982.

Leptalis .................... 4

Leptarctia ................... $\quad 85$

Leptina ................... 107

leptinoides Grote, 3154.

Leptomeris . . . . . . . . . . . . . . . . 294

Leptotes.................... . . 46

lepusculina Guenée, 984.

Lerema ..................... 53

Lerina .................... . 92

lespedezx Walsingham, 6068.

lespedezafoliella Clemens, 6364.

lethalis Grote, 4466.

lethe Fabricius, 226.

leto Behr, 98.

Leucania ....................

leucaniellus Walker, 4624.

Leucanthiza .................

leucata Hulst, 3279.

Leuce .

leucillana Zeller, 5835.

leucobasis Fernald, 5529.

Leucobrephos

leucochrysella Clemens, 6026.

Leucocora ...................

leucocycla Staudinger, 1934.

leucogramma Grote, 1778.

leucographa Geyer, 3190.

leucoloma Snellen, 4793.

leucomelana Morrison, 960.

leucomelas Herrich-Schaeffer, 840.

leucomera Butler, 900.

leuconota Zeller, 5594.

leucophæa Smith \& Abbot, 3194.

leucophxalis Walker, 4377.

leucophrella Hulst, 4675.

leucophaleratana Packard, 5266.

Leucophryne .................. . 543

Leucophthalmia ................. 291

Leucoptera ..................... 562

leucorena Smith, 1114.

leucoscelis Grote, 1152.

leucosigma Packard, 4085.

leucostigma Smith \& Abbot, 3190.

Leuculodes 
leralis Hulst, 4294.

leveltei Grote, 2823.

levipedella Clemens, 5713.

levis Hudson, 3231 (Falcaria).

levis Grote, 1331 (Oncocnemis).

lewisii Grote, 1735.

Lexis

Libatrix Linnæus, 2207.

libedis Smith, 2689.

libella Grote, 4507 .

libera Walker, 1800 (Mamestra).

libera Strecker, 3188.(Notolophus).

liberaria Walker, 3636.

libocedrus Hy. Edwards, 706.

liboraria Walker, 3699.

liburna Geyer, 2560.

libya Scudder, 610.

Libytheidæ

licealis Walker, 4354.

licentiosa Smith, 1949.

licinus Edwards, 500.

lienigiana Heinemann, 5045.

lienigiellus Zeller, 4598.

ligata Grote, 1969 (Heliophila).

ligata Walker, 1842 (Mamestra).

ligex Smith, 2373.

ligitima Grote, 1822.

ligni Givenée, 2560.

lignicolor Guenée, 1250 (Hadena).

lignicolor Walker, 3145 (Ianassa).

lignicolorata Packard, 3366.

lignigera Walker, 3145.

lignosellus Zeller, 4781.

ligularia Guenće 3450.

ligulella Hübner, 5678.

lilacina Harvey, 1823.

lilea Reakirt, 574.

liliana Hy. Edwards, 121.

lilith Strecker, 753.

lima Guenée, 2943.

limata Grote and Robinson, 4307.

limbalis Grote, 2370.

limbata Haworth, 3939 (Ania).

limbata Hy. Edwards, 2646 (Tripudia).

limbidipennella Clemens, 5503.

limbolaris Geyer, 2769.

limbopunctata Nolcken, 3360.

Limenitis . . . . . . . . . . . . . . . .

limitate Smith, 1966 (Heliophila).

limitata Walker, 3234 (Nyctobia).

limitata Robinson, 5391 (Pandemis).
Page.

\section{Limochroes}

Page.

limpida Guenée, 2182.

linda Edwards, 86.

lindana Fernald, 5235.

lindenella Busck, 5748.

linealis Fernald, 4368.

lineana Fernald, 5116 (Eucosma).

lineanu Schiffenmüller, 5035 (Olethreutes).

lineapulvella Chambers, 6027.

linearis Grote, 3033.

lineata Hulst, 3752 (Ethyctera).

lineata Fabricius, 671 (Deilephila). lineata Walker, 2539 (Diastema).

lineata Druce, 3131 (Heterocampa).

lineata Walsingham, 5494 (Pterolonche).

lineata Walker, 2332 (Schinia).

lineatella Zeller, 5693 (Anarsia).

lineatella Harvey, 1300 (Prodenia).

lineella Grote, 2907.

lineifroms Smith, 1676.

Lineodes. . . . . . . . . . . . . .

lineola Walker, 2979.

lineolata Walker, 1084.

lineosellus Walker, 4624.

lingulacella Clemens, 5572.

linita Guenée, 1976.

linnei Grote \& Robinson, 676.

lintnerana Speyer, 3083.

lintneraria Packard, 3636.

lintneri Grote, 3169 (Gluphisia).

lintneri Grote, 2156 (Ommatostola).

Lintneria . . . . . . . . . . . . .

lintneriana Grote, 5357.

lintnerii Fitch, 217 (Euvanessa).

Liopasia . . . . . . . . . . . . .

Lioptilus . . . . . . . . . . . . .

Liparidæ . . . . . . . . . . . . . .

liparops Boisduval \& Le Conte, 349.

Lipocosma . . . . . . . . . . . . . 372

Lipographis . . . . . . . . . . . . . 428

Lipoptycha................ 4. 471

liquida Grote, 1788.

liquidambarisella Clemens, 6425.

liquoraria Guenée, 3581.

liriodendraria Smith \& Abbot, 3864. liriodendronella Clemens, 6423.

lisa Boisduval, 85.

litaria Hulst, 3633.

Lithacodes.

Lithacodia...................... 210

Lithariapteryx ................. 537 
lithella Busck, 6098.

Lithocolletes

Litholomia .

Lithomoia

Lithophane

lithosella Ragonot, 4783.

Lithosiidæ

lithosina Hy. Edwards, 2595 (Annaphila).

lithosina Zeller, 5842 (Ide).

lithosioides Dyar, 804.

lithospila Grote, 1005.

Lithostege

litigiosella Zeller, 6241.

Litocala

Litodonta

litophora Grote, 3032.

Litoprosopus

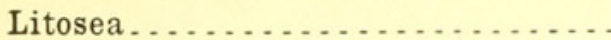

littera Guenée, 2216.

littoralis Packard, 1431.

lituralis Hübner, 3026.

liturana Walsingham, 5223.

liturata Ménétries, 883 (Apantesis). liturata Smith, 1020 (A patela).

liturella Walker, 5811 (Gelechia).

liturella Walker, 5650 (Menesta).

liturosella Zeller, 5764.

lividus Hübner, 576.

livolella Riley, 5982.

livorella Zeller, 5982.

Lixa

lixalis Grote, 3052.

lixaria Grote, 3846 (Cleora).

lixaria Guenée, 3571 (Racheospila).

lixiva Grote, 2650.

loammi Whitney, 539.

lobelix Guenée, 993.

lobidactylus Fitch, 4931.

lobophorata Walker, 3234.

loculata Morrison, 1212.

loculosa Grote, 1123.

locutia Hewitson, 640.

loda Strecker, 1179.

logan Edwards, 566.

logiana Fabricius, 5309 (Acleris).

logiana Schiffenmüller, 5312 (Acleris).

Loma

Lomanaltes

lona Strecker, 1186.

longa Guenée, 1037 (Apatela).

longa Grote, 925 (Halisidota).

Page.

549

171

169

169

267

232

253

236

220

4630 -No. $52-02$ longeciliata Frey \& Boll, 6445 (Tischeria).

longiciliata Hulst, 3244 (Paleacrita).

longiclava Smith, 1844.

longidens Smith, 1537 (Feltia).

longidens Hulst, 3303 (Tephroclystis).

longifasciella Clemens, 5554.

longilabris Grote, 3036.

longimaculella Chambers, 5912.

longior Smith, 2083.

longipalpata Hulst, 3475 (Mycterophora).

longipalpata Packard, 3296 (Tephroclystis).

longipalpella Ragonot, 4894.

longipalpus Morrison, 4612.

longipennata Packard, 3528.

longipenne Grote, 2290.

longipennella Hulst, 4820.

longipennis Walker, 3235.

longipes Druce, 2433 (Fenaria).

longipes Möschler, 4173(Podosesia). longirostrata Frey \& Boll, 6259.

longirostrellus Clemens, 4547.

longleyi French, 473.

longula Grote, 1215 (Hadena).

longula Hulst, 3454 (Petrophora).

Lophoderus ................... . 484

Lophodonta . . . . . . . . . . . . . . . . 252

Lophosis ................... 298

lora Strecker, 2387.

lorata Grote, 3179 (Euthyatira).

lorata Grote, 4016 (Sabulodes).

lorata Grote \& Robinson, 347 (Thecla).

lorea Guenée, 1842.

loricana Grote, 5265.

lorquinaria Guenée, 3747 .

lorquini Boisduval, 60 (Zerene).

lorquinii Grote \& Robinson, 943

(Androloma).

lorquinii Boisduval, 242 (Basilarchia).

lonquinii Behr, 421 (Phædrotes).

los Strecker, 6604.

lotis Lintner, 433.

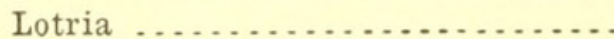

lotta Beutenmüller, 45.

louisa Hulst, 3577.

Loxofidonia................... $\quad 290$

Loxostege ................. 382 
loya Smith, 1586.

lubens Grote, 1808.

lubricalis Geyer, 3012.

lubricans Guenée, 1514.

lucasi Smith, 2672.

lucata Guenée, 3335.

luccusalis Walker, 4285.

lucens Morrison, 2389 (Dasyspoudæa).

lucens Freyer, 2162 (Gortyna).

lucernalis Hübner, 4320.

lucetiella Clemens, 6262.

lucetta Hy. Edwards, 2822 (Catocala).

lucetta Smith, 1129 (Perigea).

lucia Kirby, 440.

luciana Hy. Edwards, 2836.

lucidata Walker, 2216.

lucidicostella Clemens, 6257.

lucidiferata Walker, 3699.

lucidus Boisduval, 735.

luciferella Clemens, 6162.

lucifluella Clemens, 6141.

lucilius Lintner, 620.

lucina Hy. Edwards, 757 (Hemileuca).

lucina Smith, 1832 (Mamestra).

lucipara Linnæus, 1288.

luctiferana Walker, 5238.

luctuaria Herrich-Schaeffer, 3362.

luctuata Hübner, 3362.

luctuellus Herrich-Schaeffer, 4584.

luctuosa Hulst, 2815.

luctuosus Boisduval, 665.

luculenta Hy. Edwards, 3095.

luda Druce, 2648.

ludicostella Riley, 6257.

lugens Walker, 715.1.

lugubralis Walker, 4504.

lugubrata Staudinger, 3362 (Rheumaptera).

lugubratum Möschler, 3351 (Eustroma).

lugubrella Fabricius, 5724 (Gelechia).

lugubrella Ragonot, 4887 (Moodna). lugubris Hulst, 890 (Apantesis).

lugubris Fish, 4988 (Pterophorus).

lugubris Boisduval, 4132 (Thyris).

lugubris Linnæus, 665 (Triptogon).

lugubrosa Hulst, 3912.

lulualis Hulst, 4367.

lumbonigera Dyar, 842.
Page.

lumenaria Hübner, 3480.

lumenosa Neumoegen, 4194.

luna Morrison, 2288 (Nycterophæta).

luna Linnæus, 747 (Tropæa).

lunata Stretch, 948 (Alypia).

lunata Smith, 2159 (Gortyna).

lunata Hy. Edwards, 3135 (Heterocampa).

lunata Drury, 2986 (Homoptera).

lunatana Walsingham, 5274 .

lundana Fabricius, 5245.

lunearis Guenée, 2766.

lunifera Hübner, 2979.

luniferella Hulst, 4645.

lunigerella Ragonot, 4722 .

lunilinea Grote, 2953.

lunulalis Hübner, 4298 (Lamprosema).

lunulalis Hulst, 4644 (Oneida).

lunus Edwards, 542.

lupatus Grote, 2357.

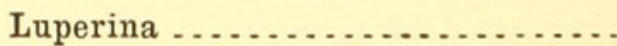

lupinella Busck, 5710.

lupini Grote, 1050 (Merolonche).

l'upini Behr, 430 (Rusticus).

lupini Hy. Edwards, 4203 (Sesia).

luridana Walsingham, 5088 (Eucosma).

luridana Walker, 5537 (Orchemia).

luridula Hulst, 3801 (Alcis).

luridula Guenée, 2558 (Anomis).

luscana Fabricius, 5237.

luscitiosa Clemens, 704.

lusella Zeller, 4623.

Lussa ......................... . .

lustralis Grote, 1782.

lustrans Grote, 4207 (Sesia).

lustrans Beutenmüller, 4126 (Triprocris).

lutarella Hübner, 5500.

lutaria Walker, 3923.

lutea Grote, 794 (Ctnucha).

lutea Smith, 2575 (Diallagma).

luteata Packard, 3272.

luteella Chambers, 6242 (Bucculatrix).

luteella Chambers, 6411 (Busckia). luteella Hulst, 4854 (Honora).

luteiceps Walker, 6617.

luteicoma Grote \& Robinson, 1039.

luteicostella Ragonot, 4914.

luteitinctus Grote, '2301. 
luteocinerea Smith, 1182.

luteocostella Chambers, 6029.

luteola Grote \& Robinson, 1930 (Anarta).

luteola Smith, 1627 (Paragrotis).

luteola Smith, 1911 (Scotogramma).

luteolana Hübner, 5345.

luteolata Hulst, 3496 (Cinglis).

luteolata Hulst, 3347 (Phylace).

luteolellus Clemens, 4609.

luteolus Reakirt, 41.

luteopallens Smith, 1957.

luteopulvella Chambers, 5941.

luteoscapus Neumoegen \& Dyar, 796.

luteositus Smith, 1645.

luteostrigella Chambers, 5647 .

lutescens Neumoegen \& Dyar, 3215.

lutina Smith, 1952.

lutosa Andrews, 2231.

lutosana Clemens, 5424.

lutosus Haworth, 5500.

lutulenta Smith, 1661.

lutulentana Herrich-Schaeffer, 5437.

luxa Grote, 2281 (Bessula).

luxa Grote, 1117 (Perigea).

luxuriosa Grote, 2389 (Dasyspoudæa).

luxuriosa Smith, 2651 (Tripudia).

lybialis Walker, 4341.

Lycænidæ ...................

lycaste Fabricius, 307.

lycea Edwards, 406.

lyceas Godman \& Salvin, 26.

Lychnosea . . . . . . . . . . . . . . .

Lycia . . . . . . . . . . . . . . . .

lyciades Hübner, 591.

lycialis Walker, 4344.

lycidas Smith \& Abbot, 591.

Lycomorpha

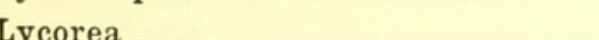

lycus Hübner, 3033.

lygdamas Doubleday, 420.

Lygropia . . . . . . . . . . . . . . . .

lymani Dyar, 841.

Lymire . . . . . . . . . . . . . . . .

Lymnadidæ .................. . . .

Lymnæcia . . . . . . . . . . . . . . .

lyncea Clemens, 675.

lynceella Zeller, 5754.

lynosyrana Walsingham, 5328.

lynosyridella Walsingham, 6028.

lynx Guenée, 2346.

Lyonetia
Page.

lyonetiella Chambers, 6157.

lyside Godart, 57.

lysimachixella Chambers, 6336.

lythrella Walsingham, 5879.

Lytrosis . . . . . . . . . . . . . . . . .

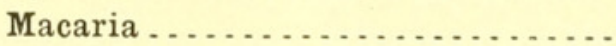

macaria Edwards, 128 (Argynnis). macaria Reakirt, 640 (Hesperia).

maccana Treitschke, 5311.

mac-cullochii Kirby, 943.

macerata Smith, 1203.

mac-glashani Rivers, 149.

machaon Linnæus, 16.

Machimia

maclure Riley, 4369.

macmurtrici Peale, 4148.

macounii Edwards, 289.

macra Guenée, 1302.

macrinellus Zeller, 4541.

macrocarpana Walsingham, 5467.

macrocarpella Frey \& Boll, 6289.

macrogaster Walsingham, 6596.

macromera Butler, 900.

Macronoctua

macropterellus Zeller, 4612.

Macrorrhinia

mactata Guenée, 1166.

macula Smith, 2655.

maculabella Chambers, 6509.

maculatis Westwood, 4277 (Desmia).

maculalis Clemens, 4495 (Nym-

phula).

maculana Fernald, 5293.

macularia Harris, 3902.

maculata Smith, 1767 (Agrotiphila). maculata Harris, 922 (Halesidota). maculata Edwards, 544 (Oligoria). maculata Riley, 6575 (Pronuba). maculata Harris, 4131 (Thyris). maculatana Walsingham, 5111. maculatusella Chambers, 5812. maculicollis Walker, 941.

maculidorsana Clemens, 5309. maculifascia Hulst, 3645. maculifer Walsingham, 6580.

maculimarginella Chambers, 5757

(Gelechia).

maculimarginella Chambers, 6510

(Tinea).

maculipennis Curtis, 5503.

maculipes Grote \& Robinson, 4258. maculisella Chambers, 6201.

563 maculomarginella Chambers, 5757. 
maculosa Behr, 2793.

maculosella Clemens, 6083.

madarella Clemens, 6084.

madarix Hy. Edwards, 4203.

madefactalis Guenée, 3069.

madetesalis Walker, 4454.

madigascariensis Saalmüller, 4807. madusaria Walker, 3963.

Mænas ..............................

mærula Hübner, 56.

Mæsia

masoides Butler, 471.

mastosa Hulst, 2811 (Catocala).

mastosa Hulst, 3798 (Nepytia).

mxstosa Hulst, 3297 (Tephroclystis).

magdalena Strecker, 2881 (Catocala).

magdalena Fernald, 4383 (Diasemia).

magdalena Strecker, 275 (Erebia). magdalena Hulst, 3896 (Melemæa). magdalena Hulst, 2288 (Nycterophæta).

magicalis Felder, 4297.

magistralis Grote, 4420.

magnalis Guenée, 4303 (Blepharomastix).

magnalis Hulst, 4481 (Noctuelia). magnana Hübner, 5411.

magnarius Guenée, 3923.

magnatella Zeller, 6157 (Mompha) . magnatella Zeller, 6429 (Phyllocnistis),

magnella Chambers, 6243 (Bucculatrix).

magnella Busck, 5542 (Paltodora). magnetaria Guenée, 3512.

magniferalis Walker, 4437.

magniferaria Walker, 3530.

magnifica Bailey, 4151 (Cossula). magnifica Strecker, 4151 (Cossula). magnifica Neumoegen, 2317 (Græperia).

magnifica Beutenmüller, 4166 (Melittia).

magnifica Grote, 2704 (Spragueia). magnifica Fernald, 4611 (Thauma-

topsis).

magnificalis Hübner, 4497.

magnoliana Fernald, 5369.

magnoliata Guenée, 3419.

magnoliella Chambers, 6424.

magualis Guenée, 4303.
Page.

Magusa Page. maia Ottolengui, 857 (A rachnis). maia Drury, 757 (Hemileuca). maizi Fiteh, 1711. major Grote \& Robinson, 3102

(Datana).

major Smith, 1284 (Feralia). major Speyer, 1801 (Mamestra). major Walsingham, 5058 (Olethreutes). major Grote, 1347 (Oncocnemis). major Smith, 2666 (Tarache). majoralis Smith, 3017. majoraria Guenée, 4008. majorella Costa, 4807. majuscula Hy. Edwards, 2721. malaca Grote, 2600. malachitana Zeller, 5044.

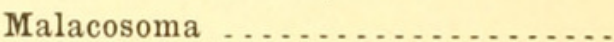
262

Malacotricha..................... malana Fitch, 1092 (Balsa).

malanum Fernald, 5025 (Exartema).

m-album Boisduval \& Le Conte, 330. malefida Guenée, 1551.

malifoliella Clemens, 6448 (Tischeria).

malifoliellus Fitch, 5687 (Ypsolophus).

maligemmella Murtfeldt, 5986. malis Smith, 1714.

malivorana Le Baron, 5319.

malivorella Riley, 6030.

Mamestra

mammuraria Guenée, 3803.

manalis Walker, 3064.

manataaqua Scudder, 557.

mancalis Lederer, 4350.

mancinus Doubleday \& Hewitson, 270 (Erebia).

mancinus Herrich-Schaeffer, 575

(Erycides).

mancipata Guenée, 3442.

mandan Edwards, 469.

manfredi Neumoegen, 4152.

Manhatta

mania Strecker, 1873.

manifesta Morrison, 1438.

manifestolabes Morrison, 1428. manitoba Smith, 996 (Apatela). manitoba Scudder, 487 (Erynnis). manitoboides Fletcher, 487. munitou Neumoegen \& Dyar, 3111. manni Mayer, 40. 
mansueta Smith, 1015.

mantalini Smith, 1106.

manteo Doubleday \& Hewitson,

3137.

manto Strecker, 3194.

mamubiaria Hulst, 3953.

mappa Grote \& Robinson, 2482.

Iiarasmalus

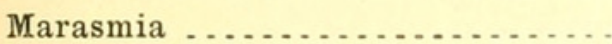

marcata Neumoegen, 766.

marcellina Cramer, 52.

marcellus Boisduval \& Le Conte, 5. marcessaria Packard, 3746.

marcia Edwards, 189 (Phyciodes). marcia Beutenmüller, 4239 (Sesia).

marcida Guenée, 2923.

marcidana Zeller, 5254.

marcidilinea Grote, 3025.

marculenta Grote \& Robinson, 4349

(Loxostege).

marculenta Zeller, 4350(Loxostege).

mardon Edwards, 522.

margarita Hübner, 30.

margaritalis Denis \& Schiffermüller,

4335.

margaritosa Haworth, 1467.

Margaronia

margartalis Hübner, 5411.

marginalis Stoll, 4320 (Diaphania). marginalis Grote, 653 (Hemaris).

marginalis Scudder, 40 (Pontia).

marginalis Walker, 4468 (Pyrausta).

marginata Harris, 4191 (Bembecia).

marginata Edwards, 440 (Cyaniris). marginata Minot, 3964 (Euchlæna). marginata Walker, 3226 (Oreta).

marginata Haworth, 2361 (Schinia). marginatus Harris, 472 (Ancyloxypha).

marginatus Riley, 6566 (Prodoxus). marginidactyla Fitch, 4956.

marginidens Guenée, 2192.

marginimaculella Chambers, 6510. marginistrigella Chambers, 6511.

maria Skinner, 151.1.

marix Grote, 2617.

marixella Chambers, 6315.

mariana Hy. Edwards, 2851 (Cato-

caìa).

mariana Fernald, 5427 (Eulia).

mariana Barnes, 148 (Lemonias).
Page.

Page.

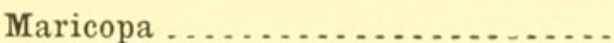
438

maricopa Reakirt, 408 (Cupido).

maricopa Hulst, 3725 (Cymatophora).

mariella Riley, 6315.

marina Grote, 1175 (Hadena).

marina Reakirt, 451 (Leptotes).

marina Packard, 3143 (Misogada).

marinaria Strecker, 3713.

marinitincta Harvey, 1836.

manona Beutenmüller, 4243.

mariposa Grote \& Robinson, 948

(Alypia).

mariposa Reakirt, 394 (Epidemia). maritima Edwards, 258.

marius Cramer, 233.

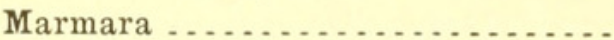

562

Marmarea ...................

marmarodactyla Dyar, 4938.

Marmopteryx ................ . . marmorata Smith, 1021 (Apatela). marmorata Edwards, 2829 (Catocala).

marmorata Zetterstedt, 1233 ( $\mathrm{Ha}$ dena).

marmorata Packard, 3436 (Marmopteryx).

marmorata Haworth, 3380 (Mesoleuca).

marmorea Walsingham, 5903.

marmorella Chambers, 5619 (Phthorimæa).

marmorella Chambers, 6512 (Tinea).

Marmoropteryx ..............

mars Fabricius, 364.

marshallana Westwood, 1232.

marsyas Edwards, 207.

marteni French, 4124.

marthesia Cramer, 3165.

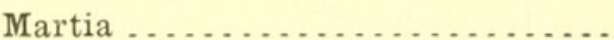

martialis Herrich-Schaeffer, 332

(Eupsyche).

martialis Guenée, 4401 (Phlyctænia).

martialis Scudder, 624 (Thanaos).

martinella Walker, 6529.

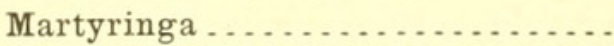
489

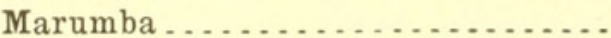

masoni Smith, 2313.

massasoit Scudder, 482.

Mastiphanes ....................

9

materna Linnæus, 2952. 
mathewianus Zeller, 4972.

Matigramma

matricaria Behr, 2143.

matronalis Frey, 900 (Parasemia). matronalis Grote, 4453 (Pyrausta). matthewi Hy. Edwards, 6608 (Hepialus).

matthewi Grote, 788 (Scepsis).

matuta Hy. Edwards, 949.

matutella Clemens, 6110.

matutina Grote, 5137 (Eucosma).

matutina Hübner, 2306 (Khodo-

phora).

maxima Neumoegen, 55.

maximella Chambers, 6202 (Nepticula) .

maximellus Fernald, 4548 (Schœno-

bius ).

mayrella Zeller, 6010.

meglashani Hy. Edwards, 6608.

meadiana Morrison, 1346.

meadiaria Packard, 3661.

meadiata Packard, 3338 (Coryphis-

ta).

meadiata Packard, 3661 (Sciagraphia).

meadii Edwards, 118 (Argynnia).

meadii Edwards, 261 (Cercyonis).

meadii Packard, 3338 (Coryphis-

ta).

meadii Grote, 2390 (Dasyspoudæa). meadii Edwards, 62 (Eurymus). meadii Hy. Edwards, 4066 (Thyridopteryx).

meanderana Walker, 5015.

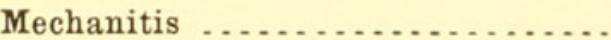

Mecoceras

Mecoceratinæ

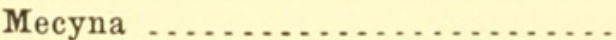

medealis Walker, 4303.

media Morrison, 2781.

medialis Smith, 3050 (Bleptina).

medialis Smith, 2168 (Gortyna).

medialis Smith, 1634 (Parogrotis).

medialis Grote, 1268 (Polia).

mediata Walker, 3370.

mediatrix Felder, 201.

medicinalis Grote, 4498.

mediofasciana Clemens, 5239.

mediofasciella Dietz, 5942.

mediofuscella Clemens, 5764.

medioplagata Walsingham, 5236.

mediostriata Walsingham, 5158.
Page.

mediostriatella Clemens, 6481.

meditata Grote, 1781.

medusa Strecker, 3202.

Megachyta ..................

Megacronycta.................. 99

megadia Smith, 1973.

megæra Smith, 1907.

megalippe Hübner, 308.

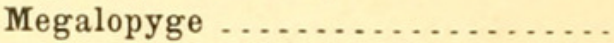

Megalopygidæ ................ . . .

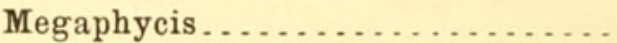

megarena Smith, 1832.

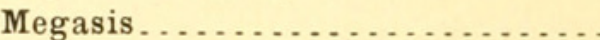

megastigma Smith, 1612 .

Megathymidæ................

Megathymus...................

megocula Smith, 2658.

mela Strecker, 416.

melaleuca Thunberg, 1932.

melaleucalis Walker, 4377.

melaleucana Walker, 5380.

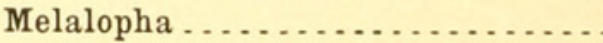

melalutea Smith, 1350.

melancholica Grote, 690.

Melanchroia .................... . .

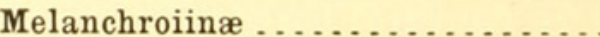

melane Edwards, 570.

melanella Murtfeldt, 5651 (Menesta).

melanellus Hulst, 4780 (Elasmopalpus).

melanic Skinner, 66.

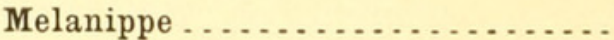

melanippe Cramer, 51.

melanis Boisduval, 4038.

melanogrammos Zeller, 4649.

melanographella Ragonot, 4663.

348

386

Melanolophia .................

melanomera Butler, 900.

Melanomma .....................

melanopa Thunberg, 1931 (Anarta).

melanopa Barnes, 3129 (Dasylophia).

melanopa Zeller, 4058 (Nigetia).

Melanoporphyria ..............

melanopyga Grote, 2147.

melanosticta Walsingham, 5048.

melantherella Busck, 5663.

Melanthia

melantho Smith, 1351.

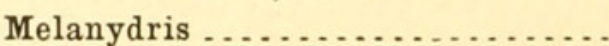

melas Christoph, 900.

Melemæa
358

358

429

427

46

46

349

349 
Melia

Page.

melicerta Schaus, 324.

Melicleptria

melinellus Clemens, 4545.

melinus Hübner, 335.

Meliopotis

221

melissa Edwards, 481.

melissalis Walker, 4391.

Melissoblaptes

Melissopus

Melitara

melite Linnæus, 27.

melitta Möschler, 779.

Melittia

Mella

Mellilla

mellinalis Hübner, 4415.

mellinella Grote, 4851.

mellinipennis Boisduval, 4199.

mellistrigata Grote, 3664.

mellitula Hulst, 2906.

mellitularia Hulst, 3980.

mellonella Linnæus, 4636.2.

melon Godman \& Salvin, 585.

melsheimeri Harris, 4059.

membranacea Morrison, 1938.

memmialis Walker, 4292.

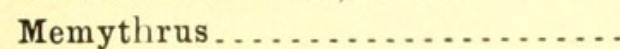

menaclas Poda, 283.

menapia Felder, 28.

menas Harris, 3132.

mendica Haworth, 6459 (Argyres-

thia).

mendica Walker, 3248 (Eudule).

mendicata Hulst, 3681.

mendocino Behrens, 749.

mendocinolus Behrens, 6612.

Menesta.

menetriesii Hy. Edwards 1.

mengelana Fernald, 5059.

mengeli Fernald, 4994.

menippe Hübner, 308.

mensurata Walker, 3487.

menthastrina Martyn, 851.

mera Harvey, 2596.

meralis Morrison, 1101.

mercedulata Strecker, 3756.

mercenaria Grote, 1519.

mercurius Fabricius, 589.

merdella Zeller, 6520.

merianæ Grote, 687.

Mericisca.

meridiana Slosson, 3249. meridionalis Dyar, 3163.

Page.

Meris ............................ 322

Merolonche ................ 9. 99, 105

Meroptera .................. 423

merriccata Dyar, 3245.

merricki Holland, 2919.1.

mersa Morrison, 1134.

mertila Edwards, 418.

mesapano Scudder, 469.

mesillx Cockerell, 3106.

Meskea

meskeana Grote, 2371.

meskearia Packard, 3998.

meskei Edwards, 505 (Anthomaster).

meskei Hy. Edwards, 2958 (Campometra).

meskei Grote, 2850 (Catocala). mesliei Speyer, 1088 (Platysenta). meskei Smith, 2687 (Tarache).

Mesogona

Mesographe

Mesoleuca

280

Mesolia

403

Mesolomia

mesospila Zeller, 5335.

Mesotype ....................... . .

mespilella Haworth, 6270.

messalina Guenée, 2910.

messoria Harris, 1649.

mestoralis Walker, 4385.

Mestra

mestusata Walker, 3941.

metacomet Harris, 529.

metagrammalis Walker, 4777.

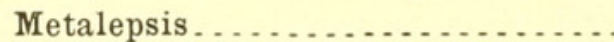

metalicella Hulst, 4785.

metallica Stretch, 4128 (Harrisina). metallica Grote, 2477 (Plusia). metallica Grote, 2662 (Tarache). metallicana Walsingham, 5388. metallifera Walsingham, 6085. metalliferalis Packard, 4635.

metamelana Walker, 5246.

Metamorpha ...............

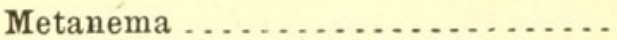

metanemaria Hulst, 3787.

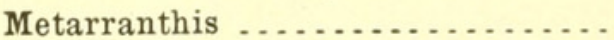

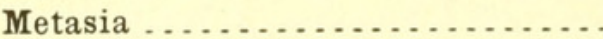

metathetis Butler, 653.

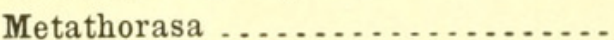

meticulosalis Guenée, 4327. 
metonalis Walker, 3036.

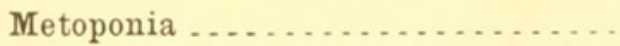

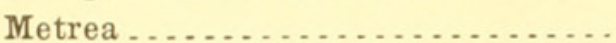

Metriochroa

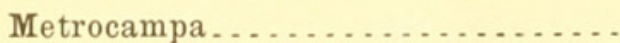

metrocamparia Guenée, 4007.

Metzneria ..................

mexicana Grote \& Robinson, 885

(Apantesis).

mexicana Behr, 2778 (Cirrhbolina). mexicana Hampson, 851 (Estigmene).

mexicana Druce, 811 (Hæmatomonis).

mexicana Reakirt, 606 (Pholisora). mexicana Boisduval, 81 (Pyrisita). mexicana Herrich-Schaeffer, 600

(Thorybes).

mexicana Hy. Edwards, 3178 (Thyatira).

mexicanaria Grote, 3868.

mexicanellus Beutenmüller, 6599.

mexicanus Beutenmüller, 4262 ( $\mathrm{Pa}$ -

ranthrene.)

michabo Grote, 876.

michrochrysella Walker, 4620.

Microcœlia .................

microdactylus Hedemann, 4968.

Microgonia

micronympha Guenée, 2898.

micronyx Grote, 1684.

microphysa Hulst, 3526.

micropterata Hulst, 3543.

Micropterygidæ

Micropterygoidea............

Microsemia .................

Microtia ................................

middendorfi Ménétries, 4041.

Midea.

midea Hübner, 48.

Mieza

milberti Godart, 218.

mildei Stretch, 3223.

militaris Harris, 840.

militella Zeller, 4658.

milleri Zeller, 4876 (Ephestia).

milleri Grote, 1563 (Porosagrotis).

milleriella Chambers, 5813.

milo Edwards, 509.

mima Harvey, 2959.

mimallonis Grote, 1556.

mimella Clemens, 5814.
Page.

212

379

564

335

495

minea Slosson, 876.

minehaha Scudder, 430.

minella Dyar, 1010.

Mineola ....................

minera Guenée, 2990.

mingo Edwards, 471.

miniana Grote, 2312 (Rhododipsa).

minians Guenée, 1950 (Nephelodes).

miniata Kirby, 807 (Hypoprepia). miniata Packard, 792 (Lycomorpha).

miniatella Ragonot, 4710.

minima Hulst, 4007 (Caberodes).

minima Edwards, 475 (Copæodes).

minima Neumoegen, 927 (Hypocrisias).

minima Hulst, 3870 (Nacophora). minima Grote, 782 (Pseudomya). minimaculella Chambers, 5735.

minimalis Grote, 1392 (Rhynchagrotis).

minimalis Grote, 3023 (Zanclognatha).

minimana Walsingham, 5194.

minimaria Guenée, 3861 (Athaloptera).

580 minimella Ragonot, 4688 (Acro344 basis).

21 minimella Chambers, 5586 (Aristotelia).

minimella Chambers, 6163 (Mompha).

minimella Chambers, 6203 (Nepticula).

minimella Robinson, 4555 (Raphiptera).

minimmaculella Chambers, 5735.

minimum Neumoegen, 4190.

ministra Drury, 3098.

ministrana Linnæus, 5481.

minna Butler, 4047.

minnicella Dietz, 5953.

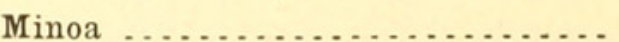

minor Busck, 6338 (Bedellia).
Page. 
minor Smith, 2955 (Campometra). minor Dyar, 6601 (Pseudanaphora).

minor Dyar, 4055 (Roselia). minor Cockerell, 221 (Vanessa). minoralis Smith, 3029.

minorana Treitschke, 5220.

minoraria Hulst, 3960.

minorata Smith, 2950 (Antiblem-

ma).

minorata Grote, 1386 (Fota).

minorata Smith, 1958 (Heliophila). minorata Packard, 3676 (Macaria). minorata Smith, 1815 (Mamestra). mintha Edwards, 408.

minualis Walker, 4503.

minuscula Morrison, 1078 (Hade nella).

minuscula Butler, 54 (Phoebis). minuscula Zeller, 4055 (Roselia). minuta Robinson, 5319 (Acleris). minuta Edwards, 2906 (Catocala). minuta Hulst, 3724 (Cymatophora).

minuta Hulst, 3267 (Gymnocelis). minuta Reakirt, 4102 (K ronæa). minuta Edwards, 182 (Schœenis). minuta Grote, 3211 (Tolype).

minutata Treitschke, 3294.

minutella Beutenmüller, 6069 (Cosmopteryx).

minutella Frey \& Boll, 6276 (Lithocolletes).

minutipulvella Chambers, 6513.

minutularia Hulst, 3506.

minutulella Hulst, 4672.

minyas Hübner, 326.

mira Grote, 2892.

mirabelle Barnes, 361.

mirabilata Grote, 3408.

mirabilis Neumoegen, 2447 (Basilodes).

mirabilis Frey \& Boll, 6364 (Gracilaris).

mirabilis Grote, 1403 (Rhynchagrotis),

miraculosa Frey \& Boll, 6119.

miranda Grote, 1109 (Caradrina). miranda Hy. Edwards, 2823 (Catocala).

miranda Hulst, 3553 (Pentopoda). mirandalis Hübner, 2726.

mirandella Ragonot, 4745.
Page.

mirifica Frey \& Boll, 6275 (Lithocolletes).

mirifica Hy. Edwards, 2789 (Syneda).

mirificalis Grote, 1328.

mirificum Strecker, 2742 (Hyblæa). mirusella Chambers, 5904.

Misa

miscecalonella Chambers, 6179.

miscecolorella Chambers, 6179.

miscecristatella Chambers, 6544.

misceella Chambers, 6515.

miscellus Grote, 1084 (Catabena).

miscellus Smith, 1202 (Hadena).

miscidice Scudder, 66.

misella Zeller, 6514.

miseloides Guenée, 1202.

misera Felder, 201 (Chlosyne).

misera Grote, 1206 (Hadena).

miserulata Grote, 2737 (Homopyralis).

miserulata Grote, 3277 (Tephroclystis).

misippus Linnæus, 145.

Misogada....................

misturata Morrison, 1614 (Paragrotis).

misturata Hulst, 3268. (Tephroclystis).

mitchellii French, 300 .

mitis Grote, 2411 (Heliophana).

mitis Smith, 1615 (Paragrotis).

mitographa Grote, 3071.

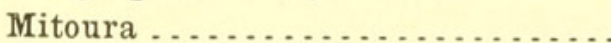

mixta Neumoegen, 931 (Euschausia).

mixta Grote, 1231 (Hadena).

mixta Walker, 1417 (Platagrotis).

Mochlocera ....................

moderata Walker, 1965.

moderna Grote, 2812.

modesta Maynard, 366 (Callicista). modesta Beutenmüller, 3105 (Datana).

modesta Bates, 227 (Eunica). modesta Hy. Edwards, 2698(Fruva). modesta Hudson, 3164 (Harpyia). modesta Smith, 3082 (Hypena). modesta Frey \& Boll, 6294 (Lithocolletes).

modesta Harris, 728 (Marumba). modesta Walsingham, 5551 (Paltodora). 
modesta Packard, 900 (Parasemia). modesta Walsingham, 4950 (Platyptilia).

modesta Kellicott, 4217 (Sesia).

modesta Morrison, 1921 (Ulolonche). modestalis Fitch, 3019.

modestaria Hulst, 3703.

modestella Clemens, 5975 (Holcocera).

modestella Hulst, 4732 (Nephopteryx).

modestus Hy. Edwards, 6615 (Hepialus).

Modiana .....................

modica Walker, 1024 (Apatela).

modica Guenée, 1158 (Hadena).

modicella Grote, 2409.

modifica Morrison, 2012.

modiola Grote, 1205.

maliusalis Walker, 4299.

morens Grote, 1613.

moschleriana Wocke, 5415.

mostana Wocke, 5033.

mostata Nolcken, 3359.

mostella Walker, 4776.

moffatiana Grote, 2237.

moilena Strecker, 1185.

moina Strecker, 76.

molestella Zeller, 5577.

mollicularia Zeller, 3935.

molliculata Walker, 3350.

mollifera Walker, 3009.

mollipedella Clemens, 5503.

mollis Walker, 3140 (Heterocampa). mollis Walker, 1693 (Paragrotis).

mollisaria Hulst, 3960.

mollissima Guenée, 2716.

molochina Hübner, 1225.

molpodia Hübner, 30.

Momophana.

Mompha

Mona ....................

monachella Hübner, 6490.

moneta Fabricius, 2472.

monetiferana Riley, 5012.

moniarium Walker, 3838.

monica Reakirt, 443.

monicaria Guenée, 3628.

monitis Fabricius, 2740.

monima Cramer, 227.

monitifera Guenée, 2715.

monitor Packard, 4077.

monochromatea Morrison, 1430.

monoco Scudder, 538.
Page.

Monocona .

Page.

Monocteniinæ

368

monodactyla Linnæus, 4981.

monodia Dyar, 2736.

monodon Grote, 2491.

monogrammana Zeller, 5086.

Monoleuca .................. . .

Monopis . . . . . . . . . . . . .

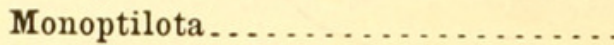

Monotaxiinæ

Monotaxis

monotropa Grote, 2978.

monstralis Guenée, 4313.

monstratella Walker, 6110

montana Morrison, 1765 (Agrotiphila).

montana Hy. Edwards, 4197 (Al-

buna).

montana Walsingham, 4959 (Alucita).

montana Hy. Edwards, 4134 (Dysodia).

montana Smith, 1252 (Hadena).

montana Cockerell, 4997 (Orneodes).

montana Behr, 195 (Phyciodes).

montanæ Grote, 2123.

montanana Walsingham, 5200.

montanaria Treitschke, 3459 (Petrophora).

montanaria Neumoegen, 3993 (Snowia).

montanata Denis \& Schiffermüller, 3459 (Petrophora).

montanata Packard, 3255 (Talledega).

montanatum Packard, 3352 (Eustroma).

montanus Stretch, 6614.

montella Chambers, 6464.

monticola Behr, 110 (Argynnis).

monticola Walsingham, 5905 (Ethmia).

monticola Hulst, 3474 (Mycterophora).

montinatella Hulst, 4857.

montinella Chambers, 5518.

montinus Scudder, 136.

montis Edwards, 245.

montisella Chambers, 6070 (Cosmopteryx).

montisella Chambers, 5513 (Glyphipteryx).

montivaga Behr, 129 (Argynnis). 
montivagus Reakirt, 643 (Hesperia).

monulalis Hulst, 4434.

monumentella Chambers, 5771.

monuste Linnæus, 32.

Moodna

mopsa Hy. Edwards, 2864.

mopsus Hübner, 384.

mora Grote, 6603.

morbidalis Guenée, 3039.

morbosa Нy. Edwards, 2745 (Cissura).

morbosa Hulst, 3641 (Episemasia).

morensata Hulst, 3261.

mori Linnæus, 3224.

morigera Hy. Edwards, 2468.

morio Linnæus, 217.

moriscaria Hulst, 3897.

mormo Felder, 313.

mormonia Boisduval, 130 (Aroynnis).

mormonia Boisduval, 313 (Chrysobia).

mormonica Neumoegen, 885.

morna Strecker, 1223.

morosaria Walker, 3675.

morosata Hulst, 3827.

morphea Godart, 189.

morpheus Fabricius, 189.

morrisata Hulst, 3428.

morrisella Fitch, 6269.

morrisonata Hy. Edwards, 4001.

morrisonella Ragonot, 4847.

morrisoni Edwards, 256 (Anæa).

morrisoni Walsingham, 6593 (Anaphora).

morrisoni Walsingham, 5159 (Eucosma).

morrisoni Druce, 3087 (Gnophæla). morrisoni Grote, 2243 (Scopelosoma).

morrisoni Edwards, 47 (Synchloe).

Morrisonia

morrisoniana Riley, 1544.

morrisonii Hy. Edwards, 4198 (Albuna).

morrisonii Edwards, 514 (Hylephila).

mors Lucas, 4036.

mortipenellus Grote, 6583.

mortua Grote, 2358.

mortuorum Guenée, 2505.
Page.

morula Grote \& Robinson, 990 (A patela).

morula Hy. Edwards, 4210 (Sesia). moschus Edwards, 597.

mossii Hy. Edwards, 375.

mucens Hübner, 1889.

mucidellum Ragonot, 4871.

mucidus Hy. Edwards, 4143.

mucorea Herrich-Schaeffer, 3141.

mucronata Grote, 2744.

muelleri Letcher, 222.

muirii Hy. Edwards, 2643 (Gyros). muirii Hy. Edwards, 355 (Thecla). muliercula Guenée, 2875.

mulleolata Hulst, 3379.

mulleolella Hulst, 4530.

multifaria Walker, 796 (Ctnucha). multifaria Walker, 1890 (Morrisonia).

multifasciella Chambers, 6131.

multifera Walker, 1102.

multiferata Walker, 3401.

multilinea Walker, 1978.

multilineata Packard, 3785 (Alcis).

multilineata Packard, 3375 (Meso-

leuca).

multilineata Hulst, 3471 (Pigia).

multilineatella Hulst, 4629.

multilineellus Fernald, 4576.

multitinellus Fernald, 4576.

multimaculella Chambers, 5509.

multiplicalis Guenée, 4286.

multipulvella Chambers, 6030.

multipunctella Chambers, 5907 (Ethmia).

multipunctella Clemens, 5477 (Ypo-

nomeuta).

multiscripta Riley, 3159 (Cerura).

multiscripta Hulst, 3305 (Tephroelystis).

multistrigata Hulst, 3304.

multivagata Hulst, 3343.

multnoma Dyar, 3097.

mundula Grote \& Robinson, 2754

(Drasteria).

mundula Zeller, 2638 (Eumestleta). munis Grote, 1696.

munitaria Herrich-Schaeffer, 3456.

munituta Hübner, 3456.

murzmula Grote \& Robinson, 1552.

muralis Grote, 1381.

murcialis Walker, 4354. 
murdockii Smith, 1679.

muricana Walsingham, 5258.

muricina Grote, 2048.

muricolor Dyar, 938 (Calidota).

muricolor Hulst, 3828 (Selidosema). muricolor Hulst, 3997 (Stenaspilates).

muricolorella Busck, 5873.

murina Walker, 812 (Comacla). murina Stretch, 908 (Euchætias). murina Packard, 5042 (Olethreutes).

murtfeldtella Chambers, 5956 (Dryope).

murtfeldtella Chambers, 6164 (Mompha).

murtfeldtiana Riley, 5244.

mus Neumoegen, 3215.

muscariata Guenée, 3649.

muscosa Grote, 1633.

muscoscula Guenée, 2607.

musculana Hübner, 5374.

musta Grote \& Robinson, 2606. mustelina Smith, 1192 (Hadena). mustelina Packard, 3154 (Schizura). mustelinalis Packard, 4434. mustelinus Packard, 6609 (Hepialus).

mutabilana Clemens, 5077. mutabilis Clemens, 4601. mutilata Smith, 1871. mutualis Zeller, 4344. muzaria Walker, 3957. muzina Oberthur, 845.

Mycterophora ...................... myellus Hübner, 4583.

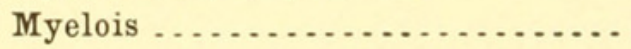

Myeza ....................

mylitta Edwards, 193.

mynandaria Walker, 4007.

mynesalis Walker, 3052.

myops Smith \& Abbot, 732.

myricafoliella Busck, 6204.

myrina Cramer, 131 (Brenthis).

myrina Martyn, 141 (Brenthis).

myrissa Godart, 131.

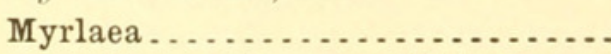

myrmidonata Guenée, 3506.

myron Cramer, 682.

myrrha Strecker, 2891.

myrta Godart, 227.

myrtaria Guenée, 3479.

myrtis Edwards, 477.
Page.

mys Dyar, 2055.

mysia Godart, 30.

mysippusalis Walker, 4410.

mystic Scudder, 520.

mystica Smith, 1859.

myus French, 527.

Nacophora ......................

329

Nadata . . . . . . . . . . . . . . . 252

Naera . . . . . . . . . . . . . . . 498

nxvia Smith, 1875 (Mamestra).

nxvius Lintner, 630 (Thanaos).

nævosidactylus Fitch, 4981.

nzevulus Smith, 1609.

nais Drury, 894 (Apatesis).

nais Edwards, 317 (Polystigma).

nana Dyar, 4076 (Euclea).

nana Hübner, 1056 (Jaspidia).

nana Haworth, 5458 (Phalonia).

nanalis Grote, 1459.

nanata Neumoegen, 2451.

nanina Dyar, 4076.

Nannia . . . . . . . . . . . . . . .

nanno Edwards, 467.

Nannodia. . . . . . . . . . . . . . .

nanus Strecker, 4159 (Hypopta).

nanus Neumoegen, 2 (Parnassius).

napa Edwards, 494.

napza Morrison, 2115.

napxalis Hulst, 4332.

napi Linnæus, 38.

Napuca . . . . . . . . . . . . . . . .

narcxusalis Walker, 4324.

narrata Walker, 2454.

Narthecophora . . . . . . . . . . . . .

uasoni Grote, 4088.

nasonialis Zeller, 4374.

nastauria Zeller, 2573.

nastes Boisduval, 75.

nastuella Hulst, 4889.

nasturtii Boisduval, 38.

Natada .......................

natatrix Guenée, 2739.

Nathalis

nausicaa Edwards, 100.

Navasota

Nealyda . . . . . . . . . . . . . . .

nearchus Edwards, 641.

nebraskx Dodge, 2836 (Catocala).

nebraskx Hy. Edwards, 4169 (Eu-

hagena).

nebris Guenée, 2179.

nebulxdactylus Fitch, 4956.

nebulana Stephens, 5359. 
nebulella Riley, 4704.

Page.

Neda. . . . . . . . . . . . . . . . .

neglecta Edwards, 440 (Cyaniris).

neglecta Strecker, $23 \times 4$ (Schinia).

neglecta Hy. Edwards, 4205 (Sesia).

negreta Reakirt, 307.

negundana Dyar, 5367.

negundella Chambers, 6360.

negussa Smith, 1876.

neleis Boisduval, 53.

Neleucania ................. . .

nelita Strecker, 2180.

nelsoni Edwards, 35 (Pontia).

nelsonii Boisduval, 355 (Thecla).

nelumbialis Smith, 4439.

\section{Nematocampa}

nemesis Edwards, 323.

nemorella Hulst, 3453.

Nemoria.

nemoris Edwards, 463 (Amblyscirtes).

nemoris Walsingham, 6293 (Lithocolletes).

nemorum Boisduval, 506.

nenoquis Reakirt, 130.

Neoarctia.

neoclesalis Walker, 4282.

neocula Smith, 2681.

Neodactylota.

neogama Smith \& Abbot, 2870.

Neolexia ................... . .

Neolophus ... . . . . . . . . . . . neomexicana Hulst, 3411 (Hydriomena).

neomexicana Smith, 1573 (Paragrotis).

neomexicana Smith, 2690 (Tarache).
Neominois

neonaria Packard, 3934.

neoninaria Walker, 3934

Neonympha ................... . .

Neophasia ......................

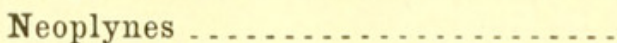

neotelis Smith, 1710.

neoterica Smith, 1857.

Neoterpes . . . . . . . . . . . . .

nephela Hufnagel, 283 (Coenonympha).

nephele Kirby, 258 (Cercyonis).

Nephelodes .................. . .

nephelotella Hulst, 4656.

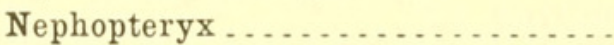
nepiasaria Walker, 3934.

Nepista . . . . . . . . . . . . . .

Page.

neptaria Guenée, 3656.

neptata Packard, 3656.

Nepticula.

neptis Smith, 1968.

Nepytia . . . . . . . . . . . . . nerea Boisduval, 882 (Apantesis). nereus Edwards, 537 (Euphyes).

Nerice .................... . . nerissa Hy. Edwards, 2907. nervata Guenée, 3702.

nervosa Neumoegen \& Dyar, 882 (Apantesis).

nervosa Haworth, 5887 (Depressaria).

nesxa Smith, 2410.

nescalis Walker, 4451.

nessus Cramer, 667 (Amphion).

nessus Edwards, 649 (Hesperia).

nestos Boisduval, 424.

nestusalis Walker, 4354.

neumoegeni Hy. Edwards, 761 (Hemileuca).

neumoegeni Skinner, 163 (Lemonias).

87 neumoegeni skinner, 30 (Tachyris). neumoegeni Hy. Edwards, 2418

(Xanthothrix).

Neumoegenia

thymus).

neurona Skinner, 438.

Neuronia . . . . . . . . . . . . . . .

nevada Scudder, 487 (Erynnis).

nevada Smith, 1595 (Paragrotis). nevada Scudder, 600 (Thorybes). nevadæ Grote, 1795 (Mamestra). 
nevadx Oberthur, 4132 (Thyris). nevadaria Packard, 3586 (Chlorosea).

nevadaria Hulst, 3627 (Deilinia). nevadaria Hulst, 3879 (Phigalia). nevadata Packard, 3317.

nevadensis Grote \& Robinson, 888

(Apantesis).

nevadensis Edwards, 118 (Argynnis).

nevadensis Stretch, 758 (Hemileuca).

nevadensis Felder, 290 (Oeneis). neumanella Clemens, 5932.

nexa Boisduval, 824.

nexalis Hulst, 4390.

nexilis Morrison, 2423.

nezahualcoyotl Strecker, 24.

nicxusalis Walker, 4286.

nicalis Grote, 4467.

nicetaria Guenée, 3699.

nicippe Cramer, 83.

nicotianix Hy. Edwards, 4228.

nictitans Borkhausen, 2162 (Gor-

tyna).

nictitans Ménétries, 900 (Parasemia).

nidificansella Packard, 6417.

nigella Hulst, 4250 (Sesia).

nigellus Strecker, 3010 (Epizeuxis). nigerlinella Chambers, 6031.

Nigetia . . . . . . . . . . . . . .

nigra Edwards, 440 (Cyaniris). nigra Stretch, 896 (Kodiosoma). nigra Edwards, 295 (Oeneis). nigra Smith, 1465 (Peridroma). nigra Busck, 5605 (Recurvaria). nigra Beutenmüller, 4254 (Sesia). nigralbana Walsingham, 5123. nigralineella Chambers, 6031. nigralis Fernald, 4378.

nigrapunctella Busck, 6065.

nigratomella Clemens, 5699.

nigrella Chambers, 5697 (Aproærema).

nigrella Hulst, 4878 (Ephestia). nigrella Hulst, 4882 (Ephestiodes). nigrescaria Hulst, 3928.

nigrescens Grote \& Robinson, 2767

(Meliopotis).

nigrescens Hulst, 3836 (Phæoura). nigrescens Hulst, 3344 (Philereme). nigricans Reakirt, 832 (Eubaphe).
Page.

nigricans Bethune, 2987 (Homoptera).

nigricans Packard, 4089 (Phobetron).

nigricans Hulst, 4758 (Salebria). nigricantella Ragonot, 4830.

nigriceps Walker, 1496.

nigridia Robinson, 5406.

nigridice Scudder, 66.

nigrifera Walker, 832.

nigritineella Chambers, 6137.

nigrimaculella Busck, 5756.

nigrina Strecker, 66 (Eurymus).

nigrima Graef, 4127 (Harrisina).

nigrinodis Zeller, 4533.

nigrior Smith, 1242.

nigripennis Grote, 1708.

nigripunctata Goodell, 4098.

nigrirena Haworth, 2339.

nigristrigella Beutenmüller, 6361.

nigritula Guenée, 2612.

nigriverticella Chambers, 6205.

nigroangulata Strecker, 3236.

nigroczrulea Cockerell, 97.

nigrocandida Hulst, 3489.

nigrocaput Morrison, 2628 (Exyra).

nigrocaput Smith, 1367 (Oncoc-

nemis).

nigrocervina, Walsingham, 5389.

nigrociliatus Zeller, 4935.

nigrocinerella Hulst, 4895.

nigrodiscalis Hulst, 3516.

nigrofasciata Zeller, 4049 (Celama).

nigrofasciata Packard, 3450 (Petrophora).

nigrofasciata Hulst, 1301 (Prodenia).

nigrofasciella Ragonot, 4811.

nigrofimbria Guenée, 2631.

nigroflava Graef, 897.

nigroguttata Grote, 1303.

nigrolinea Robinson, 5305.

nigrolunata Packard, 1931.

nigromaculella Hulst, 4896.

nigromarginata Strecker, 2804.

nigroseriata Packard, 3637.

nigrosignata Walker, 3148.

nigrosignella Hulst, 4689.

nigrostriata Walsingham, 6032.

nigrovenaria Packard, 3779.

nigrovittata Grote, 1474.

nilus Edwards, 532.

nimbata Guenée, 4010. 
nimbatana Clemens, 5031.

nimbicolor Hulst, 3529 (Eois).

nimbicolor Hulst, 3298 (Tephroclystis).

nimbosa Guenée, 1773 (Mamestra). nimbosa Hulst,3302(Tephroclystis). nimia Guenée, 1998.

ninana Riley, 5298.1.

ningoris Walsingham, 4934.

ninguidalis Hulst, 5510.

ninonia Boisduval, 28.

ninus Edwards, 358.

niobe Strecker, 849.

niphon Hübner, 378.

nisella Clemens, 5131.

niscecalis Walker, 4411.

nitella Guenée, 2179.

nitens Walsingham, 6071 (Cosmopteryx).

nitens Grote, 1998 (Neleucania).

nitida Packard, 3149.

nitidalis Cramer, 4316.

nitidana Clemens, 5010.

nitidanum Zeller, 5014.

nitocraria Hübner, 4029.

nitocris Edwards, 97 (Argynnis).

nitocris Cramer, 4029 (Mecoceras).

nitra Edwards, 20.

nivalis Drury, 4620 (Argyria).

nivalis Boisduval, 394 (Epidemas). nivalis Smith, 2285 (Oxycnemis).

nivaria Grote, 1936.

nivea Herrich-Schaeffer, 936 (Eu-

pseudosoma).

nivea Neumoegen, 3163 (Harpyia). nivea Walker, 4540 (Scirpophaga). niveana Fabricius, 5304 (Acleris). niveana Walsingham, 5338 (Cenopis).

niveella Chambers, 6244 . niveicilialis Grote, 4473.

niveicollis Smith, 2693.

niveicosta Smith, 1989.

niveicostatus Grote, 2216. niveifascia Hulst, 3280.

niveifasciata Hulst, 3386.

niveiguttana Grote, 5075.

niveiguttata Grote, 1919.

niveilinea Grote, 1575.

niveirena Harvey, 1135.

niveivenosa Grote, 1210.

niveocapitella Chambers, 6516.

niveocilia Hampson, 4319.
Page.

niveopulvella Chambers, 5704.

niveosana Packard, 5410.

niveosericeata Jones, 3922.

niviella Hulst, 4729.

nivigerata Walker, 3253.

nivihumellus Walker, 4564.

nivisellana Walsingham, 5314.

nivium Boisduval, 430.

nivosarium Guenée, 3916.

nivosata Packard, 3916.

nobilis Neumoegen, 778 (Basilona). nobilis Grote, 2358 (Schinia).

nobilis Grote, 4528 (Tosale).

nocticolata Hulst, 3255.

noctivaga Grote, 1030.

Noctua . . . . . . . . . . . . . . . . . . .

Noctuelia . . . . . . . . . . . . . . noctuella Schiffermüller, 4342.

Noctuidæ . . . . . . . . . . . . . . .

noctuiformis Walker, 693 (Cautethia).

noctuiformis Möschler, 942 (Misa). noctuiformis Smith, 1701 (Paragrotis).

Noctuinæ .

nodosella Hulst, 4915.

nokomis Edwards, 96.

Nola

nolckenii Frey \& Boll, 6444.

Nolidæ . . . . . . . . . . . . . . . . . 351

Nolophana. . . . . . . . . . . . . . . 109

Nomia ... . . . . . . . . . . . . 497

Nomiades. . . . . . . . . . . . . . 43

nominatalis Hulst, 4505.

nomion Fischer, 3.

Nomophila. . . . . . . . . . . . . . . 381

Nonagria. . . . . . . . . . . . . . . 174

nonangulata Strecker, 4021.

nondescriptus Wetherby, 4089.

nonfasciella Chambers, 6286.

nonstrigella Chambers, 5933 (Dasycera).

nonstrigella Chambers, 6230 (Opostega).

nonstrigella Chambers, 5661 (Tri-

chotaphe).

norax Druce, 4151.

nordica Smith, 1732.

norma Morrison, 2617.

normalis Grote, 2047.

normani Grote, 2009.

normaniana Grote, 1476.

norna Thunberg, 295. 
Noropsis .................... 195

nortonii Edwards, 538.

nostra Smith, 1718.

notabilis Strecker, 649.

notalis Grote, 1099.

notaria Hy. Edwards, 3114 (Odon-

tosia).

notaria Denis \& Schiffermüller, 3666 (Philobia).

notata Cramer, 3667 (Philobia).

notata Linnæus, 3666 (Philobia). notata Stephens, 3294 (Tephroclys-

tis).

notata Strecker, 2063 (Tricholita).

notatalis Walker, 4669.

notataria Hulst, 3937 (Hyperitis).

notataria Walker, 3604 (Sciagra-

phia).

notatella Grote, 2288.

notha Hy. Edwards, 4118.

Notodonta . . . . . . . . . . . . . . . .

Notodontidæ . . . . . . . . . . . . . .

Notolophus .....................

nova Fitch, 3187.

novalis Grote, 4478 .

noranglix Scudder, 40.

novaroensis Hy. Edwards, 4211.

novellata Hulst, 4015.

noverca Grote, 1824.

novimundi Walsingham, 5866.

Nuarace .....................

nubeculana Clemens, 5240.

nubecularia Guenée, 3803.

nubeculosa Zeller, 5836.

nubicola Behr, 2797.

nubiculata Packard, 3654.

nubiferella Ragonot, 4751 (Salebria).

nubiferrella Walsingham, 5881 (De-

pressaria).

nubigena Behr, 152.

nubila Strecker, 2381.

nubilana Clemens, 5050.

nubilata Packard, 4024 (Sabulodes).

nubilatum Packard, 3353 (Eustro-

ma).

nubilella Zeller, 5980 (Holcocera). nubilella Hulst, 4713 (Monoptilota). nubilifascia Grote, 3031.

nubilifasciata Packard, 3387.

nubilipennella Clemens, 6503.

nubilis Hübner, 2911.

nuchalis Grote, 2302 (Heliothis). nymphxella Hulst, 4862.

Nymphalidæ ..................

Nymphula ....................

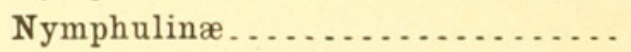

nysa Edwards, 460.

nyssafoliella Clemens, 6125 (Antispila).

nyssxfoliella Chambers, 6206 (Nepticula).

nyssaria Guenée, 3934.

Nyssia ......................

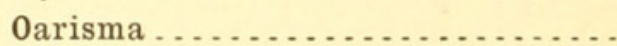

248

248

184

269

315

265

395

12

395

395

obatra Morrison, 2706.

obaurata Morrison, 4054.

obductata Möschler, 3362.

obeliscoides Guenée, 1724.

oberon Worthington, 588.

oberthuralis Fernald, 4363.

oberthurella Ragonot, 4768.

obesalis Stephens, 3079.

obesula Smith, 1554.

obfirmaria Hübner, 3947.

obfusaria Walker, 3539. 
obfuscana Riley, 5140.1.

objurgata Smith, 1690.

oblata Morrison, 1486.

oblectalis Hulst, 4372.

oblentaria Grote, 3977.

oblinita Smith \& Abbot, 1041.

obliqua Hulst, 3593 (Anaplodes).

obliqua Smith, 2215 (Fagitana).

obliqua Harvey, 2167 (Gortyna).

obliqua Packard, 3133 (Heterocampa) .

obliqua Guenée, 3001 (Homoptera). obliqua Hy. Edwards, 4084 (Mono-

leuca).

obliqua Smith, 2337 (Schinia).

obliqua Walker, 2149 (Sphida).

obliqualis Grote, 4330 (Evergestis). obliqualis Hy. Edwards, 2584 (Ple-

onectyptera).

obliquaria Grote, 3796.

obliquata Smith, 2411(Heliophana).

obliquata Grote \& Robinson, 3193

(Olene).

obliquata Smith, 2073 (Pleroma).

obliquata Grote \& Robinson, 2149

(Sphida).

obliquella Walker, 4636.2.

obliquestrigella Chambers, 5599.

obliquifasciella Chambers, 5554.

obliquifera Walker, 1092.

obliquitinea Walker, 3171.

obliquistrigella Chambers, 5599.

oblita Grote, 1357.

obliteralis Walker, 4496 (Nymphula).

obliteralis Walker, 4349 (Sphida).

obliterana Walsingham, 5201.

obliterata Stretch, 884 (Apantesis). obliterata Grote, 1054 (Microcolia). obliteratellus Zeller, 4624.

obliviosa Hy. Edwards, 3190.

oblonga Grote, 2152.

oblongostigma Smith, 1578.

oblunalis Lederer, 4401.

obluridata Hulst, 3492.

obnigra Smith, 1832.

obnigralis Hulst, 4443.

obmusella Hulst, 4671.

obruptata Walker, 3370.

obrussata Grote, 4032.

obrutella Zeller, 6226.

obscura Hy. Edwards, 972 (Apatela).
Page.

obscura Strecker, 2819 (Catocala).

obscura Fabricius, 692 (Dilophonota).

obscura Stretch, 832 (Eubaphe).

obscura Grote, 2561 (Eucalyptera).

obscura Cockerell, 217 (Euvan-

essa).

obscura Riley, 1302 (Laphygma). obscura Smith, 1827 (Mamestra). obscuralis Grote, 4493 (Nymphula). obscuralis Möschler, 4496 (Nymphula).

obscuralis Lederer, 4309 (Sylepta). obscurata MeLachlan, 137 (Brenthis).

obscurata Strecker, 2386 (Schinia). obscurata Hulst, 3367 (Zenophleps). obscurella Beutenmüller, 5906 (Ethmia).

obscurella Chambers, 5815 (Gelechia).

obscurella Dietz, 5948 (Pigritia). obscuricostella Clemens, 6280.

obscurior Smith, 2125 (Cucullia). obscurior Smith, 1964 (Heliophila). obscurior Smith, 1832 (Mamestra). obscurior Hulst, 3309 (Tephroclystis).

obscuripennella Frey \& Boll, 6382. obscuripennis Grote, 3022.

obscurocella Riley, 5752.

obscurofasciella Chambers, 6251

(Buccutatrix).

obscurofasciella Chambers, 6172

(Douglasia) .

obscuromaculella Chambers, 5848. obscuroocelella Chambers, 5752.

obscurostrigella Chambers, 6517. obscurosuffusella Chambers, 5772. obscurus Smith, 1757 (Anytus). obscurusella Chambers, 5816 (Gelechia).

obscurusella Chambers, 6164 (Mompha).

observabilis Grote, 1404.

obsipella Hulst, 4778.

obsolescens Dyar, 4112.

obsoleta Edwards, 241 (Basilarchia).

obsoleta Worthington, 2865 (Catocala).

olsoleta Grote, 2696 (Fruva).

obsoleta Ehrman, 23 (Laertias). 
obsoleta Frey \& Boll, 6279 (Lithocolletes).

obsoleta Grote, 2929 (Poaphila). obsoleta Hy. Edwards, 175 (Thessalia).

obsoleta Smith, 3019 (Zanclognatha).

obsoletalis Bergstrasser, 4352.

obsoletana Walker, 5364.

obsoletella Zeller, 5849 (Cryptolechia).

obsoletella Chambers, 6279 (Lithocolletes).

obstrictella Clemens, 6307 .

obtusa Smith, 2028 (Graphiphora). obtusa Smith, 1298 (Helotropha).

obtusa Herrich-Schaeffer, 2653

(Metoponia).

obtusa Speyer, 1476 (Noctua).

obtusangulella Ragonot, 4886.

obtusaria Hübner, 3956.

obtusilobx Frey \& Boll, 6295.

obumbratilis Lederer, 4433.

obversa Walker, 2943.

obvia Walker, 1749.

0cala ..........................

occantaria Hulst, 3958.

occata Grote, 1336.

occidens Grote, 1238 (Hadena).

occidens Hulst, 3398 ( $\mathrm{H}$ y d ri omena).

occidentalis French, 935 ( Emilia). occidentalis Lintner, 3160 (Cerura). occidentalis Riley, 6034 (Coleophora).

occidentalis Grote, 4559 (Crambus). occidentalis Smith, 3012 (Epizeuxis).

occidentalis Scudder, 68 (Eurymus). occidentalis Hulst, 4522 (Herculia). occidentalis French, 848 (Leptarctia).

occidentalis Packard, 4354 (Loxostege).

occidentalis Hulst, 4000 (Marmarea).

occidentalis Hy. Edwards, 728 (Marumba).

occidentalis Reakirt, 36 (Pontia). occidentalis Walsingham, 4982 (Pterophorus).

occidentalis Hulst, 3242 (Rachela).
Page.

occidentalis Packard, 3314 (Tephroclystis).

occidentaria Packard, 3507.

occidentata Grote, 1881 (Barathra). occidentata Packard, 3507 (Leptomeris).

occidentella Dyar, 5526 (Choreutis). occidentella Dietz, 5951 (Dryope). occidentella Chambers, 5763 (Gelechia).

occidentella Chambers, 6532 (Trichophaga).

occidentis Zeller, 6034 (Coleophora).

occidentis Walker, 3223 (Epicnaptera).

occiduaria Walker, 3898 (Anagoga) . occiduaria Guenée, 3862 (Ectropis). occiduaria Packard, 3692 (Macaria).

occipitana Zeller, 5099.

occitanica Frey \& Boll, 6284.

occulatissima Smith \& Abbot, 846. occulta Linnæus, 1462 (Peridroma). occulta Hy. Edwards, 2801 (Syneda).

occultana Walker, 5229.

oceanus Edwards, 640.

ocelella Chambers, 5743.

ocellana Clemens, 5266 (Ancylis). ocellana Schiffermüller, 5237 (Tmetocera).

ocellata Edwards, 248 (Chlorippe). ocellata Grote, 4100 (Packardia). ocellata Fabricius, 3459 (Petrophora).

ocellea Haworth, 4618.

ocellella Chambers, 5743.

ocellifera Grote, 366.

ocellinata Guenée, 3651.

ocherfuscella Chambers, 5817.

ochracea Neumoegen, 888 (Apantesis).

ochracea Edwards, 281 (Coenonympha).

ochracea Haworth, 6362 (Gracilaria).

ochracea Stretch, 873 (Platyprepia). ochracea Smith, 1275 (Polia). ochracea Behr, 2788 (Syneda). ochracea Riley, 1898 (Xylomiges). ochracealis Walker, 4529. 
ochraceana Fernald, 5097.

ochraceus Hy. Edwards, 2419.

ochrea Grote, 2755.

ochreana Clemens, 5096.

ochreata Packard, 3784 (Alcis). ochreata Butler, 894 (Apantesis). ochreata Hulst, 3918 (Eugonobapta).

ochreatus Hulst, 3924 (Ennomos). ochreella Clemens, 5959.

ochrefasciella Chambers, 6207. ochreicostana Walsingham, 5202. ochreifascia Smith, 2325.

ochreipennis Harvey, 2767 (Meliopotis).

ochreipennis Grote, 3024 (Zanclognatha).

ochrella Chambers, 5500 (Cerostoma).

ochrella Chambers, 6033 (Coleophora).

ochreoalbana Walker, 5458.

ochreocostella Chambers, 5702.

ochreofuscella Chambers, 5817.

ochreomaculella Chambers, 6175.

ochreostrigella Chambers, 5738 (Gelechia).

ochreostrigella Chambers, 5632

(Gnorrimoschema).

ochreosuffusella Chambers, 5736.

0chria . . . . . . . . . . . . . . . .

ochrifrontella Zeller, 4835.

ochrimaculella Ragonot, 4851.

ochripalpella Zeller, 5659.

ochristriata Walsingham, 6111.

ochrocephala Walsingham, 5203

ochrocomella Clemens, 5956.

ochrodactylus Fish, 4930.

ochroeomella Dietz, 5956.

ochrofuscaria Grote, 3825.

ochrogaster Guenée, 1719.

ochromelana Guenée, 5034.

ochroscapus Grote \& Robinson, 797. ochrostriata Walsingham, 6035.

ochsenheimeri Staudinger, 39.

0chyria .................... . .

ocola Edwards, 548.

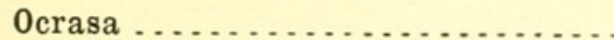

octagonella Walsingham, 6036.

octolineata Hulst, 3711.

octomaculalis Fernald, 4503.

octomaculata Fabricius, 949 (Alypia).
Page.

octomaculata Linnæus, 4472 (Pyrausta).

octomaculella Chambers, 5631 .

octonalis Zeller, 4475.

octopunctana Walsingham, 5204.

octoscripta Grote, 2502.

octosignalis Hulst, 4438.

octosignata Grote, 2502.

oculana Harris, 5237.

oculata Smith, 2376.

oculatana Clemens, 4134.

oculatrix Guenée, 2548.

oculea Neumoegen, 748.

oculiferalis Ragonot, 4536.

odiosella Hulst, 4770 .

odius Fabricius, 253.

odontata Hulst, 3437.

0dontoptera . . . . . . . . . . . . 338

0dontosia ................. 2. 251

0doptera . . . . . . . . . . . . . 336

odora Linnæus, 3006.

odyneripennis Walker, 4191.

Ecophora ................... . . . 525

Ecophoridæ ................. . . 519

Ectoperia .................. . . 400

adipodalis Guenée, 4415.

Edonia

cemearia Walker, 4005.

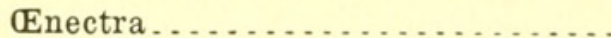

aneiformis Harvey, 3426.

Eneis . . . . . . . . . . . . . . . .

œno Boisduval, 295.

Enoe ......................... . .

cenone Scudder, 185.

cenotherxella Chambers, 6157.

cenotherxseminella Chambers, 6152.

anotherana Riley, 5453.

onotherivorella Chambers, 6152.

cenotrus Cramer, 690.

Eseis

Eta

cetus Boisduval, 264.

ofellusalis Walker, 4302.

offectalis Hulst, 5198.

offumalis Hulst, 4360.

Ogdoconta . . . . . . . . . . . . . .

ohioensis Zeller, 5521.

0idæmatophorus...............

0iketicus . . . . . . . . . . . . . . . 352

oileus Westwood \& Humphreys, 652 . oithona Strecker, 879.

okakaria Packard, 3513.

okakensis Packard, 1435. 
okeechobee Worthington, 575.

olbiella Hulst, 4847.

oleagina Morrison, 2333.

olealis Ragonot, 4535 (Chalinitis).

olealis Felder, 4315 (Diaphania).

0lene ........................

olenusaria Walker, 3759.

oleracea Harris, 38.

Olethreutes.

Olethreutinæ

0ligia

0ligoria......................

0ligostigma ..................

olinalis Guenée, 4521.

olivacea Smith, 1064 (Cerma).

olivacea Grote, 3080 (Hypena).

olivacea Morrison, 1832 (Mames-

tra).

olivaceana Fernald, 5016 (Exarte-

ma).

olvaceana Riley, 5164 (Thiodia).

olivacearia Morrison, 3880.

olivalis Grote, 4531 (Arta).

olivalis Hulst, 3717 (Cymatophora).

olvialis Hulst, 4637 (Epipaschia).

olivalis Morrison, 1581 (Paragrotis).

olivata Harvey, 2248 (Glæea).

olivatus Packard, 3140 (Heterocampa).

olivella Hulst, 4790 (Anoristia).

olivella Grote, 4550 (Mesolia).

olivia Hy. Edwards, 2899 (Catoca-

la).

olvia Morrison, 1536 (Feltia).

olivix Cockerell, 763.

oliviosa Walker, 1225.

olliusalis Walker, 4302.

olongella Riley, 6354.

olorina Grote, 1260.

olympia Butler, 3086 (Composia).

olympia Edwards, 43 (Synchloe).

olympiadella Zeller, 5714.

olympus Edwards, 258.

olynthus Boisduval \& Le Conte, 550.

olyzonaria Walker, 4005.

omaha Edwards, 471.

omega Hübner, 2486.

Omia

omicron Afzelius, 2525 (Autographa).

omicron Hübner, 2486 (Autographa).

omissa Walsingham, 5505.

0mmatopteryx ................

Ommatospila...............

Ommatostola
Page.

\section{onychina Guenée, 2068.}

onythesalis Walker, 4448.

oo Cramer, 2486.

opaca Harvey, 1529.

opacalis Grote, 3040.

opacaria Hulst, 3845.

opacella Hulst, 4897.

opacifrons Grote, 1427.

opalescalis Hulst, 4554.

opalescellum Ragonot, 4866.

opalescens Hy. Edwards, 4195.

opalizalis Guenée, 4448.

opella Grote, 832.

opelloides Graef, 831.

opercularis Smith \& Abbot, 4109.

operculella Zeller, 5616.

operosella Zeller, 6549.

ophelia Hy. Edwards, 2863.

0pheroptera ...............

0phideres .................

ophionatis Walker, 4373.

ophis Edwards, 546.

ophthalmica Guenée, 1073 (Baileya).

ophthalmicus Boisduval, 730 (Smerinthus).

opina Grote, 1287.

opipara Morrison, 1694 (Paragrotis).

opipara Hy. Edwards, 2647 (Tripudia).

opis Edwards, 128.

oponearia Walker, 3963.

0porabia ..................... 275

oporaria Zeller, 3568.

Oporinia ...................

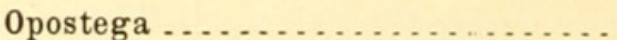

oppositaria Guenée, 3738.

ops Druce, 254.

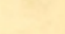


optimata Strecker, 3346.

opulenta Hy. Edwards, 904.

opuscularia Hulst, 3811.

orasusalis Walker, 4436.

oratalis Hulst, 4385.

orba Grote, 2640.

orbica Morrison, 2553.

orbicularis Walker, 1103 (Caradrina).

orbicularis Smith, 1683 (Paragrotis).

orbiculata Smith, 1920.

orbimaculella Chambers, 5477.

orbis Grote, 1396.

orbitalis Felder, 4352.

orbitulus Strecker, 424 (Agriades). orbitulus Scudder, 410 (Cupido).

orc Strecker, 4144.

Orchemia.

orciferalis Walker, 3035.

orciferata Walker, 3891.

orcus Cramer, 652.

ordinaria Walker, 3757 (Apæcasia). ordinaria Walker, 1232 (Hadena). ordinata Walker, 1649 (Paragrotis). ordinata Walker, 3647 (Sciagraphia).

ordinata Walker, 3491 (Synelys).

ordinatellus Walker, 5477.

oreadella Hulst, 4549.

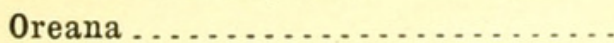

oreas Edwards, 213.

oreasella Clemens, 6455.

oregona Smith, 1985 (Heliophila).

oregona Hy. Edwards, 2397 (Mela-

noporphyria).

oregonana Walsingham, 5211.

oregonella Walsingham, 6486 (Incurvaria).

oregonella Busck, 6518 (Tinea).

oregonensis Stretch, 911 (Euchætias).

oregonensis Walsingham, 6309 (Li-

thocolletes).

oregonensis Butler, 3123 (Nadata). oregonensis Harvey, 2101 (Xylina). oregonia Edwards, 487 (Erynnis). oregonia Edwards, 17 (Papilio). oregonica Grote, 1801 (Mamestra). oregonicus Grote, 4599 (Crambus). orella Dietz, 5563.

oreodaphne Hy. Edwards, 706.

orestes Lintner, 592.
Page.

Oreta

Page.

orgyix Grote, 2626.

orichalcella Clemens, 6086.

orientalis Moore, 904 (Arctia).

orientalis Grote, 2213 (Tapinostola).

orillata Walker, 3662.

orilliana Grote, 1437.

orina Guenée, 2259.

orion Fabricius, 253.

oriunda Grote, 2098.

orizaba Westwood, 737.

orleansella Chambers, 6519.

ornata Neumoegen, 2435 (Acherdoa).

ornata Packard, 881 (Apantesis).

ornata Grote \& Robinson, 3092

(Melalopha).

ornata Ottolengui, 2471 (Panchrysia).

ornata Hulst, 3276 (Tephroclystis) . ornatalis Duponchel, 4280.

ornatella Chambers, 6265 (Lithocolletes).

ornatella Dietz, 5943 (Pigritia).

ornatifimbriella Clemens, 5818.

omatrix Linnæus, 837.

Orneodes ..................

Orneodidæ ................... . . 448

ornithogalli Guenée, 1300.

Ornix

oro Scudder, 420.

Orobena

orobia Harvey, 2015.

oronella Walsingham, 5563.

orono Scudder, 556.

orphisalis Walker, 4426.

orphnealis Walker, 4306.

Orrhodia ....................

orsa Boisduval, 194.

orseis Edwards, 191.

orsua Godman \& Salvin, 24.

orthocarpi Walsingham, 4945 (Platyptilia).

orthocarpi Hy. Edwards, 4241 (Sesia).

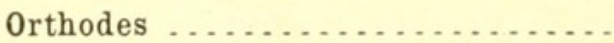

Orthofidonia ................. 304

orthogonia Morrison, 1560.

Ortholepis . . . . . . . . . . . . . 422

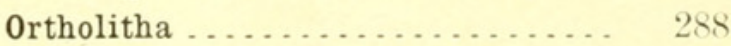

Ortholophus.................. . . 579

Orthonana .................. 273

Orthosia..................... 179 
orthosioides Guenée, 2915.

ortonii Packard, 1467.

orythia Smith \& Abbot, 223.

oryzxellus Riley, 4628.

0sceola.

osceola Lintner, 529.

oscitalis Grote, 4412.

osculata Hulst, 2865 (Catocala). osculata Hulst, 3368 (Enchoria). oslari Skinner, 536 (Euphyes). oslari Barnes, 3188 (Notolophus). osmundana Fernald, 5043.

osseana Scopoli, 5409.

osseella Walsingham, 5840.

ossianus Boisduval, 134.

ossularia Hübner, 3530.

ossulata Packard, 3530.

ostensackenella Fitch, 6265.

ostenta Hy. Edwards, 830.

ostentaria Walker, 3514.

ostreella Ragonot, 4904.

ostreonalis Grote, 4323.

ostricolorella Hulst, 4829.

ostrinella Clemens, 4886.

ostryx Clemens, 6037.

ostryxella Chambers, 6132.

ostryxfoliella Clemens, 6143 (Coptodisca).

ostryæfoliella Clemens, 6275 (Lithocolletes).

ostryxfoliella Clemens, 6208 (Nepticula).

ostryella Chambers, 6335.

osyka Edwards, 531.

otho Barnes, 926 (Halisidota).

otho Smith \& Abbot, 519 (Thymelicus).

otiosa Neumoegen \& Dyar, 875 .

otiosana Clemens, 5142.

ottoe Edwards, 491.

ottolenguii Dyar, 2513.

ou Guenée, 2493.

outis Skinner, 595.

ouwah Poling, 2898.

ovalis Guenée, 2537 (Abrostola).

ovalis Packard, 4734 (Ambesa).

ovalis Grote, 2942 (Phurys).

ovata Grote, 1025.

ovidius Scudder \& Burgess, 628.

oviducta Grote, 2015.

ovilla Grote, 4053.

oviplagalis Walker, 4528.
Page.

ovulalis Guenée, 4297.

oweni Edwards, 103.

oxalina Hübner, 2258.

oxilus Hübner, 14.

oxyacanthus Hübner, 5359.

oxybaphi Clemens, 671.

0xycnemis . . . . . . . . . . . . . . .

oxycoccana Packard, 5318.

oxydalis Guenée, 4423.

0xydia

oxygala Grote, 1959.

oxygramma Geyer, 2498 (Autographa).

oxygramma Hulst, 3420 (Cœenocalpe).

0xylos

186

oxymorus Grote, 1879.

0xyptilus.

0zonadia ...................

pacalis Grote, 4487 (Nymphula).

pacalis Walker, 2935 (Poaphila).

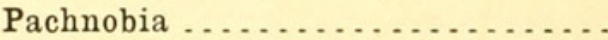

Pachylia .......................

Pachypolia ................

Pachyzancla ................

pacifica Hy. Edwards, 1083 (Acopa). pacifica Hy. Edwards, 4189 (Aegeria).

pacifica Smith, 978 (Apatela). pacifica Smith, 2162 (Gortyna).

pacifica Harvey, 2039 (Graphiphora).

pacifica Behr, 3111 (Hyperæschra). pacifica Riley, 4195 (Sanninoidea). pacificana Clemens, 5263.

pacificaria Packard, 3626 (Deilinia). pacificaria Packard, 3550 (Eois). packardaria Hulst, 3826 (Ethalodes).

packardaria Grote, 3589 (Aplodes). packardaria Möschler, 3707 (Macaria).

packardata Lintner, 3350.

packardella Chambers, 6245 (Bucculatrix).

packardella Chambers, 5732 (Gelechia).

packardella Chambers, 6372 (Gracilaria).

packardella Clemens, 5893 (Semioscopis).

packardi Zeller, 5282 (Enarmonia). 
Packardia ......................

packardiana Clemens, 5127 (Eucosma).

packardiana Fernald, 5407 (Tortrix).

packardiella Ragonot, 4823.

packardii Schaupp, 851 (Estigmene).

packardii Morrison, 3126 (Hippia). packardii Grote, 821 (Illice).

packardii Saunders, 189 (Phyciodes).

packardii Grote, 788 (Scepsis). packardii Grote, 2358 (Schinia). pacuvius Lintner, 631.

\section{Pæctes}

pretinria Dyar, 3965.

\section{Pædisca .}

pænulata Clemens, 4077.

pænulataria Grote, 3872.

pagenstecheri Möschler, 2723.

paginata Morrison, 1142.

Palada

palxmon Pallas, 469.

palæno Cramer, 66 (Eurymus).

palæno Linnæus, 74 (Eurymus).

palamedes Drury, 12.

palata Grote, 963.

\section{Palatka}

palatka Edwards, 561.

paleacea Esper, 2217 (Cosmia).

paleaceus Zeller, 4973 (Pterophorus).

\section{Paleacrita}

paleogama Guenée, 2873.

pales Denis \& Schiffermüller, 132

(Brenthis).

pales Felder, 310 (Lycorea).

palida Comstock, 4842.

palidochrella Chambers, 5592.

palilis Harvey, 2022.

Palindia.

233 palla Boisduval, 164 (Lemonias). palla French, 3094 (Melalopha).

Fallachira ................... pallens Tepper, 2293 (Edophron). pallens Strecker, 734 (Cressonia). pallens Hy. Edwards, 787 (Scepsis). pallescens Smith, 2168 (Gortyna). pallescens Grote \& Robinson, 2768

(Meliopotis).

pallialis Zeller, 3066.

palliatricula Guenée, 1067.

357
Page.

pallicornella Ragonot, 4667.

pallida Bowles, 771 (Anisota).

pallida Ottolengui, 2523 (Autographa).

pallida Packard, 800 (Crambidia). pallida Smith, 1066 (Cyathisa). pallida Hulst, 3535 (Eois). pallida Cockerell, 70 (Eurymus). pallida Lyman, 69 (Eurymus). pallida Skinner \& Mengel, 63 (Eurymus).

pallida Packard, 855 (Hyphantria). pallida Strecker, 3147 (Ianassa). pallida Edwards, 192 (Phyciodes). pallida Scudder, 38 (Pontia). pallida Herrich-Schaeffer, 4107

(Tortricidia).

pallidata Packard, 3652.

pallideflava Goeze, 54.

pallidegrisseella Chambers, 5819.

pallidella Chambers, 5550.

palliderosacella Chambers, 5558.

pallidice Scudder, 66.

pallidicollis Grote, 1505.

pallidicoma Grote, 1037.

pallidicostana Walsingham, 5180.

pallidior Dyar, 805 (Palpidia).

pallidior Smith, 1904 (Xylomiges).

pallidipennata Hulst, 4903.1

pallidistrigella Chambers, 5541.

pallidochrella Chambers, 5626

(Gnorimoschema).

pallidochrella Chambers, 5592 (He-

lice).

pallidotinctella Dietz, 5949.

pallidula Hulst, 3729 (Cymatophora).

pallidulus Hy. Edwards, 730 (Smerinthus).

pallifera Grote, 1264.

palligera Grote, 2470 (Panchrysia). palligera Smith, 3053 (Tetanolita). pallimedia Smith, 1388.

palliolella Ragonot, 4685. pallipalpis Walker, 5662. pallipennis Smith, 1672. pallisece Smith, 1988. pallorana Robinson, 5396. pallula Hy. Edwards, 969. pallulata Hulst, 3976. pallulella Hulst, 4832. palmeri Packard, 790 (Lycomorpha). 
palmerii Edwards, 318 (Polystigma).

Palmia

palmii Beutenmüller, 3103 (Da$\tan a)$.

palmii Hy. Edwards, 4182 (Memythrus).

palmii Neumoegen, 4260 (Paranthrene).

palpalis Haworth, 3079 (Bomolocha).

palpalis Grote, 653 (Hemaris). palpalis Walker, 1118 (Perigea). palpana Walsingham, 5112.

Palparia .................. palpata Packard, 3272.

palpialbella Chambers, 5820.

palpiatiella Riley, 5820.

palpiannulella Chambers, 5585.

Palpidia................... . . . palpilineella Chambers, 5696.

Palthis. . . . . . . . . . . . . . .

\section{Paltodora.}

paltodoriella Busck, 5708.

paludana Robinson, 5368.

paludata Thunberg, 3259.

Palyadinæ

Palyas

pamina Neumoegen, 751.

Pammene.

Pamphila..................

pamphilius Linnæus, 283.

pamphiloides Reakirt, 283.

pampina Guenée, 2206.

pampinaria Guenée, 3850.

pampinatrix Smith \& Abbot, 682.

pan Harris, 335.

Panapoda.

Panchrysia

pandaria Walker, 4008.

Pandemis .

pandora Blake, 755.

pandorus Hübner, 678 .

panella Busck, 5774.

Pangrapta . panicifoliella Clemens, 6128.

panisaria Walker, 3910. paniscus Fabricius, 469. pannaria Guenée, 3485. panopealis Walker, 4448. panoquin Scudder, 546. panoquinoides Skinner, 547.

Panthea
Page.

366
Pantographa

Page.

Panula.

Paonias.

Paota

Papaipema

paphia Linnæus, 748.

Papilio

Papilionidæ

Papilionoidea

Parachma

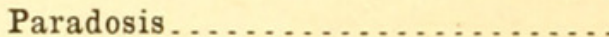

paradoxa Behr, 3162 (Harpyia). paradoxa Riley, 6576 (Pronuba). paradoxica Chambers, 6564.

paradoxum Frey \& Boll, 6397 (Coriscium).

paradoxus Grote, 2298 (Heliocheilus).

Parædis .

Paragrotis

Paralechia

140

502

Paralipsa..................... 413

parallela Grote, 1017 (Apatela). parallela Robinson, 5362 (Archips). parallela Panzer, 5500 (Cerostoma). parallela Hy. Edwards, 4096 (Cochlidion).

parallela Grote \& Robinson, 3193

(Olene).

parallela Grote, 1995 (Trichorthosia).

parallelana Walsingham, 5447.

parallelaria Packard, 3978.

Paralleiia ................... . .

paralleliaria Packard, 3978.

Paranthrene ......................

Paraphia ...................

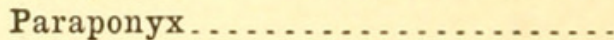

Paraptera

Parasemia ...................... . . 91

Parastichtis .................. 180

pardalis Behr, 408 (Cupido). pardalis Grote, 2708 (Spragueia). pardella Walsingham, 6621.

Parectopa .................. 557

Parennomos ..................... 318

parentalis Grote, 1751.

Parharmonia................... parinotata Zeller, 3424.

parisiana Guenée, 5303.

parmatana Clemens, 5283.

parmeliana $\mathrm{Hy}$. Edwards, 2340. 
Parnasiidæ

Page.

Parnassius

Parora

parta Guenée, 2857.

parthenice Kirby, 878.

parthenos Harris, 872.

participalis Grote, 4532.

particolor Hulst, 3712.

partita Guenée, 2618.

partitaria Grote, 3601.

parvana Walsingham, 5192.

parvicristatella Chambers, 6164.

parvimacula Grote, 2604.

parimaculana Walsingham, 5460.

paripulvella Chambers, 6087 (Ela-

chista).

parvipulvella Chambers, 5821 (Gele-

chia).

parvula Edwards, 2906 (Catocala). parvula Neumoegen \& Dyar, 829

(Eubaphe).

parvula Walker, 2700 (Fruva).

parvula Hy. Edwards, 5483 (Tri-

chostibas).

parvularia Hulst, 3518.

pareus Walsingham, 4976.

pascuellus Linnæus, 4563.

pasiphæia Grote, 2520.

passa Morrison, 1811.

Passadena ........................

passer Guenée, 1212.

passerana Walsingham, 5114.

passeraria Freyer, 3380.

passifloræ Fabricius, 91.

passulella Barrett, 4875.

pastillicans Grote, 2251.

pastinacella Duponchel, 5889.

pastor Feldier, 638.

pastoralis Grote, 1601 (Paragrotis). pastoralis Grote, 3048 (Renia).

Patalene................... . .

patalis Grote, 1900.

patefacta Smith, 1492 (Noctua).

patefacta Walker, 2089 (Xylina).

patella Druce, 817.

patibilis Walker, 2754.

patina Harvey, 1162.

Patissa ....................... . .

patricia Grote, 1992.

patriciata Grote, 3785.

Patridiva

patruelis Grote, 2636.

patula Morrison, 2636(Eumestleta). paulina Hy. Edwards, 2810.

paulus Edwards, 262.

paupera Felder, 201.

paupercula Grote, 1011.

pausis Smith, 1184.

pauxillus Grote, 2404.

paviz Behr, 1154.

pavitensis Morrison, 2777.

pavonacella Clemens, 5532.

pavonia Geyer, 731.

pawnee Dodge, 490.

peartix Edwards, 295.

peckius Kirby, 526.

pectenalxella Chambers, 5642 .

pectinaria Schiffermüller, 3965.

pectinata Smith, 2019 (Graphi-

phora).

pectinata Grote, 1431 (Pachnobia).

pectinatus Smith, 1951 (Nephelodes).

pectinicornis Smith, 2563 (Eucalyptera).

pectinicornis Smith, 1541 (Feltia).

pectinifer Zeller, 4616.

peculiana Zeller, 5300.

pedalis Grote, 2495 (Autographa).

pedalis Smith, 1675 (Paragrotis).

pedicillata Hulst, 3857.

pedipilalis Guenée, 3020.

pedmontella Chambers, 6466 (Ar-

gyresthia).

pedmontella Chambers, 5629 (Gnor-

imoschema).

pegala Fabricius, 257.

pegasalis Walker, 4636.

pegula Herbst, 257.

pelasgus Cramer, 656.

peleus Sulzer, 234.

pelidne Boisduval, 73.

pellenis Godart, 235.

pellionella Linnæus, 6520.

pellucida Herrich-Schæffer, 770.

pellucidalis Grote, 1469.

pellucidaria Packard, 3780 (Nepy-

tia).

pellucidaria Grote \& Robinson,

3907 (Therina).

pelviculella Hulst, 4888.

pembina Edwards, 411 (Cupido).

pembina Strecker, 419 (Nomiades).

pendula Ottolengui, 2440. 
pendulinaria Guenée, 3480.

peninsularia Grote, 4029.

penitalis Grote, 4439.

penna Morrison, 2999.

pennsylvanica Smith, 3180 (Euthyatira).

pennsylvanica Dietz, 5766 (Gelechia).

pensilis Grote, 1851.

Penthetria

Penthina

pentia Morrison, 2617.

Pentopoda

penumbralis Grote, 4308.

penumbrata Hulst, 3554.

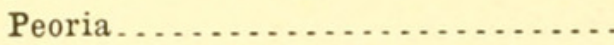

peosinata Guenée, 4010.

pepita Guenée, 2443.

peplaria Hübner, 4001.

peplarioides Hulst, 4000.

pepsidiformis Hübner, 4194.

peracuta Walker, 3370.

peralbata Packard, 3528.

perangulalis Harvey, 3073.

perangulata Hulst, 3777 (Enypia).

perangulata Hulst, 3972 (Eutra-

pela).

perangulata Hy. Edwards, 3150

(Schizura).

perangustana Walsingham, 5183

perarcuata Walker, 3705.

perattenta Grote, 1423 .

perbellis Grote, 2235.

perbrunnea Grote, 2025.

percara Morrison, 1065.

percnodactyla Walsingham, 4942.

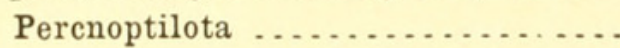

perconflua Grote, 1483.

perdiccas Edwards, 147.

perdita Grote, 1034 (Apatela).

perdita Hy. Edwards, 2831 (Cato-

cala).

perdita Dyar, 6604 (Sthenopis).

perditalis Walker, 2728.

perdricana Walsingham, 5102.

perductana Walker, 5077.

peredia Grote, 2026.

perelegans $\mathrm{Hy}$. Edwards, 702.

peremptalis Grote, 4269.

perexcellens Grote, 1726.

perfecta $\mathrm{Hy}$. Edwards, 2779.

perflava Harvey, 2654.

perfluana Zeller, 5279.

298
Page.

perforata Grote, 2027.

perfundis Smith, 2282.

perfusalis Walker, 4273.

perfusca Grote, 1600 (Paragrotis).

perfusca Hulst, 3299 (Tephroclys-

tis).

perfuscalis Hulst, 4291 (Pilocrocis). perfuscalis Hulst, 4813 (Sarata).

perfuscaria Grote, 3473.

pergamus $\mathrm{Hy}$. Edwards, 20.

pergandeella Busck, 5916.

pergentilis Grote, 1077.

pergilvalis Hulst, 4346.

pergracilidactylus Packard, 4981.

pergracilis Hulst, 3488.

pergratialis Hulst, 4731.

Periclymenobius............... 490

Pericopidæ................... 248

periculosa Guenée, 2204.

Peridroma .................... 133

Perigea ...................... 111

Perigonica..................... 168

Perigrapha ................... 168

perirrorata Packard, 3533.

periscelidactylus Fitch, 4932.

Perispasta .................... 387

perita Grote, 2642.

peritalis Smith, 1902.

peritana Clemens, 5402.

periusalis Walker, 4343.

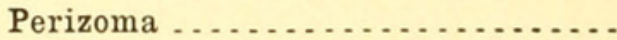

perizomaria Hulst, 4003.

perleta Hy. Edwards, 2773.

perlaria Packard, 3913.

perlata Guenée, 3913 (Metrocampa).

perlata Walker, 2923 (Remigia).

perlellus Scopoli, 4580.

perlentans Walker, 1748.

perlepidellus Hulst, 4928.

perlevis Grote, 913.

perlineata Packard, 3331.

perlubens Grote, 1896.

perlucidula Clemens, 4117.

perlutea Neumoegen \& Dyar, 3215.

permaculata Packard, 847.

permagna Grote, 2150.

permagnaria Packard, 3806.

permanans Hulst, 2875.

perminuta $\mathrm{Hy}$. Edwards, 2400.

permolestella Busck, 6182.

permunda Morrison, 1599.

permundana Clemens, 5015.

permutana Duponchel, 5313. 
pernana Grote, 2305.

pernotata Hulst, 3389 (Hydriomena). pernotata Grote, 1334 (Oncocnemis).

perolivata Hulst,3759 (Catopyrrha). perolivata Packard, 3134 (Heterocampa).

perophoroides Strecker, 3157.

perotensis Schaus, 857.

perpallida Grote, 1081 (Acopa).

perpallida Hy. Edwards, 2792 (Syneda).

perpallidaria Grote, 3632.

perpensa Grote, 1239.

perpicta Dyar, 881.

perplexa Strecker, 2857 (Catocala). perplexa Boisduval,2937 (Poaphila). perplexa Smith, 1912 (Scotogram-

ma).

perplexa Hy. Edwards, 4203 (Sesia). perplexa Hy. Edwards, 2798 (Syne-

da).

perplexalis Fernald, 4355.

perplexana Fernald, 5130.

perplexus Neumoegen \& Dyar, 4145

(Cossus)

perpolita Morrison, 1598.

perpura Morrison, 1936 (Anarta). perpura Morrison, 1698 (Paragrotis).

purpuripennis Grote, 2160.

perquirita Morrison, 1417.

perrubralis Packard, 4447.

perscripta Guenée, 1369.

perse Edwards, 172.

Perseis

persephone Grote, 880.

persicx Thomas, 4194.

persicxella Murtfeldt, 5719.

persicana Fitch, 5379.

persimilata Grote, 3477.

persimilis Hulst, 3545 (Eois).

persimilis Grote, 2404 (Meliclep-

tria).

persimplex Dyar, 6578.

persinuaria Guenée, 3934.

persius Scudder, 621.

personaria Hy. Edwards, 3772.

personata Morrison, 1623 (Paragro-

tis).

personata Walker, 968 (Raphia).

perspectalis Hübner, 4275.

perspicelella Walsingham, 6112.
Page.

perspicua Grote \& Robinson, 3106.

(Datana).

perspicua Walker, 2945 (Phurys).

perspicua Walker, 4131 (Thyris).

perspicuana Robinson, 5309.

perstrialis Hübner, 4541.

perstmuctana Walker, 5197.

persuasa Harvey, 1019.

pertextalis Lederer, 4417.

pertracta Morrison, 1961.

perturbata Smith, 1658.

perumbraria Hulst, 3817.

peruviana Walker, 4478.

pervaria Packard, 3893.

pervelata Walker, 3719.

perversa Neumoegen \& Dyar, 3221.

pervertipennis Hulst, 3320.

perviridaria Packard, 3558.

pervolata Hulst, 3660.

Petaluma.

petasitis Pfaffenzeller, 5773.

petita Smith, 1832.

petiverella Schiffermüller, 5291 .

petrealis Grote, 3039.

petreius Edwards, 646.

petrellus Zeller, 4778.

petreus Cramer, 234.

petricola Walker, 2783.

petrodactyla Walker, 4951.

petronius Lintner, 626.

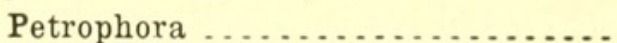

petrosa Walker, 900.

pettitana Robinson, 5336.

pettiti Grote, 2238.

petulans Hulst, 2857 (Catocala).

petulans Hy. Edwards, 2355 (Schinia).

petulca Grote, 2079.

pexata Guenée, 2112.

pexellus Zeller, 4612.

phæalis Guenée, 3012.

Phæcasiophora .................

phxdon Herrich-Schaeffer, 146.

Phædrotes ..................... . .

phrosoma Butler, 904.

Phæoura

pharusalis Walker, 4304.

phatana Hübner, 146.

phathusa Hulst, 146.

phaton Drury, 146 (Euphydryas).

phixton Grote \& Robinson, 658

(Lepisesia).

phxtoneta Godart, 146. 


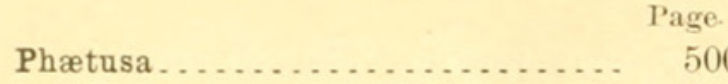

Phakellura

phalimalis Grote, 2578.

Phalænostola ....................

phalanga Grote, 2873.

phalerata Harris, 895.

phalerosalis Walker, 3048.

\section{Phalonia}

Phaloniinæ

phantasmalis Guenée, 4314.

phantasmaria Strecker, 3782.

phaon Edwards, 188.

Pharetra

Jharmacis

,haros Harris, 189.

phasianaria Guenée, 4007.

phasma Harvey, 843.

Phasyle ....................

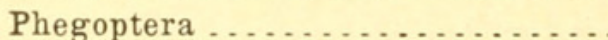

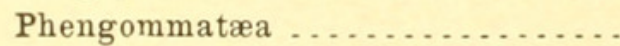

Pheocyma

Pheosia

pherecydes Cramer, 252.

pheres Boisduval, 412.

Pherne.

Phibalapteryx

Phigalia ............... . . 330,544

phigaliaria Guenée, 3872.

Philagraula ......................

philea Linnæus, 51.

phileatis Walker, 4344.

Philedia .......................

phitemon Boisduval, 437.

philenor Linnæus, 23.

Philereme

phileros Boisduval, 413.

phileta Fabricius, 32.

philetas Edwards, 645.

Philobia. .

philodice Godart, 66.

philodina Druce, 817.

Philometra

Philonome

philonomene Hübner, 74

Philopsia.

Philorygia.

Philosamia

\section{Philotes}

\section{Philtræa}

Phiprosopus

phleas Boisduval \& Le Conte, 399. phlebeculata Guenée, 3422.

Phlegethontius.

268 phlogophagus Grote \& Robinson, 2101.

phlogosaria Guenée, 3931.

Phlyctænia .................... . . 387

Phlyctænodes .................. . . 382

Phoberia . . . . . . . . . . . . . . . $\quad 232$

Phobetron ................... 356

phoca Möschler, 1915.

phocata Möschler, 3443.

phocion Fabricius, 298.

phocus Edwards, 263.

phobe Hy. Edwards, 2886.

Phœbis

phonicealis Hübner, 4448.

Pholisora........................

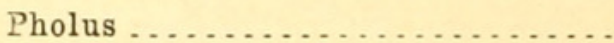

pholus Drury, 792.

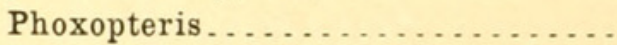

phrada Druce, 826.

phragmatidicola Guenée, 1980.

Phragmatobia..................

phragmitella Stainton, 6096.

phrasiualis Walker, 4275.

Phryganeopsis

Phryganidia

Phrygionis ..................

phrynia Hy. Edwards, 2826.

Phtheochroa ................ 488

350 Phthorimaea.................... 502

Phthoroblastis ................. 471

Phurys...................... 235

Phycanassa ..................... 55

Phycidea ................... . . . 434

Phyciodes ................... . . 20

Phycitinæ ................... 417

Phycitopsis ................. . . 420

Phylace .................... 277

phylace Edwards, 563 (Limochroes).

phylazus Drury, 515.

phylla Dyar, 4055.

phyllinaria Zeller, 3562.

phyllira Drury, 890.

phyllisalis Walker, 4424.
99

phyllophora Grote, 1484.

physaliella Chambers, 5587.

physalivorella Chambers, 5638.

phytolacex Smith \& Abbot, 1301.

piasus Boisduval, 440.

piatrix Grote, 2868.

pica Walsingham, 4936.

67 picina Grote, 1337.

5

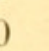


picta Packard, 857 (Arachnis). picta Felder, 3134 (Heterocampa). picta Harris, 1807 (Mamestra). picta Edwards, 195 (Phyciodes). picta Walker, 766 (Pseudohazis). pictipennata Hulst, 3670.

pictipennis Grote, 2416.

pictipes Grote \& Robinson, 4216.

Pieridæ

Piesmopoda

piger Dyar, 6597.

Pigia

pigrata Walker, 3370.

Pigritia .

pilalis Hulst, 4431.

pilipalpis Guenée, 1955.

pilleriana Schiffermüller, 5345 .

Pilocrocis

pilosaria Packard, 3944.

pilosella Zeller, 6113.

pilumnus Boisduval, 7.

Pima

pima Edwards, 50.

pimpinella Murtfeldt, 6147.

pinaria Packard, 3780.

pinastiri Linnæus, 1290 (Dipterygia).

pinastiri Linnæus, 708 (Sphnix).

pindar Smith, 1740.

pinetana Hübner, 5076.

pinetaria Hübner, 3695.

pinetum Lintner, 725.

pini Kellicott, 4193.

piniaria Packard, 3765.

pinicolana Zeller, 5229.

pinifoliella Chambers, 5614.

\section{Pinipestis}

pinivorana Zeller, 5003.

pinorum Behrens, 4192.

piperatella Zeller, 5850.

piperis Boisduval, 690.

Pippona

pirus Edwards, 607.

piscipellis Grote, 1501 (Noctua). piscipellis Zeller, 5548 (Paltodora). pisonix Busck, 5569.

pisoniella Busck, 6075.

pistacearia Packard, 3596.

pistaciata Guenée, 3563.

pithecium Smith \& Abbot, 4089.

pittacus Edwards, 551.

pitychrous Grote, 1623.

pityochromus Grote, 2456.
Page.

Page.

Pityolita

241

Pitys.......................

placata Grote, 2936.

placearia Guenée, 3980.

placentia Smith \& Abbot, 893.

placida Dyar, 3162 (Harpyia).

placida Grote, 1395 (Rhyncha-

grotis).

placidana Robinson, 5303.

placidaria Guenée, 3517.

placidata Walker, 3419.

plagiata Walker, 1302 (Laphygma).

plagiata Walker, 1478 (Noctua).

plagiata Walker, 3195 (Olene).

plagiata Walker, 3125.1 (Symmerista).

plagiatus Walker, 4147 (Prionoxystus).

plagifasciata Walker, 3898.

plagigera Morrison, 1579.

Plagiola . . . . . . . . . . . . . . . . . .

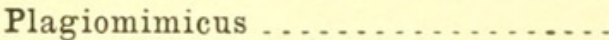

Plagodis ..........................

plagosana Clemens, 5262.

plana Grote, 2625.

planalis Grote, 2046 (Graphiphora). planalis Grote, 4522 (Herculia).

planifrons Smith, 1443.

planipennella Chambers, 6114.

plantagenaria Hulst, 3515.

plantaginis Martyn, 890 (Apantesis). plantaginis Linnæus, 900 (Parasemia).

plantaginisella Chambers, 6353.

planus Grote, 1753.

Platæa ..................... . . .

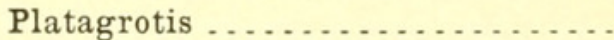

platanana Clemens, 5254.

platanella Chambers, 5750 (Gelechia).

platanella Clemens, 4652 (Lanthape).

platanella Clemens, 6209 (Nepticula).

platea Clemens, 6210.

Plathypena ............... . .

platina Skinner, 114.

platinalis Guenée, 4297.

Platœceticus .................. . . .

Platynota. . . . . . . . . . . . .

Platyperigea...............

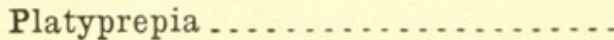

Platypterygidæ .................

Platyptilia
319 


\section{Platyptilus}

Platysenta. .

plausipennella Chambers, 6114.

plautus Scudder \& Burgess, 637.

plebeia Smith, 1503.

plebius Fabricius, 717.

plecixformis Walker, 4191.

plecta Linnæus, 1490.

plectilis Grote \& Robinson, 4413.

plejadellus Zincken, 4628.

plemyrata Felder, 3370.

Plemyria ......................

plena Walker, 4134.

plenilinealis Grote, 4491 (Nymphula).

plenilinealis Grote, 3046 (Renia).

plenipennis Walker, 2983.

plenoscripta Hulst, 3301.

pleonectusa Grote, 2261.

Pleonectyptera

Plerocymia .....................

Pleroma

Pleurasympieza

pleuritica Grote, 1652.

plexippus Linnæus, 308.

plicata Smith, 1853 (Mamestra).

plicatus Grote, 1759 (Ufeus).

plicipunctella Walsingham, 6465.

Plodia

Ploiphora ..........................

plota Strecker, 713.

plumbana Scopoli, 5291.

plumbaria Hulst, 3288.

plumbea Hy. Edwards, 808 (Нypo-

prepia).

plumbea Stretch, 822 (Illice).

plumbeella Beutenmüller, 5909.

plumbicostalis Grote, 4293.

plumbifimbriata Grote, 2705.

plumbosignalis Fernald, 4380.

plumifrontellus Clemens, 6584.

plumigerella Hulst, 4668.

plumogeraria Hulst, 3877.

plumosa Hy. Edwards, 3135.

plumosaria Packard, 3855.

pluralis Grote, 1564.

Plusia ........................

plusiiformis Hy. Edwards, 2048.

Plusiodonta . . . . . . . . . . . . . .

Plutella ......................

plutella Chambers, 5553 (Autoneda).

plutella Chambers, 5594 (Evippe).

Page.

442

108 plutella Chambers, 5657 (Trichotaphe).

Pluteloptera .

pluto Fabricius, 666 . plutonia Grote, 1228. pluvialis Dyar, 3216. pluviata Guenée, 3388. pluviosa Walker, 1237. pneumatella Hulst, 4843. pnosmodiella Busck, 6385. poana Zeller, 5064.

Poanes ....................... 49

Poaphila .................... 234

pocahontas Scudder, 484.

Pococera .................... 416

Podagra...................... 128

podarce Felder, 424.

Podiasa ...................... 567

Podosesia...................... 365

poeas Hübner, 365.

poecila Stephens, 703.

poecilana Guenée, 5134.

poetica Grote, 2463.

poeyi Butler, 30.

pohono Smith, 1352.

pola Boisduval, 165.

polaris Boisduval, 139 (Brenthis).

polaris Hulst, 3443 (Psychophora).

polaris Herrich - Schaeffer, 3444

(Trichochlamys).

polata Hübner, 3444.

poli Guenśe, 1233.

Polia

polingii Barnes, 651.

polistiformis Harris, 4179.

polita Walsingham, 5493.

politana Haworth, 5423 (Eulia).

politana Guenée, 5290(Hemimene).

politata Guenée, 4027.

politella Walsingham, 6482.

Polites .......................

politia Cramer, 4027.

pollinalis Schiffermüller, 4391.

Polopeustis . . . . . . . . . . . . . . . .

polyactinellis Zeller, 4590.

Polychrosis

Polychrysia .

polydactyla Hübner, 4997.

polydamas Linnæus, 25.

polygama Guenée, 2892.

polygoni Hy. Edwards, 4244.

Polygonia

polygrammaria Packard, 3848. 
polygrammata Hulst, 3425 .

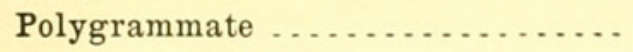

Polygrammodes ................ polygrapharia Boisduval, 3449.

Polyhymno .............................. polyommata Tepper, 743.

polyphemella Ragonot, 4800.

polyphemus Boisduval, 418 (Nomiades).

polyphemus Cramer, 748 (Telea).

Polyphrasia................ . . .

Polystigma . . . . . . . . . . . . .

polyxenes Fabricius, 22.

pomana Fabricius, 5296.

pometaria Harris, 3247.

pometella Harris, 5678.

pomifoliella Clemens, 6246 (Bucculatrix).

pomifoliella Zeller, 6270 (Lithocolletes).

pomitiella Clemens, 6539.

pomivorella Packard, 6211.

pomona Smith, 2080.

pomonana Schiffermüller, 5296.

pomonella Packard, 6246 (Bucculatrix).

pomonella Linnæus, 5296 (Cydia).

pompadour Pollich, 217.

\section{Pontia}

pontiac Edwards, 556.

pontiella Zeller, 4623.

popeanella Clemens, 6594.

popofensis Smith, 2157.

populata Linnæus, 3350.

populetorum Frey \& Boll, 6212.

populi Riley, 983 (Apatela).

populi Strecker, 2067 (Cleoceris).

populi Walker, 4144 (Cossus).

populicola Boisduval, 728.

populiella Chambers, 6373 (Graci-

laria) .

populiella Chambers, 6331 (Lithocolletes).

populiella Chambers, 6420 (Phyllocnistis).

porcellarium Guenée, 3839.

porcus Hübner, 673 .

Porosagrotis

porphyria Herrich-Schaeffer, 923. porrectella Linnæus, 5504.

Porrima . . . . . . . . . . . . . . . . porsenna Scudder, 385.

Porthetria

106 381
Page. præfica Morrison, 1463 (Peridroma). præfica Grote, 1300 (Prodenia). prægracilis Grote, 1993. pragrandaria Guenée, 3913. pramaturella Clemens, 6088. præpilata Grote, 2547. præses Grote, 2031. præstans Hy. Edwards, 4240. prasina Fabricius, 1415. pratana Hübner, 5409. pratella Hübner, 4571. pratensis Behr, 191 (Phyciodes). pratensis Scudder, 195 (Phyciodes). pratincola Boisduval, 510. pravella Grote, 4746. pravinominella Chambers, 5746. praxialis Druce, 4316. precationis Guenée, 2488.

Prenes

pressa Grote, 1418.

pretiosa Lintner, 2893.

pretoria Boisduval, 201.

prima Smith, 1100 (Anorthodes).

260 prima Slosson, 853 (Estigmene). 
prima Smith, 2059 (Perigrapha).

primaria Eversman, 3259.

primariana Walker, 5029.

primordialis Zeller, 4275 .

primulana Walsingham, 5095.

princeps Walker, 728.

princetonia Poling, 29.

principalis Walker, 4636 (Dicymo-

lomia).

principalis Lederer, 4312 (Hygro-

pia).

prini Smith \& Abbot, 719.

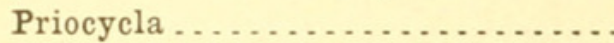

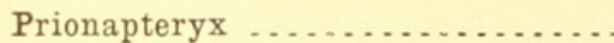

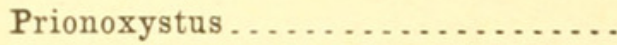

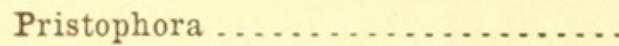

privatus Walker, 1753.

proba Hy. Edwards, 865 .

Probole ........................

proceralis Lederer, 4450.

Procherodes.

procinctus Grote, 1884.

proctivis Morrison, 1528.

procris Edwards, 475.

Prodenia ......................

prodenialis Walker, 4816.

prodeniformis Smith, 1791.

prodeuns Walker, 1998.

proditata Walker, 3699.

Prodoxus ......................

productata Packard, 3548.

profecta Grote, 3069.

profugaria Herrich-Schaeffer, 3617.

profundalis Packard, 4402.

profundus Smith, 1756.

progne Cramer, 214.

progressata Walker, 3417 .

prolatella Grote, 4628.

Proleucoptera ...................

Prolimacodes ..................

promethia Drury, 744.

promptana Robinson, 5441.

promptella Walker, 2571.

promulsa Morrison, 1915.

Promylea

Pronoctua

Pronuba.

propera Grote, 2611.

propertius Lintner, 629.

Propexus ..

propingua Walsingham, 6591 (Anaphora).
Page.

propinqua Smith, 2141 (Copicucullia).

propinqualis Möschler, 4278 (Desmia).

propinqualis Guenée, 2568 (Rivula). propinquilinea Grote, 961.

proprialis Fernald, 4496.

propriaria Walker, 3956 (Eu-

chlæna).

propriaria Walker, 3332 (Euchoea) .

propriella Walker, 4849.

proprius Hy. Edwards, 2394.

propugnaria Treitschke, 3438 .

propugnata Denis \& Schiffermüller, 3438.

propulsa Walker, 1789.

propulsata Walker, 3350.

promupta Grote, 2396.

proserpina Edwards, 237 (Basilarchia).

proserpina Scudider, 248 (Chlorippe).

proserpina Fabricius, 757 (Hemileuca).

proserpinella Frey \& Boll, 5653.

Prosoparia . . . . . . . . . . . . . prosopis Hy. Edwards, 4231.

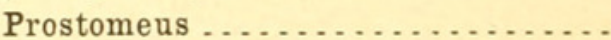

504

proteella Dyar, 3084.

Proteides .......................

Proteopteryx . . . . . . . . . . . . .

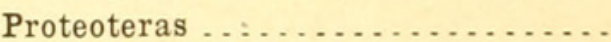

proterpia Fabricius, 80.

proteus Linnæus, 577.

Prothymia . . . . . . . . . . . . .

protillus Herrich-Schaeffer, 579.

protodice Boisduval \& Le Conte, 37.

protumnusalis Walker, 3023.

proxanthata Walker, 3738.

proxima Guerin-Méneville, 885

(Apantesis).

proxima Morrison, 1133 (Perigea).

421

proxima Hy. Edwards, 4217 (Sesia).

136

577

proximalis Fernald, 4394.

prudens Clemens, 5606.

prunatum Linnæus, 3352.

pruni Harris, 1002.

pruniella Clemens, 5693 (Anarsia). pruniella Clemens, 6034 (Coieophora). 
pruniella Clemens, 6145 (Coptodisca).

prunifoliella Chambers, 5593

(Evippe).

prunifoliella Clemens, 6213 (Nepticula).

pruniosella Chambers, 6441. pruniramiella Clemens, 6476.

prunivora Walsh, 5269.

prunivorella Chambers, 6387.

pryeri Butler, 736.

Pryocycla

psammitis Zeller, 5479.

Psaphidia

Psecadia

Psednothrix

pseudacaciella Fitch, 6267.

Pseudacontia .................

Pseudalypia ..............

Pseudanaphora ...................

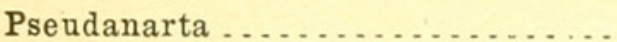

Pseudanthœcia .

Pseudanthrœcia

pseudargiolus Boisduval \& Le Conte, 440.

pseudargyria Guenée, 1954.

Pseudasopia

pseuderminea Peck, 851.

pseudoacaciella Chambers, 5759.

Pseudochelaria .................

Pseudoconchylis . . . . . . . . . . . .

pseudodorippus Strecker, 239.

pseudofea Morrison, 449.

Pseudogalleria ................ . .

pseudogamma Grote, 2492.

Pseudoglæa

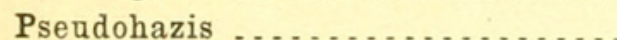

Pseudolimacodes .............

Pseudomya .................

pseudoneustria Boisduval, 3218.

Pseudopigritia . . . . . . . . . . . .

pseudoptiletes Boisduval \& Le Conte, 447.

Pseudorgyia . . . . . . . . . . . .

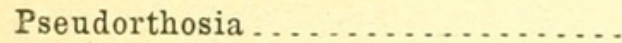

Pseudoschœnobius ...........

Pseudosiona ..............

Pseudosphinx ...............

pseudospretella Stainton, 5926.

Pseudotamila ................ .

Pseudothyatira ..................

psidii Sallé, 3204.

psilogrammaria Zeller, 3552.

$4630-$ No. $52-02$
Page.

psoraliella Walsingham, 5865.

psyche Boisduval \& Le Conte, 330.

psychialis Hulst, 4266.

Psychidæ .......................

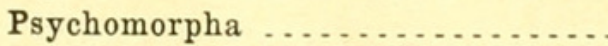

Psychophora ..............

psychotriella Busck, 6430.

Psysostegania................. ptelearia Riley, 3519.

ptelixella Chambers, 6214.

Pterætholix

352

194

287

305

pteridis $\mathrm{Hy}$. Edwards, 865.

pterodactyla Hübner, 4981 (Pterophorus).

pterodactyla Linnæus, 4992 (Stenoptilia).

Pterolonche.

187

Pterophoridæ

491

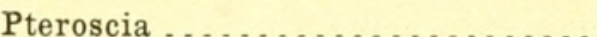

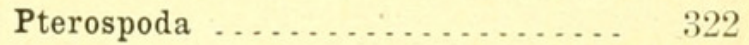

Pterotæa .....................

ptilodactyla Hübner, 4992 (Stenoptilia).

Ptilodon.

ptilodonta Grote, 1948.

Ptychoglene

ptychogrammos Zeller, 5309.

Ptychopoda ....................

Ptychopseustis puber Grote \& Robinson, 4005.

pudendana Herrich-Schaeffer, 5003. pudens Guenée, 3180 (Euthyatira). pudens Hy. Edwards, 912 (Pygaretia).

pudibundana Zeller, 5576.

pudibundella Ragonot, 4761.

pudica Hy. Edwards, 335.

pudorata Morrison, 1014 (Apatela). pudorata Smith, 1353 (Oncocnemis).

puella Smith, 2081.

puer Hübner, 472.

puera Fabricius, 2742.

pueritis Grote, 2001.

pugionis Smith, 1584.

pulchella Walker, 4622 (Argyria).

pulchella Chambers, 6377 (Graci-

laria).

pulchella Boisduval, 191 (Phyciodes).

pulchella Harvey, 2052 (Stretchia). 
pulchella Smith, 2200 (Xanthia). pulchella Smith, 1897 (Xylomiges). pulchellana Stephens, 5423 (Eulia). pulchellana Clemens, 5218 (Proteopteryx).

pulchellus Zeller, 4565 (Crambus). pulcher Grote, 6608 .

pulcherrima Grote, 2550.

pulcherrimana Walsingham, 5329. pulcherrimella Chambers, 6072. pulchra Strecker, 308 (Anosia). pulchra Dyar, 790 (Lycomorpha) pulchraria Minot, 3780. pulchripennis Grote, 2402. pulchripictalis Hampson, 4414. pulla Hy. Edwards, 279. pullana Eversman, 5228. pullata Grote, 2144.

pullatella Ragonot, 4801. pullifimbriella Clemens, 5822 . pullusella Chambers, 5823 . pulmonarium Grote, 3833. pultaria Guenée, 3911. pulvella Chambers, 6060.1 (Batrachetra).

pulvella Chambers, 6442 (Tischeria).

pulveralis Warren, 4477 .

pulveraria Linnæus, 3898 (Anagoga).

pulveraria Hulst, 3634 (Deilinia). pulveratana Walsingham, 5122. pulverea Grote \& Robinson, 3136

(Heterocampa).

pulverea Smith, 2462 (Narthecophora).

pulverilinea Grote, 2965.

pulverina Neumoegen, 815.

pulverosa Walker, 2966.

pulverosalis Smith, 3047.

pulverosana Walker, 5310.

pulverulenta Smith, 1809 (Mamestra).

pulverulenta Smith, 1126 (Perigea). pulverulenta Alpheraky, 860 (Phragmatobia).

pulverulenta Smith, 1265 (Polia). pulverulenta Felder, 613 (Systassea).

pulverulentus Riley, 6570 (Prodoxus). pulvipennella Clemens, 5858. pumila Boisduval \& Le Conte, 320 . pumilella Ragonot, 4750.
Page.

pumilio Zeller, 4991. munctana Hübner, 3083. punctanum Walsingham, 5019. punctata Edwards, 199 (Anthanassa).

punctata Walker, 3127 (Dasylophia).

punctata Packard, 865 (Diacrisia). punctata Fitch, 855 (Hyphantria). punctata Hulst, 3904 (Therina).

punctatissima Neumoegen, 778

(Basilona).

punctatissima Smith \& Abbot, 855

(Hyphantria).

punctella Grote \& Robinson, 538. puncticostana Walker, 5063. punctidactyla Haworth, 4937. punctidiscellus Clemens, 5679. punctifera Walker, 1122.

punctiferella Walsingham, 6556 (Adela).

punctiferella Clemens, 5824 (Gelechia).

punctiferella Walsingham, 6483 (Incurvaria).

punctiformis Smith, 3039. punctigera Walker, 1601. punctilimbella Ragonot, 4926. punctipennella Clemens, 5675. punctipennis Grote, 2729. punctipes Curtis, 3444. punctirena Smith, 2218. punctistriga Walker, 3207. punctivena Smith, 2968 (Capnodes). punctivena Smith, 1107 (Caradrina). punctofimbriata Packard, 3539. punctolineata Packard, 3650. punctomacularia Hulst, 3778. pungens Eschscholtz, 699. puntagorda Slosson, 3127. pupillaris Grote, 3035. pupula Hübner, 4474. pura Butler, 4108 (Carama). pura Hulst, 2846 (Catocala). pura Neumoegen, 924 (Halisidota). pura Butler, 837 (Utetheisa). puraria Walker, 3491. purata Guenée, 3498. purgata Walker, 2758. puricostella Ragonot, 4924. purinosella Chambers, 6441. puritana Robinson, 5348. purpura Walker, 6557. 
purpurana Clemens, 5357.

purpurascens Hy. Edwards, 110

(Argynnis).

purpurascens Walker, 2467 (Calpe). purpurascens Hulst, 3522 (Eois). purpurascens Packard, 6604 (Sthenopis).

purpurea Grote, 2219.

purpurella Dietz, 5939 (Pigritia). purpurella Hulst, 4772 (Salebria). purpureofusca Walsingham, 5660. purpuriciliana Walsingham, 5224. purpuriella Chambers, 6133 (Chrysopeleia).

purpuriella Chambers, 6362 (Gracilaria).

purpurifascia Grote \& Robinson, 2178.

purpurigera Walker, 2469.

purpuripennis Grote, 2160.

purpurissata Grote, 3485 (Cosymbia).

purpurissata Grote, 1775 (Mamestra).

purpurocomella Clemens, 5976.

pusilla Frey \& Boll, 6089.

pusillifoliella Frey \& Boll, 6286.

pusionellus Zeller, 4578.

pussillalis Hübner, 4623.

pustularia Hübner, 3709 (Cymatophora).

pustularia Guenée, 3618 (Psysostegania).

pustularia Hy. Edwards, 3417 (Triphosa).

pustulata Hy. Edwards, 2589 (Annaphila).

pustulata Walker, 4049 (Celama). pustulata Packard, 941 (Phegoptera).

pustuliferalis Lederer, 4338.

puta Grote \& Robinson, 2201.

putnami Grote, 2479 (Euchalcia). putnami Hy. Edwards, 350 (Thecla). putrescens Guenée, 2986.

Pyctis.

\section{Pygarctia}

pygmxa Grote \& Robinson, 4086 (Adoneta).

pygmæa Grote, 3057 (Dircetis). pygmæa Hübner, 2547 (Pæctes). pygmxella Hübner, 6467 (Argyresthia).
Page.

pygmaella Ragonot, 4717 (Pinipestis).

pygmaus Walsingham, 4929.

pygmeolaria Grote, 3818.

Pygoctnucha ................

Pyla . . . . . . . . . . . . . . . .

pylades Scudder, 601.

Pyralidæ

pyralidiformis Walker, 4250.

Pyralinæ

398

Pyralis . . . . . . . . . . . . . . .

pyralis Smith, 1047 (Apharetra).

pyralis Hübner, 2676 (Pleonectyptera).

pyraloides Strecker, 2331.

pyramidalis Walker, 4197.

pyramidoides Guenée, 1295.

pyramus Boisduval, 656.

pyramusalis Walker, 3054 .

Pyrausta ......................

Pyraustinæ .....................

pyri Harris, 4224.

pyricolana Murtfeldt, 5234.

pyrifoliana Clemens, 5237.

pyrina Linnæus, 4141.

Pyrisita . . . . . . . . . . . . . .

pyrolaria Guenée, 3816.

Pyromorpha. . . . . . . . . . . .

Pyromorphidæ ..............

pyrophiloides Harvey, 1498.

pyrrha Druce, 3172.

Pyrrharctia ................. . . 86

Pyrrhia ... . . . . . . . . . . . . . 177

Pyrrhopyga............... 47

pyrrhoura Hulst, 902.

pythion Druce, 967.

python Edwards, 552.

pyxidifera Smith \& Abbot, 4111.

quadragintapunctata Dyar, 5517.

quadrannulata Morrison, 1841.

quadranotata Strecker, 893.

quadraquina Scudder, 484.

quadraria Grote, 3635.

quadrata Grote, 1000 (A patela).

quadratalis Walker, 4327.

quadratella Zetterstedt, 4510.

quadrianmulata Walker, 3480.

quadricornis Harris, 721.

quadricristatella Chambers, 6134.

quadridentata Grote \& Robinson, 1574. 
quadrifasciana Fernald, 5419.

quadrifasciaria Packard, 3622.

quadrifera Zeller, 2645.

quadrifidum Zeller, 5024.

quadrifilaris Hübner, 2928.

quadriguttalis Hübner, 949.

quadriguttatus Grote, 6605.

quadrilinearia Packard, 3706.

quadrilineata Packard, 3497 (Cin-

glis).

quadrilineata Grote, 1835 (Mamestra).

quadrilineata Grote \& Robinson,

773 (Syssphinx).

quadrilineella Chambers, 6039

(Coleophora).

quadrilineella Chambers, 6073 (Cos-

mopteryx).

quadrilunata Grote, 1933.

quadrimaculella Chambers, 5702

(Anacampsis).

quadrimaculella Chambers, 5746,

(Gelechia).

quadrimaculella Chambers, 5927

(Oecophora).

quadrinotata Walker, 3262 (Hetero-

phleps) .

quadrinotata Herrich - Schaeffer,

3682 (Macaria).

quadriplaga Walker, 2532 (Syn-

grapha).

quadriplaga Smith, 2677 (Tarache). quadripunctana Haworth, 5409.

quadripunctaria Morrison, 3604.

quadripunctata Packard, 3419.

quadripunctella Clemens, 6395 (Or-

nix).

quadripunctellus Dyar, 6583 ( Нypo-

clopus).

quadrisignata Walker, 3679 (Maca-

ria).

quadrisignate Walker, 3647 (Scia-

graphia).

quadristigma Smith, 2008.

quadristigmalis Guenée, 4321.

quadristrigalis Fernald, 4399.

quadristrigella Zeller, 6468 (Argy-

resthia).

quadristrigella Chambers, 6231

(Opostega).

quxsita Grote, 1250.

quxsitata Hulst, 3542.

quantulella Hulst, 4884.

quarta Grote, 1414.
Page.

quebecensis Smith, 1445. quehtala Reakirt, 201.

quenselii Paykull, 883.

quercana Fernald, 5337.

querceti Herrich-Schaeffer, 4077.

querci Hy. Edwards, 4230.

quercialbella Fitch, 6259.

quercibella Chambers, 6259.

quercicastanella Chambers, 6215.

quercicella Clemens, 5851 (Crypto-

lechia).

quercicellus Chambers, 5688 ( Y pso-

lophus).

quercicola Herrich-Schaeffer, 4077.

quercicolella Chambers, 6469 (Argy-

resthia).

quercicolella Ragonot, 4754 (Sa-

lebria).

querciella Clemens, 6040 (Coleo-

phora).

querciella Chambers, 5559 (Tel-

phusa).

querciella Chambers, 5688 ( Y psolo-

phus).

quercifoliana Fitch, 5399.

quercifoliella Chambers, 5755 (Ge-

lechia).

quercifoliella Fitch, 6253 (Lithocol-

letes).

quercifoliella Chambers, 6393 (Or-

nix).

quercinigracella Chambers, 5557.

quercinigrxella Chambers, 5557.

querciperda Fitch, 4148.

quercipomonella Chambers, 5678.

quercipulchella Chambers, 6259.

quercipulchrella Riley, 6259 (Litho-

colletes).

quercipulchrella Chambers, 6216

(Nepticula).

quercitella Clemens, 6435.

quercitorum Frey \& Boll, 6253.

quercivoraria Smith \& Abbot, 3986.

quercivorella Chambers, 6296 (Li-

thocolletes).

quercivorella Chambers, 5602 (Re-

curvaria).

quercivorella Chambers, 6435 (Tis-

cheria).

quercus Boisduval, 928 (Hemihya-

lea).

quercus Ehrman, 4147 (Prionox-

ystus).

quercus Hy. Edwards, 4230 (Sesia). 
quernaria Smith \& Abbot, 3873 . querquera Grote, 2109.

questionis Treitschke, 2486.

quieta Hübner, 1942.

quietalis Walker, 4305.

quinaria Grote, 834.

quinella Zeller, 5715.

quino Behr, 154.

quinquareatus Zeller, 4558.

quinquaria Hübner, 3695.

quinqueannulella Chambers, 5606.

quinquecaudata Ridings, 4172.

quinquecristatella Chambers, 6127

(Stilbosis).

quinquecristatella Chambers, 5555

(Telphusa).

quinquefasciata Packard, 3387.

quinqueferella Walsingham, 5512.

quinquelinea Dyar, 3166 (Gluphisia) .

quinquelinea Smith, 1680 (Paragrotis).

quinquelinealis Grote, 4419.

quinquelinearia Packard, 3795 (Alcis).

quinquelinearia Packard, 3510 (Lep-

tomeris).

quinquemaculana Robinson, 5080.

quinquemaculata Haworth, 696.

quinquenotella Chambers, 6247 (Buc-

culatrix).

quinquenotella Chambers, 6356 (Gracilaria).

quinquenotella Chambers, 6300

(Lithocolletes).

quinquepunctatus Haworth, 5500.

quinquepunctella Busck, 5591 (Aris-

totelia).

quinquepunctella Chambers, 6564

(Prodoxus).

quinquepunctella Grote, 4759 (Sale-

bria) .

quinquestrigella Chambers, 6398.

quintana Zeller, 5080.

quisquiliella Zeller, 5977.

rachel Bruce, 657.

Rachela

rachelæ Hulst, 3876.

Racheospila.

radcliffei Harvey, 999.

radians Walker, 895.

radiatana Walsingham, 5163.

radiatella Donovan, 5500.
Page.

radiatus Haworth, 5500 (Cerostoma).

radiatus Strecker, 13 (Papilio).

radiatus Smith, 1444 (Setagrotis).

radicana Walsingham, 5113.

radicicolana Walsingham, 5292.

radiosalis Möschler, 4405.

radiosaria Hulst, 3996.

radix Walker, 1793.

ragonoti Walsingham, 5160.

Ragonotia .

rainierii Smith, 1868.

ralla Grote \& Robinson, 2221.

ramburialis Duponchel, 4377.

ramentalis Lederer, 4291.

ramosana Hübner, 3083.

ramosula Guenée, 1291.

Ramphodes ................. . . .

ranalis Guenée, 4302.

Rancora..................... . .

randiella Busck, 6399.

rantalis Guenée, 4354.

ranunculi Hy. Edwards, 2417.

rapæ Linnæus, 40.

Raphia . . . . . . . . . . . . .

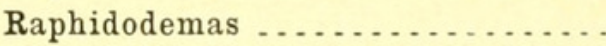

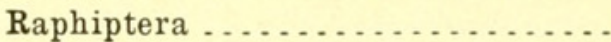

rasitis Morrison, 1141.

rata $\mathrm{Hy}$. Edwards, 4120.

ratzeburgiana Saxesen, 5233.

rauterbergi Skinner, 579.

rava Herrich-Schaeffer, 1488.

raveocostaliata Packard, 2319.

Reabotis

reakirtii Edwards, 49.

reciprocata Walker, 3332.

reconditalis Walker, 4377 (Diasema). reconditalis Walker, 4503 (Diathrausta).

reconditaria Walker, 3486 .

rectangula Kirby, 2505.

rectangulata Ottolengui, 3175 (Habrosyne).

rectangulata Fabricius, 3387 (Hydriomena).

rectaria Grote, 3599 (Anaplodes).

rectarius Dyar, 4116 (Acoloithus).

recticincta Smith, 1673.

rectifascia Grote, 2267 (Atethmia). rectifascia Smith, 2070 (Cleoceris). rectifascia Hulst, 3720 (Cymatophora).

rectilinea French, 879 (Apantesis).
99

330

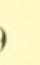

06


rectilinea Grote \& Robinson, 4095

(Cochlidion).

reclilinea Esper, 1280 (Hyppa). rectilinea Smith, 1832 (Mamestra) rectilinea Zeller, 4508 (Scoparia). rectiplicana Walsingham, 5118 . rectistrigella Ragonot, 4678. rectus Hy. Edwards, 6614. recula Harvey, 1571.

recurvalis Fabricius, 4276.

\section{Recurvaria}

recusans Walker, 2725.

redeella Chambers, 5678.

redimicula Morrison, 1737.

redtenbacheri Lederer, 4297.1.

reducta Neumoegen, 740 (Samia). reducta Grote, 847 (Turuptiana). reductalis Walker, 4299 . reductella Walker, 4744 . refecta Smith, 1368.

refectalis Hulst, 4608.

refectaria Walker, 3550.1.

reflata Grote, 3393.

reflexa Chambers, 5852.

reflexella Clemens, 5852.

refractaria Guenée, 3941.

refugalis Hulst, 4508.

refula Smith, 1702.

refulgens $\mathrm{Hy}_{y}$. Edwards, 4206.

refusana Walker, 5196.

refusata Walker, 3260.

refusella Chambers, 5709.

regalis Fabricius, 776 (Citheronia). regalis Walker, 5516 (Glyphipteryx).

regia Smith \& Abbot, 776 (Citheronia).

regia Boisduval, 423 (Philotes).

regia Strecker, 2318 (Porrima).

regina Smith, 1360.

regnatrix Grote, 4034 (Melanchroia).

regnatrix Grote, 2426 (Xanthopastis).

regulus Edwards, 539. relaxus Smith, 1644.

relecina Morrison, 1246.

relicta Walker, 2826.

reliqua Smith, 2030.

reliquana Hübner, 5005.

reluctalis Hulst, 4267.

Remigia.
Page.

remissa Hübner, 1217 (Hadena). remissa Hy. Edwards, 869 (Neoarctia). remissa Walker, 1117 (Perigea). remissaria Guenée, 4007. remota Smith, 1622. remotaria Walker, 3598. remotata Walker, 3350. rena Smith, 1706.

Renia .

reniculatis Zeller, 4271

reniculella Grote, 4712.

reniformis Grote, 1297 (Helotropha).

reniformis Smith, 2377 (Schinia).

renigera Stephens, 1829.

renunciata Walker, 3388.

repanda Fabricius, 2923 (Remigia). repanda Walker, 2918 (Siavana).

repandus Grote, 4614 (Thaumatopsis).

repentina Morrison, 1818 (Mamestra).

repentinus Clemens, 722 (Ceratomia).

repentis Grote \& Robinson, 1649

(Paragrotis).

repentis Grote, 2973 (Yrias).

repetitalis Grote, 4344.

repletalis Walker, 4454 .

repletaria Walker, 3530.

repressus Grote, 1296.

repugnata Walker, 3700 .

resedx Boisduval, 38.

residua Grote, 2820.

resistaria Herrich-Schaeffer, 3939.

resoluta Zeller, 4040 (Leucobrephos).

resoluta Smith, 1272 (Polia).

respersata Hulst, 3653.

resplendens $\mathrm{Hy}$. Edwards, 4199.

resplendensella Chambers, 6217.

restionalis Lederer, 4270.

restituens Walker, 3247.

restitutana Walker, 5383.

restorata Walker, 3651.

restrictalis Smith, 2414 (Heliodes). restrictalis Grote, 3044 (Renia).

restrictata Walker, 3487 .

resumens Walker, 1381.

resumptana Walker, 5215.

retana Walsingham, 5398.

retardata Walker, 1028. 
retecta Grote, 2815.

retectata Walker, 3673 .

retectella Zeller, 5978.

retentata Walk r, 3673 .

reticens Walker, 1649 .

reticulatana Clemens, 5335.

reticulatus Lintner, 4147 (Prionox-

ystus).

reticulatus Riley, 6568 (Prodoxus). reticulina Beutenmüller, 4137.

retinalis Lederer, 4279 .

retinana Walsingham, 5378.

\section{Retinia}

retinotata Walker, 3647 .

retis Grote, 2608.

retractaria Walker, 3647 .

retroversa Morrison, 1314.

reuda Strecker, 1700.

revayana Scopoli, 3083.

revellata Smith, 1013.

reversa Stretch, 839 .

reversalis Guenée, 4386.

reversata Dyar, 3019.

revicta Morrison, 2032.

revoccta Walker, 3881.

revoluta Walker, 2938.

Rhabdoides.

rhæa Boisduval, 421.

Rhagonis. . . . . . . . . . . . .

rhena Edwards, 554.

rhesus Edwards, 497.

Rheumaptera

rhexix Smith \& Abbot, 2296

rhinthonalis Walker, 4275.

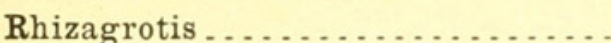

rhoda Butler, 895 (A pantesis).

rhoda Edwards, 273 (Erebia).

rhodarialis Walker, 2623.

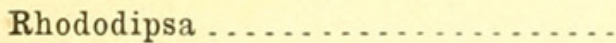

rhodope Edwards, 111.

Rhodophæa

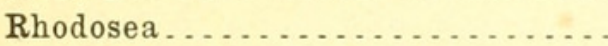

rhobus Boisduval, 692.

rhoifoliella Chambers, 6363.

rhoifructella Clemens, 5702.

rhombiferellum Frey \& Boll, 6400.

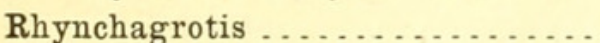

rhynchosix Dyar, 4978.

Rhyparia

rhypodella Hulst, 4735.

ribearia Fitch, 3690.

riberiaria Boisduval, 3352.
Page

ribesella Chambers, 5722(Gelechia).

ribesella Chambers, 6376 (Gra-

(cilaria).

ribis $\mathrm{Hy}$. Edwards, 754.

ricara Edwards, 646.

richardsoni Curtis, 1935.

richi Grote, 2458.

Richia

rickseckeri Behr, 851.

ridenda Hy. Edwards, 3166.

ridingsana Robinson, 5083.

ridingsella Clemens, 6558.

ridingsiana Grote, 1582.

ridingsii Grote, 947 (Alypia).

ridingsii Reakirt, 496 (Erynnis).

ridingsii Riley, 2628 (Exyra).

ridingsii Edwards, 277 (Neominois). rigida Smith, 1766 (Agrotiphila).

rigida Walker, 1942 (Anarta).

rigida Grote, 2174 (Papaipema).

rigidana Fernald, 4999.

rigidata Walker, 3386.

rilevaria Packard, 3615.

rileyana Grote, 5361 (Archips).

rileyana Harvey, 3222 (Heteropacha).

rileyana Smith, 1887 (Morrisonia).

rileyana Morrison, 1559 (Porosagrotis).

rileyana Hy. Edwards, 4201 (Sesia). rileyella Ragonot, 4877 (Ephestia). rileyella Chambers, 5769 (Gelechia). rileyella Chambers, 6254 (Lithocolletes).

rileyi Walsingham, 6059 (Batrachetra).

rileyi Frey \& Boll, 6248 (Bucculatrix).

rileyi Heylaerts, 4070 (Chalia).

riteyi Fernald, 4980 (Pterophorus). rimosa Grote, 1971 (Heliophila).

rimosa Packard, 3118 (Pheosia).

rimosalis Guenée, 4334.

Riodinidæ

riparia Morrison, 1339.

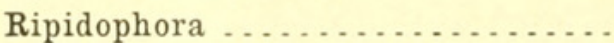

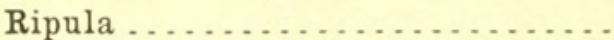

rithusaria Walker, 3698.

rivagana Fabricius, 3083.

rivata Duponchel, 3361.

rivellana Fabricius, 5060.

Rivula

rivulalis Hampson, 4311. 
rivulana Scopoli, 5060 .

rivularia Grote, 4030.

rivulosa Guenée, 2361.

robinix Hy. Edwards, 4177 (Memy-

thrus).

robinix Peck, 4147 (Prionoxystus). robinixfoliella Chambers, 5601.

robiniella Packard, 5882 (Depressaria).

robiniella Clemens, 6364 (Gracilaria).

robiniella Clemens, 6267 (Lithocolletes).

robiniella Fitch, 5601 (Recurvaria). robinsonana Grote, 5080.

robinsonii Grote, 2817 (Catocala).

robinsonii Butler, 734 (Cressonia).

robinsonii Grote, 4636 (Dicymo-

lomia).

robinsonii Boisduval, 901 (Lerina). robusta Strecker, 3107.

robustella Zeller, 4657.

robustior Smith, 1535.

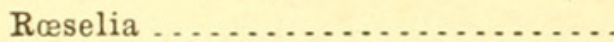

ressleri Zeller, 5170.

rogatalis Hulst, 4325 .

rogationis Guenée, 2487.

rogenhoferi Möschler, 1772.

rolandi Grote, 1375 .

rolandiana Grote, 2630.

rosa French, 834 (Eubaphe).

rosa Druce, 4461 (Pyrausta).

rosa Edwards, 43 (Synchloe).

rosa McNeill, 61 (Zerene).

rosaceana Harris, 5356.

rosacearum Boisduval, 732.

rosacella Clemens, 6041.

rosi Behr, 2988.

rosxfoliella Clemens, 6042 (Cole-

ophora).

rosafoliella Clemens, 6218 (Nep-

ticula).

rosalba Grote, 2624.

rosalinda Hy. Edwards, 2845.

rosana Linnæus, 5359 (Archips).

rosana Hübner, 5401 (Tortrix).

rosaria Grote, 1487 (Noctua).

rosaria Grote, 3927 (Plagodis).

rosasuffusella Chambers, 5575 .

roscipennella Treitschke, 6354.

rosea Beutenmüller, 3144 (Euhy-

parpax ).

rosea Walker, 3155 (Hyparpax).
Page.

rosea Harvey, 1803 (Mamestra). rosea Walker, 3226 (Oreta). rosea Smith, 2295 (Thyreion). roseata Walker, 934 (Aemilia). roseata Stretch, 3223 (Epicnaptera). roseatella Packard, 4911.

roseicapitis Neumoegen \& Dyar, 918. roseicaput Neumoegen \& Dyar, 6608. roseicosta Guenée, 2920. roseitincta Harvey, 2347. roseocostellus Walsingham, 5689. roseola Smith, 1986.

roseomaculana Herrich-Schaeffer, 5045.

roseopenella Hulst, 4903. roseopennalis Hulst, 4381. roseosuffusa Smith, 1867. roseosuffusella Clemens, 5575. roseotincta Hulst, 3508. roseotinctella Ragonot, 4922. roseticola Frey \& Boll, 6450. rossi Ross, 747 (Tropæa). rossii Curtis, 269 (Erebia). rossii Guenée, 75 (Eurymus). rossii Curtis, 3185 (Gynæphora). rostrana Walker, 5383. rostrella Ragonot, 4906.

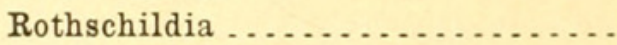

rotundalis Walker, 3016. rotundata Packard, 3252. rotundopennata Packard, 3544. rotundopuncta Packard, 3284. rotundopunctata Packard, 3284. roxburghii Gregson, 4890. rubefacta Morrison, 1806. rubefactalis Grote, 1657. mubens Hy. Edwards, 653. rubensella Chambers, 5578. rubescens Walsingham, 5709. rubescentella Hulst, 4699. rubi Riley, 4191 (Bembecia). rubi Hy. Edwards, 2989 (Homoptera).

rubicunda Fabricius, 771 (Anisota). rubicunda Walker, 2716 (Euherrichia).

rubicunda Hy. Edwards, 157 (Lemonias).

rubicundaria Hübner, 834.

rubidana Walker, 4533.

rubidella Clemens, 5578.

rubidus Ottolengui, 2494 (Autographa). 
rubidus Behr, 402 (Chalceria).

rubifera Grote, 1485.

mbifoliella Clemens, 6219.

mubigalis Guenée, 4401.

mubiginella Walker, 4778.

rubiginosa Walker, 1144 (Oligia).

rubiginosa Strecker, 2348 (Schi-

nia).

rubiginosus Morrison, 3814 (Tor-

nos).

rubivora Riley, 3578.

rubivoraria Packard, 3578.

rutra Neumoegen, 864 (Diacrisia).

rubra Behr, 742 (Samia).

rubralis Warren, 4389.

rubrella Dyar, 5501.

rubrescens Hulst, 4197 (Albuna).

rubrescens Walker, 2042 (Graphi-

phora).

rubribasella Hulst, 4809.

rubrica Harvey, 1895.

rubricalis Hübner, 4451.

rubricata Edwards, 302.

rubricoma Guenée, 971.

rubricosa Harris, 860.

mubricosta Ehrman, 832 (Eubaphe). rubricosta Guenée, 2920 (Panapo-

da).

rubrifasciella Packard, 4692.

rubrifrontaria Packard, 3589 (Aplo-

des).

rubrifrontaria Packard, 3583 (Syn-

chlora).

rubripallens Smith, 1960.

r:bripalpis Felder, 3207.

rubripennis Grote \& Robinson, 1962

(Heliophila).

rubripennis Neumoegen \& Dyar,

3123 (Nadata).

rubrisparsella Ragonot, 4738.

rubristigma Kellicott, 4229.

rubrofascia Hy. Edwards, 4212.

rubrolinearia Packard, 3512.

rubrolineata Packard, 3512 (Lepto-

meris).

mebrolineata Packard, 3571 (Racheospila).

rubromarginaria Packard, 3594 ( An-

aplodes).

mibromarginaria Packard, 3494

(Xystrota).

rubromarginata Packard, 3494.

rubropicta Packard, 828.
Page.

rubroscapus Ménétries, 797.

rubrosuffusa Grote, 2967.

rubrosuffusata Packard, 3365.

rubrotincta Hulst, 3914 (Slossonia).

rubrotincta Hulst, 3495 (Wauchula).

rudana Walsingham, 5346.

rude $\mathrm{Hy}$. Edwards, 4088

rudens Harvey, 1470.

ruderella Ragonot, 4791 (Epischnia).

ruderella Zeller, 6551 (Setomorpha). ruderella Chambers, 5678 (Ypsolophus).

rufa Haworth, 4879 (Ephestia).

rufa Grote, 3062 (Salia)

rufago Hübner, 2202.

rufaria Grote, 3849.

mijescens Boisduval, 409 (Cupido). rufescens Hulst, 3534 (Eois).

rufibasella Ragonot, 4738.

ruficaudis Kirby, 656.

ruficiliata Guenée, 3371.

ruficornis Hy. Edwards, 4252.

rufifimbrialis Grote, 4450.

rufilineata Walker, 3490.

rufimargo Hübner, 2920.

rufimedia Grote, 2371.

rufimitrellus Stephens, 5500.

rufinalis Walker, 4598 (Crambus).

rufinalis Walker, 4778 (Elasmopal-

pus).

rufipectus Morrison, 1390.

rufipennis Grote, 1556.

mufisignèlla Zeller, 4623.

rufocristatella Chambers, 6165.

rufoluteela Chambers, 6003.

rufostrigata Packard, 1107.

rufula Boisduval, 865 (Diacrisia).

rufula Grote, 2014 (Graphiphora).

rufula Smith, 1702 (Paragrotis).

rufusella Chambers, 5709.

rugifrons Grote, 2448.

rugosa Morrison, 1821.

runata Smith, 1185.

runcinaria Strecker, 3894.

rupestris Behr, 122.

rupta $\mathrm{Hy}$. Edwards, 3167.

ruptalis Walker, 4281.

ruptifasciatus Plotz, 615.

ruptostrigella Beutenmüller, 6361.

ruralis Boisduval, 486.

rurea Edwards, 529.

ruricola Boisduval, 486. 
ruricolellus Zeller, 4587

rurigena Grote, 3054.

russaria Herrich-Schaeffer, 3379.

mussata Hulst, 3521 (Eois).

russata Denis \& Schiffenmüller, 3379

(Mesoleuca).

russatella Clemens, 6484.

russea Hy. Edwards, 2492.

russula Grote, 2570.

rustica Edwards, 426 (Agriades).

mustica Fabricius, 698 (Phiegethontius).

rustica Sepp, 685 (Pseudosphinx). rusticella Hübner, 6489.

Rusticus . . . . . . . . . . . . . rusticus Edwards, 209 (Polygonia). rusticus Walsingham, 5692 (Ypsolophus).

rutila Walker, 2486 (Autographa). rutila Guenée, 2190 (Papaipema). rutilana Hübner, 5439.

rutilans Hy. Edwards, 4203.

rutulus Boisduval, 10.

sabalella Chambers, 6169.1.

sabalis Walker, 4299.

sabesaria Grote, 3887.

sabinaria Packard, 3443.

sabinii Curtis, 3443.

sabularia Guenée, 3671.

sabulella Walsingham, 5876 (Depressaria).

sabulella Walsingham, 5547 (Paltodora).

sabuleti Boisduval, 525.

sabulifera Walker, 4628.

sabulinus Butler, 4807.

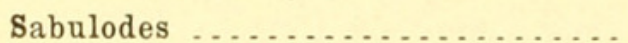
sabulosa Hy. Edwards, 2750 (Cissura).

sabulosa Boisduval, 942 (Misa).

saccatella Packard, 6145.

saccharalis Fabricius, 4624.

sackeni Grote, 2528.

sacrementi Grote \& Robinson, 952.

sadalus Lucas, 19.

sangeri Neumoegen, 776.

sxpiolus Boisduval, 409.

sxpium Boisduval, 354.

saga Kaden, 140 (Brenthis).

saga Fabricius, 2742 (Hyblæa).

saganella Hulst, 4892.

Sagaritis . . . . . . . . . . . . .

saginella Clemens, 6220.
Page.

sagittalba Ottolengui, 2442.

sagittana Walker, 5165.

sagittarius Grote, 1758.

sagittigera Felder, 421.

sagralis Druce, 4304.

Salebria . . . . . . . . . . . . . . .

424

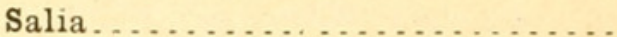

salicalis Fabricius, 3061.

salicarum Walker, 1437.

salicella Chambers, 6403.

saliciana Clemens, 5226.

salicicolana Clemens, 5225.

saliciella Chambers, 6144.

salicifoliella Chambers, 6365 (Gra-

cilaria) .

salicifoliella Chambers, 6333 (Litho-

colletes).

salicifungella Clemens, 5579.

salicipomonella Clemens, 6060.

salicis Hy. Edwards, 2594 (Anna-

phila).

salicis Harris, 1041 (A patela).

salicis Boisduval, 922 (Halisidota). salicis Behr, 2993 (Homoptera).

salicis Smith, 3061 (Salia).

salictella Clemens, 6403.

saligna Zeller, 3062.

saligneana Clemens, 5139.

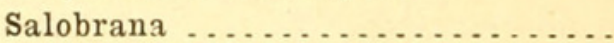

salona Hewitson, 366.

saltitans Westwood, 5297.

saltuellus Zeller, 4575.

saltusaria Hulst, 3575.

Saluda

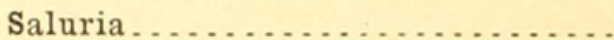

salusalis Walker, 3041.

salutalis Hulst, 4272.

sambuci Behr, 2260.

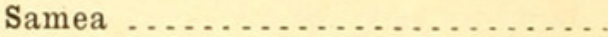

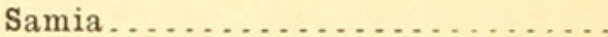

samosel Scudder, 463.

sanbornana Robinson, 5364.

samborni Packard, 4115 (Acoloithus).

sanborni Hy. Edwards, 4251 (Sesia). sancta Hy. Edwards, 982 (A patela). sancta Hulst, 2894 (Catocala).

sancta Neumoegen \& Dyar, 4122

(Triprocris).

sangaris Strecker, 6615.

sanguinaria Strecker, 794. sanguinea Geyer, 2319 (Porrima). 
sanguinella Busck, 5861 (Depressaria).

sanguinella Beutenmüller, 6368 (Gracilaria) .

sanguineola Boisduval, 827.

sanguirenosa Neumoegen, 934.

saniaria Hübner, 3468.

saniptri Strecker, 708 .

Sannina

Sanninoidea

sansar Strecker, 1274.

sapharinella Chambers, 5634.

saphirinella Chambers, 5634.

saporis Grote, 2315.

sappho Strecker, 2807.

sapygxformis Walker, 4248.

sara French, 2839 (Catocala).

sara Boisduval, 49 (Synchloe).

Sarasota

Sarata

sarita Skinner, 363.

sartana Hübner, 5470.

sassacus Harris, 488.

sassafrasella Chambers, 6567.

satanaria Guenée, 3875.

satiens Smith, 1555.

satina Strecker, 1191.

satis Harvey, 1705.

satrapellus Zincken, 4557.

saturata Barnes, 3127 (Dasylophia). saturata Grote, 2348 (Schinia).

saturnalis Treitschke, 4280.

Saturnia

saturniata Guenée, 4010.

Saturniidæ

Saturnoidea

saturnus Strecker, 2035.

satyricus Grote, 1762.

satyriniformis Hübner, 4162.

Satyrium

Satyrodes.

satyrus Edwards, 207.

sauberi Hedemann, 4635.

saucia Hübner, 1467.

saundersella Chambers, 5612 (Epi-

thectis).

saundersella Chambers, 6402 (Leu-

canthiza).

saundersiana Grote, 1333.

saundersii Grote, 878 (Apantesis).

saundersii Doubleday \& Hewitson,

201 (Chlosyne). saundersii Bethune, 2986 (Homoptera).

sauzxlitx Grote, 2195.

sauzalitoella Chambers, 6366.

savignyi Latreille, 576.

saxea Hy. Edwards, 2784.

saxicolana Walsingham, 5468.

saxifragie Hy. Edwards, 4215.

sayii Edwards, 2.

scabella Zeller, 5892.

scabra Fabricius, 3079.

scabrana Fabricius, 5299 (Acleris).

scabrana Schiffermüller, 5309 (Acle-

ris) .

scabriuscula Linnæus, 1290.

scalana Walsingham, 5188.

scandens Riley, 1620.

scandinavialis Guenée, 4392.

scapha Harris, 4092.

scapularis Strecker, 932 (Euschausia).

scapularis Hy. Edwards, 2477 (Plusia).

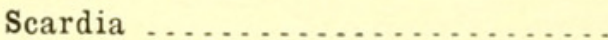

scardina Zeller, 6594.

scarletina Smith, 2392.

Scelidacantha ................. . .

268

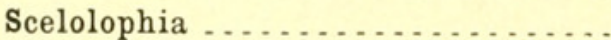

Scelorthus .......................

scepsiformis Graef, 909 (Euchetias). scepsiformis Hy. Edwards, 4180

(Memythrus).

Scepsis

schäfferi Plötz, 597.

schalleriana Linnæus, 5315.

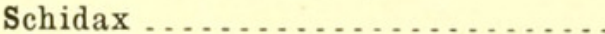

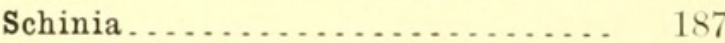

schisticolor Zeller, 4808.

Schizura .......................

schlegeri Zeller, 6558 ( Ac'ela). schlageri Zeller, 5834 (Stenoma). schonherri Zetterstedt, 1934.

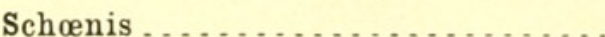

Schœnobinæ .................... 401

Schœnobius .................... . . 402

Schreckensteinia ............... . . 5 54

schulziana Fabricius, 5073.

schwarziella Busck, 5919.

schwarzii Smith, 2678.

schwarziorum Dyar, 819.

Sciagraphia . . . . . . . . . . . . . 
sciata Walker, 3911.

scintillana Clemens, 5079.

scintillans Grote, 2866 (Catocala). scintillans Grote, 4784 (Pyla).

scintillaria Hulst, 3520.

scirpana Herrich-Schaeffer, 5007.

scirpicola Guenée, 1976.

Scirpophaga .................

scissa Grote, 2323 (Caniciia).

scissa Walker, 2920 (Panapoda).

scissana Walker, 5434.

scitana Walker, 5270.

scitipennis Walker, 3111.

scitiscripta Walker, 3159.

scittivitalis Walker, 4807.

scitula Harris, 4225.

scitularia Walker, 3329.

scitulella Hulst, 4697.

sciurella Ragonot, 4852.

sciurus Boisduval, 905.

scobialis Grote, 3014.

scobiella (irote, 4730 .

\section{Scodiona}

Scolecocampa ...............

Scoliopteryx .................

scolopacirarius Guenée, 3814.

scolopendrina Boisduval, 3164.

Scoparia .

Scopariinæ

Scopelosoma

Scopolia .................

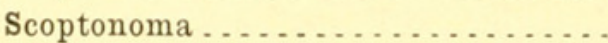

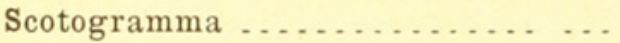

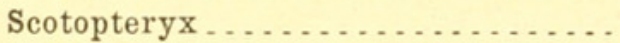

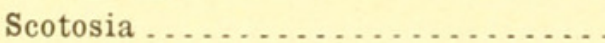

scribonia Stoll, 846.

scripta Giosse, 3173.

scriptana Hübner, 5035.

scriptaria Herrich-Schaeffer, 3270.

scriptipemnis Walker, 3008.

scriptura Boisduval, 648.

scropulana Morrison, 1434.

scropulosa Hy. Edwards, 2747.

scudderella Frey \& Boll, 6278.

scudderi Skinner, 495 (Erynnis).

scudderi Reakirt, 72 (Eurymus).

scudderi Packard, 900 (Parasemia). scudderi Edwards, 432 (Rusticus). scudderiana Clemens, 5139.

sculptilis Harvey, 1670.

sculptus Grote, 1753.

scurralis Hulst, 4447.

scutellarixella Chambers, 5639.
Page.

(5)

semialba Ehrman, 22.

semiaperta Morrison, 2060.

semiatra Smith, 1694.

semiatratum Hulst, 3353.

semiauratus Neumoegen \& Dyar, 6605.

semicana Walker, 1205.

semicirculana Fernald, 5405.1.

semicircularis Grote, 3181.

semiclarata Grote, 1547 (Feltia).

semiclarata Walker, 3606 (Orthofidonia).

semiclusiaria Walker, 3780 .

semicostata Zeller, 4995.

semicrocea Guenée, 2627.

semicyclionella Busck, 5625.

semidea Say, 295.
Page. 
semidiaphana Harris, 787. semifascia Smith, 1069 (Chytonix). semifascia Walker, 4082 (Monoleuca).

semiferana Walker, 5366. semiflava Guenée, 2633. semifuneralis Walker, 4832. semifuscana Clemens, 5:30. semifusellus Walker, 453. semilineata Walker, 2728. semilugens Zeller, 5907. semilunata Grote, 1252.1. semineale Walker, 4502. seminivealis Hulst, 2684. seminivella Walker, 4495. seminole Scudder, 501 (Erynnis). seminole Neumoegen, 4185 (Memythrus).

seminole Beutenmüller, 4237 (Sesia).

seminolella Beutenmüller, 6521. seminudaria Packard, 3909. seminudata Walker, 3909. semiobscurella Hulst, 4766. semiopaca Grote, 5908.

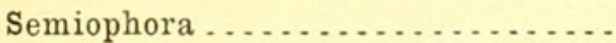

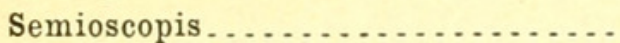
semiovana Zeller, 5243. semipectinata Hulst, 3465. semiplaga Walker, 3136. semipurpurea Walker, 2624. semiramis Edwards, 124. semirelicta Grote, 2847. semirubralis Packard, 4446. semirufescens Walker, 3150. semisigna Walker, 1145. semiusta Grote, 2099. semiustana Walker, 5390.

Semnopsyche. senatoria Fabricius, 768 (Anisota). senatoria Smith, 1864 (Mamestra).

Seneca

senecioides Hy. Edwards, 4199. senecionana Walsingham, 5347. senescens Zeller, 5305 (Acleris). senescens Grote, 1145 (Hillia). senex Walsingham, 5492. seniciella Busck, 5875. senicionella Busck, 5875. senilis Smith, 2169. sennx Linnæus, 52. sennettii Lintner, 845. sensilis Grote, 1068 .
Senta

senta Strecker, 65:3.

sentana Clemens, 5387.

sentinaria Hübner, 3511.

separans Grote, 1218.

separata Grote, 2341 (Schinia).

separatarium Grote, 3835.

separatus Neumoegen, 715(Sphinx).

seposita Hy. Edwards, 2786.

septemfluaria Grote, 3682.

septemlinearia Grote, 3682.

septempunctata Harvey, 2278.

septemstrigella Chambers, 6522.

septentrionalis Walker, 3166 (Gluphisia).

septentrionalis Hy. Edwards, 2408

(Melicleptria).

septentrionalis Tengström, 4359

(Pachyzancla).

septentrionalis Walker, 1649 (Paragrotis).

septentrionalis Möschler, 1557 (Porosagrotis).

septentrionalis Walker, 2364 (Schinia).

septentrionana Curtis, 5029.

septentrionella Walsingham, 6559.

sepulchralis Grote \& Robinson, 777

(Citheronia).

sepulchralis Boisduval, 4132 (Thyris).

sequax Haworth, 5762.

sequoix Boisduval, 709 (Sphinx).

sequoix Hy. Edwards, 4192 (Vespemima).

sequoiolus Behrens, 6612.

sera Grote \& Robinson, 2161.

serena Edwards, 2882.

seriata Druce, 3129.

seriatana Zeller, 5443.

sericarium Scott, 4878.

sericea Morrison, 2249.

sericeata Hulst, 3716 (Cymatophora).

sericeata Packard,3472(Euacidalia). sericeiferata Walker, 3245.

sericidactylus Murtfeldt, 4973.

sericinellus Zeller, 4580.

sericorana Walsingham, 5013.

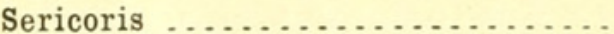

serinalis Walker, 4340.

serinaria Herrich-Schaeffer, 3927.

serotinxella Chambers, 6221. 
serotinella Busck, 5760.

serpentana Walsingham, 5161.

servata Drury, 3954 (Euchlæna).

serrata Grote, 2170 (Gortyna).

serrata Smith, 1946 (Trichopolia).

serrataria Packard, 3954.

serraticornis Lintner, 2134 (Euhar-

veya).

serraticornis Grote, 3037 (Philo-

metra).

serratilineella Ragonot, 4828.

serratipalpella Chambers, 5628.

serratissimalis Zeller, 4337.

serrativittella Zeller, 5657.

serricornis Smith, 1628.

serriradiellus Walker, 4541.

serrulata Packard, 3482.

servitus Smith, 1738.

servulella Clemens, 6540.

sescuplana Zeller, 5375.

Sesia

Sesiidæ......................

sesquialteralis Zeller, 4375.

sesquilinea Grote \& Robinson, 4005.

sesquilinearia Grote, 3967.

sesquistriatis Hübner, 4264.

sesquistriaris Hübner, 2922.

sessile Smith, 1643.

Setagrotis

Setiostoma

setosella Clemens, 5664.

severa Hy. Edwards, 3168.

sevorsa Grote, 2434.

sexatilis Grote, 1724.

sexfasciata Hy. Edwards, 4207.

sexguttata Harris, 1053.

sexmaculatis Grote, 4475.

sexmaculata Grote, 4046 (Celama).

sexmaculata Packard, 3647 (Scia-

graphia) .

sexnotella Chambers, 6282 (Litho-

colletes).

sexnotella Chambers, 6168 (Mompha).

sexplagiata Smith, 2331.

sexpunctata Grote, 2727 (Hyamia). sexpunctata Bates, 3648 (Scia-

graphia).

sexpunctella Walsingham, 6101.

sexseriata Grote, 2273.

sexsignata Harvey, 2913.

sexstrigella Chambers, 5649.

Page.

sexta Johanssen, 697.

shaleriella Chambers, 6043 (Coleophora).

shalleriella Chambers, 5928 (Oeco-

phora).

shasta Edwards, 430.

shastx Walsingham, 4943.

shastaella Beutenmüller, 6369.

shastaensis French, 888 (A pantesis). shastaensis Behr, 765 (Pseudohazis)

shastana Walsingham, 5109.

sheridanii Edwards, 382.

shisticolor Zeller, 4808.

shurtleffi Packard, 4101.

Siavana ...................

sibillalis Walker, 4322.

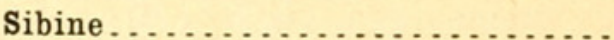

sicalis Walker, 4273.

siccaria Walker, 3909.

siccata Smith, 1566.

367

364

siculifer Packard, 3230.

Sicya ...................

sideraria Guenée, 3550.

sideroxylonella Busck, 6340.

sidus Guenée, 2242.

sierræ Harvey, 1495 (Noctua).

sierræ Hulst, 3291 (Tephroclystis).

Sigela

sigmaria Guenée, 3690.

sigmoides Guenée, 1422 (Eueretagrotis).

sigmoides Hy. Edwards, 4234 (Sesia).

signaria Walker, 3862.

signata Walker, 3127 (Dasylophia).

signata French, 2250 (Glæa).

signata Walker, 2060 (Tricholita).

signatalis Walker, 4461.1.

signatana Clemens, 5189.

signataria Walker, 3858 (Melanolophia).

signataria Walker, 3370 (Percnoptilota).

signifera Walker, 1302.

significans Hy. Edwards, 934.

significata Walker, 3153.

signipennella Hübner, 6354.

signosa Walker, 2094.

silaceata Hübner, 3381.

silago Hübner, 2199.

silens Grote, 1745.

silenus Edwards, 213 (Polygonia). 
silenus Doubleday, 335 (Uranotes). silphiella Grote, 5524.

silvius Edwards, 210.

simathis Drury, 363.

simalis Grote, 4476.

similaciella Chambers, 6426 .

similalis Guenée, 4354 (Loxostege). similalis Lederer, 4451 (Pyrausta). similana Clemens, 5144 (Eucosma). similana Hübner, 5143 (Eucosma). similaria Walker, 3497. similaris Smith, 2124 (Cucullia). similaris Hulst, 3394 (Hydriomena).

similata Hulst, 3680.

similiella Chambers, 5548.

similis Barnes, 1880 (Admetovis).

similis Strecker, 460 (Amblyscirtes).

similis Stretch, 944 (Androloma). similis Edwards, 2897 (Catocala). similis Walker, 3350 (Eustroma). similis Boisduval, 2925 (Grammodes).

similisana Walker, 5072.

simius Edwards, 465.

simplaria Graef, 3117 (Notodonta). simplaria Morrison, 1473 (Peridro-

ma).

simplex Guenée, 2519 (Autographa). simplex Walker, 812 (Comacla). simplex Warren, 4482 (Noctuelia). simplex Smith, 1343 (Oncocnemis). simplex Smith, 2334 (Schinia). simplex Walker, 1892 (Xylomiges). simpliciana Walsingham, 5317. simpliciaria Grote, 3984.

simpliciella Walsingham, 6560 (Adela).

simpliciella Chambers, 5825 (Gelechia).

simplicima Ottolengui, 2527.

simplicior Butler, 881.

simplicius Stoll, 578.

simulana Clemens, 5289.

simulans Grote, 4181.

simulata Hulst, 3680 (Macaria). simulatilis Grote, 2819 (Catocala). simulatilis Grote, 4331 (Evergestis). simulatricella Clemens, 6538. simulatus Walsingham, 6589 (Acrolophus).

sincera Zeller, 4527 (Oectoperia).
Page.

sincera Herrich-Schaeffer, 1420 (Platagrotis).

sinefascia Edwards, 238.

sineocellata Skinner, 273.

singula Grote, 1308.

singularis Neumoegen, 4666 (Dyaria).

singularis Lederer, 4435 (Pyrausta). singulella Walsingham, 6561.

sinon Fabricius, 6.

simualis Harvey, 2775.

simuata Packard, 3658.

sinuosa Grote, 2858.

Siparocera . . . . . . . . . . . . . .

siren Strecker, 2388

sirenaria Strecker, 3966.

siris Edwards, 521.

sirius Edwards, 402.

siriusalis Walker, 4354.

sistrella Busck, 5727.

sisymbri Boisduval, 34 .

Sisyrhypena ................

Sisyrosea . . . . . . . . . . . . .

sitellatr Guenée, 3439.

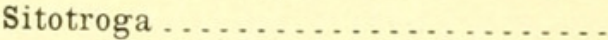

siva Edwards, 359.

skada Edwards, 469.

skinneri Barnes, 73.

slossonix Skinner, 501.

slossonella Hulst, 4764.

slossoni Hy. Edwards, 4149 (Inguromorpha).

Slossonia.

slossonia Fernald, 5534.

slossonix Packard, 4091 (Alarodia). slossonia Hulst, 3476 (Mycterophora).

slossonix Hulst, 4042 (Philagraula). slossonii Packard, 3168 (Gluphisia). slossonii Hulst, 4660 (Tetralopha). smaragdina Neumoegen, 1209. smeathmanniana Fabricius, 5435. smerdis Hewitson, 198.

Smerinthus

smilaciella Busck, 6408.

smilacis Boisduval \& Le Conte, 362. smintheus Doubleday \& Hewitson, 2. smithiana Walsingham, 5162. smithii Guenée, 2924 (Grammodes) smithii Dyar, 840 (Haploa). smithii Snellen, 1475 (Noctua). smithii Druce, 2442 (Trichocala). smithsonianus Clemens, 4123. 
Smyrna................... snellenella Walsingham, 5643. snoviana Grote, 2870.

snoviaria Packard, 3614 (Mellilla). snoviaria Hulst, 3900 (Neoterpes). snoviata Packard, 3659.

snowiEdwards, 503 (Anthomaster). snovi Grote, 893 (A pantesis).

snowi Hy. Edwards, 2529 (Autographa).

snowi Edwards, 401 (Chalceria). snowi Grote, 2294 (Thyreion).

Snowia.................. snowii Hy. Edwards, 4163 (Melittia).

snyderi Skinner, 117.

sobria Walker, 2467 (Calpe).

sobria Walker, 2754 (Drasteria).

sobria Walker, 3546 (Eois).

sobria Walker, 3143 (Misogada).

sobria Walker, 1950 (Nephelodes). sobrialis Walker, 3044.

sobrina Stretch, 930.

socia Behr, 2787.

socialis Grote, 4445 (Pyrausta).

socialis Feisthamel, 754 (Thauma).

sociata Borkhausen, 3361.

sociella Linnæus, 4636.6.

socius Butler \& Druce, 574.

sodalis Walker, 4520.

sofia Strecker, 274.

solamata Hulst, 3640.

solanella Boisduval, 5616.

solaniella Chambers, 5617.

Solenobia . . . . . . . . . . . . . . .

solenobiella Walsingham, 6485.

solfataria Guenée, 3902.

solictana Walker, 5127.

solida Ottolengui, 2484.

solidaginifoliella Clemens, 6440.

solidaginis Walsingham, 5858 (Depressaria).

solidaginis Frey \& Boll, 6298 (Lithocolletes).

solidaginis Behr, 2142 (Rancora). solidaginisella Chambers, 6298.

solitaria Walker, 3700 (Cymatophora).

solitaria Smith, 1717 (Paragrotis). solituda Hy. Edwards, 4168.

Somatolophia ................ sommeri Lefèbre, 1234.

somniaria Hulst, 3911.
Page.

somnus Dodge, 2836 (Catocala). somnus Lintner, 619 (Thanaos). somulatella Riley, 6337.

somulentella Zeller, 6337.

sonora Sicudder, 507.

sonor: Boisduval, 167.

sonorensis Felder, 316 (Chrysobia). sonorensis Felder, 422 (Phædrotes). sordida Grote, 2905 (Catocala). sordida Butler, 4358 (Loxostege). sordida Harris, 716 (Sphinx). sordida Grote, 2710 (Spragueia). sordidata Fabricius, 3387. sordidellus Zincken, 4542. sordidula Grote, 3070. sordidus Riley, 6571 (Prodoxus). sordidus Smith, 2350 (Schinia). sorghiella Riley, 4048. soror Smith, 1520. sororaria Herrich-Schaeffer, 3259. sororculella Dyar, 5525. sororiata Hübner, 3259. sororius Hy. Edwards, 763. sosybius Fabricius, 301. souhegan Whitney, 339. spadaceella Zincken, 4776. spadaria Guenée, 2572. spadicearia Denis \& Schiffermüller, 3458.

spadix Cramer, 2743 (Cissura). spadix Hy. Edwards, 351 (Thecla). Spanista. . . . . . . . . . . . .

Spargaloma ...............

Sparganothis ................ sparsaria Walker, 3552. sparsicella Chambers, 5844. sparsiciliella Clemens, 5844. sparsimacula Hulst, 3396. sparsipulvella Chambers, 6044. spartiella Bond, 4807.

spatiosaria Walker, 3862. specialis Grote, 1567. specifica Dyar, 3096. speciosa Möschler, 875 (A pantesis). speciosa Ottolengui, 2526 (Autographa).

speciosa Hulst, 3739.1 (Cymatophora).

speciosa Hulst, 3358 (Neolexia). speciosa Hulst, 3246 (Paleacrita). speciosa Hy. Edwards, 422 (Phædrotes).

speciosa Hübner, 1417 (Platagrotis). 
speciosa Morrison, 1263 (Polia). speciosa Walker, 836 (Utetheisa). speciosata Packard, 3392. speciosulla Hulst, 4651. speciosissima Grote \& Robinson, 2173.

spectanda Strecker, 2296 (Chloridea).

spectanda Smith, 1709 (Paragrotis). spectans Walker, 1009.

speculella Clemens, 6418.

speculifara Sepp, 4136.

\section{Speranza}

sperata Grote, 1029.

sperataria Walker, 3867 .

speyeri Lintner, 2131.

Speyeria.

Sphæcelodes

Sphæcelodinæ ................

spharomacaria Harvey, 3759.

Sphecodes

Sphecodina

Sphida

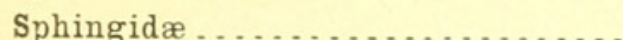

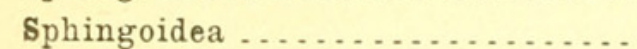

Sphinx

spiculana Zeller, 5176.

spiculosa Grote, 1831.

Spilodes

Spiloloma

spitomela Walker, 1104.

Spilosoma (= Diacrisia).

spinataria Packard, 3742.

spinea Grote, 1052.

spinetorum Boisduval, 358.

spinigera Guenée, 1001.

spinosx Guenée, 2322.

spinuloides Herrich-Schaeffer, 4085.

spirexfotiana Clemens, 5246.

spissa Guenée, 1649.

spissicomis Haworth, 6010.

splendoriferella Clemens, 6145.

spododea Hulst, 3791.

Spodolepis.

Spodoptera

spodomitrata Hulst, 3663.

spoladea ....................

spotiana Clemens, 5214.

spotiata Walker, 1889.

spoliatella Die z, 5946.

sponsa Smith, 1589.

sponsata Grote, 3431.

spraquei Grote, 917 (Pygarctia).

349
Page.

spraguei Grote, 2354 (Schinia).

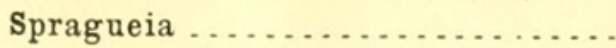

Page.

spreta Smith, 1515.

spretella Zeller, 6503.

spumosum Grote, 3452.

spuraria Christoph, 3511.

spurcata Walker, 2222.

sputatrix Grote, 1227.

squamealis Grote, 4520.

squamigera Felder, 4030.

squamulellus Zeller, 4630.

s-signata Packard, 3669.

stabiliata Walker, 3700.

stabilis Smith, 1317.

stachydana Herrich-Schaeffer, 5435. staintonella Clemens, 6337 (Bedellia).

staintonella Chambers, 6249 (Bucculatrix).

staintomella Chambers, 6090 (Elachista).

stalachtaria Strecker, 3602 .

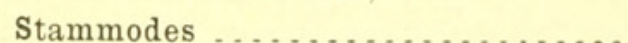

Staphylus .................

statalis Grote, 4530.

Statina .

statira Cramer, 53.

staudingeri Möschler, 1765.

Staudingeria . . . . . . . . . . . .

staurata Stephens, 3379.

Steganolophia..............

stella Edwards, 49.

stellaris Grote, 1412.

stellata Walker, 2304 (Derrima).

stellata Hulst, 3307 (Tephroclystis).

stellidaria Guenée, 4030.

Stenaspilates

343

steneles Linnæus, 225.

stenialis Guenée, 4304.

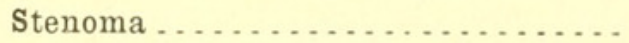

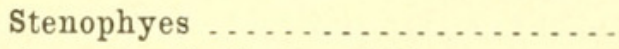

stenopteralis Grote, 4468.

Stenoptilia . . . . . . . . . . . .

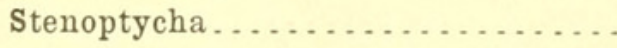

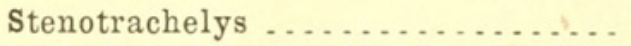

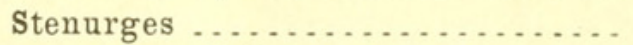

stercoreana Zeller, 5165.

Stergammatæa ...............

sternipennella 'Leller, 6006.

sterope Edwards, 161.

Sterrhinæ

stewarti Grote, 1292.

sthenele Boisduval, 265. 
stheno Hübner, 692.

\section{Sthenopsis}

Stibadium

sticticalis Linnæus, 4358.

stictophorella Ragonot, 4721.

stigma Fabricius, 767 (Anisota).

stigma Smith, 1374 (Copipanolis).

stigma skinner, 513 (Hylephila).

stigmata Grote, 1277.

stigmatella Fabricius, 6362.

stimaticus Mabille, 614.

stigmatilis Smith, 1592.

stigmosa Morrison, 1549.

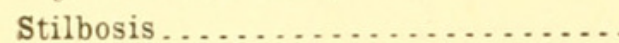

stilla Grote, 2198.

stimulea Clemens, 4075.

stipata Morrison, 1211.

stipatalis Walker, 4263.

Stiria

stolata Smith, 1984.

stoninus Curtis, 3083.

stragula Grote, 3111.

stramentalis Hübner, 4336.

stramentosa Guenée, 2166.

straminalis Hübner, 4336.

straminea Warren, 4387.

stramineana Walsingham, 5193.

siramineellus Chambers, 5679 .

straminella Stainton, 6354 .

stramineus Walsingham, 4969.

straminiella Chambers, 6528.

straminoides Grote, 5433.

straton Edwards, 505.

strattonata Packard, 3323.

streckeri Ellsworth, 146 (Euphydryas).

streckeri Grumm-Grshimaïlo, 75

(Eurymus).

streckeri Skinner, 456 (Megathymus).

streckeri Skinner, 567 (Phycanassa).

strena Grote, 2713.

Strenoloma .................

stremuana Walker, 5129.

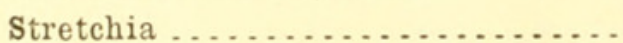

stretchii Grote, 877 (A pantesis).

stretchii Behr, 2843 (Catocala).

stretchii Butler, 848 (Leptarctia).

stretchii Edwards, 277 (Neominois).

stretchii Hy. Edwards, 1917 (Scotogramma).
Page.

580

197

streichii Behr, 2795 (Syneda).

stretchii Butler, 837 (Utetheisa).

striaria Hübner, 3625.

striata Ottolengui, 821 (Illice).

striata Edwards, 453 (Leptotes).

striata Walsingham, 5355 (Sparganothis).

striatana Clemens, 5177.

striatella Grote, 2480 (Euchalcia). striatella Busck, 5737 (Gelechia). striatella Hübner, 5540 (Paltodora). striatella Murtfeldt, 5618 (Phthorimiea).

striatella Fernald, 4615 (Thaumatopsis).

stricta Walker, 1830.

strictalis Walker, 4302.

strictella Walker, 6386.

strigata Smith, 1253 (Calophasia).

strigata Smith, 2564 (Eucalyptera).

strigata Boisduval, 4077 (Euclea).

strigata Packard, 3456 (Petrophora).

strigata Smith, 2142 (Rancora).

strigataria Minot, 3881.

strigicollis Walker, 1837.

strigifinitella Clemens, 6370.

strigilis Grote, 1742.

strigosa Bates, 309 (Anosia).

strigosa Fabricius, 883 (Apantesis). strigosa Walker, 937 (Calidota).

strigosa Stretch, 3219 (Malacosoma).

strigosa Grote, 3095 (Melalopha).

strigosa Harris, 349 (Thecla).

strigularia Minot, 3426 (Cœnocalpe).

strigularia Walker, 3662 (Episemasia).

strigulata Smith, 998.

strigulataria Smith, 2614.

striolata Zeller, 6060.1.

Strobisia

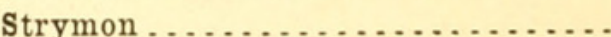

stygialis Grote, 2771.

stygiaria Walker, 4001.

stylata Smith, 1384.

stylobata Harvey, 2957.

Stylopoda.................. . styracis Guenée, 2045.

suxdicola Cockerell, 6045. 
suasa Boisduval, 403.

suavata Hulst, 3537 .

suavis Hy. Edwards, 2303 (Heliothis).

suavis Barnes, 3125 (Symmerista). subacuta Hulst, 3730 .

subænescens Walker, 4621.

subxqualis Walker, 4306.

subrquana Zeller, 5241.

subrquaria Walker, 3855.

subxquila Harvey, 1113.

subarea Hy. Edwards, 4253.

subalbaria Hulst, 3723 (Cymato-

phora).

subalbaria Packard, 3551 (Eois).

subalbicans Grote, 3137.

subalbusella Chambers, 5826.

subalpina French, 930.

subapicalis Smith, 1896.

subapicaria Walker, 3647.

subapicata Guenée, 3314.

subatomaria Wood, 3803.

subauratana Walker, 5335.

subaureola Frey \& Boll, 6260.

subaustralis Hulst, 3856 .

subbistrigella Haworth, 6167.

subcxrulea Walsingham, 5900.

subcxsiella Clemens, 4759.

suicanalis Walker, 4664.

subcarnea Kellicott, 2153.

subcedens Walker, 1158.

subcervinana Walsingham, 5004.

subcessaria Walker, 3705.

subcinctaria Walker, 3673.

subcitrina Walker, 4109.

subcitrinalis Hulst, 2634.

subcolorata Hulst, 3275.

subcolumbata Walker, 3651.

subcostella Ragonot, 4795.

subcroceata Walker, 3564.

subdentalis Grote, 4337.

subdentosa Dyar, 4081.

subdita Möschler, 1855.

subdivisalis Grote, 4277.

subdolens Walker, 1950.

subfalcata Hulst, 3736.

subfascianus Stephens, 5418.

subfasciella Walsingham, 5486.

subfervens Walker, 5478.

subflava Grote, 2151.

subflavana Walsingham, 5108.

subflavidalis Grote, 2581.
Page.

subflavidens Grote, 2289.

Page.

subflexa Guenée, 2297.

subfuscella Ragonot, 4763.

subfuscula Grote, 2036.

subgothica Stephens, 1538.

subhastata Nolcken, 3359.

subhyalina Curtis, 295.

subiridescens Walsingham, 6166.

subjecta Walker, 821.

subjectalis Lederer, 4437 (Pyrausta).

subjectalis Lederer, 4327 (Terastia).

subjuncta Smith, 1078 (Hadenella).

subjuncta Grote \& Robinson, 1796

(Mamestra).

subjunctella Walker, 6502 .

sublacteolaria Hulst, 3643.

sublapidana Walsingham, 5191.

sublataria Guenée, 3530.

sublatis Grote, 1696.

sublimaria Guenée, 3902.

sublucella Walsingham, 5495.

sublunaria Guenée, 3850.

subluteella Ragonot, 4920.

submarina Grote, 1906.

submarmorata Walker, 3647.

submedialis Grote, 4431.

subminiata Packard, 3659 (Scia-

graphia).

subminiata Packard, 3665 (Scia-

graphia).

submurraria Walker, 3859.

subnata Grote, 2871.

subnebulosa Dyar, 871.

subnicalis Warren, 4464.

subnigra Millière, 860 .

subnisana Zeller, 5189.

subnivana Walker, 5301.

subochraceus Walsingham, 4965.

subochrea Grote, 1003.

subochrearia Hulst, 4008.1 (Caberodes).

subochrearia Grote, 3766 (Caripeta). subochreata Packard, 3442 (Eurhi-

nosea).

subochreata Hulst, 3466 (Synomila). subolivacea Harvey, 2626.

subolivalis Packard, 4443.

subornata Neumoegen \& Dyar, 807.

subpallida Cockerell, 218.

subpartita Guenée, 2618.

subplicana Walsingham, 5094.

subporphyrea Walker, 1499. 
Page.

subprivata Walker, 3927.

subpunctata Harvey, 1956 (Heliophila ).

subpunctata Hulst, 3983 (Metane$\mathrm{ma})$,

subquadrata Guenée, 3492.

subreticulata Walsingham, 6470 .

subrotata Harvey, 3138.

subruberella Chambers, 5709.

subrufalis Grote, 3079.

subrufella Hulst, 4706.

subsciurella Ragonot, 4853.

subsenella Zeller, 5965.

subsequatis Guenée, 4454.

subsignarius Hübner, 3922.

subsimella Clemens, 5611.

subsinuaria Guenée, 3934.

substriata Haworth, 3361.

substriataria Hulst, 3804.

substrigata Smith, 1506.

subsylvella Walsingham, 5497

subtermina Smith, 2752.

subterminata Smith, 2043.

subtetricella Ragonot, 4670.

subtinctella Ragonot, 4742.

subtrartella Walker, 5969.

subusta Hübner, 2266.

subversuna Zeller, 5129.

subvexa Grote, 2262.

subviridis Harvey, 2809.

succandidalis Hulst, 4371.

succedana Schiffermüller, 5169 .

successaria Walker, 3468.

succosata Zeller, 3647.

-sueta Grote, 2406.

suffusa Denis \& Schiffermüller, 1454

(Agrotis).

suffusa Smith, 2017.1 (Graphiphora).

suffusa Smith, 839 (Haploa).

suffusa Strecker, 855 (Hyphantria). suffusa Smith, 1782 (Mamestra).

suffusa Stretch, 28 (Neophasia).

suffusa Laurent, 482 (Poanes).

suffusa Walsingham, 6115 (Scyth-

ris).

sutfusalis Smith, 3011 (Epizeuxis).

suffusalis Druce, 4307 (Pantographa).

suffusca Morrison, 1219.

suffusella Chambers, 5694 (Anarsia). suffusella Chambers, 5827 (Gelechia). sulfurea Grote, 4083.

sulfureana Clemens, 5331.

sulphuraria Packard, 3784 (Aleis).

sulphuraria Packard, 3691 (Cyma-

tophora).

sulphurata Packard, 4013.

sulphurea Packard, 3691 (Cymatophora).

sulphurea Neumoegen, 2450 (Stiria).

sulphurea Frey \& Boll, 6431 (Tis-

cheria).

sulphureodactylus Packard, 4971.

sulphureus Walsingham, 4971.

sulphurica Neumoegen, 888.

sumptuosalis Walker, 4450.

superans Guenée, 1004.

superantalis Clemens, 4637.

superaria Guenée, 4007.

superata Walker, 3563.

superba Hy. Edwards, 2586 (Annaphila).

superba Stretch, 888 (Apantesis).

superbaStrecker, 146(Euphydryas).

superba Hy. Edwards, 3138 (Hetero-

campa).

superba Barnes, 3178 (Thyatira).

superbella Chambers, 5582.

superbifrontella Clemens, 6372.

suppressaria Walker, 3546.

suprema Neumoegen, 772.

surena Grote, 2516.

surrectalis Walker, 3012.

suspectata Möschler, 3379.

suspicalis Walker, 4282.

sutor Guenée, 1119.

sutrina Grote, 1840.

sutrix Grote, 2657.

swainsonia Swainson, 56.

swederella Thunberg, 6372 .

syfamia Grumm-Grshimaïlo, 900.

Sylectra .................... 217

Sylepta . . . . . . . . . . . . . . 377

sylla Perty, 232.

sylvxcolella Chambers, 5720.

sylvana Treitschke, 5423.

sylvanoides Boisduval, 507.

sylvaria Curtis, 3695.

sylvarum Guenée, 2930.

sylvatica Harris, 3221.

syluaticoides Neumoegen \& Dyar, 3221.

sylvestrana Curtis, 5002.

sylvestrella Ratzeburg, 4711. 
sylvestris Edwards, 263.

sylvia Hy. Edwards, 2827.

sylvicolella Busck, 5610.

sylvinus Boisduval, 344.

Symmerista

Synaxis

Synchloe

Synchlora

Synclera

Synclita

Syneda...

Synedoida

Synelys

Syngamia

Synglochis

Syngrapha

Synnoma

synochitis Grote \& Robinson, 2605.

Synomila ..................... . . . synthetica Riley, 6576.

Syntomeida.

Syntomidæ .

syracosia Druce, 933.

syrichtus Fabricius, 652.

syringæ Harris, 4173.

syringicola Packard, 4413.

syrissa Strecker, 2064.

Syssaura

Syssphinx

Systasea

syzygyaria Hulst, 4004.

tabacella Ragonot, 5616.

tabulata Hulst, 3256 (Talledega).

tabulata Grote, 1905 (Xylomiges).

tabulella Ragonot, 4793.

\section{Tachyptilia}

\section{Tachyris}

trdialis Walker, 4425.

trniata Stephens, 3390.

\section{Tæniocampa .}

tages Cramer, 4278.

tagesalis Guenée, 4278.

taleana Grote, 5182.

talidiformis Guenée, 1087.

talis Grote, 4290.

\section{Talledega .}

talleolatis Hulst, 4649.

\section{Tallula}

tamenund Edwards, 603.

\section{Tampa}

tanaceti Hy. Edwards, 4197.

tanema Strecker, 2385.

tantalus Linnæus, 664.

tantillus Grote, 2735.

Tantura

tapella Linnæus, 6532.

tapeta Smith, 1196.

Tapinostola .

Tarache..................................

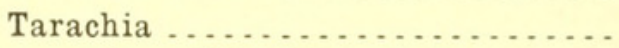

tarandana Möschler, 5173.

tarda Guenée, 1110.

tardigrada Clemens, 4077.

tarmitalis Hulst, 4774 .

tarquinius Curtis, 138 (Brenthis).

tarquinius Fabricius, 385 (Feniseca).

tartarellus Zeller, 4781.

tartarus Hübner, 652.

tatalis Grote, 4452.

tatila Herrich-Schaeffer, 228.

tatius Edwards, 632.

tacita Hy. Edwards, 357

\section{Tacoma}

tacoma Strecker, 1874 (Mamestra). tacoma Beutenmüller, 4235 (Sesia). tacomæ Hy. Edwards, 6613.

tacturata Walker, 3536.

tactus Grote, 2734.

tædata Grote, 1442 (Metalepsis).

tædata Grote, 2210 (Pseudoglæa).

tau Scudder, 28.

taumas Scudder, 523.

tautana Clemens, 5279.

taxiles Edwards, 485.

Taygete ......................
509 taylorata Hulst, 3743.

5 taylori Butler, 3891 (Dyscia).

taylori Edwards, 158 (Lemonias).

421 tearlii Hy. Edwards, 3184.

tecomx Riley, 4526.

tecta Grote, 2553 (Amyna).

tecta Walker, 1997 (Orthodes).

tecta Hy. Edwards, 4232 (Sesia).

teduscognalis Clemens, 4493.

tegularia Walker, 3698.

tehama Reakirt, 424. 
tejonica Behr, 2790.

Page.

tela Smith, 1195.

telamonides Felder, 5.

Telea

telea Hewitson, 331.

teleboa Smith, 1678.

Telegonus ....................

telifer Grote, 3148.

teliferc Harris, 1454.

teligera Morrison, 1850.

teligii Barnes, 4093.

tellias Bates, 201.

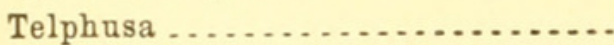

telum Guenée, 995.

tema Strecker, 3183.

temenes Godart, 15.

temnaria Guenée 3530.

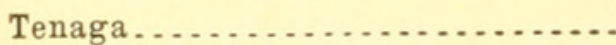

tenebrella Dietz, 5952.

tenebrescens Hulst, 3303.1.

tenebrifera Walker, 1428.

tenebrosata Hulst, 3722.

tenebrosella Hulst, 4754.

tenella $\mathrm{Hy}$. Edwards, 2770.

tenera Hübner, 905 (Ammalo).

tenera Smith, 1193 (Hadena).

teneralis Lederer, 4384.

tentoriferella Clemens, 5853.

tenuata Hulst, 3321.

tenuescens Smith, 1472 (Peridroma). tenuescens Grote, 2329 (Schinia). tenuescers Smith, 2695 (Tarache). tenuiana Walsingham, 5178.

tenuicola Morrison, 1461 (Agrotis). tenuicola Morrison, 2688 (Tarache). tenuidactylus Fitch, 4935.

tenuifascia Smith, 1329 (Oncocnemis).

tenuifascia Grote \& Robinson, 820

(Ozonadia).

tenuipunctellum Ragonot, 4866.

tenuis Walsingham, 6595 (Anaphora).

tenuis Walsingham, 6046 (Coleophora).

tenuis Grote, 653 (Hemaris).

tenuis Grote, 2739 (Isogona).

tenuistrigata Frey \& Boll, 6254.

tephra Hübner, 3193.

tephrella Ragonot, 4812.

tephriasella Chambers, 5767.

Tephrina ........................

tephrinana Zeller, 5127.
Tephroclystis ....................

Page.

269

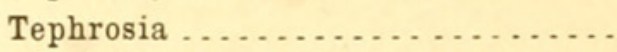

327

tepida Grote, 2107.

tepperaria Hulst, 3570.

tepperi Smith, 1512 (Noctua).

tepperi Morrison, 2458 (Plagiomimcus).

tepperi Hy. Edwards, 4220 (Sesia).

Teras ...................... 472

Terastia................... 380

teratophora Herrich-Schaeffer, 1059.

terentius Scudder \& Burgess, 628.

terissa Lucas, 57.

terlooii $\mathrm{Hy}$. Edwards, 662 (Lepisesia).

terlooii Behr, 29 (Neophasia).

termessus Smith, 1640.

termina Grote, 2981.

terminalis Smith, 1342 (Oncocnemis).

terminalis Walker, 902 (Pygoctnucha).

terminalis Neumoegen \& Dyar, 836

(Utethersa).

terminata Smith, 2029.

terminellus Grote, 1085.

terminimacula Grote, 2661.

ternariella Zeller, 5720.

ternarius Smith, 1687.

terracoctana Walsingham, 5119.

terracottella Busck, 5641.

terraria Guenée, 4030.

terrealis Grote, 1522 (Chorizagrotis).

terrealis Treitschke, 4410 (Phlyc-

tænia).

terrella Walker, 5616 (Phthorimaea).

terrellus Zeller, 4589 (Crambus).

terrenella Zeller, 4636.1.

terrenus Smith, 1651.

terrifica Smith, 1447.

territans Hy. Edwards, 2445.

territorialis Smith, 1654.

tersa Linnæus, 672.

tertia Dyar, 2057 (Perigonica)。

tertia Grote, 2351 (Schinia).

tertialis Guenée, 4413.

tesella Packard, 3165.

tesquatella Chambers, 6127.

tesquella Clemens, 6127.

tessalutella Riley, 6473.

tessellana Packard, 5028. 
tessellata Packard, 3433 (Conocalpe).

tessellata Scudder, 642 (Hesperia). tessellata Harris, 1711 (Paragrotis). tesselloides Grote, 1743.

lesseradactyla Linnæus, 4955.

tessulatella Zeller, 6473.

testacea Packard, 4106.

testata Linnæus, 3349.

testula Smith, 1667.

testulana Zeller, 5340.

Tetanolita.

teterrellus Zincken, 4589.

tethys Fabricius, 234.

tetra Smith, 1967 (Heliophila).

tetra Walker, 1698 (Paragrotis).

tetra Behr, 352 (Thecla).

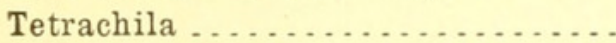

Tetracis ..................

tetradactylus Walsh, 4089.

tetradella Zeller, 4905.

tetradymiella Busck, 5640.

tetragonalis Haworth, 4358.

Tetralopha..................

tetraspitaris Walker, 4094.

tetrica Hy. Edwards, 2780 (Cirrhbolina).

tetrica Smith, 1629 (Paragrotis).

tetrio Linnæus, 685.

teucaria Strecker, 3684.

teusaria Walker, 3816.

texana Riley, 2558 (Anomis).

texana Edwards, 198 (Anthanassa).

texana French, 2838.1 (Catocala).

texana Edwards, 258 (Cercyonis).

texana French, 812 (Comacla).

- texana Scudder, 573 (Erycides).

texana Stretch, 4129 (Harrisina).

texana Morrison, 1980 (Heliophila).

texana Grote, 784 (Horama).

texana Robinson, 4618 (Ommatopteryx).

texana Smith, 2732 (Parora).

texana Smith, 1131 (Perigea).

texana Grote, 1554 (Porosogrotis).

texana Morrison, 2923 (Remigia).

texana Hy. Edwards, 4236 (Sesia).

texana Hulst, 3582 (Synchlora).

texanana Walsingham, 5294.

texanaria Hulst, 3861.

texanella Chambers, 6047 (Coleophora).
Page.

texanella Chambers, 6091 (Elachista).

texanella Chambers, 5910 (Ethmia).

texanella Chambers, 5913 (Ethmia).

texanella Hulst, 4850 (Hulstea).

texanella Zeller, 6269 (Lithocolletes).

texanella Hulst, 4673 (Myelois).

texrnella Ragonot, 4664 (Tetralopha).

texanellum Ragonot, 4865. (Homceosoma).

texanellus Chambers, 6586 (Acrolophus).

texanica Frey \& Boll, 6092.

texanus Ehrman, 13.

textor Harris, 468 (Amblyscirtes).

textor Harris, 856 (Hyphantria).

textrinaria Grote \& Robinson, 3988.

textula Herrich-Schaeffer, 4087.

thalialis Walker, 4478.

Thallophaga ............... 317

thallophilatis Hulst, 4365.

Thalpochares ..............

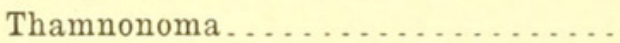

Thanaos .................... 59

tharos Drury, 189.

Tharsalea .................. 40

Thauma .................... 73

Thaumatopsis .............. 410

thaxteri Grote, 2111.

thaxterianus Grote, 1383.

thecata Morrison, 2006.

Thecla . . . . . . . . . . . . . . . . $\quad 36$

Theisoa .................. . . . 540

thekla Edwards, 179.

Thelcteria . . . . . . . . . . . . . . . . 394

Thelda . . . . . . . . . . . . . . . . . . . $\quad 379$

Thelethia............... . . 495

theodora Schaus, 1754 (Anytus).

theodori Dyar, 4153 (Hypopta).

theodori Grote, 1259 (Polia)

theona Ménétries, 178.

theonus Lucas, 452.

Thera . . . . . . . . . . . . . . . . . $\quad 282$

theralis Walker, 3027 .

Therasea ................... 213

Theretra ................. 65

Therina ................. 334

thermopsella Chambers, 6374.

theseatis Zeller, 4417.

theseusalis Walker, 4421. 
Page.

Thessalia .

thestialis Walker, 4420.

thetis Boisduval, 653.

thiemei Oberthur, 845.

thiodamus Scudder, 211.

Thiodia

Thisanotia.

thoas Linnæus, 14.

thoasalis Walker, 4294.

thoe Boisduval, 393.

Tholeria.

thona Strecker, 898.

thoonalis Walker, 4354.

thoosa Scudder, 49.

thor Hy. Edwards, 4.

thoracealbella Chambers, 5734 (Gelechia).

thoracealbella Chambers, 6222 (Nepticula).

thoracefasciella Chambers, 5867.

thoracella Walsingham, 5929.

thoracenigrzella Chambers, 5856.

thoraceochrella Chambers, 5828.

thoracestrigella Chambers, 5829

(Gelechia).

thoracestrigella Chambers, 6523 (Tinea).

thoracica Hy. Edwards, 2276 (Antaplaga).

thoracica Grote, 997 (Apatela).

thoracica Putnam-Cramer, 2119

(Calocampa).

thoracica Stretch, 3221 (Malacosoma). thoracicoides Neumoegen \& Dyar, 3221.

thorates Hübner, 666.

thoreani Grote \& Robinson, 2360.

Thorybes ................. . .

thraso Hübner, 603.

thraralis Walker, 3042.

thuiella Packard, 6250.

thula Strecker, 1181.

thule Strecker, 6606.

thulea Dalman, 870.

thulearia Herrich-Schaeffer, 3359.

Thyatira

Thyatiridæ .................

thyatiroides Walker, 3128 (Dasylophia).

thyatiroides Guenée, 2481 (Eosphoropteryx).

thycesalis Walker, 4351. thysbe Fabricius, 656.

tibiale Harris, 4190.

tibullus Scudder \& Burgess, 636.

tigrinaria Guenée, 3956.

tigris Guenée, 2539 (Diastema).

tigris Dyar, 3220 (Malacosoma).

tilixella Chambers, 6310.

tiliafoliella Clemens, 6048.

tiliaria Harris, 3884.

tilieacella Chambers, 6310.

tiliella Walsingham, 6310.

tiltella Hulst, 4655.

timais Cramer, 2426.

Timandra.

timandra Hy. Edwards, 2898.

timandrata Walker, 3490.

Timetes ................... . .

timidella Clemens, 5830.

Timochares ................

tinctana Walker, 5384.

tinctaria Walker, 3850.

tinctoriella Chambers, 6438.

Tinea .......................

tineana Hübner, 5266.

Tineidæ ...................

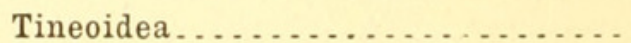

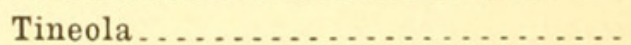

Tioga . . . . . . . . . . . . . .

tipuliformis Linnæus, 4208.

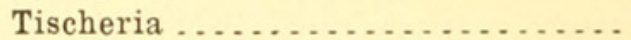

titan Cramer, 664.

titania Dodge, 2904.

Titanio ........................

Titanoceros ......................

titea Cramer, 3881.

titearia Guenée, 3881.

titubatis Smith, 1699.

titus Fabricius, 384.

tityrus Fabricius, 584.

tiviaria Walker, 3963.

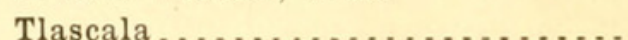

Tmetocera .................. 466 
tocoyx Smith, 1653.

togata Walsingham, 5885 (Depressaria).

togata Walker, 1998 (Orthodes). togata Esper, 2199 (Xanthia).

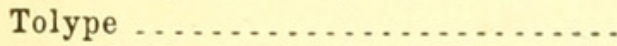

tonsa Grote, 1170.

toparius Zeller, 4579.

topazata Strecker, 3434 .

tophella Walsingham, 5549.

toralis Grote, 4449.

toreuta Grote, 3072 (Bomolocha).

toreuta Grote, 5298 (Cydia).

Toripalpus

Tornacontia

Tornos

torrefacta Smith \& Abbot, 3090.

torrida Smith, 2084.

tortilis Grote, 1174.

tortricella Chambers, 5842.

Tortricidæ .

Tortricidia

tortriciformella Clemens, 5650.

tortricina Zeller, 2696.

Tortricinæ

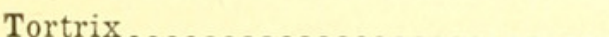

tortuosa Tepper, 3113.

torva Hy. Edwards, 4197.

torvalis Möschler, 4444.

Tosale

totu Grote, 987.

touceyellus Busck, 5680.

townsendi Cockerell, 4063.

toxana Boisduval, 326.

toxeta Gray, 325.

toxicodendri Frey \& Boll, 6304.

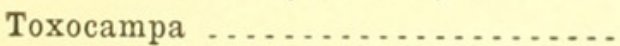

trabalis Grote, 4646 (Oneida).

trabalis Grote, 1419 (Platagrotis).

trabea Smith, 2472.

Trachea

Tracheops

Trachoma

Trachycera

tracta Grote, 1137.

tractaria Walker, 3587.

tractata Walker, 3702.

traducalis Zeller, 4279.

tragopoginis Linnæus, 1296.

Trama

tranquilla Grote, 2260.

transducens Walker, 4028.

transferens Walker, 4028.

122

331

491

417
Page.

transfindens Walker, 4026.

transfixarium Walker, 3838.

transfrons Neumoegen, 1150.

transitaria Walker, 3738.

transitella Walker, 4669.

transiturana Walker, 5364.

translucida Walker, 928.

transmissana Walker, 5128.

transmontana Neumoegen \& Dyar,

904.

transmutans Walker, 4026.

transmutata Walker, 2708.

transparens Grote, 2054.

transponens Walker, 4010.

transposita Walker, 4026.

transversa Walsingham, 5205.

transversana Walsingham, 5448.

transversata Smith, 986 (Apatela).

transversata Walker, 3170 (Ellida).

transversata Kellicott, 3379 (Mesoleuca).

transversata Thunberg, 3362 (Rheumaptera).

transversata Drury, 4026 (Sabulodes).

transvertens Walker, 4026.

trapezalis Guenée, 4282.

treatii Grote, 828 (Eubaphe).

treatii Grote, 1479 (Noctua).

tremula Harvey, 2252.

tremularia Walker, 3485.

trentonalis Lederer, 4521.

trepidella Clemens, 6394.

treueriana Hübner, 5304.

treveriana Duponchel, 5304.

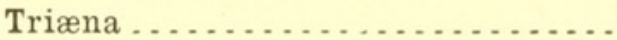

trialbamaculella Chambers, 5718.

triangulalis Möschler, 4486.

triangularis Smith, 839.

triangularisella Chambers, 5981.

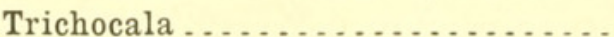

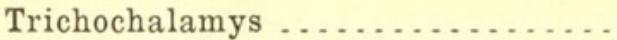

287

Trichoclea .................... 161

Trichocosmia ................. . 183

Trichodezia ................... 275

Tricholita ..................

168

Tricholonche .................. . . . 99

Trichophaga ................... 573

Trichopolia .................. 161 


\section{Trichoptilus}

Trichorthosia

Trichosellus

Trichostibas

trichostomus Christoph, 1596.

Trichotaphe

Trichotarache

trichusalis Hulst, 4571.

tricincta Harris, 4175.

tricingulatella Chambers, 6524.

triclaris Hübner, 134.

Triclonella ..................... tricolor Smith, 2722 (Cerathosia). tricolor Packard, 762 (Hemileuca). tricolor Fitch, 808 (Hypoprepia). tricolor Stretch, 896 (Kodiosoma). tricoloraria Packard, 3581.

tricolorella Grote, 4698.

tricosa Lintner, 1540.

tricristatella Chambers, 6171.

trientiplaga Walker, 1143.

trifariana Walker, 2707.

trifascia Smith, 2011 (Graphiphora).

trifascia Hübner, 2332 (Schinia).

trifasciana Haworth, 5374.

trifasciata Borkhausen, 3388 ( $\mathrm{Hy}$ driomena).

trifasciata Smith, 1647 (Paragrotis). trifasciata Packard, 3664 (Sciagraphia).

trifasciella Chambers, 6562 (Adela). trifasciella Clemens, 6251 (Bucculatrix).

trifasciella Chambers, 5725 (Gelechia).

trifasciella Frey \& Boll, 6313 (Lithocolletes).

triferana Walker, 5421.

trifolii Rottemburg, 1801.

Trifurcella ...................

trifurcella Chambers, 5911.

Trifurcula ..................

trifurculana Zeller, 5399.

trigemmana Zeller, 5134.

trigona Grote, 940 (Bertholdia).

trigona Smith, 1213 (Hadena).

trigona Hy. Edwards, 4093 (Prolimacodes)

trigona Smith, 1398 (Rhynchagrotis).

trigonana Stephens, 5312 (Acleris).

Page.

441

164

187

490

505

208

525

trilinearia Packard, 3773 (Platra). tritineella Chambers, 6049 (Coleophora).

tritineella Chambers, 5742 (Gelechia).

trimaculalis Grote, 4428.

trimaculata Boisduval, 953 (Alypiodes).

trimaculata Smith, 844 (Euerythra). trimaculella Fitch, 5843 (Eumeyrickia).

trimaculella Packard, 5721 (Gelechia).

trimaculella Chambers, 6525 (Tinea).

trimaculella Chambers, 5669 (Trichotaphe).

trimaculellus Chambers, 5680 ( Y psolophus).

trimaculosa Reakirt, 833.

trinotata Walker, 4046 (Celama).

trinotellus Coquillett, 5682 ( Y psolophus).

triocelella Chambers, 5630.

triocellella Chambers, 5630 .

Triocnemis ..................

tripars Walker, 1558.

tripartita Walker, 3128 (Dasylophia).

547 tripartitana Zeller, 5141.

tripartitus Grote, 729 (Smerinthus).

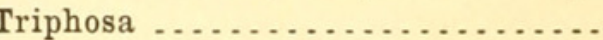

triplagiatus Smith, 2457.

triplipunctaria Fitch, 3803.

Triprocris

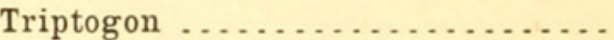

Tripudia .................

tripunctaria Packard, 3747.

tripunctata Goeze, 664 (Aellepos).

tripunctata Fabricius, 4192 (Pilocrocis).
Page. 
tripunctella Walsingham, $6102(\mathrm{He}-$ liodines).

tripunctella Walsingham, 6484 (Incurvaria).

tripunctellus Robinson, 4544 (Schœnobius).

triquetra Grote, 1294.

triquetrana Fitch, 4046.

trisectus Walker, 4604.

triseriata Packard, 3336 (Euchøea). triseriata Packard, 3257 (Scelidacantha).

trisignana Robinson, 5302.

trisignata Walker, 1053.

tristana Hübner, 5312.

tristata Linnæus, 3360.

tristella Dietz, 5945.

tristicula Morrison, 1695.

tristigmalis Hampson, 4295.

tristigmata Grote, 2240.

tristis Edwards, 2824 (Catocala).

tristis Boisduval, 635 (Thanaos).

tristrigana Clemens, 5275.

tristrigella Walsingham, 5712 (Anacampsis).

tristrigella Walker, 1093 (Balsa).

tristrigella Heinemann \& Wocke, 6014 (Coleophora).

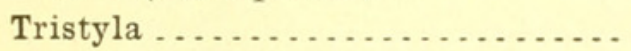

tritrniella Chambers, 6316.

tritealis Walker, 4385.

tritona Hübner, 1006.

tritonia Edwards, 266.

trituberalis Zeller, 3075.

trivinctella Zeller, 6116.

trivittana Zeller, 5177.

Trivolusia

trochilipennella Grote, 6010.

troilus Linnæus, 13.

\section{Tropæa}

trophella Busck, 5723.

\section{Trosia}

trossulana Walsingham, 5281.

trouvelotii Packard, 3133.

truncata Hufnagel, 3379.

truncataria Walker, 3603 (Epelis).

truncataria Guenée, 3902 (Sicya).

truncatellus Zetterstedt, 4598.

truncatula Zeller, 2699.

truxaliata Guenée, 4017.

Trypanisma
Page.

tubiferella Clemens, 6330.

tulcis Bates, 199.

tumida Grote, 2391:

tumidulella Ragonot, 4836.

tunicana Walsingham, 5334.

turbans Christoph, 883.

turbata Walker, 2939.

turbatellus Walker, 4581.

turbida Walker, 3165 (Fentonia).

turbida Walker, 3142 (Hetero-

campa).

turbitella Grote, 4821.

turbulenta Hübner, 1167.

turfosana Herrich-Schæffer, 5065.

turionana Hübner, 5001.

turionella Wilkinson, 5001.

turmalis Grote, 4404.

turnus Linnæus, 11.

turpidella Ragonot, 4752.

turris Grote, 1719.

Turuptiana .

tusa Grote, 1169.

tyndarus Esper, 272.

typhon Rottembury, 284 (Coenonympha).

typhon Klug, 680 (Pholus).

typica Smith, 1516.

tyralis Guenée, 4458.

tyria Slosson, 3157.

u-album Guenée, 2160.

u-aureum Guenée, 2506.

Ufeus

uhlerella Fitch, 6268.

uhleri Reakirt, 293.

Uinta

ulx Cockerell, 4609.

ulalume Strecker, 2810 (Catocala). ulalume Strecker, 657 (Lepisesia). ulicana Guenée, 5291.

ulicetana Haworth, 5169

ulmeila Ragonot, 4843 (Canarsia). ulmella Chambers, 6294 (Lithocol-

letes).

ulmi Harris, 990 (Apatela).

ulmi Harris, 3142 (Heterocampa).

ulmiarrosorella Clemens, 4843.

ulodactyla Zetterstedt, 4937.

Ulolonche

Ulophora

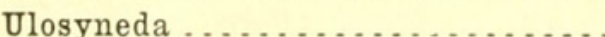

Page.

ultima Strecker, 2372.

ultronia Hübner, 2864. 
umatillaria Strecker, 3481.

umbellana Fabricius, 5889.

umbellella Zetterstedt, 5889.

umbellularix Walsingham, 6290.

umbilicata Guenée, 3493.

umbra Hübner, 2197.

umbralis Smith, 3076.

umbrata Packard, 817 (Clemensia). umbrata Walker, 3136 (Heterocampa).

umbrata Packard, 1488 (Noctua). umbraticostella Walsingham, 5855. umbrifascia Grote, 2728 (Hyamia). umbrifascia Smith, 1330 (Oncocnemis).

umbrifasciata Hulst, 3732.

umbriferata Hulst, 3732.

umbrina Grote, 2980.

umbripennis Hulst, 4719 (Pinipestis).

umbripennis Hulst, 3813 (Somatolophia).

umbripennis Grote, 2983 (Ypsia). umbrosa Worthington, 2865 (Catocala).

umbrosa Lintner, 205 (Polygonia). umbrosa Smith, 1914 (Scotogram$\mathrm{ma})$.

umbrosarium Guenée, 3839

umbrosata Packard, 3783.

umbrosus Grote, 2300.

una Strecker, 1180.

Unadilla

unangularia Herrich-Schaeffer,

3409.

unangulata Hübner, 3409.

uncana Hübner, 5259.

uncanale Hulst, 4868.

uncanaria Guenée, 3772.

uncas Edwards, 499.

uncella Heinemann, 5259.

unctulella Zeller, 5751.

undalis Fabricius, 4325.

undatus Grote, 4603.

undifera Walker, 4092.

undinaria Strecker, 3557.

undosus Lintner, 4143.

undulana Hübner, 3083.

undularia Drury, 2983.

undulata Linnæus, 3340.

undulatella Chambers, 6457 (Argyresthia).
Page.

undulatella Clemens, 4849

(Hulstea).

undulatella Walker, 4776 (Laodamia).

undulosa Walker, 722 .

unica Neumoegen, 2465.

unicalcaria Guenée, 3638.

unicincta Smith, 1164.

unicipunctellus Clemens, 5685.

unicolor Robinson, 3251 (Eudule).

unicolor Godman \& Salvin, 59

(Kricogonia).

unicolor Packard, 3143 (Misogada). unicolor Walker, 1496 (Noctua).

unicolor Hulst, 3313 (Tephroclystis).

unicolor Grote, 1760 (Ufeus).

unicoloraria Hulst, 3784 (Alcis).

unicoloraria Hulst, 3810 (Ixala).

unicoloraria Staudinger, 3380 (Mes-

oleuca).

unicolorella Chambers, 6050 (Coleophora).

unicolorella Walsingham, 6074

(Cosmopteryx).

unicolorella Hulst, 4748 (Tlascala). unicornis Smith \& Abbot, 3151.

unicristatella Chambers, 6156.

unidentaria Haworth, 3457.

unifascia Grote \& Robinson, 820.

unifascialis Packard, 4443.

unifasciana Clemens, 5348.

unifasciata Walsingham, 5511.

unifasciella Chambers, 6093 (Elachista).

unifasciella Busck, 5731 (Gelechia). unifasciella Chambers, 6317 (Lithocolletes).

unifasciella Chambers, 6155 (Mompha).

unifasciella Chambers, 6223 (Nepticula).

uniformis Dyar, 801 (Crambidia).

uniformis Smith, 2021 (Graphiphora).

uniformis Grote \& Robinson, 656 (Hemaris).

uniformis Morrison, 2997 (Homoptera).

uniformis Smith, 1910 (Scotogramma).

unijuga Walker, 2848. 
unilineata Grote, 3000.

unimacula Grote \& Robinson, 4469

(Pyrausta).

unimacula Smith, 2336 (Schinia). unimoda Smith, 2185 (Papaipema). unimoda Lintner, 2106 (Xylina). unimodaria Morrison, 3647.

unio Hübner, 2428.

unipuncta Haworth, 1953.

unipunctaria Haworth, 3803.

unipunctata Guenée, 3803.

unipunctella Clemens, 6180 (Brachiloma).

unipunctella Walsingham, 6103

(Heliodines).

unipunctellus Robinson, 4543 (Schønobius).

unisignata Walker, 1142.

unistriatellus Packard, 4566.

unistrigella Chambers, 5831.

unitaria Packard, 3560 (Annemoria).

unitaria Herrich-Schaeffer, 3807

(Lytrosis).

unitella Treitschke, 5500.

univocalis Walker, 4279.

unna PJotz, 650.

unomaculella Chambers,

6158

(Mompha).

unomaculella Chambers,

6526

(Tinea).

upupxpennella Hübner, 6362.

urania Westwood \& Hewitson, 573.

Uranotes .................. . . .

urbicola Behr, 2738.

urentis Guenée, 2536.

uroceriformis Walker, 4172.

Urola .

ursa Worthington, 519.

ursaria Walker, 3865.

ursina Smith, 2145 (Lathosea).

ursina Smith, 1051 (Merolonche).

ursula Godart, 236.

ursus Poling, 457.1.

urticaloides Fyles, 4323.

urticana Hübner, 5061.

Urula . . . . . . . . . . . . . . . . .

u-scripta Smith, 1802.

usticana Zeller, 5027.

ustipennis Walker, 3148.

utahensis Hy. Edwards, 904 (Aretia).
Page.

utahensis Smith, 2016 (Graphiphora).

utahensis Strecker, 17 (Papilio).

utahensis Hy. Edwards, 701 (Sphinx).

Utetheisa . . . . . . . . . . . . . .

uvinella Ragonot, 4747.

uxor Guenée, 2865.

uxorculalis Hulst, 4467.

vaccinix Hy. Edwards, 2407.

vacciniana Packard, 5238.

vaccinii Hy. Edwards, 2508 (Autographa).

vaccinii Riley, 4703 (Mineola).

vaccinivorana Packard, 5319.

vacunalis Grote, 4416.

vagans Boisduval, 865.

vagaria Walker, 3699.

vagatiocella Chambers, 5603.

vagella Walker, 5764.

v-alba Ottolengui, 2504.

valens Hy. Edwards, 2753.

Valeria . . . . . . . . . . . . . . . valeria Hy. Edwards, 2856.

vallus Smith, 1639.

vancouverensis Hy. Edwards, 4197

(Albuna).

vancouverensis Hulst, 3883 (Erannis).

vancouverensis Grote, 1547 (Feltia). vancouverensis Butler, 730 (Smerinthus).

vancouverensis Hy. Edwards, 705

(Sphinx).

vanella Walsingham, 5506 (Plutella).

vanella Grote, 2399 (Pseudotamila).

Vanessa .................... . .

vanidicus Smith, 1730.

vanillx Linnæus, 91.

vanusaria Strecker, 3985.

vapularis Grote, 1546.

varadaria Walker, 4007.

vararia Grote, 3887.

varia Walker, 753 (Automeris).

varia Walker, 3132 (Heterocampa).

varia Walker, 1136 (Oligia).

variabilis Busck, 5741 (Gelechia). variabilis Walsingham, 6598 (Ortholophus) .

variabilis Grote, 2209 (Pseudorthosia). 
variabilis Smith, 2050 (Stretchia). variana Fernald, 5327 (Acleris). variana Fabricius, 5359 (Archips). variana Ottolengui, 2510 (Autographa).

variana Morrison, 2214 (Tapinostola).

variana Clemens, 5189 (Thiodia). variata Denis \& Schiffermüller, 3378

(Mesoleuca).

variata Grote, 1396 (Rhynchagrotis).

variatella Clemens, 6506. variegata Walker, 4404.

variella Hübner, 5500 (Cerostoma). variella Ragonot, 4663 (Pococera). variella Chambers, 5597 (Recurvaria).

\section{Varina...}

variolana Zeller, 5319.

variolaria Guenée, 3623.

variolata Smith, 1813.

varix Grote, 1396.

varuna Edwards, 293.

vams Grote \& Robinson, 4005.

vasaliata Guenée, 3386.

vashti Strecker, 705.

vau Fitch, 3092.

vauaria Schrank, 3708.

vau-media Smith, 1833.

vau-orbicularis Smith, 1878.

v-brunneum Grote, 2204.

vecors Guenée, 1998 (Orthodes). vecors Guenée, 1117 (Perigea). vega Smith, 3077 (Bomolocha). vega Dyar, 663 (Lepisesia).

vegeta Morrison, 2743.

velaris Grote, 2325.

velata Strecker, 1769 (Agrotiphila). velata Walker, 2161 (Gortyna). velata Walker, 1998 (Orthodes). velata Walker, 1383 (Psaphidia). velatella Clemens, 6537.

velleda Stoll, 3208.

velleripennis Grote, 1603.

vellifera Grote, 3074.

vellivolata Hulst, 3854 .

velulana Walsingham, 5424 .

velutina Smith, 1952.

velutinana Walker, 5424 .

venalalis Hulst, 4432.

venalis Grote, 4409.

venata Grote, 3776 (Enypia).
Page.

venata Smith, 2042 (Graphiphora). venerabilis Walker, 1545.

venezuelensis Schaufuss, 675 .

Venilia.

venosa Butler, 1103 (Caradrina).

venosa Walker, 793 (Ctnucha).

venosa Scudder, 38 (Pontia).

ventilator Grote, 2552.

ventralis Grote \& Robinson, 4287.

ventrellus Fitch, 5685.

venus Neumoegen, 3156.

Venusia ...................

venusta Walsh, 3587 (Aplodes).

venusta Walker, 2480 (Euchalcia). venusta Walker, 3155 (Hyparpax). venusta Hy. Edwards, 2396 (Melanoporhhyria).

venusta Dalman, 836 (Utetheisa).

venustella Clemens, 6375 (Graci-

laria).

venustella Chambers, 5654 (Strobisia).

venustula Grote, 2253.

verbascoides Guenée, 1241.

verbesinella Busck, 6323.

verecunda Hulst, 2855 (Catocala).

verecunda Hy. Edwards, 4255

(Sesia) .

vermiculata Grote \& Robinson, 3087. verminalis Guenée, 4344.

verna Edwards, 528.

vernalis Morrison, 1375 (Eutolype). vernalis Edwards, 37 (Pontia).

vernata Packard, 4079 (Euclea). vernata Packard, 3234 (Nyctobia). vernata Peck, 3245 (Paleacrita). vernella Murtfeldt, 5761.

vernilis Grote, 1449.

verona Smith, 2176.

veronixella Chambers, 6051.

verrilliana Grote, 2863.

verrillii Grote \& Robinson, 1031.

verruca Fabricius, 2486.

versabilis Harvey, 2772.

versicolor Harris, 683 (Ampelophaga).

versicolor Grote, 1138 (Oligia).

versicolor Warren, 4471 (Pyrausta). versicolorana Clemens, 5018 (Exartema).

versicolorana Clemens, 5019 (Exartema).

versicolorella Chambers, 5832.

Page. 
versipellis Grote, 1736. versuta Smith, 1199 (Hadena). versuta Harvey, 2569 (Pseudorgyia).

versutella Zeller, 5753.

versutus Hy. Edwards, 2644 (Tripudia).

verticalis Grote, 1707.

vertuana Zeller, 5006.

vertumnana Zeller, 5135.

verus Edwards, 511.

vesca Morrison, 2618.

Vespemima

vesperana Clemens, 5364.

vespiformis Hufnagel, 4188.

vespipenne Herrich-Schaeffer, 4183. vesta Walker, 736 (Philosamia). vesta Edwards, 187 (Phyciodes). vestaliana Zeller, 5171. vestaliata Guenée, 3608. vestatiella Zeller, 4539. vestalis Packard, 840 (Haploa). vestalis Zeller, 5841 (Ide). vestalis Packard, 866 (Mænas). vestalis Hulst, 3920 (Ripula). vestianella Stephens, 6489. vestigialis Guenée, 4385.

Vestigifera

vestitaria Herrich-Schaeffer, 3939.

vestris Boisduval, 529.

vesulia Cramer, 4010.

vesuliata Guenée, 4010.

veterata Smith, 1128.

vetulana Walsingham, 5051.

vetusta Boisduval, 3189 (Notolophus)

vetusta Walker, 1698 (Paragrotis). vetusta Walker, 1552 (Porosagrotis).

viaca Edwards, 421.

vialis Edwards, 459.

viatica Grote, 2246 (Glæa).

viatica Harvey, 3606 (Orthofidonia).

viator Edwards, 564.

vibicalis Zeller, 4376.

viburnana Clemens, 5312.

viburnella Clemens, 6052.

vicaria Walker, 1490.

vicariana Walker, 5356.

vicaritis Zeller, 5530.

vicina Grote, 1850.

victoria Edwards, 144 (Brenthis).
Page.

Page.

victoria Grote, 2914 (Toxocampa).

victorix Grote, 659.

Victorina ......................

videns Guenée, 1088.

vidleri Elwes, 271.

vidua Smith \& Abbot, 2813.

viduata Guenée, 2811.

vidularis Grote, 3974.

vigilacella Clemens, 5504.

vigilans Grote, 1145.

vilisana Walker, 5228.

villella Busck, 5917.

villosa Grote, 2404.

villosalis Zeller, 4314.

villosella Hulst, 4808 (Etiella).

villosella Clemens, 6224 (Nepticula).

Viminia ..................... . .

vincta Walker, 1137.

vinculum Guenée, 2940.

vindemialis Grote, 2038.

vinnula Grote, 1012.

vinosaria Grote \& Robinson, 3963.

vinulenta Grote \& Robinson, 4461.1.

(Pyrausta).

vinulenta Grote, 2242 (Scopelosoma).

vinulentaria Grote \& Robinson, 3962.

violacea Edwards, 440 (Cyaniris). violacea Grote, 1151 (Hadena).

violaceana Robinson, 5352.

violacearia Walker, 3530.

violaceellus Beutenmüller, 6595 .

violacella Clemens, 6352.

violaceofusca Zeller, 5744.

violans Guenée, 1950.

violaris Grote \& Robinson, 1452.

violenta Hy. Edwards, 2862.

viralis Grote, 1212.

virens French, 2894.

virescana Clemens, 5375.

virescens Fabricius, 2296 (Chloridea).

virescens Hulst, 4619 (Ommatopteryx).

virgata Packard, 3145.

virgatella Clemens, 4759.

virgilia Hy. Edwards, 2856.

virgilius Scudder \& Burgess, 627.

virginalis Hulst, 3689 (Cymatophora).

virginalis Boisduval, 873 (Platyprepia). 
virginalis Grote, 2685 (Tarache). virginaria Cramer, 3864 (Epimecis). virginaria Grote, 3866 (Lycia). virginaria Hulst, 3921 (Ripula). virginata Graef, 3258 (Scelidacantha).

virginella Chambers, 6280 .

virginiana Clemens, 5331 (Epagoge).

virginiana Clemens, 5216 (Proteop$\operatorname{teryx}$ ).

virginica Charpentier, 798 (Ctnucha)

virginica Fabricius, 862 (Diacrisia). virginiella Clemens, 5519 (Choreutis).

virginiella Clemens, 6225 (Nepticula).

virginiensis Drury, 770 (Anisota). virginiensis Boisduval, 320 (Cale phelis).

virginiensis Edwards, 38 (Pontia). virginiensis Edwards, 387 (Tharsalea).

virginiensis Drury, 220 (Vanessa). virgo Linnæus, 874 virgula Retzius, 487 (Erynnis). virgula Grote, 1999 (Orthodes). virgulti Behr, 316.

virguncula Kirby, 875 (Apantesis). virguncula Smith, 1188 (Hadena). virida Strecker, 66.

viridans Walker, 2986

viridata Grote, 3233 (Cysteopteryx). viridata Packard, 3387 (Hydriomena).

viridata Harvey, 1058 (Jaspidia). viridescens Walker, 1381.

viridicaria Hulst, 3592.

viri liclava Walker, 4077.

viridicuprella Walsingham, 6053.

viridifera Grote, 2460.

viridimusca Smith, 1178.

viridipallens Hulst, 3579 (Synchlora).

viridipallens Grote, 2105 (Xylina). viridipennaria Guenée, 3470.

viridipennata Hulst, 3569.

viridipurpurea Hulst, 3574.

viridirufara Neumoegen, 3761. viridis Edwards, 380 (Callophrys). viridis Edwards, 487 (Erynnis). viridis Reakirt, 4080 (Euclea).
Page.

viridisignata Grote, 2509. viriditincta Smith, 1354.

viridoperlata Packard, 1913. viridula Grote, 2260.

visaliella Chambers, 6456 (Argyresthia).

visaliella Chambers, 6535 (Cyane). viscidiflorella Walsingham, 6054. vitalbata Hübner, 3328. vitaligata Felder, 4010. vitana Fabricius, 5345. viteana Clemens, 5005. vitellinana Zeller, 5432. vitellius Fabricius, 566. viticordifoliella Chambers, 6126. vitifoliella Chambers, 6421. vitigenella Clemens, 6422 . vitis French, 1785 (Mamestra). vitis Linnæus, 677 (Pholus). vitisana Jacquin, 5005. vitivorana Packard, 5005. vitralis Hübner, 4316. vitrana Walsingham, 5278 . vitraria Grote, 3903. vitrea Grote, 3056. vitrina Boisduval, 4133 (Dysodia). vitrina Neumoegen, 4200 (Sesia). vittata Fabricius, 895 (Apantesis). vittata Harris, 807 (Hypoprepia). vittatus Fabricius, 5504 (Plutella). vittifrons Grote, 1401 vittula Grote, 1790.

vitula ......................

vivida Grote, 916.

vividana Dyar, 5365.

$v$-nigraria Haworth, 3708

vocalis Grote, 1513.

volcania Perry, 54.

volubilis Grote, 1549.

volucer Hulst, 3448. volucrata Hulst, 3541. volucris Grote, 2972. voluminia Hy. Edwards, 2856. volupia Fitch, 2311. volupiatis Grote, 4462.

Volusia ....................... vomerina Grote, 1885.

vorax Behr, 1337.

votica Hulst, 2863 (Catocala). votiva Hy. Edwards, 902 (Pygoctnucha).

$v$-signatana Packard, 5365. 
vulgalis Guenée, 4299.

Page. vulgaris Grote \& Robinson, 1244. vulgivagellus Clemens, 4585. vulneraria Hübner, 4033. vulnerea Grote, 1322. vulnifica Grote, 2147. vulpina Grote, 982 (Apatela). vulpina Hy. Edwards, 2778 (Cirrhbolina).

vulpina Smith, 1630 (Paragrotis). vultuosa Grote, 1220.

vulvivaga Morrison, 1205.

waco Edwards, 475.

wacoella Chambers, 5833.

wakarusa Gaumer, 5477.

wakulla Edwards, 468.

walkeri Neumoegen, 4170 (Alco-

thoe).

walkeri Andrews, 1022 (Apatela). walkeri Felder, 736 (Philosamia). walkeri Grote, 2241 (Scopelosoma). walshella Clemens, 4072.

Walshia . Edwards, 2840 (Catocala) walshii Edwards, 5 (Iphidicles). walsinghamella Beutenmüller, 5912. walsinghami Fernald, 4957 (Alucita).

walsinghami Ragonot, 4726 (Ambesa).

walsinghami Hy. Edwards, 797

(Ctnucha).

walsinghami Butler, 864 (Diacrisia).

walsinghami Dietz, 5765 (Gelechia). walsinghami $\mathrm{Hy}$. Edwards, 2344 (Schinia).

Walsinghamia

wamsutta Harris, 526.

Wanda

warneri Harvey, 3943.

washingtonalis Grote, 4406.

washingtonia Hy. Edwards, 4203

(Sesia).

washingtonia Grote, 2112 (Xylina). washingtoniensis Grote, 1413.

wasmuthi Weeks, 23.

wauaria Linnæus, 3708.

Wauchula

wavaria Fabricius, 3708.

wawaria Herrich-Schaeffer, 3708. weidemeyerii Edwards, 238.

Wekiva werdandi Herrich-Schaeffer, 74.

wescottii Grote, 2883.

westermanni Staudinger, 1722 .

westwoodii Boisduval, 84 .

wheeleri Edwards, 259 (Cercyonis).

wheeleri Hy. Edwards, 152 (Lem-

onias).

whitneyi Dodge, 2890 (Catocala).

whitneyi Behr, 165 (Lemonias).

williamsii Dodge, 889.

wilsoni Grote, 2431 (Ciris).

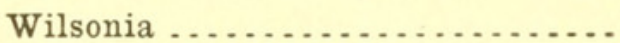

wilsonii Grote, 1567 (Paragrotis),

wingina Scudder, 516.

winnipeg Smith, 2092.

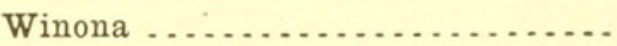

wiskotti Staudinger, 904.

wittfeldii Hy. Edwards, 950 (Alypia).

wittfeldii Hy. Edwards, 4236 (Sesia).

wittfeldii Edwards, 346 (Thecla).

wockei Möschler, 1434.

woodii Grote, 2992.

worthingtoni Grote, 1558.

worthingtoniana Fernald, 5106.

wosnesenski Ménétries, 4 (Parnassius).

wosnesenski Ménétries, 60 (Zerene). wrightarium Hulst, 3829.

wrightii Edwards, 476 (Copæodes).

urightii Hy. Edwards, 3167 (Glu-

phisia).

wrightii French, 848 (Leptarctia).

wrightii Stretch, 789 (Scepsis).

wrightii Edwards, 176 (Thessalia). wyandot Edwards, 644.

wythix Walsingham, 6055.

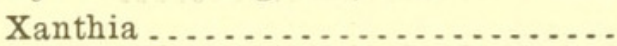

xanthia Sepp, 54.

xanthobasis Zeller, 5535.

xanthoides Boisduval, 389 (Gæides). xanthoides Guenée, 1115 (Perigea). xanthoides Walker, 5349 (Sparganothis).

xantholeucalis Guenée, 4537.

xanthometata Walker, 3614.

xanthonota Oberthur, 845.

Xanthopastis......................

Xanthoptera .................... 211

Xanthorhoe ..................... 288

Xanthothrix ................... 193

Xanthotype .................... 336 
xanthus Edwards, 647.

xeniolalis Hulst, 4301.

Xenolechia

xerces Boisduval, 417.

xicaque Reakirt, 303.

xiphixformis Boisduval, 4194.

Xylena ......................

Xylestia.......................

Xylina ........................

xylina Say, 2555 (Alabama).

xylina Hulst, 3357 (Neolexia).

xyliniformis Guenée, 1037 (Apatela).

xyliniformis Smith, 1670 (Paragrotis).

xylinoides Guenée, 1278.

Xylomiges . . . . . . . . . . . . . . . .

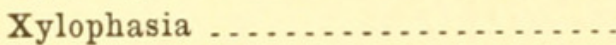

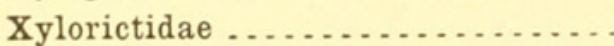

xylostella Packard, 5503.

xysteraria Hulst, 3584.

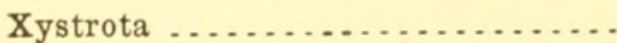

yakima Smith, 1866.

yamana Reakirt, 52.

yarrowi Stretch, 869.

yavapai Neumoegen, 759.

yehl Skinner, 558.

y-inversa Packard, 4096 (Cochlidion).

$y$-inversus Riley, 6567 (Prodoxus).

Yosemetia ..................... yosemitx Hy. Edwards, 905 (Ammalo).

yosemitx Grote, 2072 (Aporophila). youngi Holland, 133 (Brenthis).

youngi Holland, 276 (Erebia).

youngii Smith, 1429 (Semiophora).

Yponomeuta .......................

Yponomeutidæ ..................

Ypsia .............................

ypsilon Rottenburg, 1454 (Agrotis). ypsilon Forbes, 3871 (Nacophora).

Ypsiptes......................

Ypsolophus .................... yreka Edwards, 506 (Anthomaster). yreka Reakirt, 40 (Pontia).

Yrias ........................ yucсx Boisduval \& Le Conte, 454. yuccasella Busck, 5645 (Deoclona). yuccasella Riley, 6574 (Pronuba). yukatanensis Oberthur, 845 .

yukonensis Holland, 282.
Page.

Yuma

yuma Edwards, 502.

zabolicus Strecker, 4147.

zabulon Boisduval \& Le Conte, 483.

zachæina Butler \& Druce, 444.

zachana Treitschke, 5291.

Zale

zalissaria Walker, 3994.

zampa Edwards, 613.

Zanclognatha

zapulata Robinson, 5363.

Zazaca

zeæ Harris, 2159 (Achatodes).

zеæ Fitch, 4890 (Plodia).

zeellus Fernald, 4608.

zela Butler, 319 .

zelatella Hulst, 4704.

zelica French, 2810.

zelicayn Lucas, 18.

zella Dyar, 939.

zelleraria Packard, 3562.

zellerella Frey \& Boll, 6451.

zelleri Grote \& Robinson, 750 (Auto-

meris).

zelleri Grote, 1093 (Balsa).

zelleri Grote, 4639 (Epipaschia).

zelleriana Fernald, 5014.

zelleriella Chambers, 6056 (Coleophora).

zelleriella Clemens, 6451 (Coptotriche).

zelleriella Chambers, 5913 (Ethmia). zelmira Felder, 430.

zenobia Cramer, 3007.

\section{Zenophleps}

zephyria Grote, 752 .

zephyrus Edwards, 211.

Zerene .........................

zerene Boisduval, 109.

zeroe Boisduval, 395.

Zerynthia

zerynthia Hübner, 232.

zestos Hübner, 588.

zeta Ottolengui, 2521.

zetterstedti Staudinger, 1941.

Zeuzera .........................

ziczacata Walker, 3419.

zillah Strecker, 2855.

zilpa Butler, 582.

zimmermanni Grote, 4715.

zinckenana Frölich, 5076.

zinckenella Treitschke, 4807. 
INDEX TO SPECIFIC, GENERIC, AND FAMILY NAMES. 723

Page.

Zinckenia

zinghalis Walker, 4340.

zoe Behr, 2865.

zolicaon Boisduval, 18.

zonalis Grote, 914.

zonata Duncan, 664 ( Ellopos).

zonata Walker, 2734 (Homopyralis).

Zonosoma......................

zonulata Hulst, 4009.
372 zonulella Ragonot, 4674.

Zophodia .................... 429

Zosteropoda................... 164

Zotheca ..................... 182

zuni Neumoegen, 858.

zygrnidata Packard, 3300.

zygotaria Hulst, 3591.

291 zylostella Chambers, 5503.
Page.$$
4
$$ 


\section{$2 \mathrm{BHL}$ Biodiversity Heritage Library}

Dyar, Harrison G. 1902. "A List of North American Lepidoptera and Key to the Literature of this Order of Insects." Bulletin of the United States National Museum 52, 1-723. https://doi.org/10.5479/si.03629236.52.i.

View This Item Online: https://www.biodiversitylibrary.org/item/32789

DOI: https://doi.org/10.5479/si.03629236.52.i

Permalink: https://www.biodiversitylibrary.org/partpdf/28729

\section{Holding Institution}

Smithsonian Libraries

\section{Sponsored by}

Smithsonian

\section{Copyright \& Reuse}

Copyright Status: NOT_IN_COPYRIGHT

This document was created from content at the Biodiversity Heritage Library, the world's largest open access digital library for biodiversity literature and archives. Visit BHL at https://www.biodiversitylibrary.org. 